

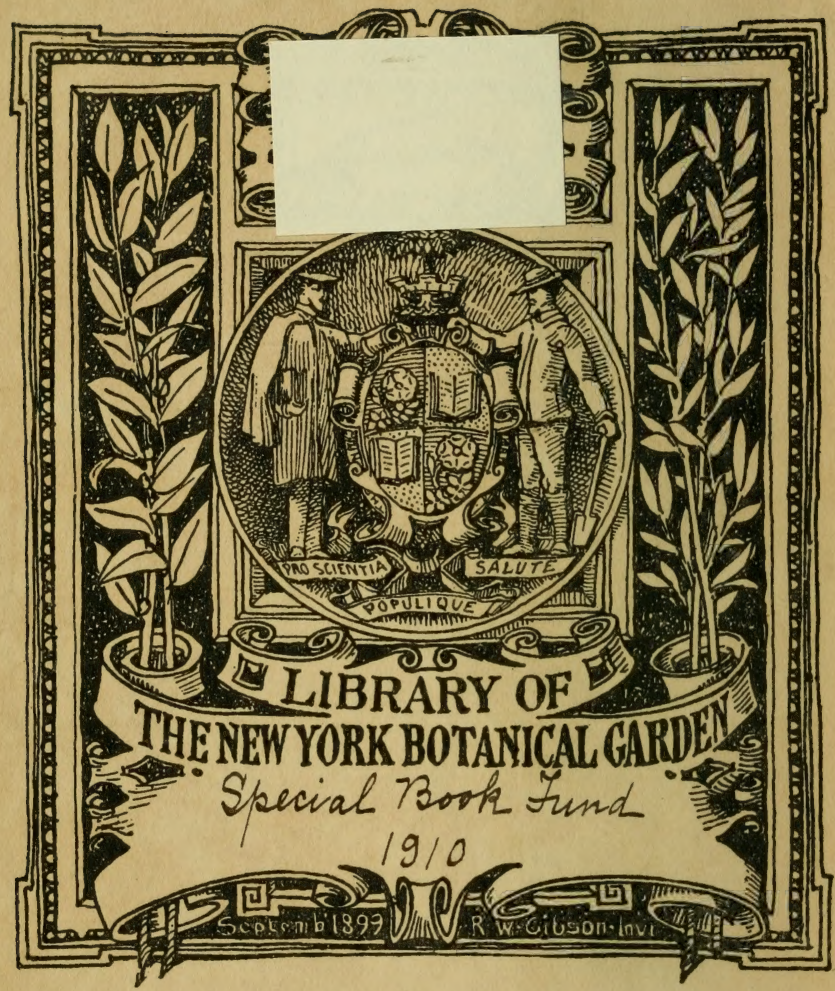

- Aus I.D. Winklers Buch" und. Mustiationhandlung in Paderborn 


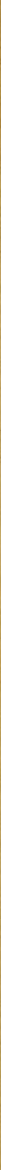

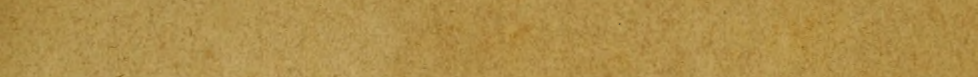

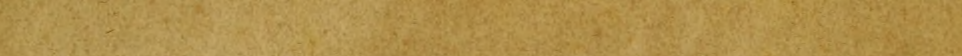

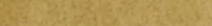

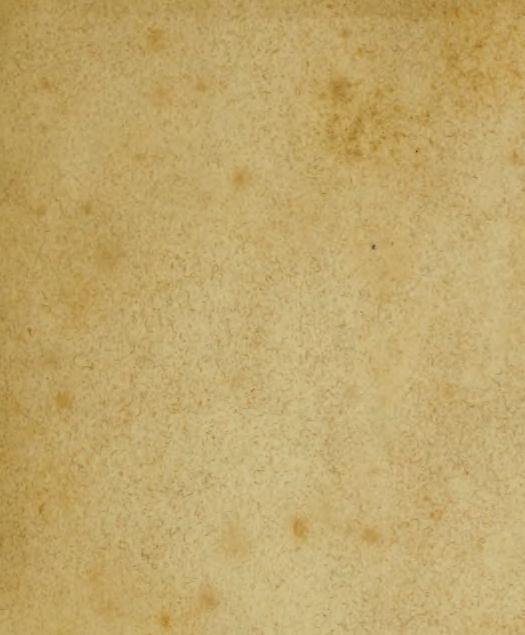

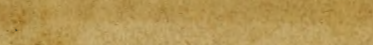

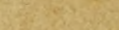





\section{Flora Soeptialens}

pon

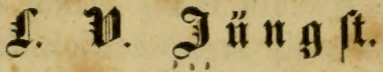

3weite ganz umgearbeitete 2 (uffage ber Flora bon Bielefelb $x$. won demielfen Berfafier.

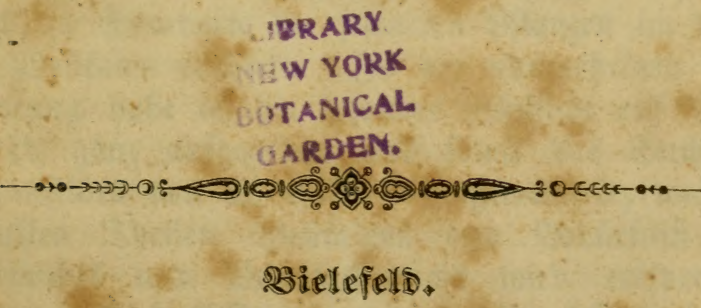

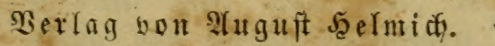
1852. 



\section{Wotede 3ux 3meiten Aluflage.}

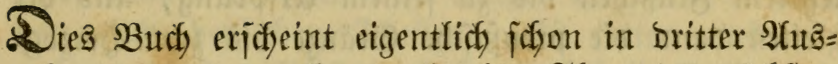

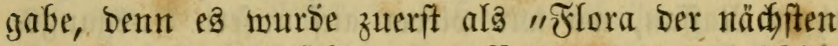

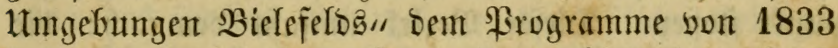

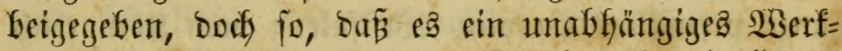

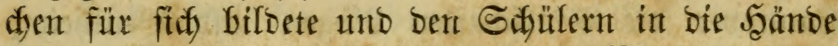
gegeben wurbe als ein Mittel, bie Prifanzen iffer

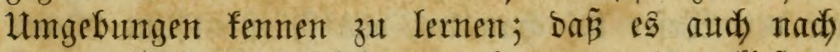
anbern Drten $2 B$ eiffalens berlangt wurbe, lieferte

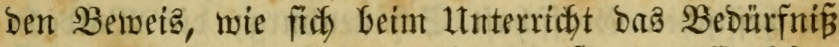

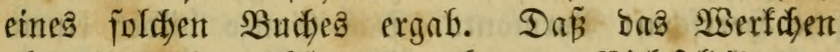

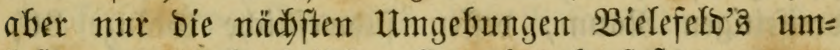

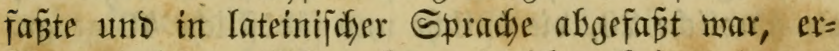
fodwerte feinen (sebrauch, und idy arbeitete barum bie "Iflora wout Bielefeld" aนక (1837), weldfe zu= gleid) bie Standorte ber feltneren Ffianzen im übrí= gen SBeitfalen enthielt. Sat ber numefrigen $14 m=$

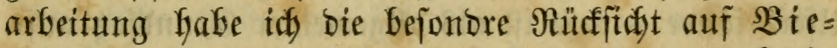
lefeld ganz aufgegeben uno fomit bas $\mathfrak{B}$ udd in eine "Flora yon MGeitfalen" umgenandelt, weil ę

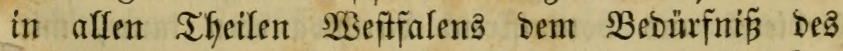
Unterrichts und Frivatgebraudis wirb entipredten fönnen. Dą Errite mag nun fein, diẹ Ẻränzen feitzuftelfen, weldye bas Giebiet bezeidynen.

Nefmen wir als füblidjen Saaptpunft Siegen an, fo folgen wir in norbwestlicter Ridytung ber 
(Sränze Der preusijçen Provinz Weitfalen bis zur Gollänbifichen Gränze, verfolgen dieje lebatre bỉ zum nörolidgen Esnde der Gamnöberidgen (Stafichaft Bent= Geim, gefn längs ber Ђaaje und oldenfurgif dyen

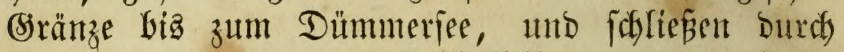
cine Rinie yon oa nadh Edhlüffelburg an Der Wefer bie nörolitye $\mathfrak{B e g r a ̈ n z u n g ~ a b ; ~ n u n ~ f o l g e n ~ w i r ~ b e r ~}$

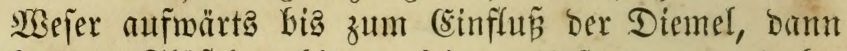
lestrem Flübchen bis zu feinem Irfprung, und be= gleiten bann bie preupijide (5iränze bis zum Seerzon= thum Salfau, wo wir wieber auj unjern 2 (usgangs=

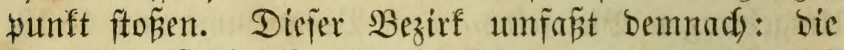
ganze preupifore Wrovinz Beftialen; yom Sönigreid) Sannover die Srafichaften Ringen und Bentheim,

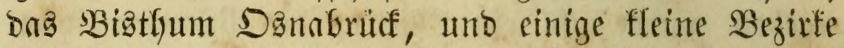
an ber Wejer bei Şameln; Das Jüritentfum Rippe= Detmold; Den linfa pon ber wafer liegenden Theil ber heffitiden (Sirafichaft Sdyatenburg; die Waldeff=

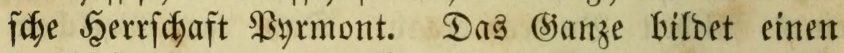

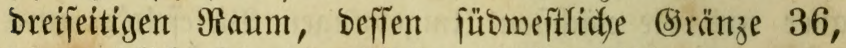
bie nörolidbe 20, bie biftiche uno füböftlidbe 40 geogr. Meilen enthalten mag. Da es aber abgeidsmact märe, dieje (Srïnzen völfig genau zu beobadyten -

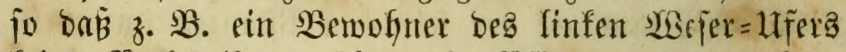

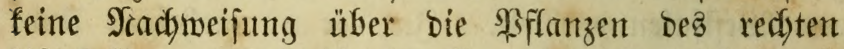

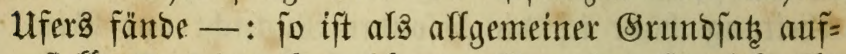
geftelft, won ben benadbarten Giegenden fo viel, alb man in einem Tage bon Den (Siränzorten unjres (B) bietes aus botanifitrend Durdwandern fann, mit aurzunefymen, foweit die Siflanzen bajelbit mix be= fant waren. (Es finden baber nod) Berüdffidti=

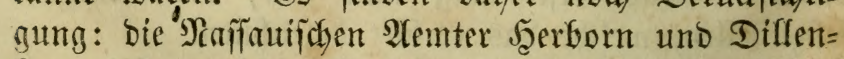

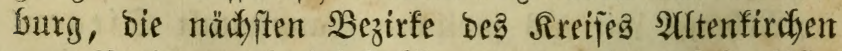

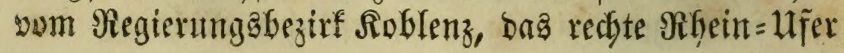




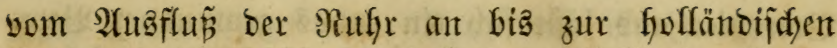
(S)ränze, die an Ringen ftozendon Thetle Der $\mathfrak{A}$ tem= bergiichen Serrichaft Meppen, Das Füritenthum Rippe= Edfauenburg nebit bem redyta yon ber siejer lie= genden Theil bes befinjuen Sdyatenturg, die an ber recten $\mathfrak{W e j e r}=$ Seite liegenden Bezirfe yon Braun= fonveig (bis (sid)ershaujen) und Şannoper, bie näd)= iten Drte won Neiederfeffen (bis (Sirebenitein), Das Jüritentfum Waldecf nebit einigen anjtozenden gro $\hat{\beta}=$ Gerzoglict $=$ heffifden Theilen. (E⿱ auf Den erften Blicf bret Scautabtheilungen entge=

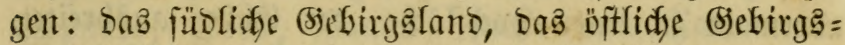

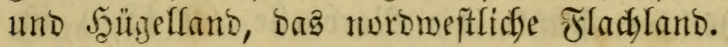

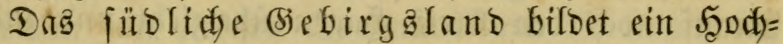

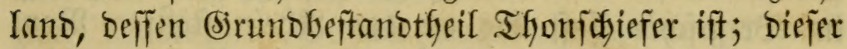
weicift in ben füblidben Ig geilen meift ber Sraumarfe, in ben nörolidben weajelt ex theila mit Riejelichiefer theils mit Ulebergangafalfitein und buntem Sand= ftein; bie einzeln anftretenden Porphyr=, Sirunftein=, Supferichiefer $=$ Duarzeres = und Bafaltbiloungen find nicht bebeutend genug, um ben Sarafter gröperer Gegenden zu beftimmen; unter Den Tertiärgebilloen tritt ber Majdyelfalf in ben norböftlidften Theilen

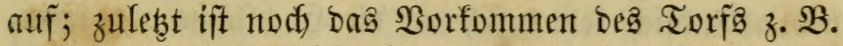
auf und an ber (Ebbe bemerfensmerth. Die Durd $=$

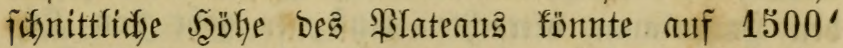
angeid)lagen werben, jebod) haben fiț bie (siemäfier

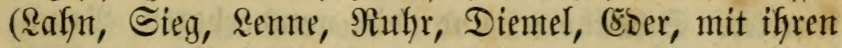
zahlreichen Zuflünfen) natürlid tiefere Furdyen ge= graben, wäfrend es andrerfeits yon höhern berg= zügen überlagert wirb. Der Mittelpunft Des Bla= teaus ift in ber (Siegeno vom Sinterberg (2146') zu judben, wo fids zugleich im Sablen arfenberg (2695̆) Der hödite \$unft Des ganzen (siebietes finbet. 
Don fier aus läżt fïch ein etmas gemunoner SBerg= zug jüblidy bis zum öberfopi (2000') verfolgen, welden lestre Siebirgafnoten bie Berbinbung nad Submeiten Gin mit bem WBeftermalo, nach Süboften fin mit ben oberbefiticisen (sebirgen (Bogelaberge u. ₹. w.) vermittelt. Diejer sBergzıg bat wiftlich bie (5irefichaften wittgenitein, weitlich einen Theil bes

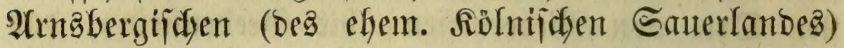
und bas Siegnifache liegen; er fentet fürzere 3meige nad) erfitrer (siegend, längre aber nach leştrer, wo

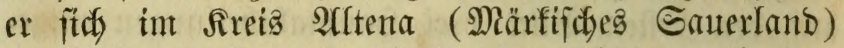

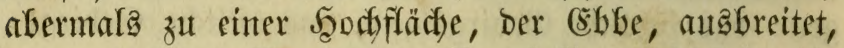
beren Göbditer Siunft Die Norbhelfe (2112') ift, barauf nod Den Sireis f̧agen überziefyt und zuleşt

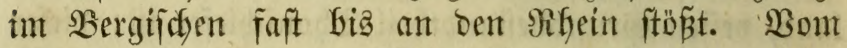

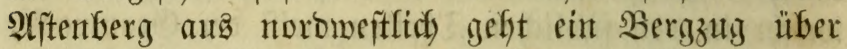
bie Şünau $\left(253500^{\prime}\right)$ und ben

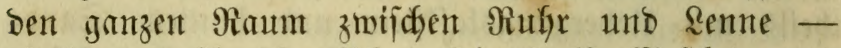

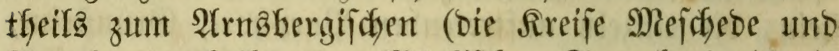

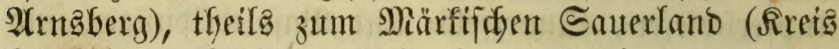
Sjerlohn) gefjörig - mit einem Siemirre won $\mathfrak{B e r}=$ gen zu überlagern, aus benen fïd) nowntals eine fleinere Bergflädye als Balverwalo $\left(1550^{\prime}\right)$ hervor=

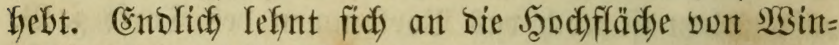
terberg norböftlidg ein britter Bergzug, ben man als

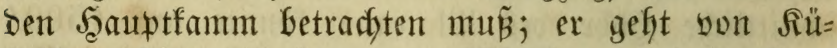
ftelberg über bie Syoppern (2כ̌41') und das pflan= zenreidge Siffelfforn und bie munberbaren $\mathfrak{B}$ rudd)=

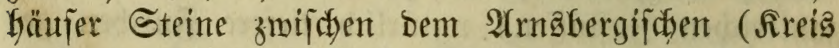
Brilon) und bem Malbecifiden in ber bebeutenden

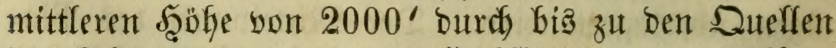
Der $\mathfrak{A l}$ me, wo man bie $\mathfrak{g}_{0}$ fofflächen yon Brilon,

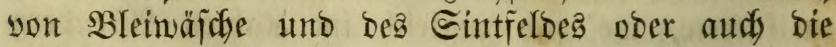
Stabt Maraberg als fein Ẽnde bezeidynen fant. 
Naid) Diten fanbet biejer Bergfamm bie Zweige Iet

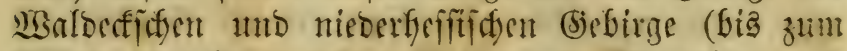

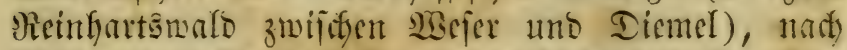

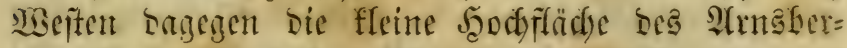
gerwaldes (Durd)idnittlich ctma 1000'), bie bent

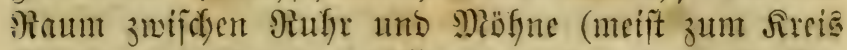

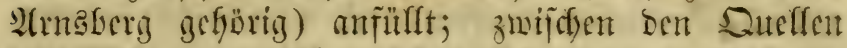

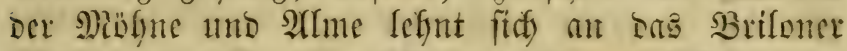

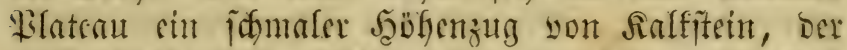

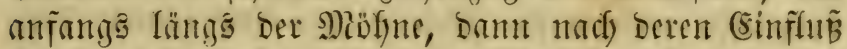

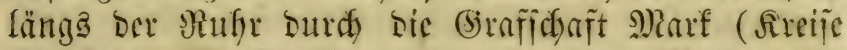
Rippitabt, Goeft, Şamm) unter Dem Samen Ier Jaan zieft, in Den weitlidyten (Siegenden Der Marf aber (in Den fireijen Dortmund und Bodum) fitd) junt Närfijoden Steinfoflengebirg verfreitert and

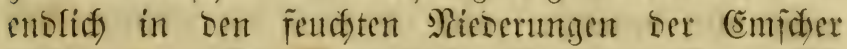
werliert. - Die Jlora biejer (Siegenden ifit ziemlida

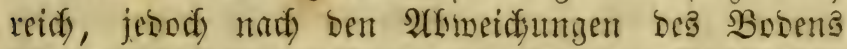

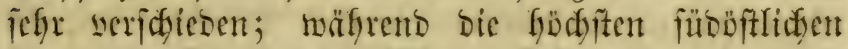
(siegenden fits Dute) jubalpine Fiflanzen (Ranunculus aconitifolius, Dentaria bulbifera, Sonchus alpinus 1. \%. w.) farafterifiten, treten uns an Dex Saar bie falflebenden, an ber Ebbe pouar bie Torf= pflanjen entgegen. - Mans nun die Şilfōmtittel be= trifft, bie mil zal Sicbote itanoen, io find fie jol= gende. Die afferjüblidsiten Bezirfe (namentlid) mein

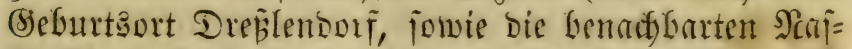
iauifden Drte Serbort uno Diflenburg) find mil

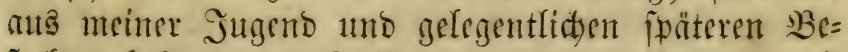
jud)er befannt, Dods ift meine Renntnip Det borti= gen reidten Flora mux lücfenfart, und ids forbe

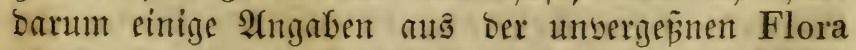
Herbornensis wun Reer (in ber $\mathfrak{A}$ ¿agabe pon 1790) folvie aus bet Jlora bet Naffau= Drantijden Ranbe 
yon Siatfaritta Şclena Dörtien (1794) cuthumt=

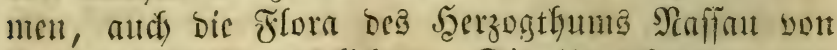
Şung (1832) verglidyen. Die limgetumign you Siegen fint von meinem vereffeten Frante, bent Frovinzial=Edyulrathe Suffrian in Miünfter, wälf= rend feines Âtuenthaltes in Siengen als Director

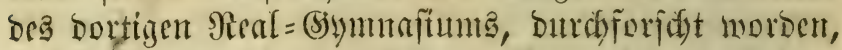
und id verboufe bemielben alfe bafint gefoürigen

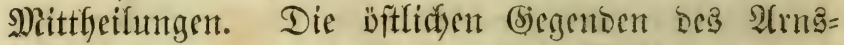

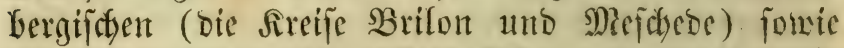

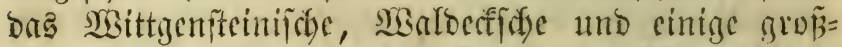
herzoglid =heifitiden Besirfe fint in ber Flora Waldeccensis et Itturensis von \$ülfer fefombelt, und idf) frabe bavon ben geeignteten (sebrautd) ge=

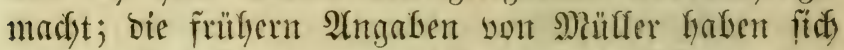
nidyt affe beftätigt, utno id babe bie Siffanzen ge= ftriffen, beren Borfanbenjesin nicht näfer Gegrünbet

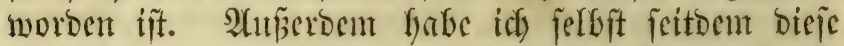

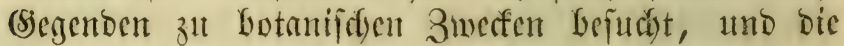
Untgebungen won Brifon fino befonters genta von

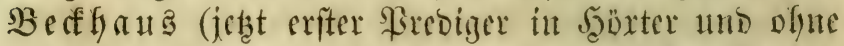
3weifel ber bedeutendite Jenner Der äftlid)en $\mathfrak{B}_{\text {ezzirfe }}$

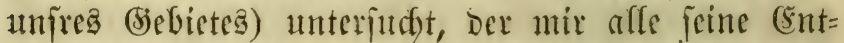

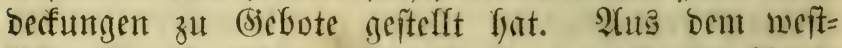
lid)en $\mathfrak{2}$ (n) Verig und Solpe) befize idd nur getegentlidse unt

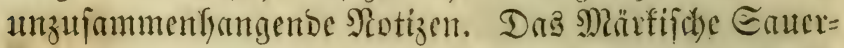
Iano (in weitefter $\mathfrak{A} 115$ orfinung genommen bie Sireî́ altena, Jierlofin uno Sangen) habe iif zwar auf

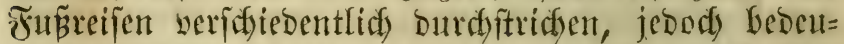
tet bas nidgt viel, bagegen liejerte mir ber weritorbne

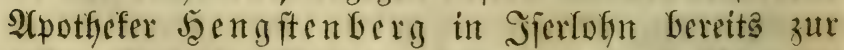
erften $\mathfrak{A}$ uägabe Notizen, Gejonbers crmünifit aber

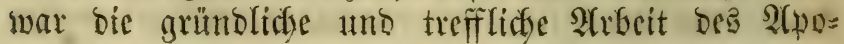


thefer you bet Maref (jebt in Samm) in bent

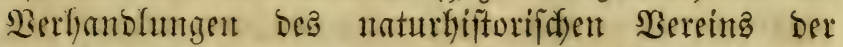

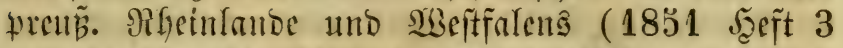

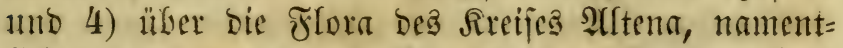

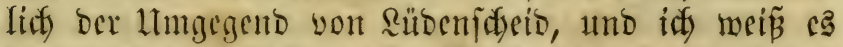

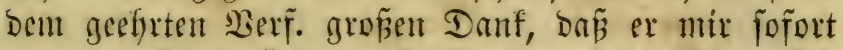
Das betreffende Sacft mittheilte, fo dai id noch redst= zeitizen (Sebraudi Dabon madon fonnte. Dis untere

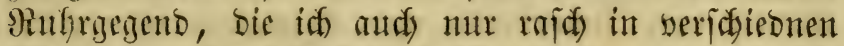
Sidbtungen durdyftriden habe, fand - was bie llmgebungen yon Şattingen betrifitt - einen fleiši= gen Botanifer in Bhlumeroth zu Şattingen, Der utidy Surd feine Mittheilungen fehr verpflidetete. Crinige Notizen über bas angränzende Bergifd ent= Iefinte idh Don won Mittaen befannt gemadyten Seitrïgen.

Der zwcite voct bitlide Theil unfres Bebietes umingt bie sisefergebirge mit ifren Thälern.

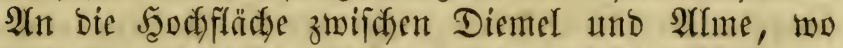

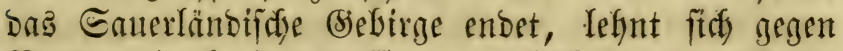
Norben ein breiter wafferarmer Şöhenzug, meift bie Egge genannt, ber bas Paberbornidye burdyduneidet; $\mathfrak{c}$ ift wie alle folgenden Bergzüge Flözgefirg, mo Salf = uno Ganditein wedyjeln. Eein weftlidser $\mathfrak{A} b=$ fall (in Die fireife SBuren und Faberborn) ift furz

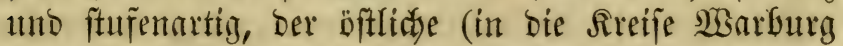
und Brafel) ift weitgeftrecft, inoem fiț Bergzüge nad) bicjer Eeite beräpteln, bie eine $\mathfrak{A}$ nzabl yon

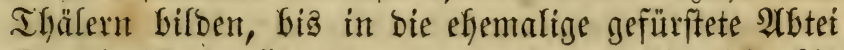

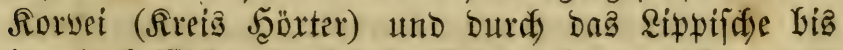
in bie helfifdue Srafidyaft Edyauenburg reidyen, und meift mit jälyem $\mathfrak{Z}$ biturz erft an Der Wejer endigen; in cinem biefer Seitenzmeige liegt als hödjter Funft her Rüterberg $\left(1500^{\prime}\right)$ zwijd 
Mit Dent Berüfyeen Der Rippifd)ent bränze tritt bie Eigge als zwar nidyt hoher (bie Gödjiten (Bitifel fitto Durdyidynittlich $1000^{\prime}$ hod a aber idyarfbezeidyneter (jebirggzug hervor, ber im 2affgemeinen unter bemt

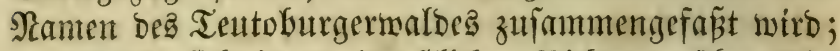

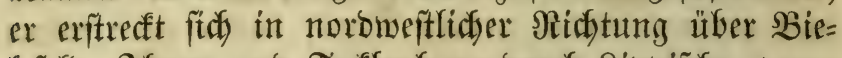
Terels, SGurg und Tefflenfurg burds Rippifdse, preu= Bifide und Gannöberidye Rambestlyeile, bis or in ber (Begend yon SGbenbüren und Bebergern fids in ber

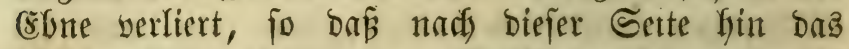

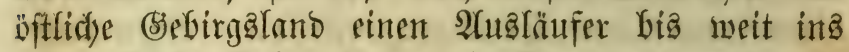

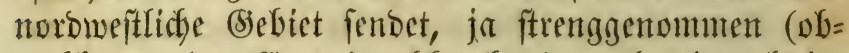
mofhl yon ber (Ems burdfbrodyen) nod) cinmal int

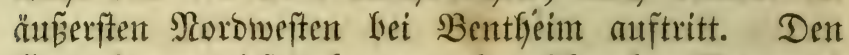
Şauptfaum biejes langen aber fdymalen Bergzugą bifben Sanbiteinberge, zu beren beiben Seiten voer

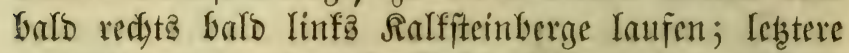
enthalten anfangas viel Majdelfalf, fpäter gefjören fie zut Sittra = Formation. Sn ber Ëntfernuttg sint= ger Meilen läuft paralfel mit bem Teutoburgerwald

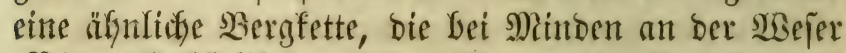
(Forta MSeftĩalifa) mit ber Margarethenflus beginnt

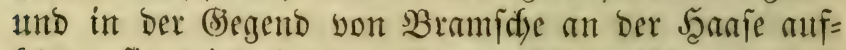
fyout; fie wirb in ber bjeographie mofle mit bem

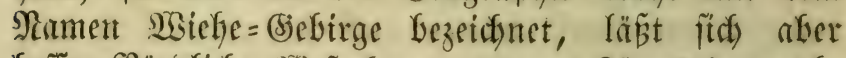

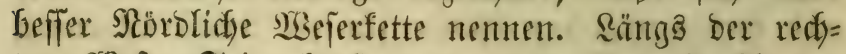

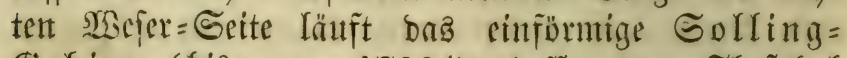

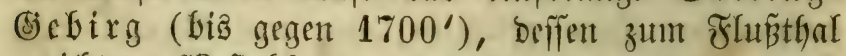

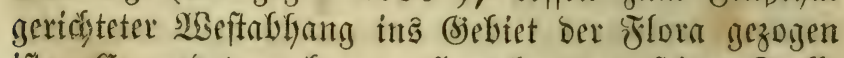

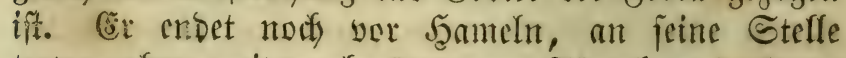
treten afer meiter abwärtä ber Süntel uno (vom Sanfentein an) bie Sdbauenburgifden isejerberge (Ruffocner Sllippe 1120'), welde mit Der Forta

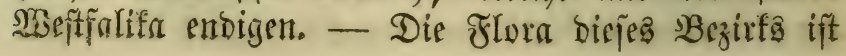


เcid) und mannigfaltig. Bon Marbutis an bis zun Sobenitein treten mandye Geltenbeiten ber mittel= voer oftoeutiden flora nuf (Coronilla montana, Hutchinsia petraea, Siler trilobum, Bupleurum longifolium u. ศ. w.). Die cigentliden Bergpflan= zen bleiben - Dod immer abnefmeno - Dem Teutoburgerwald bis in Teffenburgijefe getreu, gefn mitunter aud) bis in bie nädite (5one binab, mo aber bie farffteinlager mit nody nidyt tiejer Gand= Decfe beberft finto; . Die Srebibeen find mohl am be= zeidjnenditen für dieje Farticen. Sbwohl ids faft jeben Punft biejer Giegenden betreten habe, fo würoe

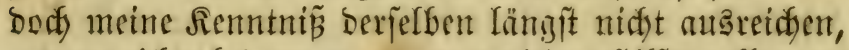
wenn nid)t bedeutente anderweitige Şifrşquellen zu Biebote geftanden hätten. Ias Pinderbormide und

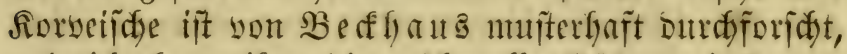

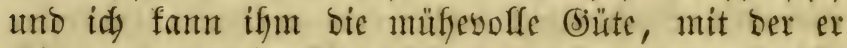

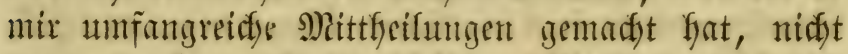
genug Danfen. (Einige fổbbare Notizen erfielt id)

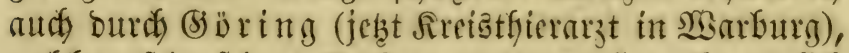
melder feit feiner (sntiermung won Sounteburg fids ber Botanif nifut entrpembet fort. Durify die fremno= lidse Bermittlung won Bbeffous erfielt idy aud bie jo nidytigen Mittheifungen über bie Flora won Javlzminden Dutch Dauber und Edaumann, De= nen id unbefannter Swrife fierdurd meinen herz= licben Danf abitatte. (Sinige $\mathfrak{A}$ ngaben aus bent benadbarten Nieberbeffen ftüben fid auf bie $\mathfrak{A b}=$ fundung Meurer's im Rintelnifen Programm

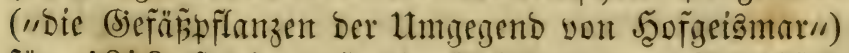
für 1848 fowie auf die Qrebeiten won \$ifeiffer

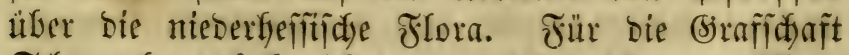

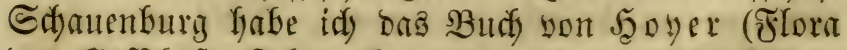
bet Saffdarft Sdammburg und 1mmgegend 1838) 


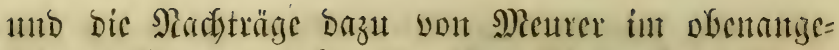

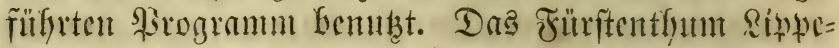

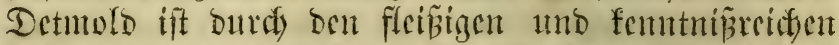

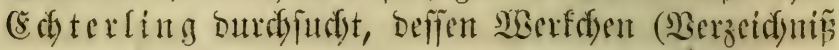
Der int Füriftenthum Ripye yorfommenton planers=

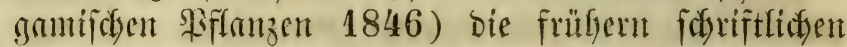
Mittlgcilungen verbulfitändigte. Die Humgebungen

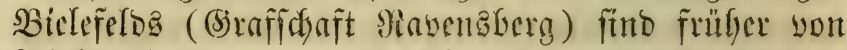
Af worben; über bas benad)barte Mlinoeniche fanden

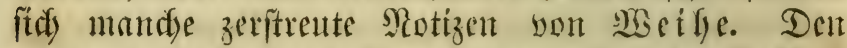

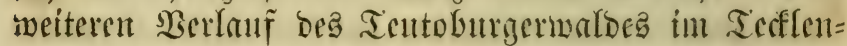

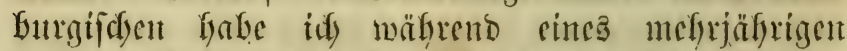
Durtigen 2 (uffenthaltes fennen gelernt. Lleber bie be= nadjbarten Sisgenton bes DEnabrüfidsen fonntent ats ber Chloris Hanoverana yon $\mathrm{Meyer}$ fowic

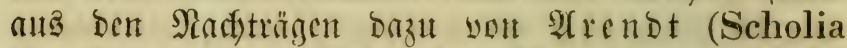
Osnabrugensia in Chloridem Hanoveranam 1837, umb (sinzefnes in ber Miergenaburger "Flora") be=

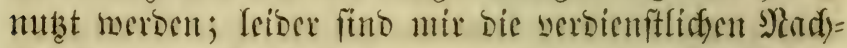

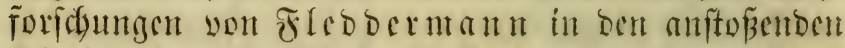

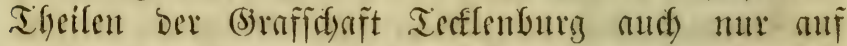
biejem mittelbaren sisege zugifonmen.

Der britte nordweftlide Theil nutere (bebre

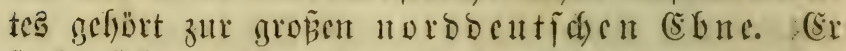

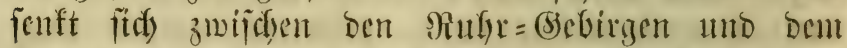
Ientoburigerwals ticr nad Diten sin bis \$aberform,

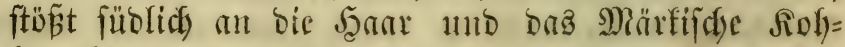

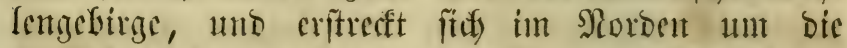
Mejerfette frerum bis an bie Mejer. Sorwohl ber Entboben vorferrident ift, fo medjeln bod bic

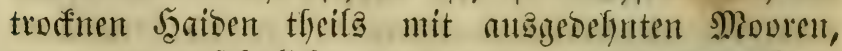
worunter anjefrnlidge Torĩmoore, theils mit idfwe= rem 2 dfferboden, theila mit bergäfnlidyen $\mathfrak{A}$ nidguel= 


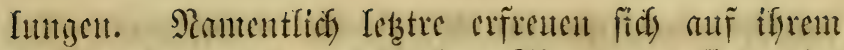
Sinlfifteinboben einer hübjden Flura; es find Dies

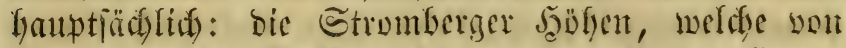

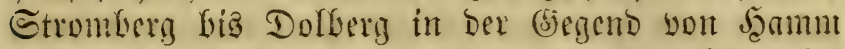

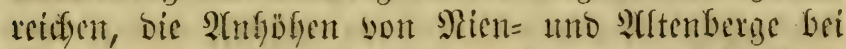

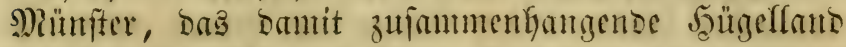

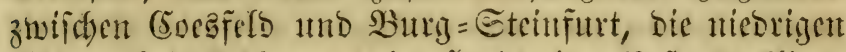

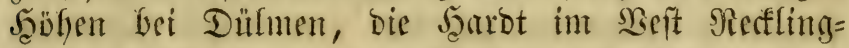

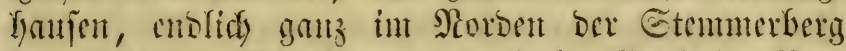

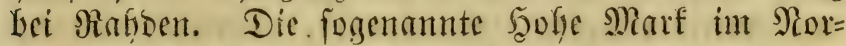

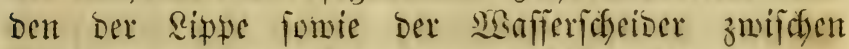

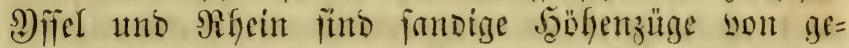
ringem botanijaent Sntereffe, uno nod) unerfeblidyer finto bie Dünenartigen Sandfügel an ber (Ems im

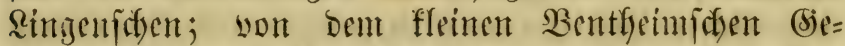
birge ift idson früber bie Mebe gewejent. In alfent möglidjen Ridftungen ift biejer Theil bes Sjebietes yon mir Durdfifteifft worben, fo bas mir ber Saraf= ter ber SBegetation butrdyeg befannt ift; zut ge=

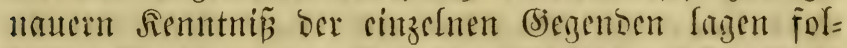

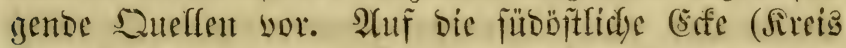
Baberborn) bezogen fith vereinzelte Notizen vom

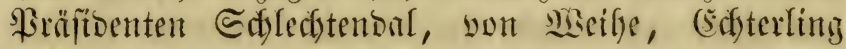
und Berffaus; hiber bie llmgebungen von sisicben= brücf bis Stromberig bin ertheilte mir Alputhefer Roetticher bereits zut früfern $\mathfrak{2}$ uffange bie will=

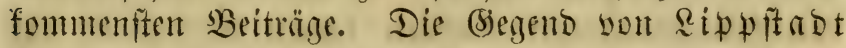
fand neueroings im 2lpotyefer $\Re$ cintige cinen fent=

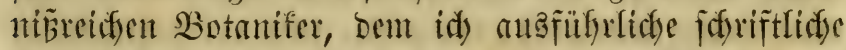
Beiträge fowie 3ujentoungen lebender Fiflanzent zut

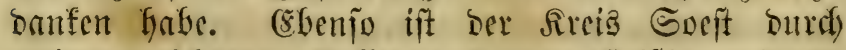

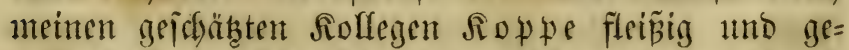

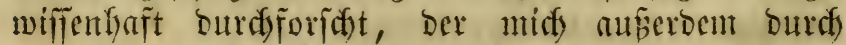

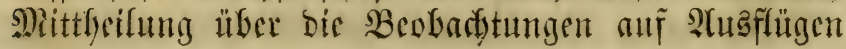




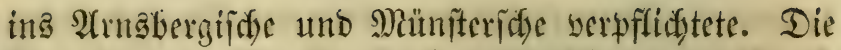
Diegento von Dortmund hat Suffrian wäfrent feines Dortigen 2 (uifentigaltes fefre grünolid fennen gelernt und mir mit gütiger uno freundofdafittidyer Riferalitüt aflez zur Berrïngung geitelft, was er Dort beubardtet hatte. Die Flora bes Beftes Meffling=

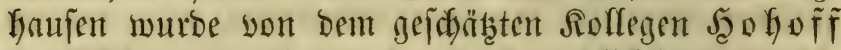
jorgfältig entworfen und mir freundlichit zhigefanot. Das nörolid yon Der Rippe gelegne Müniterfano (bie Rireife Münfter, Martendorf, Berfum, Rübing=

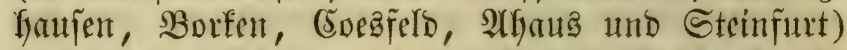
fand einen gelegrten und anerfannten $B$ efoureiber in Bמönninghaufen (Prodromus Florae Monasteriensis 1824), Defifen Beobadibtungen fid) audi bis zum Rlyein uno bis nad) Bentyeim auabefnen; na=

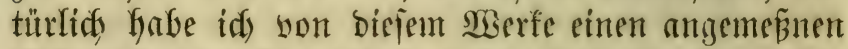
(biebraud) gemadbt, jebod) nid)t ofye mandje ergän= zento Beiträge 3. B. vom verit. Ricolat in slan= renodr, won Roppe unb Roettider, wom werit. Gäfeland in Eocareld uno won Micruel in

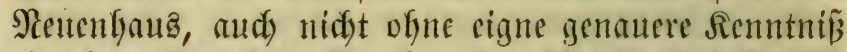

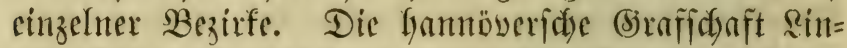
gen babe ida felbit einigermaßen fennen gelernt, wozll einzelne Notizen über bie angränzenden finn= növeriden Siezirfe in Meyer's Chloris und in Kodf'z Synopsis famen. Heber bie 1tmigloungen won Syunteburg uno Rafben famen mir fidon zut

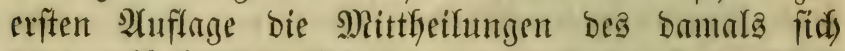
Dort aufgaltenten bö̈ring zu, uno ber leb̧te Theil

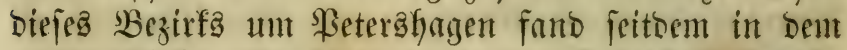

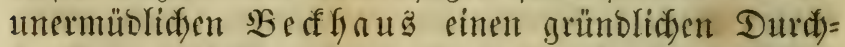
foridyer, zu befifen Mittlyeilungen nod einige $2 \mathfrak{n}$ ga $=$ ben yon Ëngelbredt famen.

Die inmre (sintidutung Des $\mathfrak{B}$ bdes betreffens, 


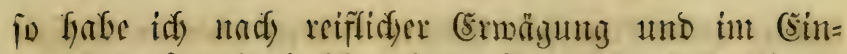
verftänoniz mit fad)funbigen Freunben bas Rinne= idse Syitem beibefalten. Dem geübten Botanifer ift es zmat gleidh, ob cr Siflanzen nad biefem voer nad) Dem natürliden E!yiteme beftimmen forf, allein id) Gabe zunädyit bie Jugeno in शage, bie zut Semtuip Der Natur forming bildet werben folf. Miag man aber fagen, was man will, fo viel bleibt un= umitüb्alids: bie Jugeno (wie jeber 2(nfänger) fann fid) mit Sidjergeit nut in Rinnefden Eyfteme zu= rectrtfinoen, wäfrend fite ons natürlidbe niddt zut über= fefen wermag und mefy barin ratheno herumtapt nls grünblid zu Nerfe geft. Sit freilidi cin ge= winfer Sorraty won Rifanzenfenntuí erworben, fo iit bic Befonntmachung mit Dem natürlicken Syitem ratfiam, und idy babe zu bicjem (Ënde cine Ueber= fitd) Iet (3iattungen nad) Ietgterm bieier 2uflage bei= gerïgt, mid) babei ber 3ufanmentelfung oer Jami= lien in Sody's Synopsis bedienend; io mangelfart bicier Berfud) nod) feit mag, fo wirb ex ez bod) wofl möglids machen, Siattungen rutd auj bicjent Sisege zu beftimmen, und jomit bem Rebret (Sele=

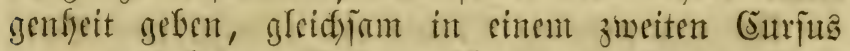

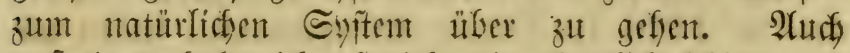
auserbem habe id), foviel mir thunlids fidien, an ben Rinnefden Namen feitgefialten *); bieje fint

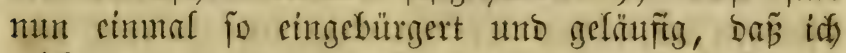
midf nut ungern yon ifnen trenne, uno Das mids bic Endut nady neuen Namen (of́t nod) Daju red)t alfermen!), wie fie bcionbers Den Franzojen anfar = tet, ordentlidy ärgern fann. NBD es bie Fortidyritte Der saifienidart mit fith bringen, werben freilids

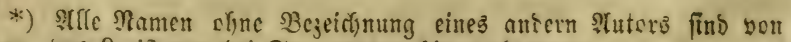

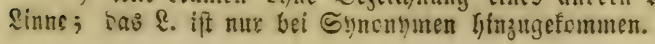


inmex mefre Rinmefde Namen fallen, aber im 2lurges ben Derfelben forlte man mefyr zügernd als rafd fein.

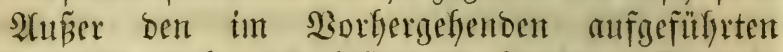
Scilfomitteln babe idy Geionoers benubt: Deutidy)= Innos Jlora von Mertens und $\mathfrak{K} d \mathfrak{d}$, die Synop-

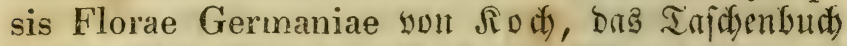
ber Deutidyen Flora won $\mathfrak{N o d}$, die Flora excursoria yon Reid)enbad, and bie Flora bon Nord = Imb M) ittel = Deutichlano yon (siar if e.

WBas die 2ufnafyme der einzelnen Pffanzen be=

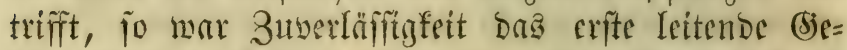

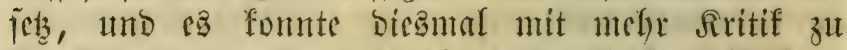
Werte gegangen weroen, als in ber frülyen Aruffrage

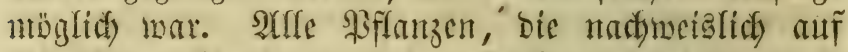
Säuidumg berubten, fond geitricben, dic mix nod ungetwiffen, füt bie id alfo nidgt cinftefyn möbte, find mit einem Siruze bezeidyet worden. Das für Den erîten Blicf Lefremoende Refultat, Dấ bie neue Âffage weniger Species als bie alte enthält, wirb bet näbrer Frürung nidbt auffallen und ber (S) [aub)= wütoigfeit bes nun $\mathfrak{A} u$ figeftellten feinen $\mathfrak{Z}$ bbruth thun.

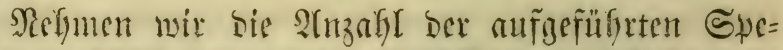
cies zu 1400 an (einige Einfdaltumgen faben dic 3abl um 12 Sammern berringert), ziefyen wir etwa 70 Sultupflanzen und eben fo biele wermiloerte Brflamzen ab, fehen wir ungefäly 90 als nodb un= gewi ilbrig, beren Standorte mit Sidyerfeit crmittelt find.

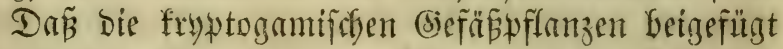

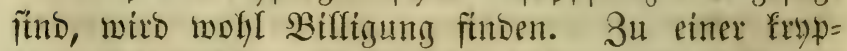

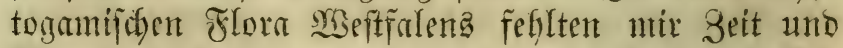
Mittel, Dod wenn folde nidit ctwa bald yon Dr.

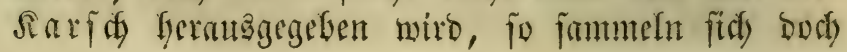




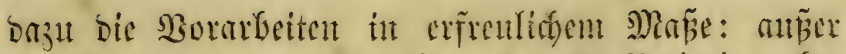
beffaus, won bet Mard und Reinige be=

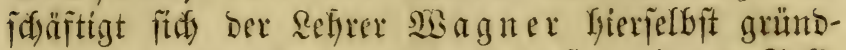

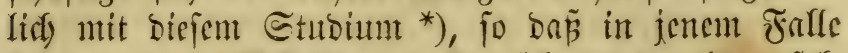

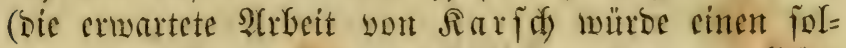
d)en (sebanfen freilich überffüfitig madjen) mïglider Miseife Diefem Bandye ein zweiter Theil, bie frypto= gantifoen Martpflanzen cutfalteno, folgen fünte,

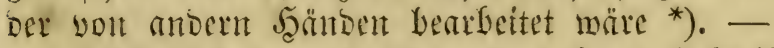

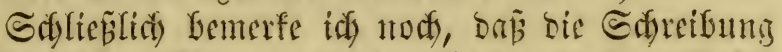
ber Dentiben Namen fowie üferfyatht bie Redit=

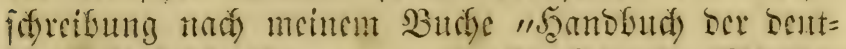

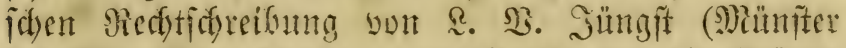

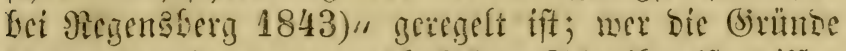

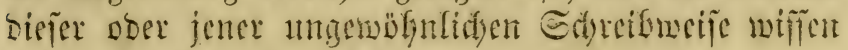
wilf, minge Dort Hadidilngent.

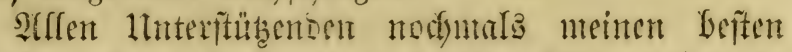
Dant, und an fie fomie an fontige Sfflanzen resunde bie sitte, mix ifle sBeobadtungen mittfeilen zit worlen!

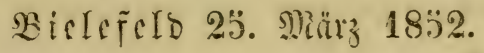

\section{3. จงแngft.}

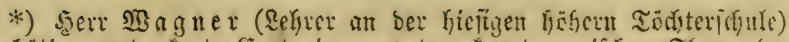
if erbotig, netroffnete (Ecuturien aus ier fryptogmifd)en Flora (3u 1 Thłr. 15 Sgr. für sie (Eent.) abyugeben, wenn man firth in perts= freien Briçen an ifu wendet. 



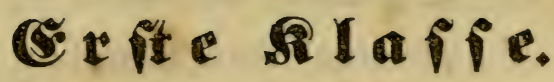 Monandria.}

\section{Sronung Monogynia.}

1) Dippunis. Tannenwedel. Blüthenfülle cine felchartige Saut (in Den ŜBinfeln ber quirligen Blätter),

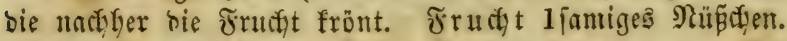

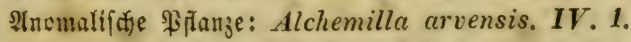

\section{Sొrommg Digynia.}

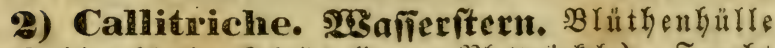
cine 2fwaltige bäutige Scheide (in ben BBlattwinfeln). Frud t

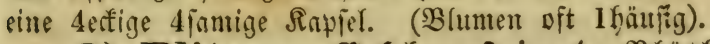

3) IBlicame. Crobecripinat. Blüthen ülls 3ipaltig. ๔ame 1, bon ber beerenartigen Jrudyt beberft.

stnemar. \$ftanjen: Festuca bromoides, Myurus. III. 2.

\section{Sronung Monogynia.}

\section{1) Hippuris. Tannentuedel.}

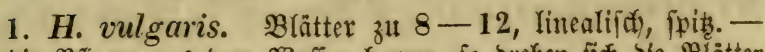
Ragt bie Pfianje aus bem Maffer hervor, fo brefen fitin ble Blatter

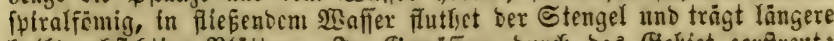

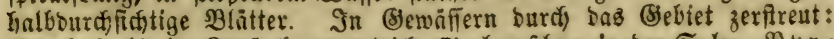

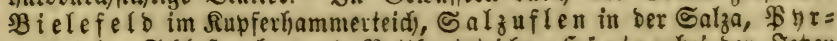

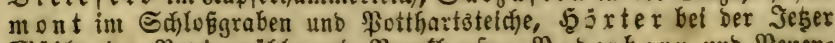

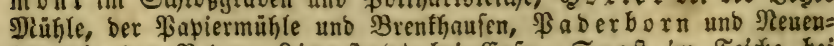
haus in ber \$uber, Rippfad bef Enfe, Soeft im Teiche bei

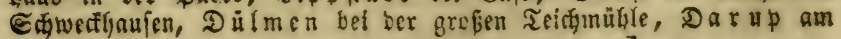




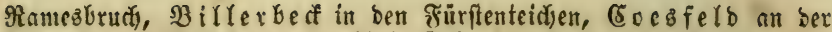
Sitabelle und SBlfotahn; im fübl. Sieb. feltener bod) z. B. Siegen

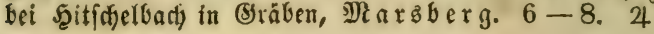

\section{Soronung Digynia.}

\section{2) Callitriche. Wisa fiferftern.}

\section{* Zute Blätter verkébrteirund.}

2. C. stagnalis. Sumpfwafier ftern. Briffel Greibent,

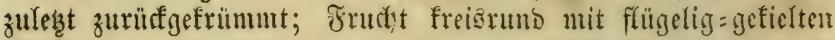

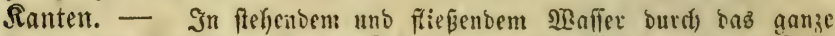

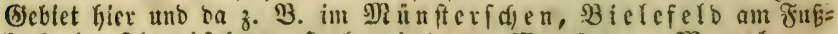

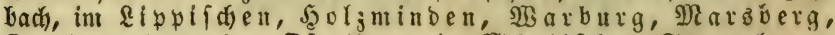

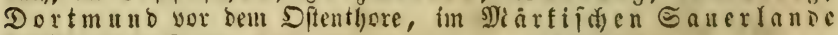
hâuกี่. $5-8.24$

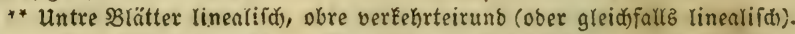

3. C. vernalis. fiurtzing. Frügliug șafjerftern Dedblätter etwas gebogen; (Briffel aufredt, bals berid)win=

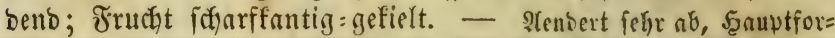
men: a stellata (C. stellata. Hoppe) obre sBlätter verfefirteirmo, weniger ausgeranbet; $\beta$ intermedia (C.intermedia. Hppe) wie vor. mit mef̧r ausgeranoeten Blättern; $\gamma$ angustifolia (C. angustif. Hрpe) alle Blätter linealificy, sory am (Brunte nicht brciter; $\delta$ minima (C. minima Hppe) in aflen Tffeilen flcincr, mcil fie auber

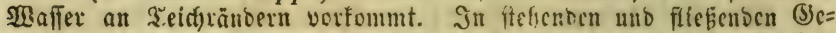
wniffern bäufiy, $\beta$ uno $\gamma$ 3. BB. bef. häufig 2 ic!cfelo beim fiuter= Gammer uno in ber Senne. $5-8.4$

4. C. platycarpa. Êt3. SBreitfrütiger $\mathfrak{X}$. Deff: Glätter firfyelförmig, an ber Spibe ziemlich gernbe; (5rrifiel Glci= bent, zulebt zurürfgefrimmt; Frudut an ben Rrnten flïgelig= gefielt. - Reniert ab wie bie yor. und biufte woht mit berfelben

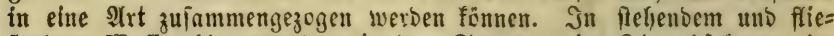

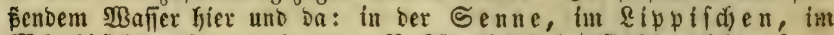

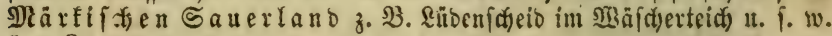
$5-8.24$

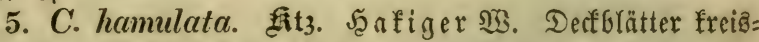
fictelförmig, an ber Splize hafig; Sriffel bleibent, felyr Iang, auseinanbertretend; Frudft an ben Ranten fdimalgeflïgelt. Nenbert ab wie bie vorigen unb bilbet mit ifyen wahl nut eine 9 trt. In fefienoen unb fliefenden (Semenffern ber. Der (Ebenen, bod) aud in

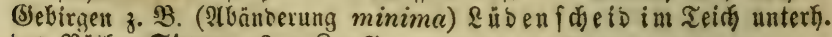

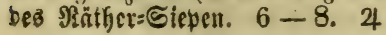




\section{Digynia.}

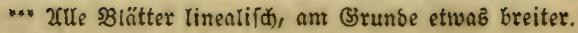

† 6. C. autumnalis. Sgerbitwafierftern. Frnd dut

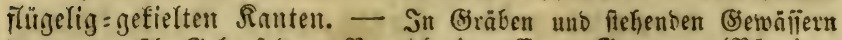

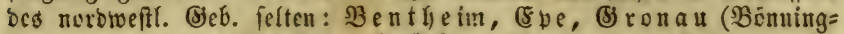

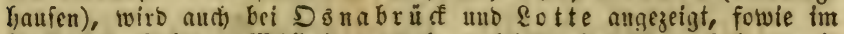

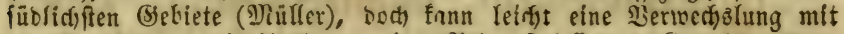
ber Albart angustifolia ber yorigen Anten fattînben. 8-10. 4

\section{3) Blitum. EEtofecripinat.}

7. Bl. capitatum. (๕nDblüthiger (ङ. Blätyen in stadften und endftünbigen ä)rigeแ Rnüue(n. - Trud)t erbbees

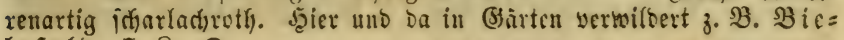
lefeld. 7.8. $\odot$

8. Bl. virgatum. Seitenblüthiger (ङ. Blüthen in

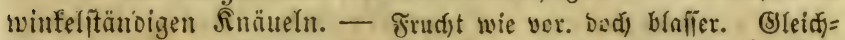

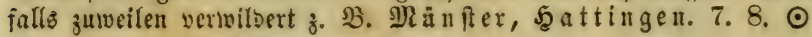

\section{Brocite Alafie. Diandria.}

\section{Soromung llonogynia.}

- şlumen uuvollftänsig.

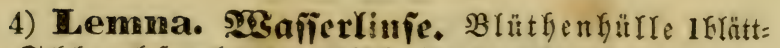
rig. $\sigma$ d) $\mathfrak{l a}_{\mathfrak{a}}$ (d) frut th $1-2$ fäct)erig, $1-2$ jamig.

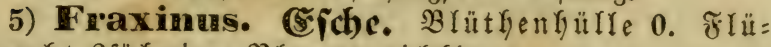
gelfructit 2 fütferig: $\mathfrak{B}$ lumen bielefig.

** SBlumen volrftänbig unterftänsig.

$\dagger$ BlumenÉrone regelmäbig.

6) Ligustrum. Raintweibe. Selta 4 jännig. Srone trichterförmig 4 fpartig. 3 eere 2 füdjerig.

7) Syringa. Siringe. Rel 4 jä̆hnig. Rrone triduterförmig 4jpaltig. $\Re$ ap fel 2 fü̈t)erig.

It Blumentrone unregetmákig. a Eamen besect.

8) Veronica. Éhrenpreis. Rel (i) 4-5theilig. Irout 4 jualtig. Rapjel 2fäcterig.

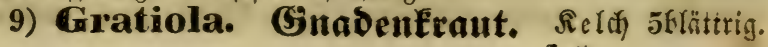


Arone 2lippig, obere Ripwe untgebogen; (nod, 2 unrudutbare Strubfäden). Ranfer 2 fächerig.

10) Pinguicala. Fetteraut. Refd 5ipaltig. Rroue 2lippig gefpornt. Rapfel lfücherig.

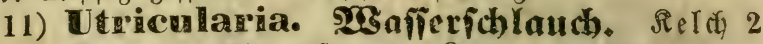
blätrig. Rrone nasfirt gefpornt. Rapfel l fädyerig.

b Eamen nackt.

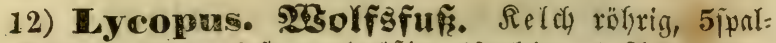

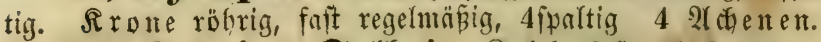

13) alvia. Salbei. Seld faft glofenförmig, 2lippig. Rrone rachenförmig. Staubäben mit Duerfortfäßen verieglen. 4 gl thenen.

\section{*** Blumen volftänoig obsritänoig.}

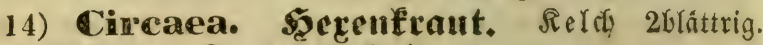
Rrone 2blätrigig. $\mathfrak{R}_{\mathrm{a} y \text { fel }} 2$ füd)erig, 2 jamig. **** Bargblüther.

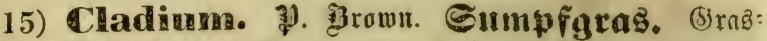

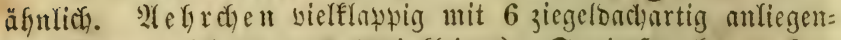
ben Rlapwen (bie unteren brei fleiner). Steinfrutht trorfen. * Anomalifine \$sflanzen: Lepidium ruderale XV 1. Schanus albus III 1. Scirpus ovatus III 1.

\section{Sronumg Digynia.}

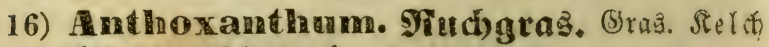

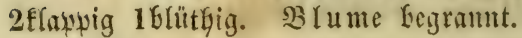

\section{Soromung Mlonogynia.}

4) Lemma. Wafferlinfe.

9. L. trisulca. Dreifurdyige N3. Blätter lamzett=

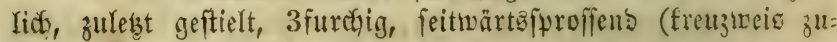

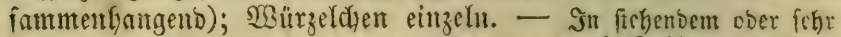

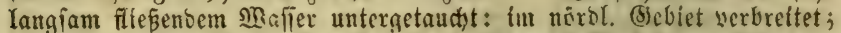

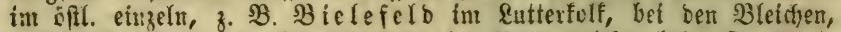
Sübbraf, Shilfe, im \&ippif dien im Rorberteicíe, bein Strnghert:

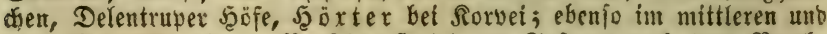

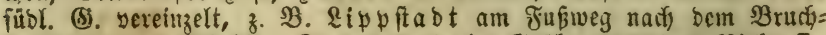
baume zat, Torffufyle, Dortmunt in Bräben an ber Biefgrife, Défebe, Berleburg. 5.6. $\odot$

10. L. minor. Rlęine $\mathfrak{W}$. Blätter berfefrteiförmig, 


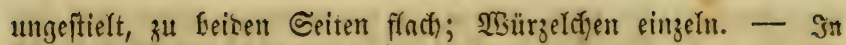
fethenbem $23 a$ ifier fifuvinment. 5. 6. $\odot$

11. L. gibba. Bu rfelige 93 . Blätter berfefrteifür:

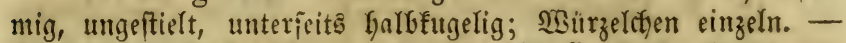

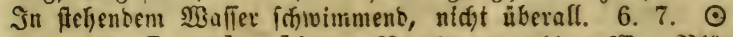

12. L. polyrrhiza. Bielwurzelige $\mathfrak{B}$. Blätter rumb:

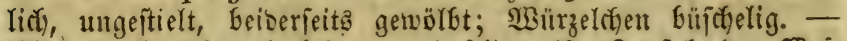

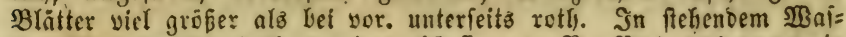

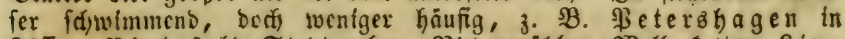

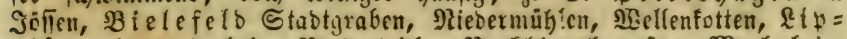

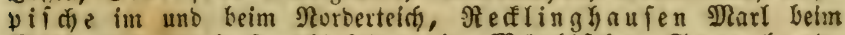

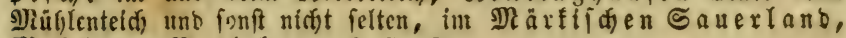
Diefdede, Berteburg. 6. 7. $\odot$

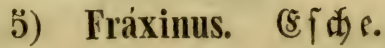

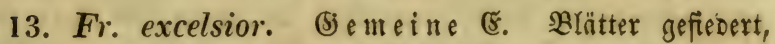

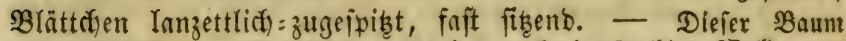
wito vielfares angepflangt, fommt aber aud in fenditen $2 B a f$ bungen wilb unb verivilbert yor; in sinlagen finbet man aud oft $F r$. pendula

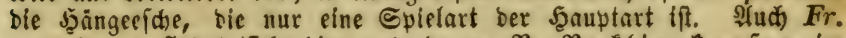

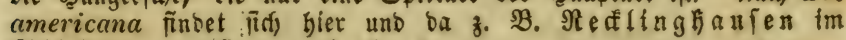
Sdjlobegartea zu soerten. 4. 5. मे

\section{6) Ligustrum. $\Re$ ainweib}

14. L. vulgare. Biemeine $\Re$. igufter. Blätter

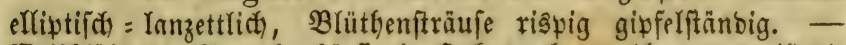

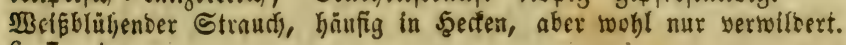
6. 7. 5

\section{Syringa. Siringe.}

15. S. vulgaris. (5) emeine ऽ. Blätter eirunb= her: förmig. - Baumartiger straudi) mit violetten ober blapbrauen ober

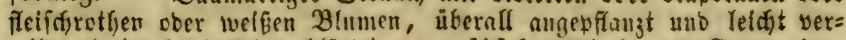
ivilberno (aud) bie feiner:blättrige perfif dye Etringe, S. persica,

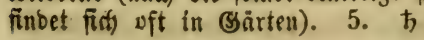

\section{8) Veronica. Egrenpreis. \\ - Blüthentrauben brattwinkeerfäubig. \\ $\dagger$ Reld) 4theilig. \\ a $\mathfrak{B l a ̈ t t e r ~ E a b l . ~}$}

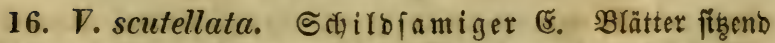
lineal = lanzettlict) entfernt = gezäfynt, Trauben abwedjelno. -

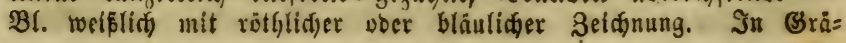




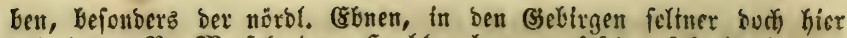

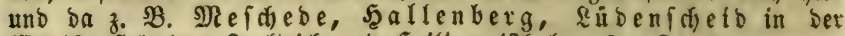

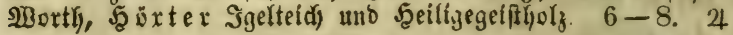

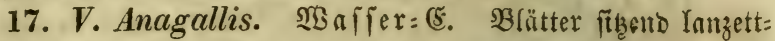
lich (ober eirund) gefägt, Trauben gegenüberftefjeno. - B!. meifit röth)lich, audi hellblau mit bunfleren Ilocrn. In felgenten

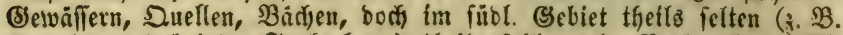
Dortmund bei ber Funfenturg) theils ferlend (3. $\mathfrak{B}$. im Rreis $\mathfrak{A l}=$ tena). $5-8.24$

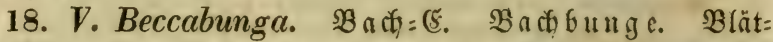
ter geftielt elliptifich geferbt=gefägt fabl, Iraulen gegemüber: ftänoig. - SBl. Blau mit bunflexcn Ilbern, felten folvie bie ganze

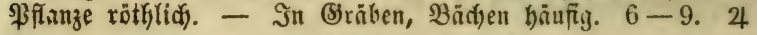
b Blätter behaart.

19. V. officinalis. (E) (f) $\operatorname{ter}$ (5. B̧ätter verfefyrteirum nit feilförmiger $\mathfrak{B} a$ fts, feingefägt, bie obern fefr furz geftielt, bie untern am Blattítiel herunterlaufeno, nebit bent aufitrefen= ben Gtengel raubbanrig; Truben gebrungen reidbblüthig. -

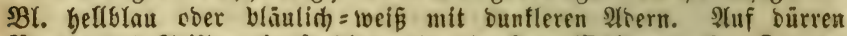
Bergen und Triften, in fandigen ober troffuen 280 loern. $6-8.4$

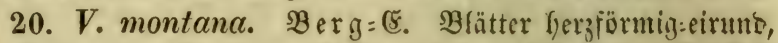
Innggeftielt, einyefdunitten geferbt=gefägt, nebit bent geftreften Stengel weidblyarig; Trauben locfer iwenigblïthig. - $B$ I.

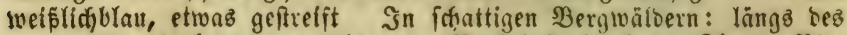

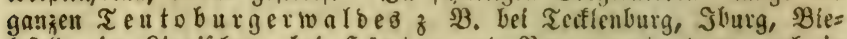

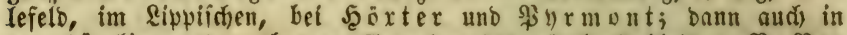
Dea bügeligen ober ebneren (senenden bes nöbl. Bebletz 3. B. $\mathfrak{P} e=$

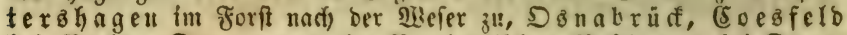
bef Barlar, Dortm uno im Rumbergifdien Buid, und bei Derne, Ramen; endida in ben fübl. (S) ebirgen z. B. Rübenfdecio im Ralf=

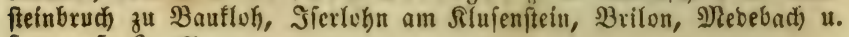
f. w. 5. 6. 24

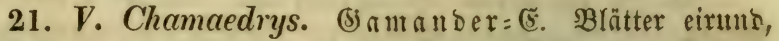
faft ftbend, eingefdnitten geferbt=gefägt; Stengel nufiteigen nut 2 SReiben zottiger Scanre. - SBl. Gel!blau mit bunfleren

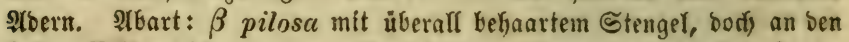

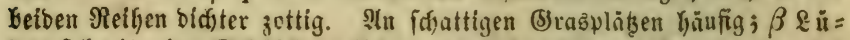
benideto im Bebuid grifdien Baufloh und bem Reuentofe, bet

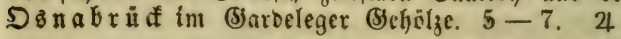

It Relch) 5theilig (ber 5te 3ipfel fehr Elein).

22. V. latifolia. Breitblättriger (E. Blätter unge=

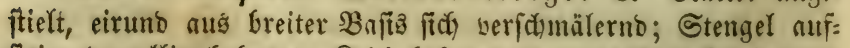

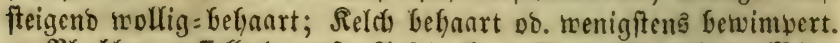

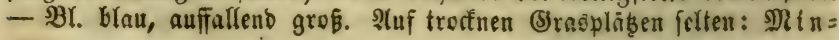




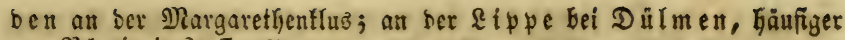
am $\Re$ hetn! 6. 7. 24

23) V. prostrata. (b) eftreff́ter (ङ. Blätter fefgr furz gcîtielt, länglich) (fât gleich) breit); Stengel niebergeftrefft, zum

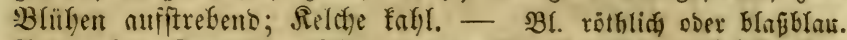

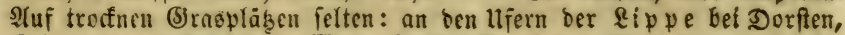

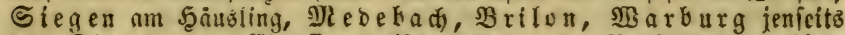

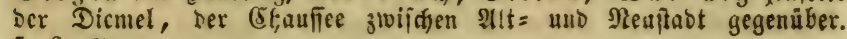
5. 6.24

** Blüthentrauben enditändig und oft nod̆ feitenftänoig, אronröbre länger alB breit.

24) V. longifolia. $\mathfrak{L} a n g b l a ̈ t t r i g e r$ (ङ. Blätter ge:

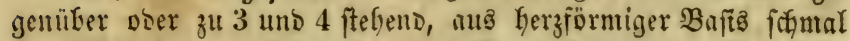
Iamzettlich Inngzugefpizbt, bis zur Epize focharf=Doppeltgezäfnt, nebit bem Stengel meichlanarig zottig. - Bl. blau. $\mathfrak{A}$ bart: $\beta$ glabra ( $V$. glabra. Schrad.) bie Blätter ganz fahl. Tuf $\mathfrak{B}$ iejen,

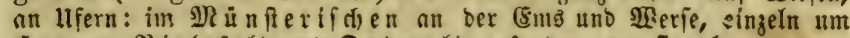
Jyantm, Bielefeld und Detmols gefunden, mo fie aber nur ver= ivileert id)eint, wie eз aud) ber Fall fein mag mit $\beta$, bie fîd am ङül=

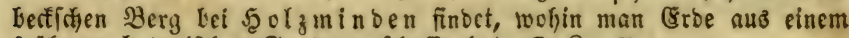
früferen botanifden Gorten geddafit hat. 7. 8. 4

25. V. spicata. 2lehrenförmiger (5. Slätter gegent=

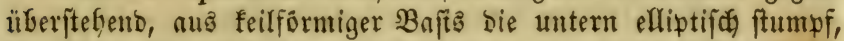
bie obern limealifa fpis, mefre ober weniger beutlich geferft= gejägt (oft faft ganzranbig), nebfit Dent. Stengel weichbef)aart. -

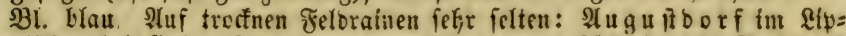

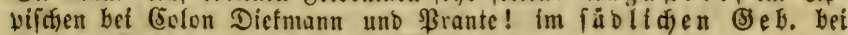
Brilon, siefdicte uno \&aažvge (Diüller) $6-84$

*** Blüthentrauben endifänbig, melft nur @đđeintrauben, inbem bie Stengel:

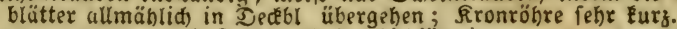

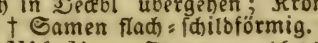

26) V. serpyllifolia. Duendelblättriger ※. Blät= ter gegeniberf́tegend eiruno geferbt:gezähnelt fahl, $\mathfrak{B}$ (üthentraube

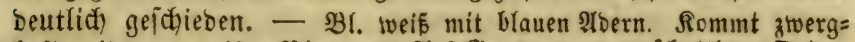
haft mit ganz tweifen Bl. עor. Nuf (S)razangern an fajattigen Drten. $5-10.24$

27. V. arvensis. Felb:(夭. şlätter herz=eirunb, bie oberen Ianzettliç ganzranbig, allmählicy in Deffbl. übergehend, Blüthenftieldyen fürzer als bie Rapfel, mufred)t. - Bl. blau. Rommt ziverglaft yor ( $V$, nana. Lam.) Saf bebauten unb whiften Felbern. 3 - 10. $\odot$

28. V. verna. Frühlings: (5. Die unterften $\mathfrak{B}$ lätter oual uno faum geferbt, bie mittleren fingerig getheilt, bie oberften in Decfbl. übergefeno uno linealifa; Bglitthenftielchen

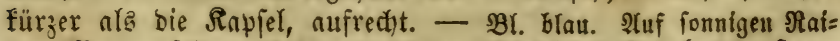

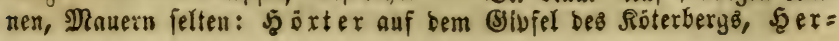




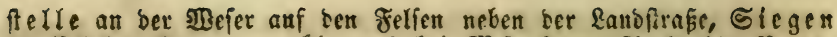

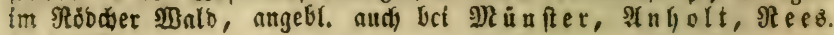
4. 5. $\odot$

†† Samer Eonḱab:bedienförmig.

29. V. triphyllos. Dreiblättriger (ङ. Die unterften Blätter eiruno ungetheilt, bie mittleren fingerig=getheilt, bie oberften in Decfblätter übergebeno uno Ianzettliç; sBlütben:

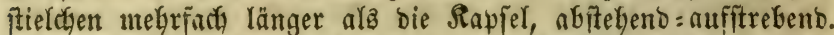

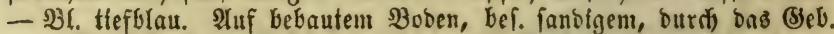
yerbreftet, boa nisht überall, in einigen (Segenben fogar fefor felten,

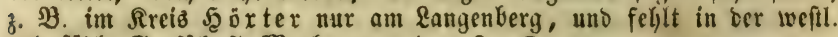
uno fübl. (Sraffidjaft Marf ganz. 4-6. ○

30. V. praecox. Früher (5. Blätter Gerzeirmo แn= getbeilt, bie oberften in Decfblätter übergefyend und Ianzettlich; Blüthenftielḑen ungefäbr fo lang als die Rapjel, aufitrebend.

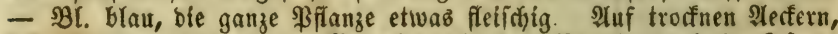
bef. thontgen, felten: im NR ü fterifden (Bouninghaujen), Jier=

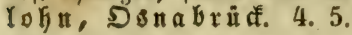

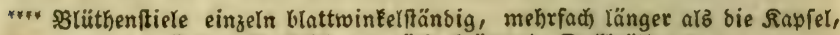

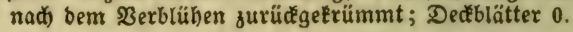

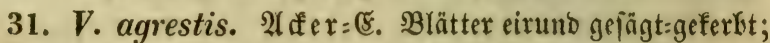
Sapfel zerfitreut = brüftg = Fehaart, runblid), fpibansigeranbet, bie Sappen aufgebunjen, an ber Nath etwas zujammengebrürt. 23. tweiflid,, ber wbere Lappen Blau ober röthlidis. STGart: $\beta$ pulchella (V. pulchella. Dec.) blüthenftảno. Blätter fómäler, bie oberen fât

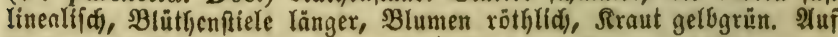

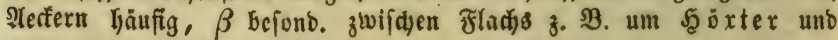
Folzminben. $4-6$.

32. V. polita. Eries. Bierliăer \&. Blätter herzför: mig:tunolida, tief gefägt:geferbt; Rapfel uon abftehenben Jaa= ren bidat=flaumig, fpibauggeranbet, \&appen fugelig=fonvex, Strub:

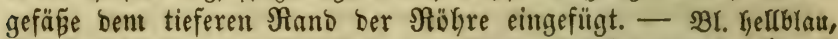

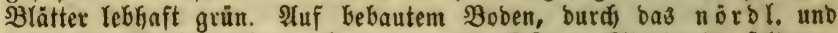
öftidje Gebiet ielyr verbreitet, nads Suben Stanoorte feltener,

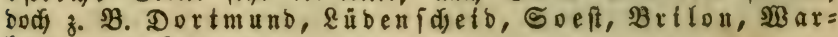
fuxg. $7-9$. $\odot$

33. V. opáca. Eries. Mattgrüner (̋. Bääter faft herzföruig, rumblich = eiförmig, feidat gefägt = geferbt; Ravfel ge= fräufelt-flaumig, fpił̧aubigerandet, in bie Duere breiter, Iappen

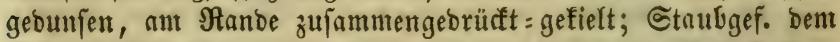

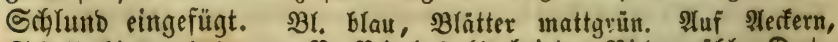
Sdyutt bier uno ba, z. BB. Bielefeld bei ber Niebermuifyle, Det = molb, אुoxter, 5ुolzminber. 4. 5. 24

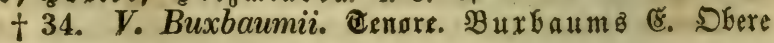




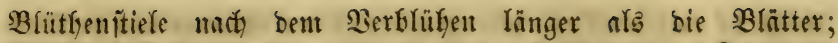

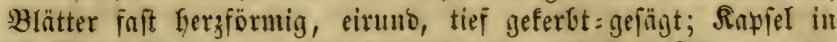

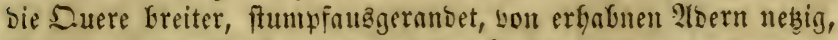
Iappen an ber $\mathfrak{R a t h}$ zufammengebrürft, fpreizend. - B3l. blau.

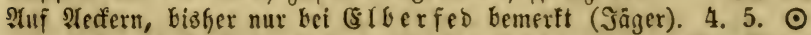

35. V. hederaefolia. Eॄheublättriger ש. Brätter fergrörmig=rundlid, ferbig, faft 5lappig; Rapiel fugelig=4lappig; Reldebipfel berzförmig, nady bem Berblüfen aufredit. - $\mathfrak{B l}$. Gertblan. STuf bebautem Boben, an Şecfen iiberall. 4-6. ๑

\section{9) Gratiola. (sinabenfraut.}

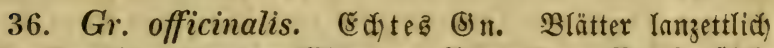
fïkeno, 3nersig, yon ber MRitte an fleingefägt; Blüthenftiele

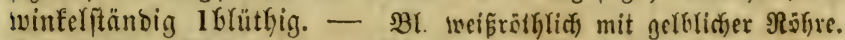

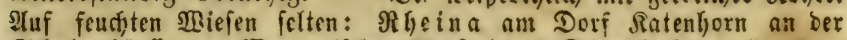
๔d)ule, fäufig am $\mathfrak{B e g}$ zwifden $\mathfrak{B}$ effel und Dinglafen. 7. 4

\section{0) Pinguicula. Fettfiaut.}

37. P. vulgaris. (5) meines F. Sporn pfriemlich, Rnp= fel eiförmig. - Bl. bunferviclett. Ituf torfhaltiyem $\mathfrak{B}$ oben burd bie (Ebenen fehr verbreitet, auth bis an bie \$eerge beß Teutoburger= walbeb z. B. bei Tefflenburg und 3 Z ielefeld, fafeint aber im fübl. unto offt. Greb. ganz zu ferlen. 5. 6. 4

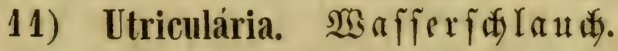

38. U. vulgaris. (5) e meiner $\mathfrak{M}$. Blätter nach allen Geiten abfitelyeno, gefiebert:bieltheilig, bie Bipfel Gaarfein, entfernt feit = bornig; Sporn fegelförmig abftekeno; Sberlippe ungetbeilt, won ber \&änge bes (Saumens; Staubbeutel zufammengetwadjen.

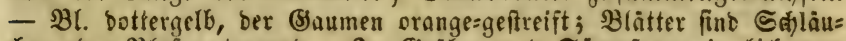

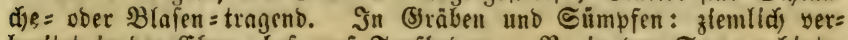

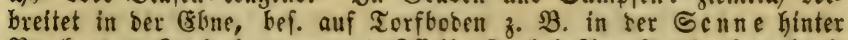

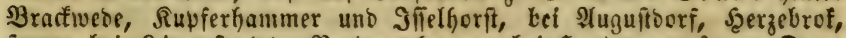

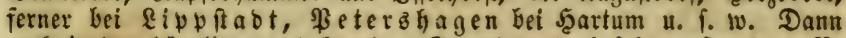

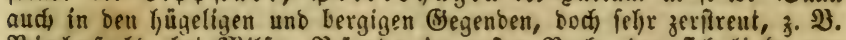
Bielefelo bei Dilíe, 3 ü n be im erfen Baff, ber ind liafz yon

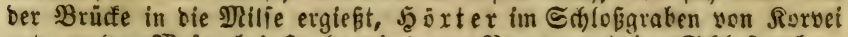

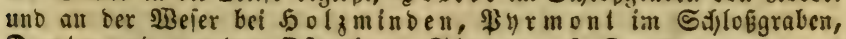
Dortmunb vor bem Ditenthore, Siegen. 6. 7. 4

+ 39. U. intermedia. fonme. Mitt ter 2 zeilig, gabelfpaltig=nieltfeilig, Bipfel borftlich, bornig=ge: zäfnelt; Sporn fegelförmig anliegend, Sberlippe ungetheilt, nod) einmal fo lang als ber (Baumen; bie frud)ttragettoen Blï: 
thenfitiele nufrecht. - 3 r. fämefelgelb, ber (3aunen unb bie Dber=

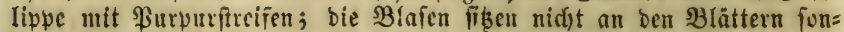

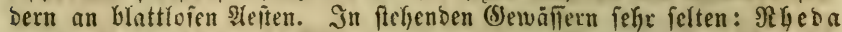

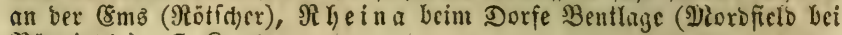
3ुönningh.). 7. 8. 24

40. U. minor. Rleiter 9ुg. Bätter nach allen Gei=

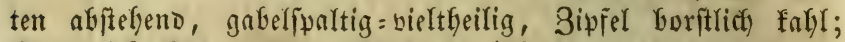
Sporn fefre furz, gefielt, abjtehend; Dberlipue augegeranbet, yon ber \&änge Deş (S) rilifigebogen. - Br. hellgefb, ber Baumen braungeftreift, nebft ben blafentragenben 3 lättern viel f́einer alß bei ben yorr. - In Torf=

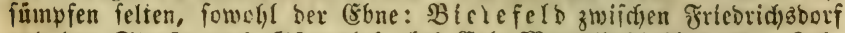

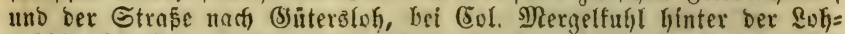

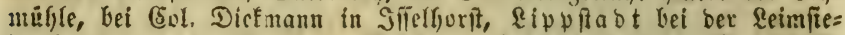

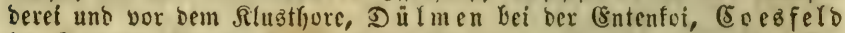
im Stevcber Benne, $\Re$ hein a bei Bentlane, als nud in bergigen (S)

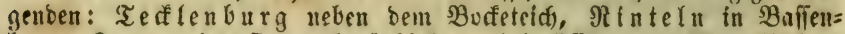

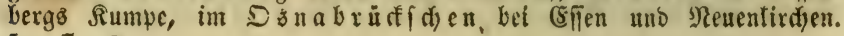
$5-7.2$

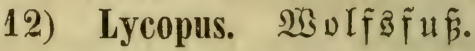

41. L. europaus. (5) emeiner $\mathfrak{3}$. Blätter gefitielt, grob eingefdenitten=gefügt, an Der $\mathfrak{B} a$ aiz fieberjwaltig; ber mittr. Sipfel ber Unterlippe faift 4effig, norf) einmal fo Greit als bie Seitenzipfel. - Bl. weís mit rothen \$unften. Ifbart: $\beta$ procerior

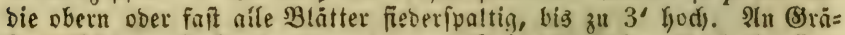

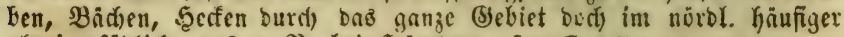

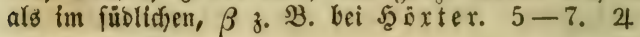

\section{3) Sálvia. Salbei.}

42. S. pratensis. Sูi obertwärts nebft Dedfblättern, Reld) uno Blume flebrig:bebaart; Blätter fyerzförmig längliç eingefchnitten bopweltgeferbt.

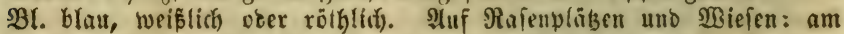

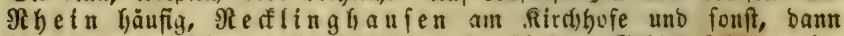
fparfamer bie lipbe hinaufiftigent, in übrigen Bebiet forye verein=

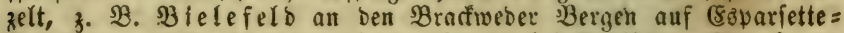

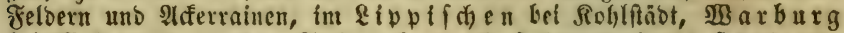

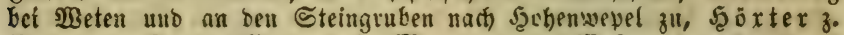
3. an ถen Stabtwällen uno in Ilenge an ber MRefer. 5-7. 4

43. S. sclarea. $\mathfrak{M} u$ a $\mathrm{f}$ a teller $=\mathbb{S}$. Stengel frautig zottig oberw. DrüftgGefanrt; $\mathfrak{B}$ lätter cirunb Doppelgeferbt, fait firzig, runzlig, bie untern Kerzförmig; Deff́bl. breit eirunb häutig

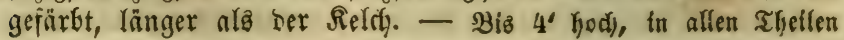




\section{Monogynia.}

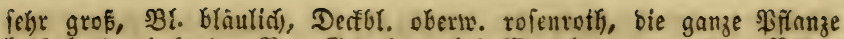

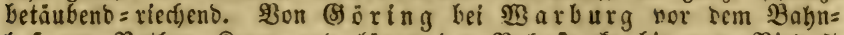

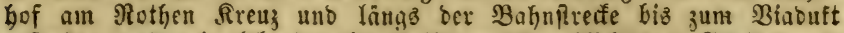
gefunben uno mir lebend mitgetfeilt, mutgmaģlth) ben (Särten ent=

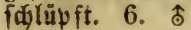

44. S. officinalis. (ׁ) ter $\mathfrak{S}$. Etengel ftranchig, 2lefte graufirlzig; Blätter lanzettlich, bicht=fleingeferbt. Br. violett. Defter in Barten gezogen uno zuweilen vectwilberno, z. $\mathfrak{B}$.

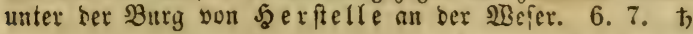

\section{4) Circaea. 5ुexenfrat.}

45. C. lutetiana. (5) enteines 5. Blätter cirumb,

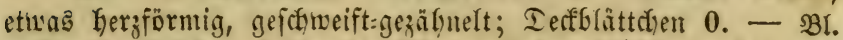

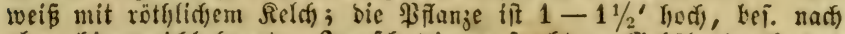

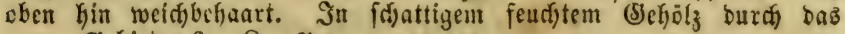
ganze sebiet. $6-8.24$

46. C. intermedia. (E)

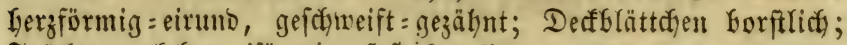
Jruidste berfefrt:eiförmig, faft fugelig. - Br. wie yor. Die

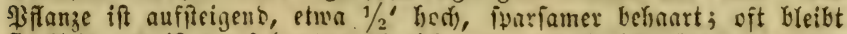
fie flein unb ift ser folgenben ähnliff, oft wirb fie fege úppig unb hat

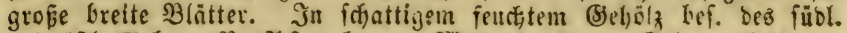

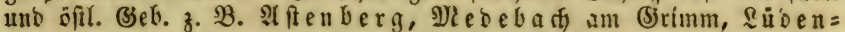

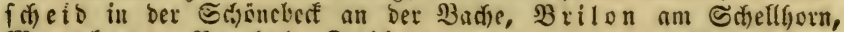
Narberg, Brafel, Drfburg, Pyrmont an Edellenberg, Bielefeld bei Dllerbifien, $\mathfrak{B}$ ünde bei Bul. Saspler, im Rippi= fiden an ber Nurbicite ber Etavelager Berge und bei Reelfird)en, J⿹勹x hagen fin Forft, Dortmun bef Doriffeld unb Saudarbe; audi in

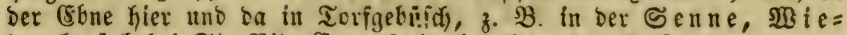

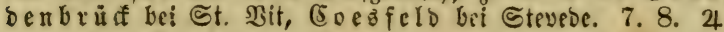

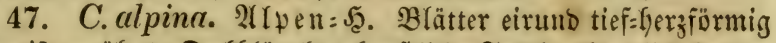

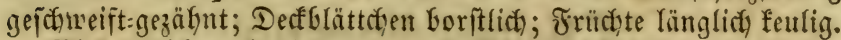

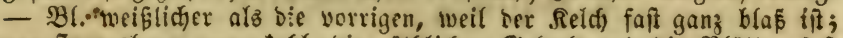

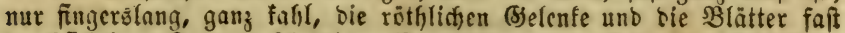

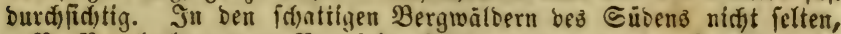
3. B. Berleburg am Burgfelo, Sallenberg an ber langen Shelle,

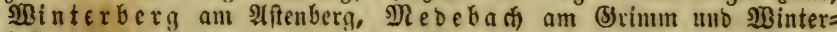

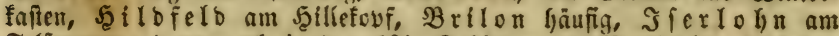
Felienmeer; bann aurd in ben oftl. (Bebirgen, z. B. Sgolzminben, Jूöter in ber Rotheminbe ant Solling uno am Röterbera, Dr $i=$ burg, Beyerungen am Naiflenberg, $\mathfrak{B}$ y $r$ mont an Bomberg

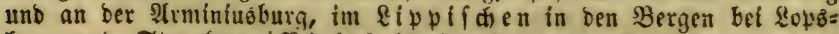
horn und Stapelage, 'B ielefelo in Baumerbe Rupferfammer, an

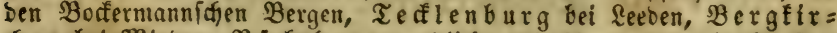

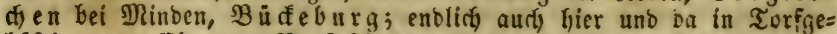

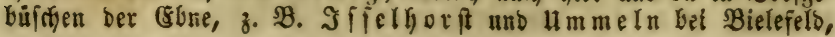




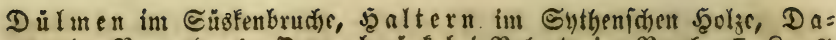

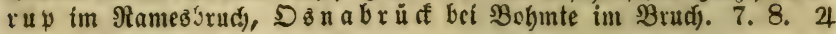

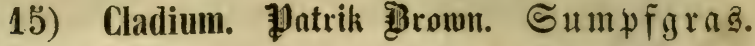

48. Cl. germanicum. Sibrà. (Cl. Mariscus R.

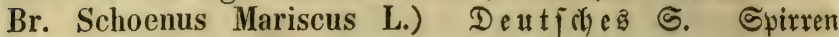
boppelt zujammengefert, eine entoftänig, bie anbern feitenit.

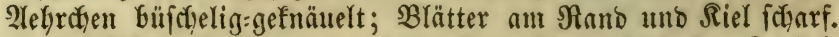

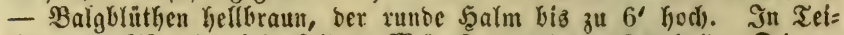
deen unb Sümpfen fefre ferten: SR ü nf ter auf Der Roerhaibe, $D$ in $B=$

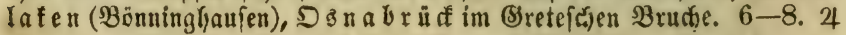

\section{Sronung Digynia.}

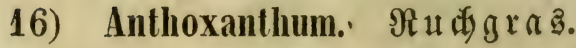

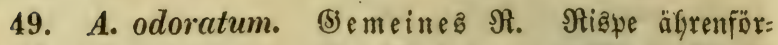

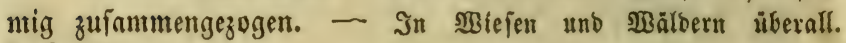
5. 6. 4

\section{Dritte DIafie. Triandria,}

\section{Sronung Monogynia.}

- Blumen oberftänoig.

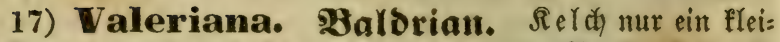

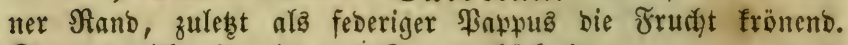
Rroue tridterförmig, am Grumbe höferig.

18) Waleriamella. Moll. Freldialat. Selth

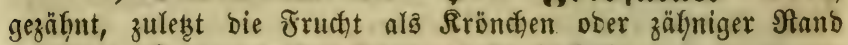
frönent. Rroule tridhterförmig, nidyt Göcferig.

19) Iris. Gchwertlilie. B Büthe»hülte 1Glätt=

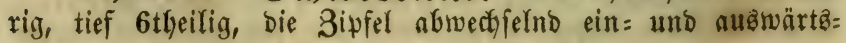
getogen. Ss riffel blumestatatartig 3zipfelig. 


\section{Triandria.}

** SBlumen unterftänbia (Éeine $\mathfrak{B a l g b l u ̈ t h e n ) . ~}$

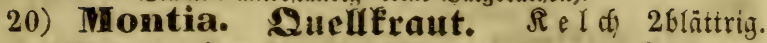
Rrone 1 blätrig. Frudit eine 3flappige 3 famige Raplel. ** Baloblüther.

a. Sૃalm Enotentoz (grazartig).

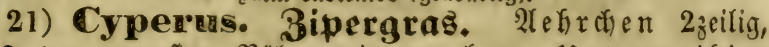
1-2 Der interfiten Bälge mitunter Ieer. Unterweibige Borfiten 0.

22) Seimpus. \$3infe. 2tefrdyen ziegelondyartio, $2-3$ der unterften Bälge mitunter leer. Unterw. BBor: fiten fürzer als bie $\mathfrak{B a ̈ l g e ~ D o e r ~} 0$.

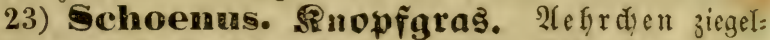
baduartig ober 2 zeilig, $3-4$ ber unterîten $\mathfrak{B a ̈ l g e ~ l e e r . ~ U n = ~}$ teris. BBorften länger n广s bie Bä̈ge ober 0 .

24) Eniophoreme. 26ougras. Aefrden bad: ziegelig. Unterw. Borften länger als bie Bälge, แad sem Berblüben in lange $\mathfrak{W}$ olle übergethent.

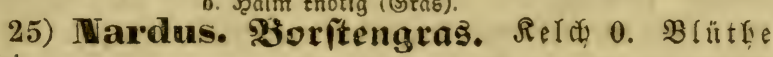
2p๊pelgig.

\section{Sronung Digynia.}

$$
\text { Balgbrithen - (5) räler. }
$$

- 2ehrocter lolüthig zroitterig.

$\dagger$ stur eine SBluthenfpelze.

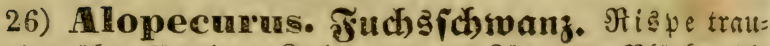

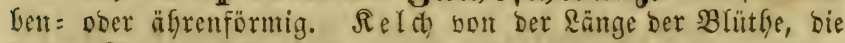
Eeisen Rlappen fait gleich) und ant (5runbe zujanmengemadtyent. B $\mathfrak{C u}_{\text {üt }}$ e unter ber Mitte begrannt.

t† 3wei slüthenfpelzen.

a. Narben föbig, zottig, aub ber Spikge berbortretens.

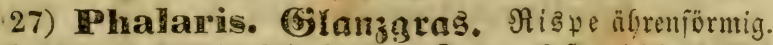
Reld länger als bie Blüthe, die Rlapye faft gleidl, etwas gefielt, zufammengebriaft. Bräthe fuorpelig unbegramt.

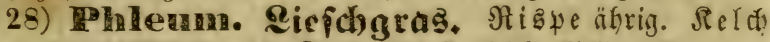
länger als bie Blüthe, bie Rlappent faft gleidy, Fielig:zujanumen:

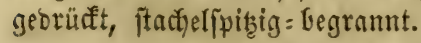

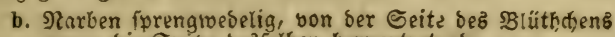
gegen bie Exike bebielben hervortretens.

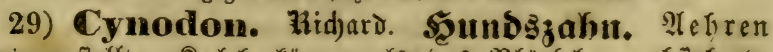
fingerig geftellt. Relef fürzer als bas $\mathfrak{B l u ̈ t g d t e n , ~ a b i t e k e n t , ~}$ Dasieltbe nur an ber $\mathfrak{B}$ ajta umfafiend, untegramnt. 
c. Narben feberig, zur Seite gegen bie sBafiz bervor: tretens.

30) Nilium. Sirfengras. Sispe. Seld Gru=

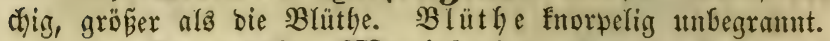

31) grostis. Rzindhalm. Rişpe. Rel grö=

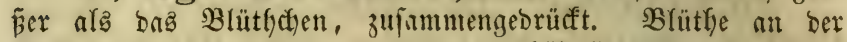

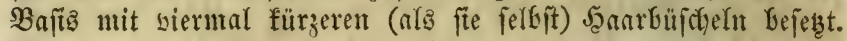

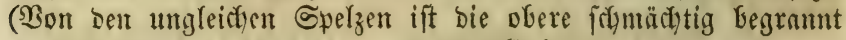
voer gramenlos, bie untere oft linfüllig).

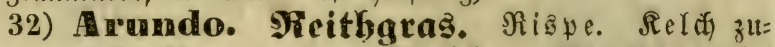

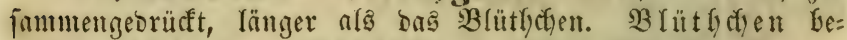
granut ober unbegramut, an (Srumbe mit berfängerten Scaarent.

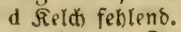

33) 耳ecersia. Swart3. Reerfic. Die 2fpelzige Blüthe geíchlofien bleibento.

** Zehrchan Iblüthig - rielehig.

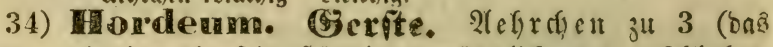
mittlere zuittrig, bie feitenftünbigen mämnlich ober gefoc)lechtas=

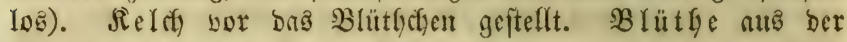
Spibe ber unteren Spelze begrannt.

*** 2erhroten 2 -viełbrithig.

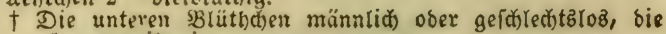
oberen zmitterig.

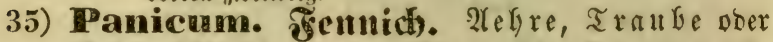
Rispe. Reld 2blüthig: untere Rlappe fefre flein ober fefly= lens, platt, obere conver. B $\mathfrak{l}$ üt $\mathfrak{l}$ d) e n unäfnlich) (oberes fnot: welig Vegramit). Narben fprengmebelig, zur Geite gegen bie Spize ferwortreteno.

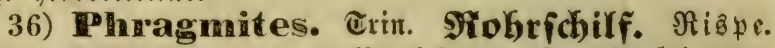
Relcit) 3-7blüthig, unteres $\mathfrak{B}$ lüthd)en nafft, bie folgenden nit werlängerten Saaren umgebent. B B lü the unbegrammt. Nar= ben furengiwedelig, zur Ceite berwortretento.

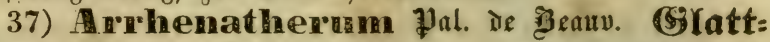

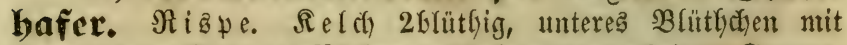

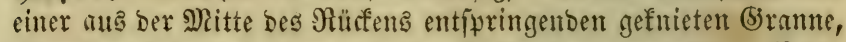
wberes unbegrannt ober aสs ber Spibe furz begrannt. Nar fen feberig, zur Geite gegen bie Baftz hervortretend.

t† Zalte SBlüthen zrwitterig, ober bie oberen männliț.

a. 2(ehrden geftielt, (Sriffel lang, sarben fprengwebelig. aa. Rizpe locker oder außgebreitet.

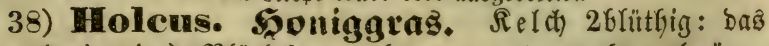
untere (zivitterige) Blïtḩhen unbegrannt, bas obere (münn=

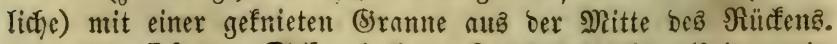
39) hima. Gdjmicle. Reld 2flütfig (beise zwit: 


\section{Triandria.}

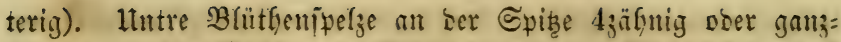
rmbig, an ber Bajts ober Mitte begramut. Blütfichen auts Der Bajta ober Weitte ber unteren Spelize fegranut.

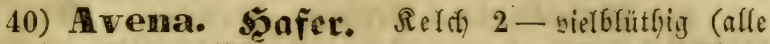

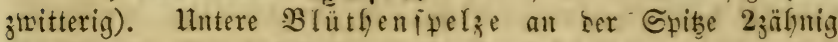
ooer 2fpaltig (bie Bipfel oit mit Boriten Gejętr), mit cimer an ber

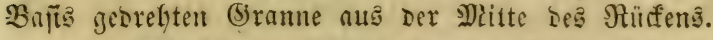

41) Flelica. \$crlgras. Selch fäutig gró̃ 1 -

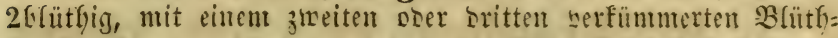

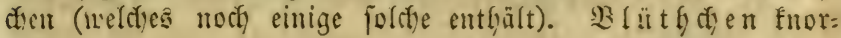
pelig unbegramut.

42) Mlolinia. Sid)rati. Meolinie. Seldt) 2 4blüthig conser, fürzer als ons Blutheden. Itntere Blüthen=

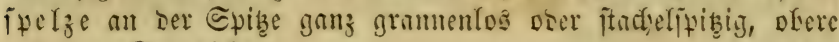
auf Dem Riel bicht uno zart genvintpert.

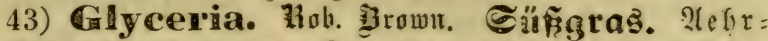

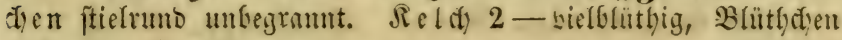
werlängert ftumip.

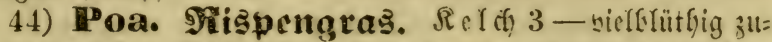

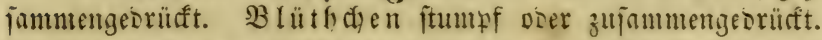

45) ERiza. Bittergras. 2lefrdyen herziörmig=

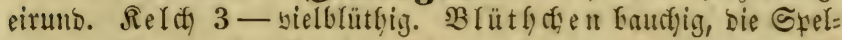
zen am (S)runbe hergërmig geöfrt, unbegramt.

46) Festuca. Sdhwinger. 2(efrden lamzett=

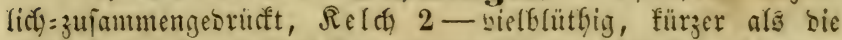

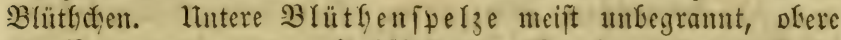

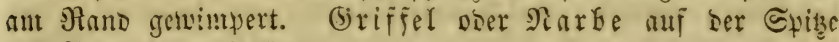

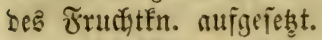

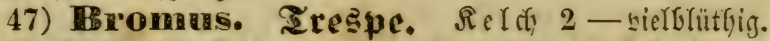
Untere $\mathfrak{B}$ lüthenifelze an Der Epibe 2 jpaltig (bie Bipfel dit ntit Borften bejezst), unter ser Epitge begramnt; sie obere anf nem Riel boritig=gemimtert. (5rifiel ober Sinrbe oferfalb

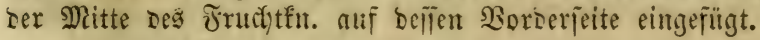

\section{bb. Nißpe traubig.}

48) Trodia. Hob. Şrown. Dreigahtr. Rel (h)

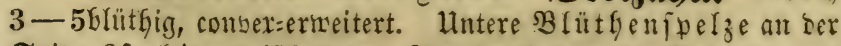

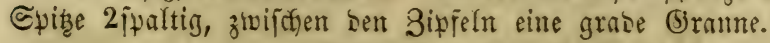

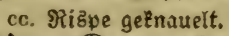

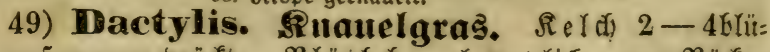

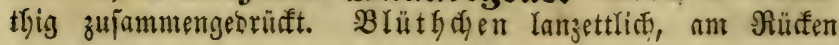




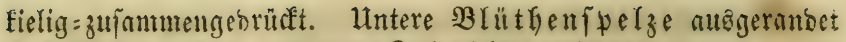
itadyelfpizgig, obere amf bem Riel bidgt gewimmert.

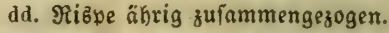

50) Koelenia. Person. Sölterie. Ref(t) 2 5 Glüthig fiefig:zujammengebrüft, faft von ber Ränge ber $\mathfrak{B}(u ̈ t)=$

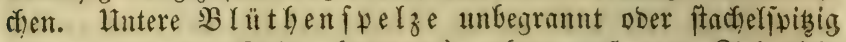
(ober unter ber Spize begrannt), obere auf Dem Riel bift) geivimpert.

ee. Xekre ober ährige Traube.

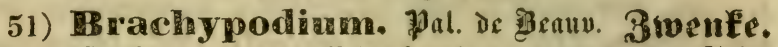

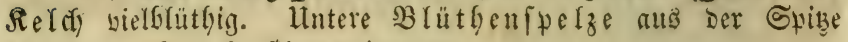
begrannt, obere Gorítig=gewimwert.

52) Cynosmus. Rammgras.. (2tefrige einjei:

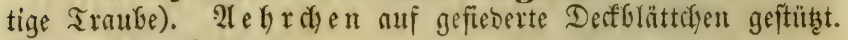
Reld $2-5$ flïtfig.

b. 2(ehrd)en Eaum geftielt. Briffel lang, Narben fäbig, zottig.

53) Gesslenia. Scopoli. Gefilerie. Rel th 2-

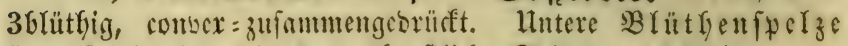
fractelfpizig (ober in $3-5$ boritlicte Exizent enbigent).

c. Zehroden fikzens. Briffel kurz. Naröen feberig.

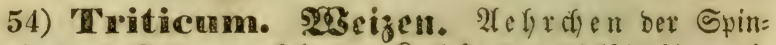

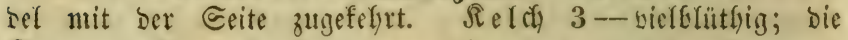
Rlappen gefielt, abgeftulgt oder fpibs ober zugefpizt, begrannt

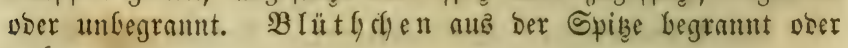
unbegramut.

55) Secale. Moggen. Fef $r$ then ber Spindel mit ber Geite zugefef)rt. Reld) 2blüthig, mit Dom 2(njatz zu cinem britten Blatthd)an; bie Rlappen pfriemlide), gletd) fang. Untere Bräthenfpelze fefr lamg begraunt.

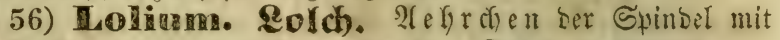

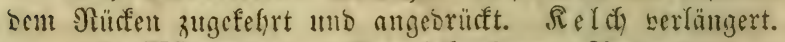

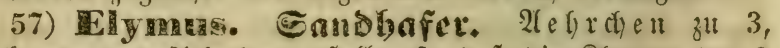

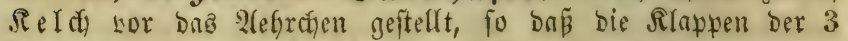

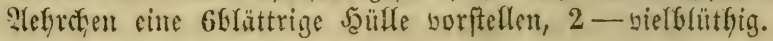

\section{Stomung Trigynia.}

58) Holosteum. Epurxe. Rel à) 56rätrig. Rrone 5blättrig. Rałfel an ber Spitge alffpringento unb vielfamig. 


\section{Monogynia.}

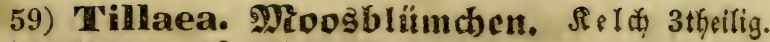
Rrone 3Glättrig. $R a \downarrow$ Ieln 3 .

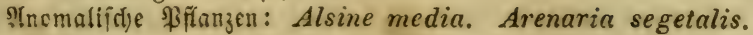

\section{Soromung Ilonogynia.}

\section{7) Valeriana. Ba Í rian.}

- Blumen gleiđfförmig zroitterig (B̊lâtter gefiebert).

50. V. exaltata. Atik. 52ofyer $\mathfrak{B}$. Sמurzel viel=

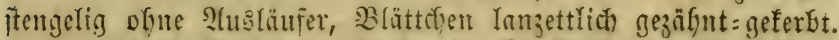

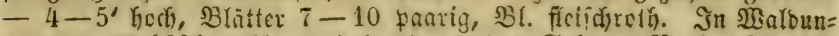

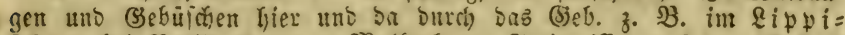

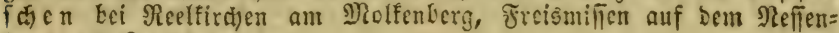
berg. 7. 8.24

51. V. officinalis. E⿺辶)

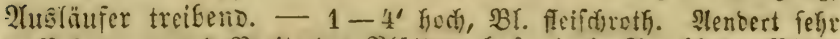
in Beflaturng und B:cite ber Blätter ab fowie in S(nzafl ber Blätt=

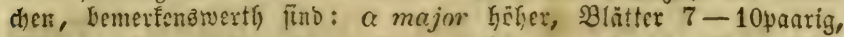

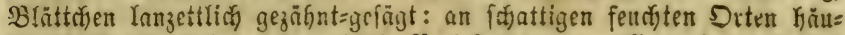
fig, felylt jeoorf in einigen iubl. Bezinfen, two $\gamma$ alfgemein verbreitet iाt; $\beta$ minor ( $\boldsymbol{V}$. angustifolia. Tausch.) nichriget, Blätter $7-10$

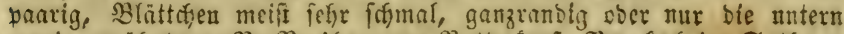

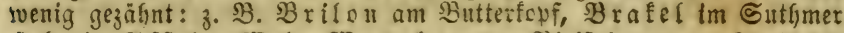

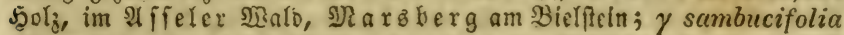

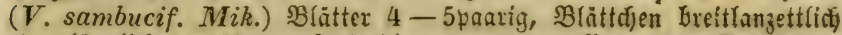

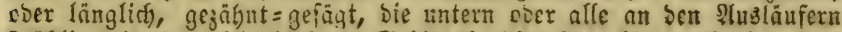

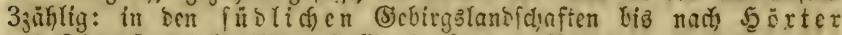

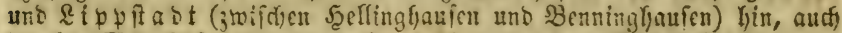
Surdjs Diarfifale Sauerlanb ins norbmeft?. Beb. bis zum

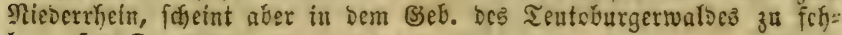
Ien. $5-7.24$

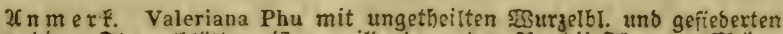

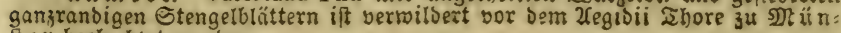
ifer beobaditet roorden.

\section{** şlumer ungleidförmig vielehig.}

52. V. dióica. Rleiner $\mathfrak{B}$. ȘGurzelblătter eirun

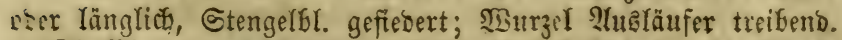
- Die Blumen mandjer Etengel fino gröEer, fleifdjfarbig, bie Staứ

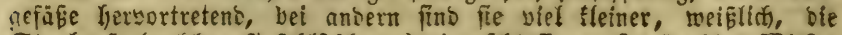

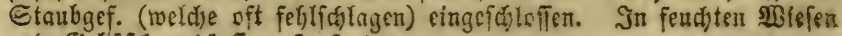

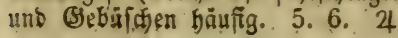




\section{8) Valerianella. Wollid). Feld fafat.}

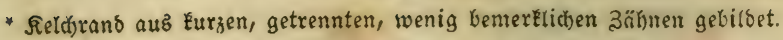

53. V. olitoria. Aloend). (Valeriana Locusta olitoria L. - Fedia olitoria. G̈äturer). (5 (t) $\mathrm{t} \in \mathrm{x} F$.

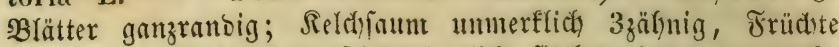
eiförmig = rundlidy, beiserfeits ziemlich flach zufammengebrïft,

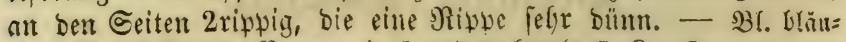

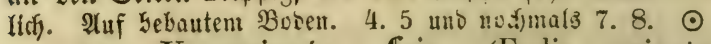

54. V. carinata. Euts. (Fedia carinata. valjl.)

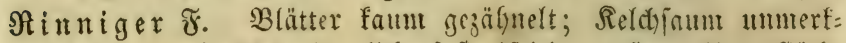

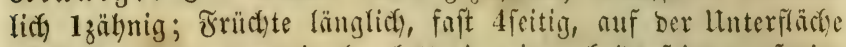
tiefrinnig, worn zieml. Wlatt, in eimen beiberpeits borjprin= genben Mano berbreitert, in Der Mitte und aur Den Ceitent

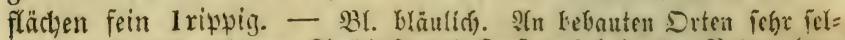
ten: zu Soeft auf bem sirdibufe und ponft auf befoutem Boben (you

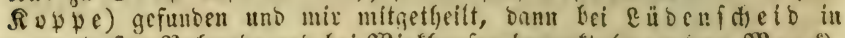
ber unterfen Mafjmebe und bei Winffauen lemerft (yon ber Maarf). 4. 5 .

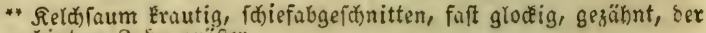
hintere Balin gröber.

55. $V$. dentata. poll. (Fedia dentata. 10all.)

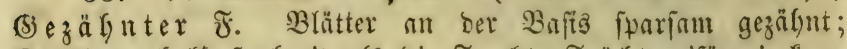

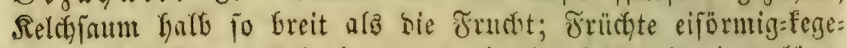
lig, finten fonvex $=3$ rippig, vorn zieml. Wlatt mit einer läng=

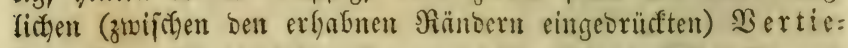

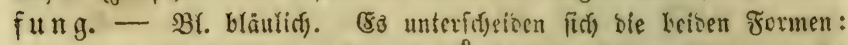
$\alpha$ lejocarpa (Valeriana Locusta $\delta$ dentata L. - Valerianella

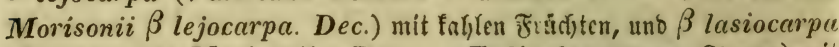
(Valerianella Morisonii a Dec. - Fedia dasycarpa. Steven) mit raufhastigen Früdften. Unter ber Sat, im nöbr. Bjeb. meif Gänfiger als Val. olitoria, nach Süben hin fertmer werbend, z. B. nod) Dort in un

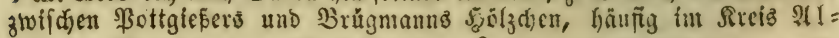
tena, $\mathfrak{N a r z b e r g , ~} \mathfrak{N e b e b a d} ; \quad \beta$ bef. auf Embboben, z. $\mathfrak{B}$. Bielefeld bet Brasfiwebe, DB̊na fdjen. $6-8$. $\odot$

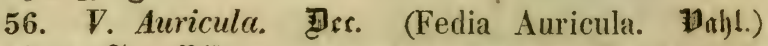
Defriger F. Blätter ganzranbig Doer cingefochitten uno

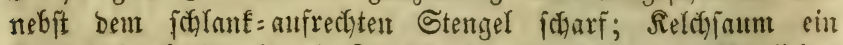

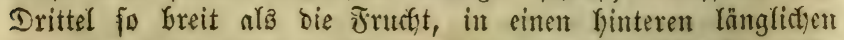

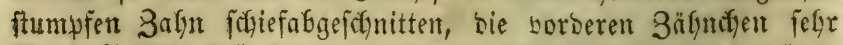
flein; Jrüdte faft fugelig = ciförnig, fein 5rippig, worn 1 fur=

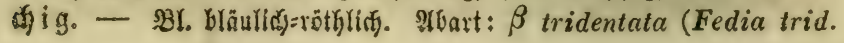


Reichbch.) bie vorbern 3ähndyen etwas bentlther. 2t:if fanbigen

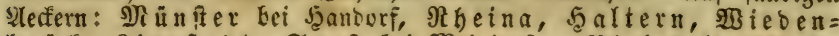
brü f́, Rippftabt, Soeft bei Deinimgien, Bieleferb Blömfe= berg, im \&ippifden ziviffen Serrntrup und Sievenhöfent bei bem

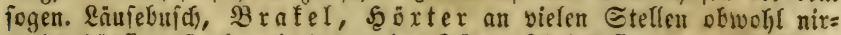

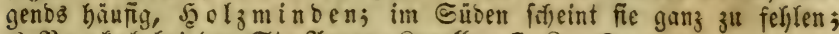
$\beta \mathfrak{Z} \mathfrak{r}$ afel liei ber St. Ifnen= Rapelfe. 7.8 .

\section{9) Iris. Squertilie.}

57. I. germanica. Deutiche $\subseteq$ (d) $w$. Blätter foumert: förmig, fürzer als ber vielblüthige Stengel; bie zurïffifebognent

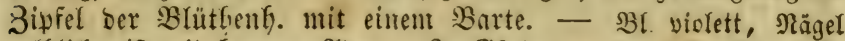

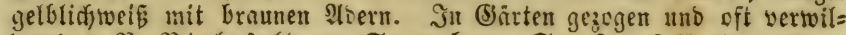
Derno 2. 23. Biclefels am Eparenberg, Soeft auf (Sartenmauern,

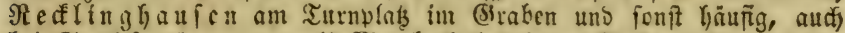

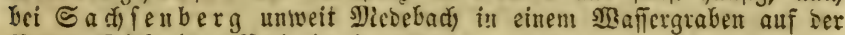
Atuen গBiefe (yon Netnige) gefunben. 5. 6. 4

58. I. Pseudácorus. (j) e me in e Sdy. Blätter

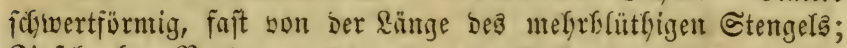

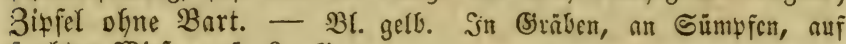
feuthten $\mathfrak{B}$ iefert. 5. 6. 24

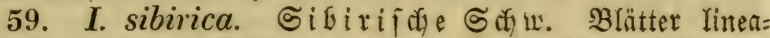
Yijơ, fürzer als ber ftielrumbe röfrige meift 2 Glutthige Stengel; Bipfel ofne Bart. - Sleufere Bipfel ber BR. Geflolau mit violet= sent Itbern, innre violett. Fluf $\mathfrak{B}$ iefen felye felten: in ber fumpfigen

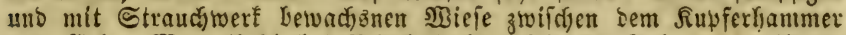
und Golvn Mergelfuhl hei Blelefeld, feit 16 Jafren verwilbert,

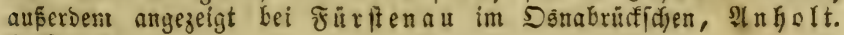
5. 6.4

2 nmerf. Gladiolus imbricatus ift vor vielen Fahren von

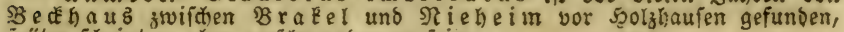

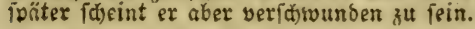

\section{0) Montia. Duellfiaut.}

60. M. fontana. - Nate etwa 1-4" lang, feifchits,

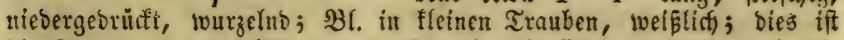
bie form a minor (M. minor $\mathbf{G m e l}$.), bie fich auf feudjten fanbi=

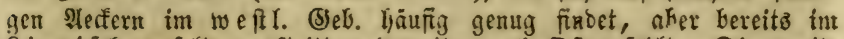
Rippifanen felten auf̣tritt unb weiter natt) Dipen feglt. Die zweile Form $\beta$ major (M. rivularis. Gm.) if böber, biв zu 6", hinfällig=

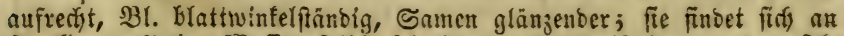

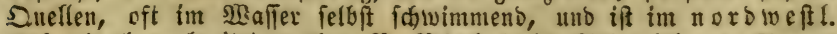
(3eb. zieml. verbreitet, aud) 3. B. S ie lefels Spiegelsberge, Senne;

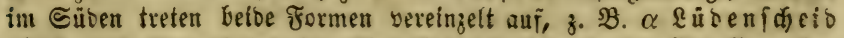

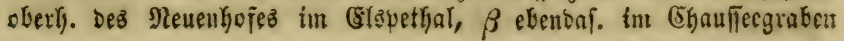




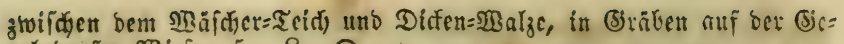
yelnborfer 2 Bicje. $5-8$. $\odot$

\section{1) Cypérus. Zipergins.}

61. C. flavescens. (5) elblid) อ 3. \$2alm ftumpf = 3 fantig, 2leite ber Spirre einfach, Bälge ftuntpf, Saülle 3blättrig,

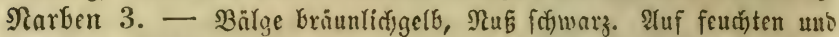
fumpifizen \$läben felir jerftreut im nöbl. Biblet: Biclefeld im Torfmocr bet Turmann uno inciter auf ber wace linfz yon ber bece:

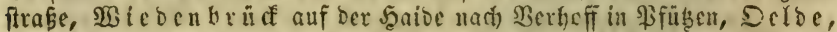
im Rippifonen bei ber Srtmüble, Refflinghaufen im Brudb, Dü $l$ men im Eeufterbrutie lint in Menge am Sisge nact) Rette bei

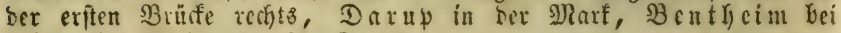
Dhue, $\mathfrak{b} u$ ute burg. $6-8$. $\odot$

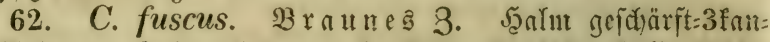
tig, 2lefte ber Spirre faft eintady, Bälge friblidw, Şülle 3blät:

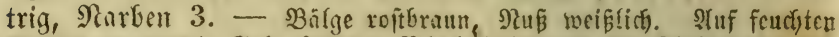
शBiefen im nöror. (5ieb. felten: Bielcfelo nuf ber Finfenbaibe yor

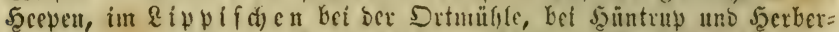
haufen, $\mathfrak{S}_{\text {of }} \mathrm{g}$ m inde

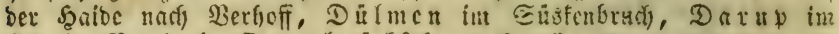

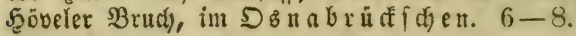

\section{2) Scirpus. $\mathfrak{B}$ inf}

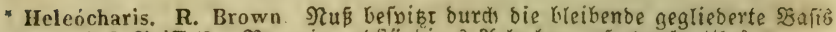

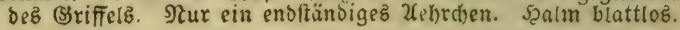

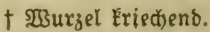

63. Sc.palustris. (Heleocharis palustris. \#.

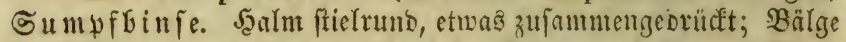

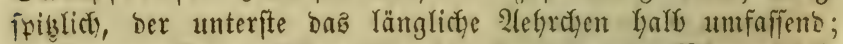

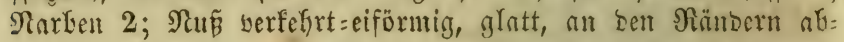
gerunbet = fumuf. - An (jräben und Simpfen häufig. 6-8. $x$

64. Sc. uniglumis. Mabl. (Heleocharis uniglumis. fink.) (sinbargige $\mathfrak{B}$. Salu ftielrumb; Bälge fpitslich, Der unterfte rumblict, bas 2lefredyen ganz umfaffent; Narben 2;

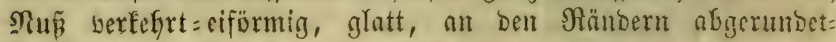

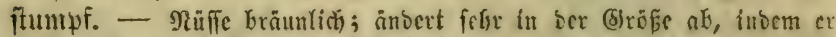
zuweilen cinige 3oll zuw. I Fuf hod) wiro. Sluf feucftem Torfboten nidit hơufig: \&fpp ff a b t bei Rangenberg (wo er umgemein hoch witro), Serforb nady Etjottmar hin, in ber Senne, Diffen, Telgie

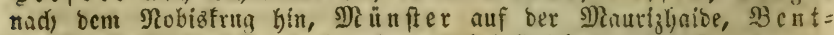
Ge

65. Sc. acicularis. (Heleocharis acicularis.

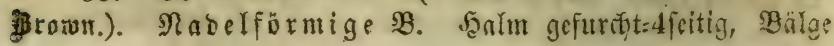




\section{Monogynia.}

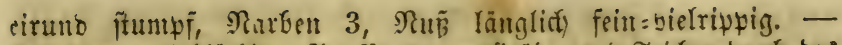

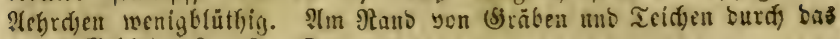
nanje Bebiet. $6-9$. $\odot$

t† $203 u r j e l$ faferig.

66. Sc. multicaulis. Smith. (Heleocharis multicaulis. findl.) Bielfitengelige $\mathfrak{B}$. Salm ftielrund;

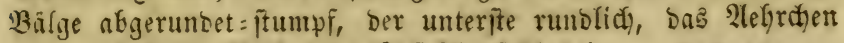

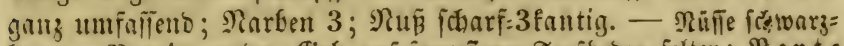

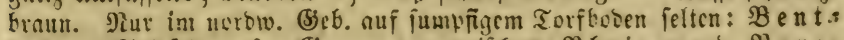

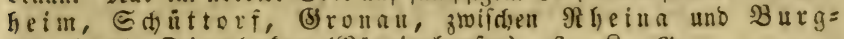

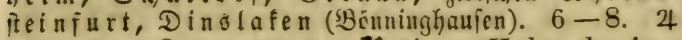

67. Sc. ovatus. \#otb). (Heleocharis ovata. M.

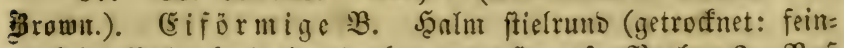
gerillt); Bälge Greit=eirund nfgerundet:ftumpf; SArten 2; NuÉ

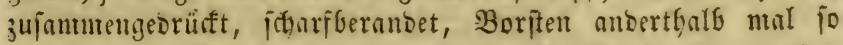

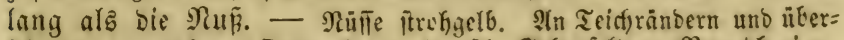
ids)wemmt gewefenen Dorten im norbweitl. (S) be. felten: Bentheim,

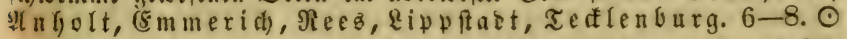

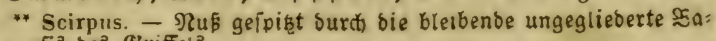
fis bez अriffela

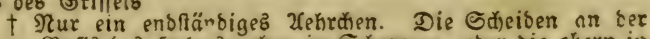
gRafiz bes 5satmb gehen in Eđuppen, oder oie obern ia

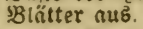

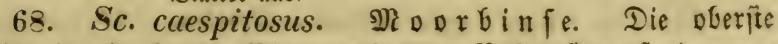
Edyeibe in ein furzeg Blatt enbigeno; Bälge f̈tumpf, ber un= terifte größ̄er, fo lang als bie eiförmige Alefre uno bicje um:

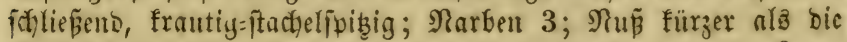
Boriten. - Die Jăalme bilben cinen bidjen Naien. Stbart: $\beta$ ne-

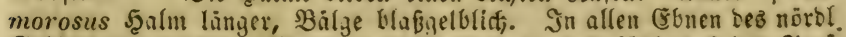

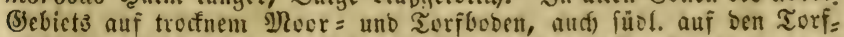

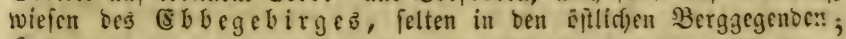
$\beta$ Peterzfagen in ber 5aaibe, im Golling beim Gilberborn. 5. 6.24

69. Sc. Baeóthryon. Éljrharot. (Sc. pauciflorus. fightf.) Torfbinfc. Ect)eiben blattlos; Barlge ftumtyf, ber unterite bas menigblïtfige Alefrchen umfanfend, ofue frautartige

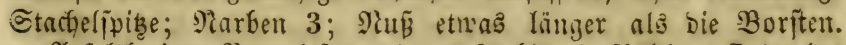

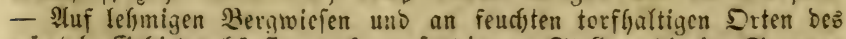
nörol. (Sebictes hău austroffnen, too ble \$finuze fleiner bleibt (Sc. campestris. Lioty.) 6. 7.24

70. Sc. fluitans. Flutlende Binfe. Santm farlafi,

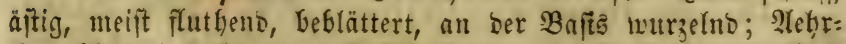

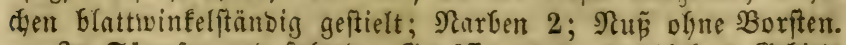

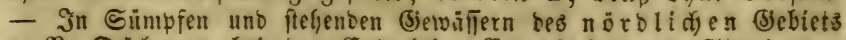

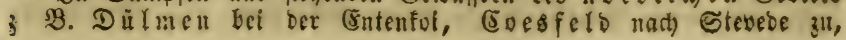




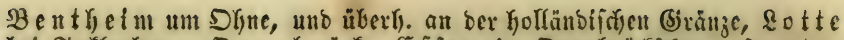

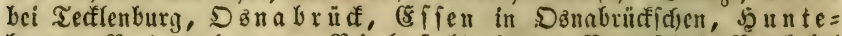

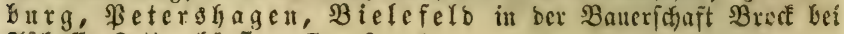

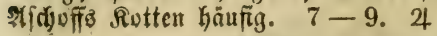

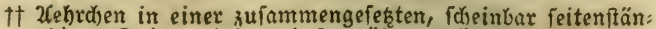
bigen Spirre, inbem bab gröbere Suitllblatt in graber Rid)tung mit bem Stengel fortläuft unb bicien zu verc längern fđòint.

a. Bälge an ber Epize ganz, frachelfikighig, ohne Franien.

71. Sc. setáceus. BBoritbinfe. Scalm fitielrumb, 2lefrchen fizend 1-4, Narben 3, unterweibige Borften 0 ,

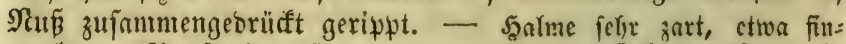

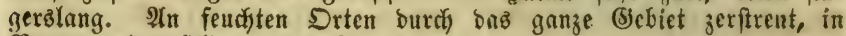
Berggegenden felten. $6-8$. 4

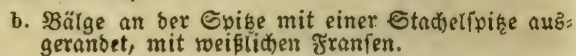

72. Sc. lacustris. Seebinfe. Salm ftielrumb, Spirre

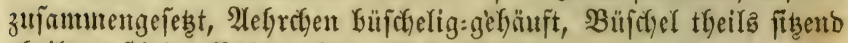

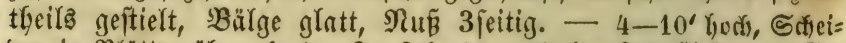
ben in $\mathfrak{B}$ lätter übergefend. In fefhenben uno langfam flieģenben (Se=

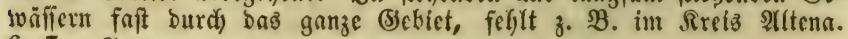
6. 7. 24

73. Sc. Tabernaemontani Gmeliu. Rleine See= binje. Shalm ftielruno; 2lebret)en büfdelig=gebüuft, eine ge: orungnere uno weniger zufummengefebte Spirre bilbent; Bälge

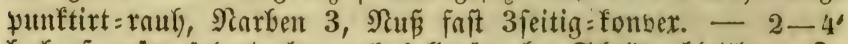
Ylods, jeegrün, änbert aber audi) Keflgrün ab; Sdjeisen blattlog. In

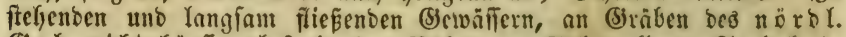

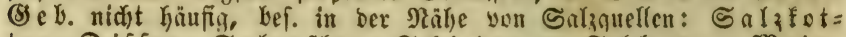

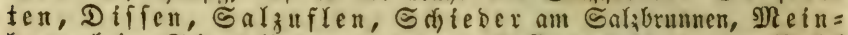
berg beim Erfwefelbrumen; bann auds (5ves fels an ber Derfer

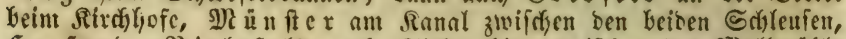

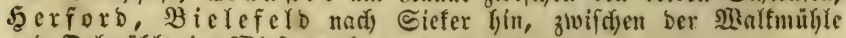
แno Delmúlyle in : Riciengraben. 6. 7. 4

† 74. Sc. Duválii. foppe. Dï口aljăe 2 . Salm unterwärta ftielruno, in bor Maitte 3 jeitig, bie Rnnten ftumpf, zwei won ben Ceiten zienrlica fonbex, die britte flach); Spirre

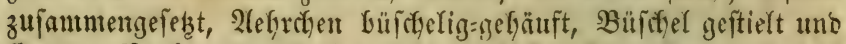

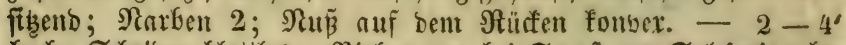
hod), Scheiben blattlos. SBisher nux bei Soeft am Galgforing be=

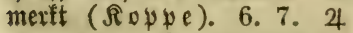

75. Sc. triqueter. Dreifeitige 23 . Salm 3fantig; Gpirre zujamntengejebt, etmas gefnmuelt, Binfichel geficlt un

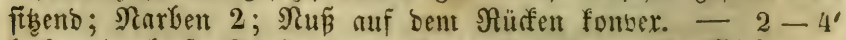
hod), bie oberfe Sdjeibe in cin Bfatt übergelycms. In SBefen, an 


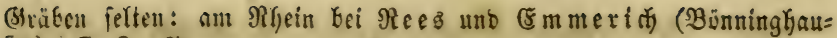
(en). 7. 8.21

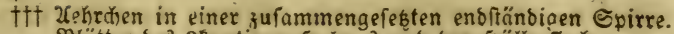
SBlätter Sez 3 Eantigen Şalmę uno ber Şülle flađ).

76. Sc. maritimus. Mleerbinfe. Bilfityel ber 2 tefy: (f)en geftielt mo fitzeno, Bälge an ber Splize ftact)elfpibig,

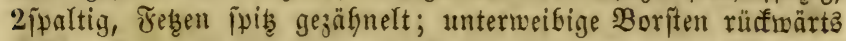

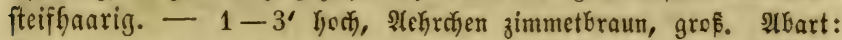
$\beta$ compactus (Sc. tuberosus. Desf.) mit Yauter fitbenben gefnauelten

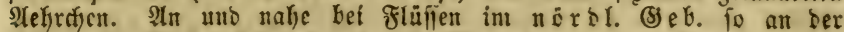

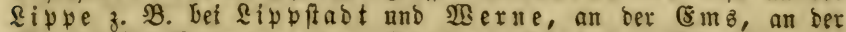
We efer bef Beverungen, şater, Rinteln, Bünde an ber Elfe unb fonft in Nenge, Ninden, æeterghagen; bant an falz= Fyaltigan Sorten z. B. Soeft am Ealyjpring bei \$arabicz, im Brudje

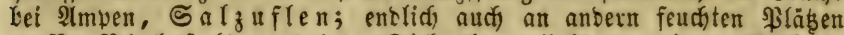
3. B. B ielefeld aus bem Eieferthure lints an cinem Braben;

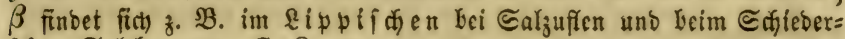
(j)ent Ealzbrument. 7. 8. 4

77. Sc. sylvaticus. S3 nlo binje. Büfatel ber 2(efrcyen

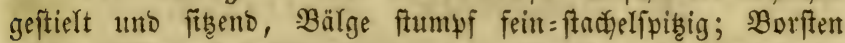

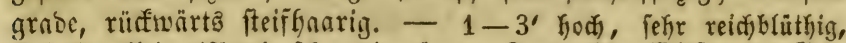

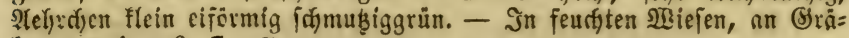
ber gemein. 6. 7. 24

Xnmert Sce radicans wirb bei $\Re$ heira angegeben, bod ift baz Borkommen zu unfiffer.

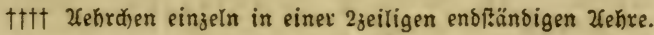

78. Sc. compressus. Pers. (Schoenus compr. L.) 马uiammengeorü of te $\mathfrak{B}$. Şalm unbeutliç 3 jeitig, beblät= tert, Bätter unterĩeitô gefielt; 2lefrecten $6-8$ Glüthig; un=

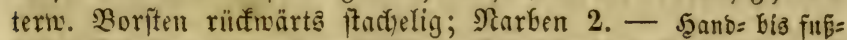

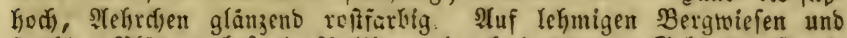
feudjten \$läben, bef. torffraltigen, burdí bas ganze Bsckiet verfitrent,

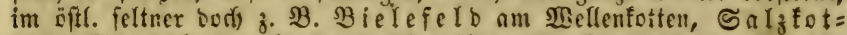

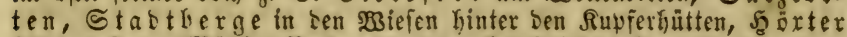
bei ber Seber Miúfle, ßeterzhagen bei friebetwarbe. 6-8. 4

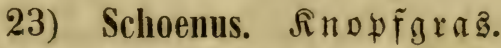

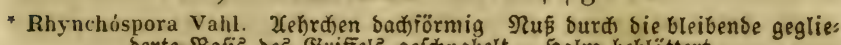
berte :Bafí bes (S)iffele gefdnnabert. Şalm beblättert.

79. Sch. albus. (Rhynchospora alba. Babl.) Mei=

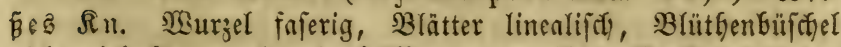
nidut wiel fürzer ala bie Şülle, untermeibige $\mathfrak{B}$ orften 10 bon

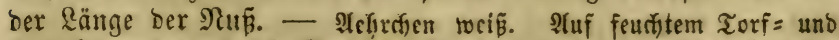

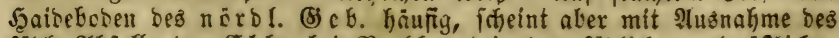

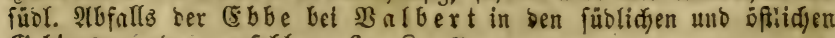
(b)birgägegenben zu fefter. $6-8,24$ 


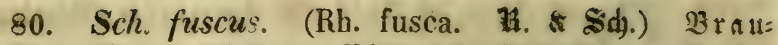

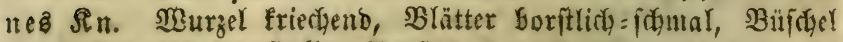
viel Pürzer alz bie Sctille, Borften 3 nodh chmmal fo lang als

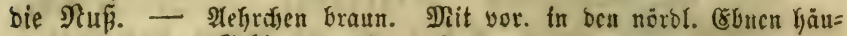
fig, fefflt in bent Bsebirgaggegender. 6. 7. 4

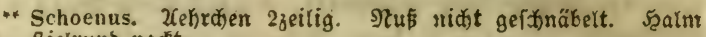
ftielruno nactet.

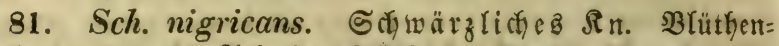

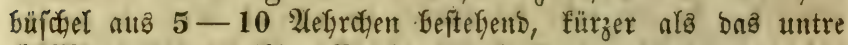

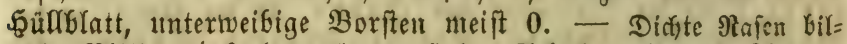

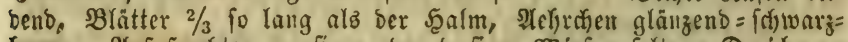

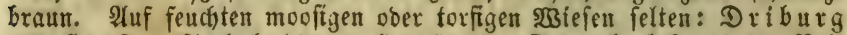

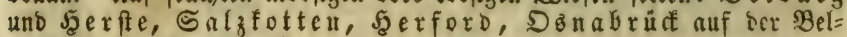
mex Jyaibe. $5-7.24$

x $n$ m. Sch. ferrug in e us foll im Nünfterfeten gefunben feir, iebors if รก่

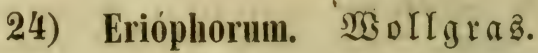 \\ * Zerhre einzeln.}

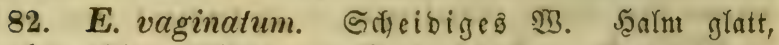
nach oben 3feitig, BBlätter am Nande fot)arf. - Murzel faferig.

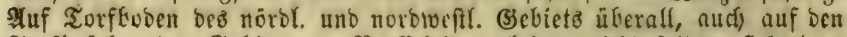

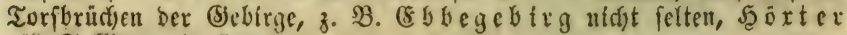
sint Sollfing. 4. 5. 24

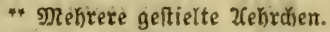

83. E. latifolium. Goppe. (E. polystachyum $\beta$. L.)

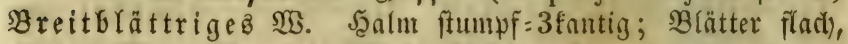
an ber Spize 3fantig; Blütfenftiele rauf. - Iuf feudisten

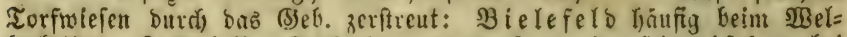

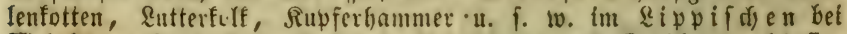

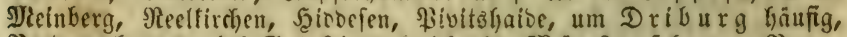

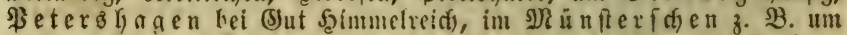

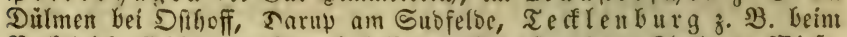

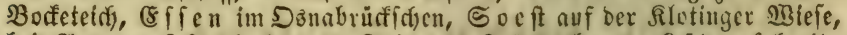

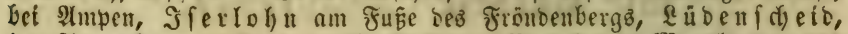

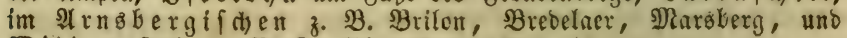
SBittgenfein z. B. Ransplie. 4. 5. 4

84. $E$. angustifolium. (Eoth. (E. polystachyum

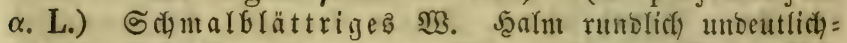
3 feitig; Blätter rinnig, an Der Spine 3 fantig, Blütfenfitiele

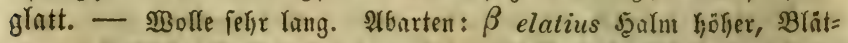
ter bis 3 sinien breit; $\gamma$ minus (E. gracile. Smith) fpannenlang,

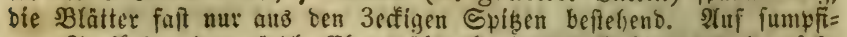

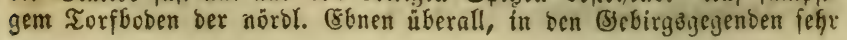




\section{Monogynia - Digynia.}

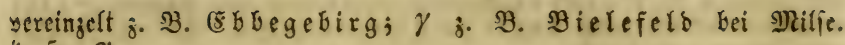
4. 5.24

85. E. gracile. Eीad). (E. triquetrum. 5ुappe)

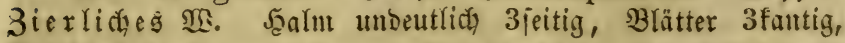

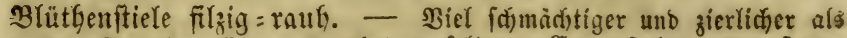
yort. SUf fumpfigen: Torfbuden felten: C oebfeld, Derften, (Bouningfaufen), รูerforb. 5. 6. 24

\section{5) Nardus. פBorftengrą̧.}

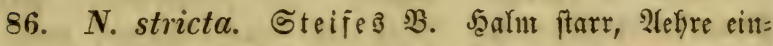

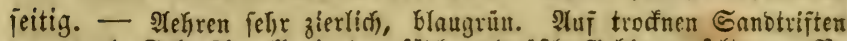

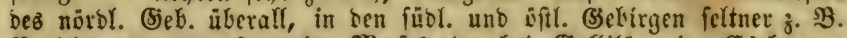

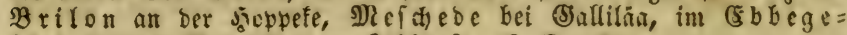
bitg auf ber Rorbgelle, an \&ohflaufe. 6. 7. 4

\section{Sronumg Digynia.}

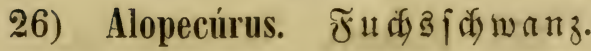

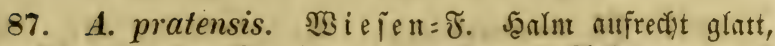

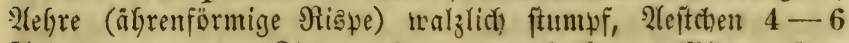
Tefrctuen tragend; Rlappen fpib, unterbalb ber \$litte zufanmengewachien, auf bem Riel zottig = gewimpert. - Ituf feuditer

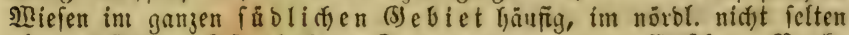
aber zerftrcut: Sferlohn, Dortmun an ber Emfdier, Re ef =

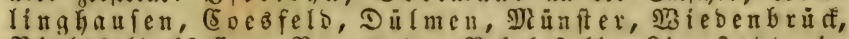
Blelefeld bäufig z. B. nad) bem Balnhef hin, gippla abt, im Etppifden z. B. Defmold yer bem Eemgoer Thure, Beterzha=

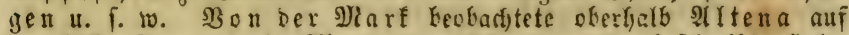

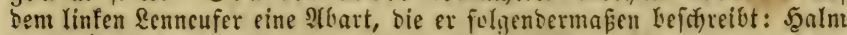

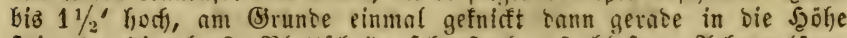

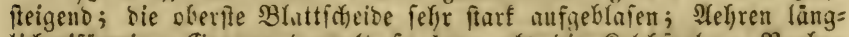

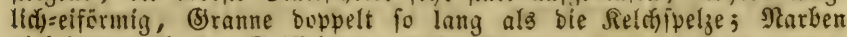
viel länger alz ber Brififfl. 5 unb 9. 4

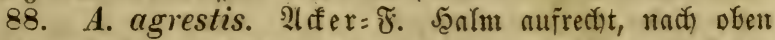

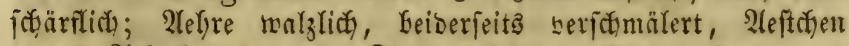

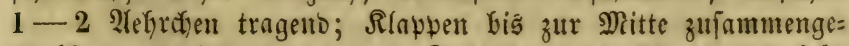

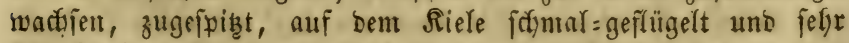
futr betwintpert. - פuf 2ecfern ber. mit Thunkoben im we fit. (5) eb. fehr hämig unb zwar biz etwa nad) Etromberg uno sipp=

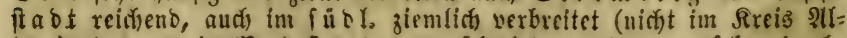

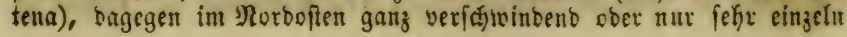




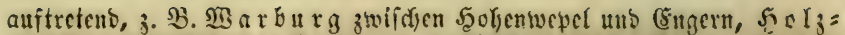

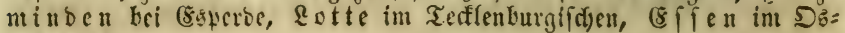
nabrüctifłen. 6.7.

89. A. geniculatus. Gefnieter $\mathfrak{F}$. Jalnt ant Brund

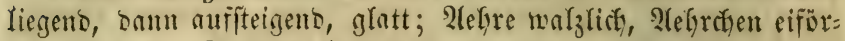
mig=länglid); Rlappen ftunџf, genvimpert, nur an (S) fammengewartjen; Spelge unter ber Mitte begrannt. - Etaub=

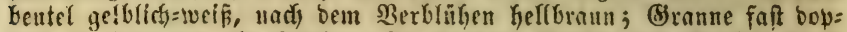

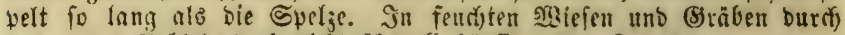
bas ganze (seblet, Dorf) nicht likerall fäufig. $6-8.24$

90. A. fulvus. Snitl). (A. paludosus. p̧al. ie ginuv.) (5) fteigens, glatt; 2lelyre walzlich, 2lelgrofsen elliptifd); Rlappen ftumpf, gewintert, mur an (S)ruto zujammengewadjen; Spelze auts ber Mitte Gegramt. - Staubb. rotfigelb, Granne fo Iang

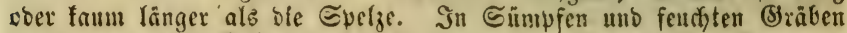

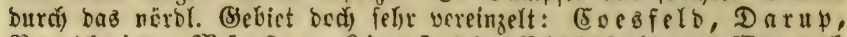

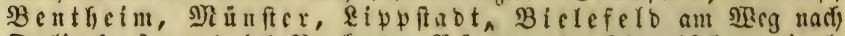

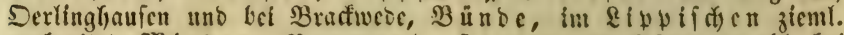

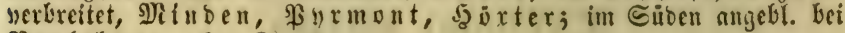
Berleburg. $6-8,2$

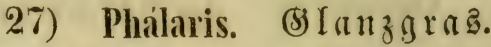

91. Ph. arundinácea. Rolirartiges (5) I. Riąue

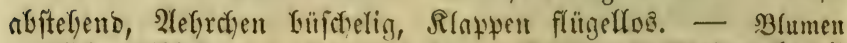

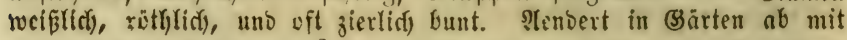

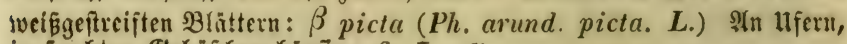
in feuditen (Bebüfdjen häufig. 6. 7. 4

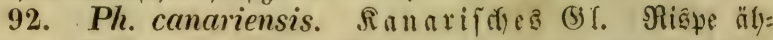
rig=oual, Rinpten auf Demt Riüfent mit eittem ganzrnmbigen

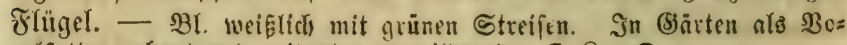
gelfutter gebaut und mitunter verwilberno. 7. 8. $\odot$

\section{8) Phléum. Ricfdging.}

93. Phl. pratense. Sisiefen=\&. 2lefire (älirenförmige

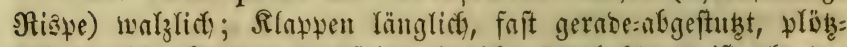
lich in eitue (bromme zugeipizgt (weld)e 3 mal fürzer ift als ber Barg), auf bem Siele fteifganrig = gewintpert. — Ienbert ab mit

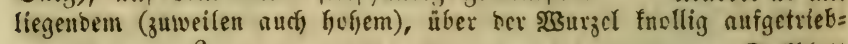
nem Şalme: $\beta$ nodosum (Phl. nodosum. L.), mit einem Deff́latt unter ber Aleliee: $\gamma$ bracteatum. Boenningh. endlitity mit anşward)= fenben Bälgen: $\delta$ viviparum. Roth. Atuf Miefen äberall, $\beta$ tweni=

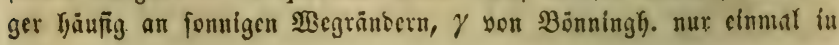




\section{Digynia.}

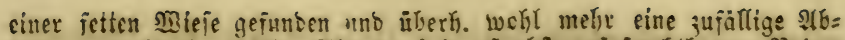

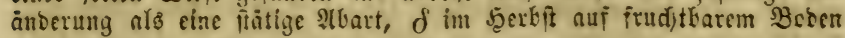
Eci jum jutweiten Mate dühemben Eremplaren. 5-10. 24

† 91. Phl. Boehméri. Mibrl. (Phalaris phleoides.

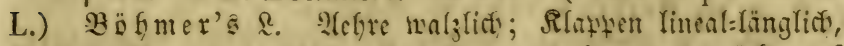

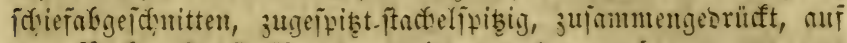

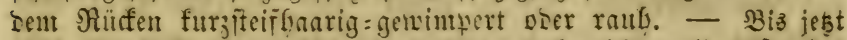

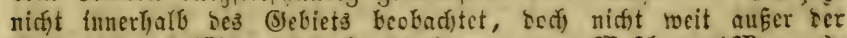

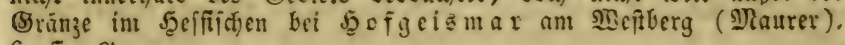
6. 7.24

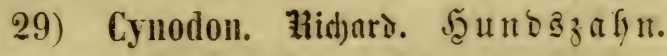

95. C. Dáctylon. Pers. (Panicum Dact. L.) Sู心tr=

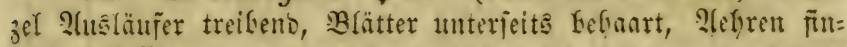
gerig=geitellt. - S. uf treffnen Eanstriften ichr felten: an ier sipue

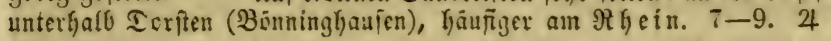

\section{0) Milium. Şirfengras.}

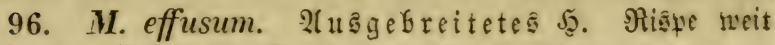

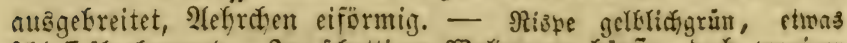

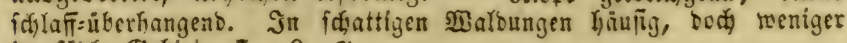
im fübl. (5ebiet. $7-9,2$

\section{1) Agrostis. Mintoratnt. \\ * 2ưe \$Bätter flad).}

† Apéra. Beauv. Untere Rlappen kürzher.

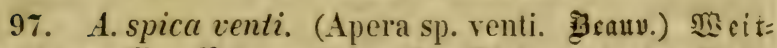

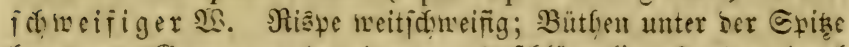
Kegramut, (jorame grabe soer etwas fodylängelig, 3 ober 4 mal

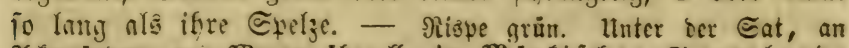

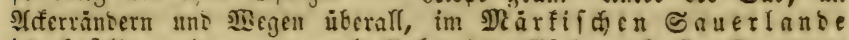

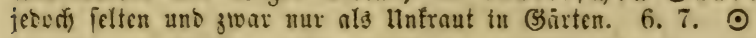

†† Untere Silappe länger.

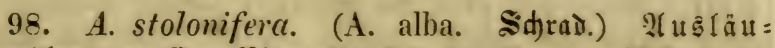

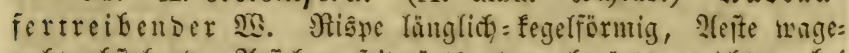

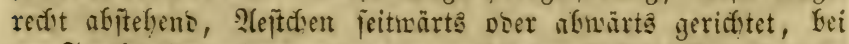

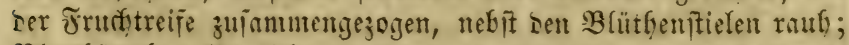

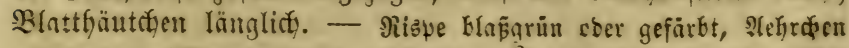
grannenlsह, felten begrannt. Ilbarten: $\beta$ gigantea. Gaud. grīber

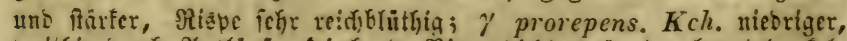

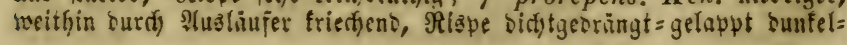




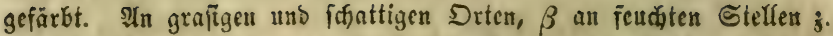

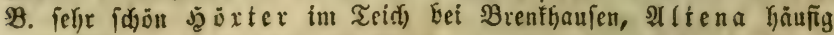
unter 33 intergetraibe (won ber Miarf), $\gamma$ auf troftnem fieinigem $B$ Boben 3. 39. an ben (siterufteinen im Rippifinen. 6. 7. 4

99. A. vulgaris. With. (5) e meiner $\mathfrak{B}$. Nisెpe cifür: mig mit gefpreizten Ileften, etwas raub; Blatthăutchen furz abgeftubt. - Ris̄pe grün= violett, aud) wohl ganz grün ober ganz

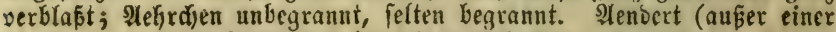
niebrigen 1' hohen form mit brandigen silef)ret)en: A. pumila. Rchb.) ab: $\beta$ stolonifera. Meyer mit langen fricdyenben গ̂tusln̈ufern. In

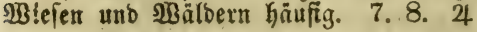

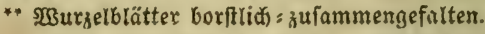

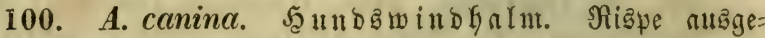

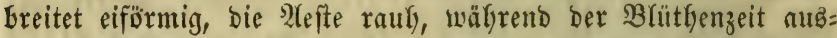
cinanderfafrend, nachber zufammengezogen; untre Syelze inter ber Mitte begramnt, an ber Spibe fein=geferbt; Blattbäutctent

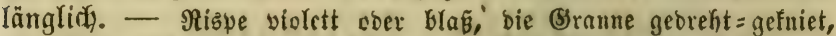

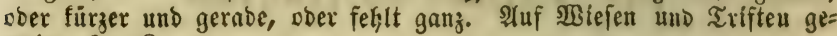
meit. $6-8$. 2

\section{2) Arundo. ङর্lif}

* Calamagrostis. Adans. Untre Rlappe Eürzer.

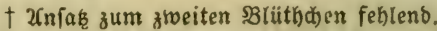

101. A. Calamagrostis. (Calamagrostis lanceo-

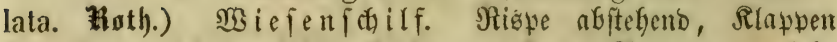

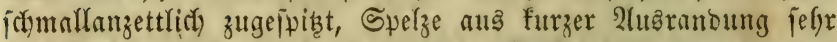

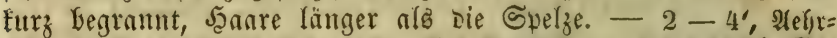

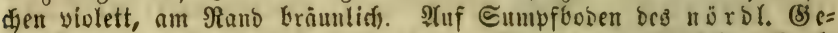
bicts felten: $\mathfrak{B}_{\mathrm{enth}}$ eim, Rheiua, Darup am Subfilde, $\Re$ edt=

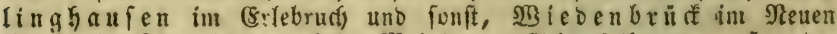
Werfe, im $\mathfrak{L}$ (p) burg. 6. 7, 4

102. A. Epigeios. (Calam. Ep. \otl).) $\Omega \pi n d=$

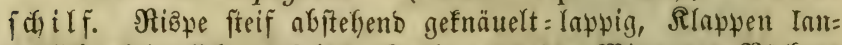
zettlich pfriemlidf)=zugefpibzt, Spelze nus ber Mitte Des SRutfens

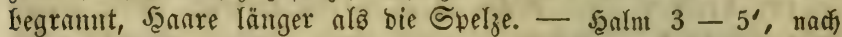

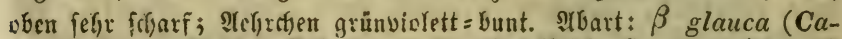
lam. glauca. Rchb.) F(ehrdyen blä́ aringelbling, Saare weniget und

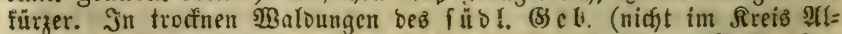
tena) ziemlidi verbreitet, fonft feltner: Soeft hinter Mallingíen,

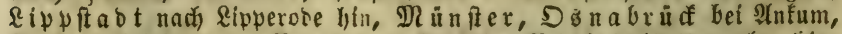

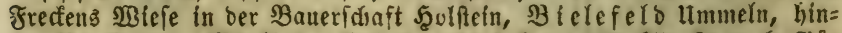

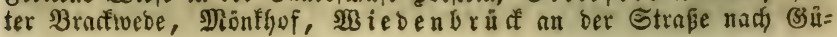




\section{Digynia.}

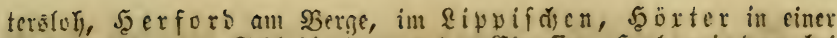

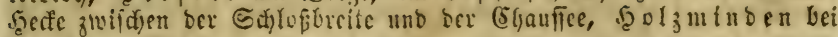

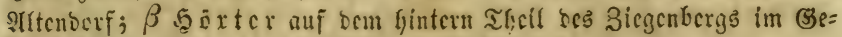
Gü (⿹) 7.82

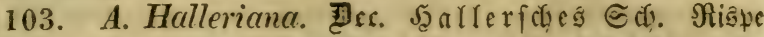
abftebend, nidut gelappt; Rlappen Ianzettlid pfricmlidi = zuge:

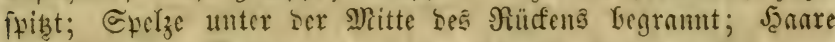

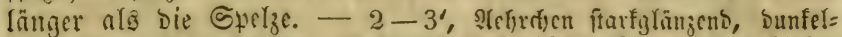

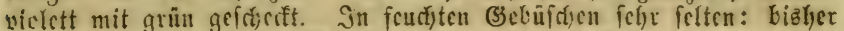

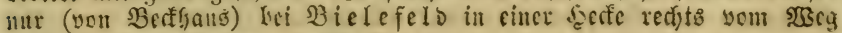
nac.) (gecpen gefunden. 7, 8. 4

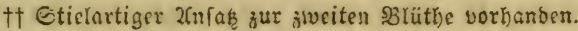

104. A. sylvatica. Sid)rat. (Agrostis arundinacea.

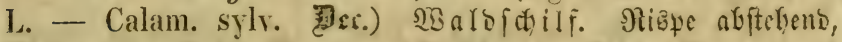
Silnppen zugefpitzt, \$rame rïrenfitändig gefnict, 5anre $4 \mathrm{mal}$

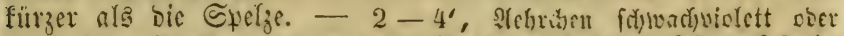

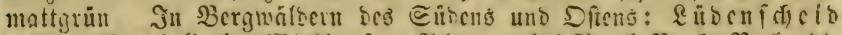

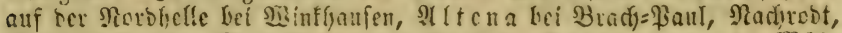

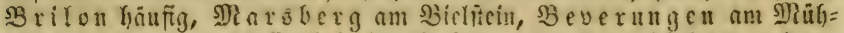

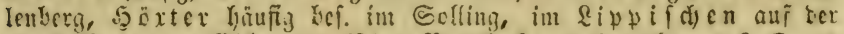

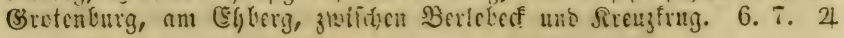

\section{** Ammophilia. Host. Untre Rlappe fürzer.}

105. A. arenaria. (Ammophila aren. Euli.) Sant

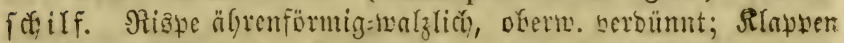

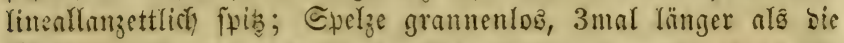

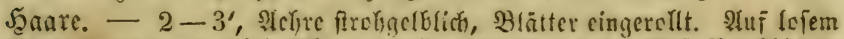

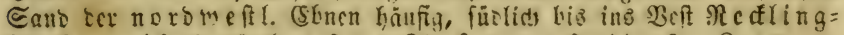

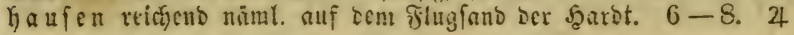

\section{3) Leersia. Swartz. ¿ecrife.}

106. L. oryzóides. Siv. (Phalaris oryz. L.) $\Re \in i \bar{B}=$

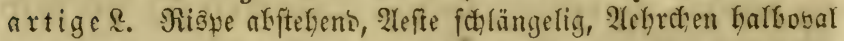

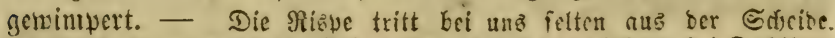

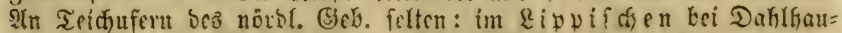

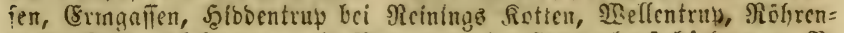

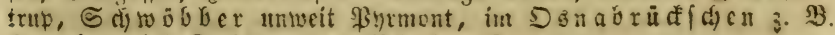
Syutekutig bei Diefnamn, am $\mathfrak{R}$ hein. 8. 9. 4

\section{4) Hórdeum. (sierite.}

* Jehrdjen alle zroitterig, begrannt.

107. H. vulgare. (5) eneine (5). 2lefraden bei ber Orrudtrcife 6 reibig, bie belben Seitenteifen mę̧r hervortretent. 


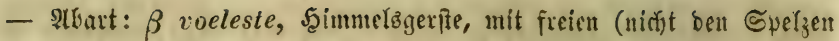

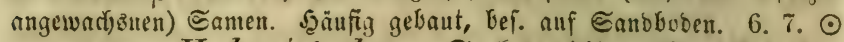

108. H. hexástychon. Sectiszeilige (5). 2lebrathen itt 6 gleidufürutige Neifen georbut. - Befonders auf Ecrym= obe: Thonboben gebaut. 6. 7. $\odot$ uno $\delta$

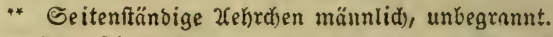

109. H. distichum. Sweizeilige (5). Ifet)rotyen bei

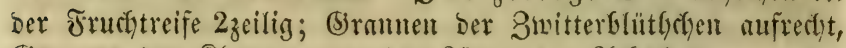

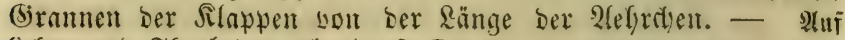

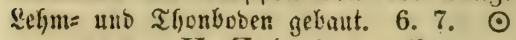

110. H. Zeócriton. Bartgerfte. (5ramen ber 3wit=

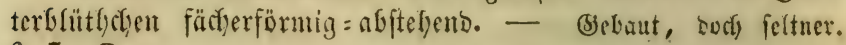
6. 7. $\odot$

† 111. H. strictum. Tisf. (H. bulbosum. Ault.) Senotige (S). (5rammen ber Buitterblütheden mirecht, (Sran=

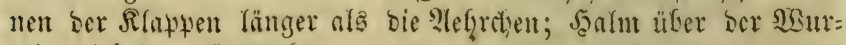

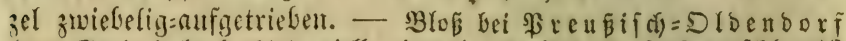

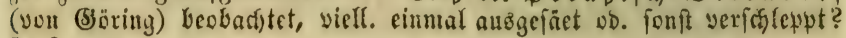
5. 6. 2

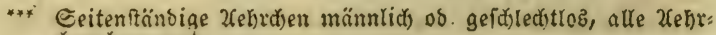
(b)en begrannt.

112. H. murinum. Miäu teläfred)en linenl=lanzettlich mimperig, bie ber Seitenälytuen borit.

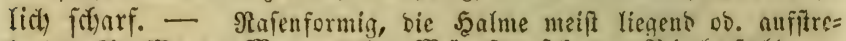

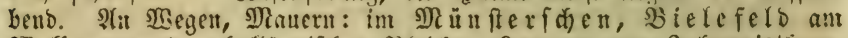

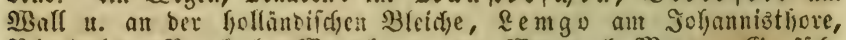

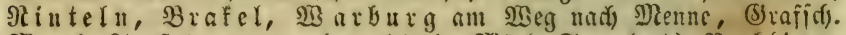

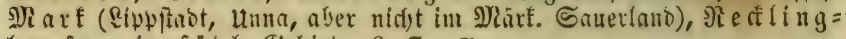

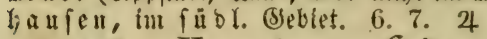

113. H. pratense. fous. (H. secalinum. Schreb.)

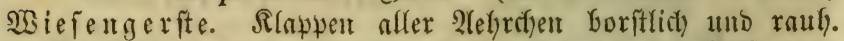

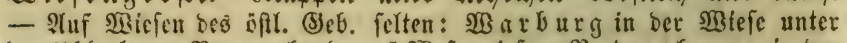

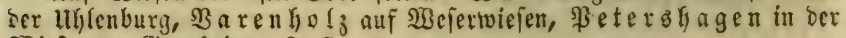
sBiefe yer Esernheim. 6. 7. -4

\section{Pánicum. Fenntid.}

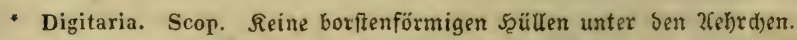

t Wefrdten in fingerige Xehren geffeltt.

114. $P$. sanguinale. (Digitaria sang. Seop.)

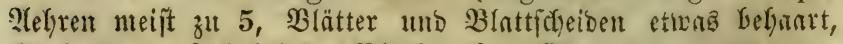

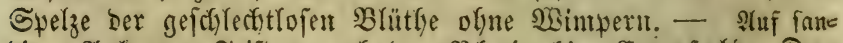

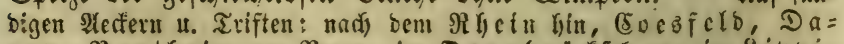

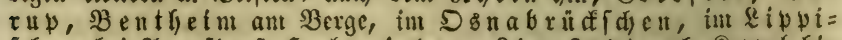

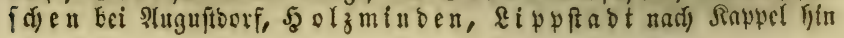


unb bei sipperobe, angeblici) audy in fïbr. Gebiet (nidjt un süben= idgeib). $6-8$. $\odot$

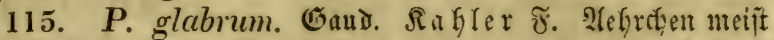

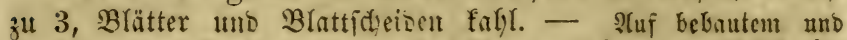

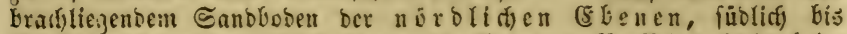

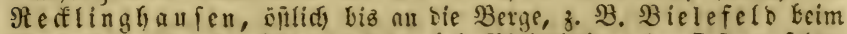

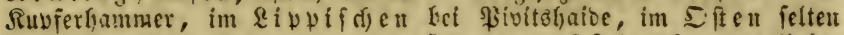

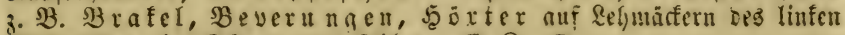

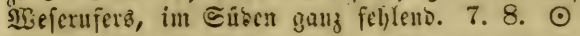

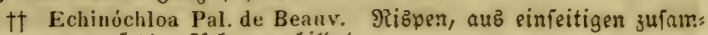
mengeferţten Zehren gebilbet.

116. P. Crus-galli. (Echinochloa Cr. g. Beauv.)

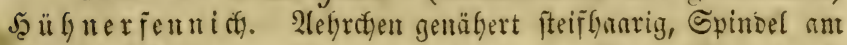

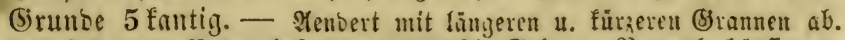

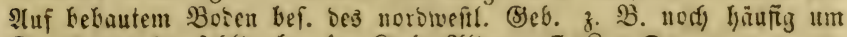

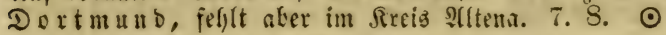

t†† Milium. Rißpe weitfdrweifig.

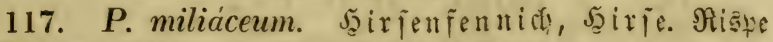

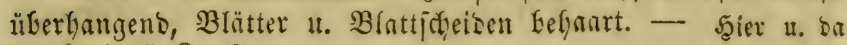
angebaut. 7. 8. $\odot$

** Setaria. Pal. de Beauv. Borltenförmige Şüllen unter ben zebrdien.

118. P. verticillatum. (Setaria vert. Beauv.)

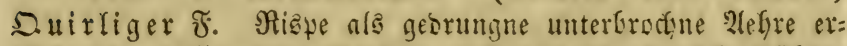

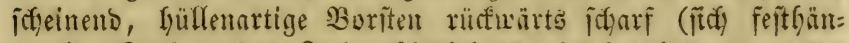

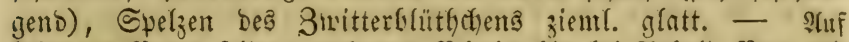

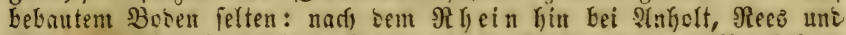

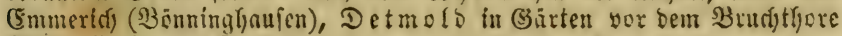

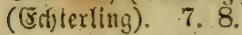

119. P. viride. (Set. vir. Beauv.) (5) $\mathrm{x}$ ü $\mathfrak{n} \in \mathfrak{x} \widetilde{s}$.

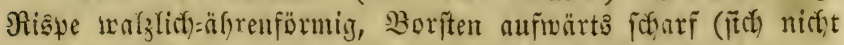
anfiängens), Spelzen Des 3mitterf(üthdens zientich glatt. Ifefre grün. Stbart: $\beta$ gracilis (P. Weinmanni $R$. et Sch.) flei=

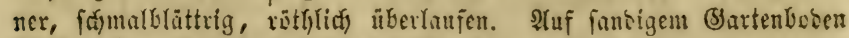

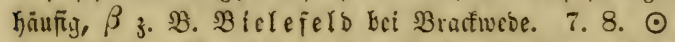

120. P. glaucum. (Set. gl. Beauv.) (\$) $\mathfrak{I} \mathfrak{b} \mathfrak{f} \mathfrak{a} \mathfrak{a}=$

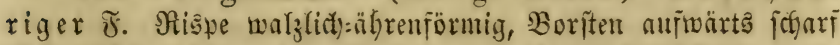

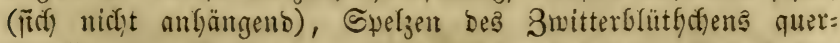

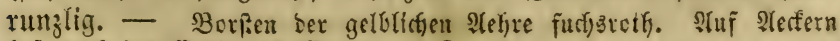
ber. nad) ber E̋rnte, an $\mathfrak{B}$ egent. 7. 8. ๑

121. P. italicum. (Set. italica. Beauv.) $\mathfrak{W} \in \mathfrak{l}=$

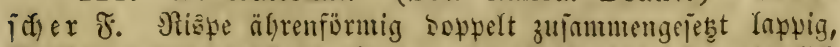
Borften aufwärts irgari, Spelzen ber 3nitterblütgd)en ziemlid glatt. - A(el)rdjen grin ober rufreraun; hüflentrtige Borften viel 


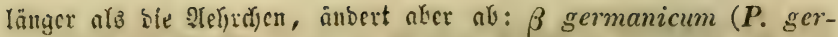
man. Rlh.) Şüllen mur cît twenig länger. Strmmt aus bem Cüben,

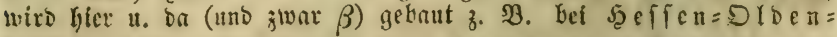

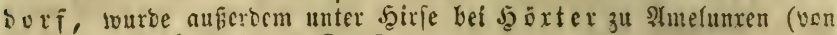
Becffaub) beobadjtet. 7. 8. $\odot$

\section{6) Phragmites. Trin. Rofrifdilf.}

122. Phr. communis. Crir. (Arundo Phragni-

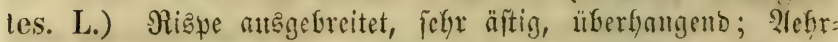

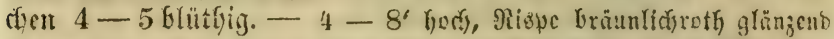

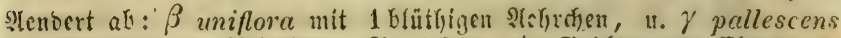

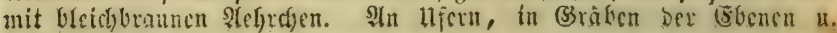

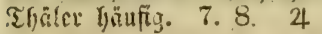

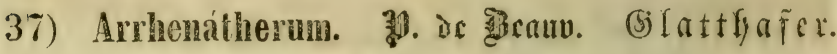

123. A. elatius. Mert. eft ctod). (Avena elatior

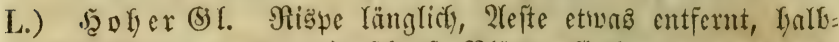

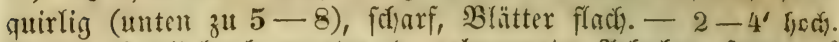

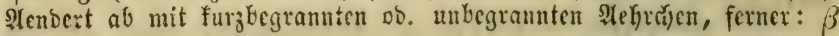
bulbosum (Holcus bulbosus. Schrad.) mit cinem Jjalm, ber itEer ber

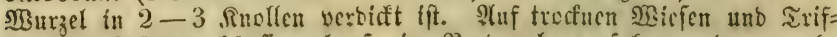
ten: im Süben baufig, chenfo im ßaberbornfden, ban mely vercinielt. 2 . B. an ber Rippc, Soeft auf bem Walpurger Etfft,

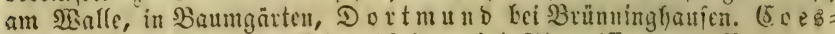

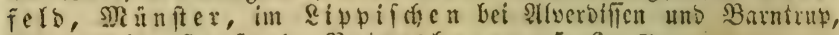
sielcfeld, Serford, łctershagen. 5. 6. 4

\section{3) Holcus. 5ุoniggrą.}

124. H. lanatus. Wrolliges 5 . TEurzel fafrig;

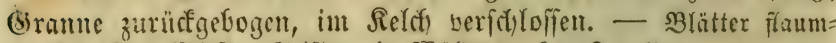

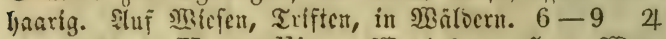

125. H. mollis. গู

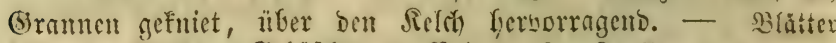

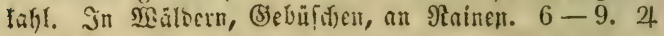

\section{9) Aira. Sibmiele.}

* Deschampsia. Beauv. Srannen nur ein wenig einvörtëgebogen u. an ber $\$$ Bafis Eaum georeht.

126. A. caespitosa. Fiafenich miele. STumzel bidit= rajig; Blätter flach, oberf. fegr rauth; (Sranten borftlich, faum fo lang als bie Epelze. - $2-3^{\prime}$ hody. Tlefrdjen grün= violett

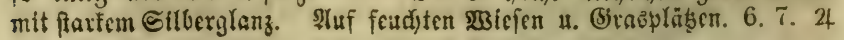


** (Avena). Brannen beutlid) in eill Sinie gebogen u. an ber Bafiz gebreht.

127. A. flexuosa. (Avena flex. Vahl.) ๔đ) đängelige S(i) m. Blätter felyr folmal, fait borftict, ftielrund=fäblids, Blattbäutchen zieml. furz abgejanitten; Niäpe abitebend =über: fangend; Blüthen faum länger ala ber fefr ungleidge Balg, l̈ber ber Baftb begramt; Gtielten ser zweiten Blütbe 4 mal fürzer nla die Blüthe jelbit. - Epiniel, Relte u. SBlüthenftielden

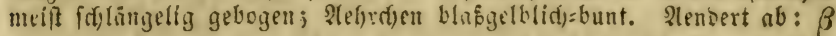
montana (A. montana L.) mit sunflex geiürten Tefordien u. mehr

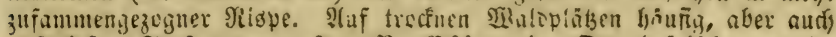

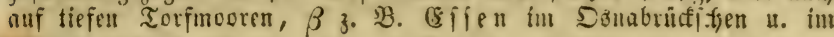
S il b 1 . 6. 7. 24

128. A. uliginosa. Weille. Sumpficfmiele. SBlät:

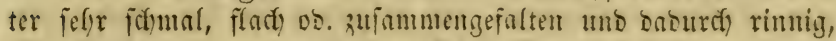

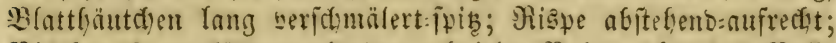
Blütyen faum länger als ber gleidhe Borlg, über ber Baft: begrannt; Stielchen der żweiten Blütbe falb fo lang als bie

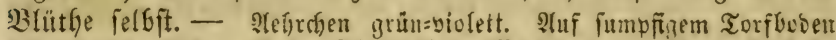

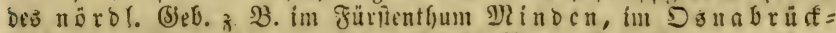

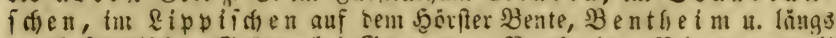

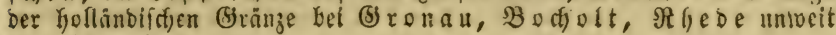
Borfen. 8. 9. 4

*** Corynéphorus. Beauv. Sranne über der Mitte Eeulenförmig.

129. A. canescens. (Coryn. canesc. Beauv.) (5) raue

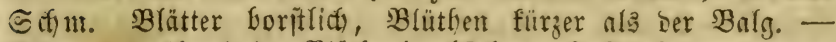

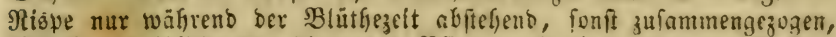

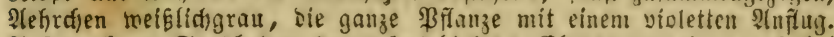

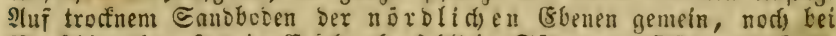

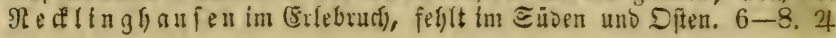

\section{0) Avéna. Şa f̃er.}

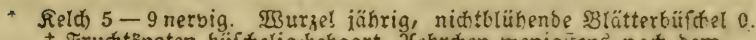
$\dagger$ Frudtenoten bifd delig:bebaart, Zehrden renigitens nad) bem Şerblüben hangend.

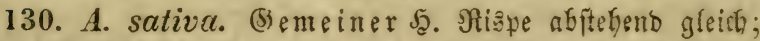

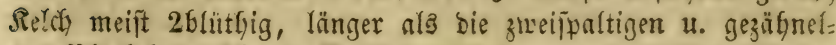

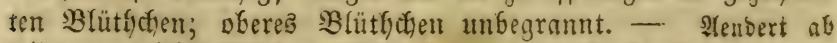
mit granmentoien Blütfen. Heberall angeosat. 6. 7.

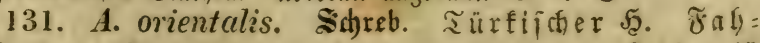

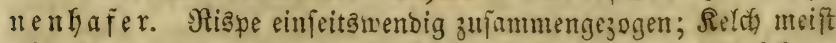
26lütbig, länger als bie 2 ppaltigen u. gezäbnelten sBlittgdeu;

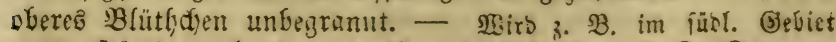

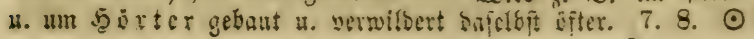




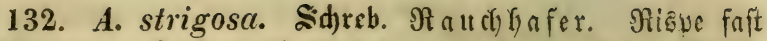

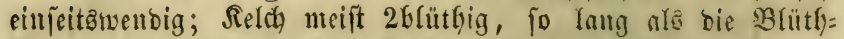

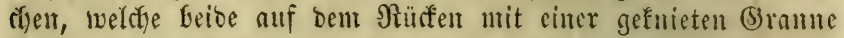

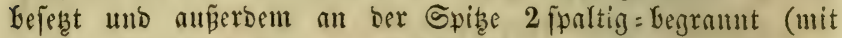
graben (Bramen) finto. - Shf Eanbboben angebout us. Dfter ver= weflbernd unter anderm Satforn. 7.8. $\odot$

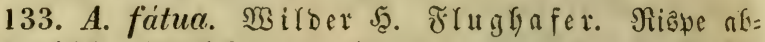

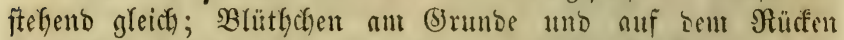

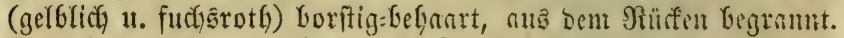
- Unter ber Sat, an Begen. 7. 8. ๑

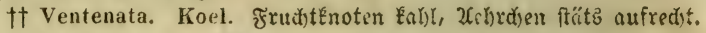

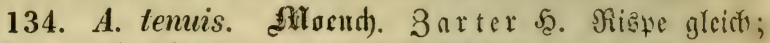

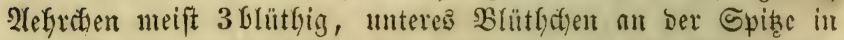

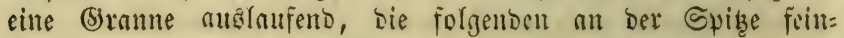

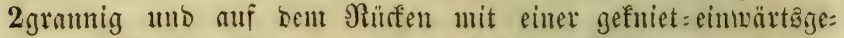

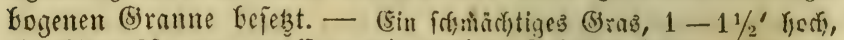

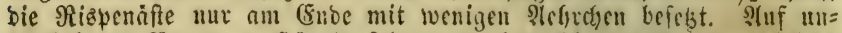

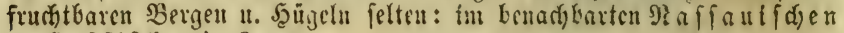
11. S马effifden! 6. $\odot$

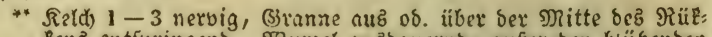
Eenb entipringend. 5̧almen nichtblühende SBlätterbufd)el treibend. SBlätter flach).

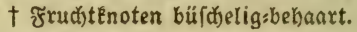

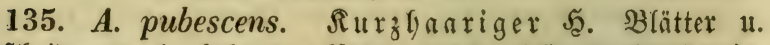
Blatticheioen zottig=behaart; Niąpe gleich, faft traubenförmig,

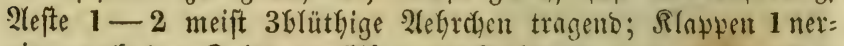
big, nach ber Sple zu filbern:troffenfäutig. - Naf trodfnen

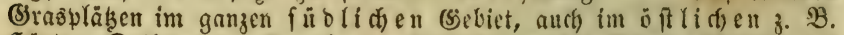

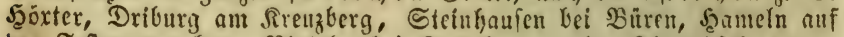
Den Feftungstwerfen, Ninteln bet Eteinbergen, in Rippifaten am

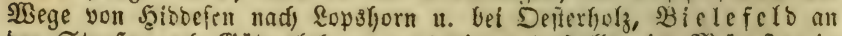

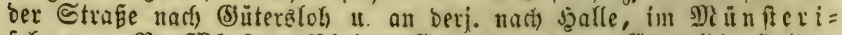

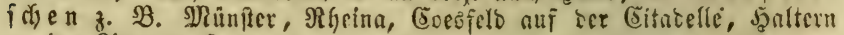
an ber sippe 1t. โ. 10. $5-7$. 2t

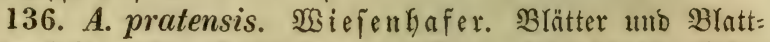

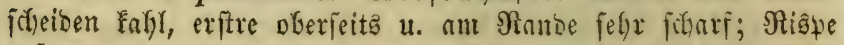
zulammengezogen traubenförmig, 2lefte $1-2$ meift 5 blüthige 2(efred)en tragend, iefre fotarf; obere Sinqpe 3 nerbig. - sBil=

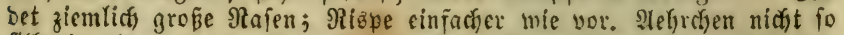

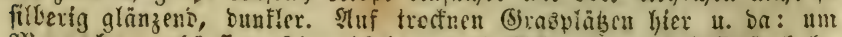

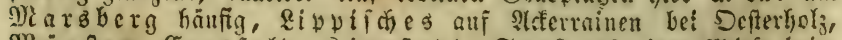

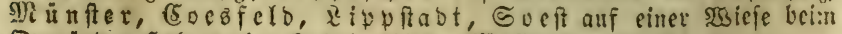

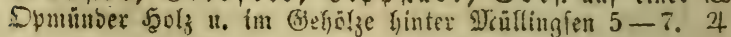

†t Trisétum, Pers. Fruthténoten Eaht.

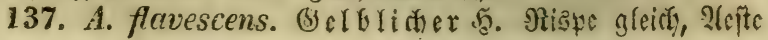




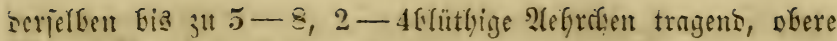

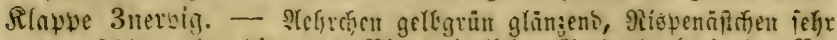

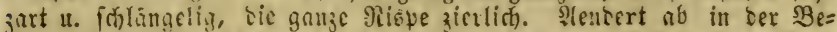

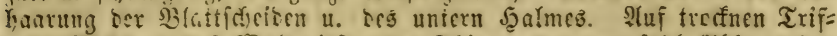

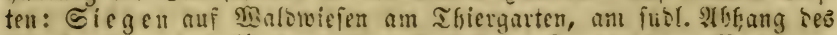

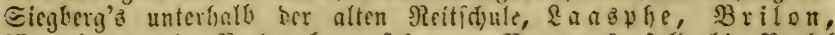

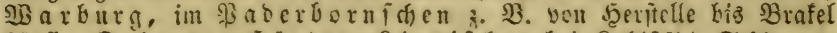

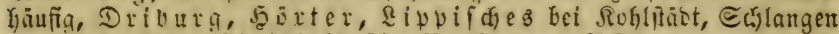

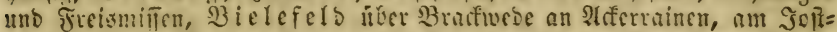

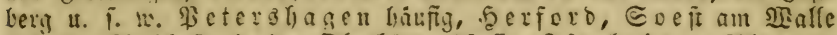

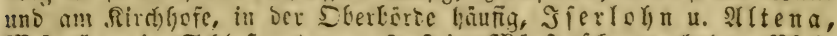

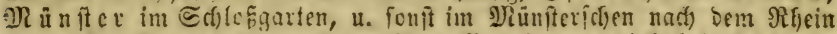

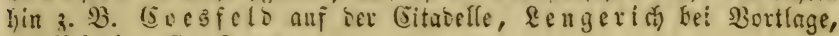
am $\mathfrak{R}$ he 1 . 7-9. 4

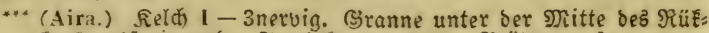
Ěnz entípringeno. Frudtitenoten Éahl. SBlätter zujammenges rollt:borftid).

13.. A. caryophylléa. Wiggers. (Aira car. L.) Nel=

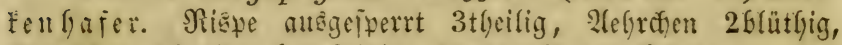

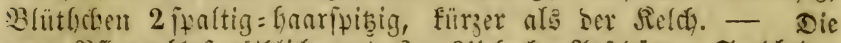

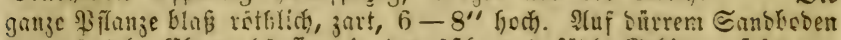

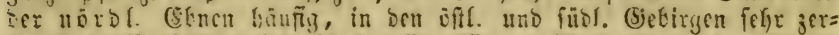

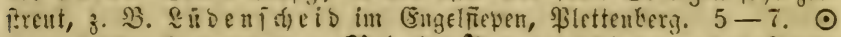

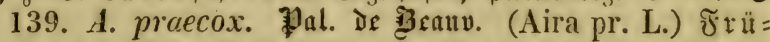

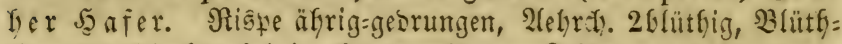

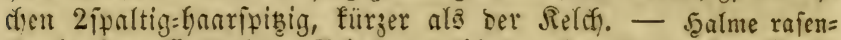

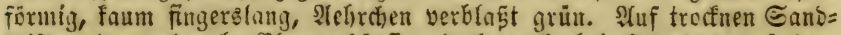

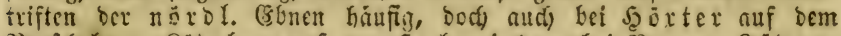

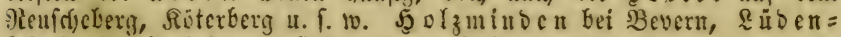

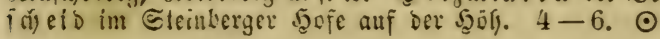

\section{1) Nélica. Ferlgras.}

† 140. M. ciliata. (5) ewimpertes $\mathfrak{P}$. Riąpe äfrits

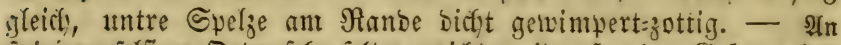

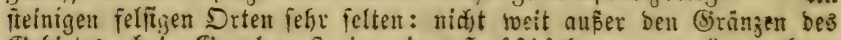

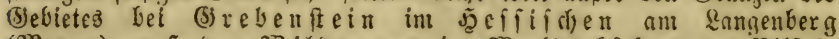

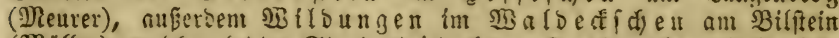

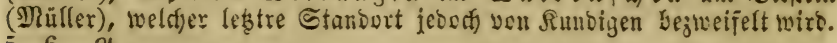
5. 6.24

141. M. nutans. Hebergangentos $\mathfrak{P}$. Riane ein= jeitig traubenförmig:zufantmengezogen, Aegreden hangent, nit

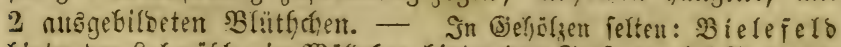

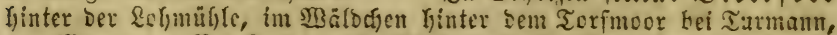

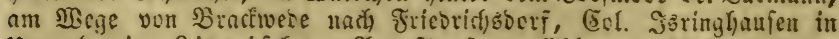

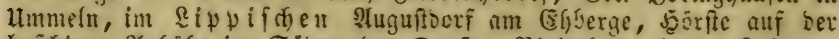

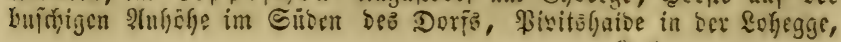




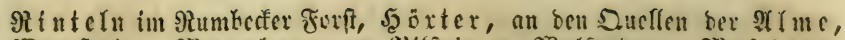

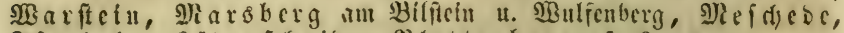

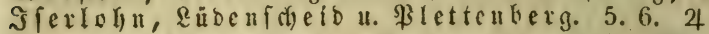

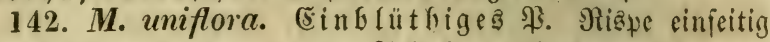
traubenförnig=zufammengezogen, Refreben aufrecht mit einen

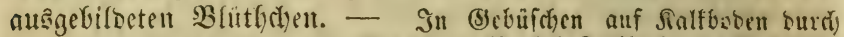

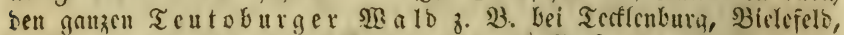
in sippifiten; bann in ten Siebirgen an ser Mefer 3. B3. Beverun= gen vor Shlanfenau, a!n Bapentitieg u. Shüflenberị, SBrafel binter E:

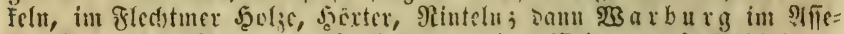

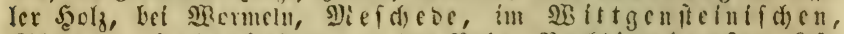

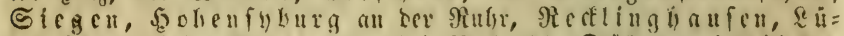

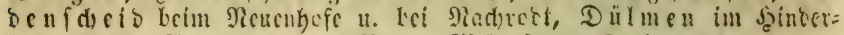

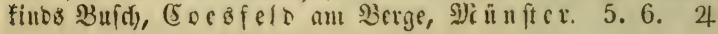

\section{2) Nolinia. Sidrank. Molinis.}

\section{M. cocrulea. Alacud). (Aira coer. L.) $\mathfrak{B}$ I auc}

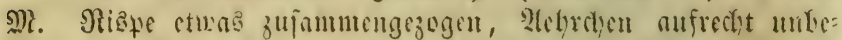

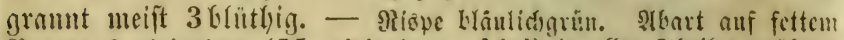
3oben: $\beta$ altissima (M. altissima. Link) in aflen Theilen grüber;

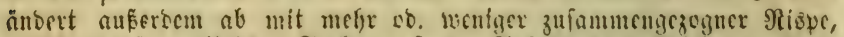

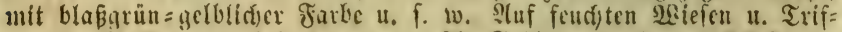

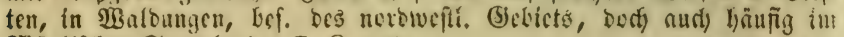

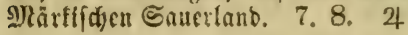

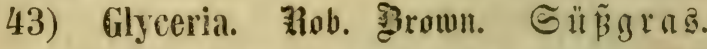

144. Gl. spectabilis. At. \& firod). (Poa aquatica L.) (3)

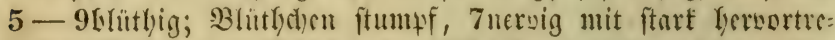

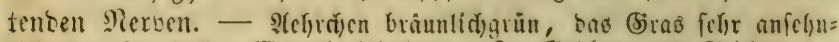

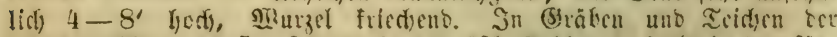

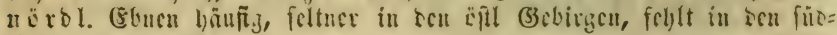
lidjen. 7. 8. 4

145. Gl. fluitans. 角. S3r. (Festuca fluitans 1.)

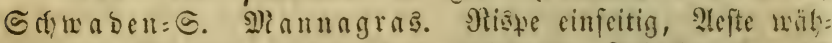

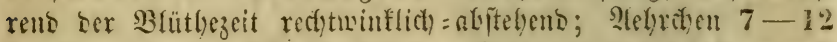
Glïtgig, an ben 2(fit angebrinft; Blütgd)en Inuzettlid), zieml. fpis, Fnervig mit farf lerwortretenben Nerwen. - Ninzal frie=

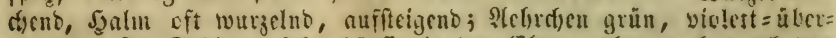

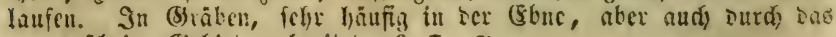
ganze übrige bsebiet verbreitct. 6. 7. 4

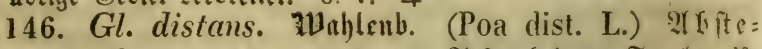

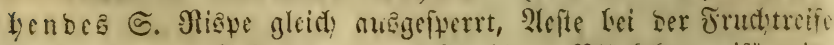

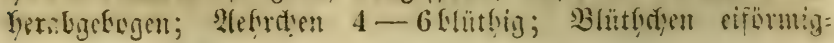




\section{Digynia.}

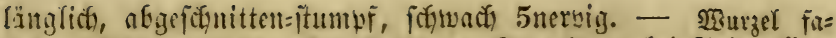

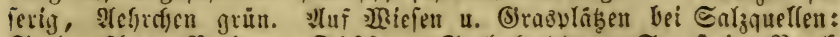
Salzuflen, Refme, Diffen, Salztotten, Soeft im Brudi)

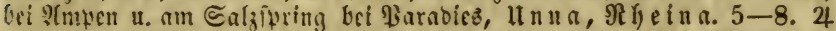

147. Gl. aquatica. Bgresl. (Aira aquat. L.) Şa affer=

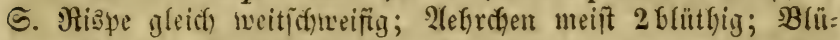

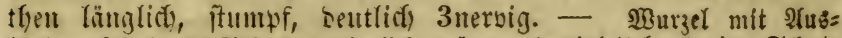
lăufern fried)ent, STefretten zierlicf) grün= uno violett=bunt, im Sithat=

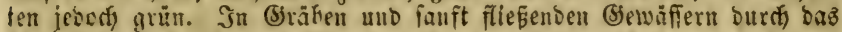

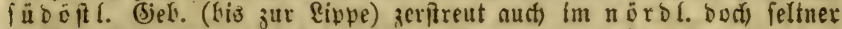

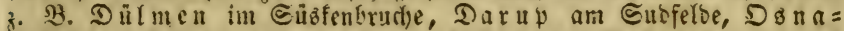

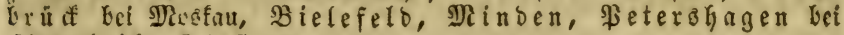
simmelreidy. $5-7.4$

\section{4) Poa. Rispengras.}

- Eragrostis. Beauv. SDbere Epelze ber Rtüthen fowie bie 2(a)je bleibeno.

† 148. P. Eragrostis (Eragrostis poaeóides.

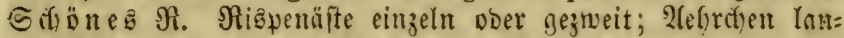

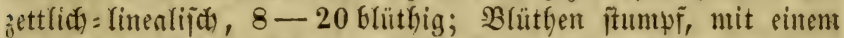

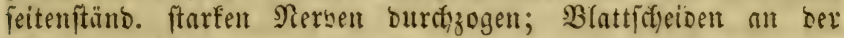
Miunbung Eärtig. - Nefrdien grünvióftt= bunt. Naf fanbigen

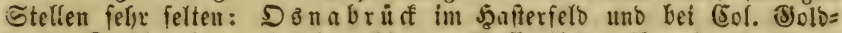

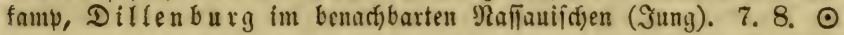

** Poa. Blüthen mit ben (Selenken ber $2(d)$ fen nbfällig.

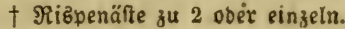

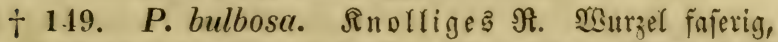

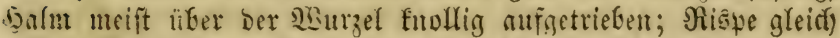

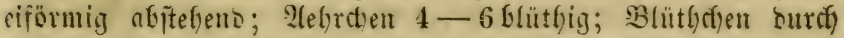

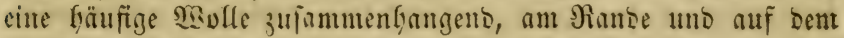
Prürfen bict)tf(aumig. - Romunt meiftens in ber Abänorung $\beta$ vivipara vor, wo fidf bie $\mathfrak{B}$ lithen in blattige Rnospen verwanielit.

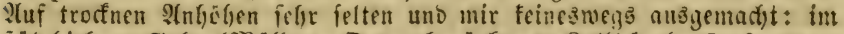

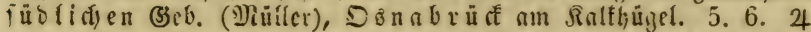

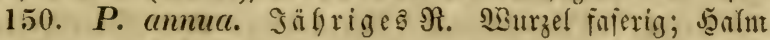

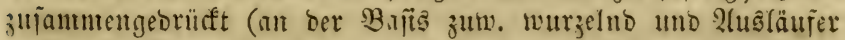

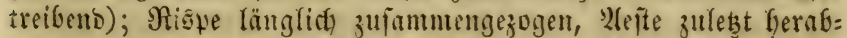

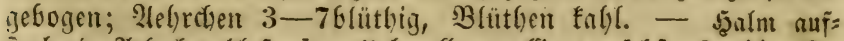

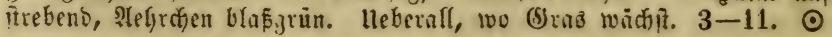

$\dagger †$ Riz̨penälte halbquirlig (bie unteriten meift zu 5).

a. গ্তুurzel faferig, ohne roeittreibende 2fubläufer.

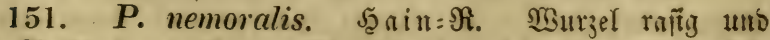

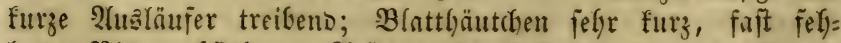

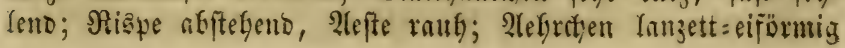




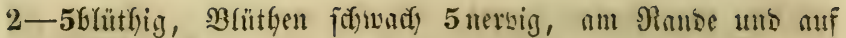

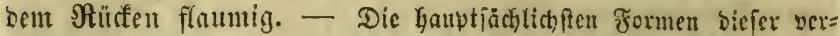

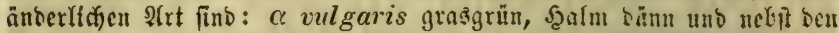

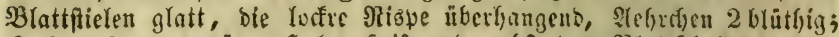

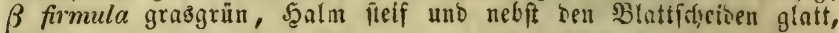

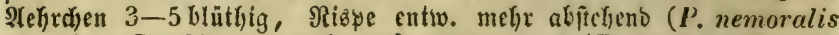
firmula. Gaud.) ober mehr zufammengezogen (P. nem. coarctata. Gaud.); $\gamma$ rigidula ( $\boldsymbol{P}$. serotina. Schrad.) bunfelgrün, Şalm fietí

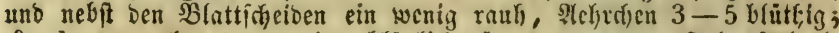

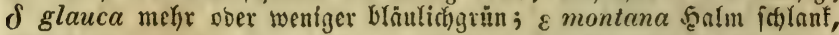

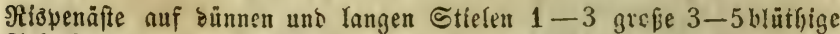

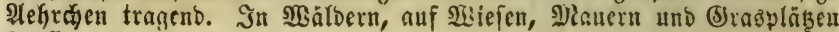
ظ่äufig. $7-9.24$

152. P. fertilis. fofot. (P. palustris. aoth). Sูicie=

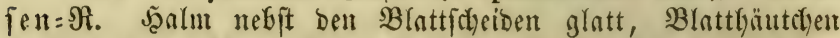

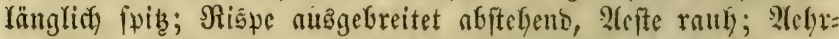

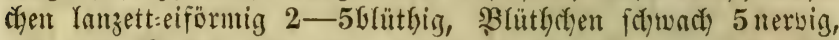

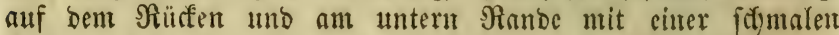
flaumigen \&inic. - MBurzel rafig, bie Bblütfdidon yor bei Spibe

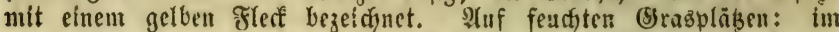

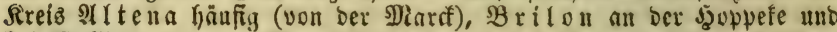

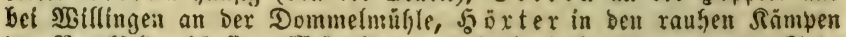

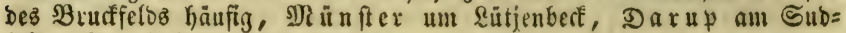

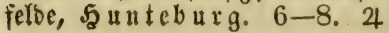

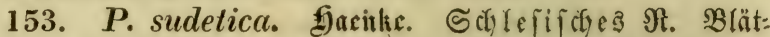

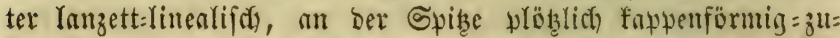
fammengezogen, B(attjudeiben nebjt bem Jăalme ftarf zufam=

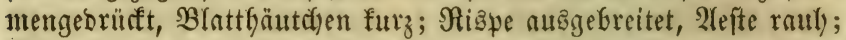

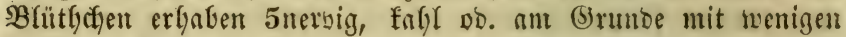
wolligen baaren bejekt. - bealm 4' hod), unfrustitbare Blätter=

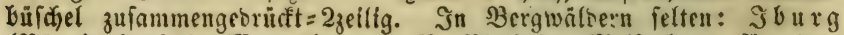

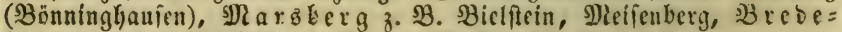

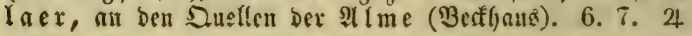

154. P. trivialis. (5) emeineg $\Re$. Blattfectionen et=

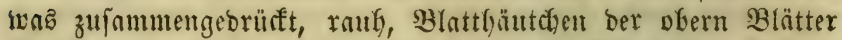

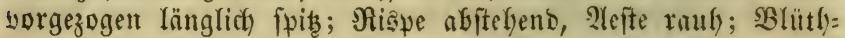
chen erfaben=5mervig, fagl, am (Brmbe fohwart) refgart. -

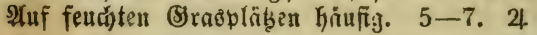

b. গ⿰氵

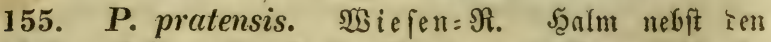
Bratticheiben fahl, bie oberîte Gd)eibe viel länger alB ibr

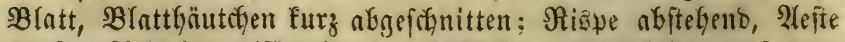
raut): 2(ef)rdyen eiförmig $3-5$ blütbig; Blüthdyen nuf sem 


\section{Digynia.}

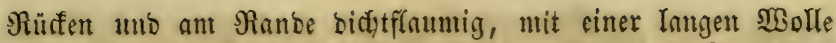
zujammentingento, beutlid) 5nervig. - 2tenbert ab: $\beta$ latifolia (P. humilis. Elırh.) bläulidggrủn, bie $\mathfrak{B}_{3}$ urzetblätter fürzer แmo

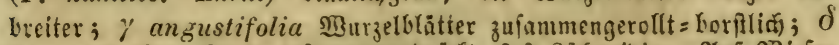

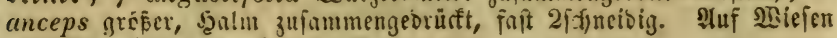
und (S) raêllăb̨en gemein. 5-7. 4

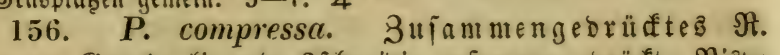

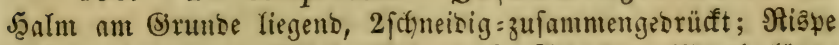

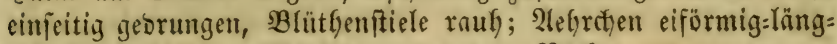

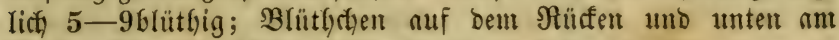

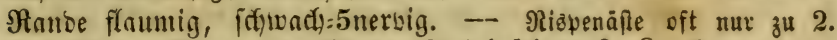

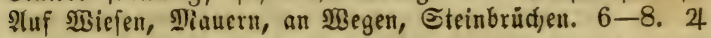

\section{5) Briza. Zittergiaz.}

157. Br. media. Nittleres 3. Aebrchen faft herz=

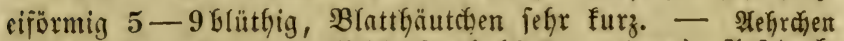
violett, ällbern aber aut) gelblidgruin ab ( $\beta$ flavo-virens). Ifuf tréf" nen Triften häufi!! $\beta$ auf jumpfiaem Torfboben bei $\mathfrak{B}$ elen (Bọ̆n= ninghaufen). 5. 6. 2

\section{6) Festuca. ङ duingel.}

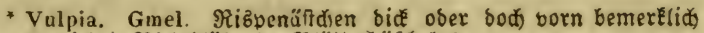

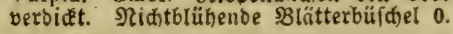

† 158. F. Myírus. (F. Pseudo-Myurus. Songr.)

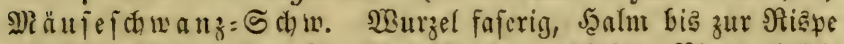

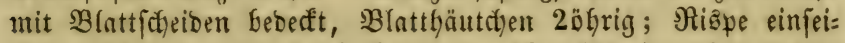
tig, berlängert, etwas überfangend, ägrenförntig zufammenge:

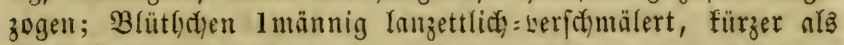

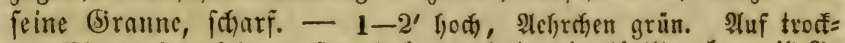

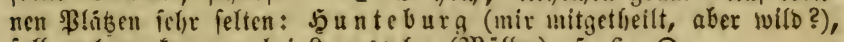

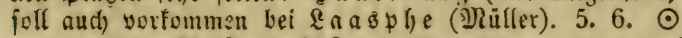

159. F. bromóides. Trespenartiger Sch wingel.

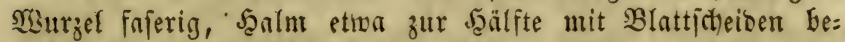

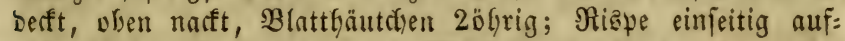

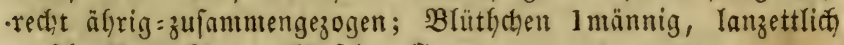
werict)mälert, fürzer alä feine (5iramme. $-1 / 2-5^{\prime}$ hodid, ble ganze

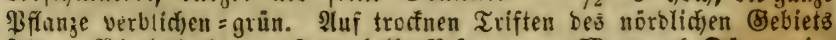
felten: Bielefe 10 am Rutterfulf, $B$ i n Rippif(t) en zwifden Nieinberg uno Befle bet bem Meilenjeiger,

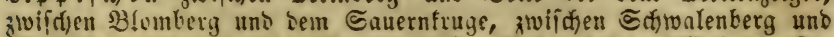

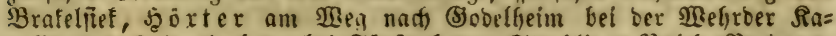

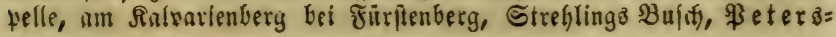




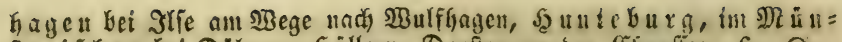

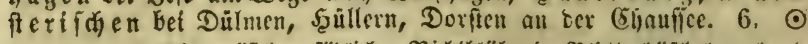

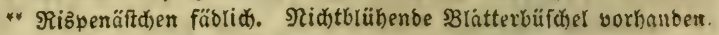

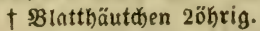

a. Zure Blätter zufammengerollt = borftich).

160. F. ovina. Gd্f afduingel. MBurzel fajerig;

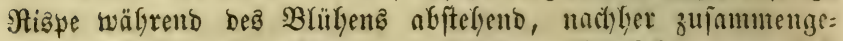

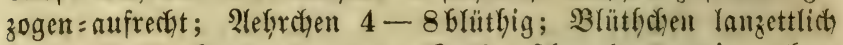
furz = ober unbegramit; untre Spelze fofwady 5nervig, obere an ber Spibe 2 zälnnig. - Iełrdien grün, oft violett überlau= for. Rommt bef. in fulgenoen Furmen vor: $\alpha$ vul garis etwa 1' hort), Blätter graşgrün, fefyr fein, etwas rauh, uno zlwar mit flcincren gran= nenlofen Relyrthen ( $\boldsymbol{F}$. tenuifolia. Sibth.) ober mit 6blüthigen Nehr= chen (F. paludosa. Gaud.), oder mit feht langen uno tünen Blät= tern (F. capillata. Lam); $\beta$ valesiaca ( $\boldsymbol{F}$. vales. Schleich. F. guestphalica. Boenningh.) etwa $2^{\prime}$ l)od), stehroben gröfer gran=

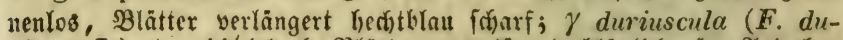

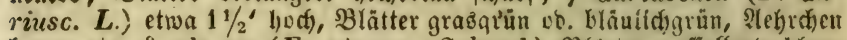
begrannt; $\delta$ glauca (F. glauca. Schrad.) Blätter nufiallend blau=

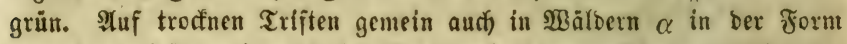

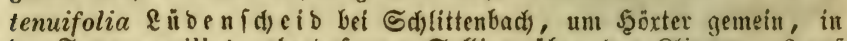
ber form capillata chenbaf. nm Eolling über ben אlippen, $\beta$ atf Felfen beฮె Ârnobergifd)en um $\mathfrak{B}$ rił on, $\delta$ in ben fübr. Gegenden bei Berleburg, Brilon, bann im Sippifiben, unter Soljeninburg an ber Rukx u. ศ. พ. 5-7, 4

b. গ্Zurzelblätter zuโammengerolut:borftlich, Scalmblätter flad).

161. F. heterophylla. fam. Sorfaiebenbrätri=

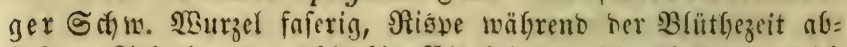

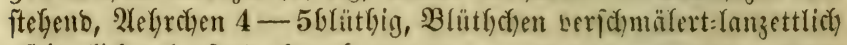
pfriemlidy:zulaufento furz:hegrannt. - 2' beris und bëber, birste

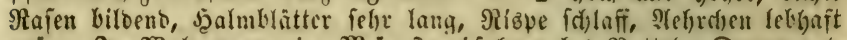

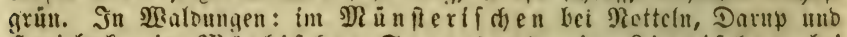
Javirbed, im פlärfifden Sauerlano, im Eipyifden boi Reelfirdien im Meierfilze. Solzminten am Gulling. 7. 8.24

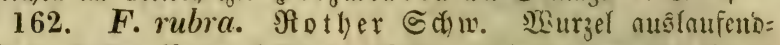

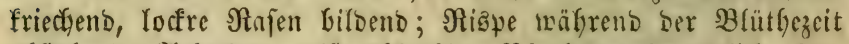
abfteheno; 2lefyrchen meift 5Glittbig; Blïtycten Yanjettlich), fïr=

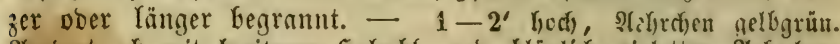

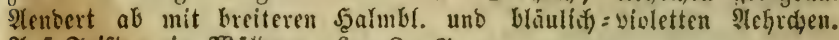

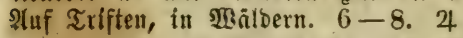

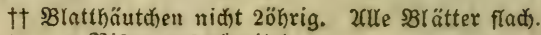

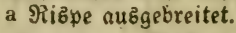

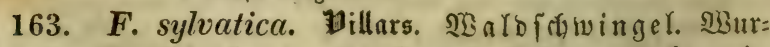
zel faferig; Blattbäutêten länglid) ftumpf; Shispe nufrect)t weit= 


\section{Digynia.}

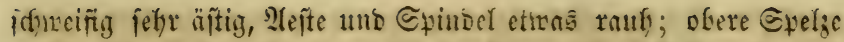

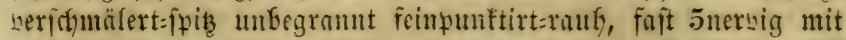
3 hersortretenten Nerwen; Fruditfnoten harridopĩy. $-3-4^{\prime}$

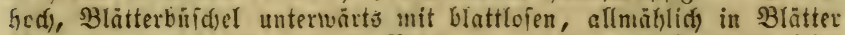

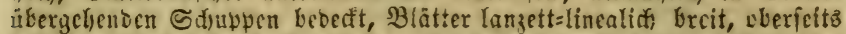

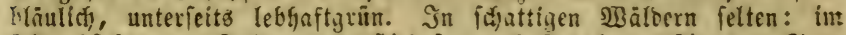

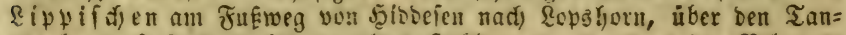

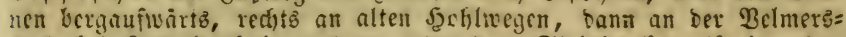
toot bei Reopelosthal an bem unte: bem Etcinbrutit entivringenben

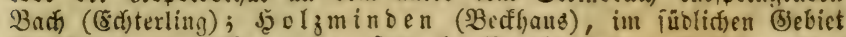
Brilon an ben Bergen ber Soupefe, Berleburg narif Ratreb hin,

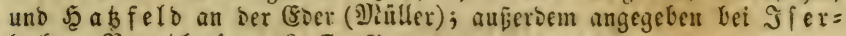
forjn, 3entheim. 6. 7. 4

164. F. gigánter. Vill. (Bromus giganteus. L.) Riejenfdutuger. Blattfüutffen fefr furz; Rispe neit=

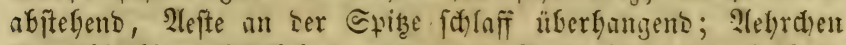
5-8Glütbig; Blüthden unter ser Epise begramnt, halb fo lantg alsె bie fallängelige (Sramue; Fruchtfnoten faf)l. $\sim 4-5^{\prime}$

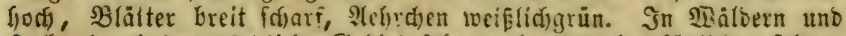

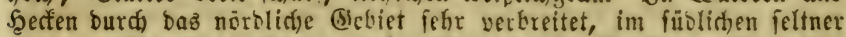

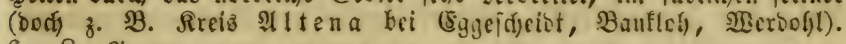
$6-8.24$

165. F. arundinacea. Sdjreb. (F. elatior. Sm.)

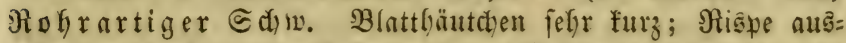
gefreitet üferf)angento, 2(efte rauf), meift geztweit, berzimeigt unto 5-15 2lefretten trageno, 2(ef)reten 4-5 Glithig; untere

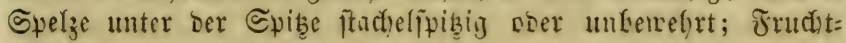

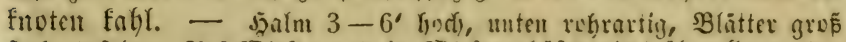

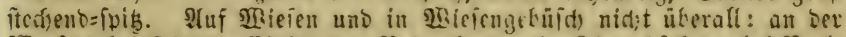

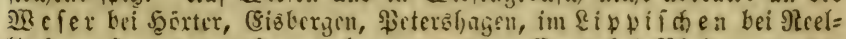

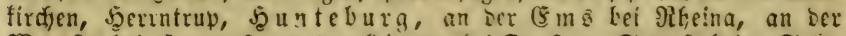
Werfe bei szantorf, an ber atiphe kei Dorften, Exeft beim Ealiz=

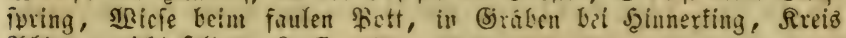
enten a nidst felten. 6. 7. 24

\section{b. Fizpe einfeitig.}

166. F. pratensis. f̧uds. (F. elatior. L.) Sicie:

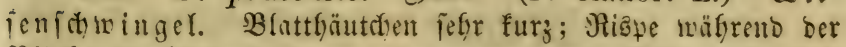
Blütfejeit afitefeno, bann zujammengezogen, 2leite rauf), (ber cine fefor furz mit 1 2fefroten, Ier anoere troubig mit 3-4 2(ebrden), 2lefyrden 5-106lütgig; Blüthden unter ser Gyibe itadelfpitzig ober unbewehrt. - $2-3^{\prime}$ hedf, Ifefrdjen grüh,

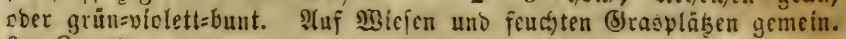
$6-8.4$

c. 3weizeilige Traube.

167. F. loliacea. E)uds. (F. elongata Ehrh.) Roldi= 


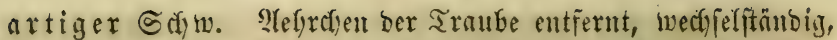
bie untern furz geftielt, zumeilen gezmeit, bie obern fiz̧end. -

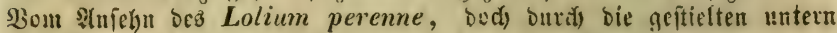

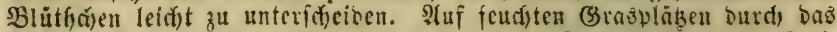

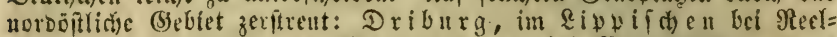

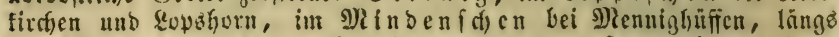

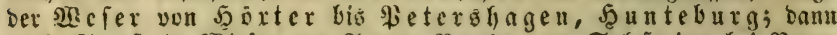

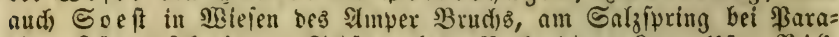

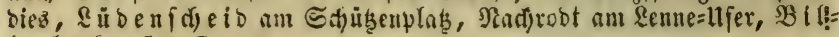
ferbeff. $5-7.2$

\section{7) Bromus. Trespe.}

* Zehr(t)en, aud) nad) bem Berblühen, vorn fđmälex.

$\dagger$ Untere Rlappe 4-5nervig, obere 5-vielnervig. Untere Sppelze 7nerrig, obere mit fteifliden Borften entfernt: Eammförmig: geroimpert.

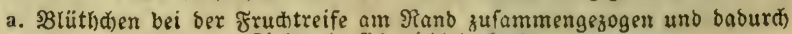
fitelruno, fid) nidit oectend.

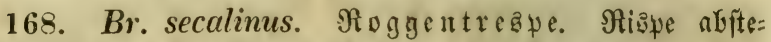

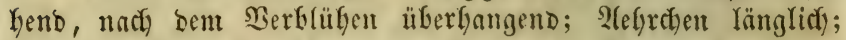

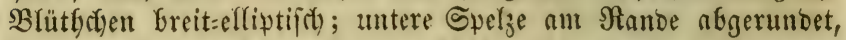
fo lang als bie obere; (Siranne fälängelig ober z̧iemlich grabe, faum über bie Blïtye herborragend (vft find bie meiften 2(efr: chen fajt unbegraunt), Blatticheiden faffl. - Die Blätter fino mitunter langgervimpert. Befonbere ซormen: cะ grossus (Br. grossus $\alpha$ Vahl - Br. grossus $\beta$ Gaud.) S(elitrtyen größer (faft 1" lang), bis 15blütrig, faffl ooer fid)arf; $\beta$ velutinus (Br. velutinus Schrad.

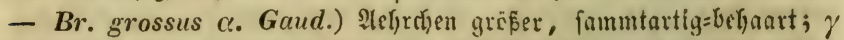

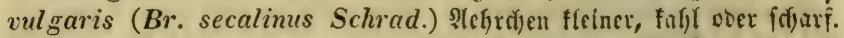
unter ber Sat: $\gamma$ felfre gemein, $\alpha$ unb $\beta$ felten,

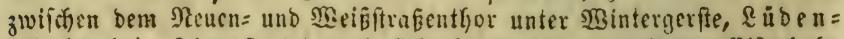

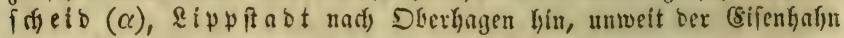

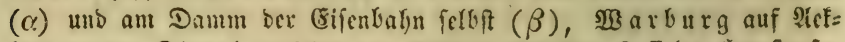

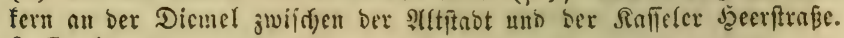
6. 7. .

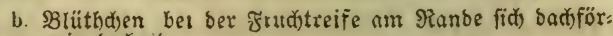
mig bedéeno.

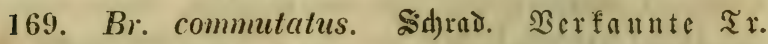

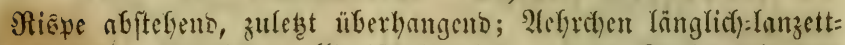

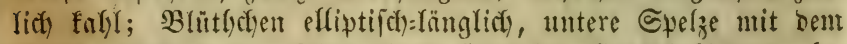
Panb oberfalb ber Mitte einen ftumpfen MSinfel bilsend, b $c=$ merflid) länger als bie ofere; (Sranme grabe, faft fo lang als ilye Spelze; untere Blatticheiden befyart. - Unter ber Eat

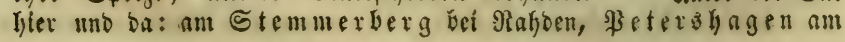




\section{Digynia.}

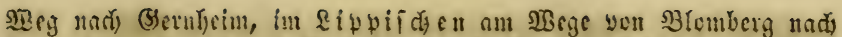

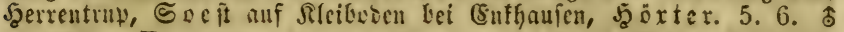

170. Br. racemosus. Traubige Tr. Mişpe affehend, nufrecht boer ctuns überbangens, nach Dem 2erflüben zufam=

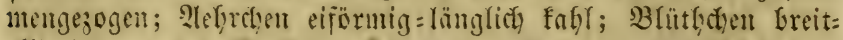

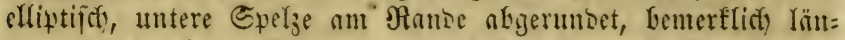
ger als bie obere; Sramme grare, fait fo lang als ifyre Spelze;

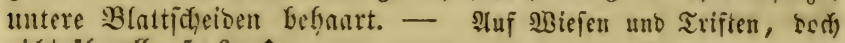
nidyt überall. 5. 6. 古

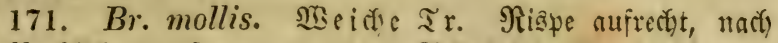

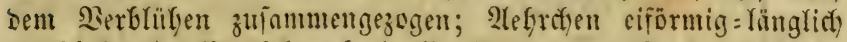

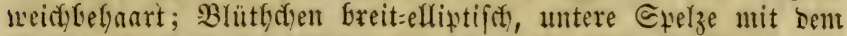
Ranbe oberbulb ber Nitte cinen ftumtpen sinfel Gilbens, be= merflich) länger als bie obere; Gramme grabe, fajt fo lang als

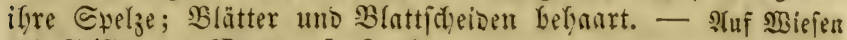

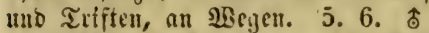

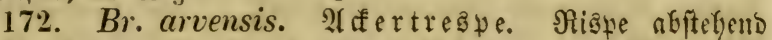

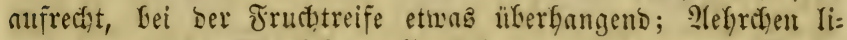
neal=Inuzettich); Blütychen efliptifor =Ianzettlich, untere Spelze

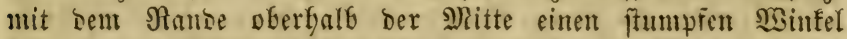

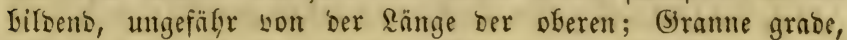
faft iv lang als ifyre Spelze; Balätter uno Bhattjdeiben be:

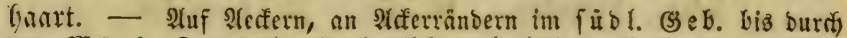
b.ıร Mã

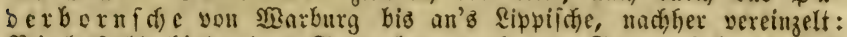
B ielefeld hinter bem Eparenberg nady bem Freubentfale hin uns am Johannisberg, Stromberg uno Delbe, Eipp îta trectits

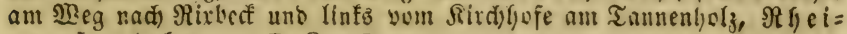

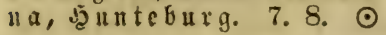

†† Untere Rlappe 1-, obere 3nervig. Sbere Epelze am Rans be Eurz= flaumbaarig.

173. Br. asper. (Festuca aspera. AR. \& fitod).)

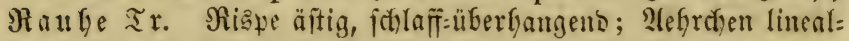

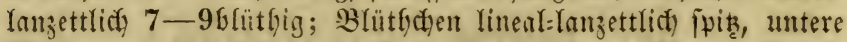
Spelze ณแล furz:2zäf)niger Spize begrannt uno länger als bie grave (5ramne; Blätter und untere Blattideiden raufgaarig.

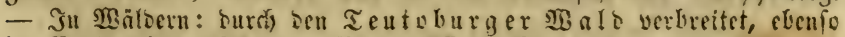
im \$aberbornffien

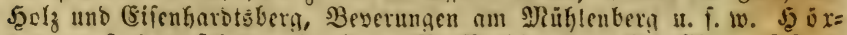

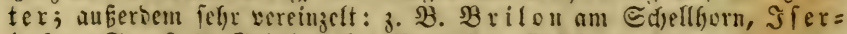

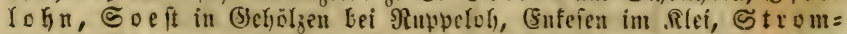

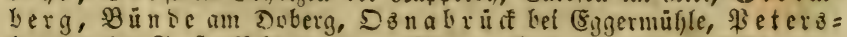

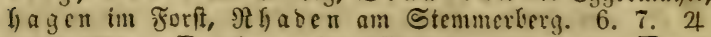

174. Br. inermis. (Festuca inermis. Tere.). (8) $\mathrm{r} \pi \mathrm{n}=$ 


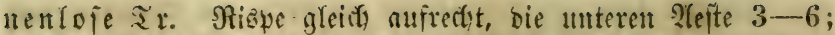

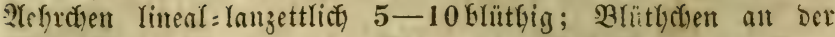

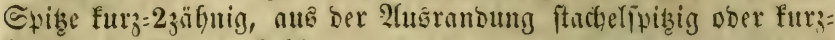

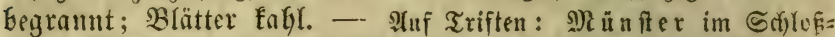

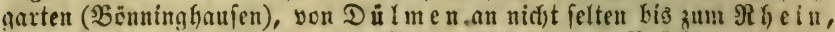

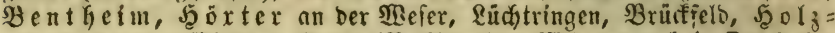
minben am șlatten Ropi (Rertfyauz), Sllinden bet Danferfen (50 $\mathrm{Her})$. 6. 7. 24

** 2(ehrchen nad) vorn breiter. Untere Rlapbe 1-, obere 3nervig. Dbere Spelze mit ftarren Borften "ammförmig:gerwimpert.

175. Br. sterilis. Ta a be $\mathfrak{T}$ r. Mispe locfer, zulekt

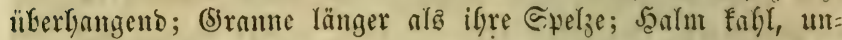

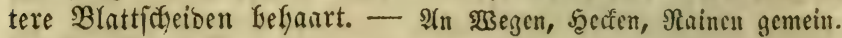
$6-9$. $\odot$

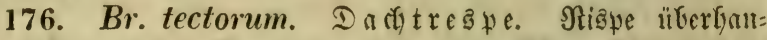
gento, fajt einfeitig; (biranne von ber ungcfähren \&änge ifjer Spelze; Salm nach oben weidhbehant. - Stuf trodfnem S3oben, Mauern, Schutt: im Süben zieml. verbrcitet (forlt aber im Sireỉ

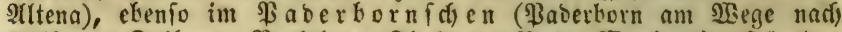

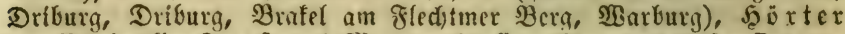
am Shetrivall, Goeft suf Nhaucrm bäufi, SBarendorf, DBna=

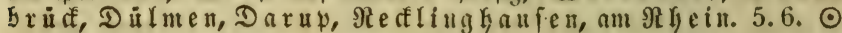

\section{8) Triódia. 录. Dr. Dreizafin.}

177. Tr. decumbens. Şrnuv. (Festuca dec. L.) Nieberliegender Dr. Niape trubig, 2leite cinfact) und

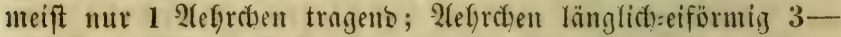

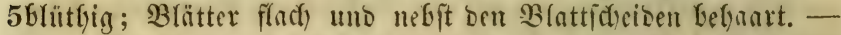
S5alm erft nicberliegent, bann aufferebent, 1' hoch. In trectuen fou= bigen Etellen im nörol. (3) Sauerlanb, Re oflinghanfen, Dortmuno (in Bérifchen foci

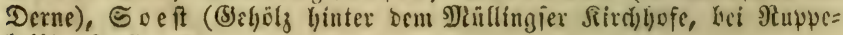
(of). 6. 7,24

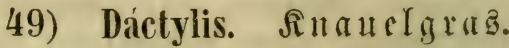

178. D. glomerata. (5) meines $\mathbb{R}$. Rişe cinjici= tig gefnauelt, untere Spelze 5nervig. - Wurzel rafig, 5antm 1-

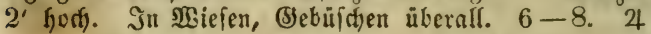

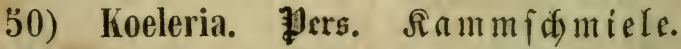

179. K. cristata. Perz. (Aira crist. L.) (5) meine

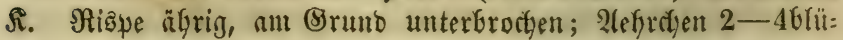




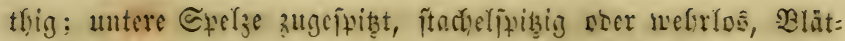
ter filad, bie untern getwimpert. $-1-2 \frac{1}{1} 2^{\prime}$ fod

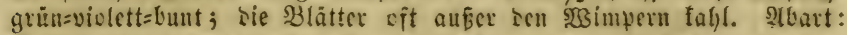

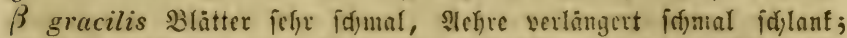

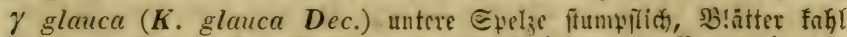

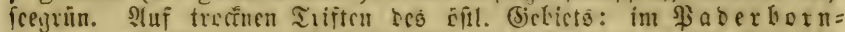

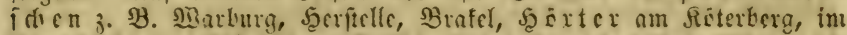

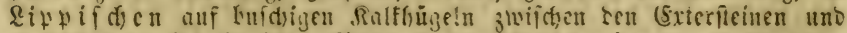
Jablghaufen, bei beciten, S3iciefeld, Etromberg uno Delbe,

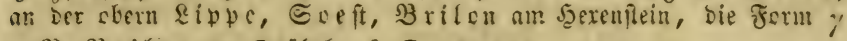
3. 3. 3rifun am Dribe!. 6. 7. 4

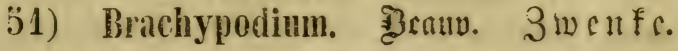

180. Br. sylvaticum. Hosm. S. Sih. (Bromus pin-

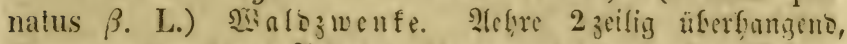

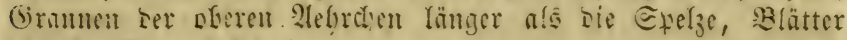

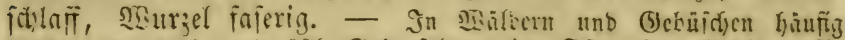

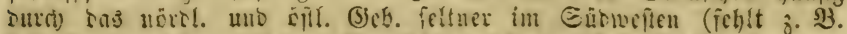

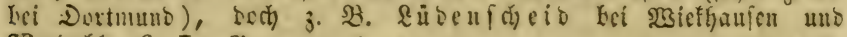
\$iscrofi!. 6. 7. 4

1ध1. Br. pinnatum. (Beauv. (Bromus pimatus L.) (b) fieserte 3w. Neffre 2 zeilig merectit ober nur wenig ïberbnngent, Grannen fürzer als bie Epelze, Blätter zientid

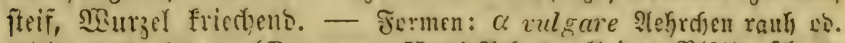
zottig; caespitosum (Br. caesp. Host) Nef(1rden flciner, şlättcr fdjma=

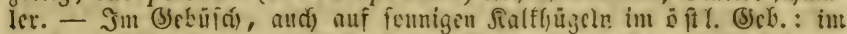

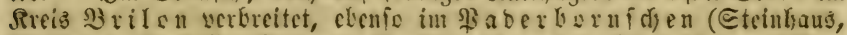

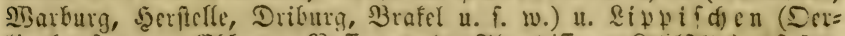

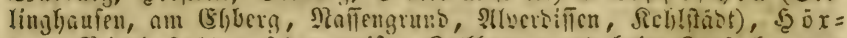

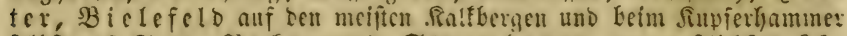

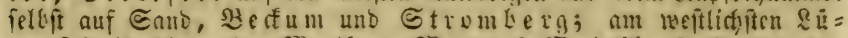

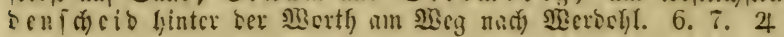

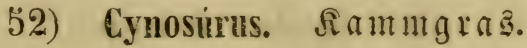

182. C. cristatus. (5) emeinesิ $\mathcal{A}$. Traute ähren= fürmig cinfeitig, bie fammf̈̈rmigen Decfblütter unbegraunt. -

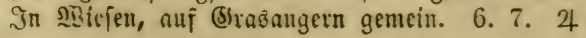

\section{3) Sesléria. Atrun. Seslerie.}

183. S. coerulea. ATr. (Cynosurus coeruleus L.)

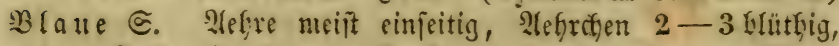
untere Sfellge in 2-4 Buriten unb eine Grante in ser 
Nitte enbigent, Boriten unb Branne nicht falb fo lang als

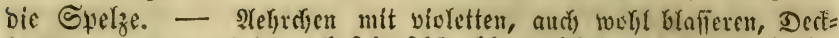

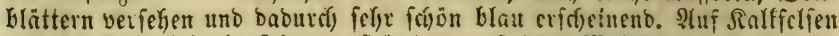

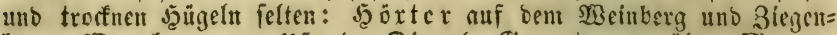
berg, $\mathfrak{B} \mathfrak{a} \mathfrak{i} \mathfrak{b}$ arg am Mfer ber Diemel, Bermete gegenitber, פia a $\mathfrak{b}=$

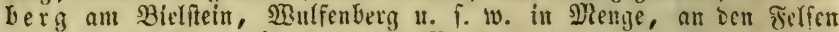

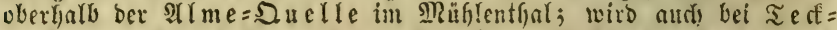
lenburg, Sferlehn auf bem Rreublerg, Sogenltmburg, uno

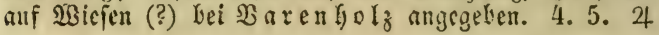

\section{4) Triticum. Mscizent.}

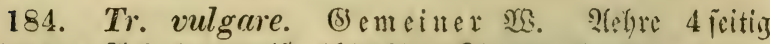

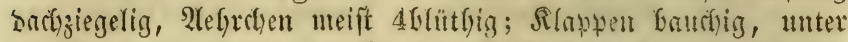

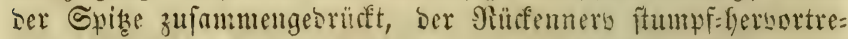
tent ; Frindte frei (nicht Geifhalt). - $\alpha$ aestivum, Sommerweis

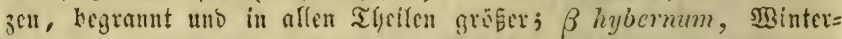

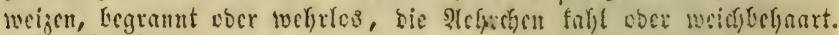
lleberall gebaut. 6. $\odot$ uno $\hat{\circ}$

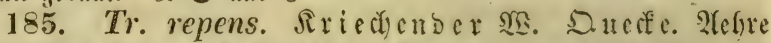

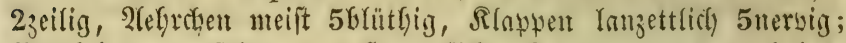

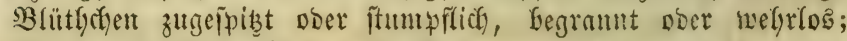

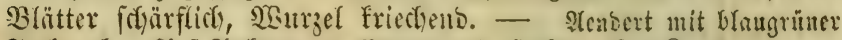

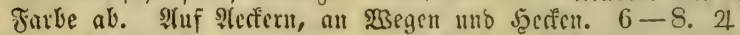

186. Tr. caninum. Sidreb. (Elymus caninus L.)

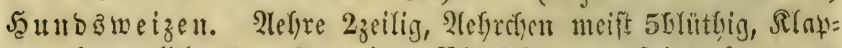

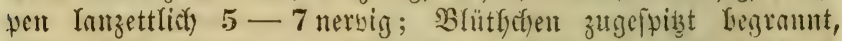

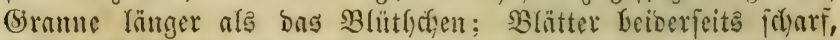

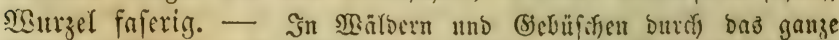

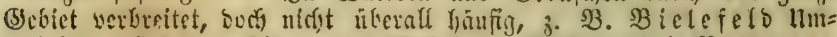

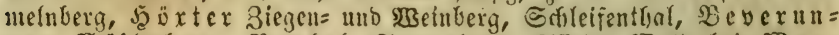

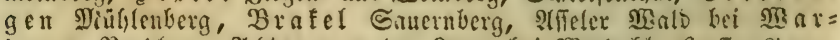

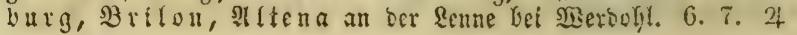

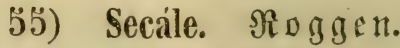

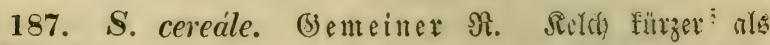
rie $\mathfrak{B l i ̈ t}$ b) बิ แnto $\odot$

\section{6) Lolium. ฉo[}

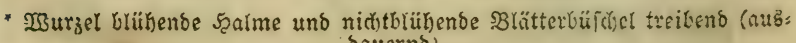
onuerno).

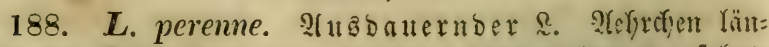

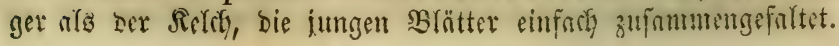




\section{Digynia ... Trigynia.}

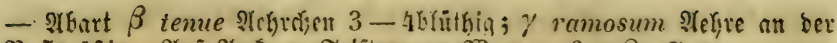

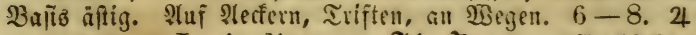

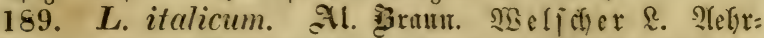
dịen länger nla Der Relch, meift ziemlich langlegramnt, bie jun=

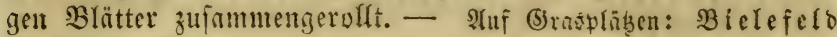
am Jofjannisberg. $6-8.24$

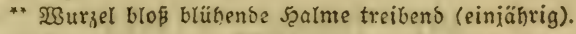

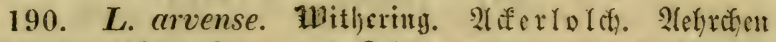

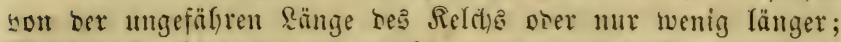
Blüthent furzbegramut Doer unbegramt. - Stuf Afcefern, befens.

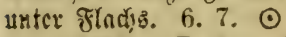

191. L. temulentum. Ëigentli dier. Tolfforn.

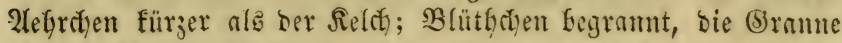

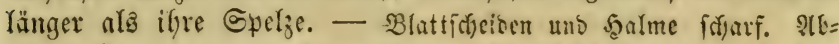
ntten: $\beta$ submuticum ( $\boldsymbol{L}$ speciosum. $\boldsymbol{K}$ och) Dic Brannen ferfe furz

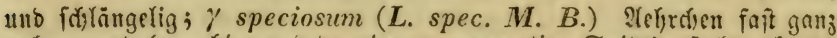

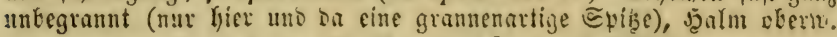

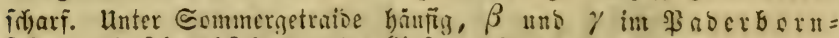
fine en uno eippifdyen unter sinfen. 6. 7. ○

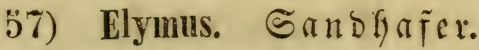

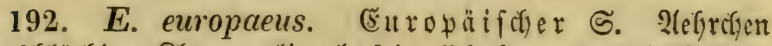
meift 2blätfig; Rlappen lineal=prriemlich begrannt, bie Granme

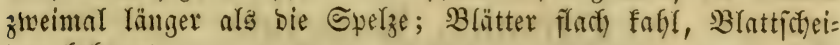
ben Gelgart. - 5ुatm $2-3^{\prime}$ hod, an ben Sincten zottig. In

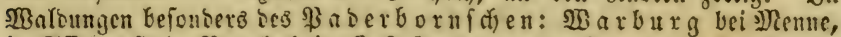

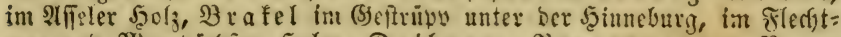

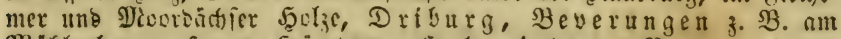

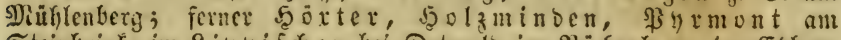
Steinbrinf, im \&ippifiden bei Detmolo im Büdjenberg, im Ëhberg

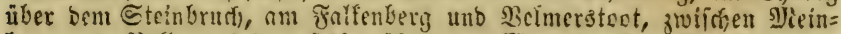

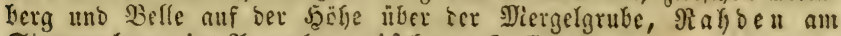

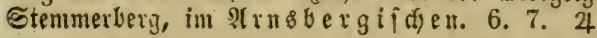

\section{Sronumg Trigynia. 58) Holosteum. Spurif.}

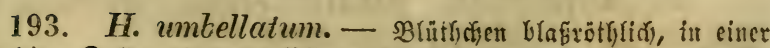

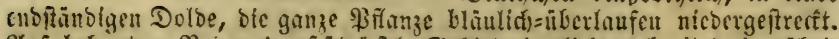

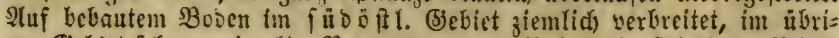

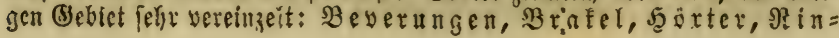




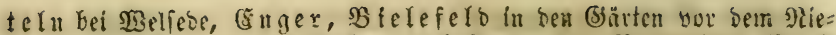

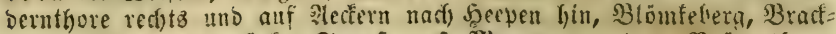

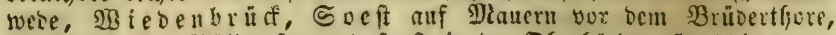
a.t Sisegen bet Mhullingen und fonft in ber 5berbarbe, 5 attingen, Re flingban unb im Sifterthal. 3-5.

\section{9) Tillaea. Tilläe.}

194. T. muscosa. - Die \$ilunze if ffein, faftig, rotfy=

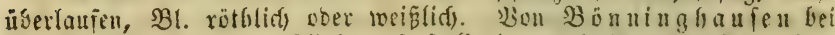

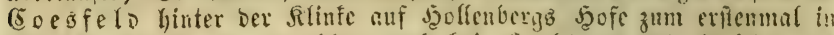

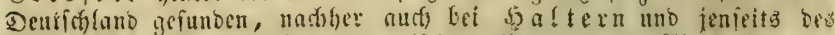

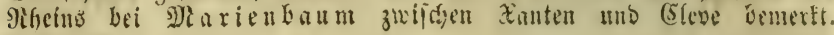

5. 6. $\odot$

\section{3ice Blatie. Tetrandria,}

\section{Sromung Monogynia.}

* slüthen volffänoig.

† Srone 1 blättrig obertänbig.

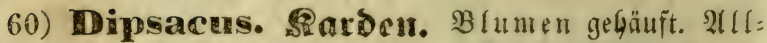
gemeine Blüthendede vielblättrig. Relch) 1 blättrig unge= theilt. Samen yom Rambe des Gleibenden Reldes gefrünt. 61) Scabiosa. Stabiofe. $\mathfrak{b}$ rumen gefäuft. צrrgemeine Blüthendede vielblättrig, ziegeload)artig obct

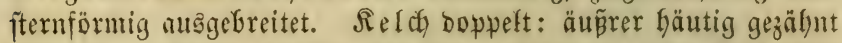
oder ganz, inmrer boritig 5ipaltig. Samen bou Gleibenden Reldye eingefortofien.

62) Sherardia. 2foferiterneraut. Reld 1 Glättrig 6 6 äfuig. Srone trichterförmig 4fpaltig.

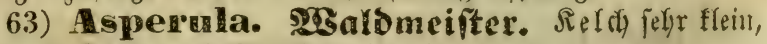
43̆ăfnig. Rrone glodfig=trid)terfürmig.

64) Gallium. Rabfrant. Refth feft fleit, 4zinf = nig. Sirne eben ober frach=gloctig. 
65) Rubia. Jätberrötbe. Releb fefr flein, 4 zäh=

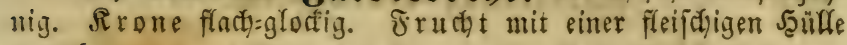
unigetert.

†† STrone Iblättrig unterftänbig.

66) Exacana. Rifterblatt. Rrone mit bauchi=

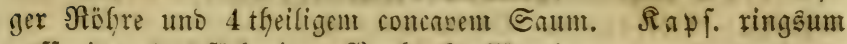
aแfipringend 1 fädterig. Siarte fopî̄örmig.

67) Plantago: $28 \mathrm{gegerich}$. Rroue mit walzen=

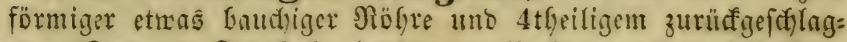

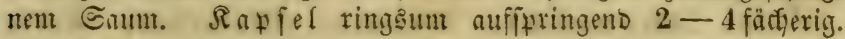
Narbe lang fäbliç.

68) Centancalus. Rrsinling. Rrone mit bau=

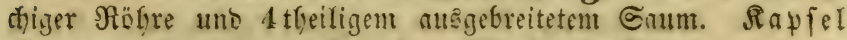

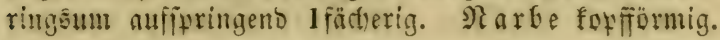

ttt Frone 4 blättrig.

69) Conmus. Sartriegel. Steinfrud t mit

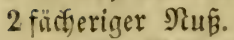

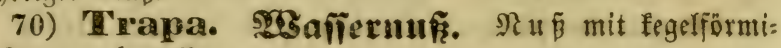
gen Dornen Gewaffnet.

"* Blüthen unbolffảnoig.

$\dagger$ ₹ruditênoten oberftänsig.

71) Najanthemsm. Wiggers. Schatten: blume. Blüthenfülle 4theilig. Beere 2-3füberig, $2-3$ amig.

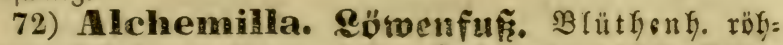
rig mit 8 theifigem Saum, bejen Bipfel nowectjelno fleiner fino. Raryoule.

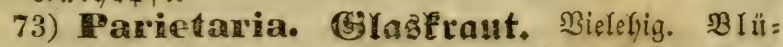
trienf. Ler zattrigen uno wriblidfen $B$ lütben glortig 4 fpal: tig. Raryople.

It Fruđotennoten untexftänsig.

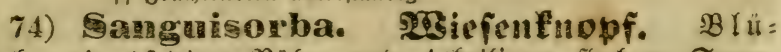

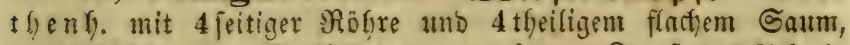
won 3 feldtartigen Deffblätern ungeben. Raplel 1 fäditerig $1-2$ famig.

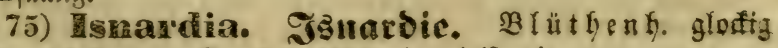
4fFaltig Gleibend. Rapiel 4 fädjerig bielfamig.

\section{Sromung Digynia.}

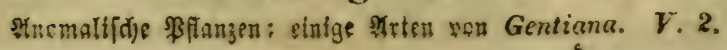




\section{Soronung Tetragynia.}

76) 耳lex. Spülfen. Seld 5zägnig. Siroue rab= förntig 4theilig. (5riffel 0. Beere 4 famig.

77) Potamogeton. Saichfenut. Brütgeny. 4theilig. (B) riffel 0. Steinfrücte 4.

78) Sagiua. Deaft fraut. Reld 46lättrig=afíte: hend. Srone 4 blättrig. Sapfel vieljamig, in 4 Sintpen auffpringent.

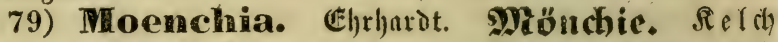
4brättrig aufrect)t. Rrone 4 blättrig. Sa+f. 1 fäd)erig biel= famig, in 5 ober 10 Bäfne auffuringend.

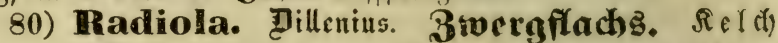

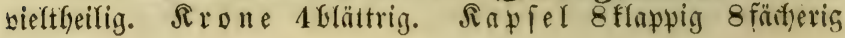
8 famig.

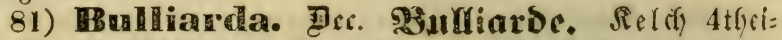
lig. Rrone 4blätrig. Sapjefn 4, vielfamig.

Itwomalifiche \$flanzen: Cuscuta V.2. Tillaed III. 3.

\section{Sronumg Monogynia.}

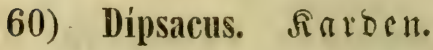

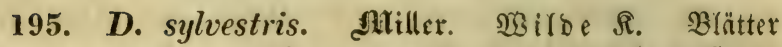

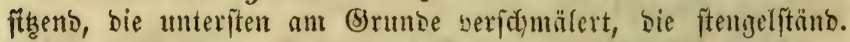
breit zufanmengewadyfen, ungetfeilt poer bie mittleren fiebel: fpaltig; Şüllfblättchen bogig=aufiteigend, länger als ber eiför: mige Ropf; Spreublättchen biegfam, in eine grnse Spitze mas:

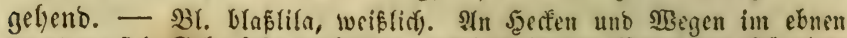

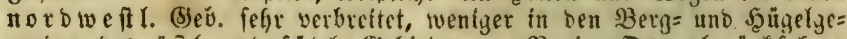

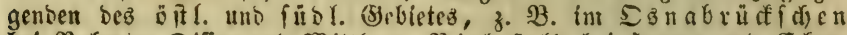

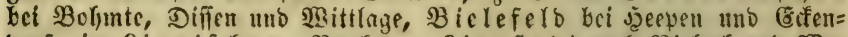

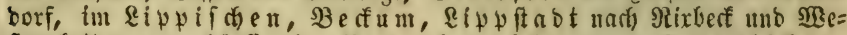
fernfolten zu, häufig im \$aberbornfden uno Rorveifden, Marberb, Nefdebe, SBinterberg, Sd) warzenberg an ber \&enne. 7. 8. $\odot$

196. D. fullonum. STE berfaro

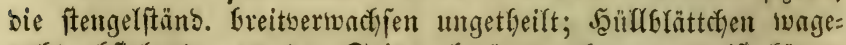
redft abfetgend, an ber Spize abwärtz gebogen, meift firrzer

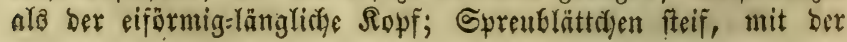




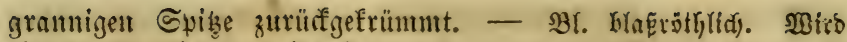
bler unb ba gebraut. 7.8. $\delta$

197. D. pilosus. Beflaarte $\mathfrak{R}$. Blätter geítielt ge=

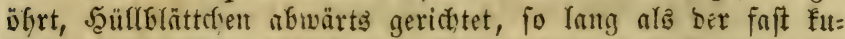
gelige Ropf; Spreublüttefen borftig=gewimpert graie. - $B$ Kr.

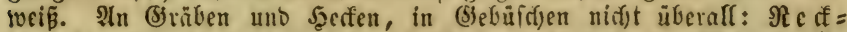

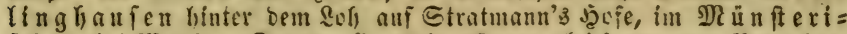

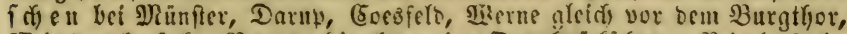

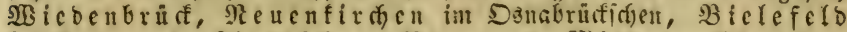

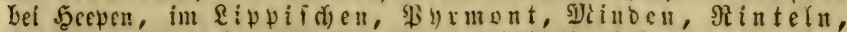

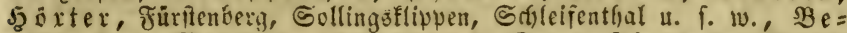
עerungu, SRefdede, la a tenberg, Sattingen, Speft. 6-8. 요

\section{1) Scabiosa. Sfabiofe.}

* Knautia. Coult. Frudutboben raubhaarig. Frone ftrablentlüthig 4fpaltig. SBlüthenËpofe flad) s Eonver.

† 198. Sc. sylvatica. (Knautia sylv. 刃ुub.) $\mathfrak{S a I b}=$

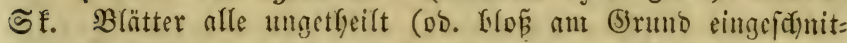
ten) efliptifich = lanzettlich geferbt, bie unteren geítielt, bie oferen

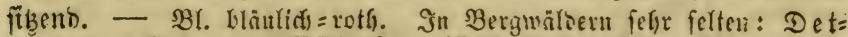

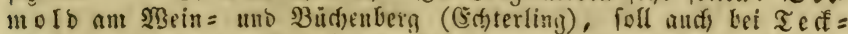

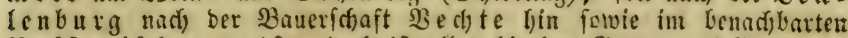
Raffa uifd) en madjên, bod) ift allez hierher (Bezonne viefleidyt nur Sibart ber folg. unb veriffieben von ber eriten Sc sylvatica. 6.7.24

199. Sc. arvensis. (Kinautia arv. Coult.) $\mathfrak{i}$ (f́er: ธf. Stengelblätter fieberipualtig, Fieber entfernt ranzettlid

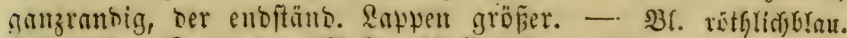

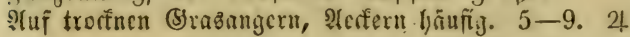

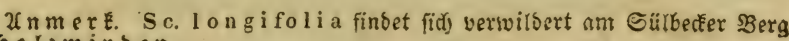
bai Ş०1子minoen.

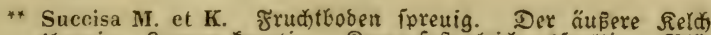
4lappig, Earpen Erautig. Rrone faft gleidy, 4fwaltig. SBlü= thentopfe faft kugelig.

200. Sc. succisa. (Succisa pratensis. Alocud.)

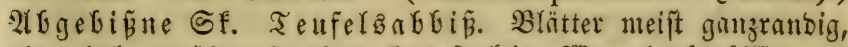
bie mittleren bfter fparfant fieberjualtig, sisurzel abgebiffen. -

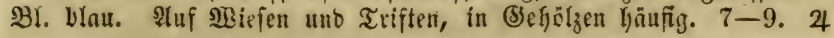

*** Scabiosa. Frudt)ooden fpreuig. Der äu Eere Reld rasförmig:

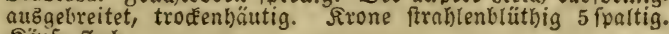
Röpfe flad).

201. Sc. columbaria. Taubet= Sf. Stentigelblätter

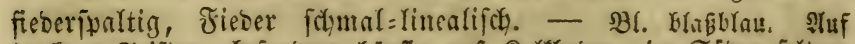

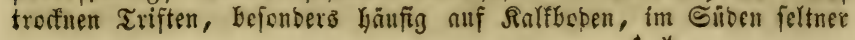




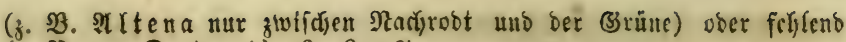

(3. 23. um Dortmunb). 6-9. 4

\section{2) Sherardia. If céf erfternfinut.}

202. Sh. arvensis. Blätter quirlig, B́lumen enbîtän:

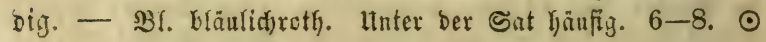

\section{3) Aspérula. Sagromeipter.}

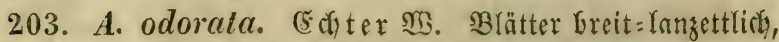
nut Ranb und Riel ficharf, oben zu 8, unten zu 6 ftelyeno;

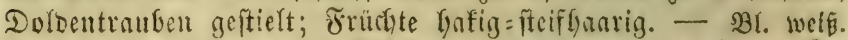

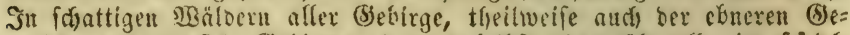

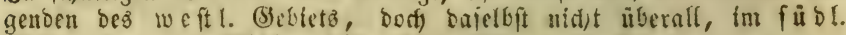

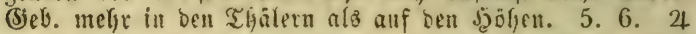

204. A. cynanchica. \$ä gefwalom. Bätter fơmal=

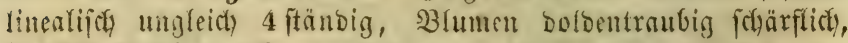

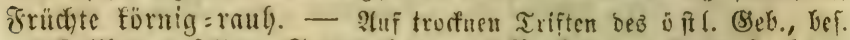
auf Ralfboden, felten: Stromberg und 3e ef um, auf bem 50 fien=

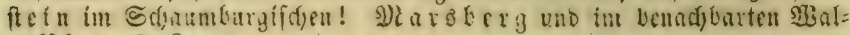
beffidjen. 7. 8. 2

† 205. A. galioides. Alarfd). Birb. Rabfrautar=

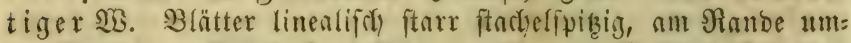
gerollt und rauly, bie ftengelftäno. meift zu 8; Früc)te glatt. -

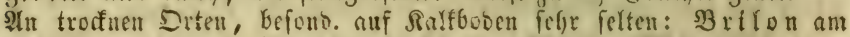

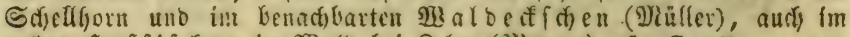

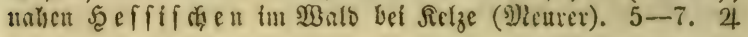

\section{4) Galium. $\mathfrak{e} a \mathfrak{b} \mathfrak{f a u t}$.}

- Błumen vielerig. Blüthenftand blattwinEertiänoig.

206. G. cruciata. Ssop. (Valantia cruc. L.). Rrugblättriges \&. Bañter 4ftübig 3nervig, BBlütfenfticle

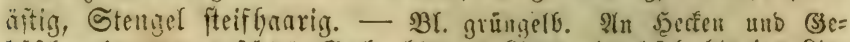

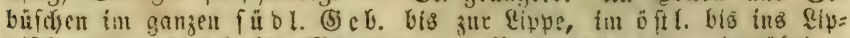

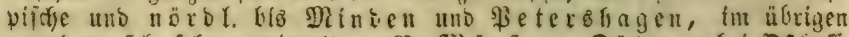

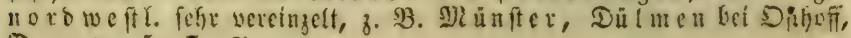

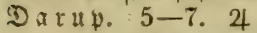

\section{** Blumen zwitterig.}

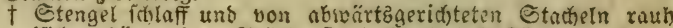
(fid) antängend). SBlüthenftano biattroinkelitänsig und $z^{4}$

207. G. tricorne. Wither. Dreiförniges

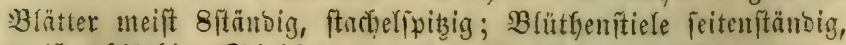

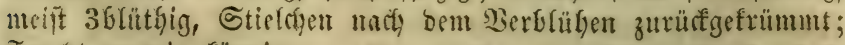

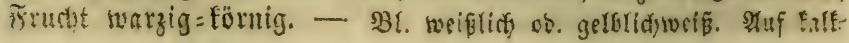




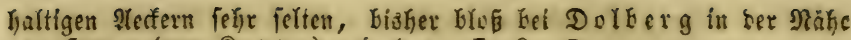
עon Jaamm (von $\Re \circ \not \vee e)$, jefunden. 7-9. $\odot$

208. G. Aparine. Rletterndes $\mathfrak{R}$. Rlebfraut.

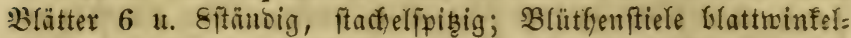

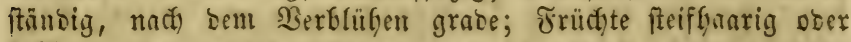
fafl. -- Bl. meiflify. Formen: a majus in alfen Theilen aröfer,

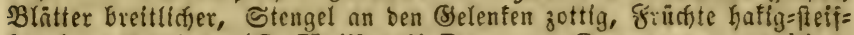
faarig; $\beta$ minus ( $\boldsymbol{G}$. Vaillantii Dec. - G. agreste a echino-

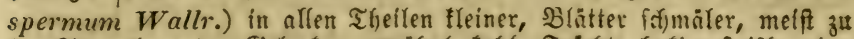

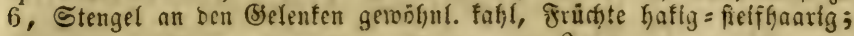
$\gamma$ spurium (G. spurium $\boldsymbol{L} .-\boldsymbol{G}$. agreste $\beta$ leiospermum Wallr.)

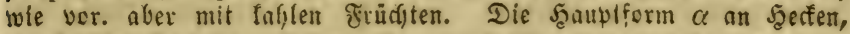

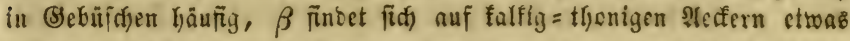

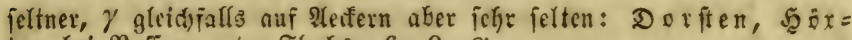
ter bei $\mathfrak{B}$ offizen unter Fladjz. 6-9. 4

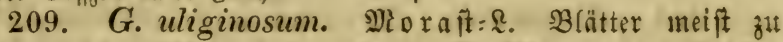
6, îtadjelfpizig; Blüthenitiele nad bem Berblüfen grnbe; Früçte förnig= rauf\%. - BBl. we:

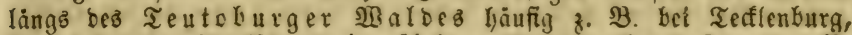

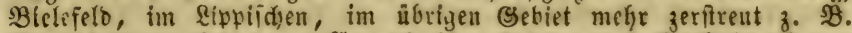

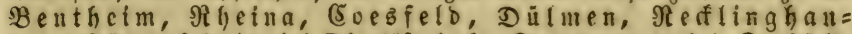

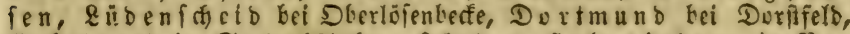

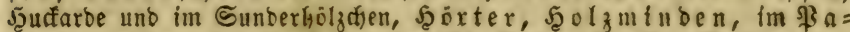
berbornfdien bei Brafel an ier St. Annen Sapelle, SBarburg auf

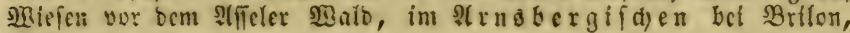
IReidjete u. F. w. $5-7.4$

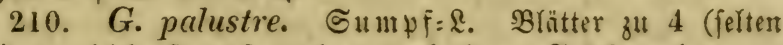

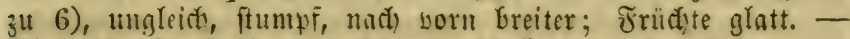

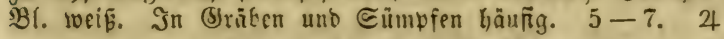

t† Etenger ofne abwärtżgeriodtete Etadjein. SBlüthenftanb ribpia.

a. Etengel ftielruno fieif.

211. G. verum. (5) 1 be ह \&. Blätter 8-10 fänoig,

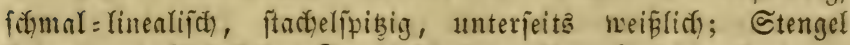

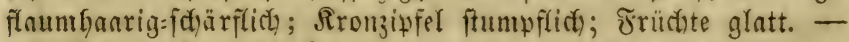
BI. gelf. Stenbert ab: $\beta$ ochroleucum mit getGlidfweífen sBlütren;

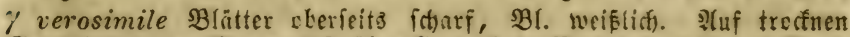

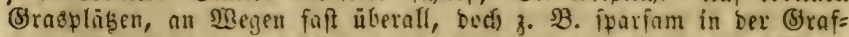

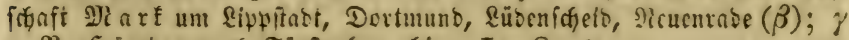

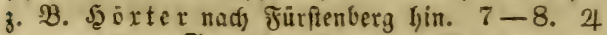

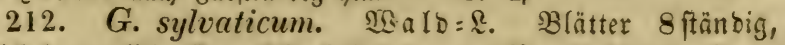

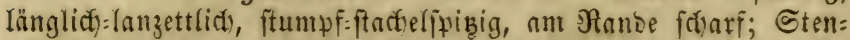
gel glatt ooer furzbelgart; Rromzipiel furzgefpibt; Früd) faffl,

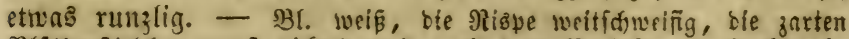

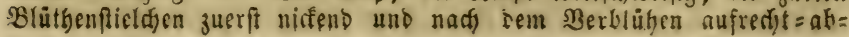




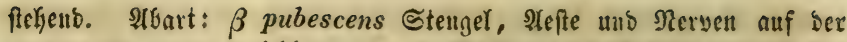

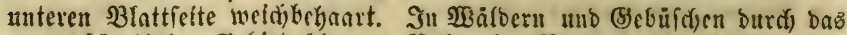

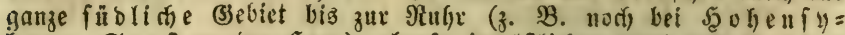

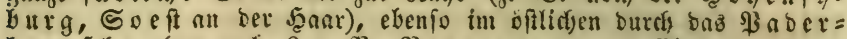

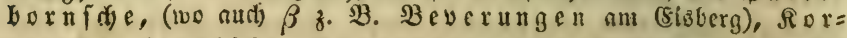

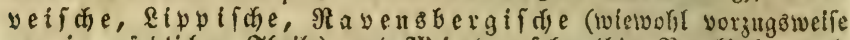

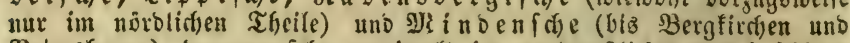
Betershagen), bagenen fehr vereinzelt in nuroiveftlicisen auf bufdigen Ralfhügeln z. 2 . Stromberg, Şavixbeff. 7. 8. 4

b. Stengel 4zckig, nid)t niebertiegend.

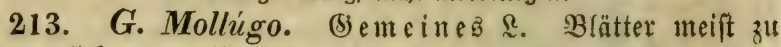
8, Ianzettlid) ober elliptifdy, ftadtelfpibig; Ctengel follaff, faifl (ober weidbefgart), mit aufgefdyollnen (Selenfen; Frithte fabl,

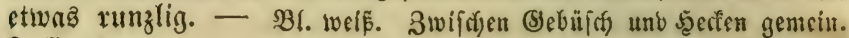
6. 7.24

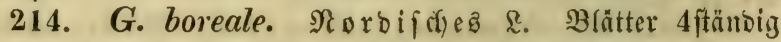

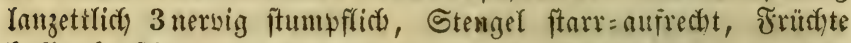

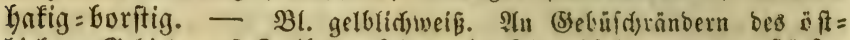

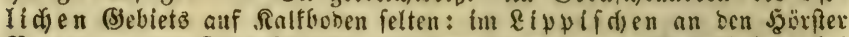
Bergen, an ber Djrenid)ludit, zwifd)en Detmold und \$ivitzhaibe, bei

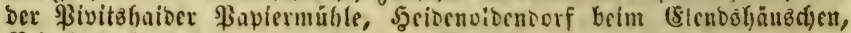

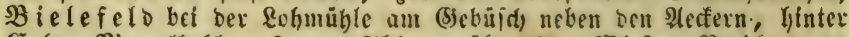

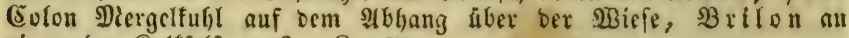
einem ser Ralfielien. $6-8.24$

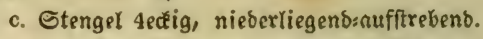

215. G. saxátile. (G. hercynicum Weig.) ซัe Blätter meijt zu 6, bie untern verfefyrt:eiförmig, bie obern Inn= zettlich (nad) born breiter); Stengel fabl; Frïchte bidftförnig=

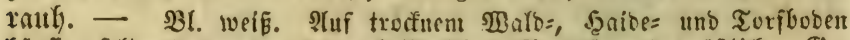

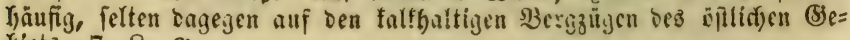
vietz. 7. 8.4

216. F. sylvestre. Pollid). Saain=?. Blätter meift 3u 8, Yineal= lanzettlich, nach) norn breiter; Stengel fabl ober

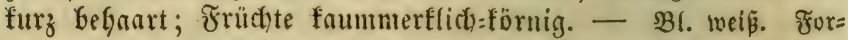
men: $\alpha$ glabrum fafli; $\beta$ hirtum (G. scabrum. Pers.) Stengel

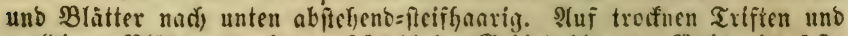

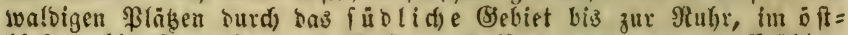

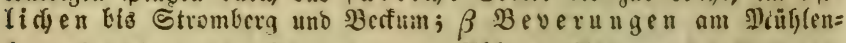

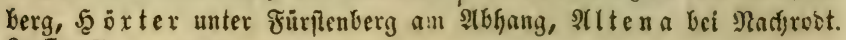
6. 7. 4

\section{5) Rubia. Förberrötfle. Efrapp.}

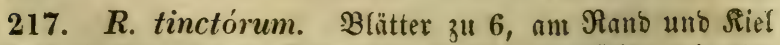

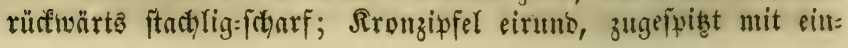


Wärtâgefogener Spibe. - Bl. gelf. STngebaut 3. B. Rtppftabt: bei Benninghauien. 5. 6. 24

\section{6) Exacum. Bitterblatt.}

218. E. filiforme. Willd. (Gentiana filiformis L.) ซasenförmiges $\mathfrak{B}$. Stengel fabenförmig äfig, W̧urzel: Glätter jđhaufelförntig, Stengelblätter fdimal. - $B$ l. golbgelb. Stuf feuts)tem fanbigem Torfboben fowic auth auf Refmboben burdi bie nerbiveft. unt nörol. (8bnen verbreitet, biz an ble Berge yur=

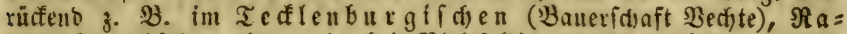

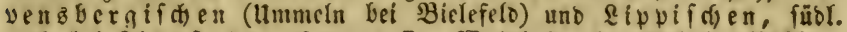

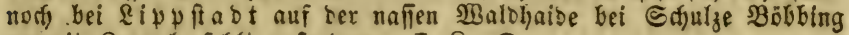
unweit Sappel, ferglt außserbem. 7. 8. ○

\section{7) Plantago. Mregerid.}

219. Pl. major. (5) rofér $\mathfrak{B}$. Blätter eiruno geftielt, S(t)aft runb, 2lefire berlängert. - $B$ l. grünliç. 2(enbert fefre

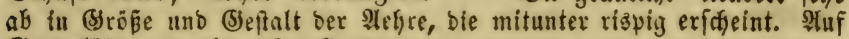
छรražpläben gemsin. 6-9. 2

220. Pl. media. Mlittlerer Ş3. Blätter elliptiơd

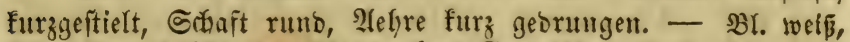

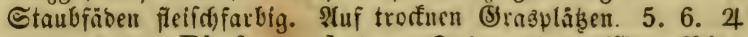

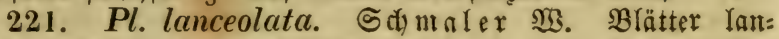

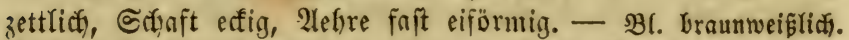
Ilenbert ab mit mefreren ober zulammengefebten Ief)ren. Stanohafte

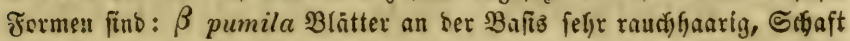
fingerzlang, ster)e faft fugelig; $\gamma$ lanuginosa Blätter ganz raud)=

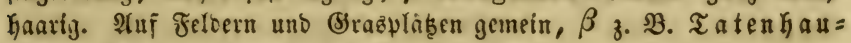
fen, $\gamma$ auf fehre troffnen $\mathfrak{x}$ tifiten. 5. 6. 4

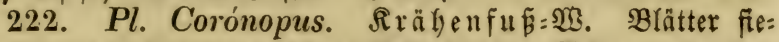

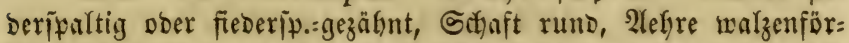

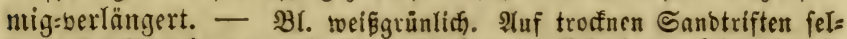
ten: Tefflenburg nad Saerbeft zu! Rheina, fingen in

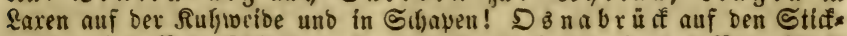

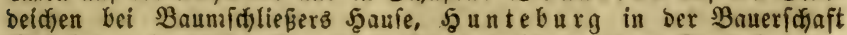
Welplage; in grofer tlebpigfeit Bielefeld auf bem Rupferhammer unter Bwiebeln, burdf einen 3ufall balyin veridjleppt? 7. 8. 4

\section{8) Centunculus. $\mathfrak{A} \mathfrak{L}$ einling.}

223. C. minimus. Ctengel äftig, Brätter abivedafelno

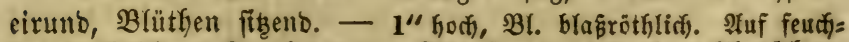

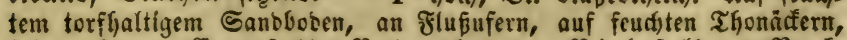

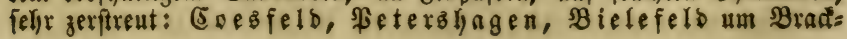




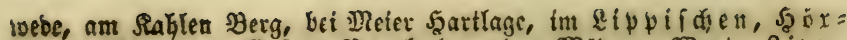

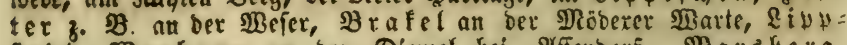

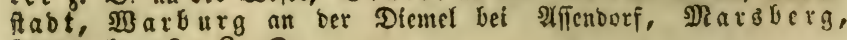

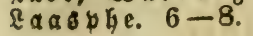

\section{9) Cornus. Şartieger.}

224. C. mascula. (5) meiner 5 . Rornelfirfót ba u n. Şüllen won ber ungefäfren Ränge ber Dolbe. -

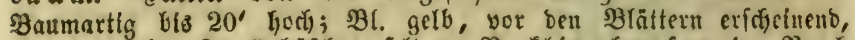

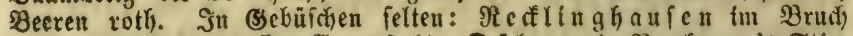

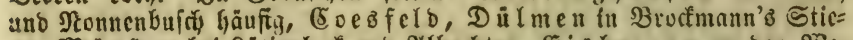

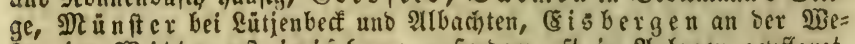
fer, im $\mathfrak{B}$ ittgenfeintiffen; auferbent oft in 2 nnfagen gevflauzt. 3. 4. क

225. C. sanguinea. $\Re$ other $\mathfrak{5}$. Trugbolben ofute

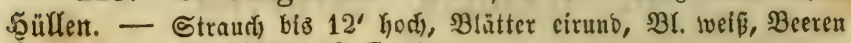

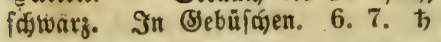

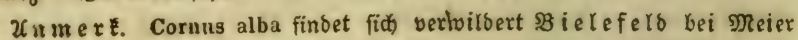
5̧artlage.

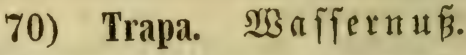

226. Tr. natans. Blätter rautenförmig gezälynt=gefägt,

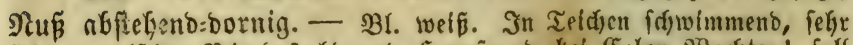

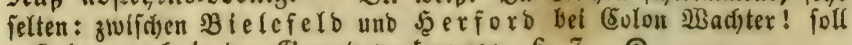
auBerbeim nodf in ter Bsegeno vortommen. 6. 7. $\odot$

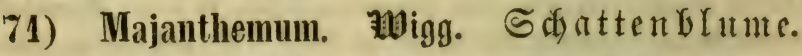

22\%. M. bifolium. Đitr. (Convallaria bifolia. L.) BYätter (2, feltner 3) Gerzfôrmig. - Bl. in cnbpannotger Traube,

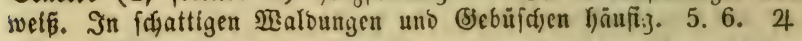

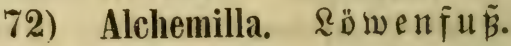

228. A. vulgaris. (5) enteiner 2 . Franenuntel. Bläster nierenförmig 7-9 9lappig, sBlüthdden in gipfelftäubigex

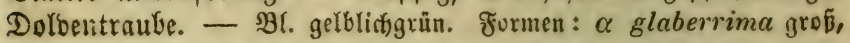

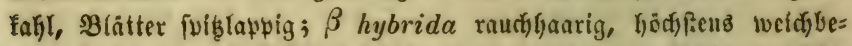

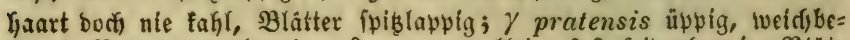
haart, $\mathfrak{B l a ̈ t t e r}$ runblappig; $\delta$ montana fleiu, faft feibenflaarig, Blä̆t=

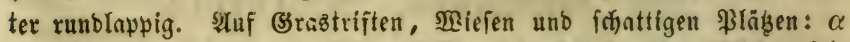

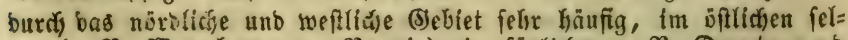

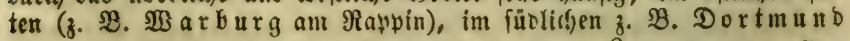

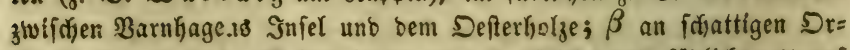

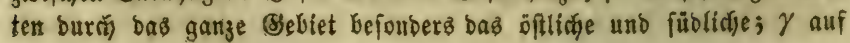




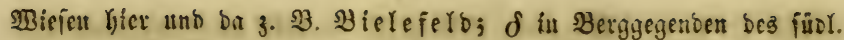
Bebietz z. B. Brilon. 5-7. 24

229. A. arvensis. Scop. (Aphanes arv. L.) Fel R. Blätter 3 theilig 3 fpaltig, Blüthen Glattminfelftünbig ge:

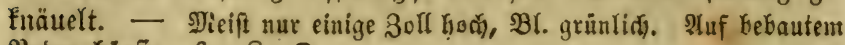
Boben hăufig. $6-8$.

if $n$ mex $x$. Alchemilla alpina fand fid früher 2 Stunben von $2 B$ i le: fers in ber Sceepenfden SBauerfdnft SBechteroifien (\$Bexten) bei (Eolon Rübbert an 2fderränbern; fie war wohl angepflangt uno ift ję̧t berid)tounben (ich fuchte fie wenigfens einen ganzen Jag vergebenz).

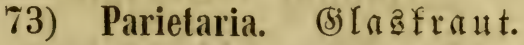

230. P. erecta. Atert. \& \&. (P. officinalis. Willo.)

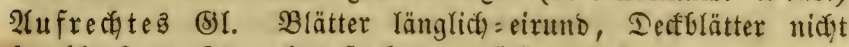
Gerablaufent, Etengel sufrecht unb fait einfad. - BBl. grün=

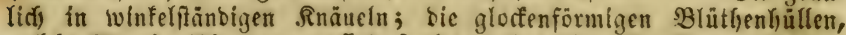

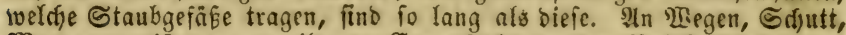
DRauern, meif nar verwifoert: CoeBfels an ber Brüffe finter bent

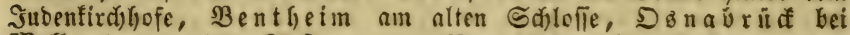
\$laflgarten an ber Ricitermaucr, Neuentirdjen im Paftoratgarten,

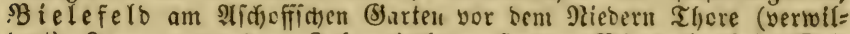

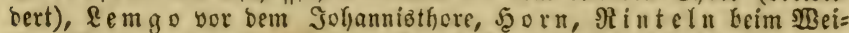
fen Thurm und in ber fleinen Grtergafie an ber Seefe, şa $x$ ter und

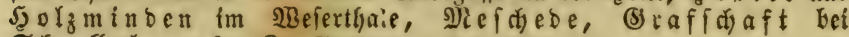
Sdjmallenberg. $6-8.24$

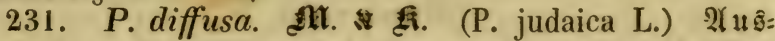
gebreitetes (5) B. Blätter eirund, Derfblätter herablnufent, Stengel hingeworfen weitfdyweifig:ä́tig. - In aflen Thellen flel=

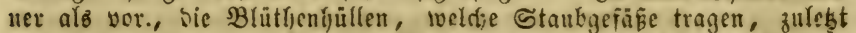

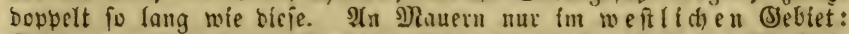

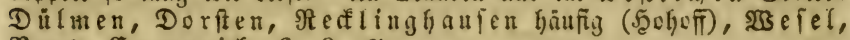

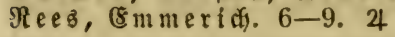

\section{4) Sanguisorba. Wiefenfnopr.}

232. S. officinalis. SIefren eiförmig=lünglide), Strub:

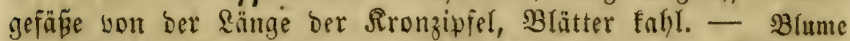
purpurbraun. In Miefern, verbreitet burd) sen ganzen Süben tm Siegnifden, MBitgenfteinfiden, Prnbbergif den, um

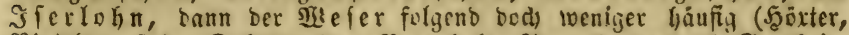
Rinteln auf ber Dofturwefos, $\mathfrak{B}_{\text {arenhol }}$, Weterğhagen nad) Bernheim

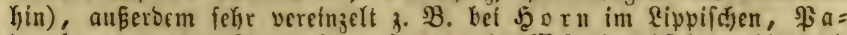
berborn an ber sippe, \&ippfadt, im Mlú nịerifden hier uno ชa. $6-8.4$

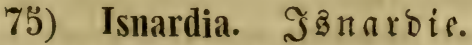

233. I. palustris. Blätter gegenüberfteffeno geftielt 
ciruns fpitg. - Die ganze \$fllanze ift oft rotly angelaufen, bie fron=

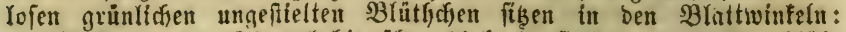

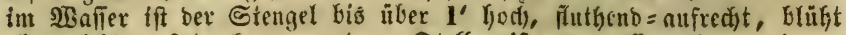
aber nidit, auf trudfen gemorbuen Stellen ift ex nut fingerlang, nicoer= geftreft $=$ warzelno, Sllithen uno Früchle treibend. In Torfigegenoen

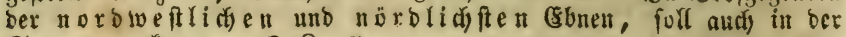
Se и и vorfonmen. 7. 8. 4

\section{Sromung Tetragynia. \\ 76) Ilex. Stedipalme.}

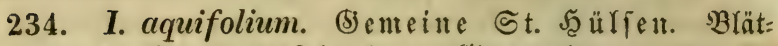
ter pergamentartig eirund fpiegelno inellig:bornig. - Straud,

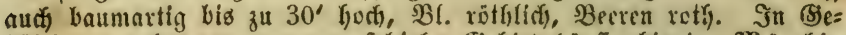

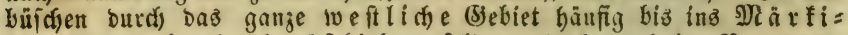

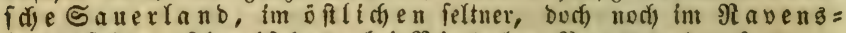
bergif den, sipplfiten, bei Rinteln, Pyrmont u. f. w. im füblichen feht bereingelt und in wen meifen Begenden ganlz feft= Iento. 5. 6. 万

\section{7) Potamogéton. Raidyfraut. \\ - Die oberen Blättex fä́wimmeno. \\ $\dagger$ Stengal einfact).}

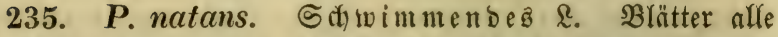
Innggeftielt, bie unteren untergetnutedten fdymäler lanzettlich ob.

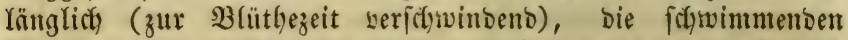

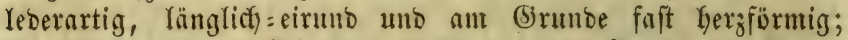

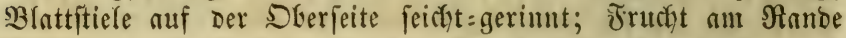

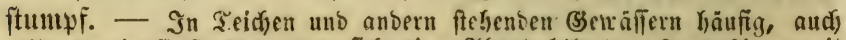
mitunter in fircéenocn, wo fid) cine 2 tbart biloet: $\beta$ prolixus mit

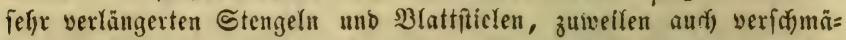
lerten Blättern; auferben fommt bie form -vor: $\gamma$ oblongus (P. oblongus. Viviäni), wo bie untergetaut(d) $\mathfrak{B}$ latter nuth) zut $\mathfrak{B}($ lüthe $=$ ztit vorhanden bleiben und bie Frühte fleiner fint, gemein in Torf= gräben ber Eenue, Dillmen in ber Entenfol, Bentheim in ber Sirechte u. ศ. w $6-8.4$

236. P. fluitans. hoth. (P. natans $\gamma$ angustatus. Autt.) Brätter alle langgefitielt, bie untergetauduten berlän= gert=fanzettlich) Durchifheinens (aud) zur Blüthezeit Gleibent),

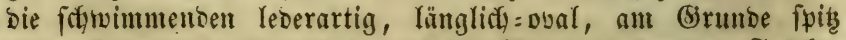
ober abgerumbet; Blattītiele auf Der DGerfeite fonsex; Friichte

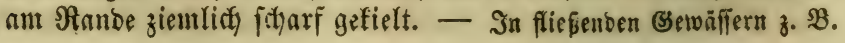




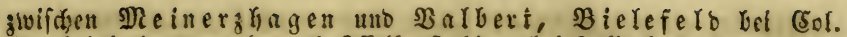

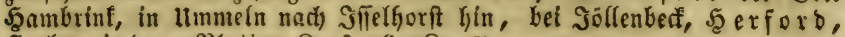
5olzminben ßlatter Ropi, 6-8. 4

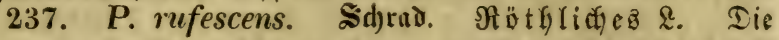
untergetrư(ป) werichntilert ftumpflid), bie fduwimmensen in ben furzen BIatt=

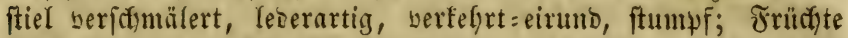
ftarf fufanmengebrüift fd)arf=gefielt. - Die Blätter füt oft röth= Itri) grin, beim Trodfnen werben befonbers bie oberen braunroth. In Teidjen und (s)äben Der ebneren (5)genden: Coeşfers, Dar up, in

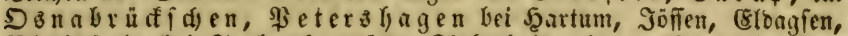
Bielefeld bei ๔ubbraff, auf Der Finfenthaide, in ber Eenne bei Col.

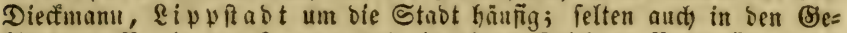
birgen z. 2 . in ber $\mathbb{R} e n n e$ und in einem Teid) zu \$ebdenfiepen bei

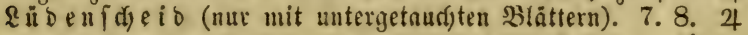

t† Stengel äftig.

238. P. Hornemanni. Atener. (P. plantagineus.

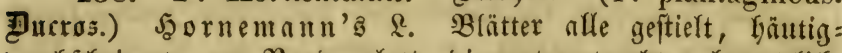
Durdyidgeinend, an Ranbe glatt, bie untergetaudyten lanzettlids,

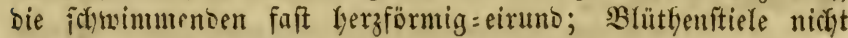
verbirft. - Die \$iflanze ift oft Uleichröth(id), fo bas nur bie unter=

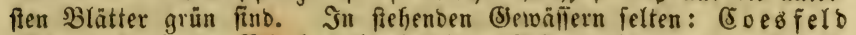
(Böninglyaufen), B ielefeld in einem Trith rechtz von ber Strafie

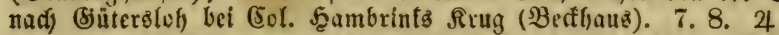

239. P. gramineus. (P. heterophyllus. Sdreb.)

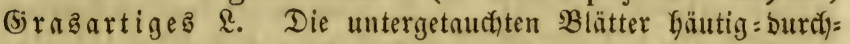
jdyeineno, Greiter ober fdumäler langettlict) (oD. fait lineal), zu=

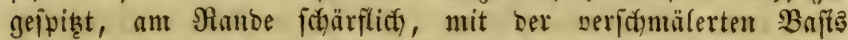
fibens, weiter obenfiu afer geftielt fowie aut fürger uno brei= ter, bie fodwimmenden leberartig, langgeftielt, lanzettlidy ober eiförmig; Blütyenftiele nach oben verbifft. - Der Stengel ift

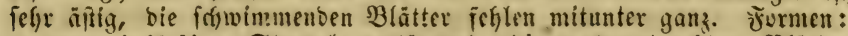
$\alpha$ graminifolius Etengel verlängert, b!e untergetauchten Blätter lang uno fefre fofmul, fdhlafi, grasantig; $\beta$ heterophyllus bie un= tergetaudjten $B$ lätter fürzer, zuriiffgetrummt, mel)r ober weniger farr.

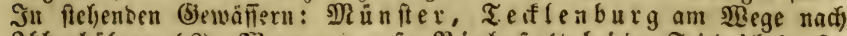
Sobenbüfren $(\beta)$, Wa a e

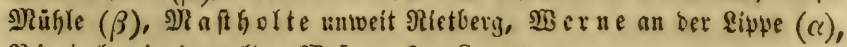
R intel $n$ in ber alten 20 ejer. $6-8,4$

** aure slätter untergetaudst.

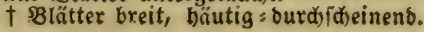

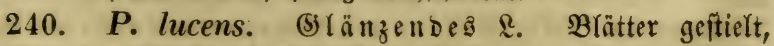

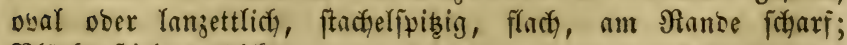
Blütbenftiele berbicft. - Sn ftehenoen uno langfam fliepenben ge: 
I $\mathfrak{B}$ ctershagen, nads Siten bis $\mathfrak{B}$ ielefeld, bann felten 3. B. im Lfpulfdea nux in Teirien bei Drbfe und Reelfirctien, int Süben

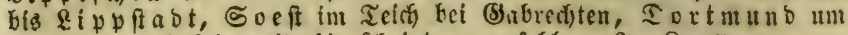
Barnljagens Snfel, weiterhin fáseint er zu fehlen. 6-8. 4

241. P. perfoliatus. Durdiwad) fenes \&. Blötter

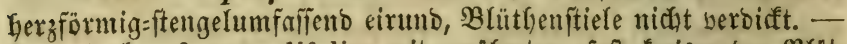
भenbert $a b: \beta$ rotundifolius mit genäherten, faft freizrunben sBlăt= tern; $\gamma$ oblongifolius mit länglidjen Blättern; $\delta$ lanceolatus mit

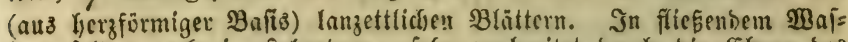
fer, felteu aud in firhenokm, fefir verbreitet burds bie \&Enen bes

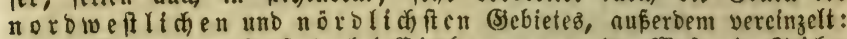
in Der $\mathfrak{B}$ erre um Şerforb, bei É

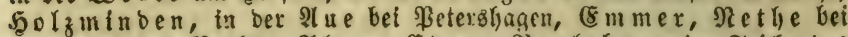

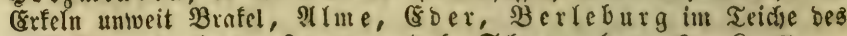
Sdjlog̈garteris, in ber \&enne unterf). Sdfivarzentierg. $6-8$. 4

242. P. crispus. Fraufes \&. B̉ätter f̈̈веnd lineal= Iangettlich ftumpflich furzftad)elfpitigig fleingefägt wellig = fraus,

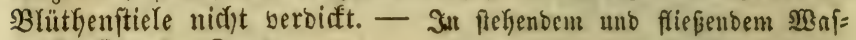
fer hăunfig. $6-8,4$

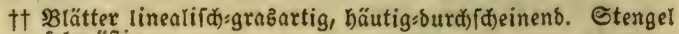
fehr äftio.

243. P. compressus. (P. zosteraefolius. Sdumad)er).

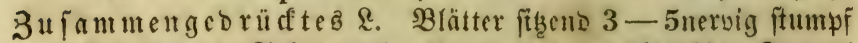
furz=ftactelfpigig, 2lebre walgenfömig $10-156$ lithig, Stengel

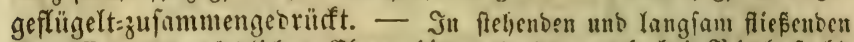

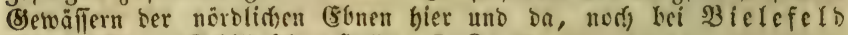
Sübbrad unb Edjllbeidjer Jaibe. 7. 8. 4

244. P. obstusifolius. Nicrt. carad). Stumpf=

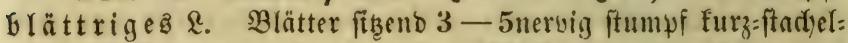
fpitzig, 2lelyre unumterbrorben 6-8blüthig von ber \&änge bę Blütbenftiela, Stengel ftumpffontig = zufammengebrüdt. - In

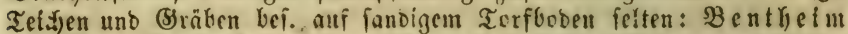
und Epe, B felefelo in ber Eenne boi Eclon Tüberman, finter bem Rupferlyammer, hinter Evlon Riemann in Riehorft. 6-8. 4

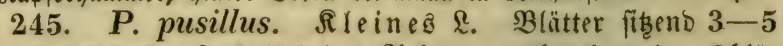
nervig fpibzlid furzitndalfpizig; 2fehre unterbrodyen 4-8blü: thig, mehrmals fürger als ber Blïthenftiel; Stengel runblict: zulnmmengebrücft. - Formen: $\alpha$ major Blätter breiter, faft $1^{\prime \prime \prime}$ Ereit; $\beta$ vulgaris $\mathfrak{B l a ̈ t t e r ~ e t w a ~} 1 / 2$ " breit; $\gamma$ tennuissimus Blätter

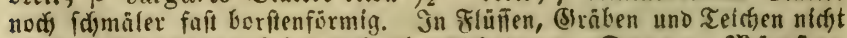
băufig: (S. Des felo bel ber Şarler Sdyule, um Darup, Slü nfter

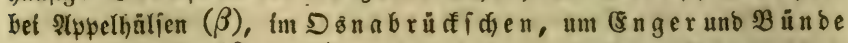
3. $\mathfrak{B}$. Düne, $(\beta$ und $\gamma)$, Bielefelo 子. $\mathfrak{B}$. Seim Jubentirdigof,

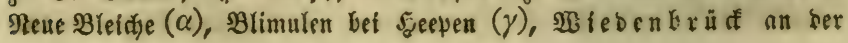




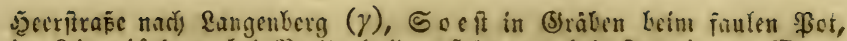

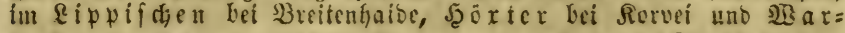

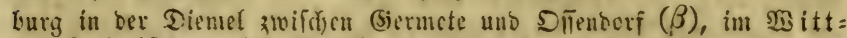

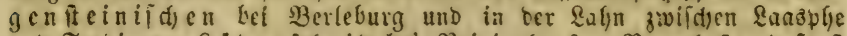

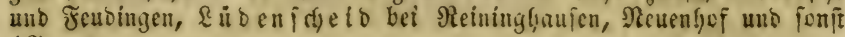
( $\beta) .6-8.24$

246. P. pectinalus. Rammblättrige $\mathfrak{R}$. Blätter nm Grunbe forcibig, fefre lang unb folmal (faft fabenförmig), ipis, Inervig; Slefye lamggeîtielt unterbroden; Etengel runs:

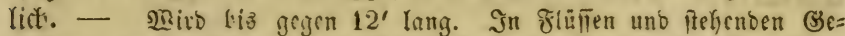

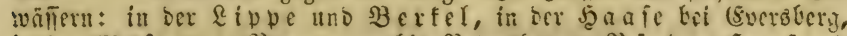
in ber פ̧⿻

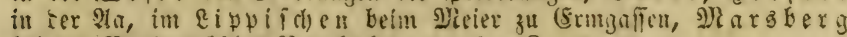
bei ber Paplermúlfe, 3 erfefurg. 6-8. 4

247. P. densus. Didht blättriges \&. B̉ätter afle

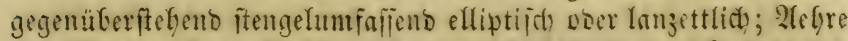
gafelfituoig furzgeitielt, nad) bem Serblüben zuriofigefrummut.

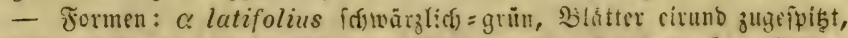

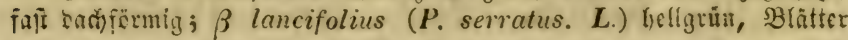

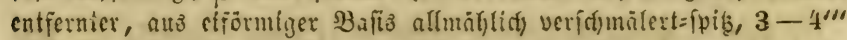
Ereit ; $\gamma$ angustifolius blafgrun, $\mathfrak{B} 1$ ätter nur 1-1 1/2" breit, lang=

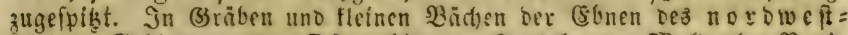

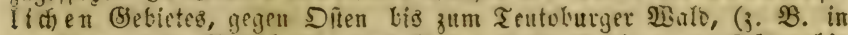

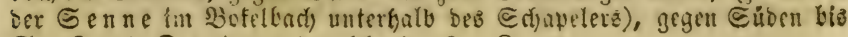
Soeft unb Dortmun reidjento. $6-8.4$

\section{8) Sagina. Maftifaut.}

248. S. procumbens. Riegentes $\mathfrak{M}$. Ctenget nie= rertiegeno, am Srumbe murzelnd, Refte aufîtrebend; Ban̈tter

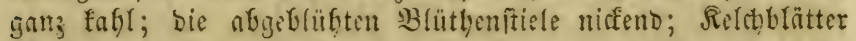

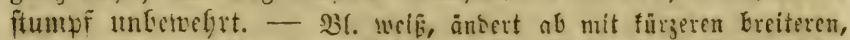

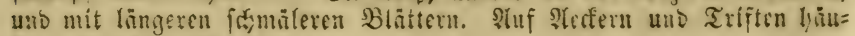
זig. $5-10$. $\odot$

249. S. ciliata. ङewimpertes D2. Stengel weit=

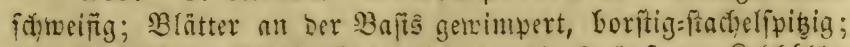

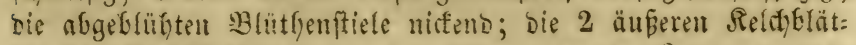

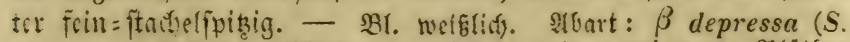
depressa. Schulz). SBlätter nur felir wenig gewimpert, B̉lütgent

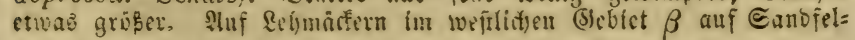
sera Bielefers ben 3weilselingen gegeniber. $5-7$. $\odot$

250. S. apétala. Rronlofes 92 . Stengel aufredtit

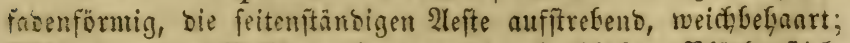

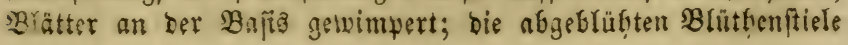




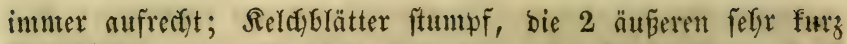

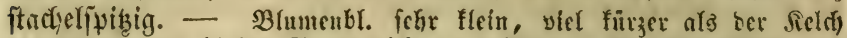

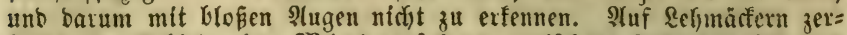

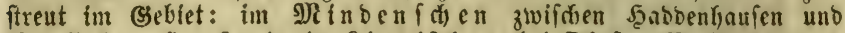

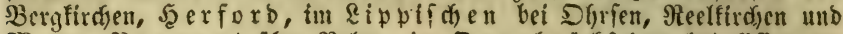

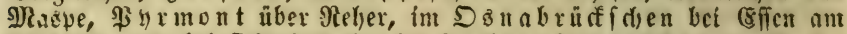
Rüffamy, unb bef Sifterfaypeln, im Te ff lenburgif Eotte, im $\mathfrak{B}$ aberbornf den um Brafel häufig, $\mathfrak{B}$ rit on $z$ : $\mathfrak{B}$.

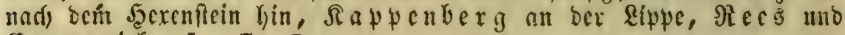
(5m merich. 5-7.

79) Moenchia. (E)

† 251. M. erecta. St. Wett. (Sagina erecta. L.) Biermännige Ml. Stengel meift 2Ghitbig, Sironblätter für:

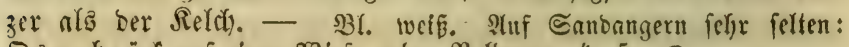

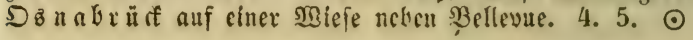

\section{0) Radiola. Gேmel. $3 \mathfrak{w e r g f f a d}$ s.}

252. R. millegrana. Simitl) (Linum Radiola L. Radiola linoides. (Em.). - Erfie äpliges \$ffänzd)en mit gegen=

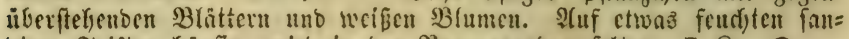

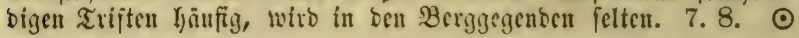

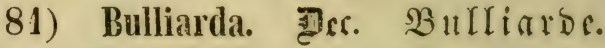

253. B. aquatica. Đृec. (Tillaea aqu. L.) Blätter

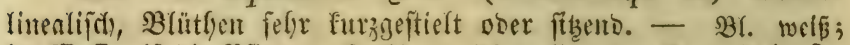

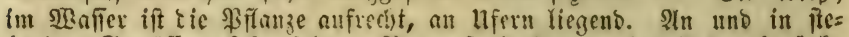

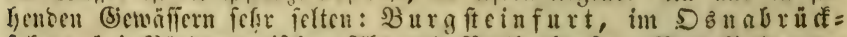

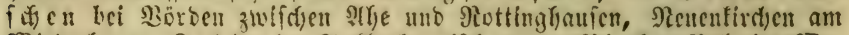

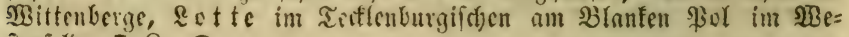
pirfits. 7.8. $\odot$ 


\section{ฮี่ Pentandria.}

\section{Soronung Honogynia.}

* Blumentrone 1blättrig unterftänoig.

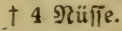

a. Sd)luns offen.

82) Echiom. Fatterfopr. Reldy 5tgeilig. Sroue glocfig, mit ungleid) 5 ppaltigem faft ractienförmigent Saum. Narbe 2theilig.

83) Lithospermam. Stcinfame. Reld 5thei= lig. Rrone trichteriörmig mit haarigem @đ)lums.

84) Pelmonaria. Oungenfraut. Seld 5 fei= tig 5jäfnig. Srone tridterförmig mit fanrigent Galums.

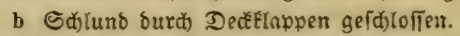

85) Somphytum. Cumpfrurg. Rel 5ici= tig 5tfeilig. Rrone walzenförmig-glofig.

86) Borago. Boretich. Reld) 5tfeilig. Srout rabjörmig, bie Rlałpen nuşgeranbet. Nalfe frei, am Grumbe

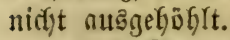

87) Cynoglossum. S2und li.j. Rrone trichteriörmig. Nuifie flatt.

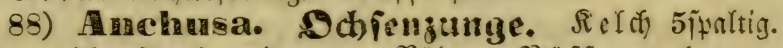

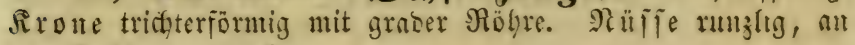
ber Bafti e eingebrürft.

89) Lycopsis. Sirummbarg. Rel(t) jipaltig.

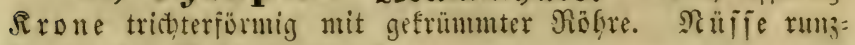
lig, an oer Brifts eingebriuft.

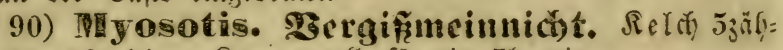
nig ober 5ffaltig. R̃rone tellerförnig Jlaptig. t† Einfäđderige אapfer.

91) Anagallis. (3auchbeil. Seld 5 theilig. Rroute rabförmig. Staubr. ant Srunbe bärtig = faarig. Rกpfel ringsum nufipringend.

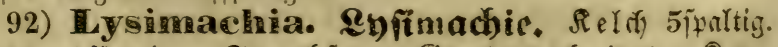
Srone rabörmig. Staubf. am (brumbe verbreitert. Rap= fel mit 5-10 Bäfnen auffipringent. 


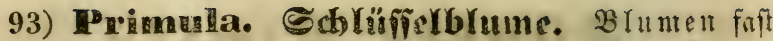

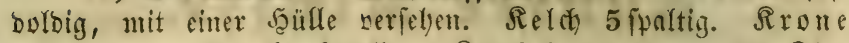
teflerförmig. Siarbe fugelig. Sanfel mit 5 ober 10 Bäh: nen nufippringello.

94) E-y Reld) 5 theilig 5 feitig. Rrone trid)terfürmig nit 5 theiligem

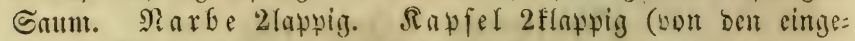
roflten R(nppentändern jueinbar 2fächerig).

95) F⿱ Rrone teflerförmig mit werfürzter siogre. Etaubgef. Der Räfre eingefügt.

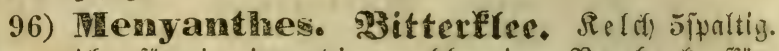
Rroue trichterförmig, inwenbig rauthlgarig. Sarbe fopfiför: mig 2laptig.

97) Villaresia. Dentęnt. BZiflarfie. Reldy tief 5theifig. Rroue trichterig=rabförmig, imvenbig fafy. Narbe 2 tryeilig.

tt† 2-4fätherige אapfer

98) Dolenonium. Streitblume. Reld ticf 5ipaltig. Srone rabförmig, Gdylund voll ben am (brumb er= weiterten Strubfäben gefdyloffen. Rarbe 3ipaltig. Rapiel 3 flappig 3 fä̀lyerig.

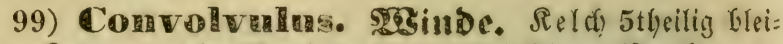

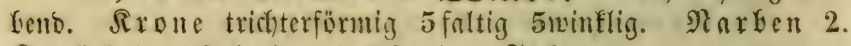
Rapfet 2-4fäd)erig mit 2 jamigen ₹äd)ern.

100) Nicotiana. TIn fent. Rrone trifferförmig 5faltig 5minflig. $\mathfrak{R}$ arbe fowf fürnig. Sapfel 2-4fäd)erig vielfamig.

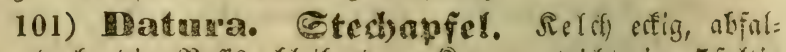

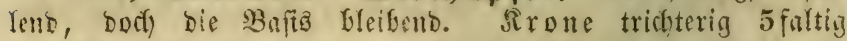
5ivinflig. Siarbe 2 lappig. Sapfel 4 ffappig 2 fäd)erig, bie Fälther 2theilig bielfantig.

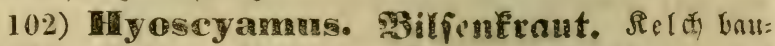

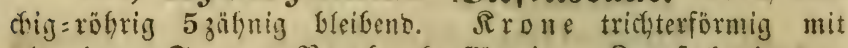
slappigem Gaum. Sarbe fopfförmig. Rapfel ringaum aufipringent.

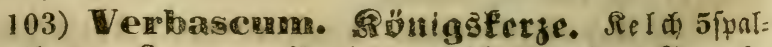
tig bleibent. Sirne rabförmig, unglein 5lappig. Staus:

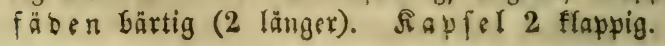


tttt 2 : Balgtapfeln.

104) Vinca. Siungrün. Rrune teflerförmig mit narftem Schlund, 5faltig, Die Eaumzipfel fd)räg abgeftutist.

ttttt Beere.

105) Solamum. Nachtichatten. Sel (h) 5-10 theilig. Rrone rabförmig. Staubbeutel zulammengeneigt (an ber Epike auffuringens). Becre freiftefent.

106) Physalis. E(blutre. Reldi) glodig 5ipaltig. Rroue rabförmig. Staubbeutel zufammengeneigt (ber Ränge

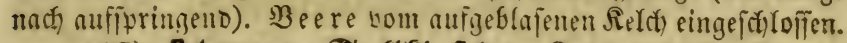

107) thopa. Ioftrirfite. Siel 5theilig. Rrone glocfenförmig mit furzer Niöbre. Staubgef. Den Sdylumb

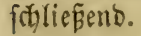

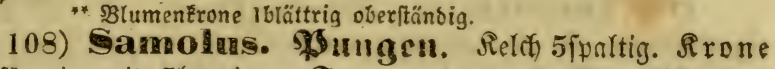
tellerförmig mit 5lappigem @aum und 5 bazmifaten ftekendert

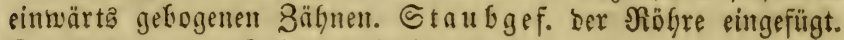
Rapiel an ber Epitze aufipringent.

109) Lobelia. Robclie. Reld 5 zăfnig. Rrone unregeไmǟ̄ig auf einer Seite aufgefpaIten, mit 5tyeiligem Saum. Rapfel an ber Spitze auffuringend.

110) Đasione. Safioue. B̧ bielblättriger Sälle umgeben. Rrone tief 5theilig. Staub= beut. zufammentangent. Sarbe feulenförmig. Rapfel an ber Spike nuffuringento.

111) Phytegma. Slapungr. B 1 umen einen Rouf bilibent. Rrone tief 5theilig mit zufammengeneigten Bipfeln. StaubF. am (5runbe berbreitert. Staubb. nicht zu= fanmentangenb. Narbe 2lappig. Rapfel an ber Seite auf: fpringens.

112) Campantia. OSlocenbrume. Arone glortig, an bem (Srunbe burch bie berbreiterten Strubfüben ge=

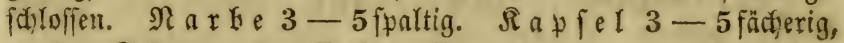
an ber Seite von ber $\mathfrak{B}$ afis auffuringent.

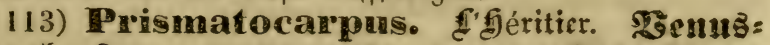
fpieger. S rone rabförmig, fürzer alä ber Selón. Staub:

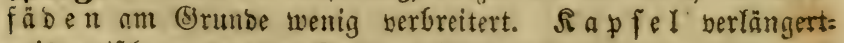

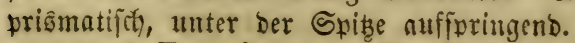

114) Lonicera. Geînblatt. Arone röfrig, an: regelmäbig 5 fpaltig. B e ere $2-3$ fädjerig (oft 2 in 1 ber:

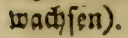




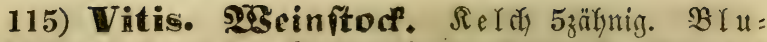
nenblätter 5, an ber Spibe zufanmentyangend. (5) riffel 0. B e e re 2fätyerig 5 famig.

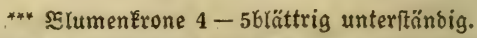

116) Rhammus. Secugooru. $\mathfrak{R}$ l (d) glorfig 4

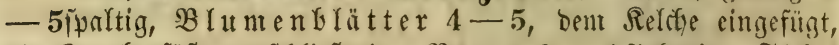

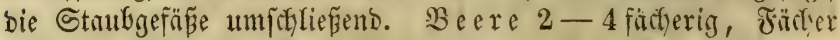
1 fantig.

117) Evonymons. Spindelbaum. Seld flact) $4-5$ ppartig, $\mathfrak{B}$ lumenblätter $4-5$, Dent Relche eingefügt,

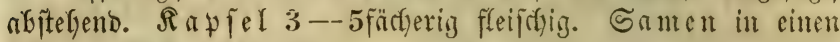
faftigen Miantel gefyüllt.

118) Impatiens. Springfanc. Seldf 2 flätt=

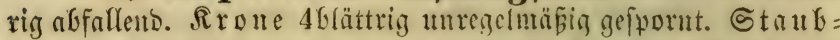

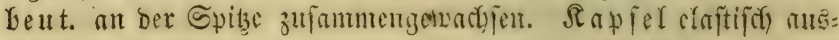
cinamber faringent.

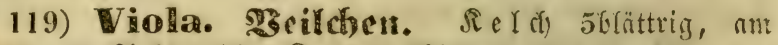

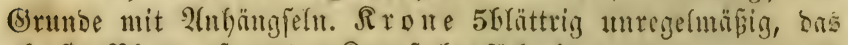

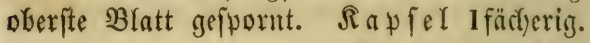

**** $\mathfrak{B}$ lumentrone 5 brättrig oberțänoig.

120) IBibes. Grachelbere uno Tolnantis:

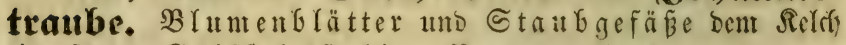
cingerügt. (s) riffel 2 jpaltig. Becre sieliamig.

121) 耳edera. Cofen. Griffel einfus. Berrs 5 f̧ädłerig, 5 jamig.

***** Błumen unvolfränsig unterftänbig.

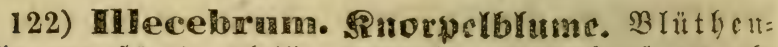
bitlle unterftänoig 5theilig fnorpclig. Staubger. 10, af: wertyelno umfrudter. Sinpfel 1 famig.

123) Clanx. Dgillofraut. Blitthen glorfig 5laquig gefärbt. $\Re$ apfel 5 fücherig 5 flałpig 5 jantig.

****** \$Bนumen unvolftän $\delta i g$ oberfänsig.

124) Thesism. Reinblatt. Brüthenfüllc bifeibent. Staubgef. Der $\mathfrak{B}$ lüthenfiufle eingefügt, won einem . grlüthenf. gefrönt.

Itnomalisclye Pranzen: einige Prten ber Battung Polygonum arto Gentiana. 


\section{Sronumg Digynia.}

* BłumE์r. IGlăttrig unterftänoig.

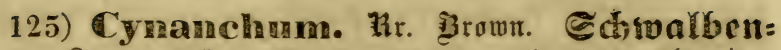
swurg. Rrone fait rioförmig, 5theilig, mit einem 5lappigen

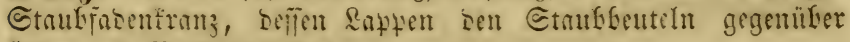
ftefin. $2 \mathfrak{B}$ algfr ü (6) te.

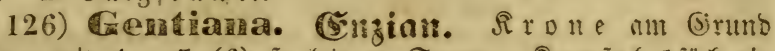

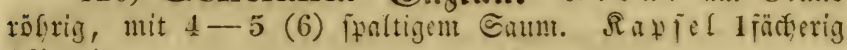
2 flapplig.

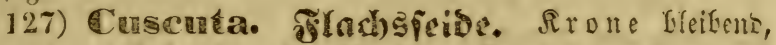

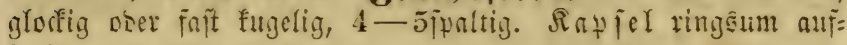
ipringent.

" ş(umér unvolutiänsig unterftänsig.

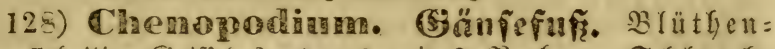

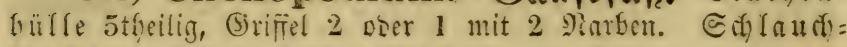

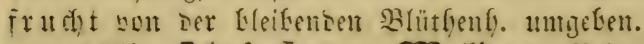

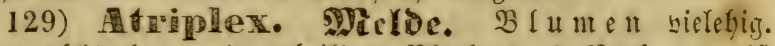
3 witterflütgen mit 5tbeiliger Blutfenth. 2 Narben, meift

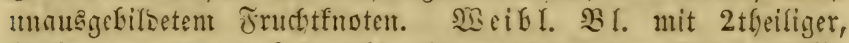

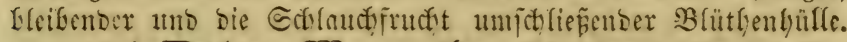

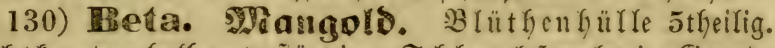

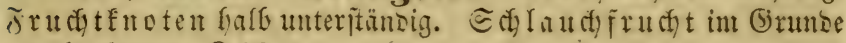
Des Gleifsenden Reldees.

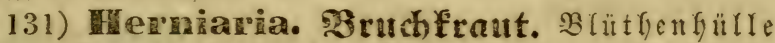

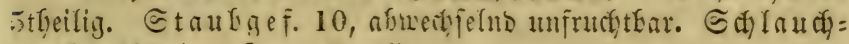
frutht 1 famig., Eame fungelig.

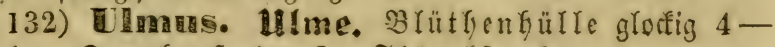
zjübuig. Staubger. 4-8. Jolügelfrutht.

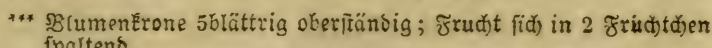
fpaltent.

† Dolbent nidjt ganz volffommen, fonsern mebr ober weni: ger einfaús.

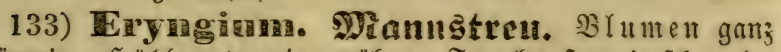

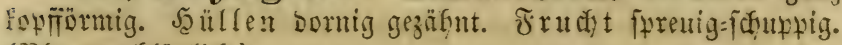
(B̉

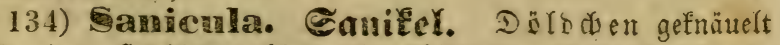

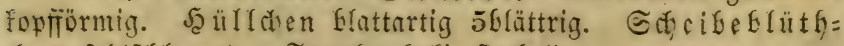
den fehliduligents. Frud t hafig=itadyelig.

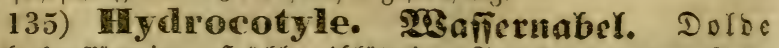

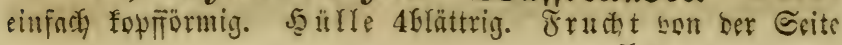




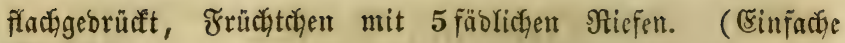
Blätter.)

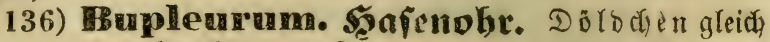
Gody. Soüllen Greitblättrig, Jrud)t won ber. Seite zufmmen: gedrürft, Früchtechen mit 5 gleichen Riefen. (BRlumen gelbr StengelGrätter einfarth.)

†† Dolden vollkommen (Bätter zufammenge feşt.)

a Seüllfe 0 ober faft 0 . Scülldien 0 .

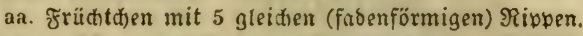

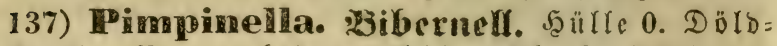
then fugelig. Blunenbläter gleidy berfegrt=hergürmig mit eingebogentem Räppdyen. Frucht non ber Geite zujammenge: zogett mit zurüffigebogenen (S)iffeln.

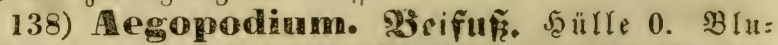
menblätter ungleich serfefrt=ferzförmig mit eingefogenem

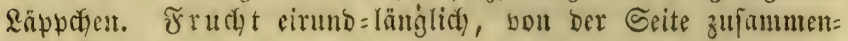
georüưtt.

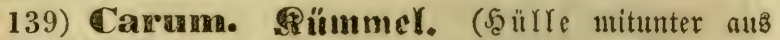

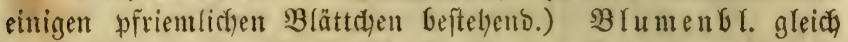
werfehrt:kergförntig mit einwärţ gefogenem Räptchen. Frucht yon ber Seite zujammengeorilift.

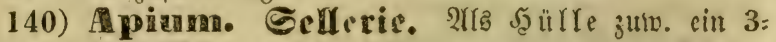

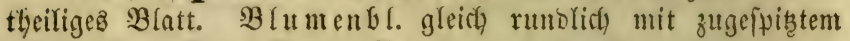
zufammengeroffem (Ënde. Frudht au ben Eeiten zufammen= gezogen, 2fuotig.

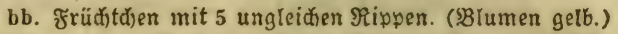

141) netherm. Difr. Sgitle 0 . Blumenbl. abgeftubst eingerollt. Fru(t) t am Rüsfen zufanmengebr. mit

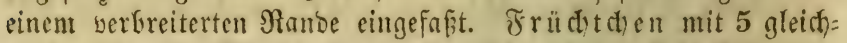

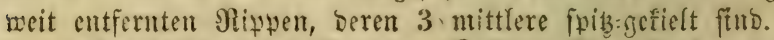

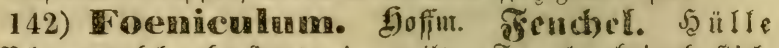

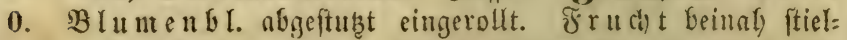

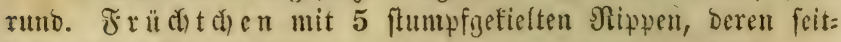
liche etwas breiter fitto.

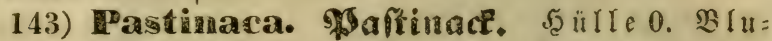

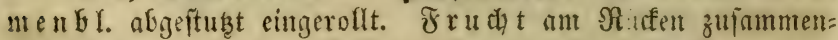

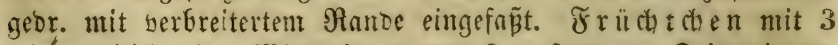
feinen gleiduweiten Diitteltippen und 2 entfernteren Geitenrippen.

b. Sculle 0 ober vorhanden, Scüllden Rätz vorhanden.

a. Früd)tđen mit 5 Scaupts uno 4 sebenrippen.

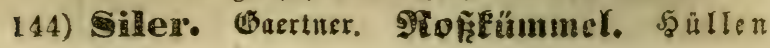




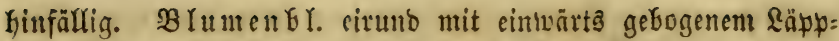

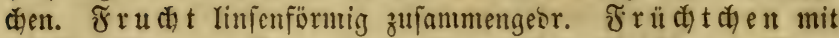
erfaben = ftumpien Sauptrippen, Deren jeitenftänbige Den Sanb bilben, und meniger hervortretenoen hohlen Nebentippen.

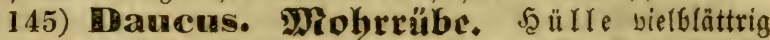

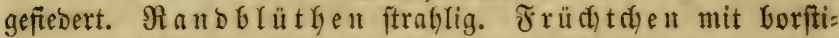
gen Scauptrippen und 1 reifig:ftacteligen Nefenrippen.

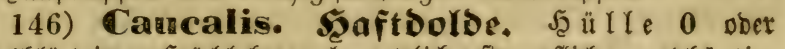

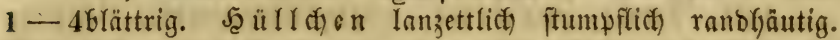

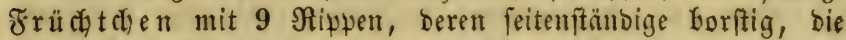
übrigen ftadyelig, ober bie 3 rürenftänoigen borftig finb.

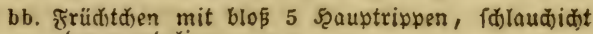
ober mandelig.

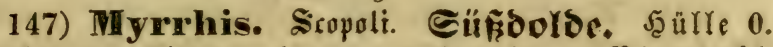

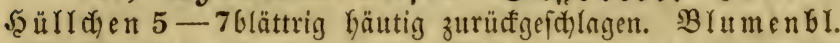
ungleich nerfefort:hergförmig mit einwärts gefogenem Räppd)en.

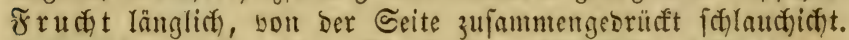

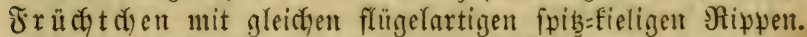

148) Arehangelica. foffur. Sngerwurzel.

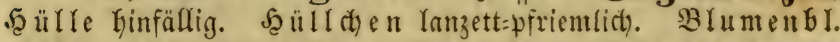
gleidy eirund, mit ber langen Epitze einw. gefrümmt. Frudt oval umb beiserfeits 2flügelig. F̌rüd)t

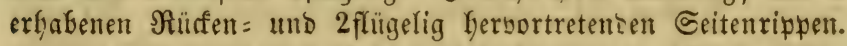
cc. Früđitchen mit 5 Scauptrippen, feft. 'Frudst am

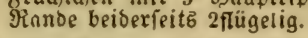

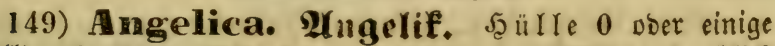

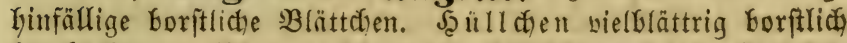
herabgebogen. B I u men bl. gleich) elliptifa) jugejpizt. Frü

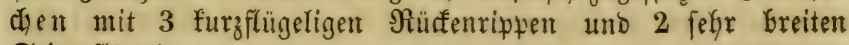
Seitenflügeln.

150) Selinum. Cilge. Jă $\mathfrak{l}_{\text {le }} 0$ vber hinfällig.

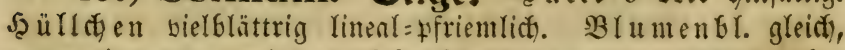
gegen cinanber geneigt, berfefrt:Kerzförmig mit einuärta gefo:

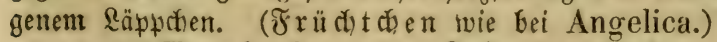

151) Levisticum. Ẽod). Ricbitüdel. Sุül= len bielflättrig breit=lanzettlich) ranobäutig zurüf(gefollagen.

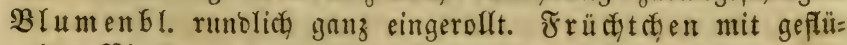
gelten Rippen, beren feitliche breiter finto.

152) Heracleum. Sgcilfraut. $\mathfrak{S}_{\mathfrak{g}} \mathrm{II}_{\mathrm{f}}$ furz

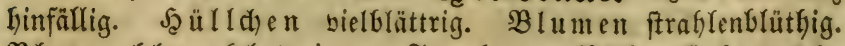

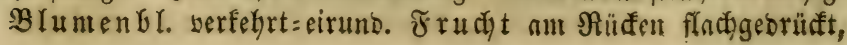




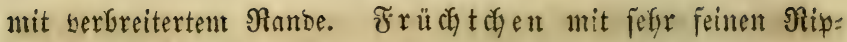
pen, beren feitficle entfernter fint.

153) Peucedanam. Saaritrang. Sf it $t_{\mathrm{f}}$

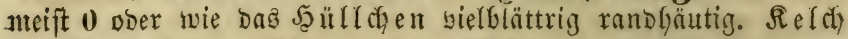

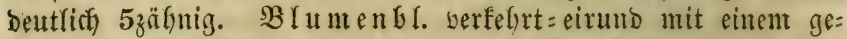

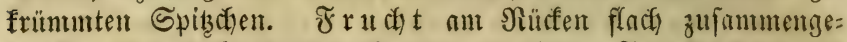

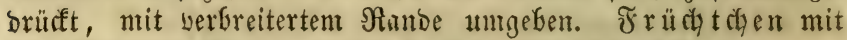

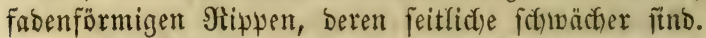

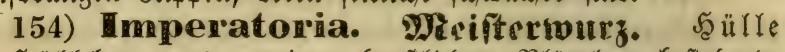

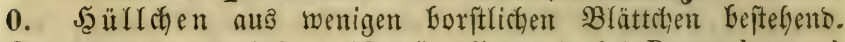
Reldifand berwiffet. (Somit alfes wie bei Peucedanum.)

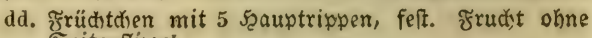
Eeitenflitgel.

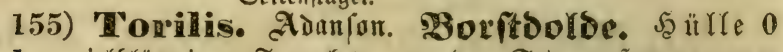

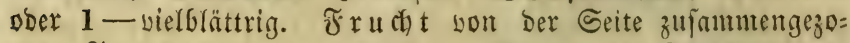

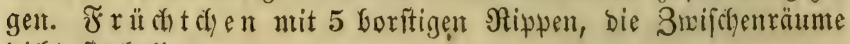
bicht ftachelig.

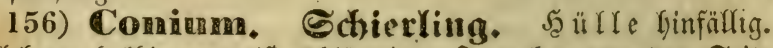

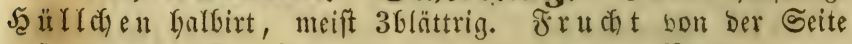

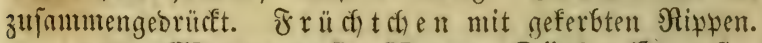

157) Chaerophyllum. Rälbertropf. Sälle

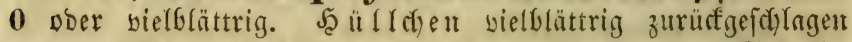

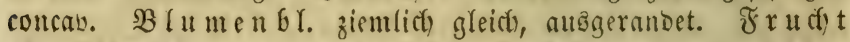

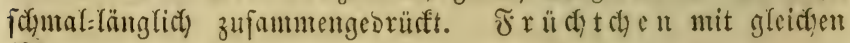
Ripuen.

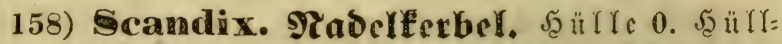

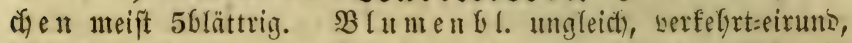

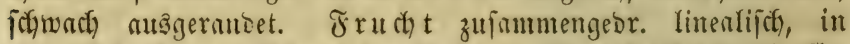

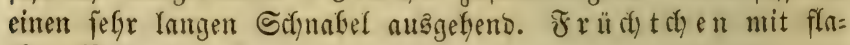
(d)en Sippen.

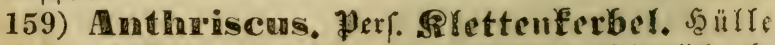

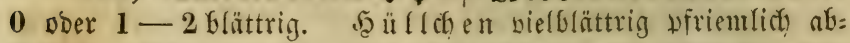

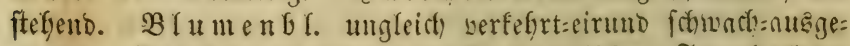

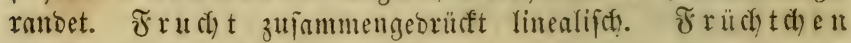
rippenlos, mit 4 furd)igem edfnabel.

160) Si

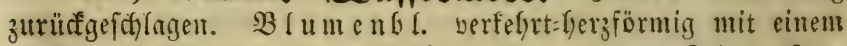
cinwärţ gebognen säpuchen. Frud $t$ non ber Seite zufam=

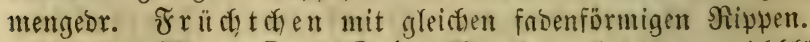

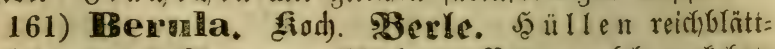
rig, faft bon ser Ränge ber Blüthet. B B umenfol. verfeffrt= 


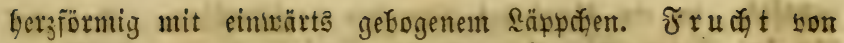
Der Geite zufammengezogen 2fnotig. Frü dyt dy en mit glei: (t)en Nipyen.

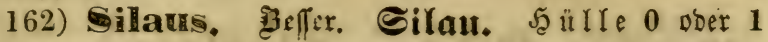

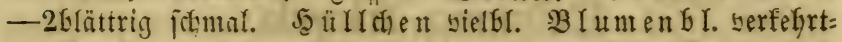

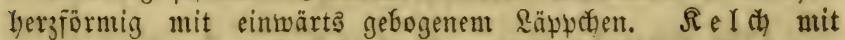

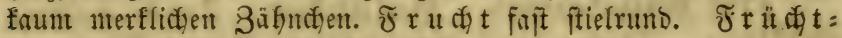

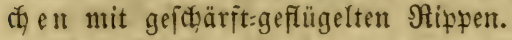

163) Seseli. Eefel. Jaürle 0 docr 1-reiçblättr.

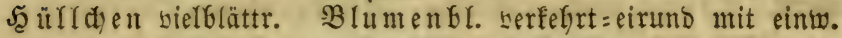
gebognen Räppchen nusgerandet doer faft ganz. Rel ch beut=

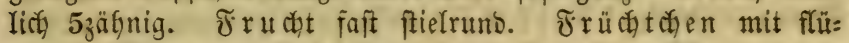
zeligen Ripwen, ieren feitlicte ein wenig breiter fint.

164) ethusa. Gartenichierling. 5ุülfe 0.

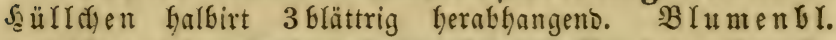

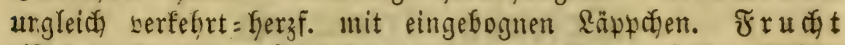

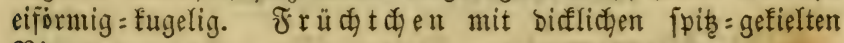
Ripper.

165) Denanthe. Rebenbolbe. $\mathfrak{g}_{\text {ülle } 0} 0$ Dber

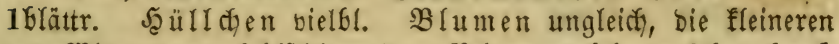

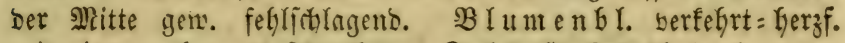

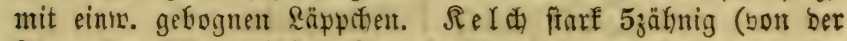
¿änge ber $\mathfrak{B}$ lumenbl.). Frad t rumblich, mit langen graben

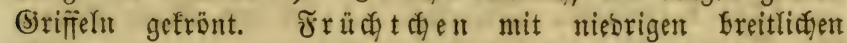
Rippent.

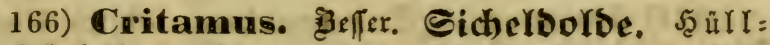

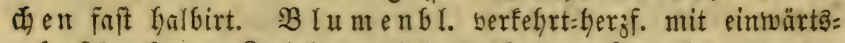

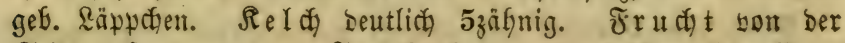

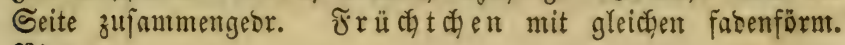
গtippen.

167) Helosciadium. fiod. Gumpfichirm.

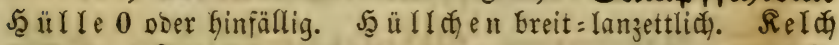
5zäfnig. Frudt obal, von ber Geite zujammengebrüft. Fr ü तु t che n mit gleiden fonenförm. Nippen.

168) Cicuta, 28 afnerichierfing. Sg it Ife 0 ob.

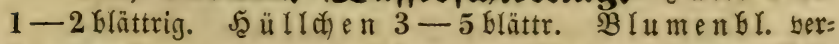

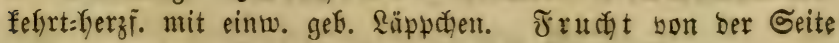

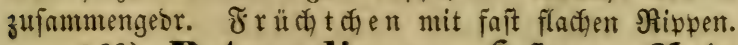

169) Petroselinum. हुoffmant. \$eterfiric.

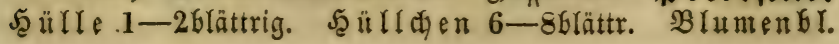




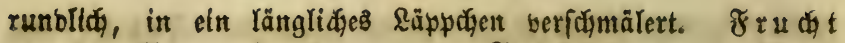

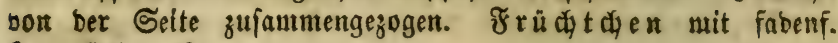
fumplidien Rippen.

\section{Sronumg Trigynia.}

170) Sambucus. Solunber. Sel 5 zäfnig oberftändig. Rrone rabförntig 5fpaltig. $\mathfrak{B}$ eere 3 fantig.

171) Viburmum. Gdhnceball. $\mathfrak{R} \mathfrak{l}$ dh 5 zălnig oberft. Sirone gloffig 5 fpaltig. $B$ eere 1 famig.

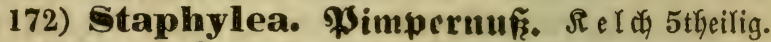
- Rrone 5blättrig. Rap 2-3 aufgeblafen zujammengewadifer.

173) Corxigiola. Ruotenfraut. $\mathfrak{R} \in($ 施 5 brättr.

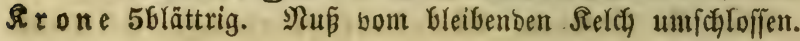

\section{Soromung Tetragynia.}

174) Tamnassia. \$amaffice. Rel 5 tyeifig. Rrone 5 blättrig mit 5 brüftg gemimperten Gdyuppen. Rap= fel dflappig bielfanig.

\section{Sromung Pentagynia.}

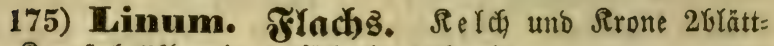
rig. Rapfel 5tlappig l0rädherig 10 fanig.

176) Drosera. Gonuentbau. Sela 5ipaltig. Rrone 5blättrig. Rapfel 1 fächerig bielfamig. Erodium.

\section{Sromung Hexagynia.}

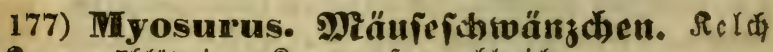
uno Rrome 5blättrig. Saryopfen zahlreidy.

श्Anomalijd) \$flamze: Ranunculus hederaceus. 


\section{Stromung Monogynia.}

\section{2) Echium. Natterfopf.}

254. E. vulgare. (5) e neiner $\mathfrak{R}$. Şöderig=fteif=

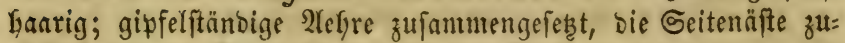
rürğgefrünmt; Rivne fïrzer als ber Relch). - Bl. blau, auds rötflidy Doer tweislid. Scauptformen: $\alpha$ init Yängeren Staubgefäßen als bie Sirone, $\beta$ mit weifsen fürzeren Stanbgefäfen als bie Rirone (E. Wierzbickii. Haberl). \{̂fuf fonnigen wüften ßläben gencin;

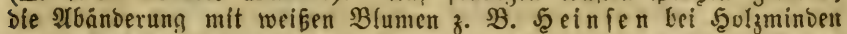

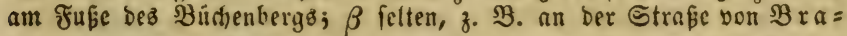

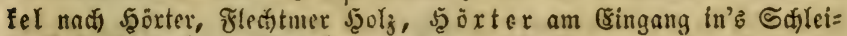
fentfal, Dielenberg, $\mathfrak{B} a \mathfrak{b}$ urg. $6-9$. $\delta$

\section{3) Lithospermum. Steinfamte.}

255. L. officinale. (5) emeiner St. Blätter lan=

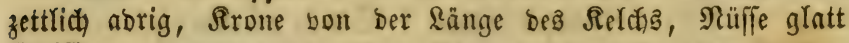

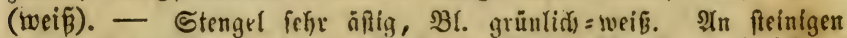

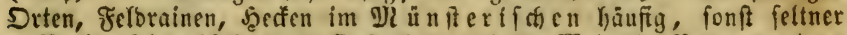

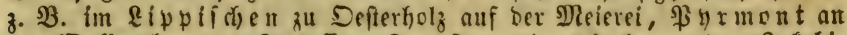

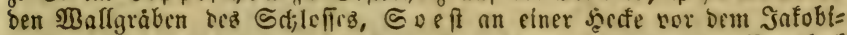
Thore, \&übenf

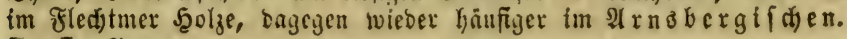
$5-7.24$

256. L. arvense. $\mathfrak{A}$ af $\mathrm{e} \mathfrak{r}=\mathbb{S} \mathrm{t}$. Blätter aberloz Ian= jettlich, bie obern fpiglidy, bie untern ftumpf; Srome von ber

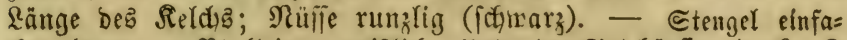

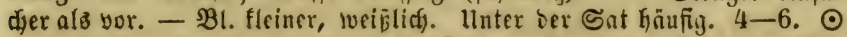

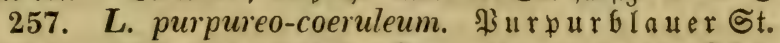

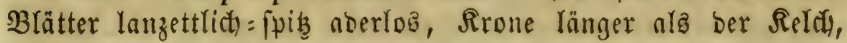
Näiffe glatt (weiß). - Die blühenben Etengel aufredit, bie nidits

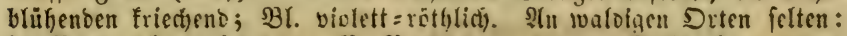
im Paberburnfilen z. B. Beverungen am Siǘlenberg, bant

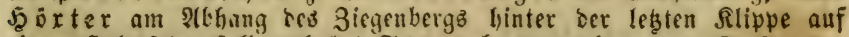
einem 5elzpfabe, foll aud) bei S $\mathrm{tr}$ o mberg vortonmen. 5. 6. 24

\section{4) Pulmonaria. \&ungenfraut.}

258. P. officinalis. (3) enteinez $\mathfrak{2}$. Blätter ber nidytblüfenoen $\mathfrak{S}_{3}$ uzelfproffen herzförmig, geftielt, am Blattjtiel fadmal Gerunterlaufeno; untere Stengelflätter fodaufelförnig, obere eirund fikend; Janare Des Stengelä borftig. - Br. yor

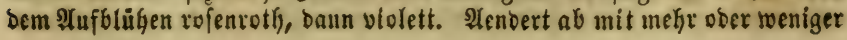




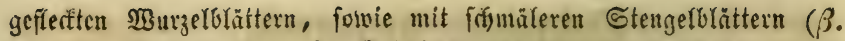

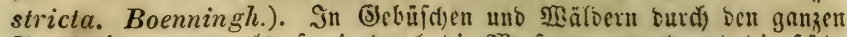
Teutoburgerwald forve burd) bie ibefergegend mo bie fïb=

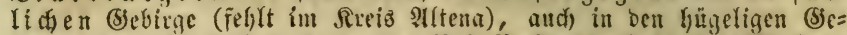

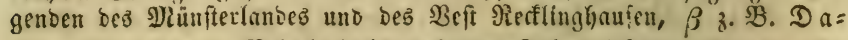
ruy, Dolberg, $\mathfrak{B}$ ielefeld auf bem Juhanniäberg. $3-5$. 4

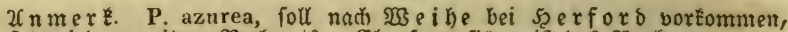

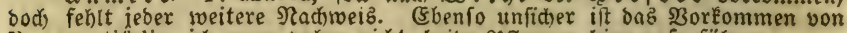
P. angustifolia, iđ wage oaker nitht, beibe şflanzen hier aufzutüüren.

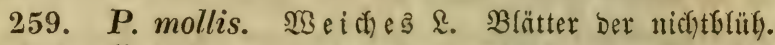

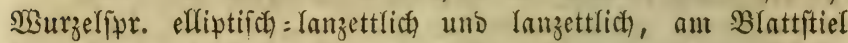

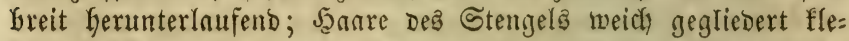
Grig = brüfig. - Die ganze Prfange weid) uno brüfig, faftiger, höber

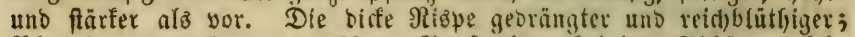

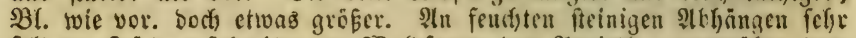

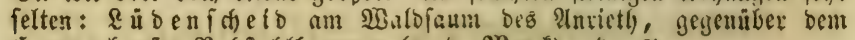
șammerfaufer Nohftalfhanmer (v. D. Narff́). 4. 4

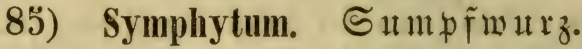

260. S. officinale. (S) meine S. Stengel äftig, Blätter eirumb=lanzettlid), am Stengel herablaufend, Sron=

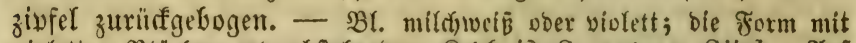

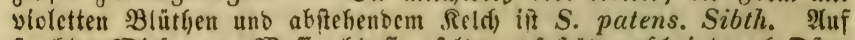

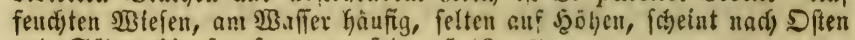

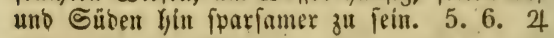

\section{6) Borágo. 3 oxetfd).}

261. B. officinalis. Blïtter elliptiog lyalb=ftengel=

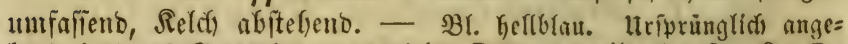
baut, jebt auf (Sartenboben an viefen Drten verwiltert. 5-9.

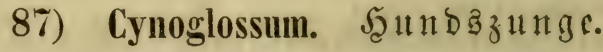

262. C. officinale. (5) e me ine 5.. Blätter fein=grau= filzig; Nüiñe sorn flad), mit einem hersortretenden Nanbe um:

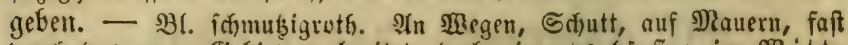

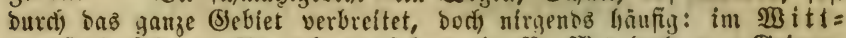

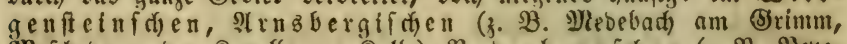
Siefibede an be: Rapelfe yor Ralle), B a derbornfden (z. B. Seve=

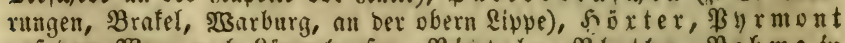

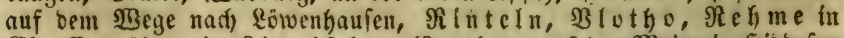

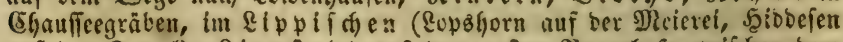
auf Der Rauzel), Eipp fia ot auf Dem eriten Bauerhofe zwifden bent 


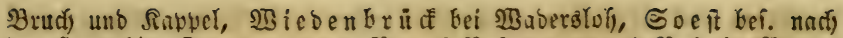

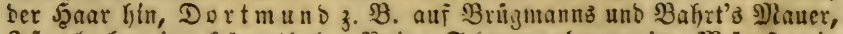

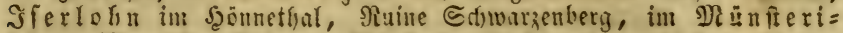

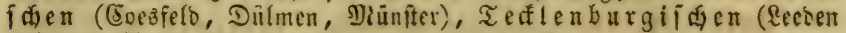

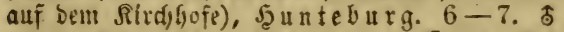

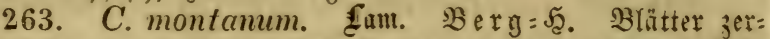

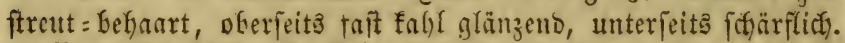

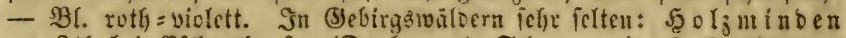

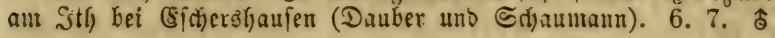

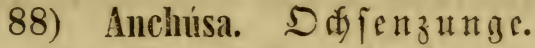

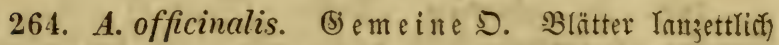

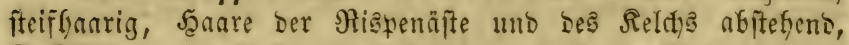

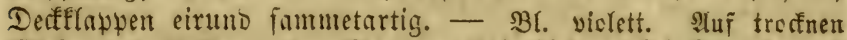

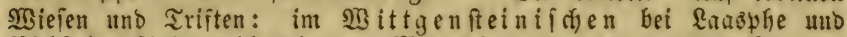
Ridjtecin, ङ di malfenberg, Nharberg, an ber untern Rippe,

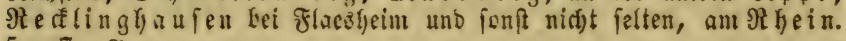
$5-7.24$

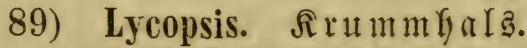

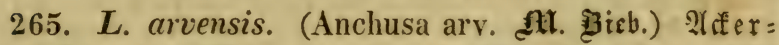

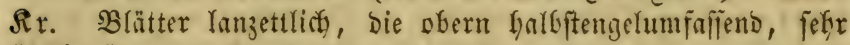
fteifGoriftig. - Bl. Kellklau, ungleidr. NIuf Nerfern gemein, mit

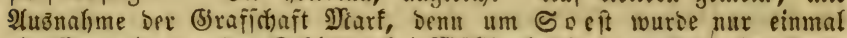

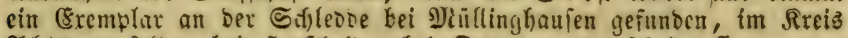
Niftena ferten bei Syeridjeid, bei Dortmund fajeint fie ganz zu ferylen. $6-9$. $\odot$

\section{0) Myosotis. $\mathfrak{B e r g i \tilde { m } m e i n n t d y t . ~}$ \\ * Caum ber Srone flact). \\ $\dagger$ Tsurzel fäisf, Érieđ)eno.}

266. M. palustris. Withering. (M. scorpioides L.)

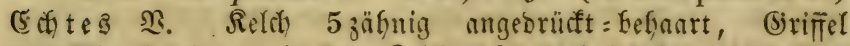
ungefäfr fo lang als ber Reldh, Etengel finntig. - Bl. vor

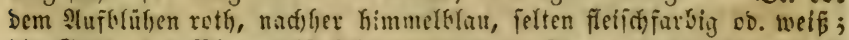
bie Brşge ser Blumen fit felfer veridfieben. Formen: a vulgaris bie Stengelfanare abțthend; $\beta$ strigulosa (Myos. strig. Rchb.) bie Etengelfaare angebrüft; $\gamma$ laxiflora (Myos. lax. Rchb.) raftig, Trauben verlängert Iofferblitthig, Blüthenftecle verlängert; $\delta$ repens (Myos, repens. Rchb.) Sieldie tiefer 5 fipaltig, Brififel länger. In

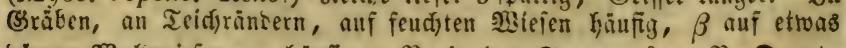

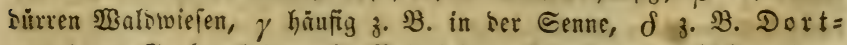

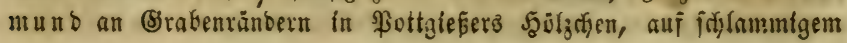




\section{Pentandria.}

Torfboben bei Rgeina und Bielefeld nari) ber Senne hitr. $5-8.24$

t† 230 urzel faferig.

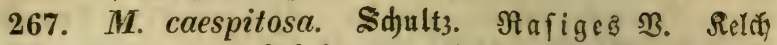

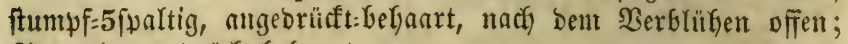
Stengel angebrïft:bebaart. - Etengel Yeidstzgereift, Blumen flei=

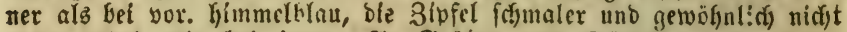

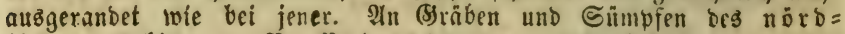

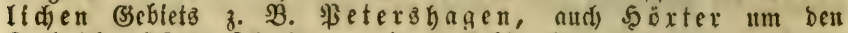

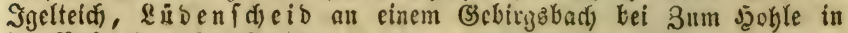
Der $\Re$ akmebe. $6-9.24$

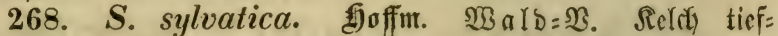
5fpartig, am (srunde hafig: boritig, nach bem Berblïfen zu= fammengezogen, Stengel abftefyend=befyart. - Br. Gimmerbrau,

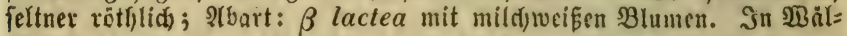

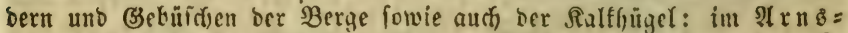

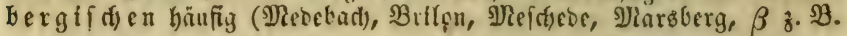

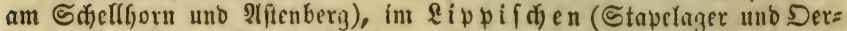

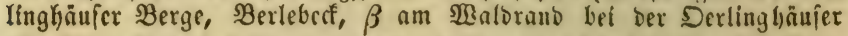
Bleiche), Fुolzminoen am Sth, $\$$ urmont, Rinteln im Rum=

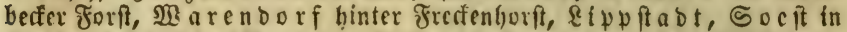
Sheffen bef Edymeffhaufen, Şol)enfyburg an Sungfernfprung, Dortmuno in Bebiufichen yor bem DBifitrafentliore und bei Derne (aud) $\beta$ ), im Beft $\Re e$ fflingha ufen, Coeßfeld am Berge unb in Der Snipe (aud) $\beta$ ), $\Re$ heina 4. 5 . o7

\section{** Saum ber Rrone fonḱa:glockig.}

269. M. intermedia. Fink. Mlittleres $\mathfrak{Z}$. Seldh

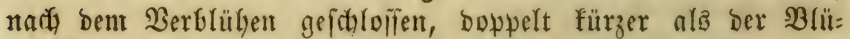

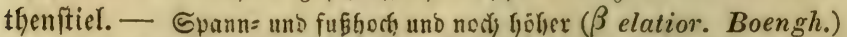
Bl. Flein, vor Dem vierblühen heflrotf, Dann himmelblau, felten weís.

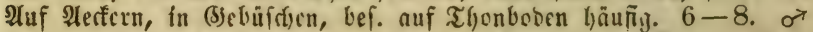

270. M. arvensis. Ehrh. (M. stricta. finti.) $\mathfrak{A}$ (f $\mathfrak{e} \mathfrak{r}=$

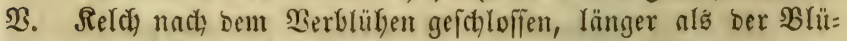
thenfftiel. - BBl. Hlein, blan; Traube an ber $\mathfrak{B a f i z e ~ b e b l a ̈ t t e r t , ~ S i r o n = ~}$ röfre eingefdylofien; Stengrl einfad) ober vieläftig ( $\beta$ multicaulis). Aluf bebautem doer brastliegentem Sanbboben băufig (

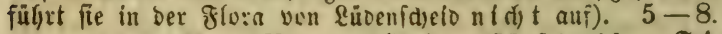

271. M. collina. Einrl). (M. hispida. Sibled)tend.) J2ü $g$ el $=\mathfrak{B}$. Reldy nact) bem $\mathfrak{B e r b l u ̈ b e n ~ o f f e n , ~ f o ~ l a n g ~ a l s ~}$

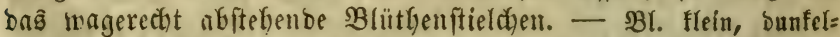
blau, Traube gुefticlt blattles, Rrontöhre eingefdilofien; Stengel zart

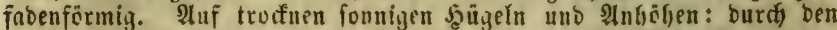
ganzen Teutobu:gerwalb 3. Z3. Teffenburg, BBielefelo um ben Rutterfolf unb am ummelnberg, im Rippifden an ber Dorenfojludjt unb ber \$ivitßhabe; fouft zerftreut im Bebiet: Siegen an ber Siegz 


\section{Monogynia.}

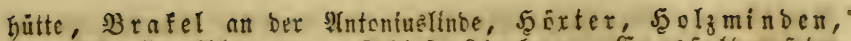

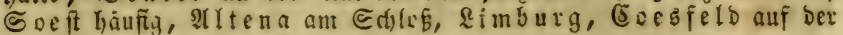
Eitabefle und yor tem Eptter Thore. 5.6. 6

272. M. versicolor. Pirs. $\mathfrak{B}$ unter $\mathfrak{B}$. Reld natd bent Nerbiuthen gejalolien, länger alş ber Blïtlenttiel. -

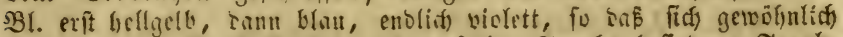
Bfumen won allen 3 Farten auf berielfon Trauke befincen; Traute geftielt blattlos; Rronrobre zulebst boppelt fo lang als oer Relch). Nuf

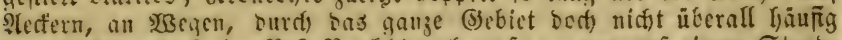

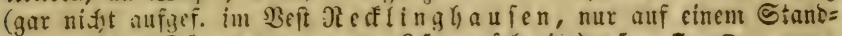

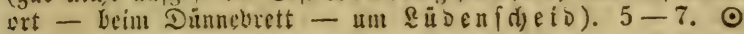

\section{1) Anagallis. (b) a u dy lyeil.}

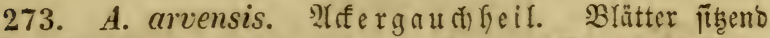
cirumb, Rel(t) etnas fürzet als bic Rrone, Rromzipfel flein=

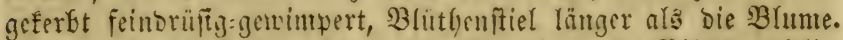

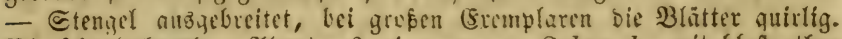
Bl. (d)arlad)coth. S(bart: $\beta$ A. carnea. Schrank. mit blaperethen

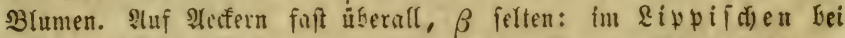

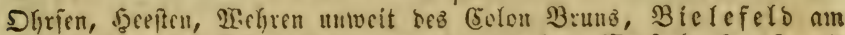

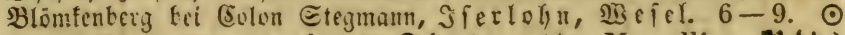

274. A. coerulea. Sidrsb. (A. Monelli. lidb.) BIauer (5). Blätter fitzend eirutro, Reld) eturas flurzer ala bie Rrone, Sronzipfel flein=geferbt brüfenlos, Bläthenftiel un=

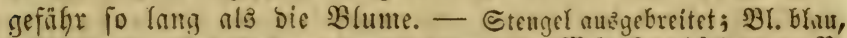

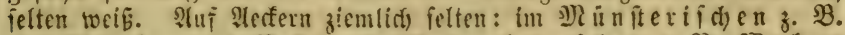

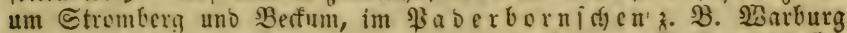
in ber Dafllfeimer Fetomarf, zlviíd)en Brafel und Dributg häufig,

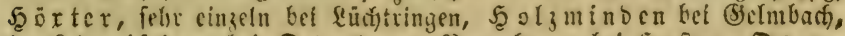

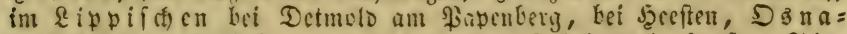

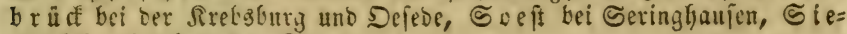
gent feffir cinjstri. $6-9$. $\odot$

+ 275. A. tenella. 3 arter (5). Blitter gefticlt ei: runolidy, Fieldr) 3 mal fürzer als bie Sirune, Rrunzipjel ganz: ranoig=fahl, Blüthenîtiel Yänger ałż bic Blume. - Etengel

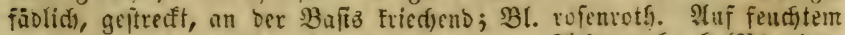

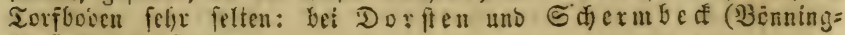
Gaufen): 7. 8. 4

\section{2) Lysimachia. 跃任adie.}

- Blumen in blattrininEelfänoigen gebrungnen Eträufen.

276. L. thyrsiflóra. Straubblüthige ‥ B́lätter

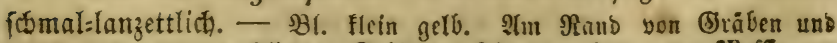

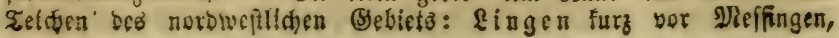




\section{Pentandria.}

Bentfeim, Bronau, Meteren, Rheina im Rienveen, $\mathbb{R}_{\text {in }}=$ fier im Ranal, $\mathfrak{5}$ unteburg; Ilefdyebe (?) 6. 7. 4

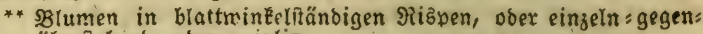
ïberftehend, oder quirlig.

† Etaukgefäße 10, frei, abwed)felnd kleiner und ohne Staub: beutel.

277. L. ciliata. (5) elvimperte $\Omega$. Blätter cirmb=

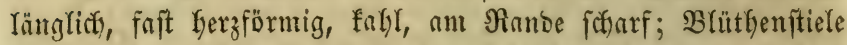
getwimpert. - Bl. gelb. In feuditen (sebuidjen foly feiten, uriprüng=

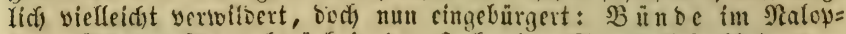

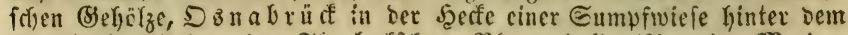

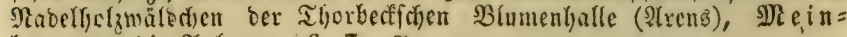
berg um bie श̂nlagen. 6. 7. 4

†† Etaubgefäß̨e 5.

\section{a. Etenget aufredit.}

278. L. vulgaris. (5) meine $\Omega$. Bhtnten it winfel-

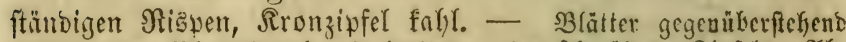

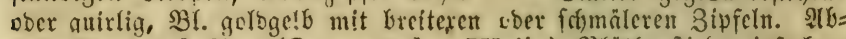
art: $\beta$ guestphalica ( $\boldsymbol{L}$. guestph. Weihe) Blütfentiele cinfadjer,

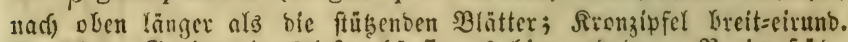

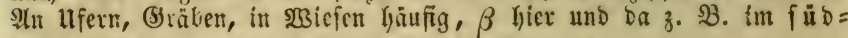
liden (Sebicte an ber Bigge. $7-9$. 4

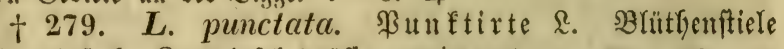
quirlig einfact, Sronzipfel brüftg=getwintpert. - 3 I. getb, am (S) runde rotbbraun; kei ber Bartenfultur fino bie Blütlenplicle mit=

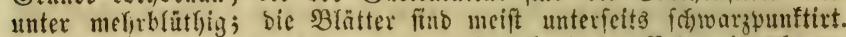
$\mathfrak{A} \mathfrak{T}$ Teidfränbern fefle felten: nux cimmal (

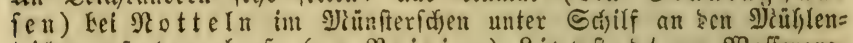

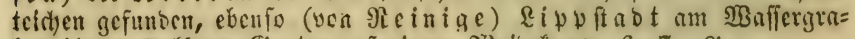
ben hinter Delfaes Sarten auf cincm Siseibefamp. 6. 7. 4

b. Stengel nieberliegens ('Blüthenftiele einzeln).

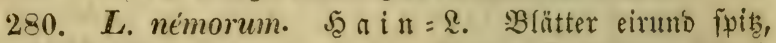

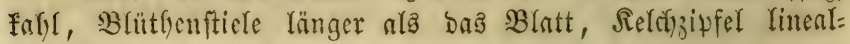

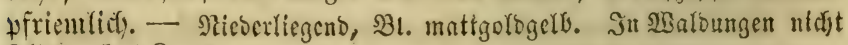
iclten. $5-8.24$

281. L. Nummularia. Piennig=尺. Bläter Lerz= fürnig=runolid), $\mathfrak{B}$ \{ïtlyentiele fürzer als bas $\mathfrak{B}$ [ntt, Seldizipfel

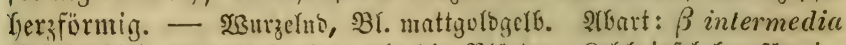
Blütyenfticle suwpelt fo lang als bie Blätter, Reldyzipfel herzförmig.

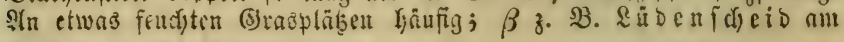
5อกส่ไนไ. 6. 7. 4

\section{3) Primula. Siflufferblame. Brimel.}

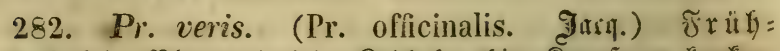

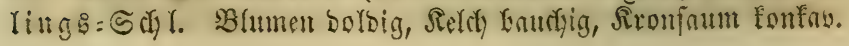




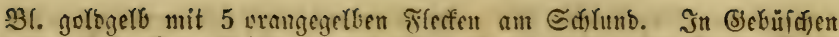
unb auf trodinen Triften ber meiften Berggegenden (3. $B$. im Rreiß

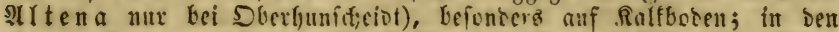

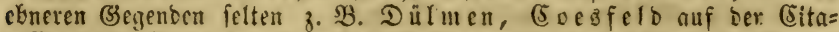

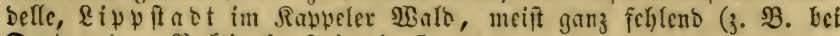
Dortmund u. Recflinglyatien). 4. 5. 24

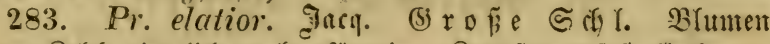

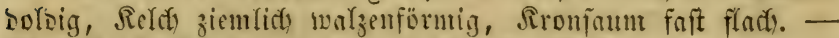

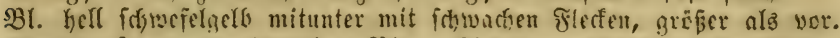

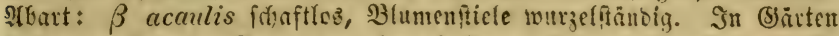
hat man fie als (5) artenyrimel in unärb!igen Evielarten. Jut

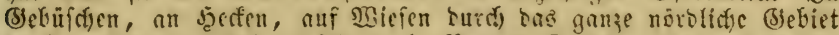

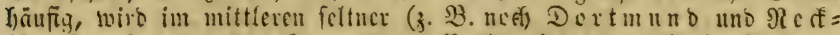

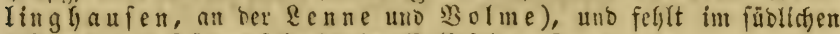
foị ganj; $\beta$ \&

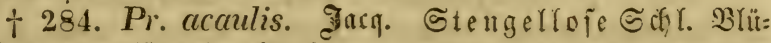

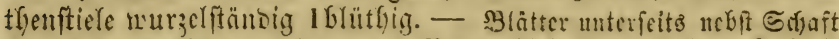

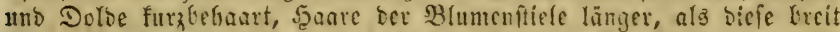
find; SBl. foumerelgelb mit 5 sunfleren Fleffen. In Sisaloungen forje

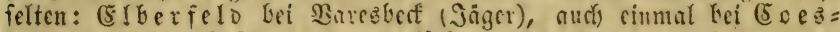

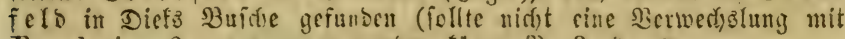
Pr. elatior $\beta$ angenummen iveroen fs̈nnen?) 3. 4.24

\section{4) Erythraea. \#id). Ia tendgülocnfraut.}

285. E. Centaurium. \ers. (Gentiana Cent. L.)

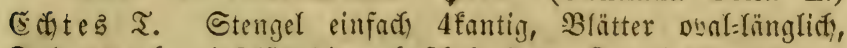
Dolbentraube gipfelittänbig gebüffcelt flach, Rrombipfel obal. -

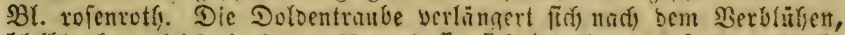

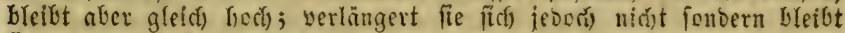
fie gebrungen, fo if es bie stbart: $\beta$ capilata (Erythr. capit. $\boldsymbol{R}$. \&

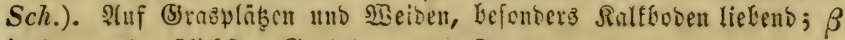
in ben norbiwefftliajffen Biegentien. 6-8.

286. E. pulchella. Erirs. (E. ramosissima. Wers. - Gentiana Centaurium $\beta$ L.) Niebliches T. Etengel

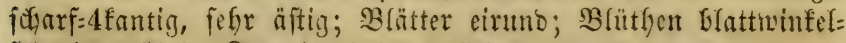

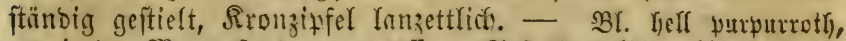

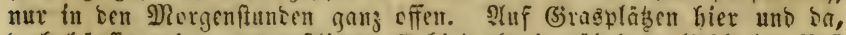

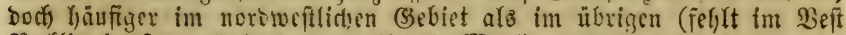

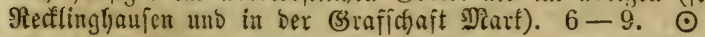

\section{3) Hottonia. Mafiferfeder.}

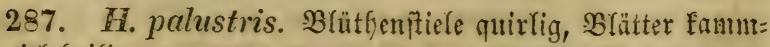

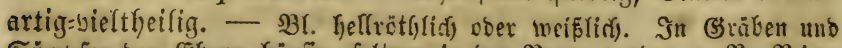

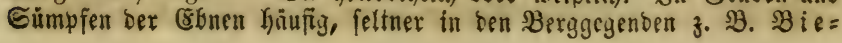




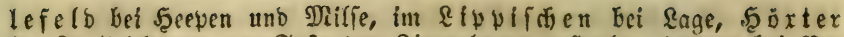

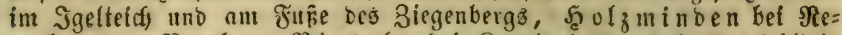

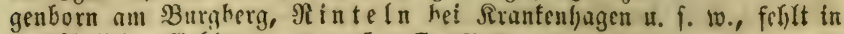
ben füblichen Bẹbirgen ganz. $5-7.24$

\section{6) Menyánthes. Bitterflee.}

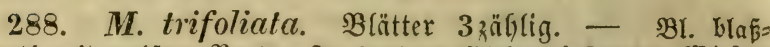

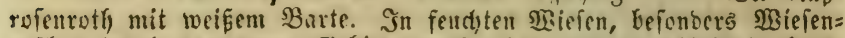

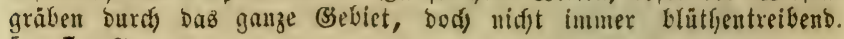
5-7. 24

\section{7) Villarsia.}

289. V. nymphóides. $\mathfrak{D}_{\mathfrak{e n t}}$ (Menyanthes nymph.

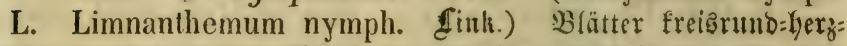
förntig fotwimmento, Blütlyen wwinfelftündig: Doloig. - Bl. hell=

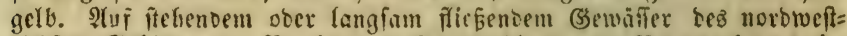

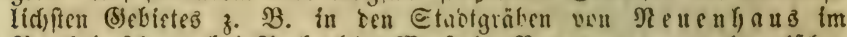

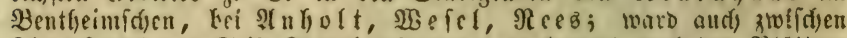

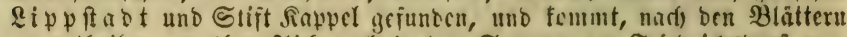

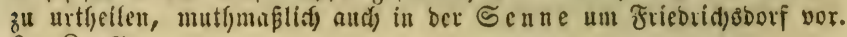
$6-8.2$

\section{8) Polemonium. Strcitrum}

290. P. coeruleum. Brätter gefięert. - $B$ l. blan,

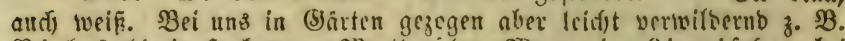

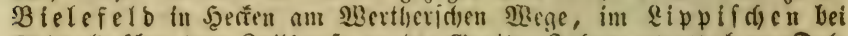
Detmu!o úker bem 30!lfaufe an Der (s)ette, Sugannettenthal am Dol= zerteidye. 6: 7. 4

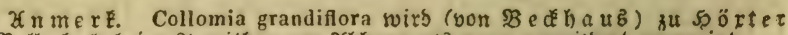

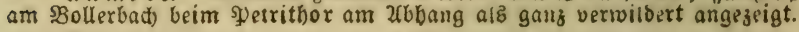

\section{9) Convolvulus. Winde.}

291. C. arvensis. $\mathfrak{A}$ f erwinbe. Blätter pfeilf̣̈rmig,

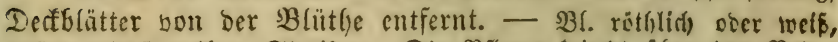

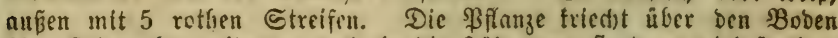
fin, feeigt aber mitunter auth) in bie Söble, wo fie bann viel üppiget mit beiteren Blättern uno oft 26 lüthigen 3 lumenfitelen verfer)en iff. शluf Aecfern gemein, bie angezcigte üppige Form hier und ba in Ses

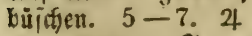

292. C. sepium. Syeffentwinbe. Blätter pfeilförmig,

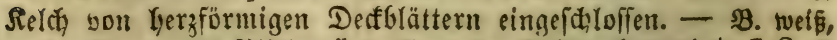

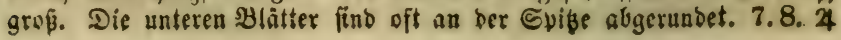




\section{Monogynia.}

\section{0) Nicotiana. Iabarf.}

293. N. Tabacum. (5) emeiner T. Blätter fitbeno länglich-lanzettlid, bie untren Verablaufend; Rronzipfel zuge:

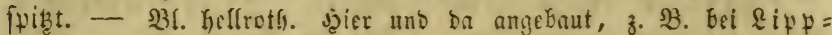

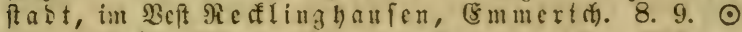

293 b. N. rusticana. 3 a 4 er $n=$ T. B Blätter geftielt

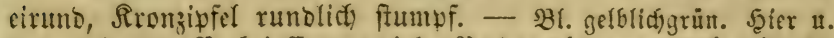

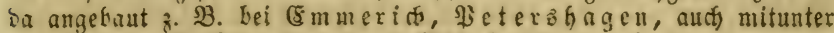

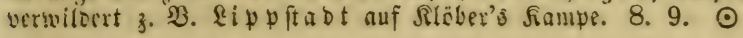

\section{1) Datura. Stedapiel.}

294. D. Stramonium. Blätter eirund fafl winflig= gezäfnt, Rapjeln boinig. - $\mathfrak{B l}$. weí. Mbart: $\beta$ chalybea Etengel, Blattîtele uno Blattnerven gerattigt violett, Relch) violett = mingelaufen, SBlume blap̧blau. 2tuf Erfiutt, in Gärten hler unb ba, sudi in (Sanjen folten und nifit fanblyaft; $\beta$ am Rieberthein (Brininghaufen). $7-9$.

\section{2) Hyoscyamus. Biflenfrat t.}

295. H. niger. $\mathfrak{B}$ lätter feverfpaltig = Eudotig, bie obern

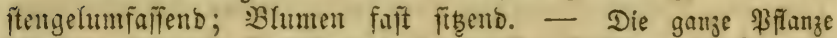

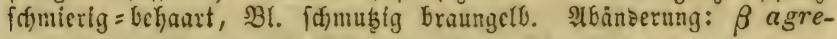
stis (Hyosc. agrestis. Kit.) bie Blätter weniger tief Eudtig, bie

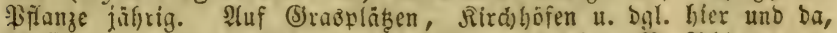

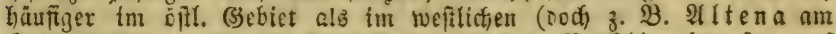

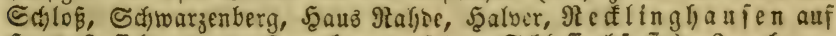

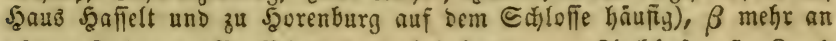

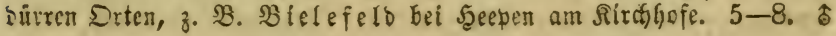

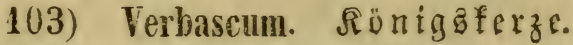

- Blätter mehr ober sweniger herablaufent.

$\dagger$ Wolle ber Staubfäben reis.

295. V. Thapsus. (V. Schradéri. Alencr.) (Se=

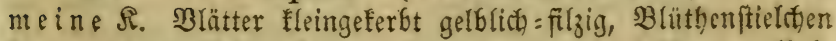
fürzer als Der Relch, Rrone triêteriörmig, Die 2 längern (faf): Ien ober fparjum befjanten) Staubjäben 4 mal fo lang als iffr auf ber einen @eite herablatfenter @taubbeutel. - B Bl. Kell= gelb, felter ganz blaß (V. pallidum. Nees $a b$ Es. - o. B. \& $\tilde{u}=$

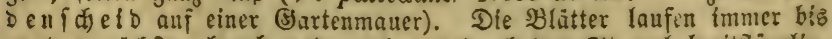

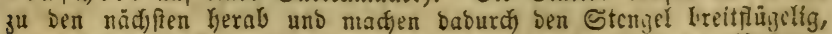

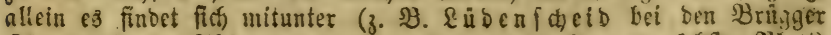

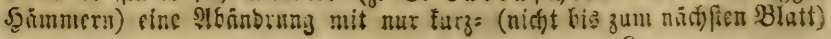




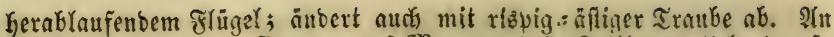
unbebauten feringen Drten, auf Inauern, bef. Ralfboben liebent, fo zleml. überall verbreitet, bodis mehr im offt. als im weptl. Bebiete. $6-8$. $\hat{8}$

297. V. thapsiforme. Sidrai. (5) ז Blätter geferbt gelbict = filzig, Blütbenft. fürzer als ber Relch), Srone rabförmig, bie 2 längern (fablen ober fparfam befan: ten) Staubfäben frum bopyelt fo lang alg igr herablaufender Staubbeutel. - Bl. gelf, bebeuteno gröper als bei wor. Formen: $\alpha$ verum Rlättex ganz (bis zu ben naidyften) herablaufent: auf trort= nen wüten Etellen bef. Der Fflufitgäler Der obern 23 efer und Die =

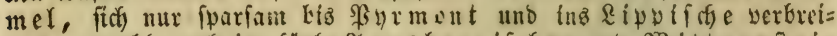

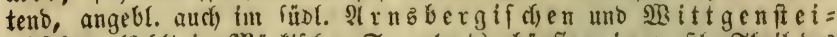

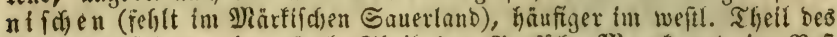

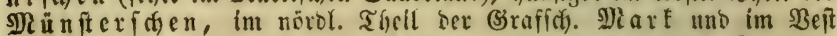
sectlinghaufen, fotwie am Rhein, ferlt in son nöbl. Begenten ganz; $\beta$ phlomóides (V. phlom. L.) SB!ätter furz= ober falbherab=

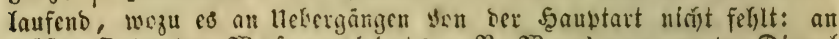

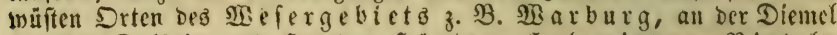

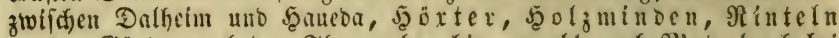
an ben (biäten nad, ben Thengruben bin, angebl. and, Dico ebadi bei Dreiglar nm Rinfenfopf und im benudyb. Sis aloedf $\gamma$ cuspidatum (V. cusp. Schrad.) obere Blätter uno Dedfblätter in einer langen Spike vorgezogen, fouft wie $\alpha$ : in ben weittictien Begen=

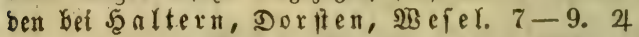

\section{t†}

298. $V$. collinum. Sid)rad. (V. Thapso-nigrum.

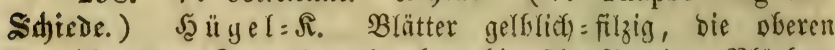

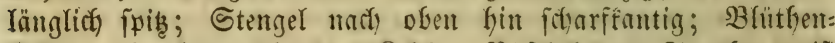
ftieldyen fo lang als ber Seldi), Büidtel der Traube meift 5blüthig; Stnubfäben alle wollig; Strubbeutel gleich, feine berjelben Gerablaufent. - Br. gelb, nidjt grof, stiva wie bei $V$. nigrum. Dicie \$fllanze wiro als Sbafato yon $V$. Thaspus uno $V$. nigrum betradjtet, und ändert fefr as, bcionder bemerfenşwerth if eine Form: $\beta$ stellato-pubescens, wo bie Rrone am Srumbe gefieft

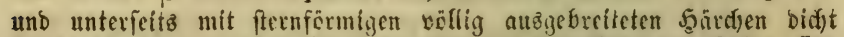

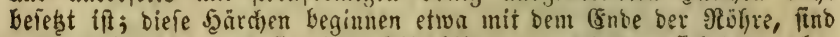
anfangz fo biçt, baf́ fie einen fifz biloen, vermindern ficf bana aber

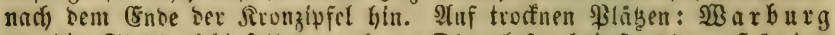
um ble Stabt nicft felten, audf am Diemelufer bei Jjaueba, Sgoxter

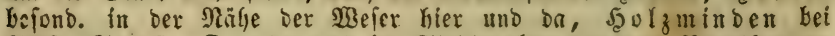
Forf, Soef, Dortmuno im. Stabtgraben vor bem Burgthor an

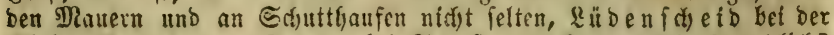

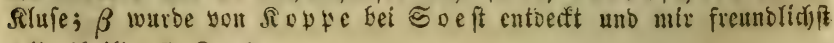
mitgettseilt. 7. 8.

299. $V$. adulterinum. ㅈod). (V. Thapsiformi-ni- 


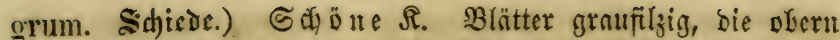
haaripibig; Stengel nady oben hin fod)arffantig; Brütyeniftieldyen

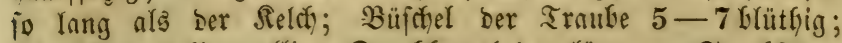
Staubfäben alle upllig; Stanlbeutel ber längerent Staubfäbent

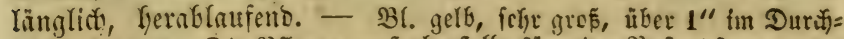
mefter fartens. Die \$sfanje mú ebenfallz für pine Baftarsform ange= iefien werselt, uno twat wen $\boldsymbol{V}$. thapsiforme uno $\boldsymbol{V}$. nigvum. 2It müfen Ete!len: Dortmund im Etaotgraben yor scm Burgthor,

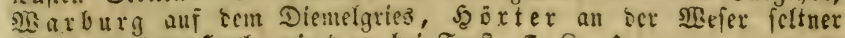

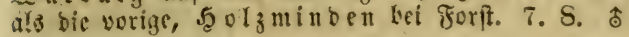

\section{*** Blätter nidt herablaufend.}

$\dagger$ Blüthen büfdelig.

a. Sisolle ber Etaubfäben weís.

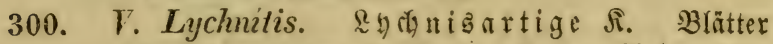

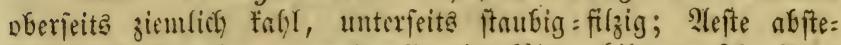

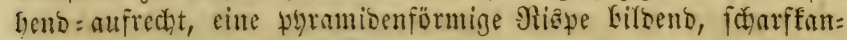

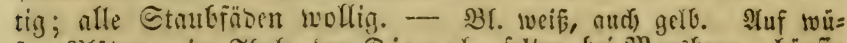

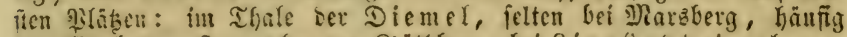

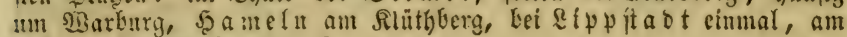
R Geln bei æeefel. 6 -8. 4

\section{b. 2Bollye ber Staubfäben purpurroth.}

301. V. nigrum. S(i)warze $\mathfrak{K}$. Blätter oberfeits jiemliç fafl, unterfeits feinfilzigh, bie untern herzförmig lang: Beftielt; Traube serlängert, bie Blütbenftieldcen noch eimmal io lang als ber Reldi); alle Etrubfüsen wollig. - BBl. gelb,

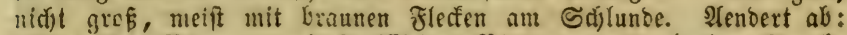

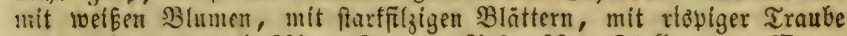

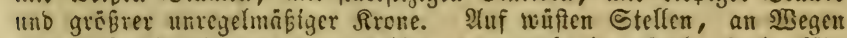

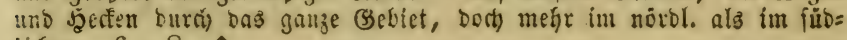
likf)en. $6-8$.

302. V. Schiedeanum. fiod) (V. Nigro-Lychnitis.

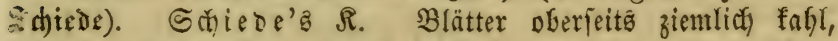
unteri. Feinfilzig, bie unteren (nid) Gerzförmig) in ben Blatt= fitiel zufanmengezogen, langgeîticlt; Traube werlängert, bie

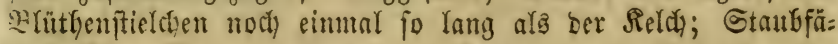
rent afle wollig. - Bl. gelb. Diefe \$fllanze ift ein Baftarb zwi= (d)en $V$. nigrum unb Lychnitis, änbert aber, je nadjoent fie ber ei=

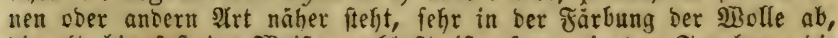

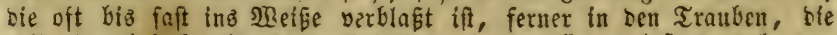

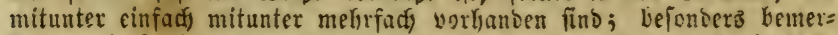

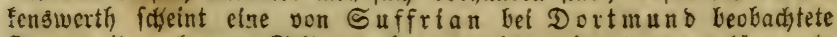
Form mit mefyreren Ceitcutrauben, weldie bie etwab verfümmerte

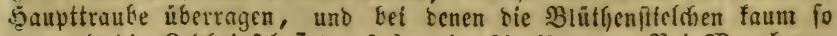
lang alz bie Relchzipfel find: $\beta$ brevipedicellatum. Bei

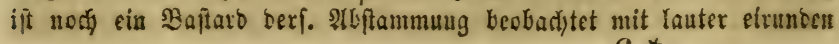




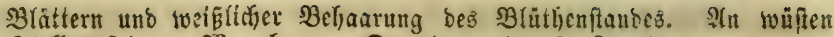

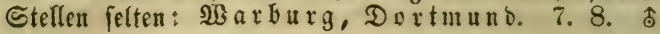

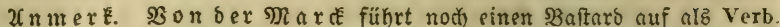

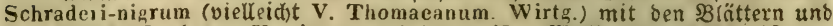

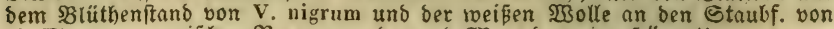

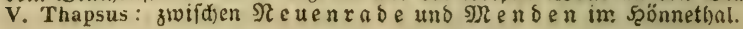

†† Blüthen eingeln.

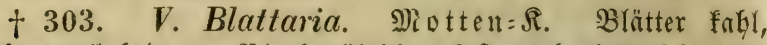

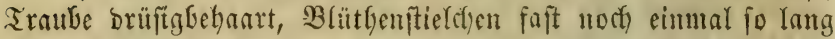

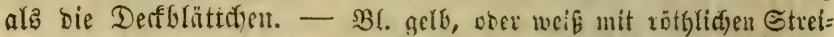

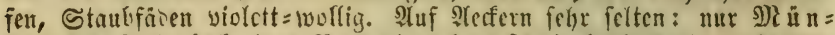

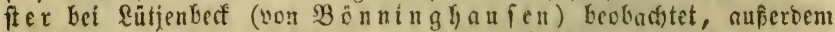

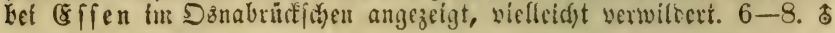

\section{4) Vinca. Sinngrün.}

304. V. minor. (5ienteines S. Stengel nieberlie:

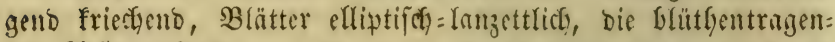
ben 2lefte nufredit. - Br. VIau. SIn fdrattigen Drten, yäufig ìn

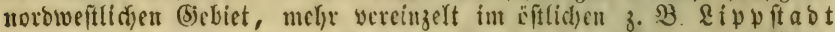

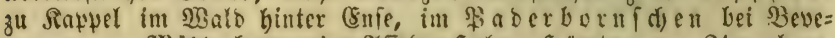

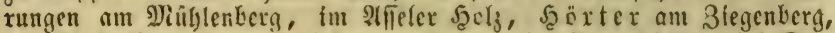

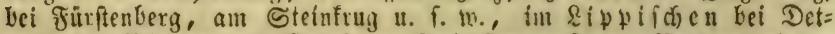

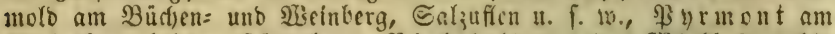

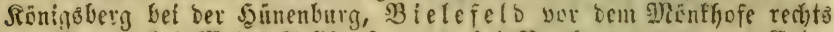

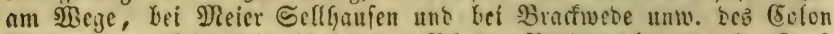

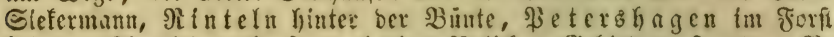

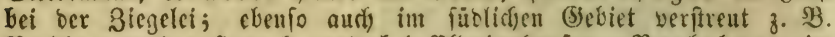
Brilon an ber șoppefe und bel çfleringlaufen, Berleburg im

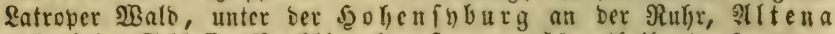

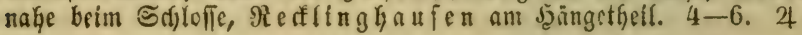

\section{5) Solánum. Siadid a t ten.}

* Etengel Erautig.

305. S. miniatum. Serml). Siotger গR. Stengel abitebeno=zottig, bie 2lefte ftarffantig=fnotig; Blätter eirumb (fait beltnförunig), budotig=gezäfut, abítefyeno=zottig. - B Bume

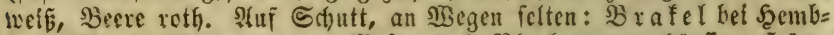

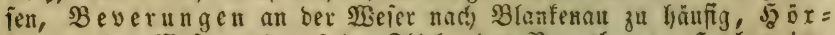

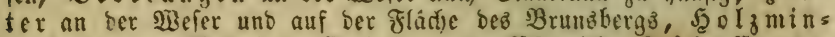

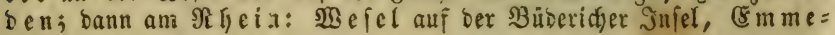
rifi. $6-8$. $\odot$

306. S. humíle. Serrub. Niebriger N. Stengel faft faghl, bie Aefte foflwadyfantig mit wenigen Snötchen; Blätter eirund (faft rautenförmig), ausgefdyineift gezähnt, faft

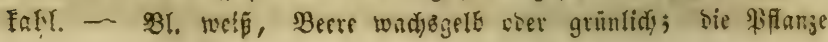




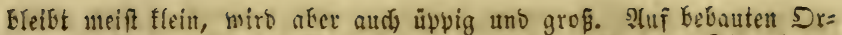

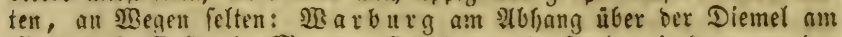

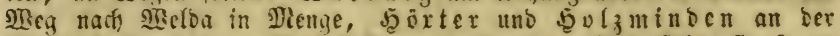
जुefer bier uno ba \&. B. bei Siorvei, unter bem Riefenftein. 7-9. $\odot$

307. S. nigrum. S(t)warzer $\mathfrak{N}$. Stengel angi: brüft=begaart, bie 2leite ftarffuntig = fnotig; Blätter eirunb

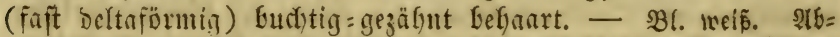
art: $\beta$ pterocculon (Sol. pteroc. Rchb.) mit ftärfer Gervertretenben

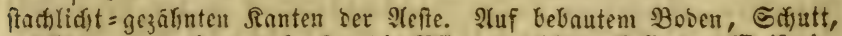

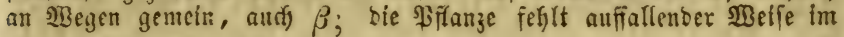
R̃eib Altena. 7-10. $\odot$

308. S. tuberosum. $\mathfrak{R}$ ollentragender $\mathfrak{R}$. $\Re \pi \mathfrak{r}=$ tofiel. Sisurzel fnollentragent, Blätter ungleida gefiesert. -

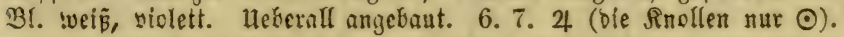
** Etengel firautisig.

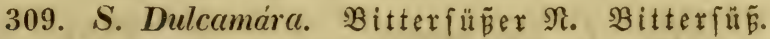
Bätter eirun = her;förmig, bie obern fpieß̃förmig. - Çin flet=

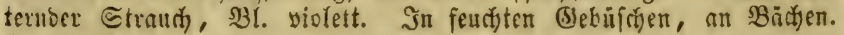
$5-7$. क

\section{6) Physalis. ङథdutte.}

310. Ph. Alkekengi. Blätter 2 zälylig ganz frib, Stcn=

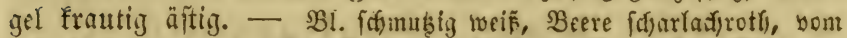

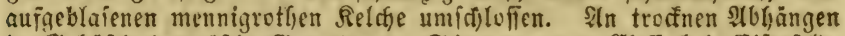
in Bebüfd) ber biftl. Biegenben: Slegen am Eleff bet Eiferfelb,

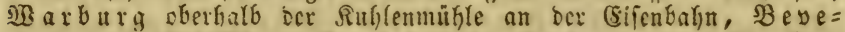

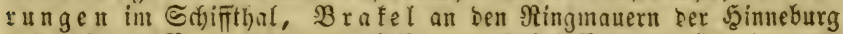

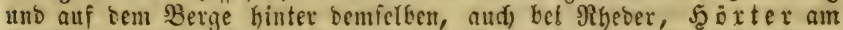

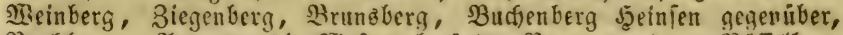

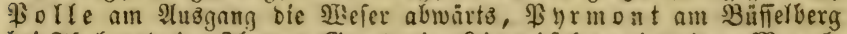

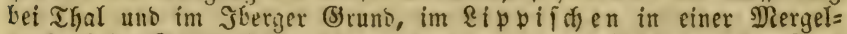
arube beim (but Mañengrund; auģerbem nur zu Därmen im Dorf Daltrup bei Col. Brelving. $6-8.24$

\section{7) Atropa. Iollfiridye.}

311. A. Belladonna. (5) emeine న. Blätter eirunt,

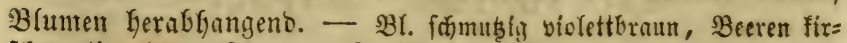
fafenartig glänjenbidiluarz. In fdjattigen Bergwäloern im Siegni=

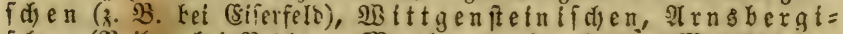

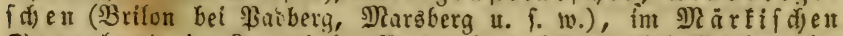
Sauerland im Remnetfial, Faberbornforen (bei MBarfurg im Rappin uns im शineler Mrals, Brafel, Beverungen), Rorvelfden, unt Pyrmont (am Sdjellenberg), im Rippifden (Detmolo int

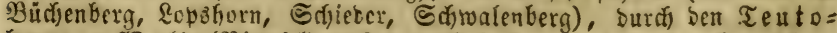
burger $\mathfrak{B}$ als (Biclefeld auf ben Nofenberg und in Den benardbar= 
ten Bergen, bei Şalle, Diffen, SGurg), MR in be n Sintgurethenfluz ; ausetbem nuts bei Rappenberg an Der \&ippe. 6. 7. 2

\section{8) Sámolus. $\mathfrak{P} u n g e n$.}

312. S. Valerandi. Blätter ftumpf; Traube zuletegt verlängert, nit Deff́blättern an ber Mritte Der $\mathfrak{B}$ lüthenftielchent.

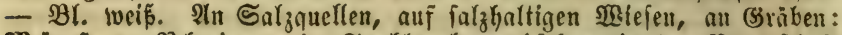

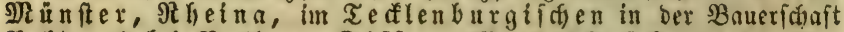

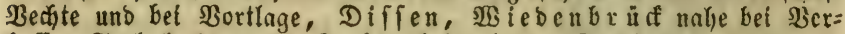

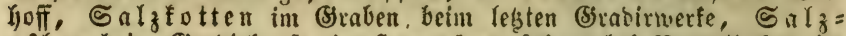

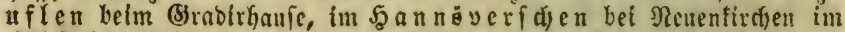

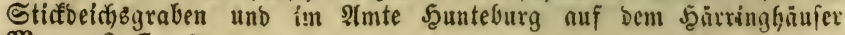
शoor. 6. 7. 4

\section{9) Lobélia. ¿obelis.}

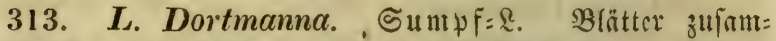

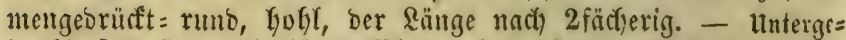

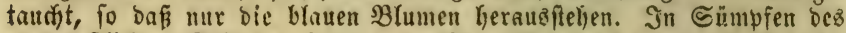

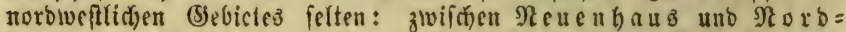
Y) or $n$ an ben Ufern eines fleinen Rinofee'z, zmifaen Dietele $n$ und Effüppingen, Dorften, Teffenurg in ber Baruerdyaft

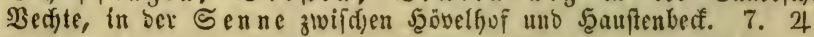

\section{0) Jasióne. Sdafrapunzel.}

314. J. montana. (b) emeitie Sd\%. S3urzel einfact

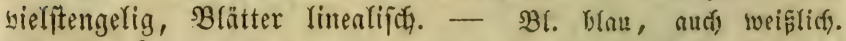

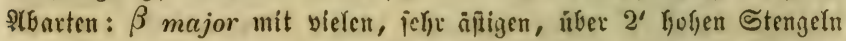

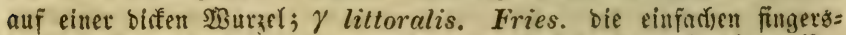

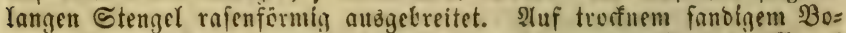

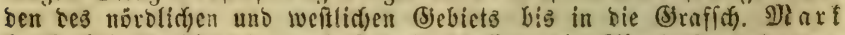
(nodf) bei $\mathfrak{B a l b e r t , ~ b o d h ~ f e l t e n ) ~ G u ̈ u f i n ; ~ b i e ~ s t l b a r t ~} \beta$ wurbe von (5) terling im Ripplichen brobaditet, uno zwar bei Tugufburf in bex Närje ber Rirdie; $\gamma$ nirgt felten auf fourdem Sanbboben. $6-9$. $\hat{\sigma}$

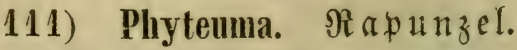

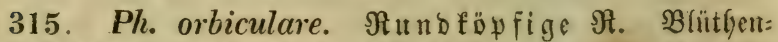
fovf faft fugelruno (nach) bem :erbliblyen etwna berlüngert): Blätter geferbt = gejägt, bie grumbittänoigen herzförntig langge:

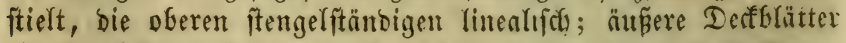

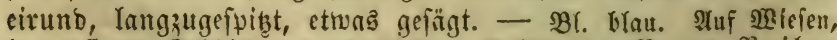
in grafigem (Bebüidy bez füblichen bebietes z. B. um SBrflon

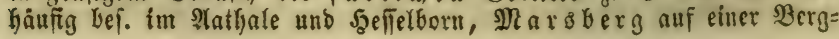


wieie unterm Biclftein nact) ber Stast zu, am $\mathfrak{A}$ fiten $b$ erg unb $\mathfrak{B}$ on,

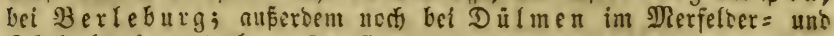
Güßfenbruck) annegeten. 5-7. 2

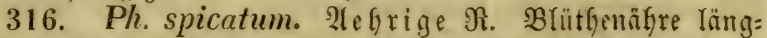
lict) (oft aud) fefor verfürjt); B̉ätter (oft ungleict) geferft= geiägt, bie unteriten bergiörmig langgeitielt, bie oberen linenlifat); alle Dectblätter linealijat). - Şinfirftlids bor Blumen lafien fid follgente fernen nuffeflen: $\alpha$ album bie eigentliffe äfrige form mit

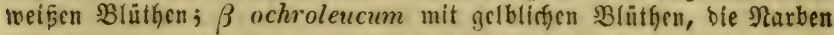
jiter blau; $\gamma$ coeruleum mit blaucn Blütficn, bie Slefre sval; $\delta$ nigrum mit Duntelvidetten Blütlen, bie stchren meljr ober weniger

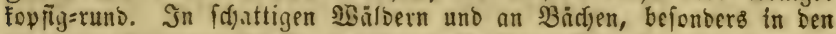

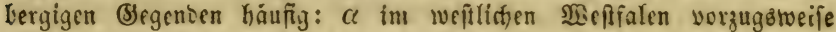
allein, two es im Tedflenburgif d) en mit $\delta$ zufammentrifft, viel

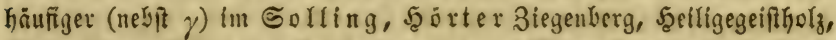

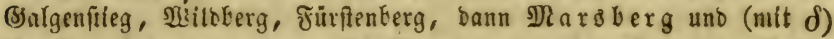

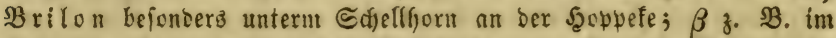

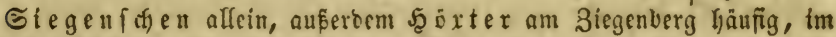

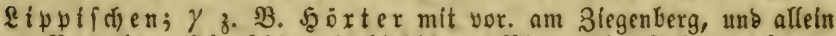
am Brunsberg, fefre fojon mit blafblauen Blumen im Golling; $\delta$ vor= zugsiveife allein im Ravenzbergif then, In inbeniden, berbornfigen, bann zerfreut im Rippif (d)

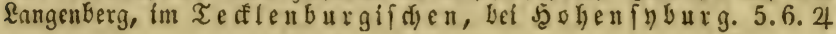

\section{2) Campanula. Gj foffenblume.}

* slätter mehr oder weniger Eahl.

317. C. rotundifolia. Nunbolättrige (5) Y. TSur= zelblätter \anggeïtielt herzförmig (Ginfällig), bie untern @tengel=

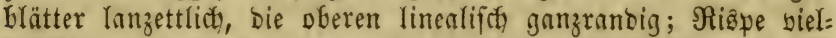

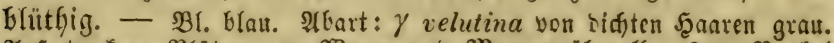

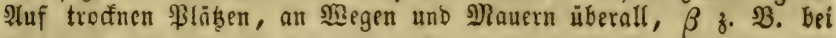
Brilon am Butterfopf. 5-9. 4

318. C. patula. $\mathfrak{2}$ uล ge breitete (S) Ү. Błätter geferbt, bie grunbitändigen länglich verfeftreiruto, in ben $\mathfrak{B}$ lattfftiel

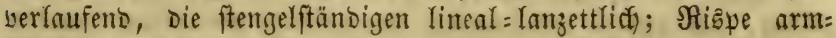
blitthig, abitefend, faft bolbentraubig, bie Alepte nach oben ge:

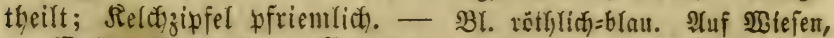

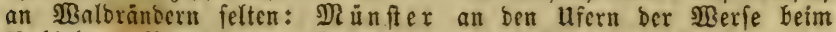
Nobisfratg, Bentlieim, Dortinun b in Bebuifhen am Edhurentwege, Sobter zivifaten seinfen uno \$olle auf Meferwiefen; auber biefen

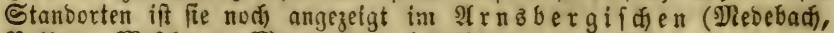
Brilon, Meiffeoc, STarsberg), bei \$yrmont, Rinteln an ber

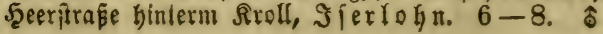




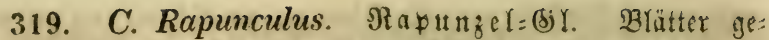
fet $5 t$, bie grunoftänoigen länglich=serfeffrteiruno, in ben Blatt: ftiel berfaufento, bie ftengelfätül. Yineal=lamzettlich; NRispe fait

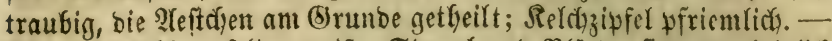

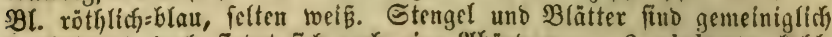
furzbefgart, boch finbet fich aud) cine stbänberung: $\beta$ glabrata fahyl, mit fleinern Bhäthen uno einfact)er Traube. Iluf troffinen Sisiefen, an

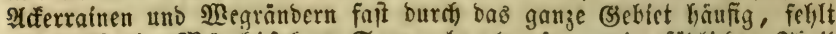

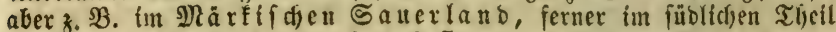

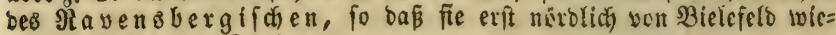
ber begints. $5-8$. $\hat{\theta}$

320. C. persicifolia. Pfirfid blättrige (3) গ. Blät= ter entfernt: feingefägt, bie grumbitänd. längliç= = berfe freteirunb, in ben Blattitiel verfaufend, bie ftengelfätäno. limeal=lnmzettlich, Trauben armbrütbig; Selchzipfel ranzettlich). - Br. auffalfend

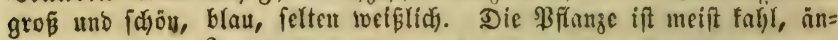

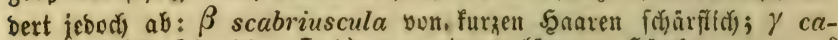
nescens (C. hispida. Lej.) von etwas längern Şärchen gratt; $\delta$

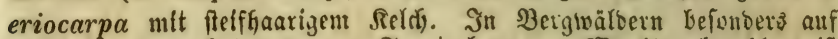
Ralfboben: burd) ben ganzen Teutoburger $\mathfrak{B}$ al' obmolf meift

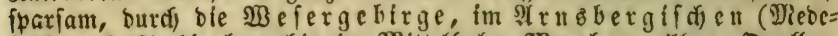

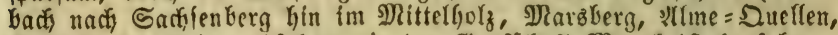

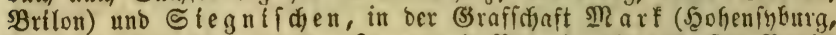

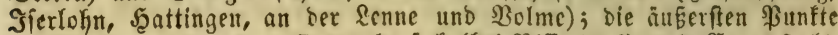

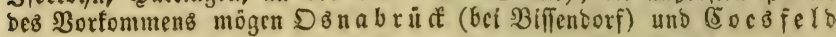
feitr. $6-8.24$

\section{** Blätter meht ober weniger fteifhaarig. $\dagger$ Blumen beutlid) geftielt.}

321. C. latifolia. Breitblättrige (3) Blätter

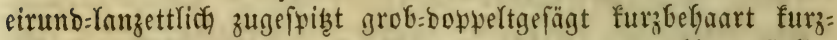
geftielt; Blüthenftiele winfelftränoig 1 blütgig traubig = geftelft; Relduzipfel eirund=Yanzettlidd; Stengel ftumpffantig. - 2 Zl. Felor

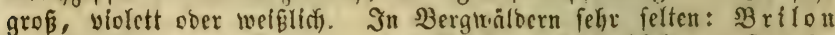

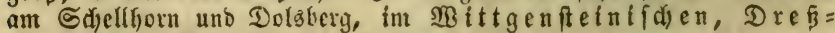
Iendorf im Sireiß Siegen. 7. 8. 4

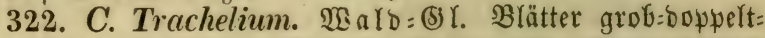
gefägt, bie untern langgeítielt Kerz̧örmig, bie obern längliç)

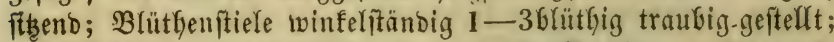
Relçzipfel cirmb:lanzettlid), Stengel focharffantig. - Bl. grop̂, Blau, zuw. weíflid). Ilbart: $\beta$ dasycarpa (C. urticifolia. Schmidt.)

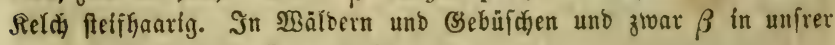
(̧̌egenb befonberz häufig. $6-8.24$

323. C. rapunculóides. Siried̂f ende (5) Y. Blätter ungleich=gefägt, etwaz raubhanag, bie untern faft berzförmigh, 


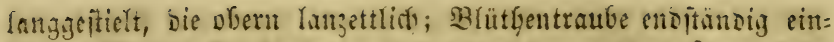

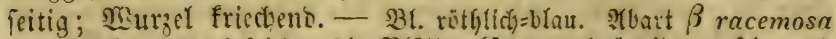
sie Trauke nifit cinfeitig, bie Blätter fürzer uno breiter. Şier uno

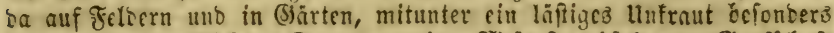

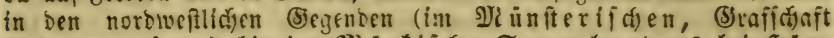

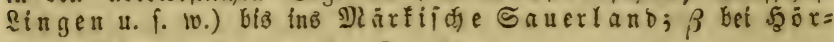
ter unb Ş⿻

\section{t† $B$ lumen fopfigsgebüfđelt.}

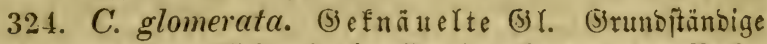

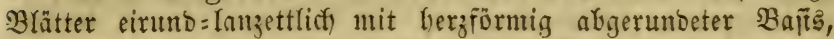

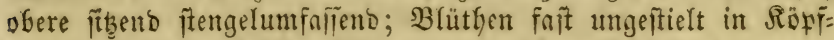
dert. - Bl. viorettblau. Die ganze Pflanje if balo futrzbarig, balb seld Eel)aart=grau, balb fur)!. Stharten: $\beta$ farinosa (Camp. farin. Andrz.) Etengel unb Untericite ber Blätter grauñilyig; $\gamma$ aggregata (Camp. aggr. Wild.) 4' forf, Blattîtiele vreiter uno ge=

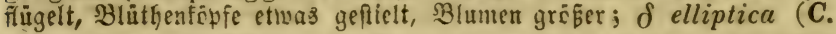
ellipt. Kit.) alle Blätter an (S)und abgerunoct ober int bẹt Blattittel yorgezogetr. 2fuf treffnell grafizen Etellen, befonbers auf Ralf, yom

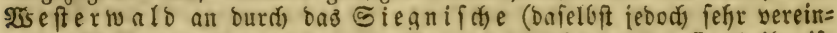

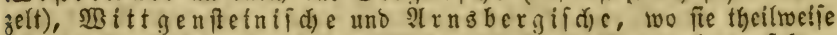

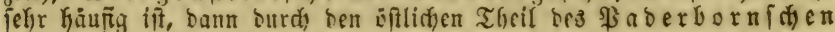

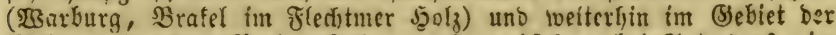

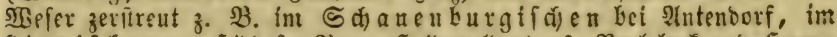

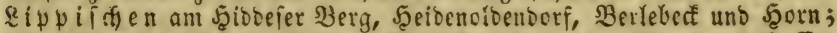

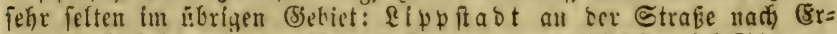
woitte linfż bei ber jungen Fappelyflanjung, ans twefllidjiten bei S trom= berg und Delbe auftreterio; $\beta$ bel $\mathfrak{B} a \mathfrak{b}$ urg mit Veronica pro-

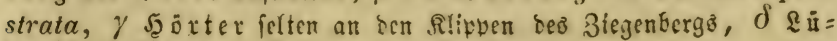

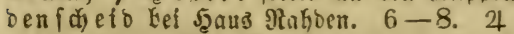

325. C. Cervicaria. Natterfopforätrige (3). BYätter Fleingefer6t, bie grumbftäno. Ianzettliç, in sen Blatt= jitiel weridymälert, bie ofern lanzett-linenlijes, bie oberiten iten= gefumfafletto; Blüthen ungeftielt in Röpfen. - Die ganze Pflanze

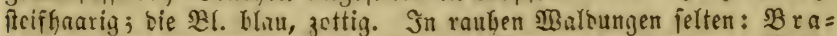
fel am Jmmenberg binter șembien in Nenge, im Sutfmer গBalb,

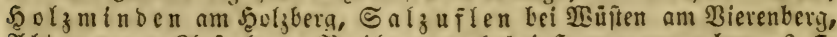

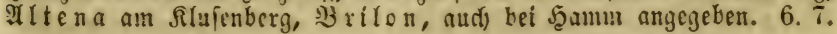

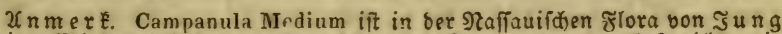

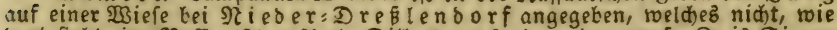

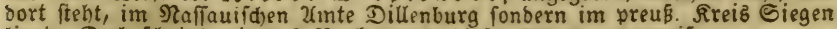

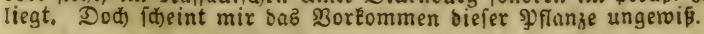

\section{3) Prismatocarpus. E'beritier. Bentifpiegel.}

\section{Pr. Speculum $\mathbf{f}^{\prime} \mathfrak{f}_{\mathfrak{r} r}$. (Campanula Speculum}

L.) Semeiner $\mathfrak{B}$. Stengel feldr äftig, Relthifipel bon ber 
Ränge Der Rrvne. - \$̧l. purpur=violett. Unter bem Getralbe ber

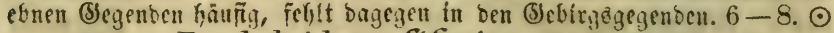

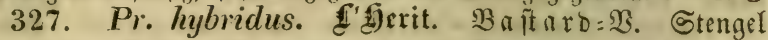

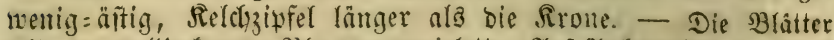
mitunter mellig=frans, 23. purpur=violett. Rluf Secfern befenters be

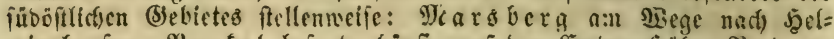

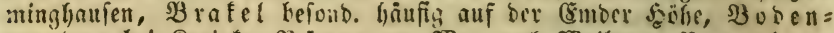

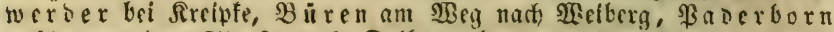
reditz yon sec Strafe nack Driburig furz yor bem Thore und am

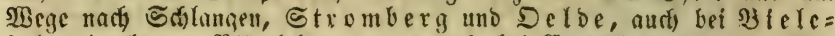
felo eimeln am $\mathfrak{B l o u m f e t e r g , ~ D a n n ~ n o d ) ~ b e i ~ E o e s f ~ f e l o . ~ 7 . ~ 8 . ~ \odot ~}$

\section{4) Lonicéra. (B) eiṕblatt.}

* Stenger fid windend.

228. L. Caprifolium. (5)arten= (5. Blüthen in Duir=

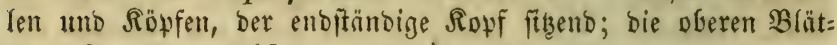

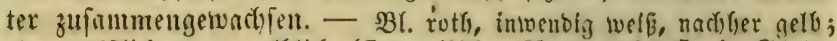
voer tweiglich, bonn grlbling (L. pallida. Host). Şäuffig in (Särten angevant uno fier und ba veriviloert; als willo angegebent una Nie be=

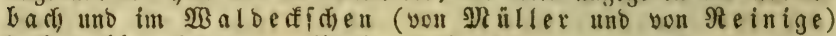

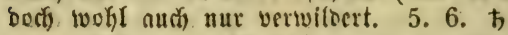

329. L. Periclymenum. ŞBild fitieften $\mathfrak{R}$ öpfen, $\mathfrak{B}$ lätter nicht zufammengewad) fen. - $\mathfrak{B l}$. gelb=

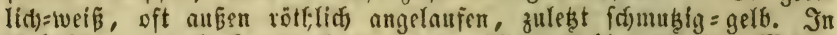

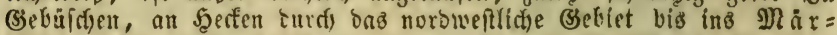

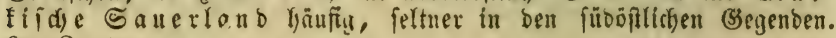
6 - 8 , 万

** Stengel aufred)t.

330. L. Xylósteum. Ją éf en=(3). Blüthenftiele 2blü: tbig fahl, ungefälyr fo lang als bie $\mathfrak{B l u ̈ t}$ then; Blätter oual

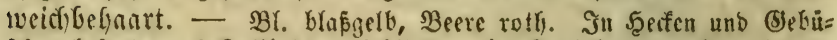
fichen befont. nuf Ralfboben, fe.jlt ganz im Tentoburgertwald und sem

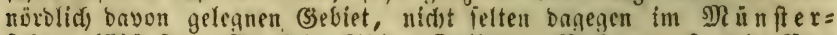

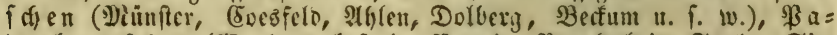
berbornforen (WGarburg bef. im Rappin, Brafel im Faulen Sie=

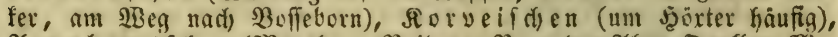

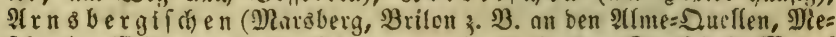

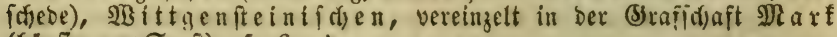
(Gäufig $\mathrm{tm}$ Socit). 5. 6. 万ิ

+331 . L. nigra. S(1) warzes (5). Bfüthenftiele 2= Glittyig fafl, mefyrmal: länger als bie Blütlyen; Blätter läng=

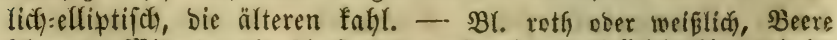

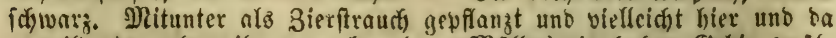

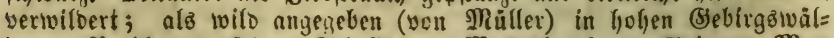

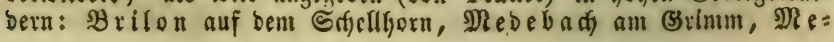




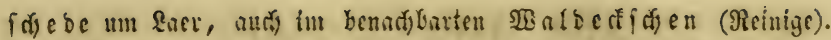
4. 5 . 方

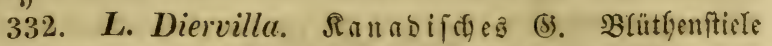

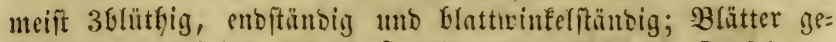

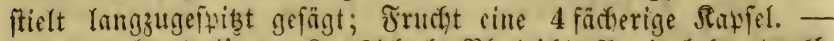

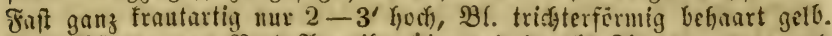

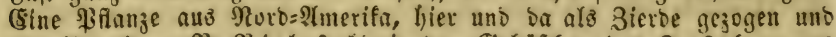

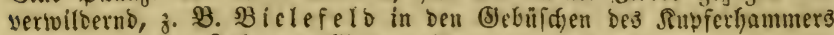
fófon feit vielen Jaghen völlig verwilbert. $5-7$. क

\section{5) Vitis. Meinftorf.}

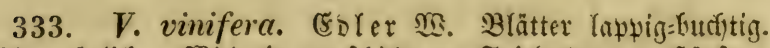

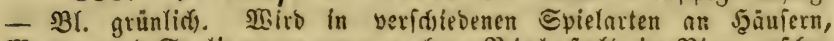

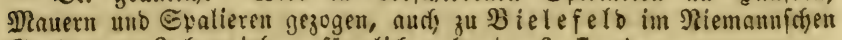
(3)arten am Jubannisterg formlid) gebaut. 6. 7. to

$\mathfrak{X} n$ mer f. Ampelopsis quinquefolia R. \& Sch. findet man bäufig twes gen feineb fid) roth färbenden $\mathfrak{E} a u b e \mathcal{B}(3-5$ zähtige $\mathfrak{B}$ lätter) an $\mathfrak{W}$ änben und Mauern gezogen.

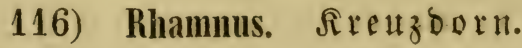

334. Rh. cathartica. Biemeiner $\mathfrak{R}$. Durnig, 2lefte

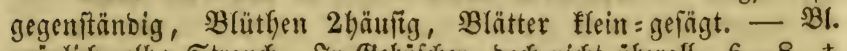

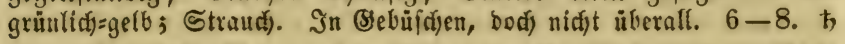

335. Rh. Frangula. (5) latter $\mathfrak{R}$ r. Unbemafînet, Iteite wechjelîtänbig, Blüthen zlnitterig, Blätter ganzranoig. - $B$ l.

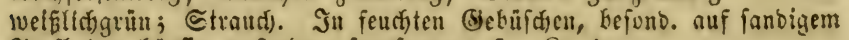
Torfloben ryäfig, auferdem fparfamer. $5-8$, h

\section{7) Evónymus. Spindelbaum.}

336. E. europaeus. (5) emeiner ऽł. Rronblätter

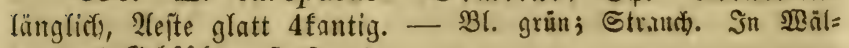

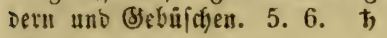

\section{8) Impatiens. Springfame.}

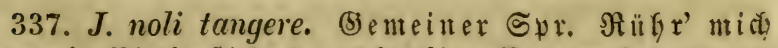
nid)t an! Blütfenftiele $3-4$ blütbig, Blumen bangento ge:

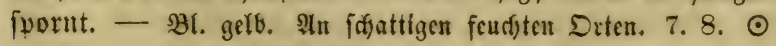

In $n$ mer. Claytouia perfoliata. Don. finbet fich völlig alz uncrout verwildert o $\mathfrak{B}$ i elefeld im $\mathfrak{B}$ üdartiden (Sarten, vielleidt früber ein: mal alb semiifepflanze gebaut. 


\section{9) Viola. Beildaelt.}

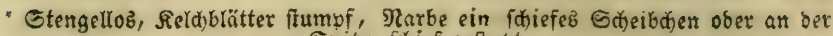
Spize foriff geftukt.

338. V. palustris. Sump S̈yeildien. Brätter nieren= förmig geferbt, nebit ben Blattfitielen fabl; Warzel friedtend. 31. bla $\hat{B}=$ lifla, bie mittleren Sivnblätter mit einem violetten Stridh, bas ungepaarte violett gentert. Abinderung: $\beta$ major bie fpäteren

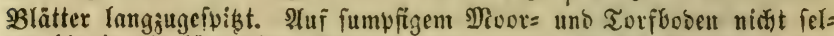
ten bis in bie fürlidgiten Bsebirge, fehlt aber z. 3 . Bei Dortmunto und

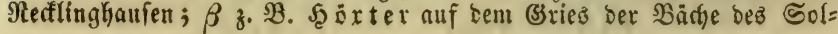
ling. $4-6.24$

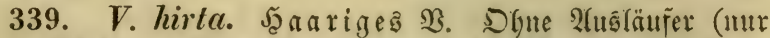
die feitenftändigen Ctämmochen berwandein firf) zuletgt in furze 2(uछläufer); SBlätter herzförmig gejügt, nebft ben Blïtbenitielen raudbarig. - 31 . violett, gerucblog. 2abunerung: $\beta$ brevicalcarata mit fehr yerfürztem ober faft'fehlenbem Sporn. In Niäloerm

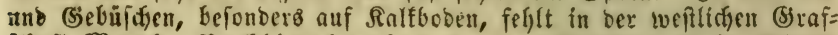
idaft $\mathbb{R a r f}, \mathfrak{R}$ fflingha afen nux am Blanfen; $\beta$ in Gärten uno auf fettem 2 arbboben. 4. 5. 4

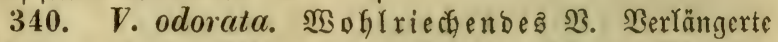

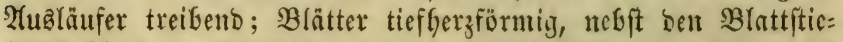

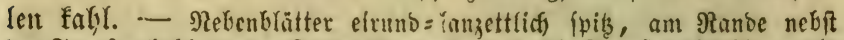
ben Franien falyl, an ber Evlke feingewimpert, bie Franien viel fürzer alz

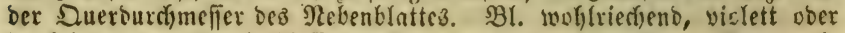
bunfel=purpurrotg mit blafferem Ragel uno etwis bunfleren शloern, bie mittleren Blätter bebärtel. Im Soumer finbet man zu Zeiten yc1= fümmerte aber bod' fruçtbare Blütfen. Âtbäberungen: $\beta$ major

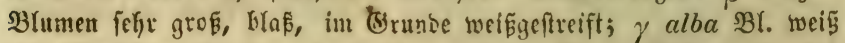

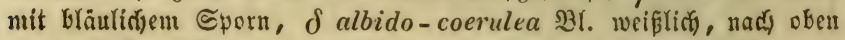

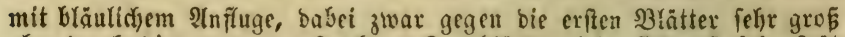
aber burs) bie grabevorgeffrecten Rronblätter (Die fich) erfit feftr pät

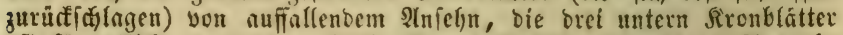

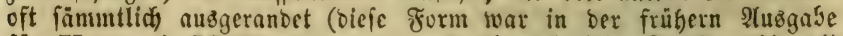
für V. suavis $M . B$. gensmmen, uno obwehl biefer Jrthlym hiermit zurüfigenommen wiro, fo bleibt fie bodi immerfin fefyr eigentfumlidy); $\varepsilon$ eflagellis bie Błumen un bกв Tuppelte fleiner, bns eine ober an= bre ber mittleren Risnblätter mitunter bartios, baz untere melyr ober wentyer aużgeranbet, bie Blätter fleiner, faf)ler uno längergefitelt, bie fpäteren im Sommer länglich herzförunig mit einer tiefen breiten $\mathcal{B} u$ dust, গ⿻

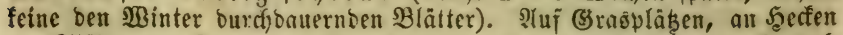
um Stäbte uno Dörier häuñ?, felylt aber meif auf Sano= und oft auch

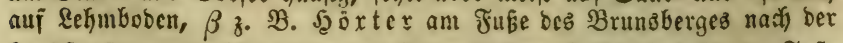

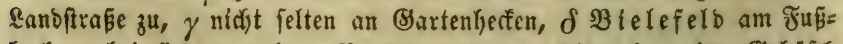

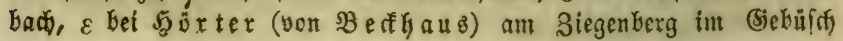




\section{Monogynia.}

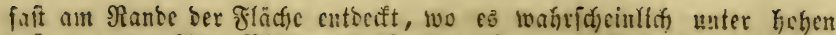

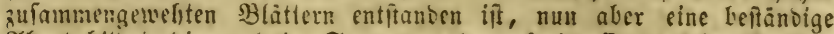

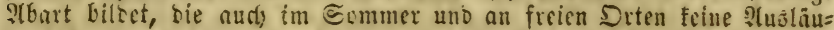
fer befumnt, uno sie für cine cigene STet fönnte angeichen werben, wenn

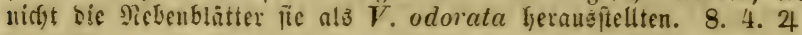

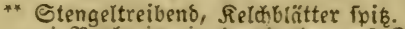

$\dagger$ Rarke in ein berabgebogenis Edinäkeldien verid)mälert.

a. Etengel nieberliegens:aufitrebend.

† 341. V. arenaria. Des. @inbueildyen. Blätter frerziörmig ftump fleingeferbt, sie untern herznierenförmig;

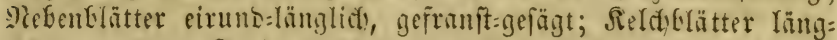

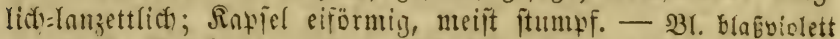

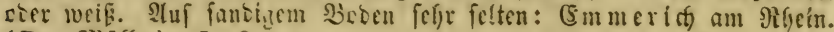
(Dr. গlüfler). 5. 6. 4

342. V. sylvestris. fam. Sูaldueilenen. Blätter fergförnig, eirund ober faft nierenförmig, furłzugefpiţt, sie untren ftumpf; bie mittleren fiengelftänsigen Plebenblätter lan: zettlich, nad) sorn berfwmälert, gefranft:gejägt; Reldhblätter Ian:

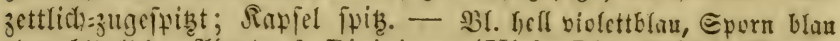
c'te: b!âulid'. Stea:t: $\beta$ Riviniana (Viola Riv. Rchb.) Blumen

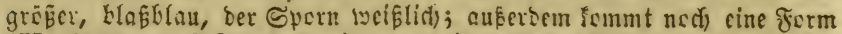
( $\boldsymbol{V}$. degener. Schweigger.) vor mit unteren frenentragenden alier unfructitearen, oferen tronenlofen aber frudstharen Bläthen, bie cift cine bebeutente Ringe (biz $2^{\prime}$ ) erreidten fann. In Tisatoungen unt (5)

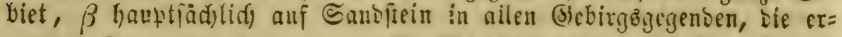

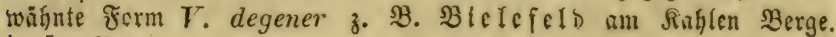
4. 5.24

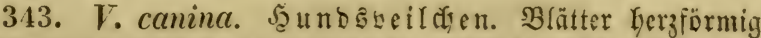
länglict=eiruno fpiblid), bie untern ftuntw; bie mittlern ftengelfit. Sebenblätter länglict):Ianzettliđ, mef)rmtals̆ fürzer algె ธer Blatt:

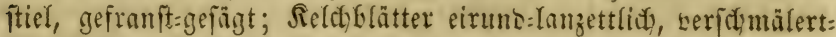
ipis; Ratfel gefunt : ftumpf mit nuggeferzter Epize. - Sporn meift boppelt fo lang ale bie Stnhängfel bes Seldis, SBl. viulett mit

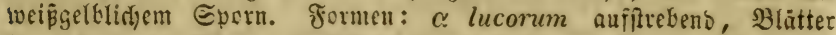

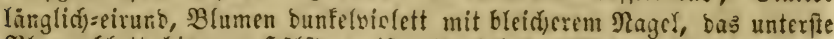

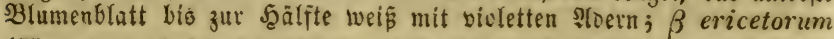
(V.ericet. Schrad.) niebrig, faft niebergeptrefft in allen Theilen fleiner, Blumen bláblau, Sporn gelblid); $\gamma$ albida ( $\boldsymbol{V}$. canina $\beta$.

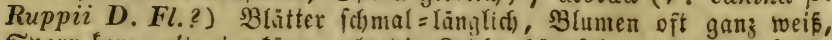
Eporn furz, mitunter fürzer als bie Seldfanhängfel - eine auffallenbe

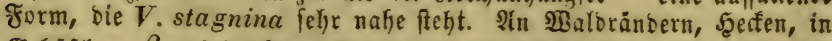

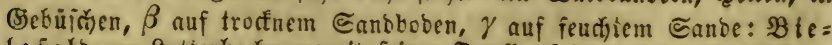
le feld am \&utterbarise unweit feiner Quefle, \&übenf(t) eib an einem

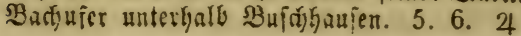


b. Stengel aufredst.

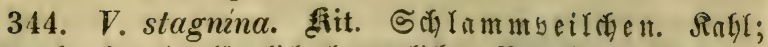

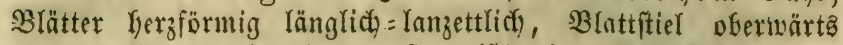
etwas geflïgelt; bie mittleren ftengelfitänbigen Nebenblätter Inn: zettlich zugefpizet, gefranit:gefägt, unt bie Sä̈lfte fürzer als ber Blattítiel, bic obern eber fo lang als berfelbe. - Eporn meift

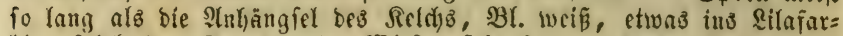

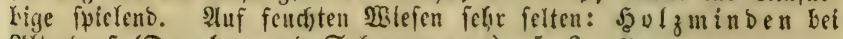
शiltendorf (D) a ber und $\subseteq$ त) a umann). 5.6. 24

345. V. elatior. fries. (V. persicifolia. At. \& fi.)

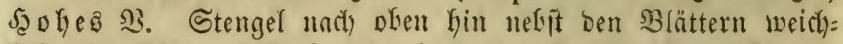
Yelonart; Blätter feicht=ferzförnig lanzettlich), Blattftiel geflügelt; Die mittleren ftengelftäns. Nebenblätter blattartig, länglich:lan= zettlid), cingefdrnitten=gezäfynt, länger nls Der Blattitiel. Epurn to lang ale bie Reldyanfyangfel voer cin wenig länger, $\mathfrak{B l}$

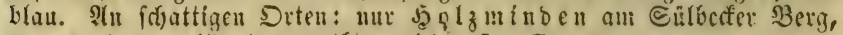
too es als vermilbert angegeben wirb. $5-7,24$

346. V. mirabilis. Sonderbares গु. Etengel ein= reibig:bebant; $\mathfrak{B}$ lätter breitberzförmig furz-zugefpizt fleingeferbt, bie untern faft nierenförmig, Blattitiel am Riele belyant, Ne= benblätter länglid) = Inmgettlict) zugefpizt, bie obern furgbewint=

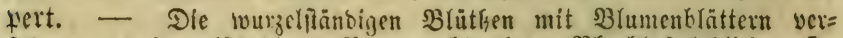

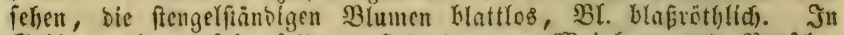

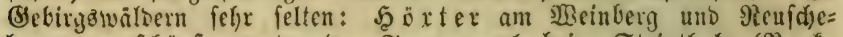
rerg, am fobünfen unter ben Tannen nah betim Stcinthale (BP eff =

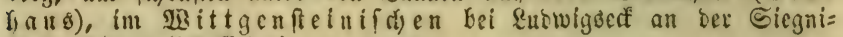
fdoen Ërānze (Suffrian). 4. 5. 4

†t Narke groß, Exugförmig.

347. V. tricolor. Dreifarbiges 23 . Stiefultter= (1) en. Stengel fantig, Blätter geferbt, Nibenblätter leierför: migffiescripaltig, ber Endzipfel geferbt. - Sporn faft boppert io lang als bie Relwanfyängfel. Formen: $\alpha$ vulgaris bie frone gro: fer als ber Jielch, biolett oft mit Sammtylanz, bie gevaarten \$Blätter am Siagel bleicher ober toeíflid) mit 3 Duntlen Sinien, baz ungevaarte Blatt an (Srunde gelb mit 7 bunflen Rinien, ber Spoun blapsidett; $\beta$ bicolor (Viola bic. Hoffm.) wie vor. Dori) Die ganze Şłume bun= befviolett, nur mit gelbem Flect auf bom ungepaarten Blatte; $\gamma$ arvensis ( $\boldsymbol{V}$. arv. Autt.) Rrone fo lang alz ber Reldi) ober fürzer, weī̄, bie belben obern 3 lätter fyelfvivlett = überlaufen, basె ungepaarte am Srumbe gelb, ber Gporn blajuiolett; $\delta$ saxatilis (V. sax. Schm.)

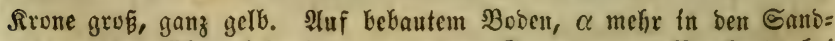
gegenben ber Elune, fefir folten in anbern (Stegenden, $\beta$ Braftwebe bet 3 ielefelo unter $\alpha, \gamma$ überall, $\delta$ gleinfalla bei Bradtwebe unter $\alpha$. $5-9$. $\odot$ unb $\$$ 


\section{0) Ribes. Sulfannistrabe unb Stadel= beere.}

* Unberwaffinet, slüthen traubig: इ ohanniatraube.

348. R. alpinum. 2llpen= . Stranbeere. Trau=

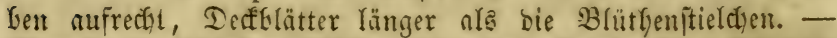

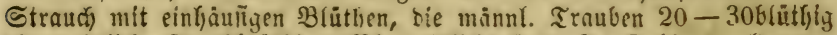

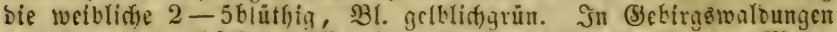

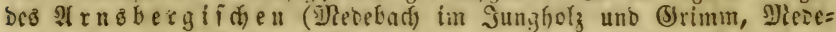

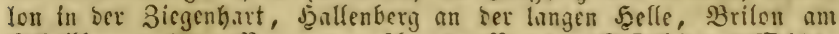
Edfellforn uno an Berge gegenuber ber Bartiere Reñeffe) uno sis it $t=$ geniteinlfiden; bunn in ben niebrigen Berggegenten an Seeffen

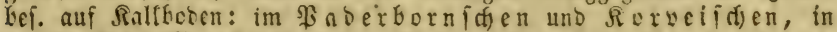
ber (Siafid). SNa arf (Seept am Brúberwalle und fonit in ber Stabt,

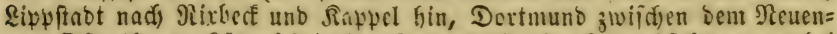

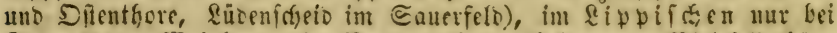

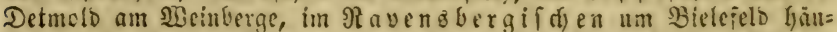

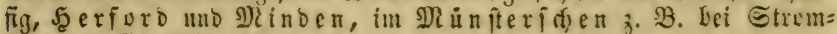
berg unto Eucớcels. 4.5. 万

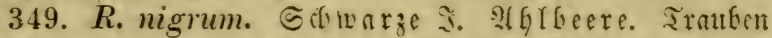
fiaumbarig hangend, Derfblätter biriemlich, Reler glorfig. -

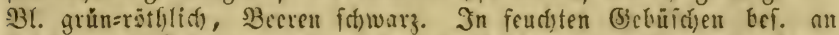
Bädjen und (Sxâben: zerîreut in sen (sebirgen des. Siegnif dien,

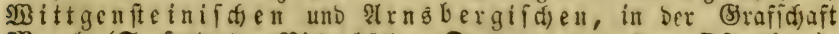
Slart (Soeft in Der Niederbortbe, Dortmuno por bem Silentfore),

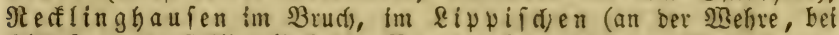

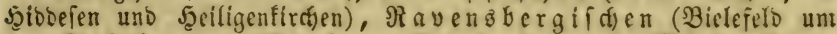
ben Rupferfammer, Dornbers, Tatenfaufen) und Slinbenf

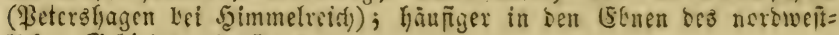
lidicn (3ebiete3. 4. 5. 古

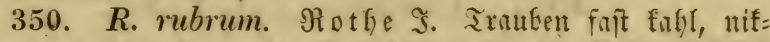
fento uno zuleb̧t hangeno; Terfblätter eirutro; Selde ziemlict) fladt. - Bl. gelfgrün, Beeren roth ober meißfich. Stbart: sylcestre

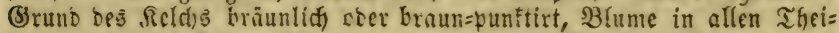

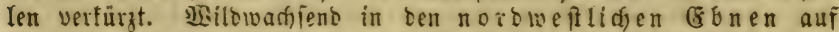

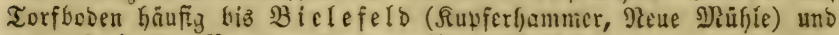
zwar $\beta$, in ben Berggegenden verwifitert. 4. 5. $\hbar$ ** Stadjelig, Batithenfticle 1-3biüthig: Etadelbeere.

351. R. Grossularia. Deff́blätter 2-3, Reld̆ gloffig,

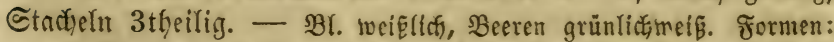
a glanduloso-setosum (R. Grossularia. L.) Frufiffnoten uno $\mathfrak{C}_{e e}=$ rer mit brüjentragenden Borfiten befegtt; $\beta$ pubescens (R. Uva crispa L.) Frudjtfnoten mit furzen weidjen brüjenlofen șarren bejeşt

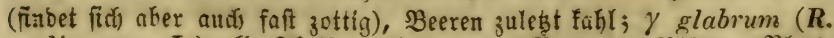
reclinatum. L.) alle Tlieile fahl, nur ber Nano ber Blâtter, Blatt= fitele, Deff́bläter unb Reldi) zipfel Getwimpert. 2uf untebauten feinigen Drten, an Nauern unb f̧efen băufig unb zwar $\beta$, ble Form $\alpha$ fommt 
aud) Gäufig sor aber mur verwilbert, $\gamma$ frjcint bIos burd, bie Rultur entftanden zu feir. 4. 5 . to

\section{1) Hédera. E $\mathfrak{f} \mathfrak{u}$.}

352. H. Helix. Blätter winflig=gelinpt, Eiejentigen der blitifenden Flefte ganz eirund zugefpist. - Rlcttrmber હtrand),

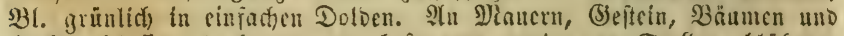

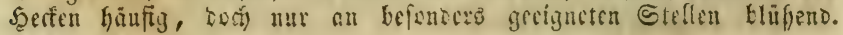
9. 10. $\mathrm{t}$

\section{2) Ilécebrum. Sinotpelbrame.}

353. I. verticillatum. Stenget nieberliegend fabenför= ntig, $\mathfrak{B l u m e n}$ quirlig. - Bl. weí, Formen: a mbens Etenget rötg!lid) angelaujen (bet uns getwóthntict)); $\beta$ pallidum ganz grün, in aflen Theilen ïppizer, bie untern B̧lumen oft einzeln in ben $\mathfrak{B}$ ratt=

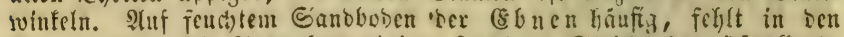

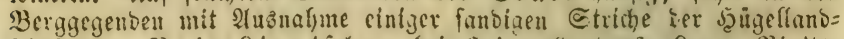

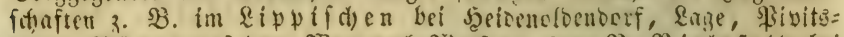

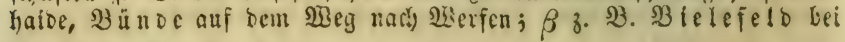
Stielfertt. $6-8.24$

\section{3) Glaux. Silldyaut.}

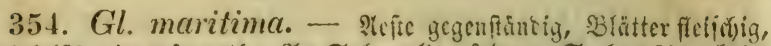

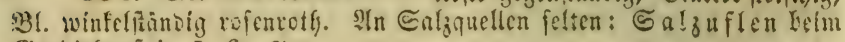
(3) rabirfyaufe! 5. 6. 4

\section{4) Thesium. Rcinblatt.}

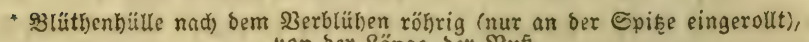

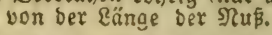

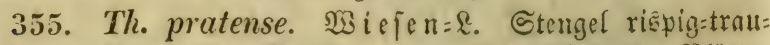

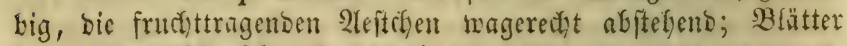

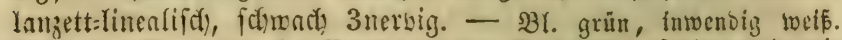

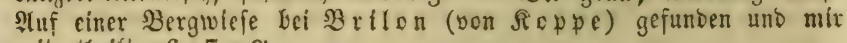
nitgetbeilt. 6. 7. 4

+356 . Th. alpinum. $2(1 p e n=\Omega$. Stengel mo 2 fefte

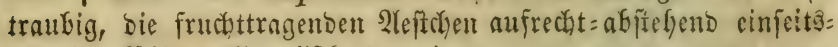
wendig; Blätter Yinenlifach 1 nerbig. - 3l. wie yor. SBirb yon

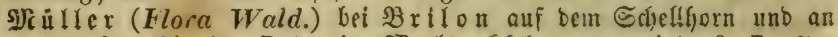

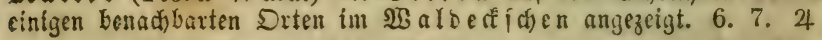

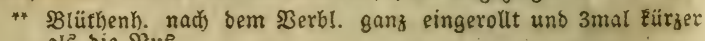
alह bie গนu.

† 357. Th. montanum. Berga 3uleţt bielftengelig, Etengel fyramirenförmig=riß̨pig mit ab= 
ftelyenben 2leftct)en, Blätter Yanzettlid) ober Yineal = Yanzettlich

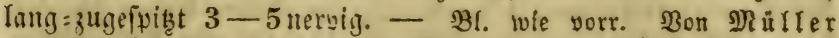

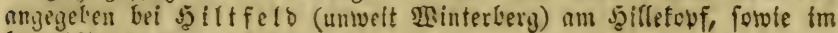
Eenadjbarten $\mathfrak{B a l}_{\text {beffidjen. }}$ 7. 8. 4

\section{Sつromung Digynia.}

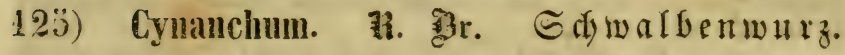
358. C. Vincetoxicum. ¥. (Asclepias Vinc. L.) Bläter ferz= eirumb, fefo zart gewimpert. - Bgl. wela. Shuf fteinigem Booen ber Raffberge: im wittigenfeintiden,

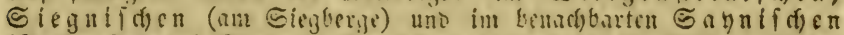

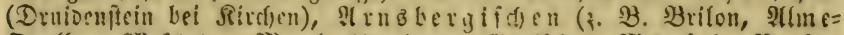

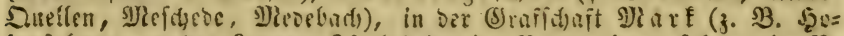

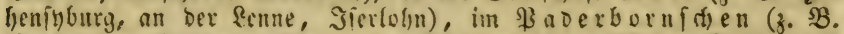

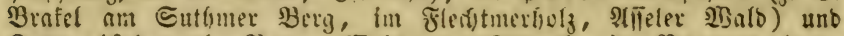

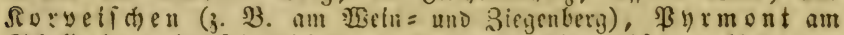

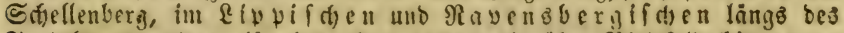
Teutofurgerwaldez (fideint aber nidft neit über Bielefelo hinaus zu

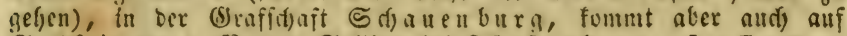
Sanbftein vor 3. B. am Solling bei Gürftenberg. 5-7. 4

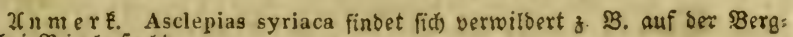
Iuft bei $\mathfrak{B}$ ielefelo.

\section{6) Gentiana. (E)zian.}

\section{- ๔đIund ber Blume nact.}

359. G. cruciata. $\operatorname{R} e \Perp z=$ (5. Bhtmen quirlig fiţent

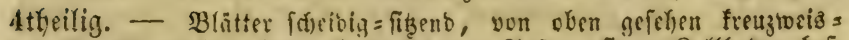

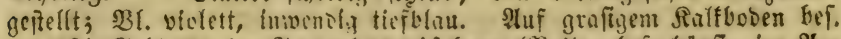

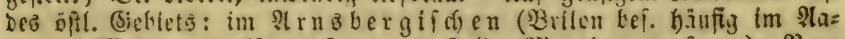

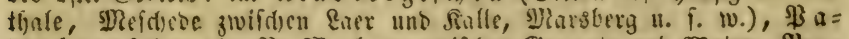

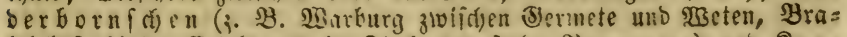

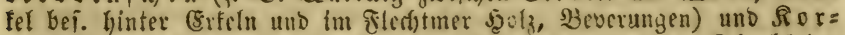
veif(t) en (häufi\} bei șexter), Eveft auf́ Triften ber Dberbortbe,

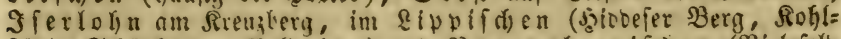

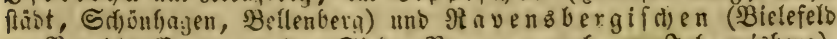

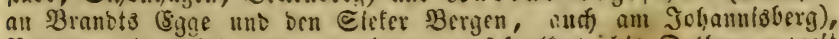
Byrmont, auf ber Stromberger Sethelferte bis Dolberg untwett Damum, Eoesfeld auf bem Berge in Der. Rnipe, Darup an ber Rapelle unb am Bantholze, Billerbeff, Sh helna. $7-9$. 4

360. G. Pneumonanthe. (3) e meitler (5. Bhtument

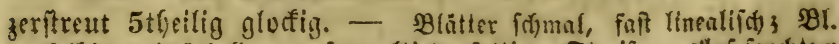

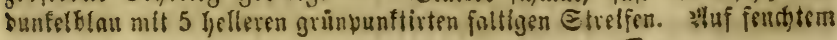




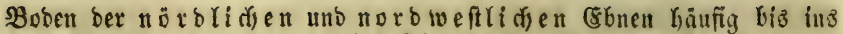

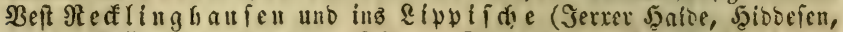
\&age, Büfingfel(s) auferbem felten: Dortmun bef Weflinghofen,

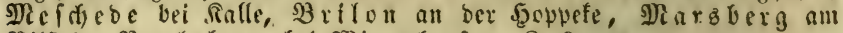

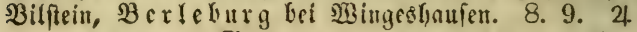

+ 361. G. verna. Früfyling $=$ (5. Etengel 1 blï: thig, Srone 5ppaltig. - Blätter elfiptif̣) ober lamzettlich, am

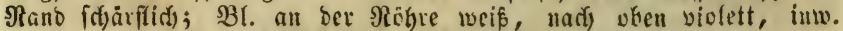
tiefblau. Stuf Bsbirgsiwiefen fefir felten: 5etburn in angränzenten

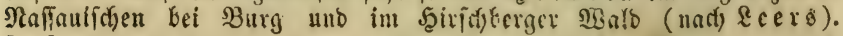
5. 6.24

362. G. ciliata. (5) \& franfter (5. B(umten giffel= ftänoig 4fpaltig eingefonitten=gefranft. - Báme ticfulou. Stuf graftgen Stelfen ber Ralfberge: Durd) Den ganzen Teutoburger =

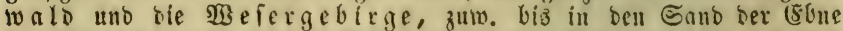
herabiteigent, atid) auf ber Ralfhügelfette sen Stromberg und scr= jenigen yon Aftenberge; ankerdem zeriteut: $\mathfrak{B}$ rifon nad, bem

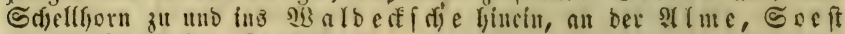

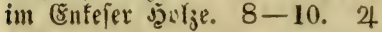

** Sd)luns (d)uppig= bebärtet.

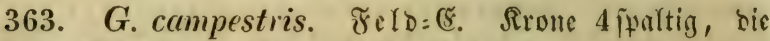

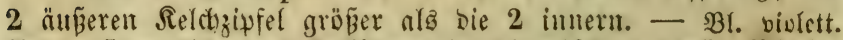

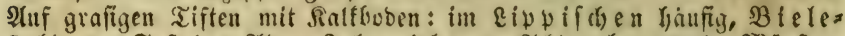

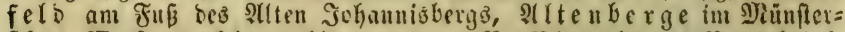

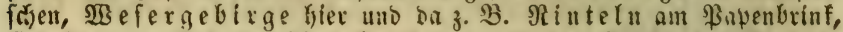

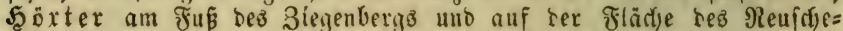

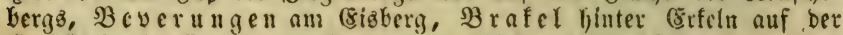

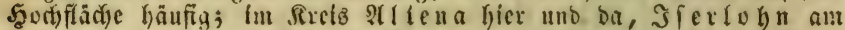

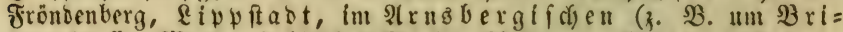

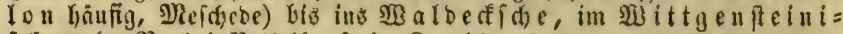
fdien (z. B. boi Bettelfauien). 8-10.

364. G. germanica. Deutider (5. Rrone 5 funt= tig; Stengelblätter eiruno, nach ber Guibe verfid)mälert. -

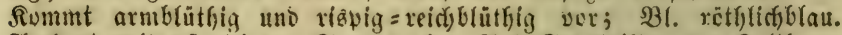

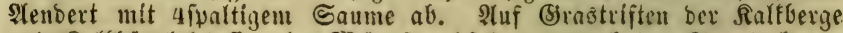

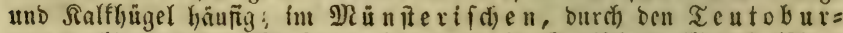

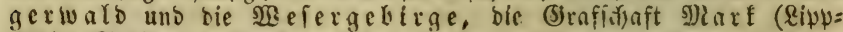
ftabt, Soeft auf ber Dlerborbe, fehit aber im gebirgigen weftlichen

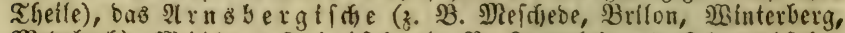

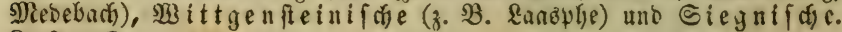
8. $9 . \odot$

365. G. Amarella. Bittrer (ธ. Rrome 5ipaltig; Sten:

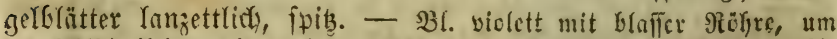
bic Säffte Eleiner als worige, inbert auds 4 fpattig ab. शreart $\beta$ uliginosa ( $G$. uliginosa. Willd.) niebrig $2-3^{\prime \prime}$ hudf, Blätter lan=

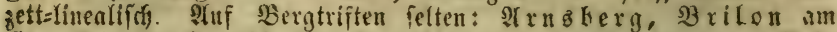

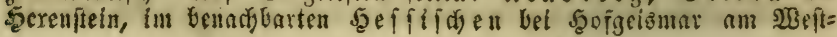




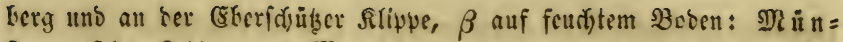

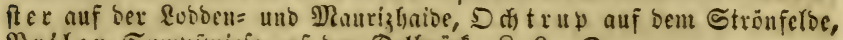
Brilon Sumpimiefe auf ber Dellurïf. 8. 9. $\odot$

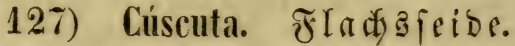

* Keftig, şlüthenÉnäur auf ein Decéblatt geftük̨t.

366. C. europaea. (5) eme ine Ff. Rronröfre whţlid,

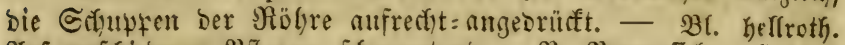

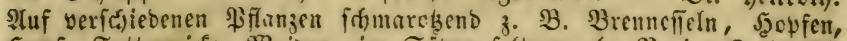

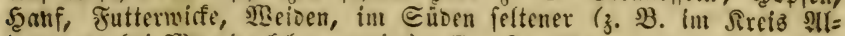

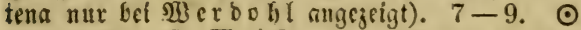

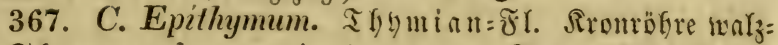

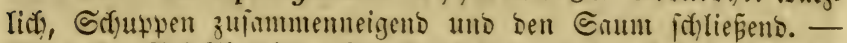

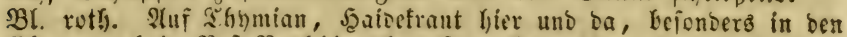

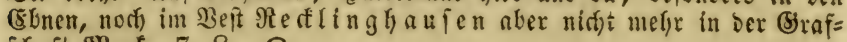

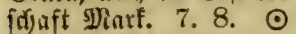

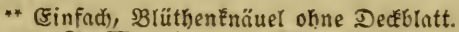

368. C. Epilinum. Whis. (Einfa die Fl. Rrontöfre

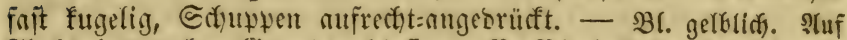

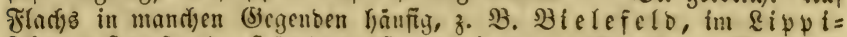

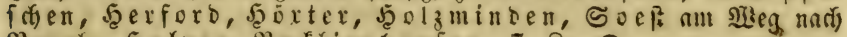

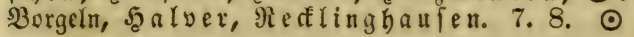

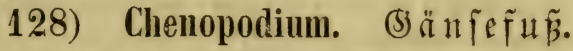 \\ * slätter edéig. \\ $\dagger$ slätter 3edig = foiebförmig ganzranoig.}

369. Ch. bonus Henricus. (Blitum bon. Henr. $\mathfrak{A x}_{\mathfrak{c y}}$.)

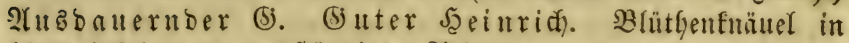

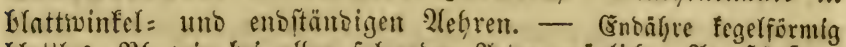

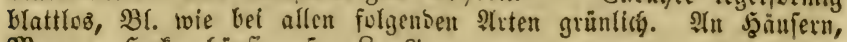

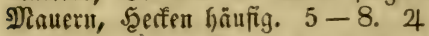

It Blattter herzförmig buästig=excig.

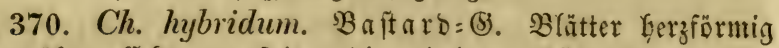

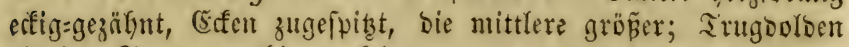
riąpig; Samen grubig:punftirt. - (5)

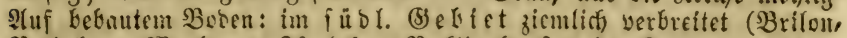

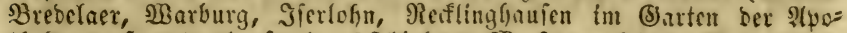

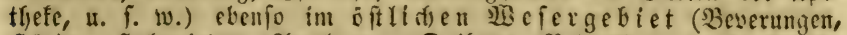

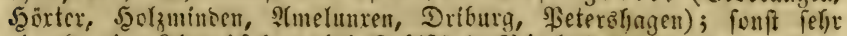

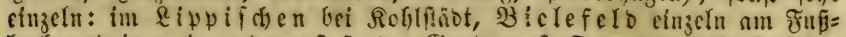

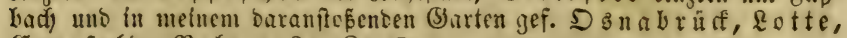
Eoezfelt, Bzeren. 6-8. $\odot$

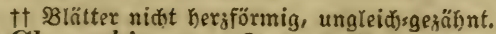

371. Ch. urbicum. Stnot=@is. Blätter 3 effig, ant Brumbe meiit in ben Blattfitiel sorgezogen; Blïtfenfnäuel in 


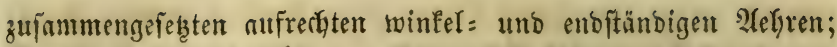

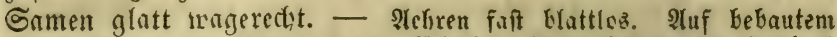
Boden felten: im Rippifien, BBielefelo in (Särten an JuBbad)

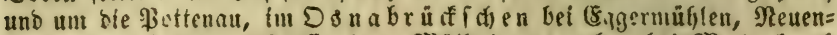

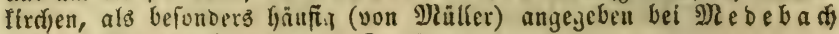
unb im $\mathfrak{x}$ a loeffiden. 7.8.

372. Ch. murale. $\mathfrak{N}$ a uer=(5). Blätter fleif̧chig=iglänzeno rautenförmig:eiruno; Trugooloen auล̇ुefpreizt blattlos; Samen

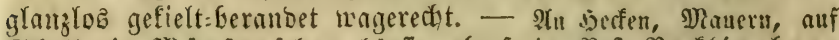

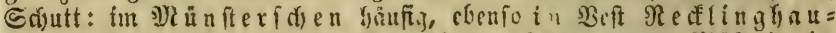

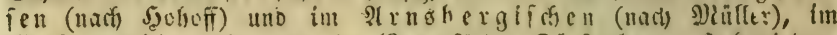

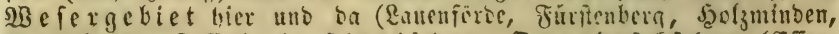

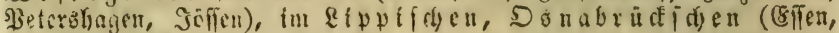

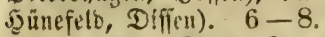

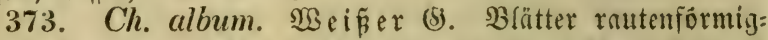

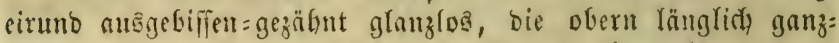
ranoig; Blütfenitans fait blattloz; Samen glatt glämeno. Formen: $\alpha$ spicatum (Ch. album L.) weißmeflig, Blätfenfnăuel äfrig zufammengeftellt; $\beta$ cymigerum (Ch. viride L.) grün, 2łtü= thenfnäuct truģolbig; $\gamma$ viridi-album (Ch. glomerulosum. Rchb.)

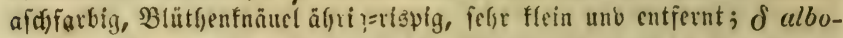
viride (Ch. paganum Rchb.) grün, Blütfstifn. g̣rob, in pyramloen= förmigen olchtgebrüngten Aehren; $\varepsilon$ riparium. Boenningh. auв̈gebrel=

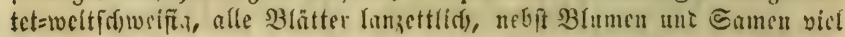

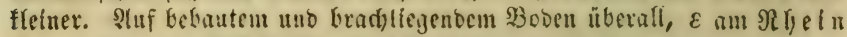

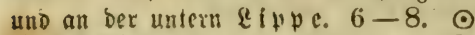

374. Ch. opulifolium. Sđdrad. ๔ đ̂neeballblätt: riger (5). Blätter rundlid)=rautenförmicy, fạt 3 lappig, fef̣r ftumpf, auลgebiffen:gezähnt, bie obern elliptifd)=lanzettlict); Trug:

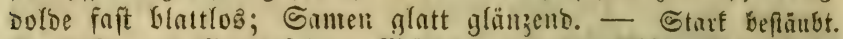

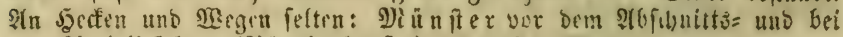

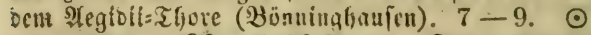

375. Ch. ficifolium. Sim. Feigenbrättriger (5).

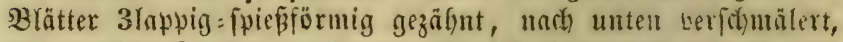
Der mittlere Rappen verlängert länglich) =lamzettlich ftumpr, bie obern Blätter lineal=lampettliç ganzronoig; Camen glänzeno eingebrücft:punftirt. - Etengel geifreift edfig, an ben Blathwinfeln purturtoth, 23lumenftund fafi blattlos. Itn 223eigen, Dirfern felten,

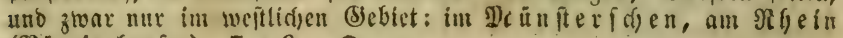

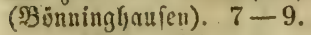

376. Ch. glaucum. (5) raugrüner (5). Blätter läng: lidu ftumpf entrernt:gezälnt, unteri. graugrïn, neblig; Gamen glatt, aufredut uno wagetedt. - Nicovion, felis ätig, faftig, tahi, cft rothgefürbt; Trauben bidjt blattloo. 2luf Edjutt, an STegen: tu 


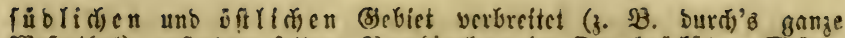

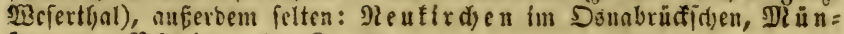
fter, am $\Re$ hein. $6-8$. $\odot$

377. Ch. rubrum. Rother (5). Blätter fleifdigglänzenb rautenförnig 3ecfig buthtig:gegälnt; 2lebren nufred)t beblättert; Samen glatt aufredyt (mur bie ber enbftündigen Blütfdyen wageredit). - Stengel furdjig rotfigeftreift, aufredst=ruthenförmig

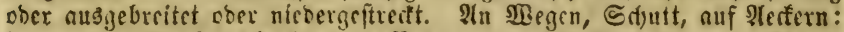
im ganzen $\mathfrak{B}_{3}[\mathrm{f}$ th

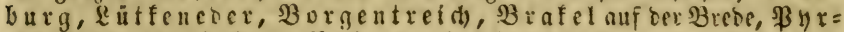
mont bet ber Giline, $R e f m e$, in Rippifden bei Salguften, Ectieber, Blomberg, Bi\}

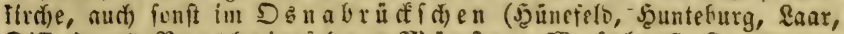

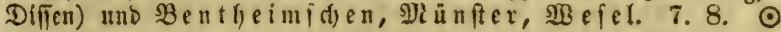

* Blättir weber ed fiz nod) gezännt.

378. Ch. olidum. Curt. (Ch. Vulvaria. L.) Stin= fenber (5). Blätter rautenformig=eirund; Trauben winfel: unb

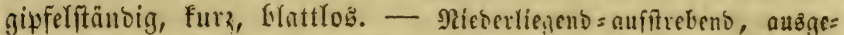

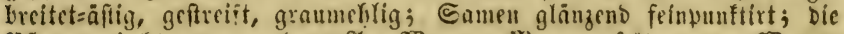

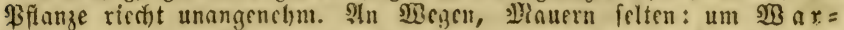
bu $\mathrm{rg}$, 3. B. am Sfenberge an ber . Rloftermaucr, und im benadjbarten

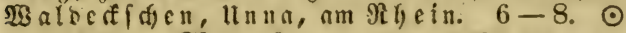

379. Ch. polyspermum. Bielfamiger (5). Blätter eiruno ftactielfpizig fall, Trauben lodfer blattlog. - Snmen glänzent, fefir frin punftirt. Formen: $\alpha$ cymoso-racemosum Traube

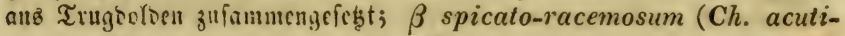

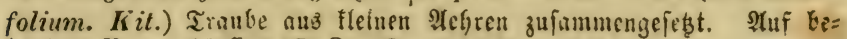
bautcu Boden bäufig. 7. 8. ○

\section{9) Atriplex. Meloe.}

- SBlumen vielehia, weiblid)e Blüthenhülte biz auf ben Bruns getheilt.

380. A. hortense. (\$) a rtenmelo e. Blätter Gerzförmig= 3erfig gezäfnt, bie obern länglict), 3effig, foft fpiefförmig. -

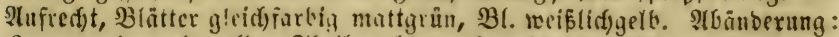
$\beta$ sanguinea in allen Theilen blutroth geförbt. SRire gebaut in

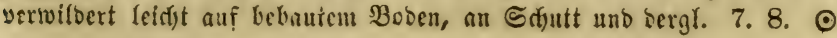

* Blumen einbäufig.

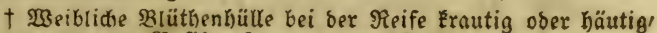
nur an ber $B$ afiz zufammengetwadjén.

381. A. patulum. (A. angustifolium. Sm.) $\mathfrak{2} u \xi g €=$

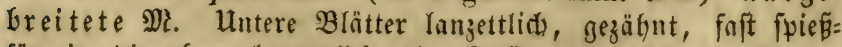
förnig, bie obern lanzettliç), bie oberftent linealif(t). - Dic un=

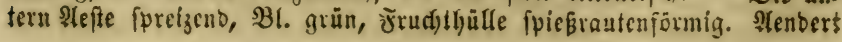


mit Blö Yanģettlichen sier Yinealifanen ( $\beta$ angustissimum) Blättern

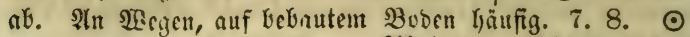

382. A. latifolium. 10ablenb. (A. patulum. Sur. A. hastatum. Poll.) Breitflättrige 9li. Untre Blätter. 3erfig:fpiefförmig gezäGnt, bie obern fpiefförmig=lnnzettlida), bie oberften Inuzettlich ganzranoig. - Die untern slepe weit ausge=

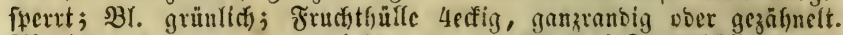
Slbarten: $\beta$ microcarpum (A. ruderale. Wallr.) Frudd)tyülle cirumb, ganzrandig uno nut fo lang ober frum länger alz ber Samcu; $\gamma$ sa-

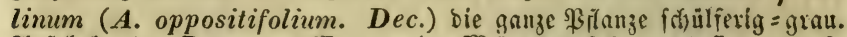

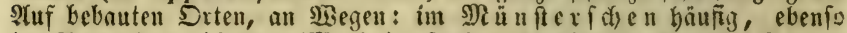

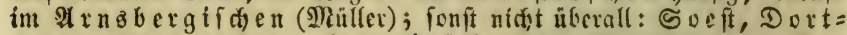

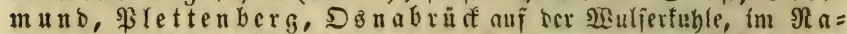

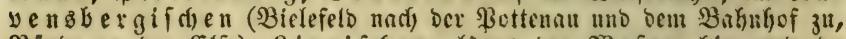

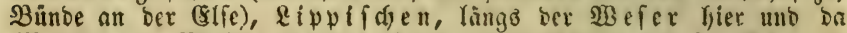

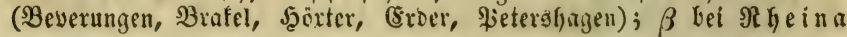
und Diffen (Bönninghaufer), $\gamma$ S ocft am Salzfuring bei \$arabiç,

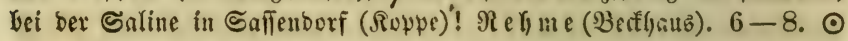

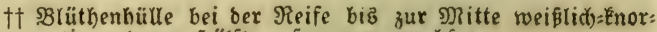
pelig uno zur Şälfte zufammengervad)fen.

383. A. roseum. Rofenmeldc. Bä̈tter eirund:3effig

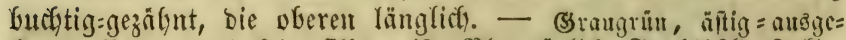

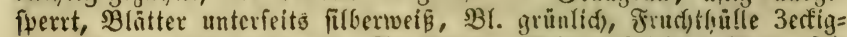

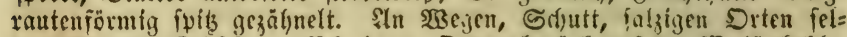

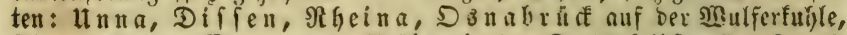

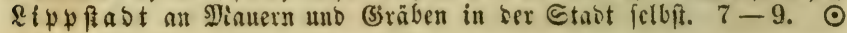

\section{0) Beta. Manguld.}

384. B. vulgaris. Itntre $\mathfrak{B}$ lätter ciruno ftumpf, oberc rhombifich:eiruno. - N(barten: $\beta$ Cicla, gemeiner $\mathfrak{M}$ a ngurb,

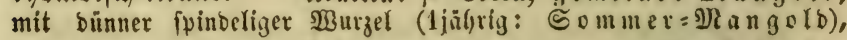

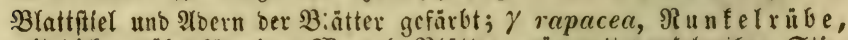

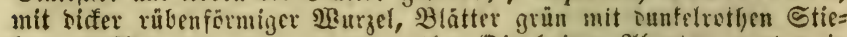

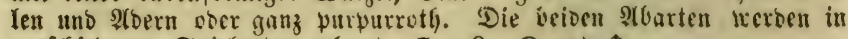

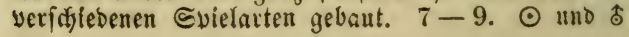

\section{1) Herniaria. şo $\mathfrak{u}$ d f $f \mathfrak{i} \mathfrak{u t}$ t.}

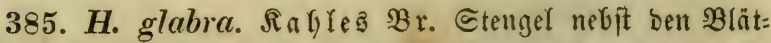

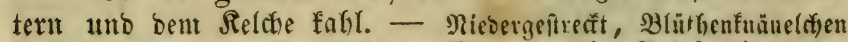
Grattuinferfitanbig, melft 10 blürthig; 3 l. gruingelb. SHuf fanbigen ober fteinigen Triften häufịg. 7. 8. 24

386. H. hị suta. Befharteż Br. Stengel nefít ben Blättern uno bem Reldue furz= aber bidhtbefanart. - Seldyzipiel

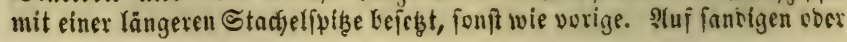




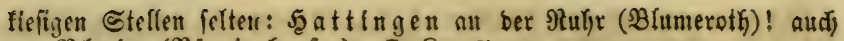
aul $\Re$ heill (Bjonninghaufen). 7. 8. 4

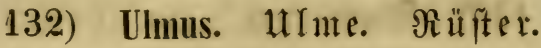

387. U. campestris. (5) enteine $\mathfrak{H}$. Blätter boppelt:

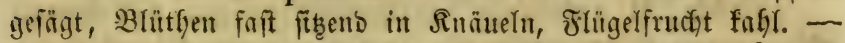
Formen: $\alpha$ nuda Rinbe ber $\mathscr{A}$ ffte glatt (Blittfen 3 männig); $\beta$ sube-

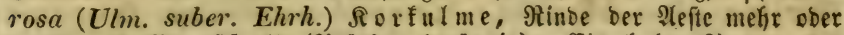

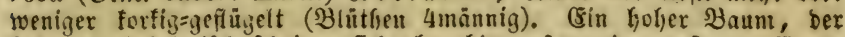

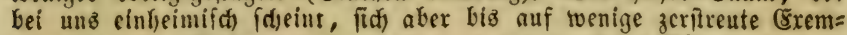
plare auz ben Bälbern verforen lyat, bagegen oft an Afleen unb bgl.

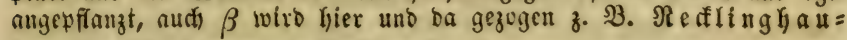

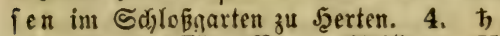

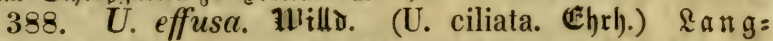
ft ielige it. Blätter boupeltgefägt, Blütyen geftielt hangend (6-8männig), Flügelfrudt am Ranbe zottig=gemimpert. -

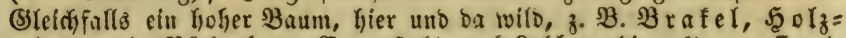

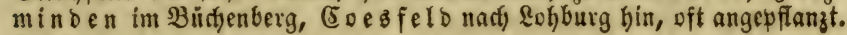
4. 5

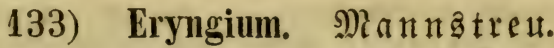

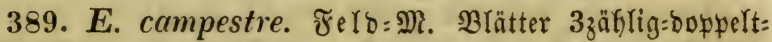
fieberipaltig negabrig borniggezähnt, bie unterften geftielt, bie

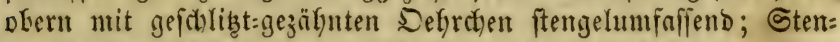

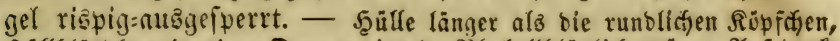

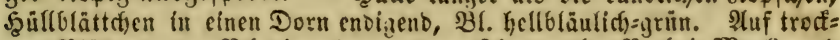
nen Pläbin: am Rhein, ber untern Rippe (3. B. bel Marl) unb

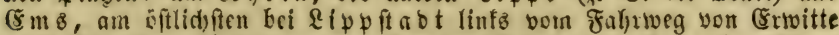

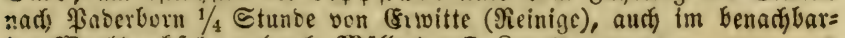

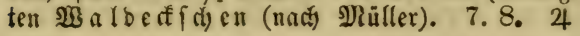

\section{4) Sanicula. Sanifer.}

390. S. europaea. TSurzelblätter fyanbförmig, Bipfel

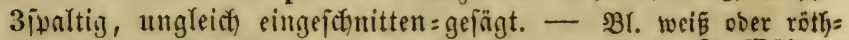

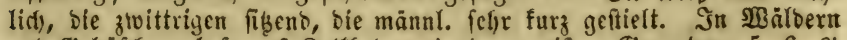
unb (3ebưfdjen, beí. a!f Ralfboben, in Den meifen Begenben. 5. 6. 2

\section{3) Hydrocótyle. $23 n$ ffernabel.}

391. H. vulgaris. Bääter fđiltoförmig freiânuno 9 ner=

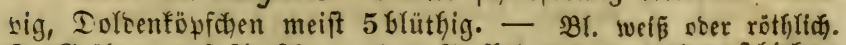

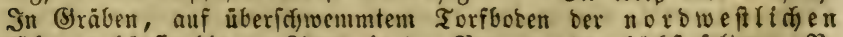

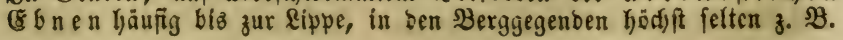


\& uีbenf Eel Solghanien, aul söterterg. 7. 8. 24

\section{6) Bupleurum. Ђafen of r. \\ * şätter niç) burchwach fen.}

+392. B. falcatum. Siđ̀elolãttriges .్. Stengel âftig; untere $\mathfrak{B l a ̈ t t e r ~ e l l i p t i f a ̆ ~ = l u ̈ n g l i c h , ~ i n ~ b e n ~ B l a t t i f i e l ~ b e r : ~}$

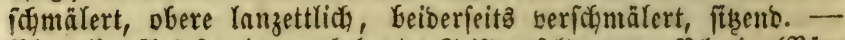
Bl. gelb. ATuf fonnigen unbebauten Triften felten: am $\Re$ Gefu (Bön= ninghaujen). 6-8. 4

393. B. longifolium. $\mathfrak{a}$ a gf rättriges $\mathfrak{5}$. Stengel

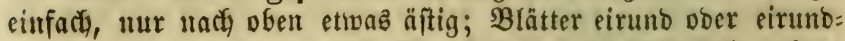
länglida, bie untern in ben Blattitiel berfdumälert, bie obern

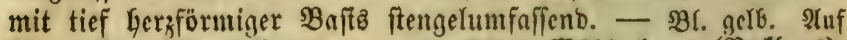
Bergen fehr felten: Beverungen auf bem Mühlenberge (Bectfaub̉). 7. 8. 4

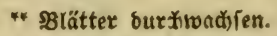

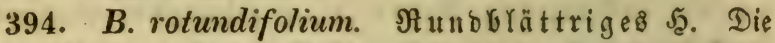

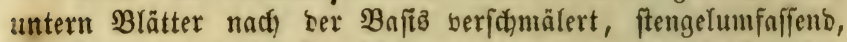

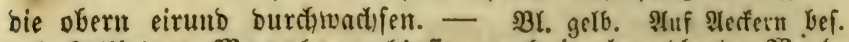
auf Ralffooben: $\mathbb{N a}$ a

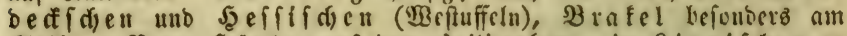

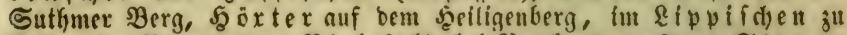
Seiben tun Pfarrgarten, Bierefelo bei Brattwete, auf Den Strom= bergtiden 50 ben von Selbe bis Dulberg fielleniv. häufig, $5 c e=$ fen, Drenftefnfurt, \&üb?nglaten, Cocofelo um Sper= wide. 6. 7. 0

\section{7) Pimpinella. Bibernerl.}

395. P. magna. (3) ró̧е 3 . Stengel gefurcht beblät:

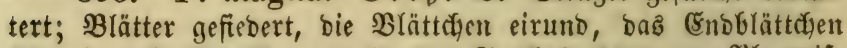

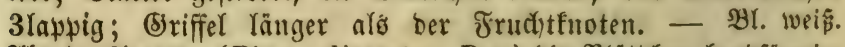

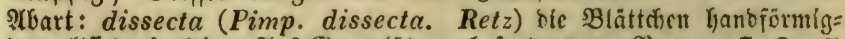

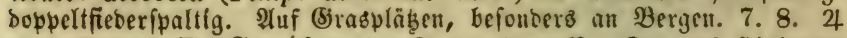

396. P. Saxifraga. (S) eneine $\mathfrak{B}$. Stengel ftielrumo zartgerieft, oberw. faf́t blattlob, fahl (ober f(aumig); Blätter gefiebert, Blättợen eiruno, etmas glänzeno; Blüthenftiele fahl;

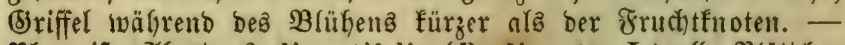

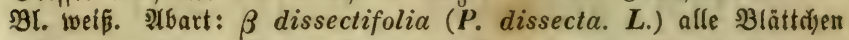

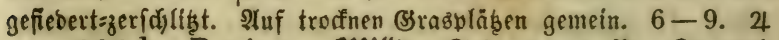

396 b. P. nigra. Willo. Sdiwarze $\mathfrak{B}$. Stengel fitel= runb zartgerieft, oberw. faft blnttloz, nebft den $B$ lättern, STeften unb $\mathfrak{B}$ lütbenftielen biđ̆tffaumbanrig; $\mathfrak{B}$ lätter gefiebert, $\mathfrak{B}$ lättç)en 


\section{Digynia.}

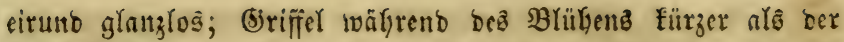

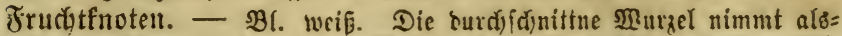

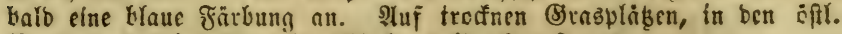
Berggegenten jebodi noif nidjt bemerft. 6-9, 4

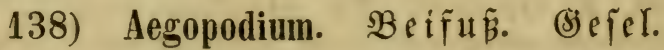

397. A. Podagraria. - Die oberfien Blantter gebreit,

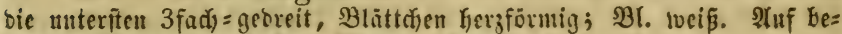
bautem $\mathfrak{B}$ cben, an Scecten, SRauern überall. 5. 6. 4

\section{9) Carum. $\mathfrak{\Re}$ ü $\mathfrak{m} \mathfrak{e} \mathfrak{l}$.}

398. C. Carvi. (s) emeiner $R$. Blätter bopwelt=gefie: bert, Blättchen fieberipaltig = vicltheilig, bie unteríten Paare an ben genteinfichaftlidjen Blattfiel freuziweiz geftellt. - Stengel

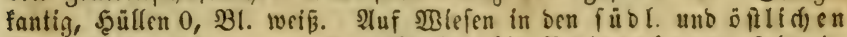
Berggegenden gemein (ber $\mathfrak{B}$ efer biz $\mathfrak{B}$ eter shagen folgent,

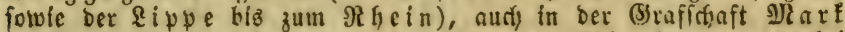

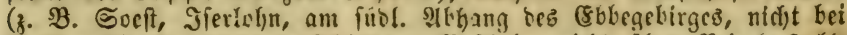

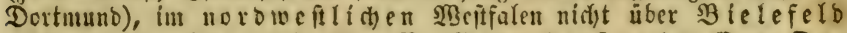

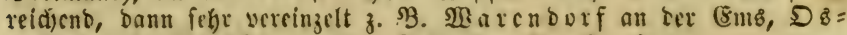
$\mathfrak{n} \mathfrak{a} b \mathfrak{r u ̈} \mathfrak{d} \mathbf{a m}$ Salloberg an ier Ruffweite. 5-7. \&

399. C. Bulbocástanum. Fiod). (Bunium. Bulboc. L.) Rnolliger $\Omega$. B Blätter boppelt= (faft 3 fad)=) gefiebert, ₹etzen

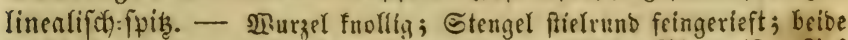

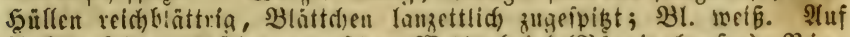

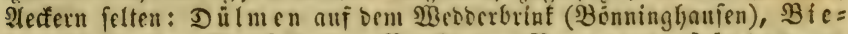

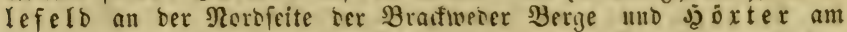

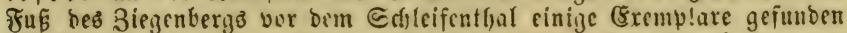
(Berff(ha) Ralfofen, hinter Dem Szomberg am (5)algenberg (Eserô). 6. 7. 4

\section{0) Apium. Sellerie.}

400. A. gravéolens. Stengel gefurcht; Brätter gefiecert, bie obern georeit, Blättden feilförnig. - Dulben fnft fibeno,

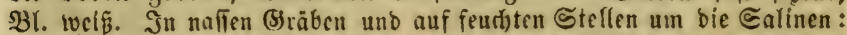
Salzufen, Diffen, Esefernfotten, Salztutten, Soeft

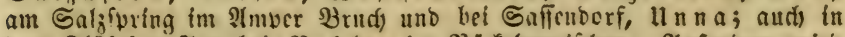

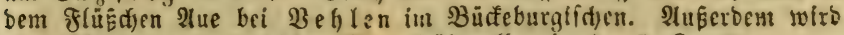

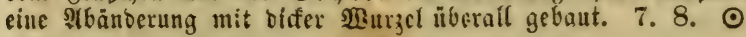

\section{1) Anethum. Dill.}

401. A. gravéolens. Blätter 3fadugefiebert, Fệen Yi= neal:Fabenförmig. - Stengel runb, graugrün, เoeip= unb grünge= 


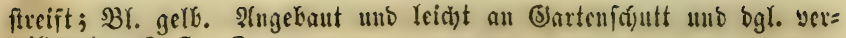
wilberns. 67 . $\odot$

\section{2) Foeniculum. foffur. Fentfel.}

402. F. officinale. AUll. (Anethum Foen. L.) BBlät= ter vielfach : zufammengejebt, Jeben linfal = pfriemlich verlüngert, Dolben 13-20itrafilig. - Stengel an ser Bafiz fiteltunb, ge= ftreift, glänzeno, fósimmelgrün; $B$ l. gelb. F̂tngebant mo mitunter ver= willotms. 6. 7. 4

\section{3) Pastináca. Faiftinaf.}

403. P. sativa. (5) cureiuer $\mathfrak{P}$. Blätter gefiebert, pler:

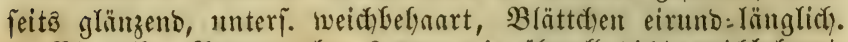
- Bl. gelb. Fenbert ab: $\beta$ varvensis überall bidtt=lveidfbetgant.

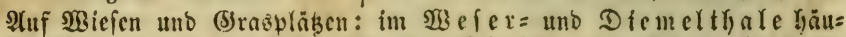

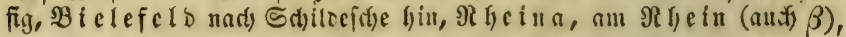

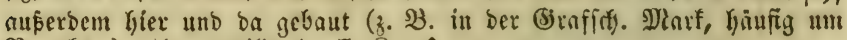
3orfen) unb werwilbert. 7. 8. \&

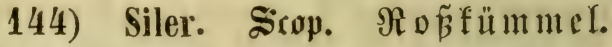

404. S. trilobum. Sisp. (S. aquilegifolium. Gartn. Laserpitium aquilegifolium. IJasq.). - Blättcr Dopyertzufam=

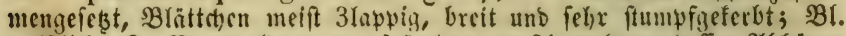

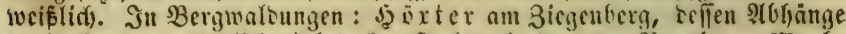

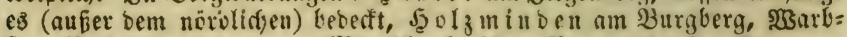

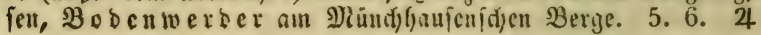

\section{3) Daucus. Mofrrübe.}

405. D. Caróta. Stengel uno Blätter fteiffarrig, Şül=

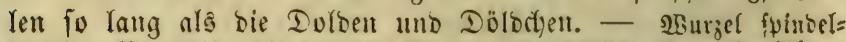

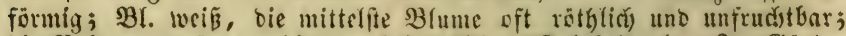
bie Behaanunig ämbert biz zur faft yölligen Saglfgeit at. In (s)äten

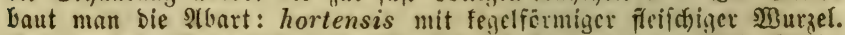

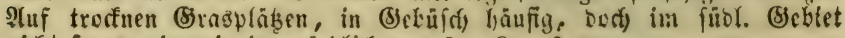
nicht fo gemein wie in uvirblict)e. $6-9$.

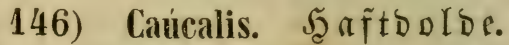

406. C. daucóides. (5̧ emeine 5 . $\mathfrak{B}$ lätter $2-3$ fart)=

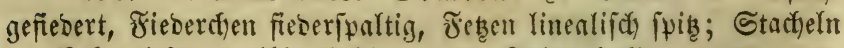
ber Rebenriefen I reibig fall, an ber Spibe hafig. - Br. meif.

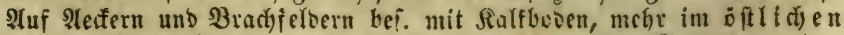

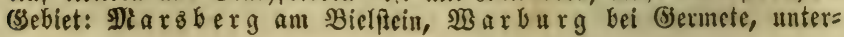




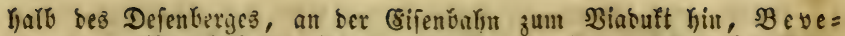

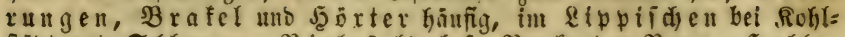
fäbt und Sdylangen, Bielefelo bef. Bractiveber Berize, 5 alle, Teffenburg bei Saus Narf, Rabben an Stemmerberg; fonft ferje vereimzelt: Stromberg, Nienberge tub Nitenberge, Soeft bri Enfeien, Jattiugen. 6.7.

† 407. C. leptophylla. ऽdimalblättrige $\mathfrak{g}_{\text {. Blät: }}$

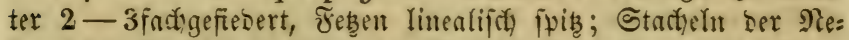
benriefen 3reifig raub, an Der Gvihe miberbafig. - Bl. weif́.

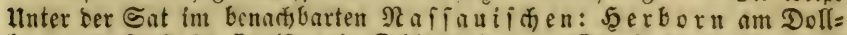

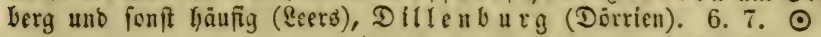

$\mathfrak{U} n \mathrm{~m}$. Cancalis latifolia mit gefieberten $\mathfrak{B}$ lättern, lanz̧cttliđ̄en einges fänittensgerägten Fieberdien, 7 Reiken 3 zeiliger roiberhaÉger Etad)eln auf ben Früdten - foll auf 2 edéern bei $\mathbb{2}$ areno orf und $\Re$ hein a borfoms men; mit C. daucoides verived)felt? Orlay a grandiflora. Hoffm. (Caucalis

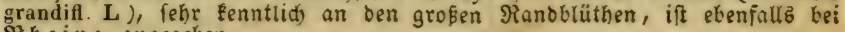
ghe in a angegeben.

\section{7) Myrrhis. Siop. Süźdolde.}

408. M. odorata. Š̊p. (Scandix odor. L.) Blätter

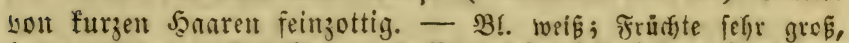

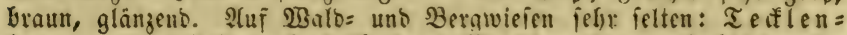

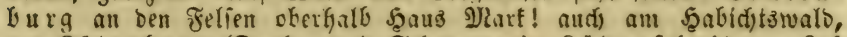

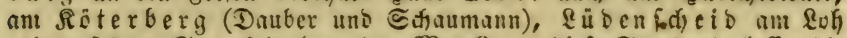
unb auf bem Sauerielb (bun ber Marfí) - bieie Etanoorte lanien bie

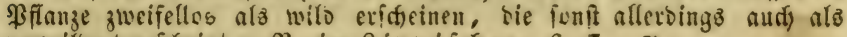

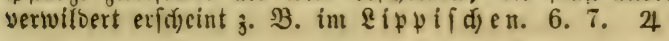

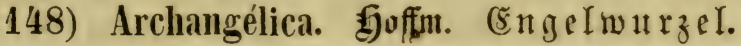

+409. A. officinalis. boffm. (Angelica Archang. L.). Blätter boppeltgefiesert, $\mathfrak{B}$ lätți)en eirumb, foịt Gerzförmig, 23lapptg, ungleidfgefïgt. - Dbere Blattîticle aufigeblafen; Dolben

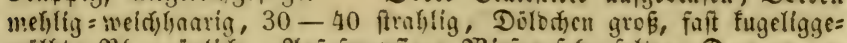

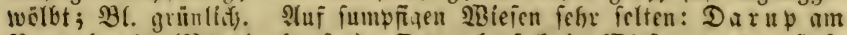

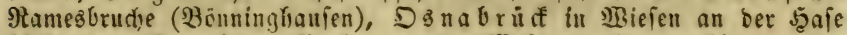

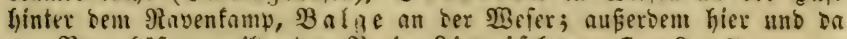
um Bauerfoffe vectuiloert 3 . B. im \&ippifd, en. $7-9.24$

\section{9) Angélica. $\mathfrak{A}$ ngjelif.}

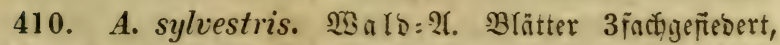

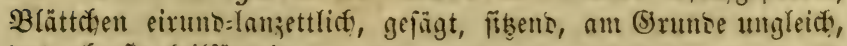
bas oberíte feiliörmig. - Etengel riffrig, meisflid bereift, fadmads

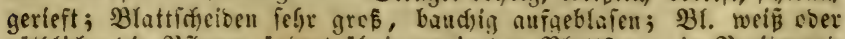

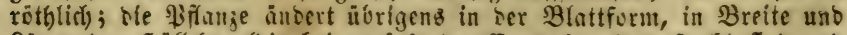

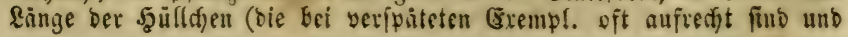




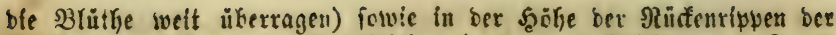
Frudite mannigfact) ab. Sluf Silefen, in feudjten (Sebüfden. 7. 8. 24

\section{0) Selinum. Silge.}

411. S. Carvifolia. Stengel gefurd̆t id)arffantig, Blät= ter 3 fad)gefiebert, Blättchen tieffieberipaltig, Jeßzen lineal:Ian=

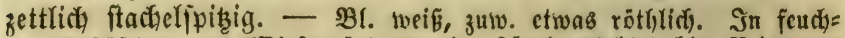

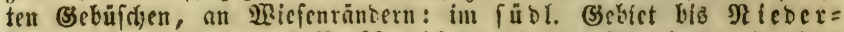

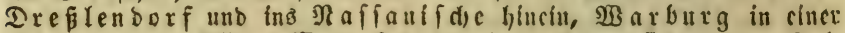

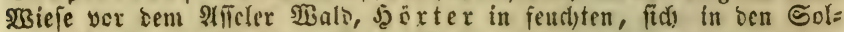

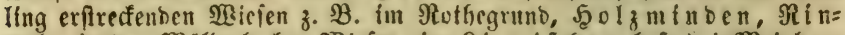

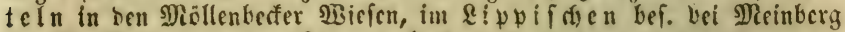
uno Reeffirdsen, an ber \&ip pe oberthalb \$aberborn, in ber Eenne,

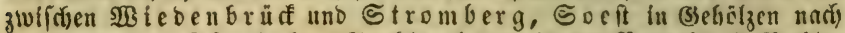

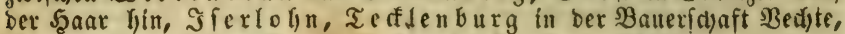
6e pesfels auf bem Berge, sBillerberf. 7. 8. 4

\section{1) Levisticum fadd). Rich ft b̈ ffel.}

412. L. officinale. find). (Ligusticum Levisticum. L.)

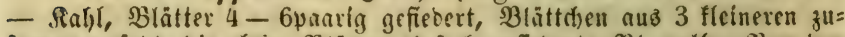

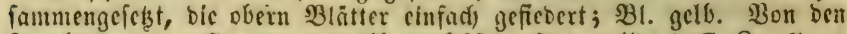
Eanbleuten anyeyflangt und an iffen Sêforn sft verwilbert. 7. 8. 4

\section{2) Heracléum. Sceilfraut.}

413. H. Sphondylium. (5) emeine ș . B Blätter gefie: hert (ober tieffiederipaltig), Fieber lappig oder hantoörmigge=

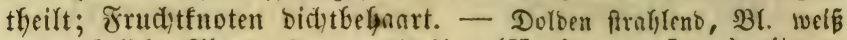
ober grüntid). NGart: $\beta$ an gustifolium (H. ele gans. Jacq.) mit ver=

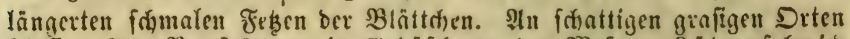

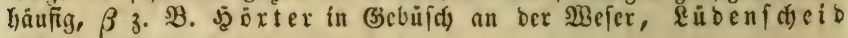
bef $\mathfrak{\text { Wefielberg. }} 6-9$. $\quad$ के

\section{3) Peucédanum. Şåx}

* Peucedanum. Fugenftriemen oberftäd)lid).

+414. P. Chabraei. Rabb. (P. Carvifolia. Dill. Im-

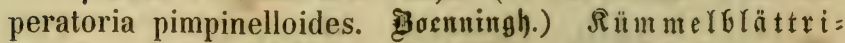

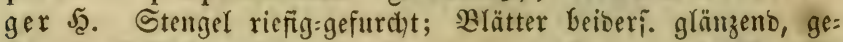
fiebert, $\mathfrak{B}$ lättchen fitzeno, vielipaltig voer bei hen oberften $\mathfrak{B}$ l.

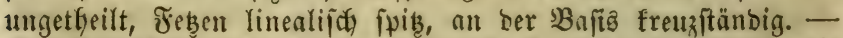

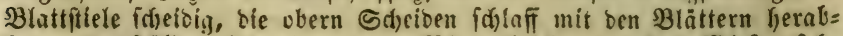

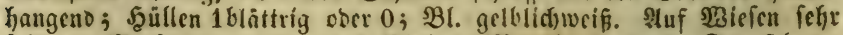

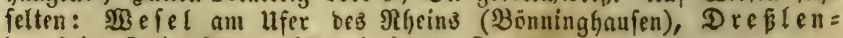
borf int Rrtî Siegen (Dörien). 7. 8. 4 
$2 \mathrm{~nm}$. P. officinale mit 5mals 3 fachizurammengefesten slättern, lineari:

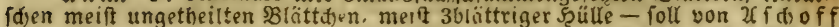
in ber Senne gefunden fein (cf. Flora III 219) unb wiro auperbem bei $\Re$ i et: berg angegeben.

** Thysselinum. Hoffm. Fugenftriemen bom frudjtgehäufe be: bedét.

415. P. palustre. Atocud). (Selinum pal. L. -

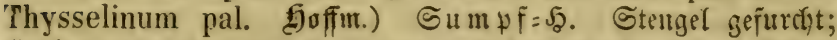

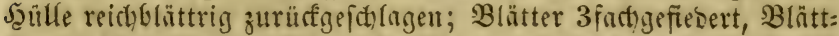
chen tiefĩeberipaltig, Fethen lineal=langettlidf fnorpelig:zugefpibst,

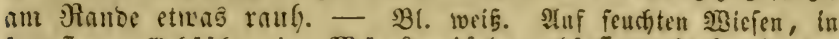

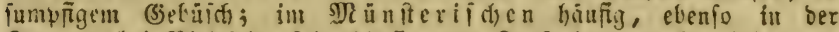

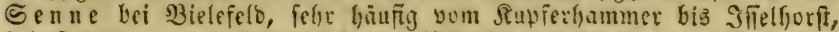
bet Edyittmar in \&

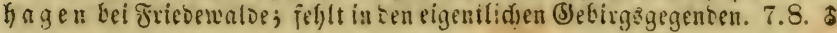

\section{4) Imperatoria. Me ifterwurz.}

$415 \mathrm{~b}$. J. Ostruthium. Etengel geftreift; B̉ätter rop:

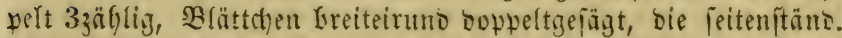
2ppaltig, bie enditäno. 3ipaltig; Blattjdeiben bäutig aufgeblajer.

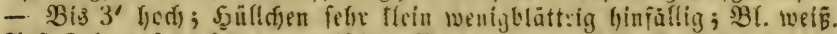

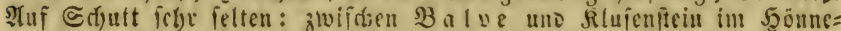

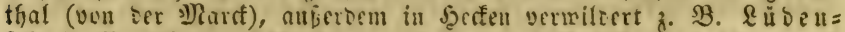

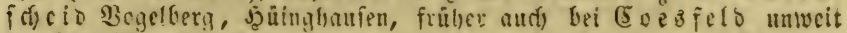

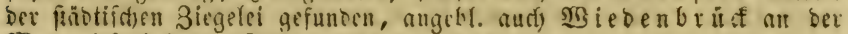

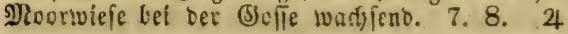

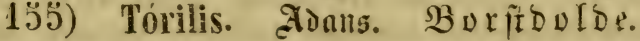

416. T. Anthriscus. Gutcl. (Tordylium Anthr. L.) Feffen: B. Stengel (oft rotgangelaufen) von abmints ange:

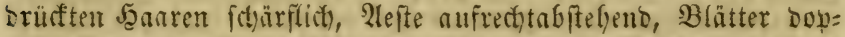

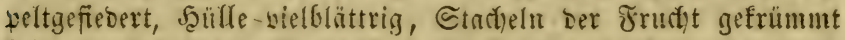

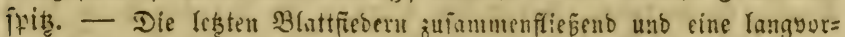

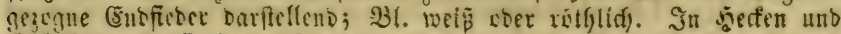

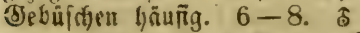

417. T. infesta. 5offm. (Scandix inf. L. - T. helretica. Gmel.). Rletten=B. Etengel niebrig mit nuฮ̈ge= iperten 2leften, BBlätter boppelgepiedert, Sällle 0 ob. 1 blättrio; Etatueln grabe, an Der Epize miserbafiģ. - Br. weiß ober

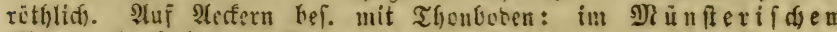

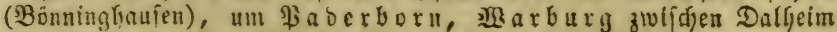
unb Jyerlinghaufer. 7. 8. ค

$\mathfrak{x} \mathrm{m}$. Torilis nodosa. Gaertn. mit geEnäuelten Dolben, weld)e ben Slättern gegenüber fiEenib find - ift con ( bit Scerrentrup ain şïngelbberg unter \&userne bevachtet worben, rookin ber

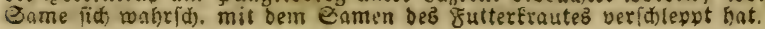




\section{6) Conimm. Sdjierlittg.}

\section{C. maculatum. (s) efle efter Gdi). Blätter} 3 fardgefiebert, Blättrden Inuzettlich) fieberipaltig; Stengel ge=

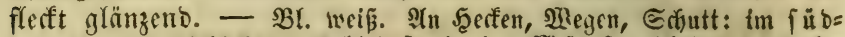

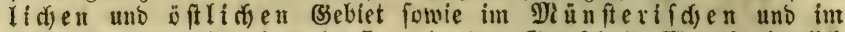

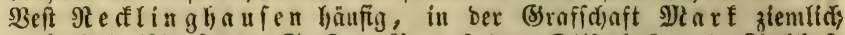
verbreitet (Eipplatat, Soeft z. 23. auf Dem Etiftohofe und Rird)foufe yon Erfivefe, Dortmund yor bem Ditentijure, Sdivarzenberg uno

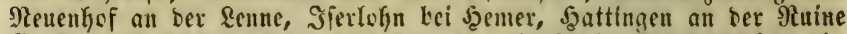

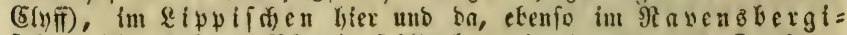
f

\section{7) Chaerophyllum. $\mathfrak{R}$ ål}

* Stengel unter ben selenken kaum angefdusollest.

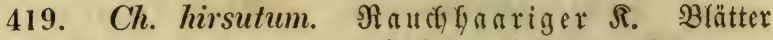

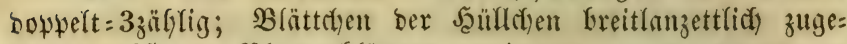
fpibst, nebit ben Blmmenblättern gewimpert. - Frufithalter an

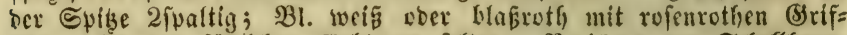

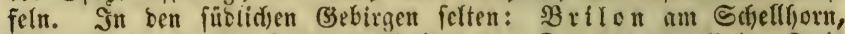
Berleburg in ben Eatroper $23 a$ loungen, Dreflendorf im Rrelỏ Sirgen auf $2 B$ iefen fowie im benadjbarten 9 a fi a ** Etengel unter ben (Selenéen fid)ttid) angeid)wollen.

420. Ch. bulbosum. $\Re$ nolliger $\Re$. Stengel an ber Baftz fteifgaarig, oberiw. fahl (rotggeflecft); Blitter mefyr=

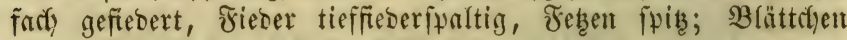

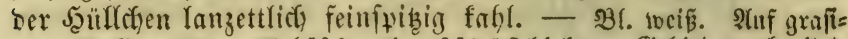

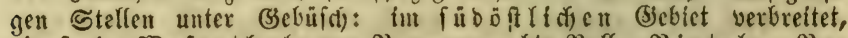

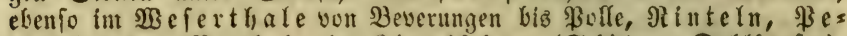

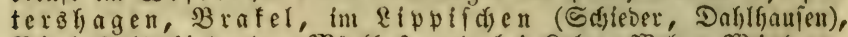

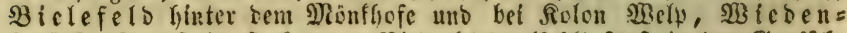

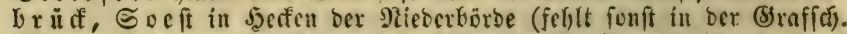

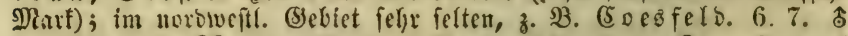
421. Ch. temulum. Berauficuber $\Omega$. Stengel nut Der Bafts fteiffanrig, oberw. furzbelaant (violettgeflerft); Blätter soppeltgefiebert, Fieber lappig = fieberipaltig, Feken furz:

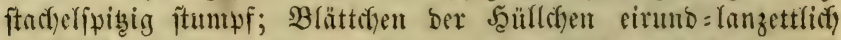

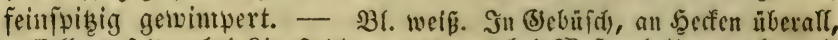

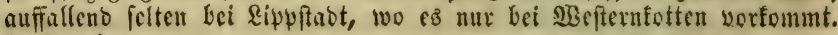
6. 7. $\$$

\section{8) Scandix. Nadelferbel.}

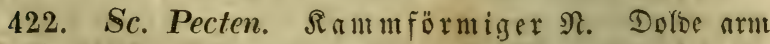

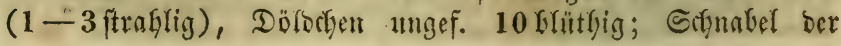




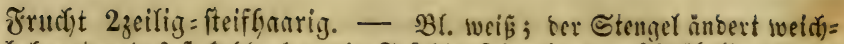

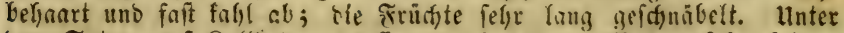

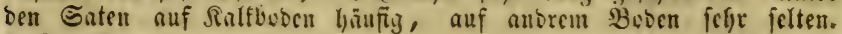
5. 6. $\odot$

\section{9) Anthriscus. foffun. Silettenferbel.}

423. A. sylvestris. foffint. (Chaerophyllum syl-

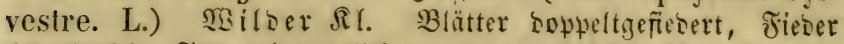

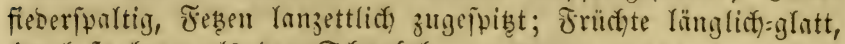
4mal fo lang als ber Edsunfel. - Derlocn enopänbig gefielt,

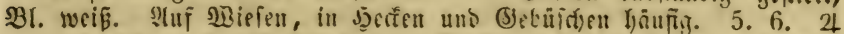

423 b. A. Cerefolium. 5offitu. (Scandix Ceref. L.) (b)arten= $\mathbb{R}$. Rerbel. Blätter 3 jadigeñebert, Fieber fieber=

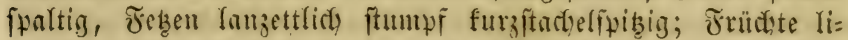
mealifd) glatt, boppelt fo lang als Der Edrunatel. - Dolisen

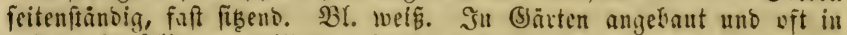
unto an benfelben verwilbert. 5, 6. $\odot$

$\mathcal{U} \mathrm{m}$. Anthriscus vulgaris. Pers. (Scandix Anthriscus L.) mit ftadeligen Früđten - wirs (von güller) in ben füoöftlid)en (Segenden bei

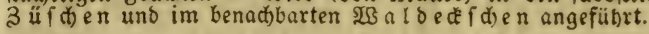

\section{0) Sium. Wafiermerf.}

424. S. latifolium. Breitblätriger $\mathfrak{2}$. SูUน

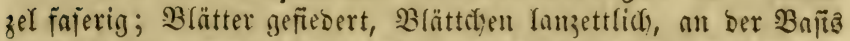
ungleich, bie ser untergetnucten boppeltfieseripaltig ober biel=

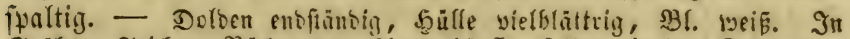

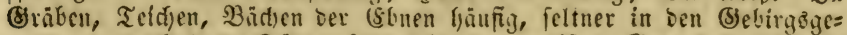
genden, nari) Dem Elïoen fogar in ten meiften (Jjegenden feblent, 3. 3. in ber (3raffedjaft פlatt. - Jn (5) הitten finoet man hier unb ba

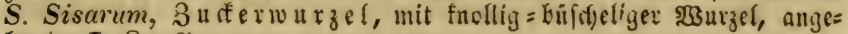
baut, 7. 8. 4

\section{1) Bérula. Eâd). B̧erls.}

425. B. angustifolia. fivod). (Sium angustifolium.

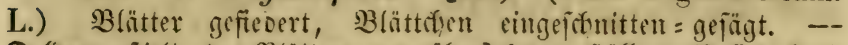
Dolden geftielt, ben Blättern gegeniterfecheno, Jäulfe meift fieseripal=

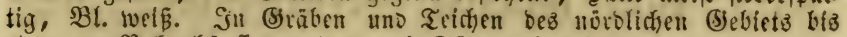

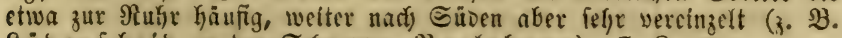
\&übenfdyetb an bet E(f)nappe, sberleburg). 7. 8. 4

\section{2) Silaus. gुefl. Silnu.}

426. S. pratensis. (Pencedanum Silaus. L.)

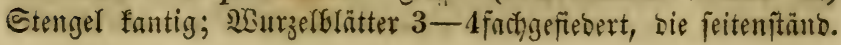


Fieber ganz ober 2tfeilig, bie enbitüno. 3tfeilis, Fezen linen=

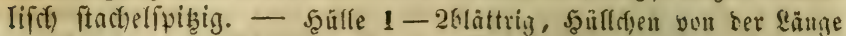

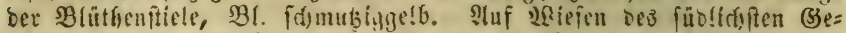

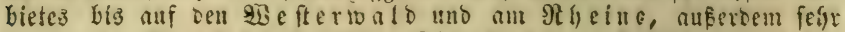
vereinzelt: Soeft bei Saultren, Rippitant zu Rappel unveit bes Steges au bem Bhteînraine nardi ocm Stift lin, Stromberg, Nienbergo im Sliniterifaten. 6. 7. 4

\section{3) Séseli. Sefer.}

* Seseli. Zưgemeine Şülte 0.

+427 . S. annuum. Etarrer S. Intre BBätter

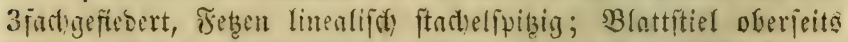
rimig; Straflen der Iolbe nuf Der Smenfeite weichbefyart;

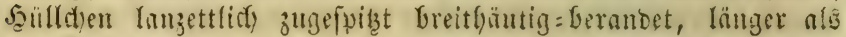

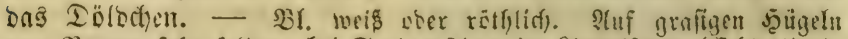

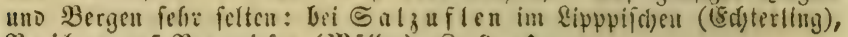
B rllon auf Berguiefen (Miuller). 8.9.

* Libanótis. Crantz. Şüllte reidublättrig.

428. S. Libanótis. Eîd). (Athamanta Lib. L. Libanotis montana. All.) Retzblättriger S. Blätter

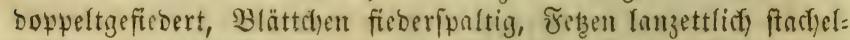

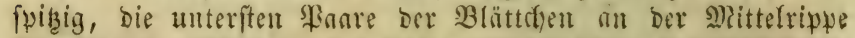

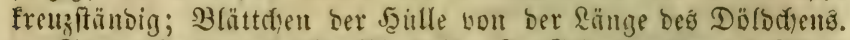

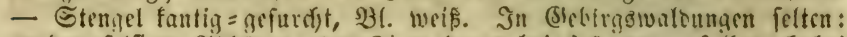

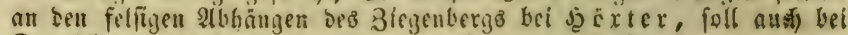

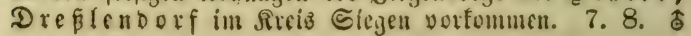

\section{4) Aethusa. (S) artenfdierling.}

429. A. Cynapium. (5) eneiner (5). Jूunbête:

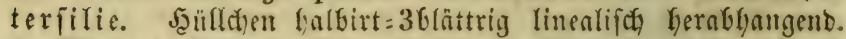

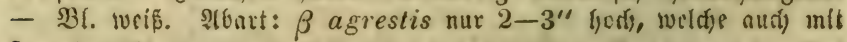

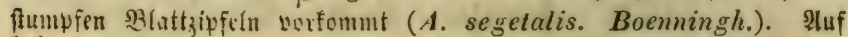
bebautem Boden, bef. In (5)irten lä̈ufig, $\beta$ hier uno ba auf Aeftern

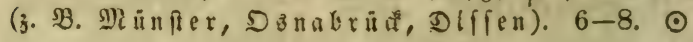

\section{5) Oenanthe. Rebendolde.}

- Oenanthe. SWurzel büfdelig: ober fuferig= Enollig.

430. O. fistulosa. $\Re$ ö hrige $\Re$. Blättethen ber $\mathfrak{3} u r=$ zelglätter flact) feilförmig gelappt, biej. Der obern Blätter Yi= nealifory, einfoch ober 3theilig, ftiefrund und nefft bem siatt=

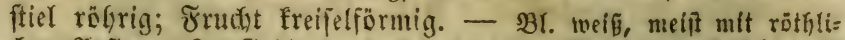

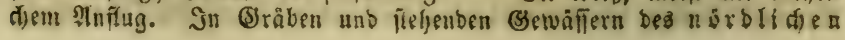




\section{Digynia.}

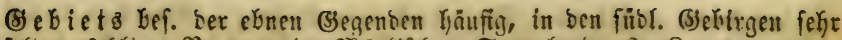
felten, ferflt z. B. ganz im Niä:fiffich Eaurrlant. 6-8. 4

431. O. peucedanifolia. Pollid). Sanaritrangbrätt=

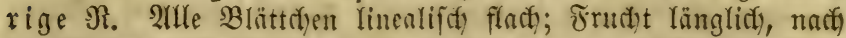

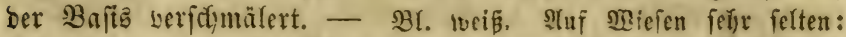

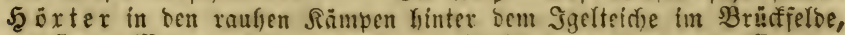

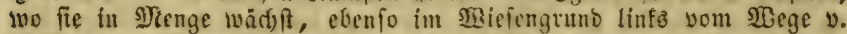

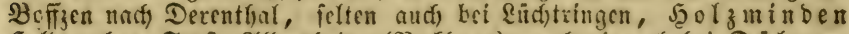

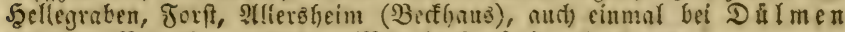
vor: Dem Burgthor gefumben (Benningtauien). 6. 7. 4

** Phellandrium. গ্রুurzel fpillbelförmig.

432. O. Phellandrium. Faur. (Phellandrium aqua-

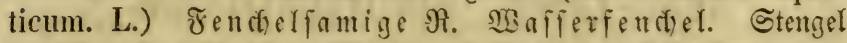

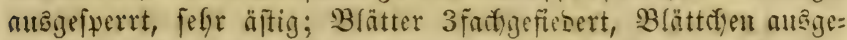
fperrt, bie untergetauthten bieljpaltig mit Ganrförmigen Bipfeln.

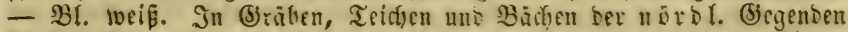
r)äufig, in ben jübr. Bebirgäyegenten aber felten ober ganz fehlent. 6. 7. के

\section{6) Critamus. Sill. Sidfeldolde.}

433. Cr. agrestis. (Sium Falcaria. L. -

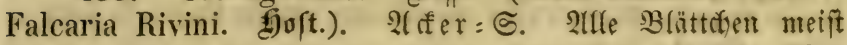

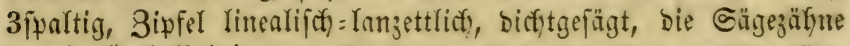

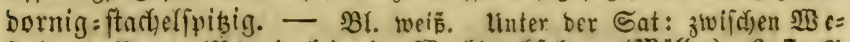

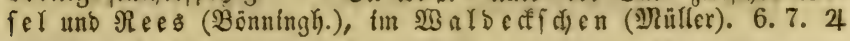

\section{7) Helosciódium. Siad). Suntfiditu.}

† 434. H. nodiflórum. E. (Sium nodiflor. L.) Rnotenblütriger S. Blätter geffebert, vieber ciruno = ran= zettliç, gleid)fërmig ftumfflict)=gefügt; Dolben länger ala ber Blüthenftiel; Stengel am Grunte liegend und wurzelns. -

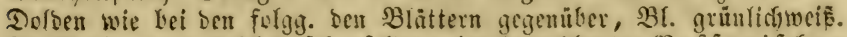

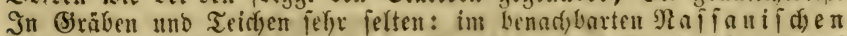

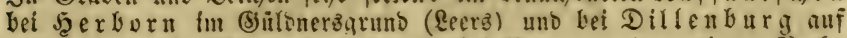

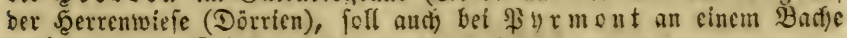
yorfomment. 7. 8, 2

435. H. repens. fa. (Sium rep. L.) Jiriedtender

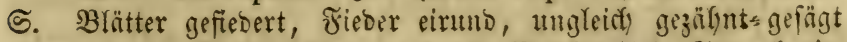
Doer gelappt; Dolben fürzer als Der Blüthenftiel; Ctengel nie=

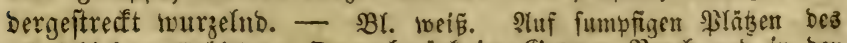

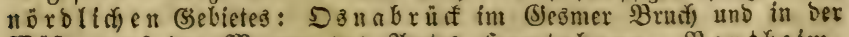

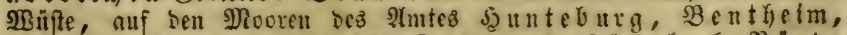

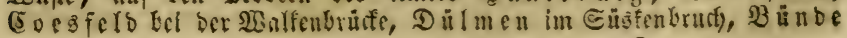




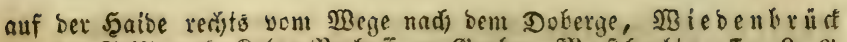
auf ber Irift nad) Solon Berbeff am (Braben, Diaftholtc. 7-9. 24

436. H. inundatum. fi. (Sison in. L.) Sifwim= mender $\mathfrak{S}$. Die Gerwortautienoen Blätter gefiebert, Jieber feilförmig 3fwaltig, bie untergetnudten fanrförmig=vieltgeilig; Dolben 2 fitrablig; Gtengel nul (Sirumbe friectend. - Br. weiñ. In feutiten (biäben und Eumpfen ber not b we ft liden (sonen ber.

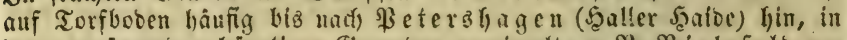
ben angränzenden hügcligen Begenden vercinjelt, 3. B3. B iclefelo un

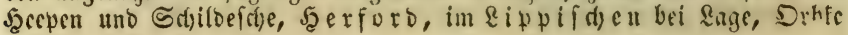
แ. ค. IV. $5-7.24$

\section{8) Cicita. Wafiferidierling.}

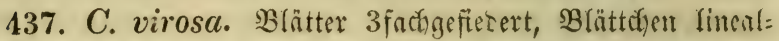

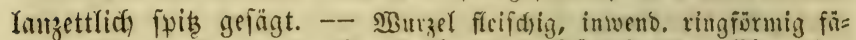

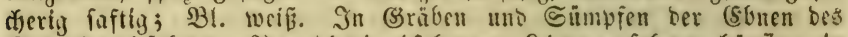
De in ben umgebungen bes Teuteburgerwaltes verefnzalt 3 . B. Bielefelo

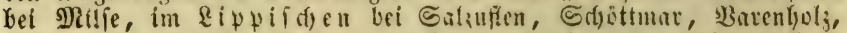

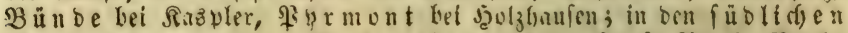

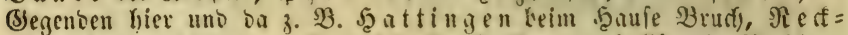

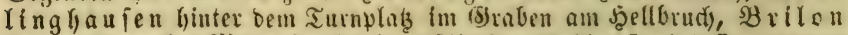

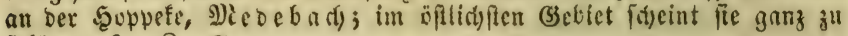
ferjlen. $6-8.24$

\section{9) Petroselinum. Ejoffm. Peterfilie.}

438. P. sativum. f)offm. (Apium Petros. L.). B̉ät:

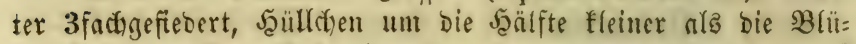

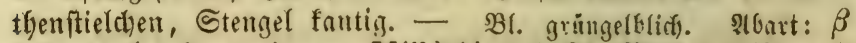
crispum (Apium crispum. Mill.) bie unterîten slitter gröfer unt fraus. Heberall gebaut, audi oft verwildornb. 6. 7. \$

\section{Sronumg Trigynia.}

\section{0) Sambúcus. 5̧olunder.}

139. S. Ebulus. 3wergholunder. 2t tic ch. Stengel

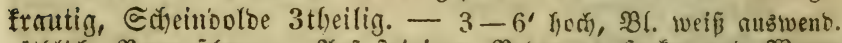

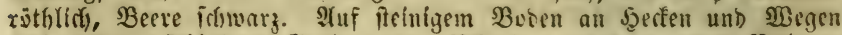

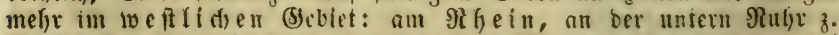

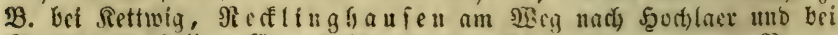
Sanbers in Sillen, Coc sfelo yor bem Eriringatffor und am Berge,

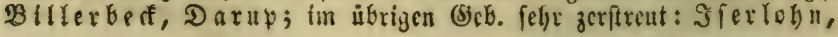




\section{Trigynia.}

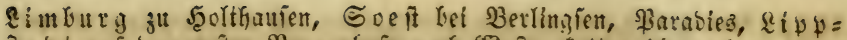

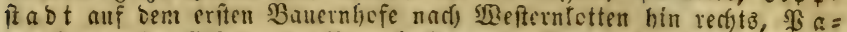
berbort in Elfen, ju Neucnbefion am Badte uber sem Dorfe,

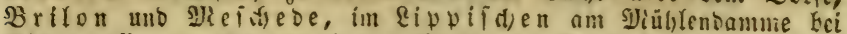

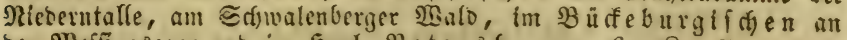

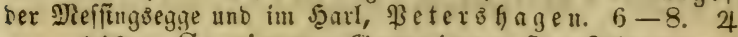

440. S. nigra. (S) neiner 5. Flieser. Gtanm

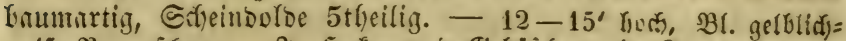

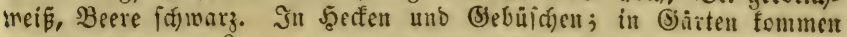

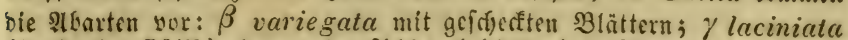
(S. lacin. Mill.), ber feterfilienblattrige fl. mit boppeltge=

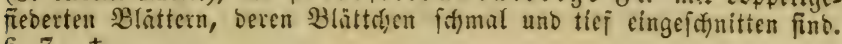
6. 7. 万

441. S. racemosa. Tranbenfolunber. Gtamnt

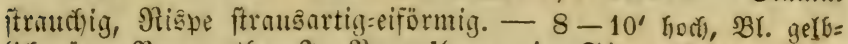

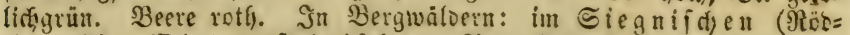

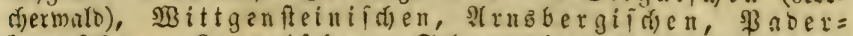

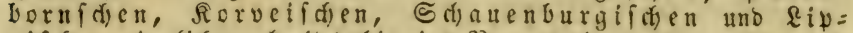

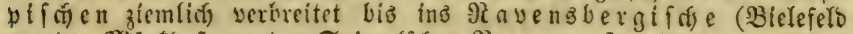

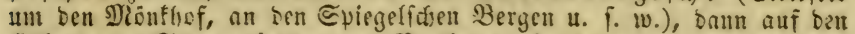

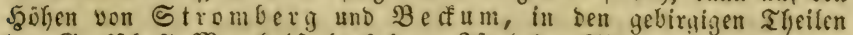

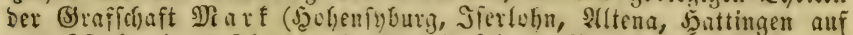

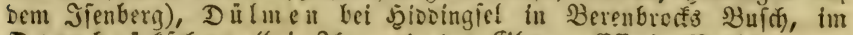
Do Stemmerberg. $5-7$. 万

\section{1) Viburnum. Sifneebalt.}

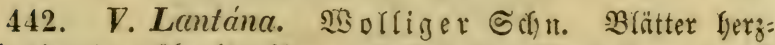

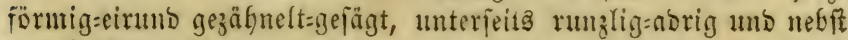

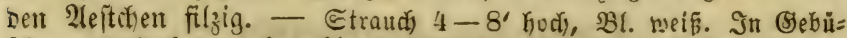

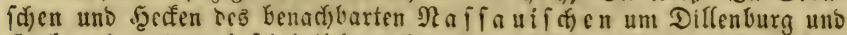

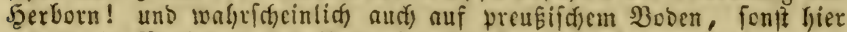
unb ba in Bobfetten verwiliert (3. B. Rippitabt im Bosfett nadi) Dem Tannenflolz $3^{11)}$. 5. 6 . 万

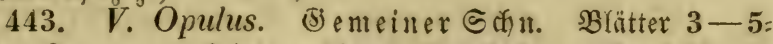

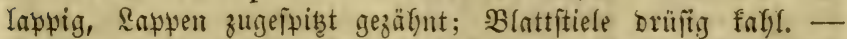

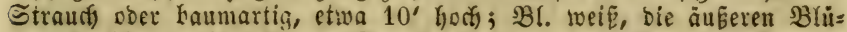

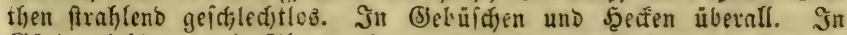

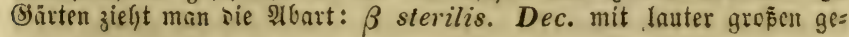
idflerfitluen Bläthen. 6 . 方

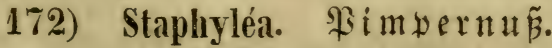

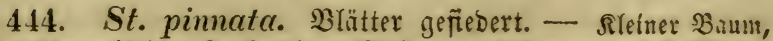

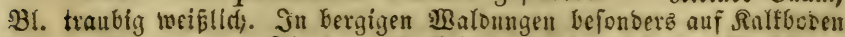
jelten: Siegen am ভlegberg (Suffrian), in benactbarten $\mathfrak{R}$ affall: 


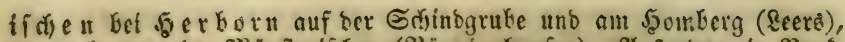

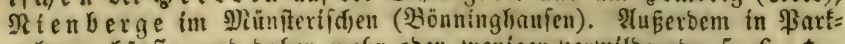

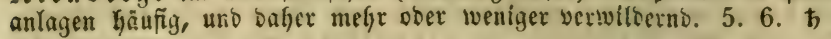

\section{3) Corrigiola. Sinotenfiaut.}

445. C. littoralis. Stengel nieberliegent, Bhïtben ge=

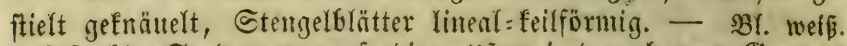
Atuf feudsten Eanowegen, an fanbigen Ufern in ben ebenen (B) egen=

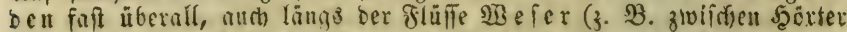

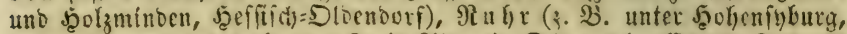

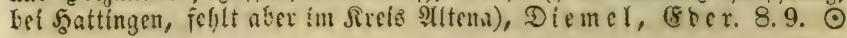

\section{Sronung Tetragynia.}

\section{4) Parmassia. $\mathfrak{B}$ arnaffie.}

446. P. palustris. Stengel 1 blättrig 1 blütfig.

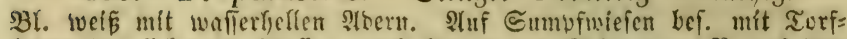

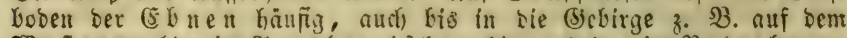

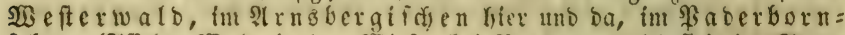

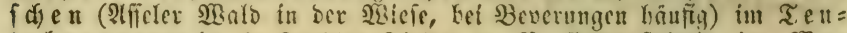

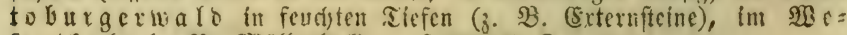

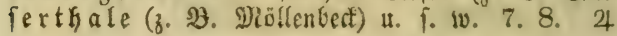

\section{Sronumg Pentagynia.}

\section{5) Linum. $\widetilde{F} \mathfrak{I a d j}$.}

447. L. usitatissimum. (5) emeiner Fr. Lein.

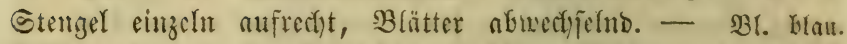

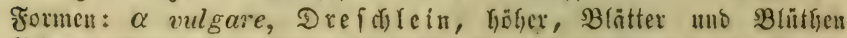

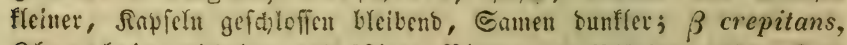

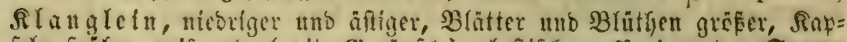

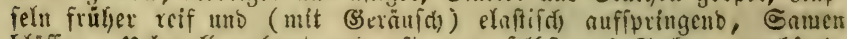
blâffer. Heberall gebaut uno oft yon felbît auf slectern wadifent. $5-7$. $\odot$

448. L. catharticum. Burgirffach ह. Reldyblätter

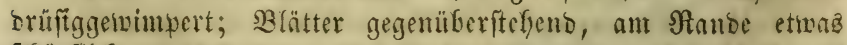

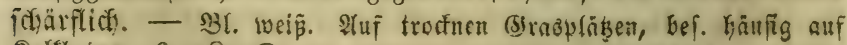
Ralfuvber. 6-8. $\odot$ 


\section{6) Drósera. Sonnentyan.}

449. Dr. rotundifolia. Nunoblättriger S. Sraft 3 mal fo lang ala bie freiêrumben Blätter. - Die ganze şffanze

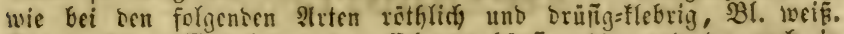

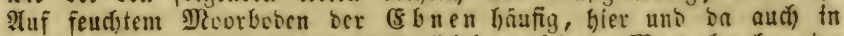
bergigen (segenden (3. B. auf bem (Eb begebirg, Ne ebels a di) untei

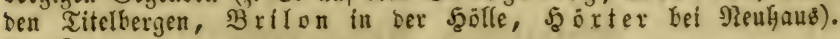
$6-8.24$

450. Dr. longifolia. (Dr. anglica. fouts.) $\mathfrak{\Omega} \pi \mathrm{g}=$ blättriger ๔. Schaft nufred)t, boppelt fo lantg als bie läng=

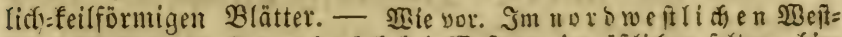

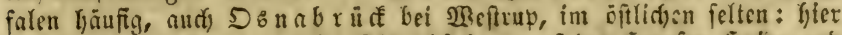

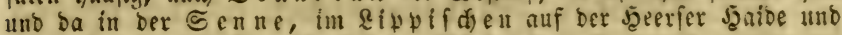
Bivitălgaibe im Eraben übe: Colon Dörnmeicr. 7. 8. 4

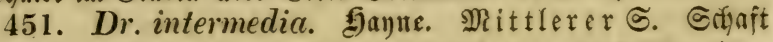

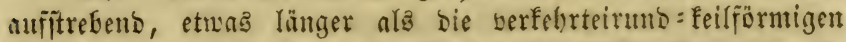

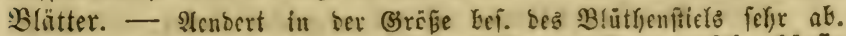

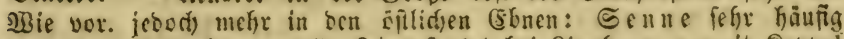
Jiz an ben Tentoburgerwalo, sippif a ot bei Ripyborg, untoeit Rappel

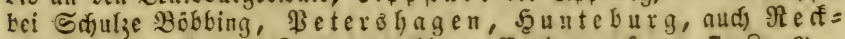
I ingl) a ufen in ber Berene unb hinter Čnning u. f. w. 7. 8. 4

\section{Sronung Hexagynia.}

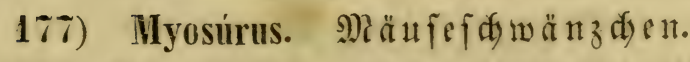

452. M. minimus. - كd)aft cinige 3olf hod), 1Grüt thig;

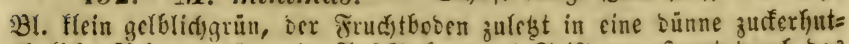

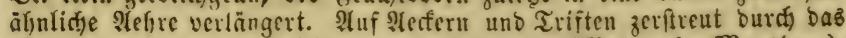
Bsebiet: felten in ren firbli dien (Blebirgen (Diebebnch), Marsberg),

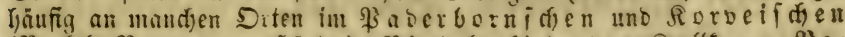
(Brafel, Beverungen, Jjexter), Rinteln hinter bem firollfuge, \$e=

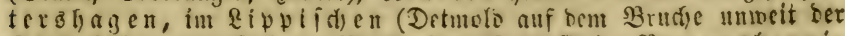

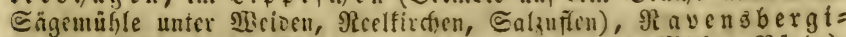
id)

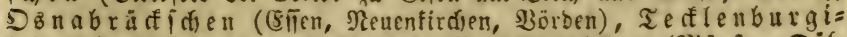

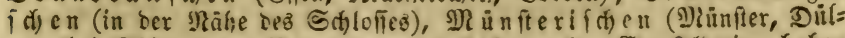
men bel Thier zum Berge uno ian 5afelbrund, Evesfelo im holjent

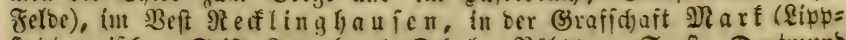
ftabt zwifich Stift Rappet unb Edjulze Bäbsing, Sceft, Dortmunb auf פlauern in ber Bethenftrabe uno auf Ileferm yer brm Difentfiore). 4-6. $\odot$ 


\section{Sedite silatic. Hexandria,}

\section{Sronung Monogynia.}

* Blumen voltrtänoig.

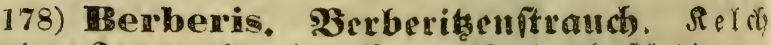
6blättrig. Rrone 6blättrig. Beere 2 fanig Dberftänbig.

179) Peplis. Afterquended. Rel di 12 zăfnig, bie Bäfure abwechjelnd fefre flein. Rrone Gblättrig. Satfel 2 fäđtjerig.

** Blumen unvorfftänsig oberttänsig.

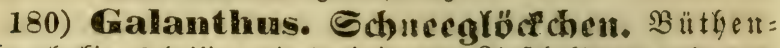
hürle glorfig 6theilig, bie orei immern Bipfel fiurzer uns aus: germildet.

181) Cencojum. Trübring fourre glorfig 6theilig, bie Bipfel gleid) (an Der Splze wer: bifft). Staubgefä в̈e yleich.

182) Narcissus. Nargiffe. Blüthentülfe tel: ferförmig mit fladem 6 theiligem Saum un einer glodign Rebenfrone. Staubgefäвe ungleiḑ.

*** Blumen unboulftändig unterftänbig. $\dagger$ Blüthenhültle Iblättrig.

183) Convallaria. Maililie. $B($ üthen $u$ ülfe

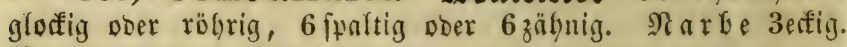
Beere 3 fäd)erig 3 [amig.

184) Isparagers. Gparger. Brüthentürle 6:

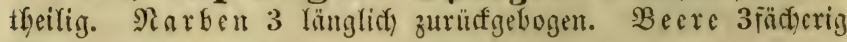
6 âmig.

185) Vuscari. Willo. SBifambiazinte. $\mathfrak{B}$ rï = thenfülte fugelig (ooer walglidy). Jrucht eine Raplel.

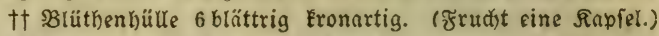

186) Tilionm. Qilie. Die brei immern Blätíten ber $\mathfrak{B l u ̈ t h e n l u ̈ l l e ~ m i t ~} 2$ Stywielen am (Srmmbe. (3) riffel 3 fpaltig. Samen flact).

187) Fuitillania. Schachblume. B(ättchetr ber Brüthenbürlen mit einer offnelt 5oniggrube au (sinme. গtarben 3 abfeftend. Samen flact). 
188) Talipa. Tulpe. Stณubgefä ве auf dem Blütbenboden cingefügt. Sriffel 0 . Narbe 3 theilig. Sn= me en flact).

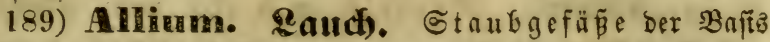
Der Blütgentülle aufgejebt. Samen fantig. (Die Dolbent

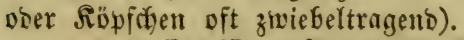

190) mathericum. Graghilie. Staubgefäßze auf bem $\mathfrak{B}$ lütgenfoben eingefügt, bie räben pfriemliç. Sa me u foutig.

191) Scilla. Mecrzwiebel. Staubgefäве an

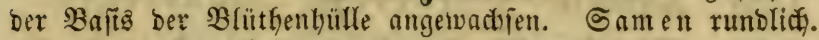

192) Ornithogalam. Rुogefmilch. Staub:

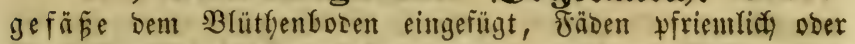
längliç. Gamen runoliç.

193) Warthecium. Aläbrimg. W(ebrenlilie. Staubgefäbe bärtig. Narbe 3 effig. Samen mit $\mathfrak{A}$. hängieln berjefyen.

t†† $\mathfrak{B}$ lüthenbülle 6 blättrig balgartig.

194) Juncus. Gimfe. Narben 3. Rapfel $3=$ fäcterig; Samen zafilreid), an Dem Rande ber Styeidemänbe

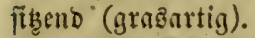

195) Luzula. Desuì. Sainfimfe. Narben 3. Rapiel Ifüdterig 3famig, Samen an bie Bafiz ber Rapjel geffeftet (grabantig).

196) Acores. Ralmus. B̧ Büthen îtan ein wargenförmiger mit Blüthed)en bedefter Rolben. $\mathfrak{R} a \mathfrak{b}$ e ftumpf fïgent. Rapjel 3fädferig, nicht nuffpringent.

\section{Soromung Trigynia.}

197) Colchicum. Beitlofe. Blut hen bülfe

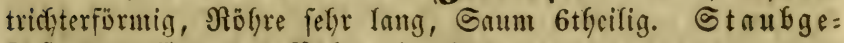

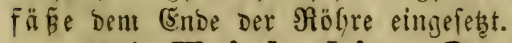

198) Troiglochin. Drcizacf. Blü thenhürle 66lättrig. (5) riffel 0 . Rapfeln 3 oder 6, zufammenge= wadtert.

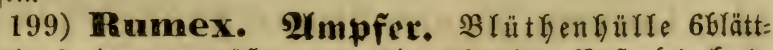

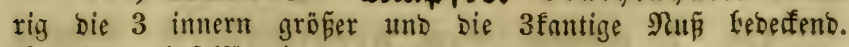
Narben pinfelförmig.

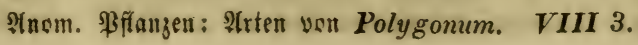




\section{Soronumg Hexa-Polygynia.}

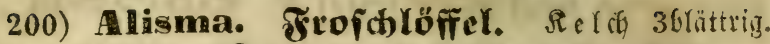

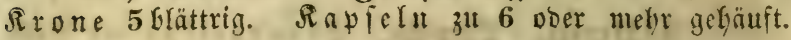

Hnou. 净anze: Triglochin maritimum. VI. 3.

\section{Sromung Nonogynia.}

178) Bérberis. Berberibe. Sauerdort.

453. B. vulgaris. Brätter เvimperig=gejägt, Traufent Gangento. - Straud), Bl. gelb. Sn (Sebüfd) anf bergigen ober hü= geligent Salfbuben hirt uno ba, z. $\mathfrak{B}$. un $\mathfrak{B}$ iolefeld (aud) auf

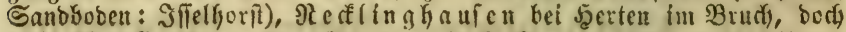
nidit äberall, fit mantigen Begenden in Şecteil gezogen uno vertwilbert. 5. 6. 方

\section{9) Peplis. Afrterquendel.}

454. P. Pórtula. Stengel twurzelno, Błätter gegen= überftäubig verfegrteiruno geftielt, SBlüthen winfelftünoig, faft

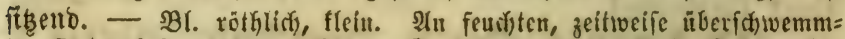

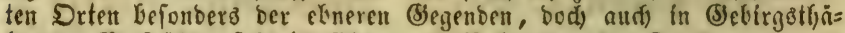

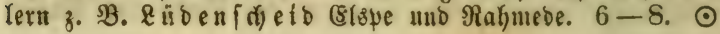

\section{0) Galanthus. Sdy neeglö of d)}

455. G. nivalis. - Stwei gefielte Blätter; Blımen uีter=

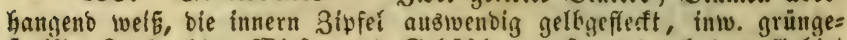

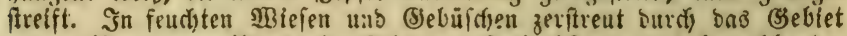

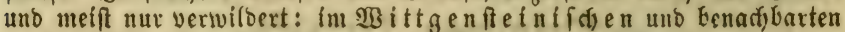

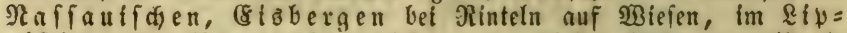

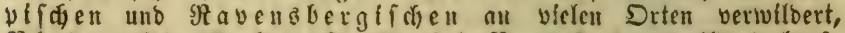

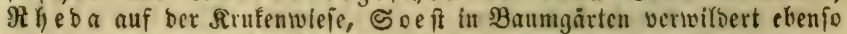

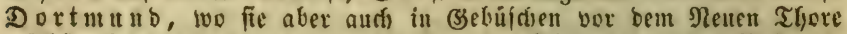

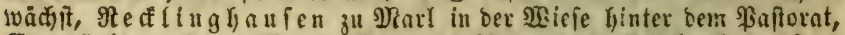

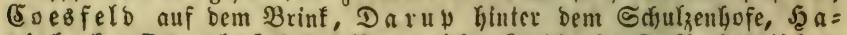

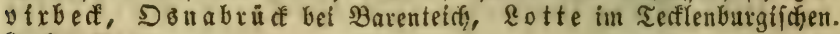
3. 4. 4

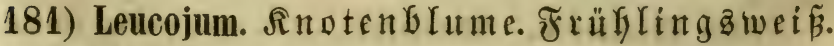

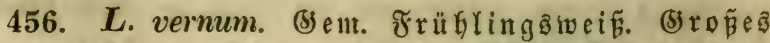

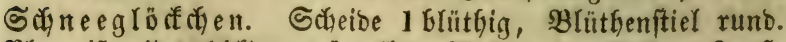

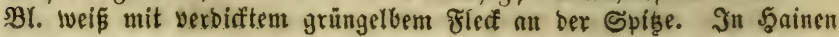


unb anf Wiefen ber jof benadjbatten $\mathfrak{R}$ a $\{i$ a uif (d) en entidjieben wild z. B. Im Thiergarten!

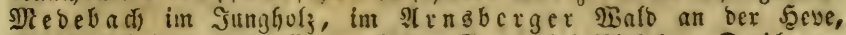

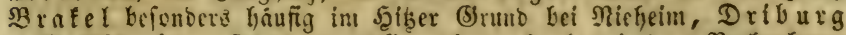

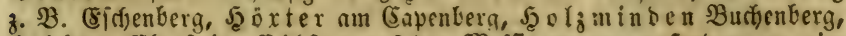

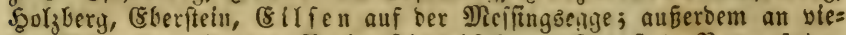
len Drten verwiloert z. SH. in Eip

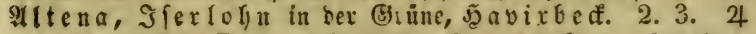

† 457. L. aestivum. Gpäte $\Re$. Gdveibe vielblü= thig, Blütgenftiele fontig. -

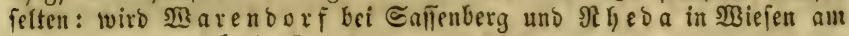
Steintuege angegeben. 5. 24

\section{2) Narcissus. Narziffe.}

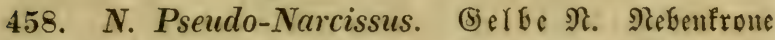

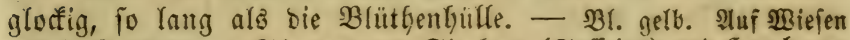

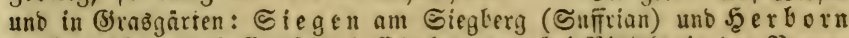

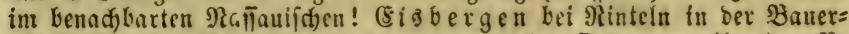

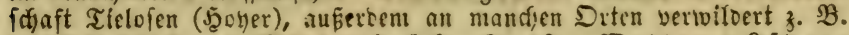

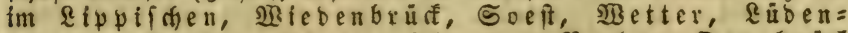

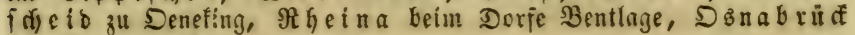

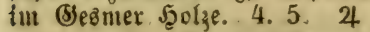

459. N. poëticus. SNE

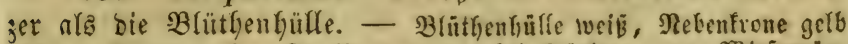

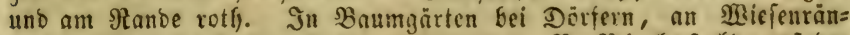
bern uno tergl. fier und ba verwiloert $z$. BB. Bielefelo nuf ber

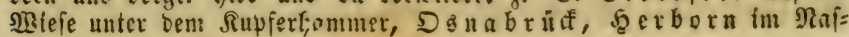
faulícien. 5. 4

\section{3) Convallaria. Miallilie.}

- Polygonatum. Turnef. Bglumen tridjterförmig, weiß́, an ber Epiz̨e grün. 460. C. verticillata. Duirlige $\mathfrak{M}$. Stengel faut= tig, Blätter quirlig. - Beete roth. In huhen (sebirgatwäldern

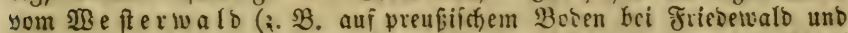

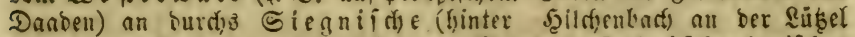

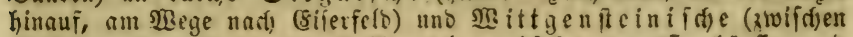

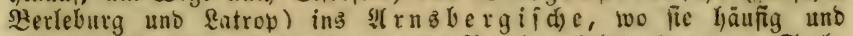

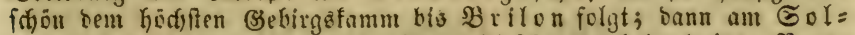

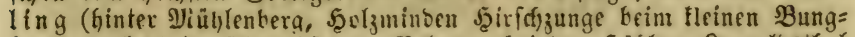

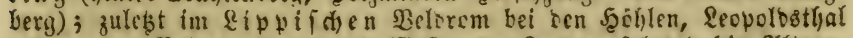

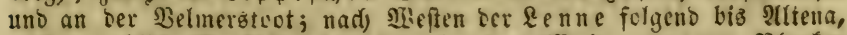
audf angeblid) Refflinghaufen in Den Maloungen am Blanfen (5ु이요). 6. 4

461. C. Polygonatum. Rantige tig, Blätter ftengelumfajlent abiredyjelno, Blüthenftiele twinfel=

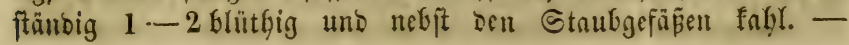


Beere violett. In büren fteinigen Bergmälbern befondor: auf Salf=

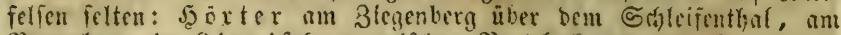

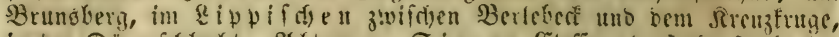

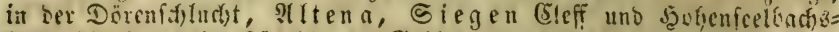

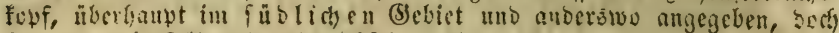
fefor oft mit folgenocr verivedfelt. 5. 6. 4

462. C. maltiflora. Bielflumige $\mathfrak{X}$. Ctengel ftiel: runs, Blätter ftengelumifaffend wedtifeluo, Blüthenfitiele winfel: ftänbig 3-5blütbig fafl, Gtnufogefäpe behanrt. - Bl. um bie

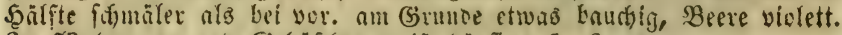

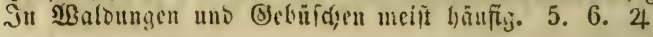

** SBlumen glocis, ganz weip.

463. C. majalis. (5) emeine 2i. Gduaft nadt balb=

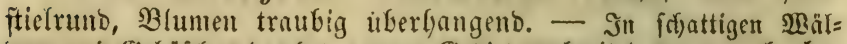

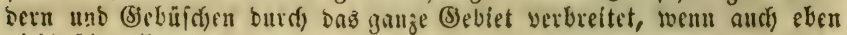
nitfyt überall. 4.5. 4

\section{4) Aspáragus. Sparigel.}

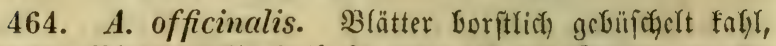
Nöbre ber Blütlenlülle balb fo lang als ber Eaum. - $B$ I.

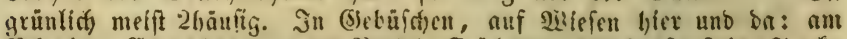

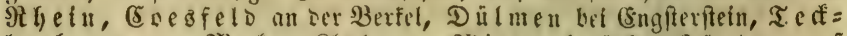

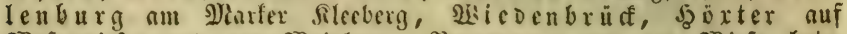

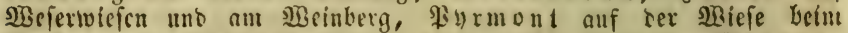

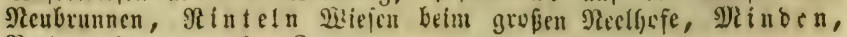

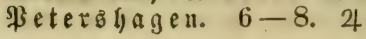

\section{3) Muscári. Tourmef. Bifamfiazinte.}

† 465. M. botryóides. Alill. (Hyazinthus botr. L.) Traubige B. Rugelfiazinte. Bblumen trabbig fugelig überfangento, bie vberften nuired)t gefd)(ed)tlos; BBlätter auf=

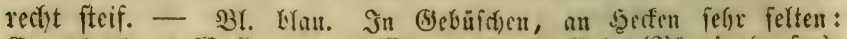

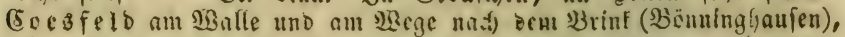

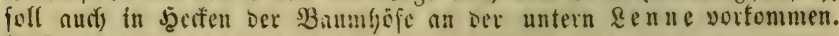
4. 5.24

\section{6) Lilium. Rilie.}

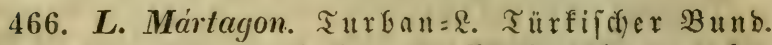

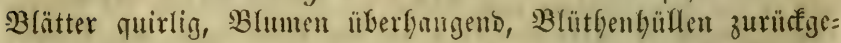

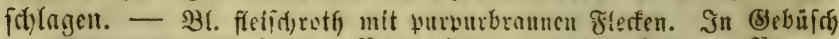
Der Esebirgägegenden felten: Berleburg auf Den Entroper Wergen,

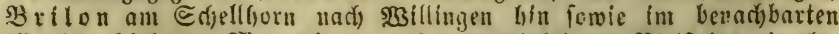

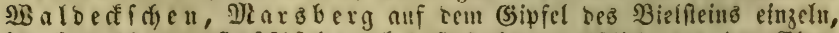

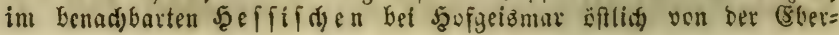




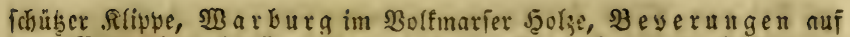

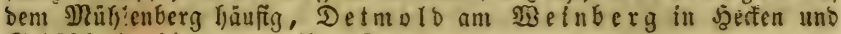
(Gebifid) (wohl nux verwilloert?). 6. 7. 4

467. L. bulbiferum. Jeuerlilie. Blätter zerifteut, Blumen aufredjt imwendig bon fleijoigen Sisarjen raub. -

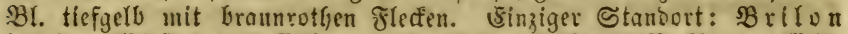

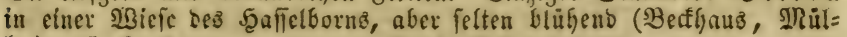
(er). 5. 6. 4

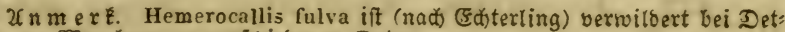
mols am 20unberg an verfdiedenen \$rten.

\section{7) Fritillaria. Sd) adb blum $\mathrm{c}$.}

468. Fr. Meleágris. Bemeine હரr. Riebitei. Stengel 1 blütbig, Blïthe ïberfongen๖, Blätter rimnig. -

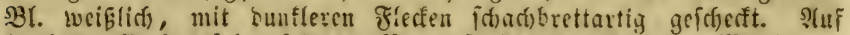

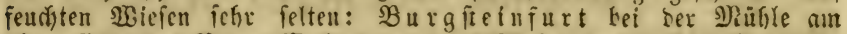

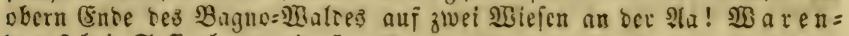
Dorf bei Eafienberg. 4. 5.4

\section{8) T'ulipa. Tulpe.}

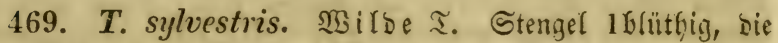
intern $\mathfrak{B}$ lätter oer Blütyenfuilfe und die Staubfüden an ber

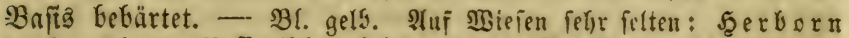

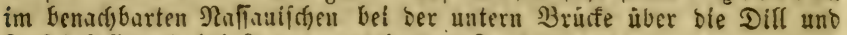
fonft ! foll outh) bei \&emgo vortommen? 4.5. 4

\section{9) Allium. $\mathfrak{x} \mathfrak{u} d$.}

- $\mathfrak{B l a ̋ t t e r ~ f ก a ~ n ก ~ n o ~ b r e i t . ~}$

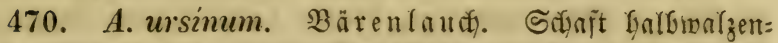

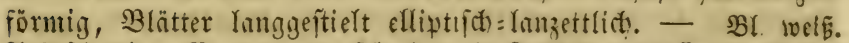

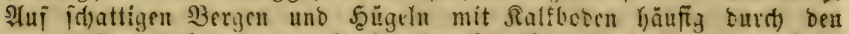
ganzen Teut oburgervalo bis ins Eippifiche, nudi ziemtidi verbrei=

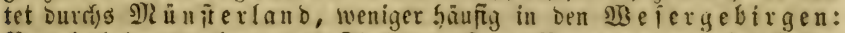

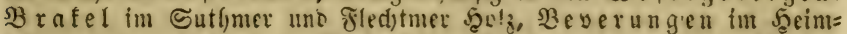

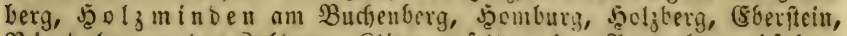

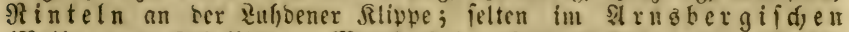
(Brifon am Edyellform, Nesebarfi im SBinterfoften) unb weiterfin

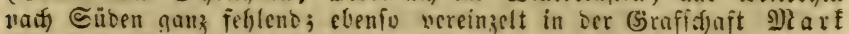

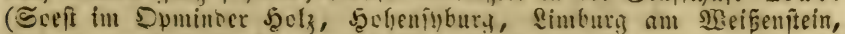

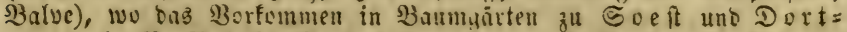

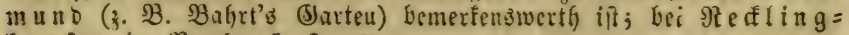

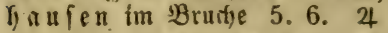

** Blätter flach unठ fadmal (grabartig).

$\dagger$ Die Dolbe nur sglüthen uno fpäter Rapfe'n tragens.

471. A. Porrum. (b) meiner ¿nutt. Borrei. Sten: 


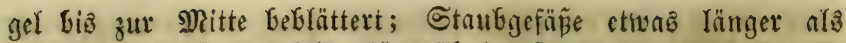
bie Blüthenfülle, wed) felg̈weife 3zäfnig; Bwiebel runblich einfacty. - BI. rofenroth mit bunfleren Rielen. Şäufi] gebrut. 6. 7. \$

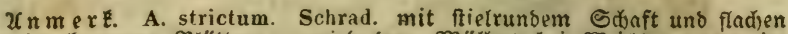

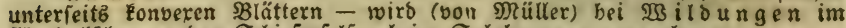
Walbedfiden an ben Sofieferfelfen beim Salzbrunnen angegeben.

†† Die Dolbe ein Röpfitien bon 3̧wiebeldsen bildend, zwifder benen die Blumen ftehen.

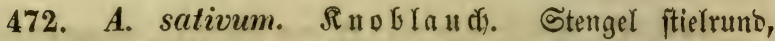

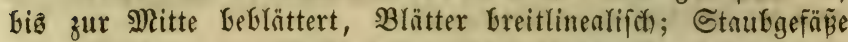
abtwechfelno an ber Baftz beiberfeits 1zäfnig; Swiebel gelyäuft,

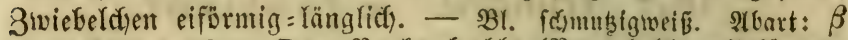

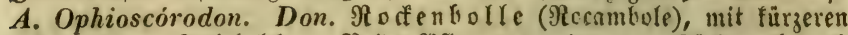

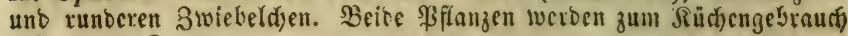
gebaut. 7. 8. 4

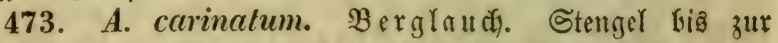
Mitte beblättert; Blätter rimnig, gegen bie Spize flachl, unter:

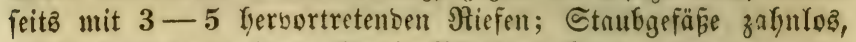
julebegt boppelt fo lang ala bie Blüthenlyullle. - Bl. rofenroth); rie eine Slappe ter Blüthenidjeite fefir lang gefdinäbeit. Fluf troffnen Triften felten: Dortmu no auf Wiauern in ber Stabt felbit (Suf= frian), Nienberge und auf ber Beerlage (Bounninghaufen),

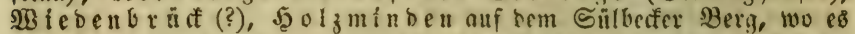
wertviftert fein frennte, im angränzenben $\mathfrak{R}$ a f ideldor şammer bei Diflenburg (Dörrien) uno am Bseiflichen Berg bel feerborn (Eecrs). 6-8. 2 *** Brätter ftielrund ober balbftietrunb, inwenbig wentigftens am
(Srunde röhrig.

$\dagger$ Die Dolde nur $B$ lüthen und fpäter אappeln tragend.

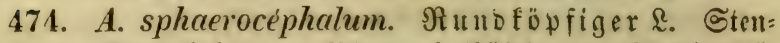

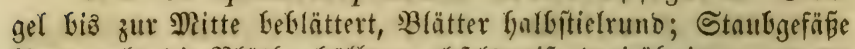

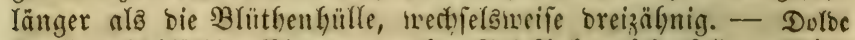

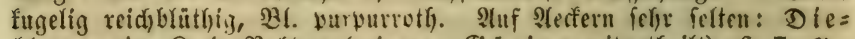

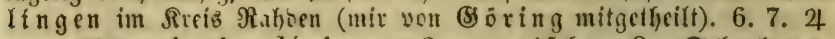

475. A. Ascalónicum. \&evantifoter \&. Sidalotte.

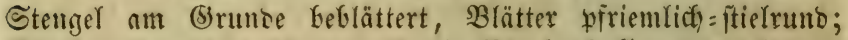

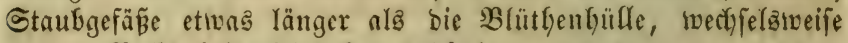

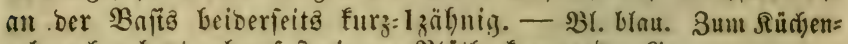

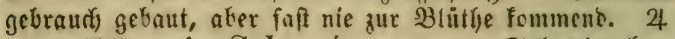

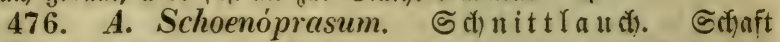
narft ober am (S)runbe armblättrig, B̉lätter pfriemlich)=ftielrunb;

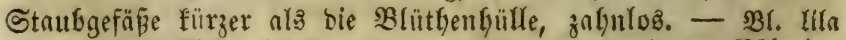

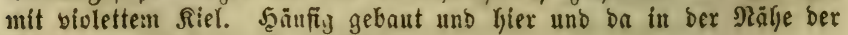
छătten vertwilberno. 8. 9. 4

47. A. fistulosum. Röbriger \&. SBintergwiebel. 


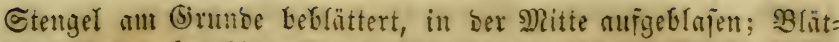

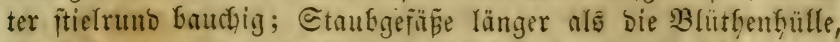

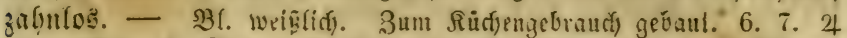

478. A. Cepa. 3wiebellaut). (5) emein: doer ๔om: merztwiefel. Etengel an (Srunde beblätert, unter ber Mitte

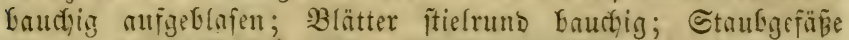

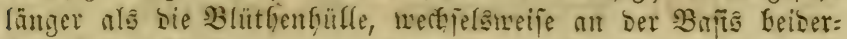

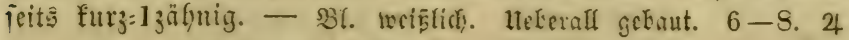
It Dorbe zroiebeitragent.

479. A. vineále. จุeinfergâlaud. Etengel big

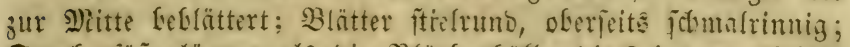

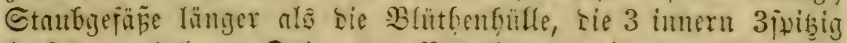
(auf ser mittleren Epitge Len Bentel tragent). - Bl. putpur=

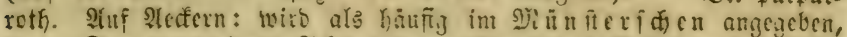

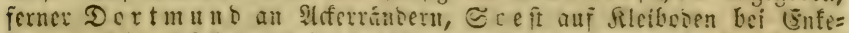

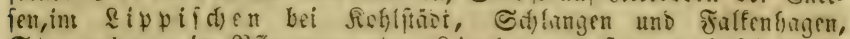

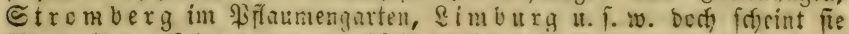

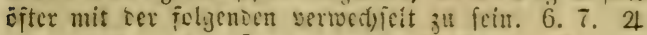

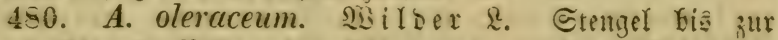
Mitte beflättert; Bläter linenlifac) rimig, nad ber Epibe fyin

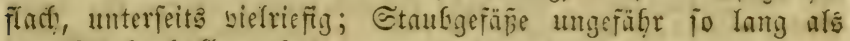

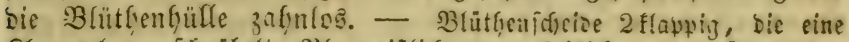

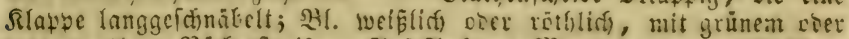

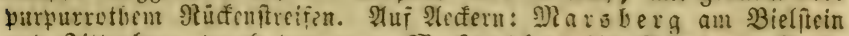

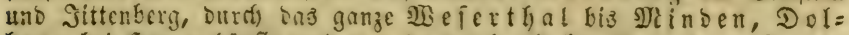

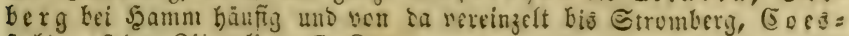
ferb auf ber 3itndelle. 7. 8. 24

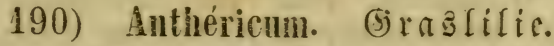

451. A. Liliágo. (5) emeine (5) r. Cotuft cinfart,

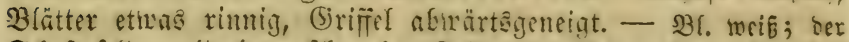

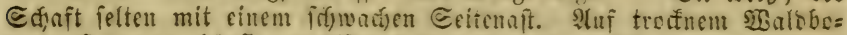

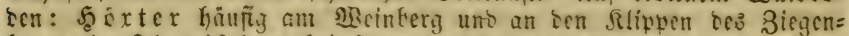

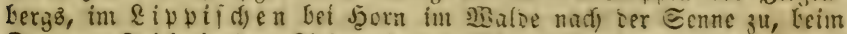

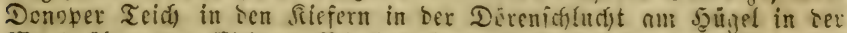

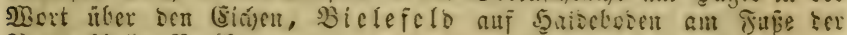
Berge hinter $\mathfrak{B}$ ruifinecie.

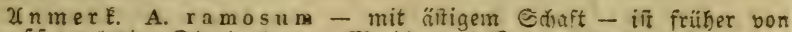

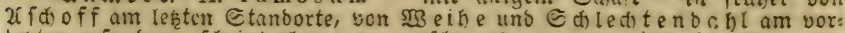
lekten gefunben, foreint aber ganj verfatwunben, wenn nidit eine Derrects: lung mit ber äftigen 2rbänberung ber vorigen itnttfano.

\section{1) Scilla. Meerzmiebel.}

$\div 4 \$ 2$. Sc. mutans. Sm. (Hyacinthus non scriptus. L. - Endymion nutans. Mumort.) Ueberbangende $\mathfrak{T}$. 
Sraube überlgntgento, Blittgentyüfe glocfig = warzig, an bet

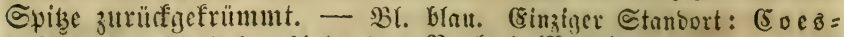

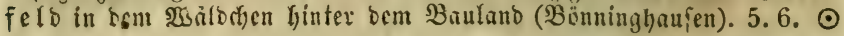

2 nm. Scilla amoena fübrt \&eers alb bei Seerborn am Sieghaufe roadffend an, bod) beutet ex feltit an, bas fie wohl nur berwilbert gevefen fein mag.

\section{2) Ornithógalum. $\mathfrak{B}$ ogefmilds.}

* Gagea. Salisb. Şlumen gelb, auß̄en grün.

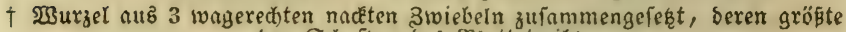
Den Edaft und 1 sBlatt treibt.

483. O. stenopetalum. Er. (Gagea stenopetala.

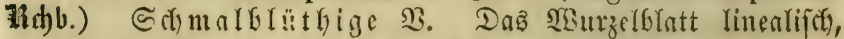

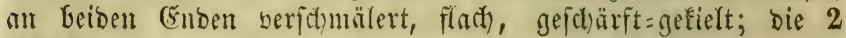

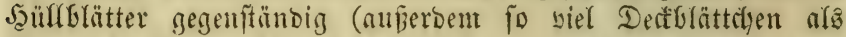
B(umen); Bimmeniticle fabl einfucl). - Stbart: $\beta$ o. Schre-

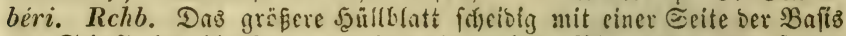

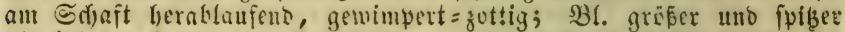

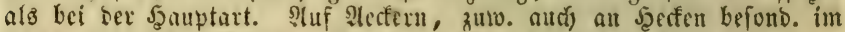

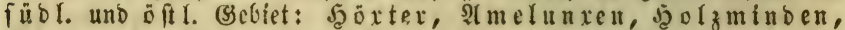

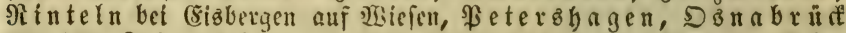

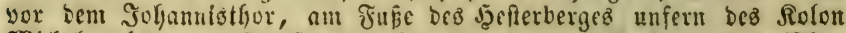

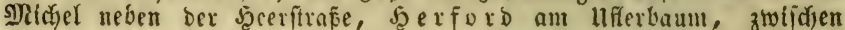

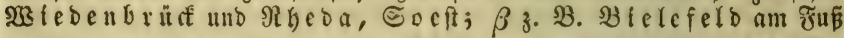

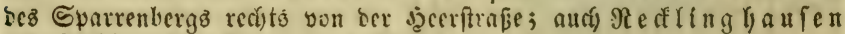

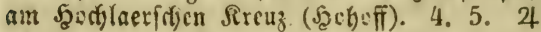

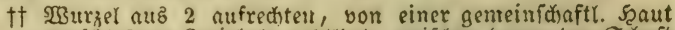
umidslofnen swiebeln gebildet, zwifden benen ber Edinft herooremmt

484. O. arvense. Pers. (Gagea arvensis. Sidult.)

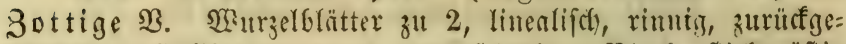
frümut; Şüflblätter zu 2 gegenfiünbig; $B$ lütbenfficle äftig bolbentranbig zottig; Blättden ber Blütlyenifticle ipize. -

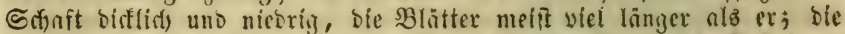

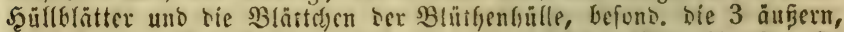

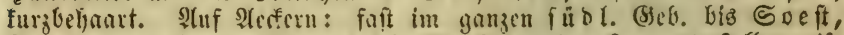

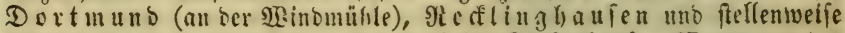

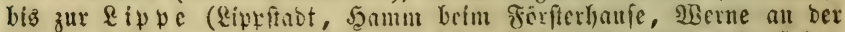

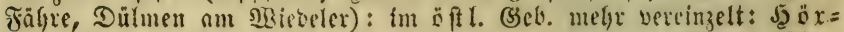

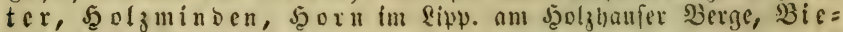

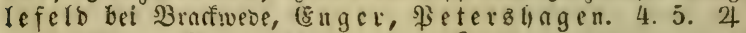

485. O. spatháceum. foumix. (Gagea spathacea. Sd.) G(heibige $\mathfrak{B}$. SYGmzelblätter zu 2, aufrecht, fäslich,

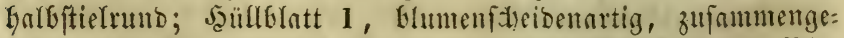
rollt, won ber einfadyen Dolse entfernt; Blättchen ber $\mathfrak{B}$ lï:

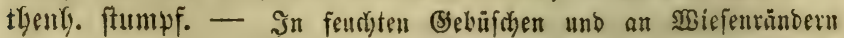




\section{Monogynia.}

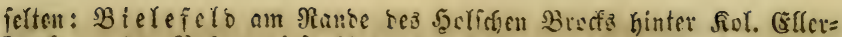

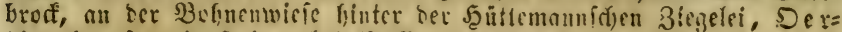
lingha 4. 5.4

††† 23 urber nur I fefte aufredite 3micber.

486. O. liteum. (Gagea lutea. Sidult.) (jelfe $\mathfrak{X}$.

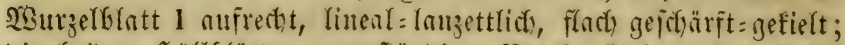

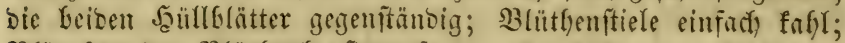

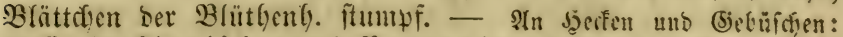

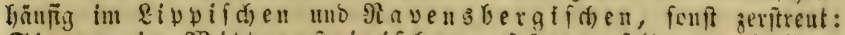

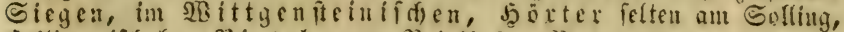

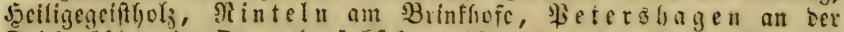

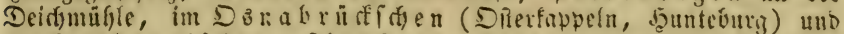

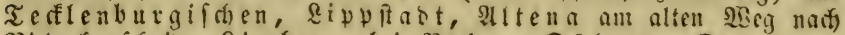
Micberfunffreid, Eimburg bei Berfum, Dälmen, Darup an Subfelbe. 4. 5.24

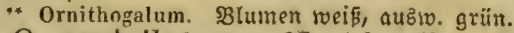

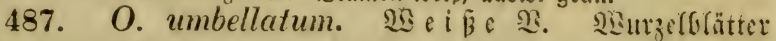
(5-8) linealifo rimig, Blätfenftiele soldentraubig, Blättd)en

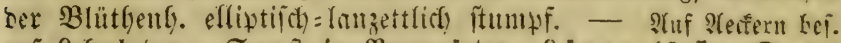
nuf Reffmboben: Eoeft in Banmginten, \& in nen hăung, Dort:

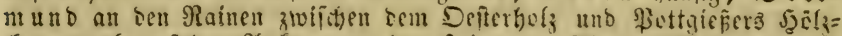

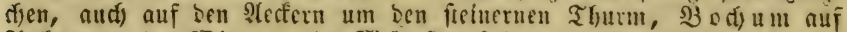

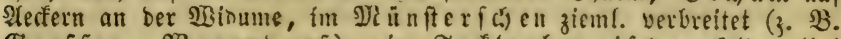
(8) reffen, STarenorf), im Tedflenburgifacn felten (bei 5aus Diarf), Berвm ol

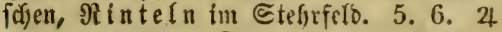

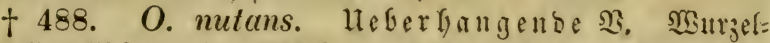
blätter linenlifđ rinnig; Blüthon traubig, zuleb̧ cinfeitämensig,

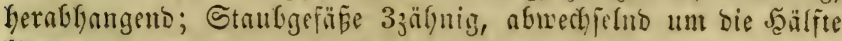

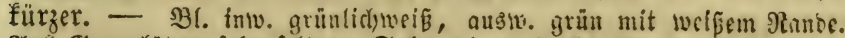

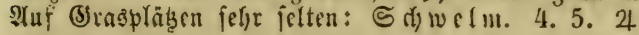

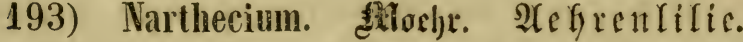

489. N. ossifrágum. 1juds. (Anthericum ossifr. L.)

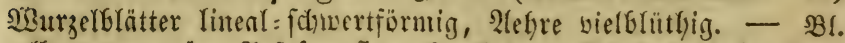

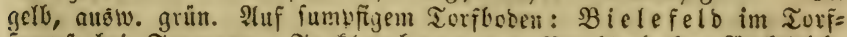

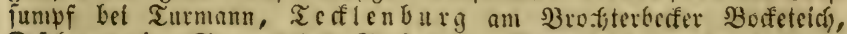
Dülmen im Sepventnoer Torfmoor, Dentfeim, im $D$ zan $a=$

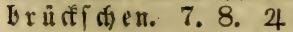

\section{4) Juncus. Simfe.}

- Linfrudotbare 5alme pfriemrida, neŏft ben blühandenden Enotenloz, am (Srunte mit blattloten Echeiden eingeldilofien.

$\dagger$ Epirte feitenftänoig georungen, borvelt zufammengefét.

a. Scalm mit umunterbrod)nem 9 Rarke angefülut.

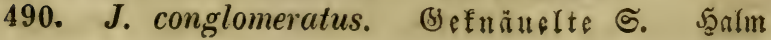


feingerillt; Briffel faft felylent ; Rapfel berfefret eif̣ormig, ge: ftubt, mit einer in ber Mitte aufgeferten ftumpfen Ěrgöbung,

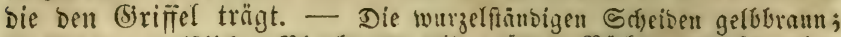

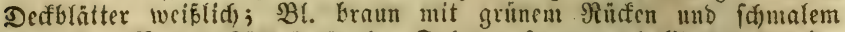

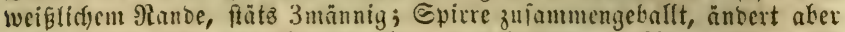

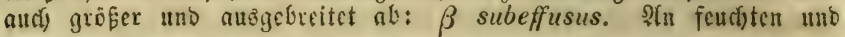
fumprigen Diten foäufig. 6. 7. 24

491. J. effusus. 2A glatt (nur im getroffuten 3uftande feingeriflt); (5riffel frift

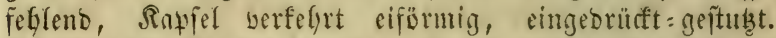

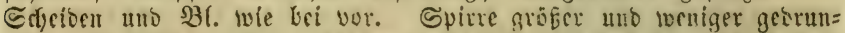
gen, oft breit ergoffen, anbert aber audi) mit faft cbenfo gebaffer Epire ab: $\beta$ compactus. Hoppe. Ftu fousten Siten. 7. 8. 24

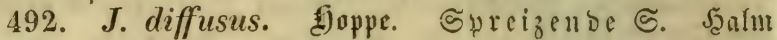
feingeriflt, Griffel benterflich), Sinpfel berfefrteiförutig ftumpf

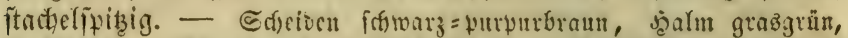

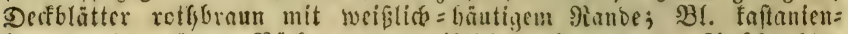

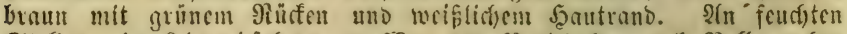

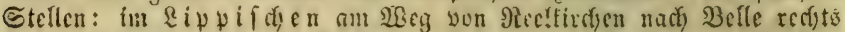

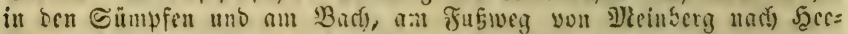

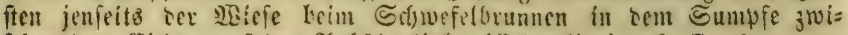

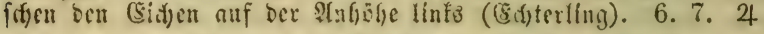

b. Şalm mit fäd)erig = unterbrodnem Mark.

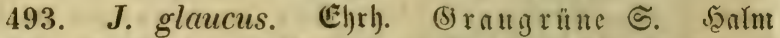

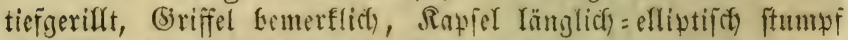

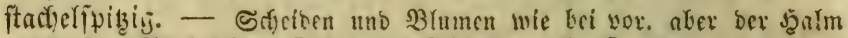
grauguär. Sิn feudyten Diten uno S:mpfen. 6-8. 4

$$
\text { t† Spirre feitenftänoig fopfig armblüthig }(5-7 \text { Bl.). }
$$

494. J. filiformis. Fa benförmige G. Santm fäb-

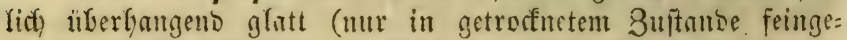
rillt), Briffel faft feglento, Rapfel runblid) fitumpf furgitad)el: fpibig. - Nutr etwa 6" hor), grägrün, Edstiben gelb= os. roth=

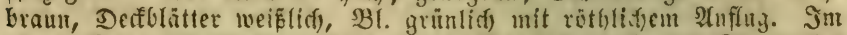

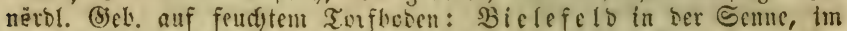

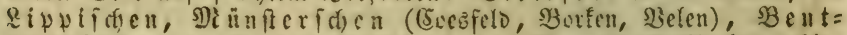

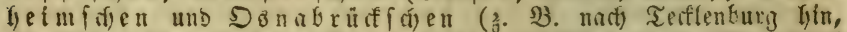

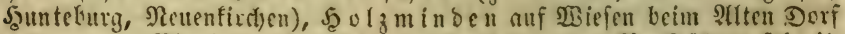

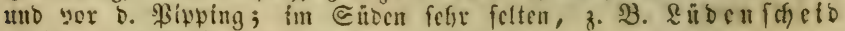

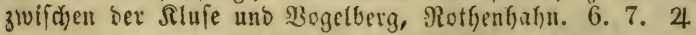

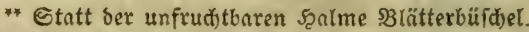

$\dagger$ \&lüthen in vereinzzelten §öpfd)en.

495. J. capitatus. Wurigel. Röpfige S. Şalnt

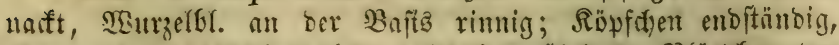

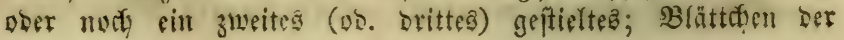




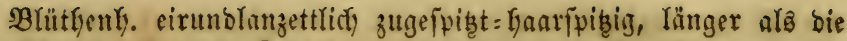
eiförmige ftuntyfe Ratfel. $-1-5^{\prime \prime}$ hodh, Blithenfsppfden wegen

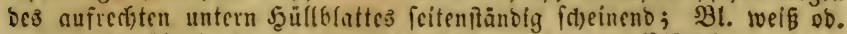

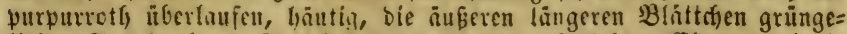

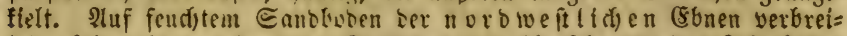
tet, ferten in ben bergigen Bspgenden auf inserfchmemmtem Rehmboben

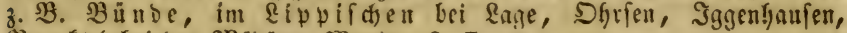

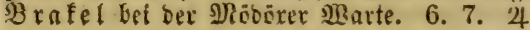

†† $B$ lüthen in zufammengefekter endfänbiger Epirre.

a. Şaln mit 2 bis 3 runsliđien şln̈ttern, bie burd) פues: wänoe beutliat) fäd)erig = Enotig find.

496. J. obtusiflorus. (E)br). StumufGluthige

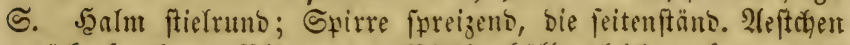
zurüffgefrocten; Blätter ber s(ütbenthülle gleidh, abgerumbet: ftumpf, etwa fo lang ala bie eiförmige fpize אapuél. - Die

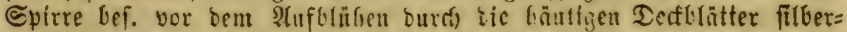

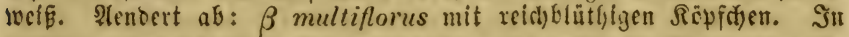
torfigen unb falzhaltigen Silmpien felten, und zivar $\beta$ : $\mathfrak{B a r e n d o r f}$, Dlffen, 5erforb, im \$aberbornf d en bel Salztotten unb in

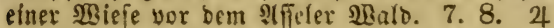

497. J. sylvaticus. Z゙id). (J. acutiflorus. E゙hrh.)

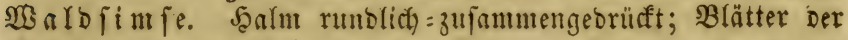
Blütfent. zugefpiţt = Eegrannt, bie innern lünger unb an ber Spize zurüffgebogen, alle fürzer als bie eiförmige zugefpikgt: gefthnäbelte Sapfel. - BBlätter bel ber Yebenden \$ilanz̧e ganz glatt;

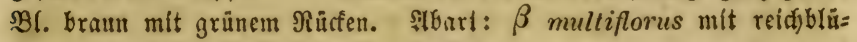

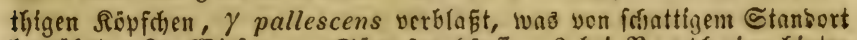

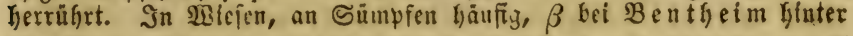

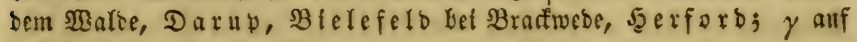
ber $\mathfrak{N}$ urbigelle. $6-8.4$

498. J. lamprocarpus. Efyrb. (J. articulatus. L.)

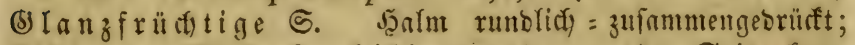
Blätter ber $\mathfrak{B l u ̈ t}$ thenf). gleichlang grabe, an ber Spizze furz= ftadtelfpizzig, bie äupern fpib, bie innern ftumtpf, alle fürzer alฒ bie ei=Inuzettförmige ftad)elfpizige Rapfel. - Blătter uno Bl. woie bet yor. Fenbert ab: $\beta$ multiflorus mit retdfbr. Rëpfofen; $\gamma$ fluitans mit fluthentem verlängertem

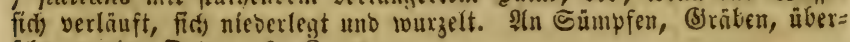
(đ) wemuten Diten. 6-8. 4

499. J. alpinus. Will. (J. fusco-ater. Sidreb. -

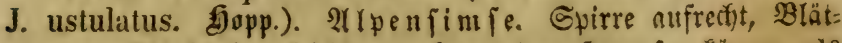
ter ber $\mathfrak{B}$ lïtfenf). gleict)lang nGgerunbet = ftumpf, firrzer als bie eiförmig = länglidye fant)elfțitzige Rapfel, bie äแpern unter 


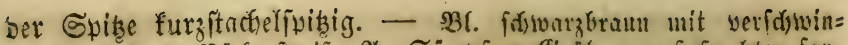

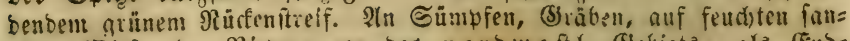

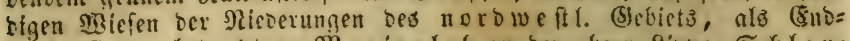

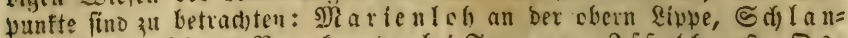

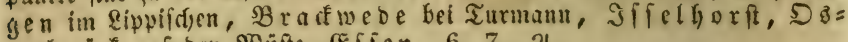

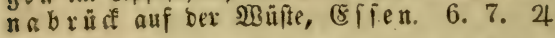

b. Scalm fäblich mit faft borftlid)en, oberfeitz fdmalrinnis gen, Enotenlofen $\mathfrak{B}$ lättern.

500. J. supinus. @lacud). (J. subverticillatus. Wulf.). Soblammfimfe. 2lefte der Efyrre verfängert, faft einfach, Röpfocten entfernt; Blätter ber Blittyent). Yanzett=

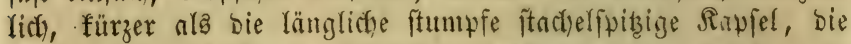

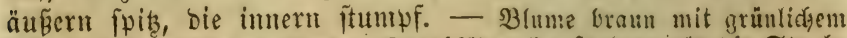

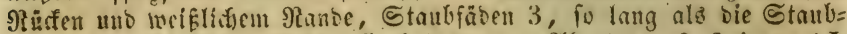

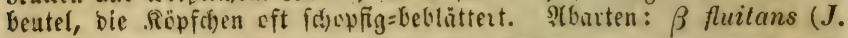
fluitans. Lam.) Şalme verlängert uno. flutf̧ent; $\gamma$ repens (J. uliginosus. Roth) Saatme liegento und avurgefno; $\delta$ nigritellus. Koch. 6mả.nige blütffen, Etaubfäocn no గi cimmat fo lang als bie Staub=

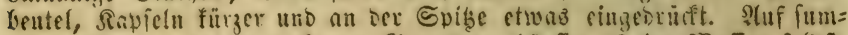

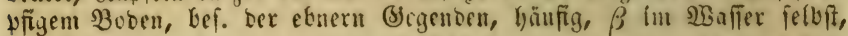

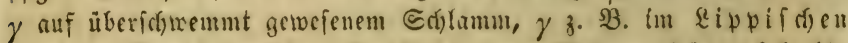

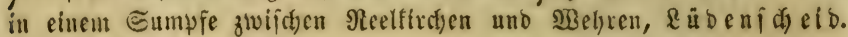
$7-9$. 24

It† Blüthen einzeln, entfernt oder boldentraubig und eine enditänoige 乡ỉzpe biloen

a. Şalm blattloz, am (Srund mit Blattībeiden umgeben.

501. J. squarrosus. Sparrige S. Blätter linen=

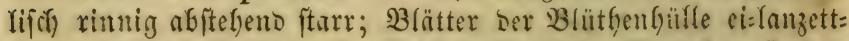
lich, yon ber Ränge ber werfefrteiförmigen ftumtyfen ftad,el:

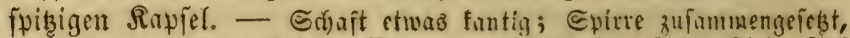

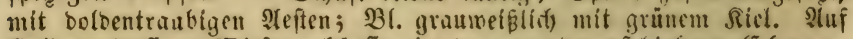

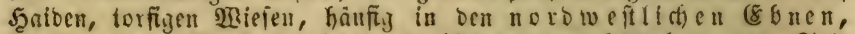
felten in ben $\mathfrak{B}$ efergebirgen (Jjöter am fisterberig unb Sol= ling) fowie in ben iübliticn. (B) ebirgen (Brilen auf ber langen

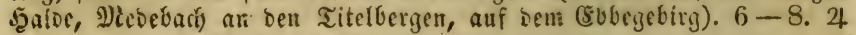
b. Şalm bevtärtert.

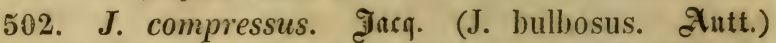

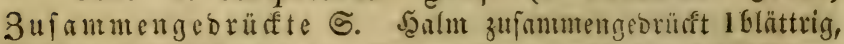
3Blätter lintealifa rinnig; Spirre fiurzer als bie Saullblätter;

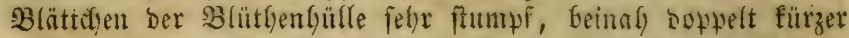

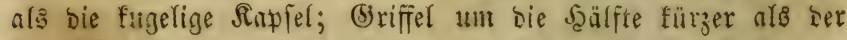

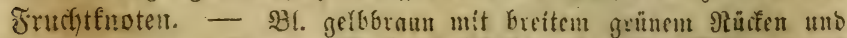

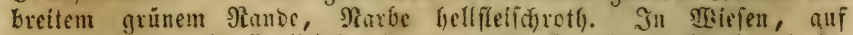

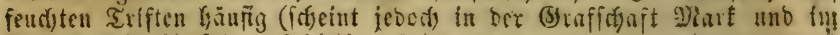
Beft Recflinghauler zu ferlfeii). $6,7,24$ 
503. J. Gerardi. fois. (J. bottnicus. Wullenb.)

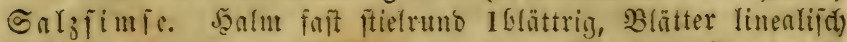
rimig; Spirre aufrect) soloentraubig; Blüthenbülle cirumb:

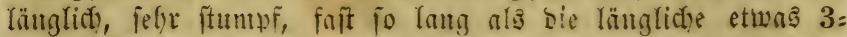

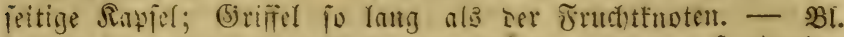

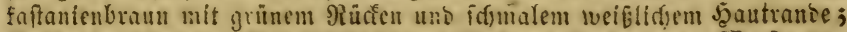

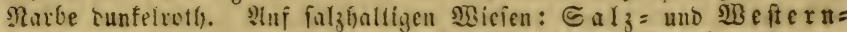

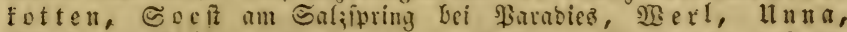
Rheina, Diffen, Ealzuflen, Refle, Sdyeder auf ter Whiefe beim Snlzbrunnen, Dribu:g. 6. 7. 2

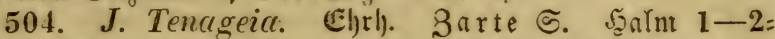
blätrig, Blatter Foritlid), an Der Bonts rimnig; 2lefte ber Spirre verlängert gnfelig nbitefents, Blätfen einjeln entfernt;

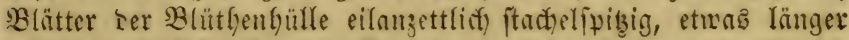

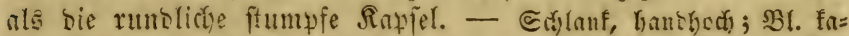

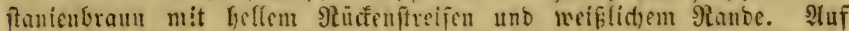

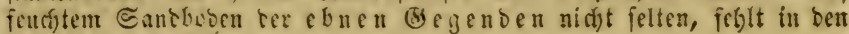

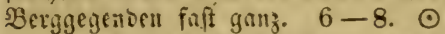

505. J. bufonius. Rrötenfimfe. Şałm beblättert,

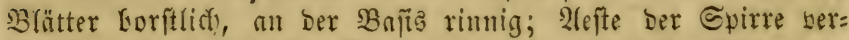
Yängert gabelig nufred)t, Blïtfen cinzeln entfernt; Blätter ber

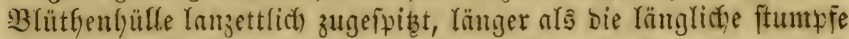

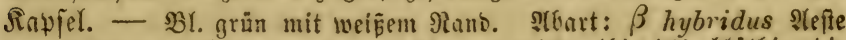

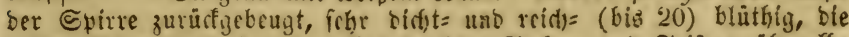

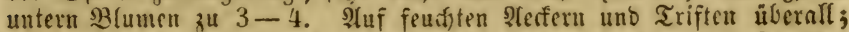

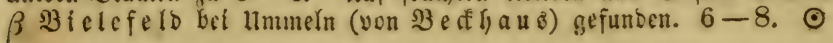

\section{3) Luzula. Dre. Sgainfimie.}

* Exirre siemlid) einfadt.

506. L. pilosa. TWill . (Juncus pilosus $\alpha$. L. -

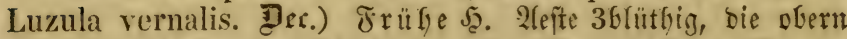

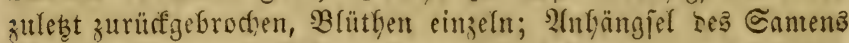
fitclefförmig; untre $\mathfrak{B}$ (ätter lanzettlid) Gefoant. - $\mathfrak{B r}$. braun

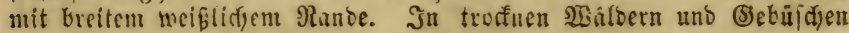
faft überall. 3. 4. 24

\section{"* Epirre geếnäurtt.}

507. L. campestris. Đore. (Juncus camp. L.) (S)e=

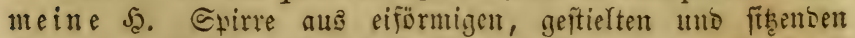
2(ef)ren zufanmengefest; $\mathfrak{B}$ lätter Der $\mathfrak{B}$ lütbengüfle zugefvibt, länger als bie runblidie ftumpfe ftactfelipibige Rapfer; Blätter

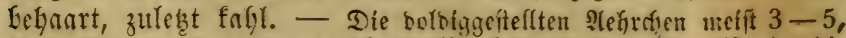

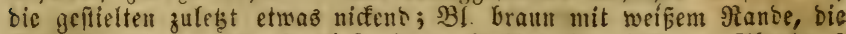

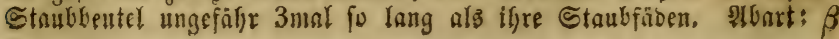


multiflora (L. multifl. Lej.) Aefren melft 5-10, alle anfiectit, Staubfäben fo lang alz bie Beuter, bie ganze \$flanze höbcr unb fiăr= fer; hiervon findet iich wieber eine form mit fur

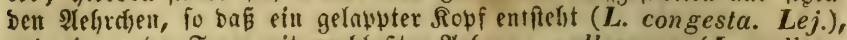
und eine anbre Form mit verblaßten Aferten: pallescens. (L. pallesc.

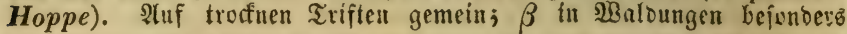
ber Berge nicht felten, bic Form congesta nuf ber Norbhelle im Elibegebirge, bie form pallescens in tieferem Sijatter. 5-6. 4

*** Spirre aubigcbreitet, mehrfad) zufammengefekt.

508. L. albida. Defr. (Juncus albidus. Gofint.) $\mathfrak{B} \in \mathbf{i} \tilde{\beta}=$

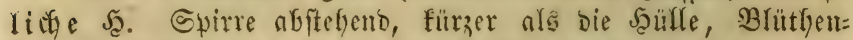

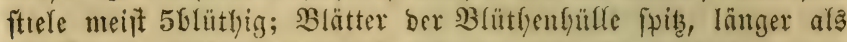

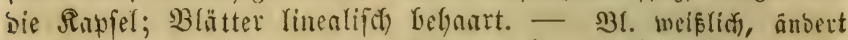
abex febr ryämfin mit röthlichen 3 lïtben ab: rubella. Hoppe. In

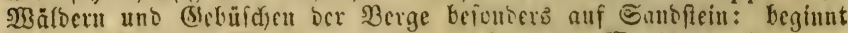
it ben eftlideren Theflem bes Teutoburger

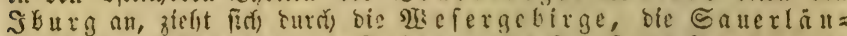

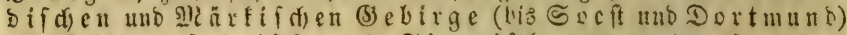

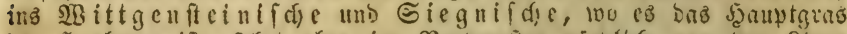

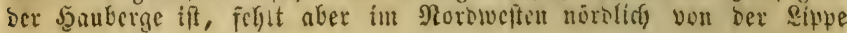
ganz. 6. 7.24

509. L. maxima. 刃er. (Juncus maximus. Ërb).).

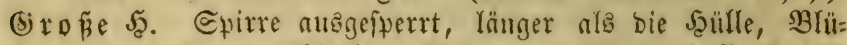
thenftiele berlängert 36 lütbig; Blätter Der Błütbenbülle ftad)el=

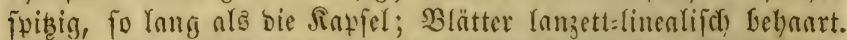

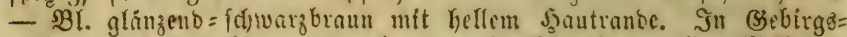
wälbern: Teutoburgerwalo vo!t Tedflenburg (im sisälodien

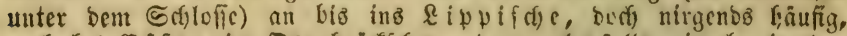
aud) bet (Effen im Dsmabrürficten, Dann cbenfalls einzcln in ben

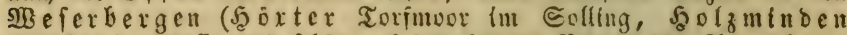

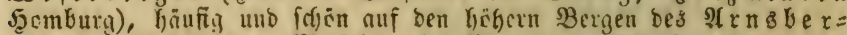

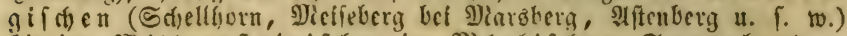
bio ins ख્a 3. auf Det Norofelle, bel Sdjwarzenberg, Nadyrodt, Thiergarten bi siltena, Şobenftein bei Retymate. 4. 6. 4

\section{6) Acorus. $\mathfrak{K} \mathfrak{I} \mathfrak{M} \mathfrak{u}$.}

510. A. Cálamus. Der obere Theil beछิ Sđhaftegీ blatt=

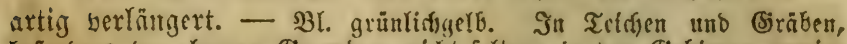

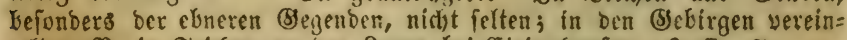
jelt 3. B. in Taitfen an ber Lenne bei Eiringhaufen. 6. 7. 4 


\section{Sorbiumg Trigynia.}

\section{7) Colchicum. 3eitlofe.}

511. C. autumnale. Sgerbifzeitlof̣. Balätter Greit

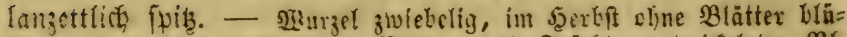

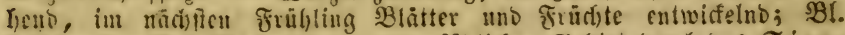

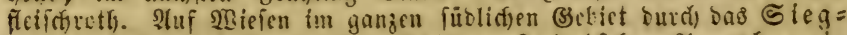

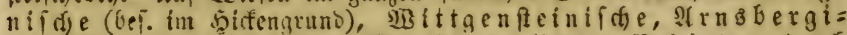

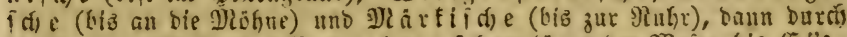
sie bergigen Theite beß $\mathfrak{T}$ a berbernf bergen bei Stinteln (weftlid) Kis Py)rmont); auferbem fïm verein= aclte Standorter angegcuen, wo es thcilweife verivilbest fein mag:

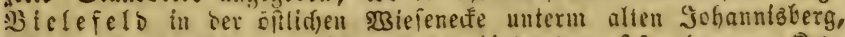

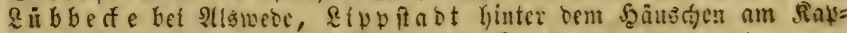
peler Thure, Dülmen und BBillerberf. 9. 10. 4

\section{8) Triglóchill. Dreiza af.}

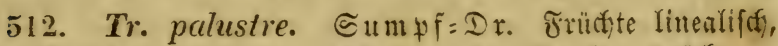

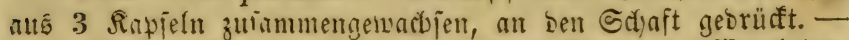

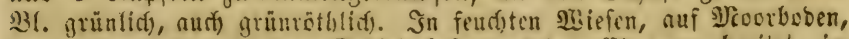

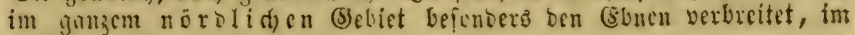
iüblidgen felten. 6. 7.2

513. Tr. maritimum. See=Dr. Jrüthte eiförmig, un=

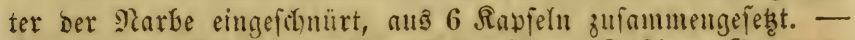

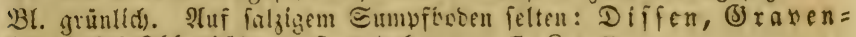
ho: fit bei Gobenbübren, รูแกteburg. 7, 8. 4

\section{9) Rumex. $\mathfrak{A} \mathfrak{p} \tilde{\mathrm{fex}}$.}

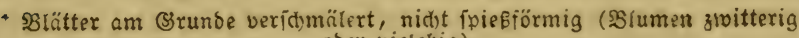
ober vielehig).

†. Frututelappen (alle ober eine) fdrsterentragent.

a. SRlüthenquirłe fämtlid) mit $\Re$ lättern geftüß̨t.

514. R. muritimus. Seeampfer. Blätter Inmett=

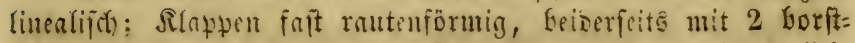

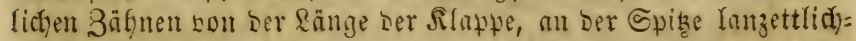
sorgezogen. - Duitle virfklütfig geitüngt, Bl. wie lei sen folgen=

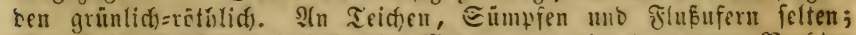
Sce it in Bráben kei Edimefe, siderne an cingestungenen Budjten

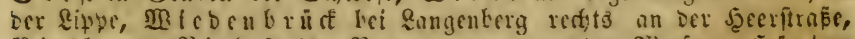

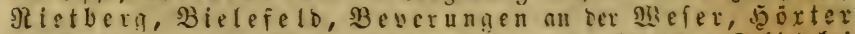

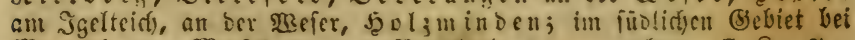
Di a rBberg, 此ftede und Berleburg angegelen. 7. 8. 4

515. R. palustris. Sm. Sumpfampfer. Błătter

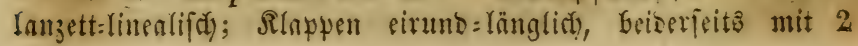




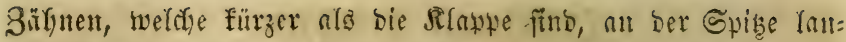
zettlidf)=borgezogent. - Quirle enffernter alz Bei vor. Ș(n Eümpfen

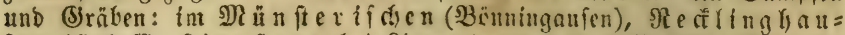

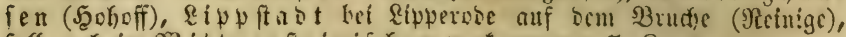
foll aud in 2 it

516. R. conglomeratus. Mlurx. (R. Nemolapathum. (E)

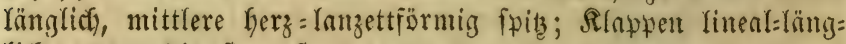
rich ganzranbig ftumpf. - Sefte weiturferieno, Duirle entfernt,

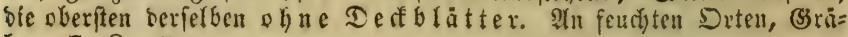
ben. 7. 8. 2

b. SBlüthenquirle blattlog, ober nur bie unterften mit einem sintte geftüist.

517. R. obtusifolius. Stumpfblättriger 2l. Untre Blätter Kerzeiförmig ftumpf, mittfere länglicl) = 3eifig neBabrig, am (5rumbe pfriemlich gezäfnt, in eine ftumpfe Epize vorge: zogen. - Duirle ziemliti) entfernt. Sthart: $\beta$ sylvestris (R. sylv.

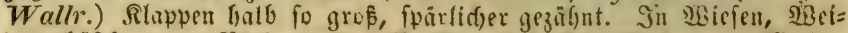

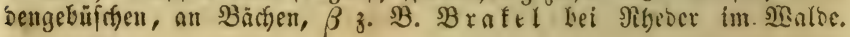
7. 8. 24

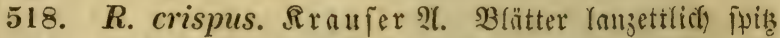

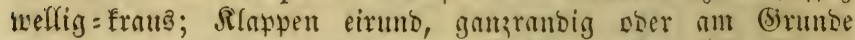

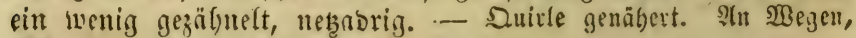

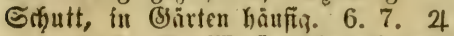

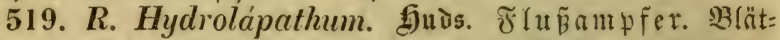
ter Immettfich, Geibericit3 berid)mälert, an Rambe weflig:flein=

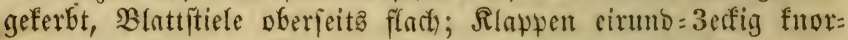
pelig nebabrig, am (5)rumbe zumeilen etwns gezägnelt. - Biz

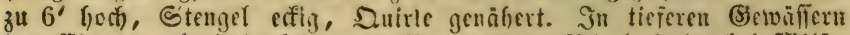

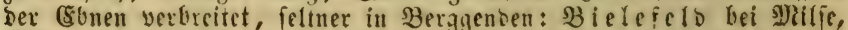

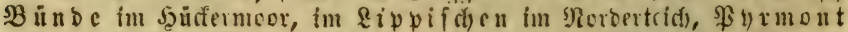

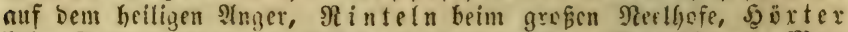

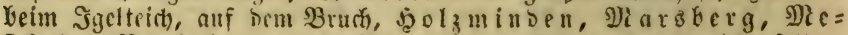

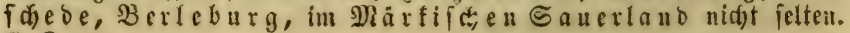
7. 8.24

520. $R$. maximus. Sidrib. (3) rof $\mathfrak{B}$ er $\mathfrak{A}$. Untre $\mathfrak{B}$ (ät= ter Yäuglich fpits, am (Srumbe fdicfeiruno ober herzförnig, Blatt= ftiele oberfeita flach und beiserfeits mit einer hervortretenden Rippe Geranbet; Ratapen 3erfig=herzförmig, ant (Srumbe gezäl)=

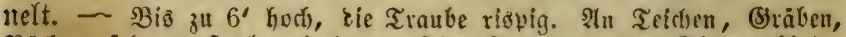

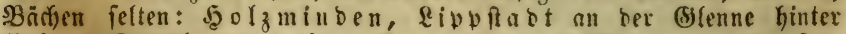

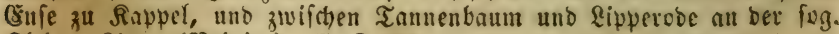
STeinen Rippe (

521. R. sanguineus. Şainamyfer. Itnterfte Blätter berzförmig=länglich), ftumpf ober fpib, bie mittleven berz=lanzett= 


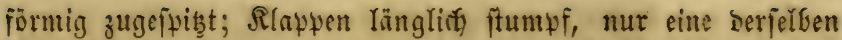

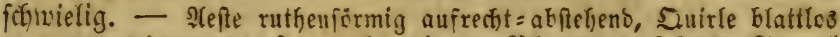
orer nur bie unter ften mit einem $B$ latte ge îu unb Slattabern blutroth. 2 (bart: $\beta$ viridis gan grun (R. nemoro-

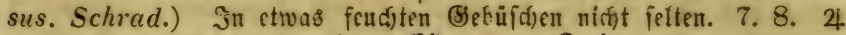

522. $R$. pratensis. Mlert. \& Fand). (R. cristatus.

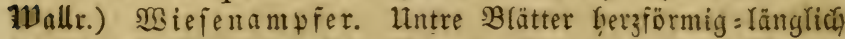
ipit, bie oberiten lanzettlidi); Rlappent eiruno, etwaş herzförmig, ftumpf, am Brunde mit 3 effigen zugefpibzten ober piriemliffen 3ähnen, an ber Exibe ganzrandig, alle doer nur eine berjel= ben fidfwielig. - Dutrle ber blattlofen Traube genälfert. In fend $=$

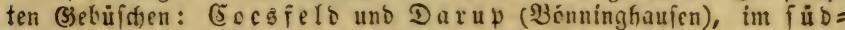

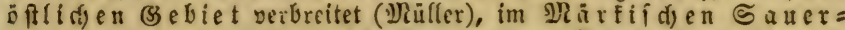

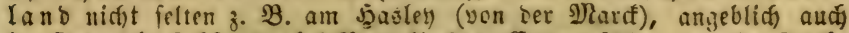

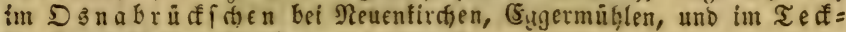
Ienburgifden Eci Rolte. 6. 7. 4

523. R. Patientia. (5)artenampfer. Untre Blätter eirunb = Ianzettlich zugejpibt, bie oberiften lanzettlich, B Iattiftele rimuenförnig; Rlappen rumblid)= Kerzförmig ftumpf neşabrig ganzrnnbig ober foum gezäfnelt, nur eine berielben fäwielig.

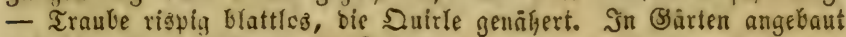
uno nitunter verwildoert. 7. 8.24

t† Frudtetrappen faymielentos.

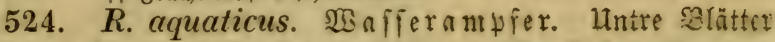

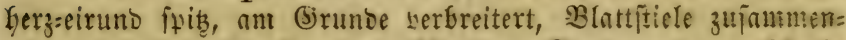

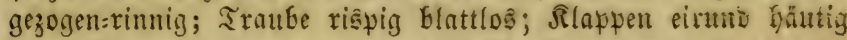

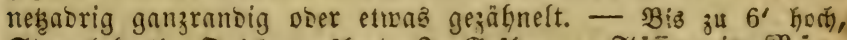

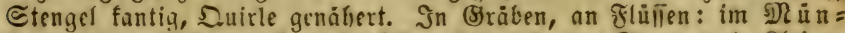

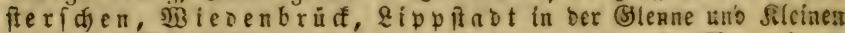

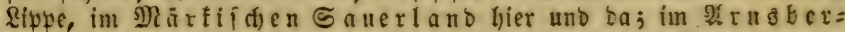

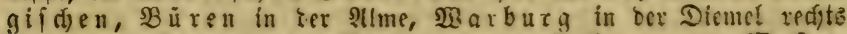
yon ber Rafifler Strabe, Brafel in ter Nethe, an ber șefer, æeters̆hagen im forft. 7. 8. 4

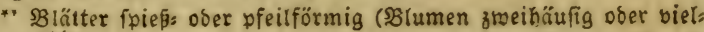
ehig).

525. $R$. scutatus. ๔đ)iloblättriger $\mathfrak{R}$. Blätter

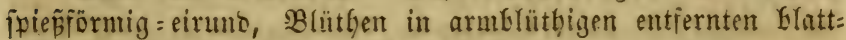
Iojen Salfquirlen, SRlnppen fetwielenlos. - - Sn feinigen Drten umb Bemäuer felten: an bem ङ

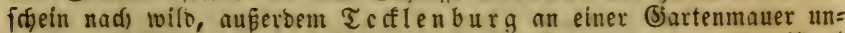
ter. Sem Єdjló unb an einigen allberen Steflen, wo er nur verwiloert idjeint. $5-7 .-2$

526. R. Acetosa. Sauerampfer. Bblätier pfeilför=

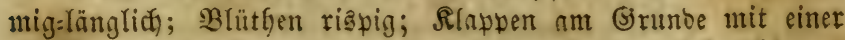

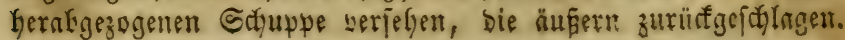




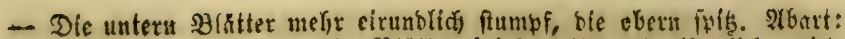

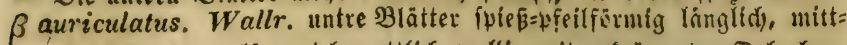

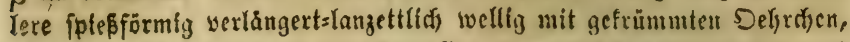
obere fofe formal uno oft zurüfigerollt; $\gamma$ multifidus wie voriger bodi

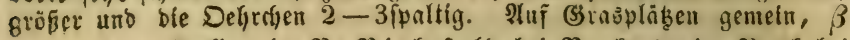
auf feutiten Stellen (z. B. Bielefelo bel Bradtwede im 2 tod hiel (Stafermann), $\gamma$ an trodneren Diter. $5-7.24$

527. R. Acetosella. R̂̉einer S. Blätter fuiebrör: mig:lanzettlidd, Blütben riäpig, Slappen fduppenlos, bic äuferu

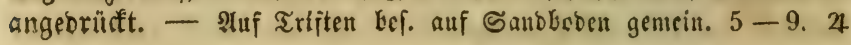

\section{Sroming Tetragynia.}

\section{0) Alisma. Frofditoffer.}

* Blätter rourzerfánoig.

528. A. Plantago. (5) enteiner $\widetilde{r}$. Sithaft quirlig=

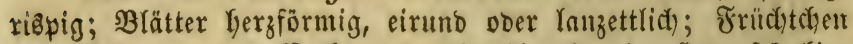

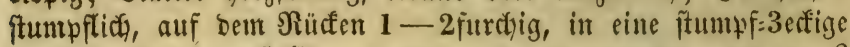

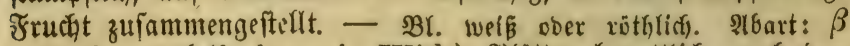
lanceolatum (Al. lanceol. With.) Slätter lanzettlid), nadg bem (Srunbe verff̧mälert, nux $\mathbf{I}^{\prime \prime}$ breit; $\gamma$ graminifolium (Al. graminif.

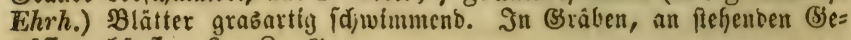

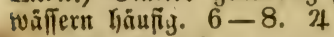

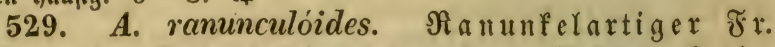
Shaft an ber Spize bolbig ober nub ber Dolbe noif eime Dolbe treibend; Blätter lanzettlidh 3nervig; Früchtd)en fduief= elliptifa 5 fantig fpib, in ein fugeliges Rüpronen zufammenge=

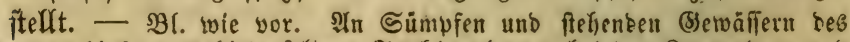

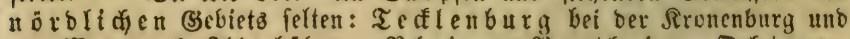

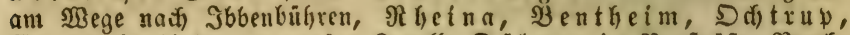

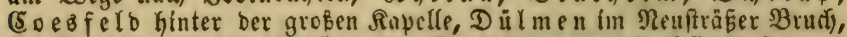

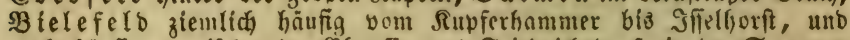
nod) lyäufiger ziwifdyen ber (Shauffice uno Friebrichsoborf, fu ber Se nue,

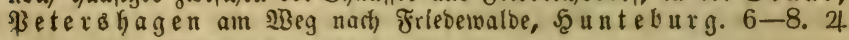
** Blätter ftengelfändig î́)wimmend.

530. A. natans. Schivimmender Fr. SBlätter ellip=

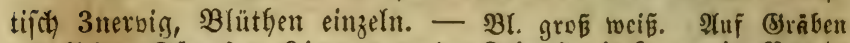

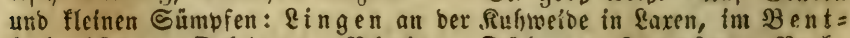

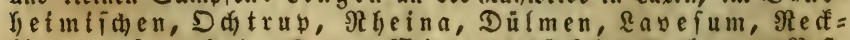

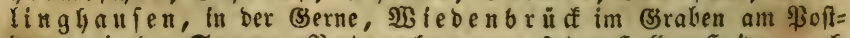

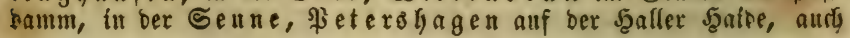




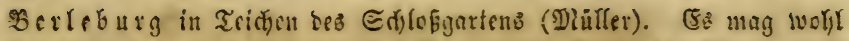

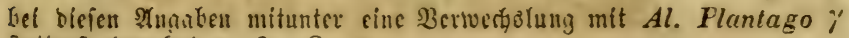
frattgefurosn lyabell. $6-8.24$

\section{Gicle slafie. Heptandria.}

\section{Soromung Monogynia.}

201) Trientalis. \$fingftblume. $\mathbb{A}_{\mathrm{f}}$ (t) uno Rroue itheilig $(6-9$ theilig). Sapfel 1 fäclerig.

202) Aéscalus. Fofifnitanic. Rel 5 jännig. Rroue 5brättrig unregelmäpig. Rayfel 3 jüdjerig.

\section{1) Trientalis. FFingft b Yume.}

531. Tr. europaea. - Blätter cirunb = langettlid, ganis=

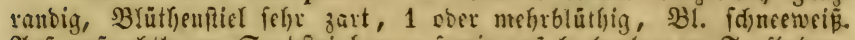

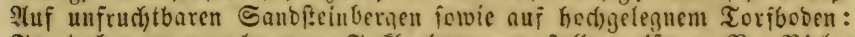
Teutoburgerwalo ven Teffenburg au fetlenveiie 8 . B. Bicle=

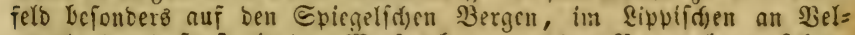

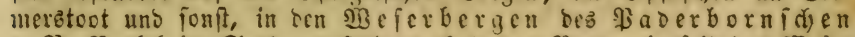

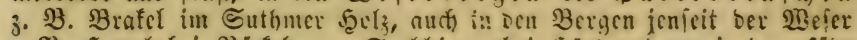

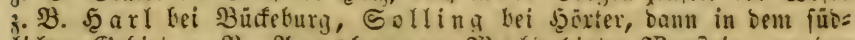

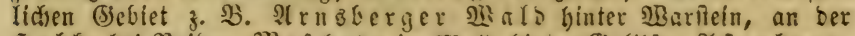

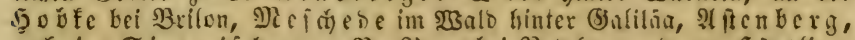

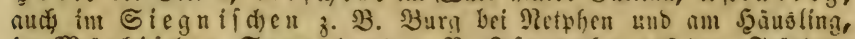

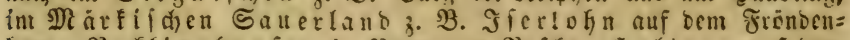

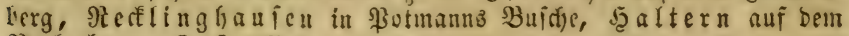
Borfenberg. 5. 6. 4

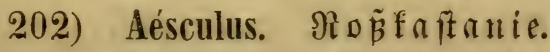

532. A. Hippocástanum. Blätter gefungert 7 zählig,

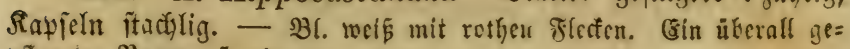
pllangter $\mathfrak{B a u m}$. 5. 方 


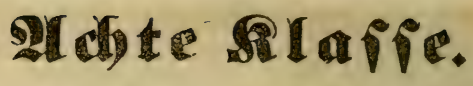 Octandria.}

\section{Sromung Monogynia.}

* Blüthe volltänoig 5blättrig.

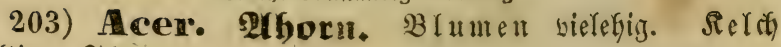
5 fpartig. Flügelfrütite 2.

** Blüthe volltänsig 46rüttrig.

204) Denothera. Racbtferze. Rel (h) 4 farl tig. Rapjel 4 färtjerig. Samen nadft.

205) Epilobionm. $: 23$ cibenröschen. $\Re e l$ th ab:

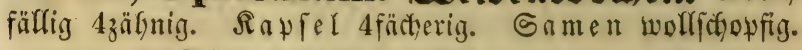

*** ştüthe vollfänoig Iblättriq.

206) Vacciniman. Speidelbeere. Rertif blei= Gend oberítändig 4zäfnig. Beere 4-5fäduerig.

207) Evica. Sacibefraut. Reldi bleibento unter:

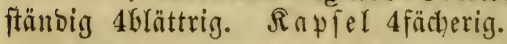

Atromaliaj) $\mathfrak{B f f a u z e n : ~ M o n o t r o p a . ~ R u t a . ~ X . ~} 1$. **** SBlüthe unvolfftänoig.

208) Daphone. Scibelbait. Brütgengülle 4 partig. Strubgefäвe ber Röbre eingefügt. Steinfrudit I famig.

\section{Sronung Digynia.}

Inomalifache \$flunzen: Chrysosplenium X. 2. Ulmus effusa V. 2. Moehringia X. 3. Atrten yon Polygonum VIII. 3. Scleranthus $X_{0}, 2$

\section{Sronung Trigynia,}

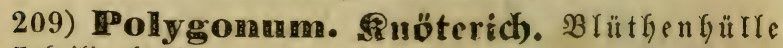
$4-5$ theilig bleibent. Staubgefäв $5-8$. (S) riffel 2

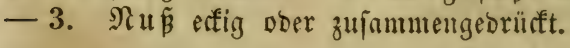

\section{Sronung Tetragynia.}

210) Tanis. Ciubcere. Relch 4blättrig bleifent. Rrone 4blïttrig. Beere oberitändig 4 fädterig. 
211) Aloxa. SBifamfraut. Rel(t) $2-3$ ipartig. Rrome 4-5fpaltig. Beere 4-5jamig, an ben Relet ge: wact)

212) Elatime. Iänucl. Rel uno Rrone 4: blättrig. Sapfel oberítunbig 4 füd)erig bieljamig.

2tnomalifache Pflanzen: Myriophyllum XXI. 6.

\section{Sronung Monogynia.}

\section{3) Acer. $\mathfrak{A} \mathfrak{p}$ orn.}

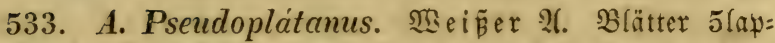
pig, ungleidi ftumpigefügt, unterjeits graugrün; Trauben ban= geno, Jruthtfuoten zottig, હtanbgefäpe boppelt jo lang als bie

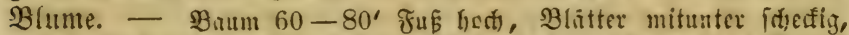

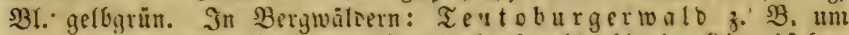

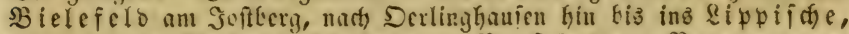
bann in sen Befergebirgen z. SB. Forter, Beverungen

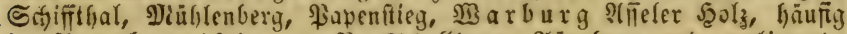

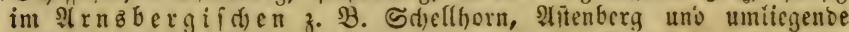

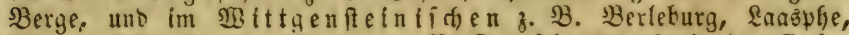

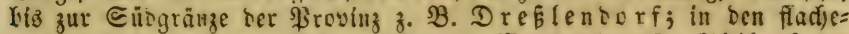
ren (Begenter felten: Etromberg, SMarendorf, Tilbef am Baumberge; auferbent eft angepflangt. 5. 6. क

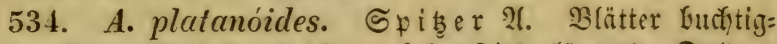

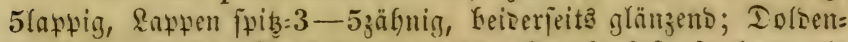

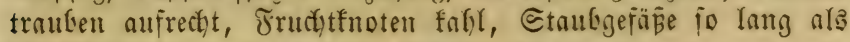

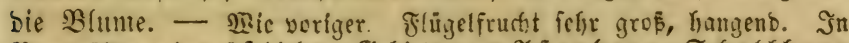

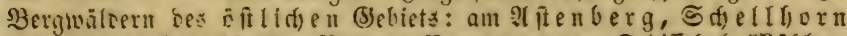
uno auberen Lenadjbarten Bergen! Beyerungen Ertiñtlal, syithlen=

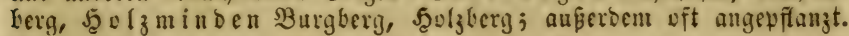
5.

535. A. campestre. Feloaforn. WaEgolder.

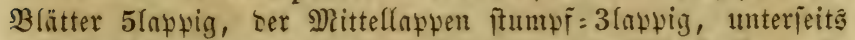

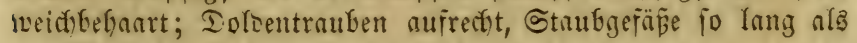

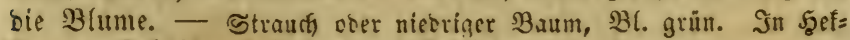

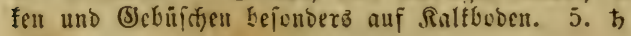

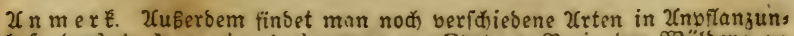

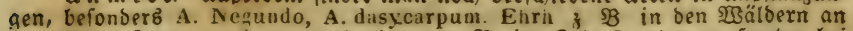
Der untern Renne, aud A. Saccharinum z. SB. im Sdilop̈garten zu Şerten bei ßed linghaufen. 


\section{4) Denolhéra. Na n teferze.}

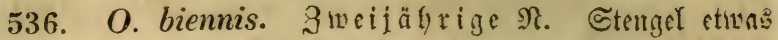

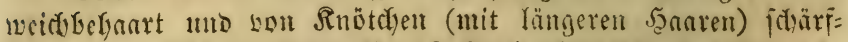

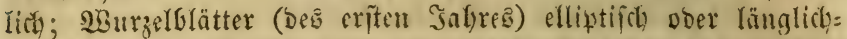
werfeforteirund, ftumif mit mufgefertem Epibchen, bie untern

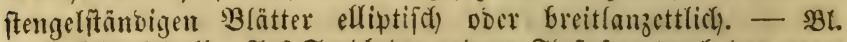

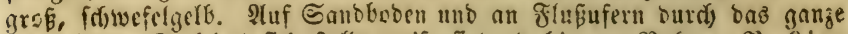

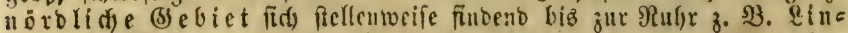

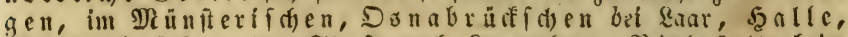

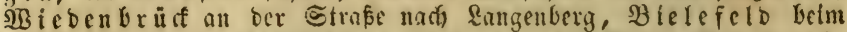

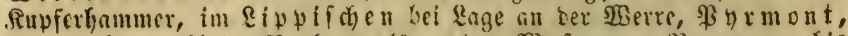

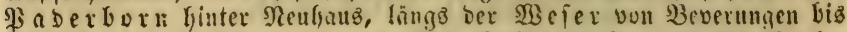

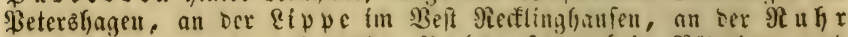

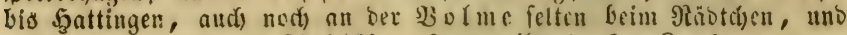
auberbem auf utho an Rírdibôfen oft werwiloert. $6-8$ क

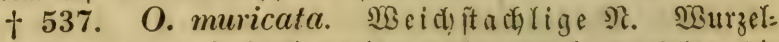

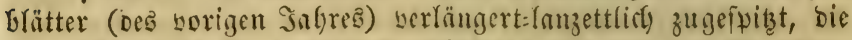

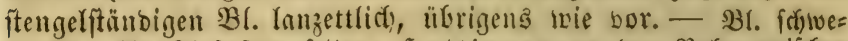

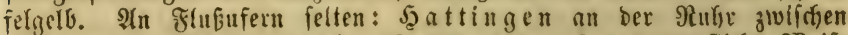

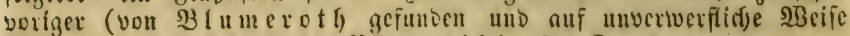

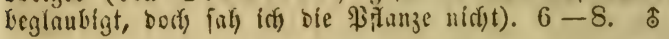

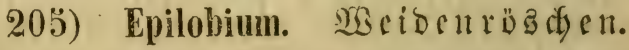

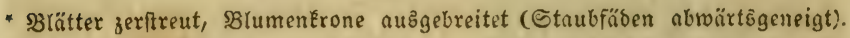

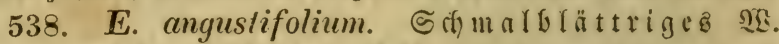

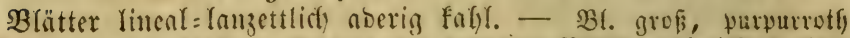
ober zuwcilen bläfier. Stendent mit breiteren Blätern ab (E. latifo-

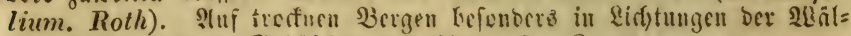

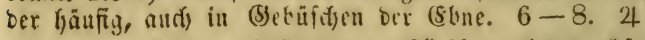

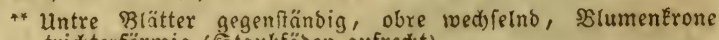
tridsterformig (etaubäben aufredi)t).

+ Etengel oine erhabene Rinien und zweizeitige sBehaarung. a. Sarben beutlid) 4 theilig.

539. E. hirsutum. 30ttige ติ গู纟. Blätter ftengel=

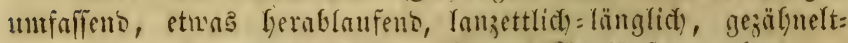

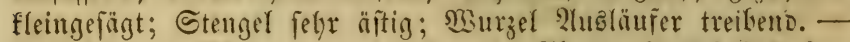
3ottigber, aart; $\mathfrak{B l}$. greb, sunfelrefonro:b. Stbart: $\beta$ glabriusculum

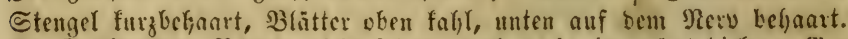

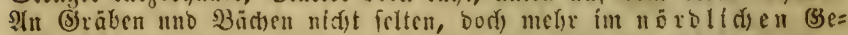

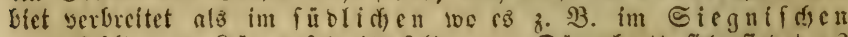

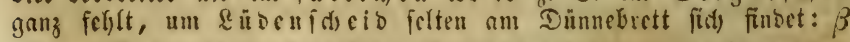

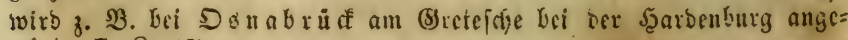
zeigt. 7.8 .4

540. E. parviflórum. \$dreb. (E. pubescens. Motl).)

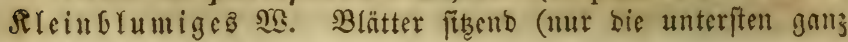




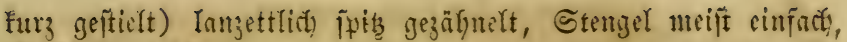

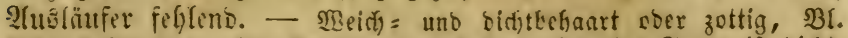
flein, hefluiviett. Wie Wrange änbert fefre ab: cine Form ift bicht=

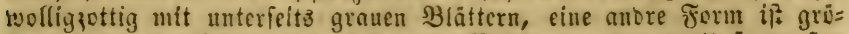
fer mit 2-3mal längeren gefrünniten Blättern unb boppelt fo groféen

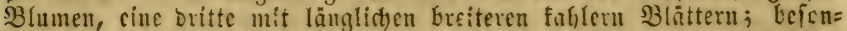
Iers bemerfensuerth) ift bie sthart: sub glabrum (E. vivulare Wahlb.)

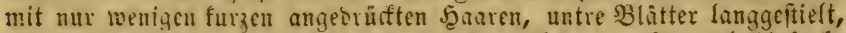

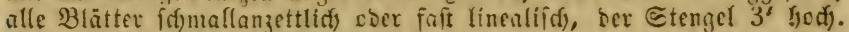

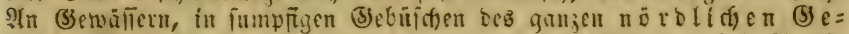
biets, fehlt aber im füolid)en; $\beta$ feffe felten: $5 \mathfrak{5} 5$ ter lee Etröh=

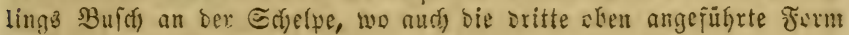
yorfummt. 7. 8.4

541. E. montanum. $\mathfrak{B} \mathrm{erg}=\operatorname{sis}$. Blätter eirums=Yan= zettlief ungleidf)= gुezäfntgefägt, sie untern gegenfitünoig futzge=

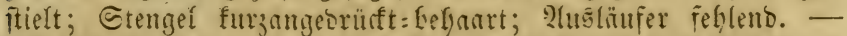

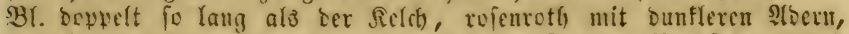

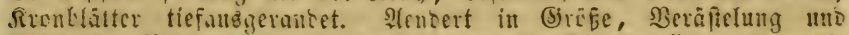

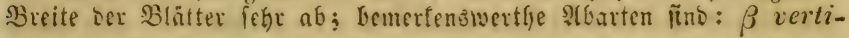
cillatum 3 lätter quirtig ju $3 ; \gamma$ ovato-lanceolatum (E. montanum

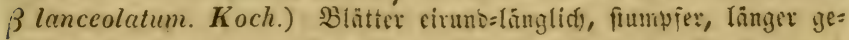
fistt; $\delta$ ramosissimum (E. collinum. Gmel.) niebrig aber nadf

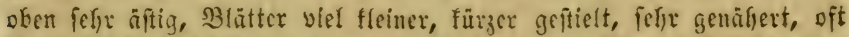
jäntliff; abwedjoclnt; $\varepsilon$ striatum mit feinen an Stengel herablaufen=

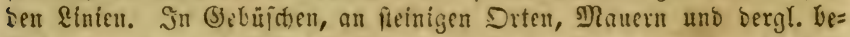

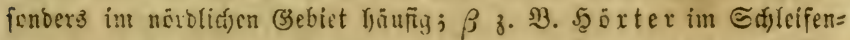

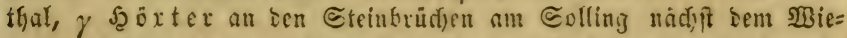
ientgal bei ginfenteriy, $\delta$ biefefelo am Eürabfang ber Eteingenbe

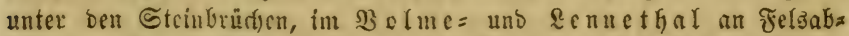

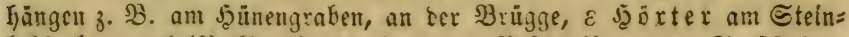

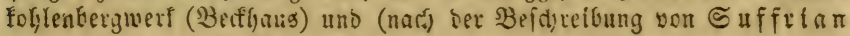

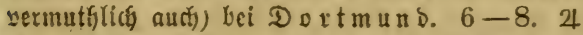

542. E. lanceolatum. Sisbast. \& flltaur. $\& a n z e t t=$ Glăttriges ș. Blätter Inmzettlich, entfernt:gezäfntgefügt, am feilförmigen (Srumbe gamjrandig, bie untern langgefitielt; Єten=

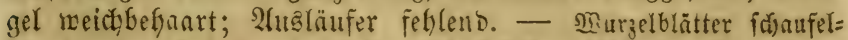

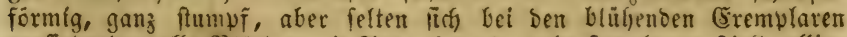

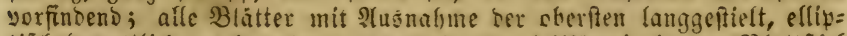

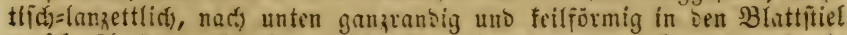

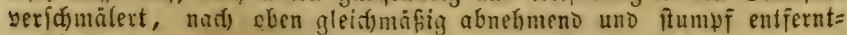

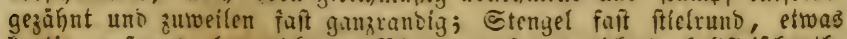

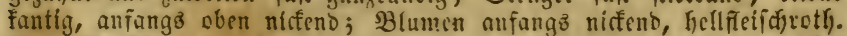

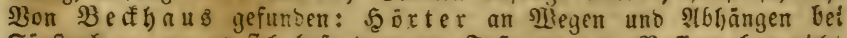

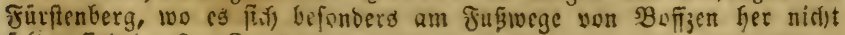
fetten finoet. $6-8.4$ 
b. গarben in eine Reule verwad) Fen.

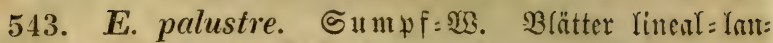

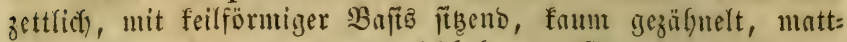

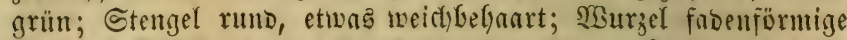

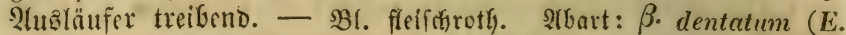
Schmidtianum. Rostk.) Blâtter breiter, beutlid)er gezäfuntt. In (5) rä= ben und Simpfen faft surch) Daz ganze (Ssebiet, bod) mibr im offlidgen:

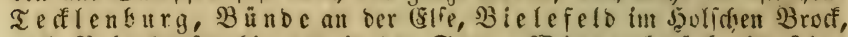

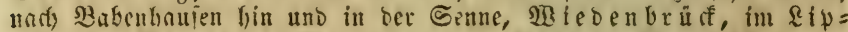
vif́, \$y Santeburg, Dülmen, Darup am Sccuelcr Felde, Sferlubn

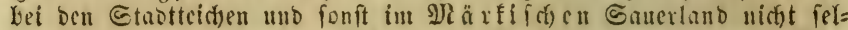

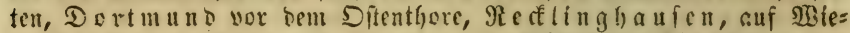

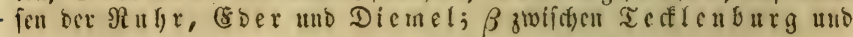

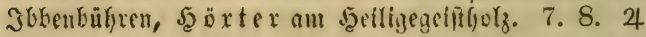

t† Stengel mit 2 ober 4 erkibnen sinien.

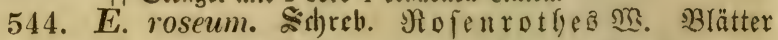

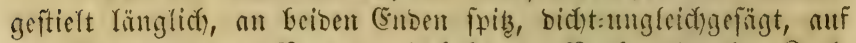

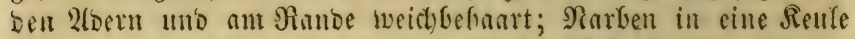

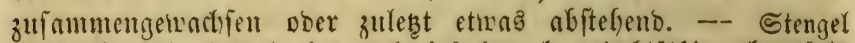

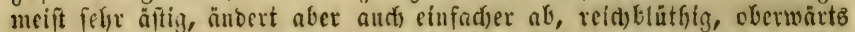
weidgbehaart; $\mathfrak{B l}$. rojenroth. Afn feud)ten Pläßen im of

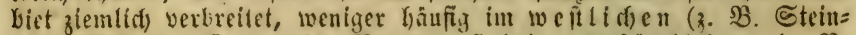

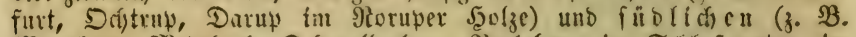

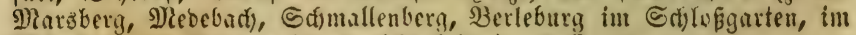

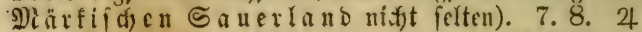

545. E. tetragónum. Bierfantiges $\mathfrak{X}$. B(ättex Ianzettlich, gleid, wom (sirmbe an mach worn fin berichmälert, gefägt=gezälut, bie obern fitzend, Die mittleren mit blattiger Bafte Gerablaufend, bic untern etwas geftielt, Narben in eine Reule zufammengewadten. - Etengel feljr äfig sder auf cinfa=

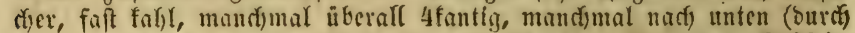
3แfammenfliefen von ie 2 Sinfen) nux 2 fantig (E. obscurum. Rchb.);

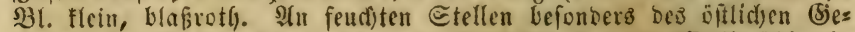

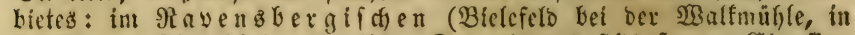

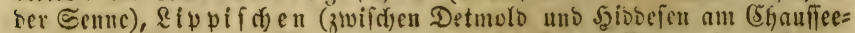

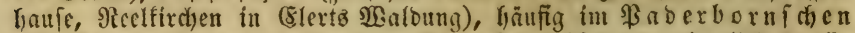

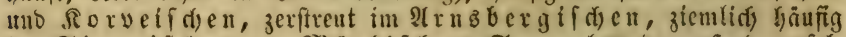

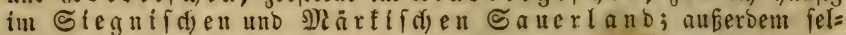
teil: Dortmund im Sunberfolze, Darup und $B$ aubberg im

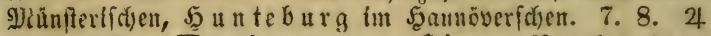

546. E. virgatum. Friss. গ⿺乚

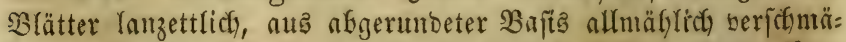
lert, entfernt=gezäfyelt, faft fitbend, bie obern furzgeftielt; Nar: fen in einer Reule zufanmengewachien oder etwas abfitefend. - Stengd wie vor. burd) $2-4$ \&inien fantig, etmas weidjbebant; 


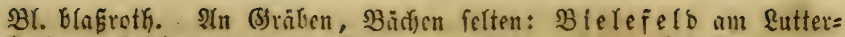

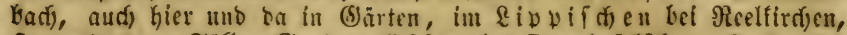

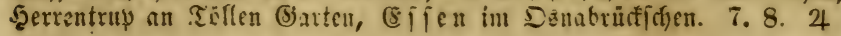

\section{6) Vaccinium. Sacibelberte. \\ * ß̊tumentrone Euget: ober eiförmig.}

547. V. Myrtillus. (5) enciute 52. Blüthyenftiele cint zeltr, "Blätter sirund Fleingefägt, 2leite fantig. - Straudi 6"

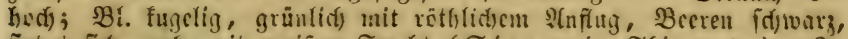

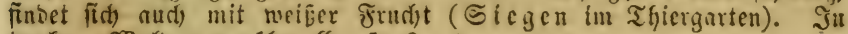

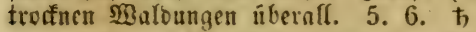

548. V. uliginosum. M゚ o or: $\mathfrak{5}$. Blütfenffiele ge= fäuft, $\mathfrak{B}$ (ätter berfefrt=eiruno ganzranoig unter j. grautgrün

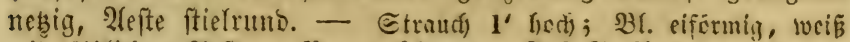

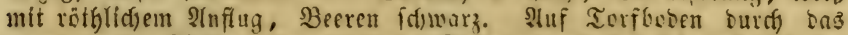

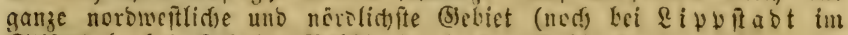

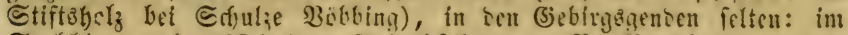

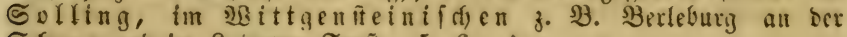
Sdjanze uno im Ratroper Forft. 5. 6. 万

** SBlumentrone gloớig.

549. V. Vitis-Idaea. Nothe $\mathfrak{g}_{\text {. }}$ Breijel $=$ Doer Srongี bie Rrone. - Niebriner immergrüner Etraud). 33t. rōtglid) ober

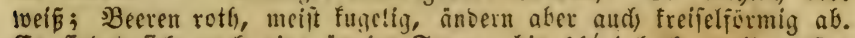

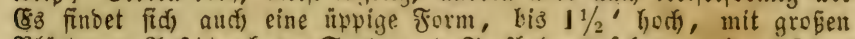

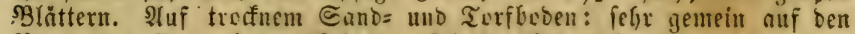

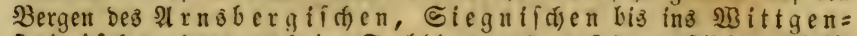

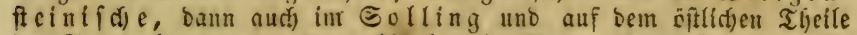
bes Teutoburgerwaldez biz in bie Genne, dann in ben weît.

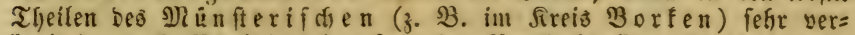

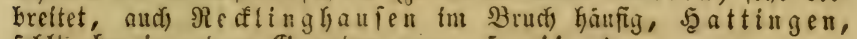
ferflt aber in anbern (slegenten ganz. $5-11$. 方 ** şlumenfrone rabförmig.

550. V. Oxycoccos. (Scholléra 0x. Mith.) ๔umpf=

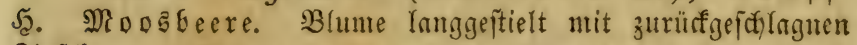

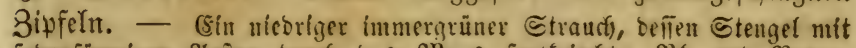

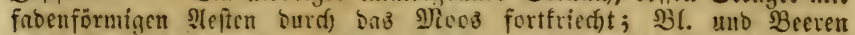

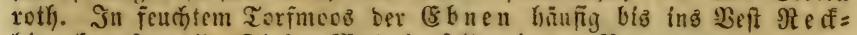

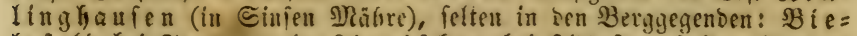

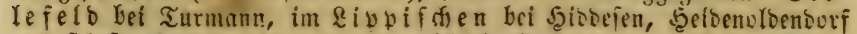

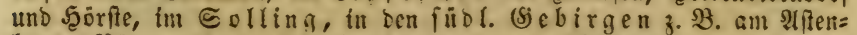

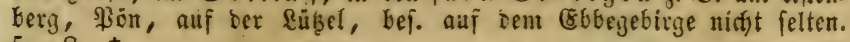
$5-8$.

\section{7) Erica. Şaibefrat.}

551. E. vulgaris. (Callúna vulg. Sulisb.) (\$e e: 


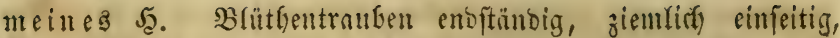

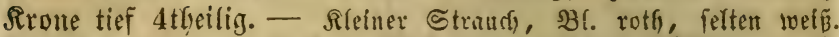

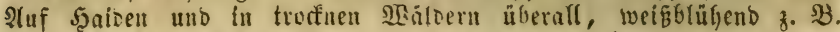
Bielefelo an Rarlen Berge, in ber Senue, im Siegnifdent. 8. 9. t

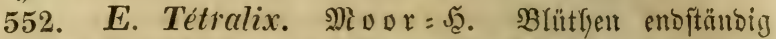
fopff̈̈rmig=bolbig überfangent, Rrone elliptifin = fugelig 4zäfnig.

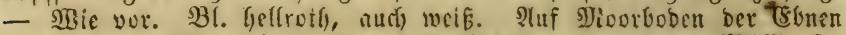

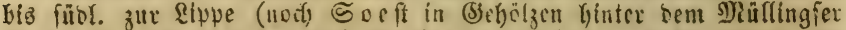

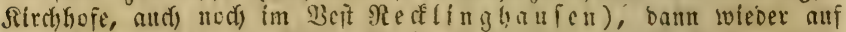

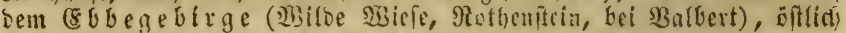
bis zu ben Jebirgen, an bie fie fier und ba finampeigt. 7 . 8. h

\section{8) Daphne. Scibelbaft.}

553. D. Mezéreum. (5) cuteiner S. Bfefferitraud. Blüthen feitenftändig fitzent, Blätter (fpäter als bie Bhumen)

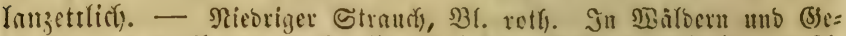

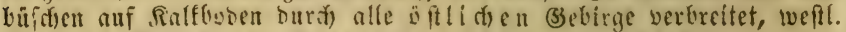

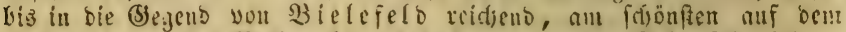

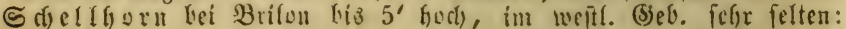

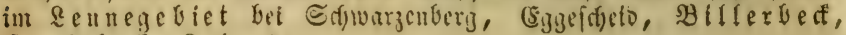

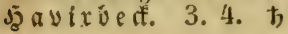

\section{Sromung Trigynia.}

\section{9) Polygonum. Sn̈̈terid.}

* Stenger einfad mit einzelner (5nbähre.

554. P. Bistorta. SצGiefen= $\pi$. Ratterwurz.

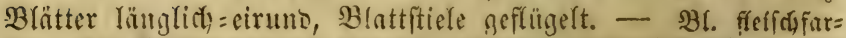

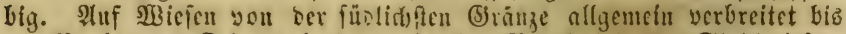
zur $\mathfrak{R}$ uf $\mathrm{r}$ und D iemel, bonn cinzeln: Brafel in sen Stabtiviefen,

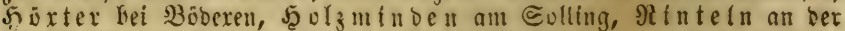

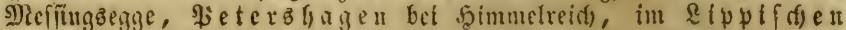
nidft felten, $B$ ielefelo aluvärtz ber Rutter ven ber Stabt all, audf bei Bractivede, Strumber y bei ber Rapeffe am Barge, Eoesfelb

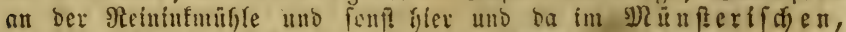

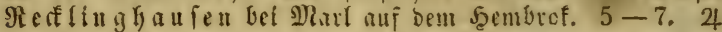

** Stenget äftig, bie Xefte in Xehren endigent.

$\dagger$ Jebren biditgebrungen walzenförmig.

555. P. amphibium. $\mathfrak{B}$ affer $=\Re n$. Whurzel fric:

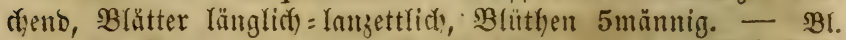
rofenroth. Formen: a natans 3 lätter formimmeno Ianggefitielt fahl; $\beta$ coenosum Stengel an auß̉getrortuteten Drten mit ben $\mathfrak{B l a ̈ t t e r n ~ n l ı s ~}$ 


\section{Trigynia.}

bergeftrefft, wurzelno, an ser @piţe aufîtrebent uno bie Blätter ber folgenion Form treibens; $\gamma$ terrestre aufredjt, Blättex furzgepticlt

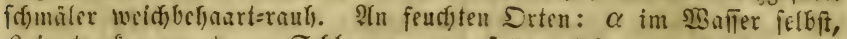

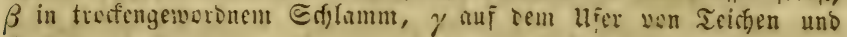
(3)räben. 6. 7. 4

556. $P$. lapathifolium. Nmpferblätriger $\mathfrak{R}$.

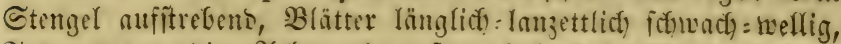
Tuten gangranbig, : (efren furz ftumpf (grün), Blütbenftiele u.

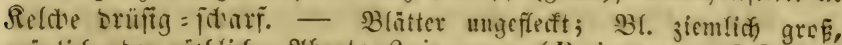
grünliç voer têtflid). Яt(art: $\beta$ incanum ( $P$. incanum. Schmidt)

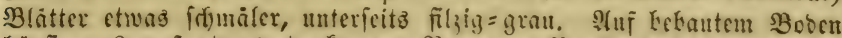

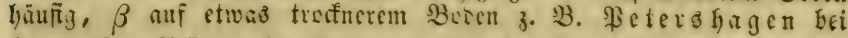

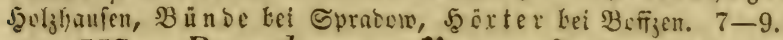

557. P. nodosum. Wers. (5) Gtengel aufĩtreleno; Blätter lamzettlich, nnch feisen Geiten berictmälert, die untren Greitrumslid); Tuten ganzrandig; (S)= lenfe am Srunce ftarf angefduollen; Trauben verlängert, et:

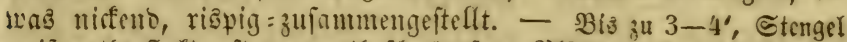
meift rothgefferft, rft ganz roth ülerlaufen; Blätter serb, Yeb́faft grün,

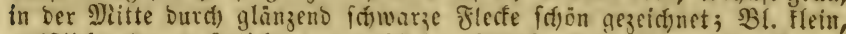

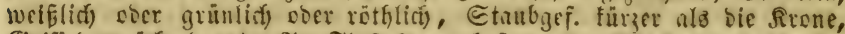

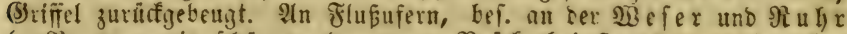
(3. B. ungemein fdōn an bet neuen Bricfe bei 5 a titingen), aber

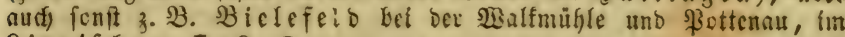

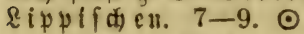

558. P. laxum. Mcidb. Schlaffer $\mathfrak{R}$. Otengel aufftrebend ober faft ganz nieberliegend; Blätter Iangettlick, an Geisen Enten ftarf berifhmälert, wellig, folnif; Tuten fefr

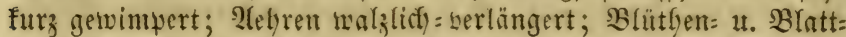
ftiele ftriegelig = raubl)anrig. - Blätter melfenz unterieltz grau,

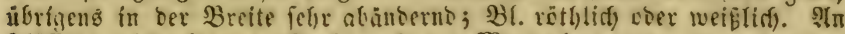

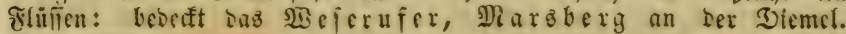
8. 9. $\odot$

559. P. Persicaria. $\mathfrak{B}$ firfiôblättriger $\mathbb{R}$. Stengel aufred)t, $\mathfrak{B}$ lätter länglid) =langettlich, Tuten gewimpert Zefren ftrausartig = Did̆t eiförmig =lânglich), Blüthenftiel glatt,

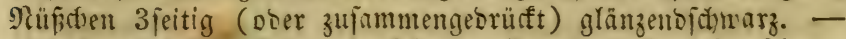

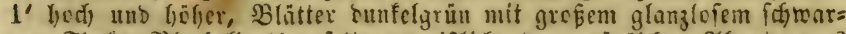

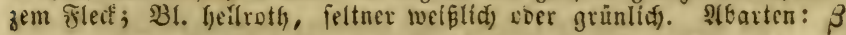
minus Etengel gebroffen=aufitrebent, bie unterfen stefe nitberge=

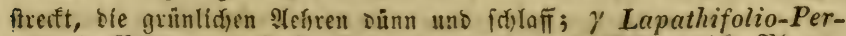

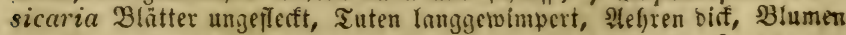

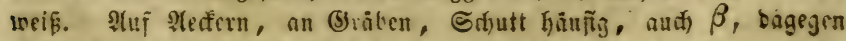

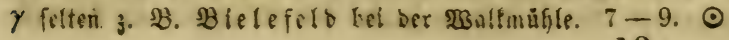




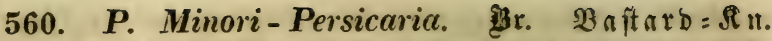
Stengel aufítrebeno berlängert äftig; Blätter lamzett = Yinenlija, faft fahl; Tuten angebriaft geivimpert; 2(2h)ren berbict unter: brodhen. - Steht zwildfen P. Persicaria hinfiditlide ber Alefren uno P. minus hinfidgtlid) ber Blätter, mag baljer ein Baftarb yon

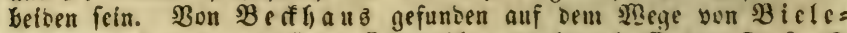
felb nady Sgeepen, unb finbet fids woht an nod mefir Doten. 7-9. $\odot$ tt Zehren ločer, fadenförmig.

561. P. minus. f⿹勹巳s. Rleiner $\mathfrak{R}$. Stengel mif:

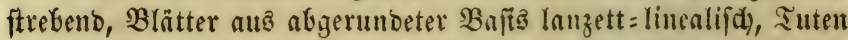
angebrǚft Gewimpert, 2(ef)ren fd)mal aufrecht, sBlumen 5 män: nig. - Fileiner und zarter alz sie ambern, Stcngel oft wurzelno;

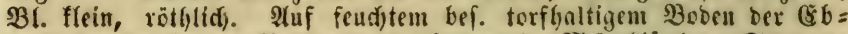

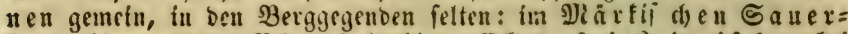
Iand hier und ba, Bielefeld hinter Eeffenburf, im? ipulf d en bei

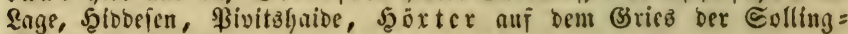

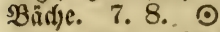

562. P. mite. Sidnenk. (P. laxiflorum. Wribe.) Mirber $\Omega$ n. Stengel aufítrebento, Blätter lanzettlids, Tuten

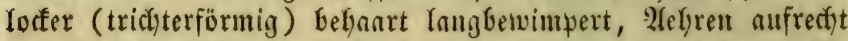
unterbrod)en, $\mathfrak{B}$ lumen 6 männig. - $2(m$ (Srunbe fried)end; $\mathfrak{B}$ !

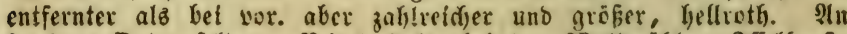
feuditen Drten felten: $B$ ielefelo bei ber 28 alfmuifle, Sifelforft,

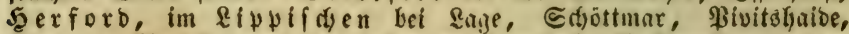

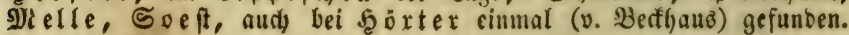
$7-10$. $\odot$

563. P. Hydrópiper. Sdyarfer $\Omega_{\text {u. }}$ Manfifr: pfeffer. Stengel aufred)t, Blätter lanzettlich) wellig, Tuten

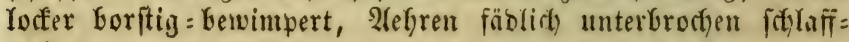

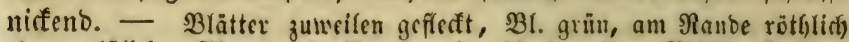

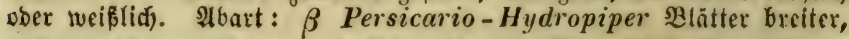

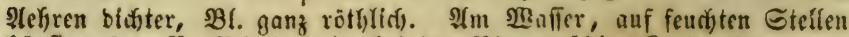

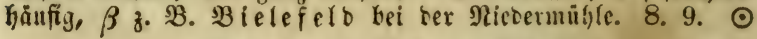

*** Stengel äftig, Blumen brattwinkelftänbig (ङSiffer 3).

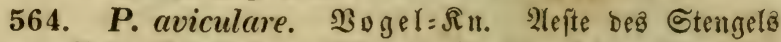
bis zur Spise beblättert, $\mathfrak{B}$ lätter elliptipd) = Ianzettlidy, am

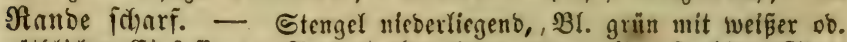
rötflidjer (Sinfaffung. Tlenbert ab: $\beta$ erectum mit auficd)tem Sten=

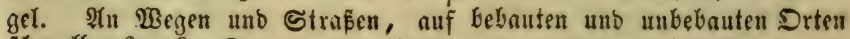
นี้

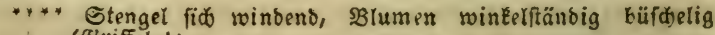
(Briffel 1).

565. P. Convólvulus. ŞBindenartiger $\Re$ r. Sten=

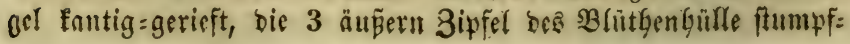




\section{Trigynia. --. Tetragynia.}

gefieft. - Die Pifanze oft roth angelaufen, $\mathfrak{B l}$. grün mit metßex

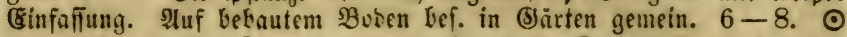

566. P. dumetorum. $\mathfrak{S}_{\mathrm{e}} \mathrm{f} e \mathfrak{n}=\Re \mathrm{n}$. Stengel glatt

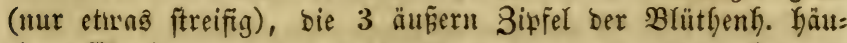

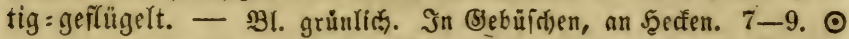

*...* Stengel aufredt, $\mathfrak{B}$ lumen in rizpent ober bolbenförmigen Trauber.

567. P. Fagopyrum. (Fagopyrum esculentum.

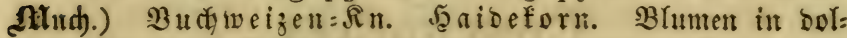
bigen Trauben, Nüfie 3 fontig mit ganzranbigen Ranten. -

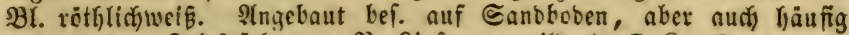

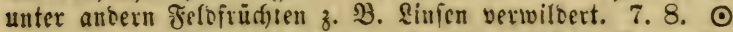

568. P. tatáricum. Tartarifder $\Omega$ n. Blunten in

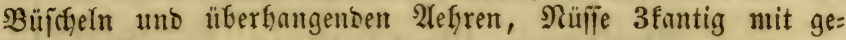

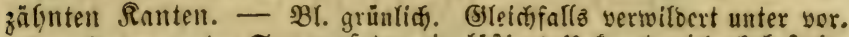
unb auferbem unter Sommerfaten ein läftiges thnfraut, jebod, kẹ. im noื่ 7. 8. $\odot$

\section{Sronung Tetragynia.}

\section{0) Paris. (Einbeere.}

569. P. quadrifolia. Blätter zu 4 (jelten zu 5 pber

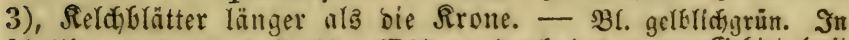

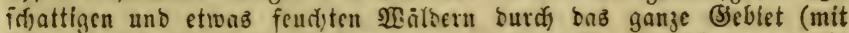

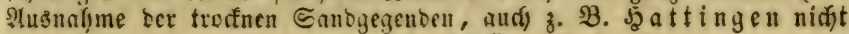

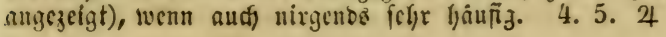

\section{1) Adoxa. Bifamfiaut.}

570. A.'moschatellina. - Der Etengel trägt nur 2 ge= gențtän

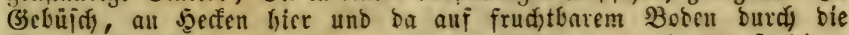

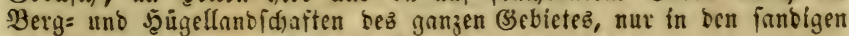

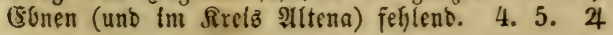

\section{2) Elatine. Tännel.}

571. E. Hydrópiper. $\mathfrak{P}$ feffer $=\mathfrak{T}$. Bătter gegen: niberîtekent, Blumen unfeelfänoig furzgeîtielt 4 blättrig. -

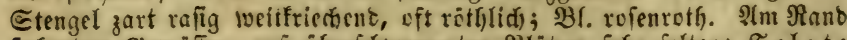

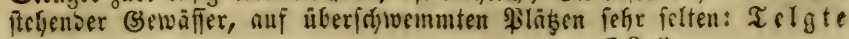




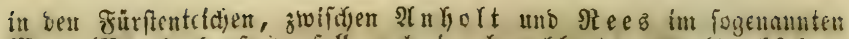

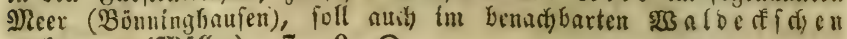
yorfommen (Miuller). 7-9. $\odot$

\section{Detute Slatic. Enneandria.}

\section{Stromung Ilexagynia.}

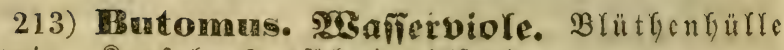
6 bättrig. Saplelı 6, 1 fütherig vieliantig.

\section{3) Bútomus. Mafierviole.}

572. B. umbellatus. - Sdiaft rumb $3-5^{\prime}$ hoort, Dorbe

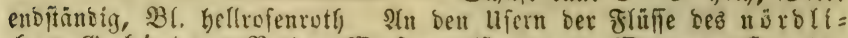

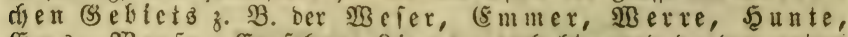
(E) $m$, $23 e r f e, ~(s m i d f e r, ~ R i p p c$, audid hler unb ba ber untern

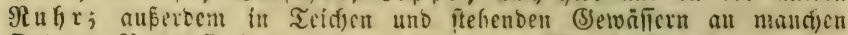

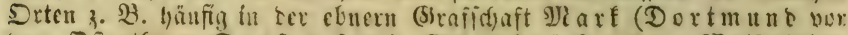

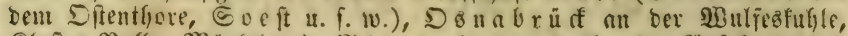

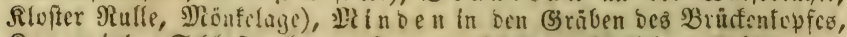

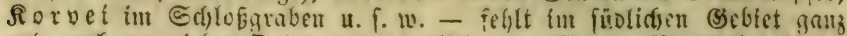

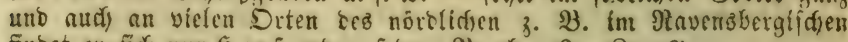
finbet er firt) nut f̧erforb auf bem Brurt). $6-8.24$

\section{Bebute Rlafie.}

\section{Decandria,}

\section{Sromung Monogynia.}

* Blumen vielblättrig.

214) Ruta. Maute. Rel(t) 4-5 brättrig bleibent. Rroubrätter 4-5 benagelt. Şoniggruben 8-10 aห

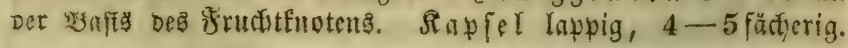


215) Monotropa. Obublatt. $\mathfrak{R}_{e}($ th $4-5$ =

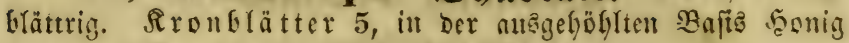
tragello. Rapiel 4-5Glättrig.

216) Ledum. Worift. Reld 5 ipartig. Rrsnc 5łlättrig. Sinpfel 5fücterig, 5flappig, wou ser Bafti an auf́: furingent, bie Gdyeibemände am Nanbe ter Siapfen.

217) Pyloola. Mzintergrün. Relth 5 fłaltig. froue 5blättrig. $\mathfrak{R} a$ fel 5 fädterig, $5 \mathrm{flapwig,} \mathrm{an} \mathrm{bent} \mathrm{fant=}$

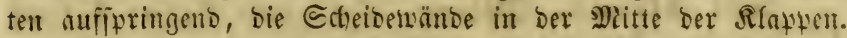
** Blumen einblättrig.

218) andromeda. 2lnoromebe. Relch 5ipal= tig. Rrone faft eiförmig, mit fpaltigem Gaum. Sapiel 5fä̈) therig.

219) retostaphylos. A Rel(d) 5 fpaltig. Rroue foft eifürmig mit 5fpaltigem Gaum. Steinfruth t 5 fernig.

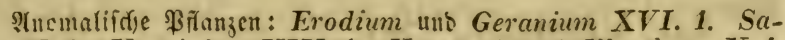
molus V.1.Vaccinium VIII. 1. Herniaria un Illecebrum V.1. Chrysosplenium $\mathbf{X}-2$.

\section{Sromumg Digynia.}

* Slüthen unvolutändig.

220) Chrysosplenium. Mirgfraut. $B($ it = thenfülle 4-5ipaltig. Staubgefä́ze 8-10. Sapfer werfefgrt:Kergförmig lfäefferig.

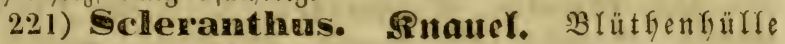
5̧ägnig. Rarbople 1.

** Blüthen sourftänoig.

222) Saxifuaga. Ctciubred. Reld 5theilig. Rrene 5Glättrig. Rapiel 2 jantubelig.

223) Dianthas. Stelfe. $\mathfrak{A} \in \mathfrak{l}$ (t) 5 zäfnig, am (5) rumbe mit Gctuppen berjegen. Rronblätter 5 , in Tange Pägel nustaufend. $\mathfrak{R}$ apfel l fädherig. Same faít fófiloförmig.

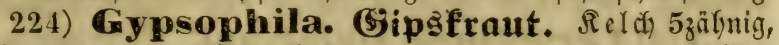
nut (3rumbe nadt. Sironbläter 5 , in cinen furgen feifför:

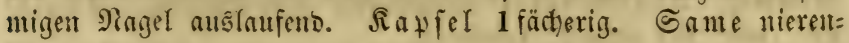
förmig=fugelig.

225) Saponaria. Seifenfrant. $\mathfrak{R}_{e}(\mathrm{~d}) 5$ zäfuig, aut (Brunbe naft. $\mathfrak{R}$ ronblätter 5 , in cinen Yangen Nagel

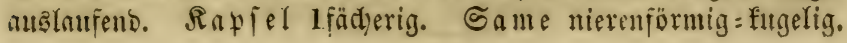




\section{Sronung Trigynia.}

* R̊̀łd) 1 brättrig 5 zähnig.

226) Cucubalus. Taubenfropf. Rrone 5 : blättrig. Beere 1 fächerig.

227) Silene. Rcimfrant. Rrone 5Gättrig. Rn〉= fel an ber Bafis 3 fädberig.

** Relめ) vieibrïttrig.

228) Alsine. Miete. Reldi) uno firone 5: (aud)

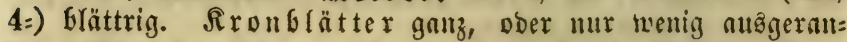
bet. Staubgefäze an (Brumbe mit 2 fleinen Drüjen geftüht. Rapfel 3flappig.

229) Arenaria. Ganofrant. Sionblätter 5, gauz. $\Re a \psi f e l$ fflappig 1 fädherig.

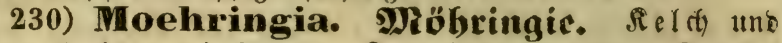
Rrone 5: (ober 4) blättrig; Rronblätter ganz. Rnple! 6flappig 1 fädterig. Santen mit einem 2(nbängfel am Nabel.

231) Stellaria. Sterumiere. $\mathfrak{R}$ onblätter 5, 2ppaltig ober 2theilig. Rapfel 6flappig.

\section{Soronung Pentagynia.}

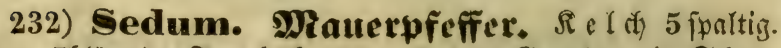

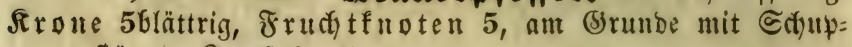

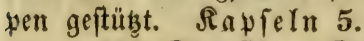

233) Oxalis. Gaucuflec. Reld und Rrone 5= blättrig. Staubgefäвe ungleid); au (5runbe zufanmenge= wactjen. $\Re_{a p f e l} 5$ flappig 5 füdherig.

234) Lychnis. Richtuclfe. Reld 5zägnig. S r o uc 5blättrig, mit ভdjuppen am હd)lunde. Rapfel 1 fädarig. $\mathfrak{R a r b e n}$ einwärts warzig, fonit fafl.

235) Arostemma. Rabcu. $\mathfrak{R e}($ dit nit 5 blatt= artigen Sägnen. Rrone 5bättrig, ohne Sd̆uppen. Rapfel 1 fäaberig. Narben einmärts warzig uno ibberafl befaart.

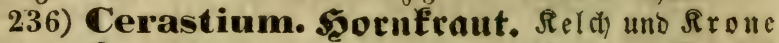
5blättrig. Rroublätter auËgerambet ober 2jpaltig. Rapfel $10=$ (ober $8:$ ) zäfnig, 1 fäbłerig.

237) Spergula. Gparf. Reld 56rättrig. Rron= blätter 5, ganz. Rapfel 5flappig, Ifädtierig. 


\section{Sromung Monogynia.}

\section{4) Ruta. $\Re$ aute.}

573. $R$. gravéolens. B̉ätter $2-3$ fach) gefiebert, Blätt= dien berfelyrteirunb; Rronblätter ganzranbig Doer gezäfynelt, plögz=

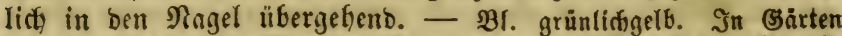

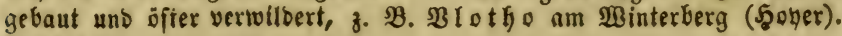
5. 24

\section{5) Monótropa. Dhablatt.}

574. M. Hypopitys. Blumen in einer Traube, Sront= Glätter gezähnelt. - Der Edjaft blattlos, mit Edjuppen befest,

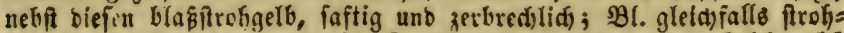

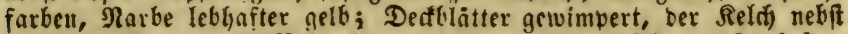
Den Rrontlättern und Befrudjtungybtheilen behant, 2(bart: $\beta$ glabra (M. Hypophegea. Wallr.) ganz farl, ber Frudiffnoten mit erkabe=

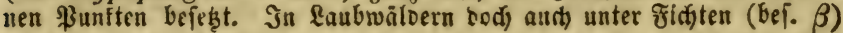

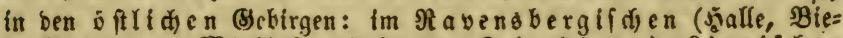

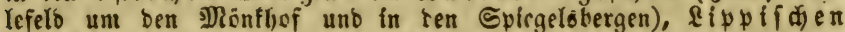
(Derlinghaufen, Stapelage, im Büdenberge u. f. w.), Pyrmont,

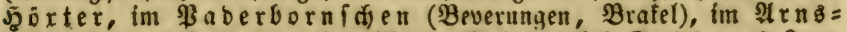

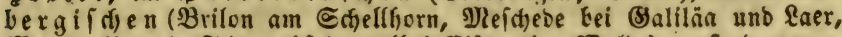

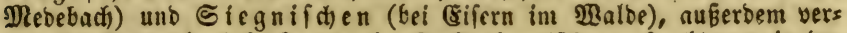
einzelt: D\&uabrü ff, \&ot te im Teff!rnburgiogen, Sूaltern in ber

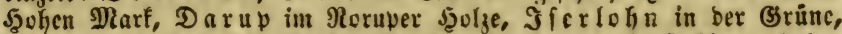

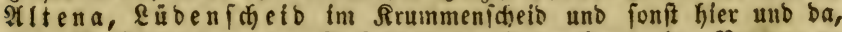

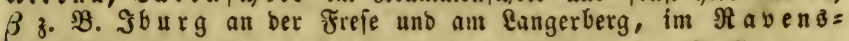
bergifden und Eippifden, Ninteln an ber Mefíngäegge, 5ुoxter am Dielenberg, Selzminben, Beverungen am Bolgen= berg, Dülmen, Eoebfelb, Darup bei ber ßapelle. 6. 7. 4

\section{6) Ledum. Porft.}

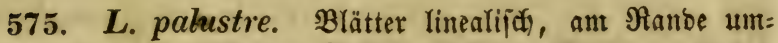
gervilt, unterieita nebit ben 2leiten roftbraun=filzig. - Riebri=

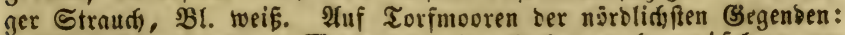

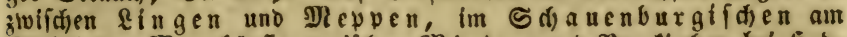

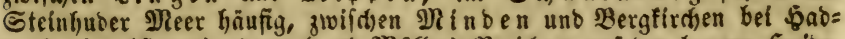

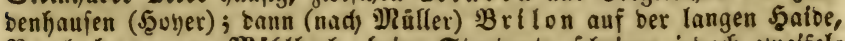
Berleburg am Niáflbad), beide Stanborte idicinen jebori zwelfel= hait. 7. 8, 4

217) Pyrola. SBintergrün.

- Blumen in allfeitiger Traube.

576. P. rotundifolía. $\Re$ unbดlättrige $\mathfrak{B}$. Blät= 


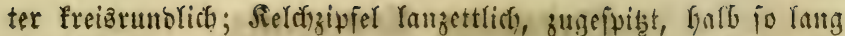

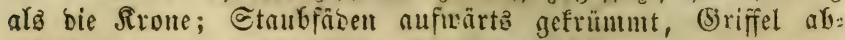

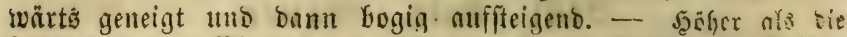

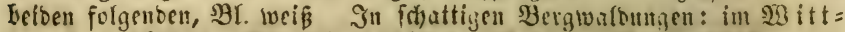

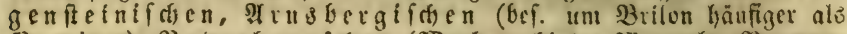

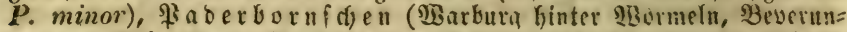

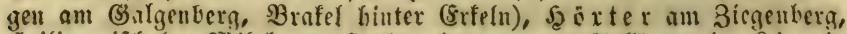

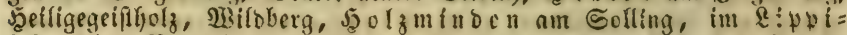

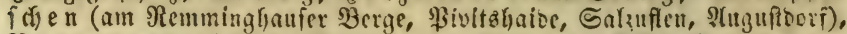

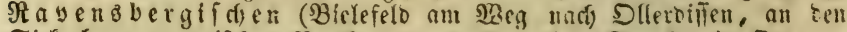

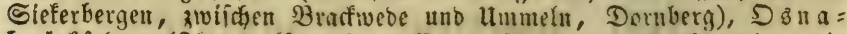
brüdf

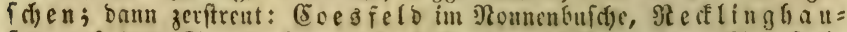
fen auf bem Shannenfump, Sattingen, Sferlofn, Sue it in

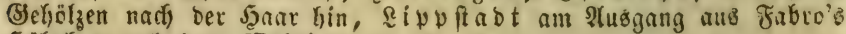
5ुölzacten nact) bem झुeinberg. 5. 6. 4

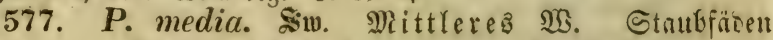
gleidförmig aufrecht; (5riffel hernusragend berabgebugen, ber

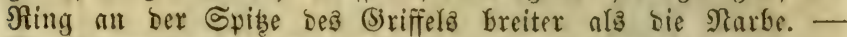

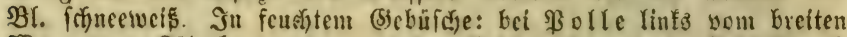

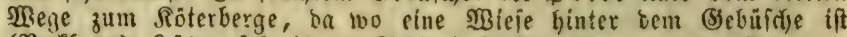

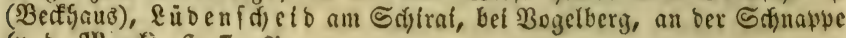
(ง. D. Slintf). 6. 7. 24

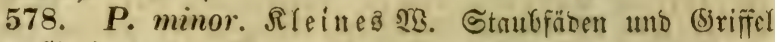
gleid)mäß̧ig aufredyt; Narbe 5ferbig, Doppelt fo breit als der

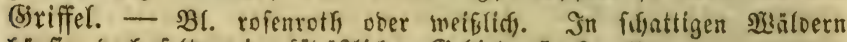
Gäufig, bodi feltuer im fübofitidsen (Sebiet. 5. 6. 24 ** $\Re$ lumen in einfeitకెmendiger Traube.

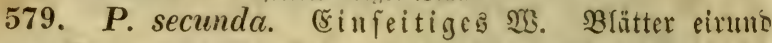

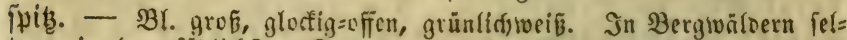

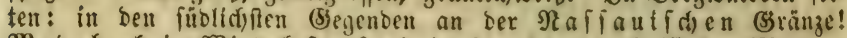

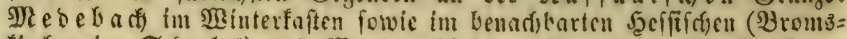

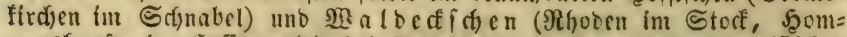

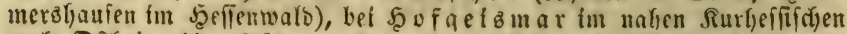
uadf) Detteim hin, friber audy im Ripplfigen bei Derlinghaufen an Der Dalpte gefunden. $5-7$. 4 **+ $\$$ Blumen in solben.

580. P. umbellata. Dorbiges $\mathfrak{1 3}$. Blätter lanzett= feilförnig. - Br. Geffrofenteth. Jn Tannentwaloungen fefor felten :

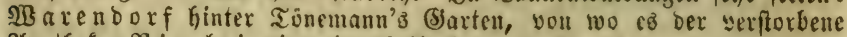
Plpothefer $\mathfrak{R}$ i col a i mir mitgetyeilt bat. 6.7 .24 **** Sdiaft 1blüthig.

581. P. uniflora. (5inblüthigeg̊ $\mathfrak{S}$. Blätter rumblich.

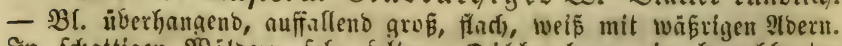

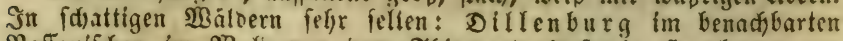
Nafiauldien im Malb vor bem Thiergarten! Polvie Şerborn an Şirfdyberg (\&eerb). 6. 7. 4 


\section{Monogyna. - Digyuia.}

\section{8) Andromeda. At noromeds.}

5\$2. A. polifolia. (s) ene ci ne 2 . Blatter lincal=

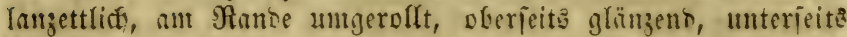

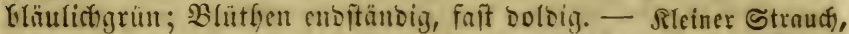

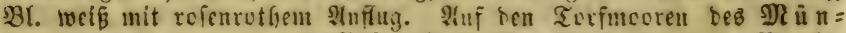

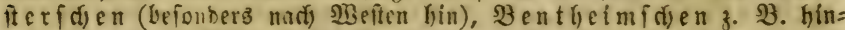

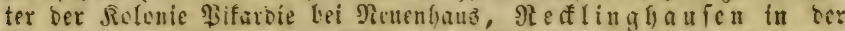

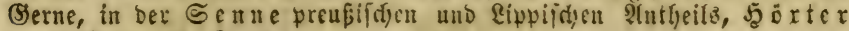
in Solling. 5. 8. 古

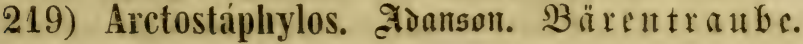

583. A. officinalis. WW. Co Grab. (Arbutus tra ursi.

L.) Etenigel nieberliegent, Blätter lesernrtig ganzrmbig. -

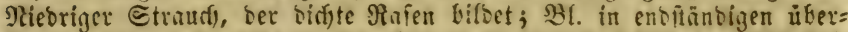

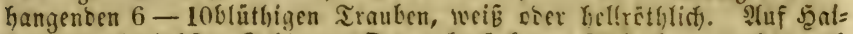

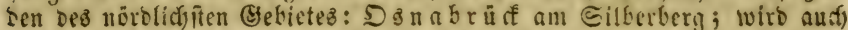

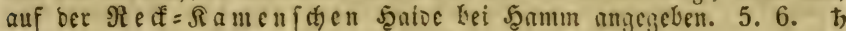

\section{Sronung Digynia.}

\section{0) Chrysosplenium. Milz fraut.}

584. Chr. alternifolium. গู่ Brätter abrwedlieluio. - Etengel 3 fantig, BBl. belocntraubig gelb.

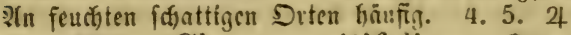

585. Chr. oppositifolium. (5) egenbrättriges $\mathfrak{M}$. Blätter gegenftänsig. - Stengel 4fautig, 36. uno Stanbort wie yorige bod) feltncr: im Sieguifden, Shittgente eintfden,

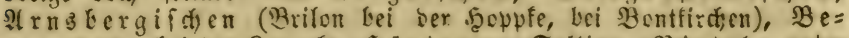

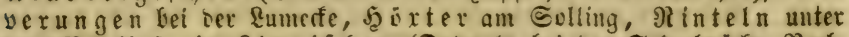
bem Brinflofe, im sipvifdien (Detmelo lef ser Sefenbrüffe, Reel=

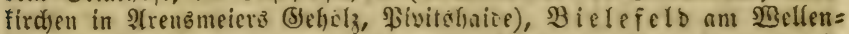

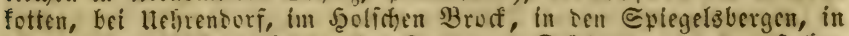
Det Senne, Tefflenfurg im Sutbern, Dit lmen in ber byolen Marf, Nottern im Sittert, Dortmund um Derue, J̧attingen,

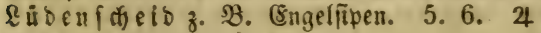

\section{1) Scleranthus. $\mathfrak{i} \pi \mathfrak{a} \mathfrak{e}$.}

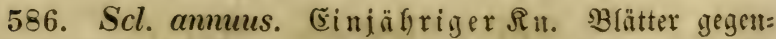

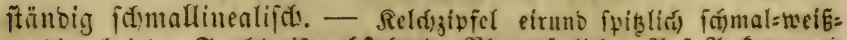

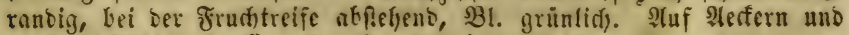

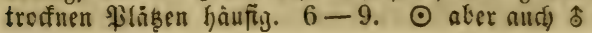




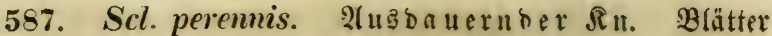

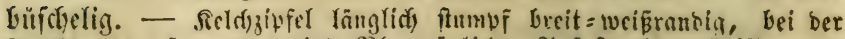

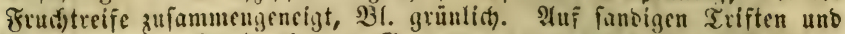

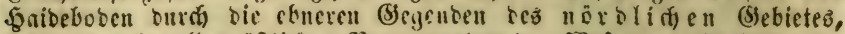

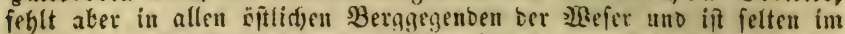

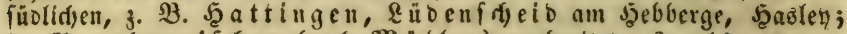

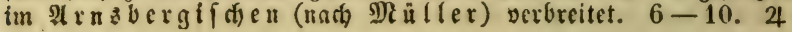

\section{2) Saxifraga. Steitibed}

588, S. caespitosa. (S. decipiens. (Eh)ly.) $\Re a j \in \mathbb{n}=$ förmiger $\mathrm{St}_{\text {t. }}$ Blätter geftielt, bie ivurzelftändigen ropettarti= gen banoförmig 5-9ipaltig mit lanzettlichen ftumtpen Bipfeln, bie îtengelftänbigen abwedsfelno 3 ppaltig. - Nafenförmia, bic Blüthenftenget 3-9blütfig. Ituf pecinigen bebirgen: einziger Stand=

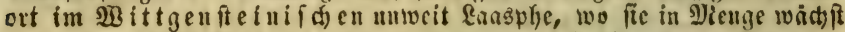
unb mir burds Suffrian mitgetheilt wourbe: ob hiermit ber Etanbort

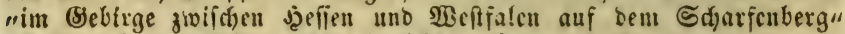

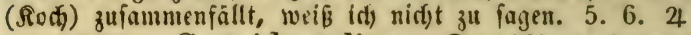

589. S. tridactylites. Dreifingriger $\subseteq$ t. Hutre Blätter verfelgrteirund:fpatelförmig ungetfeilt oder 3rappig, ofere

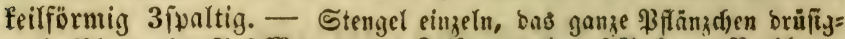

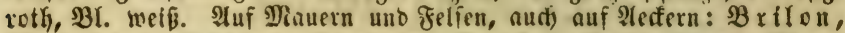

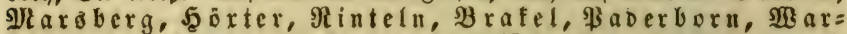
fiefn, Sgattingen, im Lippifden (Detmolo, Stapelage, Bogel=

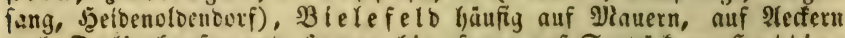

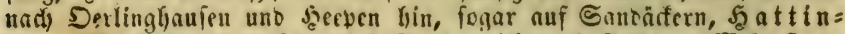

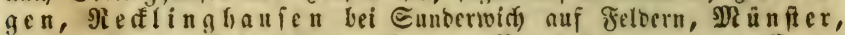

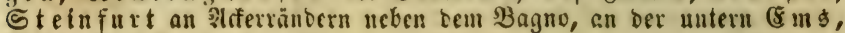

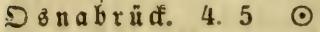

590. S. granulato. $\mathfrak{R}$ rniger $\subseteq$ t. Untre $\mathfrak{B}$ lätter nierenfömrig lappig=geferbt, obere 3-5ipaltig; SצGurgel förnig. - Stengel einzeln armblättrig äptig=boloentrautig; $\mathfrak{B l}$. ziemlid) groß̂,

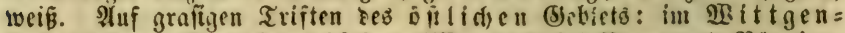
fieinif d)

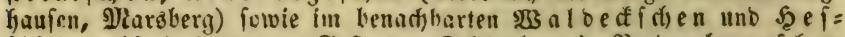
fifde (von Syerftelie und Beverungen fehte verbreitet - "Bseffefoot " - biz

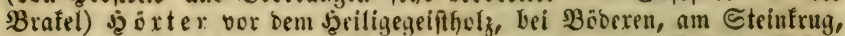
unter ben Bisgenkerg, an Roterberg; aubertem fehr felten: Dîl= men beim (Sute Engferitein, im angränacneen S/ benburgifden unmeit Quafenbrüaf zwifd)en Flabberlvhaujen und Şolloerf. 4-6. 4

\section{3) Dianthus. $\mathfrak{N e l f f e . ~}$}

* Blumen Eöpfigs ober büfdeligsgehäuft.

591. D. prólifer. Sproffende $\mathfrak{N}$. Stengel fahl; 


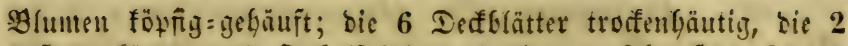
äupern fürzer uno fardyeljpibig, bie innern jefgr jtumpf uno

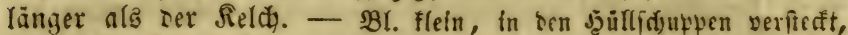

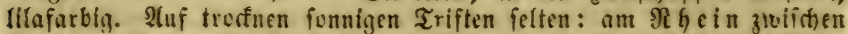

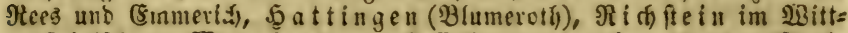

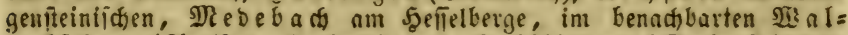

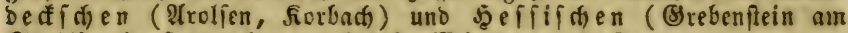

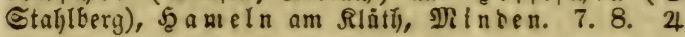

592. D. Armeria. $\mathfrak{R}$ a uhe $\mathfrak{N}$. Ctengel nebft ben $\mathfrak{B l a ̈ t}=$ tern lveidybegant; $B$ lumen gebüjchelt: Decfblätter uno Reld)=

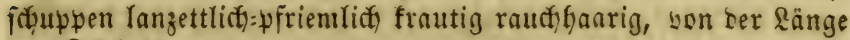
ser Reläröbre. - Etengel biz zu 3' hod, bleibt aber aud) ganj nicerig : $\beta$ nanus. $B$ l. hellfarminrotly mit hellen Punften, am Grunie

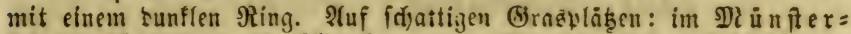

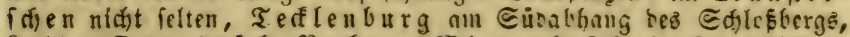

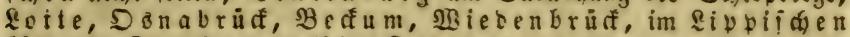
über bem Dërenfruge, ziwifasen Detmolo uno \&e ungo an Der Syeer=

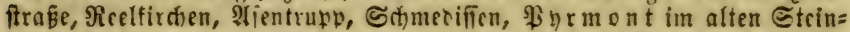

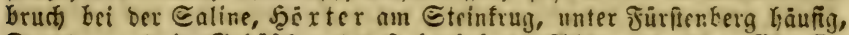

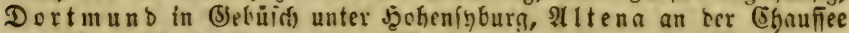
nad) Sicgberig uno fonft; $\beta$ zwifden 2 arendorf uno Deldc, \$eter $=$

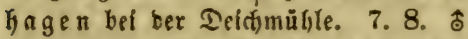

593. D. Carthusianorum. Rartäujer=9\}. Gtengel

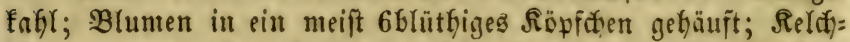
jofuppen sertrocfnet=leberig berfefrteiruno ftumpi, mit einer Branne bon ber halken Ränge bes Relchą, DecfGlätter fạt ebenio. - Blattideiben länger ala bie vorigen. Syl. farminretf mit bunfler

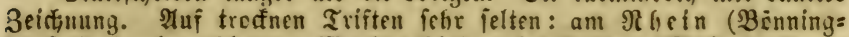

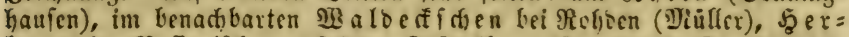

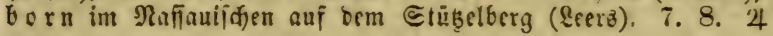

\section{** Blumen einz̧eln.}

594. D. deltóides. Fanibenelfe. Gtengel meidbehant mit IGlïthigen 2leften; Blätter lineal:Innjettliđ; Reldtichuppen

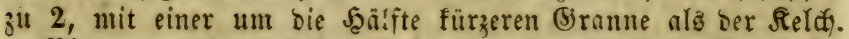
- $\mathfrak{B l}$. purpurroth mit heflen Flecfen und einem bunfleren $\Re$ ing. Nluf

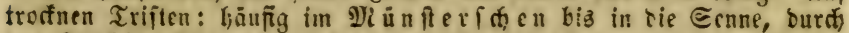

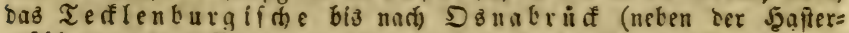

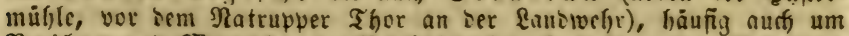

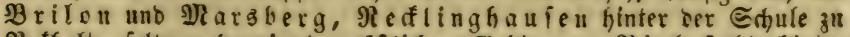
Botholt, felten aber in ben ôflimen Gesirgen: Biele felo binter

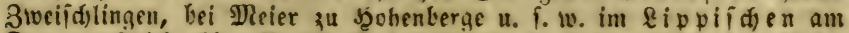

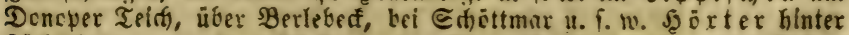

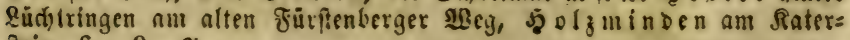
fein. $6-9.24$ 
595. D. caesius. \$n. (Dianthus virgineus $\beta$ L.) Blaugraue $\mathfrak{R}$. Stengel nieberliegend fwurzelub bichtrafig,

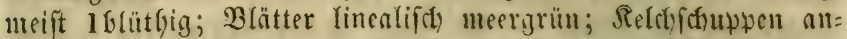
gebrüfft cirmo ftumbf, zugefpizzt ober Gegramnt, 4 mal fürzes

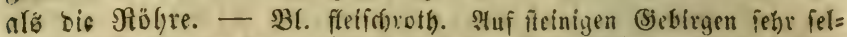

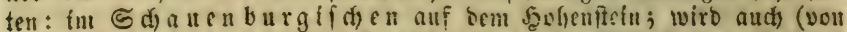

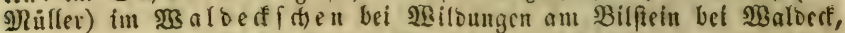
und bei (bem ficfifict)en) Itter argezrigt. 6. 7. 4

Unmere. 1 Dianthus superbus findet fid feit einigen Эakran $\mathfrak{B} i e$ : Iefelo beim Gupferhammer auf einer risiele, tookin er ouxd (Srabfamen, ber nuछ 2 raunfdoweig bezogen worben, gefommen zu fein fdrint.

Unmer $\mathfrak{E} .2$ Dianthus barbatus fand id) im Sommer 18:2 in 2 (5xem:

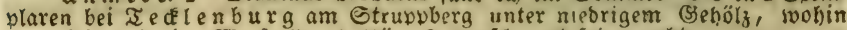
er auf irgend eine 23 etfe (Durd) Dögel?) verf(t)leppt fein modite.

\section{4) Gypsophila. (sip iffrat.}

596. G. muralis. פ⿺aner=(5). Stengel aufredit äitig= riguig, Blätfen zerftreut, Sirvnblätter geferbt ober ausgeraniot.

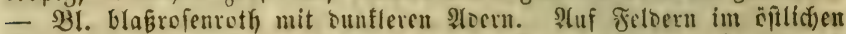

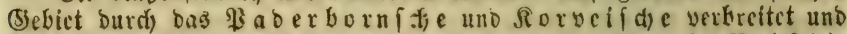

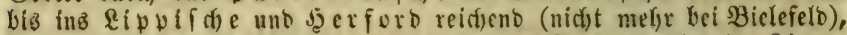

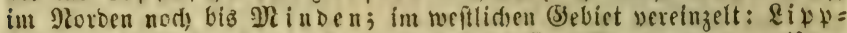

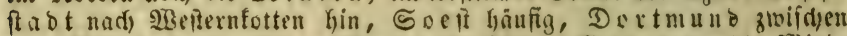

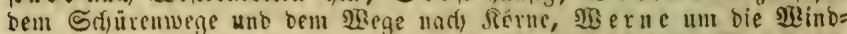

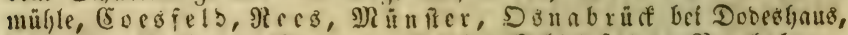

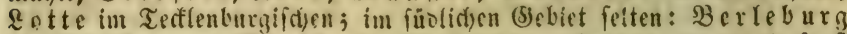

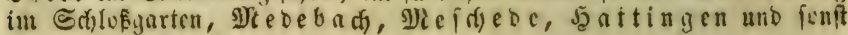
an ber $\mathfrak{R}$ uhr. $7-8$.

\section{3) Saponaria. Seifenfiaut.}

597. S. officinalis. (5) em eines ๔. Rel(t) walzenförmig,

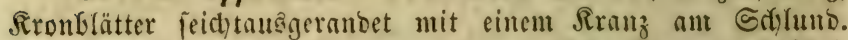

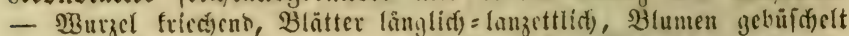

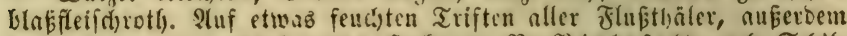

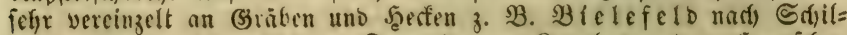

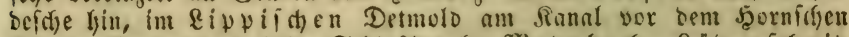
Thore, \$yrmunt beim Erblubtanal, Mebeban, Rübenfdecib

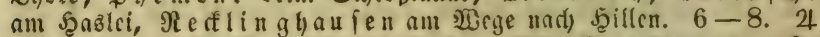

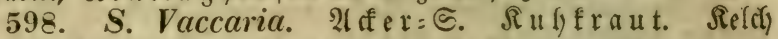
fantig = geflugelt, Rironblätter fleingeferbt vłne Siranz. -

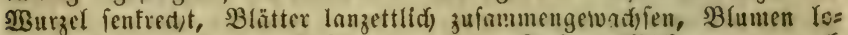

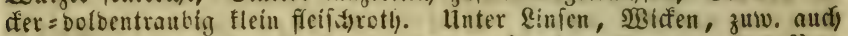

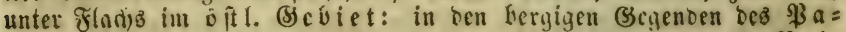

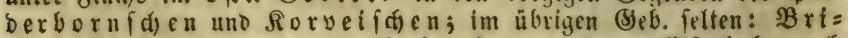
lon, Riptita ot auf cinem Rinfenaffer umbeit ber (sifenbalyn nad)

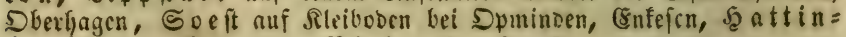
gen, Etromberg, an Rgein. 6-9. $\odot$ 


\section{Trigynia.}

\section{Sronuttg Trigynia.}

\section{6) Cucubalus. Inubenfrow}

599. C. bacciferus. - હtengel (đ)wad) flimment, weit=

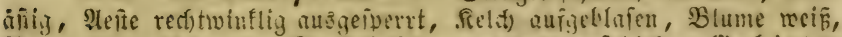

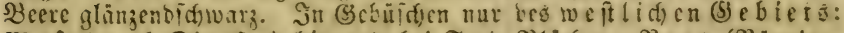

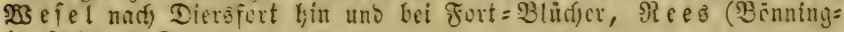
hau(en). 7.8. 4

\section{7) Siléne. Reimfrat.}

\section{* SBlumentrone oline frranz.}

600. S. inflata. Sint. (Cucubalus Behen. L.). $\mathfrak{2} u$ ige $=$ blajenes \&. Blätter efliptijes doer fanjettlict, Bfumen gufel= 1 .

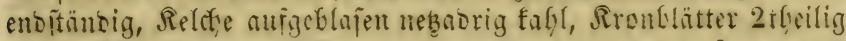

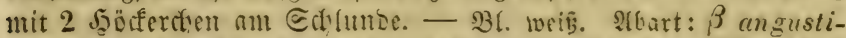

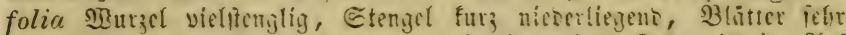

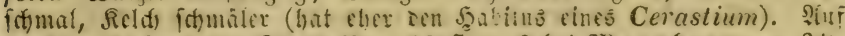

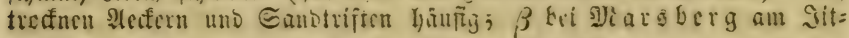

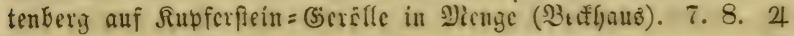

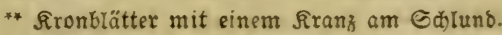

$\dagger$ Brumen in enoftänoiger (meilt boppelter) হrauke.

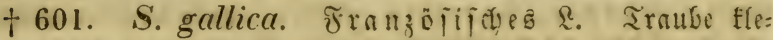

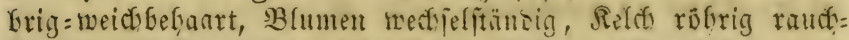
baarig mit Innzettlid) = prriemliden Bäfun, Rronblätter ber: fefrrteirumb ungetfeilt (ganzranoig ober gezäf̧nelt ober aแsิge: ranoet). - Bl. ffeif(t)farbig ober wei巨lid). 26arten: $\beta$ quinquevul-

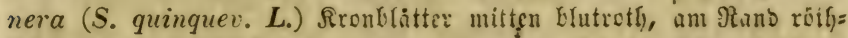

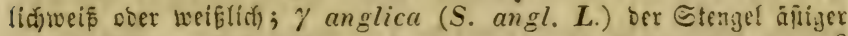

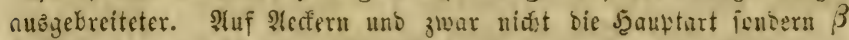

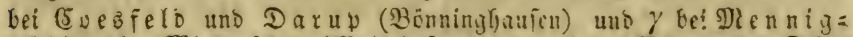

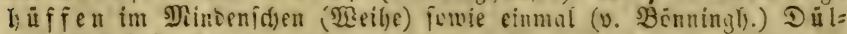
men bei Dithof gefunten; in roie fern beice als twild zu berraciten fint, fann ids nidjt fagen. 6. 7. ค

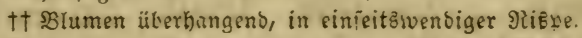

602. S. nutans. Hebertinngentes \&. Reld röfrig und etwas feulenförmig, Rironblätter tief $=2$ ipaltig. - Etcngrl am (Brund und an ten Belenfen purpurbian, weidghaarig, bie ganze

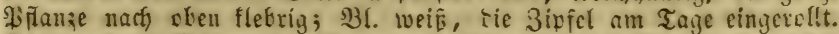

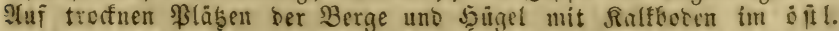

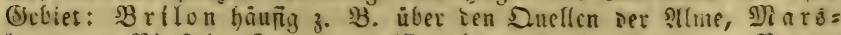

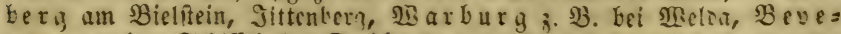
rungen im Edjifitsal, Driburg am Ricug!erg, Jjoxter untet

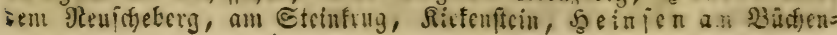




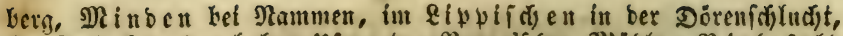

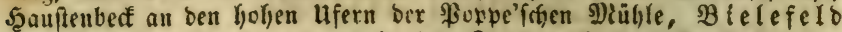
um ben Rutterfolf uno ven ba in ben Sand nad) Dem Rupferhanumer

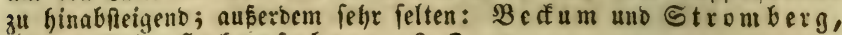

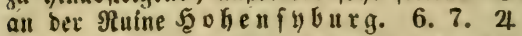

t† Blumen bolbentraubig ober bolbentraubig = ribpig.

† 603. S. conica. Regelfelaiges $\Omega$ Stengel grau= weid)behanrt, Reld eiförnig 30 ftreifig, Rronblätter berfefrt:

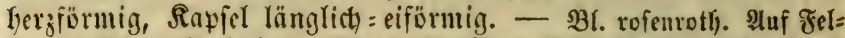

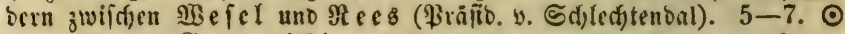

604. S. noctiflóra. $\mathfrak{2}$ ä d) gabelpualtig, nebit sen Blütgenftielen und Reldyen flebrig=zot= tig; Blumen gabel = uno enoftänoig, Reldy baudig=röhrig

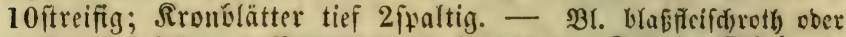

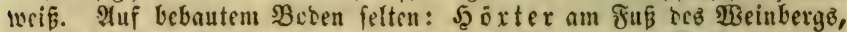
im Brüffelto, Jo $_{z}$ minbell, Bielefelo um ten Rupferhammer,

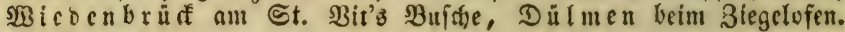
$6-8$. $\odot$

605. S. Arméria. (B) arten= . Stengel fall unb nur unter ben obern Belenfen flebrig, Riape büftelig=reidt)= blütbig, Relch röbrig = feulenförmig 10 ftreifig, Rronblätter un=

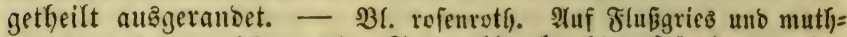

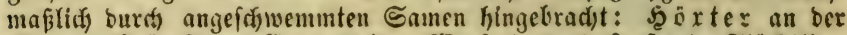

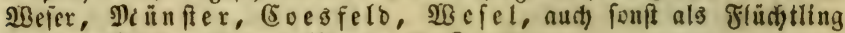

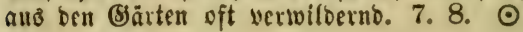

\section{8) Alsime. Miere.}

* Alsine. Wahlenb. Samen nierenförmig.

† 606 a. A. verna. Bartl. (Arenaria verna. L.)

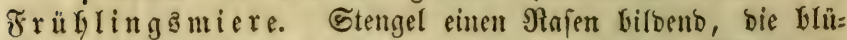
benben aufitrebend ober nufredyt 1-melyrblütbig; Blätter li= nenl = prriemlidy; Reld)blättef)en ei = lanzettlidy fpib; Rronblätter eirumb furgbenagelt, fait Gerzförmig, länger als ber Reld. -

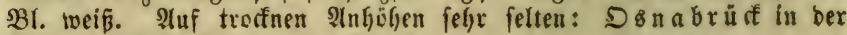
शlälje bes ธilberbergỏ. $5-7$. 4

606 b. A. tenuifolia. $\mathbf{W}_{\mathfrak{a}} \mathrm{lb}$. (Arenaria ten. L.) Feinblätrige פl. Stengel einzeln gabelfpaltig, Blätter

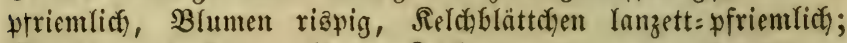
Rronbl. oval, fürzer als ber Reld). - Bl. weî́. Sluf Felbern

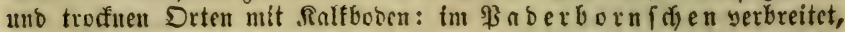

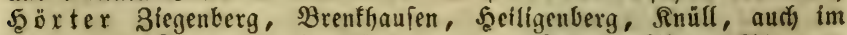

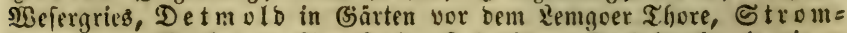

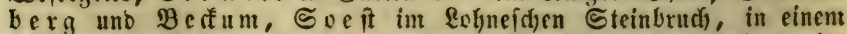

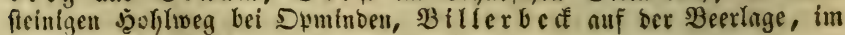

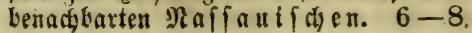




\section{Trigynia.}

Lepigonum. Whlb. (Spergularia. Presl.) Samen 3 edfig ober runblid) (geflügelt ober flügellob), গebenblätter troden: båutig.

$\dagger$ Stengel aufrecht, 2efte born eingetnid: : üterhangend.

607. A. segetalis. (Lepigonum seg. Fiod).) ๔ats

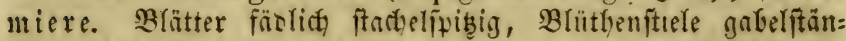

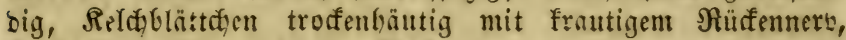

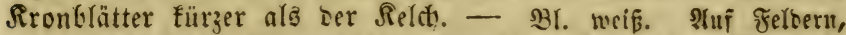
aurd auf frinigen Drten feiten: 5̧erfuro hinter sem Serge in

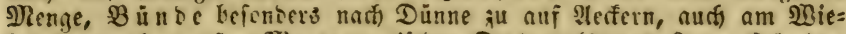

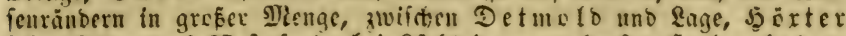
feffr felten ani gुeferfanto bei Ruiditringen, ebenfo feolzminben

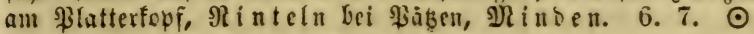

t† Etengel geftreçt aufittebeno.

608. A. rubra. Walhlb. (Arenaria rubra $a$. L.)

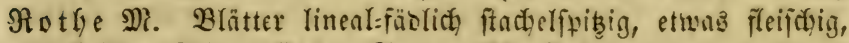
aนf beiben Geiten flat); Ganten flügeffos. - Br. roînrotr.

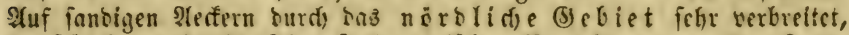

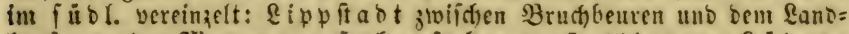

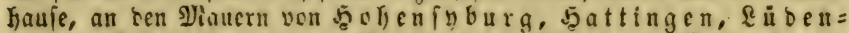

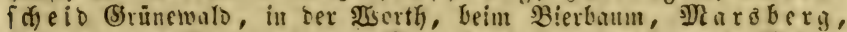

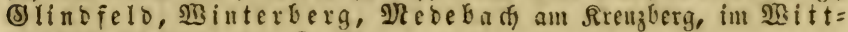
genficinficten. $6-8$. $\odot$

609. A. marina. fiod). (Arenaria rubra $\beta$ marina L. - Lepigonum medium. Wablb.) Salzmierc.

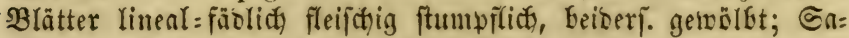

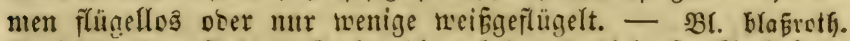
2tn falblyaltigen Doten: Ealzuflen beim Brabirhauie, Salztot=

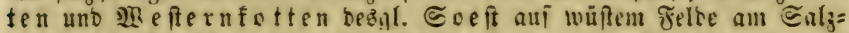

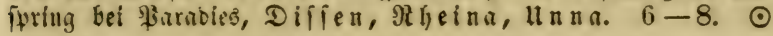

\section{9) Arenaria. Sanofraut.}

610. A. serpyllifolia. Duentelolätriges $\varsigma$.

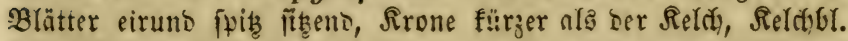

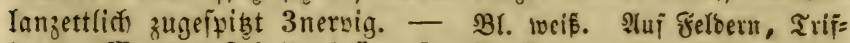

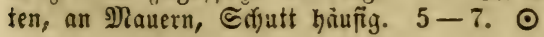

\section{0) Moehringia. Mghringie.}

611. M. trinervia. Clairv. (Arenaria trinervia. L.) Dreinervige N. Blätler eiruno fpit 3-5nervig, bie un= tern geittelt; Rronblätter fürzer ala ber 3 nersige Reld̆. -

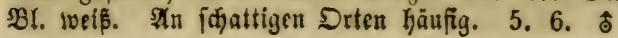




\section{1) Stellaria. Sternmiere.}

* Stengel runo, untre $B$ lätter geftielt.

612. St. némorum. Jूa $\mathrm{i} n=\mathrm{S}_{\mathrm{t}}$. Stengel fodjlaff, oberw. zottig; Bläter herzforntig zugefwizt; Sispe gabelfpal: tig; Rronblätter tief 2 fpaltig, Doppelt fo lang alg bie lan=

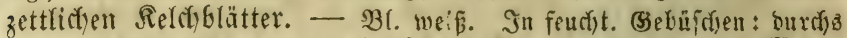

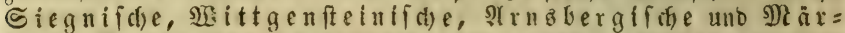

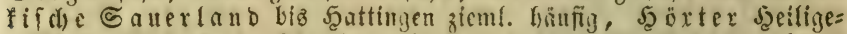

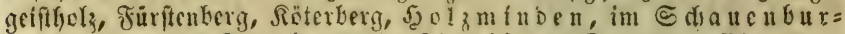

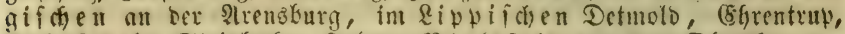
Ealzutlen im Etrinbeffer. Sulze, Biclefelo vor bem Sbertfur am

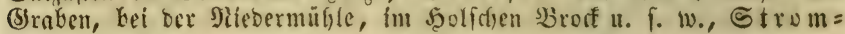

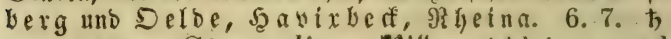

613. St. media. Mill. (Alsine med. L.) (5) $\mathrm{e}=$ meine St. Stengel aufitrebend cinreigig=belanat, SBlätter eirunb; BBlumen gabel: แnb enbftänbig 3-5männig, Rronblät=

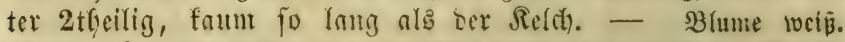
Stbatt: $\beta$ major (St. neglecta. Weihe) größer, fait von Shluflin ber vor. Blumen 10 männig; $\gamma$ minor. frein mit fleffdrigpren $\mathfrak{B l a ̈ t}=$

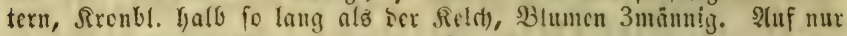

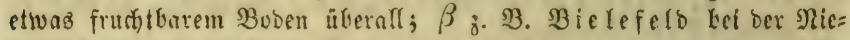

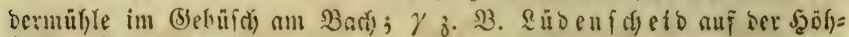
berfe. 2 -11. $\odot$

** Stengel Eantig, Blätter alle fikenend.

$\dagger$ Reld) am (srunde abgerundet.

614. St. Holistea. (5) rof̉blumige $\sigma$ t. Stenget

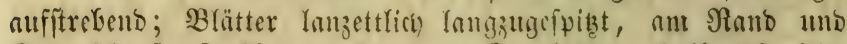
Riele forarf; Derfolätter frautig; Rronblätter balb 2 fpaltig, boppelt to lang ala bie nerwenlofen Relctblätter. - Die

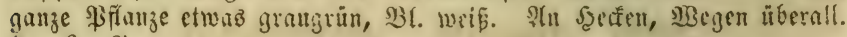
$4-6.24$

615. St. glauca. Witjer. (St. graminea $\beta$. L.) Deergrüner St. Stengel nufredt) f(burd), Deäter limenl=

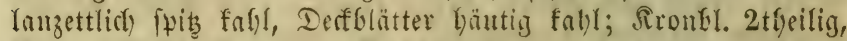
linger ala bie 3nervigen Reldublätter. - Siln feudsten fumpfiyen Steflen faft burd) bar ganze (Seb. (fifilt 3. B. bef Dortmuno uno im Sireỉ Altena, felten bei j马attingen). 6. 7. 4

616. St. graminea. (5) rasblätrige St. Stengel aแล̊gebreitet; Blätter Ianjettlid) fvib, an (Sirunse wimperig; Deffbläter fäutig, an Sanbe getwimpert; Sroubl. 2theifig, in Iang als bie 3nervigen Re(c)blätter. - SB. weį. Nenbert

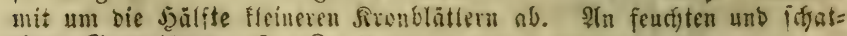
tigen Graṣpläß̧en. $6-8.4$ 


\section{Trigynia. - Pentagynia.}

†† Reld) am (srunbe Purztridterförmig.

617. St. uliginosa. Nlurr. (St. graminea $\gamma$. L.)

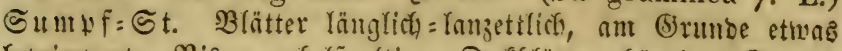

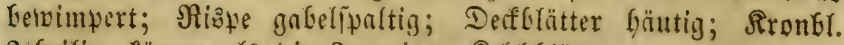
2theilig, fürzer als bie 3mervigen Reldyblätter. - $B$ l. เoeí.

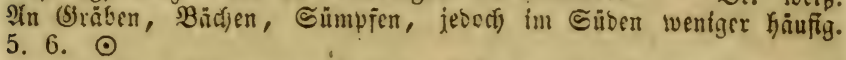

618. St. crassifolia. Ëbrh. Di ffblättrige $\sigma t$.

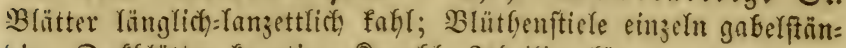
sig; Deffblätter frnutig; Sronbl. 2theilig, länger als bie ner:

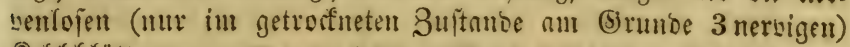

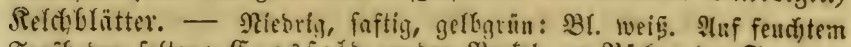

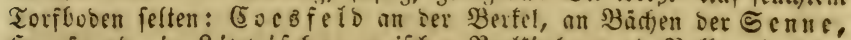

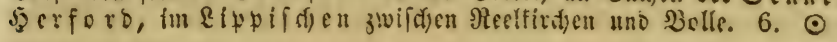

\section{Soromutig Pentagynia.}

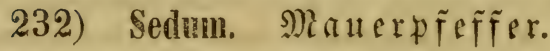

* Blätter fact) uno breit.

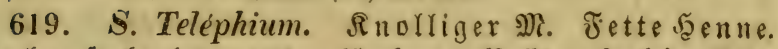

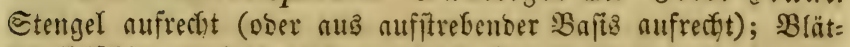

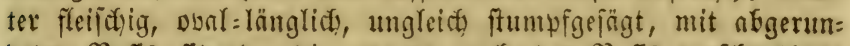

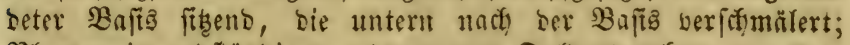
Bhumen in entitänbigen gebrungenen Dorbentratuben. - Aden= bert in Ränge und Breite ber Blätter fotwie burin ab, baf ble Staub= gefäpe melfr ober lueniger tief ten Rirenblättern eingefügt finto. Saautformen: a ochroleucum (S. maximum. S. - S. latifo-

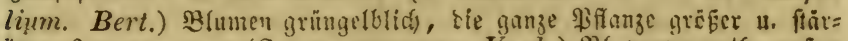
fer; $\beta$ purpureum (S. purpurascens. Koch.) BBl, purpurroth, nแf์

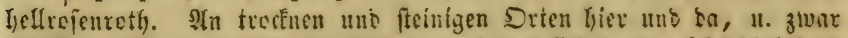

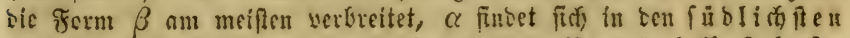

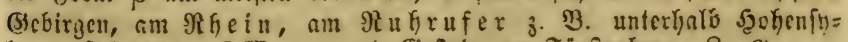

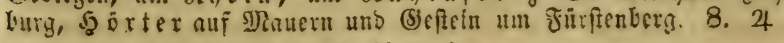

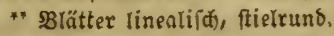

$\dagger$ Blumen weib ober roth.

620. S. allum. S2E

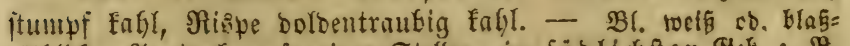

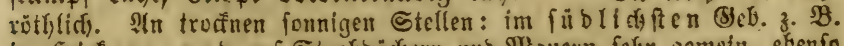

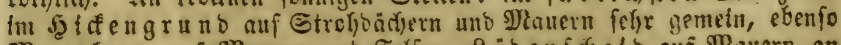

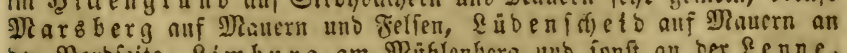
ber Nerbfeite, Rimburg am SAlthlenberg tmb ienft an ber Eenne, 
Soeft auf Etabtmanern räufig, Bielefers an Juhamistherg im

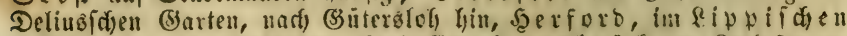

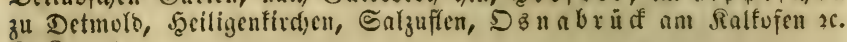
7. 8.24

621. S. villosum. Jaanriger $\mathfrak{M}$. Bätter oberjeita

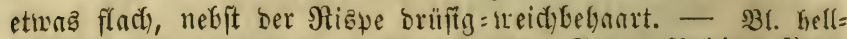

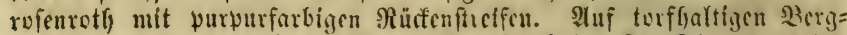

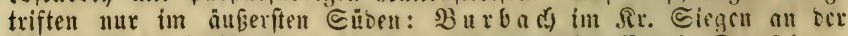

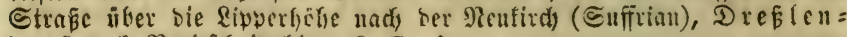
Dorf nach Breitićseio hin. 6. 7.

tt $\mathfrak{B l u m e n}$ gelb.

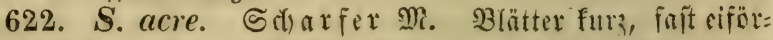
mig, fpiblich, aur dem Niüfen furfelig, mit ftumprer (meipt

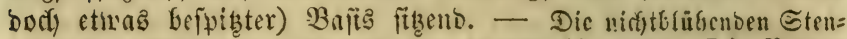
gcl 6zeilig = beblättert. Formen: $\alpha$ laxum (S. acre. L.) BBlättre

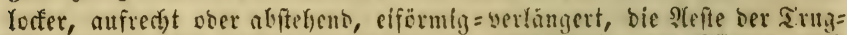
bolbe lecning = bis viclblüthig (iogar $7-10$ blüthig), bie Pffanze meift

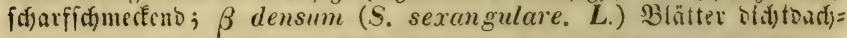

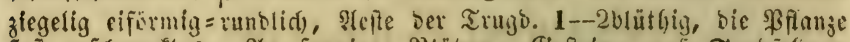

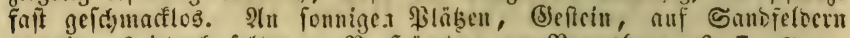

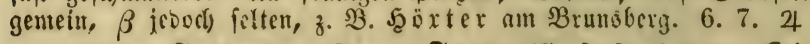

623. S. sexangulare. Autt. (S. boloniense. Eoist.)

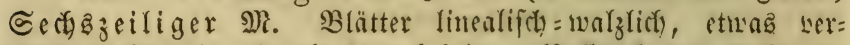

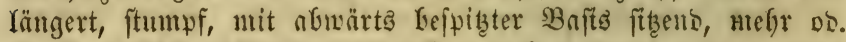

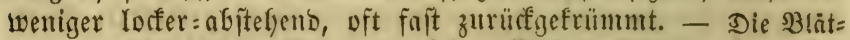

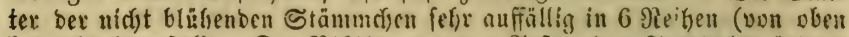
betrad)tet) geftellt. Die B̉lüthen an ocn Peîten ber Trugboloe änbern in fo ferm ab, inbem lebstre mitunter 1 -35lîthig, mitunter $6-106$ hï= thig find. llebrigens fidseinen $S$. acre utmo sexangulare finm fipezi=

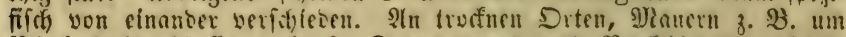
Biclefelo fäufig, ebenío Dortmulo und Reffliuglianfen,

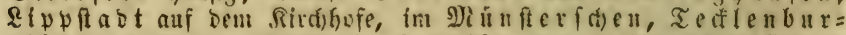

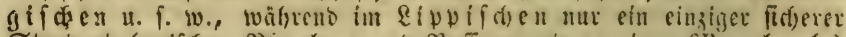

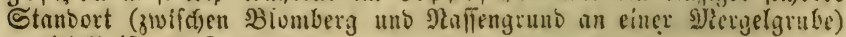
ermittelt ift. 7. 8. 24

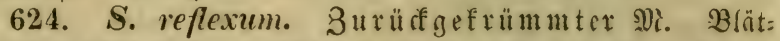

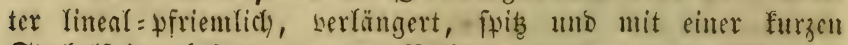

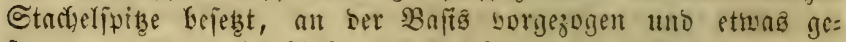
fpornt, an ben nidftblithenden Trieben uthe noer weniger ab: fitchend (oft zurüfigefrummt); 2lepte ber Trugbolbe juleb̧t zu:

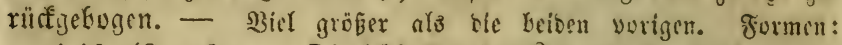
$\alpha$ viride (S. reflexum. $\boldsymbol{L}$.) Yelhaft grü, $\beta$ glancum (S. rupestre. L.) Bräulich) = soer graugrin; $\gamma$ glomeratum. Boenn. Ifbtre Form,

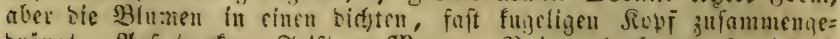

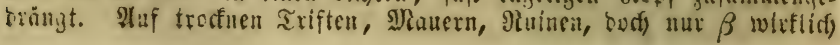




\section{Pentagynia.}

wilb, $\alpha$ bagegen, bas fonft vief in Bärteu groflangt warbe (Tripma=

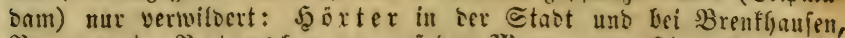

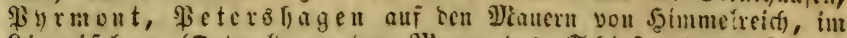

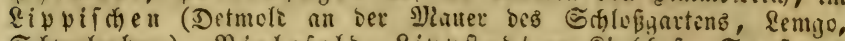

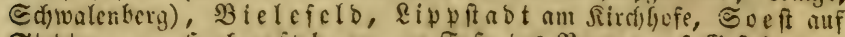

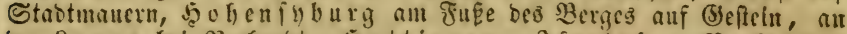

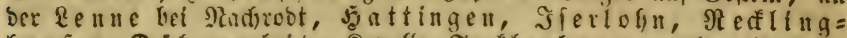

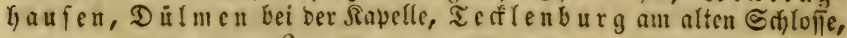

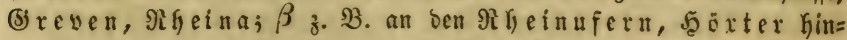

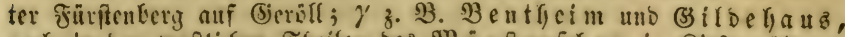

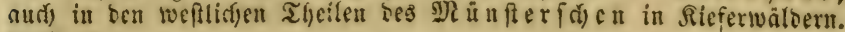
6. 7.24

\section{3) 0xalis. Snuerfles.}

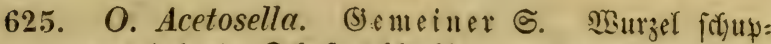

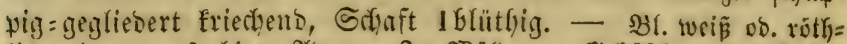

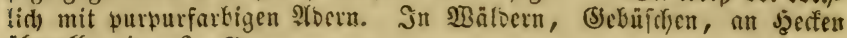
uberall. $4-6.24$

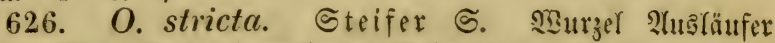
treibend, Stengel einzeln aufrecht, Nefenflätter 0, Blütyenftiele

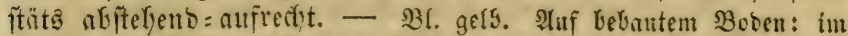

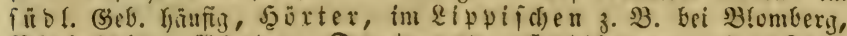
blelefelo, Metieda, Dortmun, Jattingen, Doriten,

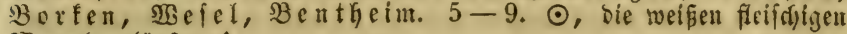
\$ีแ

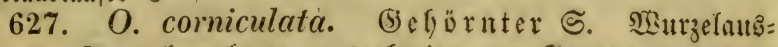

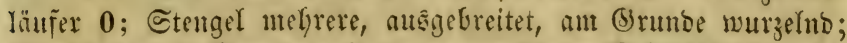

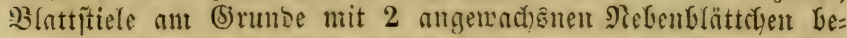

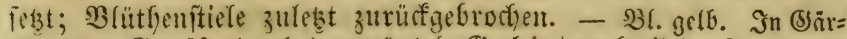

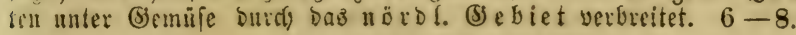

\section{4) Lychnis. Ridt tuelfe.}

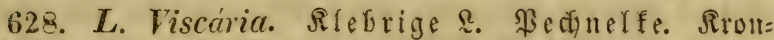

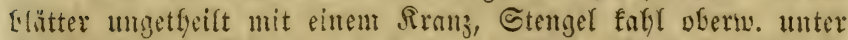

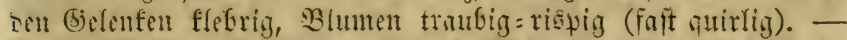

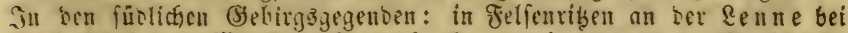

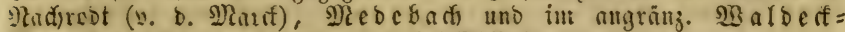

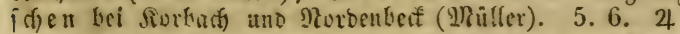

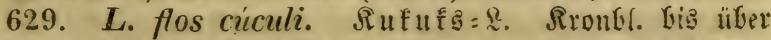

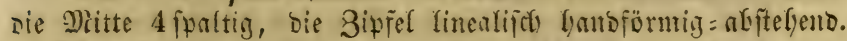

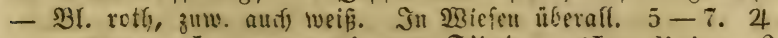

630. L. vespertina. Sibth. (L. dioica $\beta$ L.)

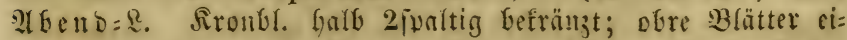

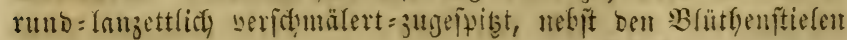




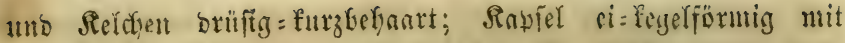

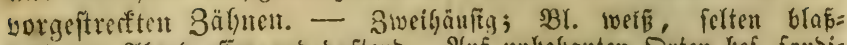

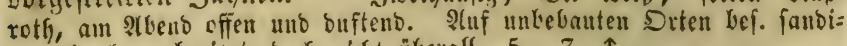
gen zieml. verbreitet, bedi nicht iberall. $5-7$. क

631. L. diurna. Sibth. (L. dioica $\alpha$ L.) $\mathfrak{i} g=\Omega$. Rronbl. ljalb 2fpaltig befränzt; Blütyenjtiele uno Reldhe non einfactyen Santen zottig; obre Blätter eirumb, plöglice zuge: fpibt; Rnpfel runolid) = eiförutig mit zurürfgerollten Säquen. -

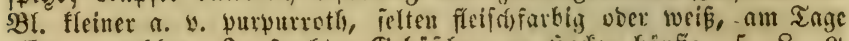

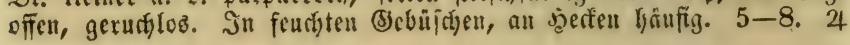

\section{3) Agrostemma. Nián.}

632. A. Githago. Rormxabon. Sironblätter unge=

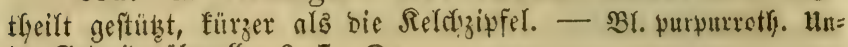
ter Betraibe ifterafl. 6. 7. $\odot$

\section{6) Cerastium. f̧ornfxat.}

* Malachium. Frics. Rapfer 5 elnppig, Rlappen 2ipaltig.

633. C. aquaticum. (Malachium aq. friss.) $\mathfrak{1}$ af $=$

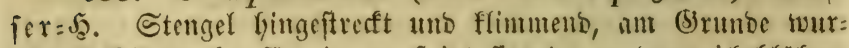

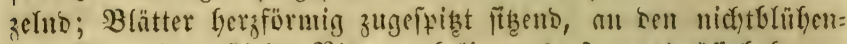

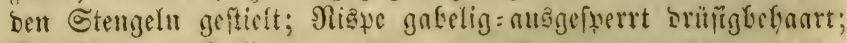

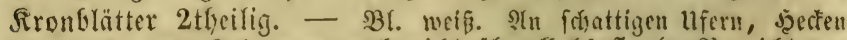

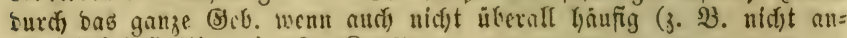
geseigt bei sattingen). $6-8.24$

** Cerastium. Fanfel an ber Epik̨e loḱtappig.

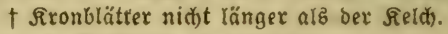

a. Dexablätter frautartig.

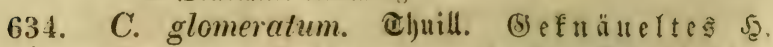
Blätter rumblid ober pyal, bie untern wie bei aflen folgenden in ben Blattftiel berfơ)mälert; $\mathfrak{B}($ umeก gefnäuelt; Deff: Reldyblätter überall Vef)nart; bie frudyttragenben $\mathfrak{B}$ lütheniticldyen fo lang als ber Relố Docr fürzer, Rronblätter ungefüfre fo Yang als ber Reldy. - Siraut gelblicfigrün; B̧. wie kei allen fol= genben tweís. SThart: $\beta$ apetalum ofye Rivonblătter. STluf belautcm,

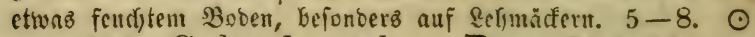

635. C. brachypétalum. Tesp. Rleinblumiges 5 .

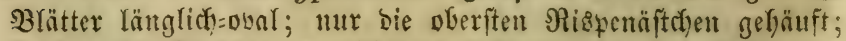

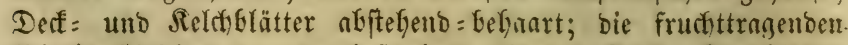
Bläthenftieldyen 2-3mal fo lang als ber Reldy; Rronblätter fo lang als ber Relch Deer fiurzer. - Sirout graugruin, Jgaare 


\section{Pentagynia.}

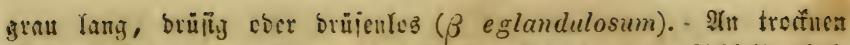

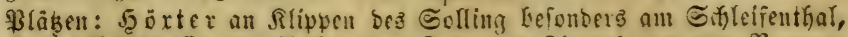

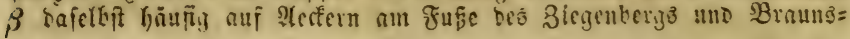
bergs. 5. $6 . \odot$

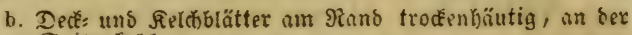
Evike Échl.

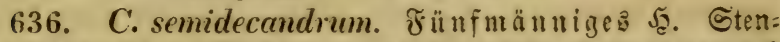

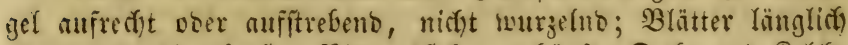

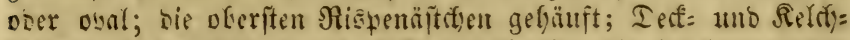
blätter an ber Epize auşgebifient:gezälynelt; bie fructyttragendon Blitffenfticlet)en 2-3mal fo lang nls ber Reldt), zurürfobebogen;

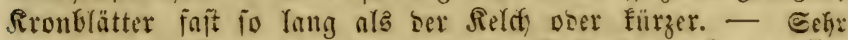
niebriq 1-3" hod), anbert mit unb ofye Drü (enhaare ab, zumeilen

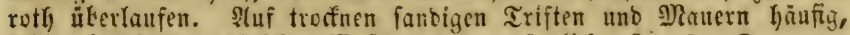
feryit aber in ten offtidien wejergegenten gänzlidy. $3-5$.

637. C. triviale. fint. (5) nueines 5 . Stengel mit= ftrebent, bie feitentiändigen nn ben untern Belenfen wurgelno;

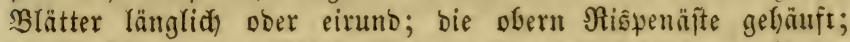
bie fructyttragenben $B$ lütfyenftieldyen $2-3$ mal fo lang ala ber Relef) voer fürzer. - Sentert mit und ofine Drüfenfigare ab, be= merfenzturtff ift eine form: $\beta$ subglabrum (holosteoides. Fr.?) flei=

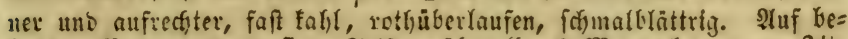
Eautem Boben und grafigen Triften überall; $\beta$ Marbberg am Sit= tenberg (Bectfiant). $5-10 . \odot$ und $\hat{\sigma}$

c. Untre Dectblätter frautartig, obere Galbtrodfenbäutig mit faft aublcufenoem grünem भiüưenftreifen.

638. C. glutinosum. Eriss. (C. pumilum. Autt.)

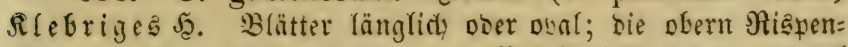

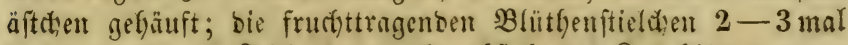
io Iang als ber Relds, Iragered)t abiteflend; Sronblätter unge=

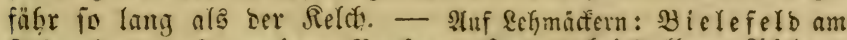

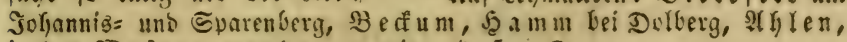
in ben $\mathfrak{T e f e r g e g e n d e n ~ g e m e i n . ~ 4 . ~ 5 . ~} \odot$

t† Rronblätter boppelt fo lang alb ber Fel(đ).

639. C. arvense. 2I f $\mathrm{e} x=\sqrt{2}$. Stengel geftrefft, ant

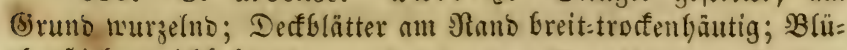
thenitiele tweid)bef)art. - Atuf founigen (5) asplägen gemein, borf) 8. .3. bei Dortmund und Santtingen fefhr eingeln. 4-7. 4

\section{7) Spergula. Spaxf.}

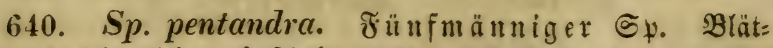
ter lineal:yfriemlios, gebuijotelt:quirlig, faft ftielrumo, unterfeits 


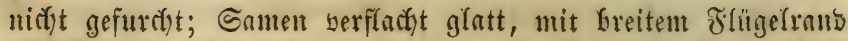

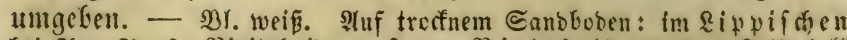

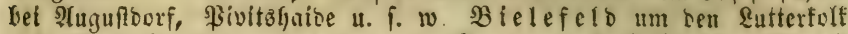
uno Supferfammer, in ber ganzen Semne, nadi Scalle bin, Sueft

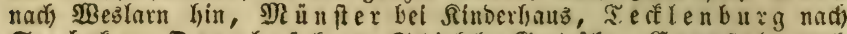

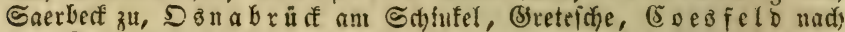
bem Dorf Etevebe hin, Rerflenghan ien ferten bet Der; ferilt im

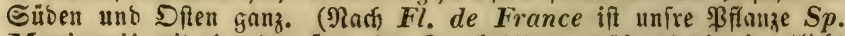
Morisonii mit efumben fiumpfen Rrunblättern, wäfirend bie eigentliçe

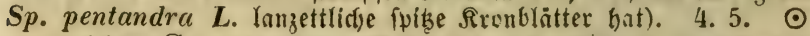

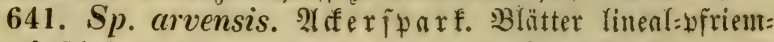
lich, gebuifdeit =quirlig, unterfeits mit einer furche burdyzogen; Samen linfenförmig mit fófmalem Flïgelramie umzogen. જ̉. tweiß́. Formen: $\alpha$ sativa (Sp. sativa. Boenningh.) Samen

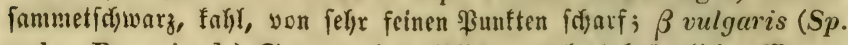

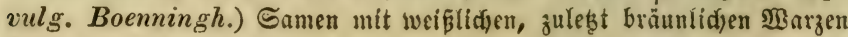
befegt; $\gamma$ maxima (Sp. maxima. Weihe.) hobler, Samen 3 mal fo

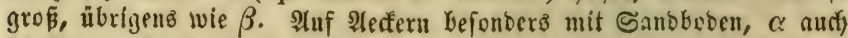
fjäfing angebnut. 6. 7. $\odot$

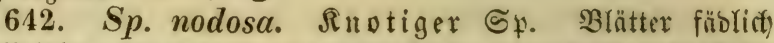
ftacherfpizig, Die untern entgegengefebt, bie obern gebüiftelt; Rronblätter boppelt fo Iang alä ber Reld). - Br. weif. Stuf

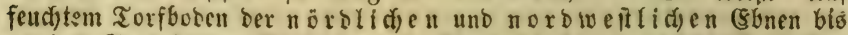

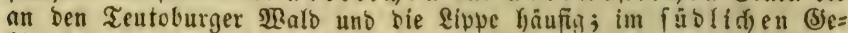

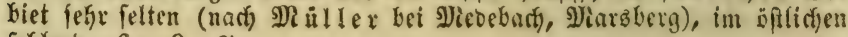
ferfleno. $6-9.2$

\section{(Citre Slafie. Dodecandria.}

\section{Sronung Mlonogynia.}

238) Asarum. Safelwury. Brüthentiulfe vberftänoig bleibeno glocfig 3 fpaltig. Narbe ftrablig 6theifig. Sapjel 6füctierig.

239) Lytheum. Mgeiberich. Rer(t) röfrig \& - 12 zäfnig. Sironblätter 4-6, ofen ber Relchrobre ein:

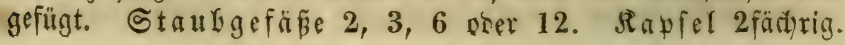




\section{Sronung Digynia.}

240) grimonia. Dbermennig. Relch frei=

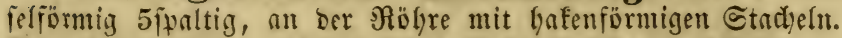
Rronbläter 5, nebit Den 6,12 Dber 15 Gtaubgeän̈ent bem Seldyrano eingefïigt.

\section{Sromung Trigynia.}

241) Reseda. Refedc. $\Re \in \mathfrak{l}$ (f) $4-6$ theifig. Aronblätter gamzrambig ober unregelmäpig zerfd)lizgt. (5) rif:

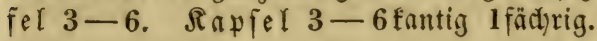

\section{Soromumg Dodecagynia.}

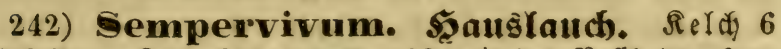
-12tfeilig. Rronblätter 6-12 mit Der Bafta ber 612 ธtaubgefäве verwadjen. Rapfeln $6-12$.

\section{Sronung Nonogynia.}

\section{8) Asarum. Scafelwulz.}

643. A. europaeum. Sisurzel friedjent, Stengel feftr

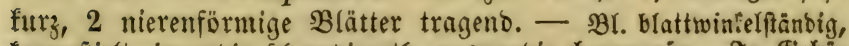

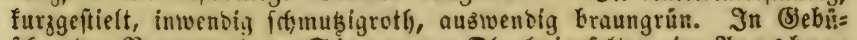

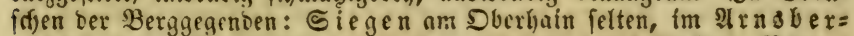

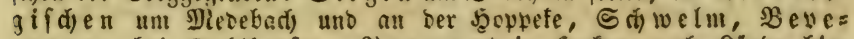

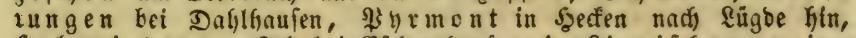

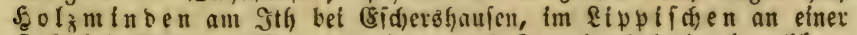

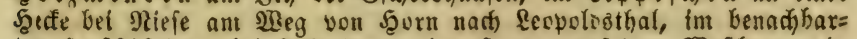

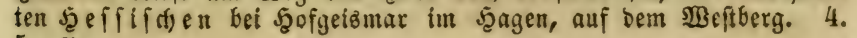
5. 4

\section{Lythrum. Ẇeiberid}

644. L. Salicaria. Blunten 12 männig quirlig=äbrig, Relche berfGhattlos mit ungleichen Büfnen, beren innre boppelt fo lang alฉ bie äuñern. - $\mathfrak{B l}$. putpurroth). N(enbert mannigfact)

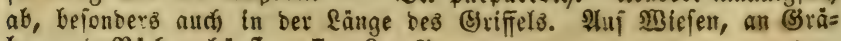

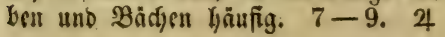




\section{Sromung Digynia.}

\section{Agrimónia. DDeruttultig.}

645 н. A. Eupatoria. (5) enteiner D. Stengel rauditang=

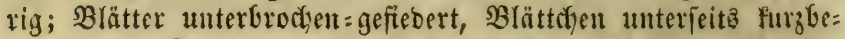
Gaart:grau; アronblätter eiruno; Fruchtfelche verfegrt:fegelförmig, ber ganzen \&änge nach gefurdyt, bie unteren Stadyeln weitafifelyento.

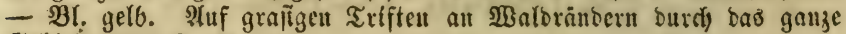
Geviet. $6-9.24$

645 b. A. odorata. Anill. 13 of friedender 0 . Stent= gel nebft ber grünen Unterfeite ber $\mathfrak{B}$ lätter uno Der Selchrögre furb̧ebaat und mit fleinen Driijen beftreut; Sronblätter läng:

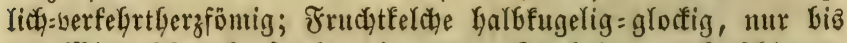

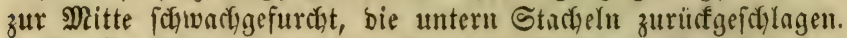

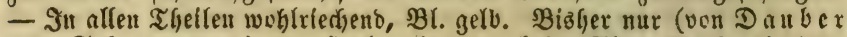

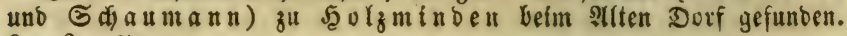
$6-9.24$

\section{Sromung Trigynia.}

\section{1) Reséda. Reféde. $\mathfrak{M} a u$.}

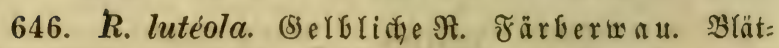
ter Ianzettlid, ungetheilt, Reldh 4 theilig. - Stengel aufredyt

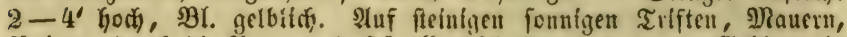

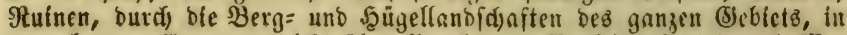

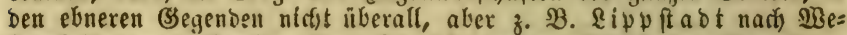
ferufotten uno (Erwitte hin, \&

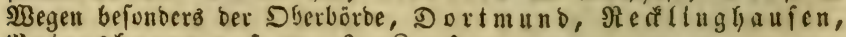
seterghagen . f. to. $6-8$. कै

647 a. $R$. lutea. (b) elbe $\Re$. Untre Blätter gefiebert, obre fieberfpaltig unb 3fpaltig, bie Bipfel wellig, Reldy 6theilig.

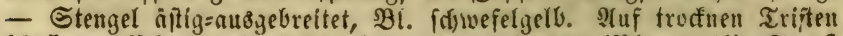

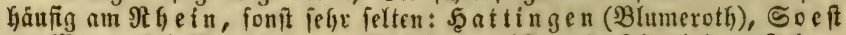

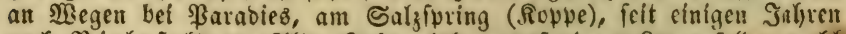
audi) $\mathfrak{B}$ ielefelo am Alten Suhannizberg auf einem \&ujernfeltoe, twofg! burdf fremben Samen hingebradfit. 6-9. $\delta$

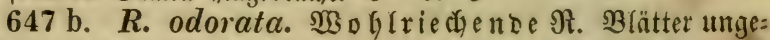
theilt ober 3 lappig, Reldi) bon ber Ränge ber Rrone. - 33 . gelblidt). In (Särten häufig angepflanzt unb zuwellen verwilbert auf (S)ar=

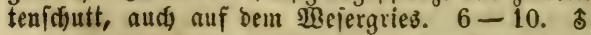

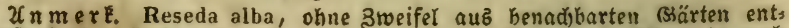

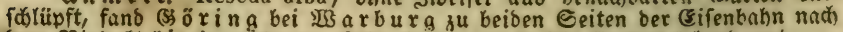

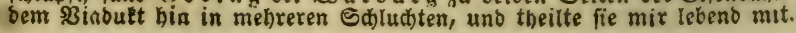




\section{Soromung Dodecagynia.}

242) Sempervívum. 5ุณ

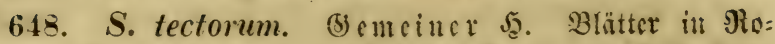

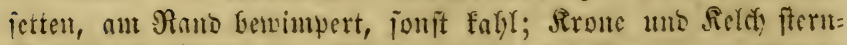

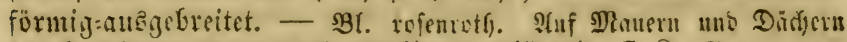
sen Landfenten gegrgen unb zumeifen verwilterns. 7. 8. 4

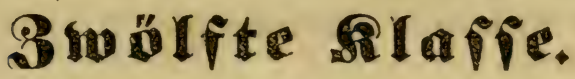 Icosandria.}

\section{Sronung Nlonogynia.}

243) FHaladelp oberitänbig 4-5theilig. Sronblätter 4-5. R̊pfel 4 -5 flaptig.

244) mygdalus. Meandef. Rel (if unterfitän= big 5fpaltig. Rroublätter 5. Eteinfrucht trodert.

245) Peesica. Sofirfich. Sel(t) unteritänoig 5:

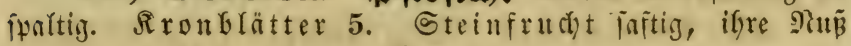

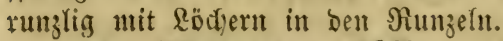

246) Pentus. Sflaume uns Rirfiche. Relti) unteritünsig 5faltig. Revablätter 5. Steinfrudt jätig, ifre NuÉ glatt ober furchig aber ohme Rỏdser.

T(nomalifdje Pflanze: Crataegus monogyna. XII. 2.

\section{Sronung Di-Pentagynia.}

247) Crataegus. Sgcip̃oorn. Stcinirut

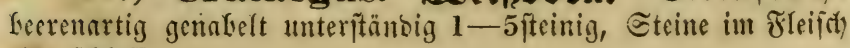
cingeitidofien.

248) Mespilus. Mizpelbamm. St siufrut Geerenattig unterfänoig, in eine beffenförmige Ërmeiterung aแล: gcheno, 2-5 fteinig, Steine in Das Ficifa) eingejenft.

249) Cotoneaster. Mrdilius. Stcinapfer: 


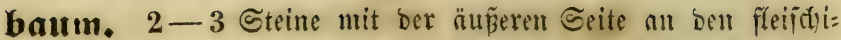
gen Reldt gewadten, unter fidt ein wenig zufummenlyangento.

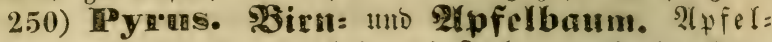
frucht unterftändig $2-5$ fäd)rig, bie sänd)er burch eine fnor= pelige Saut gebilbet und 2 jamig.

251) Gobas. Cberefobe. 2(pfelfrudit faftlos

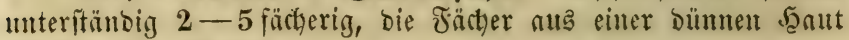
gebilbet uno 2 jamig.

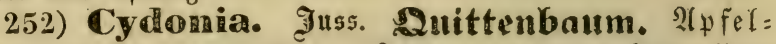

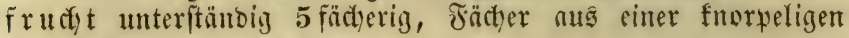
5̧aut gefildet uno vielfamig.

253) Spiraea. Epicritaube. Sapfeln oferftün= big 2-6jamig.

\section{Sronumg Polygynia.}

254) Rosa. Rofe. Relth 5ipaltig frugfürmig, zu= Yeţt in eine beerenartige vieliamige Frud)t nibergefend. Sron= blätter 5 .

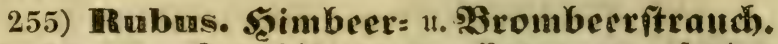
Rel di 5 ppaltig. Sronblätter 5 . sBecre nub 1 famigen Rernbeeren zujammengeietst.

256) Fragania. (Srbbece. Rel (t) 10 ipaltig.

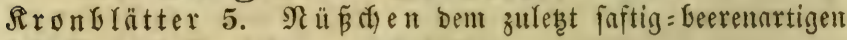
(abfallenden) Frudchtboden auffokeftet.

257) Comarum. S3lutauge. Rel (t) 10 fpaltig.

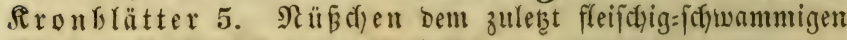
(Gleibenden) 8rudthoden nufgetejtet.

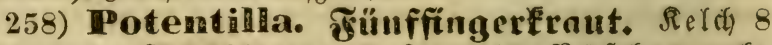

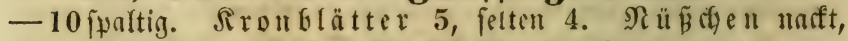
einem faftlojen Geifenden Frudtefoden eingefügt.

259) Geunn. Bonediftenfraut. $\Omega_{e} l$ th 10 fpal=

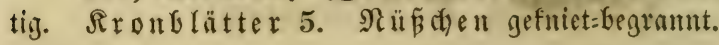

\section{Sronung Monogynia.}

243) Philadelphus. Bifeifenftraud. 649. Ph. coronarius. (s) emeiner $\mathfrak{B}$. Unediter 


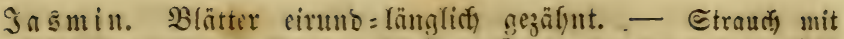

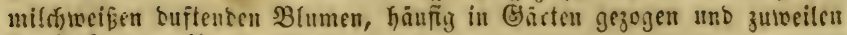
in Seefen verwilisert. 5. 6. to

\section{4) Amyggdalus. Ni «n Del.}

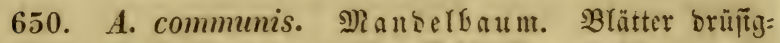

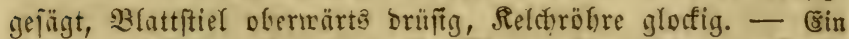

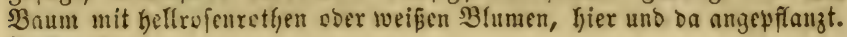
3. 4 . b

651. A. nana. 3 wergman bel. Blätter eirund=Yan=

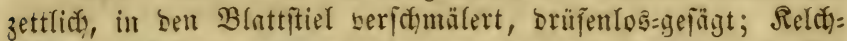

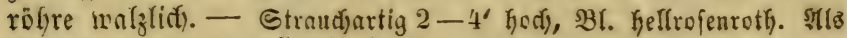

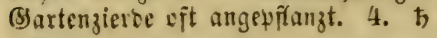

\section{0̈) Pérsica. Courn. Bifirita.}

652. P. vulgaris. Anill. (Amygdalus Persica. L.) Blätter furzgeftielt lanzettlich fd)arfigefägt. - Baum 10-16

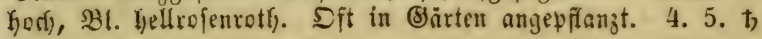

\section{6) Prunus. Pffraume und Rirfde.}

* Armeniaca. Z(priEofe. Eteinfrud)t fammtartig.

653. Pr. Armeniaca. Aprif o fenbaum. Blätter breit= eirumo, sBlüthen jeitenftündig $1-2$ furzgeftielt (Blütfenjtiele

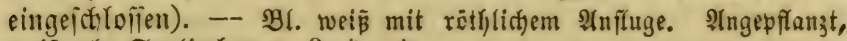
meitit alz ভpalierbaum. 3. 4. क

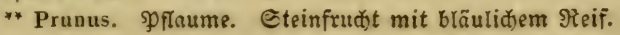

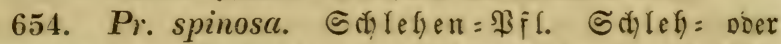

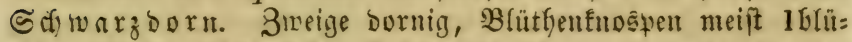
thig, Bblittfenjtiele fanfl, Früctste fugelig. - Strauth biz $10^{\prime}$

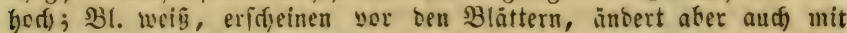
gleíd) zeitigen $\mathfrak{B l a ̈ t t e r n}$ und $\mathfrak{B}$ lumen $\mathfrak{a b}: \beta$ coetanea $W$. \& $G r$. (Pr.

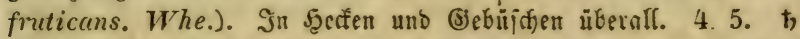

655. Pr. insititia. Rriedien= Birl. Jaaferidelefe. 3weige fanmutartig, meiīt bornenlos; Bhïthenfuospen meift 2:

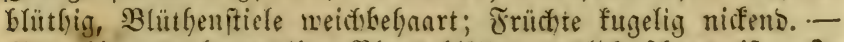

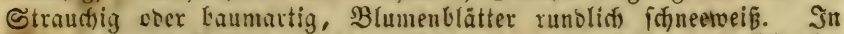

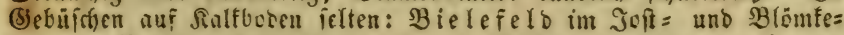
berg, in Branots Baridg finten an temt Barde, am Eparentuerg, Stromberg uni fonft im $\mathfrak{N}$ in fiferfa) en; auferbem oft um Bauer=

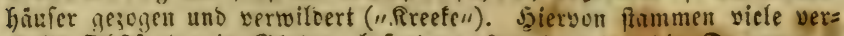
ebelte $\Sigma$ Effiforten in (särten, befonbers $\beta$ vulgaris, bic Danaszener

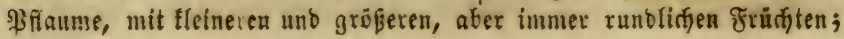


Y' syriaca (Pr. syriaca. Borkh.), bic Mhineteffe, nit fleimen getbeut

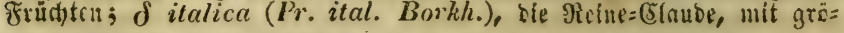
feren gefrliăgrunen Früceten. 4. 5. to

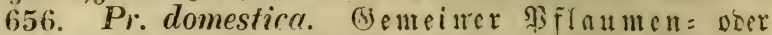

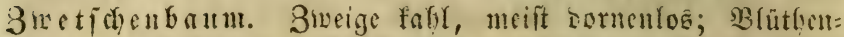

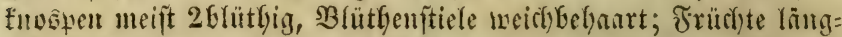

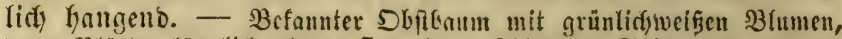

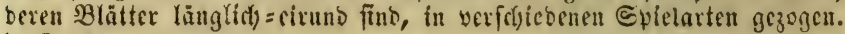
4. 5 . 万)

657. Pr. cerasifera. (E)

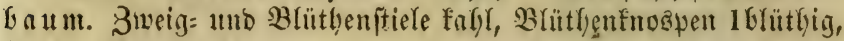

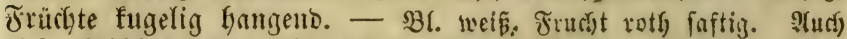
siefer Dbefbaum wirt fier und ba gezegen. 5. h

*** Cerasus. Rixf(d)e. Steinfrudt)t unbereift, Bg(umen büfdjels förmig:ooldig.

658. Pr. avium. Bogelfiridy baun. SRurzel ofye

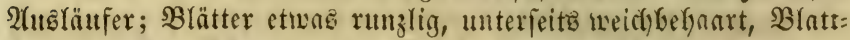

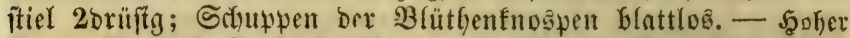

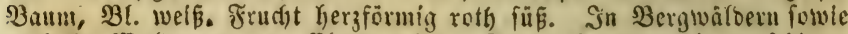

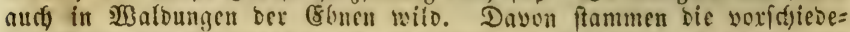

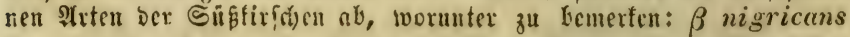

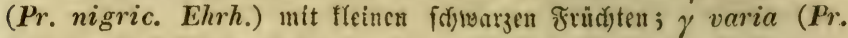
varia. Ehrh.) mit fleinen weis und votfen Frürdeten; $\delta$ Juliana

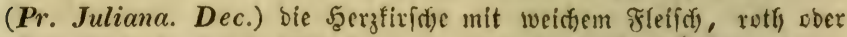
fdjwarz; \& duracina (Pr. duracina. Dec.) bie beerzfirffje mit ber= fem Fleiffy, roth ober fofwarz, $\zeta$ hispanica (PPr. hispanica. Dec.)

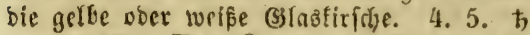

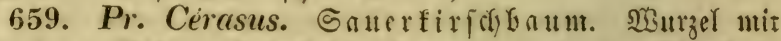

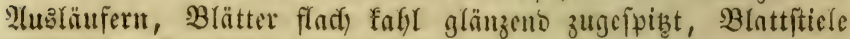

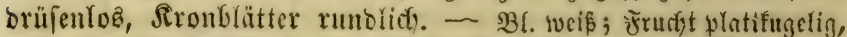

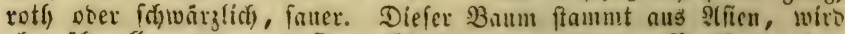
aber áberafl gezogen und findet fief ofter verwilbert z. B. Sotteln,

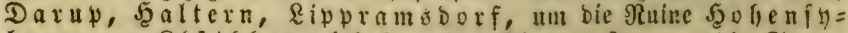

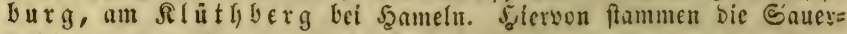

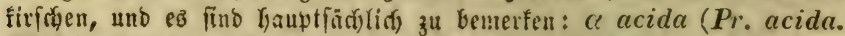

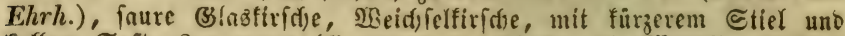
Giflem Saft, $\beta$ austera (Pr. austera. Ehrh), bie shurefle mit län= gerem Stiel und gefärbtem Saft, $\gamma$ semperflorens (Pr. semperflo-

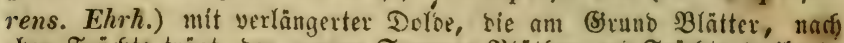

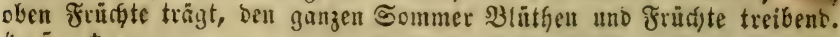
4. 5. 5

660. Pr. Chamaecérasus. Эasq. Siwergfirfale.

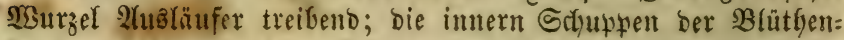

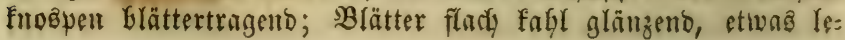




\section{Monogynia. - Di-Pentagynia}

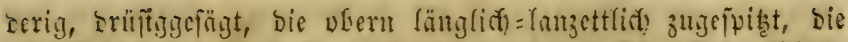

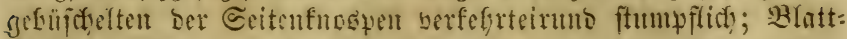

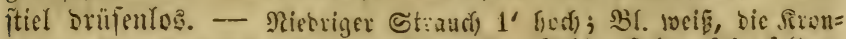

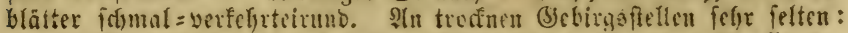

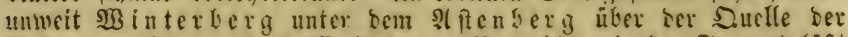

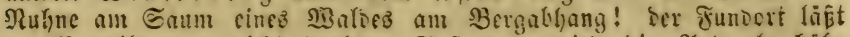

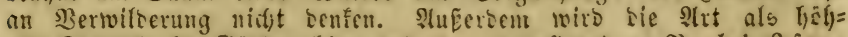

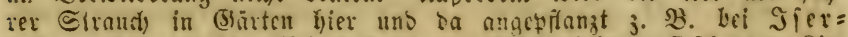

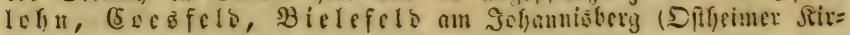
f(j, ). 5. 万

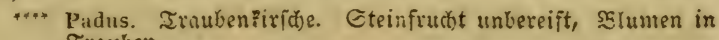
Trauben.

661. Pr. Padus. 2(f)firid)

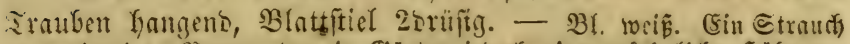

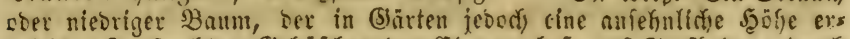

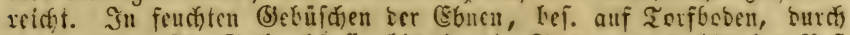
รab norbweft. (5) Refflinghaufen, felten in ten ürrigen Begenden: im Siegni=

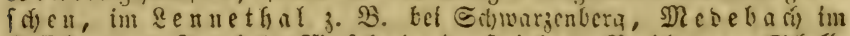

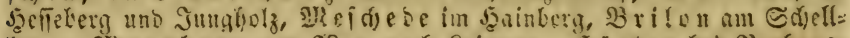

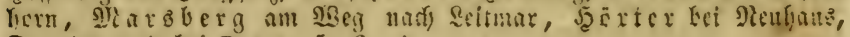
Durt mu un bei Derme. 5 . 6 . $\hbar$

\section{Sronung Di-Pentagynia.}

\section{7) Crataegus. 20ะ}

662. Cr. Oxyacuntha. Oeneiner S3. Bläter ver: fefirteirumb, 3-5lapyig, eingefợinten ober gejügt, am (5) rumbe

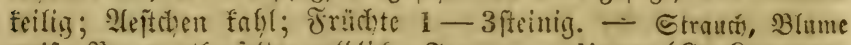
weif, Beere roth, jelten gelblit). Formen: a digyna (Cr. Oxyacan-

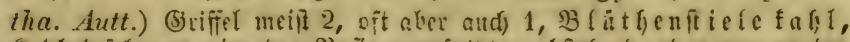

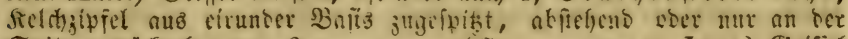

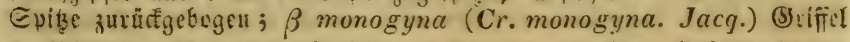

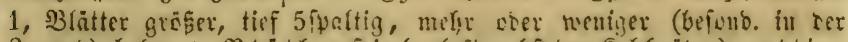

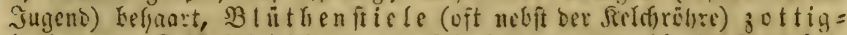

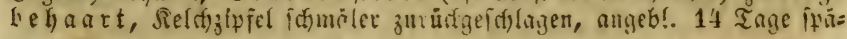
ter blïfent, negegen abev begrinbete Extaghrungen fpreden; $\gamma$ intermedia (Cr. monogyna. Fingerhuth?) (S)rî̃el 1, B̉lätter wenize:

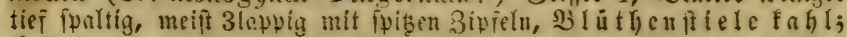
$\delta$ villosiuscula whe vor. bon die Sllutthenfitele abwärts nebfe ser

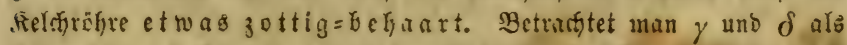

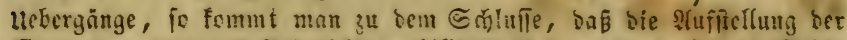

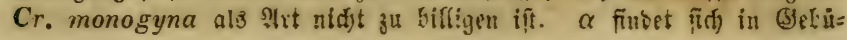




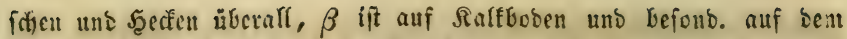

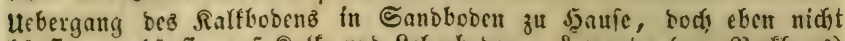

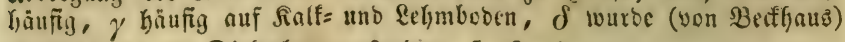

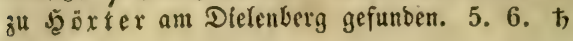

\section{8) Méspilus. Mig̨pelfau.}

663. M. germanica. Blätter längliç)=lanzettlich), unt=

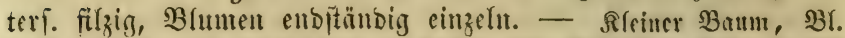

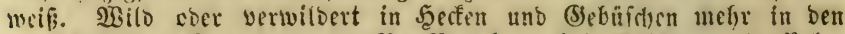
weftridsten Begenden: 3. 23. Botfen bei Bsifher und Belen

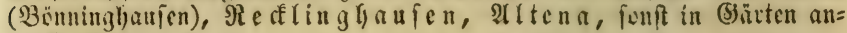
gevffangt. 5. $\hbar$

\section{9) Cotoneáster. Etro. Stcinapfelbatm. Suergutisper.}

664. C. vulgaris. finol. (Mespilus Cotoneaster. L.) Blätter eirunblid) ganzranoig, unteri. filzig; Reldhe nebit ben überhangenben Früchten fafll. - Niebriger Strauds, Bl. flein

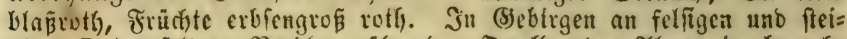

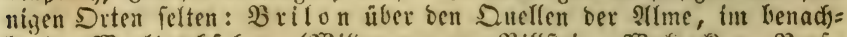

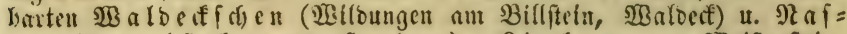

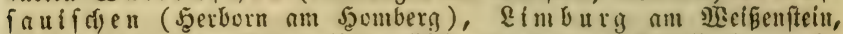

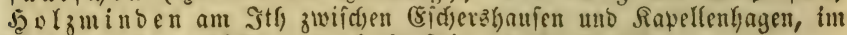

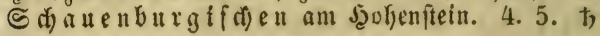

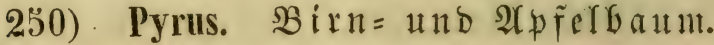

665. P. communis. Birnbaum. Blätter eirumb,

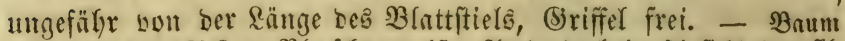

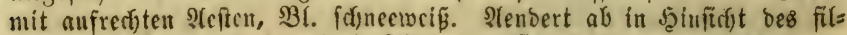

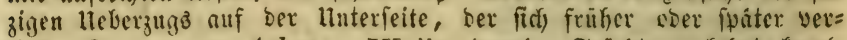
liert. Formen: a Achras. Wallr. Dorni,g, Früd)te verfeffet= fegel=

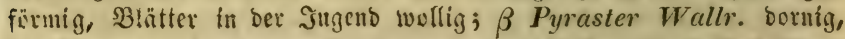

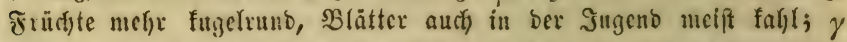
sativa. Dec. bormenlos; $\alpha$ und $\beta$ finden fidf wilto tu Bsebuifdien, an

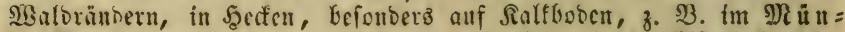

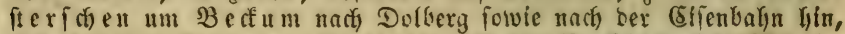

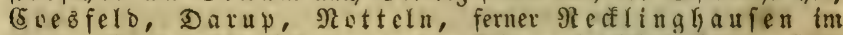

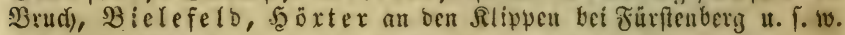
$\gamma$ wiro in (S)inten in vielectel Epiclarten gezugen. 4. 5. क

666. P. Malus. 2(p felbaum. Bl. cirumb furzzuge= ipiżt, Doppelt jo lang als die Blattítiele; Briffel bis zur Mitte

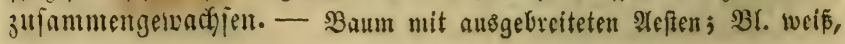




\section{Di-Pentagynia.}

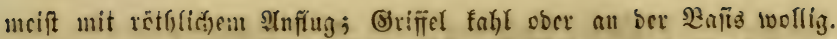
Formen: a glabra (P. acerba. Merat) s3lätter mo Fruditfnoten far)l; $\beta$ tomentosa 3 läter unterfeitz nerst ten Fruditfuoten wollig.

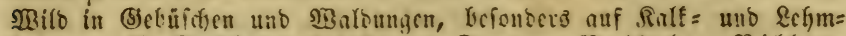
Fooen, z. B3. Dolberg bei Jamm, Darul, Netteln, Bifler=

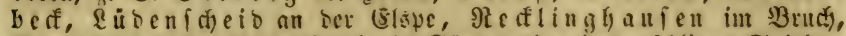

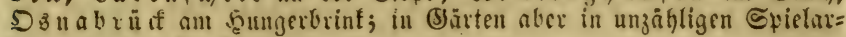
ten gezogetl. 5 . 万

\section{1) Sorbus. (Ef ferefde.}

667. S. aucuparia. (5) meine (5. Dogelberfanm.

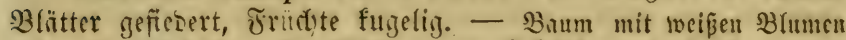

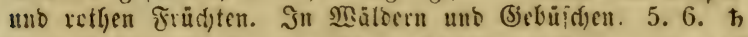

668. S. torminalis. Crant3. (Crataegus torm. L.)

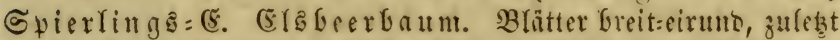

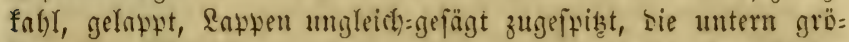

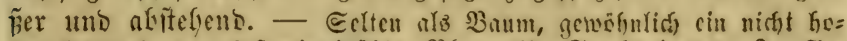

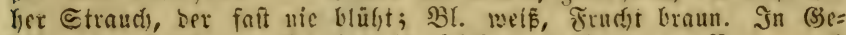

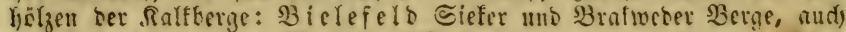

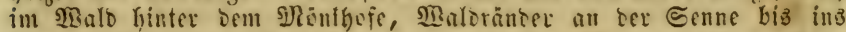

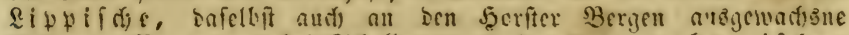

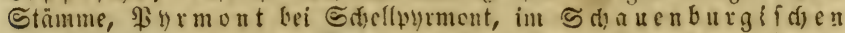

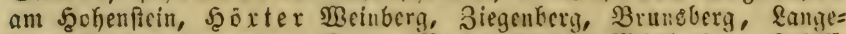

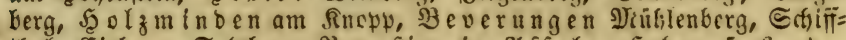

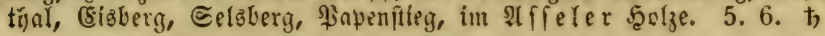

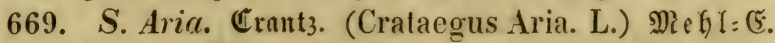

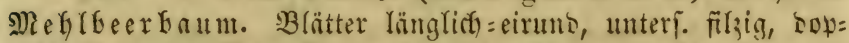
peltgeïgt ober fleingelappt, Die Cägezäfne und Räppden son

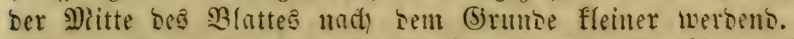

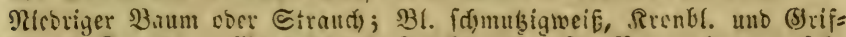

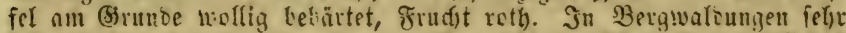

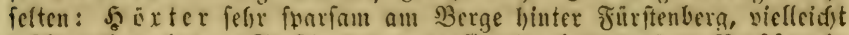

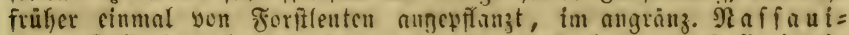

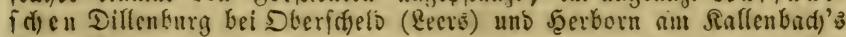
Berg (Iörrien). 5. ち

\section{2) Cydonia. Comenf. Satitenbaum.}

670. C. vulgaris. Wers. (Pyrus Cydonia. L.) Blättet eirumb gamzranbia, unter. nebft ben Relthen filzig. -

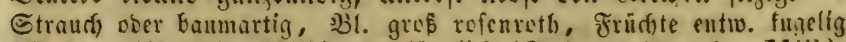
(Cyd. maliformis Mill.) soer länglid) (Cyd. pyriformis. Mill.).

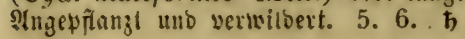

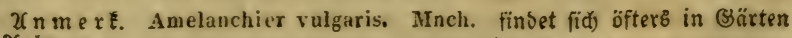




\section{3) Spiraea Epierftatoc.}

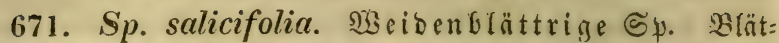
ter längliç) =lanzettlic) ungleid)gefägt, ofyue Nebenblätter, Tranbe

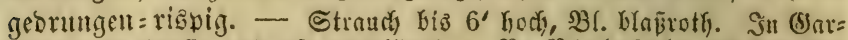
tenanlagen räufig unb oft verwelloert 3 . $\mathfrak{B}$. SBielefero um ben Riu=

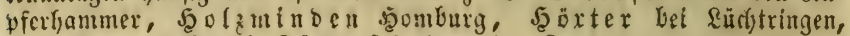

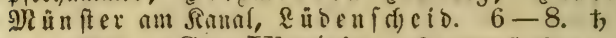

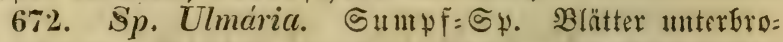

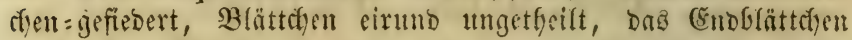

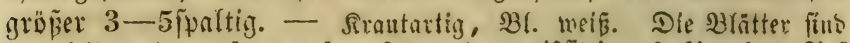

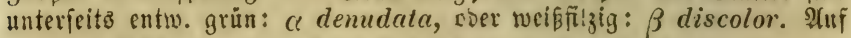

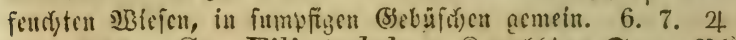

673. Sp. Filipéndula. Rnollige Gp. Bllìtter แn= terbrod)en= geftedert, sBlättchen fieberfpaltig, bie Bipfel gefägt. - Rrautartig, bie MBarzelfafern an ifren Entben zu längl!dgen Rnoflen

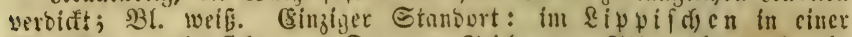

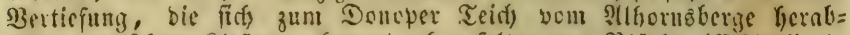

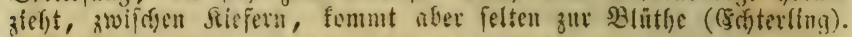
6. 7. 24

\section{Sronung Polygynia.}

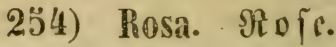

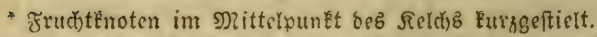

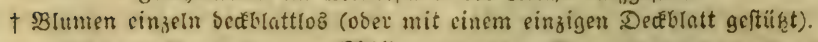

674. R. lutea. DRill. (5) elbe si. Blättcten 5-9

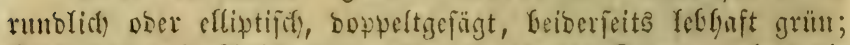

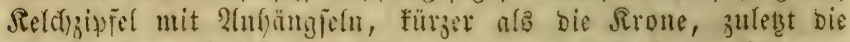

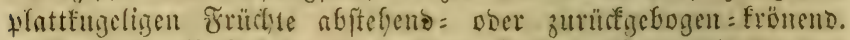

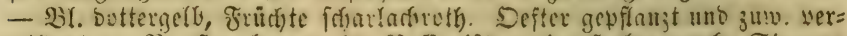

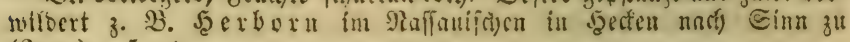
(Эแt!g). 5. 万

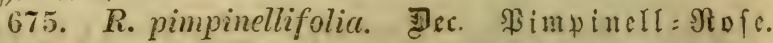
Blättuden $5-9$, rumblich voer vyal, einfact) = voer boppeltge:

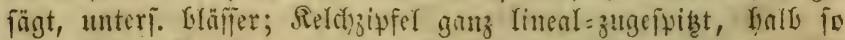

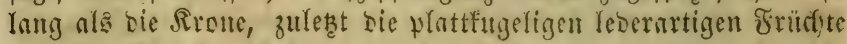

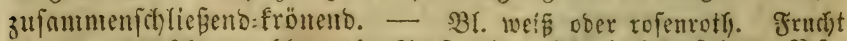

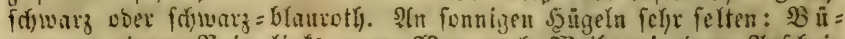

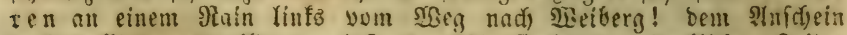

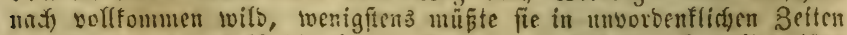

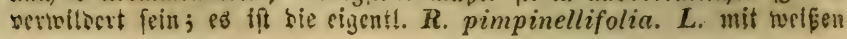




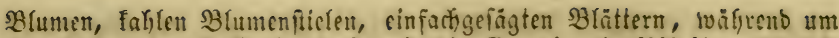
5ुerborn im SRn̄̄. (nad) Iecrä) die R. pimpinellifolia. Willd.

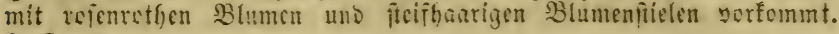
6. 7. †

†† Biumen in $3-6$ büthigen Dolbentrauben, irbe mit einem Decéblatt gefrürąt.

676. $R$. cinnamómea. Bimmtroje. @tadteln ser

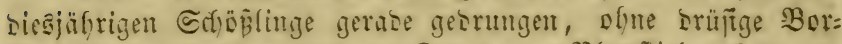
ften, bie Der Bueige zu 2 am Srumbe ser Blattîtiele gefrümmt;

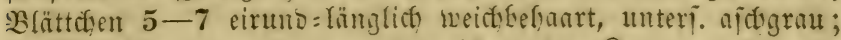
Sieldzipfel ganzranig, non ier Ränge ser Rrone, zulest bie

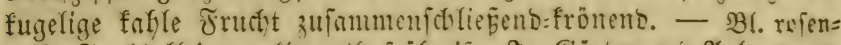

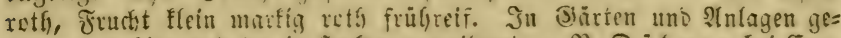

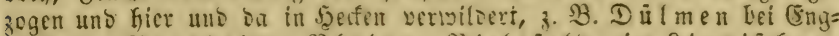

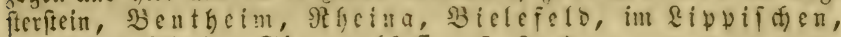
um $\&$ uี

676 b. R. turbinata. Ait. Rreifelfrüdtige ミ.

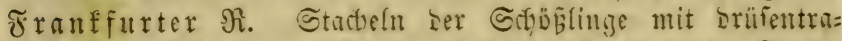
genben Boriten untermifot, in 2uter seriduminiens, Breige

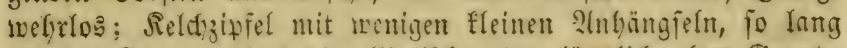

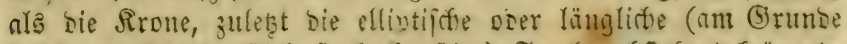

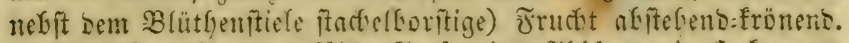

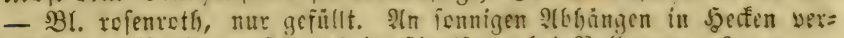

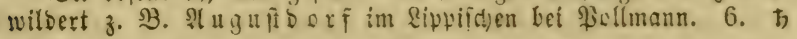

** Fruct)tEnoten langgeftielt (fo lang alz ber Etiel).

677. R. canina. (5) me ine 9i. Etndeln berb fittel=

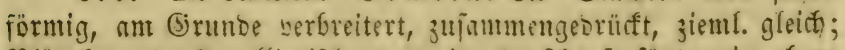

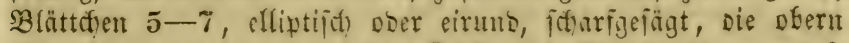

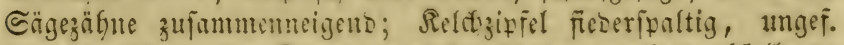
nou ber Ränge ser Irone, zuritigefolagen, fuletgt abfallens; Jruat efliptifif oscr runslifs, Enorpelig. - Br. refenroth soer

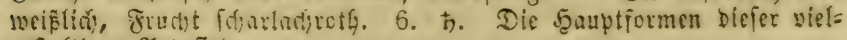
geftaltigen slit find:

a vulgaris Blattitiele gany fah! ober mit entfernten Drị̂n beftreut oier aud) am (\$)runte etwas fefluart, Blätter, Blütlgenfticle unt Reldyrobre fabl. Dubin geheren unter anbern: $R$. caesia. Lindl.

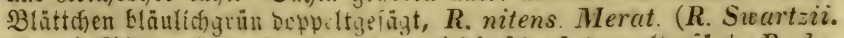
Fries) SBlätter beicerí. nlängend ungleing fot)arf = boppeltgeiäzt, $R$. du-

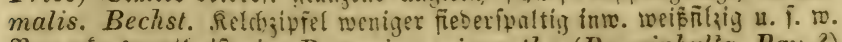
Bemerfensiverth it: cine R. canina micrantha (R. aciphylia. Rau.?) mit um bie Salfite fleineren Blätern uno Bflumen. Die Jauptart mit

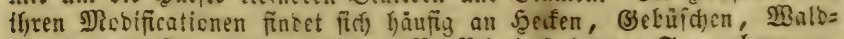
räbern, bie Frorm micrantha 3. B. Bielefels am હuarenberg.

$\beta$ dumetorum Blattfitele überall befjaart, Shlätter unteri. auf

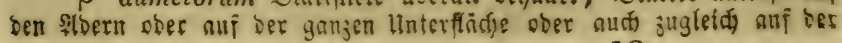




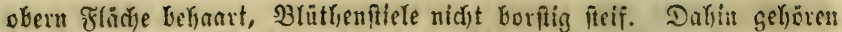
$\boldsymbol{R}$. dumetorum. Thuill. - R. corymbifera. Borkh. - R. sepium.

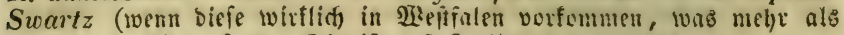
zweifellgaft ift) u. f. w. Sie ift auf Ralfboben verbreitet.

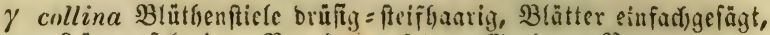
2. B. um $\mathfrak{l}$ ü hort nud bahin: R. Acharii. Billb. Seldozipfel fleinzerfest u. fü:=

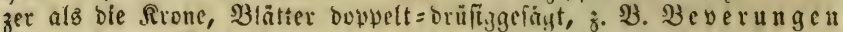
S)iüllenberg; $\boldsymbol{R}$. andegavensis. Bast. 23lätter ganz fahl oberieitz

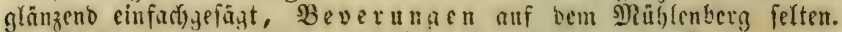

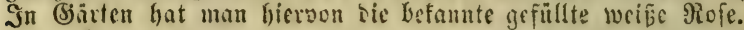

$\delta$ sepium (R. sepium. Thuill.) Blattittele uno Blätter unterí. (ober auch) beloerfeitż) mit flebrigen Driienlanaren befest, Blütfen=

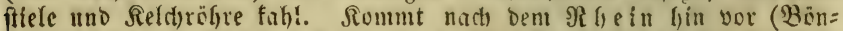

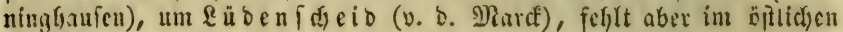
Meftfalen.

678. R. rubiginosa. Siseinrofe. Stactieln berb, fitchelförmig, nm (5irumbe berbreitert, jufammengebrïft, ungleict);

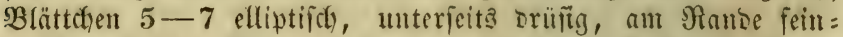
brüfggefägt, bie Gägezälne etwns abitefiend; Relchzipfel feber=

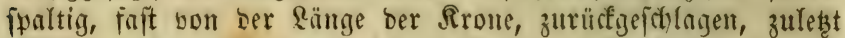
abfalleno; Jrucht rundich fnorpelig. - SBl. rofenroth. 6. $\frac{\hbar}{5}$

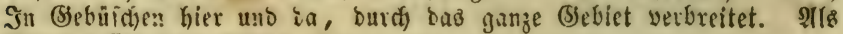
Tbarten find zu merfen:

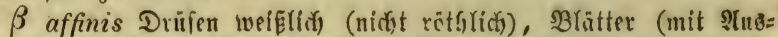

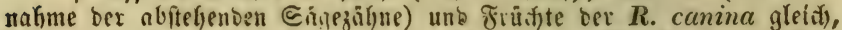

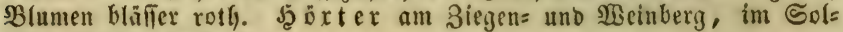
ling, $\mathfrak{5}$ ol $\mathrm{z} m$ in $\mathrm{b} e \mathrm{n}$.

$\gamma$ micrantha (R. micrantha. Smith.) Blattilicle filzig, Seldie am Brumbe fwarfam=fteiffarig, $B$ lumen lind frithte beseutent fleiner. Tuf Ralfboden: $B_{e}$ of $u m$, Stromberg, alf ben fallen

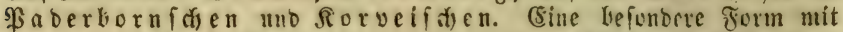

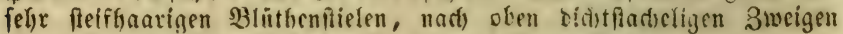
und bololig gefte!lten Früd)ten ift $\boldsymbol{R}$. umbellata Leers.

$\delta$ caryophyllacea (R. caryoph. Bess.) Blattificle fogivads)=

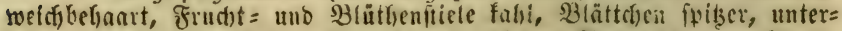

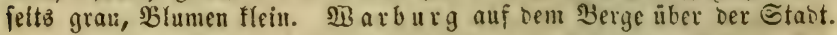

$\varepsilon$ agrestis. Savi. Blattftiele uno Interfeite ser Blätter felyr biçtbrüfi!\}, fonft bie Blätter gan fafil, fâsmäler, länger zugefpibt, brei= fact)gejägt. \&a uenför be bei Beverungen.

679. $R$. tomentosa. Simitl). Filzige R. Staiteln berb, laug, faft gerabe, nugleich; B̉ättclen elliptifich voer cirumb, boppeltgefingt, graugrün, feinbelyart; Reldsipfel fieber= beripaltig, fo lang als bie (nidft brïitg gelvimperten) Sron= blätter, zurïfigefdilagen, bleibend voer febr ffät abfnllento; Frübte runblid fnorfelig, meift ftadyelig. - SBl. weiprëthlid), 


\section{Polygynia.}

Frudjt (đ)ar(ad)reth. 2(6art: $\beta$ mollissima (R. molliss. Willd.)

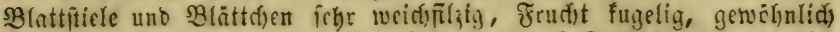

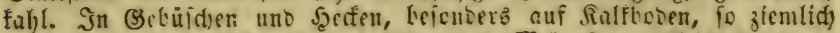

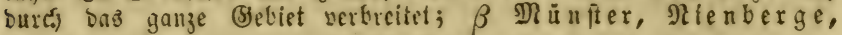

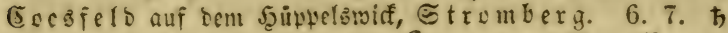

68v. $R$. pomifera. formann. (R. villosa. Wulf.)

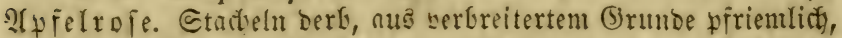
ungleiđ); Blättcten längliđ)= lanzettliđ̆ graugrün; Reldłzipfel T̈eserppaltig, fo lang als bie errüing gewwimperten Rronblätter, bleibent und die grofen fugeligen niffenten fehr ftactigen

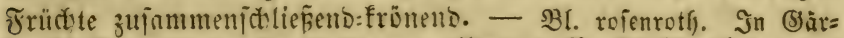

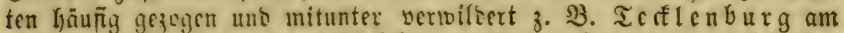

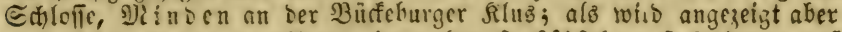

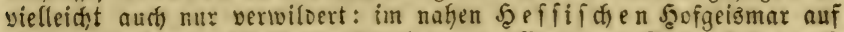

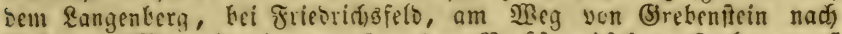

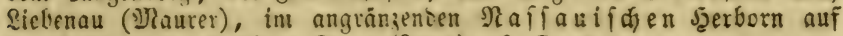

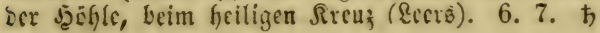

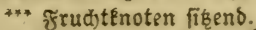

681. R. urvensis. G)us. Feroroje. Etadeln berb

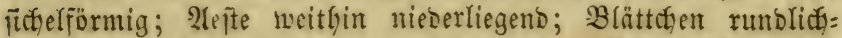

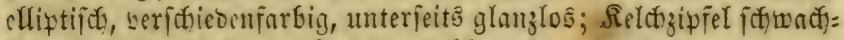

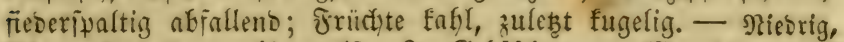

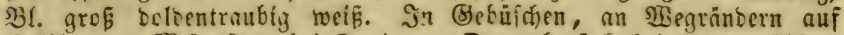

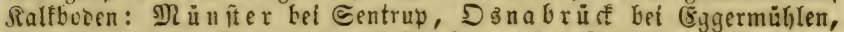

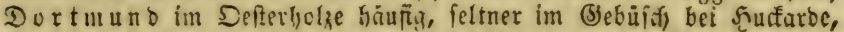
Rübenife

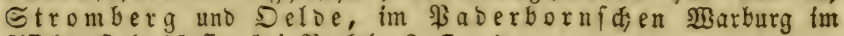

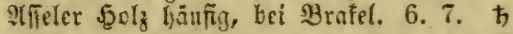

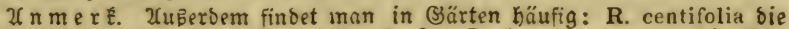

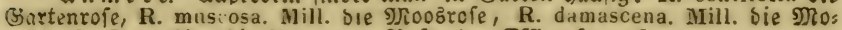
saterofe, R. gallica bie şrobencer Piofe ober Effigrofe u. f. w.

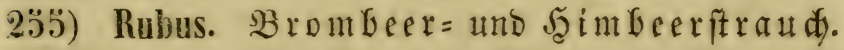 * Frü̈dte f(j)warz.")}

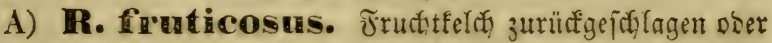

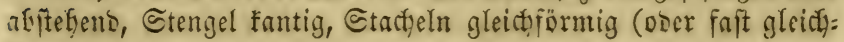
jürnig).

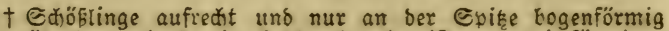
überhangend, Eantig, Eahll und unbereift, mit gleidförmigen Etacheln bejest.

682. R. fruticosus. Whe. (R. plicatus. Whe. \& $\mathfrak{H}_{\mathfrak{k} \mathfrak{e s} \text {.) }}$

*) Für diejenigen, benen ber Rubus- 2urten zu viele fins, fino von ben eigentliden Brombeeren nur fü $\mathrm{n}$ f $\mathfrak{X} \boldsymbol{x}$ te $\mathrm{n}$ (R. fruticosus, $\mathrm{R}$. Schleicheri, $\mathbf{R}$. glaudulosus, $\mathbf{R}$. corylifolius und $\mathbf{R}$. caesius) aufgeftellt $2 \mathbb{3}$ eitere $\mathfrak{B}$ eob: aditungen werben bie (ङ)attung, beren 2rrten burd) ibren Etanbort mandjerlei DRooificationen erleiben, gerwis roieber bereinfad)en. 
Ed)

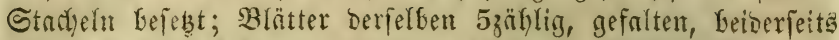

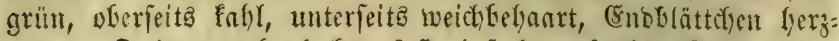
cirume; Doldentrate locfer, faft einfach, aufredt); Reldi anfer=

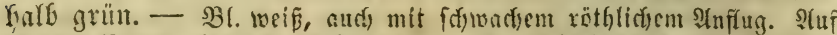

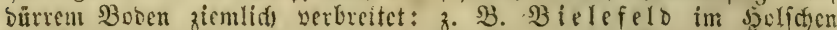

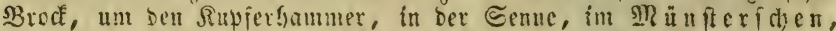

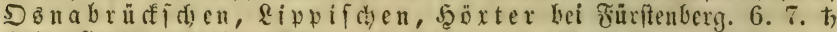
(wie alle folgenten). Nbart: $\beta$ suberectus (R. suber. Anders. R. fastigiatus. W.\& N.) Blătter nitcht gefalten, mit Yänger: vorge=

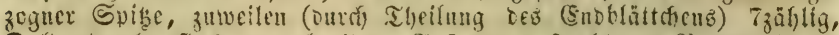

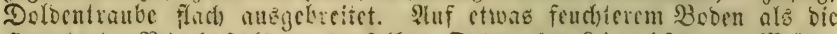

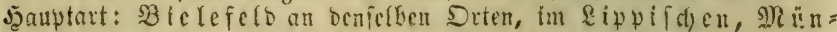

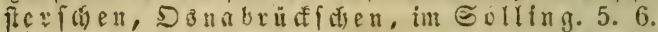

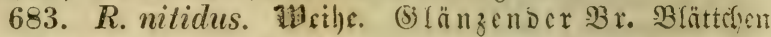

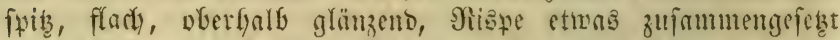

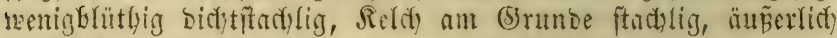

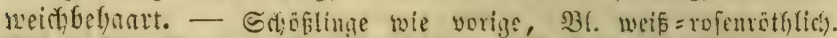

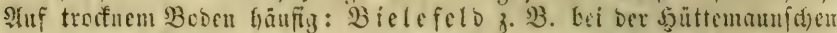

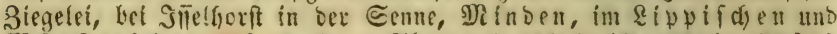

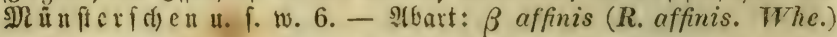

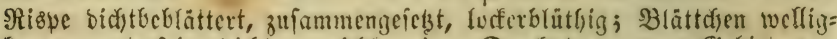

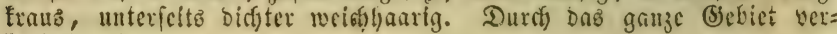
Ereitet. 6.

684. R. candicans. Whe. SEç

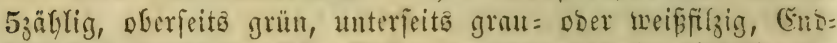

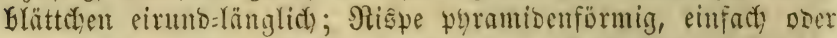

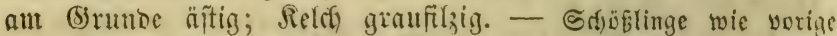

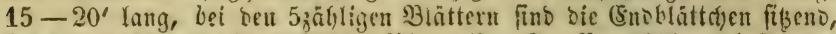

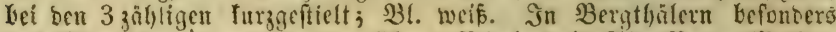

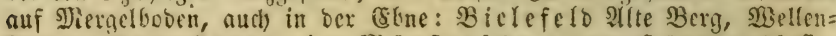

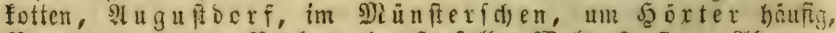

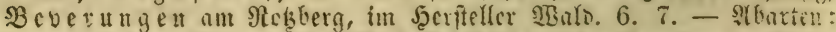

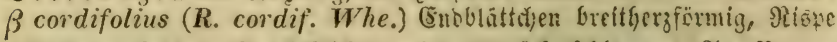

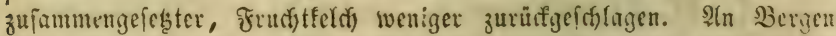

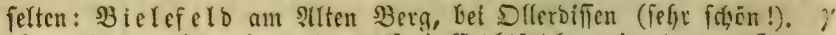
rhamnifolius (R. rhamnif. Whe.) (Enoblättd)en eirumb, ma (s) nunbe

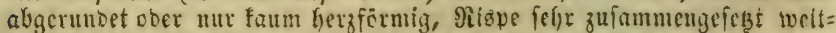

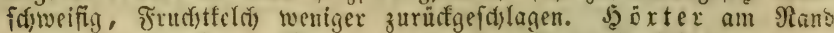

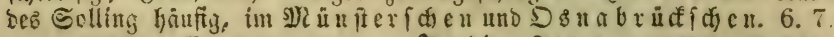

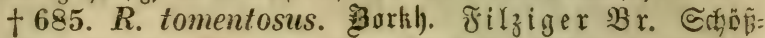
linge mit furzen und fofwadten Etacteln bejegt (jonft inie

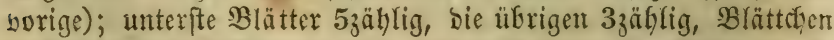
werfebrteiruto = feilförmig fpis, oferfeits grau=fternfflzio, unter=

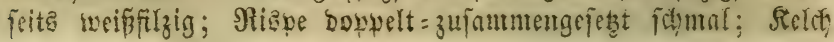




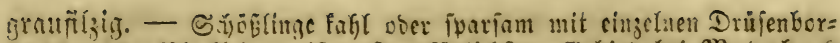

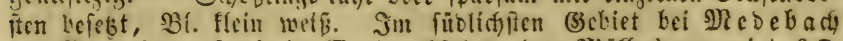

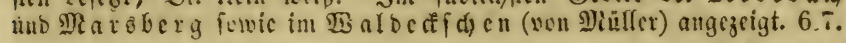

扩 ๔ä̈b̈linge bogenförmig: nieberliegent, fantig ober runo: (id), langhararig ob. zottig (nid̄t bereift und ohne Borften), mit meili gleidiformigen Etadjeln. Seld) aukerhalb filsig. a. S(t)ő̄linge orüfenloz.

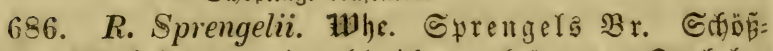
linge rumblich bebart, mit zallreidfen gefrümmten Etadfeln;

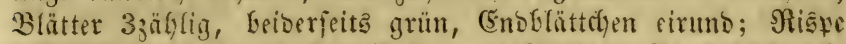

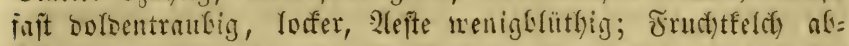

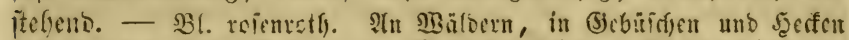

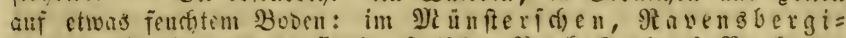

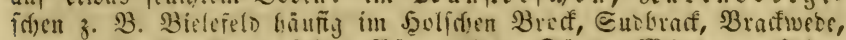

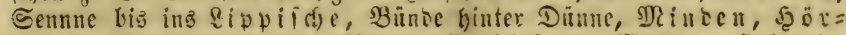

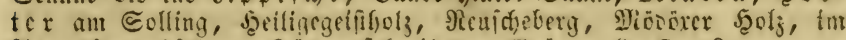

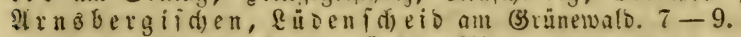

68\%. R. Schlechtendalii. Whr. Sdiled)tendal's $\mathfrak{B}$ :. Giföbringe rumblid) abitefentobefyart, mit breiten gefrümmtent હtadyeln; Blätter 5zäblig oberfeits ftriegelig, unterfeits feiben:

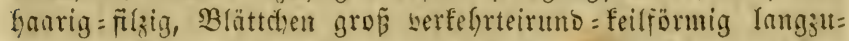

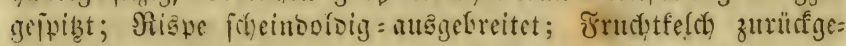

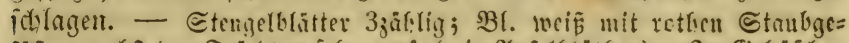

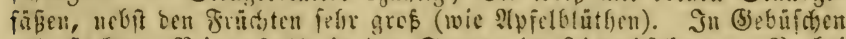

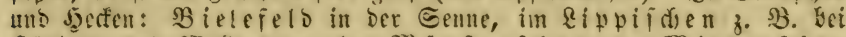

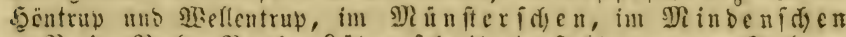

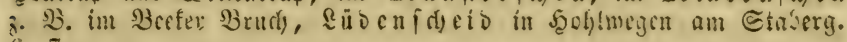
6. 7 .

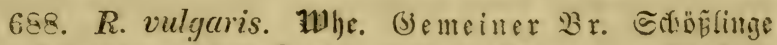
fantig fefoart, an ben Ranten mit ziemlid) graben Etacte!n

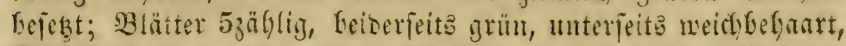

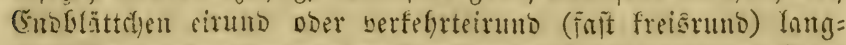
3tigejpibt, meht: Doer weniger ferzförmig; Glütfentragende Sten-

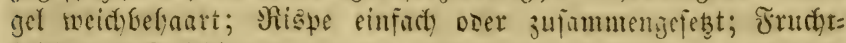

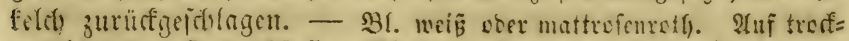
nen fanattigen Drten büufiz. Alkarten: $\beta$ carpinifolius (Rub. car-

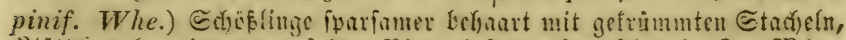

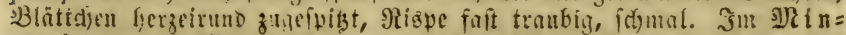

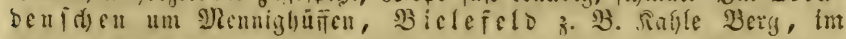

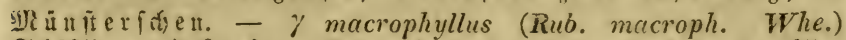
ङ

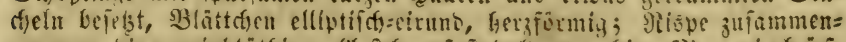

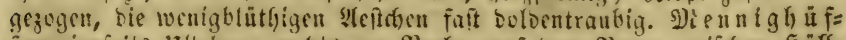

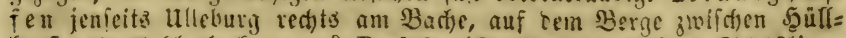

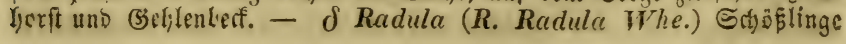




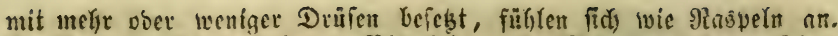

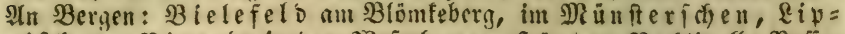

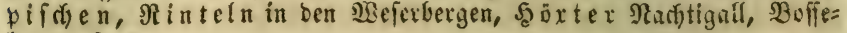
born. 6. 7.

689. R. discolor. Wybe. Berfdiebenfarbiger $\mathfrak{B}$ r. Sđöplinge fantig, nach ber Spike zu gefurcht, won anliegenocu Saaren feibenbaarig glängend, an belt Ranten mit Inugen itar: fen, graben oder etwas gefrümmten Gtadyeln befebt; slätter

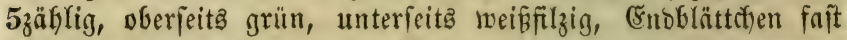

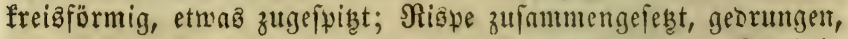
fein:weifgraubrgart uno mit zablreichen gefrummten Stad)eln

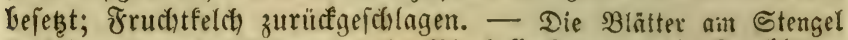

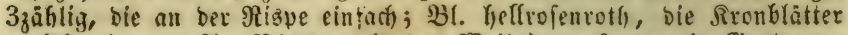
werfehrteirund. Am $\mathfrak{R}$ c

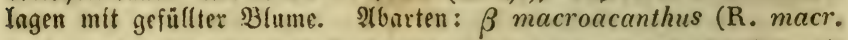

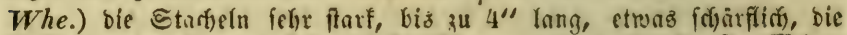

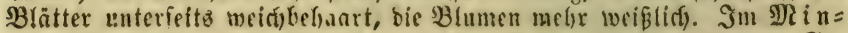
benfdien feltuer, an (bebuid) zivijdyen Bolmerbingfen nno bem (Se= birgåzuge (Weiffe). - $\gamma$ pubescens (R. pub. Whe.) meif grïp̄er,

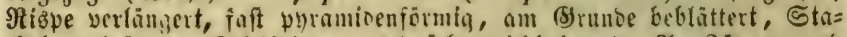

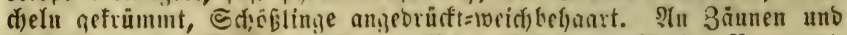
Bebüfden: im gifnoenfden, Bielefelo am Rablen Berg unb

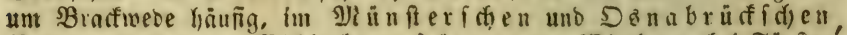

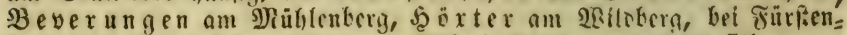
berg. - $\delta$ argeoteus ( $\mathrm{R}$. arg. Whe.) $\mathfrak{B}$ !ätter unterfeitz fillergrau, Rişpe zufammengezogen wenigblüthig, Stad)eln jo lang wie bei $\beta$ sod glatt. Im Mindenfdien um Diennighüffen bei Schepucrs Sicke

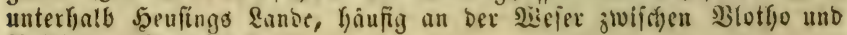
Belthetun (Deilge). 6. 7.

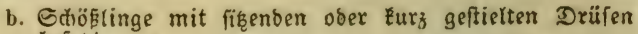
befetzt.

690. R. vestitus. Whe. Befleibeter $\mathfrak{B r}$. Siföpa ringe ftumpffantig, bicht: und abitebentebant, an ben Ranten nit zeritreuten grofen faft graben Gtad)eln Vefest; Blätter 5zäblig, oberfeits fdumubiggrün, unterfeits meiphantig fonim:

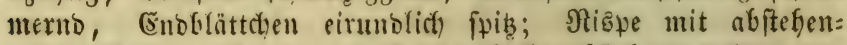

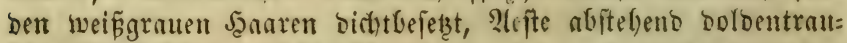
big; Fruchtfeldh zurürfgefdlagen. - $B$ I. grof, weif ober rofen=

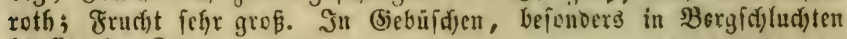
hảufig. $6-8$.

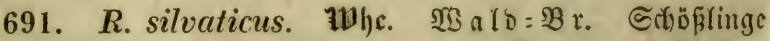
runblid ober ftumpffantig, Gehanrt, an ben Sinten un Fläd)en mit znhlreidten fleinen, etwas ungleichen, ziemlict) graben Gta=

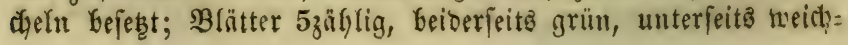




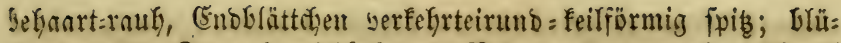

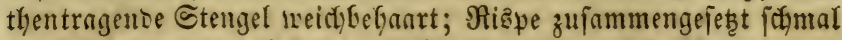

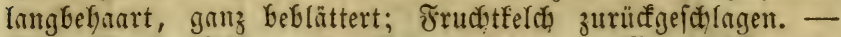

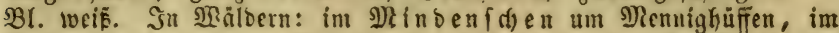

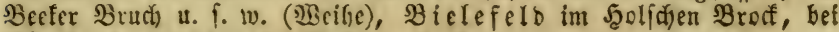

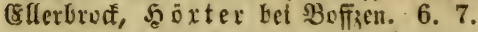

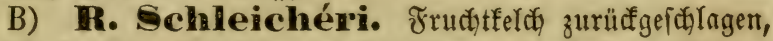
Stengel fantig, Gtactyeln ungleidyförmig (nut Ianggeftielten Drüfen umb meift mit Saaren bermifcht).

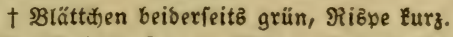

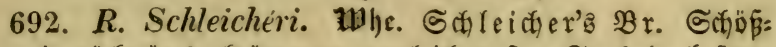

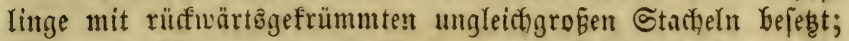

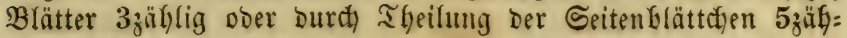

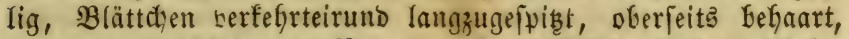

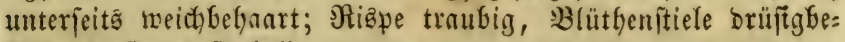

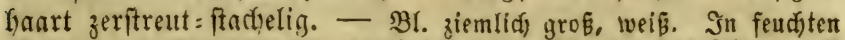

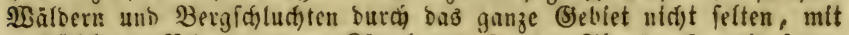
gefüllten $\mathfrak{B l}$ umen am ßöterberg. 6. 7. 24bart: $\beta$ apiculatus

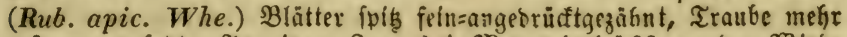

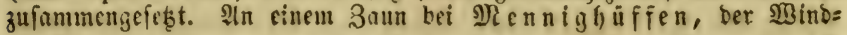

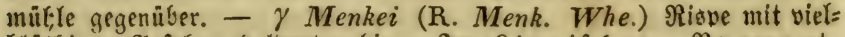

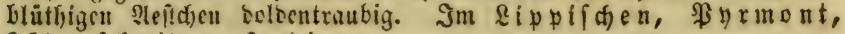
Lu benf d) $e$ ib am Saxtei.

693. R. fusco-ater. Why. $B \mathfrak{B} \mathfrak{n} \mathfrak{n}$ d warzer $\mathfrak{B r}$. Schößlinge mit rücfmärtŝgeneigten ungleiđgroben @tact)eln bicht=

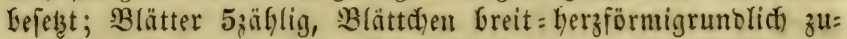

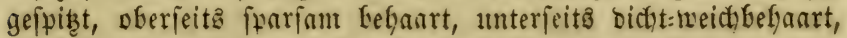

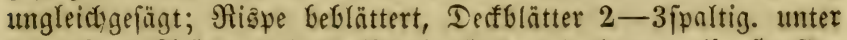
Den obern 2(eften einfad), Bhlüthenftiele mit Yangen (borftenför: migen) StadjeIn uno Borften bejebt. - B!. neteft ben Staub= fäben bunfelruth. SIn Bergabhäng̣en felten: Bielefelo bei Baraf:=

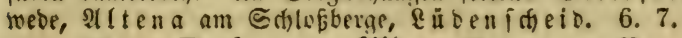

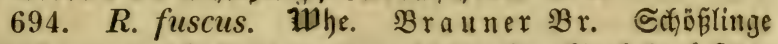

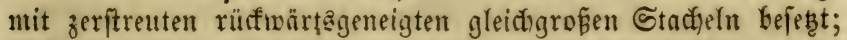
Blätter 5zäblig, Blätttten berzeirumb zugefpicht, oberfeitå wenig

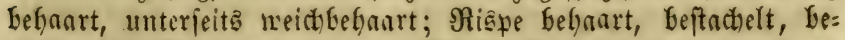
Glättert, Deffblätter blattartig; Blütbenfitiele mit langen zerffreu=

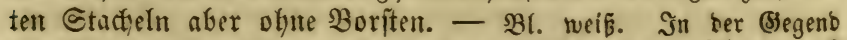

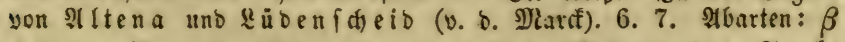
foliosus (R. fol. Whe.) গispe nerir eine zufanmmengefeste Traube

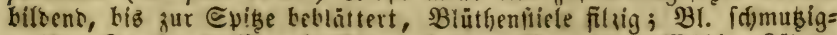

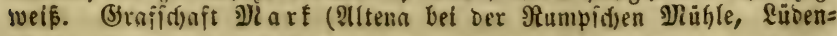

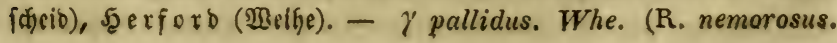




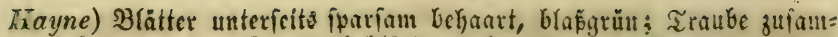
mengefest, nut am Errunbe beblättert, oberwärte mit blutrothen Drü=

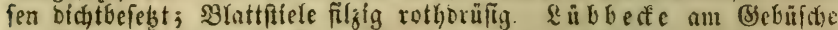

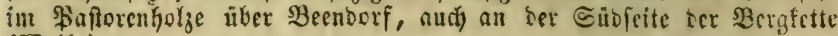
(खुSetfe).

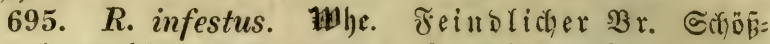
linge mit ungleichen hafenfürmigen Stadfeln bichtbefergt; Blät=

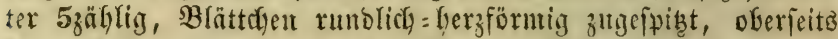

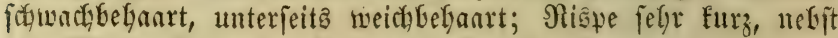
Sen Blütbenftielen weichbehaart, ftachlig, boritig, brüfig. -

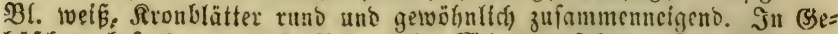

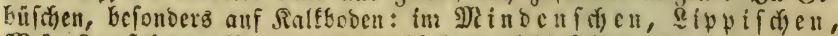

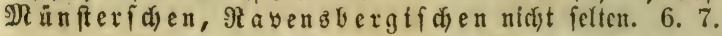

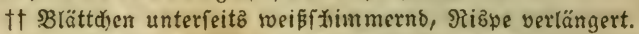

a. SBlätter 3 - ober burd) Iheilung ber Eeitenblättdxer 5 zählig.

696. R. scaber. Wha. Stharfer $\mathfrak{B}_{\mathrm{r}}$. Siföblinge

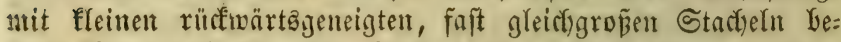

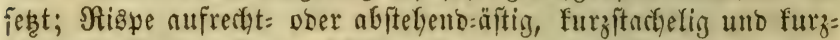
Gorfitig, Bghüfyenftiele abjtebend zottig furzorilftg bumborftig;

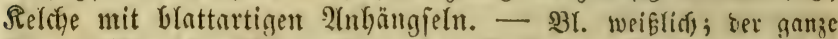
Stengel ift weid)=weifinizig, woburd) die Drüien unb Borfien zum Theil

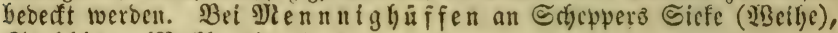
Solling (Beff(gauß). 6.7.

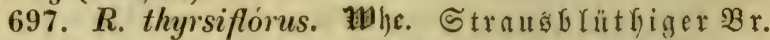

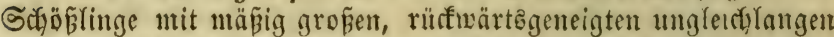

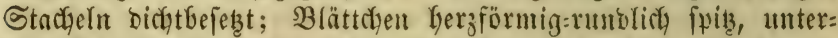

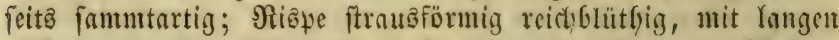

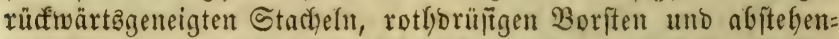

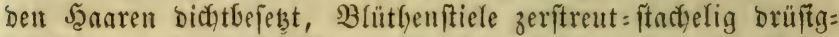

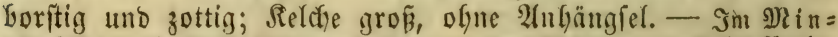

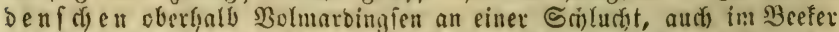

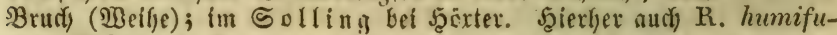
sus. Whe? 6. 7 .

+698 . R. rosaceus. Whe. Rofiger $\mathfrak{B}$ r. Schöflinge mit ungleid)langen graben Stacheln bidutbefełt; Blättchen herz= förmig = runblid) zugejpizt; Ris̄pe abịtegend:äftig, febr beblät= tert, zeriftreutiftactelig umb Goritig; Relche zottig, brifitg, fefr

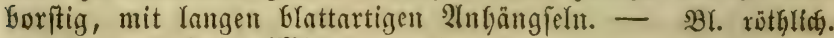
Stm stiederehein (Nidiel). 6. 7.

\section{b. Blätter 5 zăhlig.}

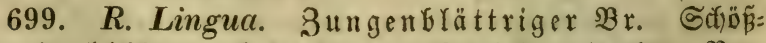
linge mit gleidglangen bafenförnigen Stadbeln, einzefnen Bor= ften, Şaren uno Drüjen befest; Blättchen ftumpf = feilfürmig 


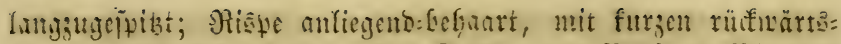

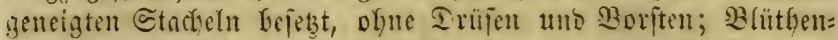

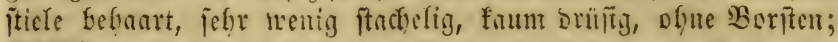

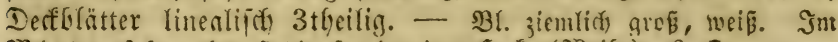

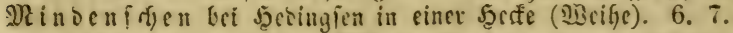

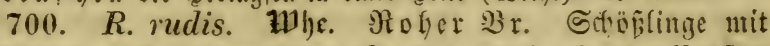

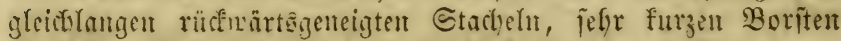

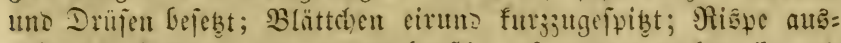

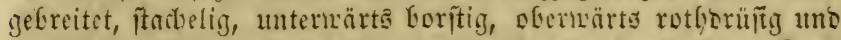

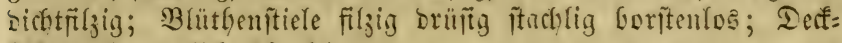

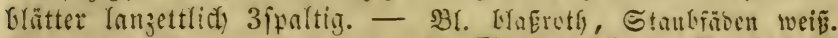

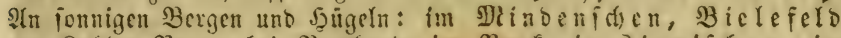

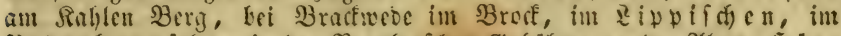

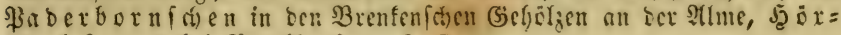
ter befonders bef Brenffinfer. 6. 7.

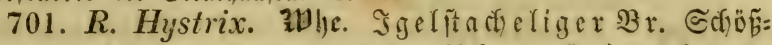

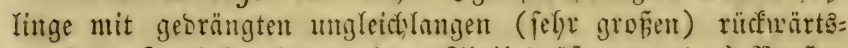

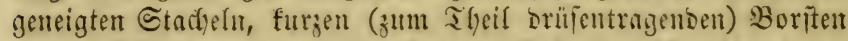

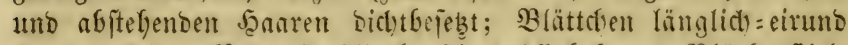

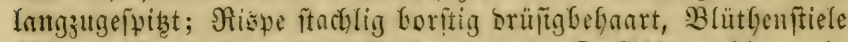

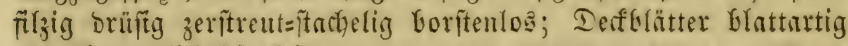

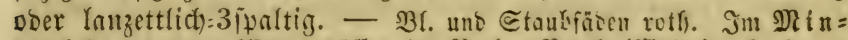

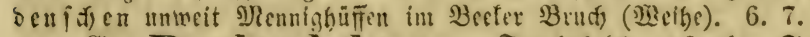

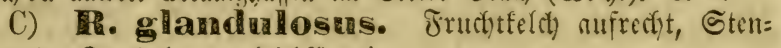
gel runo, Stadieli ungleidfö̈rmig.

† 702. R. glandulosus. Đृell. Drüfiger $B$ r. Gđöb́

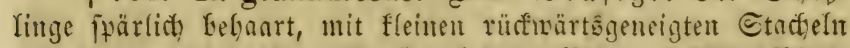

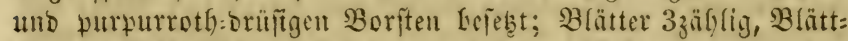

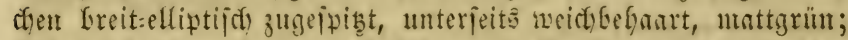
Ris̄pe fefte furz, fparjam ftadelig, mit Boriten, rotfen Irujen

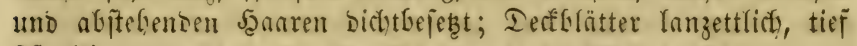

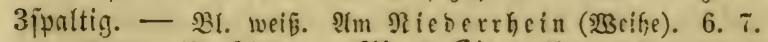

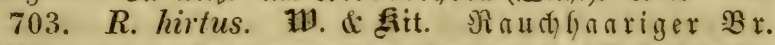

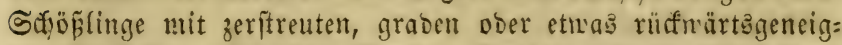

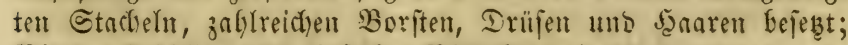
Blätter 3 zählig und einfact), Blättçyen eirund zugefpibat, an

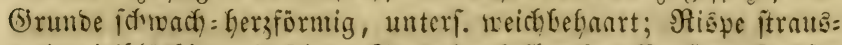
artig nielflïtfig, mit feinen Etact)efn, helfrothen Borften, Drüjen

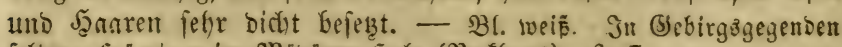

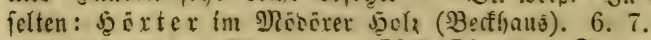

D) 704. Tr. conylifolias. Sn. Şajerblätt=

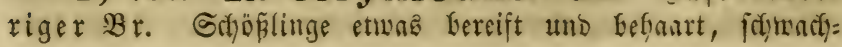




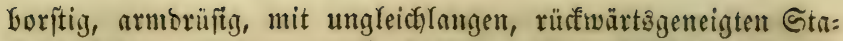

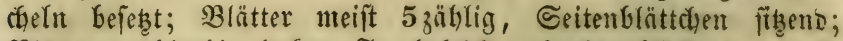

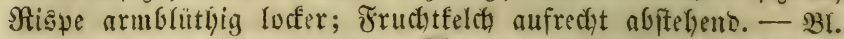

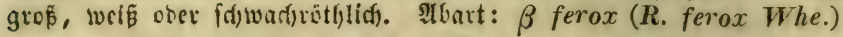

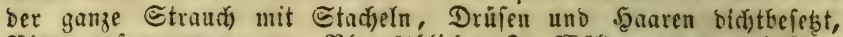

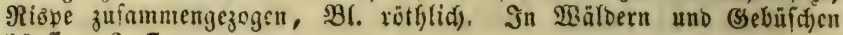
häu代. 6. 7.

E) 705. R. caesius. Bläulid̦er $\mathfrak{B r}$. $\operatorname{Rrab}=$ beere. Stengel runo meiplich: bereift, Stactheln ungleichtörntig, Blätter 3 zäglig ober $5 z$ zäblig:gefiedert mit fitzenden @eitenblätt=

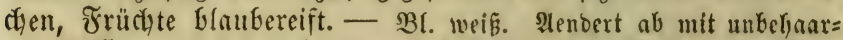

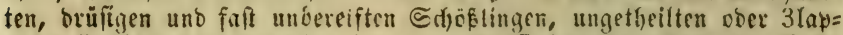

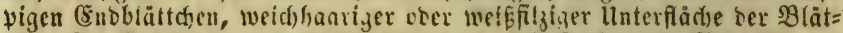

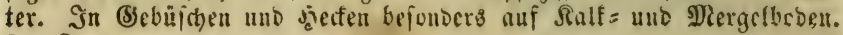
$6-8$.

** Früdite roth (aud) weißlid).

706. R. saxalilis. Frelfen $=\mathfrak{B r}$. Gdjöbringe nieber=

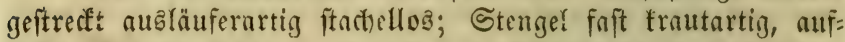

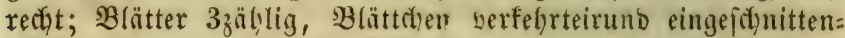
gejägt, beiserfeiţ grün; Dolsentraube $3-6$ blütbig. - $B$ I.

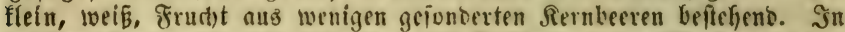

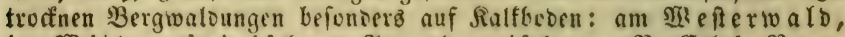

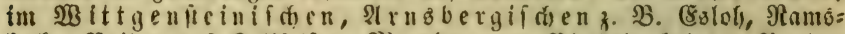

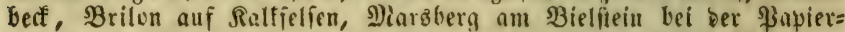

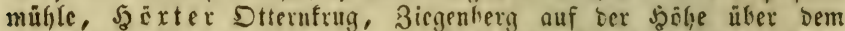
\$eterfelbe bei ben Tannen, Şavixberf, Rtefenbeff, Bielejelo unweit $\mathfrak{B r a f f m e d e}$ bei Eicferman am Bank im Brodf. Der lebtre

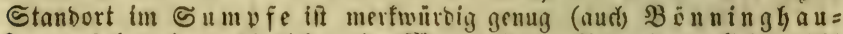

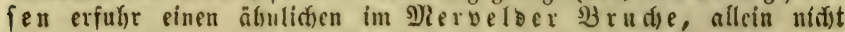

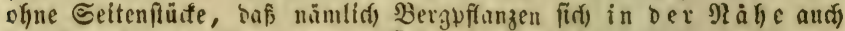
in Sumpf = แnD Torfecten vorfutocn 3. 33. Mercurialis perennis, Phyteuma nigrum). 5. 6. 4

707. R. Idaeus. Şimbecrfitraud). Gübölinge Eereift fabl, etwas fiactlig, fait aufredit; $2 B$ lätter 7 zäglig=gefiebert,

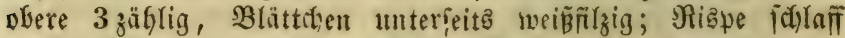

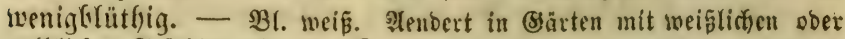
gelblidjen Früdyten ab. $5-8$. क

\section{6) Fragaria. (Evobeere.}

708. Fr. vesca. (5) e meine (ङ. Fructitfeldy weitabfte:

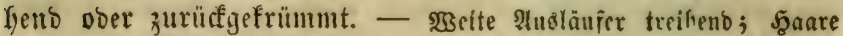

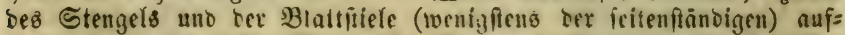
refrit ober angebrüift; 31 . weif́. Atbarten: $\beta$ semperflorens (Fr. semperfl. Duch.) Frudit ci=fegelförmig, Reldh anfangz angebrüft

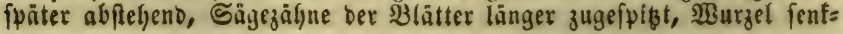




\section{Polygynia.}

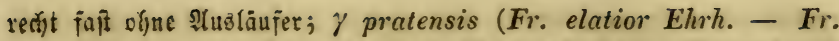

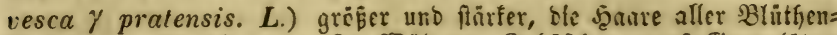

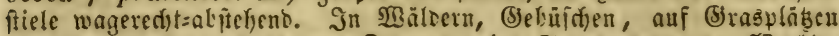

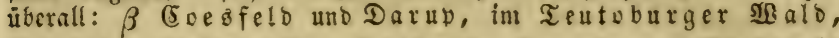

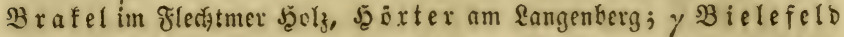

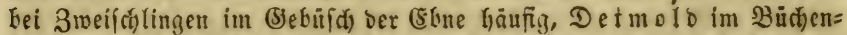
berg unb nm Sieinberg, SE oxter am Biegenbera, Jjolzminben am

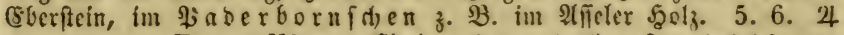

709. Fr. collina. Ë)rh. Jä̈ gel = ङ. Frutitfelity an= gebrüft, 5ुanre wagereat)t:abftelyeno, mur an ben Blütbenftielen (wenigftens ben feitenftändigen) aufrect)t ober angebrürt. -

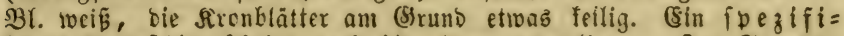

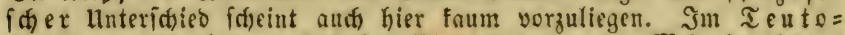

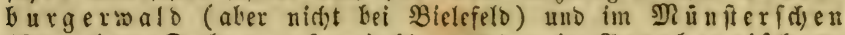
(Etromberg, Dolberg u. f. w.) hier und ba, im 2 rnsbergifaen,

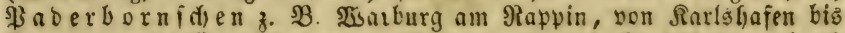

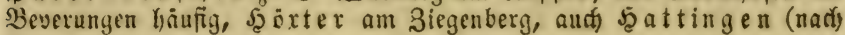
3lumeroth) 5. 6. 24

710. Fr. grandiflora. Ë)rb. Inanas: (5. Fruditfeld angebrüaft, Sanare ber $\mathfrak{B}$ latt= แno Blütgenfitiele aufrecht, Blät: ter oberjeits fajt fahl. - Bl. uno Frücjte fehr groß́. In (3)̈rten

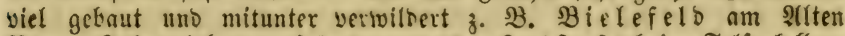

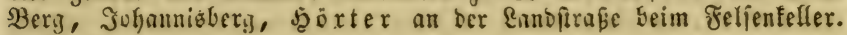
5. 6. 4

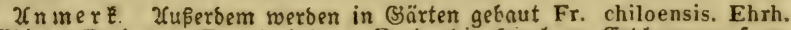
bie Ehiloes Erobeere; Fr. virginiuna. Ehrh. bie şimbeer : Erobeere น. f. to.

\section{2.ว7) Cómarum. B̧โนtauge.}

711. C. palustre. (Potentilla palustris. Siop.) -

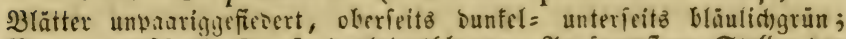

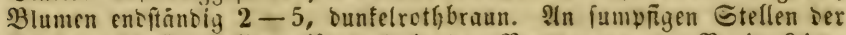

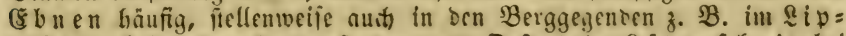

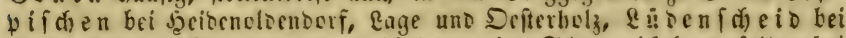
Serfdecio, im Mittgenfteinifden, im Eiegnifden felten bei Dreflendorf. 6. 7. 24

\section{8) Potentilla. ซ̋̈nffingerfinut.}

\section{* siätter gefiebert.}

712. P. Anserina. (b) än friechend, Blätter unterfrochengefiebert. - Bl. gelb. Die Blät= ter unterieitz fribenflyarig, änoern aber at: $\beta$ sericea beiberfeits feibenfaarly, $\gamma$ viridis beiterfeits grün und fparjam beliant ober

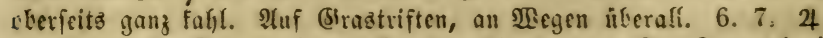

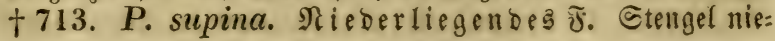




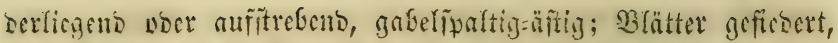

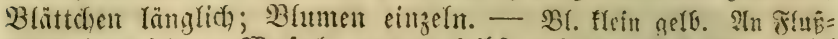

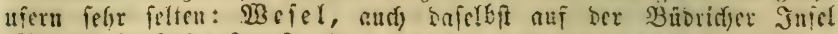
(马öuningrganicui). 6-9. $\odot$

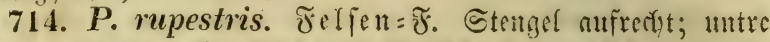
Blätter geftebert, obre 33ällig, Brättcten cirmmblich. - $3 L$

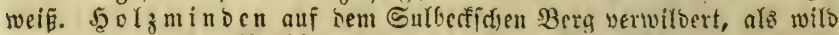

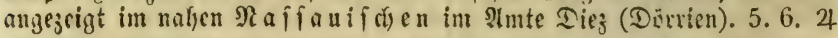

** Blätter 5-7̧̧ählig gefingert. Blumen gelb.

$\dagger$ Etengel aufredtit ober auffitrebeno.

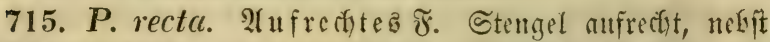
ben Blättern fteif = แnd orüfenbanrig, Blättd)en länglich), am

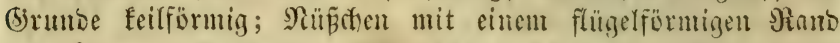
ungeben. - In fteinigen Bergabrängen forfe felten: Siegen am

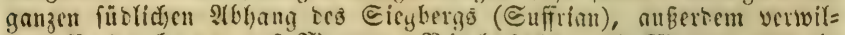
bert Faberborn auf Siauern, Bbielefelo alif Sinuern uno in

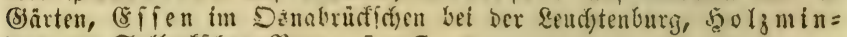
Den ain Sulberfiften Berg. 5-7. 4

t 716. P. inclinata. Vill. 2ufftrebentes $\widetilde{8}$. Stent=

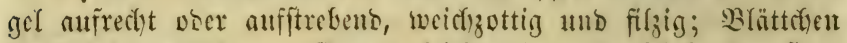

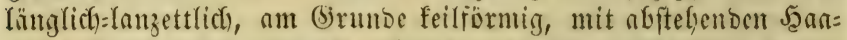

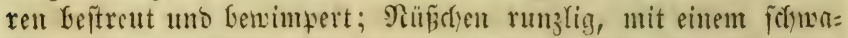

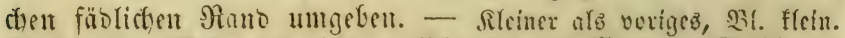

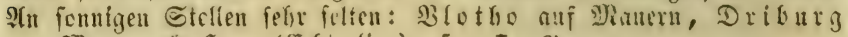
rm 2Mege nach f̧orn (Ecifterling). $5-7.24$

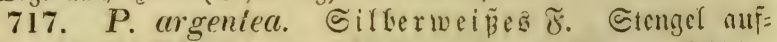

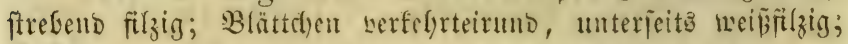

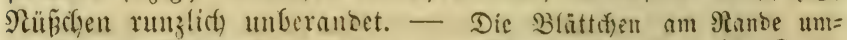

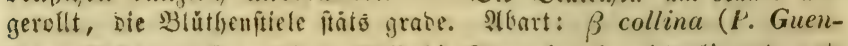
theri. Pohl. - P. collina. Wibel.) @tenget mefgr nícoerlicigno, zot=

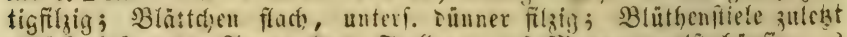

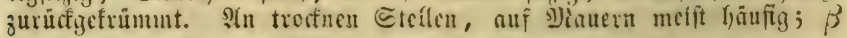

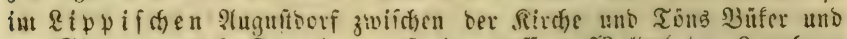

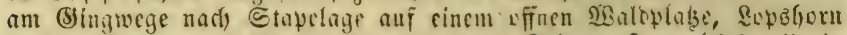

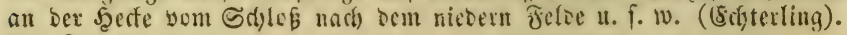
$5-8.2$

tt Etenget niebergeftrect.t.

718. P. reptans. Rriediendes $\widetilde{F}$. Ctengel cinfad) ranfenförmig über bie (Eroe Yaufend; $B$ lättchen werfefrteirunt, oberf. fahl, unteri. Gefiant; Blüthenftiele winfelitänbig einzeln,

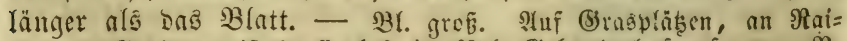

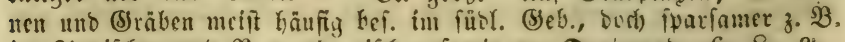
im Rippifden unb Ravenostergif́nen fowie un Dortmunt. 6-8. 4

719. P. verna. Früflings = F. Stengel nieberlie= 


\section{Polygynia.}

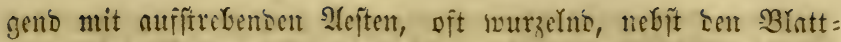

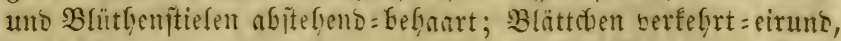
mefir ober uneniger befiunt; Blütfen givfelitänsig zeritreut

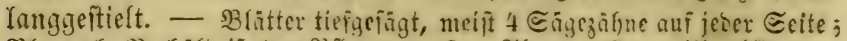

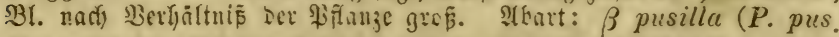
Hst.) Elcinet, Blatter beciserf. nur 2 zăínig. Nuf allen Bergen unt

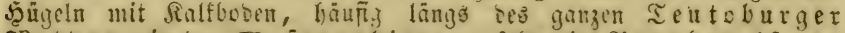

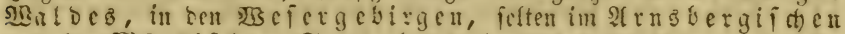

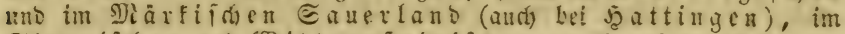
Eicgnifenen unbsittigenteinifiden, and anf ten Etrem=

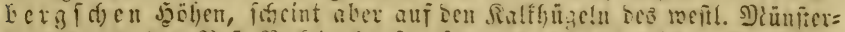

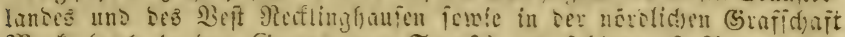

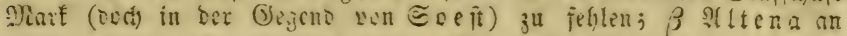

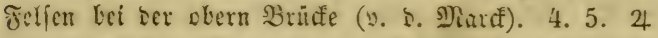

† 720. P. opaca. (3) lanzloís

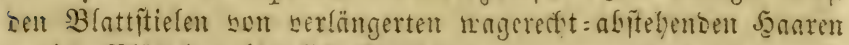

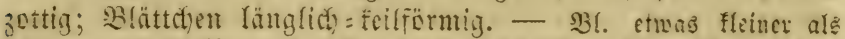

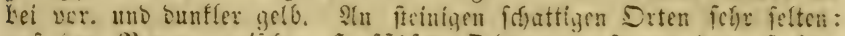

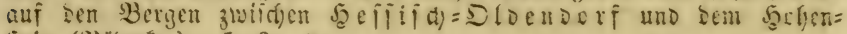

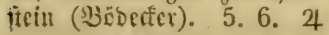

** SBlätter 3=(oo. 5) zähtig, Frontr. 4 (felten 5), gelb: Tormentilla.

721. P. procumbens. Sibth). (T'ormentilla reptans.

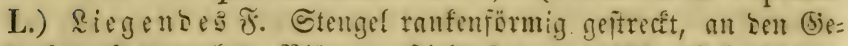

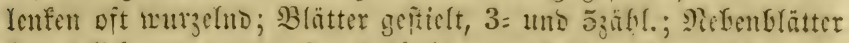
lanzettlich, ganz oDer 2-33äfnig. - Sluf grafigen eteffen un=

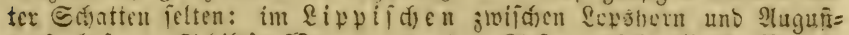

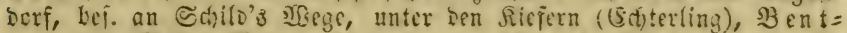

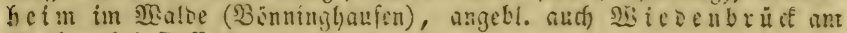
(Staben bei Sefielfe. 6. 7. 2

722. P. Tormentilla. (Tormentilla erecta. L.) Tormentill: . Tormentilfurz. Stengel auritreteno

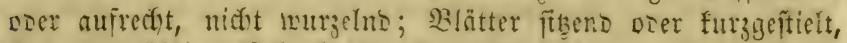
3: unb 53äblig; Nebenbläter 3-bieljtaltig. - N3l. fleiner wie

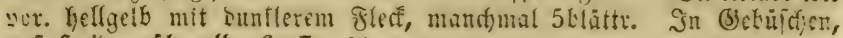
auf 5̧aiben uiberall. 6. 7. 24:

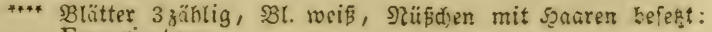
Fragariastrum.

723. P. Fragariastrum. Ëbrh. (Fragaria sterilis. L.) Erobeerartiges $\widetilde{s}$. Ctengel fotwad nieberliegents,

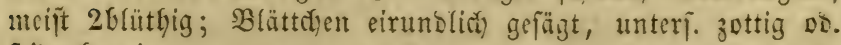

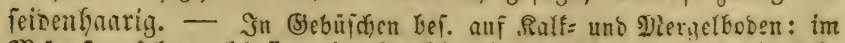

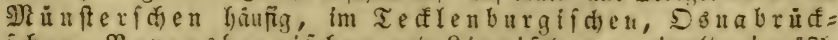
iden, $\Re$ a घensbergif

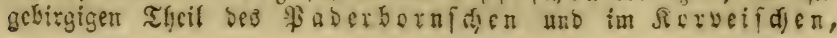




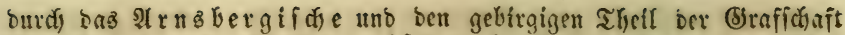
Di a rf verbreitel, im Siequifden fparfam; felten in ter (Ebne

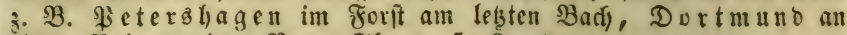
cinem Main yor bem Neuen Thore. 5. 6. 4

\section{9) Geum. Benediftenfrat.}

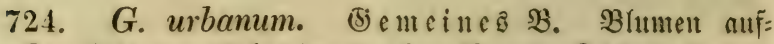
red)t, Rrondlätter werfelyrteirumb ofyne Nagel; Relet) mach bem

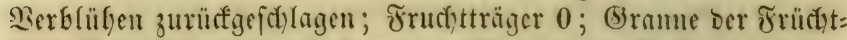

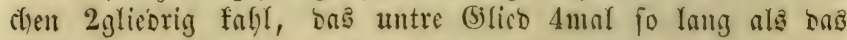

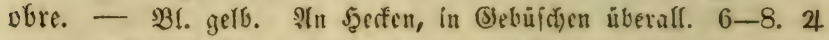

$†$ 725. G. intermedium. EEhrl. Dittleres $\mathfrak{B}$. B(unten nufref(f)

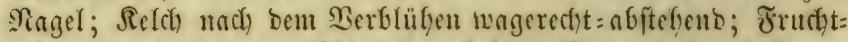

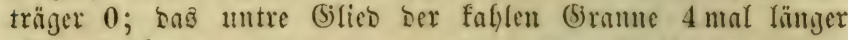

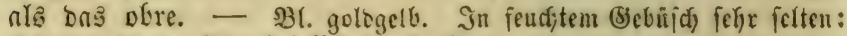

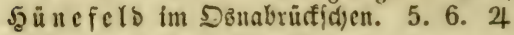

726. G. rivale. $\mathfrak{B} a \mathfrak{d}=\mathfrak{B}$. B̉(unte niffend; Rronbl.

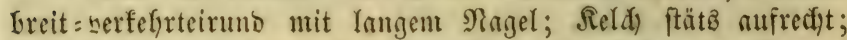

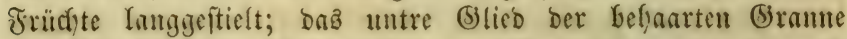

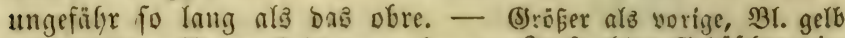

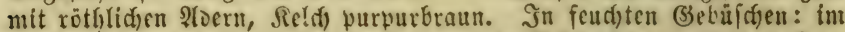
Siegniferen an ber Eerfmauelle, um ben Afitenberg und am obern Rufitthal zwifden $\mathfrak{B}$ Buterberg und Slifinghaufm, um Brifon

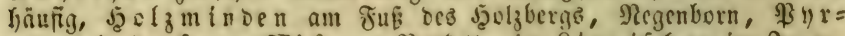

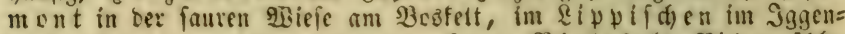
haujer Sunbert, Jecibenolbenbolf, Rage, Bi elefelo Riebermühle,

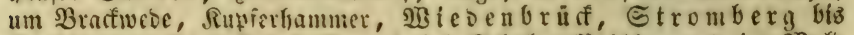

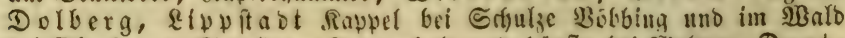

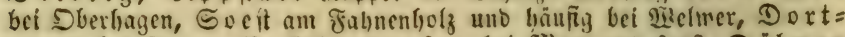
$\mathrm{m}$ u $\mathrm{n}$ bei Derne, Re fflingha ufen bei Starl und fonlt, Dülmen

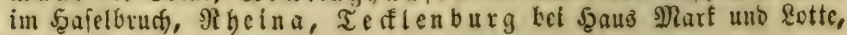
Eemföroe น. f. w. $5-7.4$ 


\section{Drecigebute Slatic. Polyandria.}

\section{Soromung Monogynia.}

* Rrone 4btättrig.

260) Mctaea. Ehriftophifraut. Selte 46lüt:

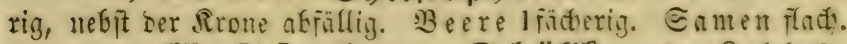
261) Chelidoniam. Schülnfraut. Rel $2=$ blättrig abfällig. Rapiel fototenförmig l füdyerig. Samen fonmig.

262) Tapaver. Mohn. Rel (t) 26lütrig afiällig.

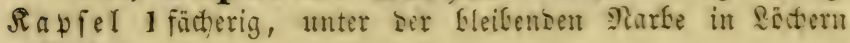
aufịpringento.

** Srone 56 tättrig.

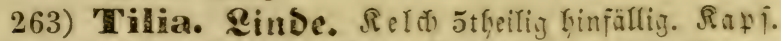

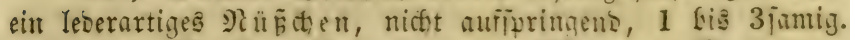
264) Helianthemom. Gärtnr. Gonnen:

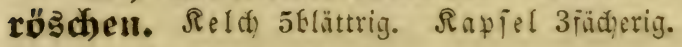

*** ₹rrone vielblättrig.

265) Eymphaea. Ietchrofe. Kelf 4-5flatt:

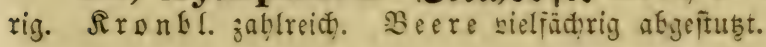

\section{Sronumg Trigynia.}

266) Delphinium. Nitteripporn. Fel frun: artig 56lätrig, Dą obere Blatt gejpornt.

267) Aconitum. Gifenbut. ReIch fronartig

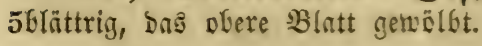

\section{Sromung Penta-Polygynia.}

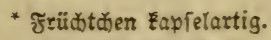

268) Aquilegia. 2Icfelei. Rel fronartig, 5= blättrig. Rronblätter geförnt, in fleijdhige Neftarion aus:

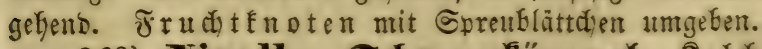

269) Wigella. Gchwargfúmmel. Reld fron: 
artig 5blättrig. Sironbr. benngelt, aut ber Bafỉ ber Platte nit einer Sanniggrube, bie surch eine Gifuppe gebceft ift.

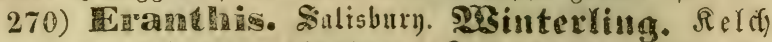
fromartig, 5-8blättrig, abfalfend. $\mathfrak{R}_{\mathrm{p}} \mathrm{nb}$ bäter lang bes ungelt, Bratte röbrig, ungleich 2lippig. Raplef feffr lang gefitieft.

271) 融 tig 5Glättrig Gleibend. STonbl. Genagelt, bie Flatte röbrig

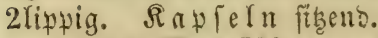

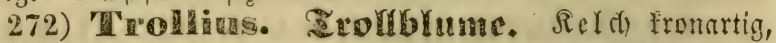
5-bielblättrig, afraflent. Sronbl. bentigelt; Blatte linen=

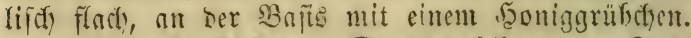

273) Callina. Dotterblame. Relct fromartig 5 blättrig. Sirone 0.

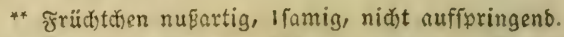

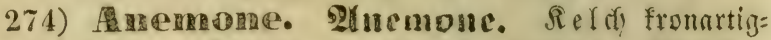

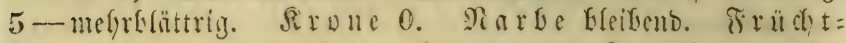

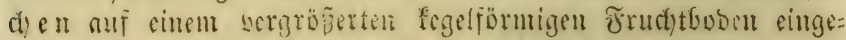

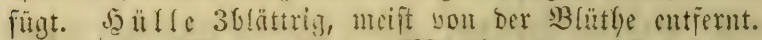

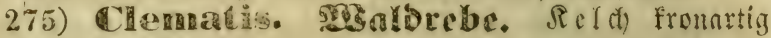

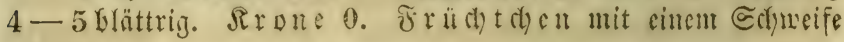
weriflyent.

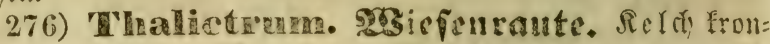
artig 4-56lättrig. Sirone 0 . Frü̈d) then ali cinem flei= nen fityeibuartigen Trutchtroden cingefügt.

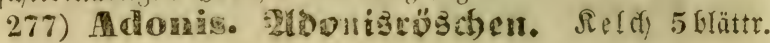
Arongläter ofme Soniggrube.

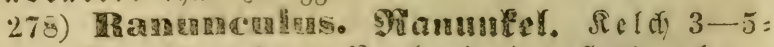

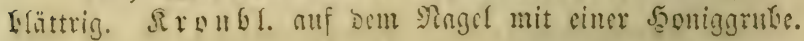

\section{Sorbming llonogynia.}

260) Actaea. (Egriftuptificut.

727. A. spicata. 2tefriges (5) r. Blätter 3zäblig=

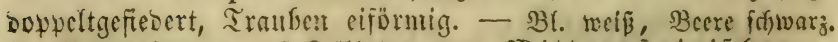

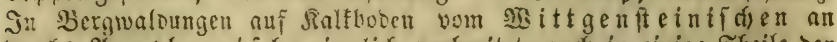

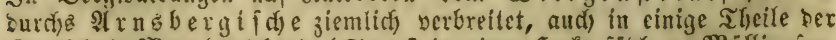

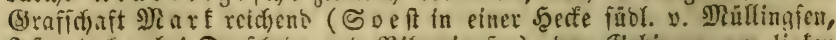
Jferlohn Kei Dapidere umb Bifueringfen), Een Betirgen am !infen 


\section{Monogynia.}

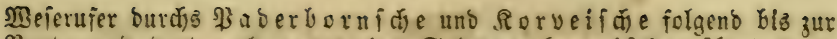

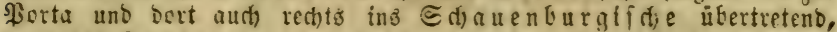
bann ien Teutoburgertwals in zimlidger Menge Eegleiteno burán

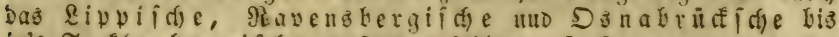
in's Teff(enburgif

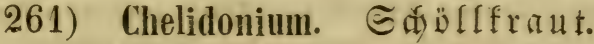

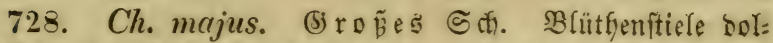
big, Releh fạt fafir, Gtaubfäten oberw. Greiter. - Blätter ins cinanberffiefirnd geñebert, wie bic ganze \$iflanze graugrün, mit fas

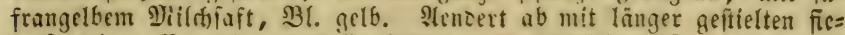

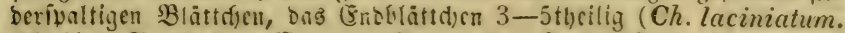
Mill.). Mtn 5eeffen, Dkauern, Sisegen übernfl; sie form laciniatum

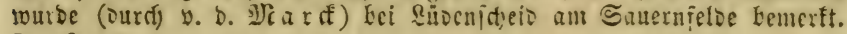
$5-9.2$

\section{2) Tapáver. Mo f.}

- Rapiel fteifhanrig.

729. P. Argemóne. Alf ermofy. Staubräben oberw. berbreitert; Reffel verfefyrt=feulenförmig, bon zerftreuten auf= rechten Borften fteiffarrig. - Stengel nebft sen Blüthenflecten

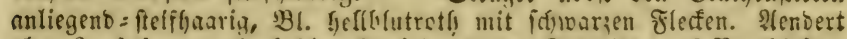
ab: $\beta$ glabrum mit fafler Rapiel. Unter (Sictraice, nuf Baschäafferm

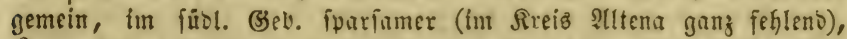

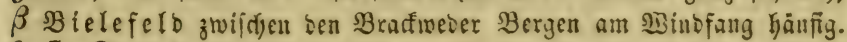
6. 7. $\odot$

\section{" Rappel faht.}

730. P. Rhoeas. (3) meiner פl. Rlatidrofe.

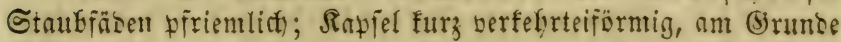

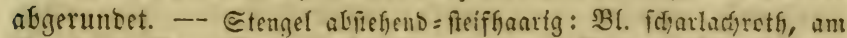
Brunbe bunfler. Iteniert $a b: \beta$ strigosum. Boenningh. mit amze=

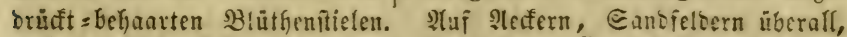

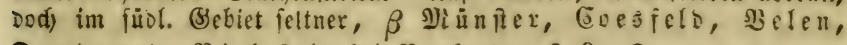
Dortmulo, Bielefe!b bei Brafiwebe. 6. 9. ๑

731. P. dubium. 3weifelhafter 代. Ctaubäben

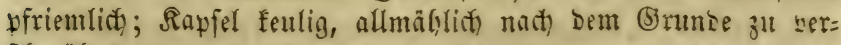

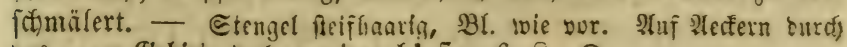
sas ganje (sebiet, bod) weniger Käufig. 6. 8. $\odot$

732. P. somniferum. (5)artenmofin. Raplel faít

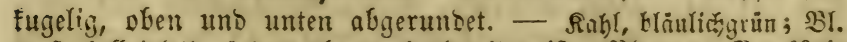
grof́, hellviclett, äntert aber aud) ab mit weífen BBlumen: P. officinale. Gmel. und mit reienrothen, ain Brund Dunfelviolett= gefleften Blumen. Ingebaut ober a!s Sierptanje grjegen. 6. 7. ๑ 


\section{3) Tilia. Rinde.}

733. T. grandifolia. (Ëhrl). (T. europaea $\beta$. L. T. platyphyllos. Scop.) (G) rößblättrige \&. Blätter

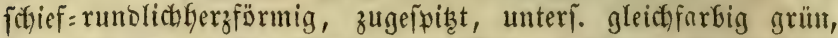

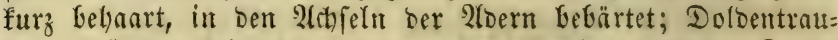
ben meift 2-3Glüthig; Rnpwen ber Narbe nufrect); Rappel fyolzig 5ripwig. - - In Malbern, bei. an ber $\mathfrak{B}$ pifer z. $\mathfrak{B}$. Beve=

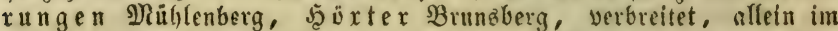

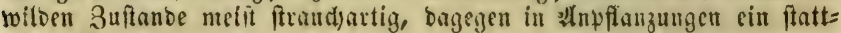
lidjer Baum. 6 .

734. T. parvifolia. Ébri). (T. europaea. $\gamma_{0}$ L.)

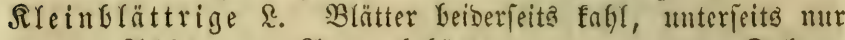
an ben 2ldfeln her 2loern bebärtet und meergrïn, Doldoen= traube 5-7blütgig; Sappen ber Narbe zulebt nagered)t=aus: eimanderfahrend; Rapfel bünnfachlig, undentlich 4-5fantig.

Formen: $\alpha$ vulgaris (T. europaea. Sm. - T. vulgaris. Hayne) 5-7blüthig; $\beta$ polyantha. Koch (T. partifolia. Hayne.) $7-11=$

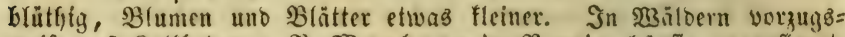

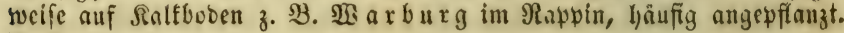
7. 古

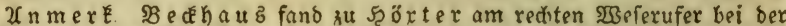

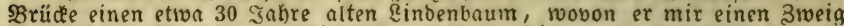
ïberfanote Derfelbe mag einmal nngepflan it fein, entfprid)t aber ourdaub keiner Diagnofe, fomeit mir Sclff̉mittll vorliegen; am nödditen würbe er $T$. pubescens. Ait. (T: americana. Walt) fteben, wenn nicht ber Eurze (Sriffel - abuefehen bon ben gefonderten Dedéblätiern u. f. w. - ihn zu weit bavon entfernte. Id bezeldine ibn vorläufig - jeber Berictitiaunn grrn entapgentes beno - vergen ber intenfiv = gelben Farbe oer Blumen alb $T$. aurea uno lafie

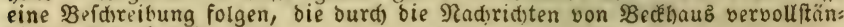
Digt roerben Eonnte.

734 b. Tilia aurea. Boloblittrige \&. Blätter foctief

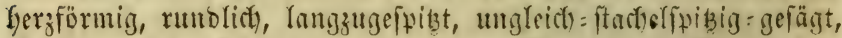
Derer. matt = bunfelgrim uno auf Den Nerven uno 2foern fefyr

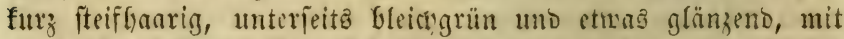

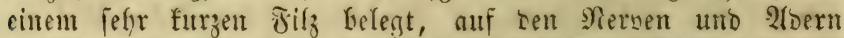
weiplich = befoart, an Den 2ldfeln beri. zottig = febürtet; Blatt= ftiele furz, gegen $6^{\prime \prime \prime}$ lang (etwa bem britten Theil ber Blatt=

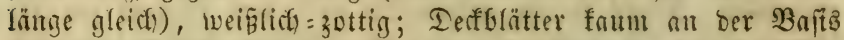
mit ben Blütfenitielen werbuncen, fonft ganz frei $=a \mathfrak{b}$ ite $=$ f)end und gleidyiant nebft ben $\mathfrak{B}$ littfenfitielen in ben Blattwin: feln fikend, furz, elliptifo, serb; BBlüthenftiele furz $\left(6^{\prime \prime \prime}\right.$ rang), fich meift in brei ebenfolange bife Blüthenftictern

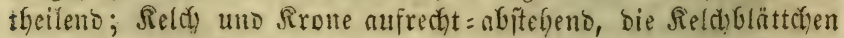
tribgelf, am Grunde fraungelb, bie Rrunblätter golbgelf; 


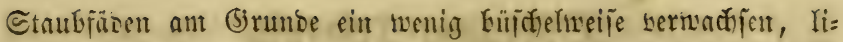
nealifâ, fo Tang als sie Rrone, nebit Den Etaubbeuteln befl=

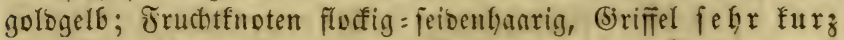

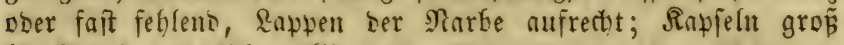
Firnförmig=rundlify mollig zartgerippt. - Der ganze Baum ift

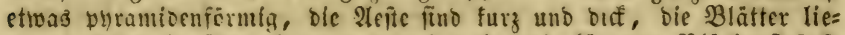

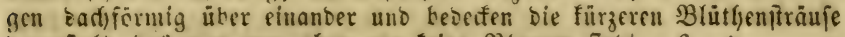

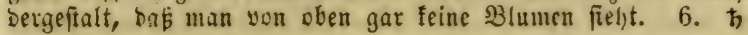

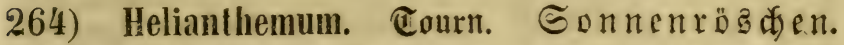

\section{H. vulgare. Gaartr. (Cistus Helianthemum.}

L.) (5) meines S. SBlätter wimperig, begaart, mit Neben=

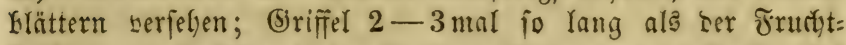

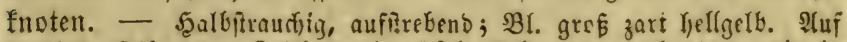

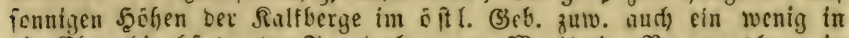

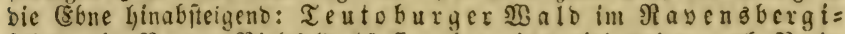

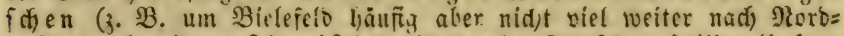

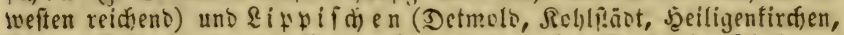

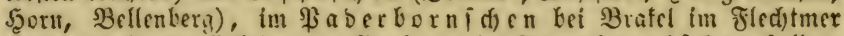

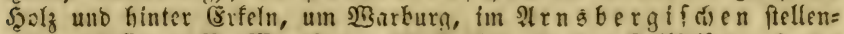

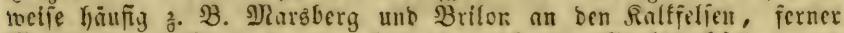

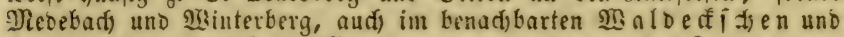

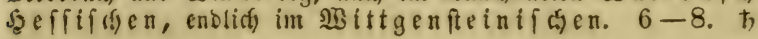

\section{6ว̈) Nymphaea. Teidrofe.}

* Nymphaea. Rild) 4blättrig, গarbe vielftrahtig.

736. N. alba. Sָลeiñe T. Blätter tiefGerzförmig,

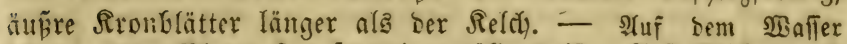

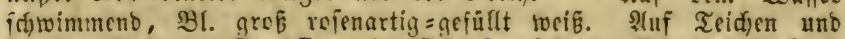

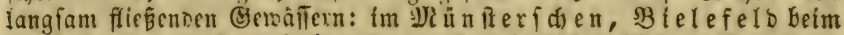
Supferhanmer uno nad) Şerforb hin, im Rippifden Deferholz,

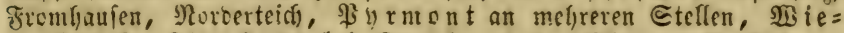

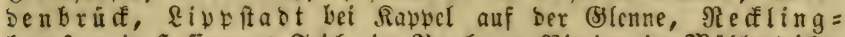

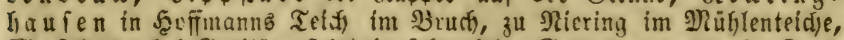

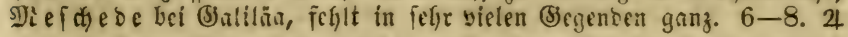

** Nuphar. Sm. Feld 5theilig, אronblätter mit einem Şonig:

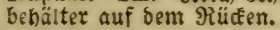

737. N. lutea. (Nuphar luteum. Sim.) Blätter hyerz=

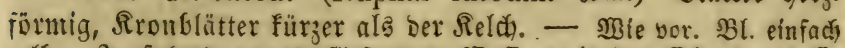

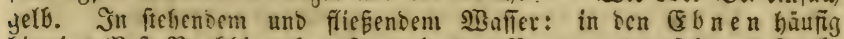

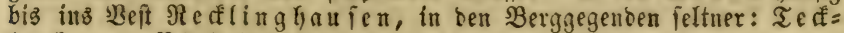
Ienbarg, Bielefeld, im Ripplifien zu Berten und Stemmen,

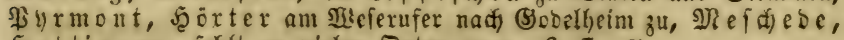
Shattingen, fochlt an vielen Drten ganz. 6. 7. 4 


\section{Sronung Trigynia.}

\section{6) Delphinium. Ritteriporn.}

738. D. Consolida. $\mathfrak{A}$ ff $\mathrm{e} r=\mathfrak{\Re}$. $\mathfrak{B}$ lätter Yimenlifict): vieltfyeilig; Blumen in armblüthigen Trauben, Frone 1 frättrig;

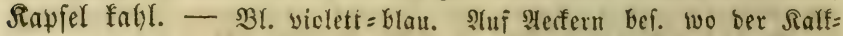

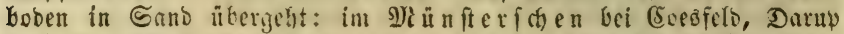

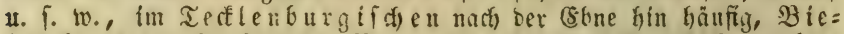

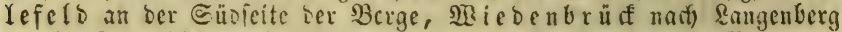

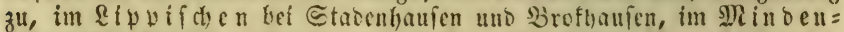

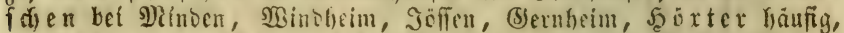

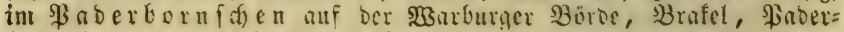

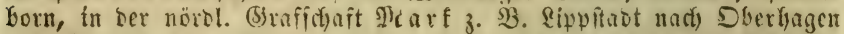
uns Ervitte fin, Seeit gemein, Dortmunb bei Jjörbe und Exhüren,

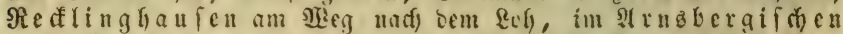

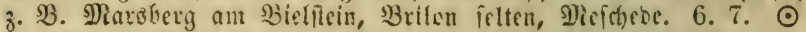

Unmerk. In (Särten zieht man verfádeone 2erten diefer (Sattung ber. D. Ajacis, ben (Sarten: Sitteriporn, ber mitunter auf (S)artenfd)utt ber: roildert.

\section{7) Aconitum. (sifenfut.}

* Slumen blau (obex weis).

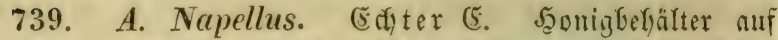
bent gebognen Nagel wagredit nidend, Eporn etwas zurürifge: frummt, bie jüngeten früd)te aแseinumberfafrento. - 2 l. blau=

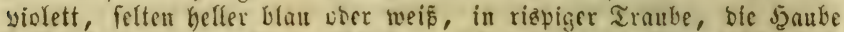

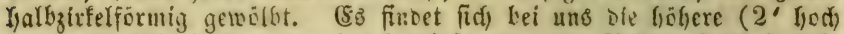

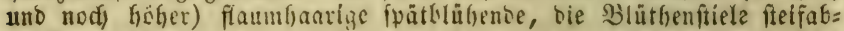
fiteffente \&Gart: A. neomontamum. Wulf. (A. neubergense. Rchb.)

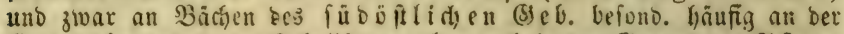

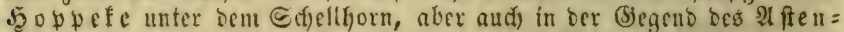

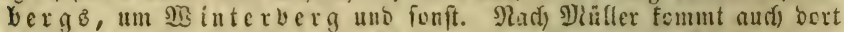
bie 2lbart $A$. pyramidale. Mill. mit aufitucbenden 23 lüthenficten

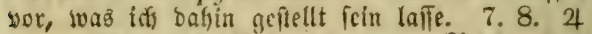

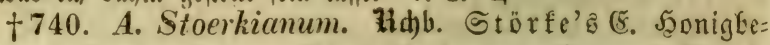
bälter muf oberw. gebognem Ragel fdjiefgencigt, Sporn latig, bie

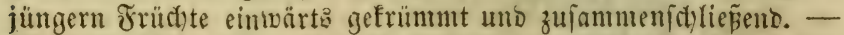

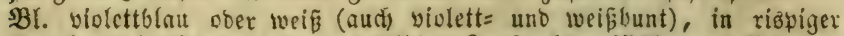

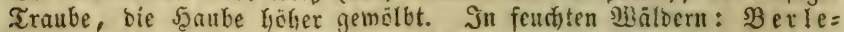
burg, $\mathfrak{B}$ ingeв̆a ler). $6-8.24$

$$
\text { ** Shutumen gerb. }
$$

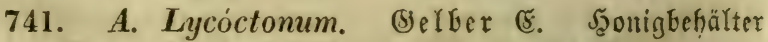
aufrecht, Sporn fäblich zirfelförmig zulammengerollt. - Blät= ter Ganbförnig 7 fpartig. Sn $\mathfrak{B a ̈ l o e r n}$ fefir zerftreut: Berleburg 


\section{Polygynia.}

in Breitenkadh, $\mathfrak{B}$ rilon auf bem Edgeflforn t. am Drülwel, Soeft

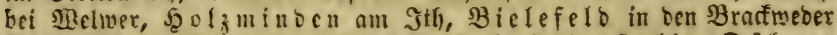

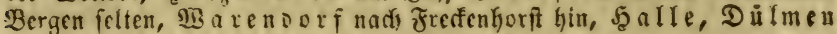
zwifden Saibsingfel uno Selon Beerenurof. 6. 7. 4

\section{Sorbmung Penta - Polygynia.}

\section{8) Aquilegia. 2 af ele $\mathfrak{i}$.}

742. A. vulgaris. (5) emeiner 2 . Blätter boppeitt

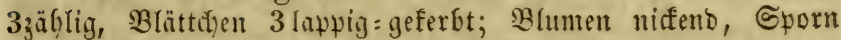
ber Rronblätter an ber Epize bafenrörmig. - Blume vislett=

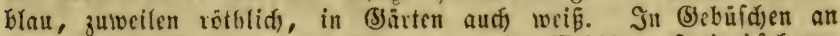
Bergen uno Anföhen auf Ralfboden: im 28 ittgenfteiniffen,

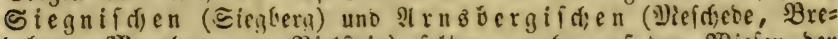
Selaer, Diarblerg an Biclftein) felten, mefre auf ben SBiefen ber

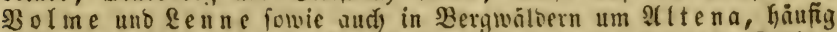

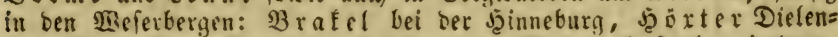

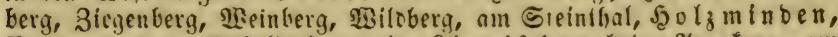

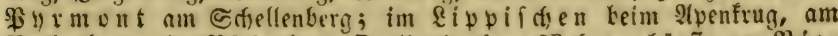

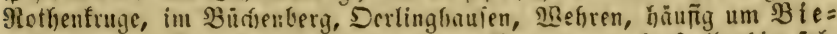
lefeld an allen Sialfberaen uno bem Sbergaug nady Saalle hin fols geno, Stromberg, Ds nabrü am Sdülerberg, $\Re$ ahben ant Etemmerterg, Ricnberge, Evezfelo binter bem Euferhoef, $D a=$ rup, Rotteln, Reflinghanfen bei Eenditerlief; auferbem oft

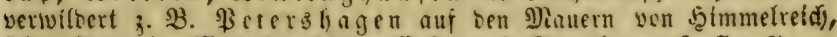

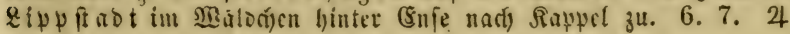

\section{9) Nigella. Sdumązfüm mel.}

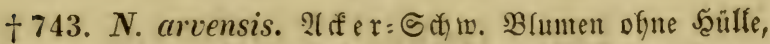

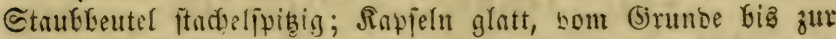
Nitte zujammengervadb

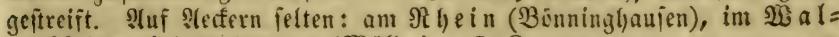

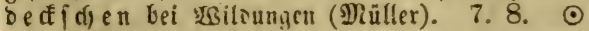

744. N. damascena. (5) arten= Sd) Sungfer in (5) rünen. Blumen son einer vieltheiligen 5aülle ungebent, Staubbeutel ofme Etadjelipibe; Rapieln glatt, biß zur Spibe vertvadyen. - Bl. bläulid), an ben Epíben uno unterieitz an ben

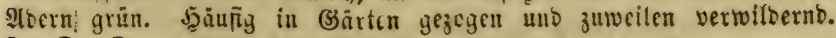
$5-7 . \odot$

270) Eranthis. Salsb. winterling.

745. E. hyemalis. Salsb. (Helleborus hyem. L.) 
Relchblättefyen 5-8 läuglich), untre Blätter geftielt 7 theilig

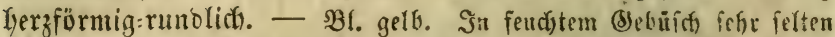

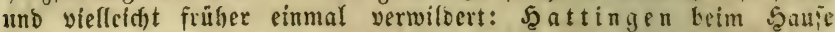

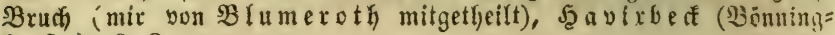
Gaufen). 2. 3. 4

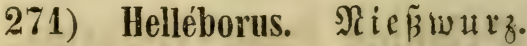

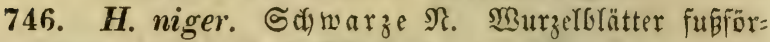
mig; Grdlaft mit 2-3 Deffblättern, 1-2 glütfig. - $\mathfrak{B}$ !. tweip. In (S)äten gevflanzt. 12-2. 4

747. H. viridis. (5) rü

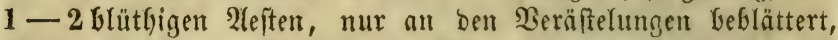

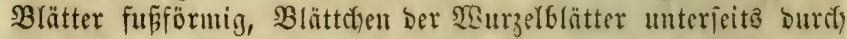
boripringende 2loern runzlig. - BRl. grün. In (sebüfd)en burdi Das Bebiet zerfirent: Eiegen am Eiegberg, im 23 ittgen ineini $=$

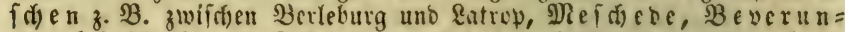

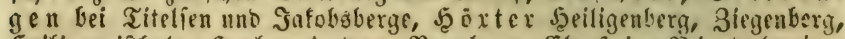

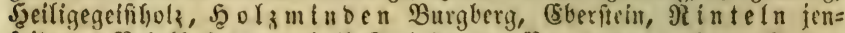

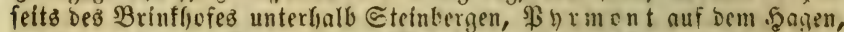

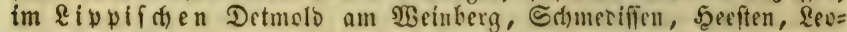
polozthal, Biere felo in ber Baueridhaft Eiffer, llefrenterf kefonberz

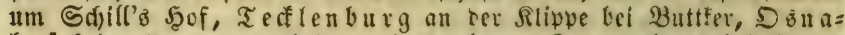
bruaf im Brabyarten bei ber soartenburg, Strumberg kei Etam=

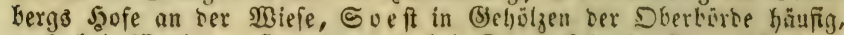

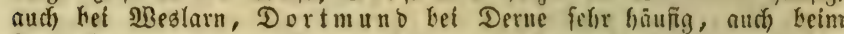
Fredenbaum nad) bem Eunberbälad)en zu, Sierlofin bei 20 ermingien, Lfmburg am Edtlobberg. Nittena bei beölmerfe, an ber Nuine

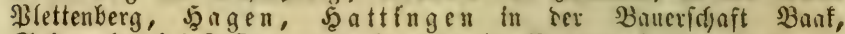
S d) welm bei Safinghaufen, Darut im Roruper Sovlze. 3-6. 2

\section{2) Trollius. Irollb lume.}

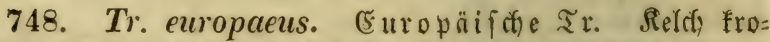
menartig 10-- 15 blättrig, faft fugelig=zufammenfollieñeno. -

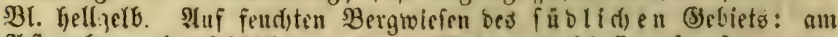

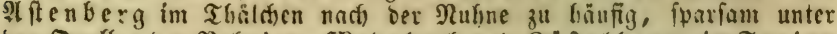

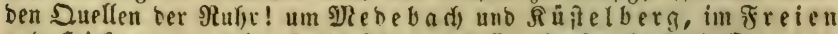
unb $\mathfrak{5}$ i f engru ub im Rreiz Siegen häuñ ebenio oberhalb Da aben nadi) Emmertéfaufen! 5, 4

\section{3) Caltha. Dotterblume.}

749. C. palustris. Ctengel aufiftretent, Blätter \ang=

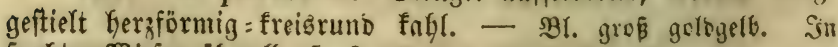
feuditen Biefen überall. 5. 6. 4 


\section{Polygynia.}

\section{4) Anemóne. Âtnemone.}

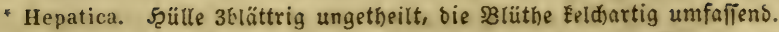

750. A. Hepatica. (Hepatica triloba. Tere) $\Omega_{e}=$ Ger = 21. Ref er Elüm d) en. Blätter 3latbig ganzrandig. -

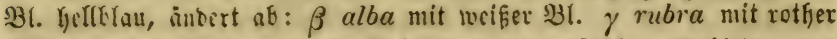

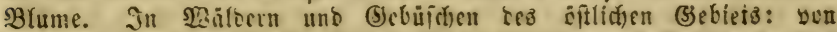

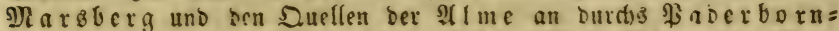
fa) e (WBarburg hinter Wormeln, im Alïeler Walb, Beverungen, Bra=

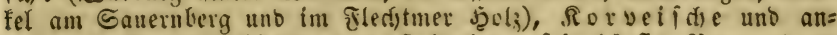

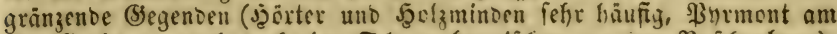

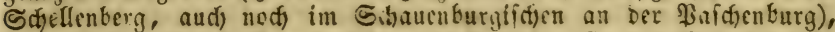
Rippffde bis ins $\Re$ a $v e n g b e r g i f() c$, two lie um Biclefelo fehr

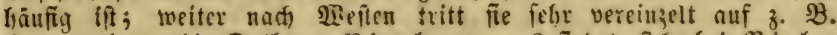
Strumbergbiz Dolbery, Nienberge; $\beta$ findect fid bei Biele = feld auf bem \&auxberg, auf bem Brrge über Brafinebe, $\gamma$ bei $\mathbb{L} 0 p s=$ horn im Ripuificen. $2-4.24$

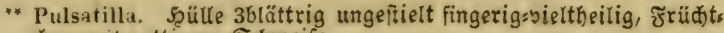
d)en mit zottigem Sdrweife.

751. A. Pulsatilla. (Pulsatilla vulgaris. Rtill.)

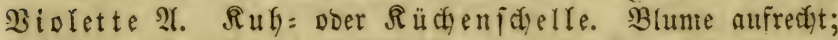
Reldblätter ant (s)rumbe glodfig, gegen bie Evize fanft aus:

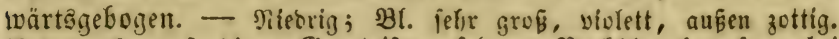

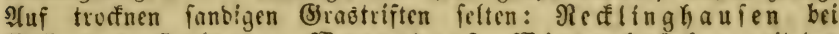

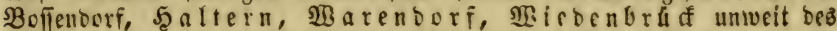

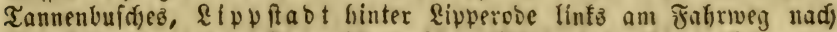

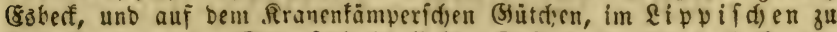

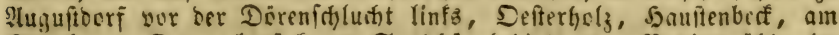

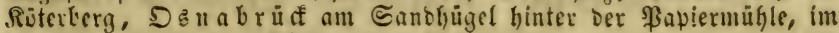

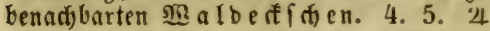

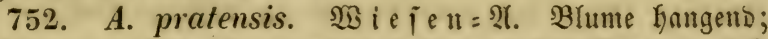

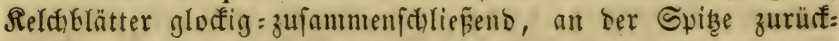

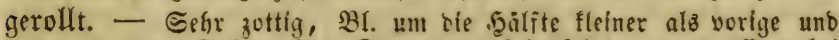

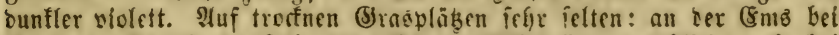

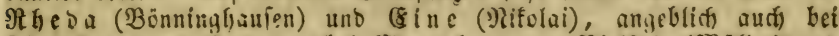

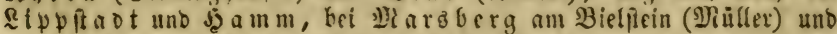

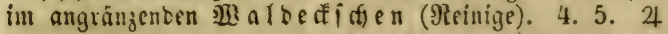

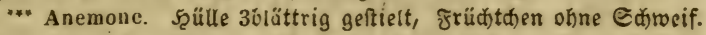

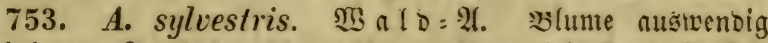

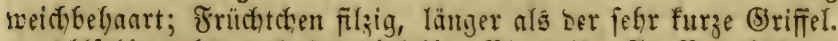

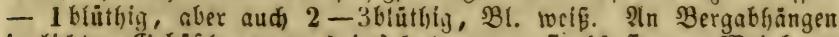

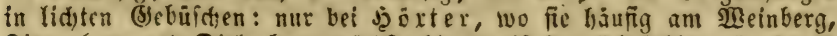
Blegenberg und Dielenberg wädhît, hier meị̂t $2-3$ blüthig. 5. 6. 2

754. A. nemorosa. J̧a in:21. Blume beiberieita fall, Blättchen berjelfen längliđ̆ itumpf; Jrrüdtchen weichbehaart,

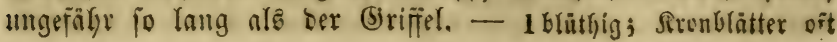




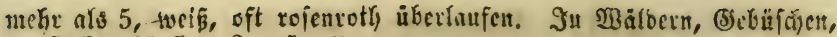

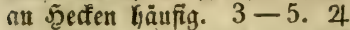

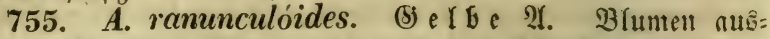

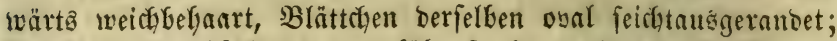

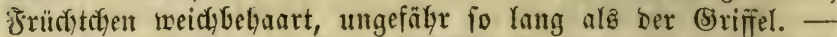
16 lüthty, oft aud. $2=$ uno fogar 3blithig, Bl. gelb. In Berglwäloem

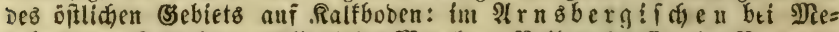

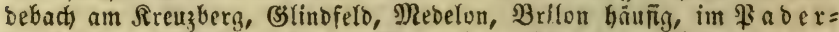
bornfd) en Bartburg hinter Borlicht, Beverungen befonbers ant

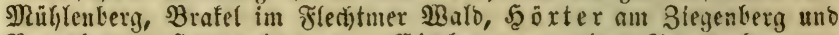
Brunzberg, Şoizminden, Eibbcrgen, im Teutoburger WB alo fparfam burds lippliche, bäufiger Bielefelo nath ber Stein=

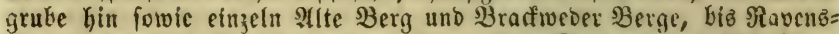

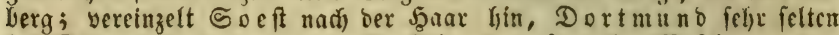

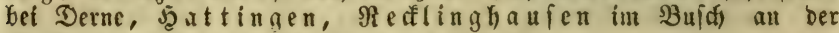
Warfmülyle und fonft nicht felten. 4. 5. 4

\section{5) Clématis. Maldorebe}

756. Cl. Vitalba. (5) emeine 93 . Stengel fletterno, Blätter gefiebert, Bläthyentyülle beiberfeitż filzig. - Br. Yever=

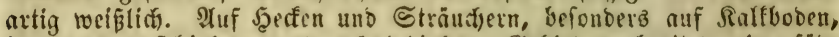

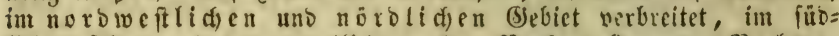

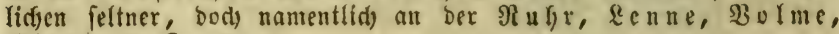

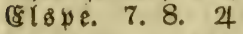

\section{6) Thalictrum. Miefentaute.}

757. Th. minus. Rreine ST. Stengel am Brumbe

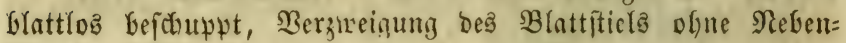

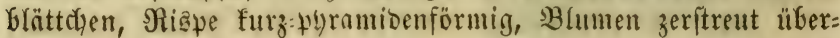

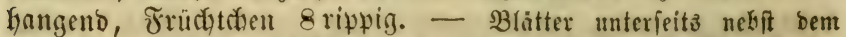
Stengel graugrün, Blattitielasen fantig, Defirdjen Der BBlattidyeiben

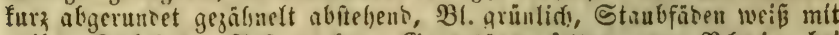

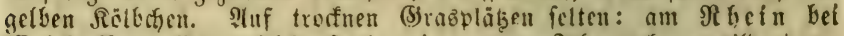

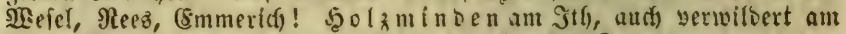

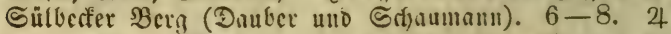

758. Th. flavum. (5) elbe $\mathfrak{B}$. STurzel friedfent, untre

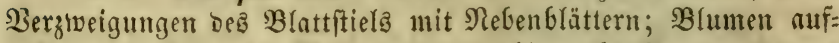
recht, ant Ënbe ber 2leite boloentraubig=gefräuft. - Stengel

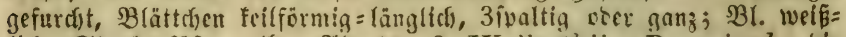
Iich), Staubgçääe gclb. Ilbart: $\beta$ Wallrothii. Boenningh. bie

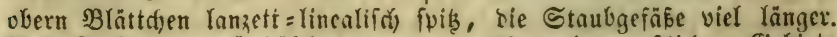

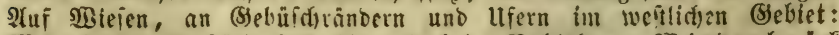

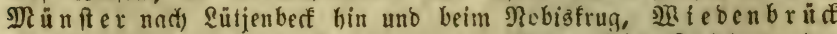
und $\mathfrak{3}$ arendorf auf Mieien an Der (5mz, Eipufabt an ber

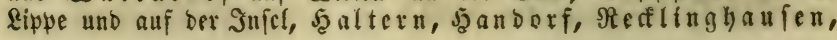




\section{Polygynia.}

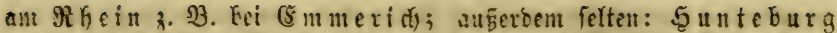

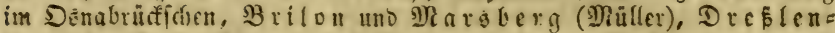
borf in Rreife Siegen nad) Sangenautach und Breitiocio hin; $\beta$ 5altern an ber Etever. 6. 7. 4

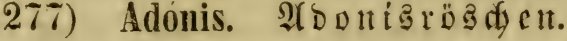

759. A. autumnalis. Saerb it $=2$. Reldy fafly, abjete= Gent, won Der folbfugelig zufammenifliefenten Rrone ent=

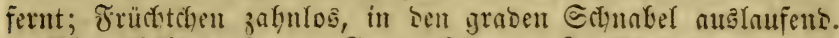

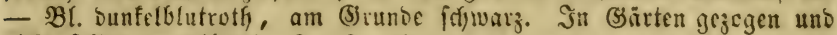
uidest feftent verwildert. $6-9$. $\odot$

760. A. aestivalis. $\sigma_{0 m m} \mathfrak{e r}=21$. Reld) fingl, an

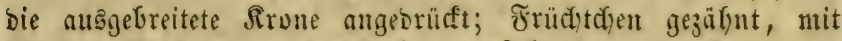
idfief = aufitrebenoem gleidrarbigem Edinabel. - Formen: $\alpha$ miniata (Ad. miniata. Jacq.) Bl. mennigrotf), am (5irunbe z̆luei= Ien fdawarz; $\beta$ ochroleuca (Ad. citrina. Hoffm.) Bl. ftrchgelf, am

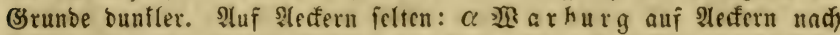

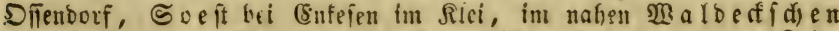

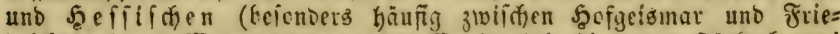

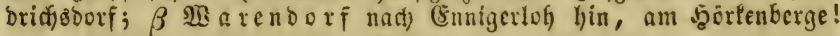
$5-8$.

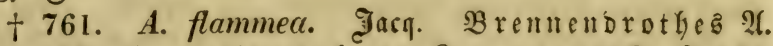

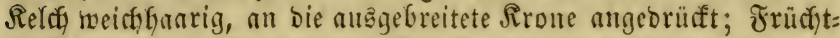
went mit einem abgerundeten $3 a$ fne ant obern Rande, und mit aufiftrebentem oberwärts brambigfdumarzem Ed)nabel. - Bl. roth, eft an ber Bafie Dunfler. Fuf Ifecfern folten: im angränzenben

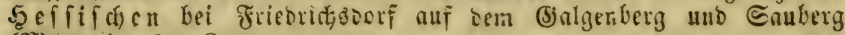
(Plauter), $6-8$.

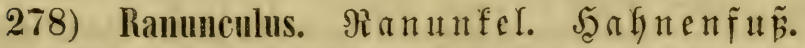

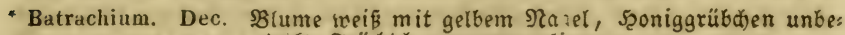
beckt, Früđhtd)en querrunzelig.

\section{$\dagger$ Blätter ungetheilt.}

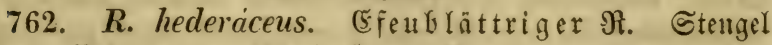
friectetlo, Blätter nierenförmig ftumtpf:5lappig. - Bl. Fehr flein.

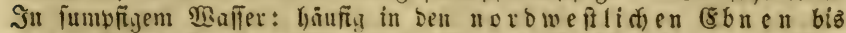

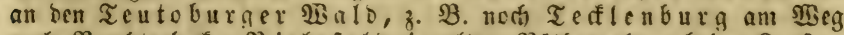

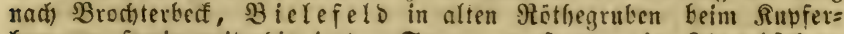
hammer, fowie meitertín in ber Genne, um Jeeepen, im sippif di en

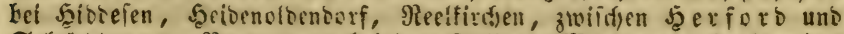

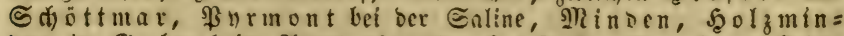

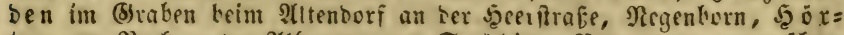
ter ant Bad unter Stlbaren, am Eollina Beverungen gegenüber,

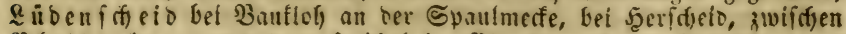

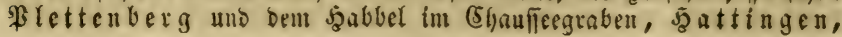




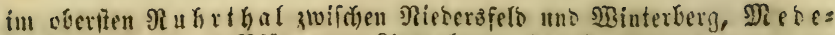

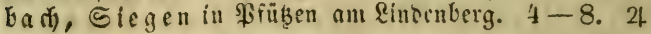

†† $B$ lätter getheilt.

763. R. aquatilis. TS a fie $\mathrm{r}=\mathfrak{R}$. Die untergetnudtent Blätter geftielt boritlich:bieljultig, die Bipfel nach allen @eiten abjeflens, bie fofmimmenten nierenförmig, laptig ooer gefpal= telt. - Gtengel fumpffantia armblüthig; $\mathfrak{B l}$. grof, Rronblätter

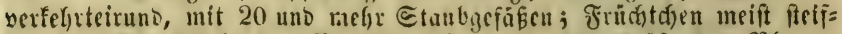

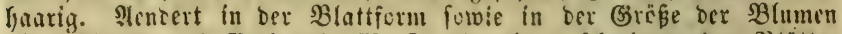
ab. Rbarten: $\beta$ retiveri. Koch. Sie ofern fommmenden Blätter 3 theilfi soer tief 3ipaltin, ifre 3ipfel 3 feitin = verfegrt siruno, fie un=

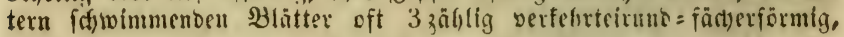
Früd)tchen meifit folyl; $\gamma^{\prime}$ paucistamineus (R. paucist. Tausch.) alle Blätter untergetaucht, Bblumen fleiner, Stanbiefäße nur 8-15.

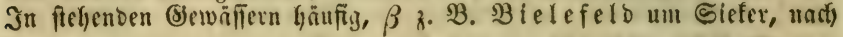

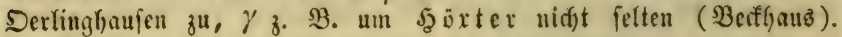
$5-8.24$

764. R. divaricatus. Sूdrank. (R. rigidus. foffm.)

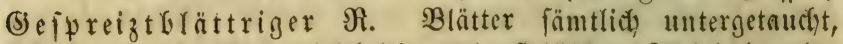
faft fitbento, forftlich = sieltbeilig, bie fteiflit)en Bipfer in eine

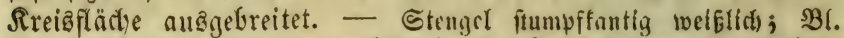
länger geitielt, Rronblätter verfebitefrumb. In ftel)enoen, etwas tiefe=

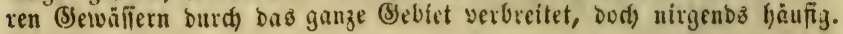
$6-8.24$

765. R. fluitans. fant. (R. peucedanifolius. All.) Fluthender $\mathfrak{R}$. Blätter fämtlid) untergetaudt, forftlid: vieltbeilig, bie Bipfel terlängert gleid)lnufent geifelförmig, un= tere langgeftielt, obere fitzend. - Stengel runo, feft verlängert,

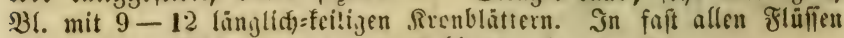

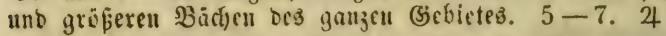

** Hecatonia. Slume weiś, mehr ober weniger rötblid übers flogen; Sconiggtübdien oberwärtb in eine Eduppe vorgezogen.

766. R. aconitifolius. (šifeututblättriger $\Re$. Blätter hanbförmig 3-7theilig, Bipfel 3pualtig zugefpizt ein= gefduitten=gefägt. - MBir haben nur bie form: $\beta$ platanifolius (R. platan. L.) $2-4^{\prime}$ hed), Blattzipfel länger acipibt, Stengcl viel=

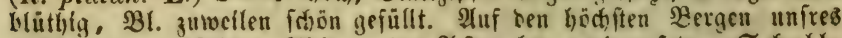

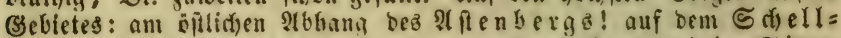

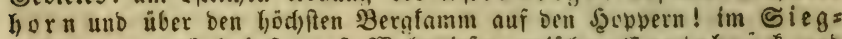

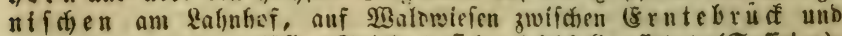
¿uber, wo bie gefüfte Epielart fidt) gleidialla finbet (Eufirian),

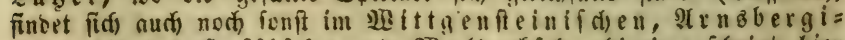

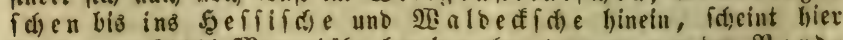

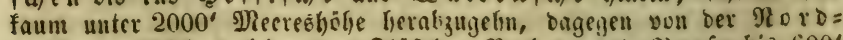

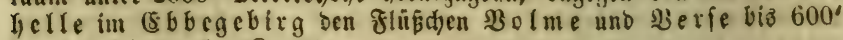
berab folgent. $5-8.24$ 


\section{Polygynia.}

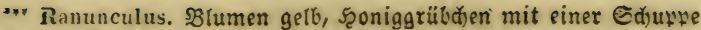
bebect.

$\dagger$ SBätter ungetbeilt fämal.

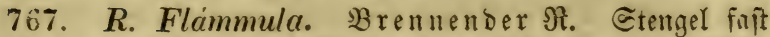
nieberlieizeno aufitrebeno; Blätter Ianzettlid, oner linealija); Frübthen mit einem furzen ftumpfen @yigden ensigens. Slbart: $\beta$ reptans Stengel ganz nicbergeitrefft uno warzelns. In

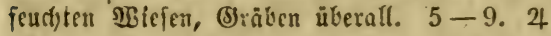

768. R. Lingua. (5) ró̈er $\Re$. Stengel fiteifaufrect,t,

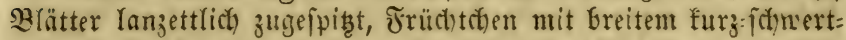
förmigem Gchnabel. - $2-4^{\prime}$ hodh, Etengel am (Srunbe quirlig=

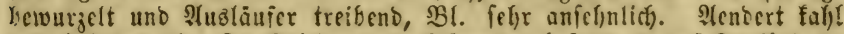
und befart ab. In Teidien uno Sümpfen befonbers auf Terfocben: Ringen in ber. ayten (5ms, SBentheim, Coesfeld bci ter Rlinfe, Dülmen in ier Enteritci, Re of linghauien an oer Fladjoberf unt fonit nidft felten, Eippit abt am Rluientfire, bei Rirlecf, Rappel,

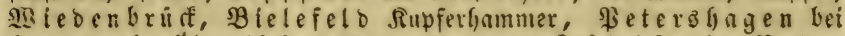
Jartum, im Elippifden Detmolo an ber Snfelwiefe, im Norber= teiti)e (auch bie befaarte Form), Stemmen, Scoxter auf oem Bruch,

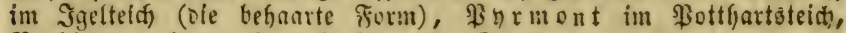
$\mathfrak{B}$ iflon nad) ber şoppete hin. $6-8$. 4

†† Blätter rundlid), etrone lappig.

769. R. Ficaria. (Ficaria ranunculoides. Moth.)

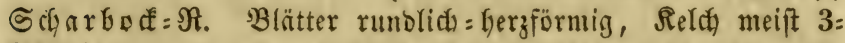

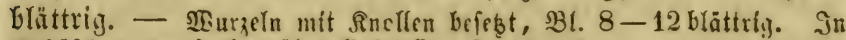

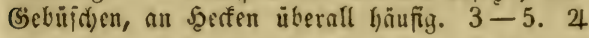

††† sBlättex getheilt ober zufammengerek̨t.

a. Blüthenftiel runo (nid)t gefurdt).

770. R. auricómus. (5) oldgelber $\Re$. SูGurzelblätter Vers=nierenförmig, ungetheilt ober 3- vielipaltig, Blattitiele ant

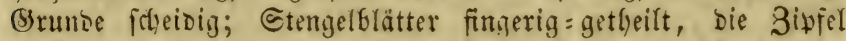

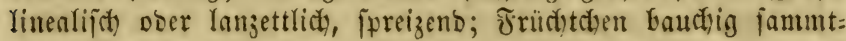
hanrig. - Seldf weidfyaarig, am Nanbe gelb; bie expen $\mathfrak{B}$ lumen

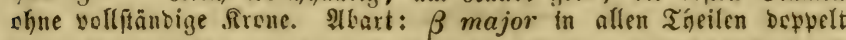

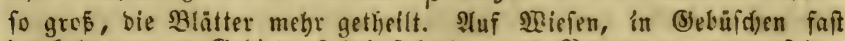
burd) bas ganze (Sebiet, $\beta$ bei NBeferbergen. 4. 5. 4

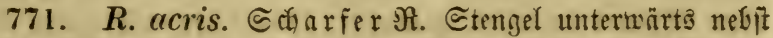

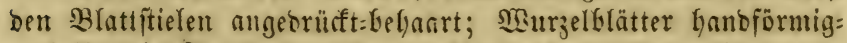
getteilt, bie Bipjel eingeictuitten:jpig̨gezähnt; Ctengelblätter 3:

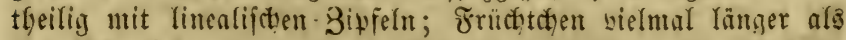

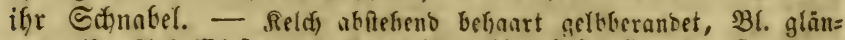

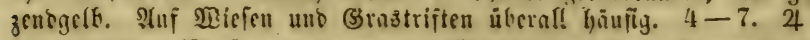

772. R. lanuginosus. SEolliger $\Re$. @tengel nebit 


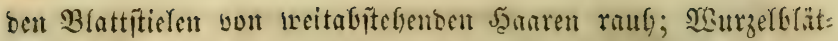

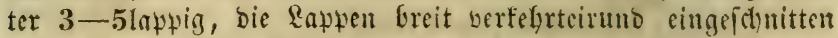

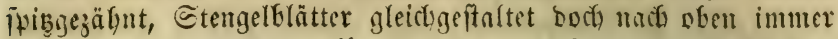

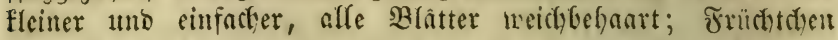
linfenförmig, etwa doppelt fo lang als iffr Safunbel. -

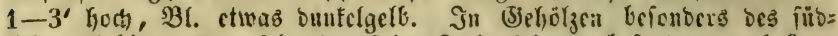

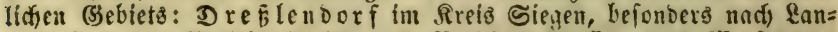
genaubad, uno Breitidgeto fin, um Brilo a häufig, aud) Miefdyebe

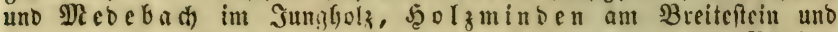

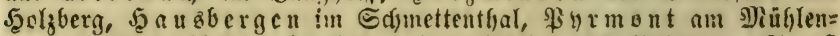
berg, im \&ippifden bei fororn, Eecpolosthal und Beforom, Soeit

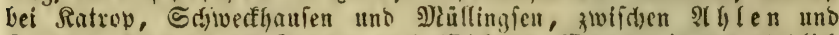

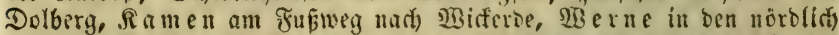

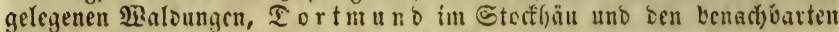
Eefholzen, Jicrlohn im Filfenmeer. $6-8$. 24

773. $R$. arvensis. If of $\mathrm{e} \mathfrak{x}=\mathfrak{\Re}$. Ctengel unten falfi;

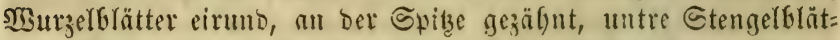
ter 3tbeilig mit Ianzettlidfen Feren, bie oberften linenlifat):biel=

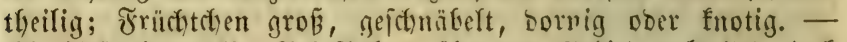

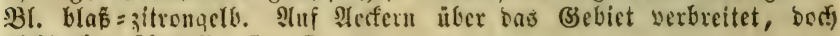
nicht eben überall. $5-7$.

b. Blüthenftiel gefurdot.

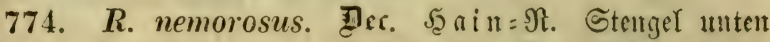

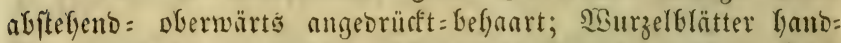
förmig=getheilt, bie Bipfel uerfefleteirund 3ipaltig gezälnt; Relds

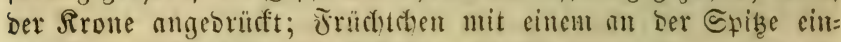

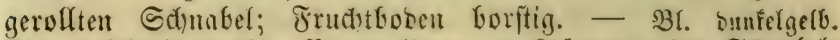

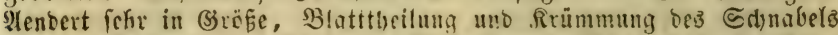

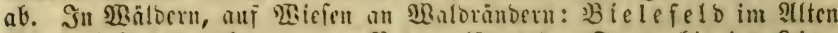

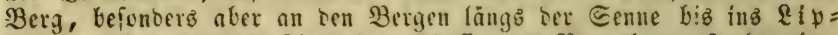

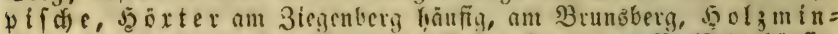

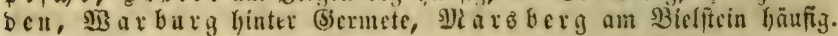
5. 6.2

† 775. R. polyanthemus. Reid̦blütfiger $\Re$.

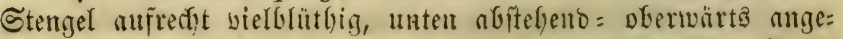
brüft=befgart; SBurgelblätter banbförmig=getfeilt, bie Bipfel 3 fpaltig ober 3 theilig, eingefdinitten (Jekent faft rinealip(t)), obere Bläter Ymenlifw = gefingert; Jrüchtchen mit einem furzen Gafenförmigen Situnabel. - Daz Borfommen biefer \$flanze ift mir nod) zweifelfaft, benn fie fojeint mit ber gröberen Form ber yor.

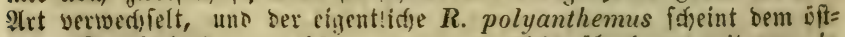
lidsen Deutíchland anzugefieren, wenn er nicht in berhaupt mit vor. in eine Âtrt zufammen zil zichen ift. Die Stanborte, two R. pol. ber ciner năfern \$rüfung bríngeno empfohlen twirb - wadjen foll, find folgenbe: im Sittgenfteinifiden, Siegen im Thiergaten 


\section{Polygynia.}

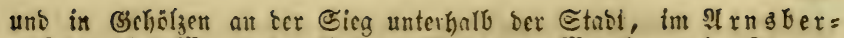

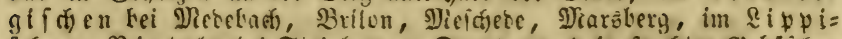
fafen, Rinteln bet Steinbergen, Dortmu no in feuditen (Bebriiden

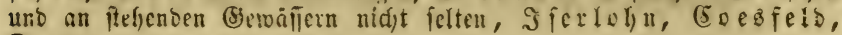
Darup. 5.6. 4

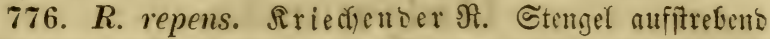

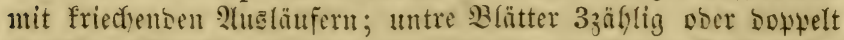

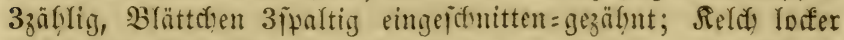
abitebens; Jrüditifen fein cingefteden = punftirt. - Die Fflanje

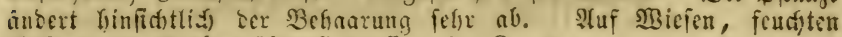
Nectern, an (5röben viberall hăufig. $6-8.24$

777. R. Philonótis. Eyrh. (R. hirsutus. Curl.)

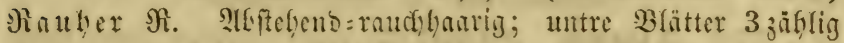

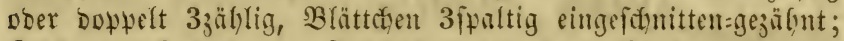

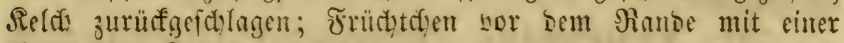
Reibe von Rnötd)en befebt. - Die ganze Siflange blafgrin, 23!.

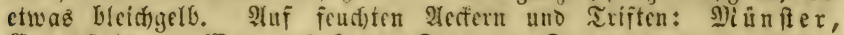
Co

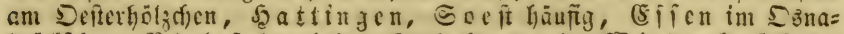
brüdidsen, $B$ ielefeld bein fupferfanmer! WB iedenbill bei

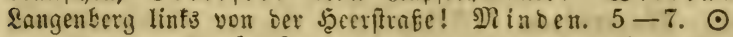

778. R. bulbosus. $\mathfrak{I}$ olliger $\Re$. Stengel ant

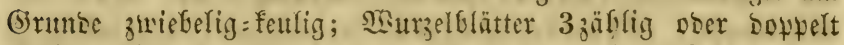

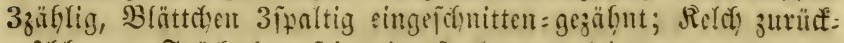
gefdulagen; Friddytden fein eingeftodien = funftirt. - Niebrig,

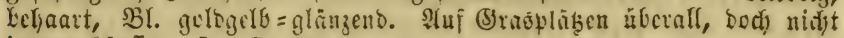
immer liăufig. $5-7.24$

779. R. sceleratus. (9)iftiyer IR. B̧ätter fleiffig, untre Ganbfömig=getbeilt, obre 3tfeilig; Reld jurüdgefdyla= gen; Jrüctitct)en fely flein, feimrungelig. - Rabi, હtengel un=

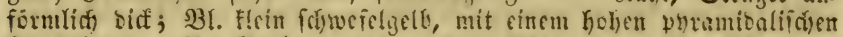

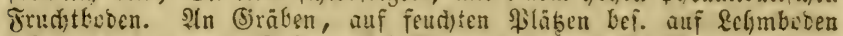

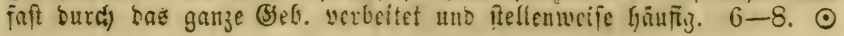




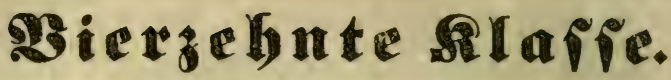 Didynamia.}

\section{Sromung Gymnospermia.}

- Reld faft regelmäßig, beutlid) 5 zähnig ober 5 frultig

$\dagger$ Dbertippe fehlend oder faum bemerklid).

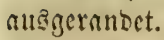

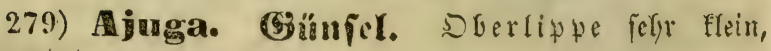

280) Teracainn. Gamander. Drerlipte 0. Re! (t) am (birunde Guffelig.

t† Doerlippe beutlid, vorhanden.

a. Sriffel uno Staubgefäbe herbortreteno, leştere nidjt pa: rallel mit einander laufeno.

281) Flentha. Mtinze. Srone trichterförmig, faft regelmä̧ig 4 fpaltig, ber obere Bipfel etwaz breiter und ausgerambet. Staubgefäвe fict) von cintumber entfernend.

282) Wlyssopus. STop. $\mathfrak{A}$ o n e rachenförmig. SGerlippe ausgeranoet; Huterlippe 3 theilig, ser mittlere Bipfel fefye breit nerfefrt=kerzförmig. Staubgefäßze แแล cinnonoer tretent.

283) Elspollia. Willd. Elgholgie. Rrone faft gleid) 4 ipaltig, ber ofre Bipfel gernbe, etmas gerrölft, ategerambet, bie untern abfeflento. Staubgefäв́ nus ein anber tretents.

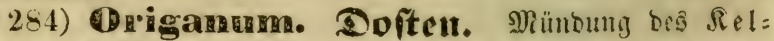
(h) bärtig. Sirone rachenformig. Dberlippe f(ad), auf: rect); Unterlippe 3 theilig, bie Bipfel faft gleid) (Der mitt: lere faum etwas breiter). Staubgef. aus einander tretento.

285) Gatureja. Ffefferfraut. Rrone raden= förmig. Dberlippe atsgernot. Unterlippe oreitbeilig. Sipfel abfefyeno, ser mittlere ettas gröper. Strubgefä antfornt, fich in einem $\mathfrak{B}$ ggen zujamuten meigend.

b. Briffel und Staubgefäß̈e hervortreteno, reştere parallel neben oinander liegend. aa. Sberlippe flad), 2fpaltig.

286) Glechoma. (\$unblrebe. Der mittlere 
Bipfel ber Unterfippe flad), serfefrt=ferzförmig. Staub= beutel paraveije ein Rreuz bildeno.

287) Wepeta. Rabenminze. Der nittlere Bipfel ber $u$ nterlippe runblich, concav, geferbt. Staubfäben

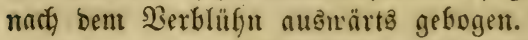

bb. Sberlippe getwölbt ober concav.

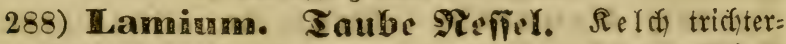
förmig begrannt. Unterl. jtalt ber Eeitenjipfel mit fleinen Zäguten serfebert.

289) Galcopsis. S3anfucfiel. Reldi gloffig = sornig. Ter mittlere Bipfel ser It nterl. faft 4crfig, an ser Bajta mit 2 huflen Eeitemähnen.

290) Galeobdolon. f)ù Gor. Gorburfer. Reld gloffig, bornig. Itnterl. fpib, 3ipaltig.

291) Rallota. Ballote. Rel thideterïrnig

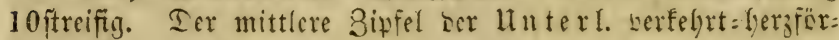
mig. $\mathfrak{R}$ ronröbre mit einem Saartratz.

292) Slachys. Bicft. $\Omega_{f} l$ if 5 fantig. Ier mitt=

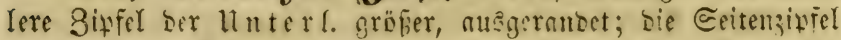

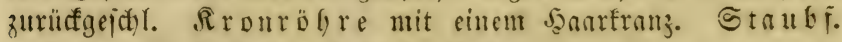

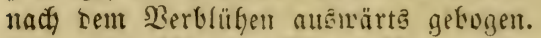

293) Retomica. Betonis. $\mathfrak{R}_{\mathrm{f}}($ d) an ber Mün= bung etwas färtig. Der mittlere Bipfel ier Unterlippe etwaอิ größ̄er, auลีgeranbet.

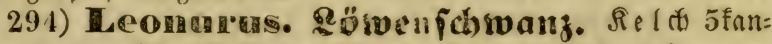
tig ungleich. Die Bipfel ber unterl. unterwärts zujammen= gejchlagen. $\mathfrak{I}$ ronröbre mit einem Sanarframz.

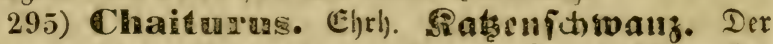
mittlere Bipfel ser Unterliphe ftumpf. Rrourägre ofine Şaลrtrang.

c. Sriffer uns Etaukaffäße in Ser Rronröhre verborgen.

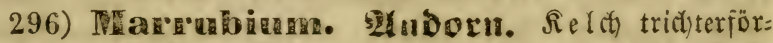
mig, fteif, loftreifig. Soberlipte 2fpaltig, limenlifor), flach. * Rield 2liwpig

† Etaubgefäbe nidut paraller neben sinariorr liegens.

297) Thymers. Shymian. Sberlippe bes

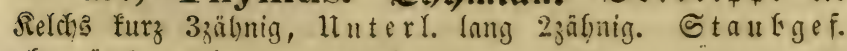

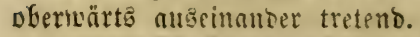

298) Calamint ha. dind). Salamiute. હtaut:

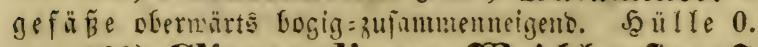

299) Clinopodiam. Seichborite. Staub= 


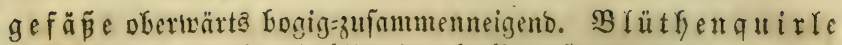

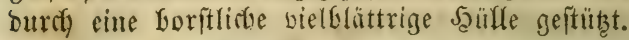

t† Staubgefäbe parallet neben einanber liegent.

300) Scotellania. \$elmfraut. Rel (i) mit ungezäfnten Sipten, mit einer contaven Gdyuppe finter ber Sberlippe. Sronrö gre ofhe Saarframz.

301) Premellas. Prumelfe. DGerlippe des

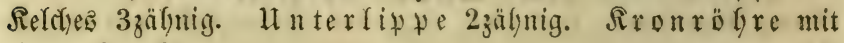
einem Sanarfram?.

\section{Stronung Angiospermia.}

* Rel(ส) 2blättrig.

302) Orobanclie. Commerivurg. Reld 2 :

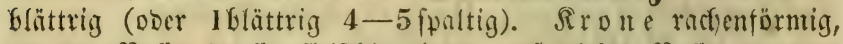

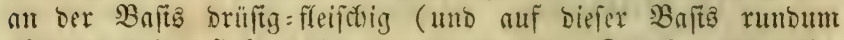
abjpringent). Dberlippe ausgerandet. Rapfel 2flappig, 1 füchterig.

** Geld, 4fpaltig (Firone tadfenförmig).

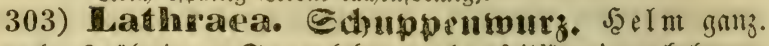
unterl. 2 zälnig. Staubleutel peilförmig, Veljant. $\mathfrak{R} a$ jel 2 lappig, 1 füdterig.

304) Euplorasia. Stugentroft. $\mathfrak{R} \in \mathfrak{l}$ (t) warjen=

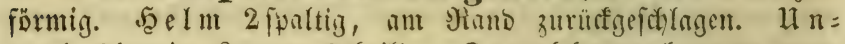
terl. 3laptig, Rappen 2theilig. Strubbeutel unten zuge=

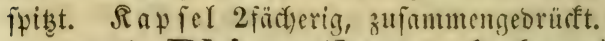

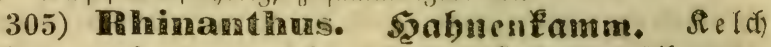

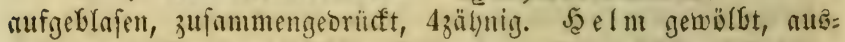
geranbet. Uuterl. flach), 3 laqpig. Staubbeutel filzig.

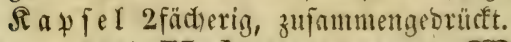

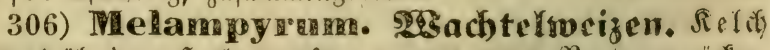

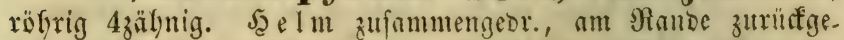
faltet. $\mathfrak{H} n \mathfrak{t} \mathfrak{x} \mathfrak{Y}$. f(ad) 3lappig. Staubb. zufammentangent.

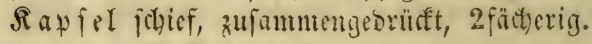
*** Rel 5ibaltig. $\dagger$ Srune rachenförmig.

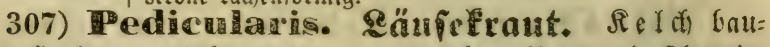

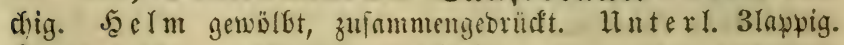

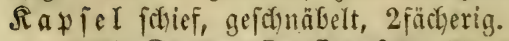

308) Scrophelavia. Biraunwurz. Rrone fait fugelig. ธิ ธum flein 5lappig, ber untre Rappen zurüdige= bogrt. Raplel 2fädjerig. 
†† Rrone mazkirt.

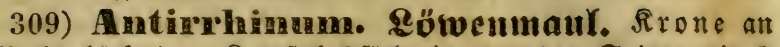
ser Bajts höfferig. Saplêl 2 fäd)erig, an ber Spiţe mit 2 Rödfern auffipringent.

310) Linaria. Scinfraut. Rrone an ber Baftis gefpornt. Raplel 2fücterig, an ber Spite mit Rlappen auj= ipringent.

t†† Srone glớig.

311) Digitalis. Fingerbut. Sirone Gauchig,

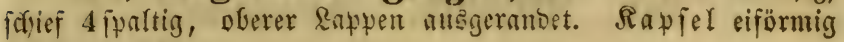
2 fäct)erig 2 flapyig.

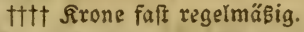

312) Venbena. Cififufrnut. Rel (t) 5 zäfnig, cin 3nign abgeftutht. Rrone telferförmig, Gaum 5lappig, et= mas 2lippig. Frutht 4 färdyerig 4 famig.

313) Limosella. Sumpfieaut. Rrone 5ipar: tig, Röfre glocfig. Rapjel 1 fäctjerig bieljamig.

\section{Sronung Gymnospermia.}

\section{9). Ajuga. (s) ünfer. \\ * șlumen quirlig.}

780. A. reptans. Rriediender (5). Stengel mit frie=

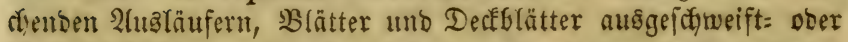

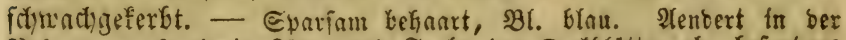
Bernarang, forvie in Ringe und Farbe ber Dectblätter ab, Gefonbers

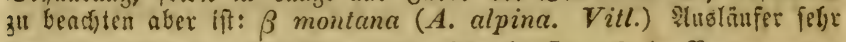

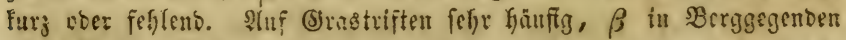

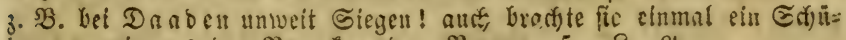
lev von mil anz sen $B$ ta ff we ber Bergen. $5-8.24$

781. A. genevensis. Janariger (5). Etengel zottig,

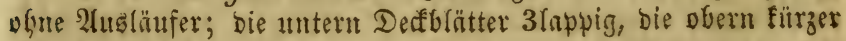

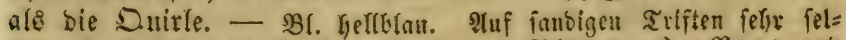

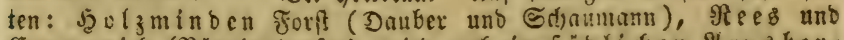
(En merid) (Bunlnghaufen), wirb and im fablidicn A rn ber=

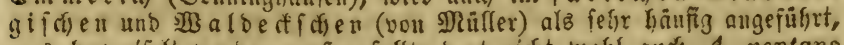
was bezlueffelt werben muÉ; follte bort nicht werfl auth A. reptans $\beta$ montana burfommen uno verweerifelt fein? 5. 6.24

t 782. A. pyramidalis. Myrami is enförmiger 55. હtengel zottig, ofue 2fuslüufer; untr: Blätter gethüt grof, 
Werfegrteirumb, obre Deffblatter sopwelt fo Inug ala bie Duirle. - $\mathfrak{B}$. flein, hellblut. Sm angräncmien $\mathfrak{R}$ a f $\{$ a uf Gorn und Dillenburg (Eecri, Dörtien) $5-7.24$

* şlumen sinzeln winkelftäubig.

† 783. A. Chamaépitys. Sidreb. (Teucrium Cham.

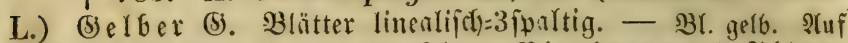

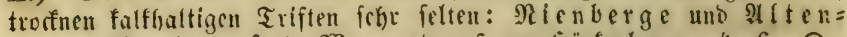

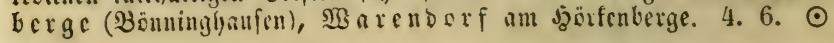

\section{0) Teucrium. (b) a $\mathfrak{a}$ a ber.}

* Reld) 2rippig, Sobrlippe namz, Unterlippe 4zähnig.

784. T. Scorodonia. (5) meinex (5). Sklätter fyer:

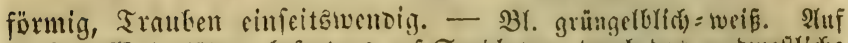

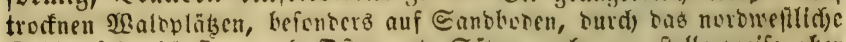

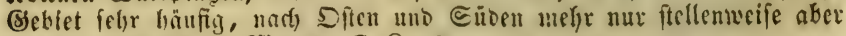
Dnna gleidifallz fu Ylenge. 7. 8. 4

** Reld) 5 zäthnig, $B$ lumen quirtig.

785. T. Scordium. Rnoblaudi) (5). SBlätter fïizento

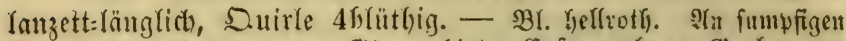

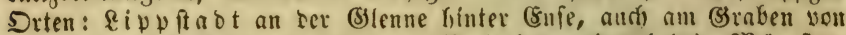

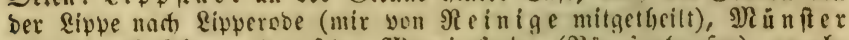

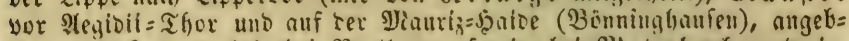

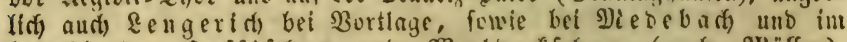

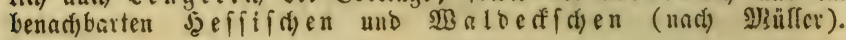
7-9. 4

786. T. Chamaedrys. (ङ (b) $t \in \mathfrak{r}$ (5). Blätter gefitielt, feilig:eirmo, cingefdnitten:geferft; D.uirle 6blütbig. - Niebcr=

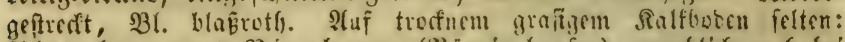
If tenberge uno Nienberge (Bominghamen), angeblids and) be!

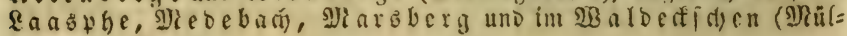
ler). $6-8.24$

787. T. Botrys. Trnuben= (5). Blätter vieltheilig,

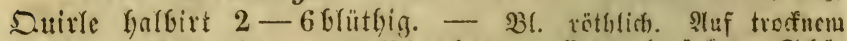

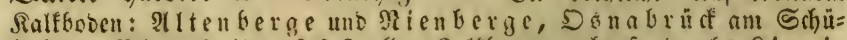
lerberg, 3 iclefelo auf foft allen Ralfbergen, ebenlo surcho \&ippl=

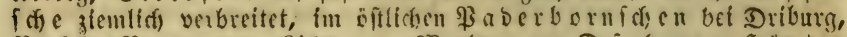

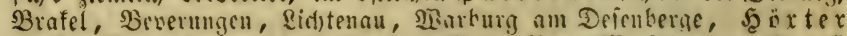

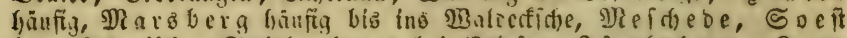

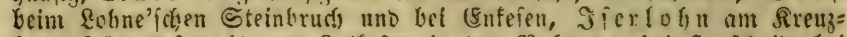

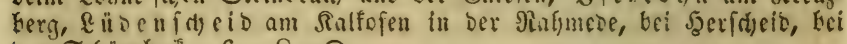
bex Erfyñeberf. $6-8$.

Unmere. T. montautum, von Scenaftenbera bri \&imbur 3 am

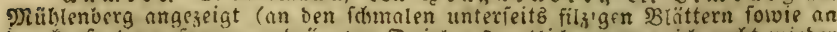
ben topfartig jufammengeorängten Suirlen Penntich, wage idi) midst wipoer

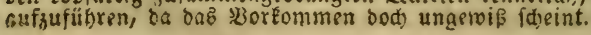




\section{1) Mentha. Miız .}

* Reld inmensig okne sart.

† Blithenquirle enbitânoig äbrenförmig.

788. M. rotundifolia. Runb blättrige MC. Blätter

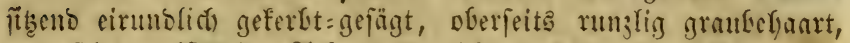

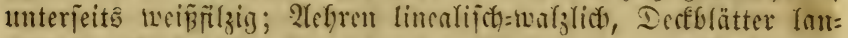

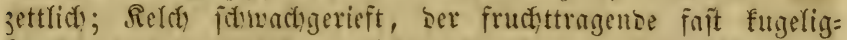

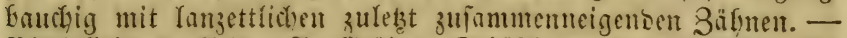

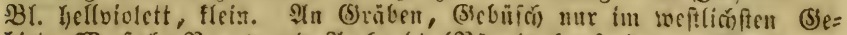

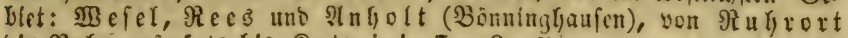

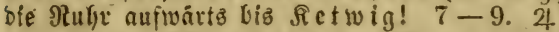

789. M. sylvestris. Mald minze. Blätter fait jüreno,

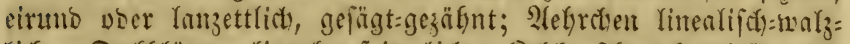
Yids, Deffblätter rineal= yfriemlid); Seldh formadygerieft, ber

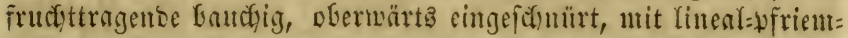

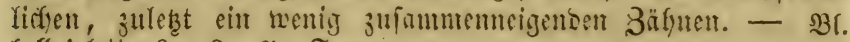
beflviolett. 6-9. 4 Formen:

Ce vulgaris (M. sylvestris. Willd.) 33(ätter fir żig fiacl) nier nur twenia wellig, äneet mit gröferen brsiteren tiefer $=$ gezähaten uno

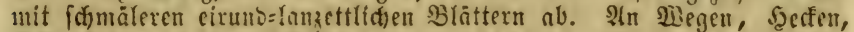

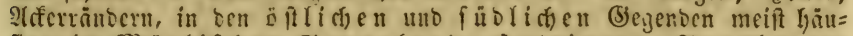

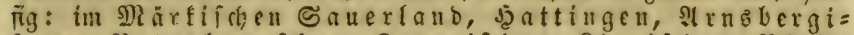

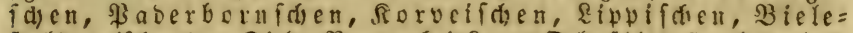

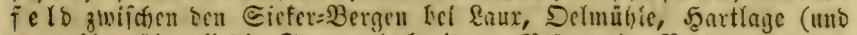

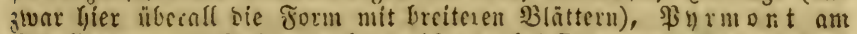
Schellenberg, im Є (n) a u

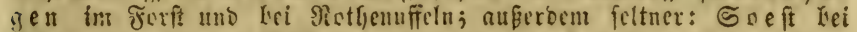
binnerfing, in ber Edjleste, Dülmen in ber Steingruie utub it

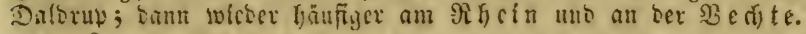

3 nemorosa (M. nemorosa. Willd.) Blätter tweit fámẩer,

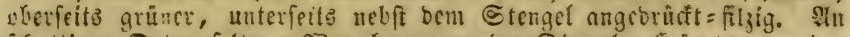

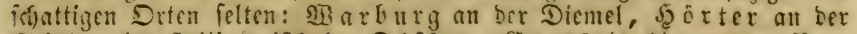

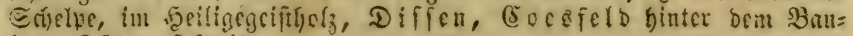
lano, \&übenfocio.

$\gamma$ mollissima (M. molliss. Borkh.) Elcnger birffizig, Bhrättev

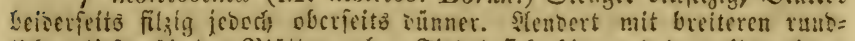

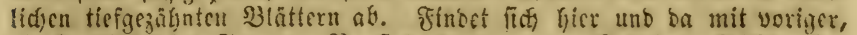
Ste breitblätrige Form 14 Tagne fpätrer.

$\delta$ candicans (M. candic. Crantz) Stenget unt Blätter Hon

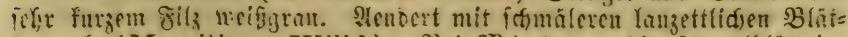

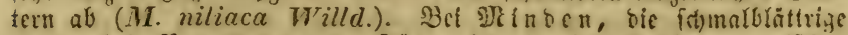

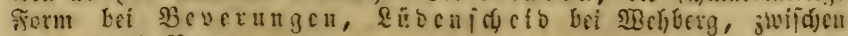
Befel und $\mathfrak{s e}$ e .

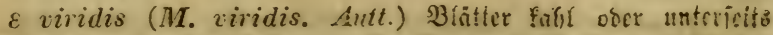

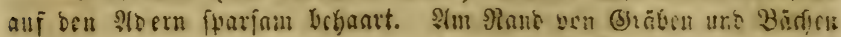




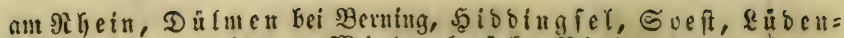
(d) efo in ber Nafmede, NB iebenbr ü df, SB ielefelo am leutter=

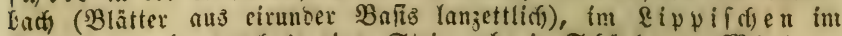

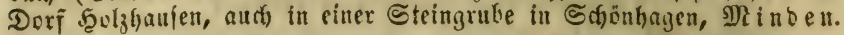

$\zeta$ crispata (M. crispata Schrad.) BBlätter faht, blafig=rumz= Yig, eingefonitten =gezägnt. SB ielefelo am Rutterbad) unter bem

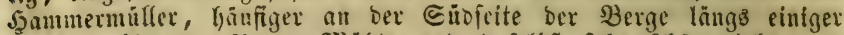

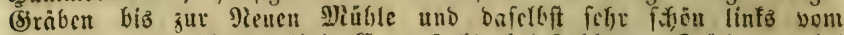
Teide, unzweifelfaft wils! (5oes felo bei Boblutg, D älmen bei

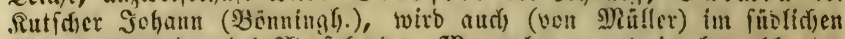

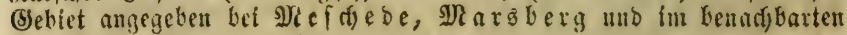
Seffif (i) $\in$ n.

790. M. nepetóides. Eீj. Diffälrige 2)i. Bln̈tter

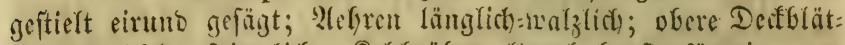

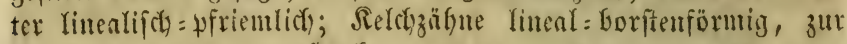
Fruditzeit gernoe norgeitredt. - $230 h i$ sin Bantaro von $M$. aqua-

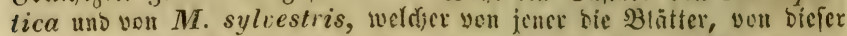
bie Slef)ren (nut biffe) hat. Formen: $\alpha$ angustifolia (M. pubescens. Willd.) Bläter fomal, farfbefant; $\beta$ latifolia (M. hirta.

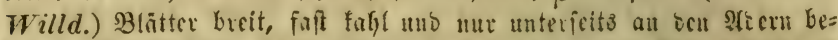

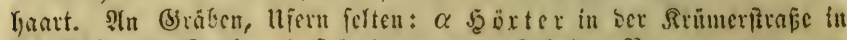

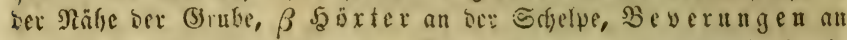

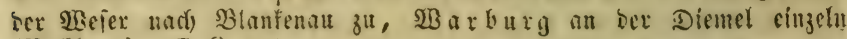
(B)edffaub). 7.8. 4

791. M. piperita. Brefferminze. Blätter geftieft,

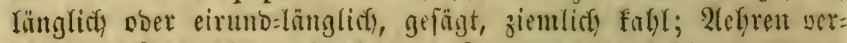
Yängert; Reldiröbre gefurdit, am (jrunbe gauz fafl. - sibart:

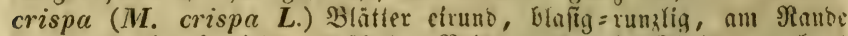

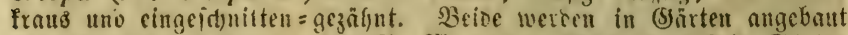

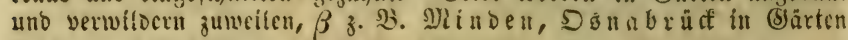
an ber Johannisfrabe. 8. 9. 24

t† $\Re$ lüthenquirle blnttwinterfänoig, ober bie oberften Eöpfig.

792. M. aquatica. WBafierminze. Bäntter gejtielt

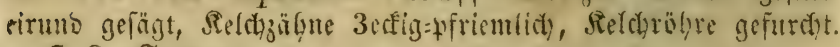
- 7.8 Formen:

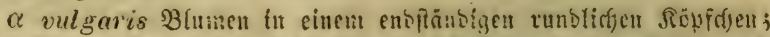
äntert ab: a. hirsuta (M. hirsuta. L.) befhant, bie Sjlätter sît fürzer gef̂telt; b. glabrata (M. citrala. Ehrh.) fafif, um bie Rieldie

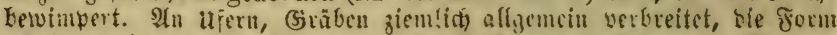

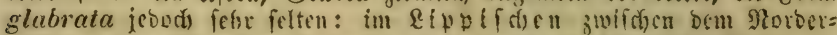

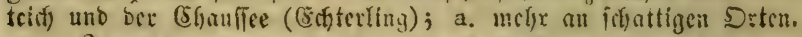

$\beta$ intermedia unter bem entefübigen Räpidyen beftuben fith

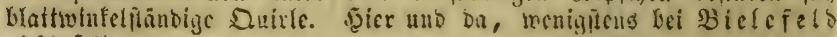
nicist felter.

y sativa (M. sativa. L.) B̧fumen nut in blattwinfelfänbigen

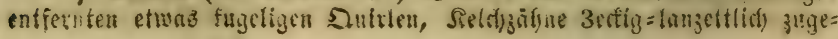




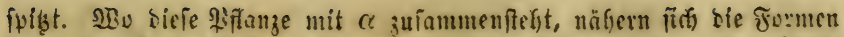

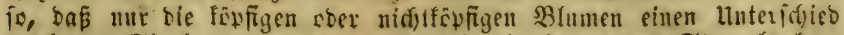
madjer. Eie fummt vor: a. vulgaris bie jaare bez Etengels her=

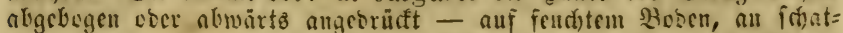
tigen lifern; b. glabra faft ganz fahl, figeint bei uns zu feflen;

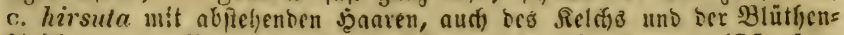
fiteldyen - 3. B. in bet Senne féfre gemeiu ; d. dentata (M. den-

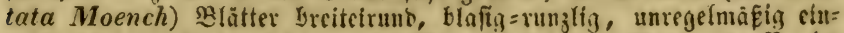
geídjuitten = gezähut, fahl - in Bauergäten vertvilbert, z. $\mathfrak{B}$. in

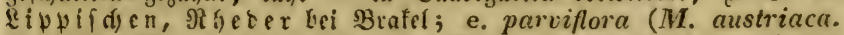
Jacq. - M. parviflora. Schultz) Rrone nutr etwas länger als her

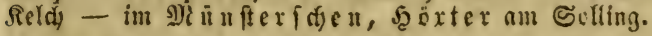

793. M. gentilis. ซeine Di. Blätter geftielt ellip:

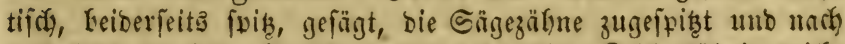
gorwärţ geneigt; Duirle entfernt fugelig; Reld) röhrig: trick)=

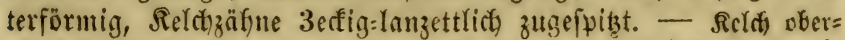

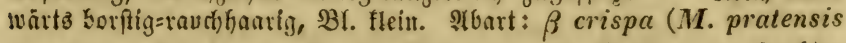

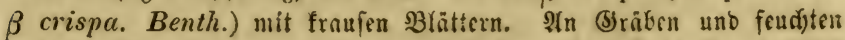

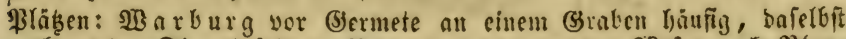

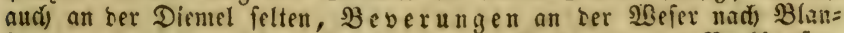

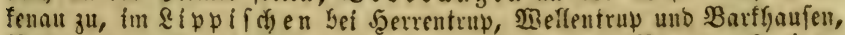

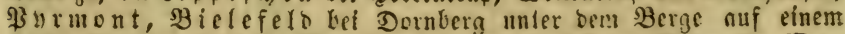
5้อfe, 我

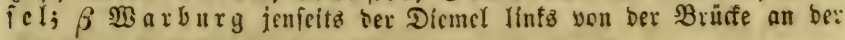

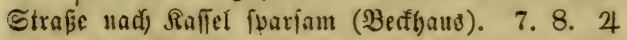

794. M. arvensis. Felominze. Blătter geftielt, siruto ober elliptifd), gefägt; Duirle entfernt fugelig; Relch)

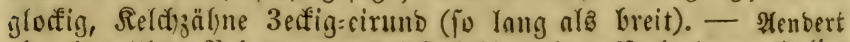
ab mit zottiger befraarung uno faft faffl, mit aufîrebentom unb lie=

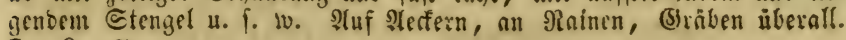
$7-9.24$ ** Feld̆ intwentig bärtig.

795. M. Pulégium. (Pulegium vulgare. Datll.)

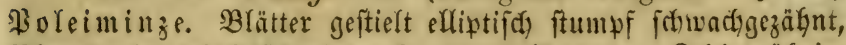
Blument in winfelftünsigen fugeligen Duirlen; Rełd̆ röhrig,

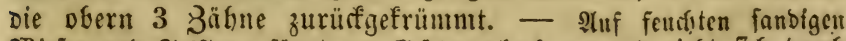

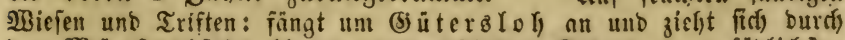

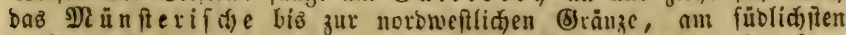

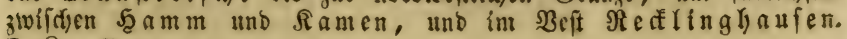
7. 8.4

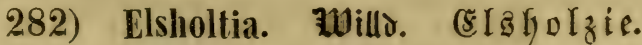

796. E. cristata. Willo. B̧ätter geftielt, eiruns obet

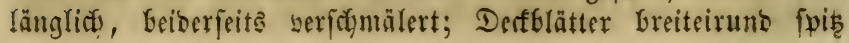


getwimpert, nebft ben genäherten Duirlen einfeitșenoig, 2(ebren

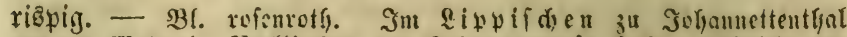

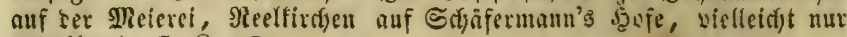
vertwilbert. 7. 8. $\odot$

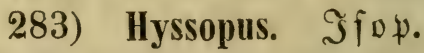

797. H. officinalis. Blätter f(c)mnalfamzettlict) ganz=

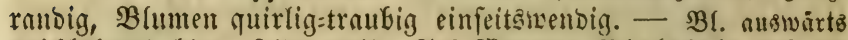

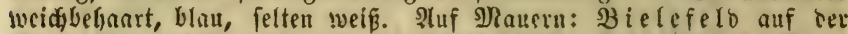

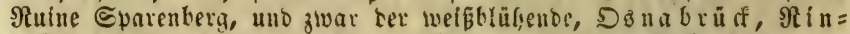
teln auf Stabtmauern (blau), Beverungen auf (Bartemmanern

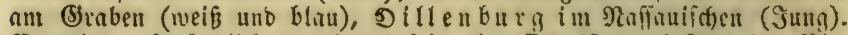

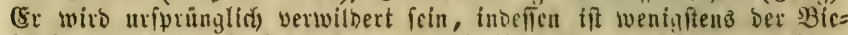

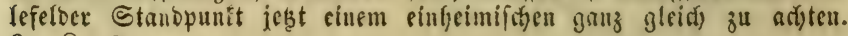
$6-8.24$

\section{4) 0riganum. Doftent.}

798. O. vulgare. (S) emeinex D. Blätter cirumb

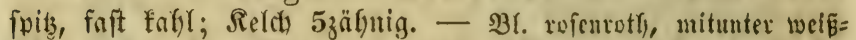

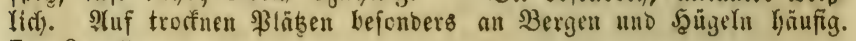
7-9. 4

799. O. Majorána. (5) artendo fiten. Miajoran.

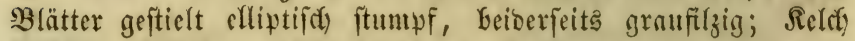

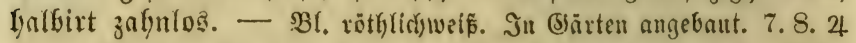

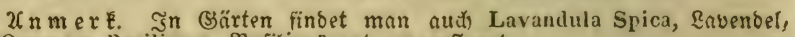
uno Ocymum Basilicum, gafilienEraut, angepfangt.

\section{5) Satureja. B̃ fefferfrutt.}

800. S. hortensis. Bfeffer: oner Boluenfraut. Sïrle. Stengel frautig, fefyr äftig; Blätter Ianzettlich fpib;

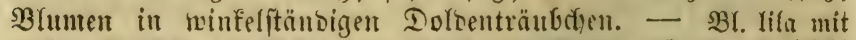

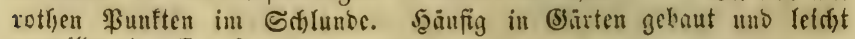
verwilbernd. $7-9 . \odot$

\section{6) Glechóma. (3) แ}

801. Gl. hederacea. Blätter nierenförmig geferbt, Seldhzäbue eiruno begramut. - Etengel friedteno, Duirfe 6blütgigg, Bl. Keflviolett. FtGarten: $\beta$ major in allen Thrilen Duppelt grëEer;

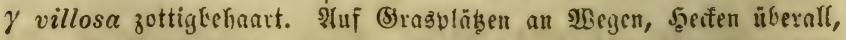

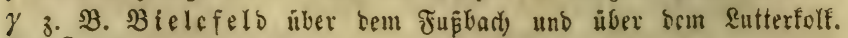
$4-8.24$ 


\section{Gymnospermia.}

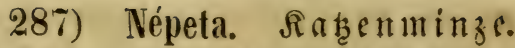

802. N. Cataria. (5) emeines R. slätter geítielt

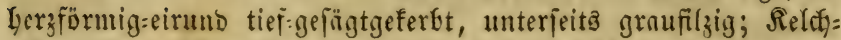

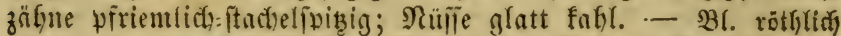

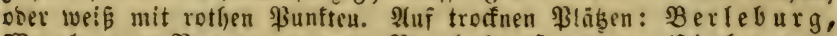

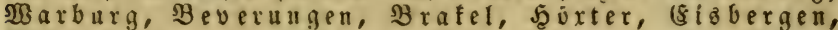

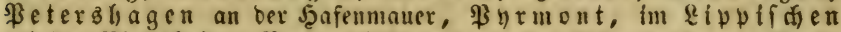

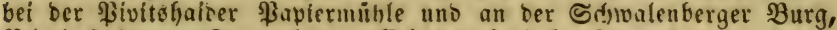

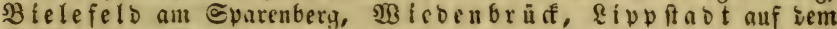
Stiftzifofe zu Rappel unto am gubinene nad) bem Eanthaufe, Soeft

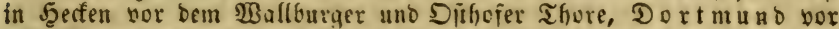
bem Wurgthore, vor bem $\mathfrak{F e f t e n t h e r e ~ a n ~ b e r ~ F u n f e n b u r g , ~ \Re e r f l i n g = ~}$

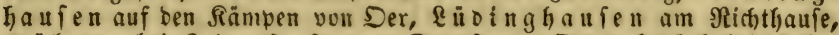

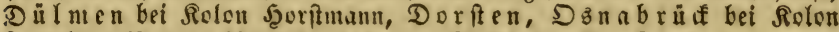

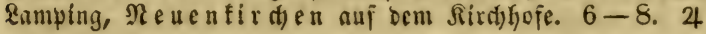

\section{8) Lamium. Taubneffel.}

\section{* Rronröhre gerabe.}

803. L. amplexicaule. Stengelumfaijen of T. Untre Blätter geftielt herzförmig=ftumpf, bie obern ftengelumfaffend

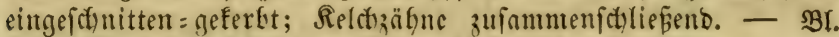

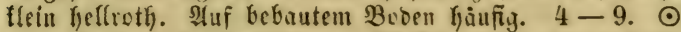

804. L. incisum. Willd. (L. westphalicum. Whs.) (Eingef(d) nit tue T. Blätter ungleid)= eingejdutten=geferbt, bie untern herzeirumb geftielt, bie obern faft rnutenförnig mit

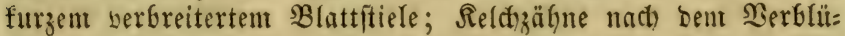

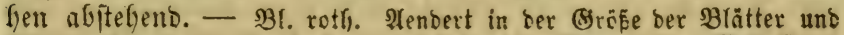

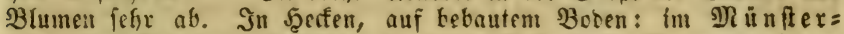

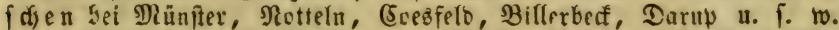

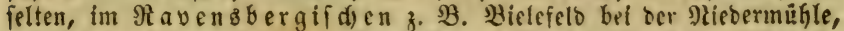

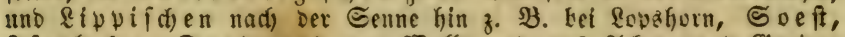

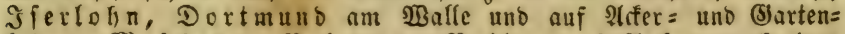
boben, Miefdyebe, Belmebe, Breflun auf Tlefern nadi bem

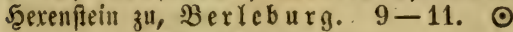

** Sironröhre geÉrümmt.

805. L. purpureum. $\mathfrak{A}_{\mathrm{oth}} \mathrm{e}$. Blätter geftielt herz= förnigg:eirund ftumip ungleid) geferbt:gefägt; Rronröfre an ber fatwachen Rrümmung inwentig mit einer Sanarleifte. - Die

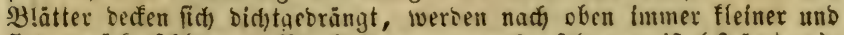

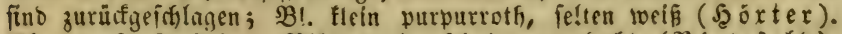
Itbart: $\beta$ decipiens $\mathfrak{B}$ lätter eingeidnitten s geferbi ( $\mathfrak{B}$ i elefelb). 2Huf bebautem Boben iiberall. $3-10$. $\odot$

806. L. maculatum. (5) efleff te T. Blätter gefitielt herzförmig:eirun zแgefpight ungไeiđgefägt; Rronröbre über ber 


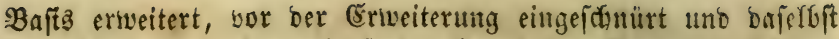

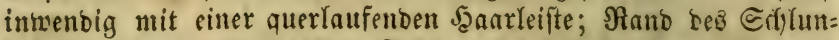
bes mit eintui pfriemlichen Bafhn auf jeber Seite. - Bl. grof,

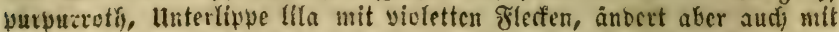

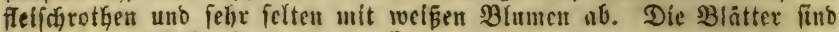

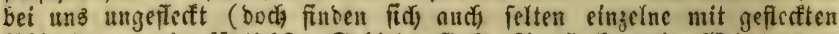

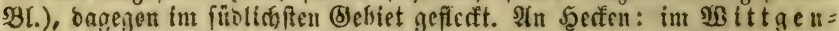

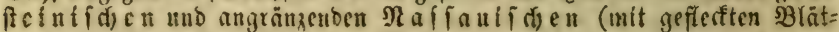

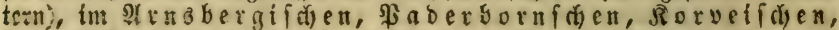
af

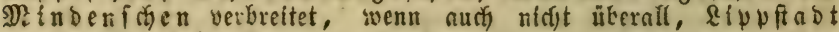

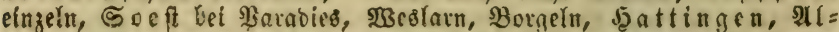

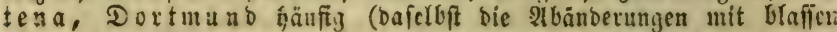

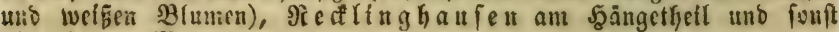
nidit felten, 此 ü n fter. 4-9. 4

807. L. album. S3eiñe T. Blätter geîtielt herzför= mig = eiruno ungleich geferbt =gejägt; Rronröbre geqdonulrt uno

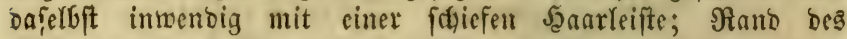

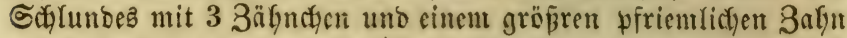

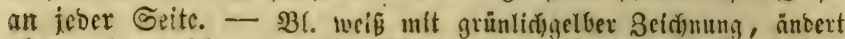

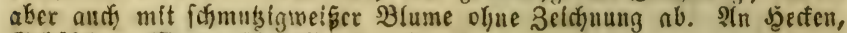
Bebü(d)en, 2 Begent ïberall. $4-8,4$

\section{9) Galeopsis. $\mathfrak{g} \mathfrak{n}$ กีneffel.}

* Stengel unter ben Selenten nidit ange(d)wollen, weidjbehant.

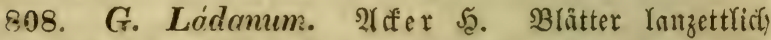

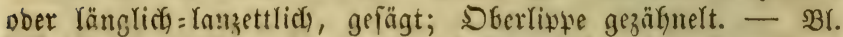

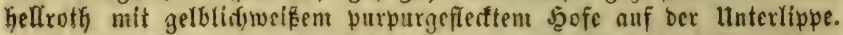
7. 8. ๑. Ẽcrmen : $\alpha$ Ĕatifolia (G. latifol. Hoffm.) Blätter läng=

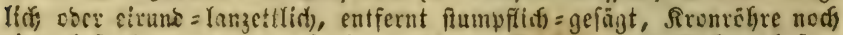

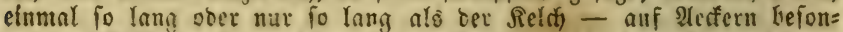

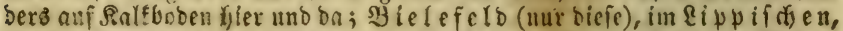

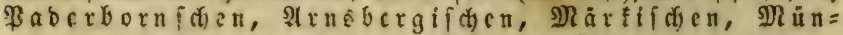

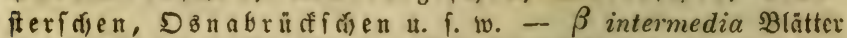
ciruno (1vic bet $G$. Tetrahit, nur frumpfer und fürger), Rrone un Díc

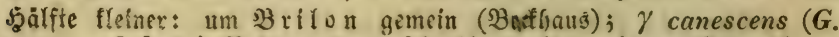

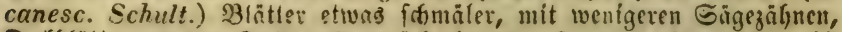

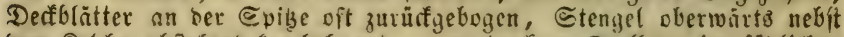

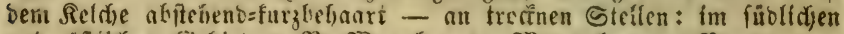

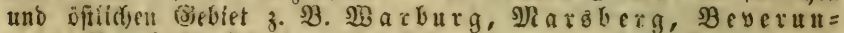

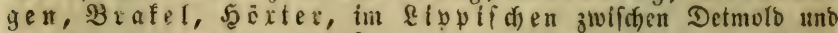
ডjiobeien am Steinbrud); $\delta$ angustifolia (G. angustif. Ehrh.)

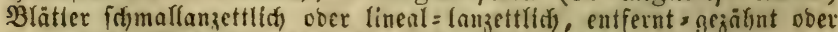

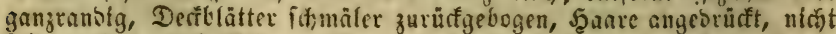
felten mit boypelt fleineren sBlumen abänderno - auf troftuem fleini= 


\section{Gymnospermia.}

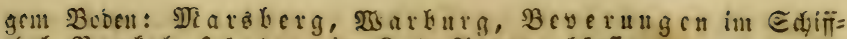

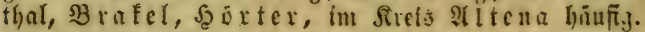

809. G. ochroleuca. fam. (G. grandiflora. E゙rb.)

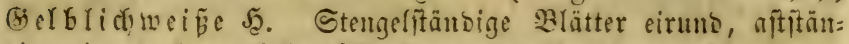

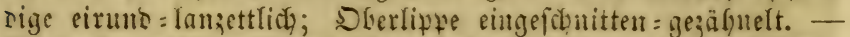

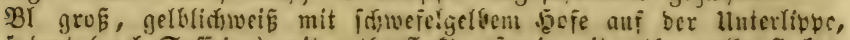

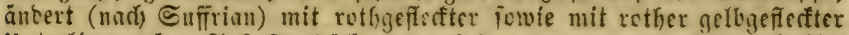

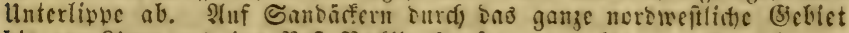

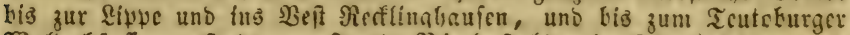

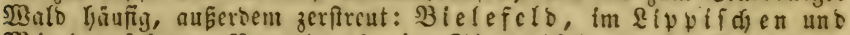

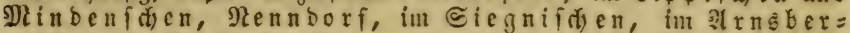

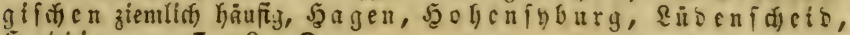
5attugen. $7-9$. $\odot$

** Stengel unter ben Gelenten angeidwivollen, fieifhaurig.

810. G. Tétrahit. (5) enteine 53. Blätter eirums fpib, (beiberieits 5-10 mal) gefägt; sie oberften Suirle genäfert; Reldyzäfne jebr lnug, non ser ungefäbren Ränge ser Rromböbre; Unterlippe jait 4erfig, flach. - Sil. roth cher weislid!, bie Unter= lipve mit gelfer rothgefiefter 3eidjung. 2tuf Ecbutest Boben, an Sgecten. $6 \div 8$.

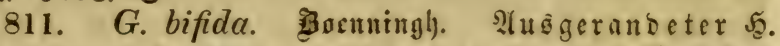
Blätter eirund = länglid) fpib, (Geiderieits $5-10$ mal) gejägt; bie oberiten Duirle genäbert; Relazäfrne felyr lang, won ber Ränge ber Rronrōfure; Der Mittelzipfel ber Interlipłe länglid

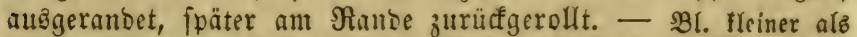

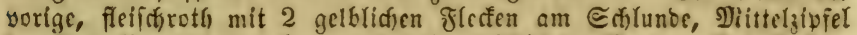

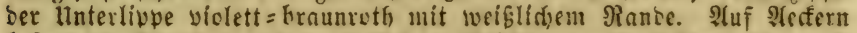

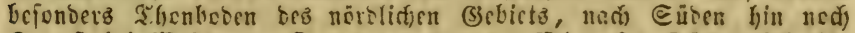

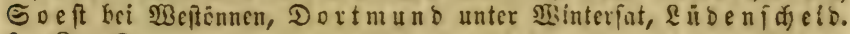
$6-8$.

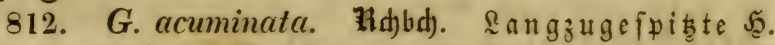
Blätter eirund = lanzettliç) langzugefpist, (beiserj. 12-16mal) geägt; Suirle oberw. nbuebmens, aber alle gefonbert; Rron=

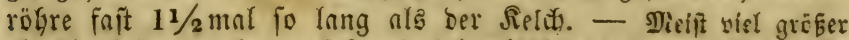
als bie beisen yorigen, fapt wie folg. blüht 14 Tage fuater. In

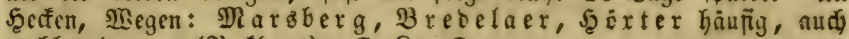

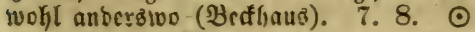

813. G. versicolor. Curt. (G. cannabina. 1ith.)

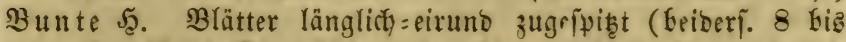
16 mal) geïgt; Rronröbre mehr alg Doptelt fo lang mie ber

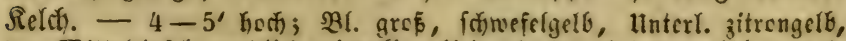

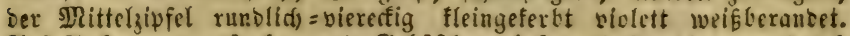

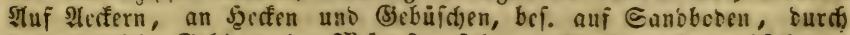

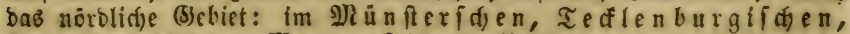

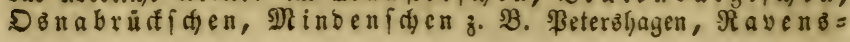




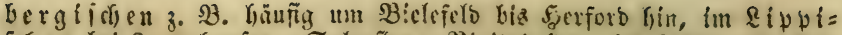

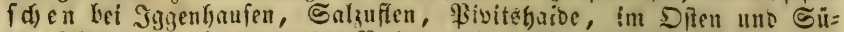

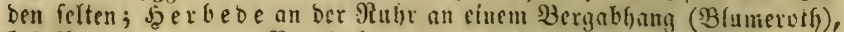

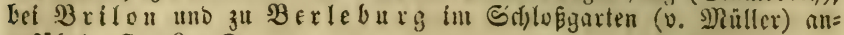
ветüfrt. $7-9$. $\odot$

\section{0) Galeobdolon. (5) (3) oloneffer.}

814. G. luteum. \$nr. (Galeopsis Galeobdolon. L.)

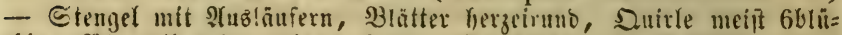

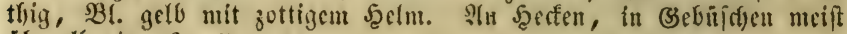
uberalt. $4-6.24$

\section{1) Ballota. Ballote.}

815. B. nigra. Є(t) waze 2 . Slätter eirumb; Relet) 5zäfnig, Bäfne begrannt. - Furmen: a foetida (B. foetida.

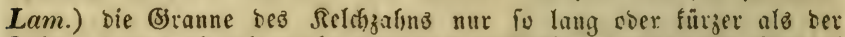

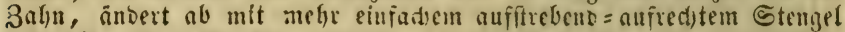
utno mii niebergeîtreftem weithin aiftigem Stengel, mit angebruiften Scaaren bcz હtengels und mit alffehenben (B. hirta. Hort. ber.),

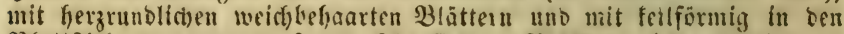
Blattpiel vergezognen folvie fdjärflichen $\mathfrak{B l a ̈ t t e u n ~ ( ~} \boldsymbol{B}$. foetida $\beta$

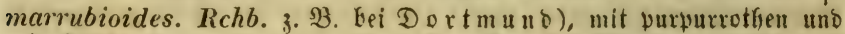

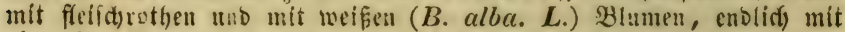
eben fo langer (Ssranne als der Sieldizalun uno mit fiñ

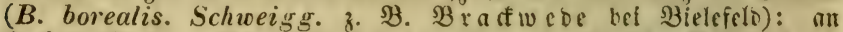

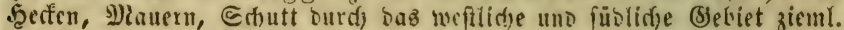

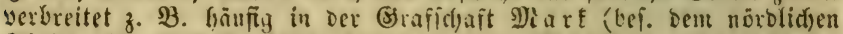

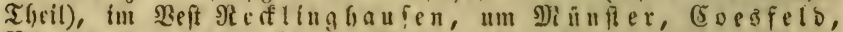
Bentheim u f. w. bis ins Ravenzbergifde und Rippif die;

$\beta$ ruderalis (B. rud. Fries) bie (G: anne bez Seldizafnz lïnger als

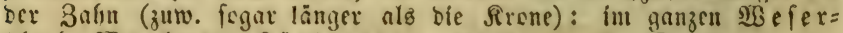

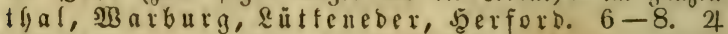

\section{2) Stachys. Bicft.}

- Suirre reidjblithig, Dectblätter fo lang ober balb fo lang alb ber Felds.

816. St. germanica. Deutficher 3. Bon bifiter

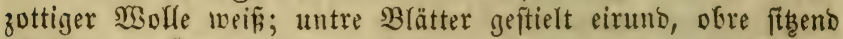

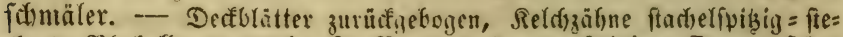

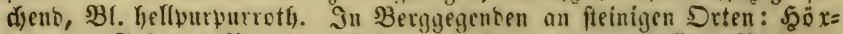

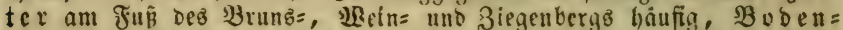
werber, Brafel bel Erfeln, bei ber Rluz reditz von Riefelu, Rob=

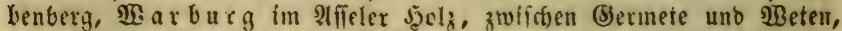

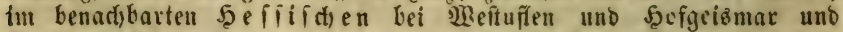

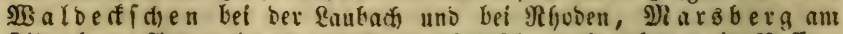

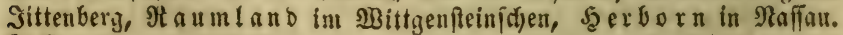
6. 7. 4 
817. St. alpina. 2tlpenzieft. Stengel raudffanrig,

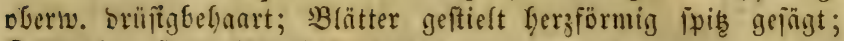

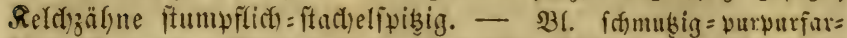

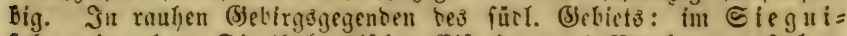

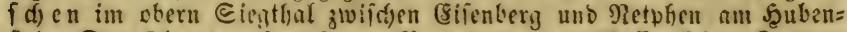

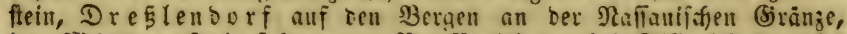
im sisttgenfteiniden z. B Berleburg bei Diffenidseio, im

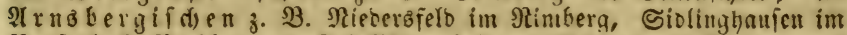

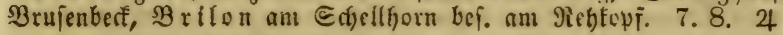

** Suirte meif 66lüthig, Decablätter Élein, Blume roth.

818. St. sylvatica. Nanfozieit. Steiffanarig, oberm.

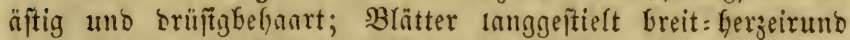
zugeipizt gefägt; S.tirle 66lütfig, Srone bowwelt fo lang alz

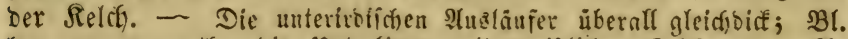

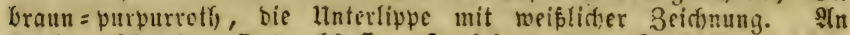

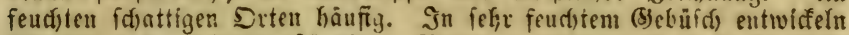
fiedf bie untera blüthenfitunbigen Blätter völlig, fo bá̉ fie lan=

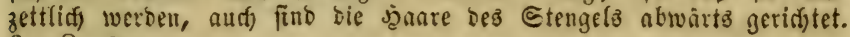
$6-8.24$

819. St. palustris. Sumpfóieft. Stengel fteifgan=

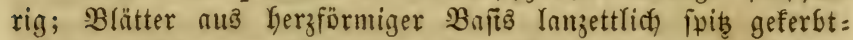
gejägt weicthanrig, bie untern furgeftielt, bie ofern fitzent; S.uirle 6-126lütgig, Rrone boppelt fo lang als ber Reld). -

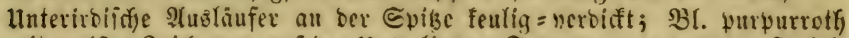
mit weifer Beidjuntng ouf Der unterlippe. Formen: $\alpha$ se getum Dufrre

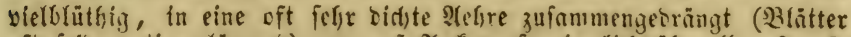
oft feibenartig=gläzzent) - auf \$ecferu fo ziemlid) überall; $\beta$ syl-

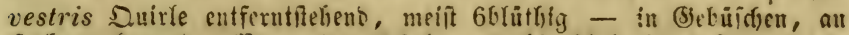

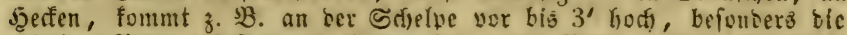
mittern 3 lätter foit yon bericlten Form uno Breite wie bei St. sylvatica, nur pläblicher gegen bie Evige zulaufent, aud) alle etwas ge=

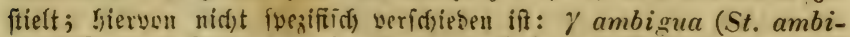
gua. Sm. - St. palustri -sylvatica. Schiede) Blätter immer ge=

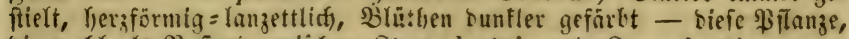
bie wohl als Baitaro ziwiid)en St. palustris uno St. sylvatica ange= felin werben barf, if beotadtet: Dortman o auf yeloern bor bem Difen= u. SBeftentfiere (Eufrian). Reflinghaufen auf Rartofiel=

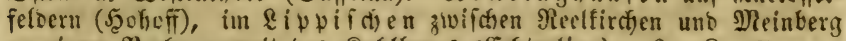

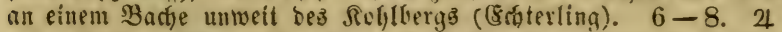

820. St. arvensis. If erzieft. Etengel iteifgarig, au (Brumbe aufítrebeno=äitig; Blätter geftielt bersförmig ge=

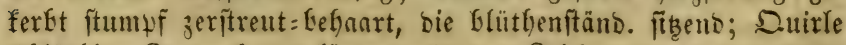
6Glüthig, Rrone faum länger ala ber Reld). - Bl. flein, blaß̧=

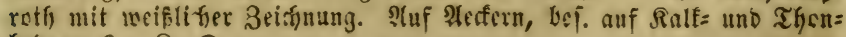
bobert. $6-8$. $\odot$ 


\section{*** Quirte 4-10blüthig, sglumentrone gelb.}

821. St. annua. Einjälyriger 3. Stengel äftig,

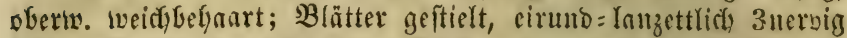
fabl; Duirle 4-6 blüt)ig, Reld) zottig, mit weidhbebnarten Stadjelfpiben, viel fürer als die firone. - 36. worislida mit

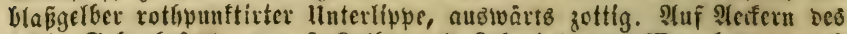

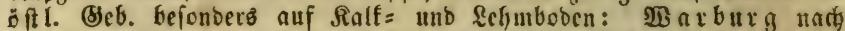
SBelba zu, B̧everungen häufig, B̧rafel am Robbenberg, bei (\&)=

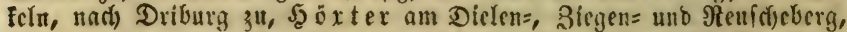

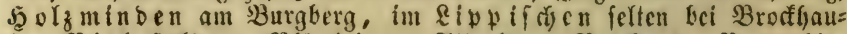
fell, $B$ ielefeld am Blömeberg, stitenberg, Bractweber Berge bin=

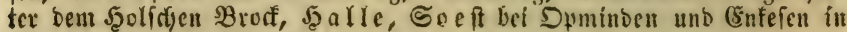

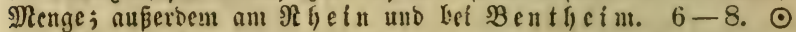

822. St. recta. (5i eraber 3. Stengel aufredit ober mufitrebeno, mebit ben Blätteru furzbeganat; Blätter gefitielt feilförmig =lanzettlich, nach worn geferfot=gefägt, bie untern ge= fitelt, bie obern blütbenftänbig eirumb zugefpizt gamzranbig; Duirle 6-106lüthig; Reldy raudyanrig mit fabler Stad)cl= paibze, ungefähr fo lang alB bie frone. - Blume gelblid) mit

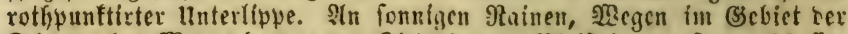

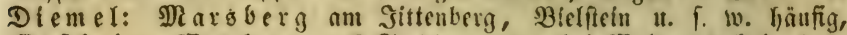

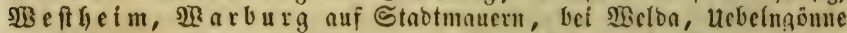

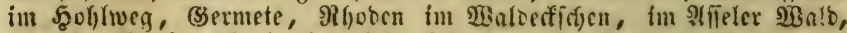
audif in $\mathfrak{B}$ efertigal aber iefor felten z. $\mathfrak{B}$. an ben slipwen bes

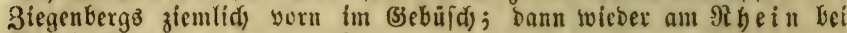

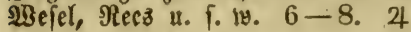

\section{3) Betonica. B̧et oni e.}

823. B. officinalis. (5) с meine $\mathfrak{B}$. Blätter aแล her $=$

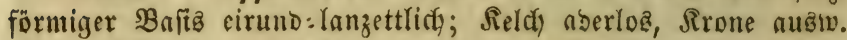

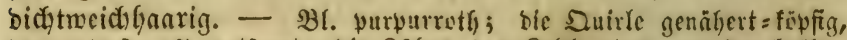

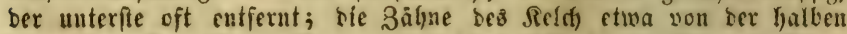
\&änge ber Rrontöhre. Formen: $\alpha$ hirta (B. hirta. Leyss.) Sten= gel furgbelyaart, Reld rauddhaariy; $\beta$ glabrata (B. officin. Spreng.) Stengel und Reldi) falfl; $\gamma$ stricta (B. stricta. Ait.) r,urh, felfr

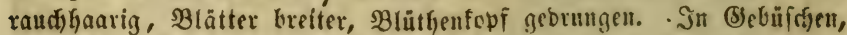

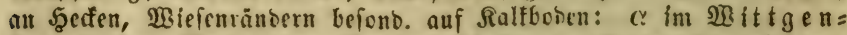

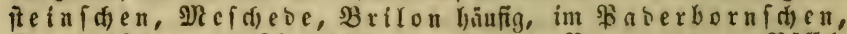
Roxvefide en und Ripuifden verbreitet, Byrmont am Büficl= berge, im Schauenburgifecen z. B. an bem Eurjoener Berge, \$eterobagen bei Raboe, SBinbreim, vor tem Forft, 3 felefeld nady Secepen hin, Wellenfotten, $\mathfrak{B}$ ún De am Doberg, im $\mathfrak{N}$ ün fic $x=$ idjen bei Stromberg, Deloe, Becfum, Deuenberge, in ber (S)raffichaft

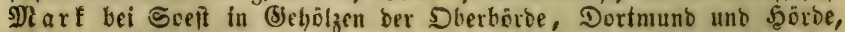

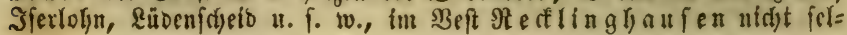




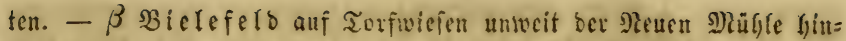

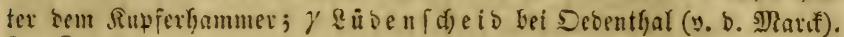
$6-8.24$

\section{4) Leonirus. ฉDivc}

824. L. Cardiaca. Die untern Blätter Vhanoförmig= 5tlfeilig cingejohnittent=gezäfynt, bie oberfte!t feilförmig ganzran=

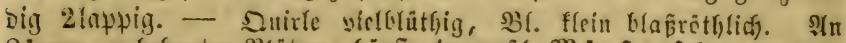

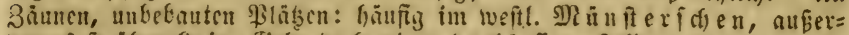

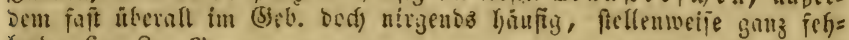
Ient. $6-8.4$

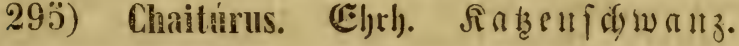

825. Ch. Marrubiastrum. Hid)b. (Leonurus Marr.

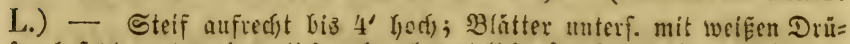

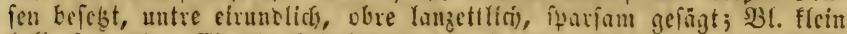

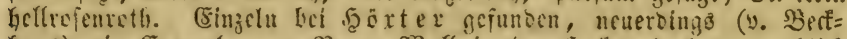

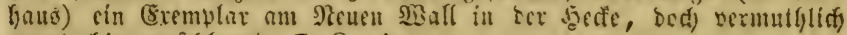
nur balifin verfoldeppt. 7 . 8. of

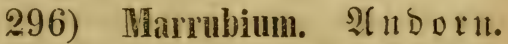

826. M. vulgare. (5) meiner 2. Etengel mebft bon eirunblichen Blätteru weiffflgig; Durrle zottig vielblüthig, faft fugelig; Reldzägne bon Der Mitte an forfl, an ser Stribe zu=

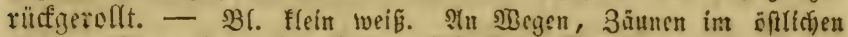

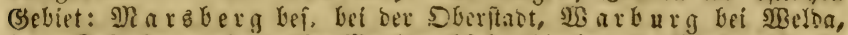

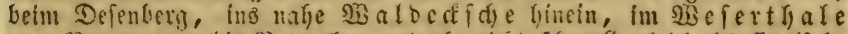

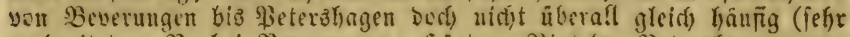

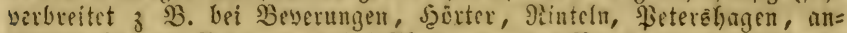

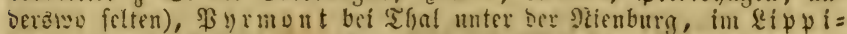

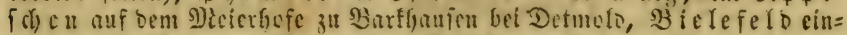
zein am Fufbady mo hinter sen Bleidien gejunden, Baberborn;

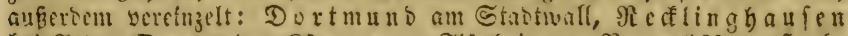

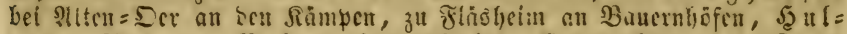

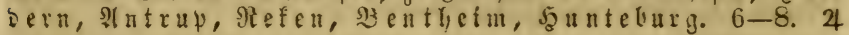

\section{7) Thymus. Thymian. Sattoel.}

82\%. Th. Serpyllum. Stengel nieberTiegent, Bläter

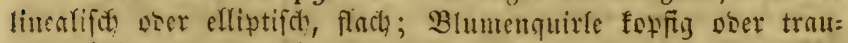

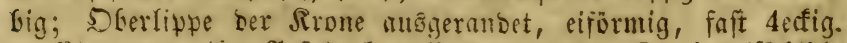

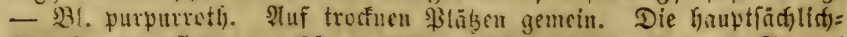

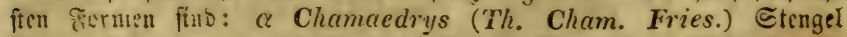

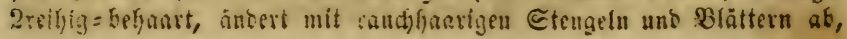




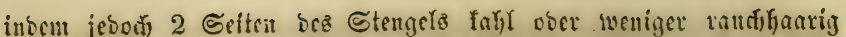
futo (Th. lanuginosus. Schk, zu Eoeffe!d nad) bem Dorf Ete= vebe hin yon Benninahaufen gefunoen), änocrt ferner ab nit grếfeten Blunen und helvortretenden Stuubgefäen (Th. sylvestris. Schreb. fefje verbreitet in bell Betiggegenoen), cincm ziculicy aufred)ten Stengel

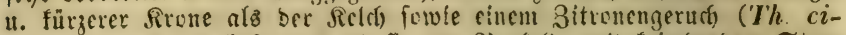

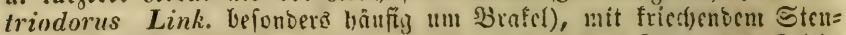

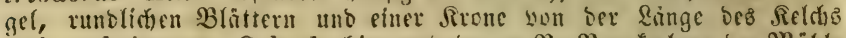

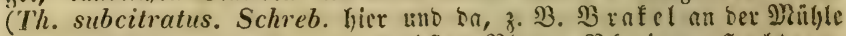

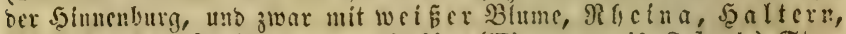
$\Re$ c ffliug $\mathfrak{a}$ a $\{\mathrm{fu}) ; \beta$ angustifolius (Th. an gustif. Schreb.) Sten=

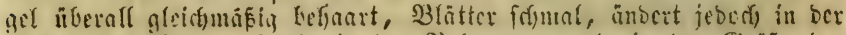

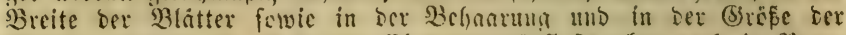

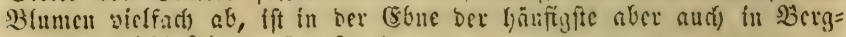
gegenten nictit feltert. $6-9$. t)

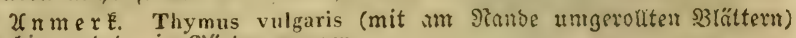
wiro hier uno ba in (siärten gejogen.

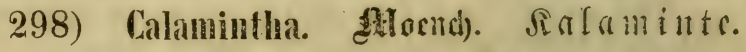

828. C. Acinos. Clairv. (Thymus Acinos. L.)

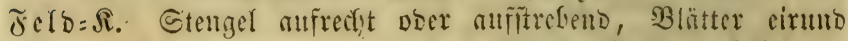

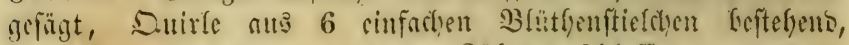

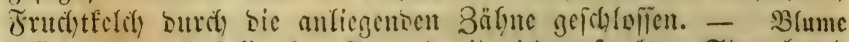

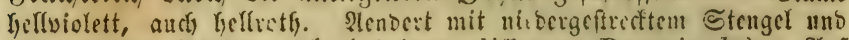
ganzranbigen Blâtterm ab (Acinos diffusus. Bnemningh.). PGuf

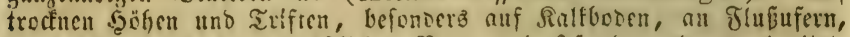

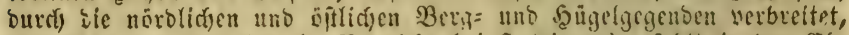

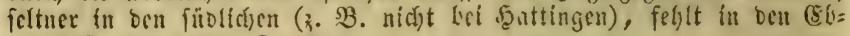
nen faft ganlz. $6-8$. $\odot$

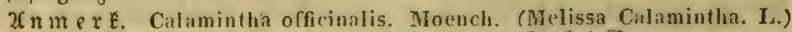
wird in (särten gezoger und vervilbert mitunter z. SB. bei SB e ver ungen; fie ift von vor. leid)t ourd) bie gatielffaltigen $3-5$ blüthigen $2 B$ !üthenffiele zu unterfideioen.

\section{9) Clinopodium. Siscidborftc.}

829. Cl. vulgare. Ctengel jottig, giantter cirmo,

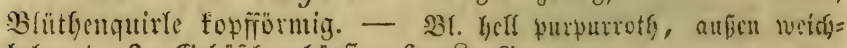

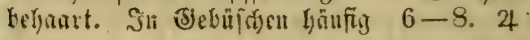

\section{0) Scutellaria. Secfmfiat.}

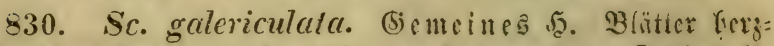

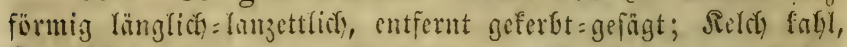

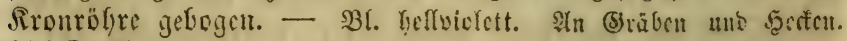
$6-8.24$

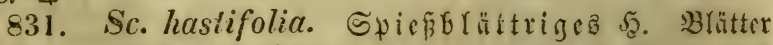

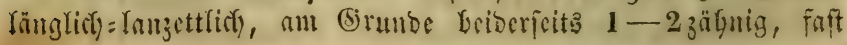




\section{Gymnospermia.}

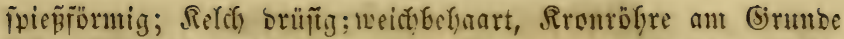

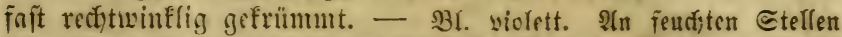

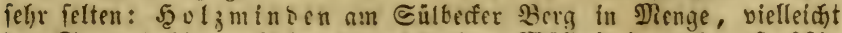

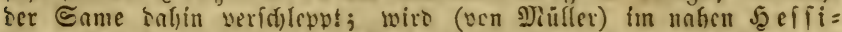

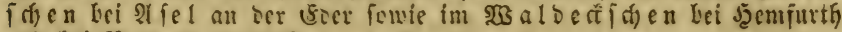
und bei 3asborf angegeten. 7. 8. 4

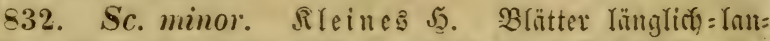

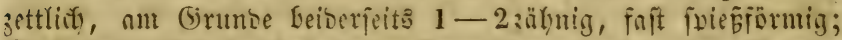

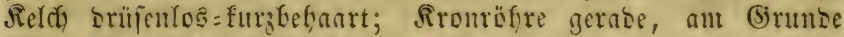

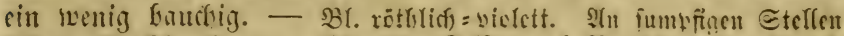
felten: Te of $\int_{\text {en }}$ bu

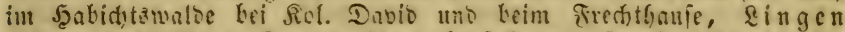

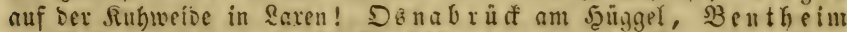

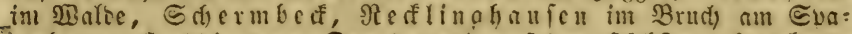

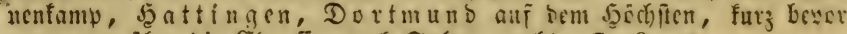

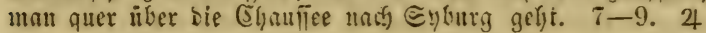

\section{1) Pruella. Frunelle.}

833. P. vulgaris. (j) nteine $\mathfrak{P r}$. Tie Büfute ser

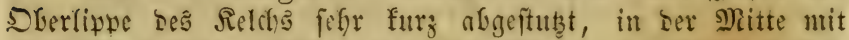

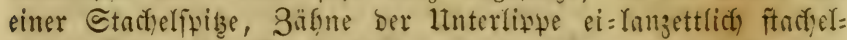

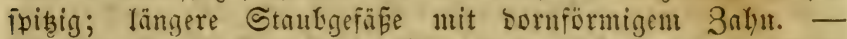

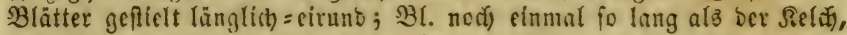
violett, felten weiß̄. SGarten: $\beta$ parviflora (Pr. parvifl. Poir.) Blumenfrone foum Yänger alb ber Relds, wcí̄ cier viclett; $\gamma$ pinnatifida (Pr. laciniata. $\mathbf{L}$.) afle $B$ lätter vier bie sbern fieterffal=

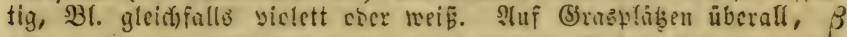

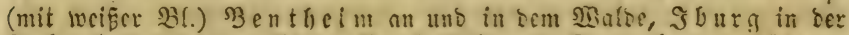
Frefyn (mit vieletter B1.), Bielefolo am Epurchberg, \&üben=

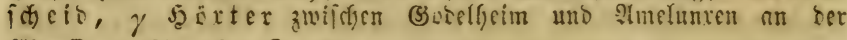
(5)aufiee reditz. $6-8.24$

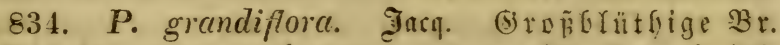

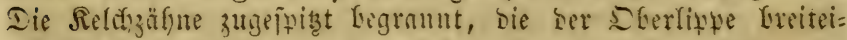

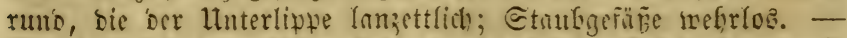

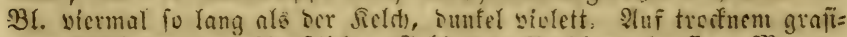

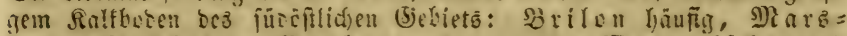

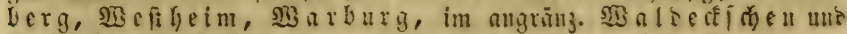
Sacfifif en. 7. 8. 4 


\section{Sromung Angiospermia.}

\section{2) Orobanche. Sommermulz.}

* Reldb 2blättrig, mit 1 Rel(b)blatte geftüţt.

835. O. rapum. Chuill. (O. major. L.) Эйben= ftengelige $\sigma$. Relch ungefübr bou ber Ränge ber Rrou= röbre; Rrone gloctig, worn an (Grunbe Gauchig, anf Dem Nü:

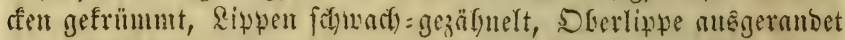
mit abfelgenden Rnpwen, ber mittlere Bipfel bet Unterlipwe Doppelt fo grof́ als bie feitenftämbigen; Staubfäben am (5rumbe ber Rrone eingefügt, unterw. ganz faljl, an Der Gpibe nebit

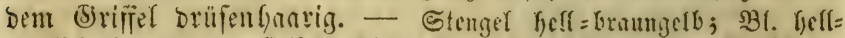

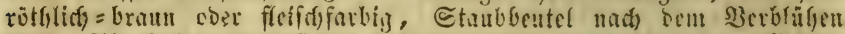

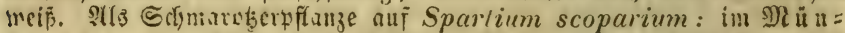

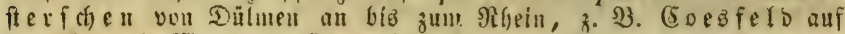

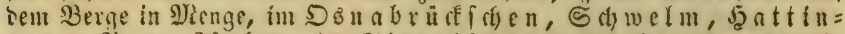
gen 3. 3. am Jimberg, im ङiegnif dien in ben Jjaubrigen manci)=

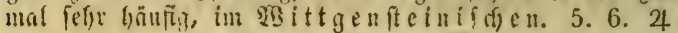

836. O. Epithymum. Ded. Ifismian= S. Rel(t)

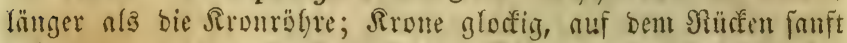

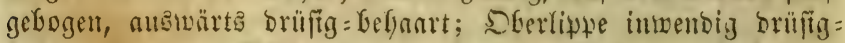

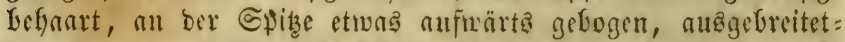
2rapyig, ber mittlere Bipfer ser Interl. Doppelt fo lang als bie feitenftändigen; Strubfäsen gleid) liber bem (Sirumbe ber Sroue eingefügt, unterwärţ̧ zeritrent = befanart, an Der Syibe neffit beut Sriffel brüfugbefaart. - Sl. gelblich, punduru= über=

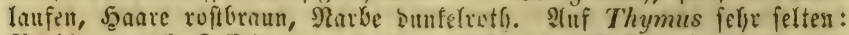

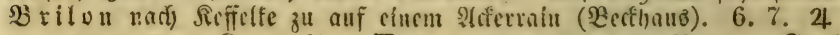

+837 . O. galii. Jubu. (0. caryophyllacea. Su.)

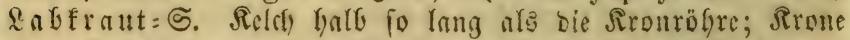

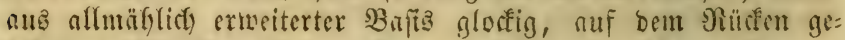
frummt; Soerfipte fecmartig mit borwärts gevidteten Rappen, Bipfel ber Interlipwe eirmb, fuft gleiff; Ctmufäden oberfyarf

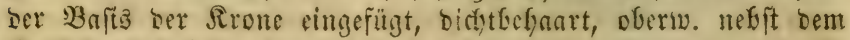

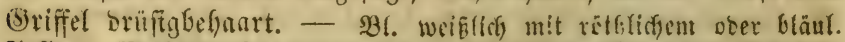

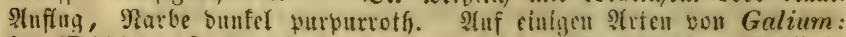

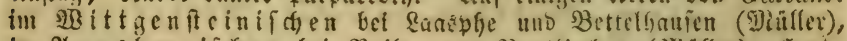

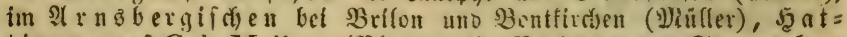

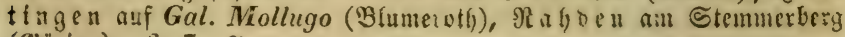
(B) öing). 6. 7. 4

838. O. rubens. Wallr. Röthlide S. Retry etwa

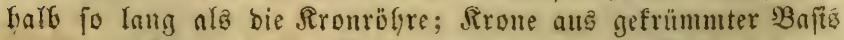
röfrig=gloftig, nuf Dem Rüden grate, an oer Spize tolutar: 


\section{Angiospermia.}

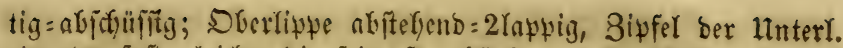
cirumb, fait gleici), bie feitenft. abftefyend; Gtaubfäben in ber

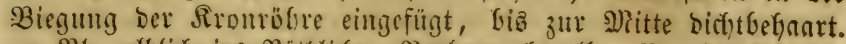

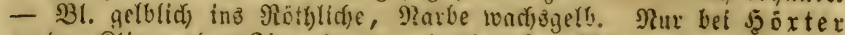

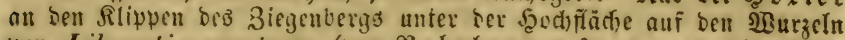

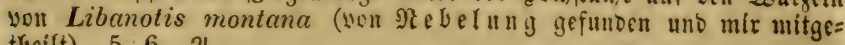
theift). 5.6. 4

† 839. O. minor. Suttor. Rleine S. Rel min=

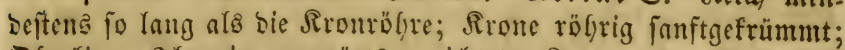
Dberlippe 2 lapplig torwäts geridstet, Rappen ber Unterlippe

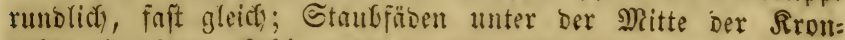
röfre eingefügt, fafl, unterw. Mit zerftreuten Săaren befegt.

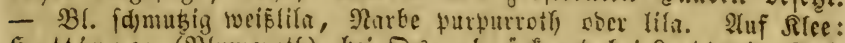

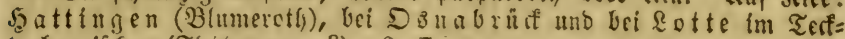

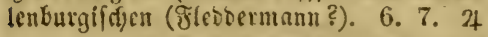

* Seld) Lblättrig, vingbum gefdilofien, mit 3 Decéblättern geftük̨t.

840. O. coerulea. Dill. B $\mathfrak{\text { Inue }} \odot$. Stengel cinfact, Reld) mit 5 lanzettlicfen fpiten Bälynen, Sipfel ber Srunfippen

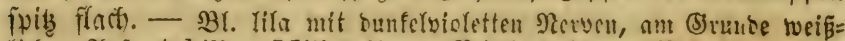

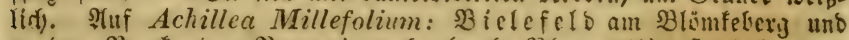

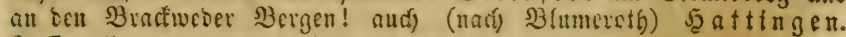
6. 7. 4

841. O. ramosa. 2leftige ๔. ๔tengel äftig, Reld

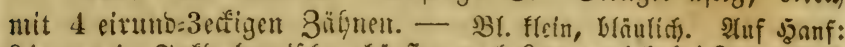

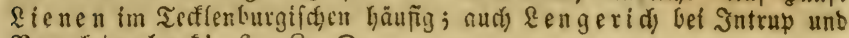
Broditerbert! 6-8.

\section{3) Lathraea. Sduppentuxz.}

842. L. Squamaria. Stengel cinfach, mur mit G(t)uऐ: pen Gefeght; $B$ lumen in biđfter einfeitâtwenbiger niffenber Tranbe;

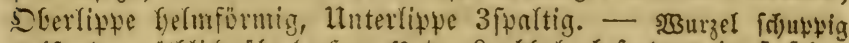

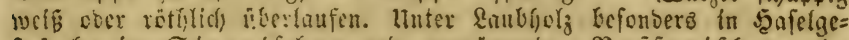

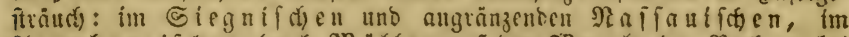

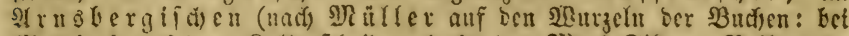

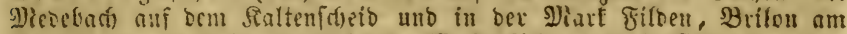

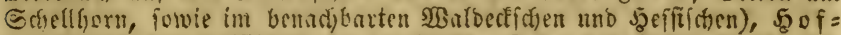

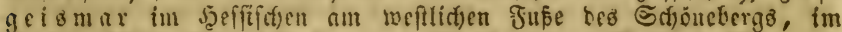

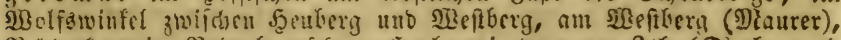

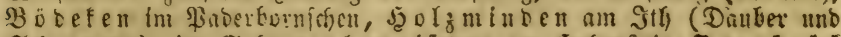

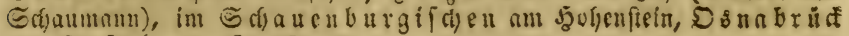

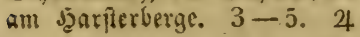

\section{4) Euphrasia. $\mathfrak{A} \Perp \operatorname{gen}$ tr oft.}

* 3ipfel ber Untertippe tiefauzgeranbet.

843. F. officinalis. (3) emeiner $\mathfrak{A}$. Stengel arftetento= 


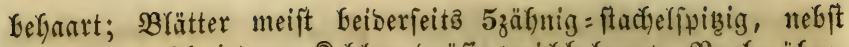

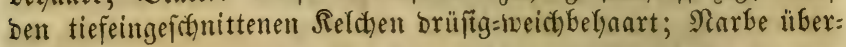
Yangend. - $B$ 1. weíß mit violetten \&inien, bie Unterlippe mit einem

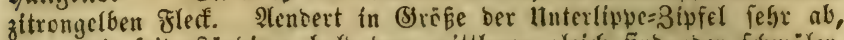
inbem bie feitcnftänbigen balo bem mittleren gleidf) find ober fémäler, ober zu 2 abgeftunpften 3äfnen zufammenfd)rumpfen; bie Form mit grofen Blumen uns faft gleidsen Sipfeln ber unterlippe ift $\boldsymbol{E}$. pretensis Rchbch. (E. Rostkoviana. Hayne). 2luf (Brabitrifien, f(d)at= tigen Drten, SBsicjen itberall. $6-9$. $\odot$

844. E. nemorosa. Wers. Sgain=?2. Stengel ange= brüctt=meichbefaurt; Blätter tiefgefägt mit hanrfpizigen Gäge= zäfnen; Reld wentiger tiefeingeft) nitten faft fabl; Narbe niffend. - Bierlicher und tleiner ala vorige, s3l. Flemer und violetter fonit ebenfo. Dic Form mit ferf fleinen $B$ lumen ift E. micrantha. Rchb. birienige mit grö́geren lilafarbigen $\mathfrak{B}_{1}$. if $E$. coerulea. Tsch. In Befjölzen, bie Form micrantha auf magrem Eandboben, bie Form

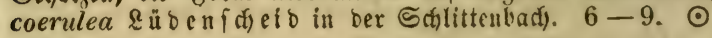

** Odontites. Dub. Bipfel ber Unterlippe ganz ober nur feidjt ausgeranbet.

845. E. Odontites. $\mathfrak{R}$ ot $\mathfrak{f} \mathfrak{e x}$ 2l. $\mathfrak{B}$ lätter Yanzett=

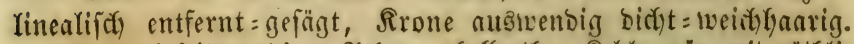

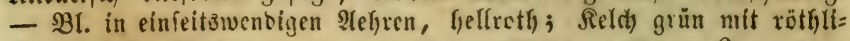

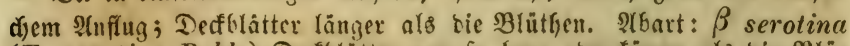

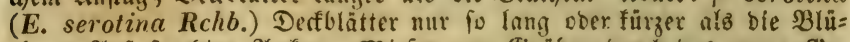

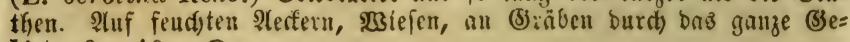
bict. $6-10$. $\odot$

\section{5) Rhinanthus. Sgafuenfant.}

846. R. minor. (Ehrl). (Rl. Crista galli $\%$. L.)

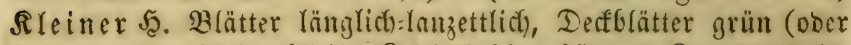
Graum, nict)t Glägelblick), Selch faftl mefft ben Sapfeln freis: runo, Sberlippe ber Rrone mit 2 furzen 3äfmen. - Bl. flein

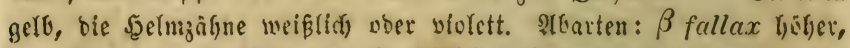
Der Stengel mit fdjwarien Etridjerden teftreut; $\gamma$ angustifolius

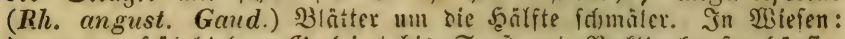

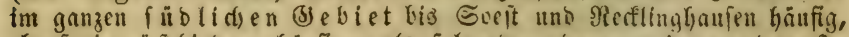

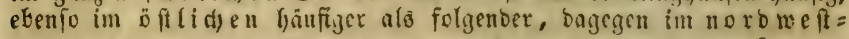

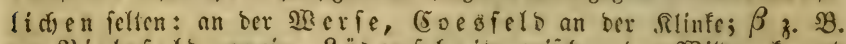

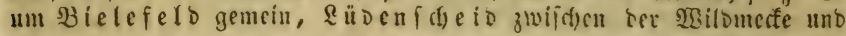
her Diarf, fefhlt an ser פigefer; $\gamma$ häufiy auf Berglvieien bei Brflon,

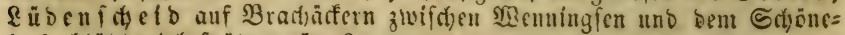

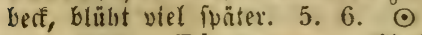

847. Rh. major. Éhrl. (Rh. Crista galli. f. L.)

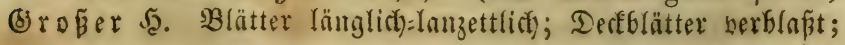




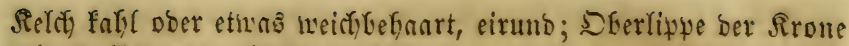
mit 2 längeren cirumen Bäfnen. - $\mathfrak{B}$. Soppelt fo gré̃ wie

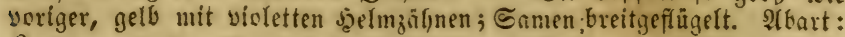

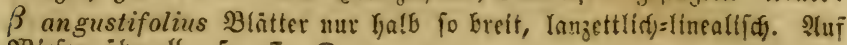

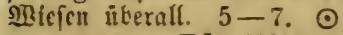

848. Rh. Alectorólophus. Woll. (Rh. Crista galli. $\%$ L. - Rh. hirsutus. Eam.) Behanrter $\mathfrak{g}_{\text {. Defflats }}$

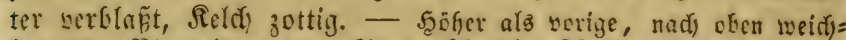

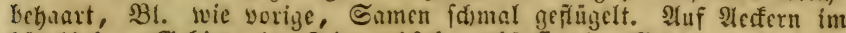

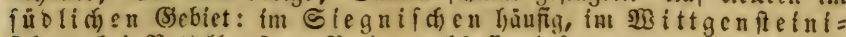

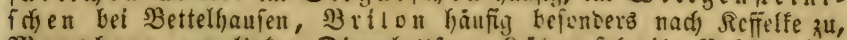

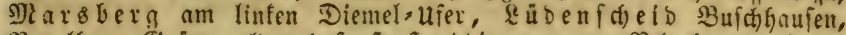

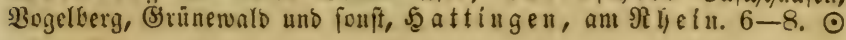

\section{6) Nelampyrum. Wad $\mathfrak{d e l}$ tweizen.}

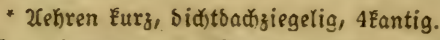

849. M. cristatum. $\mathfrak{R}$ a muartiger $\mathfrak{W}$. Deffelätter Gerzförmig, fammartig= gezähnt, zujammengefकlagen, mit ber

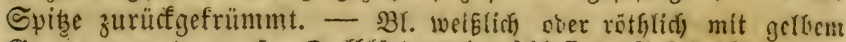

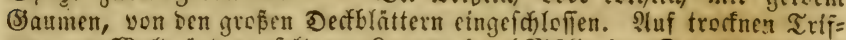

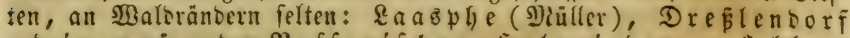

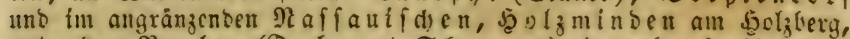

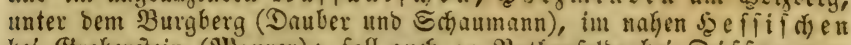

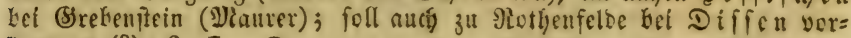
foumen (?). 6. 7. $\odot$

$$
\text { ** Zehren locker Éegelig. }
$$

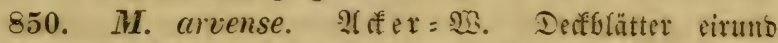

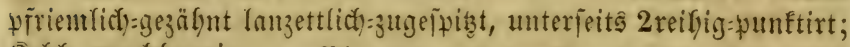

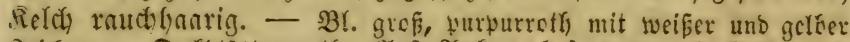

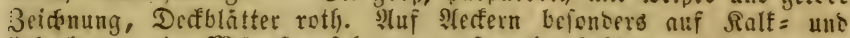

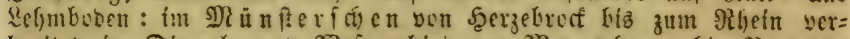

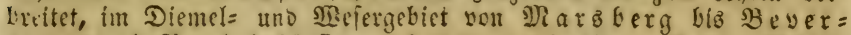

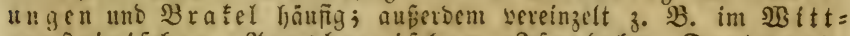
aenfeinifden, Strnebergifden, Sferlokn, Dortmunb,

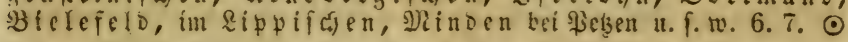
**** 2Chren lockerer, einfeitbmentig.

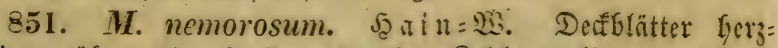
fümig gezäfnt, bie oberften fiflopfig; Seldye wollig, etra balb io lang als bie firome. - \$bl. goltygls mit brauner giöfre, bie

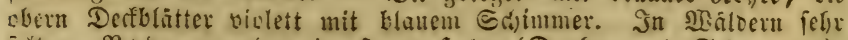
ielten: Bobentuerder im Jeger Şulge (Daúer uno Sd)aumann). 7. 8 . $\odot$

852. M. pratense. (5) emeiner 23 . Defforätter Ian=

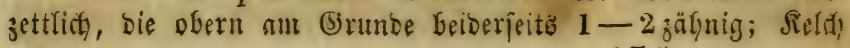
$15 *$ 


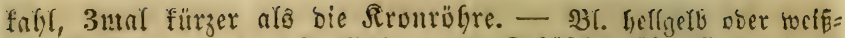

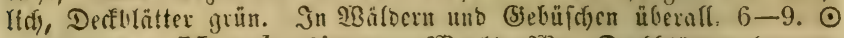

853. M. sylvaticum. NSalb=233. Derfblätter lanzett= lide) gamzranbig; Reled fahl, fo lang als bie gefrimmte Rron= röhre. - Bl. flcin, goldoclf, Derébläter grün. Jn hoben Bebirgz= wăloern: Briflon an Drübel unb auf ben übrigen Ralfbergen hä̈=

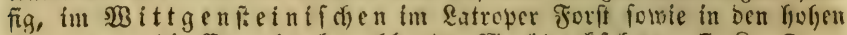

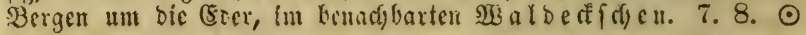

\section{7) Pedicularis. Räufefrat.}

854. P. palustris. $\mathcal{S}_{u} u \neq f=\Omega$. Stengel fteifoutfrectit, yom (brumbe an äftig; Reld) 2lappig, Rappen cirgefditten= gezäfnt fraus; Sberlippe der Rrone beiberfeits gezülnuelt. -

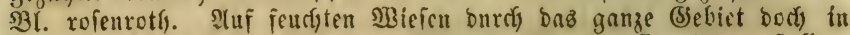
ben escenen bänfiger als in ben Bergegenden, wo fie oft mut ftellen= weife vorfommt (fiflt a. B. bei Satingen). $5-7.24$

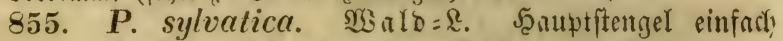

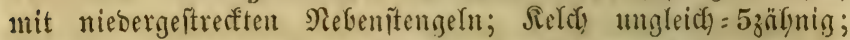

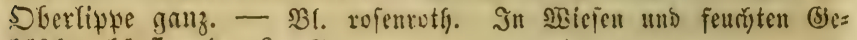

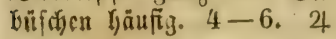

\section{8) Scrophularia. $\mathfrak{B} \mathfrak{i} u \Perp \mathfrak{4} 4 \mathfrak{z}$.}

* slumen in enoftänoigen ærauben.

856. Scr. nodosa. Sindtige Br. B̧ätter bopwelt=

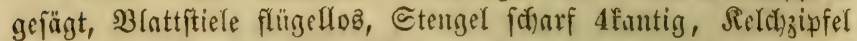

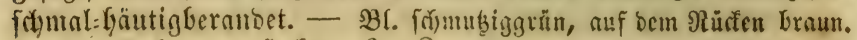

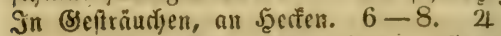

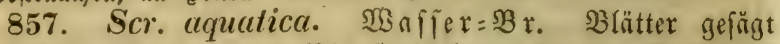
Docr geferbt, Stengel und $\mathfrak{B}$ lattítiele breitgeflitgelt, Selchzity fel

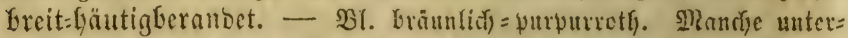
fdycibent ickt: $\alpha$ aynatica L. (Scr. Balbisii. Hornem.) founut bei uns ntifyt vor; $\beta$ Scr. Ehrharti. Stev. 33!ätter ciförmiy=längltith ober

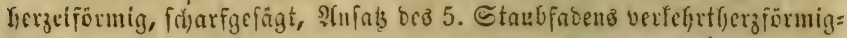
2ipaltig mit abftefenden 3ipfe!n; $\gamma$ Scr. Neesii. Wirtg. untre

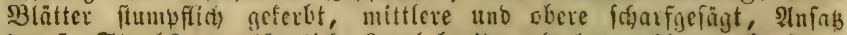

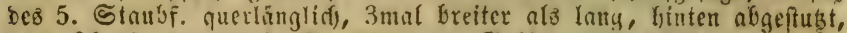

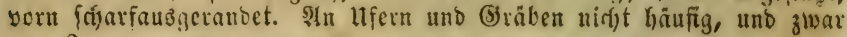
sur $\beta ; \gamma$ ant Rieberrhein bei Däñeloorf. $6-8.24$

** Blumen blattwinkeyftändig, Blüthenffiele mebrblüthig.

858. Scr. vernalis. Frühling $=\mathfrak{B}$ r. Stenget uns Blattitiele zottig, Blätter weid) bebanrt. - Br. grünl(d)gelv. In

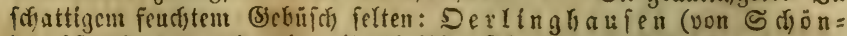

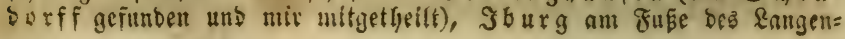




\section{Angiospermia.}

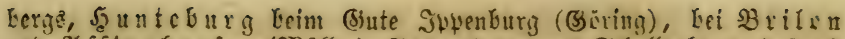

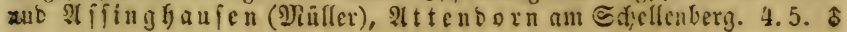

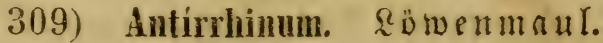

859. A. Orontium. Feld $=$ ?. SBlätter Innzettliđ, Seldi:

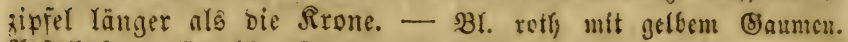

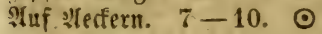

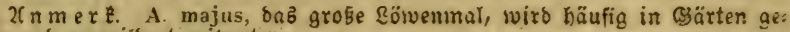
jogen und vervilbert mitunter.

\section{0) Linaria. Reinfraut.}

- Etengel nieberliegeno, fabenförmig, rantento.

560. L. Cymbalaria. Alll. (Antirrhinum Cymbal.

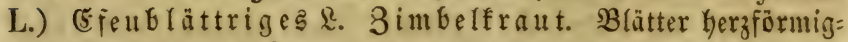
runolid) 5lappig falgl. - Bl. hellviclett mit gelten scäăern unb

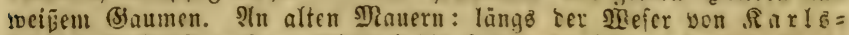

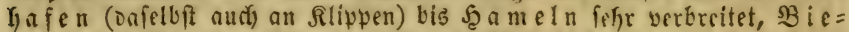

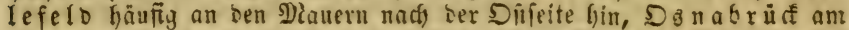

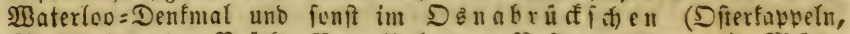

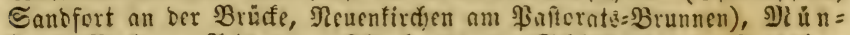

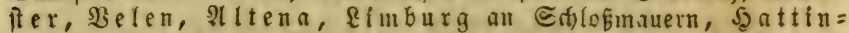
nen am Nuhtufer im Eteinfamy, auch auf einer Diauer in Şerbebe. $5-10.4$

861. L. Elatine. @till. (Antirrh. Elat. L.) Ric=

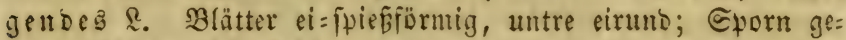

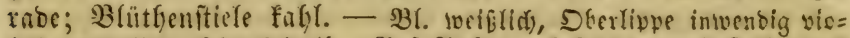

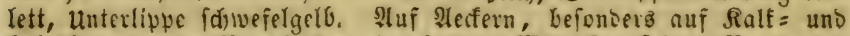

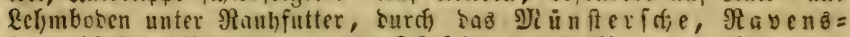
bergffese (Bielcfeld an ter Eübicite ber fialfterge, auth an bert

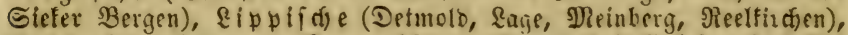

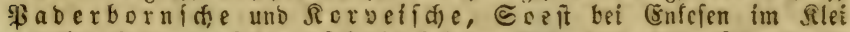

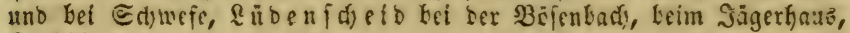
Jattingen. $7-9$. $\odot$

862. L. spuria. Atill. (Antirrh. spurium. L.) $\mathfrak{U} n=$

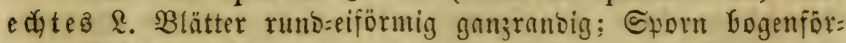

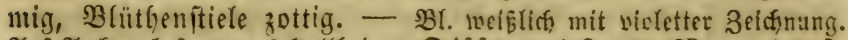
T्tuf Recfern befond. auf Raltboben: Diffen unb \&a a , 2Rarenborf, Etrumberg, Dorterg, Soattingen folten, Rienberge,

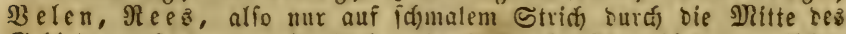

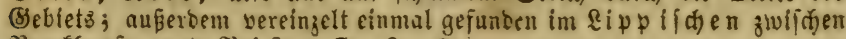

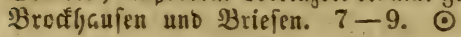

** Stengel aufreat: ; Blumen einzeln, winkelitänsig.

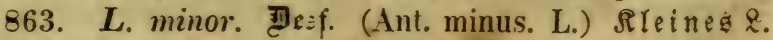
Drüfigbef̧art, Blätter lamzettlich fitumpf. - Bl. blapvislett, 


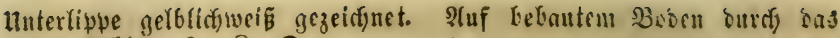
ganje Gebiet. $6-8 . \odot$

*** Stengel aufred)t mit endfänbigen Trauben.

864. L. Arvensis. 刃ुfsf. (Ant. arvense L.) श(f $\mathrm{er}=$ ฉ. Itutre $\mathfrak{B l a ̈ t t e r ~ z u ~ 4 ; ~ T r a u b e n ~ f o p f f o ̈ m i g , ~ G e r m a c t ) ~ v e r l a ̈ n = ~}$ gert; Relch und $\mathfrak{B}$ lüthenftiele brüftgbefanat; Samen geflïgelt glatt. - Bf. flein, hellblau, am (Saumen nekig. \$luf troffnen

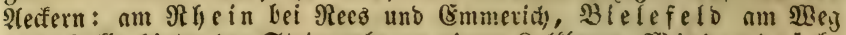

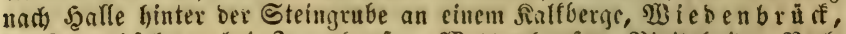

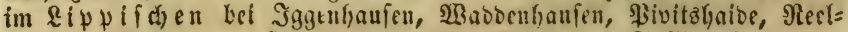

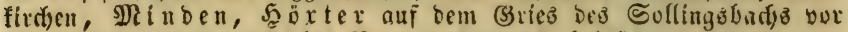

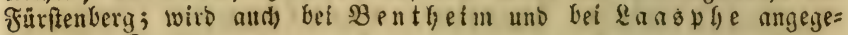
ber. 6-8. $\odot-\mathfrak{x} n \operatorname{mer} \quad$ L. simplex mit Enotio= rauhem Samen

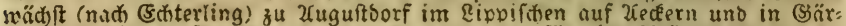
ten, Dod bält fie $B$ e dé a u b, ber fie Dort fah, für pine 2roänderung oer $L$. arvensis mit gelben. Blument.

865. L. vulgaris, Alill. (Ant. Linaria. L.) (5) $e=$

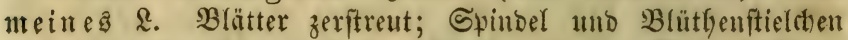
brüftgbelaart; Samen flact) geflügelt, in Der Dritte höferig= raul). - SBl. gelb mit bunflerem (Saumen. Stbart: $\beta$ Peloria mit gleidymäEiger 5 fpaltiger Blumenfrone. $6-9.24$

\section{1) Digitalis fingerfut.}

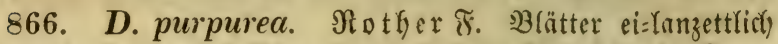
geferbt, unterfeits nebit Stengel uno $\mathfrak{B}$ lüthenfitielen filjig; Rrune

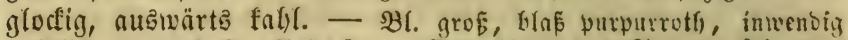

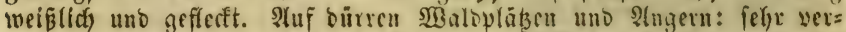

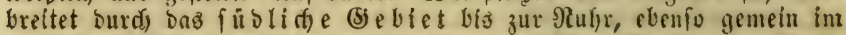

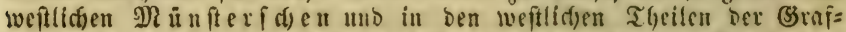

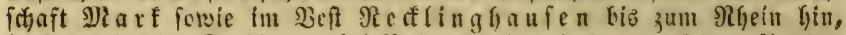
fonit vereinzelt: Driburg bei Bute, Jjo $t_{3}$ min be n auf tem Bogler,

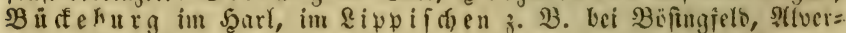
bifien, Sternterg, Rippta ad ju Rappel finter Eufe nafie beim Sthulzentofe แ. \%. 12. $6-8$. के

867. D. grandiflóra. fam. (D. ambigua. Nturr.)

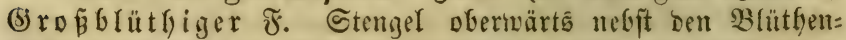
ftielen brüjẗgbegnart, $\mathfrak{B}$ (ätter läแglict)=lnแzettlict) gefägt wimperißz

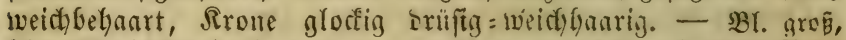

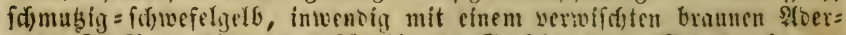
net. Su Bergwäloern bez fübliden (b) biets un 2 interberg,

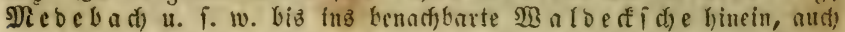
einzeln in benad)barten 9? af

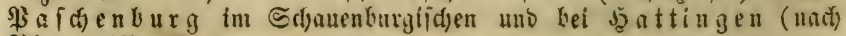
B(umeroth). 6. 7. 2

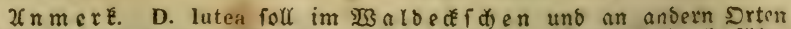
vorkommen, jebod) ift bie $23 a b r h e i t$ zu bezroeifeln. - Sie $i$ di enb a d) führt 
in feiner Flora excurs. Sub 2577 eine D. fulva Lindl. auf, alb an ben $\$ 2$ er: gen bei "Eilge (

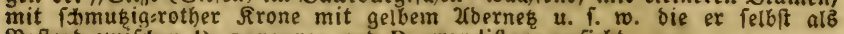
$\$$ Baftaro zroiften D. purpurea uno D. grandiflora anfiebt.

\section{2) Verbéna. Ėifenfiant.}

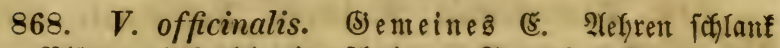

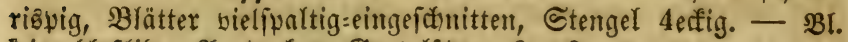

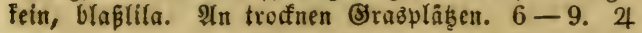

\section{3) Limosella. Sumpffraut.}

869. L. aquatica. - Etengellofe \$ranze mit fẩblichen 2⿰纟勺

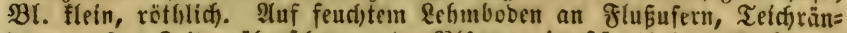

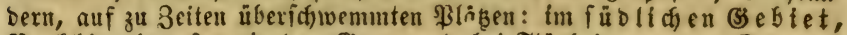

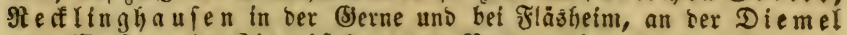

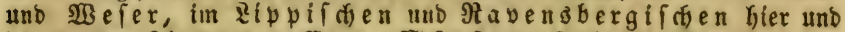

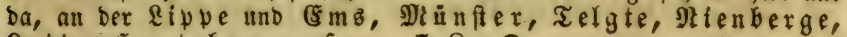
Eotte, 5ูuteburg u. f. w. 7. 8. ค

\section{Jünfolite slatie. Tetradynamia.}

\section{Sorbmung Siliculosa.}

* Sđjötđen nubartig und niät aufipringento.

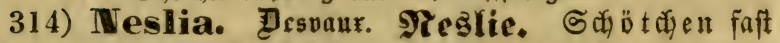
fugelig, mit bem (Brififel befrönt, Ifächerig, 1 jamig.

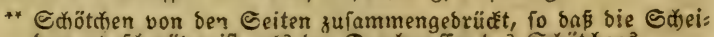

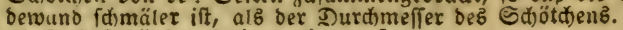

$\dagger$ Daz ভdóttchen fpringt niçtt auf.

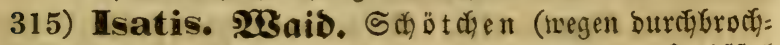

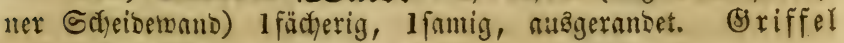
nicht berworiftehento.

316) Biscutella. Brillenfidote. S(ät then flact), ant (Brutbe unb an ber Spize ausigetanbet (briflemför= mig) 2 fäc(f)rig, Fätber 1 famtig.

317) Senebiena. Poirt. Srähenfur. Sd ôt: d)en nierenförmig. Fä d) er 1 famig. 
It Sdiötđert auffpringeno.

a. STappen Eahnförmig, auf bem গüüent gefügelt.

318) Tepidium. Secfie. S(löt thent eiförmig,

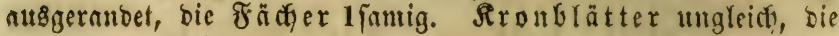
2 äuß̄eren grōß̄er.

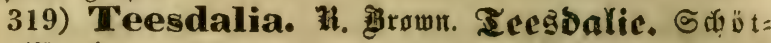
đen eiförmig, augigeranbet mit nicht ferborftebendem (5)iffer. Fä dher 2 famig. Rronblätter ungleid, bie 2 äußeren grö= Ber. Strubgefä ze geflügelt.

320) Thlaspi. Sofenniggfraut. Stritcten ei=

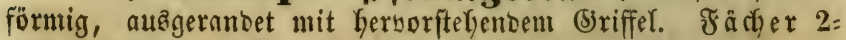
und mebriamig. Seronblätter gleich.

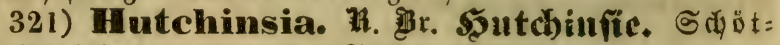

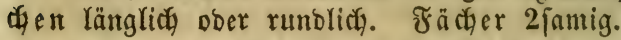

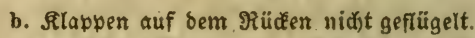

322) Capsella. Wentenat. Sgirtentafiche. Sণ öt iden berfehrt=3erfig, aubigerandet mit bervoritebendem Briffer. ซä duer bielfamig.

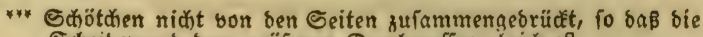
Scheibewano bem größeren Durd)meffer gleid) ift.

$\dagger$ Sdiötchen an ber Epiz̨e außggerantot, sriffel hervoriteheno.

323) Cochlearia. Röfrelérant. Gdut then

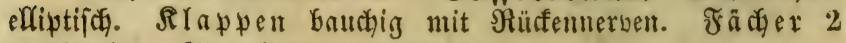
-4 famig. Staubfäben zafinloz.

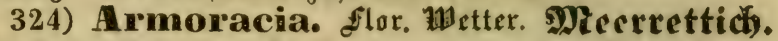

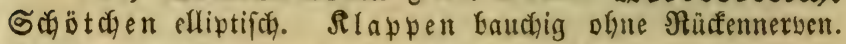

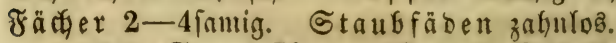

325) Camelina. Crant3. Erinbotter. Sdjöt=

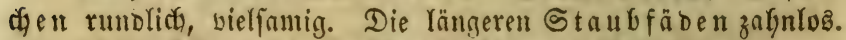

326) Ayssum. Stcinfraut. Sd otchen runo=

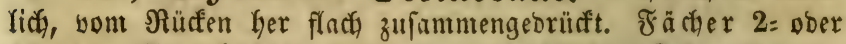
4 famig. Staubfäden nit einem flügelartigen $3 a \mathfrak{h n}$ ober ant (brunbe mit einem Sporn.

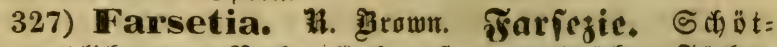

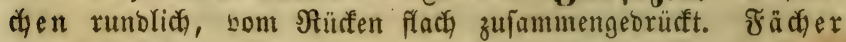
6= Doer mefriamig. Staubfä oen mit flügelartigem 2(nfang, bie fleineren mit einem 3 ahy.

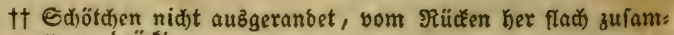
mengebrüutt.

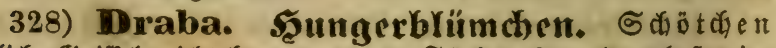

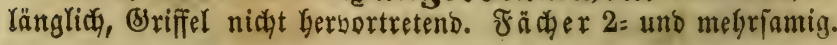




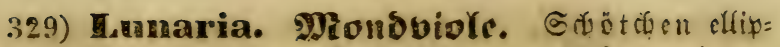

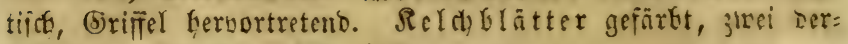
jelfert ant (Strutbe facfförmig.

\section{Sronung Siliquosa.}

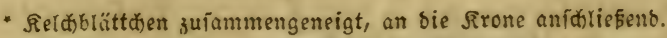

$\dagger$ 巨तt)ote ber عänge nad) 2 fäd)erig aufipringeno.

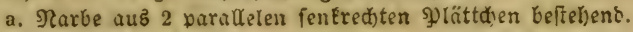

230) Hesperis. Mtachtviole. Plättâten brr

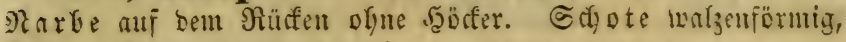
Slappen Gerwortretent $=1$ iterbig.

b. Narbe ftumpf, ober aubgeranbet, ober 2lappig.

aa. Rlappen ber linenli iđjen Sdiote Inervig ober aberig, Samen in iebem ₹rnde Ireibig.

331) Cheiranthus. Ract. Sdyote burch bie 2

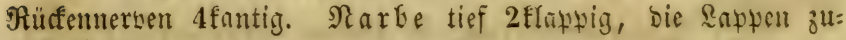
rüfơgebogen.

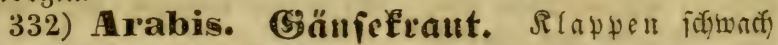
Inervig ober aberig. Narbe ftumbf.

333) Tarbarea. 3. Srowr. 23arbenbedrich. Schote ftielrunb, Rlappen gemölot mit Gersortretenoem Rers. Rarbe ftuแpf ober auติgerandet. (Bhlumen gelb).

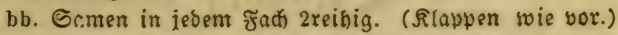

334) Turritis. Thurmfraut. Rlappen etwaต

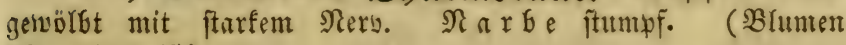

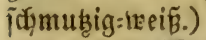

335) Erysimam. \$cderich. R R appen burd

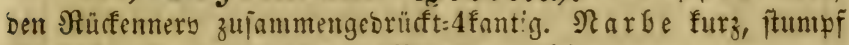
ober f(f)twech ausgeranbet. (BRlumten gelb.)

336) Brassica. Rob!. Rlał pen rinnenförmig, Inersig unb nberig. Narbe ausgernmbet.

cc. Rlappen ohne Nerven und roern.

337) Dentaria. Babnwurg. S(t) o te Innzettlich: linealifach. Samen Ireifig. Narbe ftumpf ausgefdnittert.

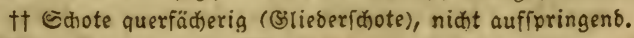

338) Raphanus. Retrich). Stị ote resernrtig, bei jebent (5)liebe eingefdnürt.

** Ћeldbblättđen abfteheno.

t† Eamen Ireihig.

339) Erucastrum. Meidb. Rempe. Sdite linealifa, in einen fegelförmigen Echnabel berlangert. Rlap: 


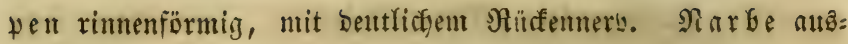
germbet.

340) Sisymbrium. Faute. S(y) o te walzenför=

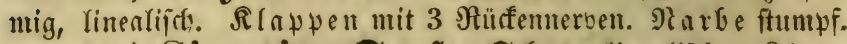

341) Sinapis. Senf. Sdjote Yinealifd. RIap:

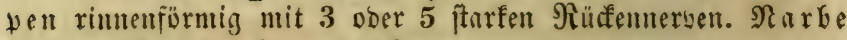
fopfig. (G) riffel Greitgebrüft.

342) Cardamine. Sdraumfraut. Sdiote

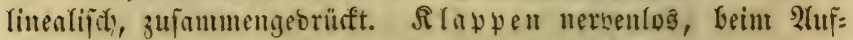
jpringen fict zuruiffrolfent. Narbe foyfig.

†† Samen 2reikig.

343) Diplotaxis. Desand. Dopperiame:

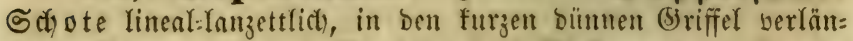
gert. Rlappen rimnenförmig mit 1 Rusfennerven. Rarbe auzgernnoet.

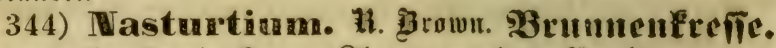
Sdy ote walzenförnig furz. Rlappent rimuenförmig, nerven: Ioz. Rarbe faft 2lappig.

\section{Soronung Siliculosa.}

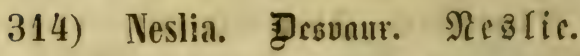

870. N. paniculata. Desv. (Myagrum panicula-

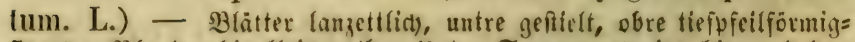

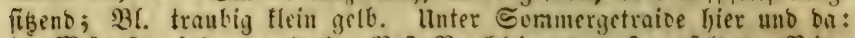

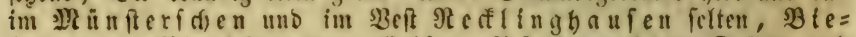

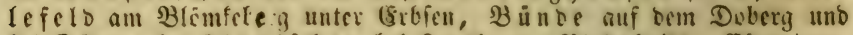
bei Dînne, im \& ippif

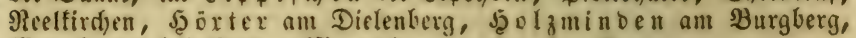

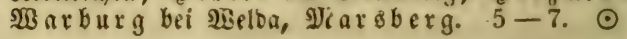

\section{5) Isátis. Maid.}

† 871. I. tinctoria. Färberwaib. Untre Blätter ge=

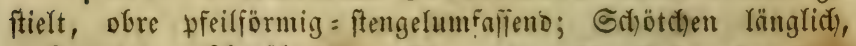

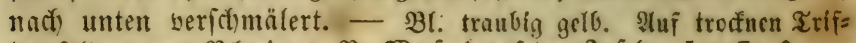

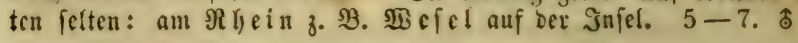

316) Biscutella. Brillenidote.

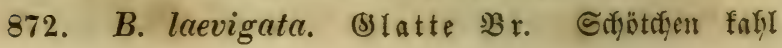


uno glatt; untre Blätter in set Blattitiel serjđmälert, ofre

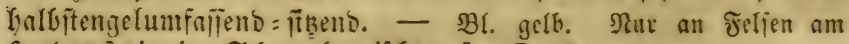

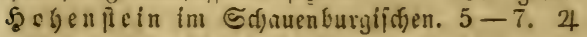

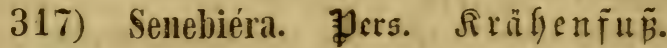

873. S. Corónopus. Poir. (Cochlearia Coron. L.)

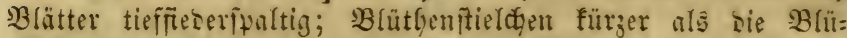

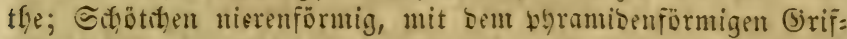

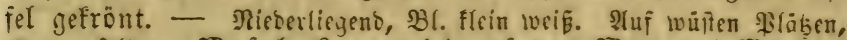

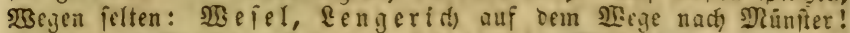

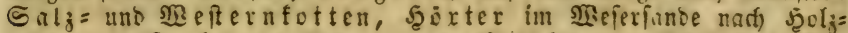

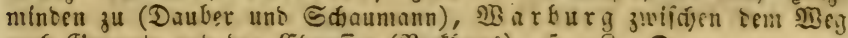

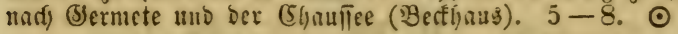

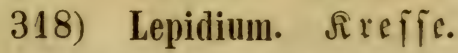

\section{* Edötđden beutlida) auzgerandet.}

† 874. L. Draba. Etengelumfaliende Rr. Hntre

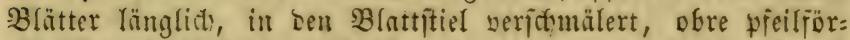

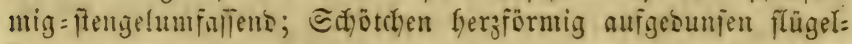

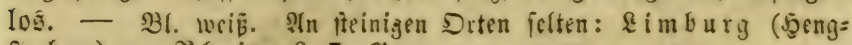
fienberg), am ภำ ใน. 6. 7. 4

875. L. campestre. 7. Fु. (Thlaspi camp. L.)

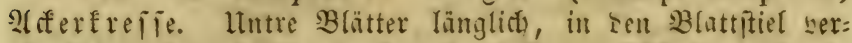

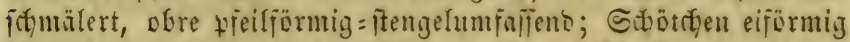
id)uptig = punftirt, von Der Nitte an breitgerlügelt. - SBlume

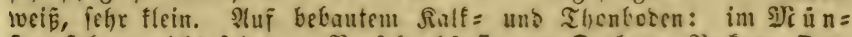

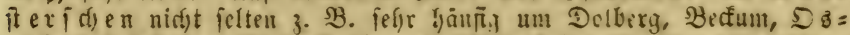
nabrü ff bei ber Bertruiernlerger jachle (cinmal mit ganjtansigen

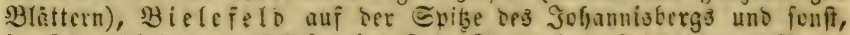

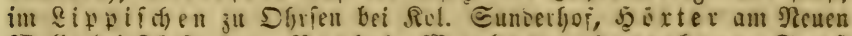

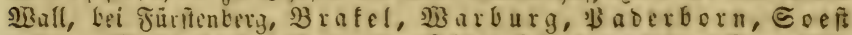

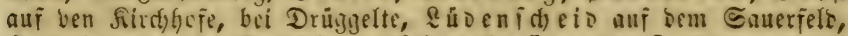

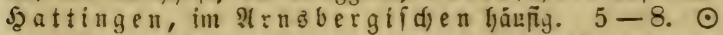

876. L. sativum. (5) artenfrefie. Hntre Blätter

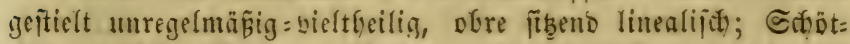
d)en rumblid):eiförmig geflügelt, an bie @pinoel angerrütet. -

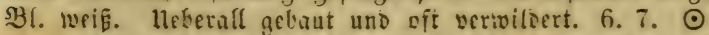

877. L. miderale. Stinffreife. Untre Blätter ge=

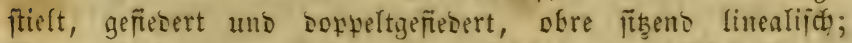

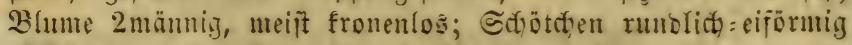

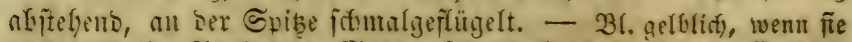

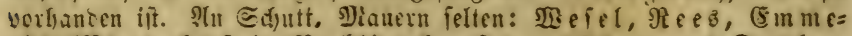
rich (Benninghaujen), Re fflingha ufen an Equtt= uno Dunghau= 


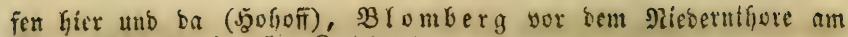

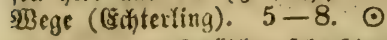

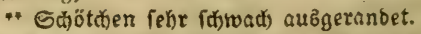

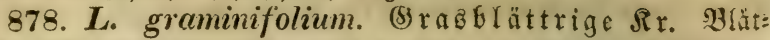

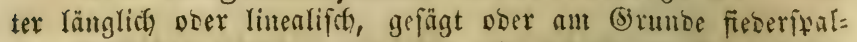
tig; Sdyotden eiförnig=ipib, mit fehr furzem (Briffel gefrönt.

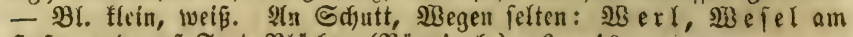
5afen uno auf̃ Fort $\mathfrak{B l u ̈ d}$ er (Bönningh.). 6-10.

† 879. L. latifolium. Breitblättrige $\mathfrak{R}$ r. $\mathfrak{B}$ lät= ter geferbt=gefügt, untre langgef́tielt eirunb, ofre auts cirum:

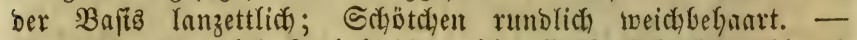

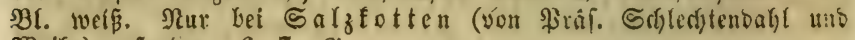
Wetfe) gefunder. 6. 7. 4 .

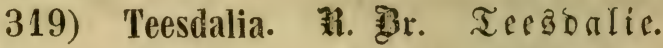

880. T. nudicaulis. 嗮. (Iberis nudic. L.)

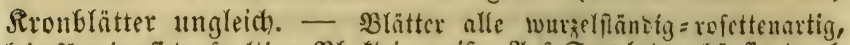

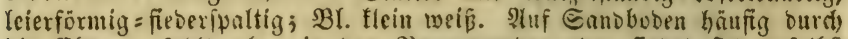
bie cennen, fehlt aber in ben Serggegenten ober finbet firl Dafelbit

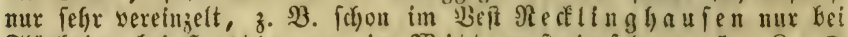

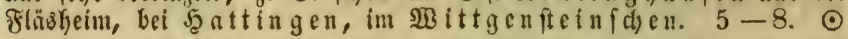

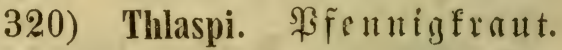

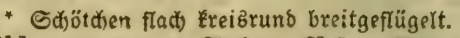

881. Thl. arvense. $2 \mathfrak{f}$ ff $\mathrm{er}=\mathfrak{B} \mathrm{f}$. Stengelblätter \äng=

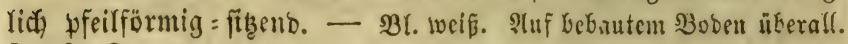
$5-9 . \odot$

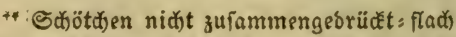

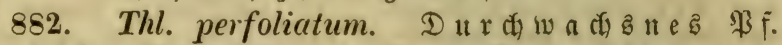

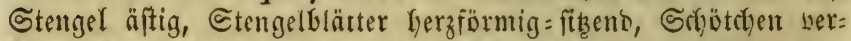

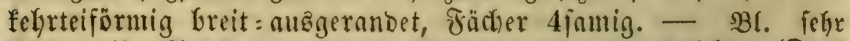

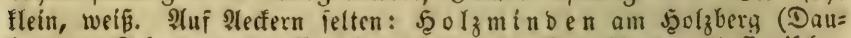

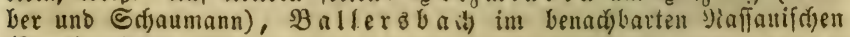
(Reerz). 4. 5. $\odot$

† 883. Thl. alpestre. $\mathfrak{A}(p \mathfrak{e n}=\mathfrak{B F}$. Ctengelbl. ei: herz= förmig, ๔d)ötchen verfehrtherzförnig, (Jriffel furz, Fäd)er $4=$

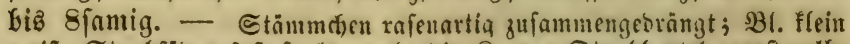
weíf, Staubfäben faft fo lang als bie Rrone, Etaubbeutel zuerît gelb, bann purpurroth, zulcbt fohwärzlici). $2(n$ peinigen Bergen felten:

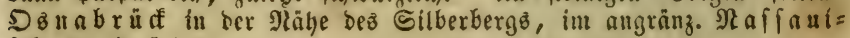
(d) en. 4. 5. 2

+ 884. Thl. montanum. $\mathfrak{B} \mathrm{erg}=\mathfrak{B}$ f. Ctengel cin= fach, Stengelbl. herzförmig, હdjötchen verfefyrtherzförntig, (Srif: fel lang, Jächer 2 famig. - Etämmớcn ver!ängert auฮläuferar= 


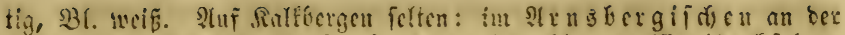

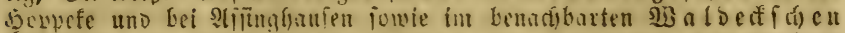

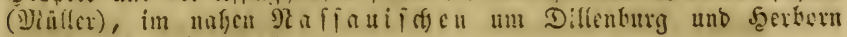
(Eecr, Dörien). 4. 5. 2

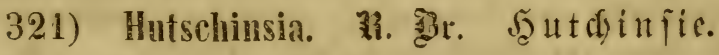

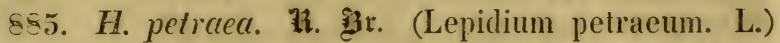

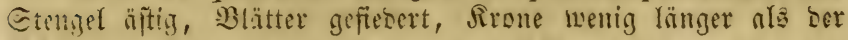

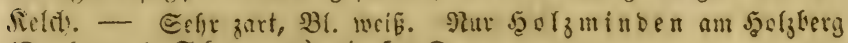

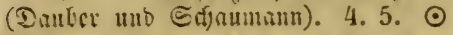

322) Capsella. Bent. Iäjd elfiat t.

886. C. Bursa pastoris. Atud). (Thlaspi B. past.

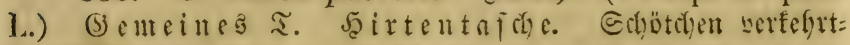

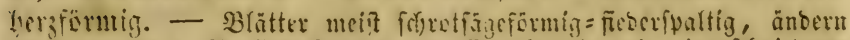

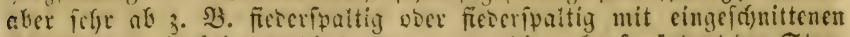

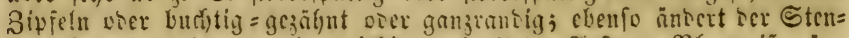

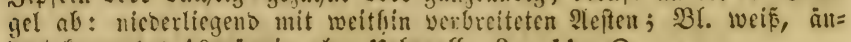
bert fronculus 10 mänig ab. Licberaf́l. $3-11$. $\odot$

\section{3) Cochlearia. Rif fifelfintt.}

887. C. officinalis. (ธู)

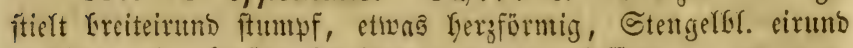

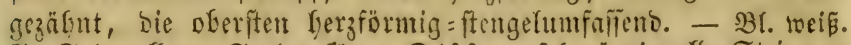
2hn Ealzquelfen: Ealouflen, Diffen, icfie uippig alle Steine an

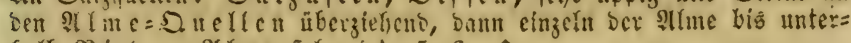

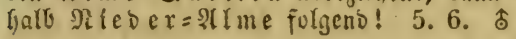

\section{4) Armoracia. S1. 30tett. Necruettid).}

858. A. rusticana. fl. Wrtt. (Cochlearia Armoracia. L.) Itntre Blätter länglid geferfst, mittlere fommartig= fieteripaltig, ofore geferbt = gefügt, aberfte fait gamzramsig. -

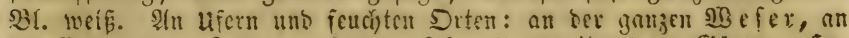

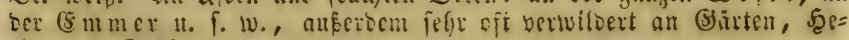

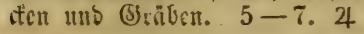

\section{3) Camelina. Crant3. Reindotter.}

889. C. sativa. CErnt3. (Myagrum sativum. L.)

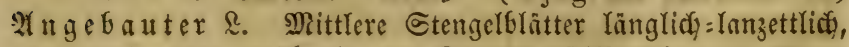
ganzranbin ober gezäfnelt, am (brunbe pfeilförmig. - Blume gelblity. Formen: $\alpha$ pilos $\alpha$ (C. sylvestris. Fr.) befaat; $\beta$ sub- 
glabra faft farfl. linter ber Gat, jeboch meift $\beta$, bagegen ift $\alpha$ fel=

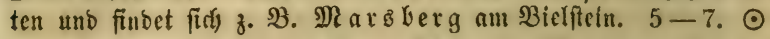

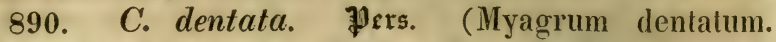

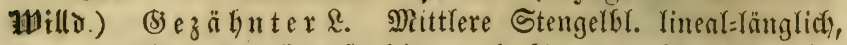
Gudytiggezäfut ober fieberipaltig, nad) finten beridgmälert aber bann wieder zut pfeilförmigen $\mathfrak{B a f t a ~ b e r b r e i t e r t . ~ - ~}$ Bl. gelb.

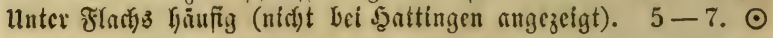

\section{6) Alyssum. Steinfraut.}

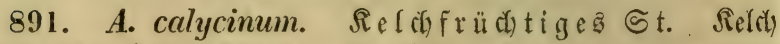
Freibento, bie beion fürzeren Strubfüden beiberfeit mit cinent borftlichen Bafune. -- Blätter gran, !anzetylidy, bie unterfen ver=

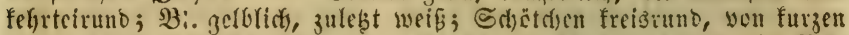

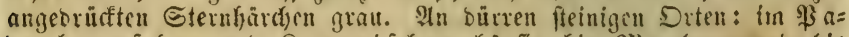

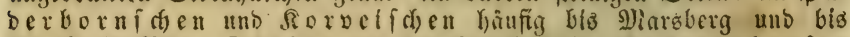

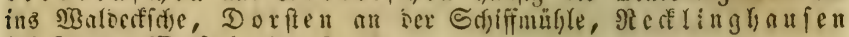

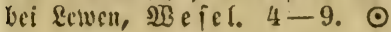

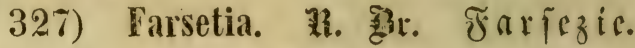

892. F. incana. H. Fir. (Alyssum incanum. L.)

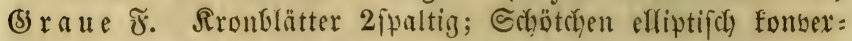

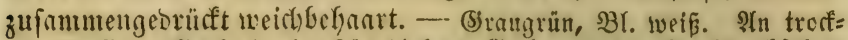
nen Steflen: $\mathfrak{B}$ efer! im füblidjen (S) B. und im $\mathfrak{B}$ alderff(d)en (Müller). $6-9$. $\$$

\section{8) Draba. Sॄungetblüm d) en.}

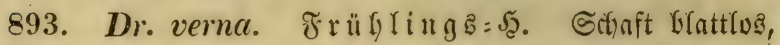
Sronblätter 2 fpaltig. - sblätter rofettenartig, Blütfenfticldfen

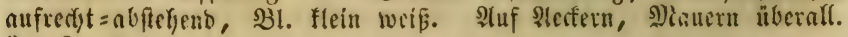
$3-6$. $\odot$

\section{9) Lumaria. Mondoiols.}

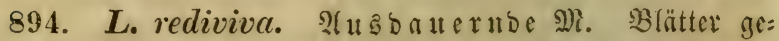
ftielt tiefgerzförnig gefägt; Cobotd)en efliptifd)=(mazettlid), an beiben Enoen fpis, Samen breiter ala Yang. - Blume grof,

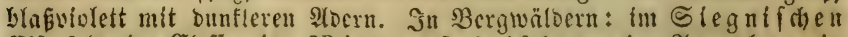

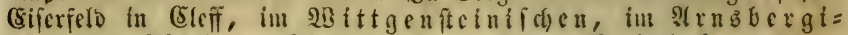

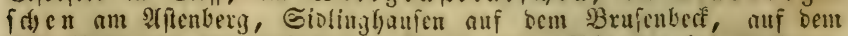

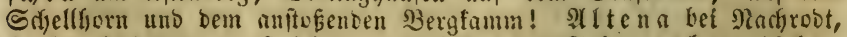

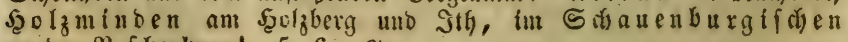
an ber \$afdenburg! 5.6. 4

895. L. biennis. Alvend). (L. annua. L.) Şwei = 


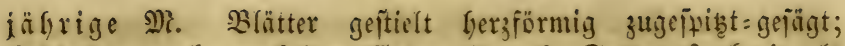

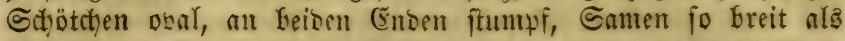

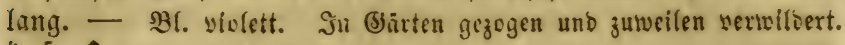

4. 5 . के

\section{Soromung Siliquosa.}

\section{0) Hésperis. গNa a d t $\mathrm{t}$ iole.}

896. H. matronalis. Rronblätter berfefrt=eirums, jefyr jîtuntf, meift mit einem sorīpringenten Spibchent. - Blume

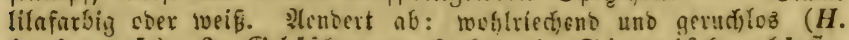

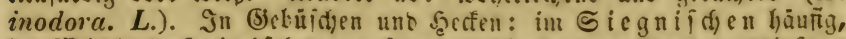

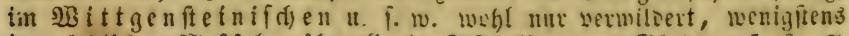

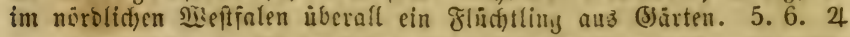

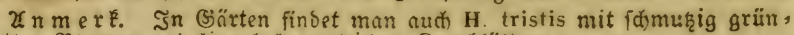
vioretten $\mathfrak{B}$ lumen uno lineal: Lanjettilid)en Rronblättern.

\section{1) Cheiranthus. \& $\mathrm{n}$ ff.}

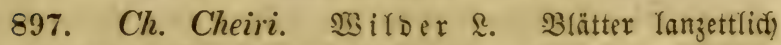

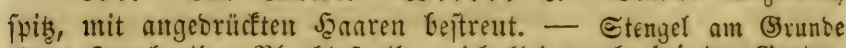

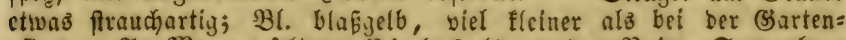

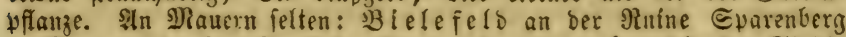

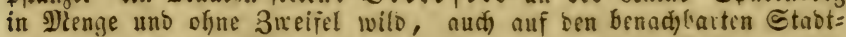

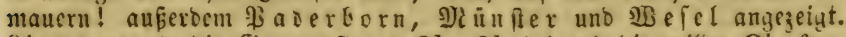
Et n ne nannte sie (Sartenpflanje Ch. Cheiri uno bie wilte $\mathrm{Ch}$. fruticulosus. 5. 6. 24

\section{2) Arabis. (5) än โคf}

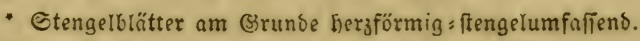

898. A. brassicaeformis. Wallr. (Brassica alpina. L.) Roblatiges (3). BBlätter fall ganzrantiog, bie untern

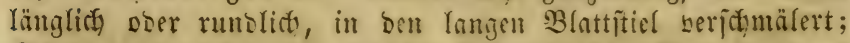

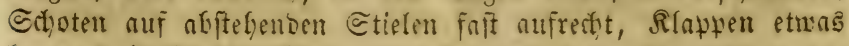

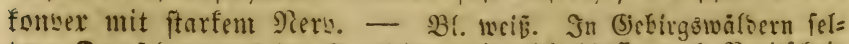

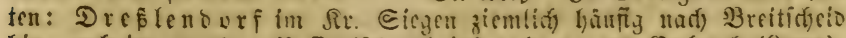

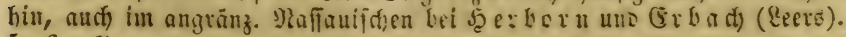
5. 6.24

† 899. A. sagitata. Dit. Bicilblättriges (5.

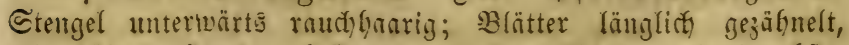

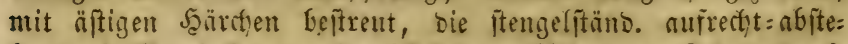

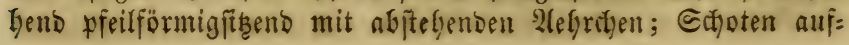


recht formallincrifiç); Camen fochnalgeflügelt feinpumftirt. -

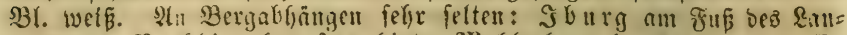

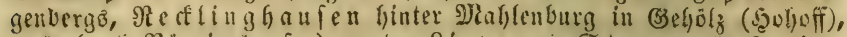
audi) (naci) Bönningbaufer) an ber Lffpe unt Stever. 5. 6. S

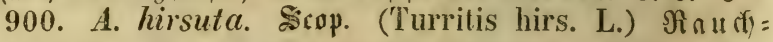

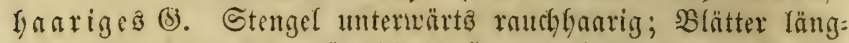
(iir) gezäfnnelt, mit meifit äftigen Saanen beftreut, bie ftengel=

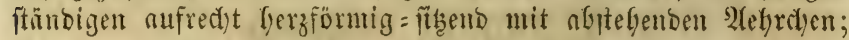

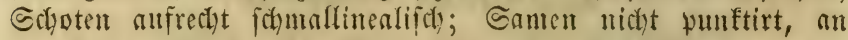

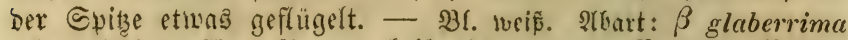

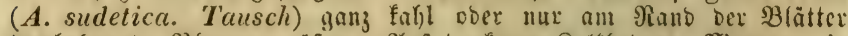

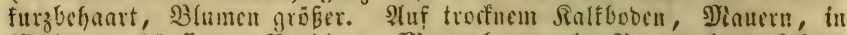

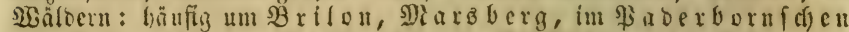

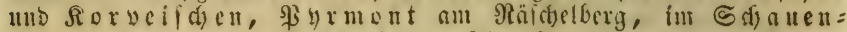

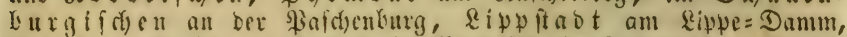

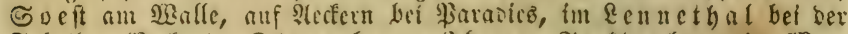

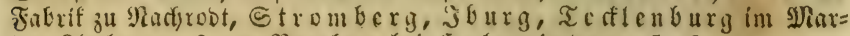

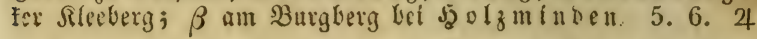

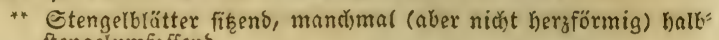
ftengelumfarfend.

† 901. A. arenosa. Sicap. (Sisymbrium arenosum. L.)

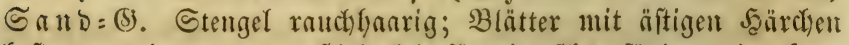
feitreut, bie untern gefiticlt leierförmig = fdyrotjügig, bie obern

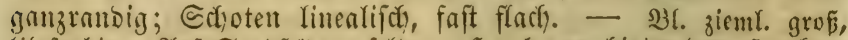
lilafarbig. Suf Eanbfolbern fetten: Sgerborn linter bem somberg

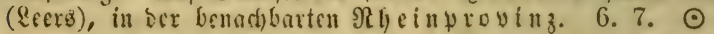

902. A. Halléri. Sa allerfdes (5). Etengel won un= ten an äftig; $\mathfrak{B}$ lätter ganzranbig oser etwas gezähnt, bie un= tern geftielt ferzförmig = runblid) ober eirumb, mit 2(nbängfeln nm Blattfticl ober ofme foldde, bie mittleren eirumb, bie obern

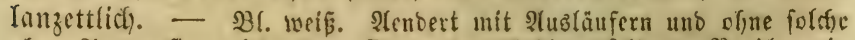

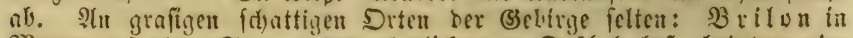

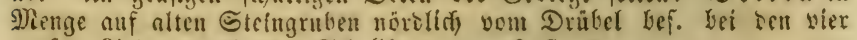
grefien Rimben, nady bem Eryellfurn zu. 6. 7. 4

\section{3) Barbaréa. 嗮r. Barbinfedrid.}

* Untre slätter leierförmig mit grobem (5nolnpwen, obre ungetheitt.

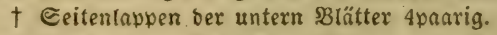

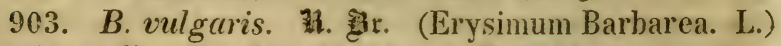

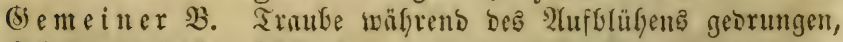
Sdyoten aufrectit=nGiteflent. - Bí. boppelt fo rang als ber fieldy, gelb. Ŝlvart: $\beta$ ciliata (B. hirsuta. Whe.) Blätter entfernt $=g e=$ mimpert. Stuf fercitem Refintroben. 5-8. 4

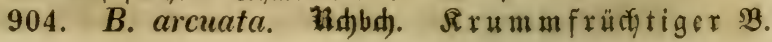




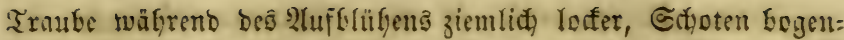

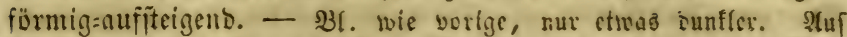

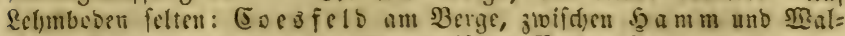

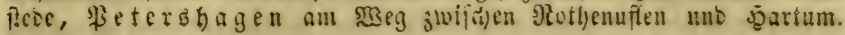
$5-7.24$

\section{t† Seitenlappen 2-3 panrig, fehic Elein.}

905. B. stricta. Antror3. Єteifer 18 . Mittlere Blät: ter ant (B)runbe leierförmig=eingejothitten, bie oberiten ungetfeilt; Edjoten an bie Epindel amgebriifft, aufrectit. - $B$ l. nur $1 / 3$

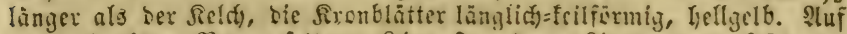

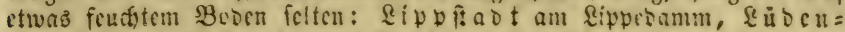

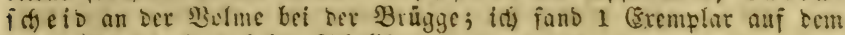

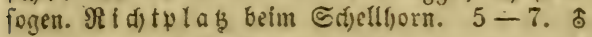

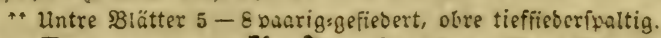

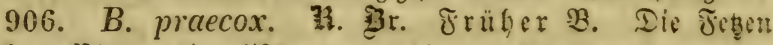
Der ofern $B$ lătter linealija) ganzranbig. - Die \$are ber untern

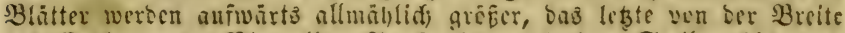

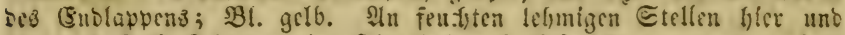

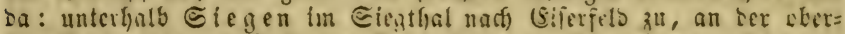

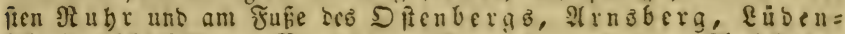

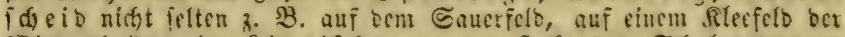

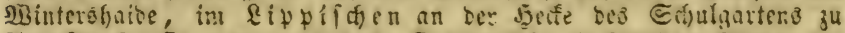
Stugutiborf; fie mag an mandfe Dite woljl mit frembem ङamen gc=

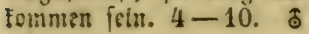

\section{4) Turritis. Thurmfrat.}

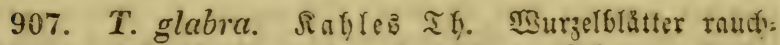
haarig, ofre fahl pfeilförmig=îtengelumfaliend; @ctioten aujredt,

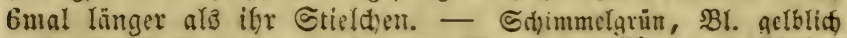

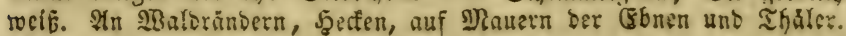
5. 6. $\odot$

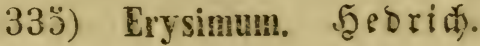

908. E. cheiranthóides. aำartiger 5. Bătter

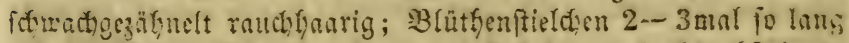

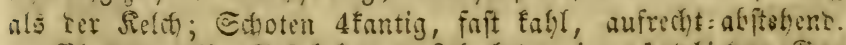

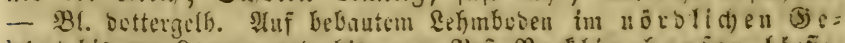

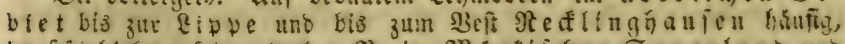

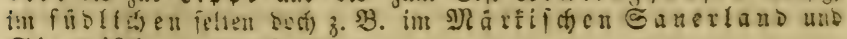

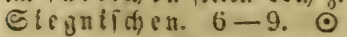

909. E. odoratum. Ehrh. (E. hieracifolium. כarq.)

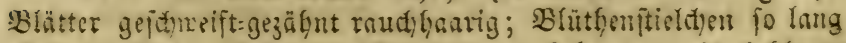

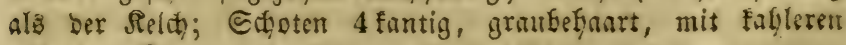

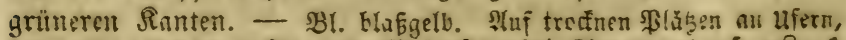

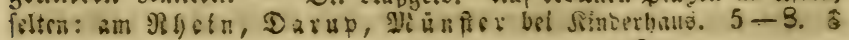


910. E. orientale. 11. (Brassica orientalis. L.) Morgenlänoif d)

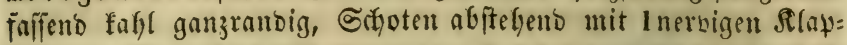

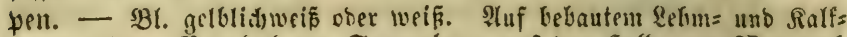
boben fetten: 2 rafel an Sauernberg, auf ber Seflle, am SBeg nach

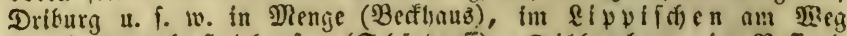

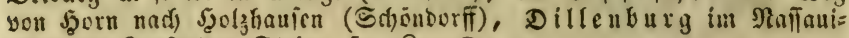
fdyer am Enufenoen @tcin. 5-8. 5

\section{6) Brássica. Sịd $\mathfrak{l}$.}

911. Br. oleracea. Bartenfugr. Blätter jơintuel: grün, bie untern geftielt leierförmig, bie obern frizeno länglic); Trauben lorfer, fod)on bor sem 2lufblüfyen berlüngert; Reldr)

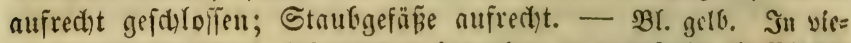
Yen Epletarten gebout, keionbers zu bemerfen: a acephala bie $\mathfrak{B l a ̈ t t e r ~}$

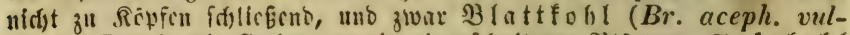

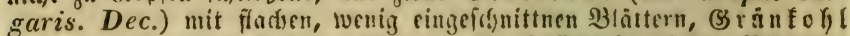
(Br. aceph. quercifolia. Dec.) mit ticiñereripaltịgen Blätteru, Oraunfohl (Br. aceph. crispa. Dec.) mit fiecerfpaltigen fraufsit

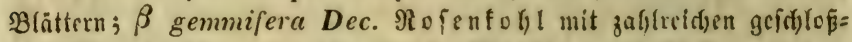
nen Blatterfipifsen; $\gamma$ sabauda $L$. $\mathfrak{B}$ irfing mit blafig = rungligen $\mathfrak{B l a ̈ t t e r n , ~ b i e ~ n u t ~ i n ~ c i n e m ~ R e t f e ~ f o ̂ l i e f e n ; ~} \delta$ capitata. L. $\mathfrak{B}$ el $\mathbb{B}=$

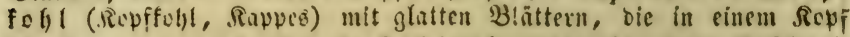

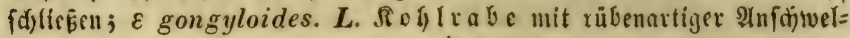

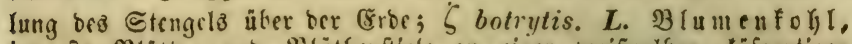

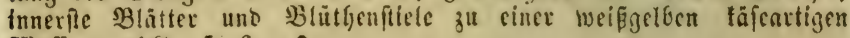
פiafie verbift. 5.6 . के

912. Br. Rapa. Näbenfolyl. Die eríten Bătter graggrün, bie fpäteren forimmefgrün, untre leierförmig, ofre

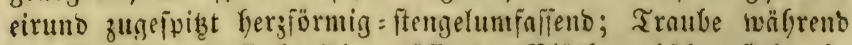

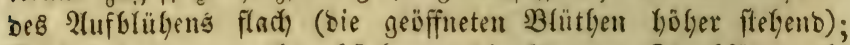

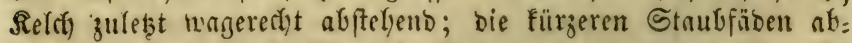
fteflento:aufítrebent. - 31 . gelb. Formen: a campestris, bie willhe

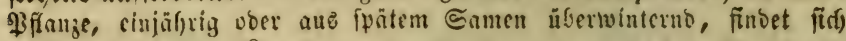

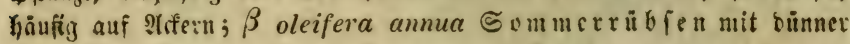

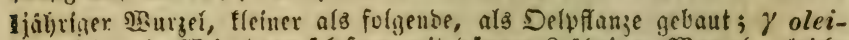

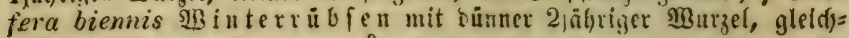
falle als Derpftame gevaut; $\delta$ esculenta Koch weibe 9 ü üe mit

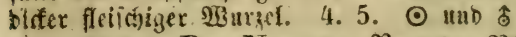

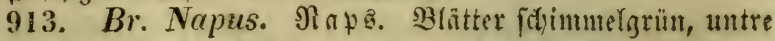

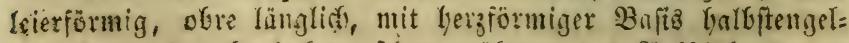

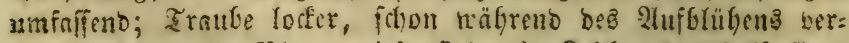

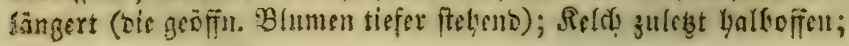




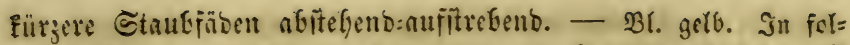
genoen Formen getaut: a oleifera anmua Eommerrałz, mit

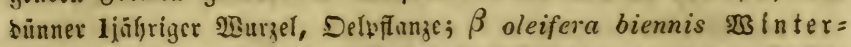
rap3, mit büner 2jüfriger Es

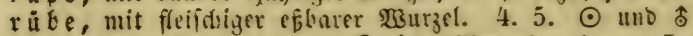

914. Br. nigra. flod). (Sinapis nigra. L.) ๔๙ jer $\Re$. Бत)

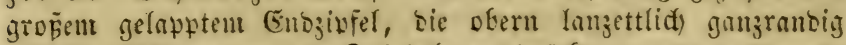

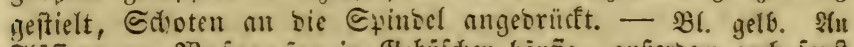

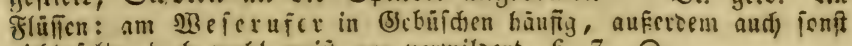

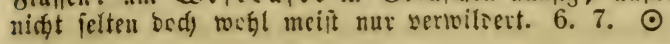

\section{7) Dentaria. $3 a \mathfrak{f}$ เ⿻u飞z.}

915. D. bulbifera. Buiebeltragentide 3 . Intre Blätter gefiebert, obre ungetgeilt, bie Blattwinfel ziriebeltragens.

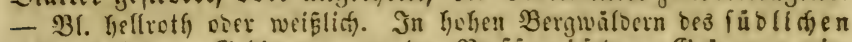

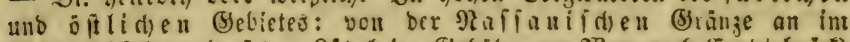

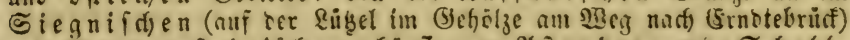

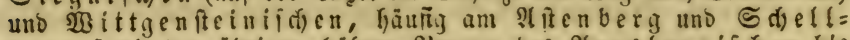

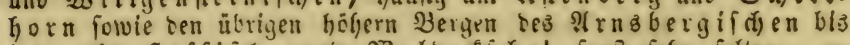

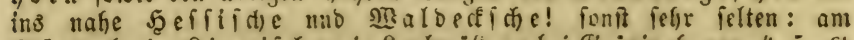
Su ntel, im \&ip

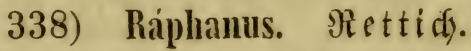

916. R. sativus. (B) artenrettid. Cripten fiterumo

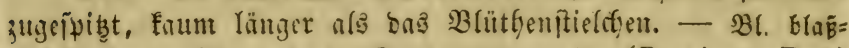
vielett ober lucí̄, gearert. Formen: a major (R. niger. Dec.)

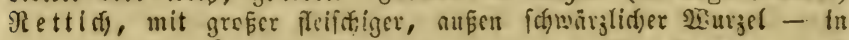

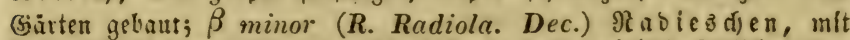
fleiner fleif(jiger (runber ober länglidger), aujen violett=rëthlid)er coer

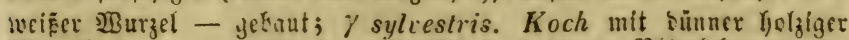

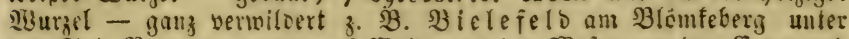

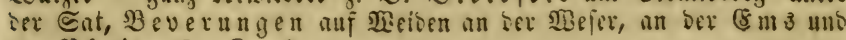
an $\Re$ hein. $6-8$. $\hat{\circ}$

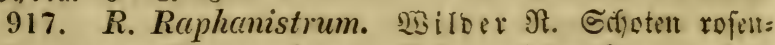

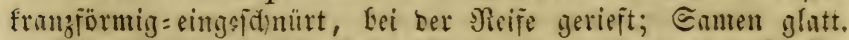
- Bl. toeíB mit vfoletten 2(bern (Raphanistrum arvense. Rchbch.),

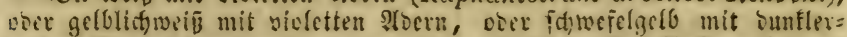
getbeit शiern (Raphanistrum segetum. Rchb.). Nuf Nerfern, bri uns

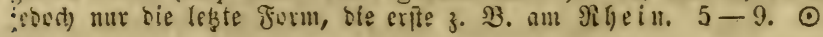

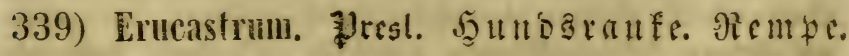
918. E. Pollichii. Sidimp. (E. inodorum. Ndbb.) 16 * 


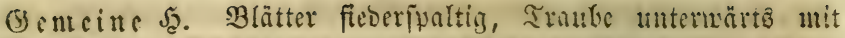

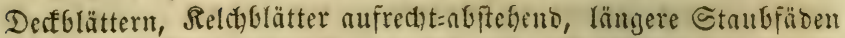

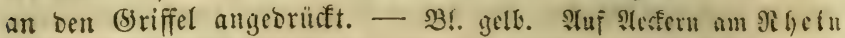

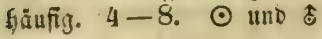

\section{0) Sisymbrium. $\Re a u f f$.}

- siätter fá)rotfägig fieberfaltig.

919. S. officinale. Scop. (Erysimum officinale L.)

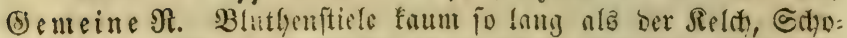
ten an ben Etengel georücít, pfrienlict)-zugefpizt. - Bl. gelt,

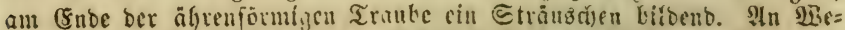

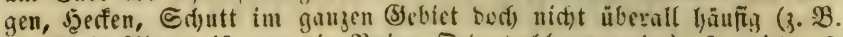

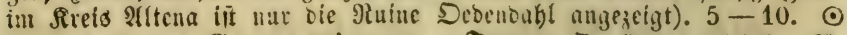

+920. S. austriacum. Jacq. Deftreicififace 9t. Etengel unb $\mathfrak{B}$ lätter fabl (oocr nur wenig fteiffantig); Ect)v=

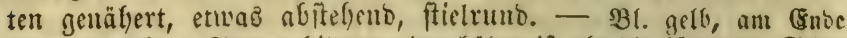

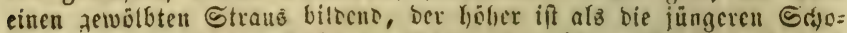

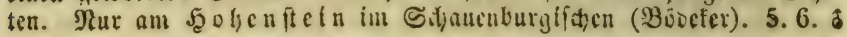

\section{* Blätter 3fad) gefiebert.}

921. S. Sophia. Fcinblätrige N. Bipfel ber

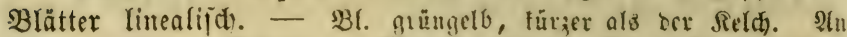

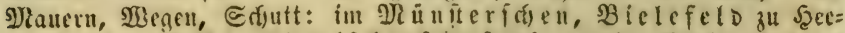

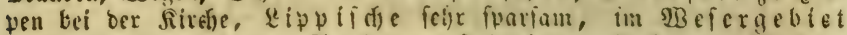

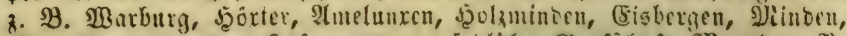

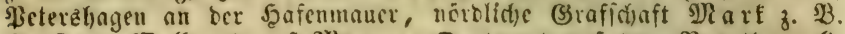
Eoeft am $\mathfrak{B a}$ all und auf Ylauten, Dortmuno auf tem $\mathfrak{B}$ urgthorwall,

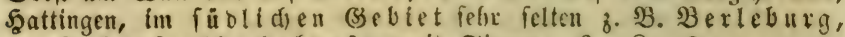

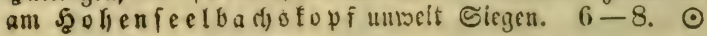

\section{*** Blättar ungetheilt.}

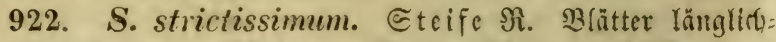

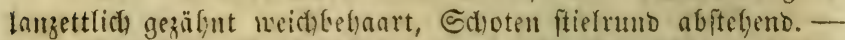

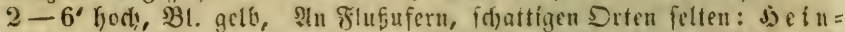

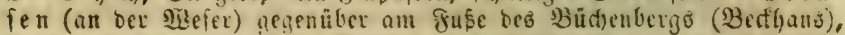

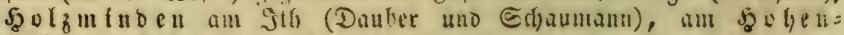
fie in im Edyauenburgifichen 6. 7. 4

923. S. Alicaria. Scop. (Erysimum Alliaria. L.)

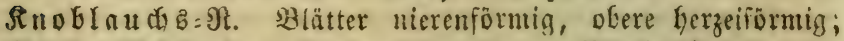
Gd)oten abïtebeno, vielmal länger als bie Blüthenftield)en. -

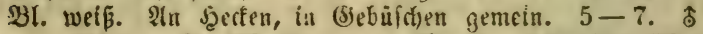

924. S. Thalianum. (Gaù. (Arabis Thaliana. L.)

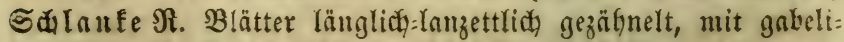

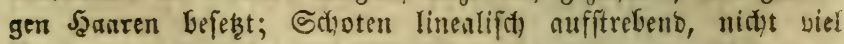

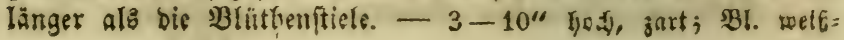




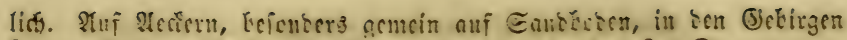

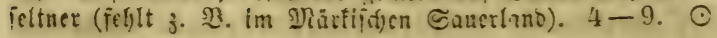

\section{1) Sinápis. ธeñ.}

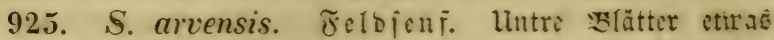

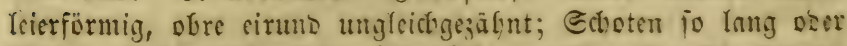

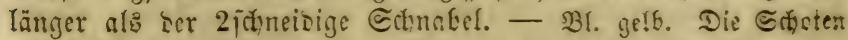

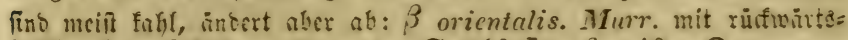

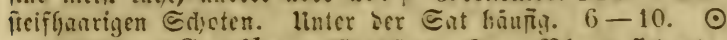

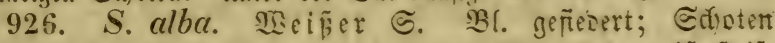

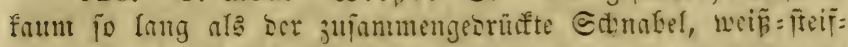

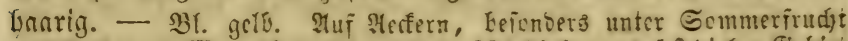

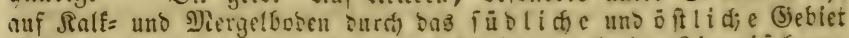

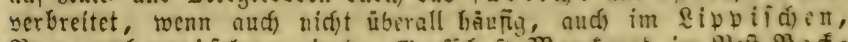

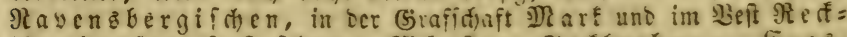

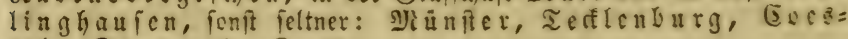
ferb, Darup. $6-8$. - $\odot$

\section{2) Cardamine. Sda a mfiant.}

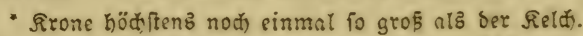

927. C. impatiens. Spring=ङ \&. Blätter tielpaarig= ge rebert mit preilförmig=geröhreltem $\mathfrak{B l a t t i p t i e l e . ~ - ~ B l . ~ E l e i n , ~}$

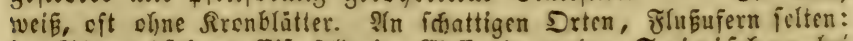

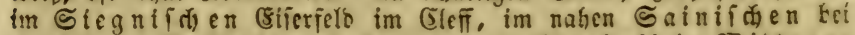

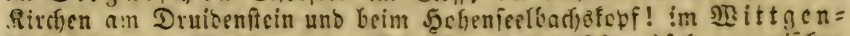

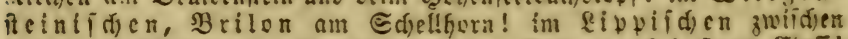

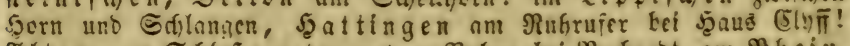

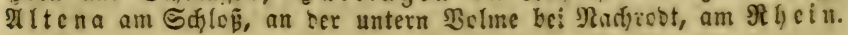
j-7. 24

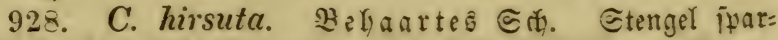

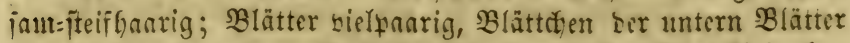
cirunblict, ser obern länglide obar linealifd, Blattitiel sf̣ne Defirten. - Bl. seppelt fo lang als ier Reld), meip. Fermen: a

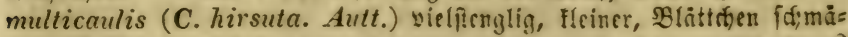

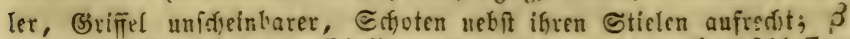

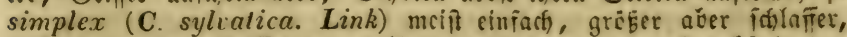

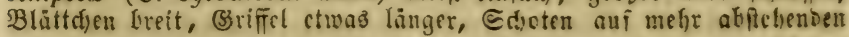

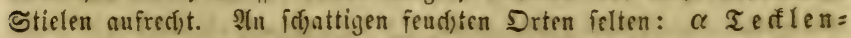

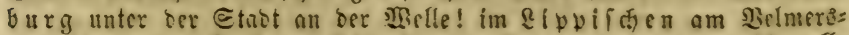

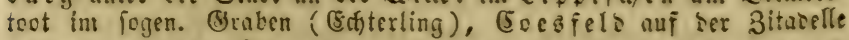
(Bönninghauien); $\beta$ Brilon auf uno an bem Edifliforn! auch

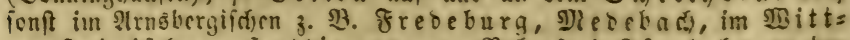
genfeinif(t)en, Jyattingen am Rubrufer! Sierlohn an ber

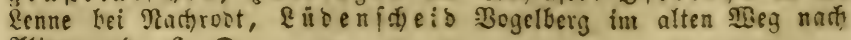
शttena. 4-6. $\odot$ 
** Frone oreimal fo gros als ber Relda.

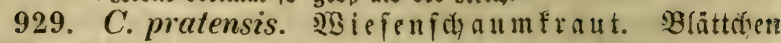

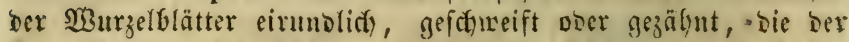

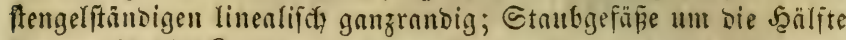
fürzer als die Rrone. - Stengel hol)! $\mathfrak{B l}$. lilarchthlid, mit bunt=

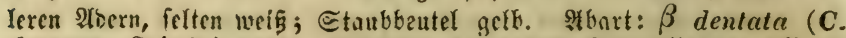
dentata. Schult.) löber, SBlättchen ber untern Stengclólătter sofigyc=

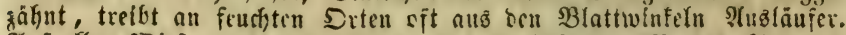

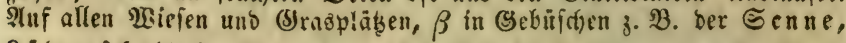
Lübenfriet im Nattenkerge, bei Selve's Silfuien. 4-6. 4

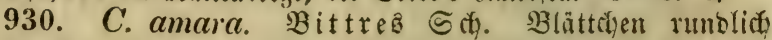

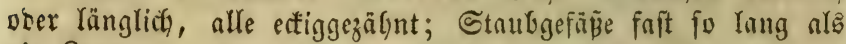
Die Rrone. - Stengel funtig gefurcht, untertoärts jectitcut=behant,

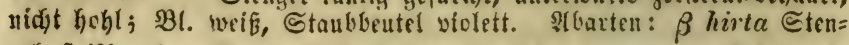
gel feiffaarig, Bluthenfticle fahl; $\gamma$ glaberime nanz falyl, ble

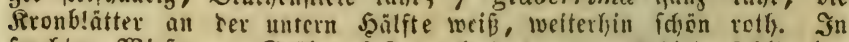

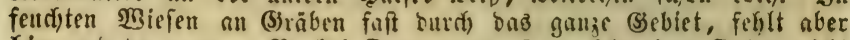

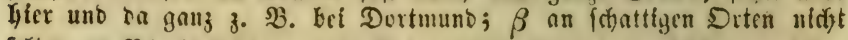
felten, $\gamma$ Bielefeld an ber Bobnenviffe Gluter ber Şüttemannd fen 3iegelci. 5. 6.24

\section{3) Diplotaxis. Der. Doppelfaute.}

931. D. tenuifolia. Der. (Sisymbrium tenuifolium.

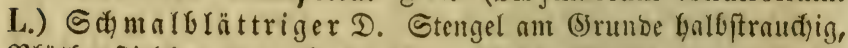

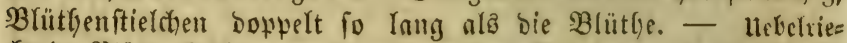

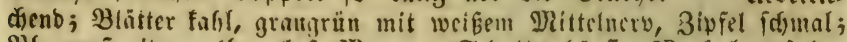

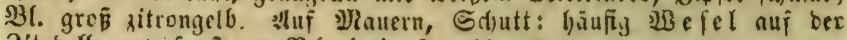
3itabelle une foult am $\Re$ f) ein! $6-10$. 24

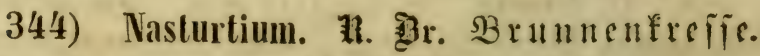
* silume weis.

932. N. officinale. H. 3r. (Sisymbrium Nasturlium.

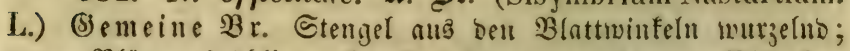
untre $\mathfrak{B l a ̈ t t e r ~} 3$ zäblig, vbre 3-7 panrig=gefiedert; $B$ lättdien

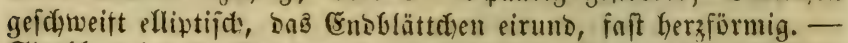
Staubbeutel gelb. Albarten: $\beta$ microphyllum. Boeming . feffe flein, Blättúen furzgefielt; $\gamma$ siifolium ( $N$. siifolium. Rchb.) fefir lana,

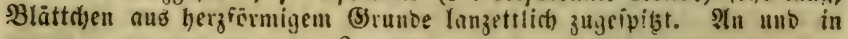

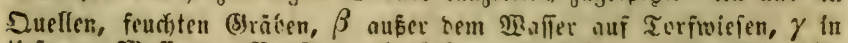

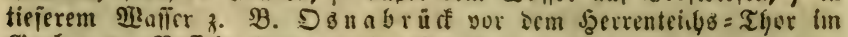

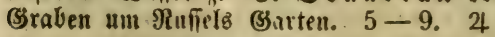

** SBlumen gelb.

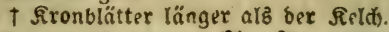

933. N. amphibium. \#. Br. (Sisymbrium amph. L.) 
Zeridiebenblätrige $\mathfrak{B}$ r. Stengel an (orunbe wurzelnb,

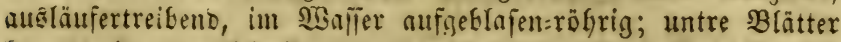

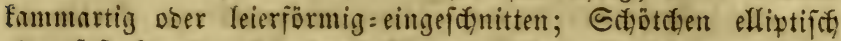
ober faft funelig, 2-3mal fürzer ala bas Stielden. - Iten=

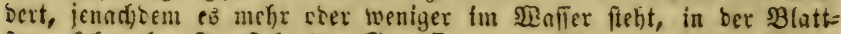

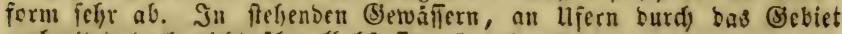

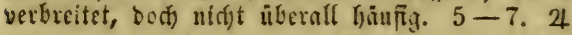

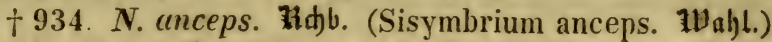

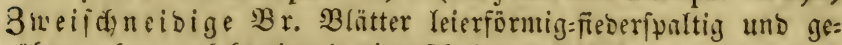

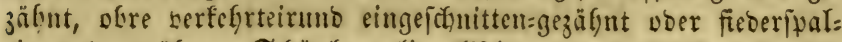

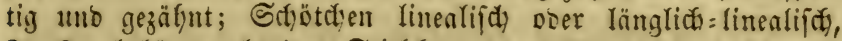
2-3mal Eilrzer als bas @tielcten. - \$tn Mfern felten: an ber $\mathfrak{R}$ ufr unterbalb Şufenimburg an ber Brüffe bei Rangidece, an ber

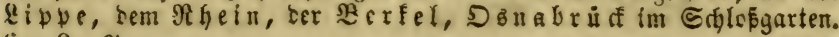
$6-9.24$

935. N. sylvestre. H. Br. (Sisymbrium sylv. L.)

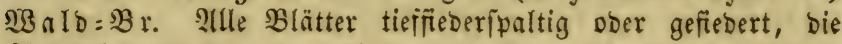

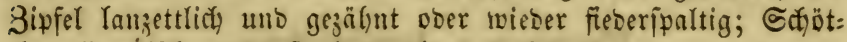

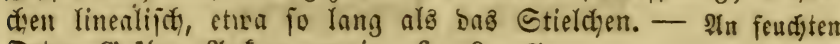
Drten, Şräben, Alefern gemein. 6-9. 4

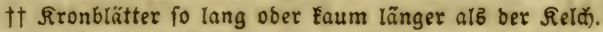

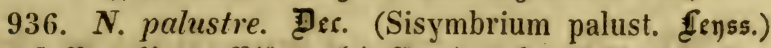

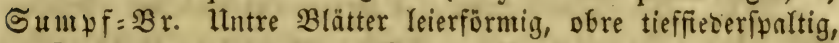
bie Sipfel länglich gezäfnt; @đoten länglich gebunjen, etwa fo

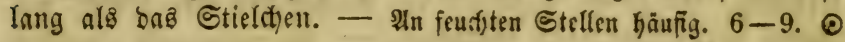

\section{Sedifebute siafie. Monadelphia.}

\section{Soronung Pentandria.}

345) Erodium. If ferit. Reiberffunabel. Reld

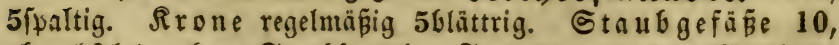
abrechfelno ofne Staubbeutel. $\widetilde{r}$ dut mit fpiralförmigem Sđunabel. 


\section{Soromung Decandria.}

346) Geraninm. Ctorchfonabel. Rel if 5= blättrig. Fitone regelntäpig 5 blättrig. Frudt mit grabent Sdunaber.

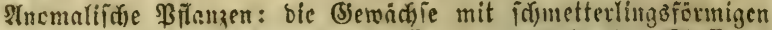

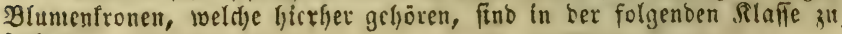
fuchert.

\section{Sromung Polyandria.}

347) Mthaea. Cibifch, Rel(t) boppelt, ber äuß̈ere $6-9$ b lâttrig.

348) Malva. Malve. Relê, boppelt, ber äupere 3 b̆ättrig.

\section{Sronung Pentandria.}

345) Erodium. Eferit. Reifyerifnaber.

937. E. cicutarium. (Geranium cicuta-

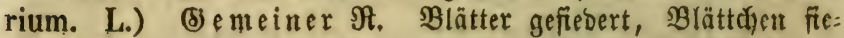
beripartig, bie Bipfel gezägnt; bie fruchtbaren Staubfäben am (Brunbe verbreitert ofge Bäfndhen. - B.. purpurrotf. Penbert ab: $\beta$ maculatum bie 2 grểeren Rronbrätter am Brunbe mit cintem gelbltden braunpunftirten fleffen; $\gamma$ pallidsm (E. chaerophyllum. Cav.) mit blapkrotfen ober tweís!itjen $\mathfrak{B l u m e n} ; \delta$ pimpinellifolium (E. pimpin. Sm.) bidjter befiaat, weniger $(2-4)$ blütfig, sitone

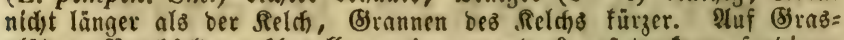
pläbzen, Brachfelbern überall gemein, $\gamma$ uno $\delta$ auf troffnem fanbigem Boben. 4-10. $\odot$

938. E. moschatum. Ait. (Geranium mosch. L.)

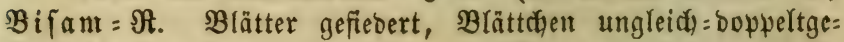
fägt; bie frudatbaren Stmubfäben am Srrumbe berbreitert $2 z \ddot{a} \mathfrak{h}=$

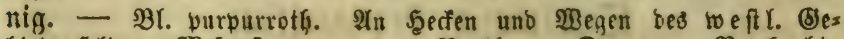
blets felten: शR unfer yor bem Reutgore, Darup, Bodgolt,

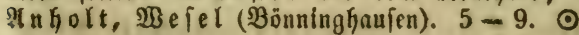




\section{Stomung Decandria.}

\section{6) Geranium. Stordididnabel.}

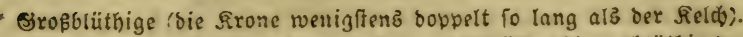

$\dagger$ Silappen querrunzlig ober querfultig. ( $B$ lüthenfitiele 2blütbig.)

939. G. macrorrhizum. (5) ró̈wurzliger St. Rrot= blätter patelig benagelt, Plagel jo lang alv ser Relct); Etnub: fäben abwärtågebugen; Rlnpwen fabl querrumblig. - Blume blutreth. Sn (Säten gezonen uno mandymal an (B)artenfyefen verwils bert. 6.24

940. G. phaeum. Sothbrauner St. Sirone finds, ctmaz zurüffgebogen, Jironbl. furgbenngelt berfebrt=cirumblich

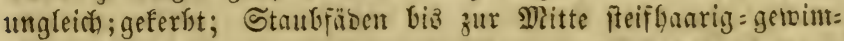
bert; Rlappen faarig, torn querfaltig. - In Şecten, fäattian

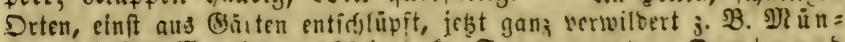

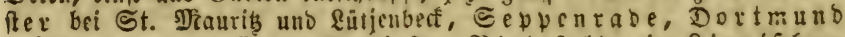

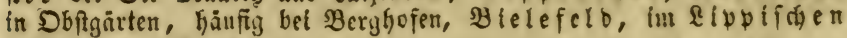
ม. \{. เo. $5-7.24$

t† Rlapben glatt.

a. SBlüthenftiele lblüthig.

941. G. sanguineum. Błutrotber $\subseteq$ t. Blätter nierenförmig 7theilig, bie Bipfel 3-vielfpaltig; Sironbl. aus:

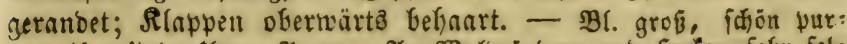

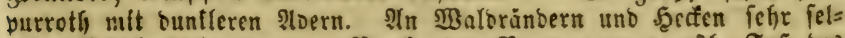
ten: $\mathfrak{B}$ felefelo an ben Brafiveder Bergen vom weftl. Fǘ beß

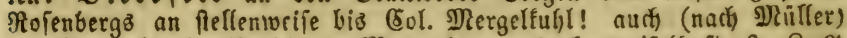

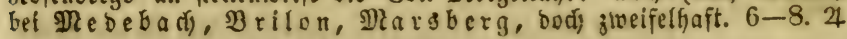

b. : Blüthenftiele 26lüthig.

912. G. pratense. SBiefent = St. Stengel aurrecht,

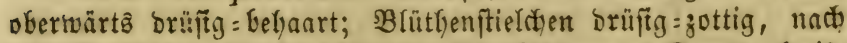
ben Berblüfyen Gerabgeichlagen; Staubfïben am (Srunbe freis̈: förmig=erweitert; Rlappen nebit bent Sdinabel abitebeno = brüfen=

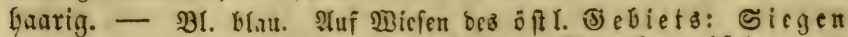

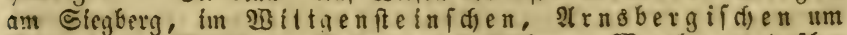
Winterberg, Mesebarb, Brilon am Şafielborn, Margberg und ü5er

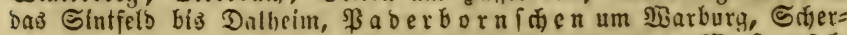
febe, Beberungen im Beverthal bei Dalfaufen, bann ber sibefer fol=

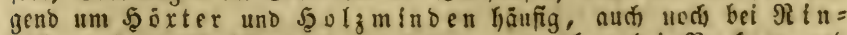
teln auf ber Dofterlocise; auperben angegeben bei $\mathfrak{B}$ ef um unb Delbe, bodi hier nefleidet nerwiltert wie fonft $\mathrm{sft}$ 子. 3 . Biele= felb am Johannisicera, in \&ippifa en. 6. 7. 4

943. G. sylvaticum. $\mathfrak{W}$ a $1 \mathrm{D}=$ St. Stengel nufredt,

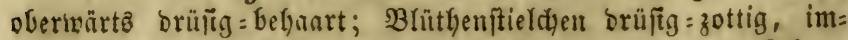
mer aufreat; Staubfäben Yanzettliđ; Rlappen nebft ben Gduma= 
bel abjtefueno = brïfenfaarig. - Bfume purbur= violett, über bcm

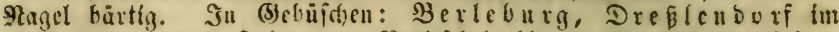

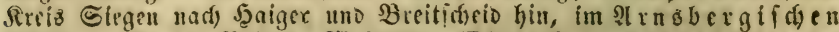

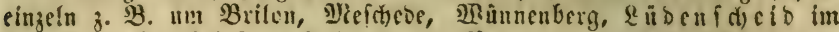

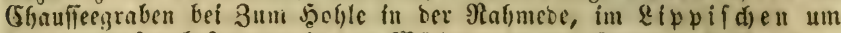
Derlinghation bejonoers in ben 98 älscrn an bet Eeme. 6. 7. 24

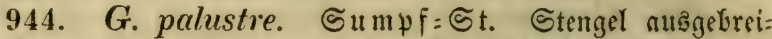
tet, obermärtz nebit ben nari) Dem Berblüben niebergebognen Blutbenftielen son briffenlofen rürfwärtogefelyrten Scaaren rauly; Staubäden Ianzettlich; Rlaquen abftebend=belyant, Gctuabel

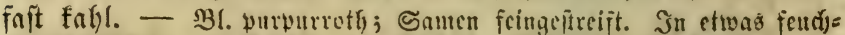

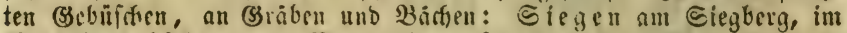

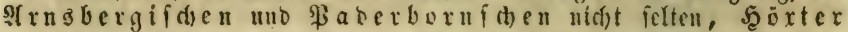

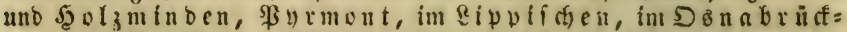

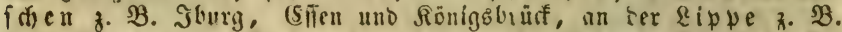

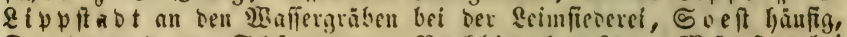

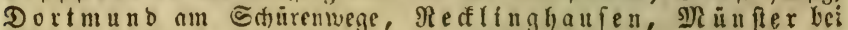

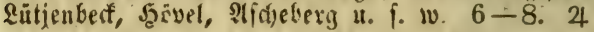

945. G. pyrenáicum. Siqrenäiffer St. Stengel aufred)t, nebit ben Blättern weidbbefanart แแlo.etwas zottig; Blütbenftield)en fein uno bidyt oriufenfianrig, nach ben Berbl.

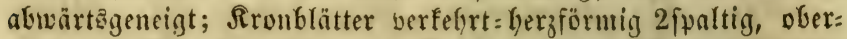

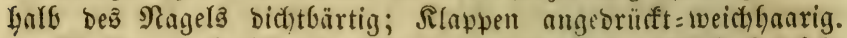
- Br. Aleiner als bei ben vorigen, purwurviclest. În Sceffer feljr felten: Bielefelo yor bem Rienern Thore, an ber hullandifben Bleide, Şerforb bei ser \&eudite - vielleidyt frifjer einmal verwil= bert. $5-7.24$

** Sileiner blüt)ige ( Srone nid)t boppelt fo tang alb ber Sisld)). Slüthenftirle 2blüthig.

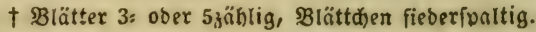

946. G. Robertianum. Stinfender St. Stengel aufred)t abitebeno = bebart; Rronblätter werfebrteirund, \änger ałz Der Relth; Rlnppen nebig: rumzlig. - Sl. roienroth mit reiflid)en Etrcifen; Slbart: $\beta$ leucunthon. Dum. mit ganz weíben

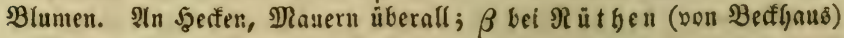
in Mlenge gejunben. $5-10$. $\odot$

\section{t† Slätter 5-9 theilig.}

a. Rlappen runzlig.

947. G. lucidum. (5) \änzender St. Stengel auf= recht, faif fabl; Sronbl. berfefyrteirund ungetbeilt, länger als ber querrunglige Seld); Rlapwen nesig=runzlig, oberw. weids= bebaart. - $B$ !. purpurreth; bie Bffanie meift roth angelaufen.

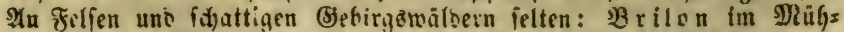

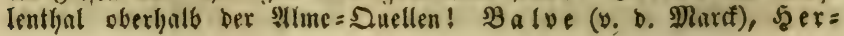




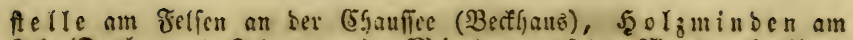
Sth (Dauber und Edjaumann), פR in ben auf ser Nlargarethenflus ! $5-8$. $\odot$

948. G. molle. Șeidter @t. Etengel nusigefreitst, weidgfebart uns zottig; Rronbl. serfebrt=fergförmig, länger als ber Seld), am (5) rambe feingemimpert; Rlappen querrmblig

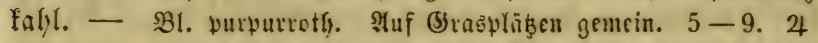

b. Rlappen glatt, behaart.

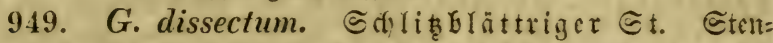
get ausigebreitet furzbef)ant; Rronbr. verfefrt= herzförmig, liber Dem Sagel bätig, fo lang als Der Reldy; Rlappen unb Gd)na=

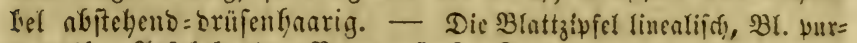
butroth. Ifuf bebautem $\mathfrak{B}$ oben. 5. 6 . $\odot$

950. G. columbinum. Tauben = ๔t. Ctmget aนพิ=

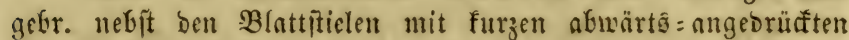

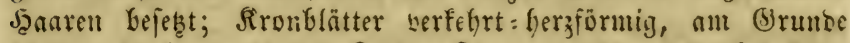
bärtig, fo lang nla ber Reld); Silnppen fafl, E(t)ubel furz=

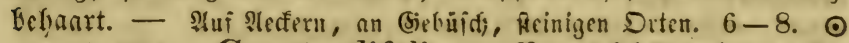

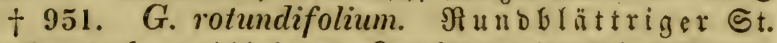

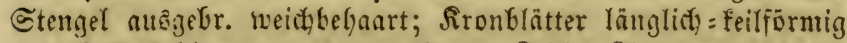

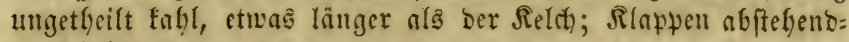

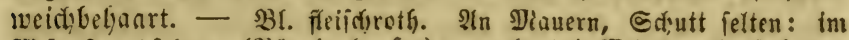

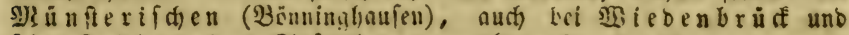

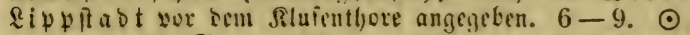

952. G. pusillum. Nicoriger હt. Elngel ausิ=

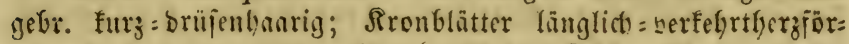
mig, fo lang ooer twenig länger als ber Seldr); Rilapten ange:

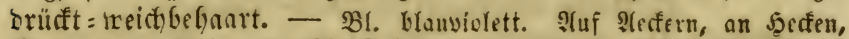

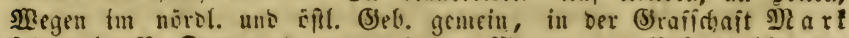

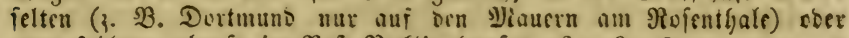
ganz fchlent, cbenjo im Beft 9lefflinghaufen. 6-9. $\odot$

\section{Sromuntg Polyandria.}

\section{7) Althaea. (sibifdy.}

953. A. officinalis. Filzig, Blätter unbeutliđ) $=3-5=$

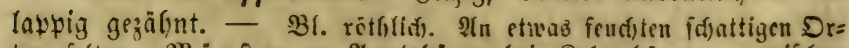

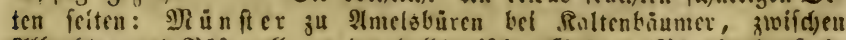

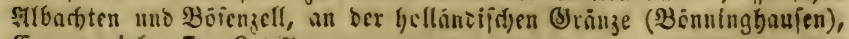
(Emertd. $7-9.2$ 


\section{8) Malva. Mal vc.}

* Stengelblätter handförmig : 5 theilig.

954. M. Alcea. Sdulibglättrige De. Stengel burd) augebrüfte Sternbaare graugrün; Fruid)ticlen fall fein=quer:

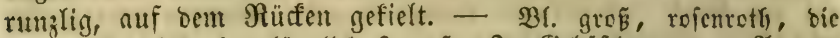

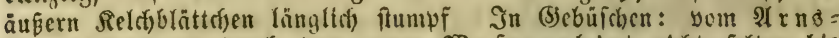
bergificen an ourch bas ganze weferge blet nicht felten bis

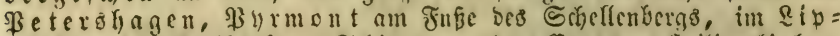

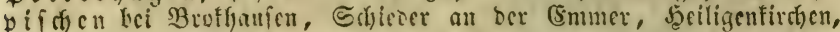

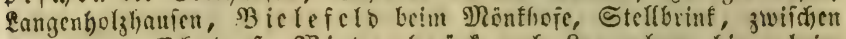

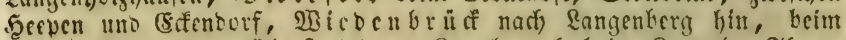

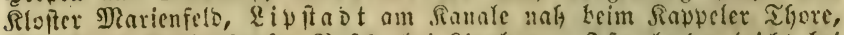

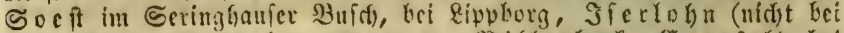
Rubenideib), Nottern, Darup, sbifterberf, (Eocsfels bet sette U. F. w. $6-8.4$

955. M. moschata. Bifam $=\mathfrak{M}$. Stengel yon $a b=$

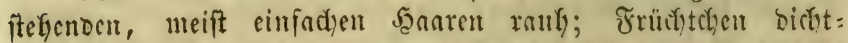
raudbharig glatt. - Bl. etwaz fleincr ala yor. Keflrofenroth,

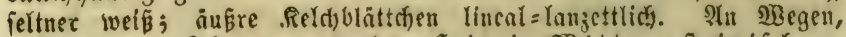

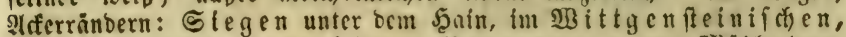

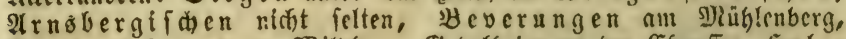

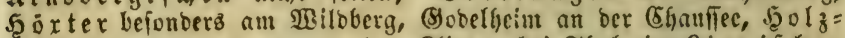

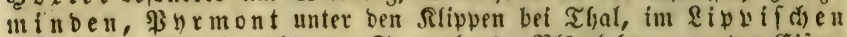
nicht felten, Bielefelo am Eparenterg, Blomfeberg, an brr Eijen= bahn u. f. w., \&ippitab t unter ben Tamen am Rirdiliofe, Socf

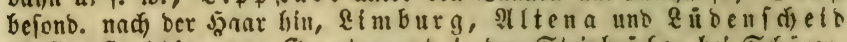

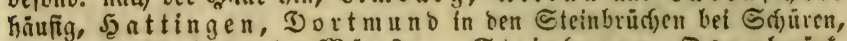
Daruy, Stefnfurt, Nünfer, Stefnberge, Sonatrút. $6-8.24$

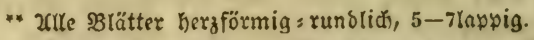

956. M. sylvestris. Wanlomalve. Rronblätter 3 bis 4 mal länger als ber Rel(t), Jrüct)tdyen fafl nezigsumzlig. Bl. Geflpurpurroth mit bunfleren Streifen, felten faft weî́ mit silaftrets fen. QItn trodfnen feinigen Drten, um Dörfer. Die Form mit IosiÉ

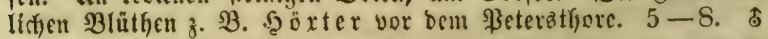

957. M. rotundifolia. (M. neglecta. Wallr.

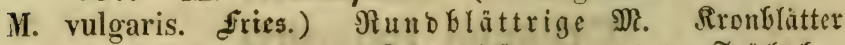
$2-3$ mal länger als ber Rel(b), tief nuşgermbet; Früd)țen

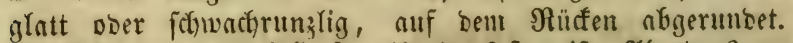
Bl. fleiner wie vor. Gelltofentoth ober faft tocí,. Sthart: $\beta$ pusilla (M. pusilla. With. - M. borealis. Wallm.) Blitfenftirle ge=

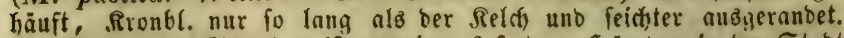

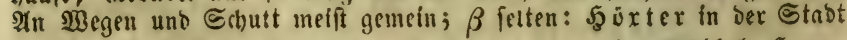

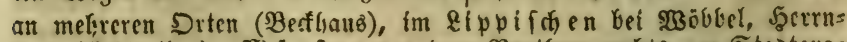

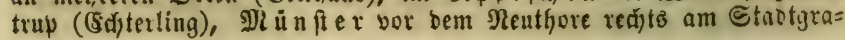




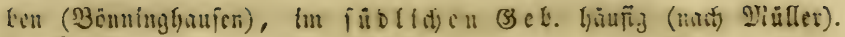
$5-9.24$

Un mert. I. M. crispa, mit eckig = Exaufen SBlättern uns gek̂nauelten sBlüthon, finoet fid), ben (Särten entfdiübft, bermiloert bier urb ba; aud) 11 . mauritiana mit aufrediten, nebit $B$ latt: und $\mathcal{B}$ lütbenftilen faif Eablen Eten: geln tt. bunkller purpurrothen Blumen, mag zutvellen verrolloert vorfommen. is n mere. 2. Lavatera thuringiaca fand fid früher bei Sorves vermil: sert, ift aber verfdrounden.

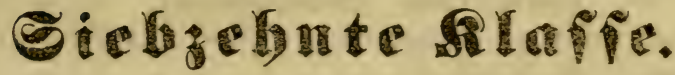 Diadelphia,}

\section{Sromung Hexandria.}

349) Conydalis. Denten. Sermbufd). Selth 2 blättrig. Rione radjenfürmig gripornt. Edjote 2 flappig vieljantig.

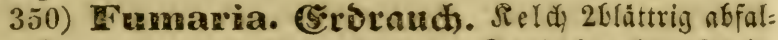
Ient. Rrone unrege!mäpig deffornt. Steiufrudt lfamig.

\section{Stonung 0ctandria.}

351) olygala. Secugblume. Reld 5blüttrig

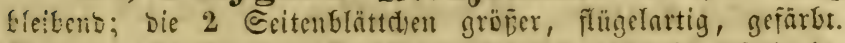
Sitone radeniormig. Sapfol berfefirt=firgfërmig 2 füderig.

\section{Sromung Decandria.}

- Etaubfaben monnorlwhifa) (in einer Maffe).

† SBlätter einfno ober 3 ä̆blig.

352) Spartiam. Sfricmeraut. Reld fait $2=$

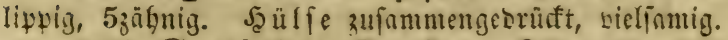

353) Genista. Ginfter. Reld) 2lipplig, Die Dber: lippe 2tbeilig, bie Unterlipwe 3 fpaltiy. Narbe einuärta $a b=$ abiduifitg.

35.4) Cytisus. Giciffeler. Ie!d 2lipti, Dber= 


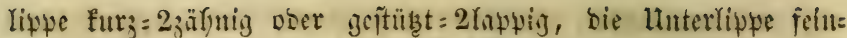

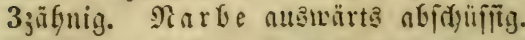

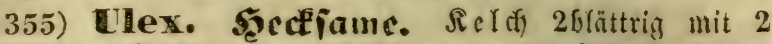
Derffrüttern. Eี่

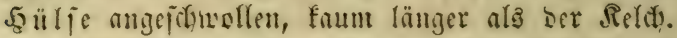

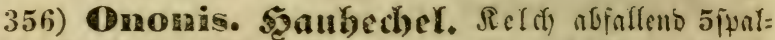

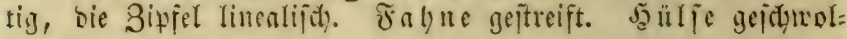
Iell, fingent.

†† Brätter gefiebert.

357) Aathyllis. Szunderaut. Seldi baudyig,

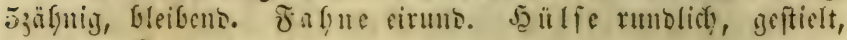
mit bent Seldye bebecft.

* Etrubfäben biabelphifa) (9) betfelben verwad) (eit, I allein frei). † Eigentlide Şüllen.

a. Slätter gưbreit.

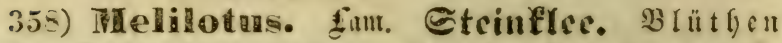

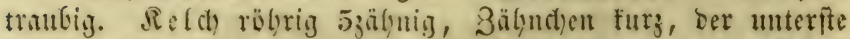

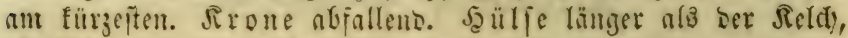
abrallems.

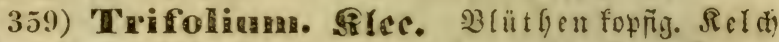

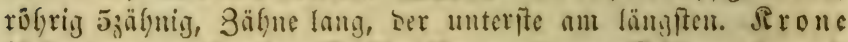

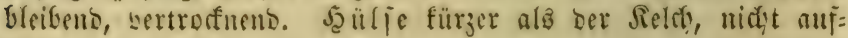
ipringello.

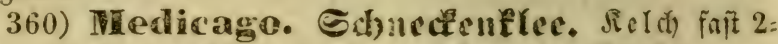

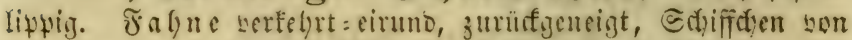

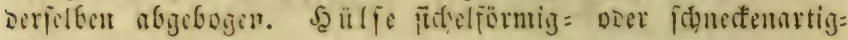
geiruntert.

361) Lotas. Echotenfres. Rerdh fait 2 rippig,

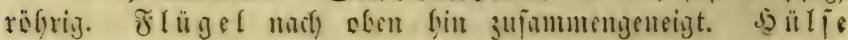
walgenformig.

\section{b. Blätter geriebert.}

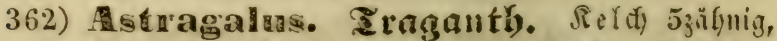

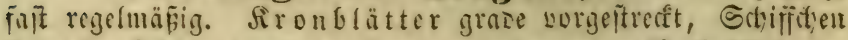

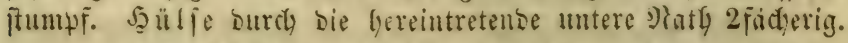

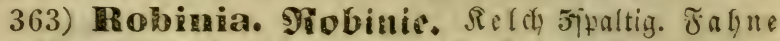

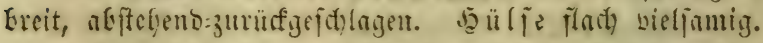

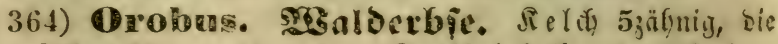

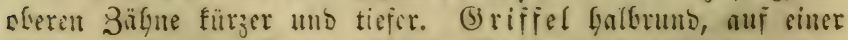

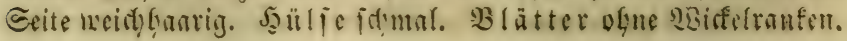


365) Lathyrus. Wratterbie. Bä tter mit Sisit: feIranfen; fonit wie Orobus.

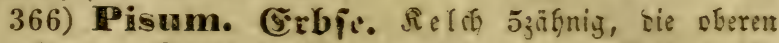

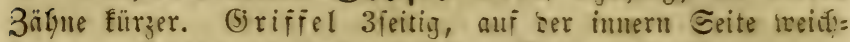
Faarig. Sälie zuiammengebrüft. Samen fugelig.

367) Phaséolas. \$3olure. Refu 2lippig, Efer: lippe $2=$ Hnterlppe 3 zabnig. (s) riffer, staubiäben und

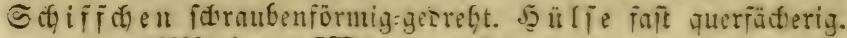

368) Vicia. RBiafe. Relf 5jäfnig, sie oferem

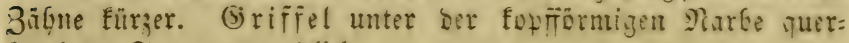
bärtig. Santen rumblid̆.

369) Enume. Rinfe. Seldy falt io lang als tie Arone, 5tfeilig, Die Biptel ungleiá, lang zujejpiţt. Narbe foprinermig, überall fefuart. Eament fhattuno.

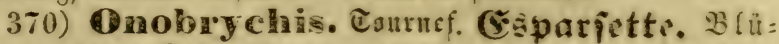

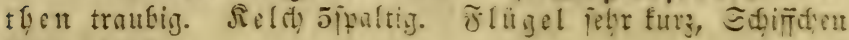
içief abgeftutst.

\section{t† હs!ieberbülfern.}

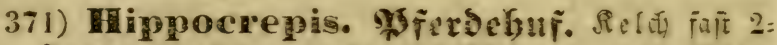

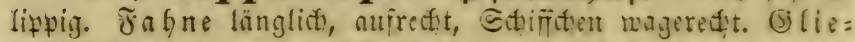

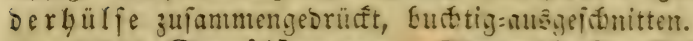

372) Ondithopas. Bogelfaf̆. Ret( 5zänig.

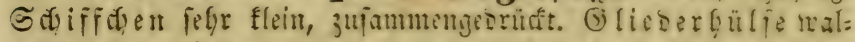
zenförmig, gebogen.

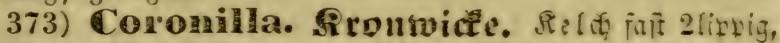

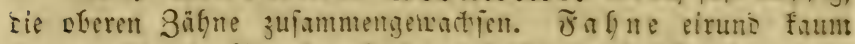

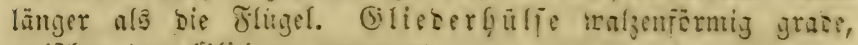
zivificten ben Glisbern serengert.

\section{Soronung Hexandria.}

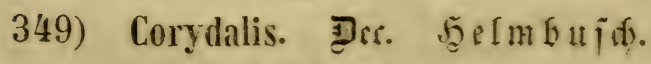

* Trsurazl Enollig.

$\dagger$ Deachblätter ganzransig.

958. C. cara. Sibigg. (Fumaria bulbosa $\%$ L. -

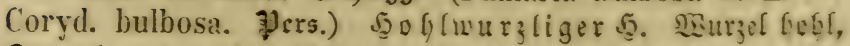

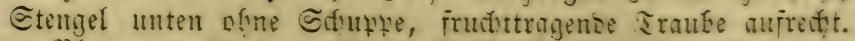

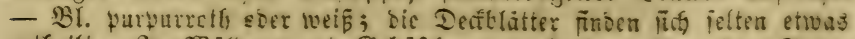

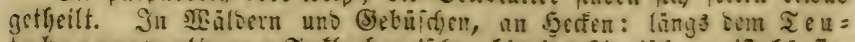

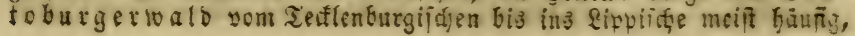




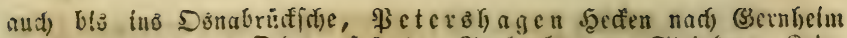

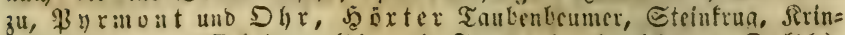
gel, unter Dem Migeinterg (hicr Die Form mit abmeidjenben Defol.), 3̈ verungen bef. en Mliblenbera, auf ben Jjeben bon Strom=

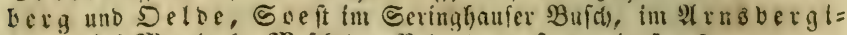

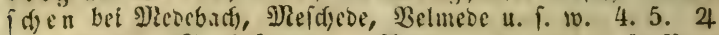

959. C. fabacea. Yirs. (Fumaria bulbosa $\beta$. L.) Bofuenartiger 5 . SBurzel nidyt bofbl, Gtengel unten mit blattlofem fouppenförmigem $\mathfrak{B}$ lattítiel; fruchttragenoe Traube nid)t verlämsert, wenigblütbig, gebrungen, liberfangend. -

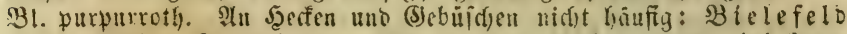

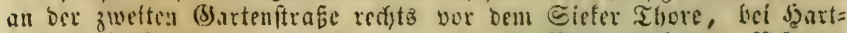

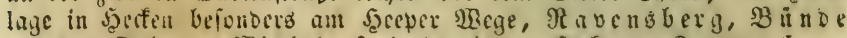

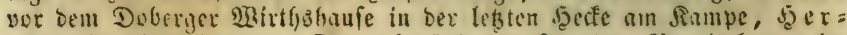
ford bef Enterbämer, Dönabrä of und $20 t t c$, Sberlebarg im Schlo

\section{t† Deḉblätter fingerig = getheilt.}

960. C. digitata. Bers. (Fumaria bulbosa $\gamma$. L. - Coryd. solida. Sm.) (5) efingerter 5 . Wurzel nidyt fobl, Stengel unten mit Sduuppe, frudttragenbe Traube ver:

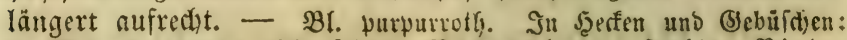

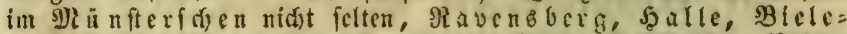

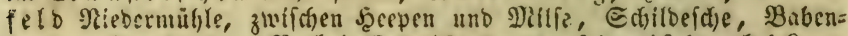

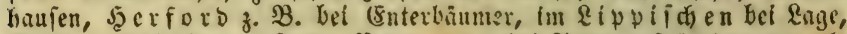

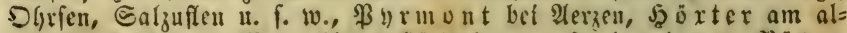

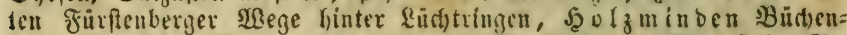
berg, Burgberg, \$et ershagen nar) (biernlycim zu, Soeft im Se=

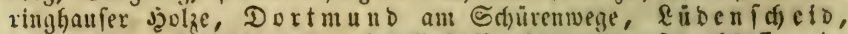

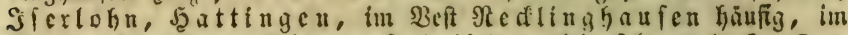

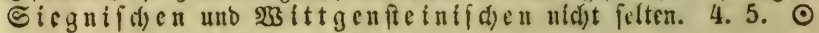

** Tुsurzel äftig s farerig.

961. C. lutea. \$자. (Fumaria lut. L.) B!ätter

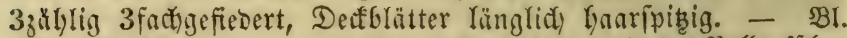

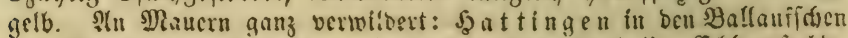

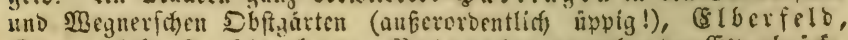

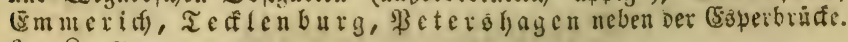
$6-8.24$

"** 203urzel einfad).

962. C. claviculata. Disc. Rletternoer S. Blät:

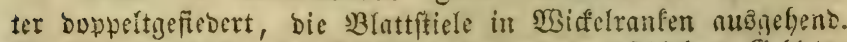

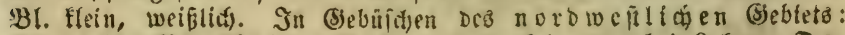

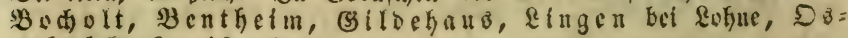

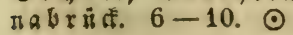

\section{0 ) Fumaria. (5roraud).}

963. F. officinalis. Gemeiner 5 . Meldblätter 


\section{Hexandria. - Octandria.}

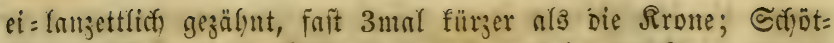

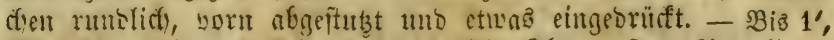

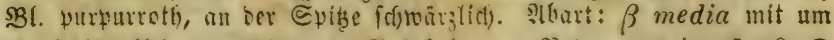

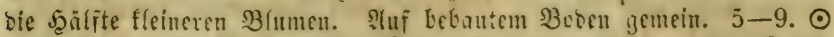

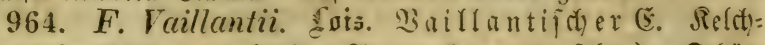

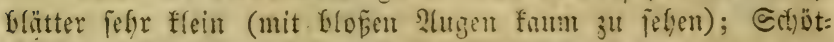

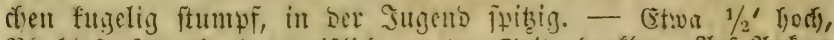

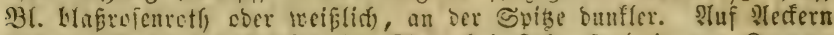

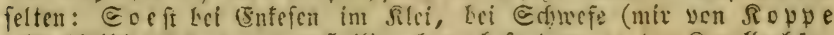

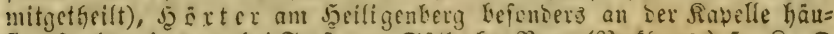

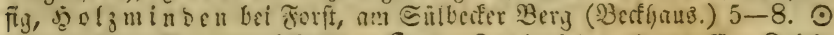

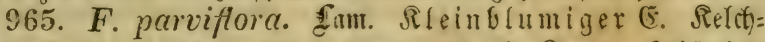

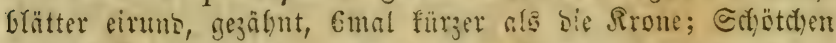
rumblich furzjugeppizt. - Eefre zart, nler gegen 3' roof, Blatt=

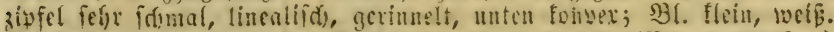

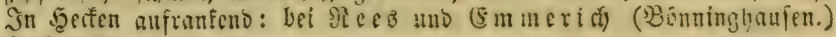
6. 7. $\odot$

\section{Sronung 0ctandria.}

\section{1) Polygala. Nifuzblum ๕.}

* Traube vielbtutthig.

966. P. vulgaris. (B)meine $\Re r$. Blätter fómul= Innzettlid, sic unteriten fleiner efliptija); flügelartige Reld)blät= ter elliptifich soer eirumb; Dedfelätter fralb fo. Iang ala bas Blütfenfitieldyen. - Die 3 Nerven Der flügclartigen Reldhblätter

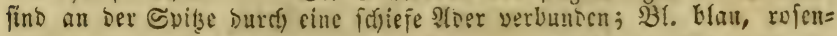

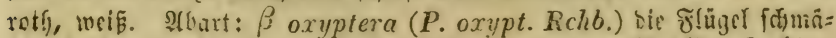

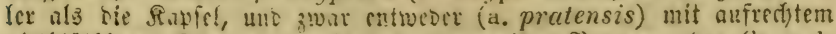

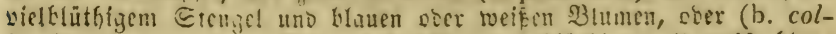

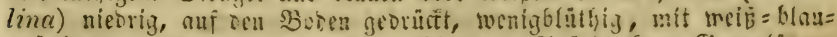

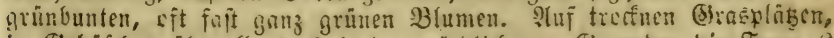

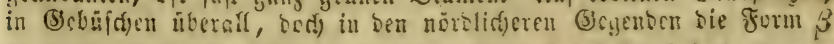

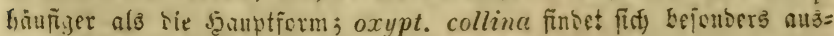
gezeiclynet nuf Turfwieien ber Ecnne. 6. 7. 4

967. P. comosa. Sidh. Gaptige ßr. Die feitm= ftünoigen DecfGlätter fo lang als bie Blïtfenftielchen, bie ofer=

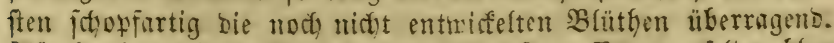
Flügel wic vorige; Bl. rofenroff) mit grinen Rerben, folten Elau

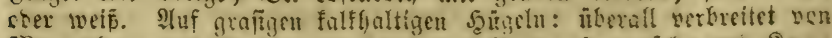

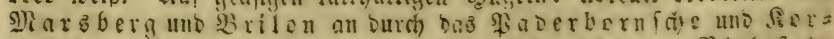

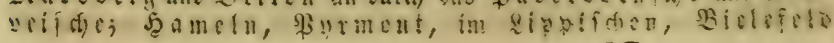




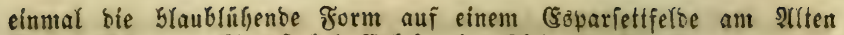
Berge, Эburg. Sueft bei Enfefen in Silet. 6. 7. 24

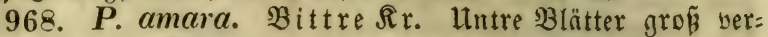
fefrteiruno, eine Nopjette bilbeno, obre länglid): feilförnig; Flï:

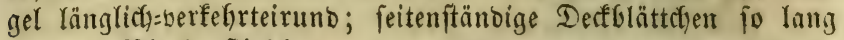

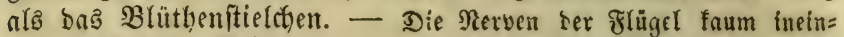

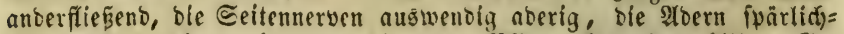
äftig, nicjt nebig = werbunben: bie ganze \$ffanze hat sinen bittern (S)e= f(t) marf. Formen: $\alpha$ genuina ( $\boldsymbol{P}$. amarella. Crntz) B(umen gró̈, blau, bie Flügel oft linger als bie Rapiel, $3 B$ urzelblätter fehr grof

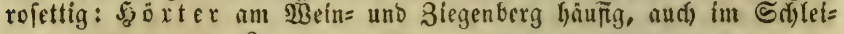

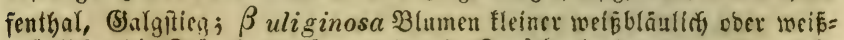
grünlid), bie Flügel oft lürzer als bie fiapiel, lestere entweder melse zugcruntet ( $P$. austriaca. Rchb.) ober mefr fellförmig ( $P$. uliginosa Rchb.): in $\Re$ a vensbergif d) en zumal um Bbielefe id felje verbreitet fowohl auf trudfnem Mhud

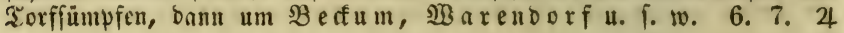

** Traube meift 5 blüthig.

969. P. serpyllacea. Wrije. (P. depressa. Wznd.) Duendelartige $\mathfrak{R}$. B Bätter Inujettlid), bie untern elliptifí), bie mittlern fait gegenftänbig; Flügel elliptifit). - Blumen zu=.

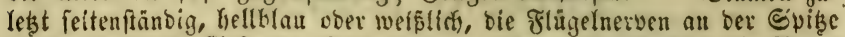
fdräg incinanterfléfend, Ecitennerven auswendig aberig, bie strern äftig neşig=verbuncen. Thu Jabeboten: im \&ipplfthen bei Rage,

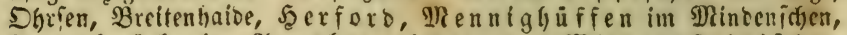

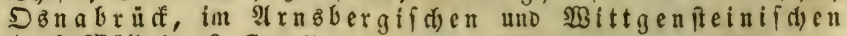
(nad) 9lülfer). 6. 7. 4

\section{Sronung Decandria.}

\section{2) Spartium. Prriemfraut.}

970. Sp. scoparium. (Sarothamnus scoparius.

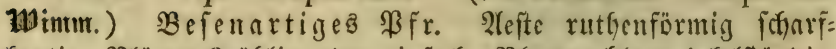
fantig, Blätter 3 äglig Doer einfach, Blumen blattwinfelftänbig,

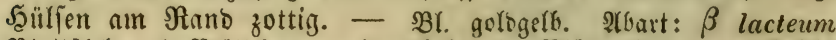

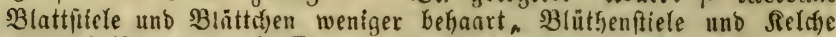
etwas fleifd)iger uno bläfier; bie Blumenfrone gefblistiveís ober mil(t)=

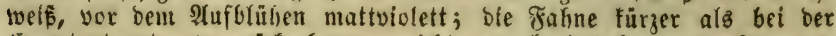

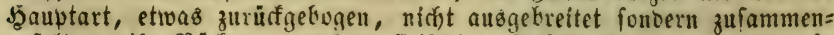

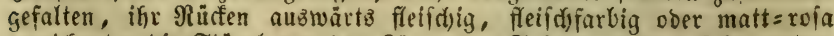
gezeidfinet; bie Flügel von ber Ränge Der Fafhne uno von feffr gartem

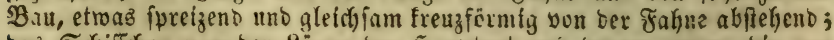
bas Erjiffchen von ber länge be: 


\section{Decandria.}

bern Theile auffallene länger. In einigen (Segenden nuf עerfd)iebenen

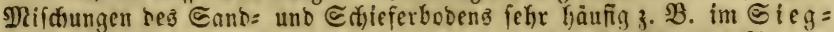

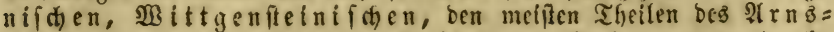
bergifden, int weftliden (Sjebiet von Stcinfugen an burdsz

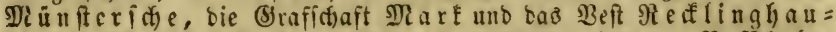

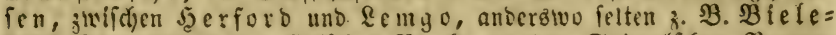

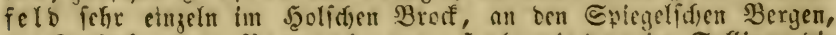

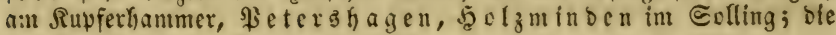

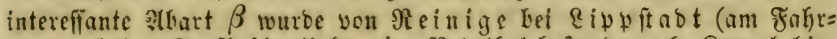
weg nath) ber Torffulile linfz, im Rabelfolzbeftand nach Sappel hin,

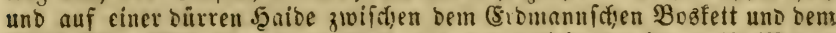

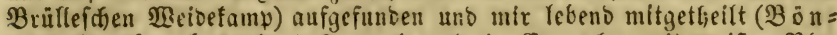

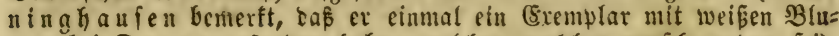
men bei $D a r \| p$ gefunden fabe, weldyez nadjher veridjumben fei). $6-8$. t

\section{3ä3) Genista. (binfter.}

* Unberwaffinet.

971. G. tinctoria. Färbeginfter. Rahl, Blätter

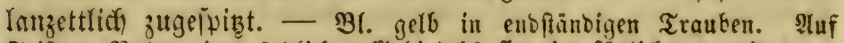
Triften, Maimen im nörolidgen Siebiet häufig, im füslidjen weniger ge= uein. $6-8$ ち

972. G. pilosa. Bebaarter (53. Blätter Ereitlan= jettlici) ftuntpr, nebit Rleften, Blütbenftielen, Relduen, Blumen

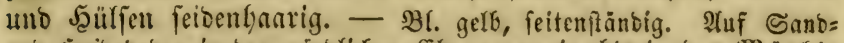

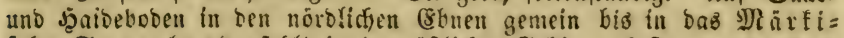

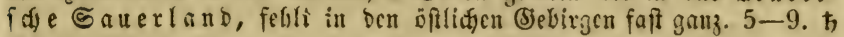

\section{** Dornig (\$Blumen traukig).}

973. G. anglica. Englifoter \$). Zeftuden nebit ben Blättern fahl. - Bl. gelb. (Gine fallanfere frorm ịt $G$. arcuata. Ar.). Fuf (Sirastriften, fowshl torf = als falfyaltigen, ourds bas noroweftlict)e (S) ebiet gemein biš füslich ins Beft Recflinghaujen

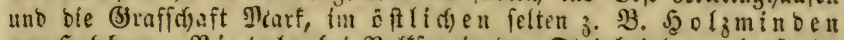
am Soljbery, Rinteln bei Bolffen in ten @teinbrinten, ebento in

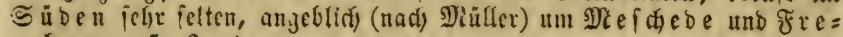
Deburg. 5. 6. 万

974. G. germanica. Ientider (अ. Ifefted net

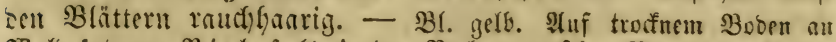

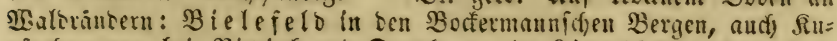
yferfummer bci Ricoief und Durnberg, im \&ippifdien Ealyuficm,

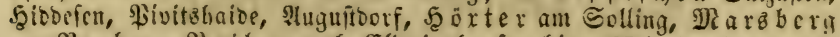

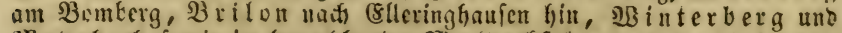

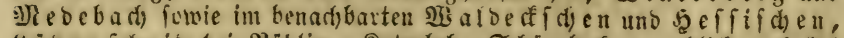

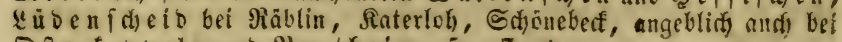
Diterfappeln uno $3 e n t h e i m .5-7$. 万 


\section{4). Cytisus. (Sis î́fflee.}

975. C. Laburnum. (5) emeiner (5). Bolfucu finut. (5) oloregen. Trauben feitenftändig reidblütyig fongent an=

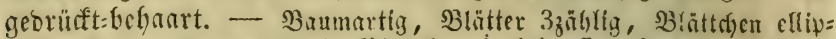

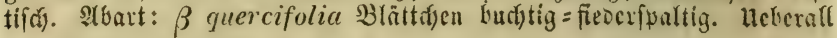
angepflangt, $\beta$ feltem. 4. 5. 万

+976. C. sagitialis. Enod). (Genisia sag. L.) (5i $\mathrm{e}=$ frügerter (5). Stengel nieberliegend 2 fduneibig: geflügelt ge= gliebert. - Slätler einfact), B̉l. gelb. Thf troctnem SBalbboben

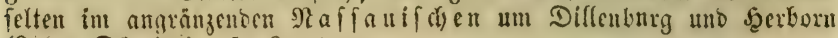
(Eecrä, Törrien). 5.6. 万

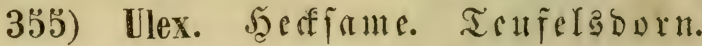

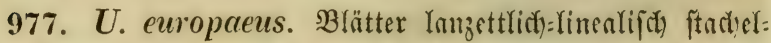

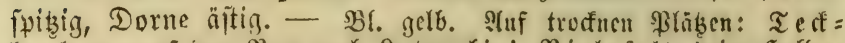

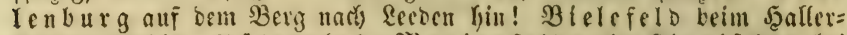

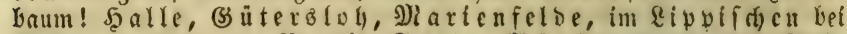

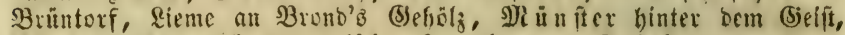

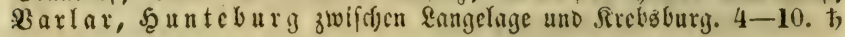

\section{3ว̈6) Onónis. Şa}

978. O. spinosa. Dornige J. Stengel murredyt doct aufitrebend, won $1-2$ reifigen saaren zottig unt zerftreut= brüfentyarig; 2lefte bornig, Dorne meift zu 2 ; Sălffe fo lang

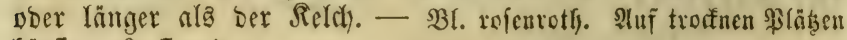
そुäufig. 6. 7. ฤ

979. O. repens. (0. procurrens. Wallr.) $\mathfrak{A}$ ri $€=$ (⿻)

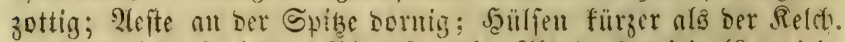

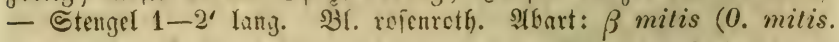

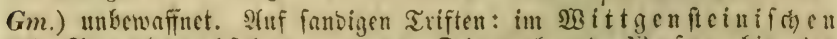
utmo Iำ

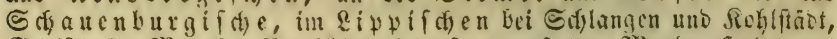

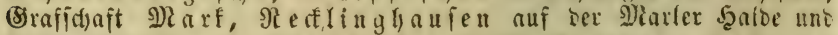

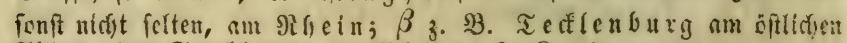

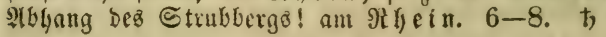

\section{7) Anthyllis. $\mathfrak{X} u n$ Dfrat.}

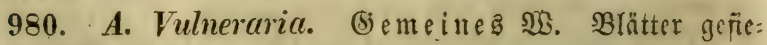

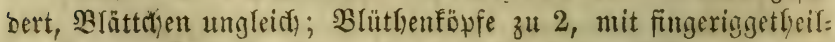

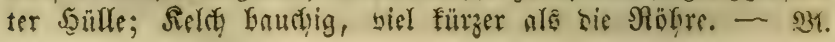




\section{Decandria.}

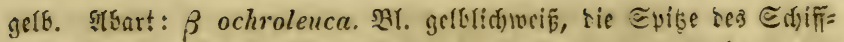

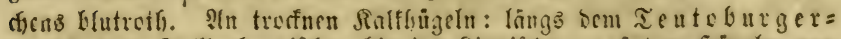

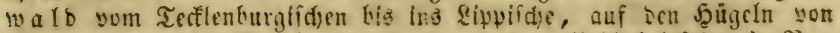

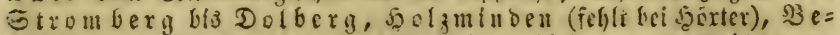

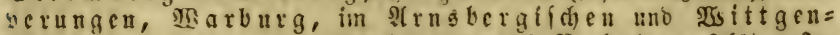

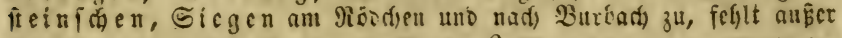

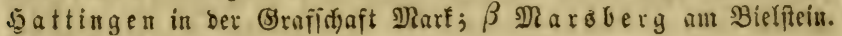
$5-8.24$

\section{3̈8) Melilótus. fant. Stcinflee.}

981. M. macrorrhiza. Mers. (MI. officinalis. Willd.) sangwurzeliger St. Stengel aufredt; Flügel unb Ediff:

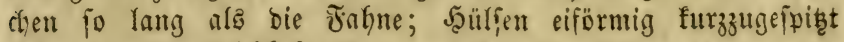

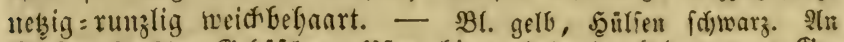
Misiefen, feuchten (Bebuifden, Heern hier uno sa burd) bas ganze (jie=

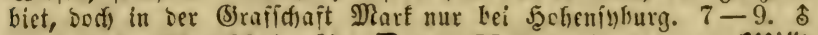

982. M. officinalis. Desr. (M. Petitpierreana. Millo.) (Echter St. Gtengel aufitrebent; Jlügel fo lang als bie Jahne,

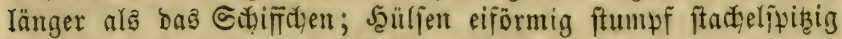
querrunglig, etivas neģig, faflel. - Bl. gelb, Şülicn hellbcaun.

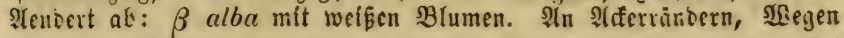
ierftrent: Bielefeld wor bem Eiffer Thore, im sipulforen bei

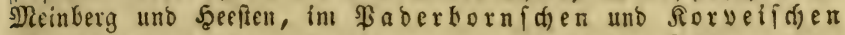

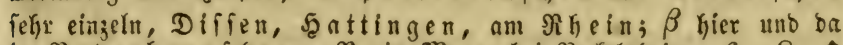

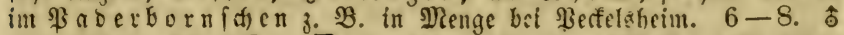

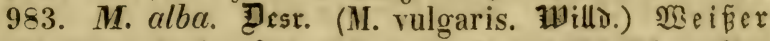

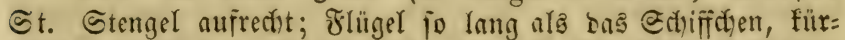
zer als bie Faf̧ne; Sallifen eiförmig ftumpf ftadyelfpibig netgig=

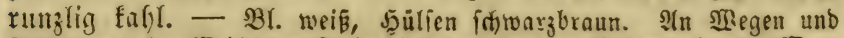

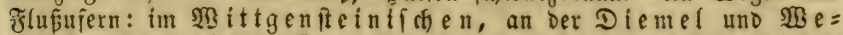

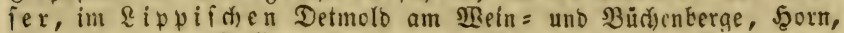

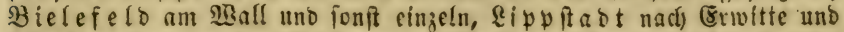
Sberfagell zu, an ber $\Re$ a fir unterfalb Jabfeninfurg und bef fattin=

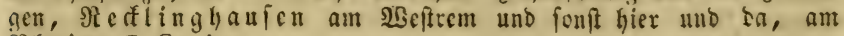
Rheir. 7. 8. 요

\section{5̆9) Trifolium. אIę.}

* Die einzinen $B$ lüthen tizkent.

† Reldh) auben weidtbehaart ober gottig.

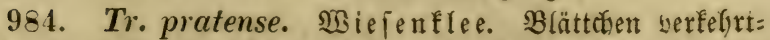
cirumb ober elliptifar); Nebenblätter eirunt, Hröblich in eine

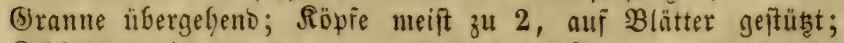
Ield) 10neroig. - $\mathfrak{B l}$. purpurroth. $\mathfrak{A}$ bart: $\beta$ sativum (Tr. sativ. 


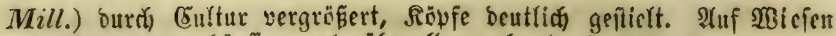

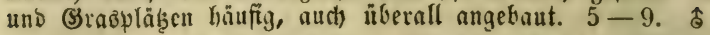

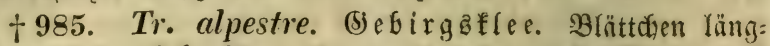

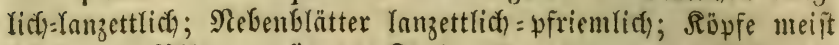
zu 2, nuf $\mathfrak{B}$ lätter geftübt; Reld 20 nervig. - Stengel ganz

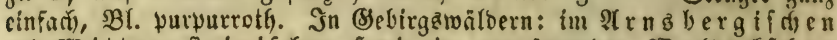

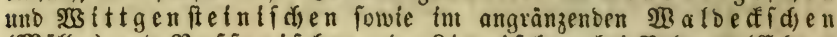

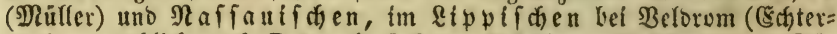

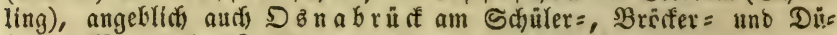
fruper $\mathfrak{B e r g} .6-8.24$

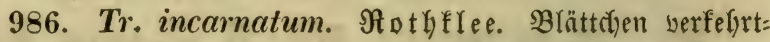
ciruno geîtubt; Nebenblätter eiruno gezälnelt; 2lefren eiförmig zulebst walzlich), einzeln, ofne $\mathfrak{B l a ̈ t t e r f u ̈ l l e ; ~ R e l d ~ 1 0 n e r v i g . ~ - ~}$ Stengel nebit ben Blättern zottig; $\mathfrak{B l}$. Dunfelpurputruth, felten hcllex.

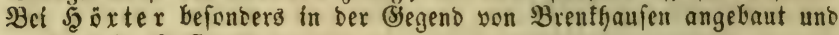
vertvilbert. 6. 7. $\odot$

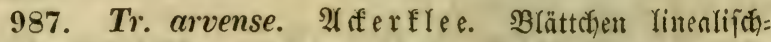
länglich; Nebenblätter eiruno:zugefpitzt; Söpforen eingeln, fefr

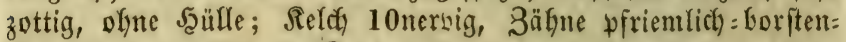

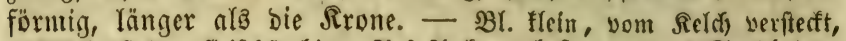
weislict), ppäter fleifdjarbig. Aluf Ifectern, befonders auf Sanbboben, bäufitg. $6-8$. $\odot$

+988. Tr. striatum. (G) e ft r e if ter $\mathbb{R}$. Untre Brätt=

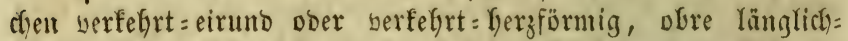

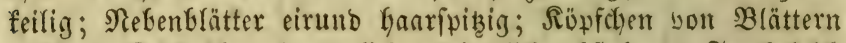

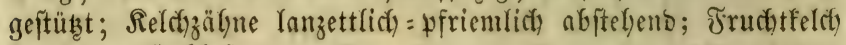

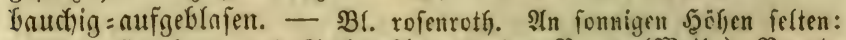

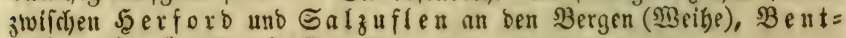
beim, 5erburn. 6. 7. $\odot$

989. Tr. fragiferum. (ธ̌robeetflec. Blättcten ellip=

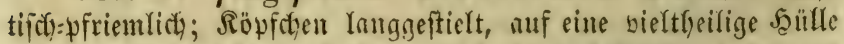
geftübt; Frudtfeld aufgeblajen bäutig nebabrig. -- Stengel

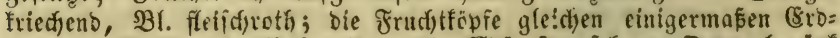

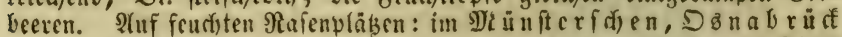

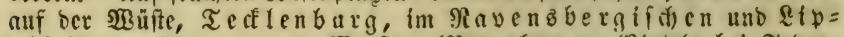
wif d e n zerfreut, an ber $\mathfrak{B}$ e fer (ßeterzisagen, SRinteln kel Tusen= mann, Şoxter, 3everungen), Sia a burg felten, Swe it bet Barabiez, STmpen, $\Re$ efflingli a u fen; fdrcint im füdlicjen (Bebiet ganz zu fel)= Үen. $6-8.4$

†† Ricld auben Eahl.

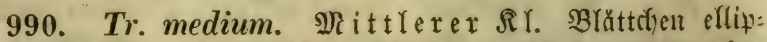
tijđ); Nebenblätter Ianzettliç berichnälert; Röpfe einzeln olgne

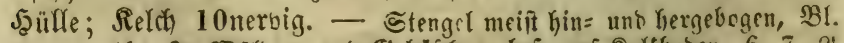

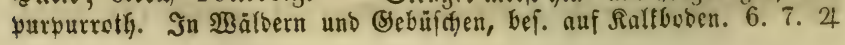




\section{Decandria.}

" Bräthen fidutlid geffielt.

$\dagger$ Blumen reeís ober hellroth.

991. Tr. montanum. Bergflee. Ctengel nufrect; Blättchen länglich)= Yanzettliç), unterfeits Gef)anart; Rebenblätter

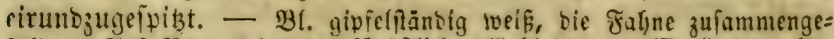

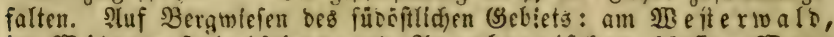

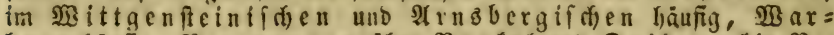
$\mathfrak{b u r g}$ häufig, $\mathfrak{B}_{\text {everungen }}$ ủber $\mathfrak{B}$ rafel und $D$ riburg berborn; Dann wereinzelt am Teutoburgerivalo bei Bielefelo, hin=

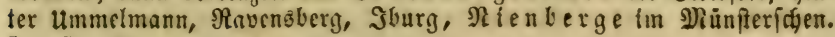
$5-7.24$

992. Tr. repens. Rriediender RI. Stengel nieber: liegeno wurzzelno; Blättd)en verfefirt=herjförntig; Nebenblätter

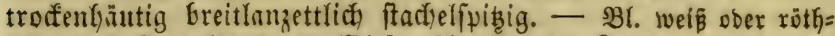

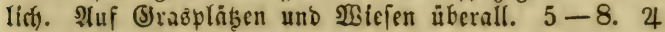

993. Tr. hybridum. Baftaroflee. Ctengel aufitre: Fent, gang fafhl, röfrig; Băättchen berfelyrteirumo voer ellip:

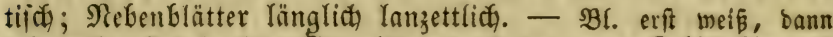

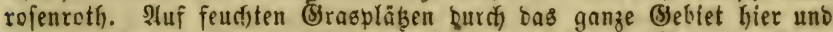

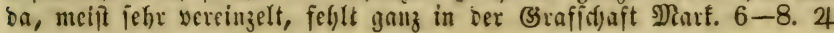

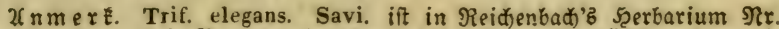

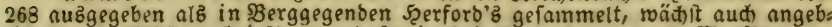

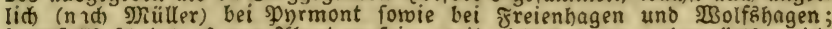
jebenfallz fdeint pe nur 2lbart zu fein: mit nid)t hohlem, oberwärtz roeid): behaartem Stengel.

†† Blumen gelb.

994. Tr. agrarium. (b) olb flee. Stengel nufrecht;

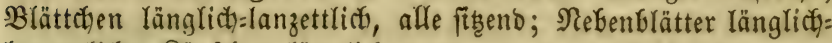

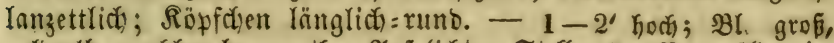
gologelb, narifher braunroth. Stuf lidgten Etellfen ber Bergivälber in

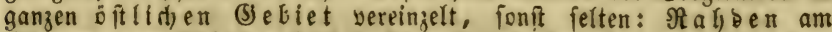

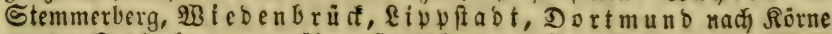
3u, ber Funtenburg gegenüber, $\mathfrak{F a t t i n g e n , ~}$ fenbrüfe, am $\Re$ he in. 6-9.

995. Tr. procumbens. Nieberliegender RY. Blätt=

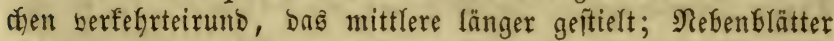
eirunb. - Ettwa $1^{\prime}$ lang, $\mathfrak{B l}$. Flétmer als voríge. Formen: $\alpha$ ma-

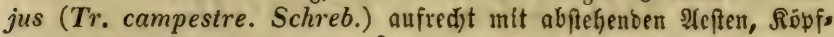
chen größer, Bl. bunfelgelb; $\beta$ minus (Tr. procumbens. Schreb.)

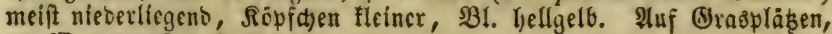
an $\mathfrak{B e g e n}_{\text {. }} 6-9 . \odot$

996. Tr. filiforme. ₹abenförmiger RY. Blättuthen feilförmig, Nebenflätter eiruno, Röpfd)en wenigblütfig (1020 blüthig). - Stengel auzgetreitet, 4-10" lang; Bł. feffr flefn,

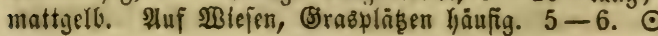




\section{0) Medicágo. Schlte df entflec.}

997. M. sativa. \&utter= S (4). \&uzerue. Cten= gel aufredut; Trauben längliç; Seullen jơnecfenförmig (2 bis 3 mal) getounden, in Dittelpunfte offen, fall. - Bl. violett Doer blän!fid. Sglet unt ba angebant, auberbem an mandisen Steflen wöllin verwildert 8. B. In Den Mुefergegenden biz \$eterblyagen, Betum, Gerlohn, Darup. $6-8.24$

998. M. falcata. Siduelföruiger Srun. Gtengel nieberliegend ober aufftrebeno; Trauben furz; Jeulfien firdelför:

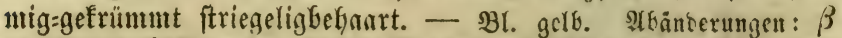
versicolor (M. media Pers.) Bl. anfangz gelf, banu grü, zuleb̧t violett; $\gamma$ major (M. procumbens. Bess) Stengel verlängert lie=

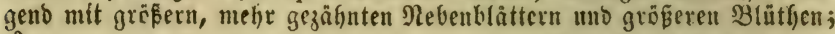
$\delta$ minor in aflen Theflen fleiner uno zarter, Blättd)en faft ungezälynt,

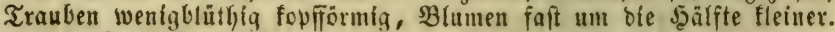

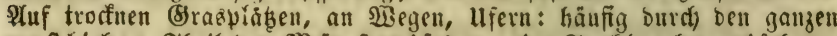

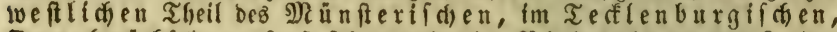

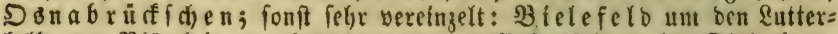
folf, ant Blömfelerg, Şoxtero an ber MBefer felten, bei Dielenberg,

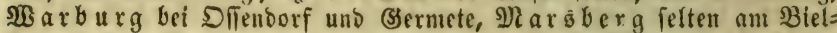

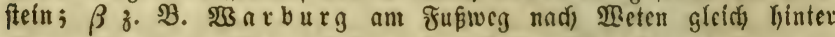
Sermete, $\gamma$ im iveflidien (Sebiet, $\delta$ z. SB. bei Nienberge. 7-9. 4

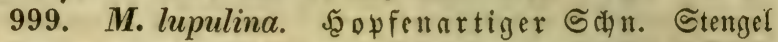

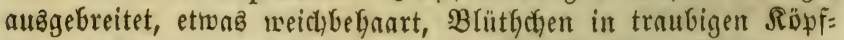

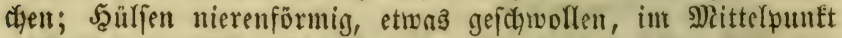
gefólollen. - Bl. gelb. Formen: $\alpha$ vulgaris șülien fafl pbex angebrüdt=tveidjyaarig; $\beta$ glandulosa (M. Willdenoroii. Dec.)

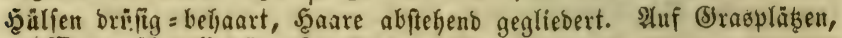
an $\mathfrak{B e g e n ~ u ̈ b e r a l l . ~} 5-9$. $\odot$

† 1000. M. minima. Rleinfter Sdyn. Stengel nieberliegeno 4fantig; Blutbenftiele 1-2blütbig; Saulfen 5unal

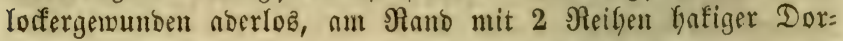

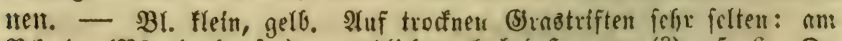

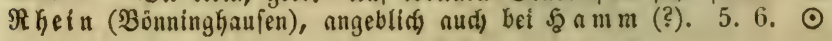

\section{1) Lotus. Sidotentfee.}

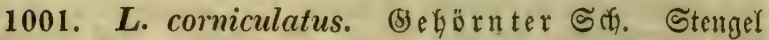

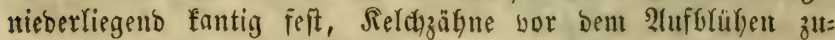

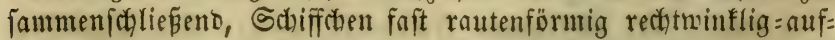
f́teigend. - Bl. gelb, Staubfäben verbreitert. Formen: $\alpha$ vulgaris fafhl ober zerftreut= behaart; $\beta$ ciliatus $\mathfrak{B l a ̈ t t d y e n ~ u n b ~ R e l d h ~}$ langbewimpert; $\gamma$ hirsutus ganz raudiharig. In Sistejem, auf (3rasz= 


\section{Decandria.}

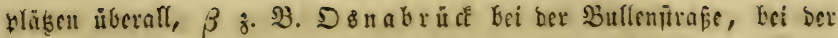
Divelaburg. $5-9.24$

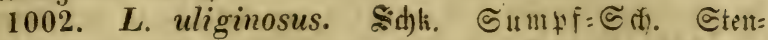

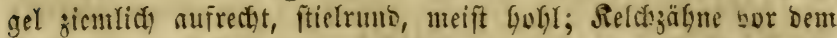

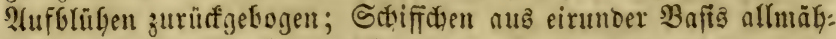

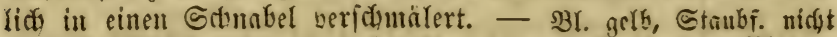

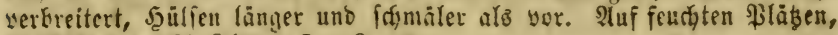

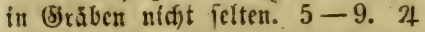

\section{2)' Astrágalus. Iragant.}

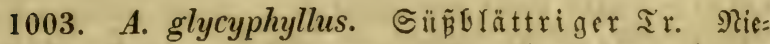
bergefîtrefft; Blätter ungleidfpanrig = $(5-6)$ geficbert; Şulfert

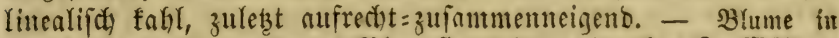

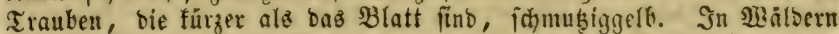
unb (bebüfden auf Ralfboben: Durrfy ben ganjent Teutoburger=

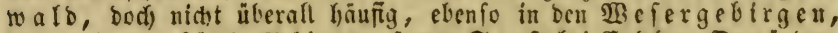
feltner in ben fübl. Behirgen; ferner Soeft bei Enfeien, Spmünden, Serimghaufen, auf ben Ralfhügeln von Stromberg bis Dolberg, auf senjentigen yon Coeźfe is uns Birlerbeff, Bün be am Doberg, Rahoell am Stemmerberg. 6. 7. 4

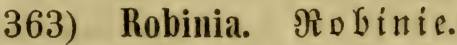

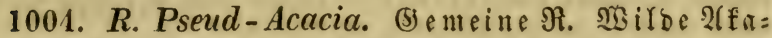
gi e. Blättchen eiruno, Traube Kangent, Jaülyen fafl. - Ein

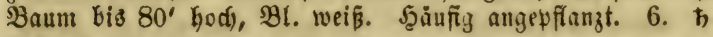

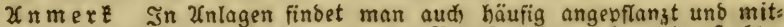
unter berwilberno Colntea arboriscens, ben $\mathfrak{B}\{$ a $f$ e $u$ it $r a$ d), mit aufgeblas fenen J̧úlfen uno gelben Slumen, feltner C. cruenta. Ait. mit gelbrothen 8lumen.

\section{4) 0robus. 2iBaldertife.}

* Stengel ungeflügelt (Eantig).

1005. O. vermus. ซrühling $=\mathfrak{S}$. Blätter $2-3=$

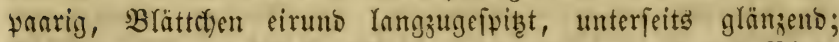
Traube iwenig: (meift 4) blïthig, etiva io lang als ong Blatt.

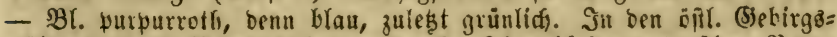
twältern: bon Bielefeld an burdh

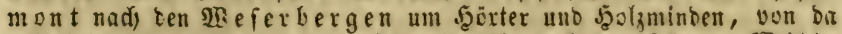

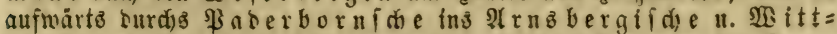
genfteinifde; fonit felir vereinzelt: Stromberg an ber Sireuz=

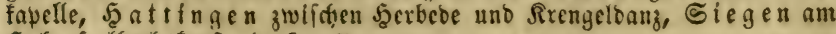

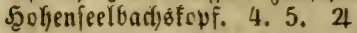

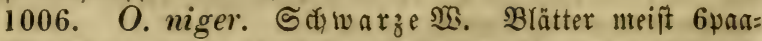

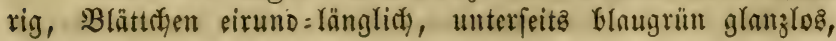




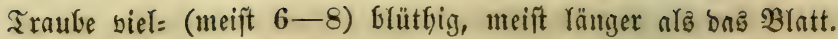
- Bl. purpurroth; beim Treafnen wirb bie ganze \$flunge fidwarz. In Bergiwalocrn felten: Bielefelo am Süvabhany ber $B$ erge bis

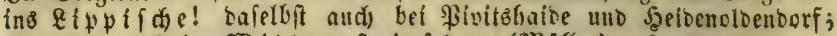

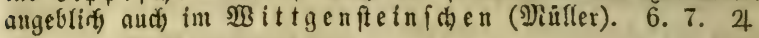

*+ Etengel geflügett.

1007. O. tuberosus. Inollige $\mathfrak{3}$. SGlätter 2-3=

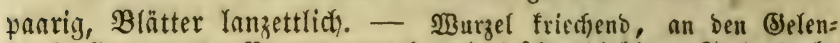

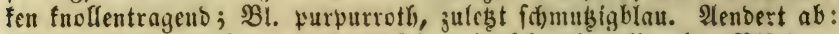
$\beta$ tenuifolius. ( 0 . tenuif. Rth.) mit fdgmalen linealen Blättern. In Bergwälbern, befonters nuf Sanb= vber Sambiteinboben : im $\mathfrak{T} \in \mathrm{u}=$

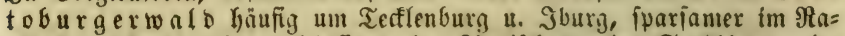
vensbergifdsen, wieber häufiger in sippifatsen, im Solling, im

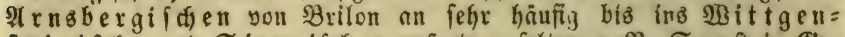
ficinifde und Giegatfde; auberbent felten z. B. Soeft in Eese= hölzen ber Sberböroe, \&úbenfigeid, Jferlohn. 5. 6. 4

\section{5) Lálhyrus. PIatterbfe. \\ " Etengel ungeflügelt (fantig).}

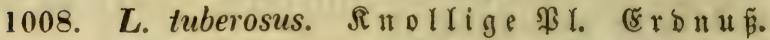
Rafy; $\mathfrak{B a u z z e l ~ f a ̈ b l i d ) ~ m i t ~ f d y w a r z e n ~ R n o l l e n ~ a n ~ b e n ~ ( b e l e n f e n , ~}$ Nebenblätter Yinealifoc). - Blume purpurroth. Sim $\mathfrak{R}$ gein auf Tecfern, Gefonbers um Dutsburg! angebl. aud) Minden bef Dan= ferien (5oyer) uno im Retppifd en (?). 6. 7. 4

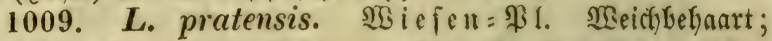

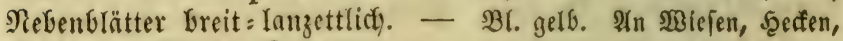
(5xáben gemein. $6-8.2$

** Etengel geflügelt

$\dagger$ Slätter Ipanrig.

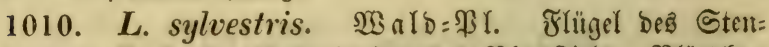

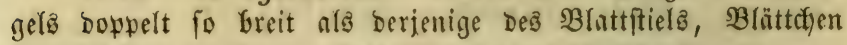

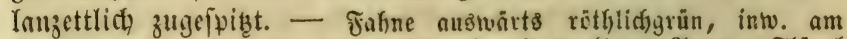

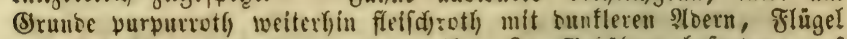

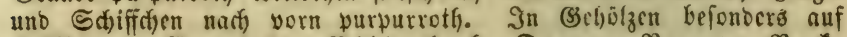
Ralfboden: Coezfelo, Billerbeff, Darup, Rorup, Re ff́

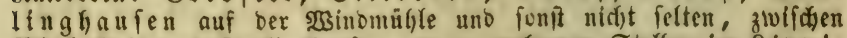
Bielefelo unb Derlinghaufeil und an mehreren Stellen im Rippl= fden, faft im ganzen ise fergeblet bod vereinzelt z. B. Beve=

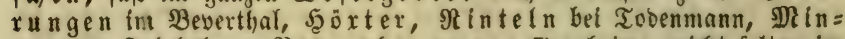
ben am Jafobăberg, geters hagen nor Bernheim; nidet felten im

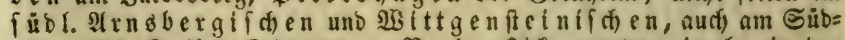
rande bes Reefes Slegen z. B. im Shiffengrund; cenzeln in ber

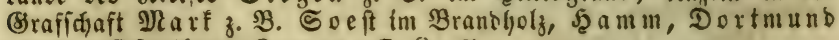
yor bem Difentlyore, Ramen. 7. 8. 24

1011. L. platyphyllus. 敢t3. Stumpfolâttrige 


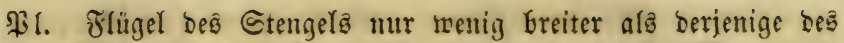

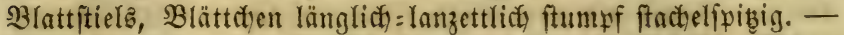

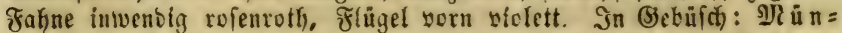

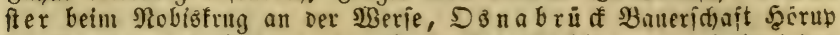

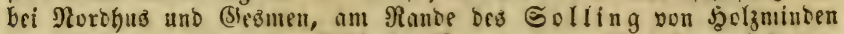

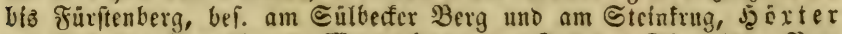

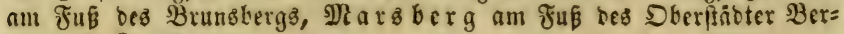
gโรె. 7. 8.2

1012. L. latifolius. Breitblättrige $\mathfrak{x l . ~ F l u ̈ g e l ~}$

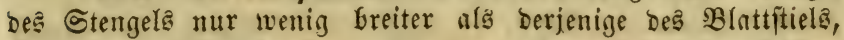

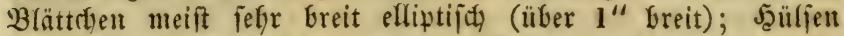
mit glatten Rüfenfielen; Gamen faum zum britten Theile

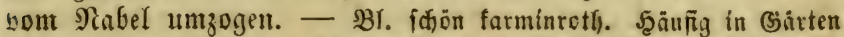
gezogen und mitunter yofl verivilbert, wohin benn aud bie angebl.

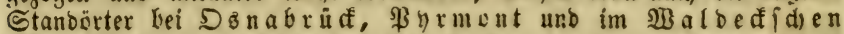

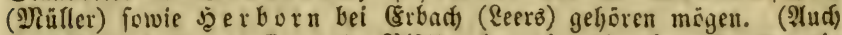
L. heterophyllus, befien untre 3 lätter 1 parig, bie oliern 2-3pantig finb, wiro yon ber Dörtien bel Dillenburg im angrän. Naf= fauifden angegeten). $6-8.24$

†† \$Blätter 2-3panrig.

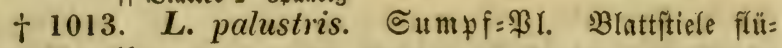
gellog, ja)malferandet. - Bl. überkangent, bläblau ober fellro=

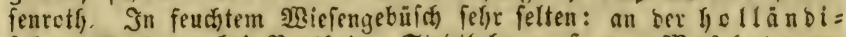

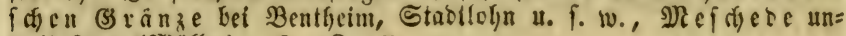
weit Raet (Y)üller). $6-8.4$

\section{6) Pisum. Erbie.}

1014. P. sativum. (5) a $\mathrm{r}$ te $\mathrm{n} \in \mathrm{r}$ b f e. Blütfenftiele 2-meforblütgig, Gamen fugelig (beflgelb). - $B$. meis. In verfojiebuen Spiclatten gezogen, felye bemerfengwerth ift aber: $\beta$ ramulare (P. ramulare. Moriss.) Flügel แno Sdiffichen purpurrotf),

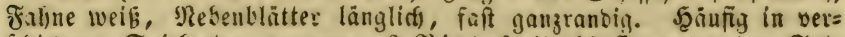
fdiconen Epiclarten gejogell, $\beta$ Biclefelo häufì unter ber ভat, bejenders um Braffwede. 4. 5. $\odot$

1015. P. arvense. Felderbje. Blütheniftiele 1-2= blütbig; Samen fantig=eingebrïfft (graugriun mit braunen

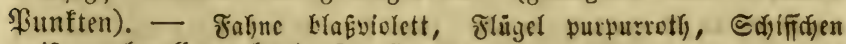

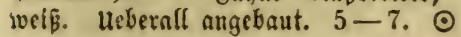

\section{7) Phaséolus. $\mathfrak{B}$ of ne.}

1016. Ph. vulgaris. S(t) nittbohne. Traubent für=

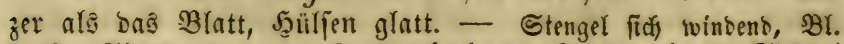
weíp. Stbart: $\beta$ nanus 3 wergbohne, אrupbohne, Stengel nici)t (iiñ ivinbenb, nicbrig. Heberall gebaut. $6-8$. $\odot$ 
1017. Ph. multiflorus.

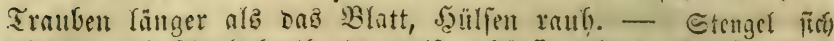

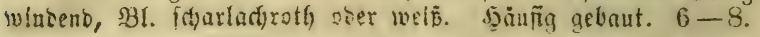

\section{8) Vicia. Wibte.}

* Blumen in langgeftielten Trauben.

1018. V. Cracca. Bogelwi iffe. Blätter 10-12= panrig, mebjt dem Gtengel weichbefaart; Nebenblätter gamy=

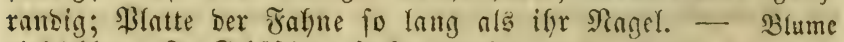
vislettbian. In Gebüften, Saeffen gemein. 6. 7. 2

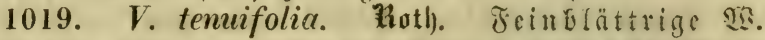

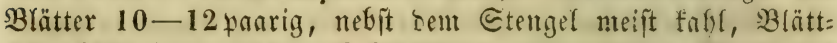

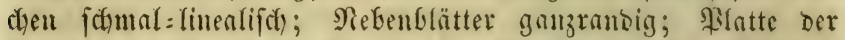

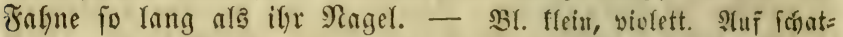

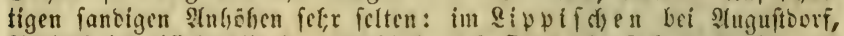

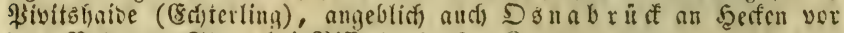
bem Natruper Thor, bef bifiendorf. 6-8. 24

1020. V. sylvatica. MSalowiffe. Blitter 7-9= paarig, Nebenblätter fanmartig=gezägnt. - $\mathfrak{B}$. weiflid)violett.

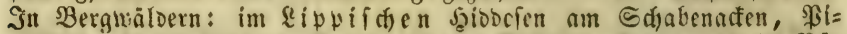

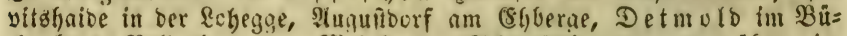
dhenberg, Bellenberg Dem Nicinberger Sdivefelbrunnen gegenüber, im

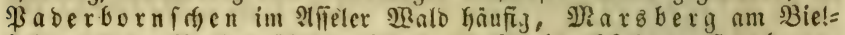

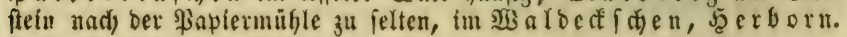
6. 7. 24

** Blumen blattwinkelftënoig.

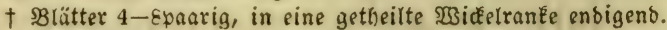

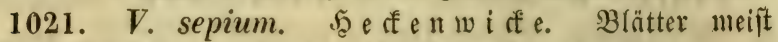

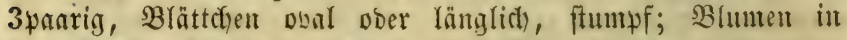
furzgeftielten buifcheligen Trauben, meift zu 4-5. - Formen:

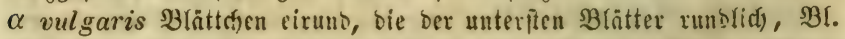

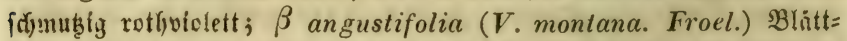
then eirun $\delta=$ länglid) ober eirund $=$ lanzettlid), 3 l. wie vor. $\gamma$ interme-

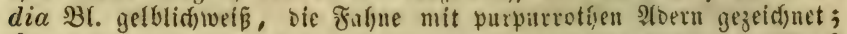

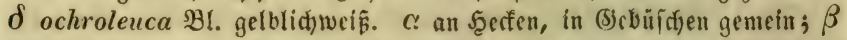

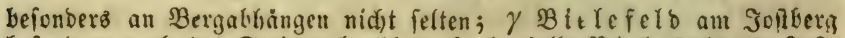

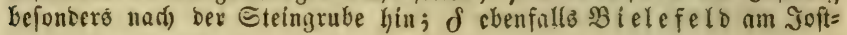
berg. $6-7.4$

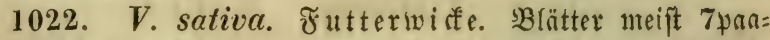

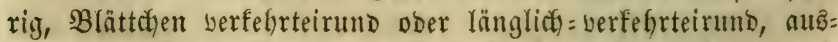

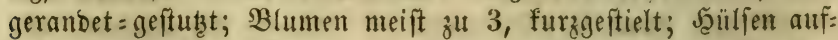

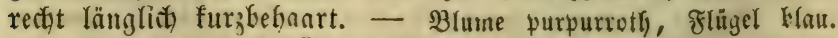
Heberall gebaut uno häufig verwilbert. $6-8$. 
1023. I. angustifolia. 吕h. $\subseteq(1)$ malblittrige

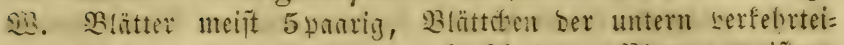

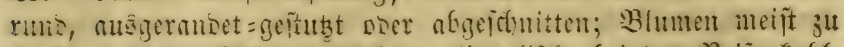

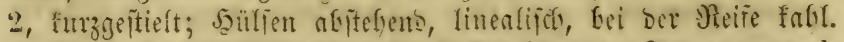

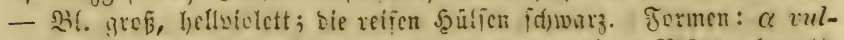
garis ( $\boldsymbol{V}$. segetalis. Thuill.) Bînttcijen ber stern 23lätter Yanzett= lif) =linealifig); $\beta$ angustissima (V. Bobartii. Forst.) Blättchen

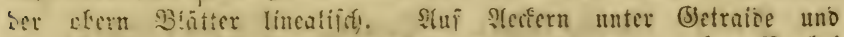

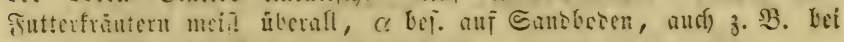
\$eterghagen getraut 5.6. 6

†† Blätter 2-3parrig, in eine Stad)eltipiąe ensigens.

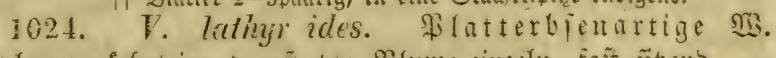

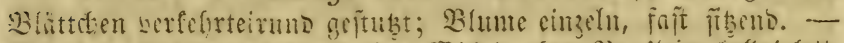

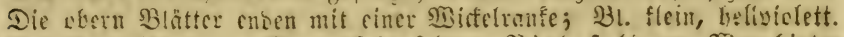

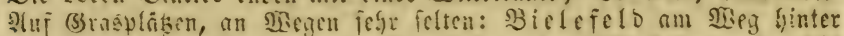

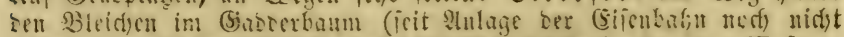

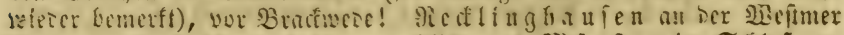

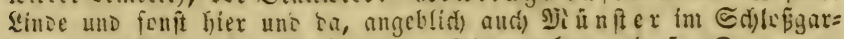

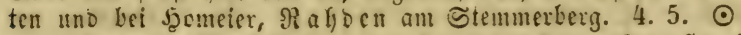

1025. V. Faba. B̈olnentiffe. (5rofje Bobne.

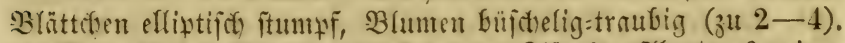

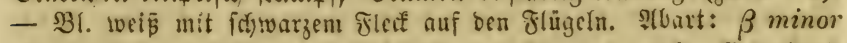
( $\boldsymbol{r}$. equina. Rchb.) in allen Ilyellen fleinet. Heticrall gebaut. $6-5 . \odot$

\section{9) Ervum. Rinffe.}

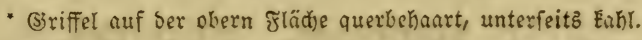

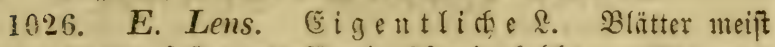

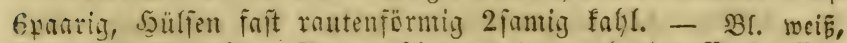

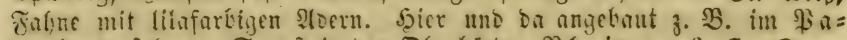

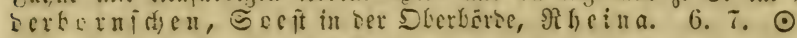

** Brif̄el obetwärts kilberall greidfförmig behaart.

1027. E. hirsutum. Befgarte \&. Blätter meift

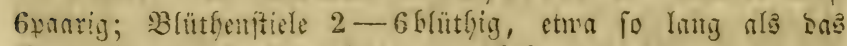

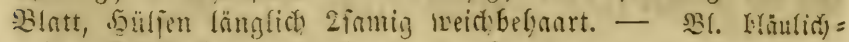

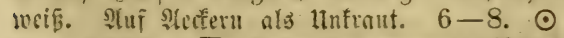

1028. E. tetraspermum. Sierjamige ̊. Blätter 2-4parig; 3 lütheniftiele 1-26lütbig, unbegrannt, etwa fo

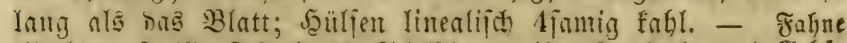

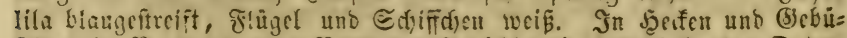

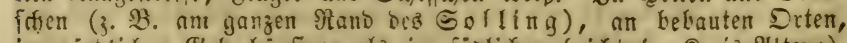

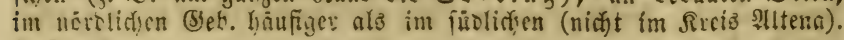
6. 7.

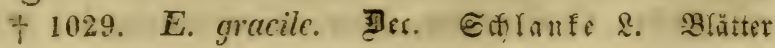


$3-4$ parrig, Błüthenítiele $1-4$ Grütbig, in eine begrannte Spike enbigento, zulekgt boppelt fo lang als bas Blatt; Şülien Yinealifoch, meift 6 famig, fafll. - Bl. wie vor. beds bebeuteno

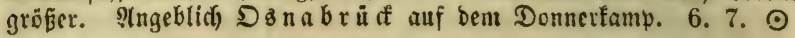

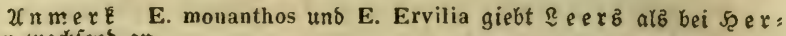
born wadjend an.

370) Onobrychis. Courn. Espariette.

1030. O. sativa. (5) enteine 区. B Blithentítiel bopwelt

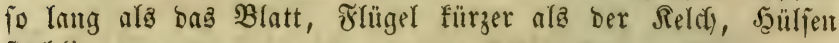
ftad)lig. - Bl. rofenroth geftreift. Suf tructnem Ralffioben ange=

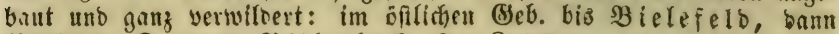

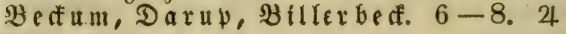

\section{1) Hippecrépis. R्̃erdefut.}

1031. H. comosa. Sthopfiger $\mathfrak{B}$. Bhument ant

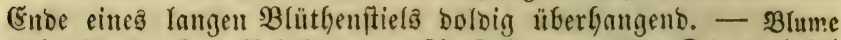

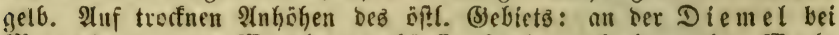

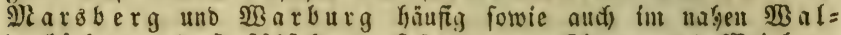

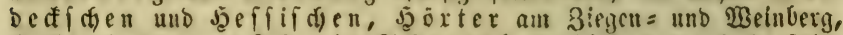

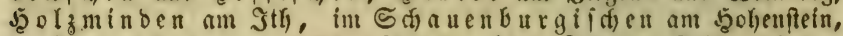

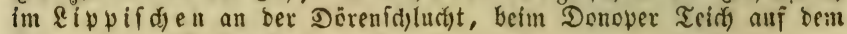
शtlfornzberg, Derlingfaufen. 5-9. 4

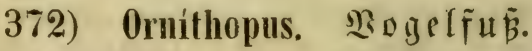

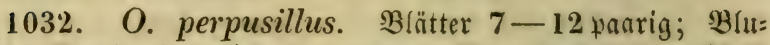
men fovfï̈rmig $(\mathbf{l}-5)$, bon einem gefieberten $\mathfrak{B l a t t e}$ geftübt.

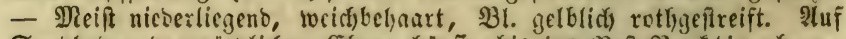

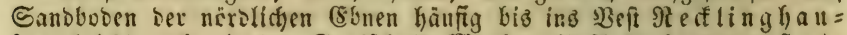

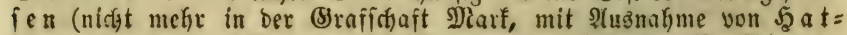
tiugen), in ben bift. und fübl. Berggegenden felten z. B. Si

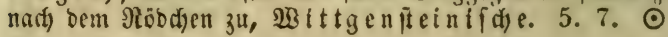

\section{3) Coronilla. Sixunmidfc.}

1033. C. varia. $\mathfrak{B} u n$ te $\mathfrak{\Omega}$. Blätter meifit 10 tra

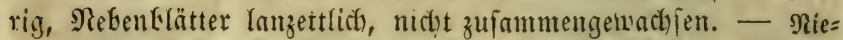

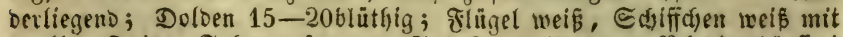

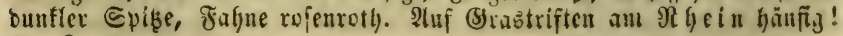
$6-8.24$

1034. C. montana. Sisp. (C. coronata. L.) Berg= 


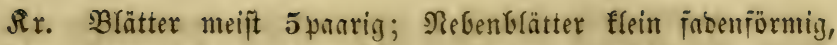

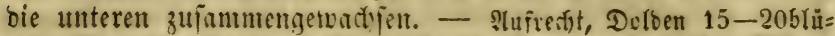

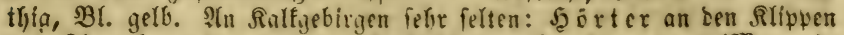

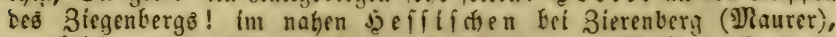

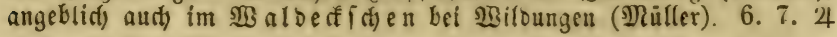

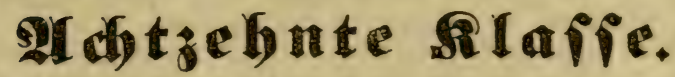 Polyadelphia.}

\section{Sromumig Polyandria.}

374) Hypericum. Jobanniş 5theilig. Rrone 56lättrig. Sapfel 3-5 füdthig vieliannig.

374) Hypéricum. Sohanniฐfraut.

- Reldrano nadit. $\dagger$ Stengel sufredit.

1035. H. perforatum. Durifitatiges S. Etengel

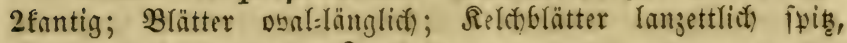
boppelt io lang als ber Frudtfinoten. - Bl. gelb wie bei allen folgenben Irter. Stbart: $\beta$ latifolium (H. commutatum. Nolte)

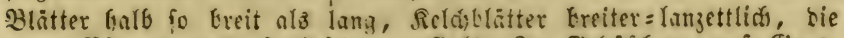

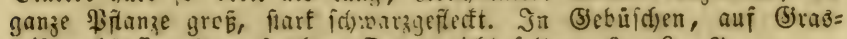
triften häufig, $\beta$ an feutsten Soten nidit felten. $6-9.24$

1036. H. quadrangulum. (H. dubium. Eefrs.) $\mathfrak{B} i \mathrm{er}=$ fantiges S. Ctengel f(t)wadt):4fantig; Bratter eirumo; Reld)=

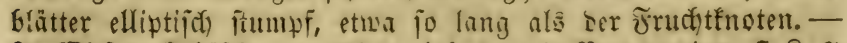

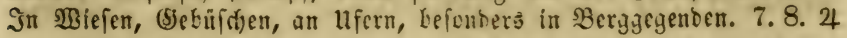

1037. H. tetrápterum. Etics. (H. quadrangulare. Snt.) Bierflügeliges Э. Etengel geflügelt:4fantig; Blät: ter cirund; Neldyblätter lanzettlids zugejpizht, etwa io lang als

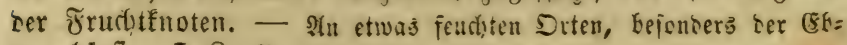
nen, băuîtg. 7. 8. 4

tt Etengel niebertiegent.

1038. H. humifusum. Nieber I i egendes 9 . Eten=

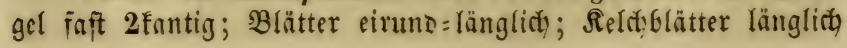


ftumyf ftachelipizig, bopwelt fo lang als ber Fructftenoten (zu= meilen feintgezännt). - $\mathfrak{A} u f$ fanbigen uno Ielymigen, etwas feuditen

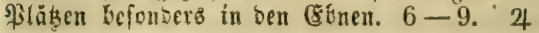

** ラelthrano gezähnt uno meift brüfig:geroimpert. $\dagger$ Stengel aufrectit.

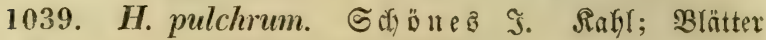
Tïkento ftumyf, unterfeits.graugrün; Relchblätter verfebrteiruno

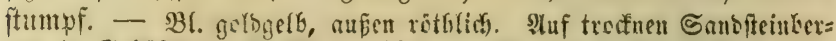

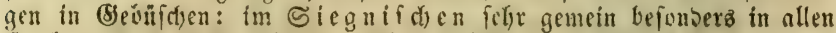

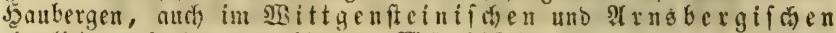

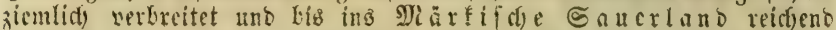

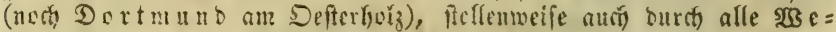

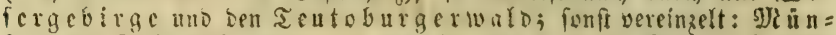

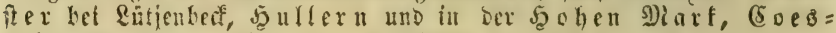
felo an Berge, Bentheim finter bem Faloe, Junteburg, \$etcrähagen in Forfi uno bei Rarbe. $7-9.24$

1040. H. montanum. $\mathfrak{B} \mathrm{erg}=\mathfrak{J}$. Stengel faffl, wenig

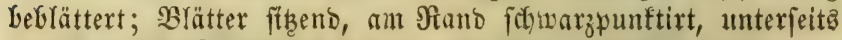
etwab rauf; Relchblätter Yanzettlich) fpib. - Bl. fopfartig zu= fammengebrängt, hellgelb. Sin Bergwälbern, Eefonters auf Ralfboben :

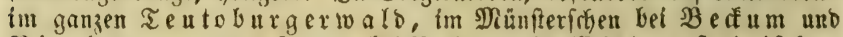

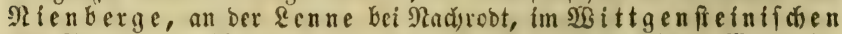

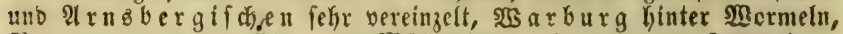

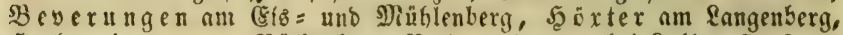
5ुำ

1041. H. hirsutum. Bebaartes $\mathfrak{J}_{\text {. Stengel nebit }}$

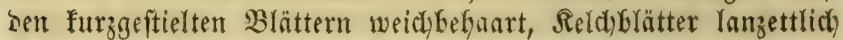

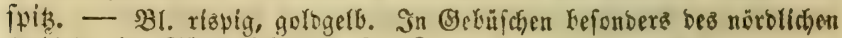
Gebietz, im Eüben feltuer. 6-8, 4

t† Stenger nipserliegeno rourzerno.

1042. H. elódes. Sumpf=S. Stengel mebit ben fingen=

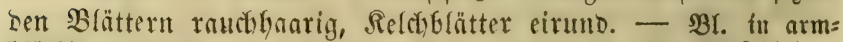

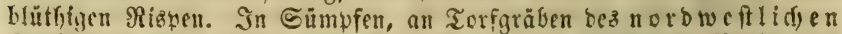

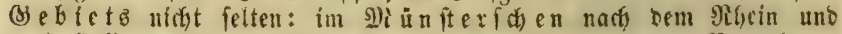

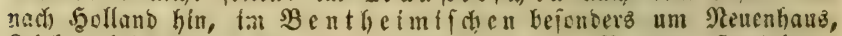

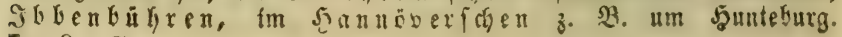
$7-9.24$ 


\section{Syngenesia. \\ Reunchnte SIafie. \\ Syngenesia.}

\section{Sronung Polygamia aequalis.}

* Ulle Blüthen gefdrweift.

t SBiüthenboden nadet (ohne Epreublättchen ober Borften).

a. গুappuz gefiebert.

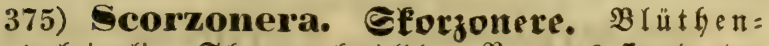
Defe badyziegelig, Schuppen breitlich. Baptus fibeno oder geftielt, feine Fieberchen in einanber gemebt.

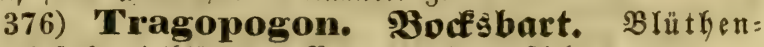
befe einfach, vielblättrig. ßappus langgeftielt.

377) Feontodom. Röwengabn. B̧üthens.

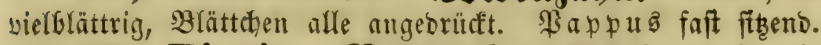

378) Picris. Ritterich. Blüthendede biel=

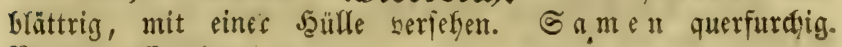

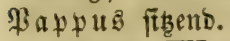

379) Thrimcia. Moth. Sundglattich, B̉ $\mathfrak{u}=$ thenbeffe bielblättrig einfach, am (Sirunbe mit einer Saüle. Brätbenboben grubig. Bappus der Gdueibe gefiebert fikend, Deg Strabls fouppig.

b. פpappus haar ober borftenförmig.

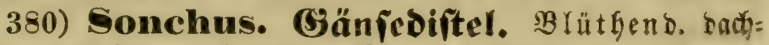

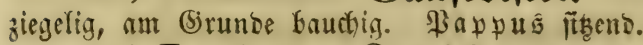

381) Lactuca. Zattid. B (ütheno. Dadzirgelig, meift 8 blättrig. $\mathscr{B} \mathfrak{I}$ üt b e $\mathfrak{n}$ (wenig zablreich) 1 - 2 reifig. Frudt in einen fabenförmigen Schnabel zugefpizt. $\mathfrak{B} a p p u s$ geftielt.

382) Crepis. SSippau. Blüthenterfe mit einer

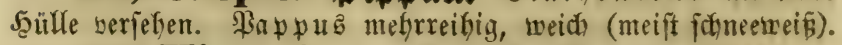

383) Hieracium. Sabichtsfraut. B (ut ben=

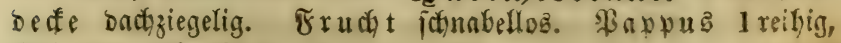
iteif und zerbrechlid (iđunubigneiż).

384) Helminthia. Fुurmlattich. B Yüthen s. boppelt: bie äußre loffer 5 blättrig, bie innre gleicf sflüttrig. Frud $t$ quergefurdyt. 


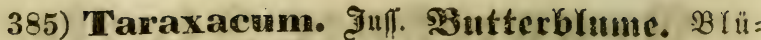

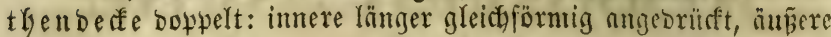

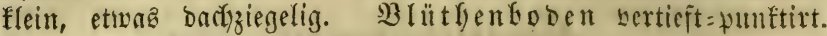

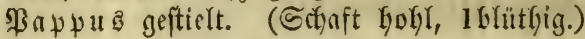

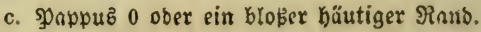

386) Lapsana. Yainfob). $\mathfrak{B}($ int hend. einfact)

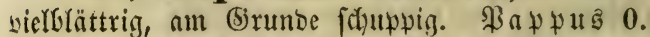

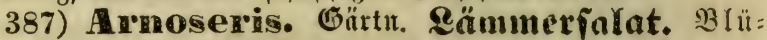
thendedfe einfact), bielblättrig, eiförmig (am Endte fugeligig),

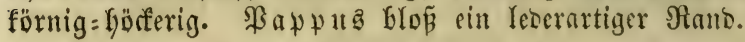

t† \$Blüthendečé fpreutig ober borftig.

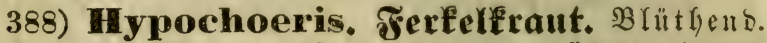

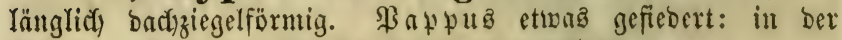
Geffeibe geftielt, in Straflel fiseno doer geftielt.

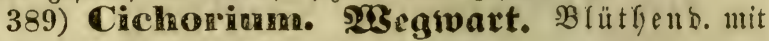

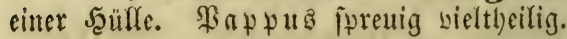

** 2arle Blüthd)en röbrig, mit 5fpaltigem Saum.

$\dagger$ şappuz borftich ober foreuig.

390) Arectiam. Plette. Blüthenberfe flugerig,

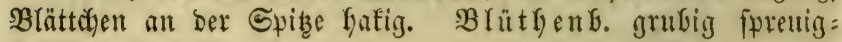
Eoritig.

391) Serratula. Scharte. Brüthenderfe faft walzenförmig, sBlättçen ftumtef, feft angebrüaft, randfÿutig. Blüthenb. ipreuig.

392) Carduns. Diftel. Blütgenderfe Gauthig, Brättufen in einen Dorn aแล่ ipretig.

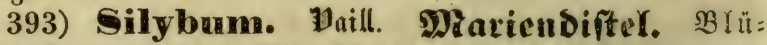
thenberfe badyziegelig, Blättchen aun (5)runbe blattartig, ange:

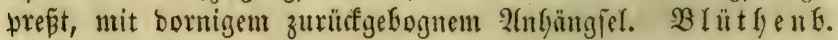
Goritig=fpreuig.

394) Omopondon. Erferbifter. Błütheno.

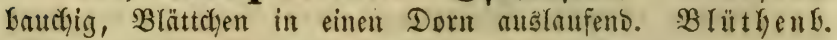
löd)erig=zellig. Früct) te 4 fantig, quer=gefurd)t.

†† গुappus gefiebert.

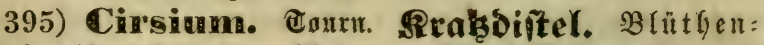

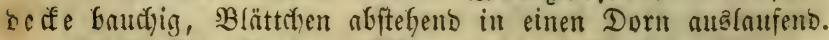

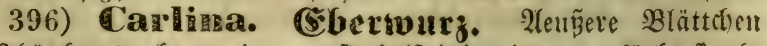

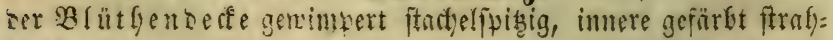
Ientrörmig. 
*** 2ule Blüthdyen röhrig, 5zäthnig.

397) Chiysocoma. (5olobaar. $\mathfrak{B}$ I ït fent.

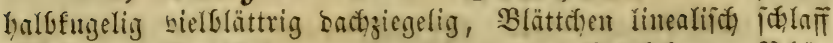

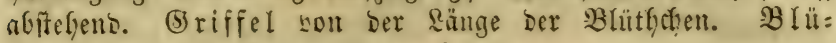
thenf. mit fefr fleiner Spreu Gefebt.

398) Eqpatoniam. RSafperboit. Blüthent. ondrziegelig walgenfömig. (5) riffel fefr lang. Blüthen= bo o en naft.

399) Bidens. 3weizabu. B Büthenb. einfad,

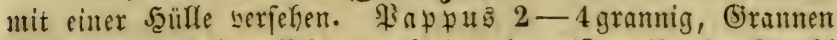

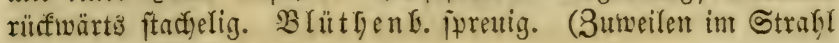
gefidueifte Blüthdyen).

\section{Soronung Polygamia superflua.}

- 2ưe \$lüthd)en röhrig.

400) Artemisia. 28 ermuth. B lütfendefe

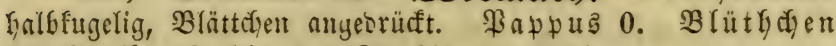
ber Grfeife 5ipaltig, bes Strahls ganzrandig.

401) Tanacetum. Fainfarn. $\mathfrak{B} \mathfrak{u}$ ü $\mathfrak{h}$ e

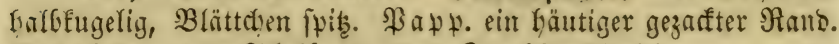

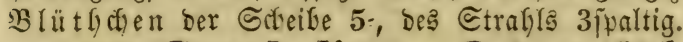

402) Gnaphalium. Raţenpfötchen. B̊Ĭ:

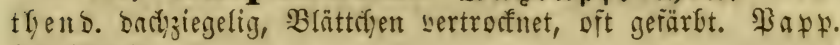
baarī̄rmig.

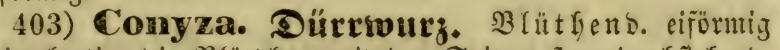

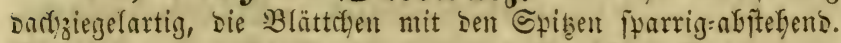

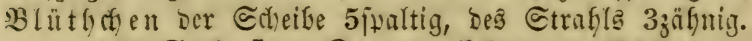

404) Cotala. 2augerablume. B büt hend. viel=

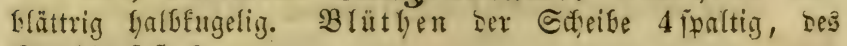
Strable fait 0 .

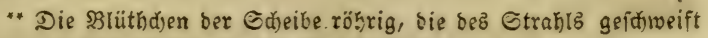
$\dagger$ ફ̧apkuz haarförmig oder borfttid̄).

\section{a. Blüthenboden nacét.}

405) Erigeron. Berufg̈raut. B tüt hen befe

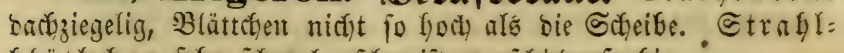

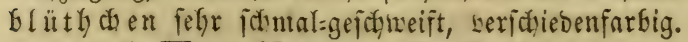

406) Tussilago. SEuflattich. B Büt the n b e if e eiförnig, Blättchen gleiđh, an Der Epibe bäutig, fo hod) als bie Edeife. Etraflol. lang ober abgeptutht.

407) Solidago. (Golbrutbs. B fit thend. Ioffer: $18^{*}$ 


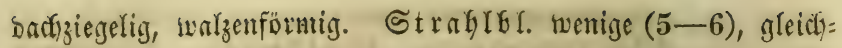
farbig.

408) Senecio. Sreufraut. B Büthenঠ. wal: zenförntig, bie Blättctyen an ber Spibe brantig =gefleft; am Srumbe mit Groppent.

409) Cineraria. 2richerant. B Büthent. eint fach, vieltheilig, gleichlang.

410) Aster. 2liter. Brütgenb. Iorfer=bartyziegelig. Strafilgl. berichiebenfarbig.

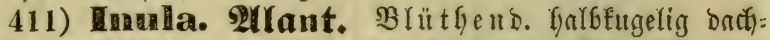
ziegelig, Blättcten mit ber Epize abftebend. Staubbeuter ant (5rutibe 2gramig.

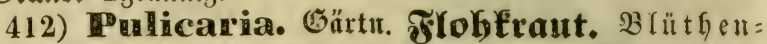

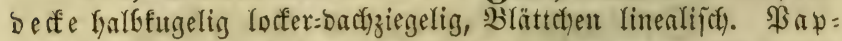

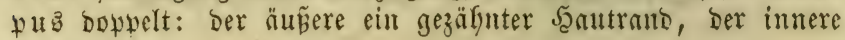
fyarrförntig.

\section{b. SB!üthenboben foreutig.}

413) Amica. 280 blverleif. Bguthent. halb= furgelig, in boppelter Neibe bielblättrig. Staubf. Der Etrabl: blïthigen frei, ofme $\mathfrak{B}_{\text {eutel. }}$

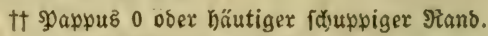

a. Blüthentioben nacét.

414) Bellis. Dafarliebchen. Brüthend. faft balbfugelig, bielblättrig, Blättç̧en in 2 Pleifyen, gleiđ̆ lang. Blüthents. getwölbr.

415) Chrysanthemum. 23 udberblume. Blüt hend. halbtugelig badfziegelig, bie Blattdyen Yederartig,

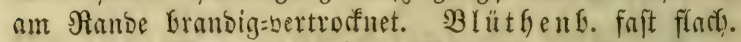

416) Matricaria. Ramille. Blüthend. half=

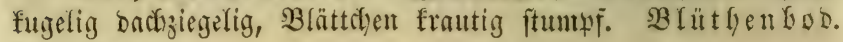
fegelförmig.

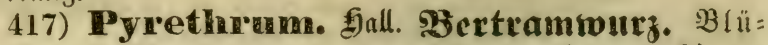
thenderfe halbugelig bactziegelig, Blättchen (nugedrutft) am

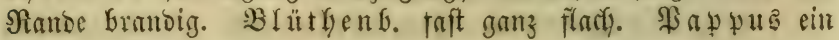
r)äutiger ア゚ano.

\section{b. SBlüthenboden forettig.}

418) nathemis. Soundsfamille. B hüthend.

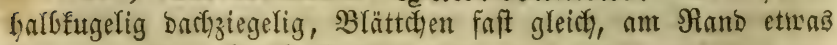
Granbig. $B$ lüthenf. fegelförmig.

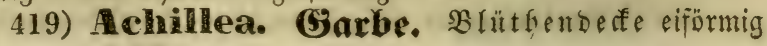




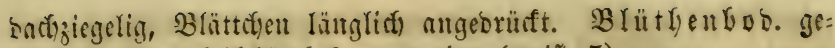
wölbt. Strablblithdien wenige (meift 5).

\section{Soromung Polygamia frustranea.}

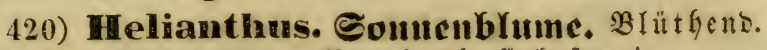

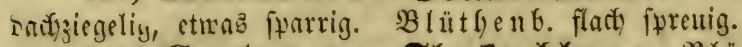

421) Centaurea. Flocenblume. Bluthent. eiförmig frutchig badtziegelig, Blättchen bertroffnet ober gewint:

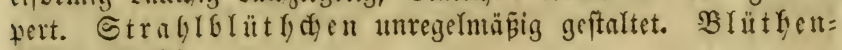
Go den rorftig.

\section{Sromung Polygamia aequalis.}

\section{5) Scorzonéra. Sforzonere.}

1043. Sc. hispanica. (5) artent= Sf. Sdy warz= wurgel. B̧ätter lanzettlid. - $\mathfrak{B l}$. gelb. Sn Bärten gebaut

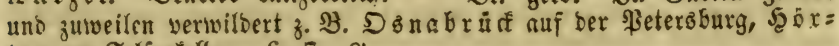
ter am Felienfeller. 6. 7. 4

1044. Sc. laciniata. (Podospermum laciniatum.

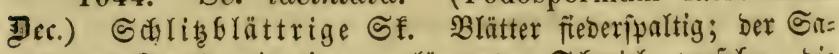
nent ant (Sruno mit einer berlängerten Gdywiele beriegn, bie

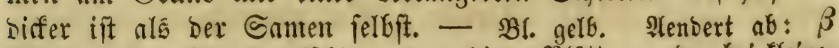

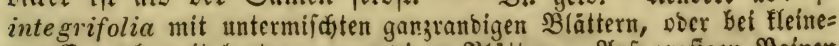

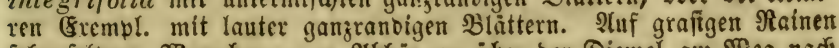

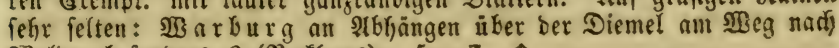

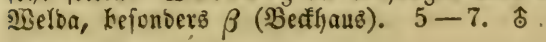

\section{6) Tragópogonl. $\mathfrak{B}$ of â $\mathfrak{b}$ art.}

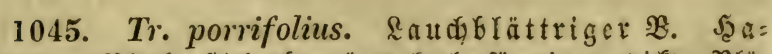

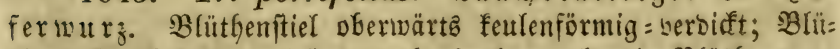
thenterfe 8blättrig, faft sowpelt fo lang alß bie Blüthen. -

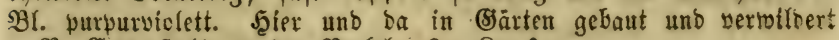
3. B. हैоев feld an ber Berfel. $6-8$. of

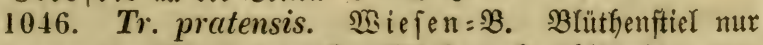
menig unter ber $\mathfrak{B}$ lume verbifft; $\mathfrak{B}$ lüthendeffe 8blättrig, unges

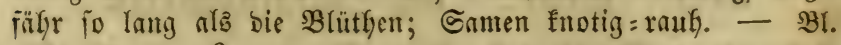
gelb. Sfharten: $\beta$ minor $(\boldsymbol{T r}$. minor. Fries) bie $\mathfrak{B}$ lutthen boppelt io furz als bic Blüthenberfé, $\gamma$ tortilis bie Blätter an ber Ephige mellig

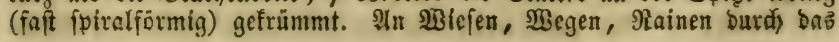




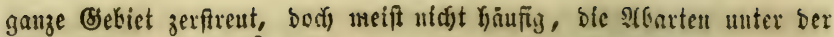

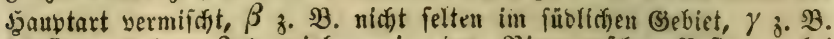
hăufig auf bem Johannißberg in ber Niemannichen Befibung bel B telefeld, in ben fübl. Bebirgen. 5-7. $\hat{\circ}$

\section{7) Leóntodon. ฉอ̈wenzafin.}

1047. L. autumnalis. (Apargia aut. Willd.) $\mathfrak{g}_{\mathrm{er}} \mathrm{b}$ it $=$

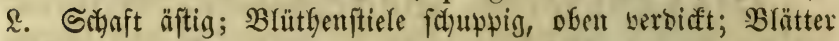
Guchtig= ober feberipaltig = gezäfut, meift fabl voer mit einfachen

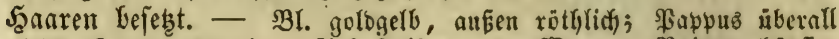

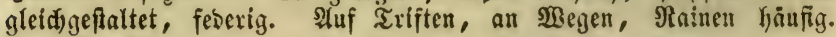
$7-10.24$

1048. L. hastilis. Spieffïrmiger \&. Gduft einfach, oben verbifft; Blätter gezähnt ober fiebiripaltig, fafll ober mit 2-3gabeligen 5araren beję̧t. - Bl. getb; bie inmern Strahlen bez ßappuz feberig, bie äüern furz rauli. Formen: $\alpha$ vulgaris (L. hispidum. L.) Bglätter vober aud) Stengel uno $\mathfrak{B} l$ ü= theni. behaart; $\beta$ glabratus (L. hastile. L. - Apargia guest-

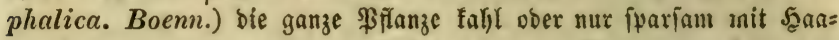
ven heftreut; $\gamma$ hyoseroides Blätter bia zur MRittelvippe fieberthei=

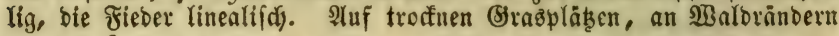

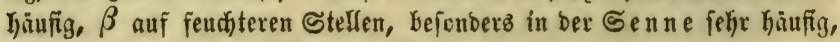

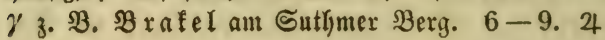

\section{8) Picris. Bitterich.}

1049. P. hieracióides. (S) eneiner $\mathfrak{B}$. Blätter ften=

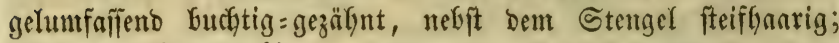
Blumen doldentraubig. - Bl. gell. Nenbert in Blattform uno Blüthenftand feftr ab, bemerfenbiwerth ift: $\beta$ umbellata. Nees mit

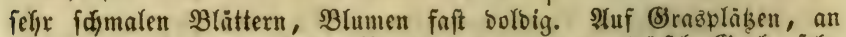
Megen und Syerfen burd' bie Berggegenden bes norboft. (B) eb. Felyr

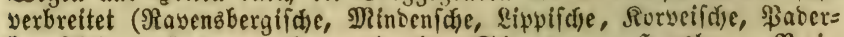

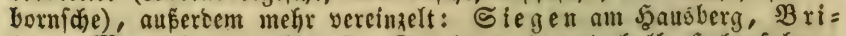
Ion, MRarberg, Eveft, Dortmun unterbalb Solyeninburg, Jattingen, an ber Renne, Müniter, Dülmen, Copgfeld, Rafben am Stemmerberg; $\beta$ z. B. Beyerungen am Mühlen= berg. 7. 8. के

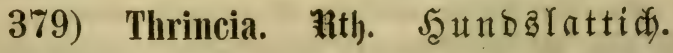

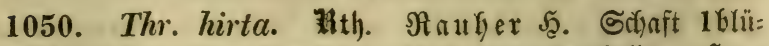

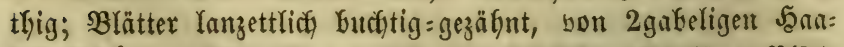

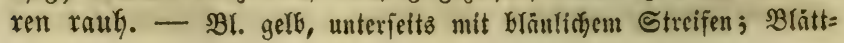




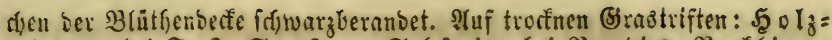
minden bei Furit, Soe it am Salzipring bei \$arabies, sie ef I ing = fia $a$ e

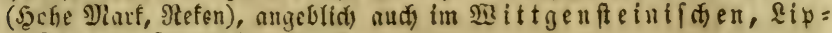
vifiden แ. F. เo. $6-9.24$

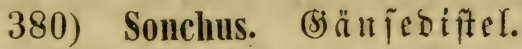

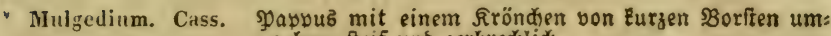
geben, fteif und zerbre(t)lid).

1051. S. alpinus. (Mulgedium alpinum. Caff.)

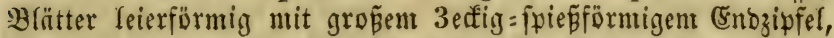
bie obern mit geflügeltem Blattfiel herzförmig = ftengelumfaf= fend; Traube briff̈gbefiant. - Bl. blau. Sn hulfen Bevirgg= wälbern: Brifon auf bem Edjellforn unb feiner fübl. Fortfekung!

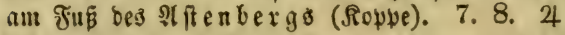

** Sonchus. গুappuz ohne Fröndjen, weid) uno biegfam.

$\dagger$ Etengel äftig, 2efte bolbentraubig.

1052. S. oleraceus. Rohlartige (5). Bl. länglid, f(c)rotfügig = ficberfpaltig ober ungetheilt, bie itengelfätünigen am Sirund herzförmig mit zugeppighten Deforchen; Früd) quer: rumz̧lig, beiberfeits 3riefig. - Bl. gelb wie bei ben folgentert.

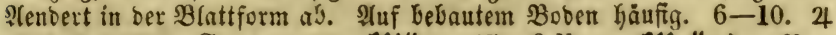

1053. S. asper. Will. (S. fallax. Wallr.) $\mathfrak{B}_{\mathrm{e}}=$ wel)rte (5). Blätter vwal=längliă), bie obern bornig=gezälynt hergförmig mit abgerundeten Deforchen; Früd)te glatt, Geioerf.

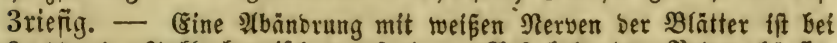
\&otte im Tefflenburgifaten gefunden. Tluf bebautem Boben häufig. $6-9$.

†† Etengel einfady, nur an ber Epiz̧e bolbentraubig.

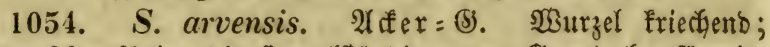
Blätter fid)rotjägig, bie ftengelftänbigen am Brunb Kerzförmig, bie oberiten ungetfeilt; $B$ lüthenbülle nebji ben $\mathfrak{B}$ lütbenitielen gelb = brüftgGefgart. - 2 uf Aefern hier uno sa. 6-8. 4

1055. S. palustris. Sumpf= (5). NBurzel nidft frie= dyento; Blätter fafrotjägig=fieberipaltig, bie Bipfel Ianzettlid

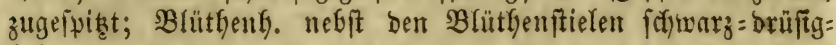

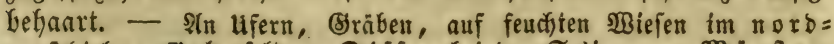
tweftidien (s)b. Felten: Diffen bei ber Saline, am $\mathfrak{M}$ ün fiter

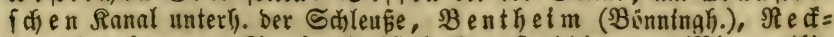
Itughaufen am Saerbrudi) (Jुohofi), Sattingen (Bilumeroth),

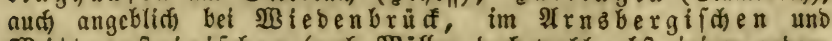

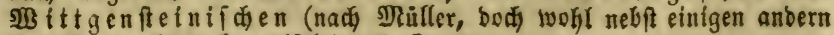

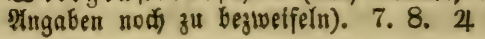




\section{1) Lactúca. Rattidy.}

1056. L. sativa. (bartenlattidy. Rattichalat.

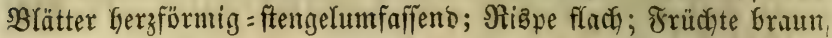

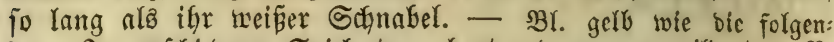
bert. In verfdietenen Epielarten gebaut und zuw. vertwitbert $3 . \mathfrak{B}$. an ber $2 B$ efer. 7. 8. $\odot$

1057. S. Scariola. WBilber \&. Blätter am Brumbe

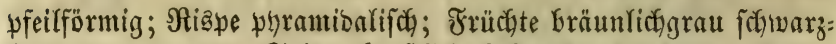
Gerandet, an ber Spize Gorfflichy=befyaart, fo lang alz ber weiñe Sctunabel. - Die Blätter am Riele ftadjelig, ftachelipibig =

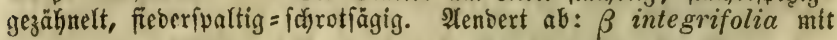

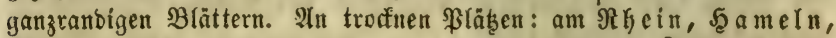

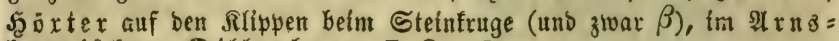
bergifden, Diflenburg. 7. 8. ○

1058. L. muralis. frelen. (Prenanthes mur. L.) Mi a uerlattiç. Blätter geftielt, Yeierförmig=fieberipaltig, bie

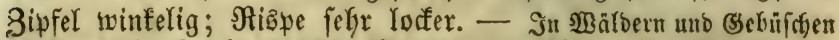

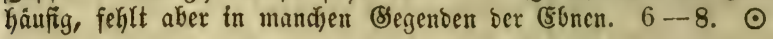

\section{2) Crepis. Fippau.}

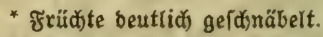

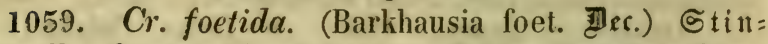
fenber B. Stengel äjtig beblättert; Blätter fobrotfägig=fieber= fpaltig, bie oberiten lanzettlich, am (Srunbe ticfeingeid)nitten; Blüthenberfe uno Blüthenftiele brüftg:graubefjaart. - $B$ l. gelb wie bie folgenben. Ruf 2 (nhiöhen beionoerz auf Ralfboben im oft $i=$ d) en Bebiet: $\mathfrak{M B a b}$ arg zwifiten Bermete und Meten, Driburg,

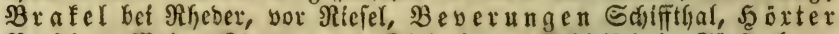
Reuf(d)e=, פBein=, 3iegen = uno Dielenberg, Echleifthal, Fürfenberg,

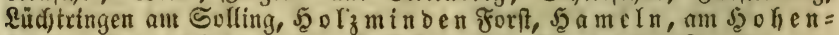
ftein, \$aberborn, Soeft Enfefen bei Rlieve. 6-8.

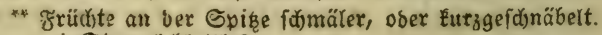
$\dagger$ Etengel blattloz.

1060. Cr. praemorsa. Caurd). (Hieracium praemorsum. L.) 2 g gе

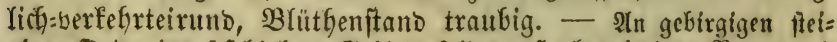

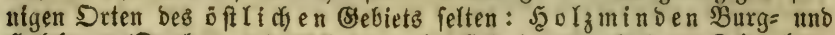

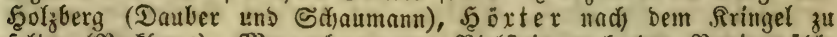
felten (Bectf(a), , Nia

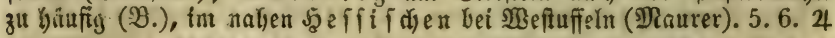
tî Stengel beblättert, an ber ভpize bolbentraubig.

1061. Cr. biennis. S weijälfriger $\Re$. Blätter fơrot= fägig = fêberipaltig, bie mittlern mit furz gerölyrt=gezälyntent 


\section{P. aequalis.}

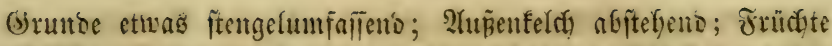
13riefig. - In MBiefen, an (3)räben, Seefen: beginnt bei Bicle =

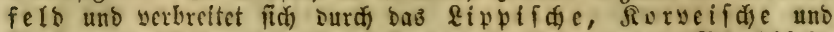

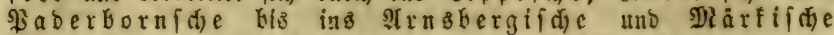
Sauerland, aurd) bei Szattingen; fonft folfe cingeln: an ber Eipye und am Rhein, Neuentirden uno fanteburg in

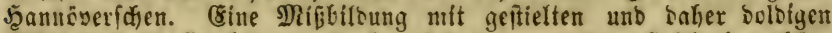

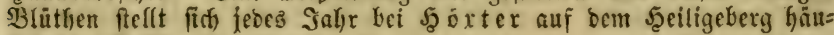

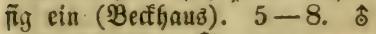

1062. Cr. tectorum. Dadypipłau. Hntre Blätter Ianzettlid) budftig=gezalynt, mittlere Yinenlifor pfeilförmig, ant

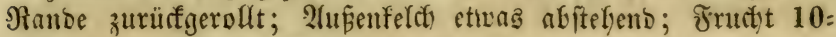

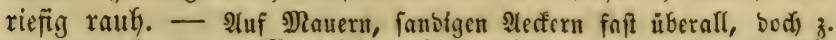
$\mathfrak{B}$. in ber Sraffidjaft Marf felten (\& ü Denfd) eib auf bent Gauerfelb). $6-9$.

1063. Cr. virens. Dill. (Cr. pinnatifida. Willi.)

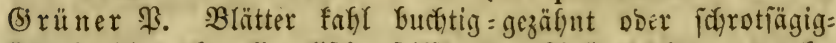

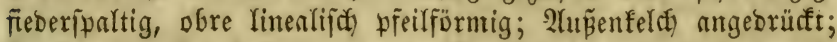
Frucft 10riefig glatt. - $\{$ lbart : $\beta$ agrestis $(\boldsymbol{C} r$. agrestis. $W$.

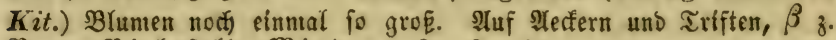
B. um Bielefelb, Ninden. 6-9.

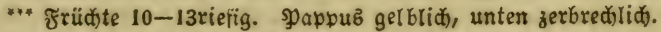

1064. Cr. paludosa. Atoend). (Hieracium paludosum. L.) ๔umpfpippau. Blätter fafl, untre länglicf) fpits ictrotjägig=gezäfnt, ofre cirumb berzförmig=ftengeluminffento lang=

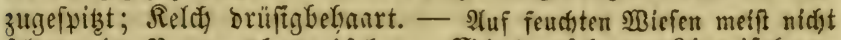

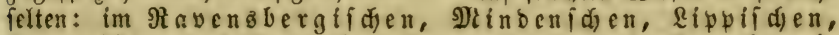

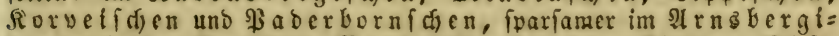

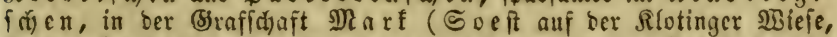
Tliften bei Theiningfen, Dortmun o im Sunterkolze, \&übenfolet

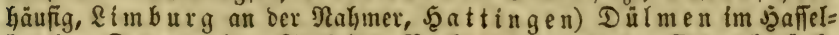

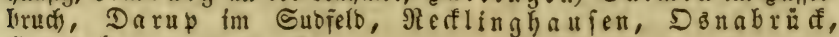
รูunteburg. 6.7 .24

\section{3) Hieracium. Şabidatâtaut.}

* Stenger blattloz ober unten wenigbeblättert.

$\dagger$ Stengel ivenig: (1-5)blumig, mit Xusläufern. SBlumentrone gelb.

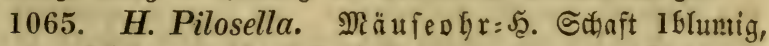
Blätter verfefyrteirunb:Yänglid, fteifGaarig, unten graufitzig. -

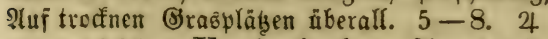

1066. H. Auricula. Aturifer.: S. Stengel blattlog Dber 1 blättrig, 2-56lumig; Blätter bläulid̄grün zungenförunig, faft ganls fahl, am Brrutbe getwimpert. - Formen: a subglaboum fleiner, oft nur 1 Glumig, blaugrün; $\beta$ setosum größ̈อr zerfireut= 


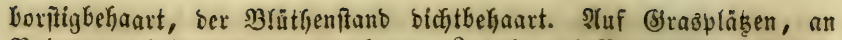
Rainet, $\alpha$ befonberz auf Terfboben, $\beta$ methi auf Bergtriften. शน

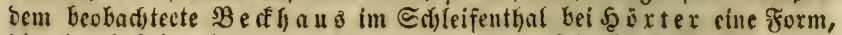
bie cinc finbribe (H. praealto-Auricula) zu fein fineint. 6-8. 24

t† Stengel mit 2-3 geEnäuelten $\mathfrak{B}$ ไumen.

1067. $H$. aurantiacum. Pomeramzenblumiges 5 . ๔tengel unterwärţ armblättrig, lang : raudh hanrig, wberwärts

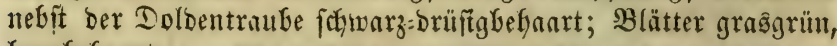

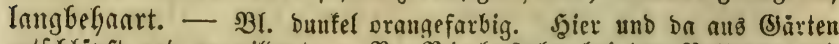

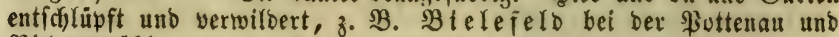
Niebernmügle. 6. 7. 4

ttt Stengel vielbrumig borbentraubig. SBl gerb.

1068. H. praealtum. Dill. 50 bes $\mathfrak{J}_{2}$. Stengel wenig; Glättrig, fafil ober zerftreutborftig = befaart uno weich hanarig;

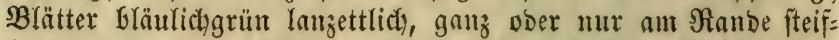

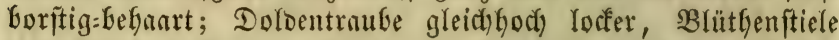
und Blüthenderfe grutbef)anrt. - Formen: $\alpha$ vulgare $(\boldsymbol{H}$. Alorentinum. Willd.) S(uzlâtufer feflitenio ober ftatt berielben blumen= tragenbe Seitenftengel, Stengel faffl, $\mathfrak{B l a ̈ t t e r}$ am $\Re$ tanoe und auf ber Nittefrippe ber unterfeite borfig gerwimuert, änbert aber auć intt mehr beljaartem Stengel unb idjwargbrüfitgen behaarten Blütfenfitelen

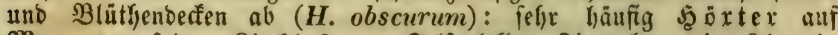
Nauern, auf bem Rírdhtofe, am Felfenfelier, Siegenberg, im Rippi=

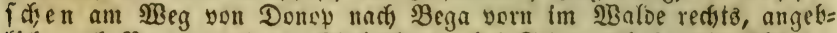

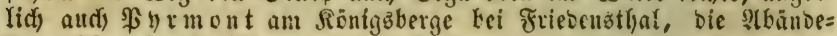

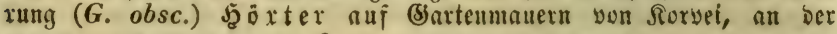
Strape nad) Dittbergen; $\beta$ stoloniferum (H. Bauhini. Bess.) fäb=

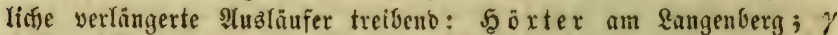
fallax $(\boldsymbol{H}$. fallax. Dec.) Hus̆läufer fegleno ober piatt berfelben blü= henoe Seitenfenger, Sdjaft ziemliaf) faGl, BBlatter oberfeitz mit Peifen

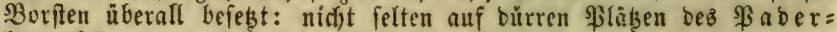
bornforen um \$Barburg, Beverungen, Brafel. 6. 7. 4

1069. H. pratense. Cauld. Sis ie fe $n=\sqrt{2}$. Stengel

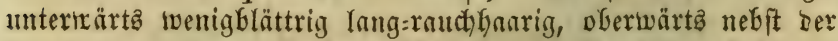
gebrungenen Doldentraube bruifg: uno boritig = fotwarzbefanat;

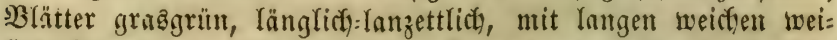

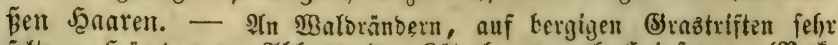

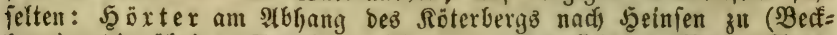

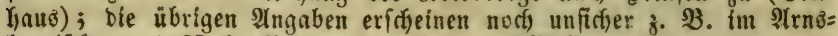

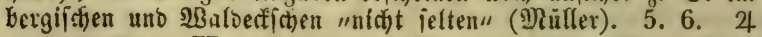

1070. H. murorum. $\mathfrak{N a} \mathfrak{a} \mathfrak{e} \mathfrak{r}=\mathfrak{5}$. Stengel meift $1=$ Glättrig, mad) oben mebft 2lefiten uno Blütfendeffen grau= uno

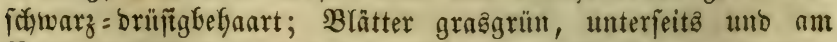
Aanbe raudgharig, bie murzelftänbigen eiferzförntig gezälnht, 


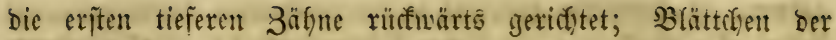

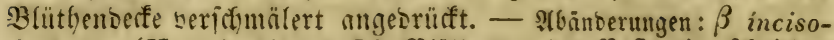

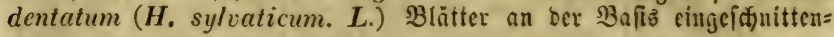

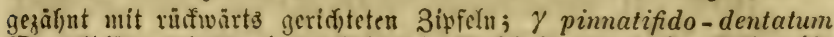

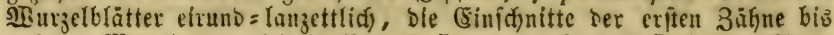
auf ben Sitttelnery reiffend (io baß́ fie ganz gejonbert funb), Der Sten=

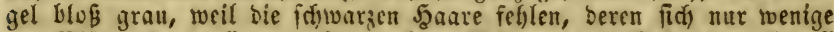

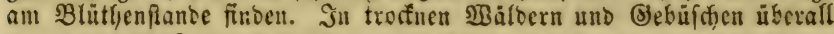

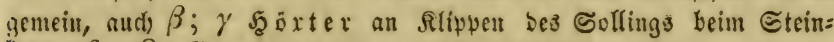
frug. $6-8.24$

** Etengel ganz bebrättert, mit bleibenden grunbftänbigen $\mathfrak{B l a ̈ t =}$ tern. SBl. gelb.

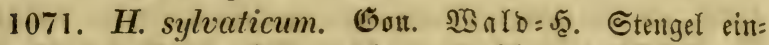

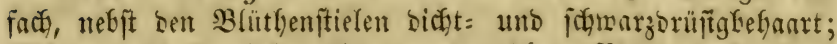

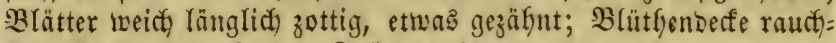
Yharig, in getroffnetem Zuftande fdyarz werbens. - Etengel weniger fteif a!z folgenbe, $\mathfrak{B l a ̈ t t e r ~ f p a r f a m e r ~ u n o ~ w e n i g e r ~ l a n g ~ v e r = ~}$

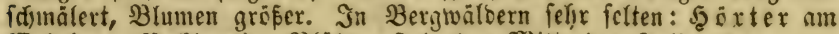

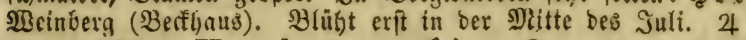

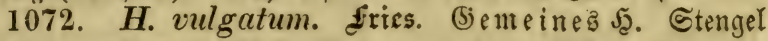
pberwärts nebit Den Blïthenfitielen uno ber Blüthenbecfe grau=

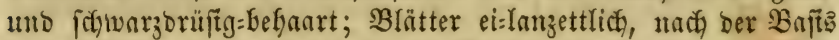

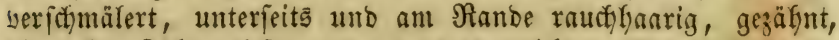
bie erĩten Bähne tiefer unb vortwärts gerichtet; Blütfendeffe im getrocfueten Suftande unberändert. - IGart: $\beta$ latifolium $(\boldsymbol{H}$.

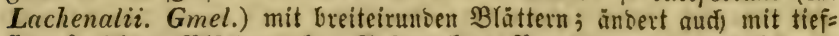

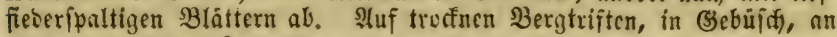

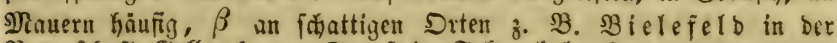

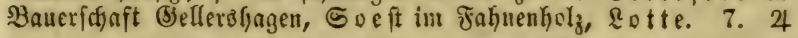

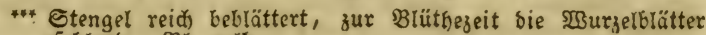
fehteno. SBl. gelb.

1073. H. boreale. firiss. Norbijat äftig, fât Doldentraubig; Blättchyen ber Blüthenderfe angesrürft,

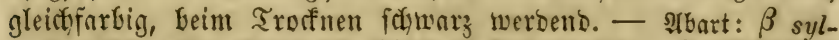
vestre (H. sylv. Tausch.) Blüthenberfe ganz fahl. Iñ Behüidhen burda bas ganze (sebiet hier und ba (biäher gevilynlich für $\boldsymbol{H}$. sabau-

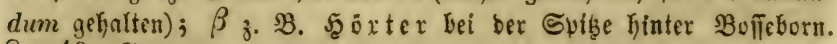
$8-10.24$

1074. H. rigidum. E)artm. ( $H_{4}$ laevigatum. Willo.) Starres S.. Stengel äftig, faft Dolbentraubig; Bblättcten ber

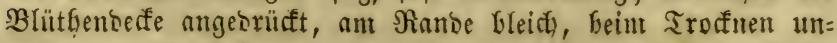
weränbert, bie äแEern bei Den jungen Blütfenfnöyfen nufred)t und bieje überragent. - Itbart: $\beta$ coronopifolium $(\boldsymbol{H}$. asperum

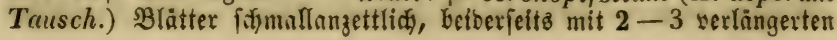




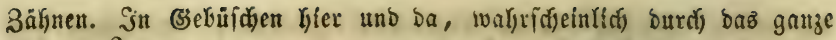
(5)biet, $\beta$ z. B. Bielefels hinter Bractwete nad, Colon Siefermann,

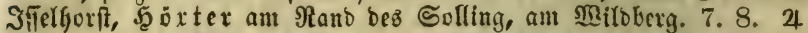

1075. H. umbellatum. Doldiges 5 . Etengel äitig,

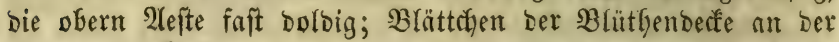

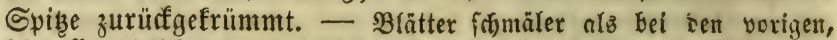

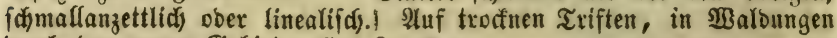
burd) Das ganze (sebiet. $7-9.24$

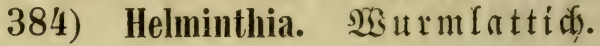

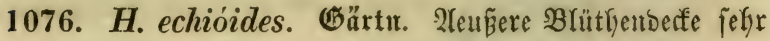
groß́, wie bie ganze Bffanze mit ftackligen Spizen bejebzt. -

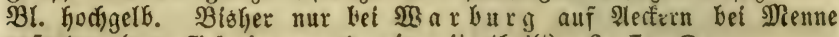
gefunben (yon (s) ôring, und mir mitgetheilt)。 6. 7. $\odot$

\section{5̋) Taráxacum. đuff. sButterblume.}

1077. T. officinale. Wig. (Leontodon Taraxacum. L.). (Gemeine $\mathfrak{B}$. Ringerblume. Gdift röfrig

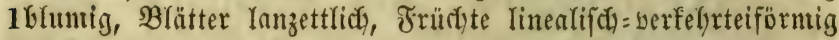
gerieft. - BI. get5. 4-9. 24. Die Formen Diefer vielgeftaltigen

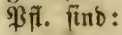

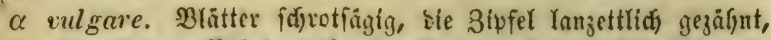

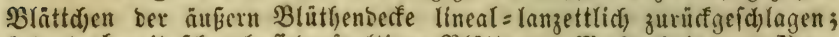
änbert $a \mathfrak{b}$ mit fdjmal = fieserfpaltigen $B$ lättern: 'T. laciniatum. Pers.

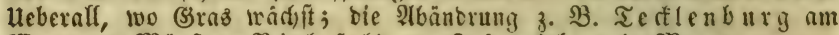
Terg naরi) Münfer, SBiclefelo am Johaunióberg in Nenge.

$\beta$ laevigatum (T. laevig. Dec.). B3lätter fa)rotfägig = fieber=

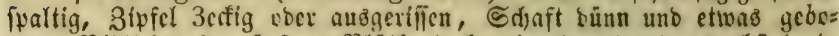

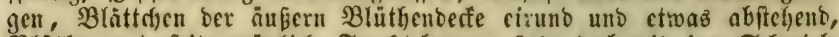

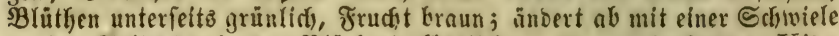
an ber Evißge ber innern Blüthenbrefblätte)en: $T$. corniculatum. Kit.;

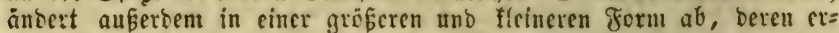
ftere żuveilen blaugrunlid) ift. N(uf fonnigen Triften, befonbers auf Ralfboben, burch bic Berggegcnoen bes (s)cbietg verbreitet, bie fidivie=

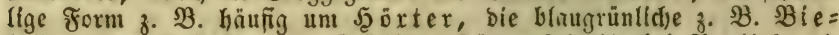

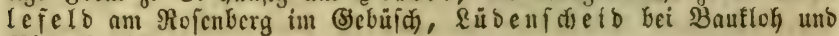
Rieberyunidjció.

$\gamma$ intermedium (T. Scorzonera. Rchb.). B̧lätter fachrotfäglg=

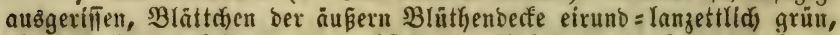

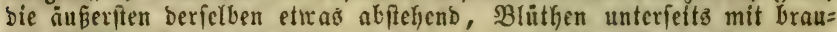

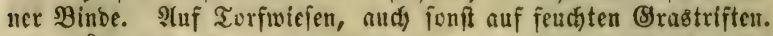

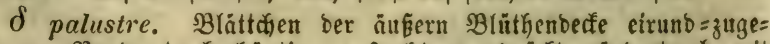

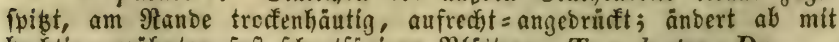

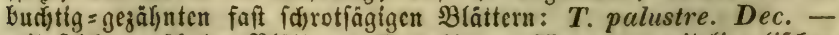
mit fédùt gezähnten Blättern: T. salinum. Hppe. - mit Yinealifdjen 


\section{P. aequalis.}

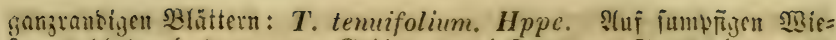
ien wehl ourd) Das ganze (B)ebict, wentigfters am Teutoburger=

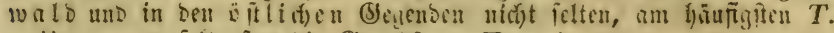
salinum, am feltenten bie Brundform T. palustre.

\section{6) Lapsana. Rainforl.}

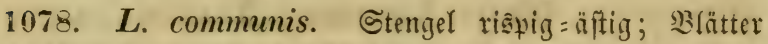

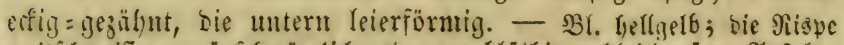

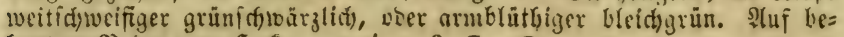
Eirutem Boben, an Seeften gemein. 6.7. $\odot$

\section{7) Arnoseris. Gartn. Rämmerialat.}

1079. A. pusilla. Gaartn. (Hyoseris pus. L.) Etengel blattlos ä́tig, Blütfenftiele und ofen fentig=terbiaft

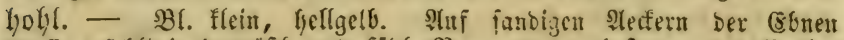

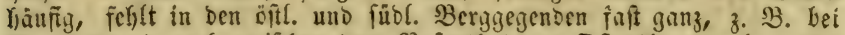

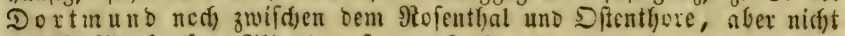

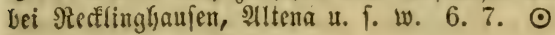

\section{8) Hypochoeris. Ferfelfraut.}

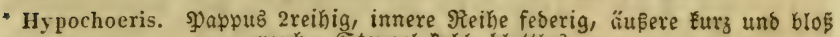
rauh. Stengel Eahl, blattlob.

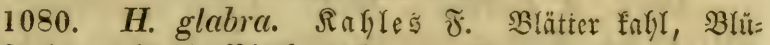
thest fo lang als bie Blïtgendecfe. - Bl. gelb. NGuf fanbigen

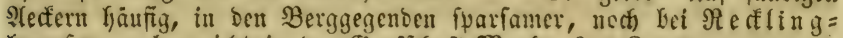
y) a uf

1081. H. radicata. \&angwurzliges $\widetilde{~}$. Blätter

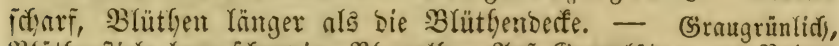

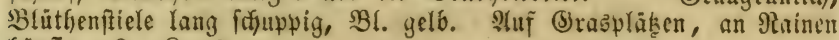
f̧ăuñg. $6-8.24$

$$
{ }^{* *} \text { Achyrophorus. Scnp. \$pappuz Ireihig, fämtlid) feberıg. }
$$

1082. H. maculata. Siop. (Achyrophorus macu-

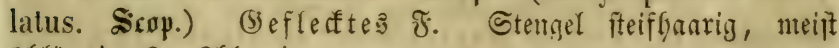
1 blättrig, 2-3Glumig. - Blätter meî̃ braunfleffig, B̉lüthen=

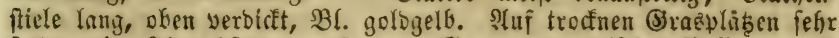
felten: im Ripyifiden auf eirem (jrabanger zwifiden \$ollumann 19

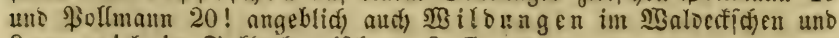
Iengerid in Teffienburgifiden. 6. 7. 4

\section{9) Cichorium. 19 egwart.}

1083. C. Intybus. (5) emeiner Mis. Bithorie. Hntre

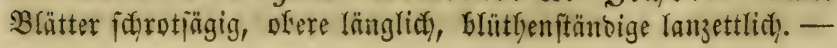




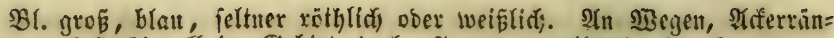
berm faft ibstall im (sebiet, body oft nut verwildert. $6-9.24$

1083 b. C. Endivia. (s) arten= M. Enbivic. Intre

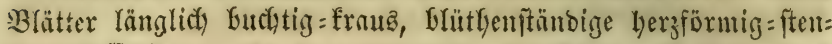

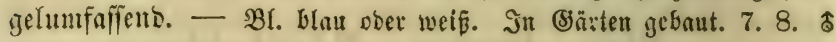

\section{0) Arctium. 爪lette.}

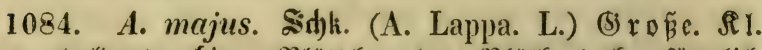
Blumen bolbentraubig; Blättclen ser $\mathfrak{B}$ (lïtfyenberfe fämtlid)

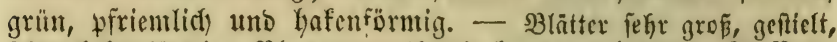

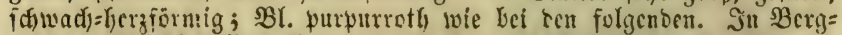

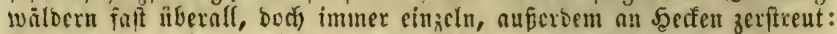

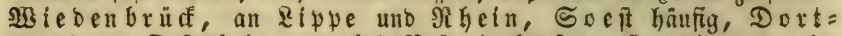
munb am Defterfiolze uno bet Brünninghauten, $\mathfrak{S}_{\text {attingen, int }}$ Rente= und Solmethal, Reftinghaufen, Evesfeld, Da=

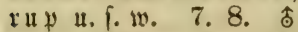

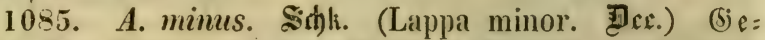

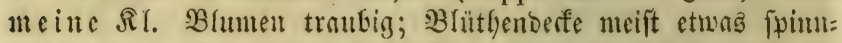
imebig=zottig, bie imern Blättchen an ber Spibe furtumrotry.

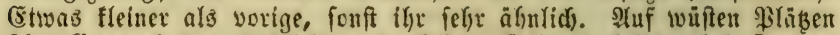

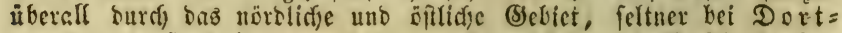

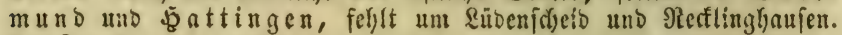
$6-8.24$

1086. A. Bardana. Willo. (Lappa tomentosa. famr.) Filzige $\mathfrak{i} 1$. Blumen boldentraubig; Blüthendecfe ftarf fpim=

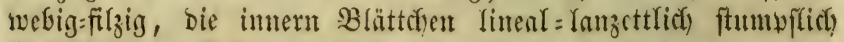

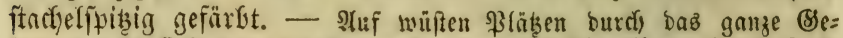

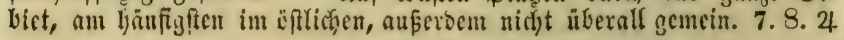

\section{1) Serraitula. Sdyatt.}

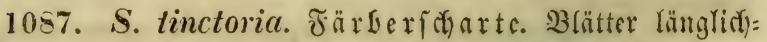

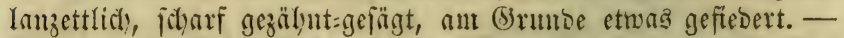

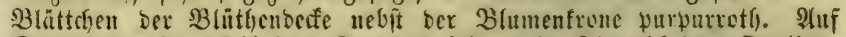

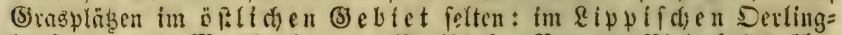

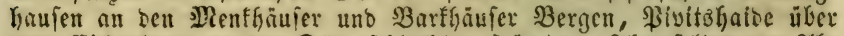

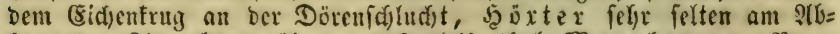

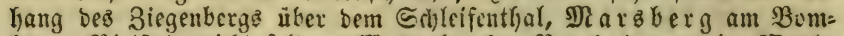

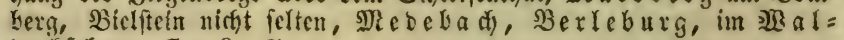
Decifider. $7-9.4$

\section{2) Cárduus. Diftel.}

* Biüthenftiele verlängert.

1088. C. nutans. Heberfangende D. Bätter tief= 
fieberifaltig bornig unterbrocten = herablanfent, Blumen einzeln

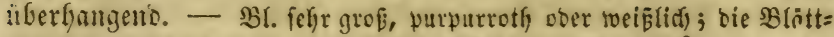

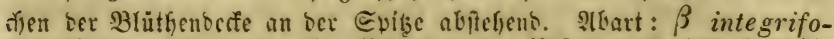
lius 23 lätter faft ganżranbig, Blättd)cu ber 23 lüthenbecfe beinah vällig

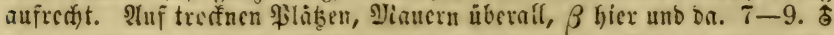

† 1059. C. tenuiflorus. Curt. Sdymalblütgige 2 .

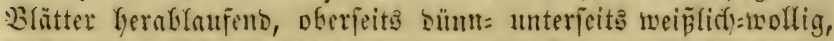
Gudbtig unb fieberipaltig, mit eirmoen exfigen gęälnten borni=

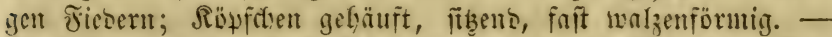

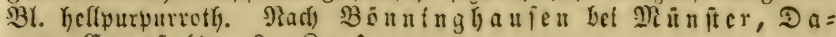
rup, coевfeld. $6-8$. 站

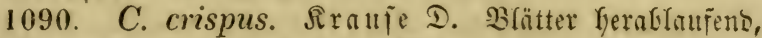

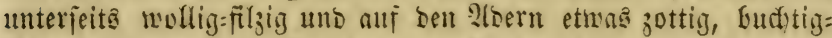
fieberipaltig mit breifappigen gejäfnten bornig=geirimwertent

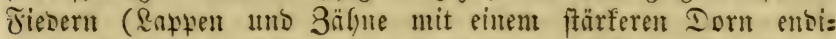
gento); Blumen gefüuft uno einzeln, runolich, auf sornigen

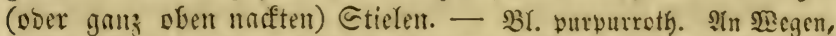

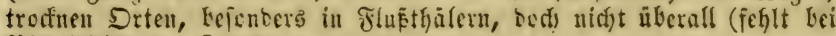
Bieleficlo). 6-8. $\hat{\circ}$

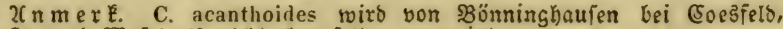

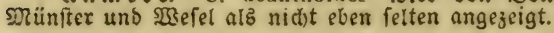

\section{3) Silybum. Waill. Nariendiftél.}

1091. S. Marianum. (Carduus Marianus. L.) -

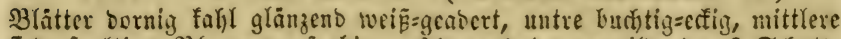
rieberipaltig; 31. purpurfarbig. Şier und ba verniloert auf Erfutt,

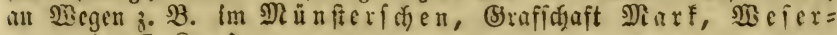
geyert. 7. 8. ชे

\section{4) Onopordon. Ejeloiftel.}

1092. O. Acanthium. Etengel etwaŝ molli.j, Durdy bie

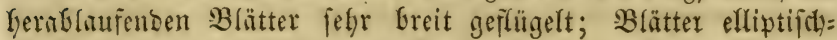

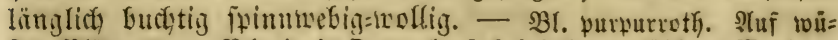

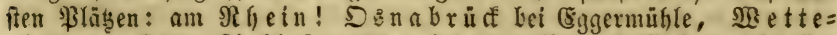

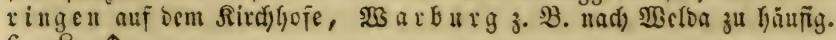
$6-8$. के

39ä) Cirsium. Tourm. Sirabifitel.

* \$lätter oberieitz bornig=Ĕurzhaarig:

1093. C. lanceolatum. Sirop. (Carduus lanceolatus.

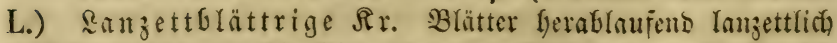
tiefrêterjpaltig mit 2 fpaltigen bornigen Bipfeln, umterpeits neb̂f 
Dent eiförmigen $\mathfrak{B}$ hütgendecten fpimmebig = wollig. - SB. pur=

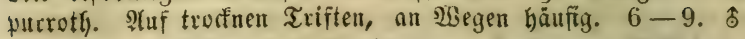

** \$lätter oberfeitz ni(đ)t bornias:Éurzhaarig. Slättdjen ber $\mathfrak{B l u ̈ =}$ thenbecte mit einfad)em Dorn ober faft wehrloz.

$\dagger$ sglüthen zmitterig.

a. SBlätter kerablaufend.

1094. C. palustre. \$rop. (Carduus palustris. L.)

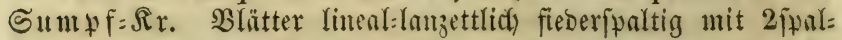
tigen itadgelfpibigen Bipfeln, zerftrcut:befanart, Blumen traubig=

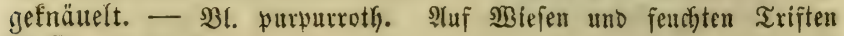
häufig. 7. 8. के

\section{b. Blätter nid̀t herablaufenb.}

1095. C. acaule. All. (Carduus acaulis. L.) હten=

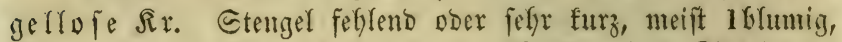
BBlätter fieberjpaltig nit eirunoen gegïfnt:-bornigen Sipfeln. S1. purpurrotf. SIlbart: $\beta$ caulescens (Cnicus dubius. Willd.) einen meift mefrblumigen Etengel Kis zu $1^{1 / 2^{\prime}}$ hod treibent, ber

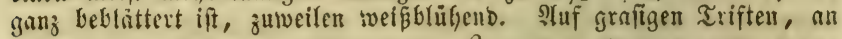

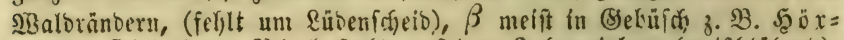

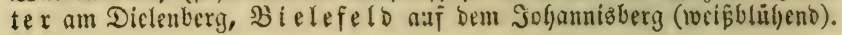
7. 8.24

1096. C. oleraceum. Ssop. (Cnicus oleraceus. L.) Roflartige Rr. Blätter umfaffend hergförmig Dornig=gemim: pert, untre fteberfpaltig, obre ungetheilt; Blumen gefäuft, mit

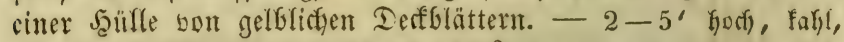
gelblidfgrün, Bl. gelblid)weí. St(bart: $\beta$ dissectum mit lauter tief=

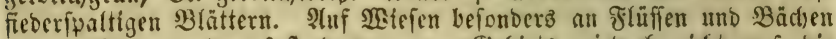
in ben Berggegenden faft Des ganzen (Bebiet3, jevod) nidjt auf bie

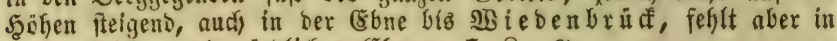

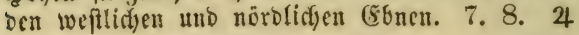

\section{†† Blüthen zweihäutig.}

1097. C. arvense. Sisp. (Serratula arvensis. L.)

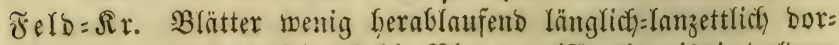

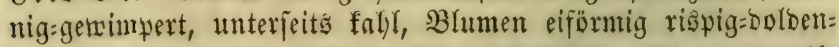

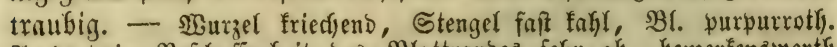

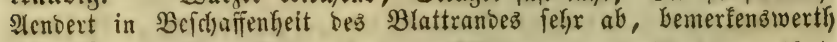

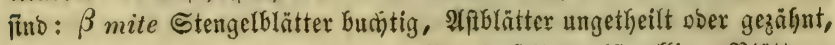
bie Dornen weidfer; $\gamma$ vestitum mit unterfeito weį́)

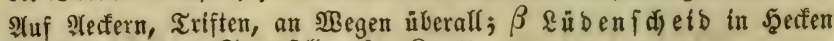
am Eok uno an Sauerfelto. $6-8$. 4

*** Baftarbformen.

1098. C. hybridum. E(tod). (Cnicus palustri-oleraceus. Sab.) Blätter zerftreutbefaart, bie untern herablaufend tief= feberipaltig, bie obern weniger herablaufeno ungetyeilt, gezäfynt 
unt gelappt, Dorniggenemimpert (bie Bär)ne uno Dorne mit ftär=

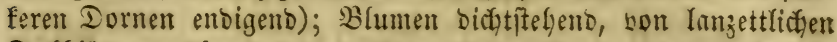

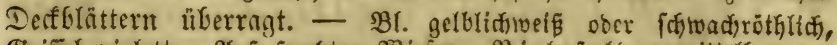
Griffel violett. STuf feudten Sisicen: Bitlefels unmittelbar yor

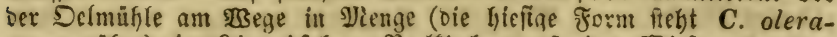

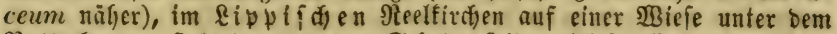

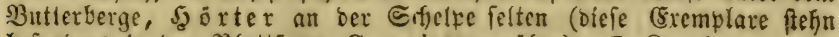
befonbers in ber Batattorm C. palustire nüfer). 7. 8. के

1099. C. decoloratum. Fiod). (C. rigens. Mallr. Cnicus acauli-oleraceus). Blätter zerifreut= meidifanrig bor: nig=genimpert, bie untern fuectitg=ficoeripaltig mit eirumben faft 2lappigen Bipfeln; 2Aefte serlüngert mit unigetgeilten gezäfynten

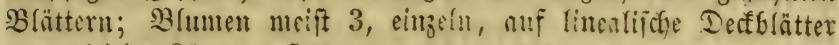
yon gleicher Ränge geftübt. - Bl. gerblidjweip. Iluf Bergwiefen :

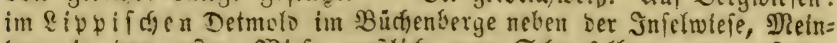

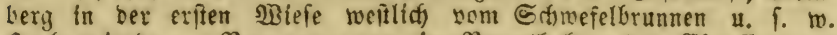
Solzminden, Beverulgen im Beverthal an ber (Efaurife nadi 23arbury. 7. 8. 4

\section{6) Carlina. (5 berwurz.}

† 1100. C. acaulis. Etengelloie E. Etengellos vber einen furzen Stengel treibent, 16fumig. - Bl. Fef)r grof,

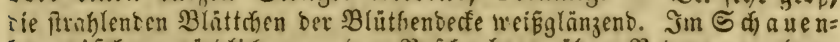
burgifden nërthith yon ber Bafdenburg liter Brienengen (yom

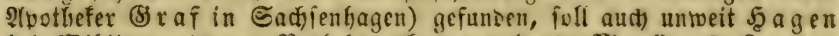

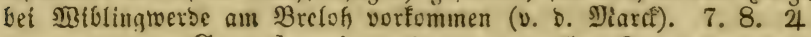

1101. C. vulgaris. (3) enteine (E. Etengel aufredit, faift Dolbentraubig, 2-mefrelumig. - Blätter unteríitz fein= wollig; BIT. Glafroth, Etrablen gelbglinzerib, gleid, ber vorigen wie

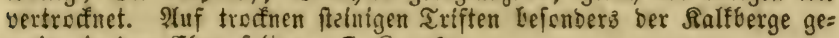
mein, in ber Esbne felten. 7.8. \%

\section{7) Chrysocoma. (Siolofiar.}

1102. Chr. Linósyris. (Linosyris vulgaris. Cass.)

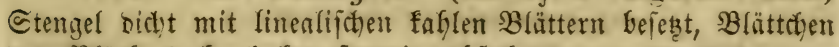

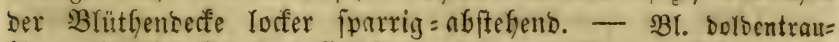
big, gologelb. Sth fand fie 1830 tedjto vom গgeg von El Eerfelo

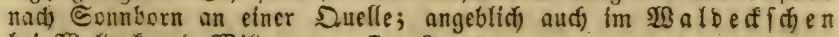
bet Salberf unb withungen. 7-9. 4

\section{8) Eupatorium. WEafietooft.}

1103. E. cannabinum. Blätter geftielt, $3=$ ober 5treily,

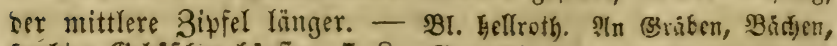
feudsten (Bebuifthen häufig: 7. 8. 24. 


\section{9) Bidens. 3meizafn.}

1104. B. tripartita. Dreitheiliger 8 w. Blätter geftielt, 3 theilig ober fieserfpartig = 5theilig mit lamzettlicfen gc: zälynten Biffeln. - Bl. gclo, Strahlblüthen meift fehleno, ferfe felten aber auds mit benfelben. S:ln feuchten Drten, Stäben. 7-9. $\odot$

1105. B. cernua. Niffender $3 \mathrm{w}$. Blätter ungetheilt lamzettlich gefägt. - Błt. âherfangeno, gelb. Formen: a eradiata shye Straflblüthen; $\beta$ radiata (Coreopsis Bidens. L.) mit groß̂̄en Strahlblüthen; $\gamma$ minima nur 1 -4" hod), meif 1 blumig. Itu

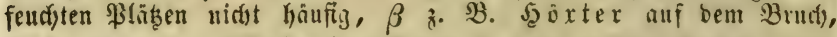
Folzminten, Stufenbrod und Solte in ter Sente (ferilt

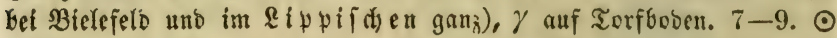

\section{Sromung Polygamia superflua.}

400) Artemisia.

- SBüthenboden sottig.

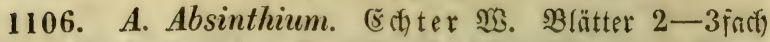
gefiebert mit Innzettlicten ftumufen Sipfeln, filberwein = fitzig; BIattítiele ofme Deflrchen. - Bl. gelb. Itm Dörïer, Stäbte, an Felbränbern, urfprủngliđa) mur vertwilbert. $7-9.24$

* SBlüthenboben Eabl.

$\dagger$ SBlätter vielípaltig

a. Siein Dehrchen am (3runs bez Brattftielz.

1107. A. Abrótanum. (Éberreis= S23. Stengel ftraud)= artig aufrecht:rispig; untre $\mathfrak{B l a ̈ t t e r}$ bowwelt geftesert mit fefir fámalen Bipfeln, obre und blüthenftänoige 3fpaltig ober ganj; Blumen faft fugelig, grauliç). - Bl. gelb. Su (Särten Yjicr uno ba angevflanzt. 7.8 . 4

\section{b. Dekrodsen am (sruno bes SBlattfiels.}

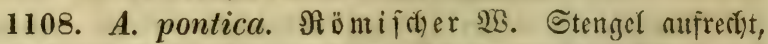

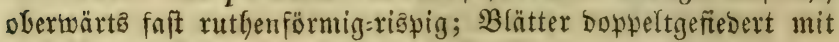
linealifa)en Bipfeln, unterf. filzig; Blumen etwas fugelig, grau,

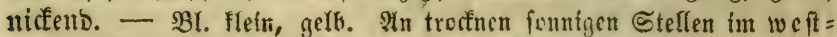

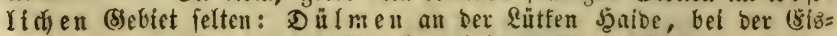

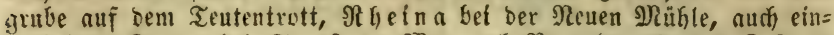

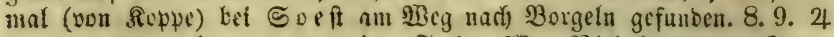

1109. A. campestris. Feld $=\mathfrak{T 3}$. Nichtblübende Sten= gel rajenartig, bie blügenden auffitrebeno = rišpig; Blätter 2 - 


\section{P. superflua.}

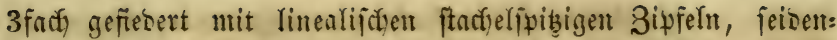

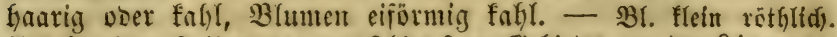
Nuf fanbigen Triften bes weftlid îen Bebietez an ber Ritpe $z$.

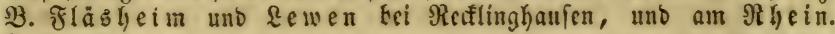
8. 9.24

1110. A. vulgaris. (5) meiner SูS. Ctengel murectit ätìg; Blätter ñeserfpaltig mit Inuzettlidyen zugefpibten Bipfeln,

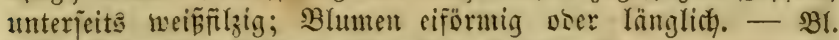

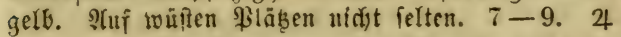

†† $\mathfrak{B}$ lătter ungetheilt Eabl linealifád.

1111. A. Dracunculns. (3) artente. D. Dragon ober ङ3

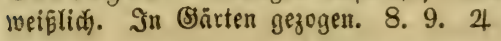

\section{1) Tanacetum. Яainfarn.}

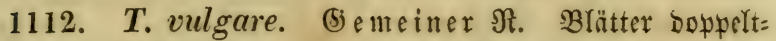

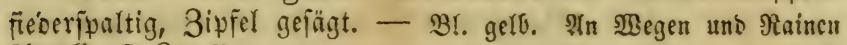
überall. 7. 8. 24

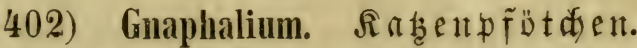

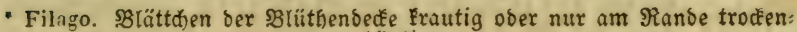
bäutig.

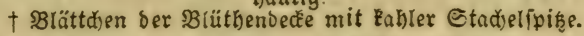

1113. Gn. germanicum. Willd. (Filago germanica.

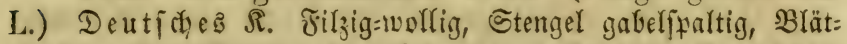

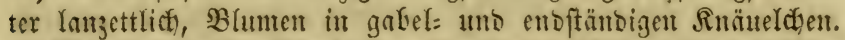
- Bl. gelblid)weíf. SIltart: $\beta$ pyramidatum (Filago pyramidata. Goud.) ber Saauptftengel niebriger, bie श्tepte meît verlängert unb nie=

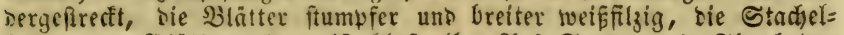

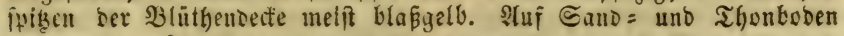

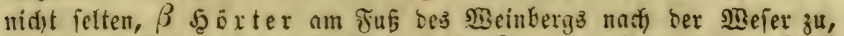

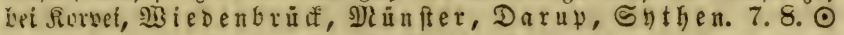

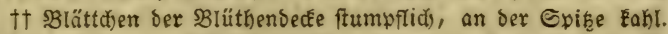

1114. G. arvense. Will . (Fil. arvensis. L.) $\mathfrak{2} \mathfrak{d} \in \mathfrak{e}=\Re$. Diătwollig; Stengel rişpig, 2lepte aufrecht, faft einfad), ziem:

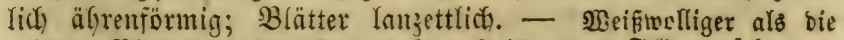

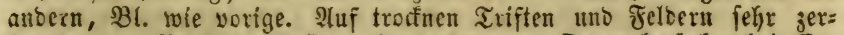

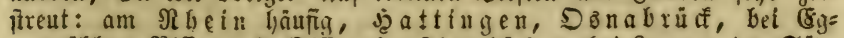
germulyler, Biffenborf, Dillen, im \&ippif é en bei \&age an ber Süb=

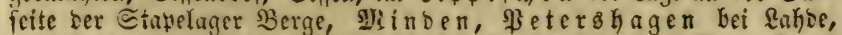
5olzmben, 5óxter, Brałel, Beverungen, Marberg

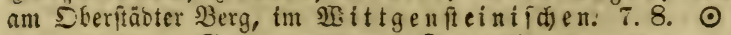

1115. Gn. minimum. Sin. (Gn. montanum. Willd.)

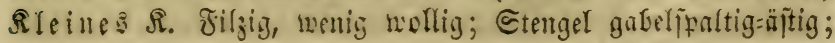




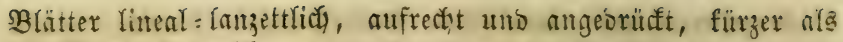
bie Bhumenfuäutelden. - Bl. wie vorige. 2af Sambboben ber

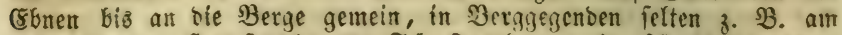
röterberg, Serptelle uno Für tenberg, in fübliden (Bse= biet. $7-9$. $\odot$

+1116. Gn. gallicum. Sim. (Fil. gallica. L.) $\widetilde{\jmath} \mathfrak{a} n=$

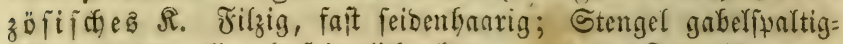

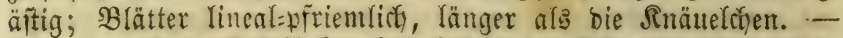

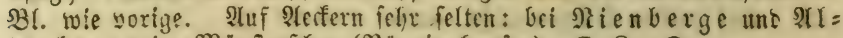

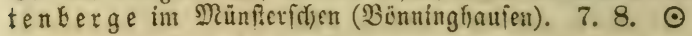

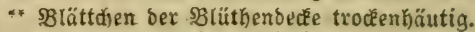

$\dagger$ Gnaphalium. 2OBeiblides :Rlüthen mehrreihig.

a. Şlumen einbäufig.

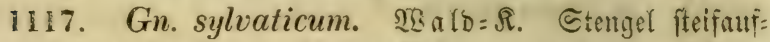

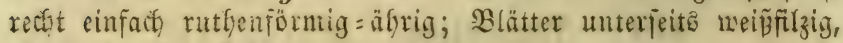

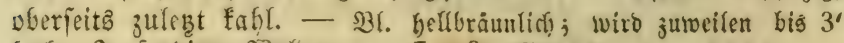

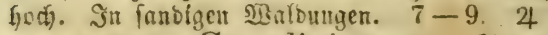

1118. Gn. uliginosum. $\varsigma_{4 m} f=\Omega$. Stengel bout

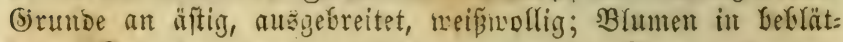

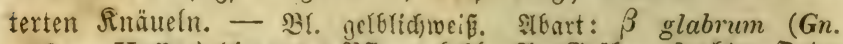

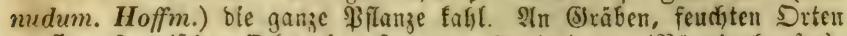

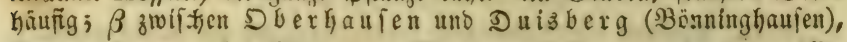

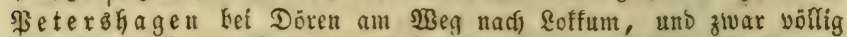

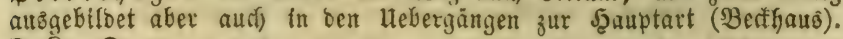
7. 8 . $\odot$

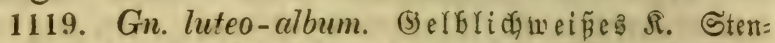

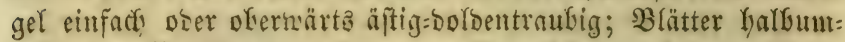
faliend wolligbefgart, bie untern ftumpf, bie obern nad ber

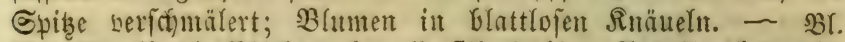

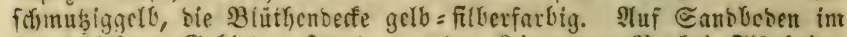
nörolishen (bsebiet zerftreut: an ber Rippe z. B. bei Fläsheim, Sythen, Shut ufter, Telgte, Bentheim, fingen im Drffc

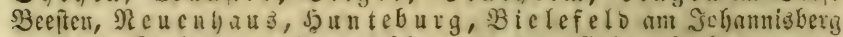
in einem Braken ber glimannidgen Bsirten, (Solon Elefermann in

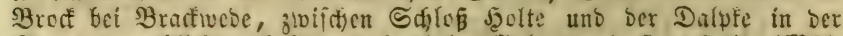

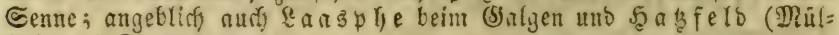
(er). 7. 8. $\odot$

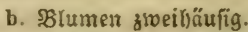

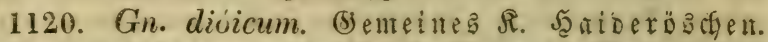

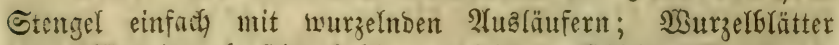

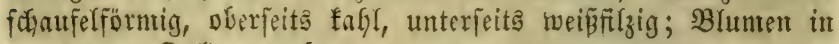
georängten Dolsentrauben. - BC. helfuupurroth ober weis. ITuf

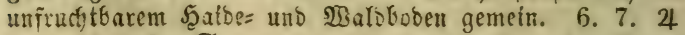

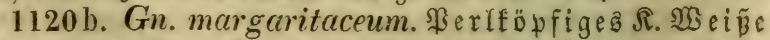

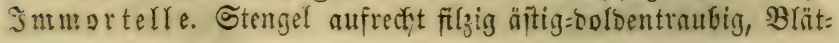




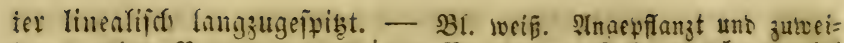
len an alten Burgen verwiltcit $\mathfrak{o}$. $\mathfrak{B}$. an ber Sd) a uentarg bci Ninteln. 7. 8. 24

t† Helichrysum. Gaertn. TSeiblide Stüthan menige, Ireihig.

1121. Gn. arenarium. (Helichrysum aren. Baertn.)

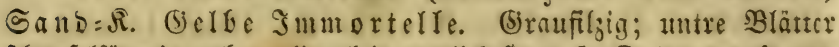
id)aufelförntig, obere lineal=lanzettlide ftumtif; Dolsentraube zu= jantmenge

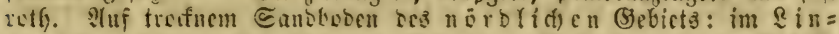

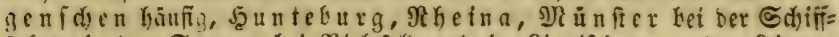

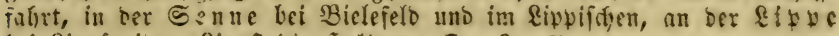
bei Rippipringe, Rippplabt, J̦altern. $7-9.4$

\section{3) Conyza. Dürrwarz.}

1122. C. squarrosa. SูEeiffbef)art, Blätter eirumb

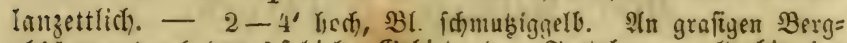

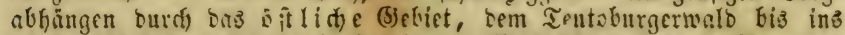
Terflenburgifdye folgent, fouft felten 3. B. Iippftabt am $\mathfrak{B e g}$ nací SiBefernfutten beim erfiten Bauernhoje, Soeft in ber Dberborbe, Dortmund am Erfurrenorge, Sattingen, an ter \&enne unt

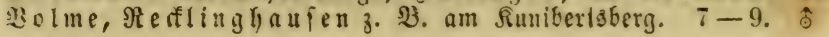

\section{$404)$ Cótula. Raugenglume.}

1123. C. coronopifolia. Stengel liegento, Aefte 1 frut:

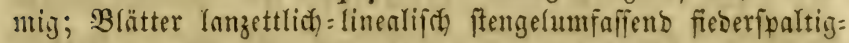

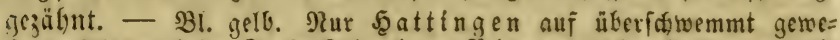
fenen \$lägen beim Dorfe Sticpel ven B I $\mathrm{me}$ roth gefunden unb mir getrofnet mitgetgeilit 7.8 . $\odot$

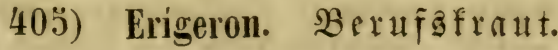

1124. E. canadensis. Ranabif

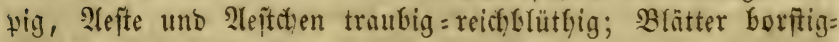

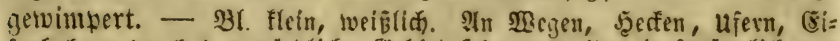

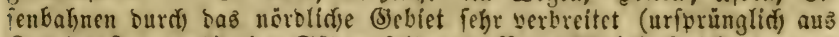
Ranaba panmment), im Süben felten z. B. nidft bei Sgattingen und

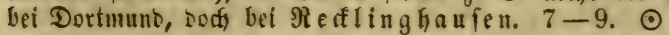

1125. E. acris. Stharfes B. Raudhanig; Stengel traubig, zulebt faft ooloentraubig, 2lefte 1 - 3 blumig. - Die

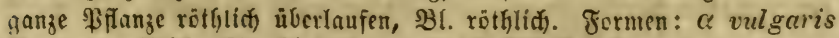

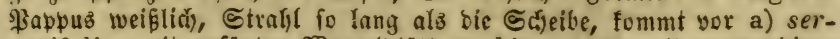
ratifolius mit gefägten $\mathfrak{B}$ Burzelblättern, b) muralis mit ganżranbigen Misurgelblättern, c) humilis vielftenglig, Ettengel meift 1 blumig, Blät= ter gewögnlid) wellig; $\beta$ rufus (E. serotinus. Whe.) \$appus rotty= 


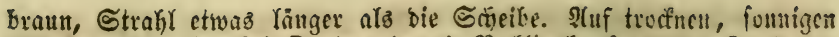

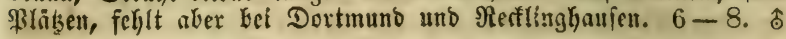

\section{6) Tussilago. Sூu $\mathfrak{r}[a t t i d$.}

1126. T. Fárfara. Rereiner 5. Sdinft 1blumig. -

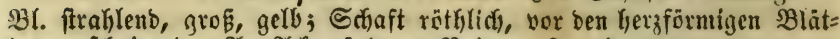

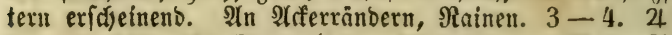

1127. T. Petasites. (Petasites officinalis. Atoend).)

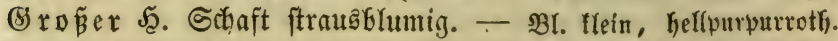
Ilenbert $\mathfrak{a b}: \alpha$ hermaphrodita (T. Petasites. L.) zwitterblüthig, Der Straus eifürmig mit gröBeren Blumen; $\beta$ femina ( $T$. hybrida.

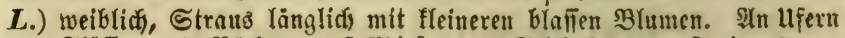

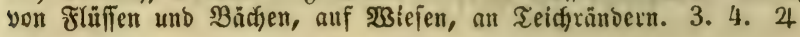

\section{7) Solidago. (5o oldrutbe.}

1128. S. Virgaurea. (S) enteine (5). Blätter ellip=

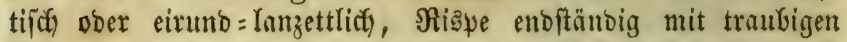

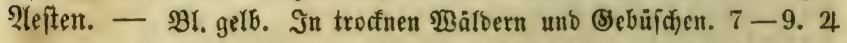

\section{8) Senecio. אieuzfrat.}

* Shne Strahr.

1129. S. vulgaris. (5) emeines Rr. SBlätter ftengel= umfañen buchtig:fieberipaltig gezäfnt. - Bl. getb wie bei allen folgenben. Stuf bebautem Boben überall. 3-11. $\odot$ ** ธtrahl klein, zurüdégeroult.

1130. S. viscosus. Rlefrige $\mathfrak{R}$. Rlebrig:brüfig:

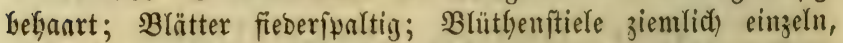
nacf) ofen berbifft; 2(unenfeldy lorfer. - 2 n geidyübter Stefle

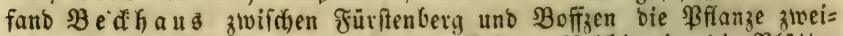

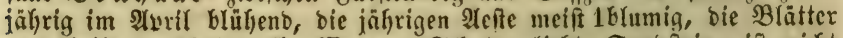

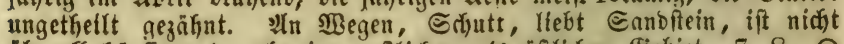

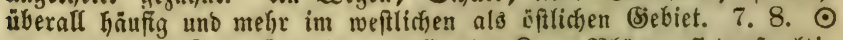

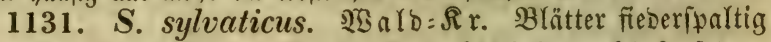
fpinnmebig= weichbefgart, Blüthenftiele büfchelig = gefhüuft faben=

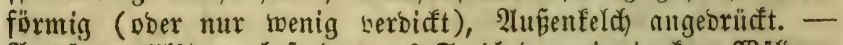

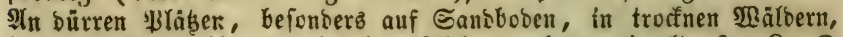
im weftridjen sesebiet gemein, im siplidjen metix vereinzelt. $6-8$. $\odot$ *** Strahl abftehend.

$\dagger$ Siătter getheilt

1132. S. erucifolius. $\Re \mathfrak{a}$ tenblät trige $\mathfrak{R} \mathfrak{x}$.

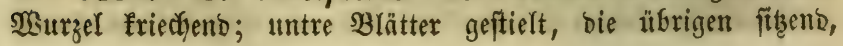




\section{P. superflua.}

alle ficseripaltig, Fieser linenlija, gezägnt uno fieberipartig, bie ber Bajts fleiner gamjranbig öhrdtenförmig; 2lupenfelda meforblättrig, angerrürt, fyalb fo lang als ber Sauptfeld, an ber Eqize geflecft. - Abart: $\beta$ tenuifolius. Jacq. bie fieber ber

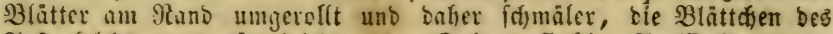

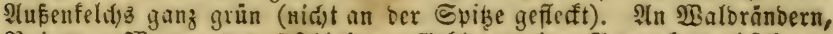

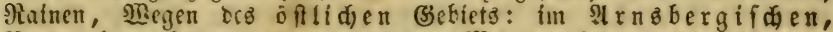

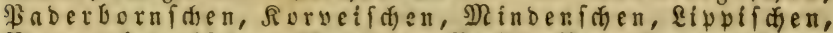
Ra a ye thbergif chen (Bielefelo z. B. 2lte Berg, Steingrube), und ben Bergyingen bis inz folgens, fonft auric bei Coesfelo und Daruy; $\beta$ fdeint bagegen

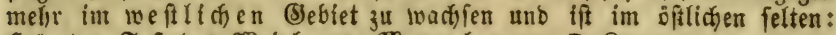

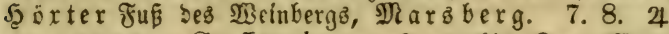

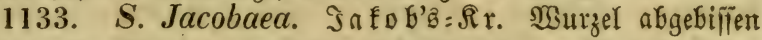

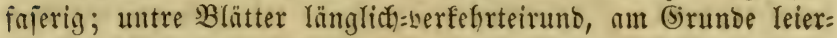
förmig, obre mit bieltheiligen Defrechen fengelumfañen, fieber: fualtig, Fiebern gezäfnt ober fajt fieberipaltig, sorn 2 fpaltig,

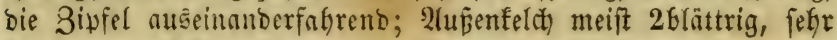

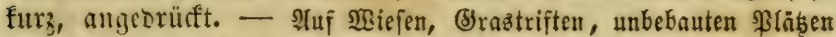
gemein. 7.8.

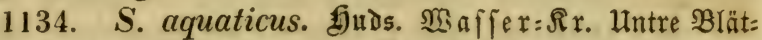
ter geftielt lïnglid =eirund, am (jrunbe berfdimälert unb faft ungetheilt, bie mittleren mit getheilten Defrecten falbftengel= unrafient, ant (3)rund eingeidnittent Doier Yeierförmig (bie fei: tenftündigen Fiebern fơräg auf ber Mittelrippe ftefend), Der (Enblappen eirumb:länglich), bie oberften fieberipaltig ober unge= theilt uno gezäfnt. - Bl. groß́. N(bart: $\beta$ barbareaefolius. Rchb.

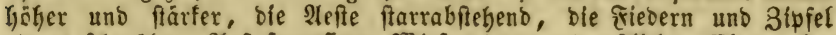

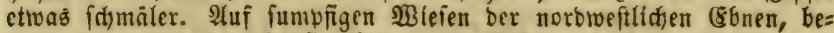

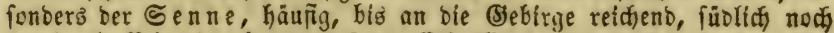

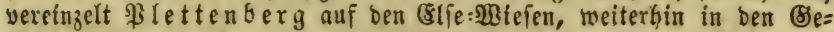

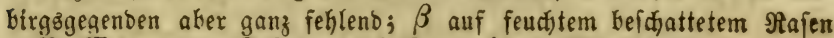
3. B. SBerne am fakiveg nady Rappenberg! 7-9. \&

$\mathfrak{x}$ merke. S. erraticus. Bertol. (S. barbareaefolius. Krock.) foll bei Re u e nrabe vorkommen.

†† ßrătter ungetheilt.

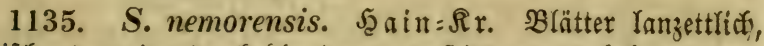
elliptifa ober eirumb, falll ober unterfeits etwas befaart, un=

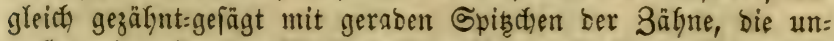
terîten in einen geflügelten $\mathfrak{B l a t t f i t i e l ~ b e r l a u f e n d , ~ b i e ~ o f e r n ~}$ Ttabero (ober auch alle geftielt); 2lupenfeldy $3-5$ blätrig, fo lang ala ber Samuptfeldh; Straflblüthen 5-8. - פib $5^{\circ}$ hod.

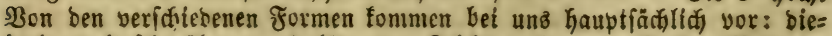

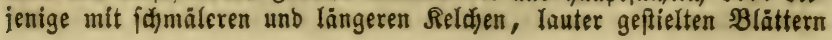


(S. Fuchsii. Gmel. - S. ovatus. W.), uno biejenige mit etivas fđ̃)

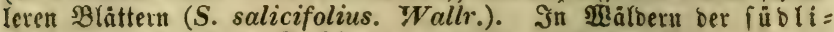

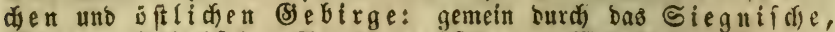

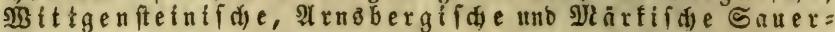
Iand (nod) bei Sattingen) biz inb $\mathfrak{B} e r a i f d e$, fwarfamer im $\mathfrak{B} a=$ berbornidien, Rorvetiden uno sfwhifden, reidjend bis zum

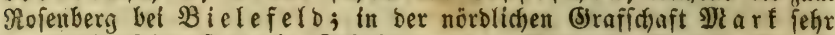

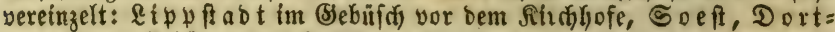
mun alt Sdfütentvege fparfam. $6-8.24$

1136. S. sarracenicus. Sarrazenifdes fir. Blät: ter ziemliç fabl länglid)=lanzettlida, felyr fpibe, bie unteriten in den geflügelten $B$ lattitiel berfdumälert, die übrigen mit breiter

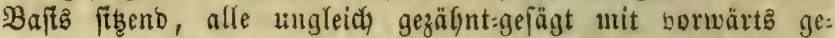

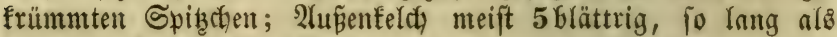

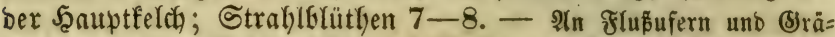
Ven: am ganzen $\mathfrak{B}$ eferufer bis Blotho, im \& NBerre bel Rienlyagen uno ber Jiggenfauter Mühle, im $\mathfrak{E}$ anethal unterhalb bes शieuenhofeb, bei ber Shnappe, Dälm en bet Jjibbingiel, ant $\mathfrak{R}$ Gein z. $\mathfrak{B}$. zwiftien $\mathfrak{B}$ eiel und Diersfort. 7. 8. 4

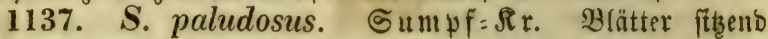

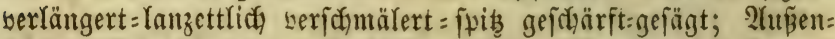
felda meift 10 blättrig, balb fo lang als ber 5auptfelda; Stralyl: blütbeat zablreich $(13-15)$. - Nannshod). Bci uns bie Form mit unterfeits weisfirzigen Blättern (S. Sadleri. Lang). In fun=

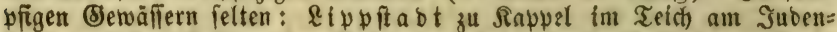

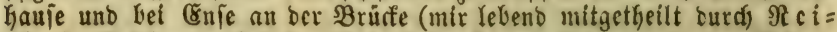

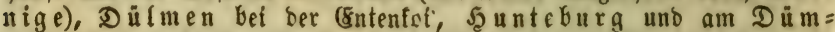
meriee, angeblidi audi \&otte im Tefflenburgifdien unb $\Re$ inteln auf ber Infel. $6-8.24$

\section{9) Cineraria. $\mathfrak{A}$ id ficaut.}

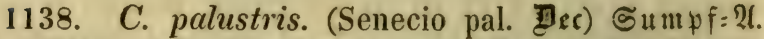
Dottig; Blätter lanzettlich Galbịtengelumifaffeno, untere butdig: gezähnt. - Bl. Kellgelb. SAuf Sumpfboben befonters in torfreidfen

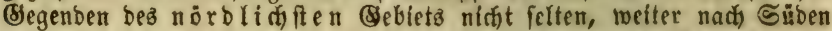

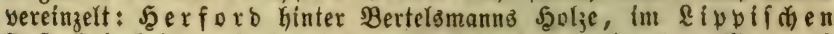
Defterholz bef ben \&utterteidien, Salz forten neben bem MBeg narif uriprung, Soeft im Brudib bei Smpen, Beyerungen im Brud) bei รูaаrbrǘt. 6. 7. 4

1139. C. spathulaefolia. Gmel. (Senecio spathulaefolius. Des.) Spatelblâttriges $\mathfrak{A}$. B̉ătter oberfeitz fpinn= twebig=flortig, unterfeits weiffwollig, bie untern eiruno geftielt, bie ofern fitzenb. - Bl. gelb. Bon Dauber bei Fुolzmin ben auf bem Burgberg befm Telegrapfien aufgefunben, unb zwar bie fámalblättrige ซorm. 5. 4 


\section{0) Aster. $\mathfrak{A}$ itex.}

1140. A. Tripolium. Stranonfter. SBlätter etwas fleifhig, linealij(c)=Lamzettlich), meift ganzrandig, nebit Dem Sten=

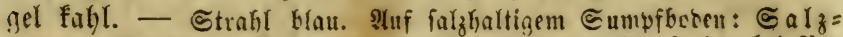
"flen, Diffen, (graventurft, Soeft am Salzipring bei qa= rabies, Salztotten. 8-10. A

1141. A. salignus. Willd. $\mathfrak{x}$ eioenblätrige 2 . Stengel riäpig=bolbentraubig, fait fably ; Blätter lanzettlich), ganz= rantoig ober in ber Mritte mit wenigen afftefenden હägezäh)en,

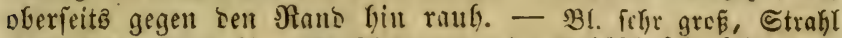

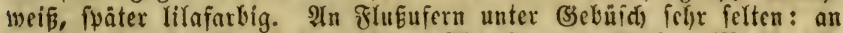

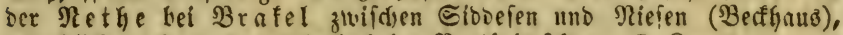
angeblidy auth an ser $D$ infel im Bentfrimidyen. 7. 8. 4

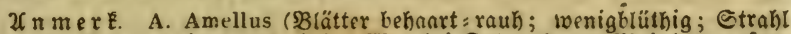
blau) giebt (5) d) terling alh einige গgal bei Detmols am 23 einberg gefun: ben an, vermuthet aber felbit, $\delta a \bar{\beta}$ ex bort nicht roilo wadje. Ebenfo verwil: bert mitunter A. Novae Belgiae (mit locfrer SBlüthendel(ke, rötblid)sbiolettem Strahl) z $\mathfrak{B}$. $\mathfrak{B}$ i elefelo vor ber Finfenhaibe, Ş öxter au ber (Srube vor ber 巨tnot, unter Fürftenberg, 2 p

\section{1) Inula. $\mathfrak{A} \mathfrak{I} \mathfrak{n} \mathrm{t}$.}

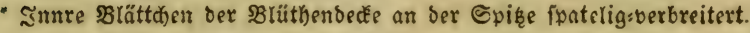

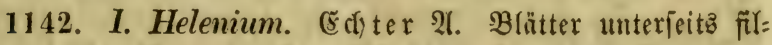
3i引, ungleidugezäfnt, bie ftengelftändigen herzeirumb ftengelum:

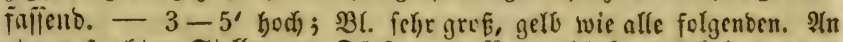

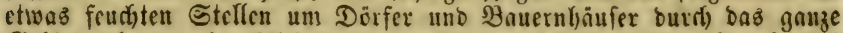

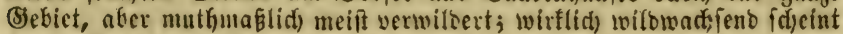

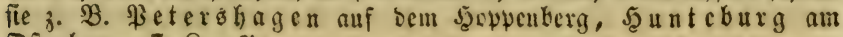
Dftenuerg. 7. 8. 4

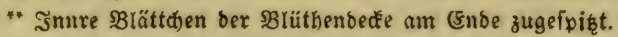

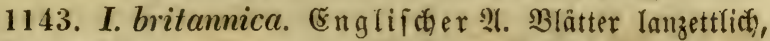
unterieits nebit bem Stengel zottig=filzig; Frïchte Fefonart. -

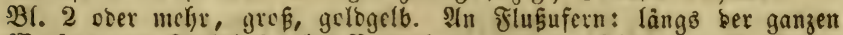

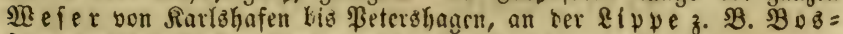
fendorf bei Rectlinghaujen, unt bem Rhein. 7. 8. 4

1144. I. salicina. SWeibenblättriger \&. Blätter

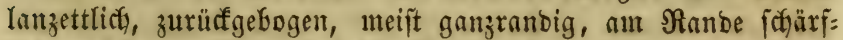

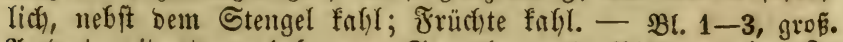
Renbert init etwas befaarten Stengeln unb Blättern ab. In

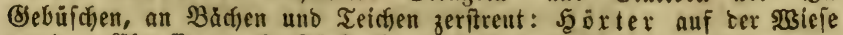
an ber (E)

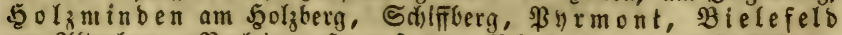

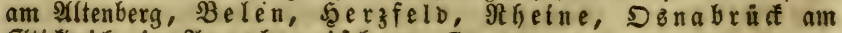

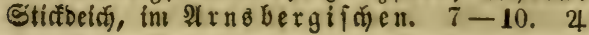


412) Pulicaria. Gartm. Floff faut.

1145. P. vulgaris. Garrtı. (Inula Pulicaria. L.).

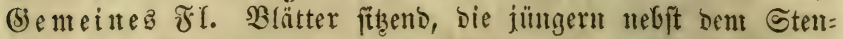
gel zottig; Ctrafilblüt)en ivenig länger als bie Sitheibeblüthen. - $B$ l. flein, fdjmukiggelb. Itn feudften \$lä̉en um Dörfer und Bauernbüfe im weftlidien (sebiet häufig, éemfo im füblidgen, fonit fparfam: an ber Mgefer, im sippifden bef Blomberg,

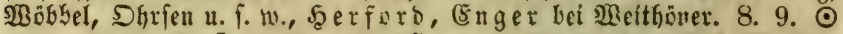

1146. I. dysenterica. Gacrtı. (Inula dys. L.) $\Re \mathfrak{l} \mathfrak{r}=$

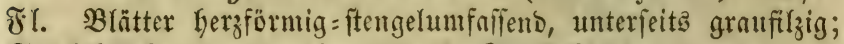
Straflblüthen weit größer als bie Seteibeblüthent. - Bl. grö=

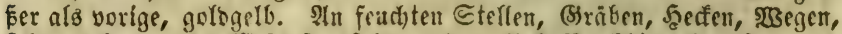

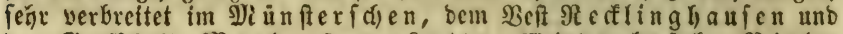

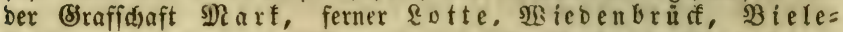
feld um Seepen an ben $\mathfrak{B}$ egen unb um Braftwebe, im Eippifden

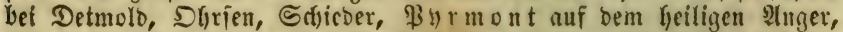

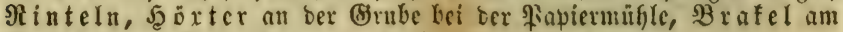
Bad) bei bem sefundbrumnen. 7. 8. 24

\section{3) Arnica. Misolfluerleif.}

1147. A. montana. Berg= S3. Stengel nufred)t be= Yjant; Blätter Yängliçy=eirutno, bie Geiben ftengelitänbigen gegen=

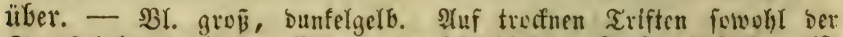

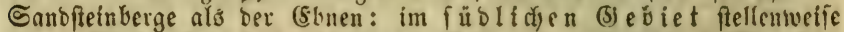

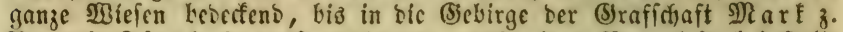

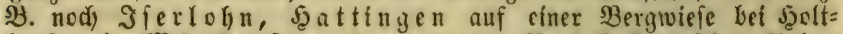

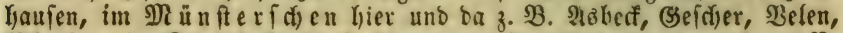
Rhe ina in Dorf Sohenforft, läng bem Te ut tuburgerwalb z. B.

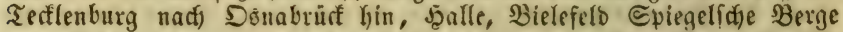
uno Echilnefder Sacioe, im Eippifdien, in ter Senue, am Solling, Betergh agell auf ber şaibe bel Düren. 6-8. 4

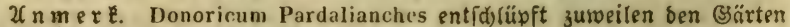

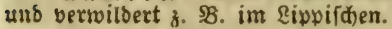

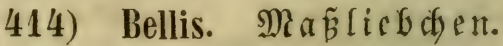

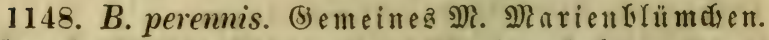
S(f)aft nadft 1 blüthig, Blätter fduaufelförmig geferbt. — Etrahl weí́ ober röthlid, in (Bärten oft gefüllt (Taujendfdjön). Heberafl. $3-11.24$

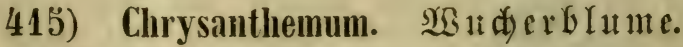

1149. Chr. segétum. (5) elbe $\mathfrak{3}$. Strafl mit ber Sđjeibe

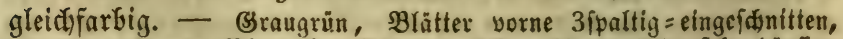
bie obern figento; Bl. gelb. Thuf \&efimädern Gier uno ba jeht bäufig: 


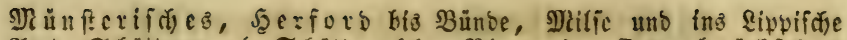

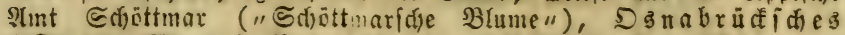

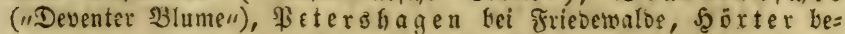

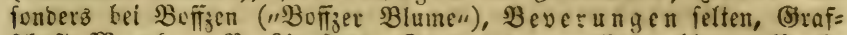

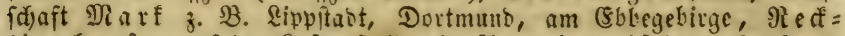

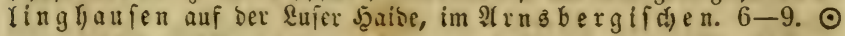

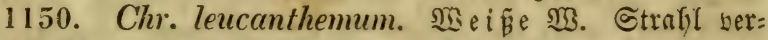
iđuiebenfarbig. - untre Blätter langgeiplelt fwatelförmig, obre fisent;

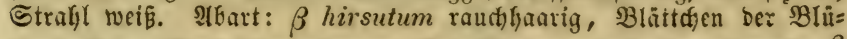

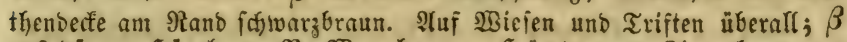

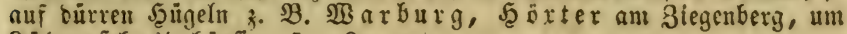

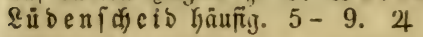

\section{6) Matricaria. $\mathfrak{i} \pi \operatorname{milf}$.}

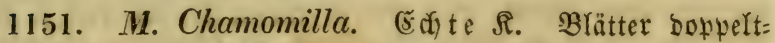
linealipafereberipaltig fafl, Blütfenfoben hohl. - Bl. gelo mit

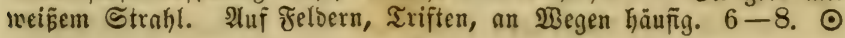

\section{7) Pyrethrum. fall. Bextraminux}

1152. P. corymbosum. Willd. (Chrysanthemum cor. L.) Dolbentraubige $\mathfrak{B}$. Blätter weidbefhart gefiebert, bie

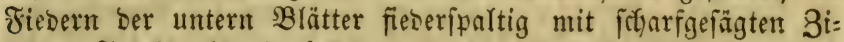

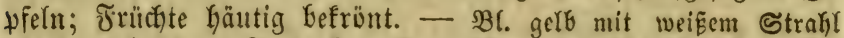
wie bie folgenten. In trof́nen \$3ergwälbern bez fit bo

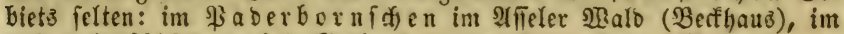

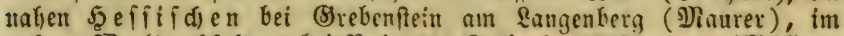

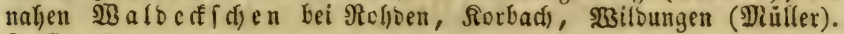
6. 7. 4

1153. P. Parthenium. Sim. (Natricaria Parth. L.)

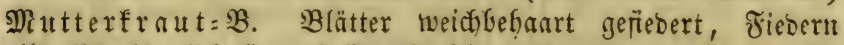

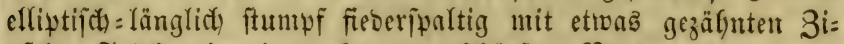

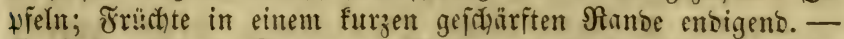
2(n Jiecten, Sdjutt, Nhauern um Dörfer und Stiote faft überafl im Eebiet, bod, nur verwiltert, bagegen anfdseimenb völlig wild an ben Rlippen ber פiargarethenfluz bei Dinden, unt auch loghl f̧olz= min ben an Rlippen über Regenbern. 7-9. 4

1154. P. inodorum. Sm. (Chrysanthemum inod. L.) (b) erudf lofe $\mathfrak{B}$. Blätter $2-3$ fadfieberipaltig mit linealipat: fabenförmigen Bipfeln. - Blütbenbobe: Galbfugelig, innen marfig.

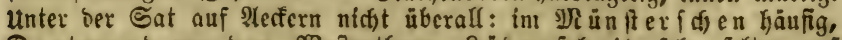
Dortmuno yor bem BBefenthore, \&ubenfide ib felye felten auf

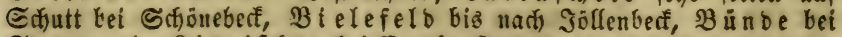

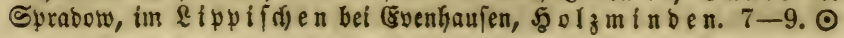




\section{8) Anthemis. 5ூuแถ์}

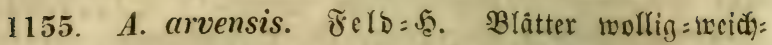
haarig, oopweltfieberfpaltig mit limeal: Yamzettlicf)en ungetheilten Doer 2-3 fachgezäfnten Bipfeln; శruct)tboden serlängert:fegel: förntig, immenbig marfig; Friud)te ftumนf: 4 fantig, äupere mit

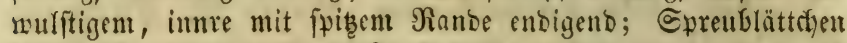
lanzettlidy, in cime itarre Etad)elfpibe ausgetyend. - Bi. gelb

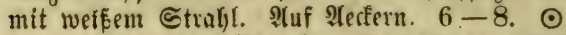

1156. A. Cótula. Êtinfende J. B(ätter ziemtid fafl,

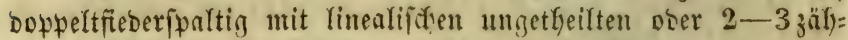
nigen Sipfeln; Frudttroben serlängert = fegelförmig, intwenbig marfig; Epreublättrfen lineal:Gorftlid); Frinchte Geinaly ftielrumb mit fleingeferbtem $\Re$ ans. - $B$ f. wie worige. Stuf bebautem $\mathfrak{B} \mathfrak{c}=$ ben fât burdis Bsebiet, fefit aber an eluigen Eteflen ganz z. $\mathfrak{B}$. um

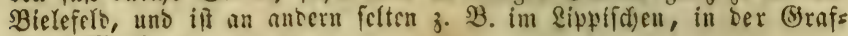
ífaft Mart. $6-8$. $\odot$

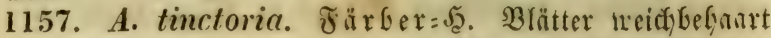

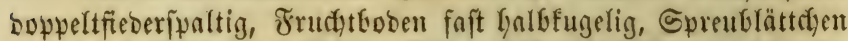

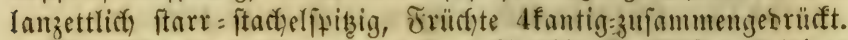

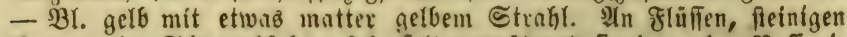

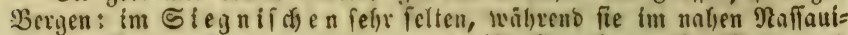

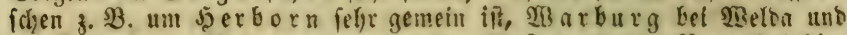

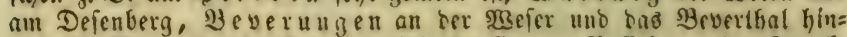

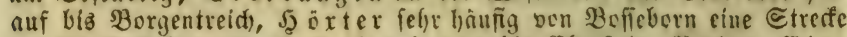

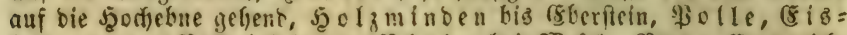

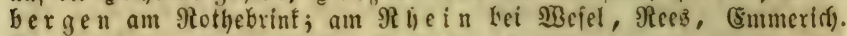
$7-9.24$

\section{9) Achilléa. Bå a b e.}

1158. A. Ptármica. Sumpfgarbe. Baräter linealifach

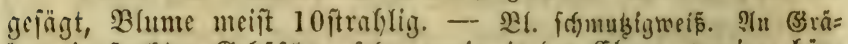

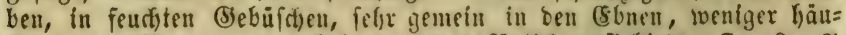

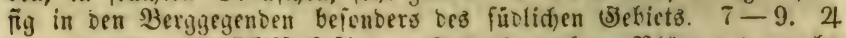

1159. A. Millefolium. Sतi) afgarbe. Blätter boppelt: rieberipaltig, Fieberdien $2-3$ fpaltig ober gefiebert $=5$ ipaltig

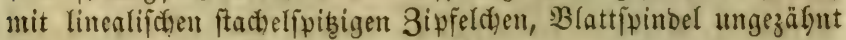
ober nur an ber Spize etwas gezägnt. - Bl. weí̈ ober roth. Stentert ab wollig = zottig uab faft fahl, mit breiteren uno fd)mäleren

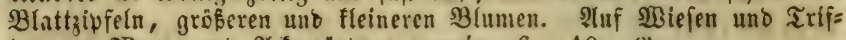
ten, an \$Segen und Afferräubern gemcin. 6-10. 4

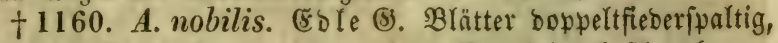

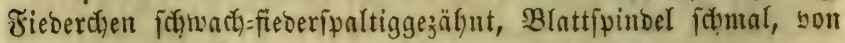
Der Mitte bes̉ Blattes an gezấnt. - Bl. tweî̉. Stuf fonnigen

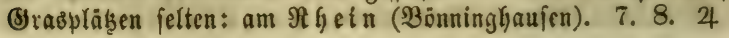




\section{Sronung Polygamia frustranea.}

\section{0) Helianthus. Sonnenblum $\mathrm{r}$.}

1161. H. connums. (5) emeine S. Bglätter fümtlid

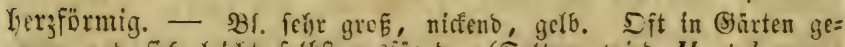

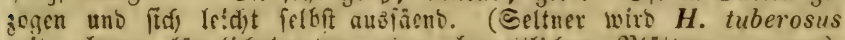

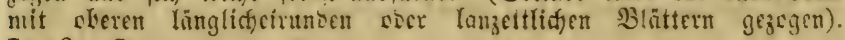
7-9. $\odot$

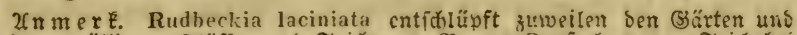

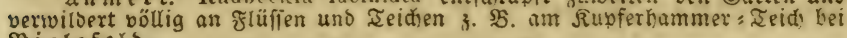
$S B$ ielefero.

\section{1) Centanrea. Flo ffentulute.}

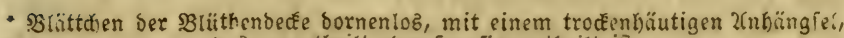
Dab ungetheilt ooer franfig: getheitt ift.

1162. C. Jacea. (5) e meine $\widetilde{F} l$. Blätter lamgettlider, ungetfeilt ober bie untern entfernt: budtig oser fieserifuntig; Rnbängiel die ganze Blütgenderfe bebectent, fonfan, un=

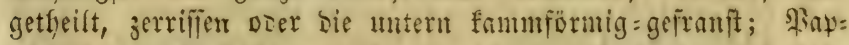

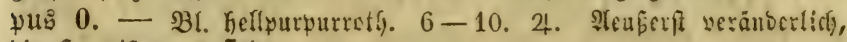
bie Saatformen fint:

$\alpha$ genuina alle Înhängfel ungetheilt ober nux eingeritien= ge=

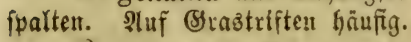

$\beta$ pratensis (C. pratensis. Thuill.) bie untern ober anth) bie

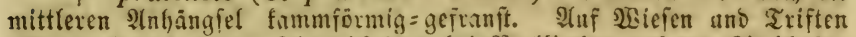

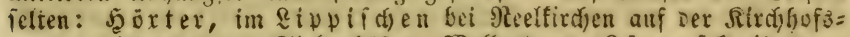

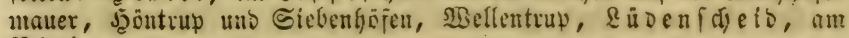
Rhein.

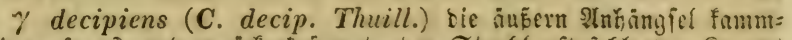

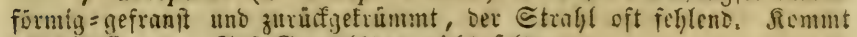
sft lfspfiy yor. Suf (3)raspläben nidjt felten.

$\delta$ capitata (C. nigrescens. Dec.) Efine Ctraf)!, rie Infüng= fel ungetheilt ober bie untern fammformig = geframit; blefht oft filj: flein uno lofumig, änoet überfaupt bicoer nannigfads ab uno fommt

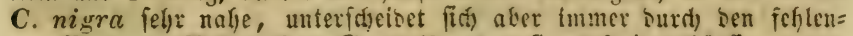

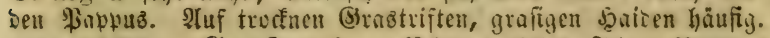

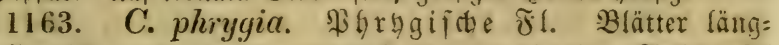

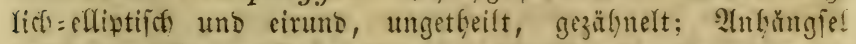
rangpfrientlid) zurüfigctrummt fieberig=gefranit, biej. Der in= nerften Aeige runbliç zerrifien=gezäfut, bon ben Franfen ber

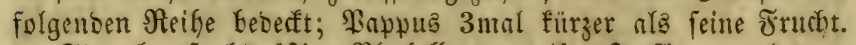

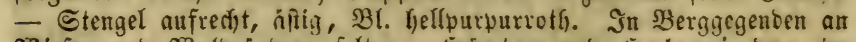

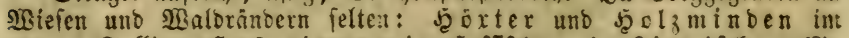

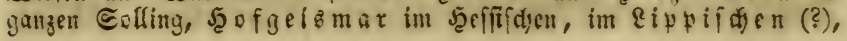




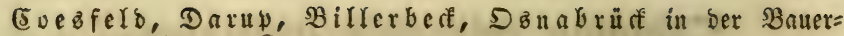
forfaft unphaufer. 7. 8. 4

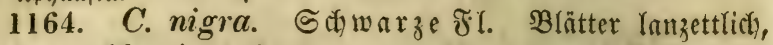
zientidid) raudblyarig, bie untern gezäbnt ober fait buchtig; S(nyängiel aufrecht lanzettlid) gefiebert: framitg, Jranjen borftig, genäbert und bie $\mathfrak{B}$ lïthens. verbeffent, bie innern 2 (ntgängiel

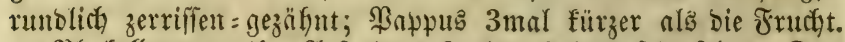
- 2l. Kelfpurpurroth. STuf etras feuditen Triften fegre felten: $D a=$ rup am Söveler Feloe, $\mathfrak{Z}$ efel am Rheinufer (Bönninghaufen), \&ü =

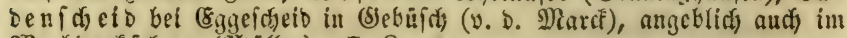

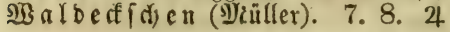

* 2rnbängfel trcafenbäuttig, franfig=gefpalten, die Enofranie Greiter und ftäréer, oft bornig.

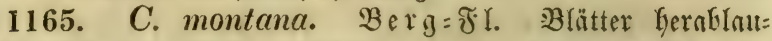

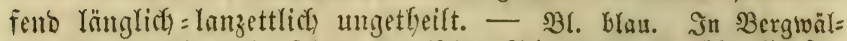

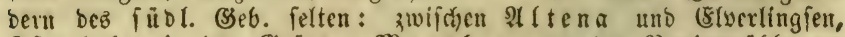

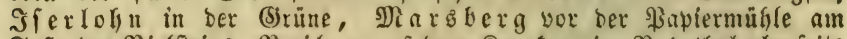

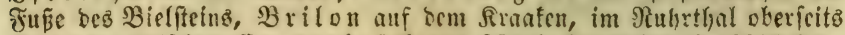

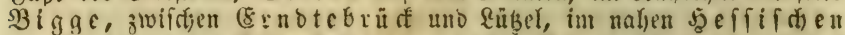

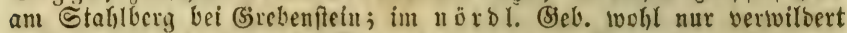

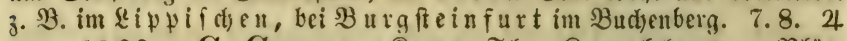

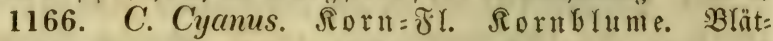

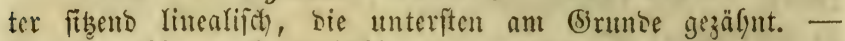

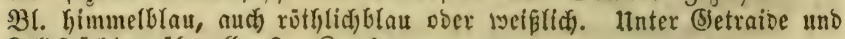

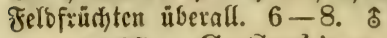

1167. C. Scabiosa. Sfariofen $\mathscr{F}$ I. Blätter fie: beripaltig voer boppeltfiererfy., dic Bipfel mit einem fortwie= ligen Funfte enbigend; 2lubüngiel joturarz 3 ceffig fpis gefranft.

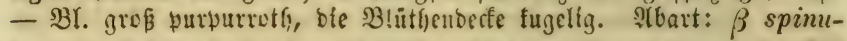

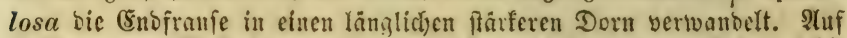

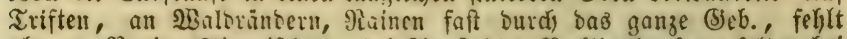

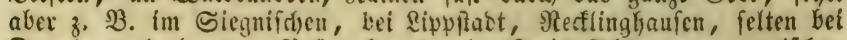

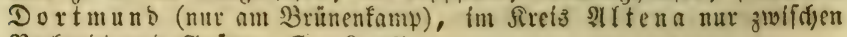

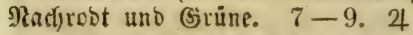

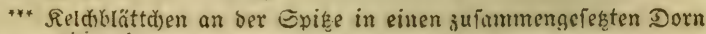
entigeno.

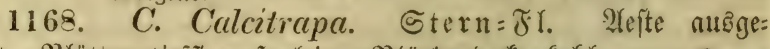
iperrt, Blätter tiefīiederipaltig, Blüthendeffe falyl. - Durne

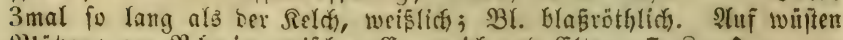

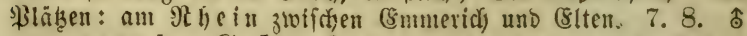

1168 b. C. benedicta. Benedif ten=85. Blätter flalb=

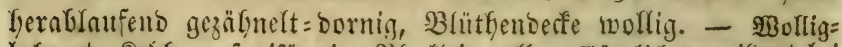

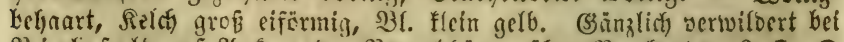
3 telefeld auf Recferm ber Bergabhänge über Bractwebc. 6. 7. ๑

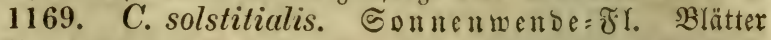

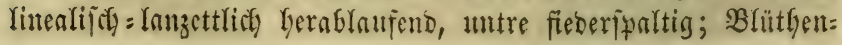




\section{Gynandria.}

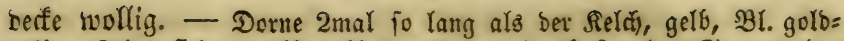
gelb. Beigt fiet) zuweilen hier uno ba, burdf fremeen Samen ober

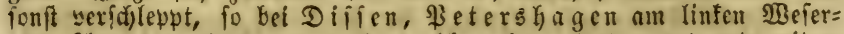

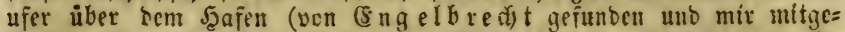

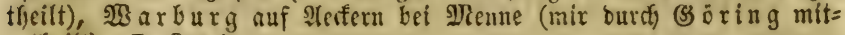
getfeilit). 7. 8. के swilbert.

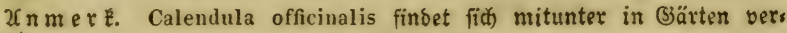

\section{Buanigite Nafie. Gynandria.}

\section{Sronung llonandria.}

- 25urzel Enollentrageno (Staubbeutel angewad)fen).

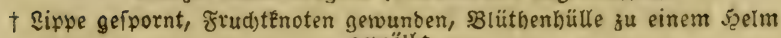
gevóbtbt.

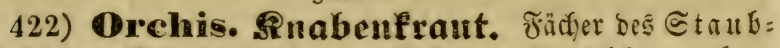

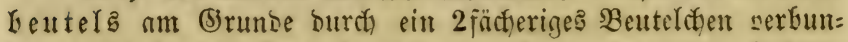
sent. Stiele ber Staubmafien auf 2 getrenten Saltern ruteno. Rippe abftefient.

423) Anacamptis. Mid). Gtrausorche. Für(her

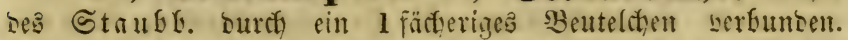

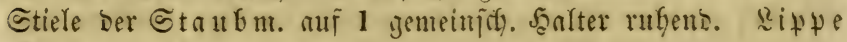
abiteleno, nicit getwunden.

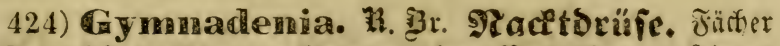
res Staubeutels ant (5iunte ofne Beuteldyen. Sippe abptefeno.

425) Lencorehis. Aluner. Szeifzorde. Sebe Staubmaife einer bejombern nadten Iriffe gerabe (nich)t jeitlidi) angefügt. Rippe nurrecijt.

426) Platanthena. Thid). Wlatantbere. Fät)er

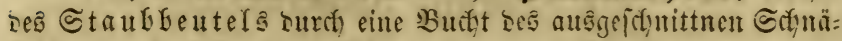
feldfens getrent. Sippe fangeno ungetgeilt.

t† Rippe fporntoz.

427) Ophrys. Infeftenblume. Blütตen 
uno sippe abfechent. Beuteliten 2, getremt. Staub= maifen geftielt, gelappt.

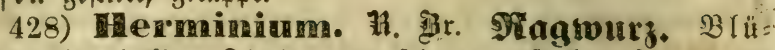
thengülle gloffig. Bipfel und sippe aufrecht. Rippe ant

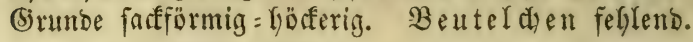

** गָsurzel büfdelig.

$\dagger$ Eippe fpornloz, 2gliebrrig.

429) Cephalanthera. Hich. 23 aldoügrein. Bitfel ber Brithenliulle aufrecht, etwas zufanmenneigent.

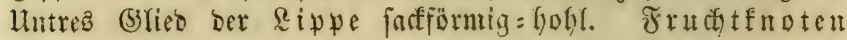
getwundert.

430) Epipactis. Midh. Etendelswurz. B(ü= thenhürle gloffenförmig, etwas abftegento. Hutres (s)lies ber

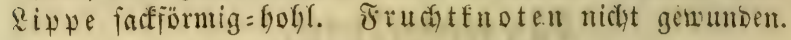

t† Sippe fpornloz, nicht gegliebert.

a. Frudtefnoten nid)t georeht.

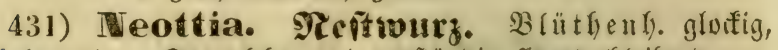

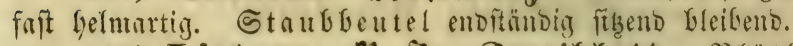

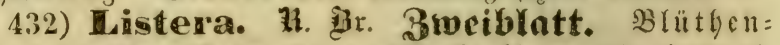

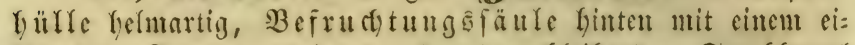

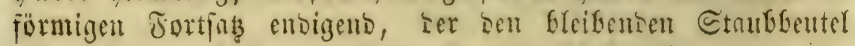
trägt.

\section{b. Fruditenoten georuht}

433) Spiramthes. With. Drebäbre. $\mathfrak{B} I \mathrm{il}=$ the intzeno. Whurzelfafern fnollig.

434) Goodyera. औ. 3̧r. Gubnere. Strub: beutel geftielt. S3ur zelfafern nicht fundlig; forrt wie bor. *** Tुourzel häuttig s zroiebelig.

$\dagger$ Rippe geffornt.

435) Epipogium. (U)t. Tanaten = Drobe. ๔porn aufgeblafen mufred)t.

tt sippe nidist gefpornt.

436) Plalaxis. Sw. Bartorche. \&ippe linten alsigefreitet, am (5) rumbe bns (sriffelfäulchen umfaffent.

\section{Soromung Diandria.}

437) Cypripedinm. Frauenfouly, $\mathfrak{B} \backslash$ ĭ $=$ thenbulle abitefend mit bautig = aufgeblafener Rippe. $B_{e}=$ frudtungafüule an ber Spibe 3fpaltig. 


\section{Soronumg Hexandria.}

438) Anistolochnia. Siterluzei. Blühenh. fronartig röfrenförmig, Röhre an Srumbe banchig, an ber

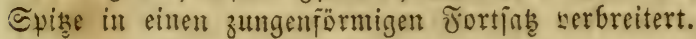

\section{Soronung Monandria.}

422) Orchis. Sinabenfraut. Drafe.

* গ্ভ3urzelenollen ungetheilt. runorid).

$\dagger$ Deč̉blätter Inervig.

a. Sippe 3theilig, ber झnittelzipfel nad) vorne verbreitert unb 2 [paltig (meift mit einem aähnd)en in ber Epalte;

1170. O. fusca. Jatq. (0. militaris $\beta$ et $\gamma$. L.)

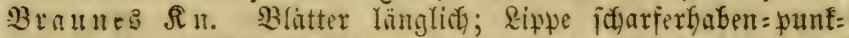
tirt, Geitenzipfel Yimenlijed), Rnppen bes Mittelzipfels eiruns

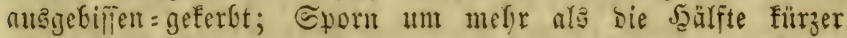

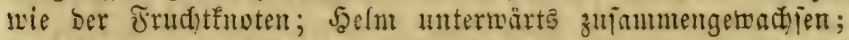
Deffblätter vielmal fitrzer ala ber Fructffnoten. $-2-3^{\prime}$ hod, Syefm sunfelpurpurrotfif soer grülich) mit bunfelpurpurrotgen ßunften, عippe weís soer hellroînroth mit puryurfarbigen erhabnen \$unften.

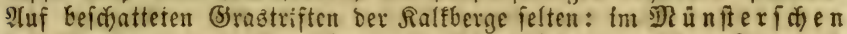
tei Nitenberge und Stromóerg, im Rippifdien zmifáten \&age unb

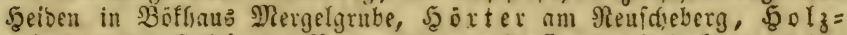

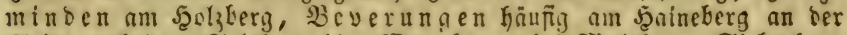

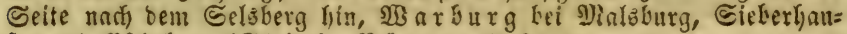

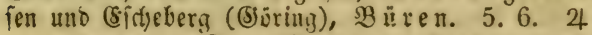

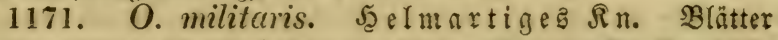
länglid); Rippe fothrferfuaben=puntirt, Geitemzipfel linealija),

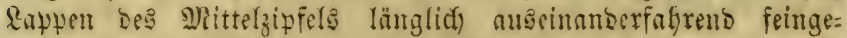
ferbt; Syorn um mefor als die Sanlffte fürzer mie ber ฮrudut:

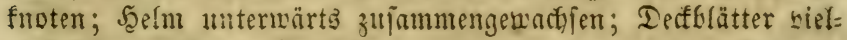

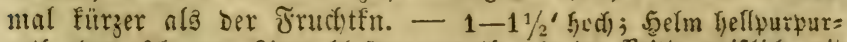

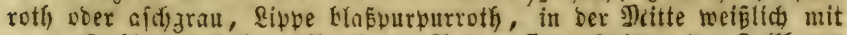
purpurifarbigen erhatenen \$untten. STuf grafigen Triften ber Ralfberge

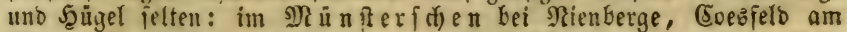
Berize, Fieffenforit uno Dolberg (wo fid) \$ftanzen mit purpurrothem unt ioldse mit afdifarbigem saelme finben), B Belefeld angebl. am Illtenberg fefr felten, im Eippifden tei Derlínghauien und

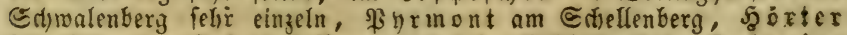

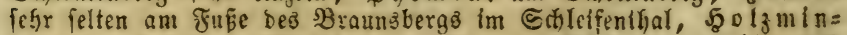

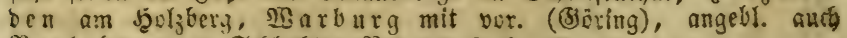

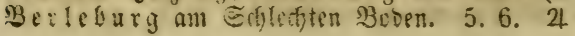




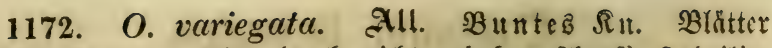
längliç; Rippe punftirt (bod) nidht erhaben = fchari) 3 theilig, Seitemzipfel ränglich, Mnittelzipfel breit = verfefrteirumb, alle fpizgezäfnt; Şelmzipfel zufammenneigend, bie 2 immerften nut wentig fürzer alz ber rilffenftäubige; Sporn uno Decf́blätter Galb fo lang alsె ber Jrudttfnoten ober länger. - Estwa 6"

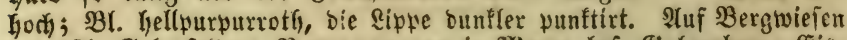
bes offl. Beb. Feiten: Beverungen in פlenge bef. Balgenberg, CEiš

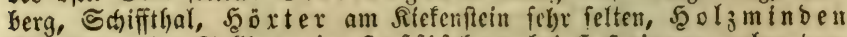

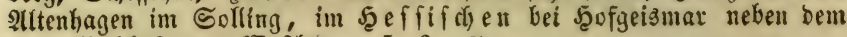
Subenfirsighofe, am Meptierg. 5. 6. 24

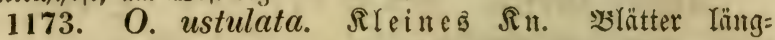
lich =lamzettlich; Rippe fanmentig = wunftirt 3 theilig, Seitenzipfel länglich =linealifơ, Mittelzipfel 2 fpaltig mit länglich = lineali= fuden Rappen, alfe ettuas geferbt; Sporn 3mal fürzer als ber

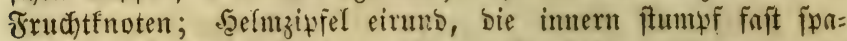

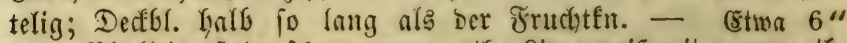
hod); Bl. flein, Selm fofilwarzpurpurroth, Rippe weí mit putpurroth.

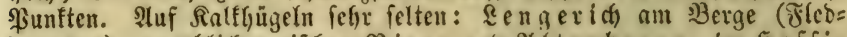

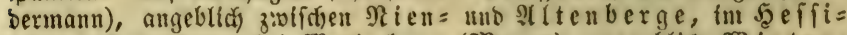

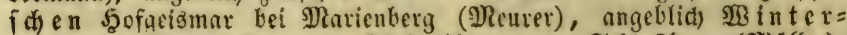
ber $g$ am SBinterfaften unb $\Omega$ iff

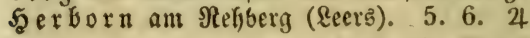

b. Rippe tief =3fpaltig, Mittelzipfer ungetheilt.

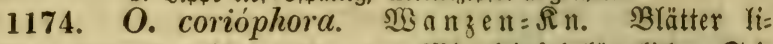

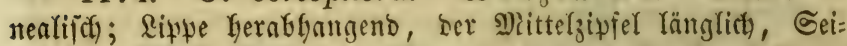
tenzipfer fürzer; Sporn fegeffỏming gefrümmt 2-3ntal fürzer

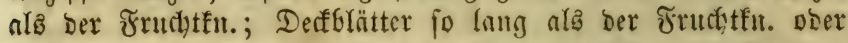

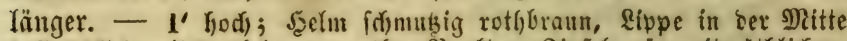
Gellrötglid) mit bunfelpurpurrotfjen \$Bunften, 3ipfel grün mit rötglidjem

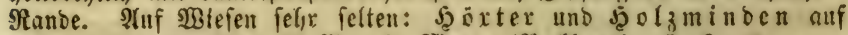

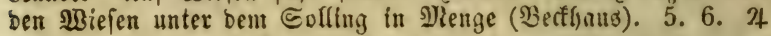

\section{c. Rippe 3tappig mit breiten Eur hen \&appen.}

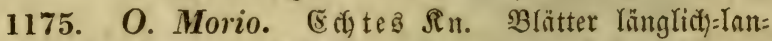
zettlid); Mitteflappen afgeftutzt = ausgeranbet; Sefmzipfel zu=

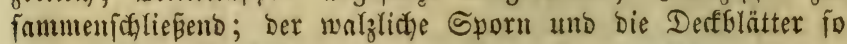
lang als ber Fruthtfnoten. - Adehre locfer armblüttrig, bie un=

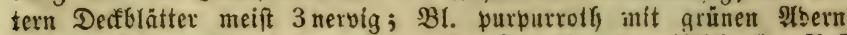

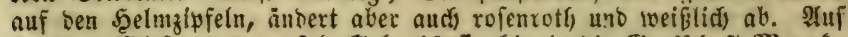
feursten פ⿹\zh13一 im Dift. aurit) auf troctnen Triften, bod) vercinzcli: $\mathfrak{B}$ i clefeld $3 . \mathfrak{B}$.

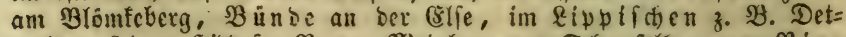
molb auf bem Sjibbejer Berge, Dicinberg an Erriwefelurunnen, $\Re$ in=

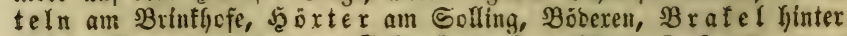
Erteln, $\mathfrak{B}$ e 


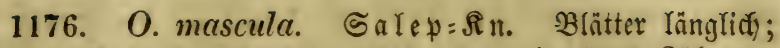

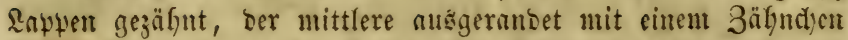

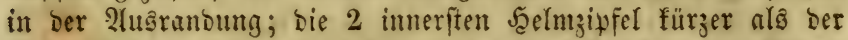

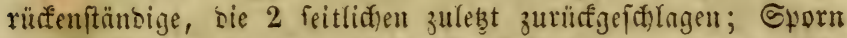

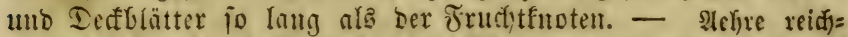

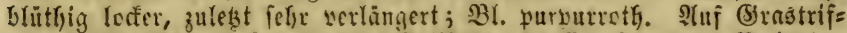

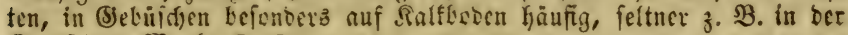
(Stafifiaft פarf. 5. 6. 24

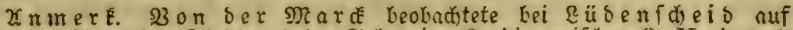
Wुicfen zwifden ber Etabt uno ber Fohr eine Orchis zrvifden 0 . Morio unto o. mascula, bie ihm nicht zu beiben zu gehören fdien; er beláreibt fie fols

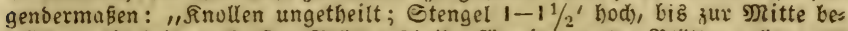
blättert, oie beiosu oberften $\$ B$ lätter fd)eibenförmig, untre SBlätter gröber alB bei 0 . Morio boch nid)t fo breit und ftumpf wie bei 0 . mascula; Deckblätter Inervig, faft fo lang alz ber Fructiténoten; Selmaipfel balo zufammenfalie: feno (rvie bei 0 . Morio), bals bie äußjern zurückgeid)!agen (mie bei 0 . mascula), Ptark = (aber nid)t grüns) geftreift; Sporn bogenförmig: getrümmt, a $n$ : fteigen $\delta$, beinah fo lang alb det Frudtenoten; Rappen oer Rippe geferbt, länger alb bei 0 Morin, abir niđt mit rauhen \$ounften an ber $\mathfrak{B}_{\text {afiz }}$ befest; Etnubbeutel gelblic), SBliithenitaub gelb; Slüthen weiflid)." (Sinige İheile biefer SBefdreibung oüriten auf 0 . pallens paffen, boib muti id bie Sadje bahingeftellt fein lafien.

\section{†† Deḉbiätter 3- mehrnarvig.}

1177. O. laxiflora. fam. Sofferb Blätter Yinenliịd) =lanzettlid); Ripwe 3lapwig, ber PRittelfapwent tiefausgeranbet breiter; Sporn wrizlict, fürzer ala ber Frut(t)t=

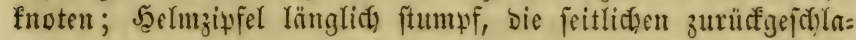
getr. - Nefre verlängert loffer, Bl. purtyurroth. Bei unz nur bie SIbart: $\beta$ palustris (O. palustr. Jacg.) Niittelfapwen ber Rippe fo

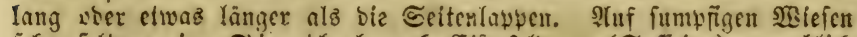
ichr fclten: im Siegthal nact) (siferfelo ju (Eufirim), angeblidg

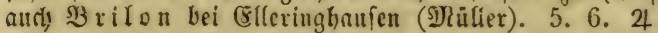

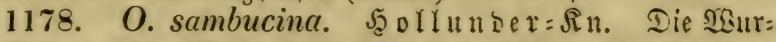

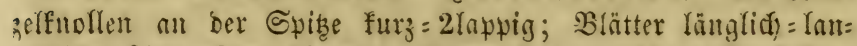
3ettlid; Riple furz=3lappig; Gporn fo lang als ber Frudutfu.;

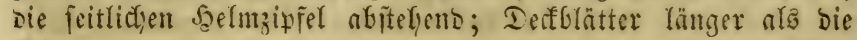

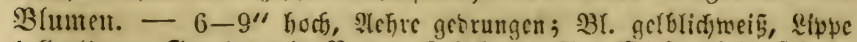

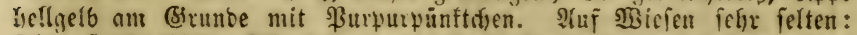

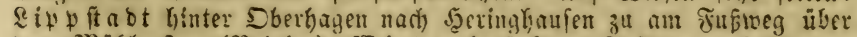

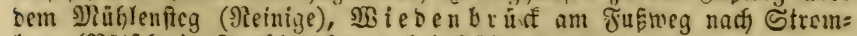

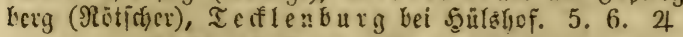
* Trsurgelf́nollen hansförmig = getheilt (Rippe 3lappig).

1179. O. maculata. (j) ffle féte $\mathfrak{R} n$. Ctengel fejt, meift 10 blättrig, bie unterften Blätter länglicí, bie mittleren lanzettich, bie ofich berffeimert (berffblattartig, boch bas oberfte noch) weit won ber 2(efre entfernt); bie feitenítänoigen ફ̧elm:

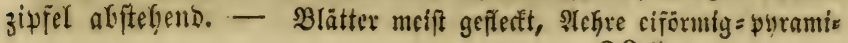




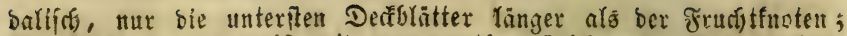

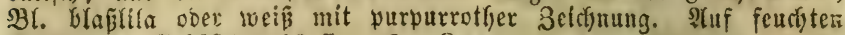

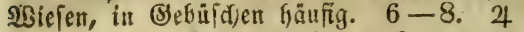

1180. O. latifolia. (0. majalis. Zabb.) Breitblät $t=$ rige $R_{n}$. Stengel röbrig 4-6blättrig, Blätter abjtehent, bie untern doal ober linglicf, ftumpf, bie obern fleiner Inn=

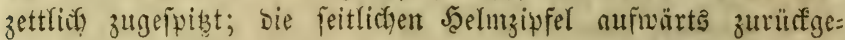
fơlagen. - Blätter cfit grflicft, Fefre oft verlängert, untre und

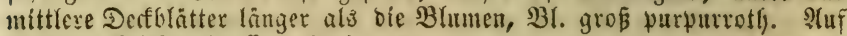

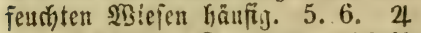

1181. O. Cngustifolia. Wimm. \& Grab. (0. incarnata. L. - 0. latifolia. Zad)b.) Stengel röfrig 1-66lättrig,

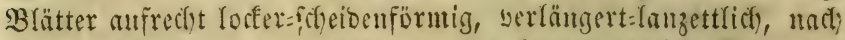
oben berfduntert uno julebt in eime fappenförmige Spige zu:

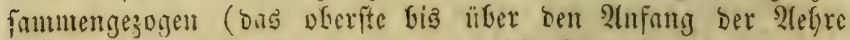

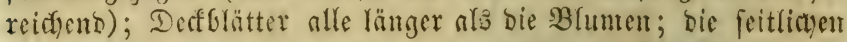

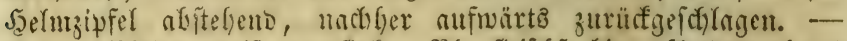
Eteif, $\mathfrak{B}$ lätter meift ungeflectet, $\mathfrak{B l}$. fleiffefarbig. Stendert ab: $\beta$ haematodes (O. haemat. Rchb.) mit bunfelrotg = geffelften Blätterm,

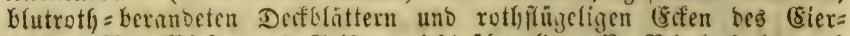

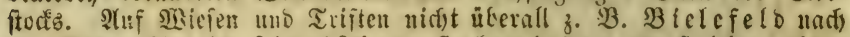

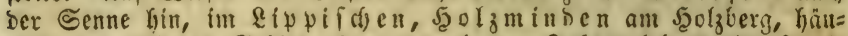

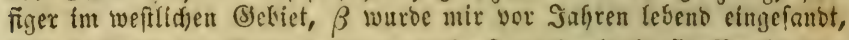

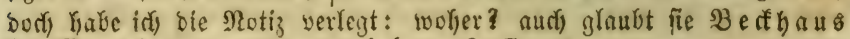
bei Marzberg gefunben zu haben. 6. 7. 4

\section{3) Anacamptis. Fidd). Straugord e.}

1182. A. pyramidalis. Hitd). (Orchis pyramid. L.)

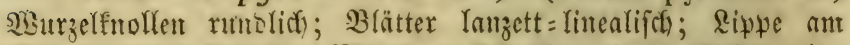
(Sjrumbe mit 2 jeitliç)en \$iättchen, 3theilig mit längliçen glei= rien ganzranbigen ftumpfen Rapyen. - Feffre gebrungen, Eporm

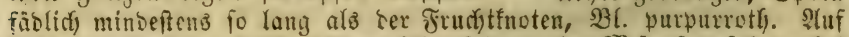

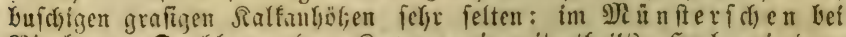

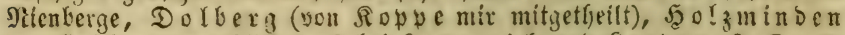

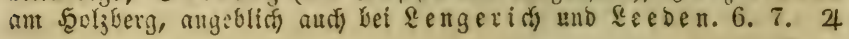

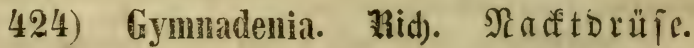

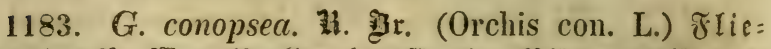

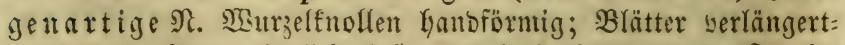
Ianzettlich; Sporn füblict), faft boppelt fo lang alä ber Fruedt:

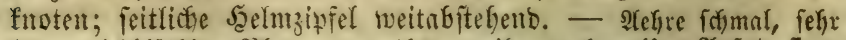

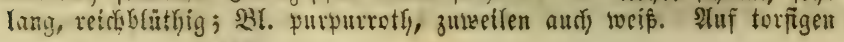




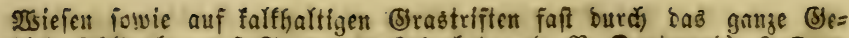
biet, jefilt aber auf Eand= und Refymboden (z. B. Dertmumb). 6. 7.24

+1183 b. G. odoratissima. \#id). (Orchis odor. L.)

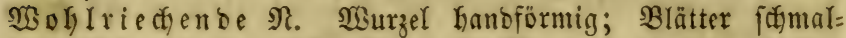
lanzettlich unb linealifa; Cyorn fäblida, etrwa fo lang als bet

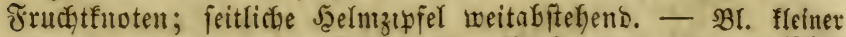

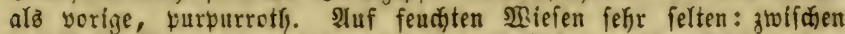
Morbhorn und Meuenhaus im fogen. Bufdjlag an ber Beffite (Dr.

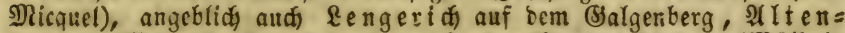

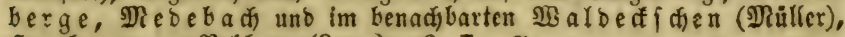

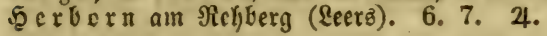

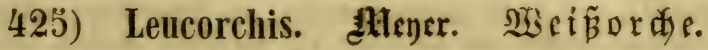

1184. L. albida. Altener. (Satyrium albidum. L. -

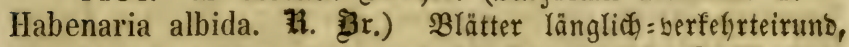

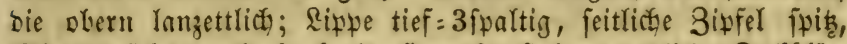

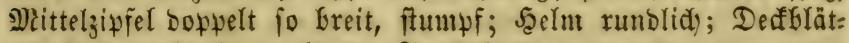
ter 3nervig fo Yaug ala ser Fruđ)tfnoten. - Bl. flein, grün=

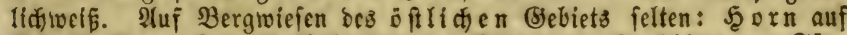
Wëgers Ramp, Recpolbsthal, auf ben $\mathfrak{B}$ iefert am Solling yon für=

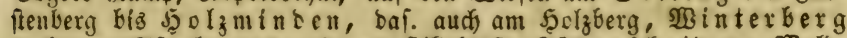

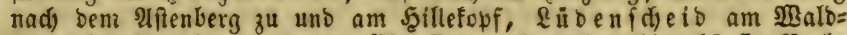

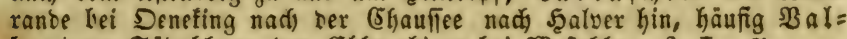
bert an Cübabhang bes Esbbegebirgs bei Mefrebbe. 6. 7. 4

\section{6) Platanthera. Fidd. Platanthere.}

1185. Pl. bifolia. Kitd). (0. bifol. L.) $\mathfrak{W}$ ei cipve limealifa ungetfeilt; Sporn ettra bowpelt fo lang nla

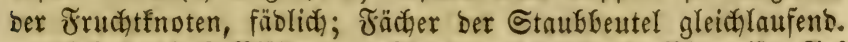

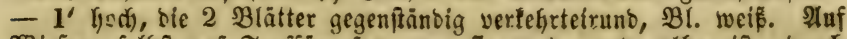
SBieien, felbit auf Torfímpfen, wo fie zarter unb gelber ift, burdf bie (Ébnen bes (3) bietz yerbreitet, feltner in ben Berggegenben. 6. 7. 24

1186. Pl. chlorantha. Cuftor. (B) elbgrüne B . Lippe linealifa) ungetheilt; Sporn boppelt fo lang als ber Frudets

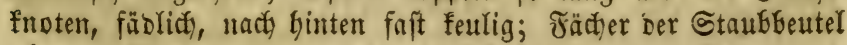
oben genähert, unten nuseeinanderfahrens. $-2^{\prime}$ hoct), Blätter wie vorige, Bl. gelblicjgrün. In Bergwälbern tefonbers auf Ralt nidjt felten. 6. 7. 4

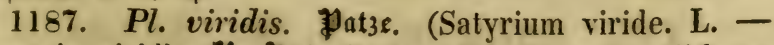

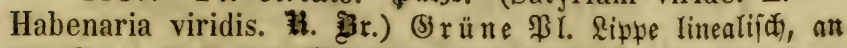
ber Spize 3 zäfnig, Mittelzahn fefr furz; Gporn fefr furz, Geutelförmig; Staubbeutelfüßher unten auseinanoerfafrend. -

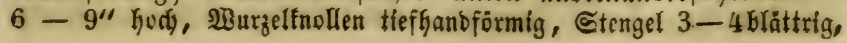




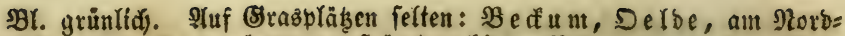

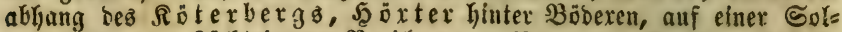

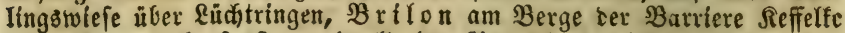

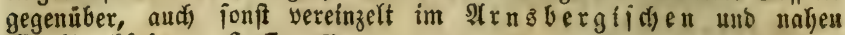

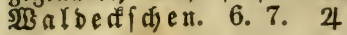

\section{7) Ophrys. Tnifeftenblume.}

1188. O. muscifera. follis. (0. myodes. Sw.) Flie= genblante. Lippe länglidy fanmutartig, in ber Mitte mit einem faft 4edfigen fallen Fleafen, 3 fpartig, Geitenlappen lanzettlich, Deittellapwen boppelt fo lang, an Der Spise tief=2lappig (oflue 2(urfäng

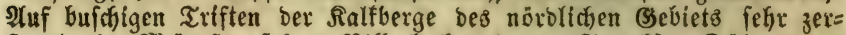

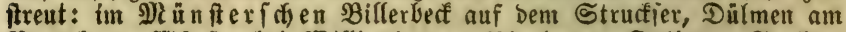
Baumberg, Niünfter bei $\mathfrak{B}$ Billinghegge, Nienberge, Dolberg, Freifen=

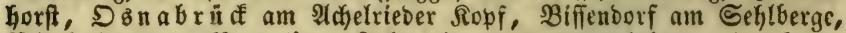

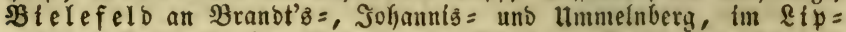

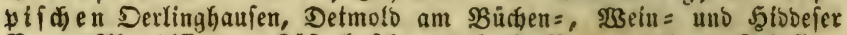

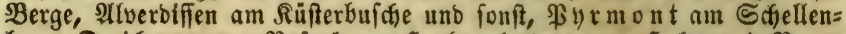

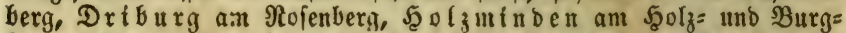

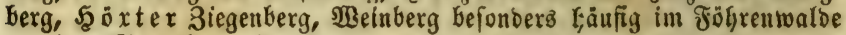
vor bent Tanzplak. 6.24

1189. O. aranifera. fouds. Spinnenblume. Sippe länglich = verfefrteirund ungetheilt, gebunfen = getwölbt unb ant

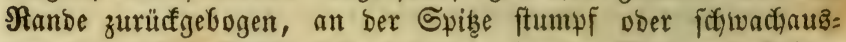

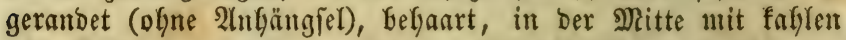
\&ängalinien. - Sippe purpurWraun voer gegen ben Rano hin gelb= Iidh, bie fahlen Rinien trübgelb. Iluf grafigen Ralffügeln fefir felten:

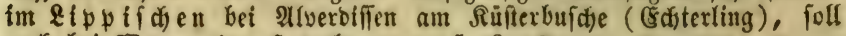
audi bet $\mathfrak{B S}_{\mathrm{a}} \mathrm{ren}$ o orf yorfommen. 5. 6. 4

1190. O. apifera. 6)ùs. Bienenblune. Sippe runb=

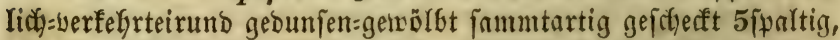
bie 2 bintern Rnppen eirunb und etwas abftelento, bie 3 vor= Dern zurüfofgefrümmt, ber nittelfte in cin fahlea 2 (n)fängfel enbigent. - Rippe braun mit gefblidjer 3eidjnung. Sluf Euîfigen Ralfhügeln felten: am Teutoburgertwald felir cillzeln z. SZ.

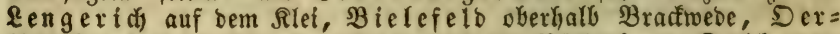
It $\mathrm{gh}$ a u fen am Selfáen, Detmolo im Büdjenberge, Driburg,

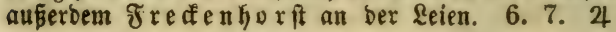

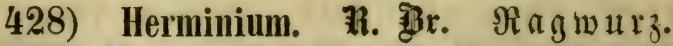

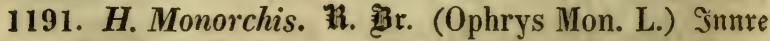
Sipfel ber $\mathfrak{B l u ̈ t}$ thenfülle 3rappig, Nittellappen verlängert; Sipye

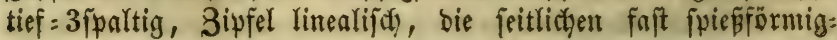


abjeteno, ber mittlere soppelt fo Inng. - Saum 6" hod.

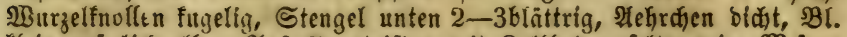

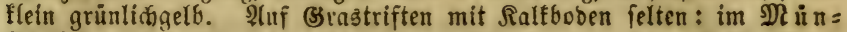
fterfinen bei Stromberg hinter bem Stcinbrudy auf ber Trift, Nien=

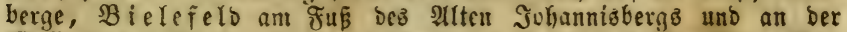

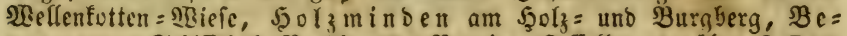
ver ungen Sdjifttal, $B$ riflon ber Barriere Reffelfe gegenüber. 6. 7. 4

\section{9) Cephalanthéra. \#id). WBalbygglein.}

1192. C. pallens. hid). (Epipactis pallens. Sw.)

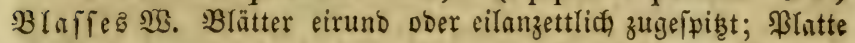
ser Rippe herzeirumb, Greiter als lang; afle Bipfel ber :Blüthen:

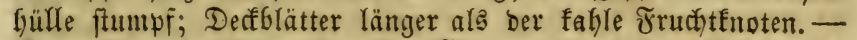

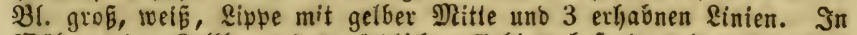

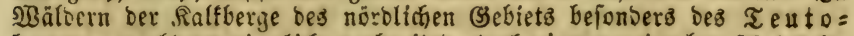
burgertual bes ziemliá) verbraitet, bodi immer einzeln, fajeint im Sỉben zu fehlen. 5.6 . 24

1193. C. ensifolia. Mid). (Epipactis ensif. Sw.) Sch wertblättriges $\mathfrak{W}$. Blätter Yanzettlich, bie obern fefyr verichmälert; Platte ber Ripwe fefrr ftumpf, breiter ala lang;

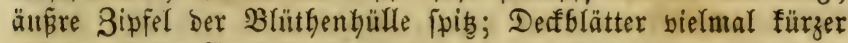

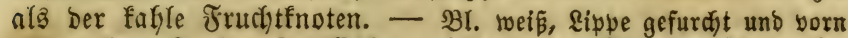

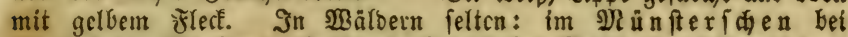

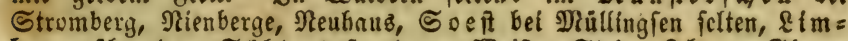

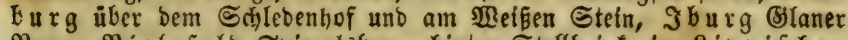
Berge, Bielefeld Spiegels̈bcrge hinter Stellbrinf, im \&ippifd) en Detmolo im $\mathfrak{B u ̈ c h e n b e r g , ~} 2$ luguftoorf am Elyberg, Stapelager Berge,

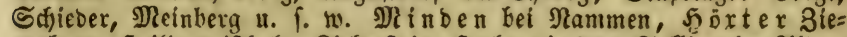

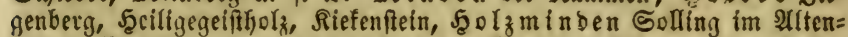
ljagen, SBurgberg, im \&ennethal aun șeg von Teinbeln nad, Dhle. 6. 7. 4

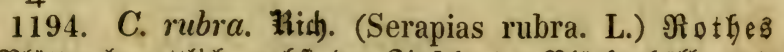
W. $\mathfrak{B}$ Yätter Iangettlid), nebft ben Bipfeln ber Blütfyenfülle und

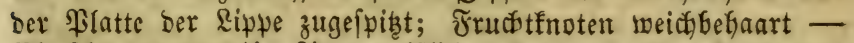

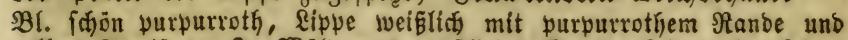

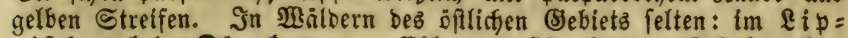

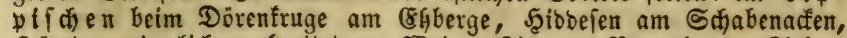
So oxter ziemlidy verbreitet am $\mathfrak{B}$ ein=, Biegen=, SBrunbberg, Riefen= fein, bef Dvenhaulen, $\mathfrak{S}_{0} \mathfrak{l}_{z}$ minben am Burgberg, $\mathfrak{B}$ a rburg im

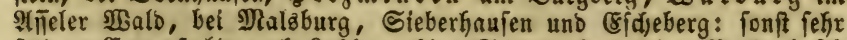

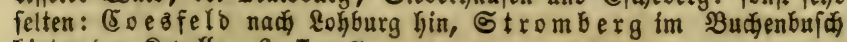
linter Der Rapelfe. 6. 7. 4

\section{0) Epipactis. Mich. Stendelmurz.}

1195. E. latifolia. สำ. Breitblättrige St. Blătter 


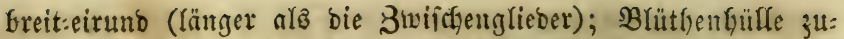
Yegst weitabftegend, bic Bipfel alle fabl; Platte ber Ripye zu=

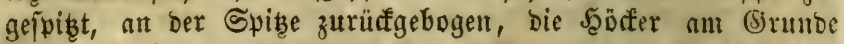
berfelben glatt. - Blüthengülle grünlid)roth, Ripwe ge!blicţrotf.

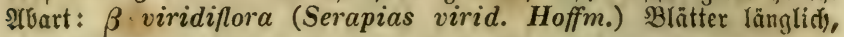

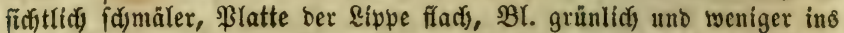

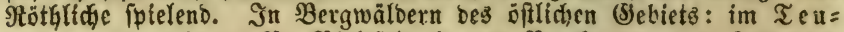
toburgertwalo z. F. Bielefelo in ben Bactueser uno Remmerb= hager sBergen, int Eippifdyen bet Sdywalenberg, Fur in ont, Dri= burg, Jēoxter uno Brafel häufy, Beverungen befonders Máflenberg, $\mathfrak{B a r b u r g}_{\text {im }}$ Affeler 2 alo hinter Wormeln unb

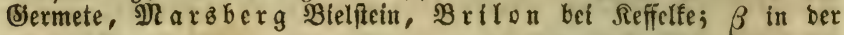
(g6ne: Bitelefeld in ber Serne, unt ben Rupferfiammer und nady

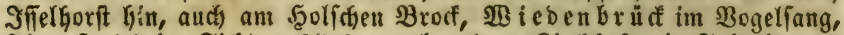

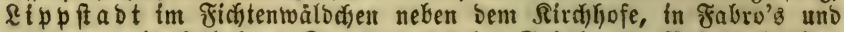

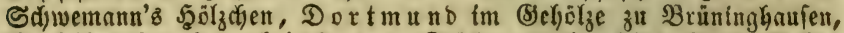

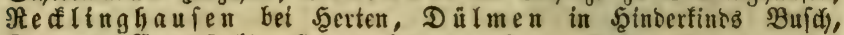

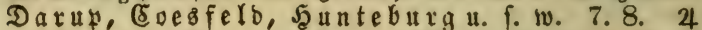

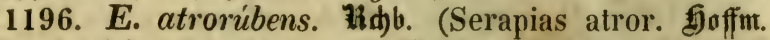
- Ep. latifolia $\beta$ rubiginosa. Gaud.) G G)

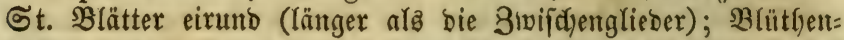
bülfe glodfig offen, bie 3 äufern Sipfel etwaz belgant; Blatte

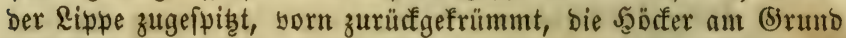
berjelbent faltig: fraus. - Bl. Fleiner als vorige, bunfeleraunroth

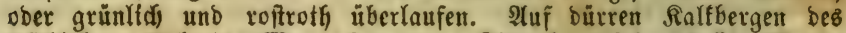

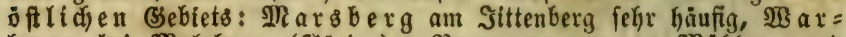
burg bei Dalburg (böring), Beverungen a!n Dathleu= uno

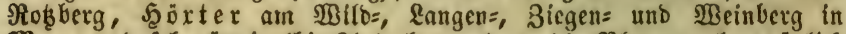
Nenge uno feĭgr üppig (bis $2^{\prime}$ hod), wo benn bie $B$ lume mehr grünlifi

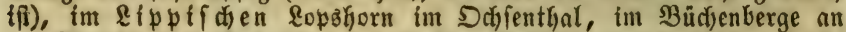

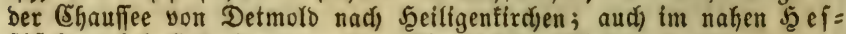

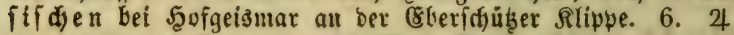

1197. E. microphylla. EEłrb. Rleinblättrige St. Blätter lanzettlich (bie nittleren uno obern faum fo lang als

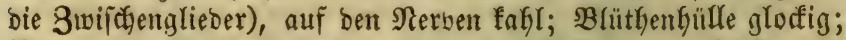

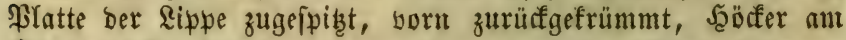

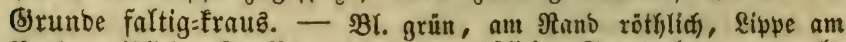

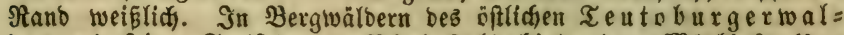

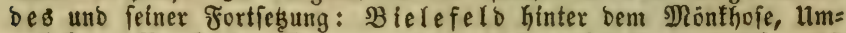
melnberg, SBraftweber SBerge, im \&ippif dien bet Derlinghaufen und tim Barffauler RTee, Stapelager Berge, Ëfberg bei Aluguftoorf, Sdibalenberg, Driburg, $B$ rafel Sauernberg, Sutfimer

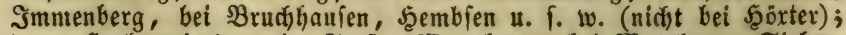
bant Solzminden in Forf́, $23 a r b u r g$ bel Malzburg, Sieber=

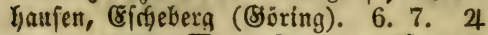

1198. E. palustris. CUtrt3. (Serapias longifolia. L.) 
Sumpf= St. Blätter Imuzettlidy; Platte ser Ripte rutolidy: ftumpf, fo Yang als sie Bipfel der Blütfentgüfle. - BBr. grau=

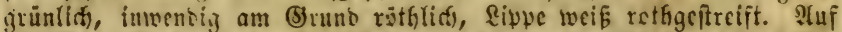

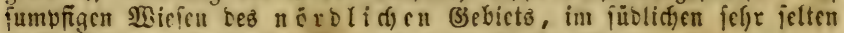

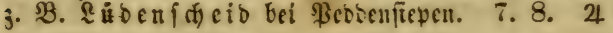

\section{1) Neottia. Neft to $\mathfrak{x}_{\mathfrak{r}}$.}

1199. N. Nidus avis. Hid). (3) emeitre 2R. Bogel= nteft. Stengel blattlos mit cirumsen Gerbioen bejebt; Rippe

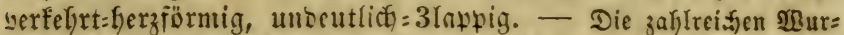

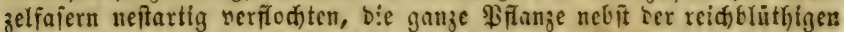

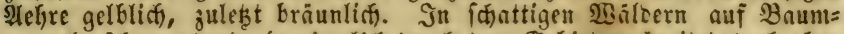

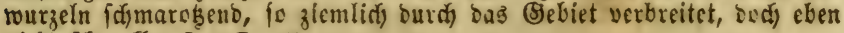
nifit überall. $5-7.24$

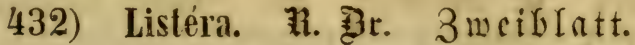

1200. L. ovata. 3. 3r. (Ophrys ovata. L.) Eirun=

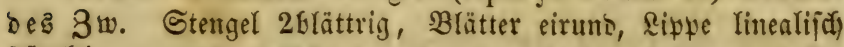

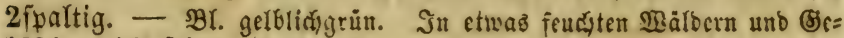
büfdjen nidgt felten. 6. 7. 4

\section{3) Spiranthes. Fidd. Dichähre.}

1201. Sp. autumnalis. Hid). (Ophrys spiralis. L.)

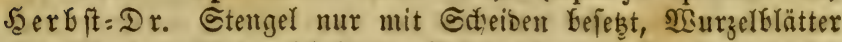

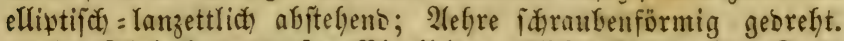

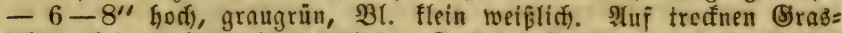

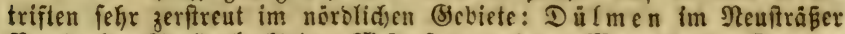

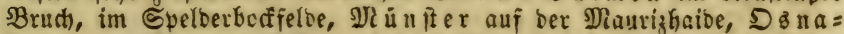

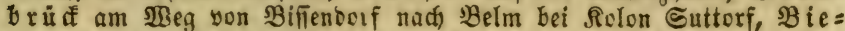

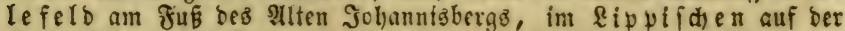

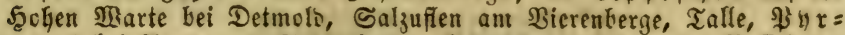
mont bei Aerzen am Tobtenberge, 5 oxter bet Börexen, Bofleborn,

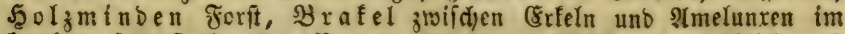

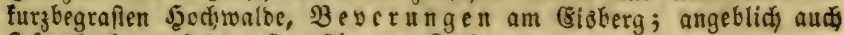
Sierlohn auf bem 5engitberge. 8. 9. 4

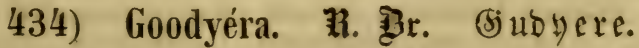

1202. G. repens. H. (3). (Satyrium rep. L.) Sten= gel ofermärts nebfit Den $B$ lättern befaurt; untre Blätter eirumb,

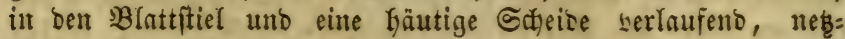

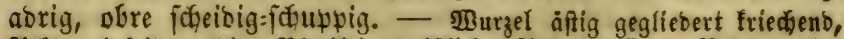
2lehre einfeitsmentig, Bl. flein weiflidj. Aluf moofigem $B$ oben unter

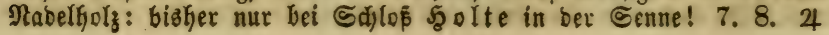




\section{3̈) Epipógium. Gmel. $\mathfrak{B} a n \pi n e n=D$ rdye.}

1203. E. aphyllum. Gmel. (Satyrium Epipogium. L.)

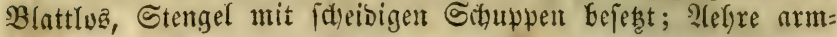

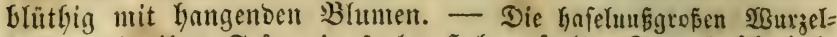

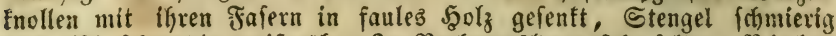

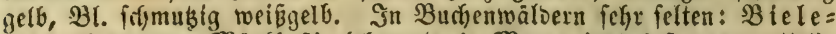
fel'b hinter bem Mönffgef! (ehemals in Menge jebt fait auşgerottet),

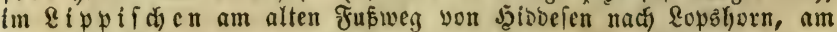
Fuß̄ bez (Elikergz, an ben Stapelnger Bergen, im Sdjualenberger

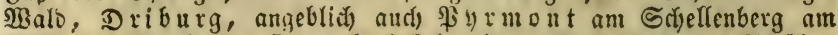

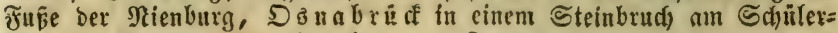
berg, bel నimmern am $\mathfrak{B e b e b e r g . ~ 7 . ~ 8 . ~} 4$

\section{6) Malaxis. Siw. $3 a \mathfrak{r t o r d}$ c.}

1204. M. paludosa. \$w. (Ophrys paludosa. L.)

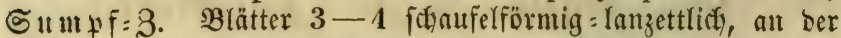
Gpibe forarf; Stengel 5fantig, Rippe aubgefgöhlt fpizlid). 3art, hanbhod, Traube verlängert vielblüthig, 3l. grünlid). Thuf Torfboben bes nörol. Beb. Felten: Coesfelo im Steveber Benne, Dülmen im Seppentaber Bente, Telgte in ben Teirfen. 6. 7. 4

1205. M. Loeselii. Sw. (Ophrys Loes. L. - Sturmia Loes. ładbb.) 3 3weiblättrige 3. Blätter 2 länglid)= lanzettlicl); Stengel 3 fantig; Rippe ciruno gefielt, mit ber Spibe abwärţ gentigt. - Eรttwas ftärfer, Traube wentgerblüthig (3-12),

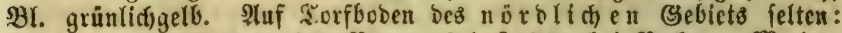
Dülmen im Seppenraber Benne, Dieftedo bei Beffum, Nein=

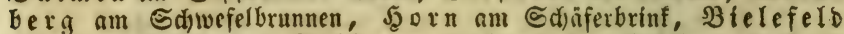

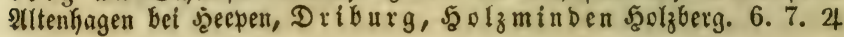

\section{Sֲromung Diandria.}

\section{7) Cypripedium. Frauenfdu}

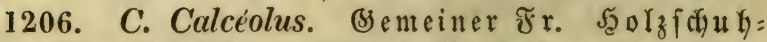
blume. Stengel beblättert, Blätter elliptif(d):Ianzettlich nerbig. - Bl. 1-2 givfelîănsig, Relchblätter 4 putpurtraun, länger als

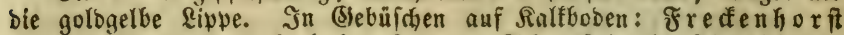
auf ber Renen, Borgholzhaufen am Sdjomfein, im Rippifacen

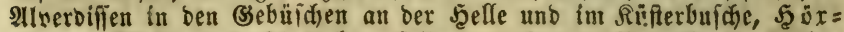

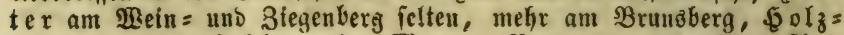
minben am Jjolgerg in Nenge, Beverungen \$apenftieg,

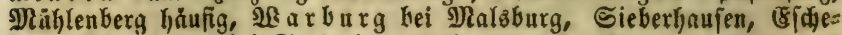
berg, Şerlohn bel Sunbwig und ફsemer. 5. 4 


\section{Soromung Hexandria.}

\section{8) Aristolochia. Diterluzet.}

1207. A. Clematitis. (5) enteine D. Stengel rumo nufred)t, meift einfach), Blätter langgejticlt, $\mathfrak{B l u m e n ~ G l a t t w i n f e l = ~}$

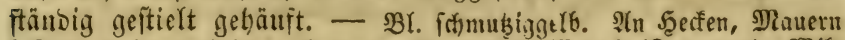

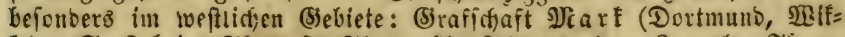
febe, Soept beim Thomafer Thore, Eipuftabt yor bem Rappeler Thore,

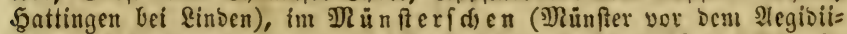
Thore, Dülmen an Der Rütten Salde, (Sveşfelo vor bem Retter Thore), Reflingfallfen um bie Stabt an Seeffen, audi) bei ber Ronmenbe

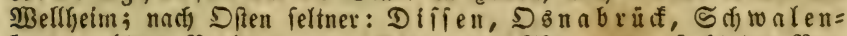
berg. (Das Bortommen an Bärten und Thoren veruriadit ben Ber=

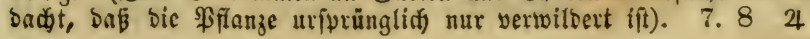

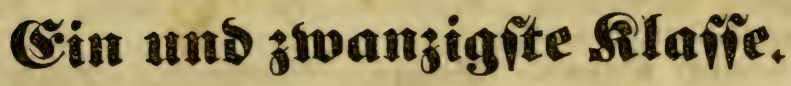 Monoecia.}

\section{Soronung Androgynia.}

439) Calla. Shlangenfraut. Blumenføeibe 16lättrig. $\mathfrak{R}_{0} l_{b e n}$ walzenförmig, bon allen Seiten mit beli Befrudfungstbeilen bebefft. Staubbeutel boppelt. Narbe Fithento. Frudit beerenartig.

440) Mum. Arou. BIumenfitheibe 16lättrig. Rolben an ber Spibe feulenförmig naft, am (5runte nit Frudytfnoten, in ber Mitte mit Staubbetteln und fotingenar= tigen Drüjen bejebt. Beere lfantig.

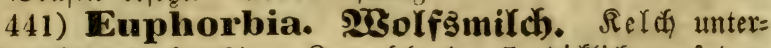

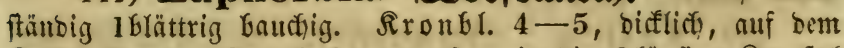

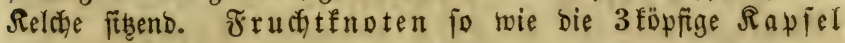
geftielt.

\section{Soronung Nlonandria.}

442) Wajas. Najabe. B $\mathfrak{l}$ ï thenfdei be 4blättrig frugförmig, an ber Spibe 2-3zäfnig, ben Staufbeutel eng 


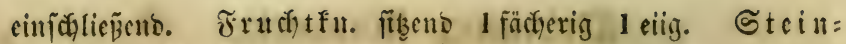
iruct t faftlos 1 famig.

443) Zamnichellia. Bannichellic. $\mathfrak{B} \Upsilon \mathrm{iu}=$ thenbülfe ber männlidjen $\mathfrak{B}$ lume 0 , bie ber weibliçen $\mathfrak{B}$.

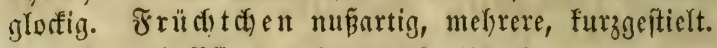

2tromal. Pflanze: Callitriche. I. 2.

\section{Sronung Triandria.}

444) Typha. Yobrfolbc. Afefre walgenförmig

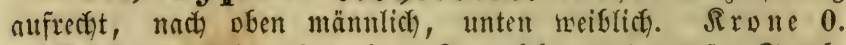
of Relch unbeutlidy) 3blättrig. Staubbeutel 3 auf 1 Stnutb: faben. \& Reld harrförmig. Raryodie 1, geftielt, mit

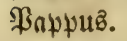

445) Sparganium. Tgelfolbe. $B \mathfrak{n}$ men in

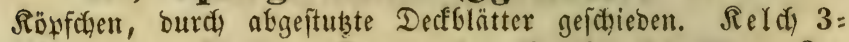
blättrig unterftannoig. Rrone 0 . Narbe 2 fpartig. Ra= xyop fe jaftlos, 1-2jamig.

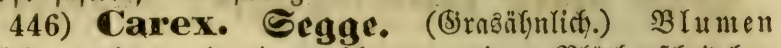
in 2lefren, jebe mit einem idfupenartigen Bläthenfidyeioffen (Balg). Reldi und Rrone 0. (B) riffel einfady.

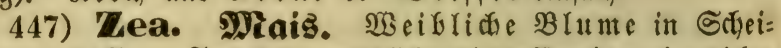

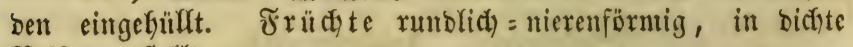
Reifyen geiftellt.

\section{Sronung Tetrandria.}

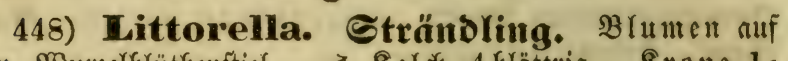

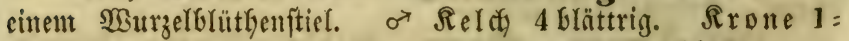
blättrig 4 fpaltig. Staubb. hergförmig. \& Derabätter 3. Rrone ungleidy 4paltig. (5) riffel lang.

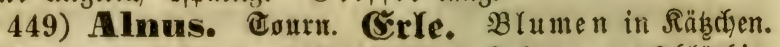

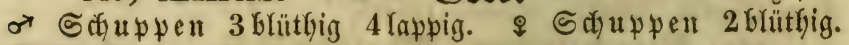
$\mathfrak{N}$ ú 2 2făduerig 2 famig.

450) Urtica. פornneffel. Blumen in win:

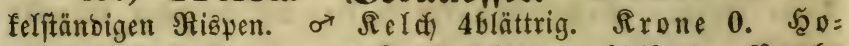
niggef. bedterfürmig. \& Reľd 2 blättrig bleibend. Narbe zottig. Samen 1.

451) Mopus. Maulbectbaum. Männlide

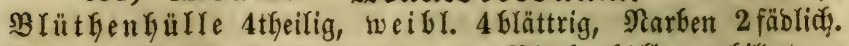
Fru 


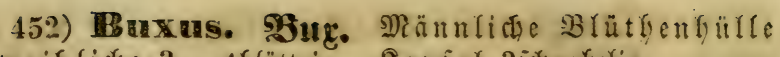
$2=$, weiblid)e $3-4$ bättrig. Raviel 3jănablig.

\section{Sronung Pentandria.}

453) Xanthiem. Epitzfrette. B B umen in

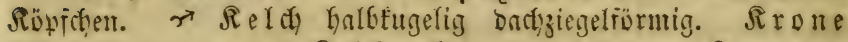
röfrig, 5 jpaltig. \& Seld) 2 blättrig 2 blütfig. Rrome 0. Steiurrucht troden ftachelig.

454) Marantus. Ormarant. $\mathfrak{B}$ lumen in gefnäuelten $\mathfrak{A}$ (efren. or Reld gefärbt $3-5$ tfeiliog. Rrone

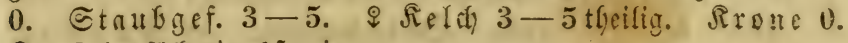
Rapiel lfütherig liamig.

\section{Soronung Polyandria.}

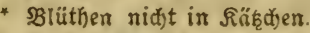

455) Ceratophylliman. \$orubratt. B (ume

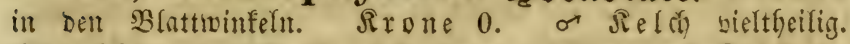

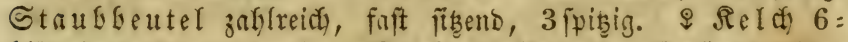
Glättrig bactzziegelförmig. গia

456) Tlly yophyllem. Iaufenoblatt. BIu=

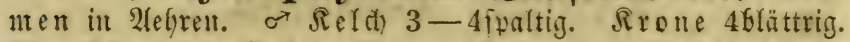
Staub6. 8. I Reldi 4jpaltig. Rrone 0. Rarbe rütig. İufie: 4.

457) Sagittan'ia. Sof feiffraut. Rel( 36lätriy.

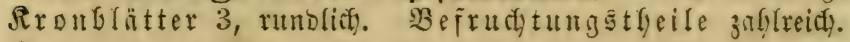
Samen batziegelig.

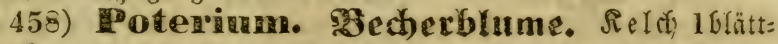
rig. Serone 4 jpaltig. Eriffel 2 . शarbe pinfelfömig.

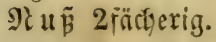

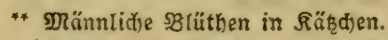

$†$ TSeiblidfe Blüthen einzetn (Enoßpenartig).

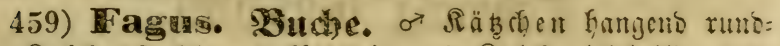

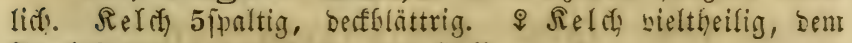
Jrutftfmoten angemachjen, mit $\mathfrak{S}_{\text {Lifle. }}$

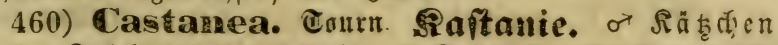

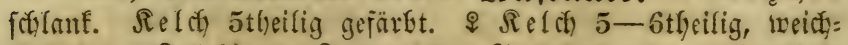

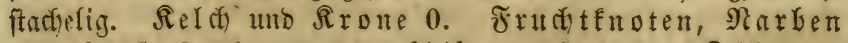
umb Nailife 3 ; lekgtere won fleifenton ftadyeligen Reldye eint gẹthlointer. 


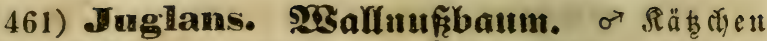
bifflich. Reld $2-6$ theilig. \& Relch 4 jüfnig nbfallento. Sroute 4blätrig frautartig. Narbe 2. Steinfrutilt flei=

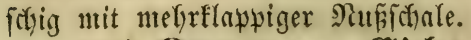

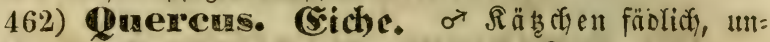

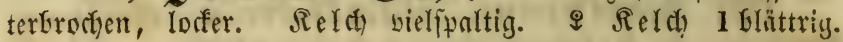
Narben 3. $\Re$ ú eine Eidtel.

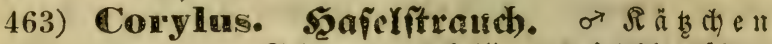

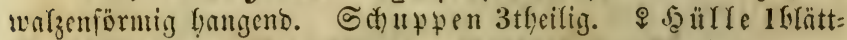
rig, blcibens, zerrifien, 2lippig. (s) riffel 2. Niuß.

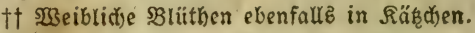

464) Canpinass. Seainbucbe. or $\mathcal{K}$ ä matzenförmig hangend. S(t)upen gewimpert. Stanbb. an

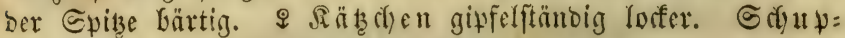
Wen 3 lappig. (5) riffel 2. Nun.

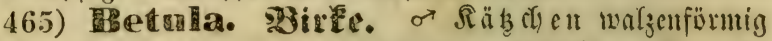
fangeno. Sothupen zu 3, fothiörmig, 3blüthig. Staub=

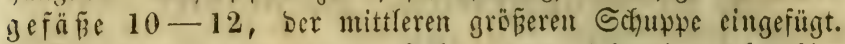
\& $\mathfrak{R}$ ä (5) riffel 2. Flügelfrud t lamig.

\section{Soronumg Honadelphia.}

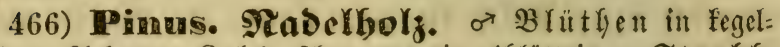

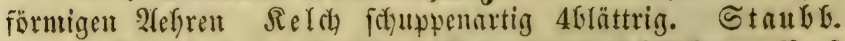
2. \& Brüthen in Baffen. Sतluppen 2 blütfig. Nub geflitigelt.

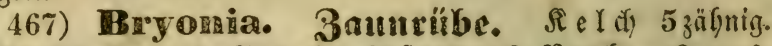
Rrone 5tfeilig. o7 Gtaubgefäre 3. Q Narben 3, aus: geranbet. Beere.

\section{Soromung Androgynia.}

439) Calla. Sorblangenfiaut.

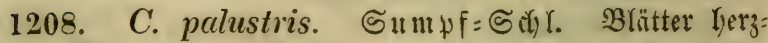

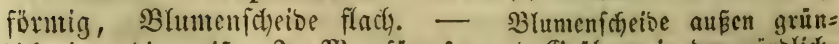

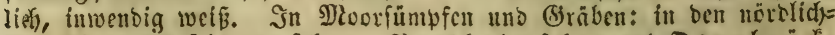

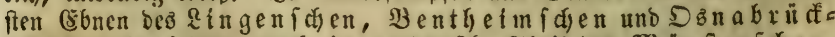
forfen nicht felten, aud im norbiveftl. Theil bez פe ünfterf dो en, bam in ber Senne be 5̧olte, \$olfanz und Etufenbrocf, unb in 


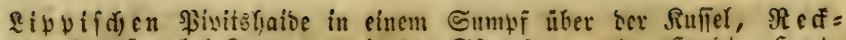

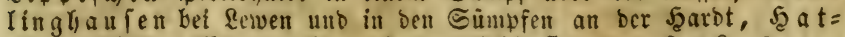
tingen felten (sblumeroif), auperbem forlt fie gan. $6-9$. 4

\section{0) Arum. গYTron.}

1209. A. maculatum. (5) ễle feter 2 . Etengellos,

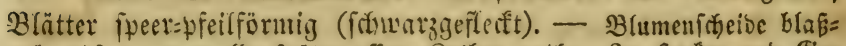
grün zuifammengerollt, fpäter offen, Solben reth. In Seeffen und (Be=

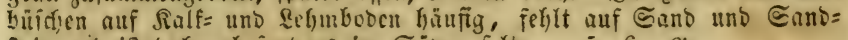
féia unib ift Dahjer bejenders im Eüden feltner. 5. 6. 4

\section{1) Euphorbia. פgolfasutild.}

- Dorbe 3ftrahlig, bie etrahten wieberfolt 2gabelig.

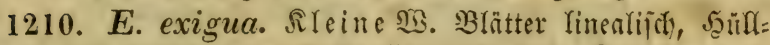

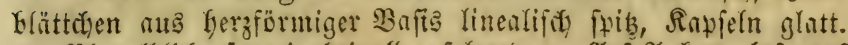

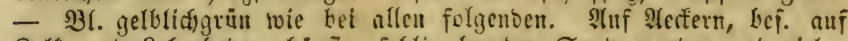

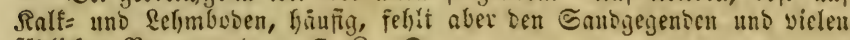
fübliçen Berggegendert. 7. 8. ค

1211. E. Peplus. (5) arten= 13. B Blitter geîtielt ser=

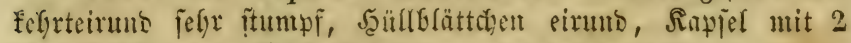

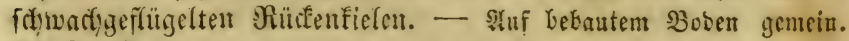
$7-9$. "* Dolbe 4fitraflig, Etrahlen wieserfolt 2gabelig.

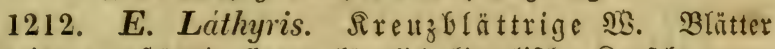

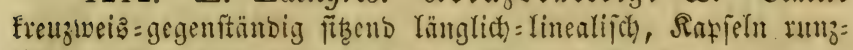

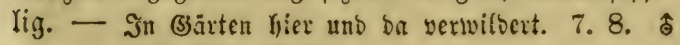

*** Dolbe 5 ftrablig.

$\dagger$ Strablen einfad) 2gabelig.

† 1213. E. dulcis. ๔ü̃

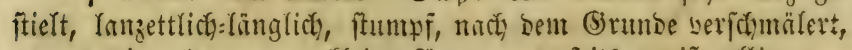
gamzrandig ober worn fleingefägt, unterpeits weip̄mollig. -

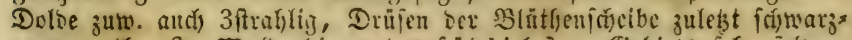

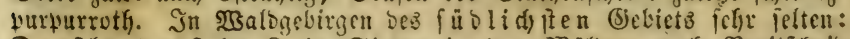

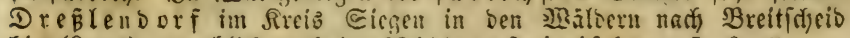

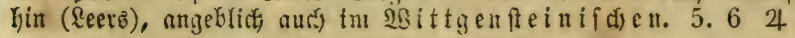

t† Strablen 3gakelig mit 2gabeligen 2 Ceften.

1214. E. helioscopia. Sonnentwendige S3. Blätter feilförmig fitsend, worn gefïgt; Ratfilln glntt. — Stuf betautem 3oden überall. $6-8$. $\odot$

1215. E. platyphyllos. Breitbrättrige \$2. Blätter

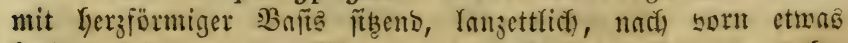

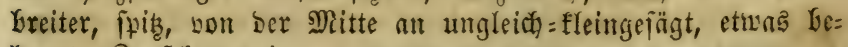

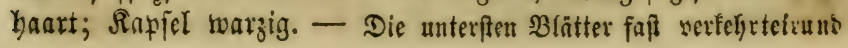




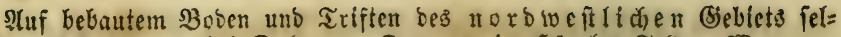

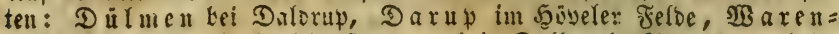
borf hinter Frectenforft! Jुa $\mathrm{m} m$ bei Dolberg! Stromberg beim Bfiaumengatten. $6-8.24$

\section{**** Dolbe vielftrablig.}

† Strahlen roieberholt 2 gaberig.

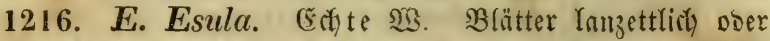

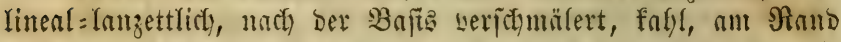
nach ber Spize zu etwas raub, bie untern furzgeftielt, bie nft=

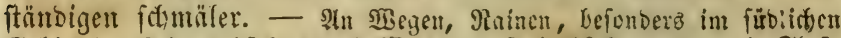

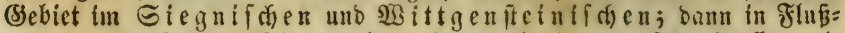

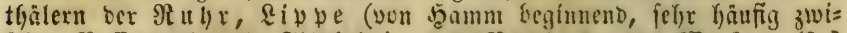

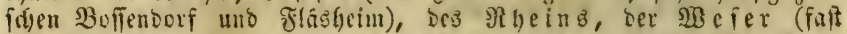
überall, Dod meif feht einzeln), auferbem fehr zerfteut: Soeft am

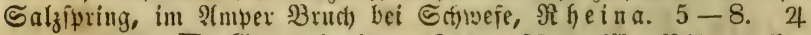

1217. E. Cyparissias. Biłrefien=223. Blätter fibend

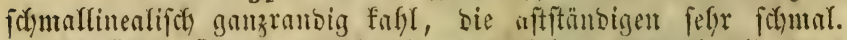
- Gis finden fici) oft verfrüpvelte unfrudjtbare Stengel mit ctuas

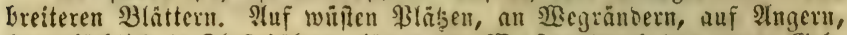

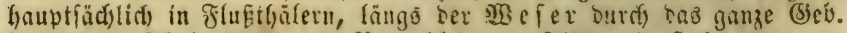
folvofl in Thal als an ben Bergabfämgen, felten bie Saife ganz et=

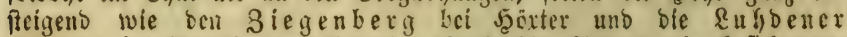

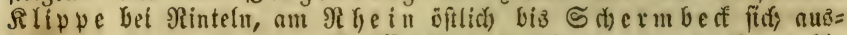

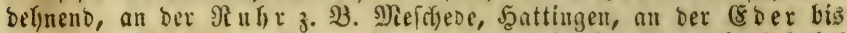

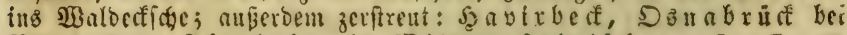
Brandeuburg, Sifrlofn, im sibitigente infinen. $5-7.24$

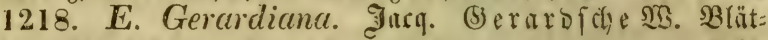

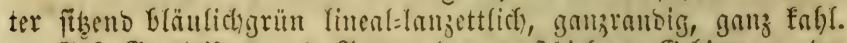

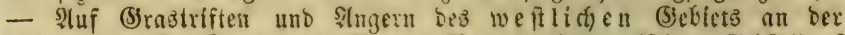

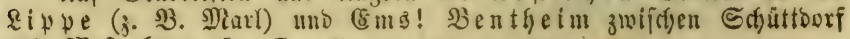
แกเ Rूeftenberg. $5-7.2$

t† Strahlen 3gabelig uno weiter 2 gabelig.

1219. E. palustris. $\odot u m p F=2 S$. Blätter fitzend Inn=

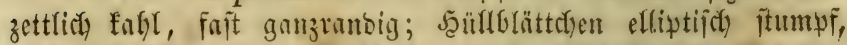

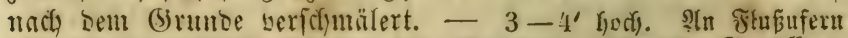

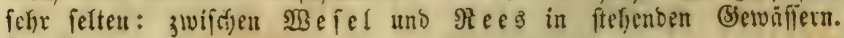
$5-7.24$

\section{Sromung Monandria.}

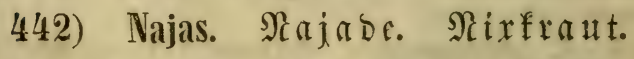

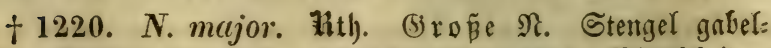

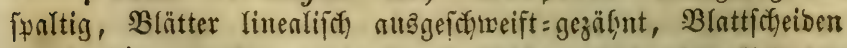
gamżranbig. - Blumen 2hăufig. In Teidjen unb langfan fließ̈enben 


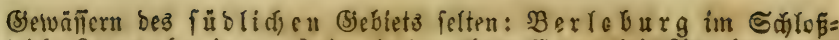

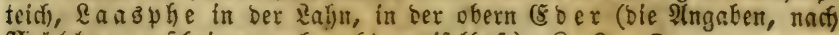

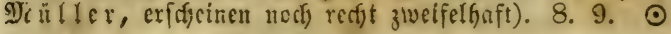

\section{3) Zamichellia. 3antid)eltie.}

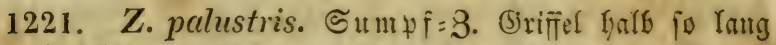

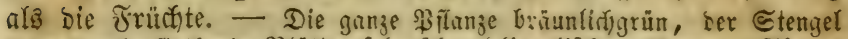

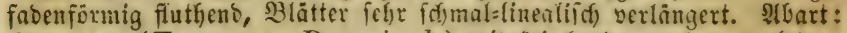
$\beta$ repens (Z. repens. Boenningh.) mit friect)entem unb murzelnbem Stengel. In Teicten und Eủntyfen felten: Eoeźfeld, Darup am

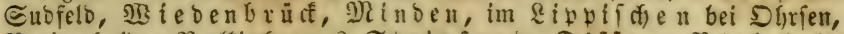
Brcitenhaibe, Reeffircten; $\beta$ Eteinfurt, Diffen, B iefefeld

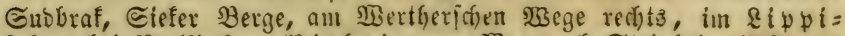

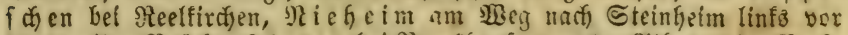

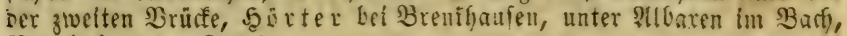
3 erreburg. 8-10. $\odot$

\section{Sromung Triandria.}

\section{4) Typha. Sofifolbe.}

1222. T. latifolia. Breitblättriger $\Re$. Blätter

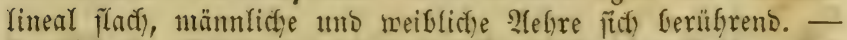
$3-6^{\prime}$ hod, , Blätter 4-6" breit. In Teidten umb (Bräben, aud) wohl fleinen Bädjen burdy bas nörolidfe Gjebiet verbreitet, aber

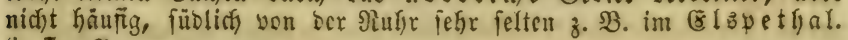
6. 7.24

1223. T. angustifolia. S(b) alblättriger $\Re$. Blät= ter lineal, untermärts faft rimig; männlicte $2(e f)$ vo bon ber

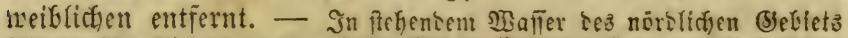

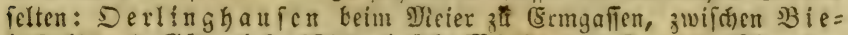

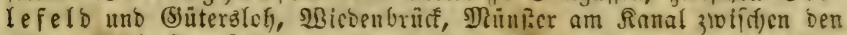

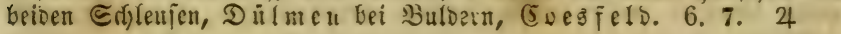

\section{4ว) Sparganimm. Jigelfolbe.}

1224. Sp. ramosum. fonds. (Sp. erectum $\leftrightarrow$. L.)

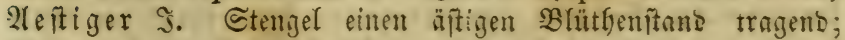

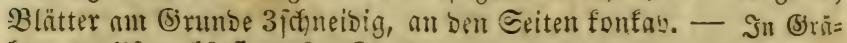
ben, an ufern lyăuig. $6-8.4$

1225. Sp. simplex. fulds. (Sp. erectum $\beta$. L.) Einfather Э. Stengel einen einfatten tratkigen Blütyenftano tragend; Blätter am (5runbe 3fantig, an sen Eeiten flact). -

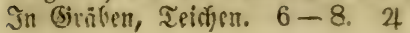


1226. Sp. natans. Sdwimmender Э. Stengel einat einfachen $\mathfrak{B}$ (üthenftano tragent, mit mur einer männlichen $2(e$ er)re ant Enoe; Blätter liegend voer fđhuinuteno. - In Teldsen, Sümpfen bes nö ro li â) en Bebietz felten: Dílmen in ber Entenfoi,

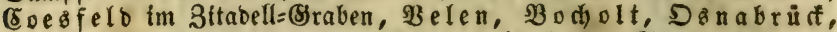
5ुunteburg im Sdienmoor, Bielefelo in ber Genne, befonbers

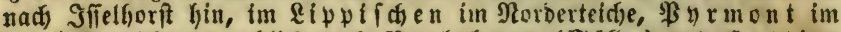

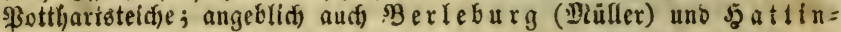
gen (B)lumeroth). 4-6. 2

\section{6) Carex. Segge.}

\section{A. Vignea. Beauv, গarben 2. \\ - Uehrowen eingeln endfänoig. \\ $\dagger$ Jehrden 2 häufig.}

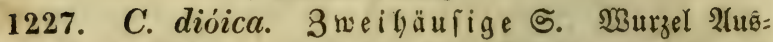

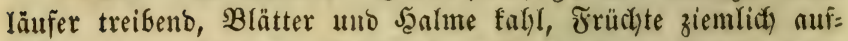

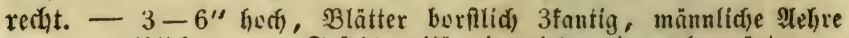
lineal, weiblidje oval; Fridate plförmig viclnervig, oberwärts an

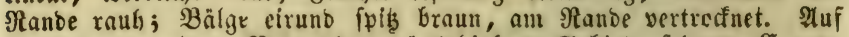

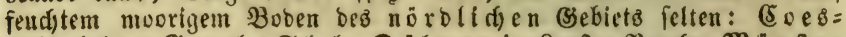

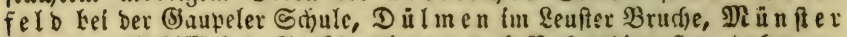

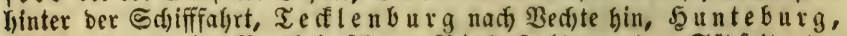

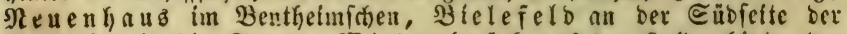
Berge bis in bie Senne, 33 febenbrü auf ber Jatibe hinter ber Biêt. 4. 5.24

+1228. C. Davalliana. Sint. Davalf

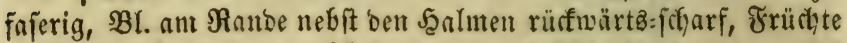

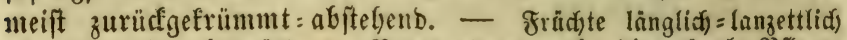

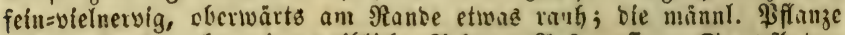
trägt mitunter oben cinc twciblidge Hegre. 2luf graffgen Sumpfhoben fehr felten: zlwif́djen Billerbeff und Dpletwieff (Bönninghaufon). 5. 6.24

\section{t† Xehrd)en ibiürig (oben männlid), unten weiblid).}

1229. C. pulicaris. Flobfegge. Frudite entfernt

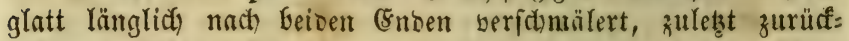
gebogen; BBälge affüllig. - 6" hoor, NBurzel fajerig, Balättex

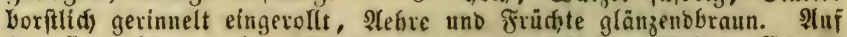

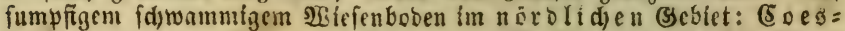

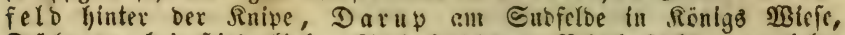
Dülmen bei Sinbcrfinf, Salz fotten, $B$ ielefelo an vielen

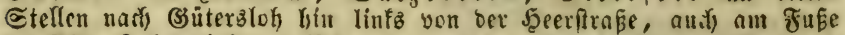

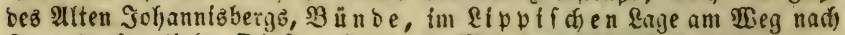

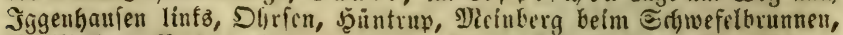

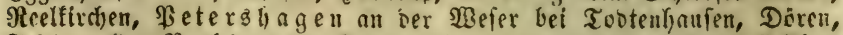

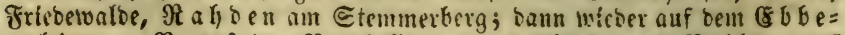
gebirg z. B. auf ber Nurbbelie, une angeblidy audy Brifon auf Der Eangen Şatbe. 5.4 


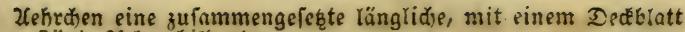
geitükęte wehre biloent.

† Ueh)răsen oberwärtz meift männlid).

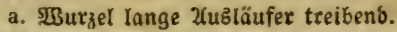

1230. C. disticha. f)uds. (C. intermedia. (1)ad.) 3weizeilige S. F̧alm an Den Ranten rauf; Flefre boppelt

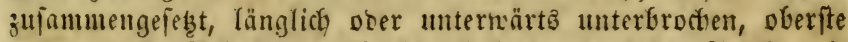
Itno unterfte 2(ef)rdyen meiblich), mittlere mämnlich); Friid)te ei= förnig, ctwas getrölft, 9-11 nervig, mit fơmałem Nanbe untrgeben. - I' hodj; unterfecz Decfblatt eirunb, in eine borfillide

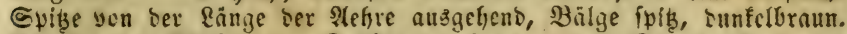

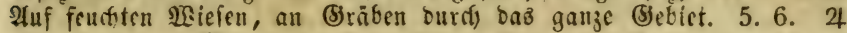

1231. C. arenaria. Sandiegge. 2felgre boppeltzu=

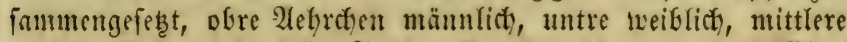
an ber Spike münnlid); Früc)te 7-9nersig, sou ber Mitte

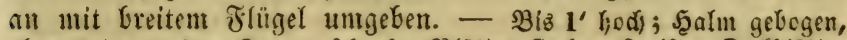

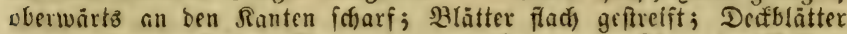

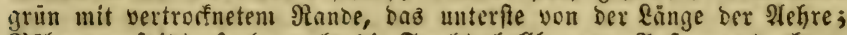
SBälge zugefpibt, fo Inng alb bie Fructit, hellbraun. Iluf ganz troffnem

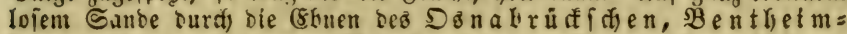

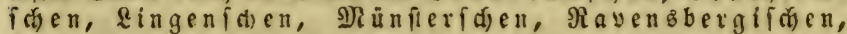
Qippifenen uno Paberbornfden, bíz an bie Berge reidjent,

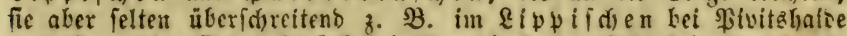

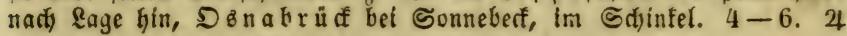
b. श्ssurzel fafertg, ofne Xuzläufer.

1232. C. vulpina. ซ̛uth

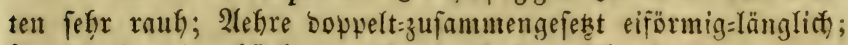
Friachte fperrig = abftefleno eiförntig flactgenölbt 6-7nersig. -

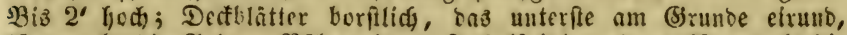

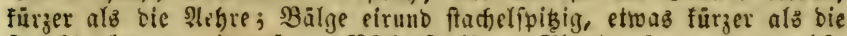

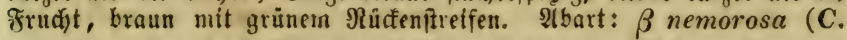

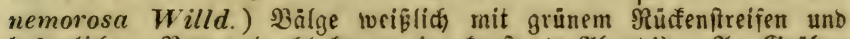

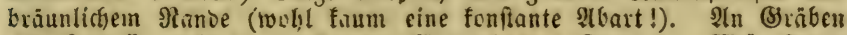

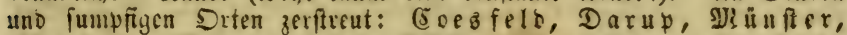

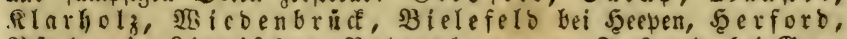

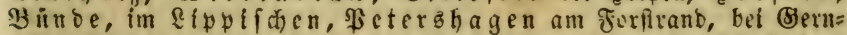

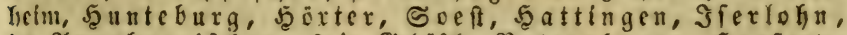

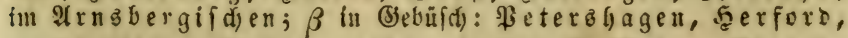

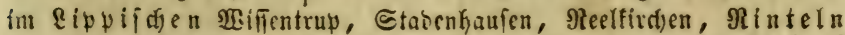
bel Erter, 5erford hinter bem Berge, Bielefeld Soljdebrouf u. โ. เพ. 5. 6. 4

1233. C. muricata. Sperrfrüetige ๔. Şalm mur oberwärts jđärfflict); 2(ef)re zufanmengefebst; Früd)te pperrig,

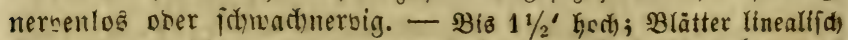
ffarf); Itefire bidit, unten etwas unterbrod)en, Deffblätter Eurz aus

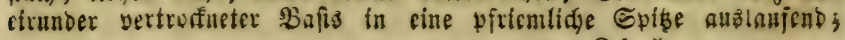




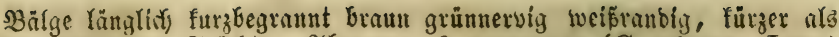
bie eiformigen Frübte. Albarten: $\boldsymbol{\beta}$ nemorosa (C. vivens. Lam.)

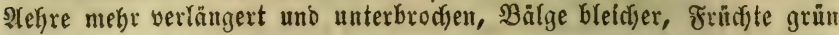
uno oft ein wenig gröber; $\gamma$ virens (C. virens. Hppe.) bas unterfte

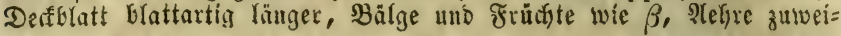

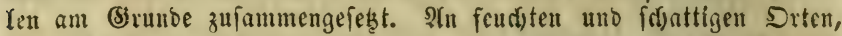

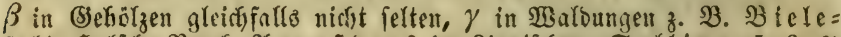

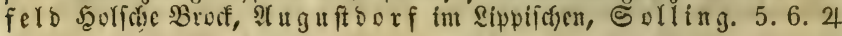

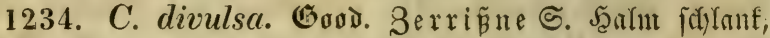
etwas überbangend, obermärta föärflid); 2(elyre zแfammengefęt

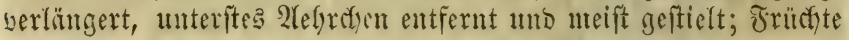
mufredit = affitefond, nerwenlos ober undutlich = nersig. $-1-3^{\prime}$

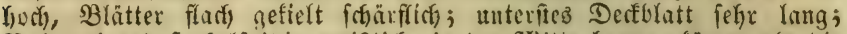

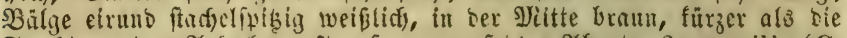

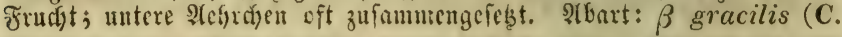
guestphalica. Boenningh.) Fृatm bis 4' lang, fefyr fdjlant uno

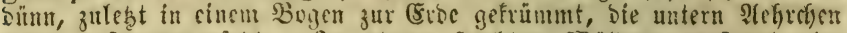

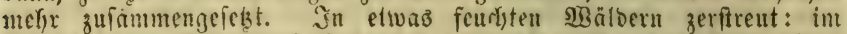

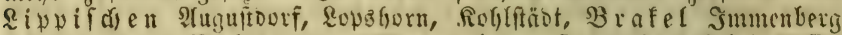
bet jembien, Rahben am Stemmerberg, So nabrü of bei Rafle=

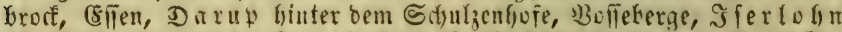

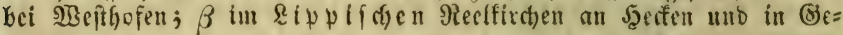

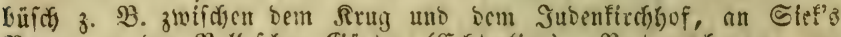
Berge, an ben Bellefden (särten (Edjterfing), Beteröbagen am 5eoppenberg (Bectifyauz). 5. 6. 4

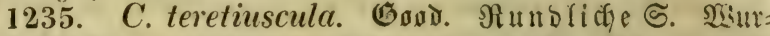

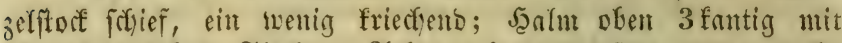
f(d)

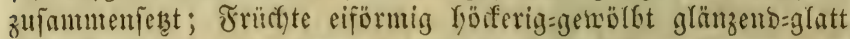

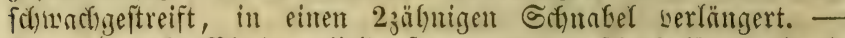

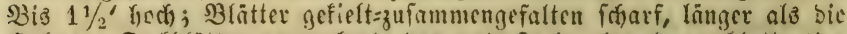
5alme; Dedfelätter: vertrodfuet, Dab unterfte in cine furze blattartige

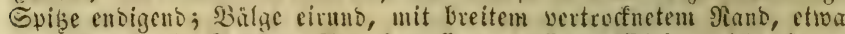

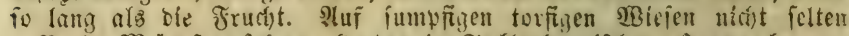

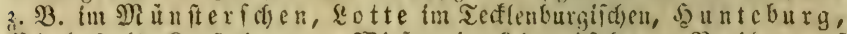

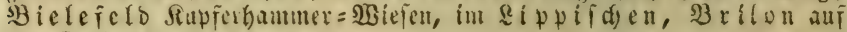
Der Delbrüct. 5. 6.24

1236. C. paniculata. Rispige S. Salut fant mit cbnen Fläcten; 2fefre risplig (fonft wic vorige). - 3is $4^{\prime}$

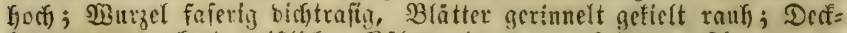
blätter vertrorfuct ivelflict); BBalge ciruno jugefpibt, roftbraun mit

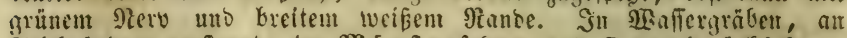

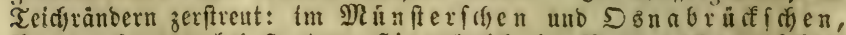

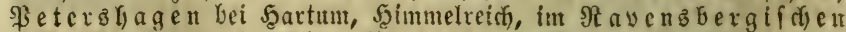

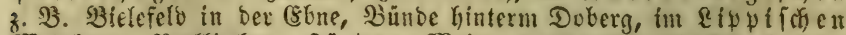

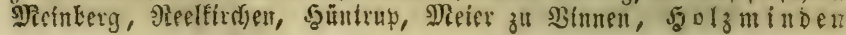




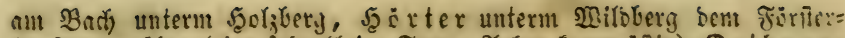
haufe gegenüber (cine fefyr flcine Form, शlehre faum äptig), D riburg, Eoefi am Teidh hinter sem sjinnerfing, Bráben bei Ealicnberf,

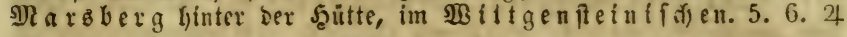

†† Narben 2; Yehrdyen am Grunbe männlid, in einfoder zetre toed) felfänoig.

a. $\mathfrak{B} 3$ urzel weit Eriectient.

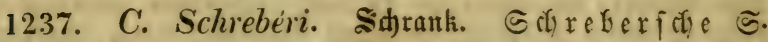

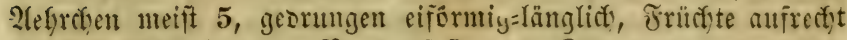

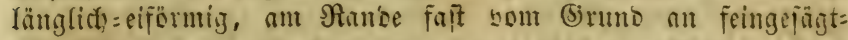
mimperig. - 3-6" hod), Salm zart glatt ftumpffantig, ctrras

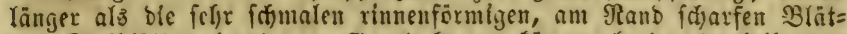

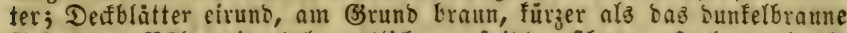

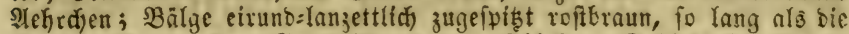

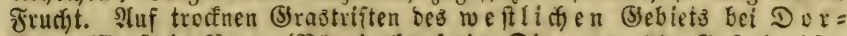

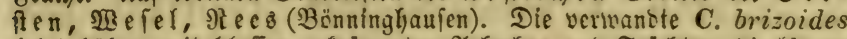

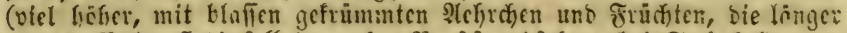

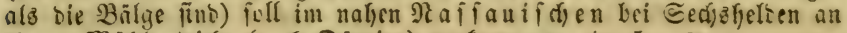
cinem DRüflentcicfe (nad). Dôrten) vorfommen. 4. 5. 4

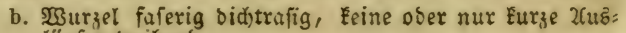
läufer treibeno.

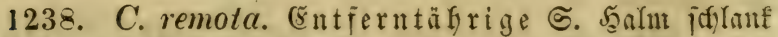

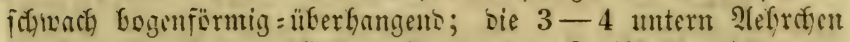

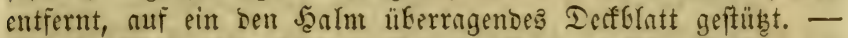

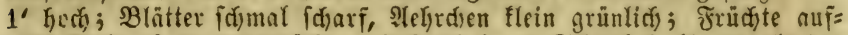

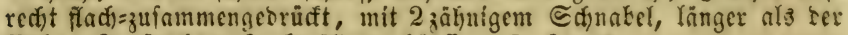

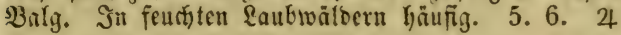

1239. C. stellulata. Goov. Sternförmige S. Refir:

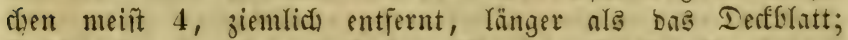

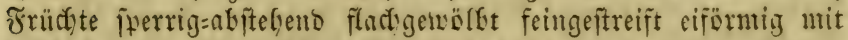

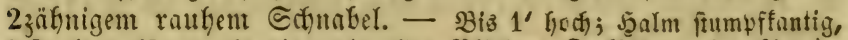
faft glatt, fürzer alz bie gerinnelten Blätter; Def́tblätter Kaarfürmig,

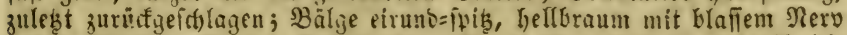

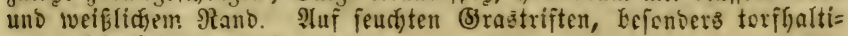
gen, nidjt felten. 5. 6. 4

1240. C. leporina. Jgajenjegge. Saftrten meift 6 ,

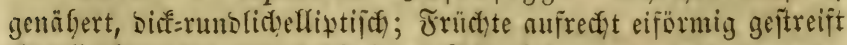

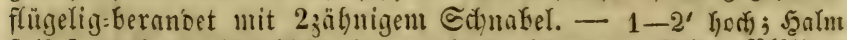

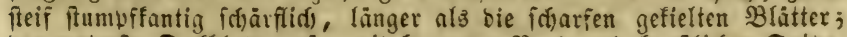

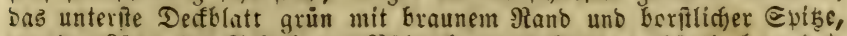

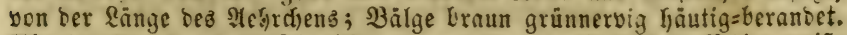
Abart: $\beta$ argyroglochin (C. argyr. Hornem.) jarter, Bălye wei $\tilde{i}=$

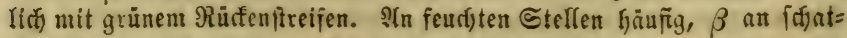
tigen Drten felyr felten: Biclefeld bet Bractuebe am Jufireg im

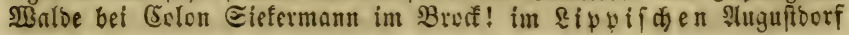




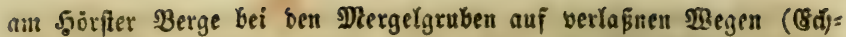
terling). $5-7.24$

1241. C. elongata. Verlängerte S. Aebroben läng:

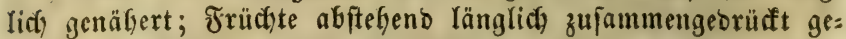
ftreift, mit faft ungetbeiltem Gdanabel. - 1-2' hod); 5alm

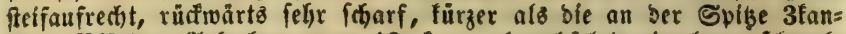
tigen $\mathfrak{B l a ̈ t t e r ; ~ H e h r d h e n ~ g e g e n ~ 1 2 , ~ f u r z , ~ a b w e c h i ́ l n o ~ e i n e ~ l a n g e ~ f o ́ t b m a l e ~}$ 2lehre bifoend; Bälge eiruno braun breit=iveláranbig, fürzer alz bie

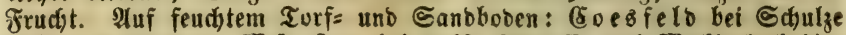

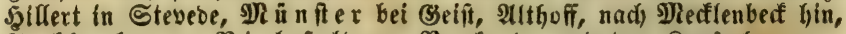

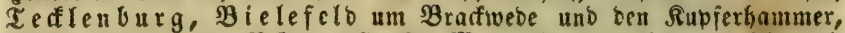
Mille, Şerforb, $B$ ü refor), Şunteburg, im Eipplficen, 2 rafel unweit ber St.

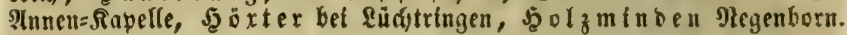
5. 6. 24

+ 1241 b. C. heleonastes. Ëhrb. Torffegge. Salm rauk; 2lefroben 3-4 runoliđ genäbert; Früchte eiförmig zu= fommengebrüft: 3 fantig glatt, in einen furzen ungetbeilten, am

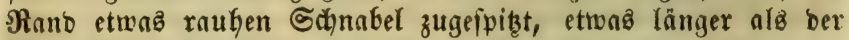
Balg. - 1' hod). Huf ben nörblidfen Dooren fehr felter: Re ep p n bet Eiferwege. $5-8.24$

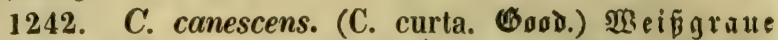
S. 2lefrç̧en 5-6, eiförmig:länglich, etwas entfernt; Früçte piförnig feingeftreift zufammengebrücft, mit furzem (â)wad)aus:

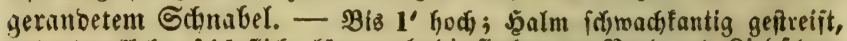

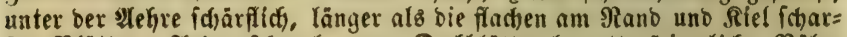

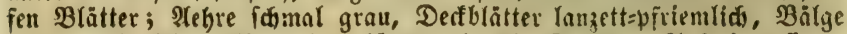
efrunb grünlią) = weífranbia, fürzer alo bie Fiud)t. Fluf fumpfigem

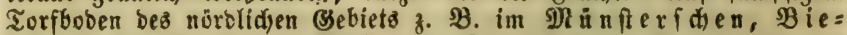
lefeld bei Braffuete, Mitle, im Ripulfiden, Betershageu bef Rientnigge, am $\Re$ öterberg beim Forflerhats, im Gorring băuîg. 5. 6. 4

+ 1243. C. loliacea. \&oldartige S. Aefrotien meift 4, ziemlid entfernt, bie fruchttragenten runblid; Frühte ellip: tijdftumpf fdonabellos, sorn ganzrandig, geftreift. - 1' yoda; Murgel furge 2 Uusläufer treibend; Şalm glatt, an ber Spibe rauh.

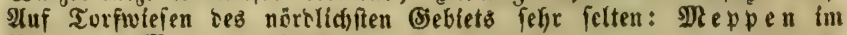
Burtanyer Sloor unweit Rhebe. 5. 4

t†† গarben 2; Uehroben am (Srunbe männlid), bie 2-3 untern roieber (aub 2-5) zufammengefest.

1244. C. Boenninghausiana. Whe. Bönninghau=

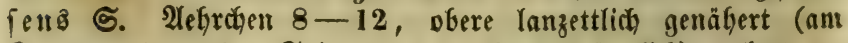
(Sruno uno an ber Spibe ober surdyaus männlia), zulę̧t ge= frümmt, untre entfernt; Frïhte aufrecht mit 2ppaltigen Gidna:

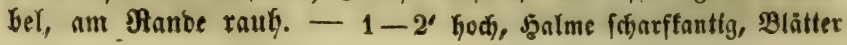




\section{Triandria.}

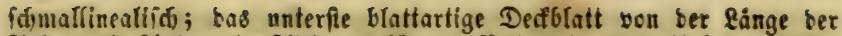

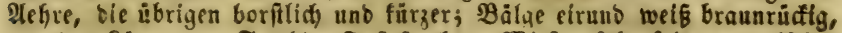

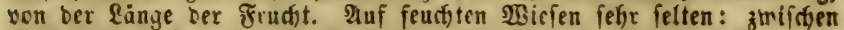
Jalle und Elifen am Fufe Der Berge von $\mathfrak{B}$ ön ninghaufen entbeft, balli im \&iypifden am $\mathfrak{M g g}$ yon Reelfirchen nad Belle

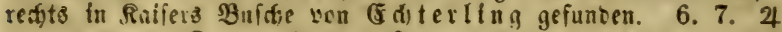

1245. C. axillaris. Bood. WB infelährige S. Salm fteif; bie $3-4$ untern $2(e f r d) e n$ entfernt, bab unterfte auf ein îfeifes über bie 2lebre binausragendes Dedfblatt geftübt;

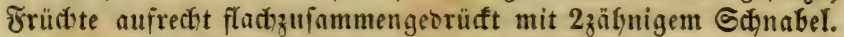

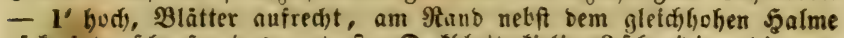

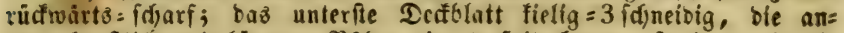
bern borîlid uno fürexer; Bâlge eiruno fvib braun, fo lang als bie Frust. Fuf @umpfriefen felten: bei D riburg am Fufe ber Jourg zuerf (in Deutidland) yol $\mathfrak{B}$ ethe aujgefunden (ater ganz zum Trod: nen aufgefammelt unt taher faum mefir vothanten), bann von $\mathfrak{B}$ o $n=$ ningfiaufen an mefreren Drten gefunben: zwiidien 5 a mm unb Drenfteinfurt an ber Chauffee, Darfelb, Serzebrod, Dis= fer, 5alle. 6. 7. 4

*.. Enbftänbige Xehre männliđ), feitenftänbige weibliă (felten bie enditánbigen an ber Spize roeiblid, ober mehrere männs lidie). Früđte f(d) nabellos oorr kurz geídnäbelt, Eabl.

† 1246. C. stricta. Bood. Gteife $ఠ$. Blatifdeiben alle treçig=gefpalten; männlidge 2lefre $1-2$, tweiblidbe $2-3$

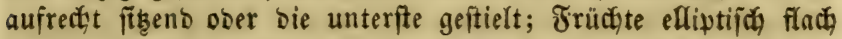

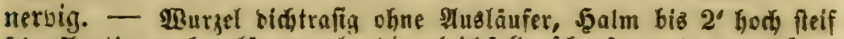

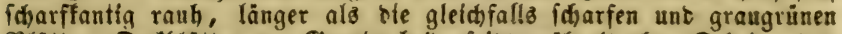

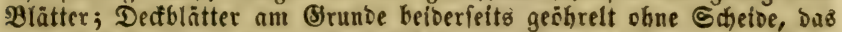

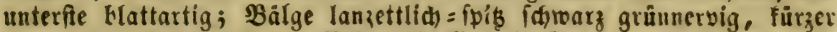

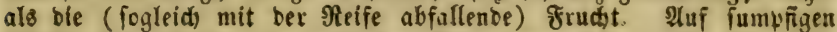
פBieien fefre felten: an mefreren Drten angezeigt (3. B. Eippitabt, Socft), tons mir jecod) eingefandt if, ift vielmehr C. paludosa; audi Y̧onninglyaufen giebt in feinem Prodr. bas Borfommen an ber

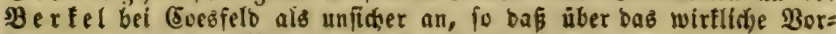
femmen nod) niditz Beffimmtes feftifelit. 4. 5. 4

1247. C. vulgaris. fries. (C. caespitosa. Autt.) (B) emeine S. Blattiacioen nidht netzig=geipalten; Das unterite

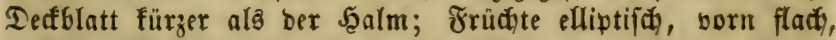

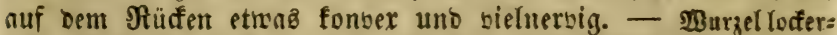

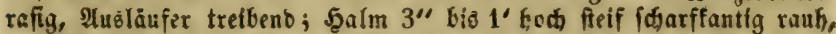

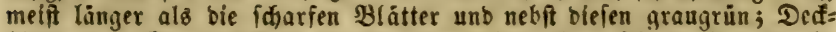
blätter am Bruno beiberielts fehr furz = (sie obern fajwark $=$ ) geöhrelt, bas unterite blattartige felten fo lang als ber Salm; Bälge eirunb

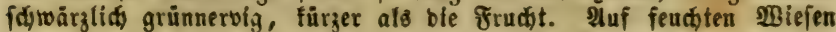
gemein, aber audi auf trofinem Sanbboben $3 . \mathfrak{B}$. in ber Senne. 4. 5. 4

1248. C. acuta. Sduneiben be S. Blattialden nidit neß̧ig:gefpalten; basิ unteríte Def́flatt länger alล ber நalm; 


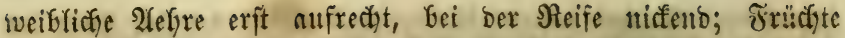

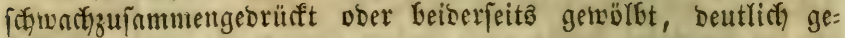

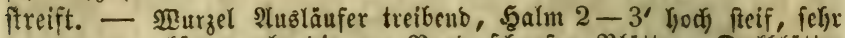

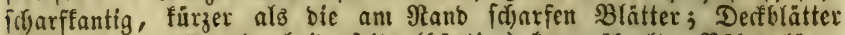

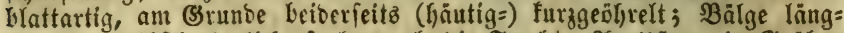

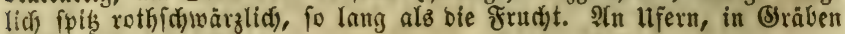
ไăurtig. $4-7.24$

B. Carex. গarben 3. (Enoftänচige 2(ehre männlid) (ober beren untre ş(üt)en männliđ()).

* Früd) fđanabelloz ober kurzgefđnäbelt.

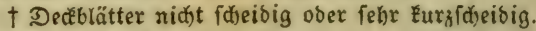

a. Früü)te Eaht.

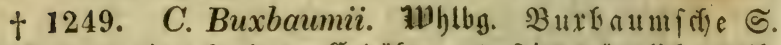

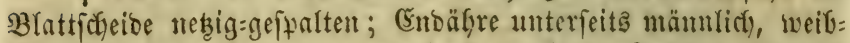

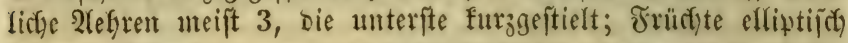

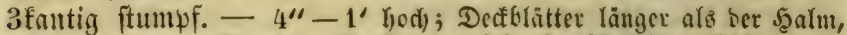

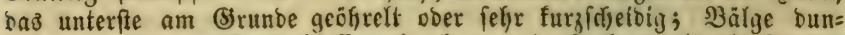

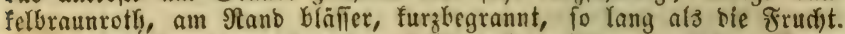

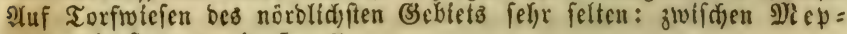
we ll unb Seanren. 4. 5. 4

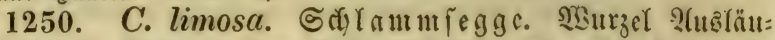

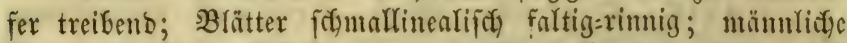
2lefye einzeln, weibliffye $1-2$ genäfert fyangento fang = mo

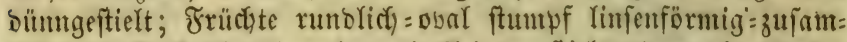
utengebrürft faljl bielnersig, mit fleinemt ftielrumbem abgeid)nitt=

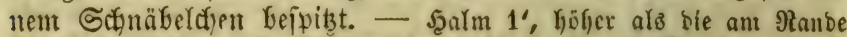

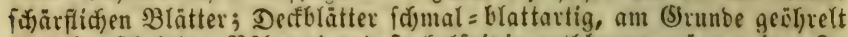

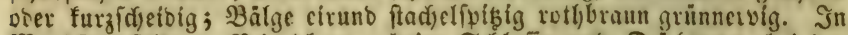
Moräften felten: $\Re$ f etberg beim Edjlofie und $D$ in 1 men bei ber

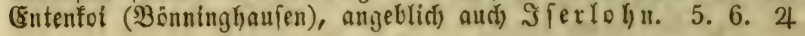

\section{b. Früdte reidjbebaart ober filzig.}

1251. C. pilulifera. Billenfegge. STsuzel fajerig;

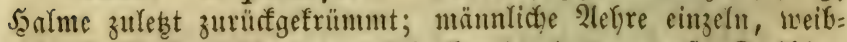
fiçye meift 3 genäbert rumblic) fitzento; bas unterfte Iestelatt

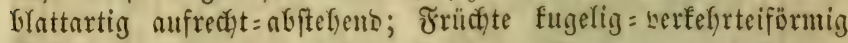
3 feitig. - Sjałm 1', länger als bie am Rano unb Ritel frorarfen

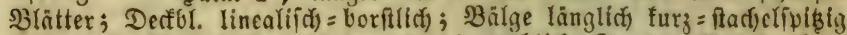

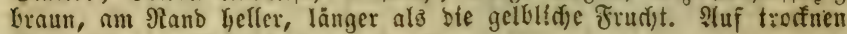
(B) rastriften in बrebuifict. 4. 5. 4

1252. C. montana. Bergiegge. গু̧̧urzel fajerig georungen=raftg; mämnlidge $\mathfrak{A}$ efgre cingeln, meibliche $1-2$ ge= nägert eiförntig; Deffblätter Gäutig ftengelumfafiento, begrannt vocr mit blattartiger Spibe berfefen; Frürdyte länglica = ber= fertrteiförmig 3 feitig; Bälge ftumpf ober geftutht, ftadfel= 


\section{Triandria.}

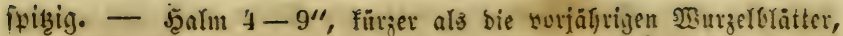

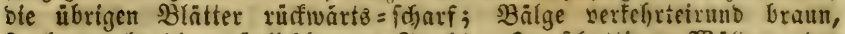

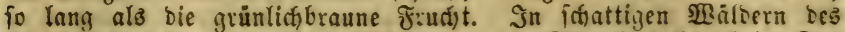

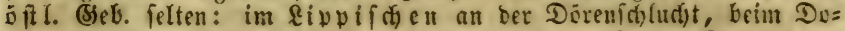

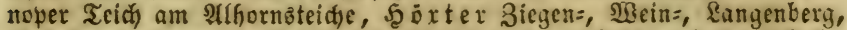

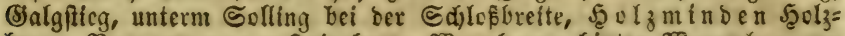

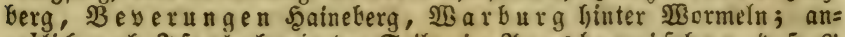

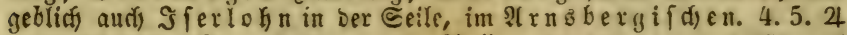

1253. C. ericetorum. Woll. 5ुa ibefegge. Șurzel

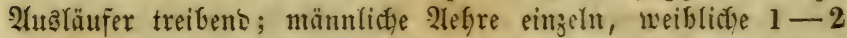
genäfert eiförmig; Deffbl. Käutig ftengelumfaileno fph ober Gegrannt; Frürthte werfefrrteiförmig 3 jeitig; Bälge serfefrtei=

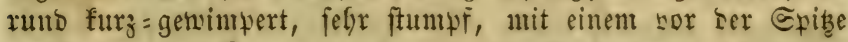

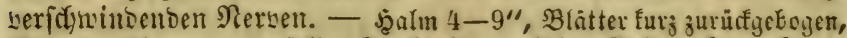

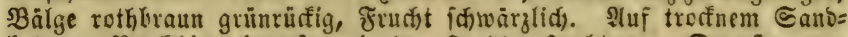
Goben: $\Re$ c flinghaufen in Sel Sarbt, Sgaltern, Doriten am

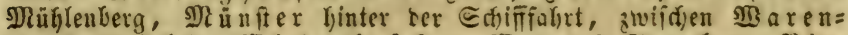

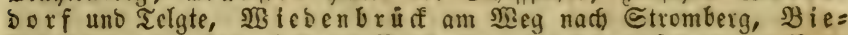
lefeld um ben \&utterfulf und Braffwere, im Rippifden am Ranb

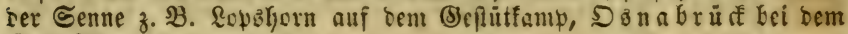

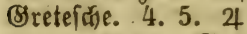

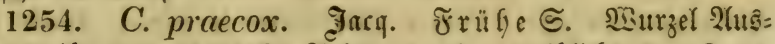
läufer treibenb; mämnlich) 2lef)re einzeln, meiflicte $1-3$ ge=

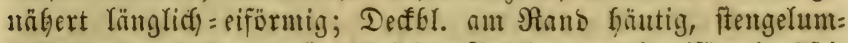

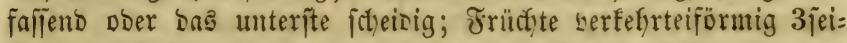

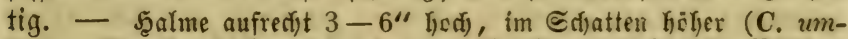
brosa. Host.), fo lang als bie vern 3fantigen und id)urfen Blätter;

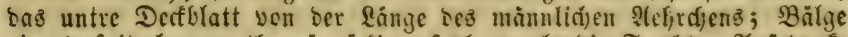

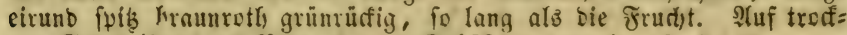

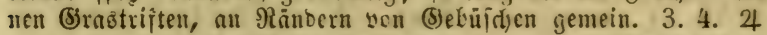

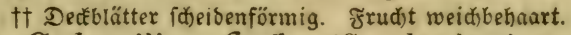

1255. C. humilis. f(ey). (C. clandestina. Good.) Nięrige ๔. B̉lätter rimnig, länger alsิ ser Şalnt; mämrl. 2lefre einzeln, meibliche $2-3$ entrernt, meift 36 lütfhig, alle geftielt, Blïthenịtiele non einem Gäutigen Iefflatt einge:

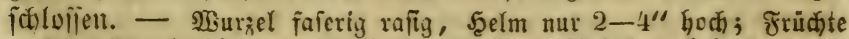

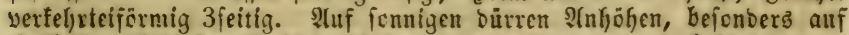

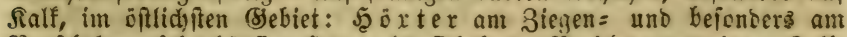

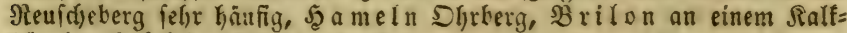
htigel naf bel ber Stabt. 4 . 2

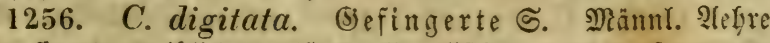

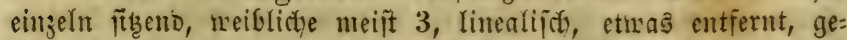
ftielt, bie fruchttragenden loffer, Blüthenîtiele von einem Gäuti=

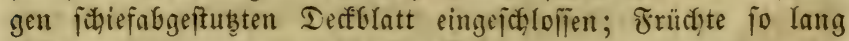
als Der aแติgeranbete gezäfynelte Balg. - Murzel fajertig rafig; 


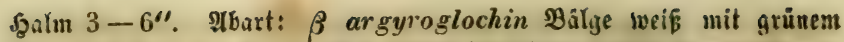
Rerv unb braunem Rane. Auf etwo Etrumbera, Blelefelo băufi, im Eippliaen an ben Stas

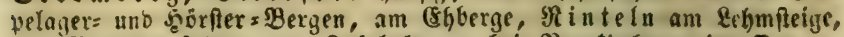
im $\mathfrak{R}$ indenfdern am Safobsbern, bef Bergfirdien, im Donas

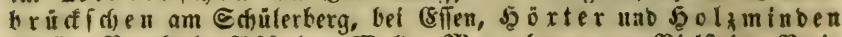

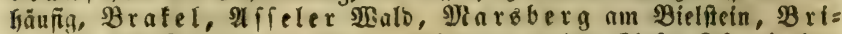
lon an ber Dueflen ser Alme, Alt tena an ber Rlufe, Sferlohn; $\beta$ im बđatten unter vor. (vielleidit $\mathfrak{B e r a n l a f i u n g}$ zur Berwectselung uit C. ornithopoda, weldye man hier unb ba melnte gefunben zu Laten). 4. 5. 24

$$
\text { †t† Deăbrätter fareibenförmig blattartig, Frudot Fabl. }
$$

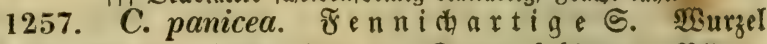

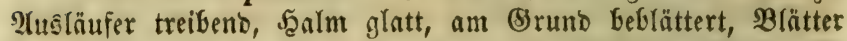

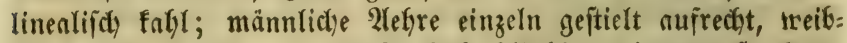
liche meift 2 entfernt aufrecht locferblüthig, bie unterfte lang: geftielt; Früchte faft fugelig=eiförmig. - 1' God), \$lätter graus

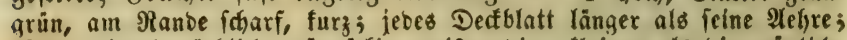

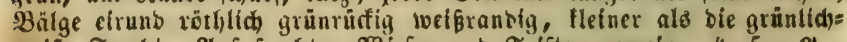

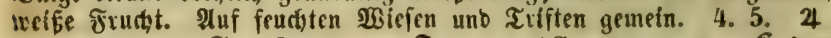
1258.
C. glauca.
Ssop.
(C. recurva. Ginds.)

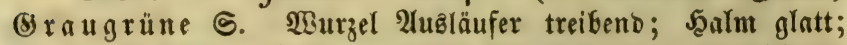
männl. Adehren meift 3 , weibliçe $2-3$ entfernt walzlich ge= brungenblüthig langgeftielt, zuleşt hangeno; Früchte elliptif(d) : zujammengebrängt: fonbex nerbenlos, etwoz raut). - $1^{\prime}$ ' hod, graugrün; Blätter abteffeno, niebriger als ber an ben (Eden fóarfé Şalm; Decfbl. faum faseibenförmig geöhrt; $\mathfrak{B a ̈ l g e ~ e i r u n b z u g e i p i g t ~}$ purpurbraun grünervig, fo lang als bie Frudyt. In $2 B i e j e n$ und an idjattigen Drten häufig. 4. 5. 24
1259. C. maxima. Scop.
(C. agastachys. (E)hrh).

C. pendula. Good.). Erope männliche $\mathfrak{H e f r e}$ einzeln uno nebit ben reibliden gefrümmt, zulekgt hangeno, weiblidfe meift 4 entfernt walglich gebrungen, bie untern fichtlid)=geftielt; Früchte elliptifd 3 fantig, mit fur:

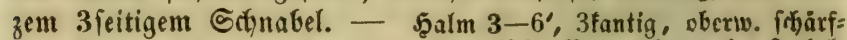

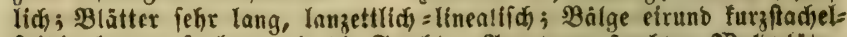

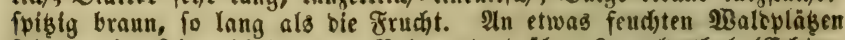

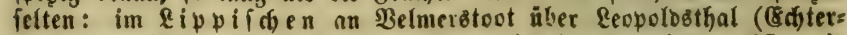

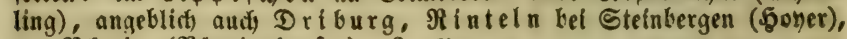
am $\Re$ hein (Böninghauen). 6. 4

1260. C. strigosa. (f)uds. (C. leptostachys. Ehrb.)

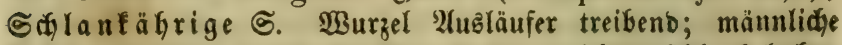
2lefire einzeln, weibliche meift 4 entfernt nidfent idalanf loder: blüthig, bie unterften fichtlid = gefitielt; Irüd)te länglids)=lanzett:

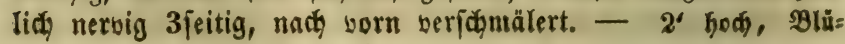




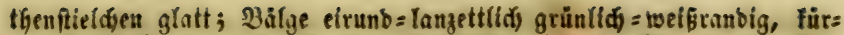
zet als bie frudjt. In feuditen Eebüfdjen felten: \$erforb, $\mathfrak{B}_{e}=$ tersbagen im Forft nad) bem Ranbe, etra Soletcrsheim gegenüber,

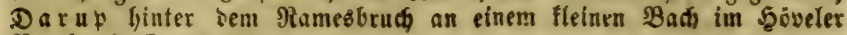
Brudy. 4. 5. 2

1261. C. pallescens. BIafie S. Sצurzel fajerig;

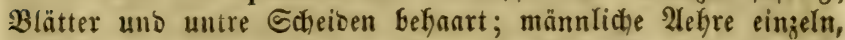
weiblidte $2-3$ genäfert niffent länglid)=eiförmig georungen

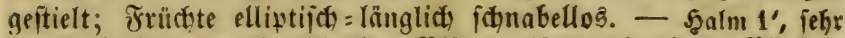
idsarf, fo lany als bie aufred)ten Blätter, fürzer als bie Def́tblätter; wociblidfe Pefren oft mit eintagen männlichen Blüthen endigend; Bälge

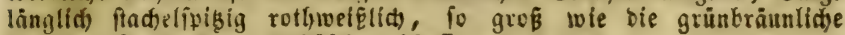
Frudjt. In feudften (sebrifden häufig. 5. 6. 24

*. Früđte geíanäbelt, Sd)nakel beranbet, 2fpaltig mit gerabe vorgeftredten 3ähnen. Diännlide Xehre pinzeln enoftänbig.

1262. C. flava. Belbe S. Ş3urzel fajerig; neibl.

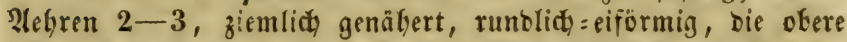

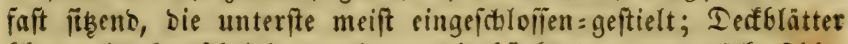
blattartig furzicheibig, zuleght weitabiteheno ober zurüfigefdila: gen; Jrüßste aufgeblafen mit zurürfgefrümmten @dnabel. -

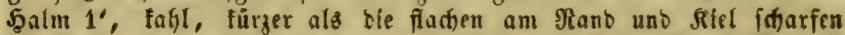
Blätter, uno viel türzer als bie Deffblätter; Sälge braungelb mit

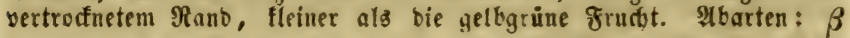
lepidocarpa (C. lepid. Tsch.) Früd)te fleiner, fürzer geidunäbelt; $\gamma$ angustifolia $\mathfrak{B}$ lätter felt, fómal uno gerinnelt, bie vherîten Iecf: blätter ben șalm nur wenig=, sie antęn weitüberrageno, bns unterfte

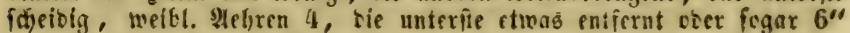

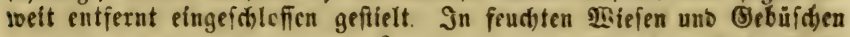

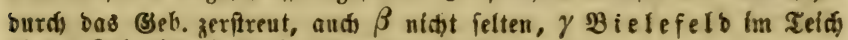
Ginter Rol. Sganibrint tn limmeln. 4. 5. 4

1263. C. Oederi. Ëbrh. Deberidue S. Früdte flein mit gerabem @dnnabel (jonfit wie vor. - nidjt wohl bló̉ eine bom Boben beoingte, freilid, faharf bezeidunete uno

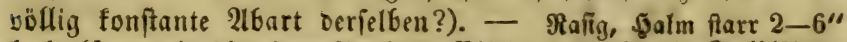
hod, fürzer als bie rínnenfërmigen Blätter unb als bie Dectblätter;

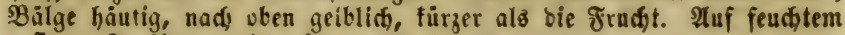
rafigem Torfboben nistit felten. 4. 5. 24

1264. C. fulva. Good. Belfbraune S. SWurzel furge 2Haläufer treibeno; weibl. 2Aebren $2-3$ nufredut eiförmig= länglid) gebrungen, bie unterite entfernt fid tlid): geptielt; Defí: blätter langíd)eibig, bas unterfte blattartig, fo lang ober län:

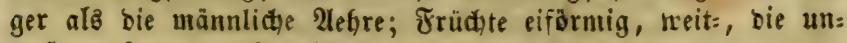

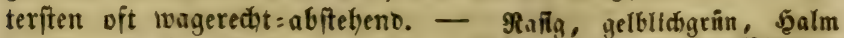
1-2', nady oben ícharf, etwas höher alo bie glatten fladien Blätter; B(attf̧äutdjen cirunt furz abgeidanitten; $\mathfrak{B a ̈ l g e ~ i p i s ~ b r a u n ~ g r u ̈ n n e r v i g ~}$ 


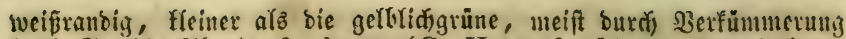
Golgle Frud(f). 2(bart: $\beta$ glauca (C. Hornschuchiana. Hppe) bläu=

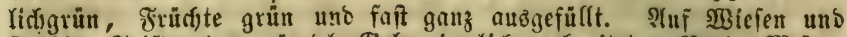

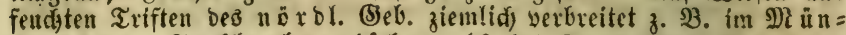
ferfden, Teffenburgliden ( $\beta$ bei lotte yon Fleboer=

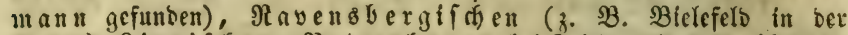

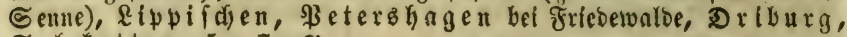
Salzfotten. $5-7,24$

1265. C. distans. Entferutälirige ธ. 23umel rafig; weiblidye 2lefren meijt 3 aufred)t eiförmig=lünglich ge= Drunger, bie unterfte weitentfernt fichtlicis = geftielt; Deffolitter langfdyeidig, bie unterften blattartig, länger als bie mannlidse 2lefyre; Früchte eiförmig mervig, bie feitlidfen Nerben eil wenig

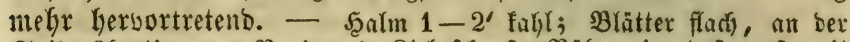
Splbe 3fantig, an Rano uno Riel fdharf; Bälge ciruno fumpf, mit rauljer Stadjelipibe enbigeno, roftbraun mit grünem Rürfen, fürzer alsె Die Frudit; bie 3äfue Der Frucht an iffrent innern Nanto mit dorn=

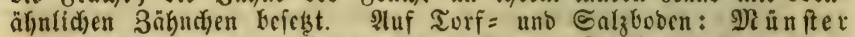
auf ber Rörhaibe, im Miecruelber Bruth, Diffen, Salzfot= ten, Soeft am Salzipring im Amper SBruct), Itnna, strtena ziwi=

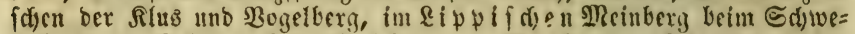
felbrumen, Sryfeber beim Eulzhrumen, Driburg, Sinter an ber

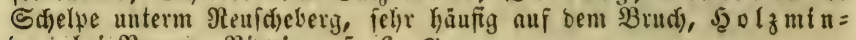
De it bei Bevern, Bipping. 5. 6. 24

+ 1266. C. binervis. Sm. Brveinervige S. Sur= zel raitig; weiblidue slebren meift 3 aufrects entfernt gebrun=

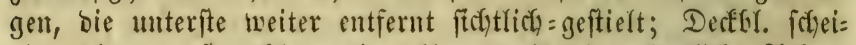

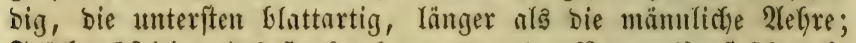
Frïd) 3 feitig mit 2 ftarfen Kerbortretenben Nerwen (fonft fodwatif) nerbig). - J̧alm 1-2' fafl, Bälge cirund fumpf nit raufjer Sta=

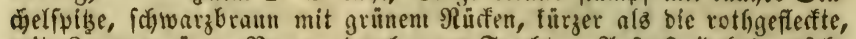

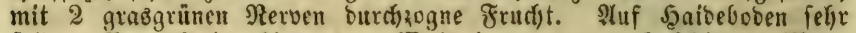

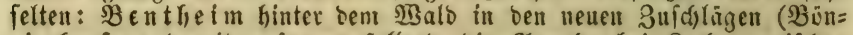
ninghaufen; bamit zufammenfallend bie शngabe bei Sods: zivifden Bentfeim unb Norbhorn?) 5.6. 4

1267. C. sylvatica. f⿹勹巳us. (C. Drymeja. (Ẻ)rb.)

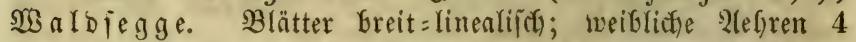
langgeftielt entfernt loffer lyangend, Jrücle efliptif(c) 3 feitig glatt mit linealijdyen Gdinabel. - Shalm 1-2', fo lang als bie

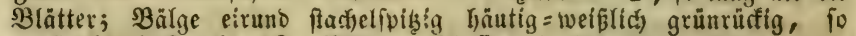

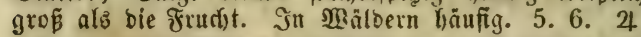

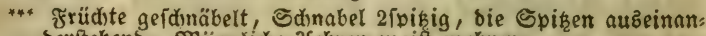
berftehens. Mäunlid)e 2(ehren meit mehrere.

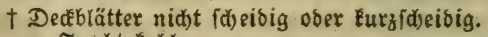
a. Fruddt Éahl

1268. C. Pseudo-Cypérus. Biperíegge. Diämil. 


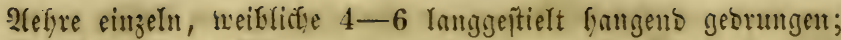

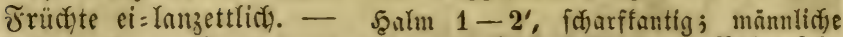

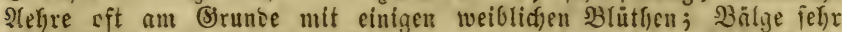

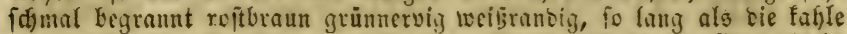

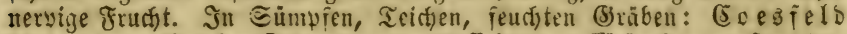

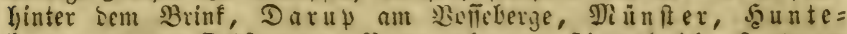

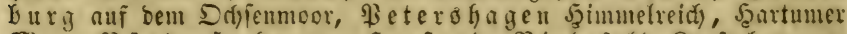

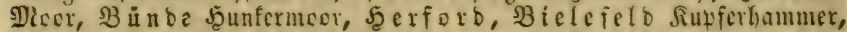

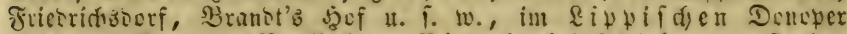

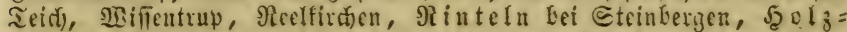

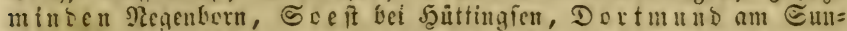

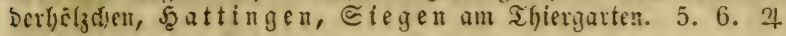

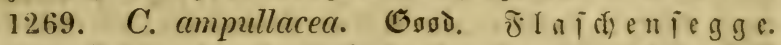

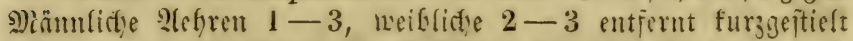

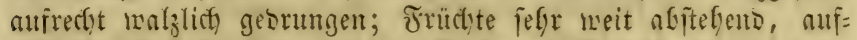
gefrlafen, faft fugelig, auf Lem Raufen meift 7nersig. - Shalm

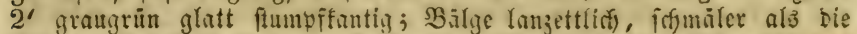

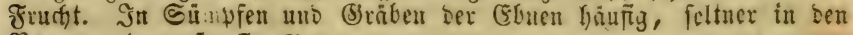
Be:ggegenben. 5-7. 24

1270. C. vesicaria. $\mathfrak{B}$ lajenjegge. N) ren $1-3$, weifliffe $2-3$ enternt, fithens oeer furzgeitielt,

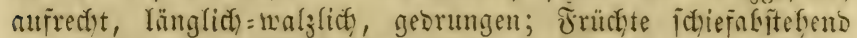

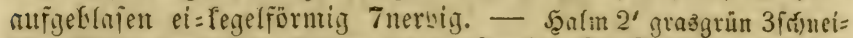

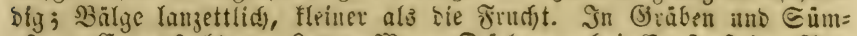

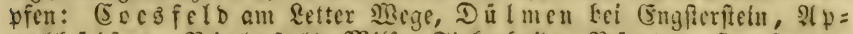

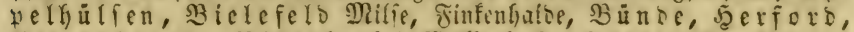

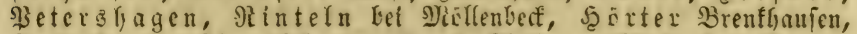
Sigelteidf, im Rippifden, હeeft filotinger wiefe bel Stmpen,

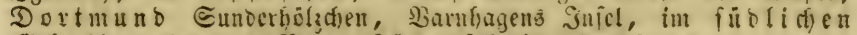
Geb. Ljeer unb ba, 3. 3. um \& if Denfideis. 4-6. 24

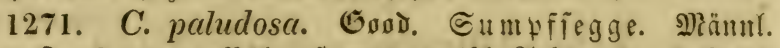

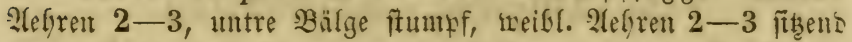

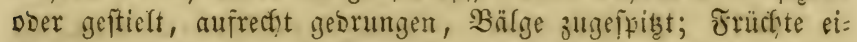

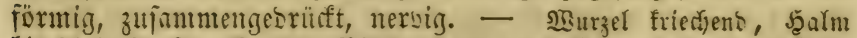

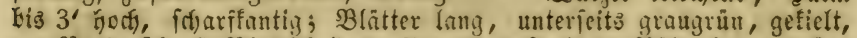

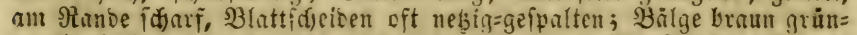

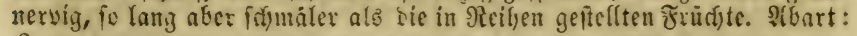

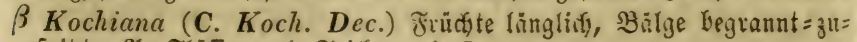

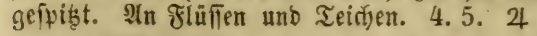

1272. C. riparia. Cart. Uferjegge. Mämliche

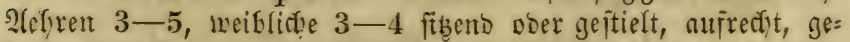

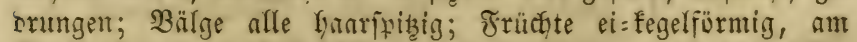

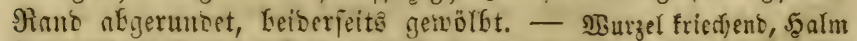

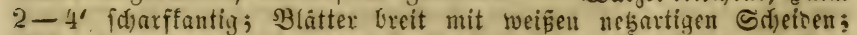

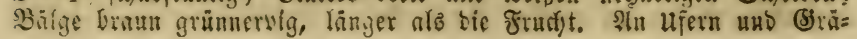


ben burdi bas (B)b. zerftreut, am yăufigften an ben Flüfen in bev gene. 4. 5.24

\section{b. Fruăt Eurzbehaart.}

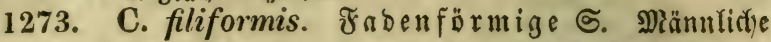
Ylebren 1-2, weibliche $2-3$ entfernt aufrerbt, länglid̆ oder

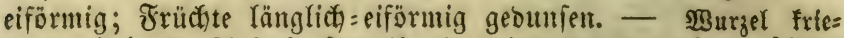
d)end; Salm 2-3' hoch, fumpifantig, glatt ober nut oberiv. fdjärf= Iích; Blätter rinnig, faum breiter alz ber şalm; Decfbl. am (B)rumbe mit brauner weífranbiger gewimperter Sdfuppe; Bälge lánglidi = lan=

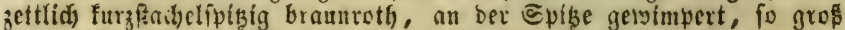
als ble Frucht. In SRoräften uno Simpien: श्? uี n fter auf ber Rör=

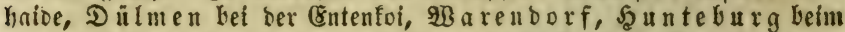

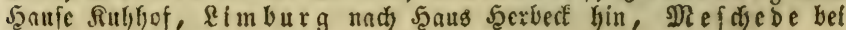
Enite. $4-6.24$

t† Dedélätter langf heidig. Frud)t behaart.

1274. C. hivta. BBehaarte S. SBlätter unb Schei: ben bebant, ntinnlidye alebren 2 , weiblidue $2-3$ aufredbt

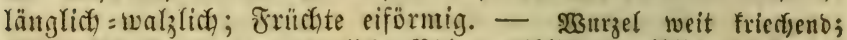

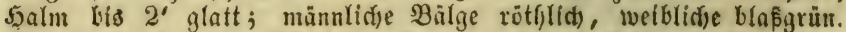
Ilbart: $\beta$ glabrata (C. hirtaeformis. I ers.) fahl mit 2(usnafyme

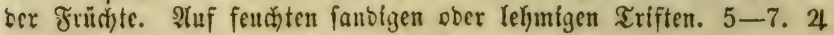

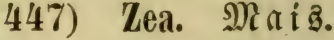

1275. Z. Máys. Männlidąe $\mathfrak{B}$ lütbe in amsagebreiteter

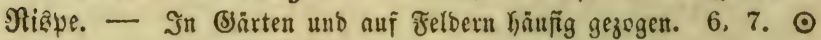

\section{Sromung Tetrandria.}

\section{8) Littorella. Stranding.}

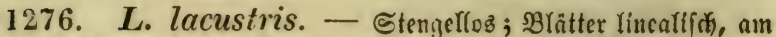

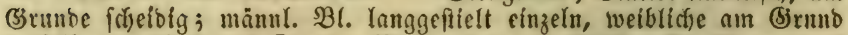

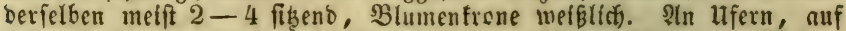

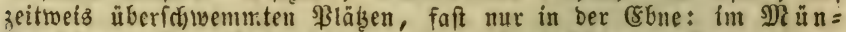

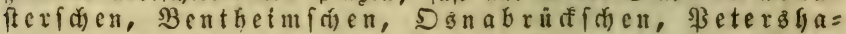

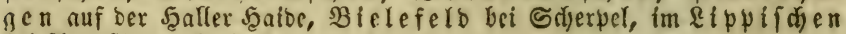
bel sturuftoorf, Ealzuffen. 6.7. 4

\section{9) Alnus. Coum. Erle. CIf er.}

1277. A. glutinosa. Grertr. (Betula Alnus. L.) (5) emeine (5. Bääter rumblich ftumpf flebrig, unterfeita an

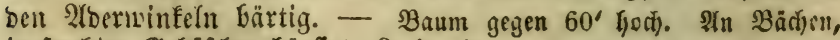

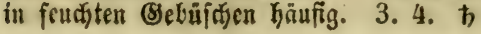




\section{Tetrandria. - Pentandria.}

1278. A. incana. Der. (5) raue (5. Blätter eiruto fpib, unterfeits grau=meid)befhart, an ben 2(bertwinfeln naft.

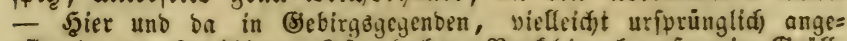
planzt: am Solring, Jferlohn, Re fflinghanfen im Erüll. 3. 4 . क

\section{4ว̈0) Urtica. Brennefĩel.}

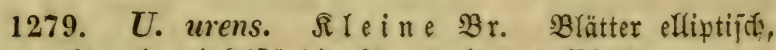

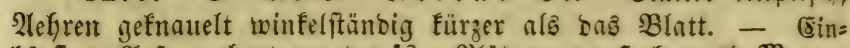

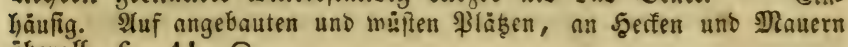
uีberall. 6 -11. $\odot$

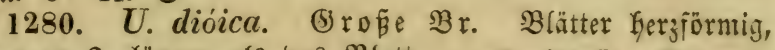

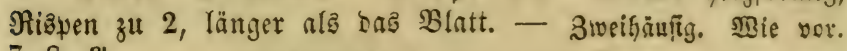
7. 8.24

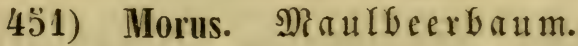

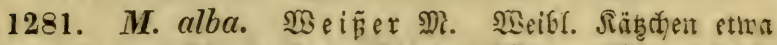

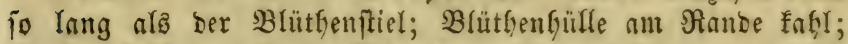

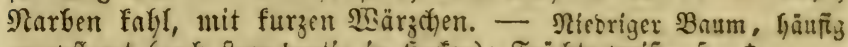

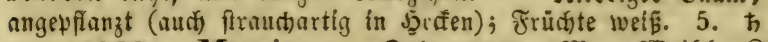

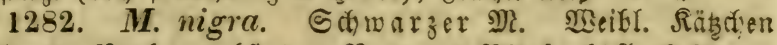

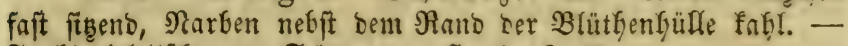
Erudat violettigiwarz. Seltner angepflanzt. 5. b

\section{5̋2) Buxus. $\mathfrak{B} \mathfrak{u} x$. $\mathfrak{b} \mathfrak{u} \mathfrak{b} \mathfrak{a} \mathfrak{m}$.}

1283. B. sempervirens. Blätter reserartig eirumb,

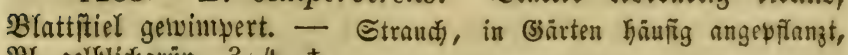
BI. gelglictggrün. 3. 4. ち

\section{Sromung Pentandria.}

\section{4ว̈3) Xanthium. Spibflette.}

1284. X. strumarium. (5) e meine $\sigma_{y}$. @tengel mefrlos, Blätter herzförmig 3lappig. - Bl. grungclblid), ซruর্]t

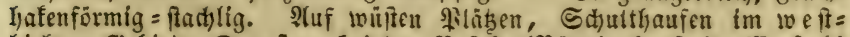

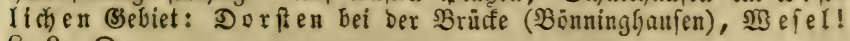
8. 9 . $\odot$

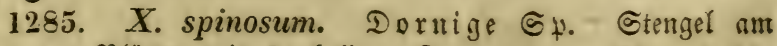
(5)runb ber $\mathfrak{B}$ lätter mit 3 gabeligen Dornen. - $B$ l. grünlid). Einige Dale (yon Suffrian) bei ভiegen an Edjlelfmihldjen 


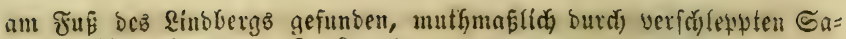
men bahin gefommen. 7-9. $\odot$

\section{3̈4) Amarantus. $\mathfrak{A} \mathfrak{m a \mathfrak { a } u t .}$}

1286. A. Blitum. (5) emeiner 2 . Stengel weit=

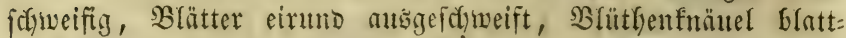

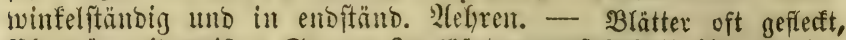

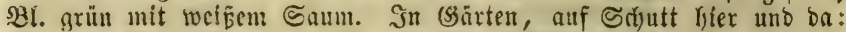

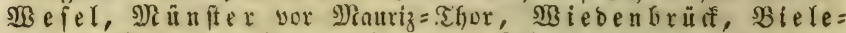

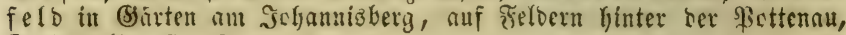
Detmolo. 7 -9. $\odot$

\section{Stonung Polyandria.}

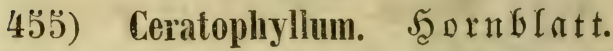

† 1287. C. submersum. (5) lattfamiges S. Blat: ter 3 mal gabelfwaltig in 5-8borítenförmige Bipfel getbeilt; Früchte an Der Spize mit einem Dorne, Der meformals fürzer

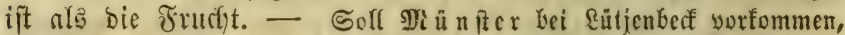
you $\mathfrak{B}$ ö nu

1288. C. demersum. Dorniginmige $S_{2}$. Bătter

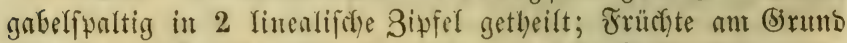
mit 2 zurürfgefrümmten Dornen, an Der Spiz̧e mit einem Dorn fo lang Doet länger ala bie Frutt)t. - Stengel unter

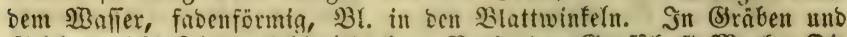

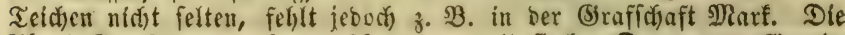
Ilbart C. platyacanthum. Chamisso mit fladien Dornen am Brunbe

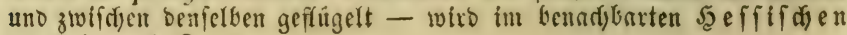
ingezeigt. 7. 8. 2t

\section{4ว̈6) Myriophyllum. Ianfendblatt.}

1289. M. verticillatum. Datitblütyiges T.

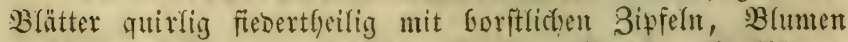
in Grattwinfelftänbigen uns ägrenförmigen Duirlen, Deffblätter

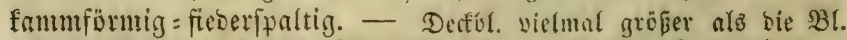
unb bie Fieber berf. nidgt ferge bidit fiefento. 2(bart: $\beta$ pectinatum

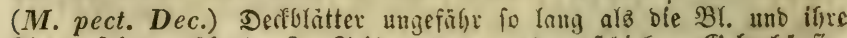

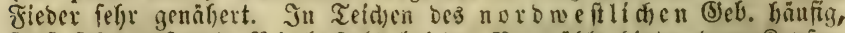

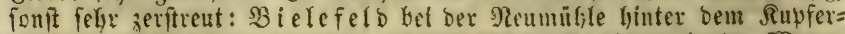

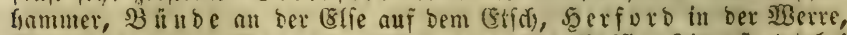

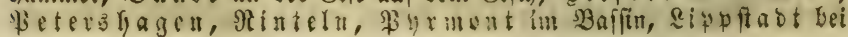




\section{Polyandria.}

ber Reimiebcrei unb bel Rapper im Stiftzteid), Sattingen (nach B(umeroth). 7. 8. 4

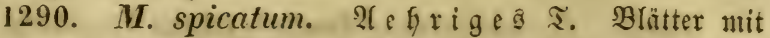
Forftliden Bipfern; Blumen in äfrigen Suirlen, bie jungen

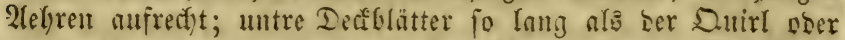

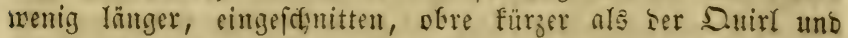
ganzrambig. - In Tcidjen und Gräben sez noroweft. Beb.

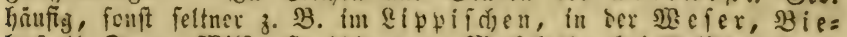
le felo Eemne, SRilie, $\mathfrak{b}$ attingen, Jief

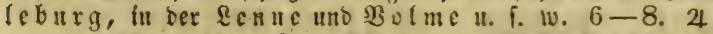

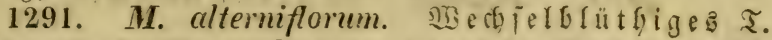

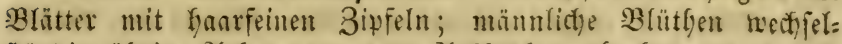

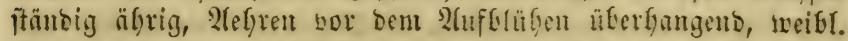

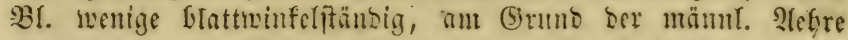
quirlig. - In fergeneen (G)

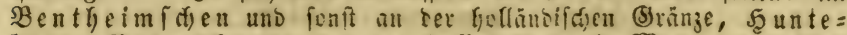

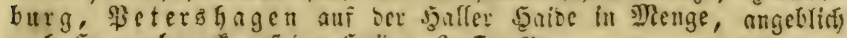
aud) Jुerzebra if auf ber şaike. 6. 7. 4

\section{4วั7) Sagittaria. Sifeilfiat.}

1292. S. sagittaefolia. B̉ättet freilförmig zugefpitht,

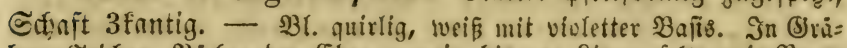
ben, Treidjen, Bădien ber (Ebne gemein bỉ zur Rippe, feltner in Berg= gegenben 8 . B. B ielefeld Suobraff, NRilfe, im Rippif di en um

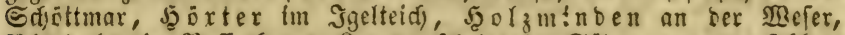
Rinteln in Bafientergz Rump; fdjefnt in ๔uben ganz zu ferflen. 6. 7.4

\section{4วั8) Poterium. Bedserblume.}

1293. P. Sanguisorba. Stengel etwas fantig, B̉ät=

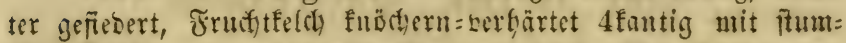

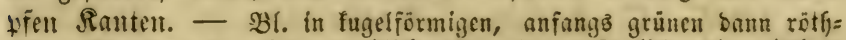

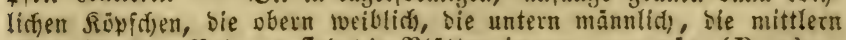
sft żvitterig. 'Bei uns fino bie Blätter tmmer-graugrü (P. glau-

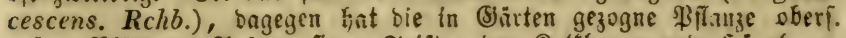

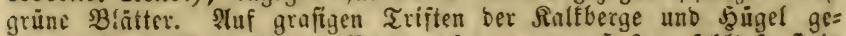
mein, aber 3. 3. aud nedi \$etershagen am Jjafen, feghlt fouft in ber (s)bne gemeluiglid) ganz. $5-7.4$

\section{9) Fagus. $\mathfrak{B} \mathfrak{d} \mathfrak{e}$.}

1294. F. sylvatica. Blätter eirumo faffl getwimpert. - Baum etwa $100^{\prime}$ hodi), in Thälbern. In Sarten hat man eine

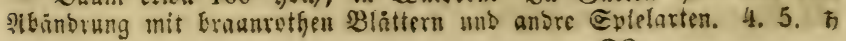


460) Castánea. Courn. Raftani

1295. C. vulgaris. Eam. (Fagus Castanea. L.)

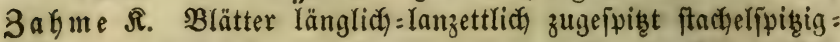
gefägt. - Baum $50-70^{\prime}$ body. In (5)ärten, im weptididen (S)eb.

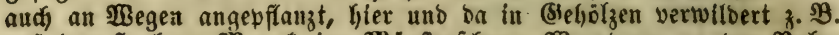

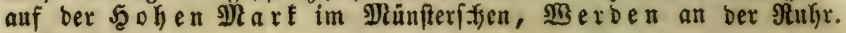
5. 6 . 方

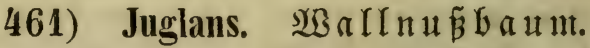

1296. J. regia. Bo emeiner $\mathfrak{S}$. Blätter 3-4paarig

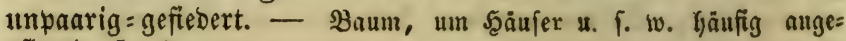
pflangt. 5. b

\section{2) Quercus. (sid)e.}

1297. Q. sessiliftóra. Sim. (Q. Robur $\beta$. L.) Ste $i$ ne $i$ d) e. Blătter langgefitielt unterjeits etwaz beljant, Früchte fitzento. - Baum in Bergivaldungen bez öftr. (5) eb. biz

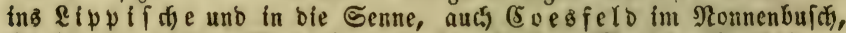

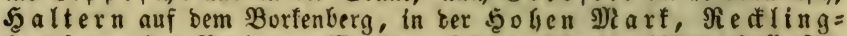
haufen, im $B a l v e r B_{B}$ lo, \&übenfde ib rinter Sellerfen, Soefit im Brandiglz. 5. h

1298. Q. pedunculata. E⿺ Ehrh. (A. Robur $\alpha$. L.)

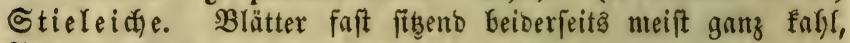
Früchte gefftielt. - Şuher Baum, überall befonderz aber in ber (8)bne; änoert zuwcellen mit etwaß beutlicher geftielten $\mathfrak{B}$ lättern $a b$ (Q. intermedia. Boenn.). 4. 5. के

\section{3) Córylus. Şafelftraud.}

1299. C. Avellána. (5) e ne $\mathrm{i}$ ก $\mathrm{e} \mathfrak{r}$. gloctig, an ber Spize etwns abjetebend. - Strautio, in Bebi:

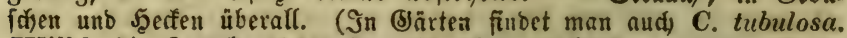

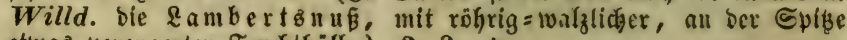
etwas verengerter Frudththüfe.) 2. 3. 万

\section{4) Cárpinus. Şainbud)e.}

1300. C. Bétulus. Blätter eirunto faltig boppeltge=

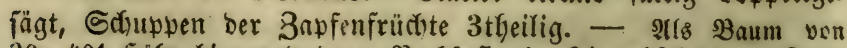

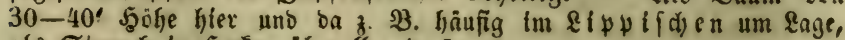

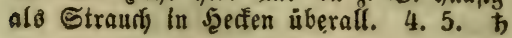




\section{5) Betula. Birfe.}

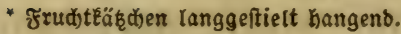

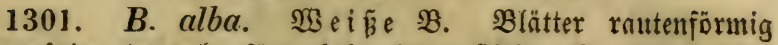

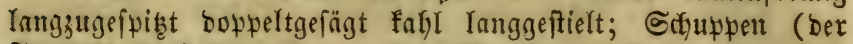

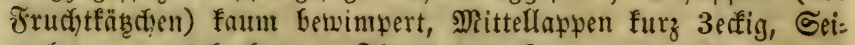
tenlappen zutrürfofogen; Flügel bes Samens boppelt fo breit

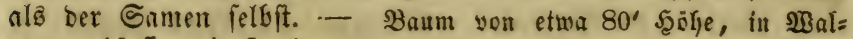
Dungen häufig. 4.5. Ђ

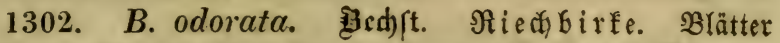

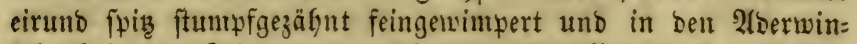
feln behaart; Cd)uppen rautbharig, Mittellappen furz 3erfig;

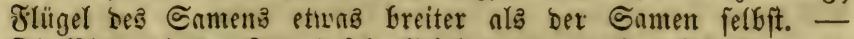
Die Brätter in ber Jugente felfre flebrig unb angenefin riechento. Unter yor. befonbers auf Eanbboben. 4. 5. 万

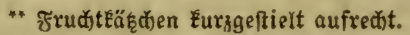

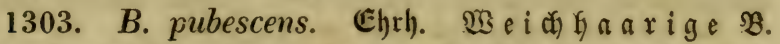
Blätter furzgeftielt, cirunblich ober herzförntig = eirund, fpib,

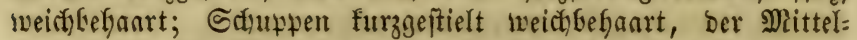
lappen zungenförmig= berlängert, bie Geitenlappen runblid). -

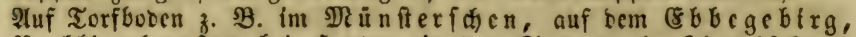
Redflinghaufen bei Jyarten, in ber Senne, im Rippifínen, fm Solring (Pfeiffer). 4. 5. क

1304. B. davurica. Wallas. Daurifude B. Blăt= ter langgeftielt, rautenförmig ober länglich) = eirunb, zugefpit̨t,

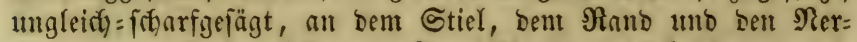

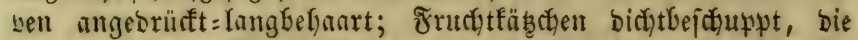
Struppen furzgeftielt rauchbanrig, ber Mitteflappen breit:3edfig werlängert, bie Seitenlafpen zugerunbet. - 2 (uf toarbigem $\mathfrak{T}$ orf $=$ voben z. B. im Solling (Pieiffer). 4.5. to

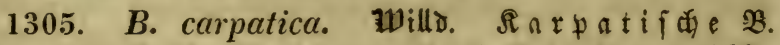

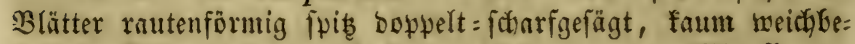
raart; Schuppen langgeftielt meidfbefaart, ber Drittellappen zungenförmig=berlängert; bie Seitenlappen fodjef = geftubt. -

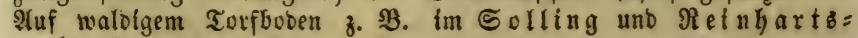
wa to. 4. 5. क

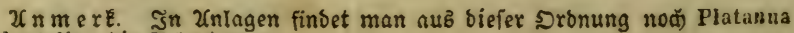
occidentalis, bie ฐु- Iatane. 


\section{Stronumg Monadelphia.}

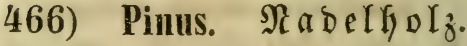

1306. P. sylvestris. Riefer. Fö̆re. B̧ätter zu

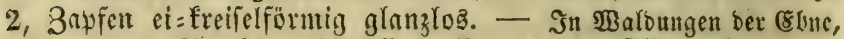
befonbers auf. Sandboben überafl, in Berggegenben felten unb unt an= gepflanzt. 5. 6. th

1307. P. Strobus. S2: eimuth

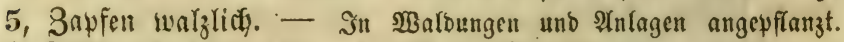
5. 6 . 古

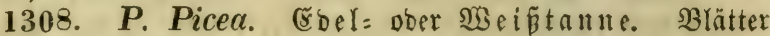
cinzelu famm Gläulidłweipen Rinien; 3apfen walzlich aufredht. - Sgier uns

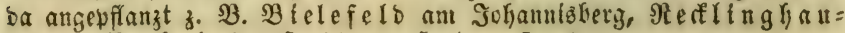

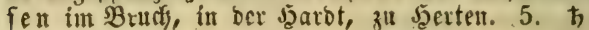

1309. P. Abies. Rothtanue. Fid te. Bläter cin= zeln zerftreut ftadyelipilzig, faft 4 fantig; Bapfen warglich hangento.

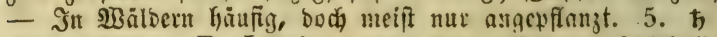

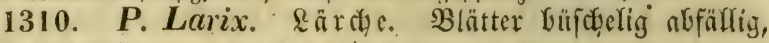

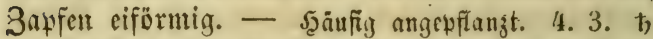

2 m mex . In Xnlagen finbet man aud) twohl P. C(mbra, bie 3irbel: Eiefer, und einige anore 2 rten biefer (Sattung angepfl inzt. Sonft findet fich aud) Thuja occidentalis uno $\mathrm{Th}$. orientalis, ber \&ebenbbaum.

\section{7) Bryonia. 3uาเübe.}

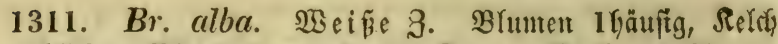
Det weiblidyen $\mathfrak{B l}$. fo Iang alsิ bie Rrone, Narben fafl. -

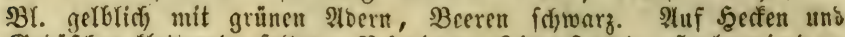

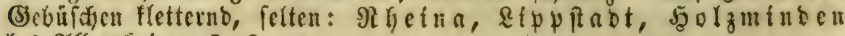
bei Allerbilim. 5, 6. 24

1312. Br. dióica. 3weifräufige 3. Blumten 2'= Gäutitg, Relde ber weiblidyen $\mathfrak{B}$ lume hale fo lang als bie Rroue,

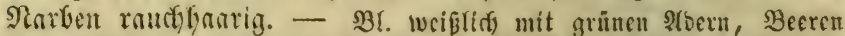

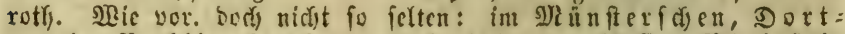

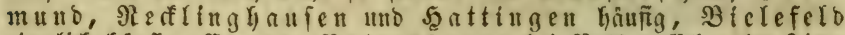

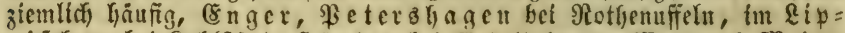

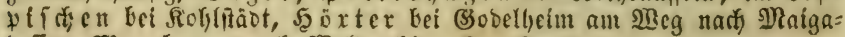

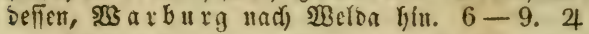

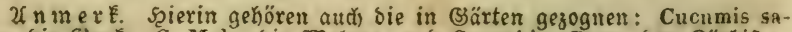

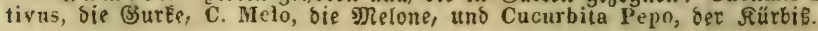




\section{Dioecia.}

\section{Bwei uns swantigite slatie. Dioecia.}

\section{Soronung Diandria.}

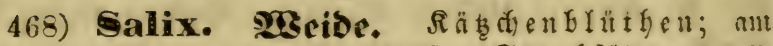

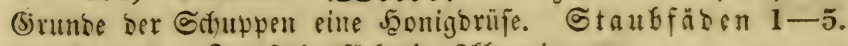
Rarben 2. Rapfel 1fütterig 2flappig.

\section{Sronung Triandria.}

469) Empetrum. Kaujchbeere. or $\Omega_{e}($ di $3:$ theilig. Rrone 3 blätrig. \& Staubgefäpe (3) unfruttit= bar. (5) riffel meift 9. Beere 9 jamig.

צuromalifa) \$ftanzen: Valeriana diocia. Carex dioica unb Davalliana. Salix triandra.

\section{Soronung Tetrandria.}

470) Viscum. Miftel. or $\Re e l(t) 4$ theilig. Irone 0. Staubbeutel langzugeipist, bem Seld, angelwadjien. \& Reltr) 4blättrig. Rrone 0. (S) riffel 0. Beere l jamig.

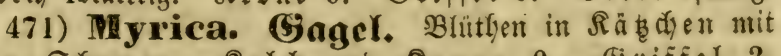
bolfen Guppen. Reld uns Rrone 0 . (5) riffel 2. Steinfrudit 1 jamig.

\section{Sronung Pentandria.}

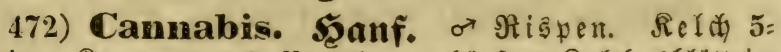

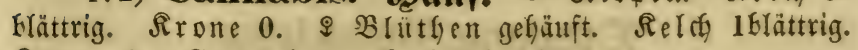
Srone 0. (j) riffel 2. $\Re$ ú 2 lappig.

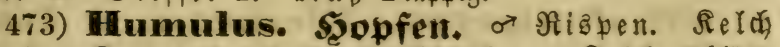
5blättrig. Rrome 0. \& Bapfenblüthen. Reld 1 blätt= rig. Rroue 0. Sriffel 2. Schlaudrutat.

474) Spinacia. Spinat, of $\mathfrak{B} l u$ uthenfultle 4: theilig. \& slüthentülre $2-3$ fpaltig Gleibend. (5) riffel

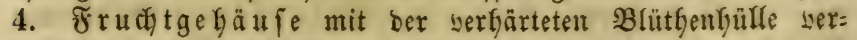
wadjien.

Promalifafe \$flanzen: Ribes alpinum. Bryonia dioica. Salix pentandra. 


\section{Sronung Hexandria.}

SInomalifate $\Re$ flanzen: Rumex Acetosa und Acetosella.

\section{Sromung 0ctandria.}

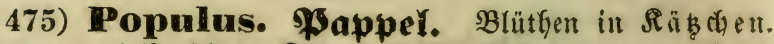
Sd) uppen bielipaltig. Rrone trichterförmig ganz. Nar= ben 4. Rapfel 1 fädtherig 2 flappig. Samen au ber Bafts toollig.

\section{Sronumg Enneandria.}

476) Mercunialis. Bingerfraut. $\Omega_{e}($ d $) 3=$ theilig. Rrone 0. Staubbeutel Duppelt. (5rifiel 2. Rapfel 2 füpfig 2 fäd)erig 1 famig.

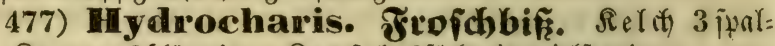
tig. Rrone 3blättrig. Rapfel 6fädherig vieljamig.

\section{Soromung Decandria.}

Inomalifiche Pflanzen: Lychnis diurna umb vespertina.

\section{Sromung Dodecandria.}

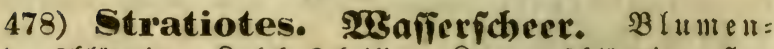

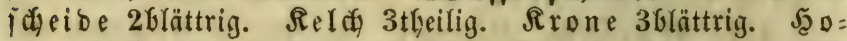

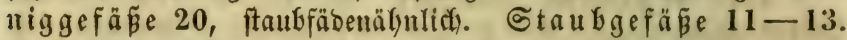
(5) riffel 6, 2tjeilig. Beere 6färtherig vielfantig.

\section{Sronumg Polyandria.}

F̂nomalificte Fflanzen: Stratiotes aloides. Populus nigra.

\section{Sronumg Monadelphia.}

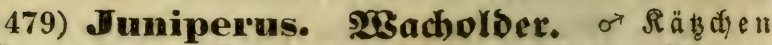

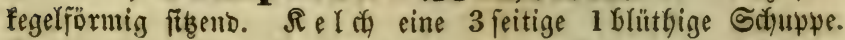
Rrone 0. Staubgefäвe 3. Q Reld 3theilig. Rrone

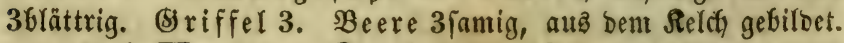

480) Taxus. Tazbaum. Rel di vielblättrig, mit einer faulle werfeber. Srome 0. Staubbutel fobloförunig Spaltig. Narbe 1. Santen 1, bon bemt zulebet beerenför: migen Reldye eingehüflt.

Inomalifáe Pranze: Bryonia dioica. 


\section{Sronung Diandria.}

\section{8) Salix. His cibe.}

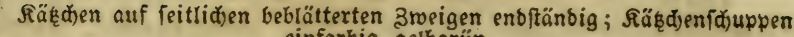
einfarbig gelbgrün.

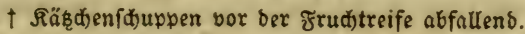

1313. S. pentandra. F̛̉̆ o wal, beiberfeits berfd)mälert, bidyt=fleingefägt, fafll; Blattfticl oberwürta brüfig; Nebenblätter eirumb gernbe; Blüthen 5-10= ntämnig; Ratpfeln fafhl furzgeftielt. - Straud $4-9^{\prime}$ hod, fel= ten ein Baum; Bglätter lorbeerartig, fino zerrieben wof)lriedjento; bie

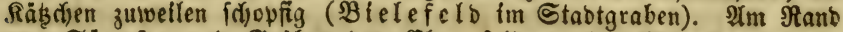

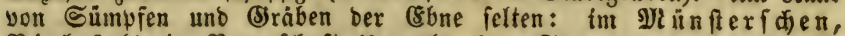
Bielefelo in Baueridaft ulmmeln (am Stabtgraben angeptanzt),

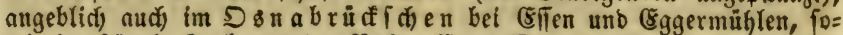
wie im fübr. (3) $\mathrm{e}$ b. an ber $\Re$ Rufre, Crber, Diemel (?). 5. 6. b

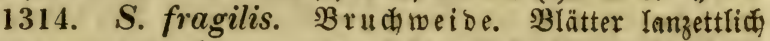

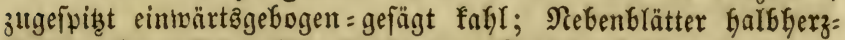
förmig ftumpflid; $\mathfrak{B l}$. 2 månnig; אapfeln fahl geftielt. Baum gegent $40^{\prime}$ hodf. 2rbart: $\beta$ sericea (S. Russeliana. Sm.)

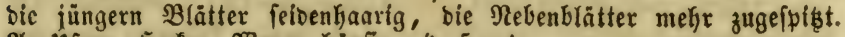

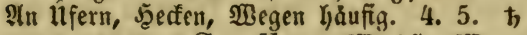

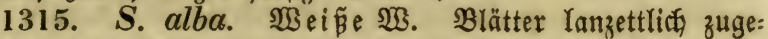
fipibet fleingejägt beiberfeitz peibenfaarig; Nebenblätter Ianzett: lici); $\mathfrak{B l}$ l. 2männig; Rayjeln ftumpf fahl furzgeftielt. - $B$ aum

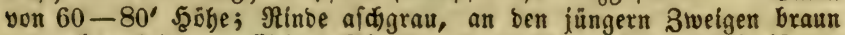
unb oberwärts graufilzig. 216art: $\beta$ vitellina (S. vitell.) jüngre 3tweige bottergelb ober lebhaft $=$ roth. 2 an 2 Begen, $u$ fern gemein. 4. 5 . म

1316. S. babylonica. Trauerweibe. Blätter linea:

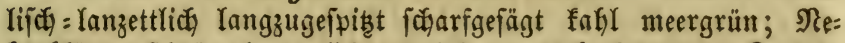
Eenblätter ia)räg = Ianzettlid) zugefpint zurürofgefrümutt; Rapfeln

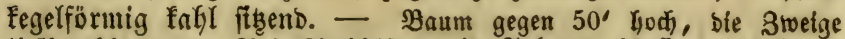

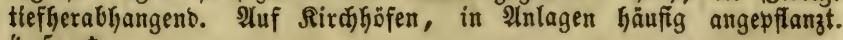
4. 5. 方

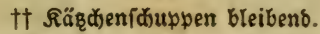

1317. S. triandra. Dreimännige $\mathfrak{S}$. Blätter lant=

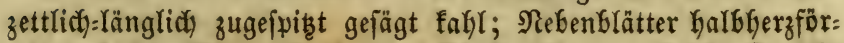

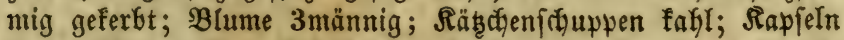
ei=fegelförmig ftumpflich fahl geftielt. - Baum bis $30^{\prime}$; hodf,

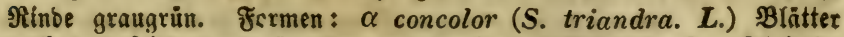

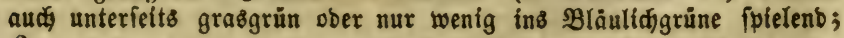
$\beta$ discolor (S. amygdalina. L.) Blătter unterfeits bläulidigrủn. 
In Ufern, (b) bũ

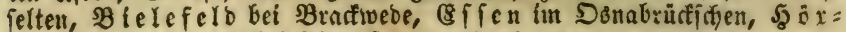
ter, angeblich aud bel lip p fta b t. 4. 5. 万)

1318. S. undulata. Ĕbrb. NBerrenbrättrige $2 \mathfrak{Z}$. Blätter lanzettliă, fehr lang zugefpikt, wellig=gefägt, ziemrich

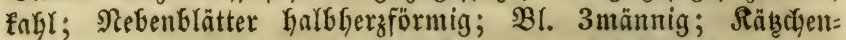
farupwen an ber Spibe bärtig; Rapfeln ei=fegelförmig fumpf: lich fabl geftielt. - Straud 10-18' lodj, gelbliagrü, bie jun=

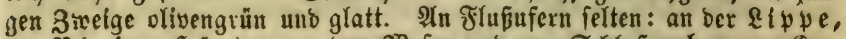

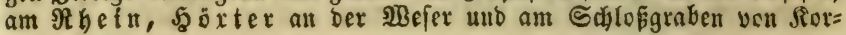
vel. 4.5 . 万

1319. S. hippophaёfolia. Obuill. Seebornartige

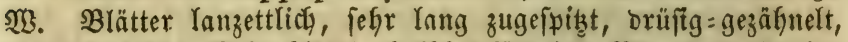
ziemlid farbl; Nebenblätter halbberzförutig; Slume 2 männig; Räkgchenfduwpen raudblyarig; Rapfeln fegelförnig fabl furzge=

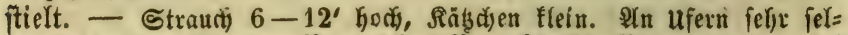

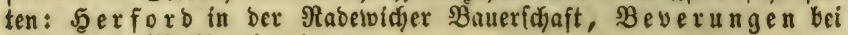
\&auenförbe (Becthaus). 4. ち

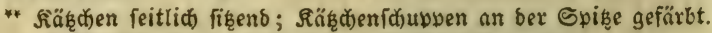
$\dagger$ Staubbeuter roth, nad bem Berfäuken føwarz.

1320. S. purpurea. $\mathfrak{B} u \mathrm{r} \downarrow \mathrm{r}$ we i $\mathrm{e}$. Blätter ber: feGrteirumb=lanzettlich fdyarfgefägt flaç fagl; Blütben I mämnig (burch Sujammentwadjung ber Strubfäben); Sapfeln filzig; Narben fefr furz, eiförmig, faft fibento. - Straud you 3-4' STn ufern und feudisten Drten nidjt felten. Formen: a humilis (S.

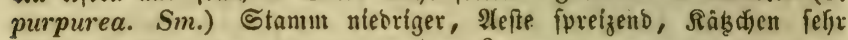
fdjlant: z. B. In ber Genne gemein; $\beta$ Lambertiana (S. Lambert.

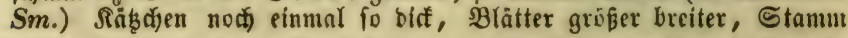

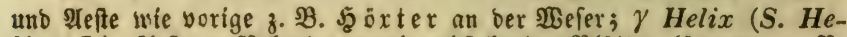
lix. L.) Âfefte aufitehend, toenig abftehyeno, Blätter länger: z. $\mathfrak{B}$.

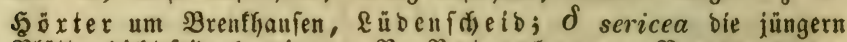

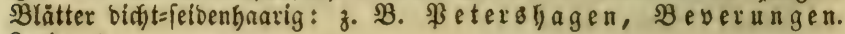
3. 4 . 方

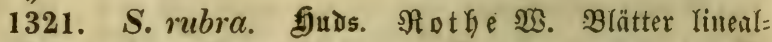

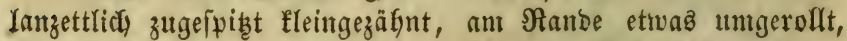
ziemlid fabl und zuletgt oberieita glänzend; Nebenblätter linea:

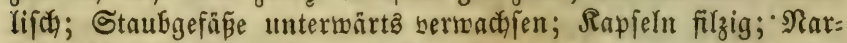

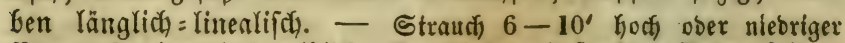
Baum, Sweige alatt aelblid). In IIfern uno feudsten Drten felten:

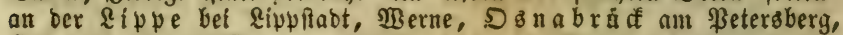
Serforb an ber $\mathbb{B}_{\text {erre nach }}$ Uffen him. 4. h

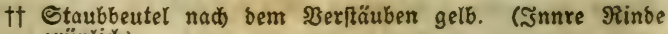
grüntiç).

1322. S. viminalis. Sor $\mathfrak{b}$ we i be. Blätter faft gamz= 


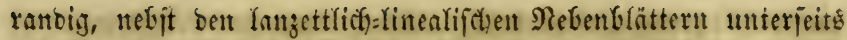

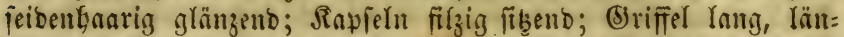
get als bie Sanare ber Schuppen, Narben fabenförutig uno meif́t ungetyeilt. - Strau() $12-16^{\prime}$ hod, swcige grüngelblid,

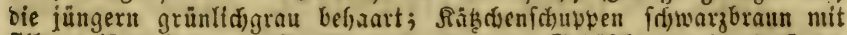

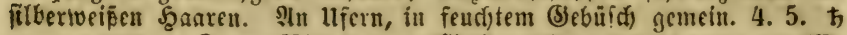

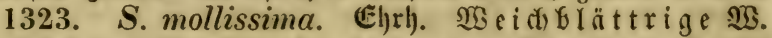
Blätter fait ganzranbig, unterfeita feinfizzig; Rebenflätter eiruno fpis; Sapfeln filzig fizento; Briffel fo lang als bie Saare bet Schuppen, Narben linealifich 2 ppaltig. - Baumartig 12' uno

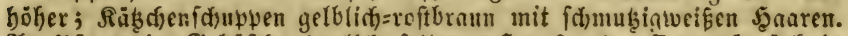

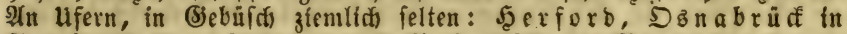

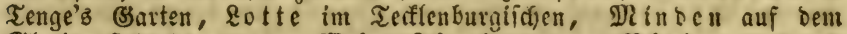

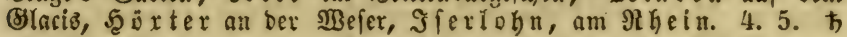

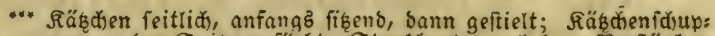
pen an ber Epiąe gefárbt; Staubbeutel nad) bem Seritäuben gelb; Rapieln langgeftielt.

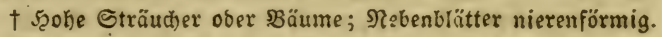

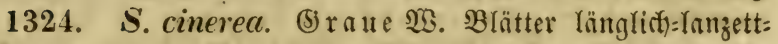

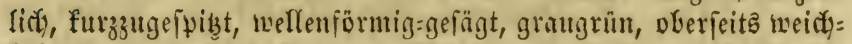
- Gefaart, unterfeits furz=graufizig. - Straudi $8-10^{\prime}$ hod),

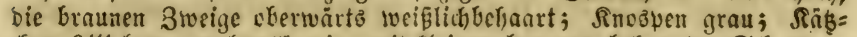

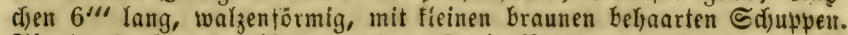

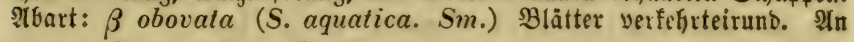

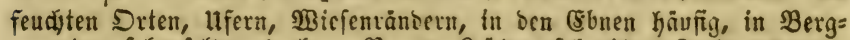
gegenben fefre felten, ood) $z$. B. um \& it $b e n f$ ef eib. 3. 4. क

1325. S. Cáprea. Salifwe id e. Blätter eiruno ober

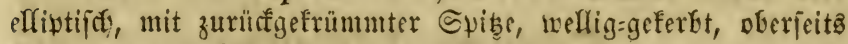

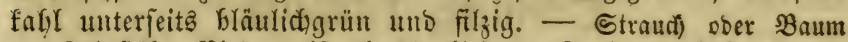

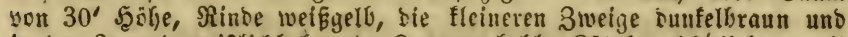

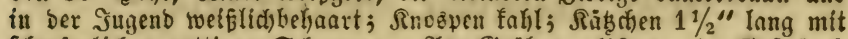

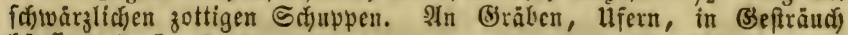
háufig. 4. 5. 方

1326. S. aurita. Dhr we ibe. Blätter serfefrteirunb,

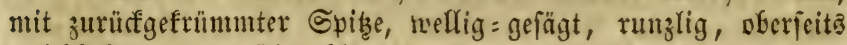

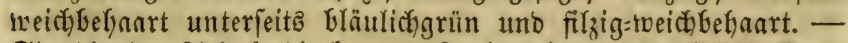

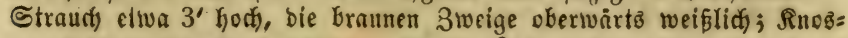

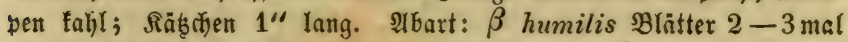

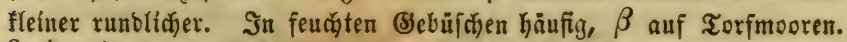
3. 4 . $\hbar$

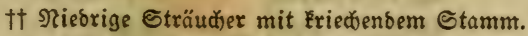

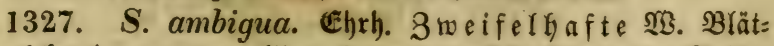
ter berfefrteirumo ober elliptifa, mit zurüfofefrummter Spibe, ganzranbig ober entfernt=gezäfnelt, unterfeits rüzlig=nbrig 


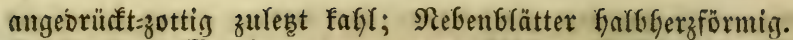

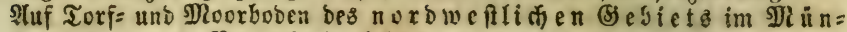

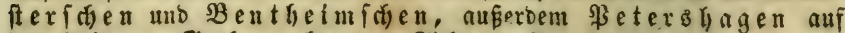
ber Saabe am Siraben neben bem Fitifentuald. 4. 5. th

1328. S. repens. Rriecf we i be. Blätter obal ober Ianzettlich ganzrandig, mit gefrümmter Spikge, unterfeita feiben= haarig oder grau; Nebenblätter lanzettlich ipib. - 2 tuf feud) = tem ๔and = und Sloorboben, aud) auf troffnen Triften, befonbers in ber (8)one gemein, auth auf bem \& b begebirg. Formen: $\alpha$ vulgaris Blätter lanzettlid); $\beta$ fusca (S. fusca. Sm.) Blätler lanzett=

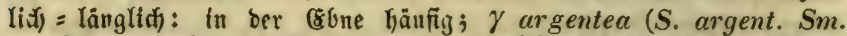
- S. arenaria. L.) BBlätter oval, unterfeitz ober belberfeitz feiben=

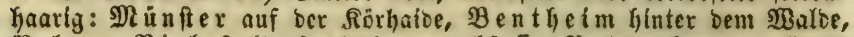

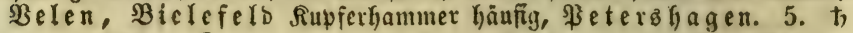

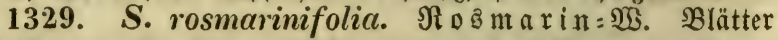
Yinealifid ober limeal = Yanzettlich, mit geraber Spibe (jonjt wie borige). - Stuf feucfitem Torfboben felten: $\Re$ efflinghaufen im

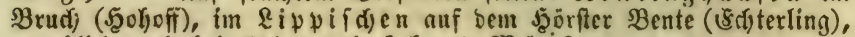

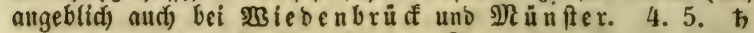

+ 1330. S. Doniana. Sim. Don'z SB. Blätter oft gegenftänoig, Yanzettliç ober verfefrteirumb=lanzettliă, mit ge= raber Spize, oberfeitz fpiegelno unterfeitz feibenfaarig, zulebt

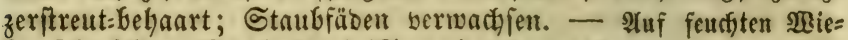
fen felyr felten: Steinfurt (Sonber). 4.5. 万)

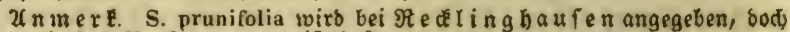

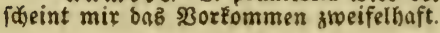

\section{Soromung Triandria.}

\section{9) Empetrum. $\Re \mathfrak{a} u \mathfrak{d}$ beere.}

1331. E. nigrum. Stengel ftrautitartig nieberliegent. - Rleiner Straud), Blume ivinfelfitinotg parputroth, Beeten fdjwarz.

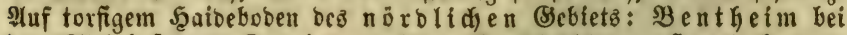

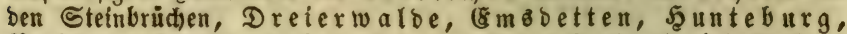

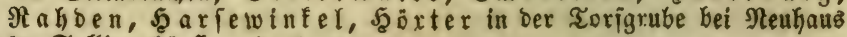
$\mathfrak{i m}$ Solling häufig. 4. 5. ถ

\section{Soronung Tetrandria.}

\section{0) Viscum. Mifter.}

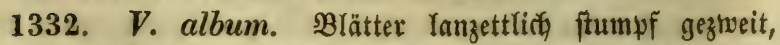
Stengel gabeläftig. - Belbgrün, Blitter Yeberartig. 2Tuf Båumen, 


\section{Tetr-, Pent-, Octandria.}

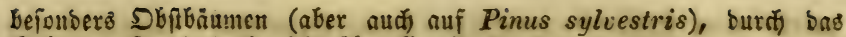
Gebiet zerftreut, bod nicht itberall. 3. 4. 万

\section{1) Myrica. (3) agel.}

1333. M. Gale. Blätter Ianzettliđa, an ber Spitze

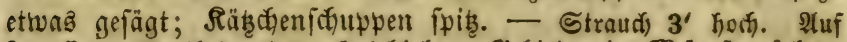

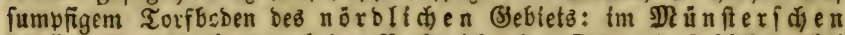

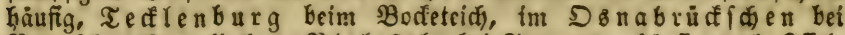

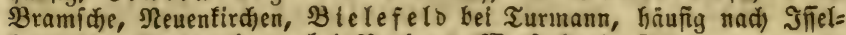

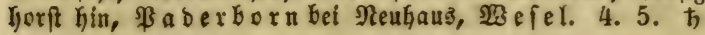

\section{Soronung Pentandria. \\ 472) Cánnabis. Şan}

1334. C. sativa. Blätter gefiebert. - Şăufig ange= baut bejonberz in Sanogegenben. $6-8$. $\odot$

\section{3) Humulus. $\mathfrak{g} \mathfrak{0 p f e n . ~}$}

1335. H. Lúpulus. Stengel fiț twindens, Brätter Yerzförmig gelnppt. - In şecfen als Sdjlingpflanze. 6. 7. 4

\section{4) Spinacia. Spinat.}

1336. Sp. oleracea. Blumen gefnäuelt Glattwinfel= ftänbig. - Formen: c: spinosa (Sp. spinosa. Mnch.) Blätter am

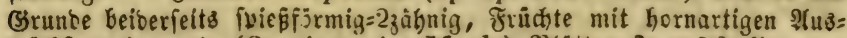
wǘdf fen; inermis (Sp. inermis. Mnch.) Blätter ftumpf =3edig coer

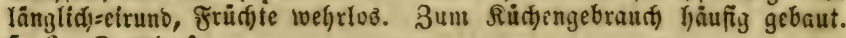
5. 6. $\odot$ unb $\hat{o}$

\section{Sronung 0ctandria.}

475̃) Pópulus. Fappel.

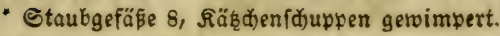

1337. P. alba. Silberpappel. Blätter herzeiförnig=

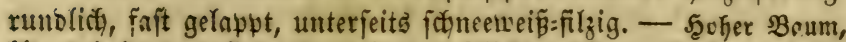

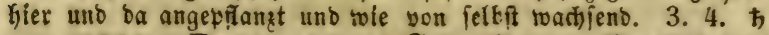

1338. P. canescens. Sm. (8) $r a$ lte $\mathfrak{P}$. Blätter unter= jeitz graufilzig. - wie vorige bod feltner. 3, 4. क 1339. P. trémula. Sitterpappel. હəspe. Blätter 


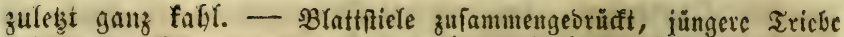
fiteifhaarig, SBlätter anfangz feibenartig=zottig (änbert auch angebrüăt wolltg ab: P. villosa. Lang.), Narben Glutroth. Mälber, Bebuifage. 3. h

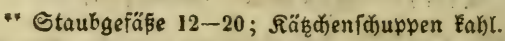

1340. P. pyramidalis. Hoz. (P. dilatata. Ait.) $\Im_{t a}=$

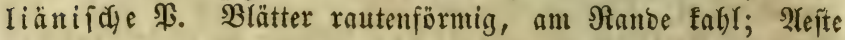

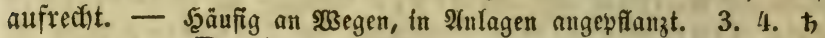

1341. P. nigra. Schwarzwappel. Blätter 3erfig:

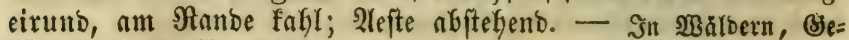
Büfdjen, an feuditen Stellen. 4. 万

1342. P. monilifera. đat. אanadifate ß. Blätter

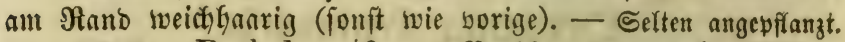

1343. P. balsamifera. Balfampappel. Bäätter

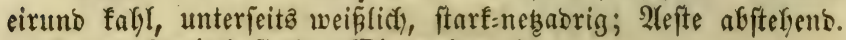
- Rnospe harzig buftent. WRle vorige. 4. 万)

\section{Soronung Enneandria.}

\section{6) Mercurialis. Bingelfiaut.}

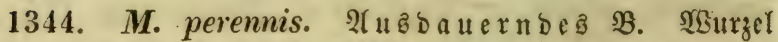

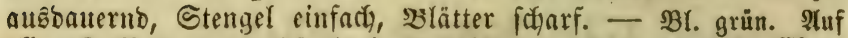

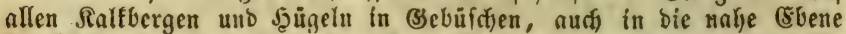

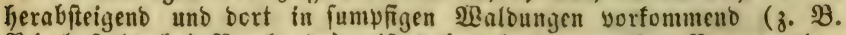
Bielefelo bei Brarfwede), ift baker in ben meifen Berggegenden băufing uno fehlt fonft ganz. 4. 5. 2

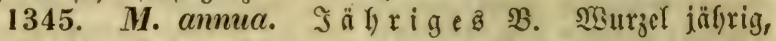
Stengel äftig, Bäätter faf)l. - $\mathfrak{B l}$. srüngelb. 2(uf bebautem $\mathfrak{B}_{\mathfrak{D}=}$

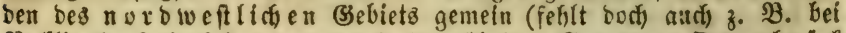

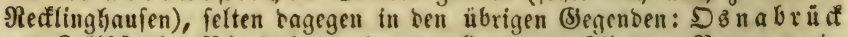
am Ralfguget, Rinteln unter Der Rubbener Rlippe, \$yrmunt, Föxter vor bem Rorveier Thor auf ben Rämpen, femgo bor Dem

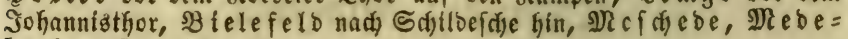

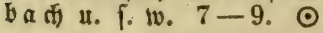

\section{7) Hydrócharis. Frofd bí.}

1346. H. morsus ranae. Blätter freisิrund:nierenför:

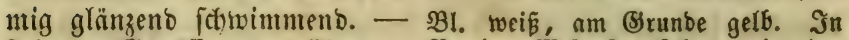

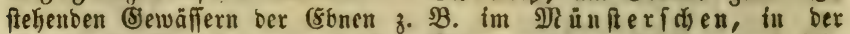

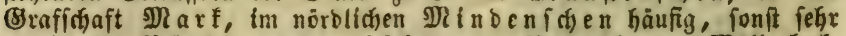

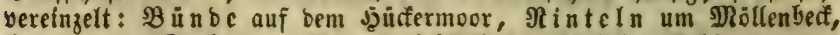
5ु oxter im Sraben von Rorvel; ferglt in ben füblidjen Bebirgen ganz. 7. 8.4 


\section{Dodecandria. - Monadelphia.}

\section{Sronung Dodecandria.}

\section{8) Stratiotes. SBafferfdect.}

1347. Str. alóides. Blätter fợwertfürmig = 3 jeitig

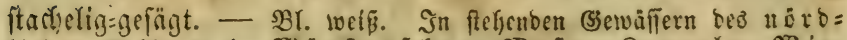

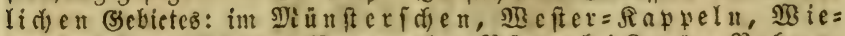

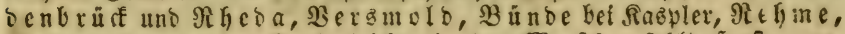

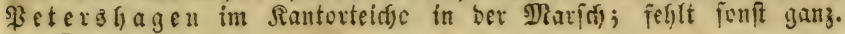
$6-8.24$.

\section{Sronung Monadelphia.}

479) Juniperus. Madid older.

1348. J. communis. (5) meiner \$․ Blättex ju 3 abjetyeito lineal = pfrientid mit fted)enter Spize. - Straud),

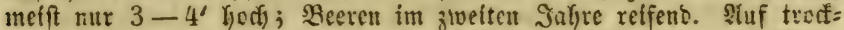

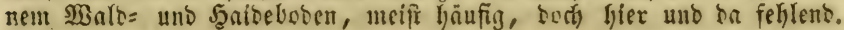
5. 6. 方

Unmert. J. Sabina, ber Sabebaum, fintet fich sureilen in Knlagen angepflangt.

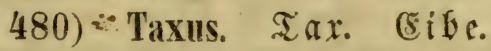

1349. T. baccata. Blätter Yinealijes ipitz, Blunten

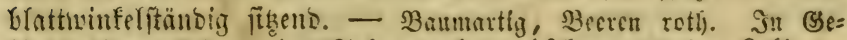

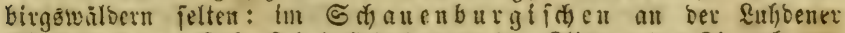

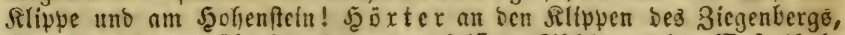

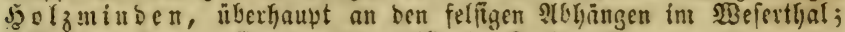
allferem sit angepflangt unb yertviloert. 3. 4. th 


\section{\&ubang.}

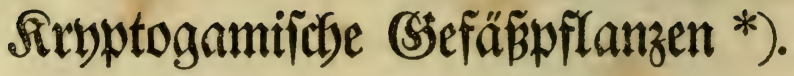

$\rightarrow$

\section{I. Ëquifetaceen. Đ尹er.}

481) Equisétum. Sdy adf telgarm.

- Frutcttragende Etengel früher, verblafit; unfruchtbare fpäter, grün.

1350. E. arvense. (5) emeiner 5 (h). Frudittragende Stengel ftrohfarbig aftlos, nit entfernten walzlichen aufgebla: fenen trodenfäutigen Gdyeiden; unfrudutbare Gtengel etwas raub, mit 4fantigen 2 (eften. - Sommt yor mit äftigem Som= merifengel, ber mit einer Fruditähre enoigt: $E$. campestre. Schultz

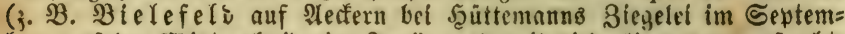

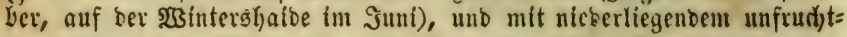
baren Ǵtengel ( $\boldsymbol{E}$. arvense $\gamma$ decumbens. Meyer); änbert außer= bem ab: $\beta$ nemorosum (E. nemor. Braun. - E. pratense. Rth.)

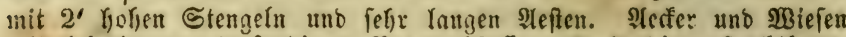
mit lefynigem und fanbigem 30 ben häufig. 3. 4. Sie unfrudjtbaten Stentiel im Gommer. 4

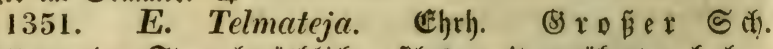
Fruchttragenoer Stengel rötblict, nftloz, mit genäberten bect)er= förmigen tiefgefdrlizten Sd)eiben; unfrudftb. Stengel bielfad): quirligäfitig, 2lefte zu $30-40$, 3ecfig, enblidy herablyangend. -

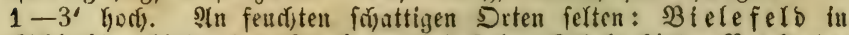

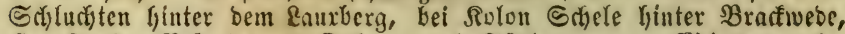

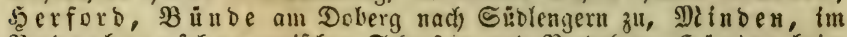

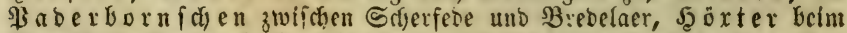
Braunfohlentergwerf, $\mathfrak{S}$ ohlenburg bei Stabtolbendorf, in ber naljen Rgeinurovinz an ber Däffel. 4. 5. 4

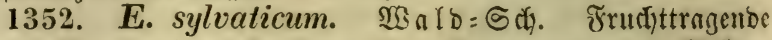
Stengel äftig, mit vielen boppelt=geäftelten 4fantigen 2leften,

*) Lebar bie Framilien und Battungen vergl. bie nadjfolgende Ueberfidit. 


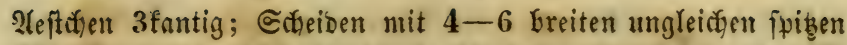
3äfnner. - 1-2' hodf; bie frudjttr. Stengel mit ben unfrudjtb. gleitryzeitig, fterben aber im Sonmer ab, während Irştre bis zum

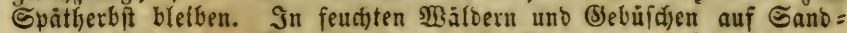

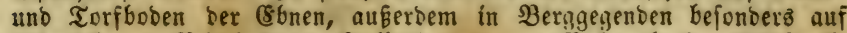
Eefmäfern: Bielefeld Mellentotten, am Bohnenbad, Gübbract,

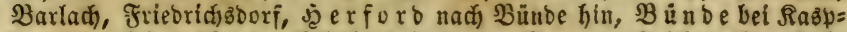
ler, im Rippliden bef Siboeien, am Donoper Teidh, Brafel,

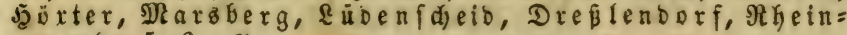
gegent. 5. 6.24

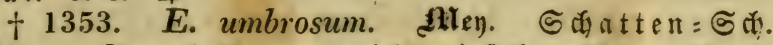

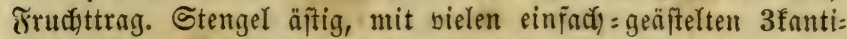
gen 2(eften; Gdyeiben follafi, mit 10-12 yfriemlidyen, ant

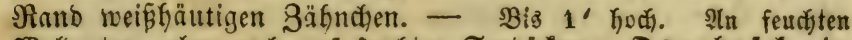

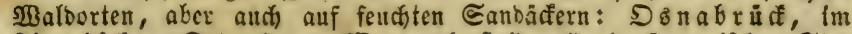

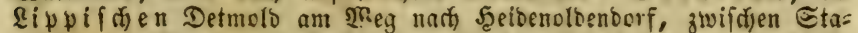

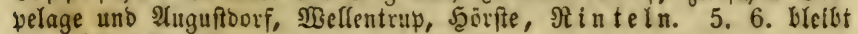
gew. biล 11. grün. 4

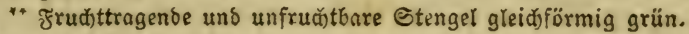
+ zehren ftumpf.

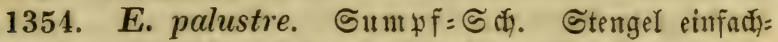

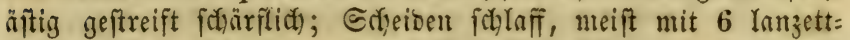

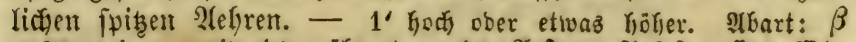

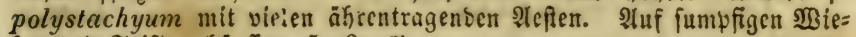
fen unb Triften häufiu. 5. 6. 4

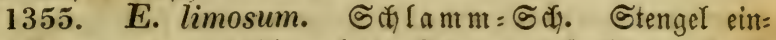
fach), felten etwos quirläftig, glatt; Scheioen aufreclyt, meift mit

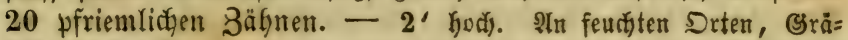
ben. 5. 6. 4

\section{tt 2lebre zugerpişt.}

1356. E. hyemale. $\mathfrak{S}$ inter $=$ Sd). Stengef meift cinfautf, 14-20rippig; Gdueiben flad)rippig. - 1-4' hod),

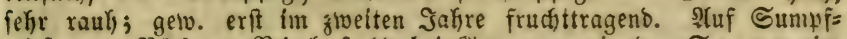
wiefell, an Bădsen: B ielefelo bei Turmann, in ber Senne, im

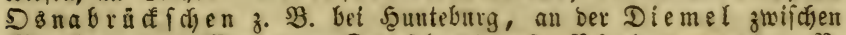
Mlarsberg umo Marburg, Dréstendorf, Rhefngegeno z. BB. Reanbershogle bel Nettman. 7. 8. 4

\section{Marjitleaceen. \$3?}

\section{2) Pilularia. Fillenfr aut.}

1357. P. globulifera. Blätter grasaartig borittia

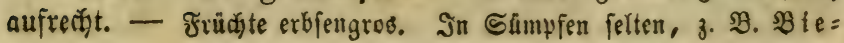


I f felo in fleinen (Bemäfiern ber ๔enne um Bartad), nuf ber Finfens

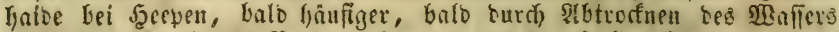

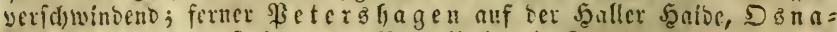

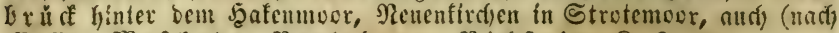

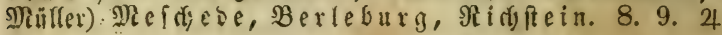

\section{Rycopobiaceen. 㖶re. \\ 483) Lycopodium. B̉ärlapp.}

* Früd)te einzeln in den $B$ tattroinkeln.

1358. L. Selágo. Tannen=B. Stengel aufredyt äftig, Blättex 8 zeilin abftebent = bad)ziegelig Yinenl= lanzettlict) zugefpitzt raul\%. - Gtwa 6" hody. Stuf fetter 5olzerbe uno auf Turfboden: Bierefeld Steingrube, Dlletiffen, Eumberg, Bract= weoer Berge, Dornberg, bet Turmann unto weiterfin in ber Senne bei Thiberman liẹufig, Sfterfappelu, gerlofin am Freuben= berg, 28 up perthal, (\$bbegebirg auf o. Nurblelle, SBaterberg

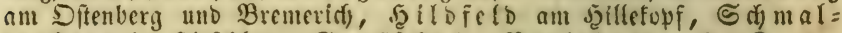

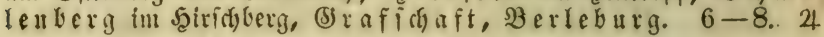

** Früchte in gixfelftänbigen käh(t)enartigen 2tehren.

$\dagger$ Xehren fizzens, pinzeln.

1359. L. annótinum. Sproffender $\mathfrak{B}$. Stengel

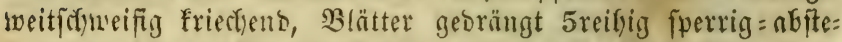

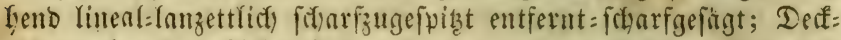
Glätter (an Den 2(efren) herzeirumb. - In Berglualbungen: int

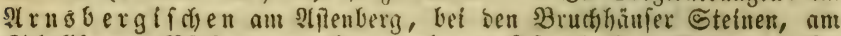

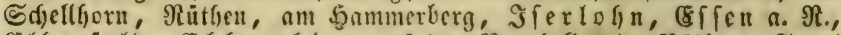
Elberfelo, Ebbegebirg auf ber 9lorohelle, fur Räther, Teu= toburgerwald un Derlinghaufin, Bielefelo an Der Stcingrube

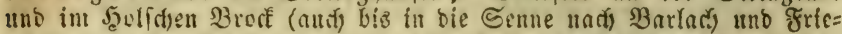

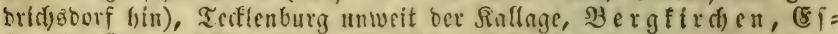

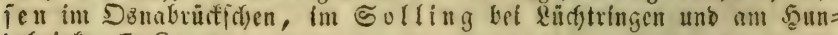
bebrinf. 7. 8. 4

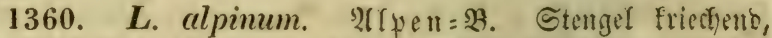
Slepte Güflyelig gabelig=getfeift; Blätter 4 reifig angeorüct

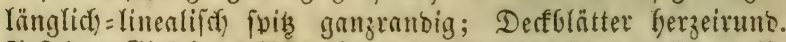

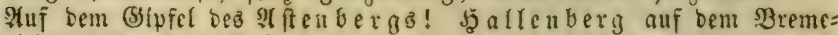

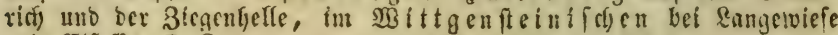
uno sliofi. 7.8. 4

1361. L. inundatum. Sumpf $=\mathfrak{B}$. Stengel furz wurzelno; Blätter 5reifig lineal=pfriemlids fperrig: nbftebeno

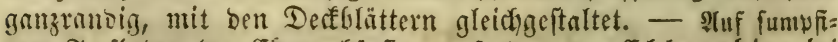

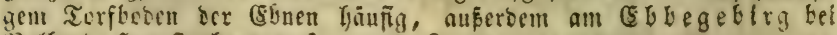
ỉnlbert, Sgengftenberg น. F. 10. 7. 8. 24 


\section{Rycopodiacen. - Farmfrăuter.}

\section{it Uergren geftielt.}

1362. L. clavatum. Reulenförmiger $\mathfrak{B}$. Stenger friefiend weitichneifig mit furzen aufífeigenden 2feften; BBlättę

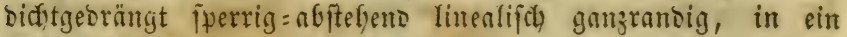
farbloles Sanar enbigent. - Etengel 2-3' lang, Alerjen zu 2.

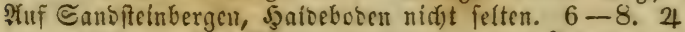

1363. L. Chamaecyparissus. B̧ran. (L. complanatum. Autt.) Bipteffenurtiger $\mathfrak{B}$. Stengel nus frie: đentoer $\mathfrak{B} a$ its in mebrere aufredyte gleidhtofe zujammentgebrürfte Ilefte getbeilt; Blätter gleidhgeftaltet idfupwenförmig berathlau= fento itarr ppis, am Ctengel meift 8:, an Dent Neften 4reifig.

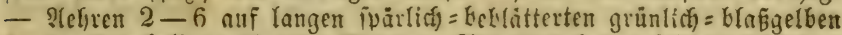

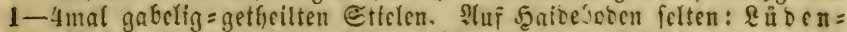

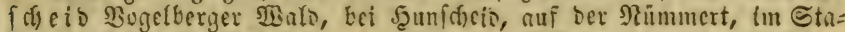
berg, Sierlokn bei fethmate, im narjen PRgeingebirge bef Soliu=

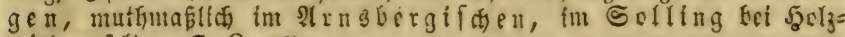
minben feltert. 7. 8. 24

1361. L. complanatum. FIadier $\mathfrak{B}$. 2lefte 2 fannei=

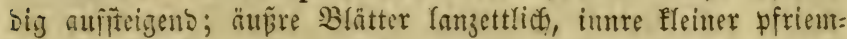
lid (jonft wie bor.). - In (jebirgabaltern felten: Bielefero

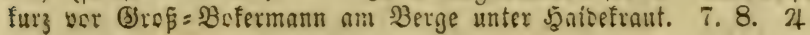

\section{FaนnEิäuter. filics.}

\section{4) Grammitis. Siw. $\mathfrak{B}$ olf $\tilde{f} \mathfrak{r} \pi$.}

1365. Gr. Ceterach. Sw. (Asplenium Cet. L.) Whebel (\&nub) ranzettlich ftumpf fieberipaltig, Fiesern genñfert,

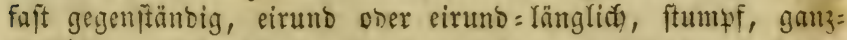

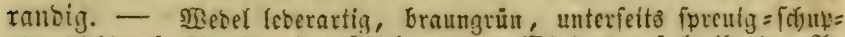

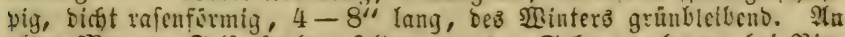

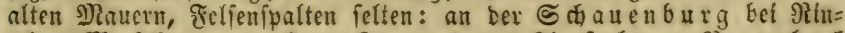

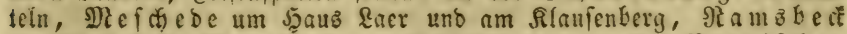

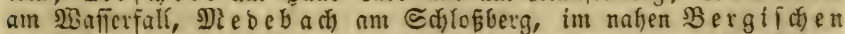

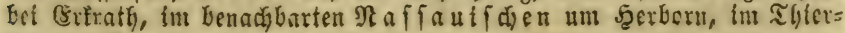
garter. $6-10.24$

\section{8วั) Polypodium. Tưpfelfarn.}

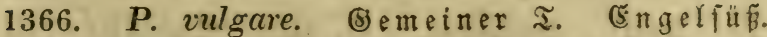

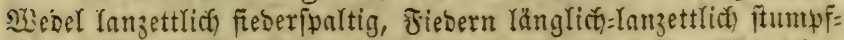

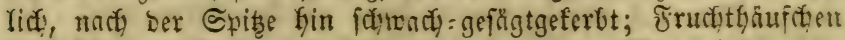

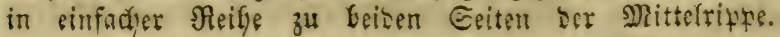




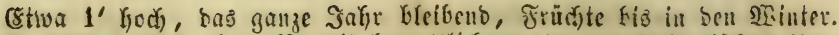

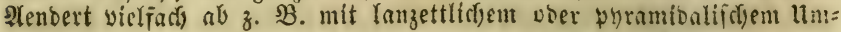
fang bes গ্রencla, befonbers bemerfensimertf fino: $\beta$ auriculatum

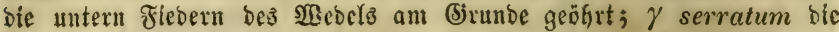

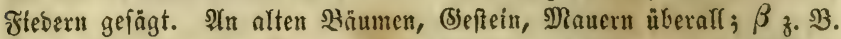
sielefeld an alten BBammurzeln bes Ummelnbergez, $\gamma$ bafelbft an

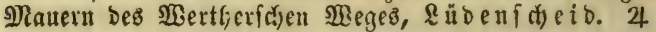

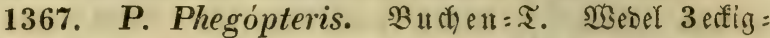
cirunb, faft pfeilförmig, langzugefwibt, weichbefart, gefiebert mit fieberipaltigen Fiebern; Frudithäufdyen faft ranbftänbig. Bis 1' hodi), zart, mattgrün; bie untern Jiebern herabgebegen; bie

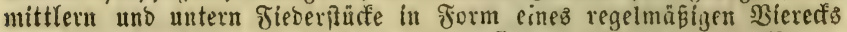
zufammengewadf fen. Sn feudyten uno mofïgen \&aubwälbern bor Serge, aber auds auf Torfboben: im 23 ittgenftefr fiden und at $x$ ng ber=

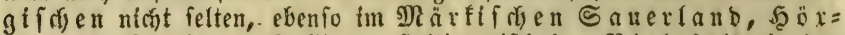

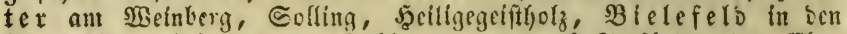

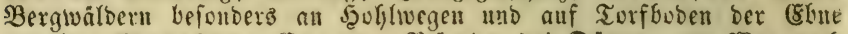

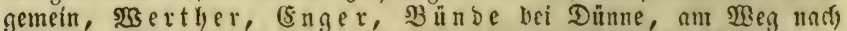

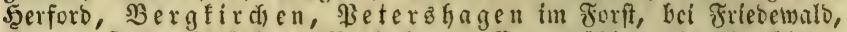

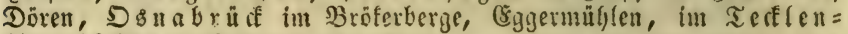
buxgifden it. f. to. 6. 7. 4

1368. P. Dryópteris. (Eict) en = T. Seber faft bel=

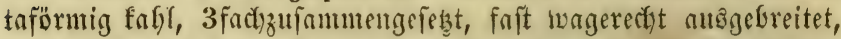
Fieberchen länglich, ftumpf, ganjranbig ober fidunadgeferbt; Fruchtbäufochen ranbitänoig, ftïtz gefondert. - Stengel biz 1'

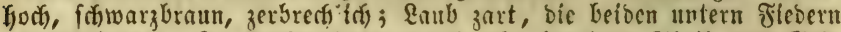

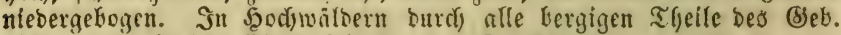
nidjt felten, in ben Ebonen feltmer. $6-8.4$

1369. P. Robertianum. foffin. (P. calcareum. Siv.)

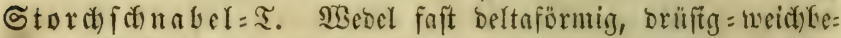
Gaart, 3 factzuifanmengepest, mit ben Fiebern aufrecht; Fru(t)t:

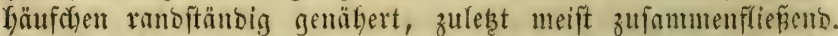

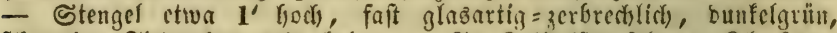
fdutupig; Ficoercten wie bet vor. Aln Sinffelien felten: Silufen=

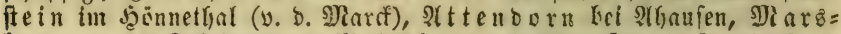
berg an ber Felafuppe bes̉ $\mathfrak{B}$ ulfenbergz mit Marchantia hemisphae-

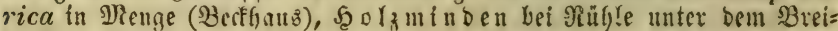
tenftein (Dauber umo Sryaumann). 6-8. 4

$\mathfrak{Z n m e x t .}$ Woodsia hyperborea. Koch. $\beta$ ilvensis foll im beractear: ten $\Re$ ieberheffen vorkommen.

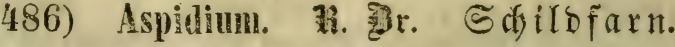

1370. A. aculeatum. Sim. (Polypodium acul. L.) Stachliger Sol. SWebel länglich =Inuzettlich boppeltgefictert, 


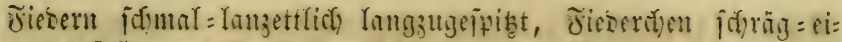
rutb, faft monoförmig, ungleid = sorniggezäfunt. $-1-3^{\prime}$ lang,

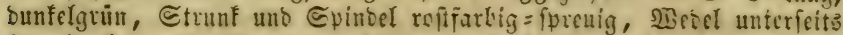
fireulg = Eefhant. Fermen: a vulgare (A. lobatum. Swo.) Fiescrdyen

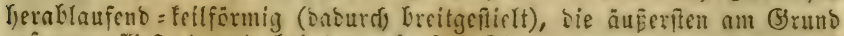

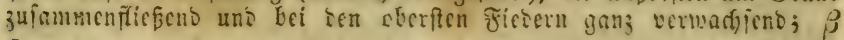

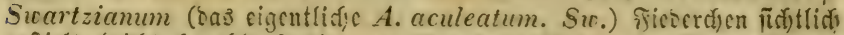

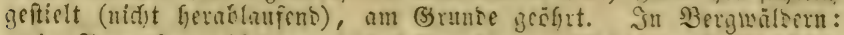

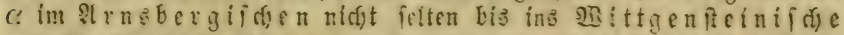

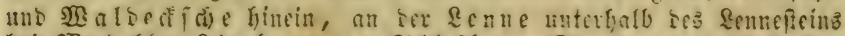

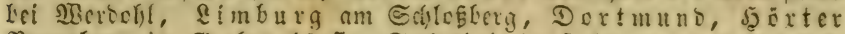

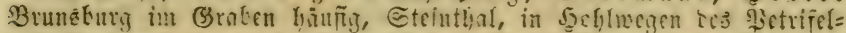

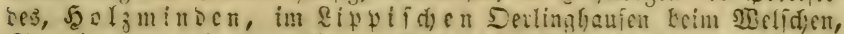

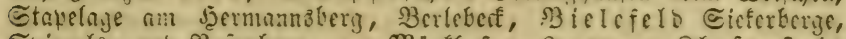

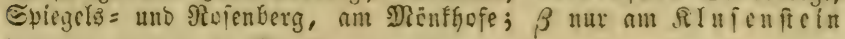

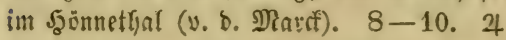

\section{7) Polystichum. Mitb. '̧iunftraxn.}

* 2roser gefiebert, bie Fiebern fieberfpaltig.

$\dagger$ Fieberlapwen ganzranbig ober etwas aubgeidweift.

1371. P. Thelypteris. 3ith. (Polypodium Thel. L.)

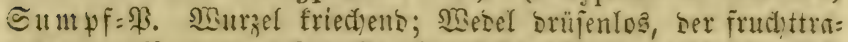

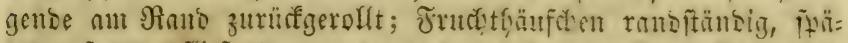

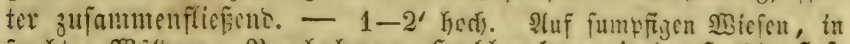

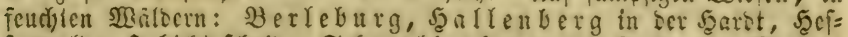

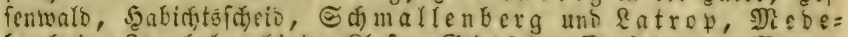

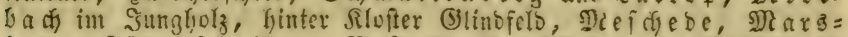

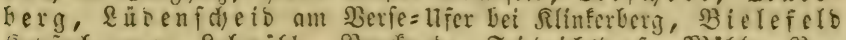

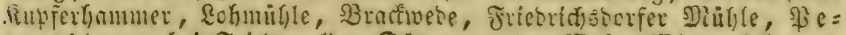

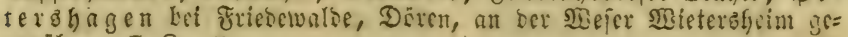
ถูenú์er. 7.8. 4

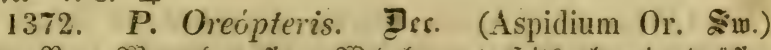

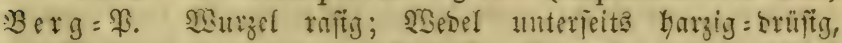

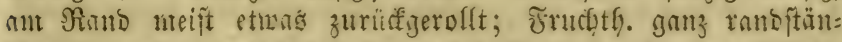

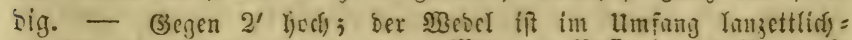

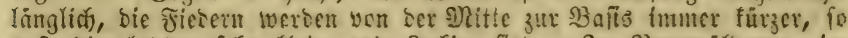

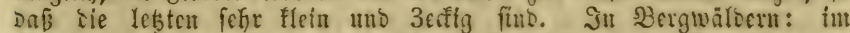

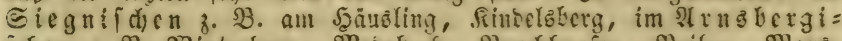

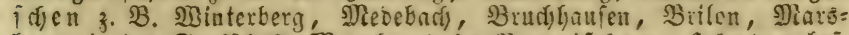

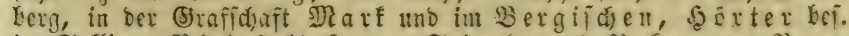
in Eolling, Bielefelo Enur=, Eplicgeis = uno Boffermanns B3arac,

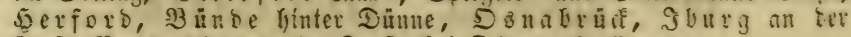
Jiefe, Peterbhagen im Jurff, bei Doren. 7. 8. 4

\section{扩 Ficdertappen fieberipaltig.}

1373. P. Filix mas. Path. (Polypodium Til. mas. L.) 


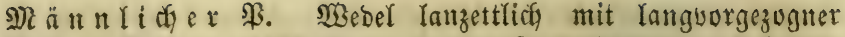

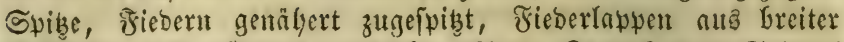
Baftz Yüuglich, ftumpf, geferbt=gefägt; Strunf umo Spintel fprenblättrig. - 2-3' bock; änbert ab mit entfernteren Fiebern, Yängern fieberîualtig = gelappten Fieberdien, bercn Rappen gezälinelt fino

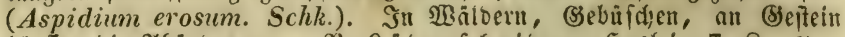

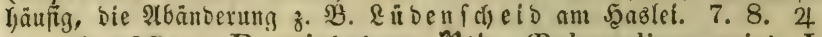

+ 1374. P. cristatum. Pth. (Polypodium crist. L.) Rammförmiger T. MBebel verlängert=Inuzettlid), Fiebern cirundolnzettlidy ftuntpf entfernt, Fieberlappen eirunblidy, gegent

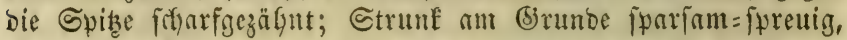

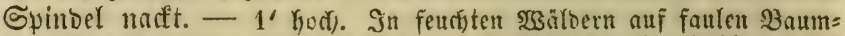

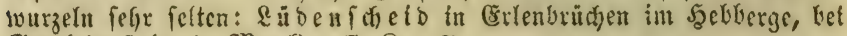

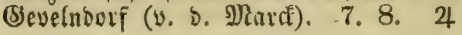

** Tredel duppeltgefiedert.

1375. P. spinulosum. $\mathbb{2} \mathfrak{e r}$. (Aspidium spin. Sw.)

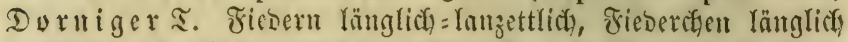

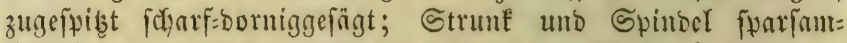

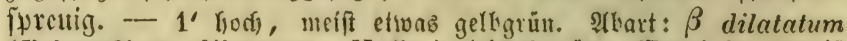
(Polypodium dilatatum. Hoffm.) Tethaftarüu, SBecoel im llutrí

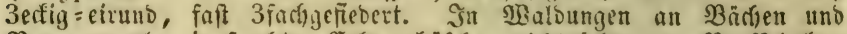

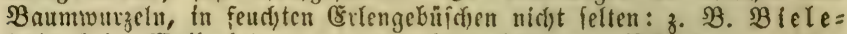

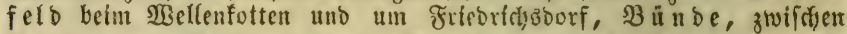

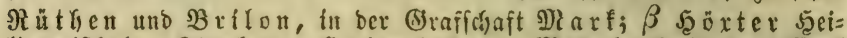

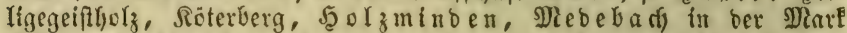

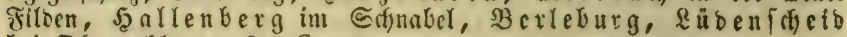
bet Dberivefberg. $6-8.24$

\section{8) Cystópteris. Sernb. Blafeñarn.}

1376. C. fragilis. (Perrib. (Polypodium fragile. L.)

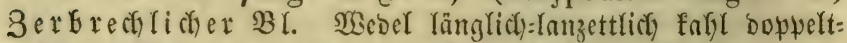
geffebert, Ficbercten eiruno ftuntpf eingefduitten, Bipfel geferbt= gezäfnt, ant (brumbe feifförmig=berfd)mälert; Spindel geflïgelt

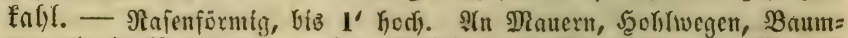

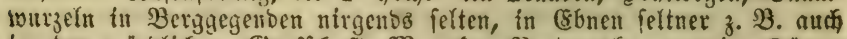

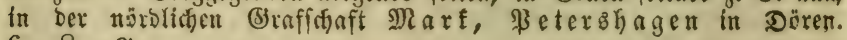
$6-8,24$

\section{9) Asplenium. Streifenfarn.}

* Trebel einfadigefiebart.

1377. A. Trichómanes. $B \mathfrak{r} a$ un er Str. Struñ glân= jento:fafwarzbraun fornartig; Fiebern abwechjelno rumblich ge: 


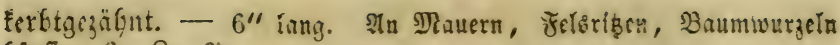
f)åufig. $6-8.4$

** Tssebel 2-3fandigefiebert.

1378. A. Filix femina. Sernh). (Polypodium Filix

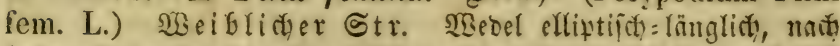

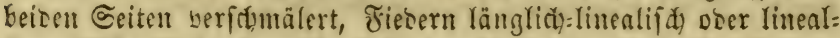

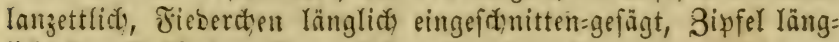
(iid) $2-3$ zägnig; Epinoel fparam: fprentg. $-1-2^{\prime}$ hod.

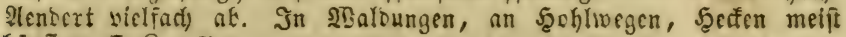

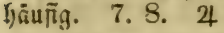

1379. A. Breynii. 角t3. (A. germanicum. Weiss.)

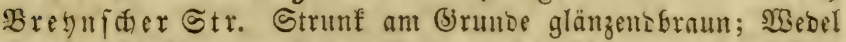

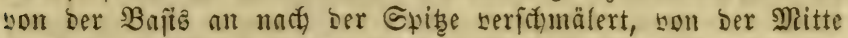
an bis zur ভpize einfactgefiebert; Fiebern wedtjelftänbig ent= fernt nufred)t Eeifförnig, an ber Spiţe eingefdunitten = gezäfynt,

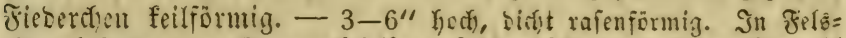

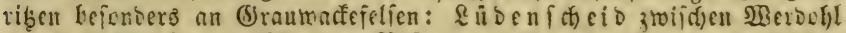

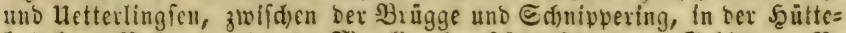

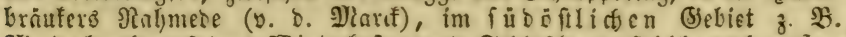

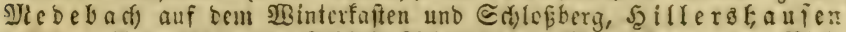

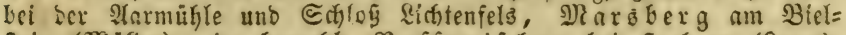
fleit (Diúfler), im benadjb. Raffaulfọen bei Şerborn (Eeerā). 7. 8.2

1380. A. Ruta muraria. (5) emeiner ๔t. Dianer= raute. Ctrunf grün; SBebel 3effig=cirund 2-3fadigeficbert,

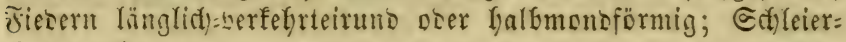
chen gewwimpert. - 2-6" lang, rafenförmía, immer grün, im $\mathfrak{u m}=$

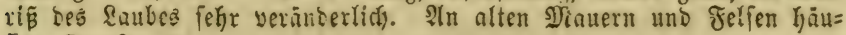
fig. $7-9.24$

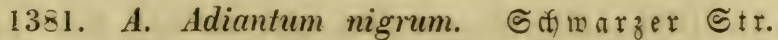

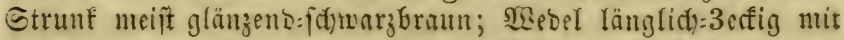
langborgezogner Spise, boppelt= uno faif 3 fachgefiebert, Fiebern

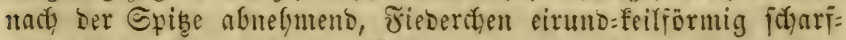

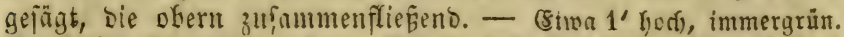

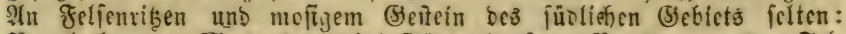
Berlebirg, Dlezebath bei Dübinghaulen, Briten an ben Fel=

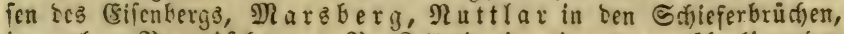

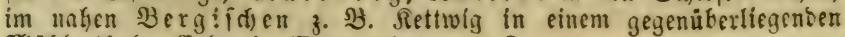
Miäflentfale, Erfrat), פsuppertfa!. 7. 8. 4

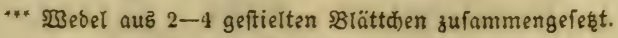

1382. A. septentrionale. Sw. (Acrostichum sept. L.) Nörolidier Str. Strunf faum abgejonbert, glatt, faben= 


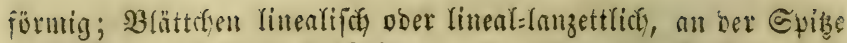

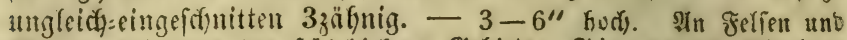
Dhanern befonders bes fübliden bebiets: Siegen an Stegberin

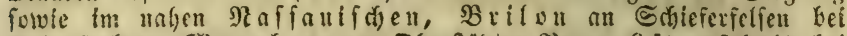

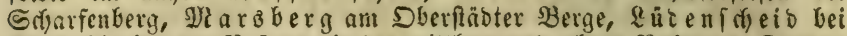

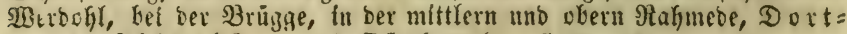
mu

\section{0) Scolopendrium. Sw. Şixfdyunge.}

1383. Sc. officinarum. Siv. (Asplenium Scolop. L.)

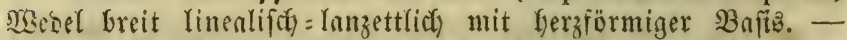
$1^{\prime}$ lang. Fta fdyattigem Felzgeftehn, in alten Brunnen: Siegen in.

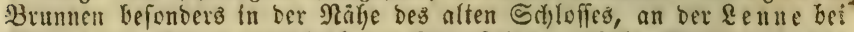

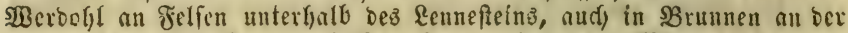

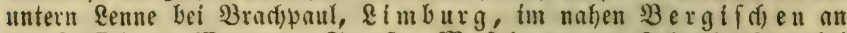
Der Duifiel uno Toupper, Soeft, Mefdre be am Sdjweigeritege bei

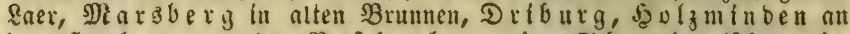

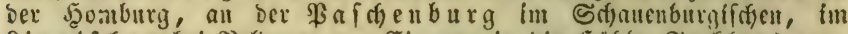

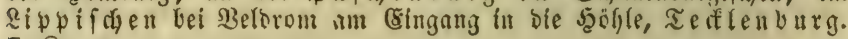
7. 8,2

\section{1) Pteris. Saumifarn.}

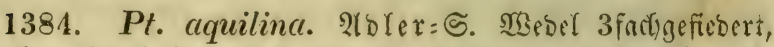
Frieberchen lineal = lanzettlich ftumpf ganzrandig = ungerollt, bie

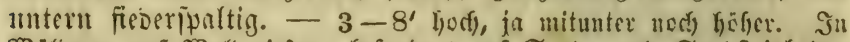

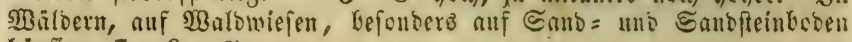

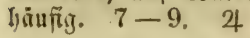

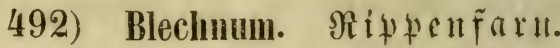

1385. Bl. Spicant. Mith). (Bl. boreale. Sw. - Os-

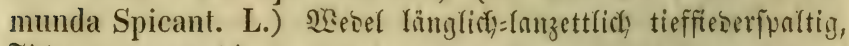

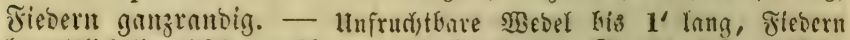

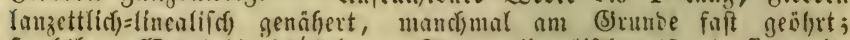

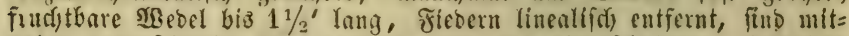

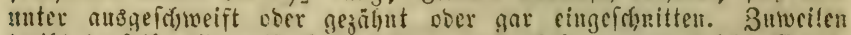

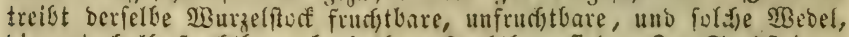
bic untergalb frucsitbar vbergalb unfruchtbar finb. In Sanbieinge= birgen und auf Torfboben gemein, ferilt 3 . B. auf Eefmboben. $7-9.24$

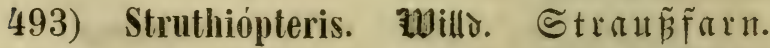

1386. Str. germanica. Willo. (Osmunda Struth. L.)

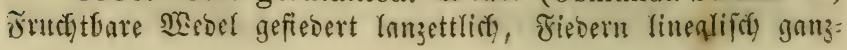


rmobig, fait walzlid; unfrudytbare Mecber soppeltfieberipartig,

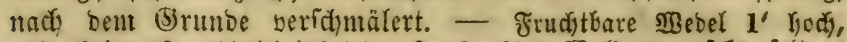

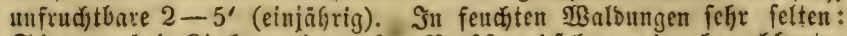
Siegen bei Rirdjen, im naijen $\Re$ affa uif

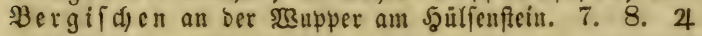

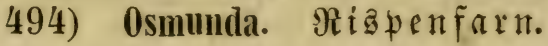

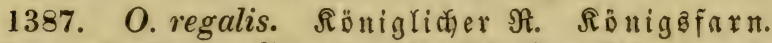

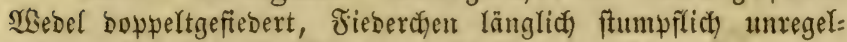

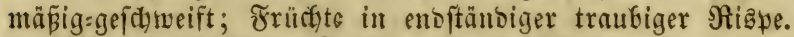

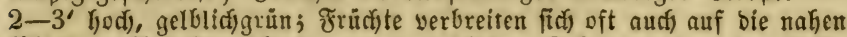

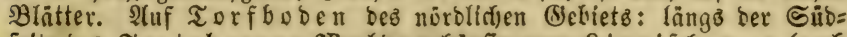

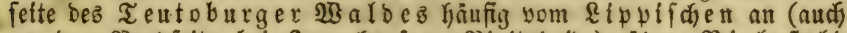

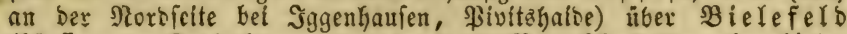
(häuffi you Rupferfanmmer an burdi bie Baueridjaft 1 mmeln, Ginter

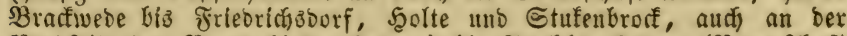
Rurbfeite Der Berge hinter 5eeten) bi

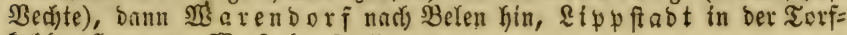

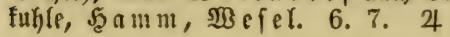

- 493̈) Botrychium. Sw. Mondrate.

1388. B. Luncria. Sw. (Osmunda Lun. L.) (5) e =

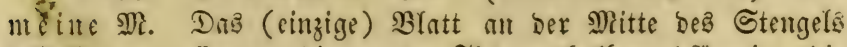

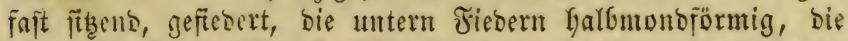
ofern feilfürmig fatwatigefofweift ober geferbt. - 3-9" rods;

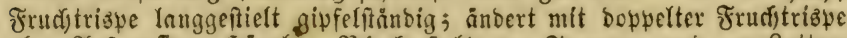

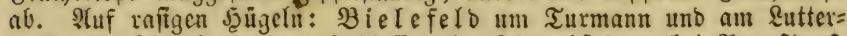

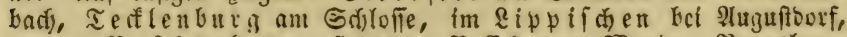

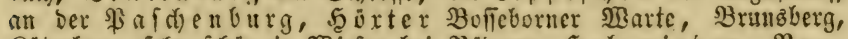

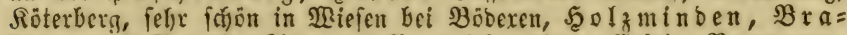

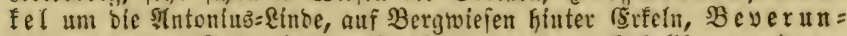
gen auf bem Balgenverg, Brilon auf bem Sdjellfiorn und am

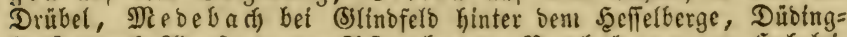

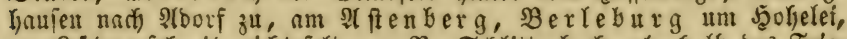

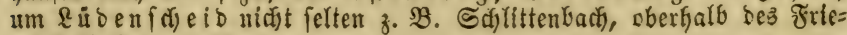
Dridjstlyales. 6. 7.4

1389. B. matricariaefolium. हf?

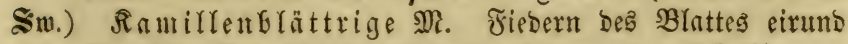
ober Yänglich, fieberipaltig = gelappt, Rappen $2-3$ ferbig. SBie yorige auf troffnen Triften fehr ferten: im stpuifolen ant

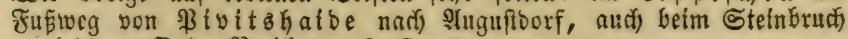
all lekgtrem Drte, Brifon. 6. 7. 4

\section{6) 0phioglossum. Natterzunge.}

1390. O. vulgatum. Dnsి (eimzige) Blatt ftengełumt= 


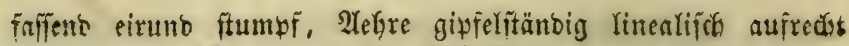

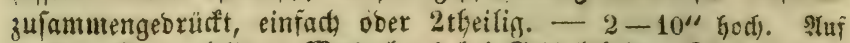

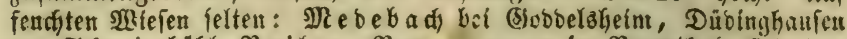

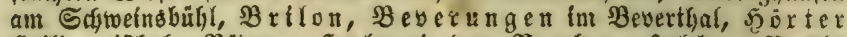

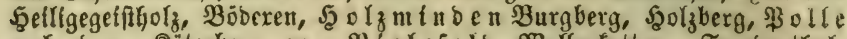
nach bem Röterberg $z^{u}, B^{2}$ ele fe lo Bollentotten, Freubenthat,

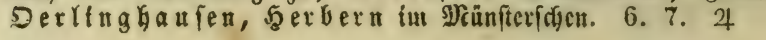




\section{Meberfidd}

ser

in Şebiet vorkonmenben Gatumgent

- naty bem

maturlichea syfteme.

$\rightarrow \rightarrow+x+\infty$ 



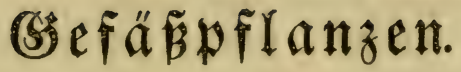

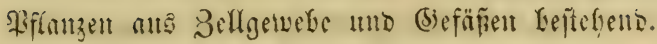

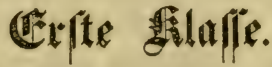

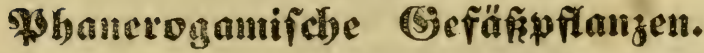

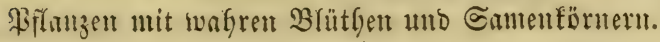

\section{Errite Satwotatheilung.}

\section{Jingfaferige phanerogami/d)e Gefäßzpflamzen:}

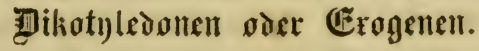

(5)

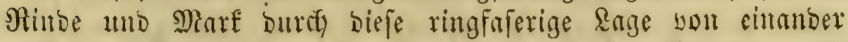

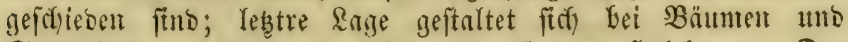

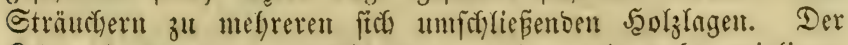
Reim ift mit zwei gegenftänbigen, felten mit melyx quirligge: fteflten Reinblättern verfeben.

\section{sirite unternbtheilung.}

Blütf̧en Lollitänbig vielblättrig unterftändig.

A. Z̈rucftenoten zafilreich, gefonbert, bie eimzelnen griffeltra=

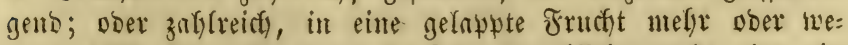
mger berwachfen, bie einzelnen Rappen griffeltragento; Doer ein einzelner Jrutfftnoten mit einem einzigen feitenftünbigen Gn= menträger.

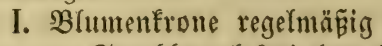

a. Stanbbeutel frei (ant (5rambe nidft berwarffen), Stanb= gefäß̆e unterweibig 
1. 33erberibecn Ment. Ctaubfentel mit 2 Rlat: tent auffipringent.

Relcs 6 Grättrig; Rronbr. 6, nut Brontme 2 oritĩtg, Berte 2-3 famig: Berberis 178.

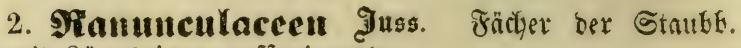

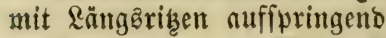

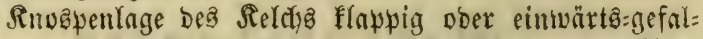

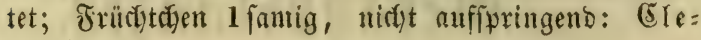
matioeen

Seld fronartig, Rrome 0: Clematis 275.

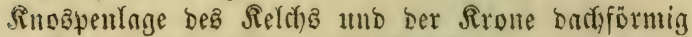

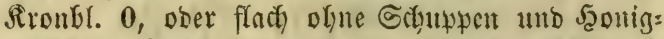

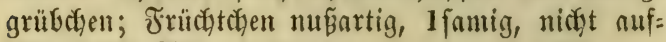
fpringent: 2 tnemoneen

Seldi) fromartig, Rrone 0

ofne Sälle unter ber Blume: Thalictrum 276.

mit 3 blättriger Glattartiger Jaürle unter ber Blume: Anemone 274.

Selda 56lättrig, แmutittelbar unter ber 5= Dber mebrblättrigen Rrone: Adonis 277.

Sronbl. an (5runbe mit eirem fifuppigen ober

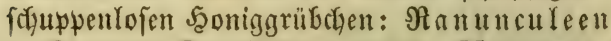

Nagel ber Rronfl. Inug fäblict): Myosurus $17 \%$. Nagel ber Rronbl. furz: Ranunculus 278.

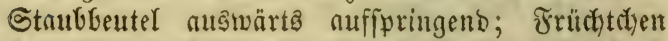
fapfelig, einwärts aufipringend, ntefriamig: $\mathfrak{S}_{\mathrm{e}} \mathrm{l}=$ reboreen

Blüthe regelmäbig

Reldy fronartig, Srone 0: Caltha 273.

Sroute borbanben

Platte ber Rronbl. Yineal, Joniggrube fochup. penไos: Trollius 272.

Blatte ber Rronbl. röbrig

Relda abfällig: Eranthis 270.

Relch Gleibeno; Helleborus 271.

Platte Der Sironbl. 2 fpaltig, Joniggrube bef(c)uppt: Nigella 269.

Rronbr. trichterförmig gefpornt: AquileBhüthe unregełmäpig

$$
\text { gia } 268 .
$$


ofres Retchef. gefpornt: Delphinium 266.

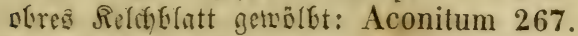

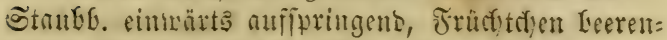
artig: Itneigentlide sinunculaceen

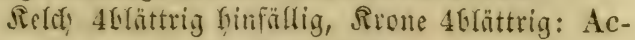
taea 260.

b. Rionbl, añ Demt 1 blättrigen Relch

3. Erambalacen Dir. Rrone nuf bem (jrunce Ies Reldis befintigt. Etmubigef. fo wiel ober boptelt jo siel als Sironblätter, nuf bem Reldi befeftigt. Jruthtf. mit unterflänoiger ๔đ̧uppe

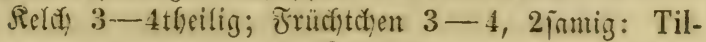
laea 59.

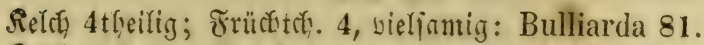
Reld 5theilig; Jrüchtd). 5, bielfamig: Sedum 232.

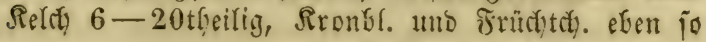
viel: Sempervivum 242.

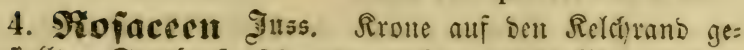
pitellt. Ctaubger. 20 uno mefir, gleidyfalls nuf beut Relchrano befeftigt

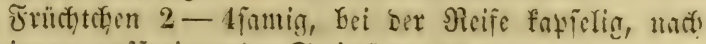
imen nufipringend: Spiräaceen

Relch 5ftrattig, Rrone 5Glättrig: Spiraea 253.

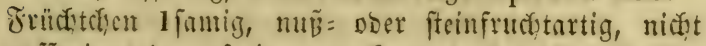

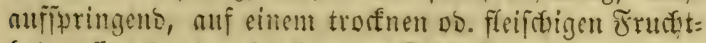

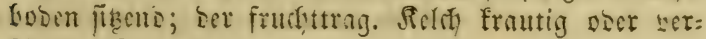
färtet: Dryabeen

Belch 5 fwaltig

Reldh unter ben Saum mit zablreidfen fonfigen

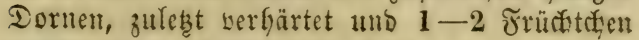
sinfochliếend: Agrimonia 240.

Relch ofune Dornen; zablreidye Eteinfrü(țte

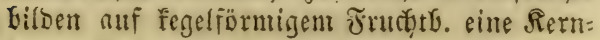
Geere: Rubus 255.

Relet) 10 ipaltig mit 2 reiffigen Bipfeln

Rüfie mit bleibendem Briffel begrannt: Geum 259.

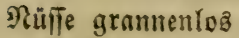

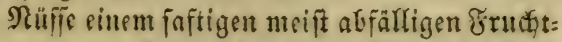
boben eingefügt: Fragaria 256. 


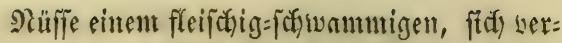
größernoen Frudytb. eingefügt: Comarum 257.

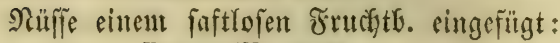
Potentilla 258.

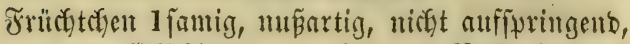
won ber fleifchigen und bei ber Beife inftigen Reldyröfre eingeidylofich: গlo feen

Reldl frugartig 5fpaltig: Rosa 254.

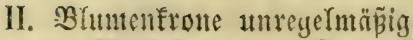

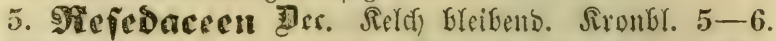

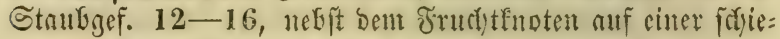
fon brifftgat Sifeibe beferfigt

Sielch 1 Glättrig 4-6treilig: Reseda 241.

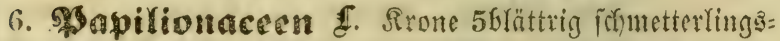
förmig. Strubg. zufmmengetwadjen, ober einer bavon frei. Fructit cine Soulffe.

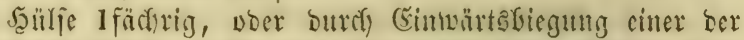

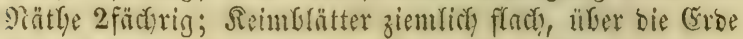
ficrsortretend: Roteen

Strubgef. alle zufammentigconadjicn

Flügel ber Srone am oferm Simbe zierlidy faltig: tunzlig: (5) eniftern

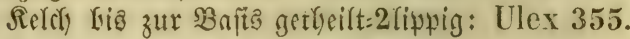

Seld) 2lippig, G(biffichent ftumpf

Griffel freisförnig = 3ufmunengeroldt, oberw. berbreitert, nach immen f(aci): Spartium (Sarothamnus) 352.

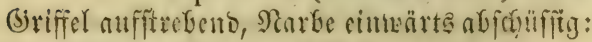
Genista 353.

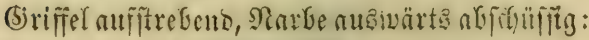
Cytisus 354.

Flügel ber Srone nidyt taltig=tumglig: Antfgyl= ribeen

Reldy 5 fpartig, bei ber Jrutritreife offen: Ononis 356.

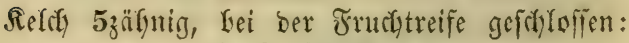
Anthyllis 357.

@trubgef. bis auf einen einzelnen zufammengetwad, fen Blätter gebreit, Sälje 1 fäslyrig: Trifolicen 


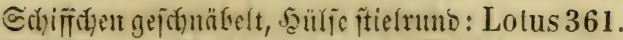

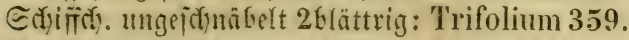

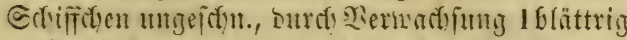

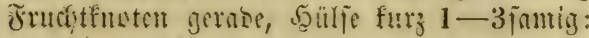
Melilotus 358.

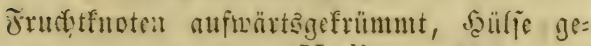
unuten: Medicago 360.

\section{Blätter gefiebert}

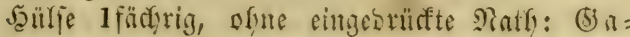
regeent

(S)riffel sorn bïrtig, wallie flutt: Robinia 363. Sät(je bur(t) bie untre cimmärtsึgebogne Nath

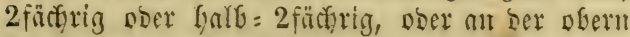
Natf eingebruint: 2 f ftragaleen

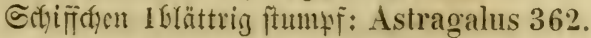

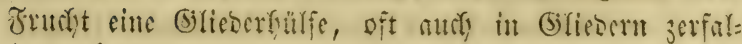
lento: sebyfareen

Blütfyen Dolbig

Sdjiffichen gefornäbelt

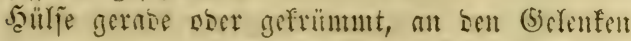
zแfammengezogen: Coronilla 373.

Şüle an ber obern Rath Guditig=auลgefoduitten unt Tnppig: Hippocrepis 371.

G(biffochen ungef(t)täbelt: Ornithopus 372.

Blittyen tratbig: (E) febs) fareen

Geilfe 1 gliebrig 1 famig berfefyrteiförmig: Onobrychis 370 .

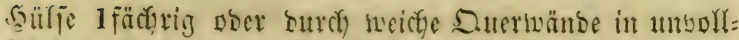
ftänbige Fächer getfeilt; Blätter unterbrodfent=gefiebert,

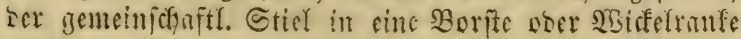
enbigend: Bicieen

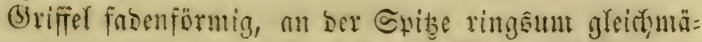
Big:befant: Ervum 369.

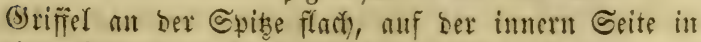
citter Rängslinie bebart

Blätter mit sูsiffelrment Lathyrus 365.

Blätter ofue SBiffefranfen: Orobus 364 .

Srifĩel 3 fantig, won Der Seite zufanmengebrüsft, an Der Słibe Gärtig: Pisum 366.

(5rifielel unter ber Sprite nuf ber äupern Ceite bärtig 
(sirifiel gernbe auffitrelseno: Vicia 368.

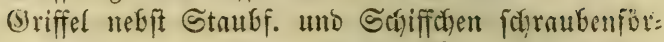
mig:gebreft: Phaseolus 367.

B. Jruckffnoten cinzeln; Samenträger 2 ober megr, ber SWand Dbet den Siffeidetwänden angetwactifen.

I. Blumenfrome regelutäßig 4 blättrig

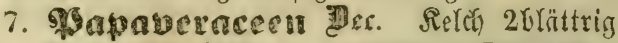

Rayfel unoflftämbig= bielfächrig: Papaver 262

Rnpiel füotenförnig 2flappig: Chelidonium 261.

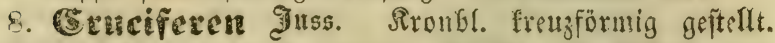
Staubr. 6, wobon 4 länger. Frucţt cine Sdyote ober cin Sdjötufen

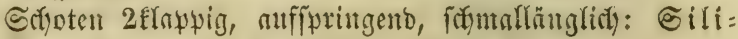
qu ofen

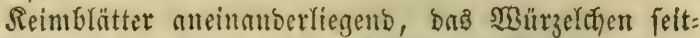
(iii) nuf ber Spalte der Reimbläter (Gamen zufam: mengebrürt): $2(r a b i$ bee

RInplen Der Siboten nersenlos doer nur ant Sirunbe mit fibtwadgen Nerben

Samen in jebent Fan Ireiging

Seimblätter flach (20urzel faferig): Cardamine 342.

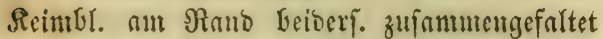
(Wirurel fleiffigig): Dentaria 337.

Eamen in jebem Frad 2reibig ober unregerntäßig gereift: Nasturtium $\mathbf{3 4 4}$.

RInpyen $1-3-5$ nervig

Samen in jebent Fach I reibig

Narben 2 ppaltig mit zurüdfgefrummen \&ay= pen: Cheiranthus 331.

Rarbe ftumbf ober ausgeranbet Solyote fait ftielrund ober 4feitig: Barbarea 333 .

SÆyote zufammengebrüft: Arabis 332.

Samen in jebent Fad 2reigig: Turritis 334.

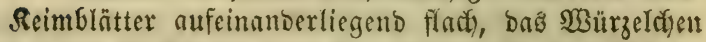

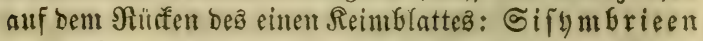

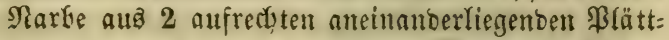
dien gefilbet: Hesperis 330 .

Narbe ftumpf ober ausigeranbet 


\section{Der Battungert.}

Rlappen ber (bierfeitigen) Sctpote 1 nerbig: Erysimum 335.

Rlappen (fonter) 3nervig: Sisymbrium 340. Reimblätt. aufeinanterliegenb, rimniggefintet ober um

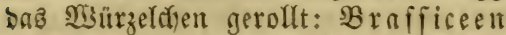

Sament in jesem sande 1 reibig futgelig

Rlappen 1 nervig: Brassica 336.

Rlappen 3-5uervig: Sinapis 341.

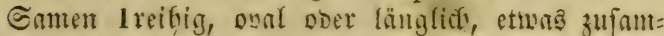
mengebrüfft: Erucastrum 339.

๔anten in jeoem fuctje 2reifig: Diplotaxis 343.

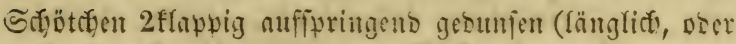
otal, ober fugelig, ooer bou sticten fer zufammenge:

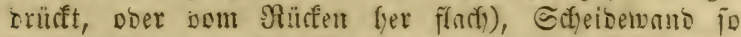

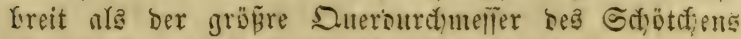
wer bod) nur etwas folmäler: Rafifepten

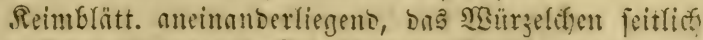

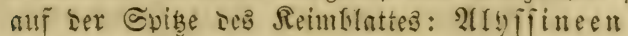

Etaubfiro. mit einem flïgeffürmigen 3afn soer

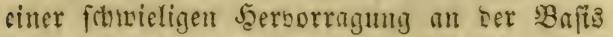

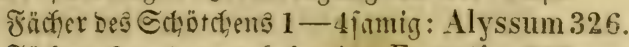
Jä̌cher 6= poer meforfomig: Farsetia 327.

Staubfäben zatulog

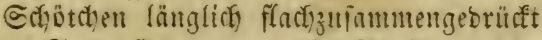

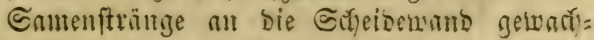
fen: Lunaria 329.

Samenftränge frei: Draba 328.

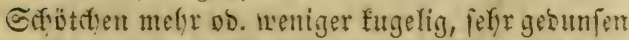
Rlapwen mit Rutenters: Cochlearia 323.

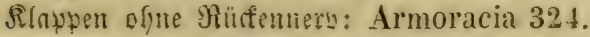

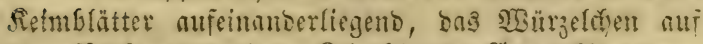
Iem Rürfen bes citten Reimblatts: Camelineen

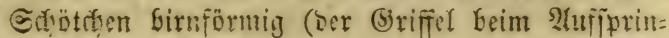
gen auf einer ber Rlappen fitgen Gleibent): Camelina 325.

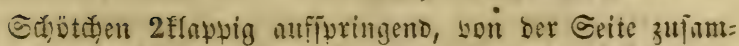
mengebrüft; Rlaptent fafnförmig, nuf bem Rürfen ge=

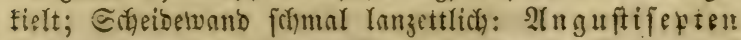

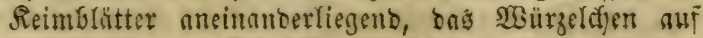
ser Epalte Def Reimblätter: Tglaspibeen 
bie längetn Stankfäben mit einem flumenblatt: äfnl. 2Unfatze: Teesdalia 319. bie Stauffübou ofne 2tujab: Thlaspi 320.

S(jötd)en Griffenförmig 2fäd)erig: Biscutella 316.

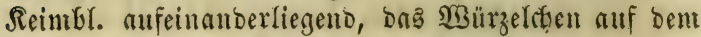

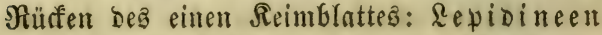

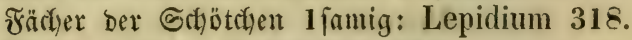

Făd)er 2 fámig: Hutchinsia 321.

Fäđther vielfantig: Capsella 322.

Reimbl. aufeinamberliegent, gegen fid) felbfit zuriuf= gefaltet: $\mathfrak{B}$ rach 4 farpeen

Sifjotchen faft 2 fnotig, Färder 1 famig: Senebiera 317.

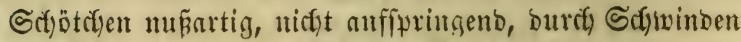
ber Gedeibewand dĩt lfächrig: Nucamentacen

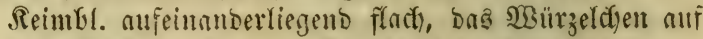

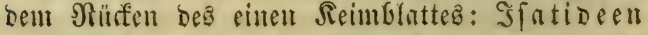

Godjötd)en son ber Geite f(act)zujammengebrilift:

Isatis 315 .

Schötçy. fugelig mit au[gefebtem (3riffel: Neslia 314. (s)lieberfülfen, fich quer in Ifamige (s)lieber tremento: \&omentaceen

G(j)oten Yinenlifd): Raphanus 338.

II. Blumenfrone regefunäßig 56 bättrig

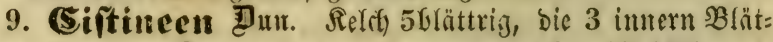

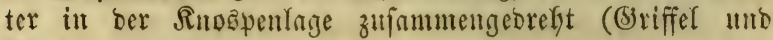
Narbe einfody)

Rapfel Ifächrig 3 flappig: Helianthemum 264.

10. Droferacecu Dre. Relch) 56 lättrig, bie Blätt=

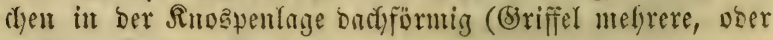
melirere ftzende Narben)

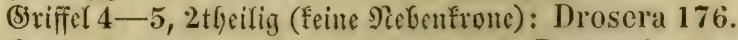

(Sriffel 0, Narben 4 fitzend (9ebenfrone): Parnassia 174.

III. $\mathfrak{B}$ (um

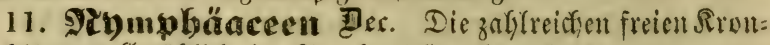
blätter aflyüblich it Strubgefäpe vibergetyem

Selut 4-5 blättrig: Nymphaea 265.

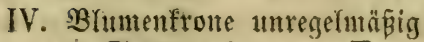

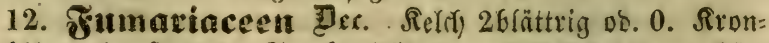

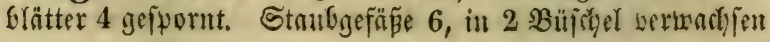


Brucht cine mefrinanige Sälife: Corydalis 349.

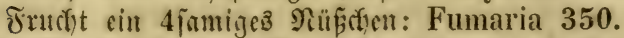

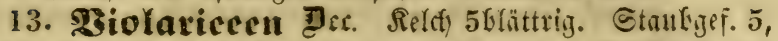
bie Ctaubb. Dem Jrudytfn. engantiegent. Sriffel 1 mit ic)räger :arbe

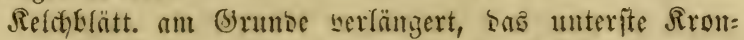
blatt geipornt: Viola 119.

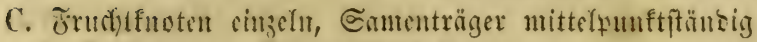

I. Selch in ber Rnoäpenlage flappig

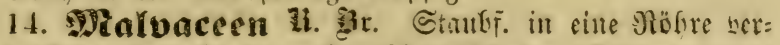

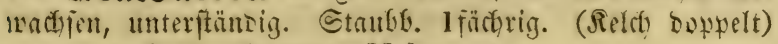
äแก๊rer Selch 3blättrig: Malva 348.

äuñer Relch 6-9 fpaltig: Althaea 347.

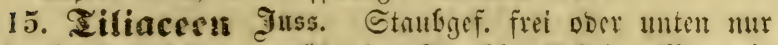

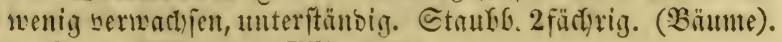

Rrone 56lïttrig: Tilia 263.

16. \$ibamuecu M. S3r. Ctrutigef. bem Sieldy aufge=

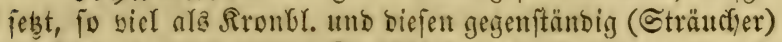
Selch 4-5 jpaltig, fironblätter 4-5, Beere 2-4= fädfrig: Rhamnus 116.

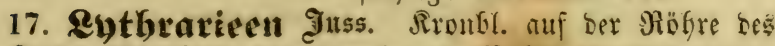
Releds, Gtrulbgef. Darunter in Der Röfre cingefügt

Seldi) röhrig waIzenförmig, bie Jaälfte ber 8-12 马üfute beş. aufrectht, bie Sărifte abfte= heno: Lythrum 239.

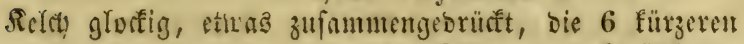
Der 12 8ügne zurüafgeid) (ngen (Staubgef. 6, Rronbl. 6, fef)r f(üchtig, oft ferf(ent): Peplis 179.

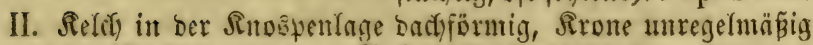

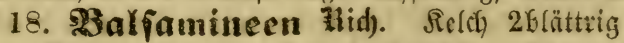

Srome gefpornt, Sapjel elaftift auscinatoerjpringent: Impatiens 118.

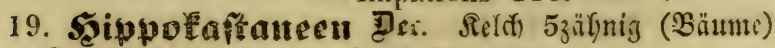
Rrontil. Ianghentrigelt: Aesculus 202.

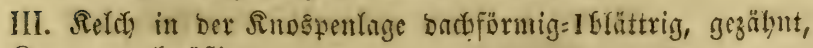
ภำ regelmäß̄ig

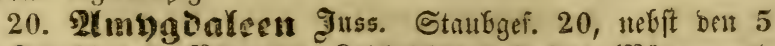

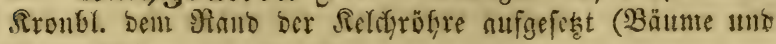
Sträu(t)er) 
Steinfrudft faftloz: Amygdalus 244.

Steinfr. faftig, Stein furchig unb löfyerig: Persica 245. Steinfr. faftig, Stein glatt ober ofme \&ad)er: Prunus 246.

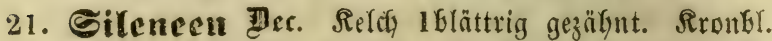
(5) unit Den (10) Strubgef. unterweibig, auf einem melyr oder weniger bemerflichen Fruditträger eingefügt

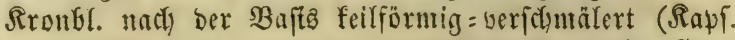
an ber Spike 4f(appig): Gypsophila 224.

Rronbl. mit langent fotmalem Nagel

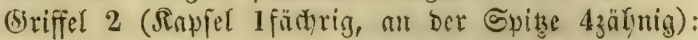
Saponaria 225.

Brifiel 3

Beere 1 fütrerig: Cucubalus 226.

Beere an (Stumb 3fäd)rig, an ber Gpize 6 flap: pig: Silene 227.

Briffel 5

(5riffel unterf. Warzig, fonft. fafl: Lychnis 234. Briffel anterfeitz warzig, fonft überafl befbant (RelchzäGue Glattart.:Lerlängert): Agrostemma 235.

IV. Selits in ber Runospenlage onchförmig, tiefgetheilt ober melorblättrig; Srone meforblättrig

a. Jruthtfnoten 1 fäd)rig (vicleiig)

22. \$ortulacen Эuss. Reldh 2 fpartig. Staub=

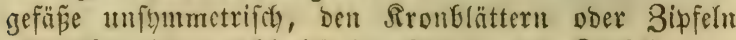

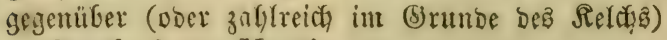

Strufiger. 3: Montia 20.

23. IrIfincen Der. Reld) $3-5$ blättrig (oder tief: 3-5theilig). $\quad \mathfrak{B l a ̈ t t e r ~ o f m e ~}$ Rebenbl. (mit 2(uø̉nafme won Spergula tuts Lepigonum). Staubgef. cintm ¿rüftgen Singe eingefügt

Rapfel 3flappig: Alsine 228.

Rapfel 4-5flappig

Santen nicrenförmig ungeftügelt: Sagina 78.

Samen freisrund geflïgelt: Spergula 237.

Rapiel 6frappig

Rronblätter ganz

Samen forilbeïrmig (Stautgef. 3-4-5): Holosteum 58. 
Samen nierenförmig mit einem 2(ngängịet: Moehringia 230.

Gamen nierenförmig of) 2(n)ängโ์ Arena: ria 229.

Rronbr. 2 fpartig ober 2theilig: Stellaria 231. fiapel 8-10flappig: Cerastium 236.

24. \$aronychieen St. foil. Relü) 5theilig. Blät= ter mit truefenbäutigen Nebenblättern

Rrontel. won ber Ränge bes Reldj: Teleplyieent Staubgef. 5, Narben 3 fizento (Rapf. 1 jamig, nicut nufipringent): Corrigiola 173.

Rronbl. fefre flein ober 0 ; Gtanbgef. 10, afmert)= felno umfructitbar: Silecebreen

Selctsipfel f(act) =fonfan: Herniaria 131.

Sildyzipfel fnorpelig: Illecelorum 122.

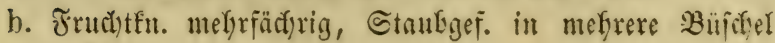
berwadyen

\section{S2npericineen Defs.}

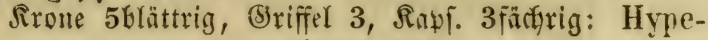
ricum 374.

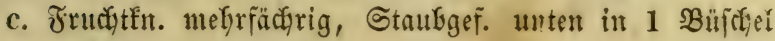
verwadifent

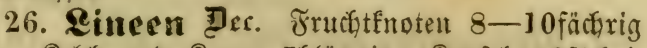

Relch) uno Rirone 5blättrig, Fapfel 10Fücţrig: Linum 175.

Reldy 4jpaltig, 3ipfel 2-3ipaltig; Rapfel 8fädurig; Radiola 80.

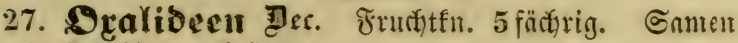
mit fleiffhigem elnftifoth auffpringendem Mantel

Staubgefäß̄e 10, ธie 5 äußern fürzer; Griffel 5: Oxalis 233.

28. G̈eraniaceen Đer. ซrudtefn. 5füdurig, Fächer 2 eiig, bei ber Reife 1 fantig. STriffel zu einem langen Sdynabel bernadjen

Stinabel der Fructit gerabe (Stnubgef. 10): Geranium 346.

Sdinabel fpirafförmig (Staubgef. 10, wobon ab: wectfelno 5 unfru(ţtear): Erodium 345. 


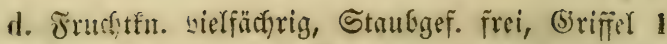

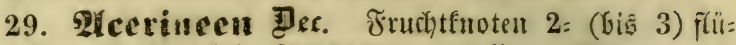

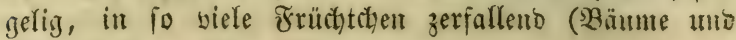
Sträu(t)er)

Strubger. 8: Acer 203.

30. Trmpelibecn fauth. Staubgef. 4-5, vor bie Rronbl. gefteflt. Frudt eine Beere

Frone an ber spize zujammenlyangeno: Vitis 115. 31. Selaftrincen h. Sigr. Staubgef. 4-5, mit

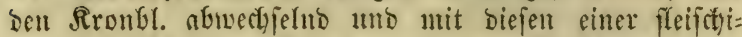
gen unterftänoigen Sofheibe auf bem Reldhboocn ein= gefïgt

Rapfeft 2-3 nufgeblajen, nut ber $\mathfrak{B a j t}$ zujammen= getradfen; Samen fnöthern: Staphylea 172.

Rapfeln 3-5fächrig fleifchig (Bätter cinfači) Evonymus 117.

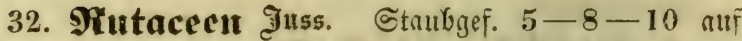
ciner unterweibigen Gifeibe ftefgent. Fruchtfn. 3-5= rappig

Reld bleibent, Rronbl. (4-5) benngeit, Sgoniggru: ben 8-10 am (S) Fruditfnotens: Ruta 214.

33. Menotropeen Mutt. Strubgef. 10, wovon 5 in bie $B$ Bud fent, 5 z̧wificten die Drüfent gefteflt. (BBlattloje, nut

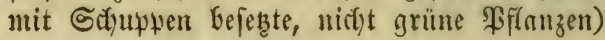

Selti) uno bie glorfige am (5iruno böfferige Sirone 5Glättrig: Monotropa 215.

34. Whrolacen fitit. Strubgef. 10. Rront.

5. Frutctftr. ofyne Erţeibe und Driffen

Reler) 5 fpartig bleibeno, Staubb. mit 2 Röctiern nuf= fpringent: Pyrola 217.

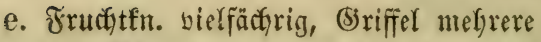
35. Cratineen Camb. Rronbl. 3-5 unteriveibig, eben fo biele ober boppelt fo biele Staubgef. Briffel $3-5$.

Reldy 2-4jpaltig, Rapfel bieljamig: Elatine 212. 


\section{Bweite Ilnterabtheilunis.}

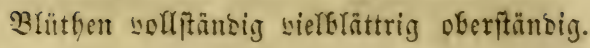

A. כrutuftefnoten 1 fäd)rig

36. Gironularicen Đer. Єtaubige 5, mit sen Rronbl. ivechyelno (Sträucţer)

Rron: unt Reldhflätter bem Reldy eingerügt: Ribes 120.

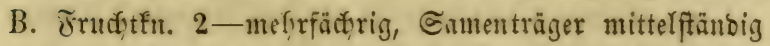

I. Srmbgej. 4 mal jo biel als Sironbl. ober nud mefr

37. \$omaceen findl. Blätter mit शebenblättern.

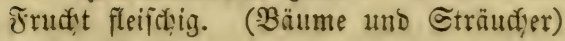

Steinfrucht:

Steinfx. 1-5iteinig, Geerenartig, in cine fợnälere

@deife enbigent: Crataegus 247.

@teinir. 5iteinig, in eine Feffenförmige Errweitrung aแล̊gefyent: Mespilus 248.

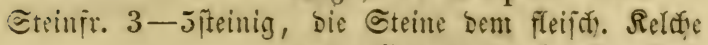
nur anliegent, nach oben frei: Cotoneaster 249.

Plpfelfiructeft

J

ซädyer bieffantig: Cydonia 252.

Fäd)er 2jantig: Pyrus 250.

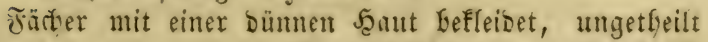

(Jrututt faftlog: beerenartig): Sorbus 251.

35. \$G Gilabelpheen Đon. Blätter gegenítänbig, ofme Pefenflätter. Jrucht eine 3-10fädhr. Rapjel. (@trïucher)

Relctizipiel uno Rronbl. 4-5, Ranjel 4-5 fädurig: Philadelphus 242.

II. Gtaulger. io biel als Rironbl, uno nit ihnen wedfielno, Doer boppelt io viel

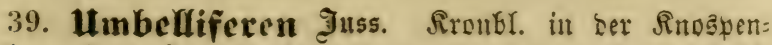
lage cingerolt. (5) rif̈el 2, aus ciner liberweibigen 2 jpat= tiger Gdjeibe herworgetents

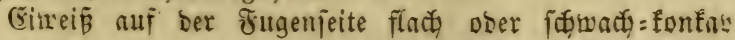

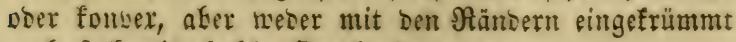
nodi farfartig = fohl: Sorthofpermen 
Frudit son ber Seite zu[ammengezogent Dber flad

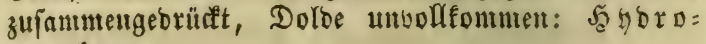
cotuleen

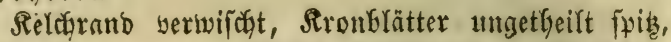
Dolbe fopfiörmig meift 5 blit= thig: Hydrocotyle 135.

Frucist in Duerburdeffernitt faft fitielrunb, Dolbe un:

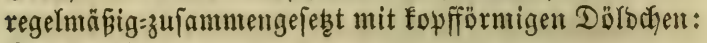
Ganiculeen

Reldyrano 5zägnig, Frudft hafig=ftadyelig: Sanicula 134.

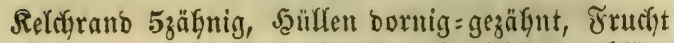
fpreuig= ichuppig (B̊lumen blä!= (iç): Eryngium 133.

Frudbt yon ber Seite beutlid, zufanmmengebrüfft,

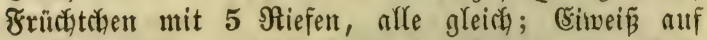
ber Frugenpeite ziemridy flach ober fonbex ober ftiel= rutb; Dolden bollfommen: 2 mmineen.

Rronblätter ganz

seronbl. eingeroldt ober eintwärtşgefrünunt

Rronbl. an ber Spibe abgefdutten (BBlt= men gel(b): Bupleurum 136.

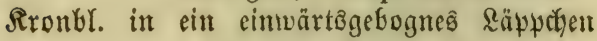
beridumälert: Petroselinum 169.

Rronbr. fternförmig = augิgebreitet

Rronbl. mit einem gernden ober eingebognen Spizchen: Helosciadium 167.

Sronblätter mit biçteingerofltem Spibç্য় Apium 140.

Rronbl. werfegrtferzförnig, mit einem fleinen

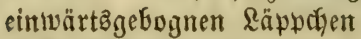

seldarano unmerflids

Thäldhen ber Frudut ofme Striemen: Aegopodium 138.

Thälç̧en 1 ftriemig, Frudyt länglida: Carum 139.

Tgăldyen 3 ffriemig, orudat 2fnotig: Pimpinella 137.

Reld्h 5zähnig

Thälchen ber Eruçat 1 ftriemig 
Der Ssattuntgen.

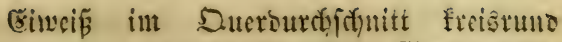

(ซrustht 2 fnotig): Cicuta 168.

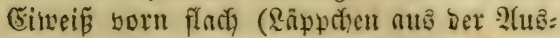
ranbutg Der Rronbl. Kerwortre= tent): Critamus 167.

şăldyent 3 ftriemig

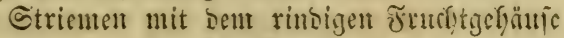
beberft: Berula 161.

Striemen auf ber Dberfalade: Sium 160.

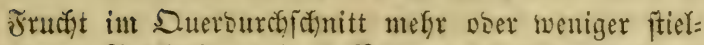

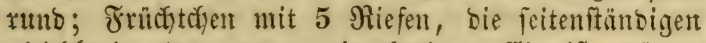
gleichbreit ober mur wenig breiter; Čitweís auf Der Jugenfeite f(ad) ober faft ftielrums; Dolde solffont= men: Seperineen

Rronbl. gamz rmmslict) cingerolft (BC. gelb): Foeniculum 142.

Rironbl. mit einwärtsిgefognem Räppch)

Ifyälchen I f́triemig

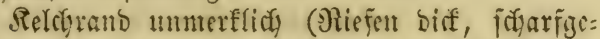

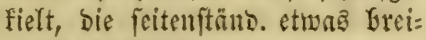

ter): Aethusa 164.

Reldyramb gezähut

(5riffel aufrect)t, Frud thträger angetwaç=

fen: Oenanthe 165.

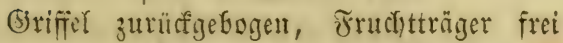

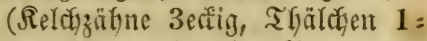

Giz. 3ftricmig): Seseli 163.

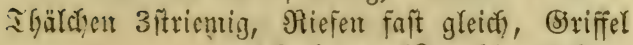
zแnürffgefogen (Jironbl. mit Grei= ter Bait? fitsend, gelb): Silaus 162.

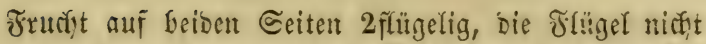

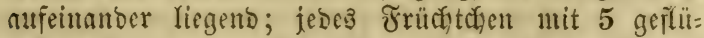

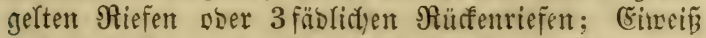

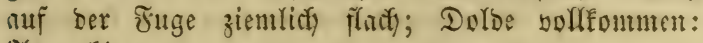
2lugelicen

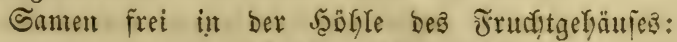

Archangelica 148.

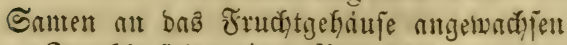

Aronbl. fpikg: Angelica 149. 


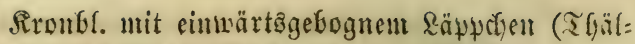
dien 1 ftriemig, Reld)rand ummerflich)

Rronbl. runolich (BI. gel(b): Levisticum 151. Rronbl. verféfgrtberzförntig: Selinum 150.

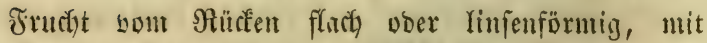
einent serbreiterten DDer geflügelten Rant untge=

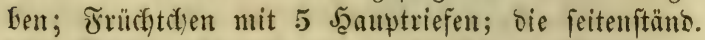
bem Nand anliegend ober mit ifyn berfontelzent; Nebenriefen 0 ; Eimeif born flact); Dolde bollfon= nten: Beucedaneen

Riefen fefyr fein, bie 3rüsfenftänto. gleidyweit, bie feitenftäno. entfernt, den Nano beribyreno ob. von ifgm beberft

Aronbl. berfefrtherzförmig (Stricmen feulig, Fruchtrand abgefladit): Heracleum 152.

Rronfer. cingeroflt (B/. gelb): Pastinaca 143. Riefen fäblid, gleicfiweit abftelyento

Rronbl. abgef(c)nitten bid)teingerollt (Br. gelb): Anelhum 141.

Rronbr. verfef)rtgerzförmig

Reldiran'o berwifict: Imperatoria 154.

Reldyranto merflich (Frugenftriemen mi ber Dferf(äd)e): Peucedanum 153.

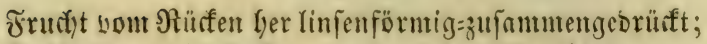

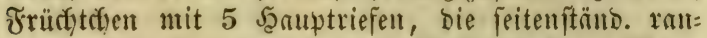
Dent; (Eimein born ziemlidy flad); Dolbe volffont: ment: Silerineen

Nebenriefen 4, weniger herwortretent: Siler 144.

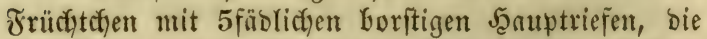

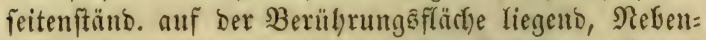
riefen 4, mefyr bervoripringent; ftachelig; (Simein flach ober faft falgitielrumb, worn zientl. platt; Dolde bolffommen: Daucineen

Rebenriefen 1 reifig=ftadyelig: Daucus 145.

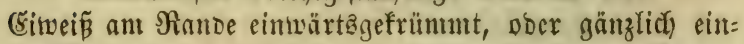
gerolft, ober an ber Innenfeite rinnig won einer \&ängä: furdie: Eamphlofpermen

Früchtct)en mit 5 fäblictyen, borftigen Doer ftadsligen

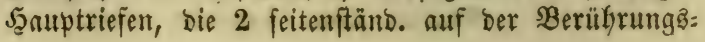


flädue liegend; Rebentiefen 4, melye Gerwortretens, ftadjelig: Eancalineen

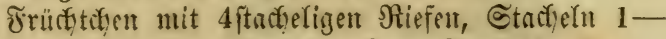
3reifig: Caucalis 146.

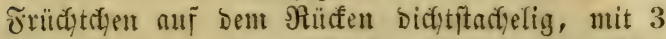
Dazivifthenliegenden Borjtenteifyen: Torilis 155.

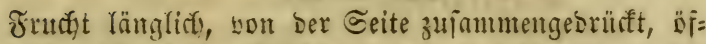

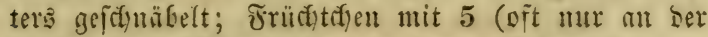
Epitze Gemerflidsen) Samptriefen; Nebentiefen 0 : Scindicineen

ซrucht gefक्wäbelt

Jrüdutchen riefenlos, C(t)ubel 5rieños: Anthriscus 159.

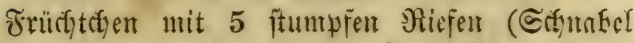
ซruç่t ungeidunäbelt (ang): Scandix 159.

Früdftethen mit 5 ftumperen Riefen: Chaero.phyllum 157.

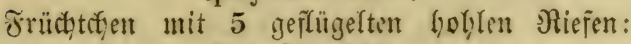
Myrrhis 147.

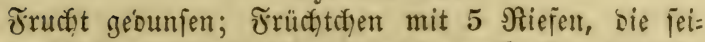
temitäno. ransendo ober bor bem Rambe liegello: Smbruen

Riefen erfaben geferft: Conium 156.

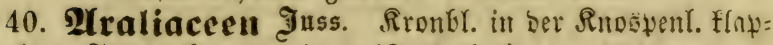
tig. Fruct)t beerenartig. (Strüuther)

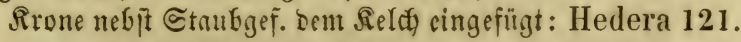

41. Corneen Dere. Rronfl. in Der Rnospenl. flatpig.

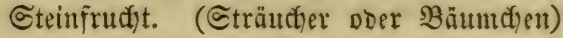

Rronbl. und @taubgef. 4: Cornus 69.

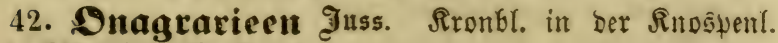
bachförntiģ. Grififel 1.

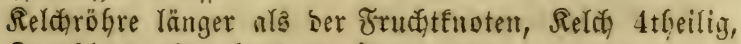
Rronbr. 4, Staubgef. 8: Dnagreen

Snment naft: Oenothera 204.

Gamen jodopfîg: Epilobium 205.

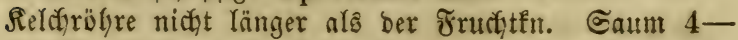
6theilig Gleibent: Juffienen

ซrucft fapjelig aufipringeno: Isnardia 75. 


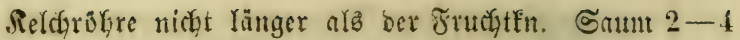
ffrultig Gleibend: Circäcen

Strubgef. 2: Circaea 14.

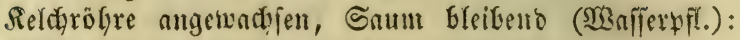
Sybrocaryen

Frudut mußartig füüchern, Strubgef. 4: Trapa 70. 43. Sacifrageen $\mathfrak{Z}_{\mathfrak{e n t}}$ Rronbl. in Der Rnoģpent. brdfförntig. SGriffel 2 poer melyr. (Staubgef. 10)

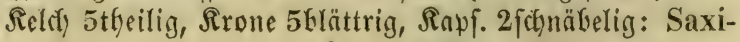
fraga 222.

Blïtfenty. 4-5fpaltig, Rapf. werfef)rtferzförmig 1 f̈̈̈if)= rig: Chrysosplenium 220.

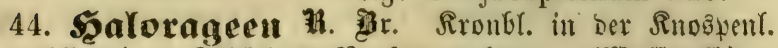
badjförmig. Şriffel 0, Rarben mefrere. (NGafīerpfi.)

Blütben einfäuĩtg, Rrone 46lättrig, Rlüfe 4: Myriophyllum 456.

III. Staubgef. fo viel als Rronbl. und Diefen gegenftünbig

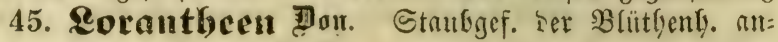
gewadifen. Beere 1 famig.

Blüthen 2fäuitg: Viscum 470.

\section{Dritte Unterabtheilung.}

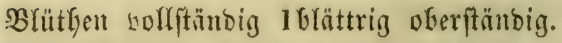

A. Stauthgefǟe vor eitrer übertweibigen geferbten Scheibe eingefïgt 46. S3accinicen Der. Staubgef. Der Rrone nidyt ange= wadbjen. (Sträud)er)

Beercufrud()t 4-5fär(f)rig: Vaccinium 206.

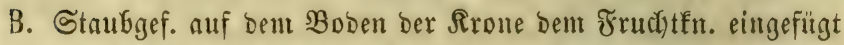
47. Eucurbitaceell Iuss. Staubgef. 5, babon 4 para = weife zufantmengewachien, daz 5 frei

Staufibeutel frei, Beere 3-6famig: Bryonia 467.

48. Sobeliacen IIIss. Staubgef. 5, Stnubf. frei, Srone unregelnuäpig

Staubfeutel nerwachfen, Rronbl. gefpalten: Lobelia 109. 49. Campanulaceen Эuss. Staubgef. 5, Staubfäd. frei, Sirone regelmäß๋̋

Bipfel ber Srome berwachjen, zulekt bon ber Baftâ an firit rọ̈ento 


\section{ber Brattunizen.}

Stauter. Ufriemlich, Staubb. zufammentangend: Jasione 110.

Ctaubf. am (3runse verbreitert, Staubr. Frei: Phyteuma 111.

Srone 5 ifartig, meift gloffig; Rapi. freifecïormig, mit $3-5$ \&öffern mufiptringent: Campanula 112.

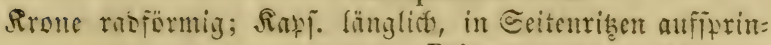
gent: Prismatocarpus 113.

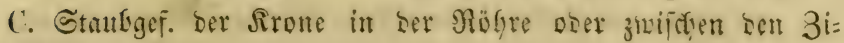
Wêtu cingefügt

50. Compofiten GDans. Ctanfbentel in eine Stofre serwadjent. Sironzipfel in ser Mnoŝpenlage flappigig. (Zu= jammengeferste $\mathfrak{B l i u t h e n )}$

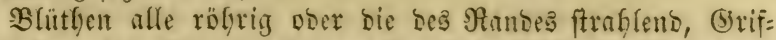

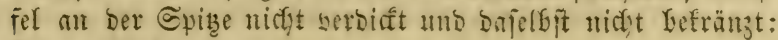
(5orbubiferen

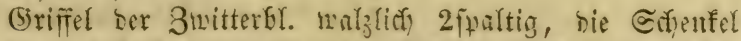
lang, faft ittielrumb ober etwis feulis, oferw. son fei=

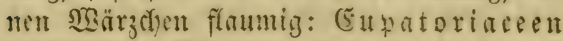

Bhätfen alfe zwitterig (unb röbrig): Eupatorieen

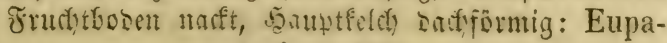
torium 398.

Blütgen bielefig: Tuffilagiuen

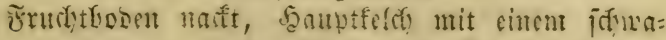

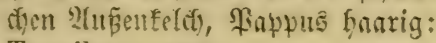
Tussilago 406.

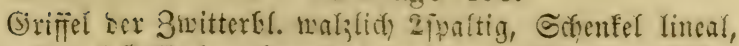

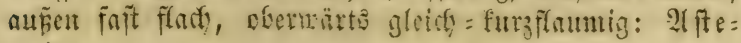
roibeen

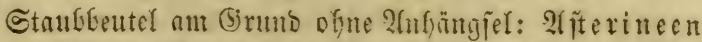

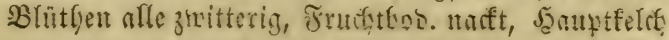
bad̂dfürmig: Chrysocoma 397.

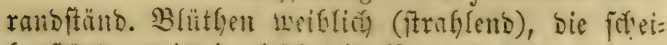

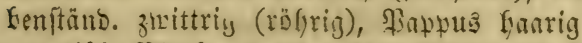
weibl. Blitthen meftreifig: Erigeron 405. weibl. $\mathfrak{B}$ titthen I reibig

Rantbl. verjediesenfarbig (Glau): Aster 110. Ranbor. gleidffintbig (gerb): Solidago 407.

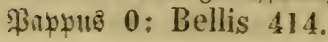




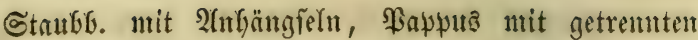

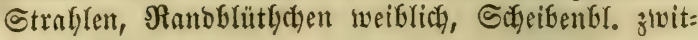
terig: $\$$ muleen

Bappus bopweft, ber äußre in einten gezäfnten

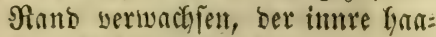
rig: Pulicaria 412.

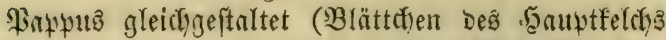
mit ber Spitse abjetend: Inula 411 .

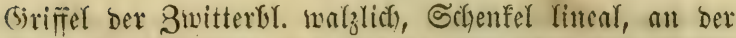
Epibe pinfelfürmin und geftutzt ober über beut sinjel mit einem Anfüngfel werjefen: Senecioiben

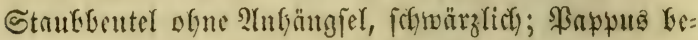
grant ober fronförmig: Saeliantheen

Sampteếd bactiformig: Helianthus 420.

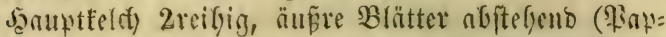
แแล 2-4gramig, Bramneแ rükt=

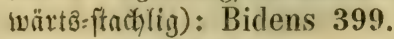

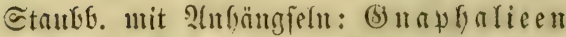

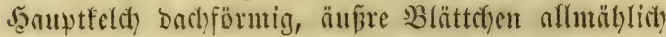
fürzer: Gnaphalium 402.

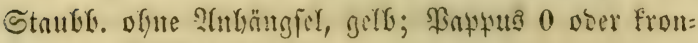
förmig: 2tutgentibeen

alle Blütísen röbrig

গandbr. ganzrabig, Sament berfefrteifürmig: Artemisia 400.

Rmbbr. 2fpaltig, Ganten fantig=geriflt: Tanacetum 401.

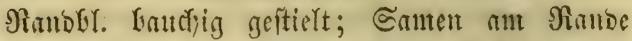

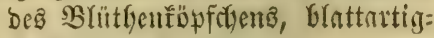
f(act): Cotula 404.

Gorfeibenbl. röfrig, Sianbbr. ftraflento

Frudfetroben nadft

Frudettr. fegel=warzenfürmig: Matricaria $\mathbf{4 1 6 .}$

Fructits. Fonber doer fait fractis

Samen bäutig=gefrönt: Pyrethrum 417.

Srmen unift: Chrysanthemum 415.

Frudettroben fwrettig

Manbblüthouen mit eirunblicyem Canm: Achillea 418. 
Mantนr. mit länglidiem Gnum: Anthemis 417.

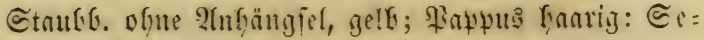
necioueen

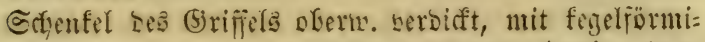
ger Spibe entigeno: Arnica 413.

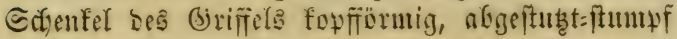

5autptfel(t) einfad): Cineraria 409.

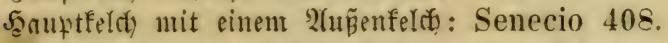

(5riêtel ber Buitterfl. oben in einen Rnotent werbifft, ant Snoten oft furzbefaart: (5y) nareen

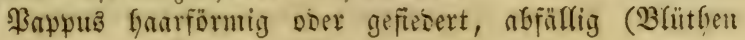
3witterig): (Earbuineen

Frud)tfosen lötherig=zellig: Onopordon 394.

Frutetb. Fratuig ober iprenig= Goritig

Papqus hanrförmig: Carduus 392.

अappus gefiebert

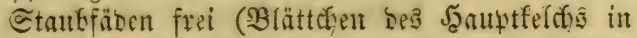
einen Dorn ober eine Streffel=

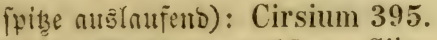

Ctanbjäbon in cine Naffe berwachjen: Silybum 393.

Bapduล nแล finfülligen Borĩten gefilbet, Blättd)en

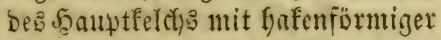

Spite entigent: Arctium 390.

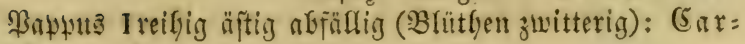
lineen

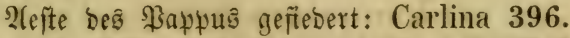
Эarputa bleibeno 2 reifig, bie innerifte Reife länger: Serratuleen

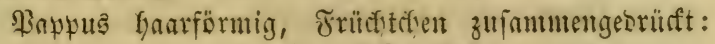
Serralula 391.

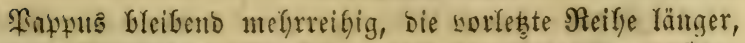

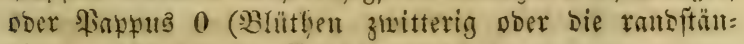
bigent geffelesthtlos): Centrurieen

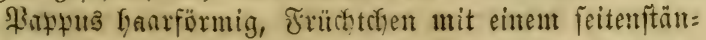
bigen $\mathfrak{N a b e l : ~ C e n t a u r e a ~} 421$.

Blittfent fümtlich zwitterig uno ftrafleno; (Srifiel nidit

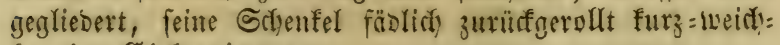
hanrig: Eidgoriaceen 


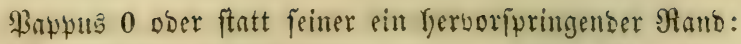
ravianeen

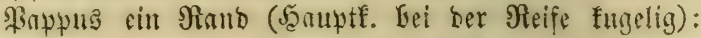
Arnoseris 387.

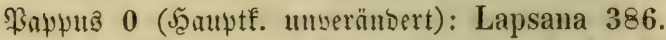

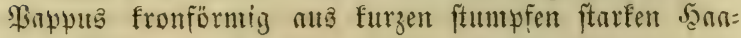
ren: Cidforieen

Samptfeld) nit einem Nebenfelet): Cichorium 389.

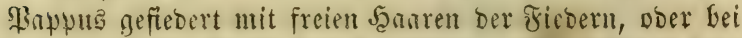

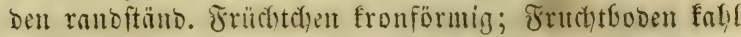
odur feinjajerig mit bleibenten fajern: Reout obonteen Bappus ber randftün. Jrüchtd)en fronfürmig: Thrincia 379.

Pawpus gleichförmig gefiedert

ßappus abfällig (Die Strafyen ant (Srund in eimen Ning verwad)|en): Picris 378.

Fraputa bleifono (5auptfeld) Doppett)

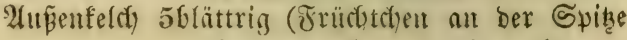
abgerunoet.ftumpf mit berlänger= tem fübl. G(t)nabel): Helminthia 384 .

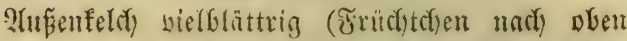
טerf(d)สีlert): Leontodon 377.

Bappua gefiebert mit werwebten Saaren der Fiebern: Scorzonereen

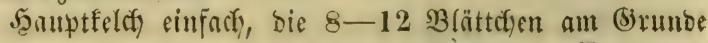
zuFammengetwadyen: Tragopogon 376 .

5ุauptêl(t) bad)förmig: Scorzonera 375.

Sappus gefecbert, Jructutboen fureutig mit nefärliger Sprell: Saypoditurioeen

Saruptfeldy oactyürnig: Hypochoeris 388.

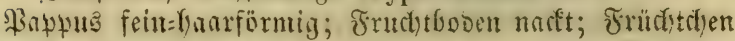

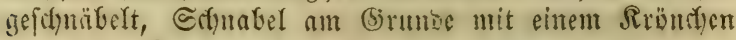
umgeben: Ehollorilleen

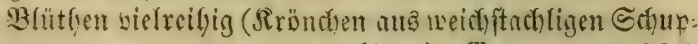
pen gefiloet): Taraxacum 385 . Fappus fein=Kanrförmig; Frut)tb. nafft; Früd)tdyen f(nd)=zufammengebrituft, fochnabelloz ober mit einem un= Gefrönten Sdinabel mbigemb: Lactuceen 
Erilchtetyen in einen fäblichen Gifnabel enbigent: Lactuca 381.

Früdteffen fodnabellob: Sonchus 380.

Bappus fein = Yaarförmig ober pfriemlicf) Gorftig, Frilu,t: dien ziemlide walzlich ober fticlrumb: Erepibeen

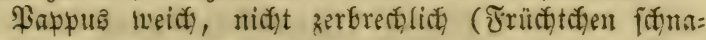
bellos ober gef(x)äfelt): Crepis 382.

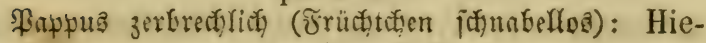
racium 383.

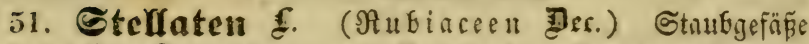
frei (4). Rromzipfel in ber Rnospentage flappig. (B Blätter quirlig)

Rrone trichter= ober glocfenförmig

Saum des Relchrands bermifát: Asperula 63.

Saum bes Relơntong gezäfnt: Sherardia 62.

Rrone flach ober rabförmig

Jructit 2fnotig troffen: Galium 64.

שrucht 2 fnotig faftig: Rubia 65.

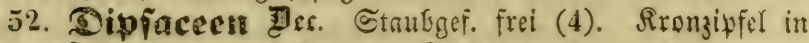
ber Sinospenlage Eachförmig. Sield boppelt

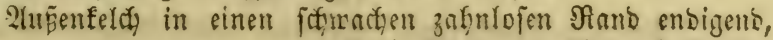
Intrenteld am Enbe berfenför= mig: Dipsacus 60.

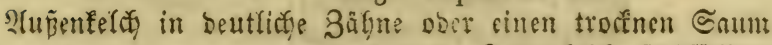

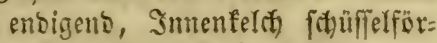
mig Gorítig: Scabiosa 61.

53. Zalerianeen Des. Staubgē. frei (3). Sironzipfel

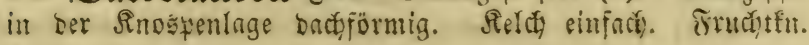
1 ciig

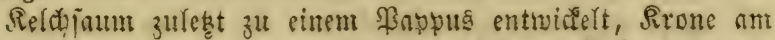

Crumbe befferig: Valeriana 17.

Reldjaum gezäfnt, jeltner unnterfid): Valerianella 18.

54. Saprifoliaceen Inss. Staubgefäp̃e frei. Rron=

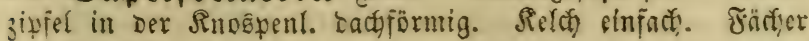
Desి J̛ruchtfn. 2eiig

Rroue rabförmig, Erifiel umb Narben 3-5: ๔am= buceen

Beere 4-5jamig (Rräuter): Adoxa 211.

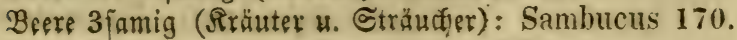




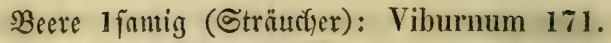
Rrone röfrig Doer glorfig, oft unregelmǟ̄ig, (sirifiel 1 fäblich: Ronicereen

Beere 2-3fäd)erig (Strüıdłer): Lonicera 114.

\section{Bierte Internbtheilung.}

Blütben volfftänbig 1 blättrig unterfitänbig.

A. Fruthtfnoten 4, 1 eiig, einer unterweibigen Sdyeibe ant= fitsend; Sriffel 1, mittelft ber Sibeife mit bent Frutefffnotent zuf ammentangend

55. 30ragineen Des. Statbgef. 5, nit Den Rron= zipfein wect) jelno

Näffe 4, Dem bleibenden (Briffel angetwad)fen: (E) no: gloffeen

Niuffe glattgedrüct ireict)facthelig: Cynoglossum 87.

Näffe 4, ber unterweibigen Sdyeibe eingefïgt, nut brumbe mit einem gebunfenen gerieften Ning berieten umb imme:

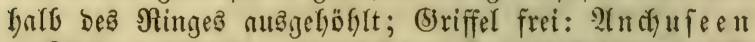

Srone rabförmig, Setwölfchen furz auşgermbet: Borago 86.

Srone tridgterförmig, Gd)lund burth ftumpfe (5)wälb: (d)en verengert

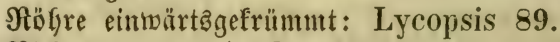

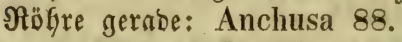

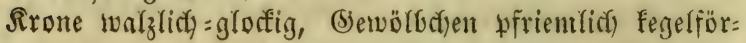
mig = zufammengeneigt: Symphytum 85.

Nürife 4, ber unterweib. Grfeibe eingefügt, ant (5rumbe niçt aนถิ

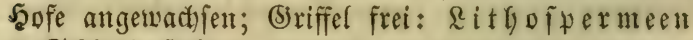

Schlund frei

Srume gloffig, im Sdalumbe unbef)anat: Echium S2. Sroute tridyterförmig nit befyantent Schlund: Pul-

Sidjlunb nidyt frei monaria 84.

Sd)luno burch 5 belfante Frnten etwas berengert:

Lithospermum 83.

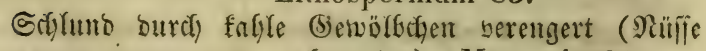
unbermbet): Myosotis 90. 


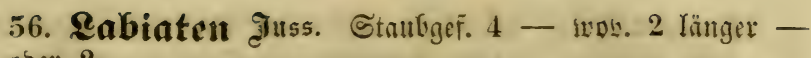
Dber 2

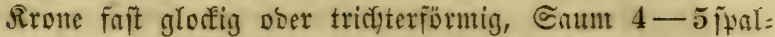

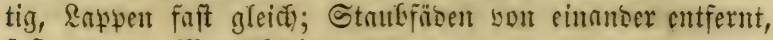
faft gerabe: Nenthoibeen

Strubgefäв́ alle bollftänbig

Srone trich)terf̈̈rmig 4jpaltig, Särffdent ber @taubr. gleichlaufent: Mentha 281.

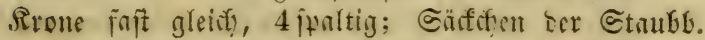
חแจ๋einnแberfafretlo : Elsholtia 283.

2 Staubiger. sollitänbig, bie andern unfuddythar ober 0: Lycopus 12.

srone 2 lipłig; mu 2 fruchtbare @taubgejäp̃e, farallel unter ber Sorerlitwe liegent: Nonardeen

Strubgef. zafnlogs: Salvia 13.

Sirone 2lippig; Gtanbgej. von einanber enterent, oreriv. auseinanberfafyrent voer unter ber Dberlippe zujammen: meigent; Särftyen ber Staub6. won einaneer getremt, an

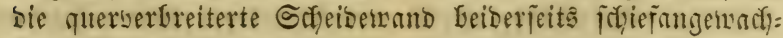
ien: Satureineen

Reldi yolleommen 2lippig

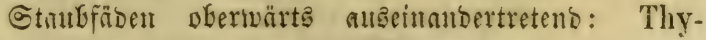
mus 297.

હtrubr. oberw. Koggig zujanmenneigenb

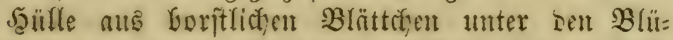
thenquirlen: Clinopodium 299.

Blütfyemuitrle ofue Şuffe: Calamintha 298.

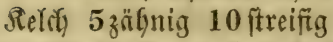

Gtaubjäben obernärts auseinnoertretenb: Origanum 284.

Staubräben oberw. Eogig=zujanmenneigent: Satureja 285.

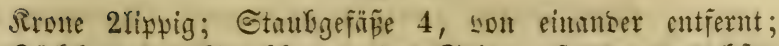

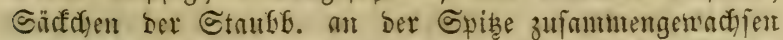

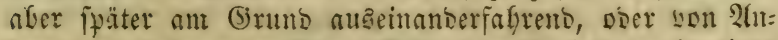

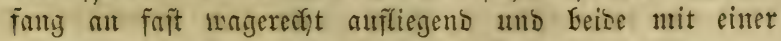

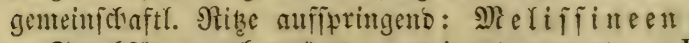

Staubfübor ofermärts maseinanoertretent: Hyssopus 282. 
Srone 2lippig; Strubgef. unter ber Sberlippe gleidglau= feno, genäbert (zulebt mand) mal zur Seite hinabgebogen), bie obern Yänger; Relchzägue zuletent abịtelyento Doer zu= fammengeneigt: Nepeteen

Unterlippe fonfab: Nepeta 287.

Huterl. flach (Staubg. in 2 Sireuze gefteflt): Glechoma 286.

Sirone 2lippig; Stanbgef. unter ber Dberlippe gleiḑlau= fent, genäfert (zulę̧t mandimal zur Ceite finabgebogen),

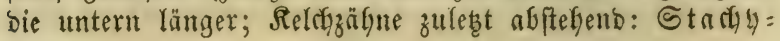
been

Rronrögre inwentig mit einem unterbrochnen fanar: ringe (Nüfĩe an ber Spize 3erfig abgef(snitten): Marrubium 296.

Rrour. inmenbig mit einem umunterbrodfyen Sanarringe feitenfänd. Sipfer ber Unterlippe zabnförmig Do. 0: Lamium 288.

feitemitün. Bipfel ber Unterlippe hofyl=zafynförmig: Galeopsis 289.

feitenfiäno. Sipfer ber Unterlippe fpis: Galeobdolon 290.

feitenftäno. Biłfer ber Unterlippe fituntyi

Nuifie oberw. nfgerumbet

Stanbfǘoen nady ben Serflügen gerabe: Ballota 291.

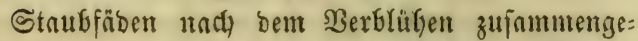
bref)t uno nusiwärta gefogen: Stachys 292.

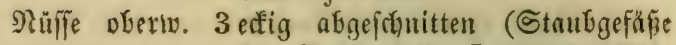
of) 2(nfäng(el): Leonurus 294.

Sronröhre inwenbig nadt

Nüffe oberiv. zufammengebrüft abgerumbet: Betonica 293.

Nüife oberw. 3 exfig abgefdunitten: Chaiturus 205. Sroute 2tippig; Staubgef. unter ber Dberlippe gleid)lau= fent, genähert; Kelch 2lippig, bie Sberlippe ungetbeilt ober furz=3zägnig; Relch zulekgt flad)=gefortlofien: Scu: tellarineen

Rrone intwenbig mit einem ununterbrochnen Sgarring:

Prunella 301. 
Rrone invenbig naft: Scutellaria 300.

Rrone llippig, Sberlippe 0 Dber fegr furr; Nilije nets: artig = rumzlig: 2 li ug g i been

Rrone inwendig mit einem umuterfrodfnen saarring:

$$
\text { Ajuga } 279 .
$$

Srone inwendig naft: Teucrium 280.

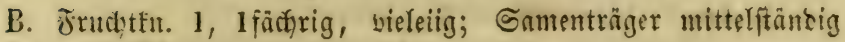
frei walylicis

57. \$rimulaceen Dent. Rrone regelmäpig. Ginut: gefäp̈e Den Rronzipfeln entgegengefeßgt

Stnubgef. (meift 7) auf einen $\Re$ ing Kefeftigt, in tweld)ent bie (meift 7) Rronblätter zu= fammengetwachfen find: Trientalis 201.

Staubger. (5) auf bem (5) befeftigt

Rapfel 5frappig: Lysimachia 92.

Rapfel ringsumauffipringend: Anagallis 91.

Staubger. Der Inngen Röhre ber tellerförmigen frrme eingefügt

Rrone 4tfeilig, Staubgef. 4: Centunculus 68.

Rrone 5theilig, Staubgef. 5

Reld 5ipaltig: Primula 93.

Relch 5theilig: Hottonia 95.

Strulbgef. Der furzen Räfre Der flactauşgebreiteten Rrone eingefügt (Reldh) halboberftänbig, Staubgef. 10, wobon 5 unfrufit= Gir): Samolus 108.

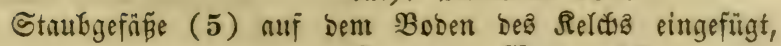
Rrone 0: Glaux 123.

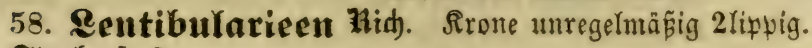
Staubger. 2.

Relch 5ipaltig: Pinguicula 10.

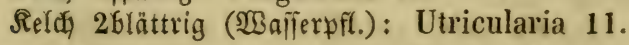

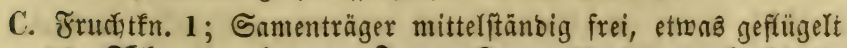
59. Wlantagiucen Inss. Rrone 4 fpaltig trocfenfäutig

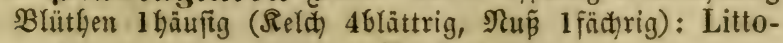
rella 448.

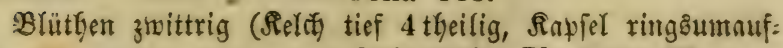
fpringetio): Plantago 67. 


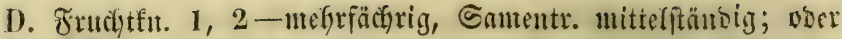

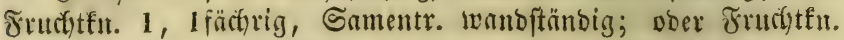
2, Samentr. wanditänoig

I. Strubgrer. unterneibig, unter einer fleifchigen Gidjeibe ein= gefiingt, ber Arone gar nidst ober nur wenig anfangent, frei

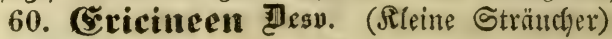

Frucht beerenartig: 2Ir buteen

Steinfrudft 5famig: Arctostaphylos 219.

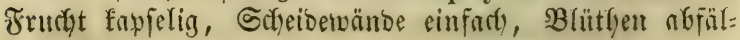
Yig: $\mathfrak{A}$ morontebeen

Sipfel 5fächerig 5ffappig (Staubgef. 10): Andromeda 218.

Fruddet fapfelig, Blätfen berwelfend=bleibend: Ericeen Rrume 4theilig ober 4zäfnig (Stanbgef. 8): Erica 207.

II. Staubgef. Der Rrone eingefügt, zuinumengewadtyen 61. \$olngalecu Juss. Stmubgef. (8) nu Brumb in eine, weiterfin gefpaltme Röfre berwactjen

Strubbeutel 1 färdrig: Polygala 351.

III. Staubgef. Der Rrone eingefügt, frei

a. Staubgef. 2, pber 4 worunter 2 länger; Srone ut= regelmañ̄ig Doer ungไeict'

62. Srobaucheen IItss. Fructefn. 1 fächrig. On= menträger 2, gegeniberftefent. Samen fefir flein umb

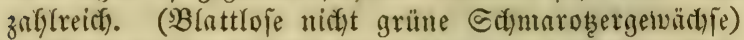

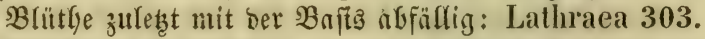
Bhitthe zulebgt abfällig, aber bie ringšmut=abgefprungure Bạṫ zurürfífifend: Orobanche 302.

63. MGinantbaceen DRe. Frildete 2 fädjrig. Staub= beutel am Brunde 2 f́tadyelipibig.

Reldi) 5zälynig: Pedicularis 307.

Seldi) 4 zäfunig

Santen glatt

Reldy atfigeblafen (Sament geflitgelt): Rhinanthus 305.

Reld) röGrig (Drerlippe Der Rrone mit zurürf= gefd)lngnem SRand): Melampyrum 306.

Samten rippig (Rapjel ftuntf): Euphrasia 304. 


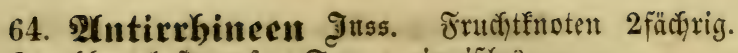

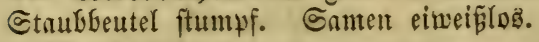

Strubgefǟ̉e 2

Narbe 2plattig: Gratiola 9.

Narbe ungetfyeilt (Rapiel auegernot): Veronica 8.

Staubgef. 4, mobon 2 länger

Rrone fait gleich: Limosella 313 .

Srone 2lipyig

Srone am (S)rumb föoferig, Rayfelt mit Röct)ern nufipringent: Antirrhinum 309.

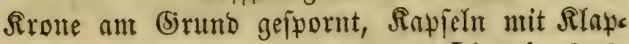
pen auffipringento: Linaria 310.

Sirone glofig mit fuiefent Saum: Digitalis 311.

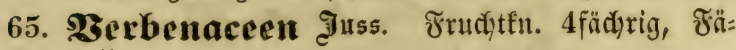
cher leiig.

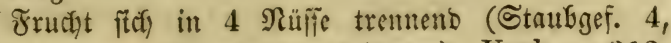
wowon 2 länger): Verbena 312.

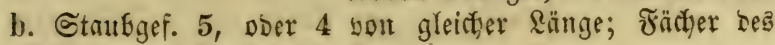
Fruêtut'notens $1-2$ eiig.

66. 2Aquifoliacen Der. @tmubgef. mit ben Nron= zipfeln wechjelnb

Rrone rabfürmig 4-5theilig: Ilex 76.

67. Convolvulacecu Juss. Stmugef. (5) Der Röfre Der 5lappigen Rrone eingefügt

Narbe 1: Convolvulus 99.

Narben 2: Cuscuta 127.

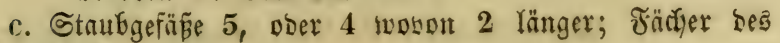
Frudutfn. bieleiig

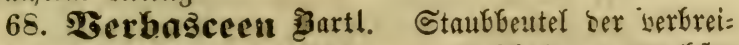
terten Gpibe ser Staubfäben quer ob. fătring angewadjent Staubgefäß̈e 5: Verbascum 103.

Strubgef. 4: Scrophularia 308.

69. Wolemoniaceen findl. Gtaubeutel (5) auf́=

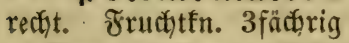

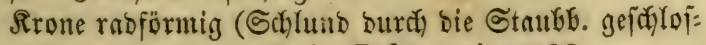
(en): Polemonium 98.

70. Gentianeen 3uss. Staubbentei (5) miredft. Fruçtfn. 1-2 fäçrig. Rrone melfento

Fructen. auf cine unterweib. Sitheibe gefteflt pber mit Drüfen umgeben, Blätter wedhelnd: $\mathfrak{M}$ entantfeen 
Rronte tridjterförmig, Narbe ungetgeilt: Menyanthes 96.

Rrone rabförmig, Narbe 2theilig: Villarsia 97. Reinte untertveib. Scheibe, $\mathfrak{B l a ̆ t t e r ~ g e g e n f t u ̈ n o i g ~}$

Rrone trichter $=$ ober tellerförmig, Narbe 1

Reldy und Rrone 4theilig: Exacum 66.

Reldi uno Rrone 5theilig: Erythraea 94.

Rrone gloffig, Narben 2: Gentiana 126.

71. Golaneen 3uss. Staubb. (5) nufrectat. Rrome abfällig, in ber Rnoz̈penlage gefaliet. Frudthtftr. 1$2-4$ fäărig

Frudat eine Beere

Sirome glodfig: Atropa 107.

Srone rabförnig

Staubb. Der Ränge nach auffprittgend: Physalis 106.

Staub6. an ber Spibe nit 2 Deffnungen auf: fpringeno: Solanum 105.

Fruçut cine $2-5$ fädurige Sapjel

Srone trifaterförmig faltig 5 fantig

Relé abfällig mit bleibenber Baftz: Datura 101.

Seldy Kleibend: Nicotiana 100.

Srone trichterförmig, niḑt faltig: Hyoscyamus 102.

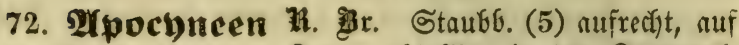
ber Narbe liegend. Rrone abfällig, in ber Rnob̄pent. fásiefgebreft. Frudutfn. 2 mit 1 gemeinfadyaftl. (Sriffel. Blumenftaub pulberig

Sirone telferförmig: Vinca 104.

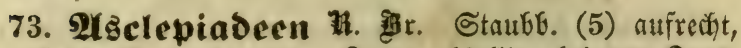
auf ber Narbe liegend. Rrone abfällig, bei ber Rnos: pent. bachförmig. Fructetfrt. 2 mit 2 (Sriffelt uno 1

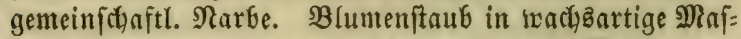
fen zufanmengeorängt, welche an bie 5 Drüjen ber großenen 5 fantigen Narbe angefieftet fino

srone rabförmig 5 theilig, Balgfapieln 2: Cynanchum 125. 


\section{ber Battmiget.}

\section{ซ̛̈uñte Ilnterabtheilung.}

Brïtren แmเollftändig, Bhätgenbülle einfaç ober 0.

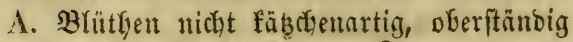

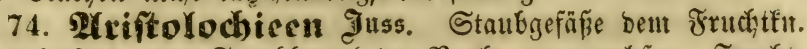

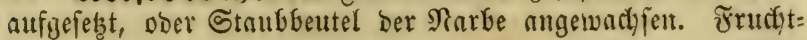
fnoten vieleiig

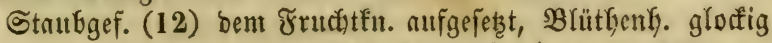
3-4 jpaltig: Asarum 238.

Staubbentel unter bem Frudtten. angewachlen, Błhäthenh. Gaudrig:gloctig: Aristolochia 438.

75. Sgippuribeen Eltk. Staubgefǟe 1, bem Frucktfit.

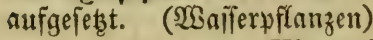

Fructitfit. 1 eiig: Hippuris 1.

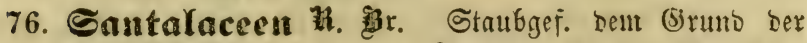
Sipfel Der Blittyent). eingefingt. Fruchtfn. 1 fächrig $2-4$ eiig Blütfyenf. Gecther: ober triduterförmig 4-5 fpaltig: Thesium 124.

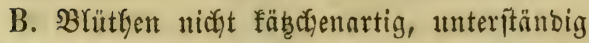

I. Frileste in mefrere Früd)tchen fith tremento

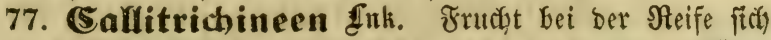

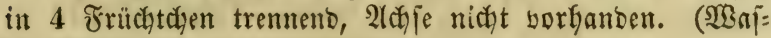
ferpflanzen)

Strubgef. 1, Narben ungetgeilt: Callitriche 2.

78. Cupborbiaceen 3uss. Früdtden 3, felten 2

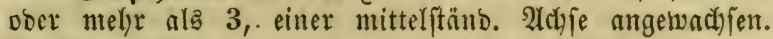
Narben getfeilt

Rapiel 3ศđnäbelig: Buxus 45\%.

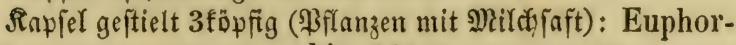
bia 441 .

Rapfel 2 füpfig: Mercurialis 476.

II. Frucht niçt auffipringeno

a. Blätter mit Nebenblättern

79. \$olngoueen Эuss. Nebendr. bent Stengel tutenförmig untgebento

Blüthent. tief $=6$ theilig, (Sriffel 3, Narben federig: Rumex 199.

Blüthyenty. 3-5theilig Gleibeno, Narben 2-3: Polygonum 209. 
80. Sanguiforbeen findt. Nebenbl. am $\mathfrak{B}$ latt= itiel fitsend

B(üthenl). 8theilig, bic Bipfel abmechjelno fleiner: Alchemilla 72.

Blätfgent\%. 4 fpaltig (gefärbt), Sarbe fopfig: Sanguisorba 74 .

Blïtfyenf. 4 fpaltig, Narbe pinfelförmig vieltheilig: Poterium 458.

81. Articaen 3ีtss. Nebenbl. frei abfällig

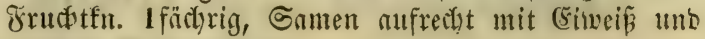
grabem Reim

Bfütfyen 1 ober 2 fäuftg, weibl. Blütfyenty. 2 thet= lig, sarbe fitseno fopfig = pinjel: fürmig: Urtica 450.

Blütfen sielefig, BB(ütfent). glorfig 4fpaltig, (Sirif= fel fäblidy, Narbe fopfig= pinfel= förnig: Parietaria 73.

Fructitfn. 1eiig mit baugendem (Fichen; Gamen of ne

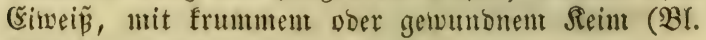

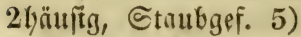

weibl. B(ätlyenf. 1 blättrig, auf einer Seite ge= ipaltert: Cannabis 472.

meibl. Sgülfe fófuppenförmig an einem Bapfen: Humulus 473.

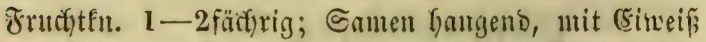
unb frummtem Reint; Frudt) Geeremartig: Morus 451.

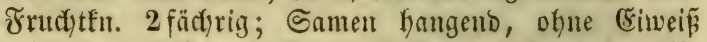

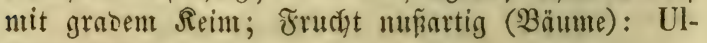
mus 132.

b. B̊ätter ofye Nebenblätter; $\mathfrak{B}$ lüthen 1 Gäuftg, bie weibl. ofgne Blütbentülfe

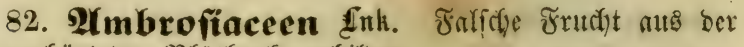
werfärteten $\mathfrak{B l u ̈ t h e n Y . ~ g e b i l b e t ~}$

weibl. Blüthe in cine 1 blättrige Salifle eingeidglofien:

Xanthium 453.

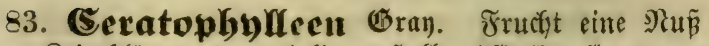

Reimblätter 4, quirlig geîteflt (MBafferpflanzen mit gabeligen $\mathfrak{B}$ (ättern): Ceratophyllum 455. 


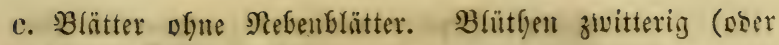
vielefig), Reint gernbe

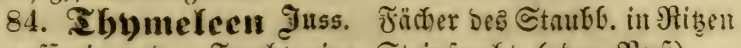

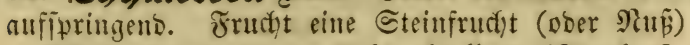

Blütbenf). 4jpaltig gefärbt abfalleno (Stuubgef. 8): Daphne 208.

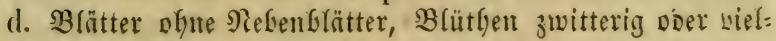
effig, Reim frumm ober fafraubenförntig getwumben

85. Gelerantbeen fulk. Eiffen an einem ton ber

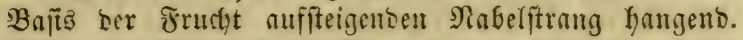
Röfre ber $\mathfrak{B}$ (litt)enf. gloffig, zulegt berfärteno uno bie

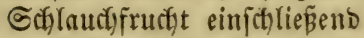

Sel(t) 5 zägnig, Srome 0 : Scleranthus 221.

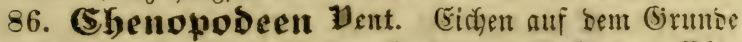

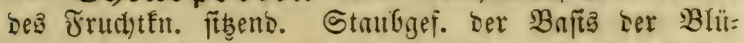
thent). eingefügt, Den Bipfefn Derielben entgegenge êt

BlütGen zivitterig, Blüthenf. 3-5 pualtig

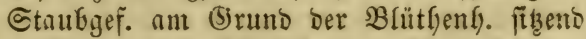

Samen aufredt: Chenopodium 128.

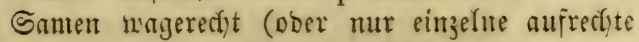
bazıi (d)en): Blitum 3.

Stantgef. einem fleifdigen, Den orudotfn. untge= benben $\Re$ ing eingefügt: Beta 130.

Blüthen 2lagerig, zum. mit vielebigen geniföht

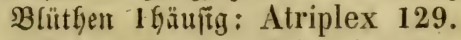

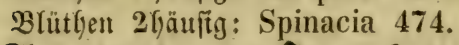

87. 2Imarantaceen ItIss. Gamett im (5rumb ber Echlauchfrucht angefeftet. Etaubgef. unterweibig

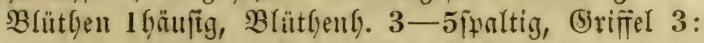
Amarantus 454.

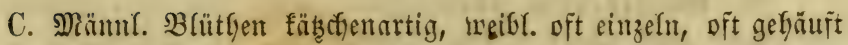

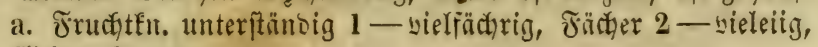
(Eid)en hangento

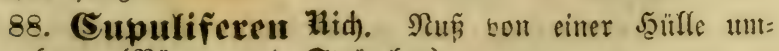

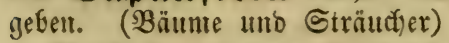

Staubgef. auf einer Blüthenf). eingefïgt

Jrudjt unten mit einent Becfer umgefen: Quercus 462.

Frutut ofne Becter

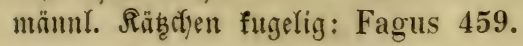




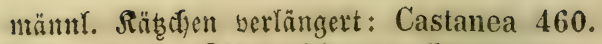

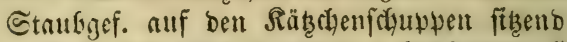

Nuß̈ mit einer 2 fpaltigen bleibenoen Saüfe: Corylus 463.

Puß́ mit einer blattartigen lyalbirten Şülle umgeben und mit ben Greibenden Reldy befrönt: Carpinus 464.

b. Fructutur. unterfiänbig, nit 1 geraben (Eiç)en

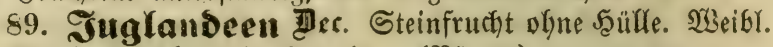
Blitthenf. 4blättrig frautig. (B̈äume)

Steinfr. mit 2-4flappiger Nuffichale: Juglans 461.

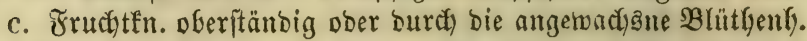

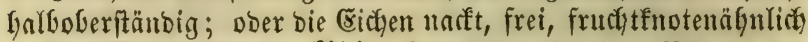

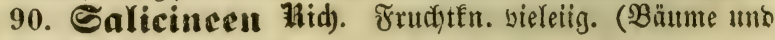
Sträแ(̧)er)

Befrucfutungattyeile an Der Bnję ntit $1-2$ Drïjen, Blütbenfülle 0: Salix 468.

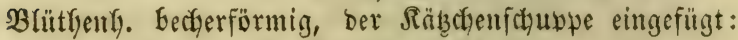
Populus 475.

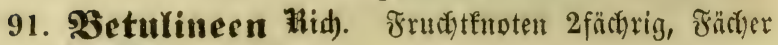
1 eiig. (Băume)

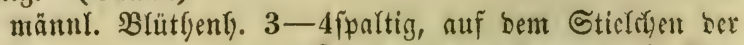

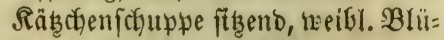
thent). 0: Alnus 449.

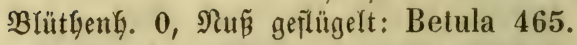

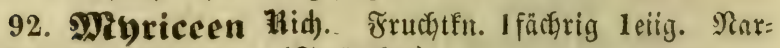
Gen 2 , berlängert. (Sträuđ̌̀)

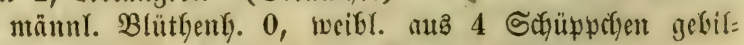
Det: Myrica 471.

93. Soniferen Iuss. Same nadt, won einte Sdyein= beere ober einem 3apfen eingefdyloffen. (Nadelfölzer)

Frudit ein Yolzartiger Bapfen: Pinus 466.

Fruckyt eine Scheinbeere

Sdyeinbere aus 3 fleifobigen Sctuppen gebilbet: Juniperus 479 .

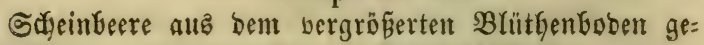
biloet: Taxus 480 . 


\section{3weite Şamptabtheilung.}

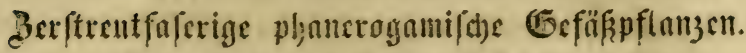

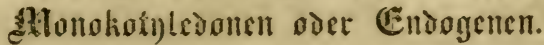

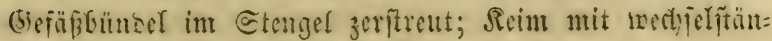
digen Reintblättern.

A. Frudiffnoten mefrere getremut, ober mefir ober weniger zu= janmengetwaffen und erfit bei ber 9Reife obertw. auscinamber: treteno oser won ber mittelftänsigen 2 (d) je fid trement jeber

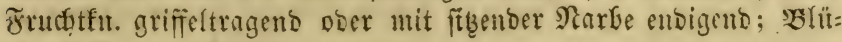
thenthuille unteritänoig

a. Frud)tfn. 1-2 eiig

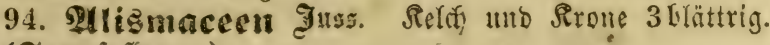

(Sumpfnf(anzen)

Blïtben znitterig, Staubger. 6: Alisma 200.

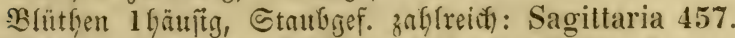

95. Juncagineest Wid). B(ütfenty. 6theilig, fromar= tig Doer frautig. (Sumpfpffanzen)

Narben 3, feberig: Triglochin 198.

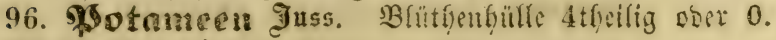
(งูa)iferpf(anzen)

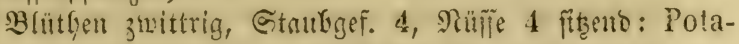
mogeton 77.

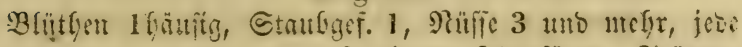
nự einem fabenfürm. Träger: Zannichellia 443.

b. Truthtfn. פielciig

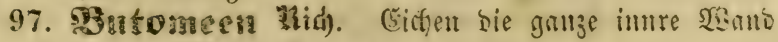

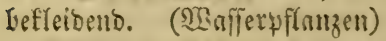

Blätfenf. 6blättrig fronartig, ๔taubger. 9: Butomus 213.

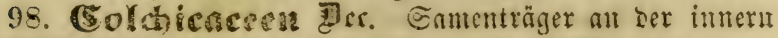
Niatf, befeftigt. (Sinubgef. 6)

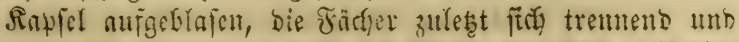
an ber Spitze eintwärta aufiptin= gento: Colchicum 197.

B. ซruç大tfnoten 1, unterftänbig

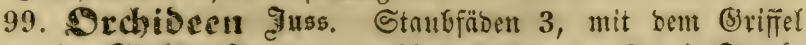
in eine ๔äule zufammengemendyen, bnvon $1-2$ nit Stmub: beuteln berfehen 
Staubbentel ganz amgetwad) fen; Staubmañe fleinflappig

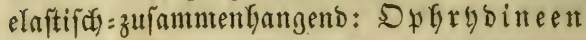

Rippe gefpornt (Frutditfn. getwunben)

Fädher Der Staubb. gleidylaufeno, unterw. meinan= berliegents

Fäd)er ber Staubb. Durd) ein $\mathfrak{B}$ euteldyent berbunbent

Beuteleffen 2färf)rig (Stiele Der Staubutafien auf

2 getrennten $\mathfrak{g}_{\mathfrak{a}}$ Itern eingeje(st):

Orchis 422.

Beutelchen 1 fädofirig (Stiele ber Strubm. auf

1 gemeinid aftl. Sạlter cingejelzt):

Anacamptis 423.

Fandter ber Ctrubb. ofme Benteldyen: Gymnadenia 424.

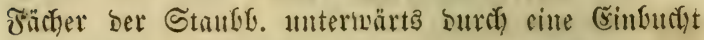
getremut

Sporm Inug fäblict): Platanthera 426.

Eporn furz forfförmin: Leucorchis 425.

Ripye fpornlus

Blitthent). abitésutio, Bentelchen 2: Ophrys 427.

Blütheng. glorfig aufredit, Beuteldyen 0 : Herminium 428.

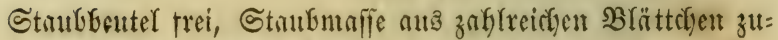
faumentefert ober melylig: Rimodoreen

sippe gefpornt (Sporn aufgeblajar aufred): Epipo-

Sipue fporntos gium 435.

Rippe 2 gliebrig

Frutchtfnoten ungeiticlt gewumben: Cephalanthera 429.

Fructetfn. geiticlt, nicyt gewumben: Epipaclis 430. sippe nicht gegliesert

Blütbenty. glorfig

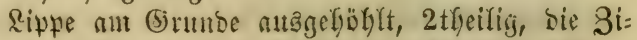
pfel feilfürnig: Neottia 431.

Sippe 2 fpartig herabfangent : Listera 432. B(üthent). ract)enförmig (Rippe eingefdylofīen)

Stmbbeutel fitient: Spiranthes 433.

Staubb. geftielt: Goodyera 434.

Gtaubrutel 1 frei, Stmibmaffe warkgartig: Malaxibinen 
B(ütíenf. nfĩtefent, Riłpe fpornlos: Nalaxis 436. Blütfyen 2 mümig: (Ey)ripedien

Reldy abiftento, Ripte aufgeblafen baudsig: Cypripedium 437.

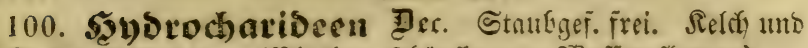

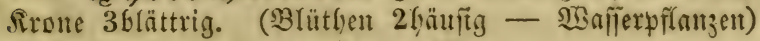

Staulbgef. 9: Hydrocharis 477.

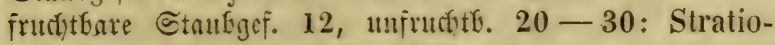
tes 478.

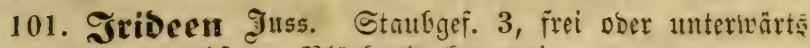
3แโanmengewad jert. Blütfenty. fronartig

Gaum ber Blütyenty. 6 theilig mit abmectyfelno zuriafige: $\therefore$ bognen Bipfeln: Iris 19.

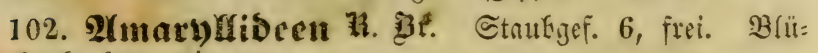
thenty. fronartig

Blütfenfy. tellerförning mit gloffiger Nefenfrome: Narcissus 182.

Blüthent\%. gloofig, tief 6 theilig

Bitfil oer Blittgent). gleidf): Leucojum 181.

intre Bipfel ber Blattyeng. fürzer aแşgeranbet: Galanthus 180.

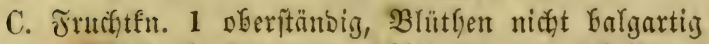

a. Blütyenty. fromartig, 6Grättrig ober 6theilig

103. Riliaceca Đes. Frucht trof́ct mufĩwringent

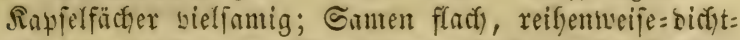
iibereinanderliegend; Samenfaut Gleidy, nidạt fruptig: Tulipeen

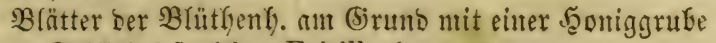
(5rifiel 3 fpaltig: Fritillaria 187.

(5)riffel angetheilt: Lilium 186.

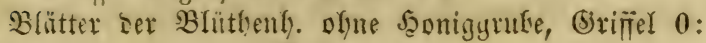
Tulipa 188.

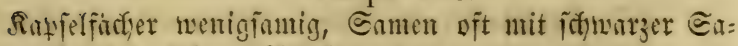

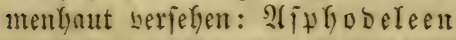

Blüthe gegliebert=geftielt: Anthericum 190.

Blitthe nicht gegliebert=geitielt

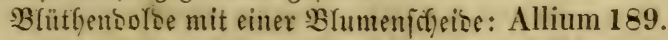

Blüthen ofne Blumenidyeise

Ctrubgefäp̃e เem Frudutfoben eingefïgt: Ornithogalum 192. 
Staubger. Det $\mathfrak{B}$ ajţ̧ der Blütrjenty. eingefügt: Scilla 191.

BBlütbenty. Iblättrig 6zäfnig; Raฟfelfädyer swenigfanig, Somen mit fotwarzer Gamenfaut: Semerocalliben Blütgen fugelförntig: Muscari 185.

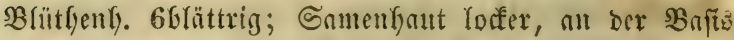
und Spize mit einem 2ubängiel

Staubfäben bärtig: Narthecium 193.

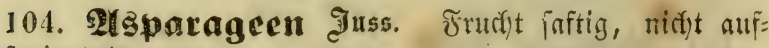
fpringend

Blütbenf. 8Glättrig, immre Blätter fronartig: Paris 210. Blütbenf. 4blättrig flach): Majanthemum 71.

Blütbenty. 6blättrig unterftänoig gegliebert = geftielt: Asparagus 184.

Brütyenf. glurfig ober rölyrig, 6ppaltig ober 6zäfnig: Convallaria 183.

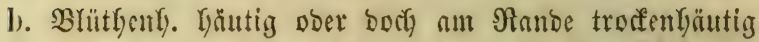
105. Funcacecu Bartl. SBlütgenf. 6blättrig, felđ: förmig, ant Ranoe trorfenbäutig. Blütyen zwitterig.

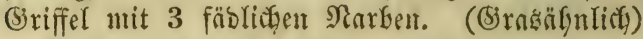

Rapjel vielfamig: Juncus 194.

Sinpler 3 fantig: Luzula 195.

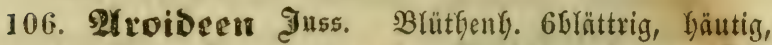
nut ber Spize frnutig, Doex 0 . SBlütgen auf einell Rol= ben geffellt

Blüthen zivitterig (Narbe fïgento ftumtf): Acorus 196.

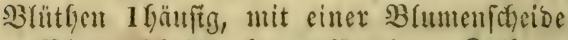

Blamenfdyeibe fappenförmig, Rolben oben naft: Arum 440.

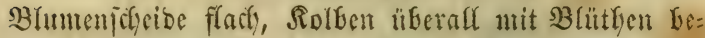
Derft: Calla 439.

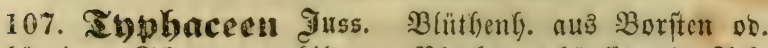
fäutigen Eifuppen gebilbet. Blïtyen 1 bäuftg, in 2lef:

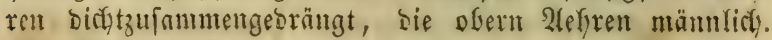
(Nañeryflanzen)

2(eljren walzlich: Typha 444.

2(ef)ret fugelig: Sparganium 145.

108. Irajabeen fik. Blüthenf. 0. Blütben zerftrent. (গ্)afferpflanzen) 


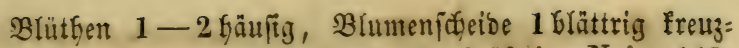
förnig 2-3zäfnig: Najas 442.

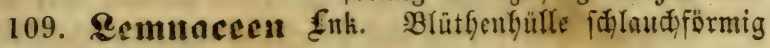
ungetfeilt

Blïtfen zhrittrig, Stnubger. 2: Lemna 4.

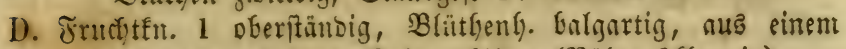

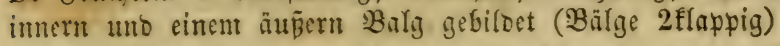

110. Enperacen 311ss. Etaubfeutel an ber Spithe

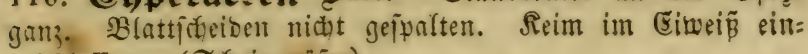

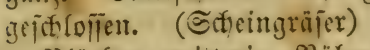

:Błlïthen zwitterig, Bälge 2reigig: (5) bereen

Bäfge zafitreid, mir bie unterften unfrudtbar: Cyperus 21.

Bälge 6-9, nur bie oberiften frudtetbar: Schoenus 23.

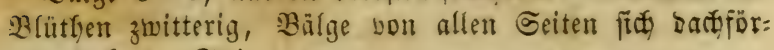
mig beffent: Scirpeen

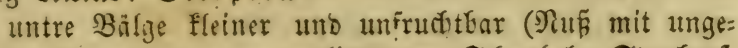
gliebertem Sdfuabel, Staubger.

2): Cladium 15.

untre Bälge gröperer ober gleidgrof́, 1-2 berielten unfruchtbat

Borften eingeidlollen ober 0: Scirpus 22.

Boriten Gerwortretent, viel länger als die Bälge:

Blüthen 1 făultg: (Ea riceen

Eriophorum 24.

innrer $\mathfrak{B a l g}$ eine flafedenförm. Blüthenth. fpäter eine ๔dienfruttit fildend: Carex 446.

111. Giramineen 3uss. Staubfentel an ber @fitze unb an ber Bapis gejpalten. SBlattfdeioen geipalten. Reim auper=

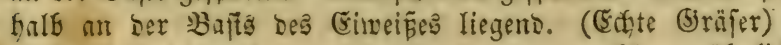

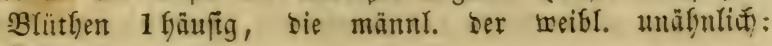
SIi) reen

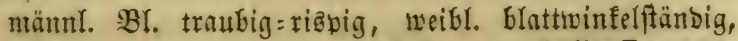
von @efeiben eingefyült: Zea 447.

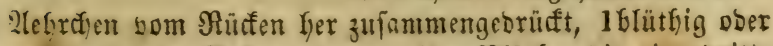

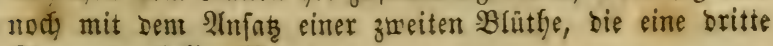
Rlappe barftellt: $\mathfrak{B a n i c e e n}$

untre Rlappe fleiner, an bie fladi)e ober ziemrl. fladte

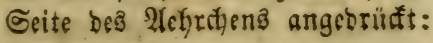
Panicum 35. 
Alehrdien you ber Seite her zufammengebrinft 1 bli:thiy mit einem fpelzigen $2 \mathfrak{l n}$ jab zu einer zweiten ober britten untern $\mathfrak{B}$ lüth)e, ober mit $2-3$ untern mäunl. sBlüthen; Briffel Kang, Narben fáblich Doer faft fprengwedelig, aus

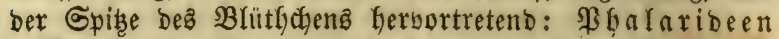
Blütbe am Brande nit 2 grannenlofen Gifuppen: Phalaris 27.

Blüthe am Grounbe mit 2 beyrannten Spelzen, bie Yän= ger ałō bie Bläthen felbft funto: Anthoxanthum 16.

Zlehrdyen bon ber Geite her zufammengebrüfft 1 blütlyig poer nod) mit bem $\mathfrak{2}$ njä zu einer obern Blütye, in einet einfact)en Traube wedfelftänbig voer riäpig; Rlappen fo Iang als bie Blüthen ober länger; (S)riffel lang, Narben werlängert fäblich Gelaart, nub Der Spibe ber BBl. Kerbor= treterlo: $\mathfrak{A}$ lopecuroibeen

Epelzen 1 flappig: Alopecurus 26.

Spelzen 2flappig, Rlappen gefielt, faft gleich), länger al: bie $\mathfrak{B l u ̈ t}$ the: Phleum 28.

2(effrchen von ber Geite Ker zufanmengebrüfft 1 blütbig, in einfeitige 2 (efren georonet und zhar auf ber Hnterfeite ber 2 fehrohenfpindel eingefügt: Cogloribeen

Narbe fprengwebelig, unter ber Spibe beb $\mathfrak{B l u ̈ t}$ ) chents Gerbortreteno: Cynodon 29.

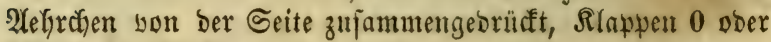
felyr flein: Dryzeen

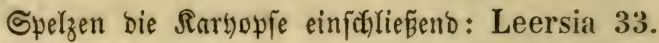

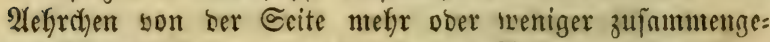
brilft, 16 fütfig ober nod) mit bem 2 lnjatz zu einer obern Blütle; Decfipelzen 2; Griffel 0 ober furz; Narbe fede:

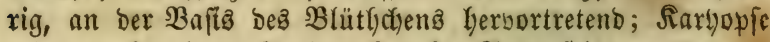
mit ben häutigen Spelzen bebeft: 21 groftibeen

Spelzen fafl ober am (5rumb mit fefre furzen Sanaren umgeben: Agrostis 31.

Epelzen am Grumb mit 5anaren umgeten, bie länger finto alb bie Spelze breit ift: Arundo (Calamagrostis) 32.

Reforthen fontsex, som Räifen ber etwas zujammengebr. (ober ftielrunt) 1 blüthig; (Sriffel 0 ober furz; Narben

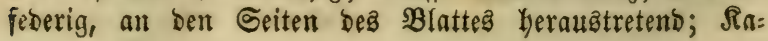


ryoyie yon ben berfärteten Spelzen bichteingemiffelt: Stipnceen

Swelze fïrzer als ber 2 flappige bauddige Blutthe: Milium 30.

2leffrden 2-reidjblütfig; (Srifiel serlängert, Narbe fpreng= unebelig, aus ober über ser Mitte ber Blüthe Gerwortre: tent): $\mathfrak{A}$ runbinaceen

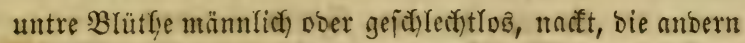
zwittrig, mit verlängerten $\mathfrak{S a n =}$ ren umgeben: Phragmites 36.

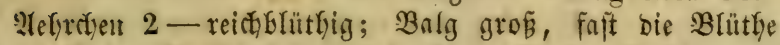
leberfend; Siriffel 0 ober jefr furz; Narbe fäblich, aแเ

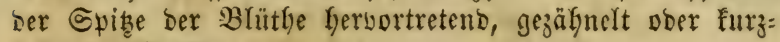
betiant: Seģleriaceen

untre Spelze $3-5$ zäfinig=begrannt: Sesleria 53. Iehrchen 2-reidfblüthig, bie endftäno. Blüthe oft ver: fünmert; $\mathfrak{B} a l g$ grof́, fait bie ganze $\mathfrak{B}$ lïttye untgebent; (5riffel fefye furr ober 0 ; Narben federig, beiberjeits aus ber $\mathfrak{B a f t s}$ Der $\mathfrak{B l u ̈ t}$ he Gerbortretend: $\mathfrak{2}$ yenaceen

2lefrrchen 2 blüthig sielefig

untre $\mathfrak{B}$ lïthe männlid begrannt, obre ztwittrig gran:

nenlos: : Arrhenatherum 37.

untre $\mathfrak{B l a ̈ t}$ the zmittrig grannenlos, ofre mämulia Gegraunt: Holcus 38.

2efrocten 2-bielbrüthig ofwittrig

untre Spelze an ber Spibe abgeiänitten 4 zăgnig,

am Srumb voer nuf Dem ßüufen

begrannt: Aira 39.

untre Spelze an ber Spize 2 fpaltig ober 2gramuig, auf bem ßiuffen begrant: Avena 40. untre Spelze an ber Spibe 3zäfnig, ber mittlere Znfm ftacherfpizzig: Triodia 48.

untre Spelze an ber ungetheilten (ober 2 fpaltigen)

Spize weffrlos ober ftadyelppitzig:

Koeleria 50.

Telyrçen granmenlos, bns untre ober 2 untren woflfom: men zmittrig, bie anbern unboll: fonmen: Melica-41.

2lebreden 2 - reid)blüthig mit ciner oft berfünmerten enb: ftäno. Blüthe, Beftielt; Balgflappen flitzer als bie närofite 


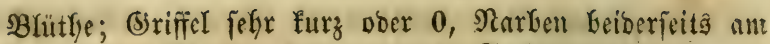

(Srund ber Blüthen Gervortretend: Feftucaceen obre Spelze auf ben Rielen fänmig = geivimpert

Gramme unter ber Spize: Bromus 47.

(branne aแt ber Spike: Brachypodium 51. obre Spelze auf bent Rielen feingenimpert ob. Id) arflict), Blüthohen am (Brumbe ferzförnig: Briza 45.

Blüthent auf beut Rüuffen ftielrund

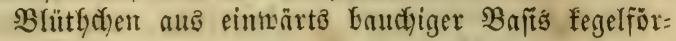
mig = zulauient: Molinia 42.

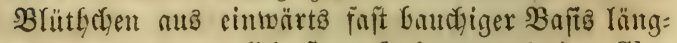
Yicit) : ftumpf (grannenloz): Gly. ceria 43.

Blütrocten Inuzettlidy oocr Yanzettpfrientich

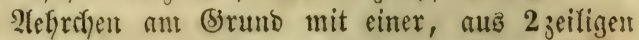
Spelzen zufanmengeferzten 5̧itll: Cynosurus 52.

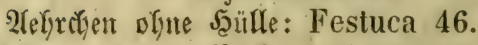

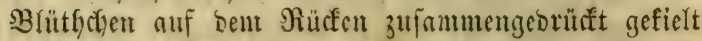
Blütgd)en ftactyelfpibig ober begramut: Dactylis 49 . Blüthen gramentos: Poa 44.

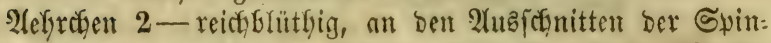
bel fikento; endftänbige Blüthe oft berfümmernd; Briffel fchr furz oder 0 ; Narben federig, beiberi. aus bem (Srumb Der Bläthe Kersortretend: $\mathfrak{g}_{0}$ rbeaceen

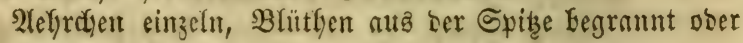
gramentob

Aefrecten ber Spinbel mit ber Seite zugefefirt

RIappen eirumb ob. eirund:Inmettlic): Triticum 54.

Rlappen pfriemtich: Secale 55.

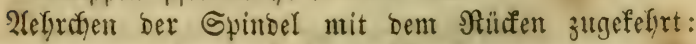
Lolium 56.

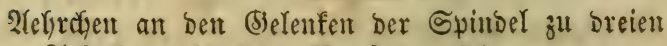
2tefreften 16 füthig; Hordeum 34. 2lefirdyen 2-vielflütgig: Elymus 57.

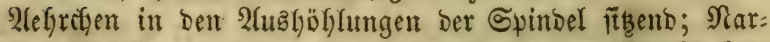
bet iäblid weidjbefanrt, aub ber Spike ber $\mathfrak{B}$ lüthe Ger: nortretend (Balg fehlent): Nardoibeen

Blüthe 1 männig: Nardus 25. 


\section{Bueite filalle.}

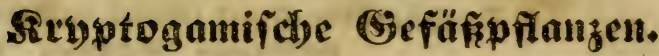

Der Gtengel hat F̆aferGündel mit Gpiralgefäẽen. Die SMur= zel ift fajerig. Bäätter find yorlandent ober feflen. Deutlidje

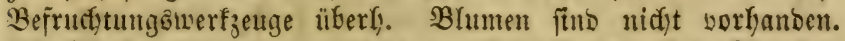

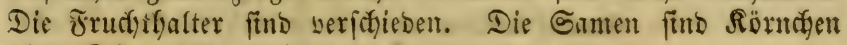
ofue Reinte (Evoren).

A. Stengel gegliebert

112. Squifetaceen 刃ुfr. Stengel blattlos, nebit ben 2leften (wenn joldhe worfyanon) mit gefpaltnen Tuten ungeben

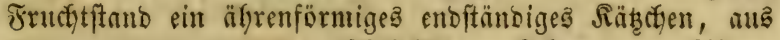
fohiloförm. Sdyuppen gebilbet: Equisetum 481.

B. Etengel ungegliebert, Glattartig Dber blättertragento

I. Blätter uno Stengel gejonbert

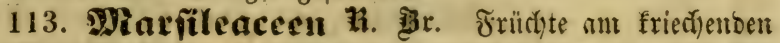

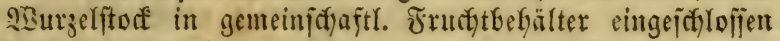
(ivafferyflinzen)

Fruchtber. 4 fächerig, zulekgt in 4 saqpen aufïpringend: Pilularia $\mathbf{4 8 2}$.

114. Sycopodiaceen Dere. Srüd)te cinzeln umb frei zwijđ)en ben Blättern am Gtengel ftehend

Stengel nieberliegend ober friect)ent, $\mathfrak{B}$ (ätter fod)rauben= förnig georonet (meift grün): Lycopodium 483.

II. Blätt. mit bem ๔tengel zu cinem (Glatturtigen) Mebel vereinigt 115. ซarnfräuter voet Filices fீ.

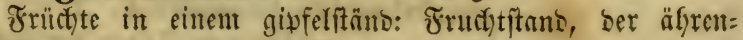
förmig ober rišpe ift: Dphiogloffeen

MSerel getheilt: Botrychium 495.

SSebel ungetyeilt: Ophioglossum 496.

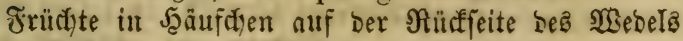

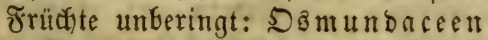

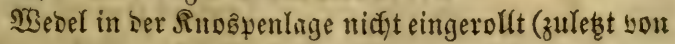
ben Früc)ten oft rispenartig zu= jammuterigezogen): Osmunda 494.

Jrüchte mit einem geglieberten $\Re$ Ring, $\mathfrak{W}$ ebel in ber Iugent eingerolft: Polypobiaceet 


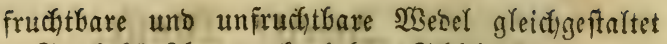
Frndytfäufchen naft (of)ne Sdj(eierdyeri)

zruchthäufchen lineal (Wiedel unterjeiţ mit rofteraunen Schuppen biditbe= befft): Grammitis 484.

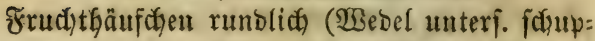
penlog:): Polypodium 485.

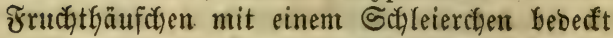

Fruchtlyäufchen punftförmig ober rumolid,

Salleierdyen in ber Mitte Der Frudythäuf: disen angebeftet

Sdgleierdyen freišrund fochild förmig, an ben Geitem überall frei: Aspidium 486. Sif) leierden nierenförnig, bon ber Mitte aแz an ber Geite am nie= renförm. 2luşanitt angebeftet: Polystichum 487.

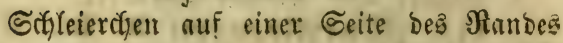
angebeftet, zulebst fichtlich zurürf= gefdidagen: Cystopteris 488.

Frudgthäuf

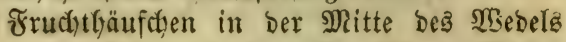
Fruthth). nuf ben Duteradern (19iedel gettrei(t): Asplenium 489.

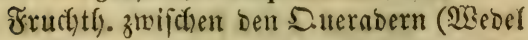
itngetfyeilt): Scolopendrium 490.

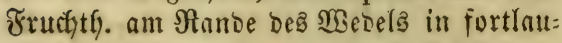
fenoen Rinien: Pteris 491.

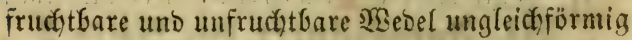
ซrud)tbäufdyen linienförmin, umunterbrocten auf beiben Geiten ber Mlitteirippe (unfruchtbare Tiedel gefiedert): Blechnum 492.

Fruchtbäufchen rumblidy, an beiben Ceiten ber Fiebern, in einander verflofien (unfrudutGare MSedel boppeltifieser= fpaltig): Struthiopteris 493. 


\section{Negiter.}

A.

Acerineae

Acer

- campestre

(139.

- dasycarpum. हुำr. 139

- Negundo

- platanoides

- Pseudoplatanus

- saccharinum

Achillea

- Millefolium

- nobilis

- Ptarmica

Achyrophorus maculatus.

$$
\text { Scop. }
$$

Aconitum

- Lycoctonum

- Napellus

- neomontanum. গ⿺辶. 196

- neubergense, $\Re($ b. 196

- Stoerkianum. $\Re$ dıb. 196

Acorus

- Calamus

Acrostichum septentrionale 357

Actaea

- spicata

Adonis

- aestivalis

- - ochroleuca

- autumnalis

- citrina. $5 \mathfrak{T}$ fim.

- flammea. ङॄq.

- miniata. J゙ฯ, Adoxa

-- moschatellina Aegopodium

- Podagraria

138. 374

139

139

276. 382

300

300

300

119. 400

132

191. 365

192

192. 364

Aesculus

137. 371

- Hippocastanum

Aethusa

137

71. 377

- Cynapium

112

- - agrestis

112

- segetalis. Bnngh. 112

Agrimonia

- Eupatorium

- odorata

Agrostemma

- Githago

Agrostis

167. 365

168

168

150. 372

164

14. 402

- alba. Sdir.

27

- arundinacea

29

- canina

28

- spica venti 27

- stolonifera 27

- - gigantea. (अaub. 27

- - prorepens, 尔. 27

- vulgaris. Bith. 28

- - pumila. $\Re$ d b. 28

- - stolonifera. গ(ey. 28

Aira 14. 403

- aquatica

- caespitosa

- canescens

32

- caryophyllea 35

- coerulea 36

- cristata $\quad 44$

- flexuosa 33

- - montana 33

- montana 33

- praecox 35

- uliginosa. $\mathfrak{W}$ Eुe. 33

139. 385
147 Ajuga - alpina. Bill. 206.389

139. 385 Ajuga alpina. Bill. 206. 389

68. 376 - Chamaepitys. ๔d) 210

105 - genevensis 209 
Ajuga pyramidalis

- reptans

Alchemilla

- alpina

- arvensis. ๔c.

- vulgaris

- - glaberrima

- - hybrida

- - montana

- pratensis

Alismaceae

Alisma

- graminifolium. (86rf). 136

- lanceolatum. 2Bitf.

- natans

- Plantago

- ranunculoides

Allium

- Ascalonicum

- carinatum

- Cepa

- fistulosum

- oleraceum

- Porrum

- sativum

- Schoenoprasum

- sphaerocephalum

- strictum. Eđjrb.

- ursinum

- vineale

Alnus. Trm.

- glutinosa. Bacrtm.

- incana. Dec.

Alopecurus

- agrestis

- fulvus. Sm.

- geniculatus

- paludosus. 23 .

Alsineae

Alsine

- marina

- media

- rubra. $\mathfrak{3 g r 6}$.

- segetalis

- tenuifolia. 2BĞlb.

- verna. BBrtf.

Althaea

- officinalis
209 | Alyssum

209

209

49. 394

57

57

56

56

56

56

56

397

120. 397

136

136

136

136

119. 399

124

124

125

124

125

123

124

124

124

124

123

125

316. 396

334

335

13. 402

25

26

26

26

25

372

150. 372

159

160

159

159

158

158

248. 371

251

Alyssum

Anagallis

Anchusa

Anemone

Anethum

Angelica

Anthemis
- incanum

Amarantaceae

Amarantus

- Blitum

Amaryllideae

Ambrosiaceae

Amelanchier vulgaris. A)(nd). 175

Ammophila arenaria. \&nf.

Ampelideae

Ampelopsis quinquefolia

Amygdaleae

Amygdalus

- communis

- nana

- persica

Anacamptis. $\Re$ d

- pyramidalis

- arvensis

- carnea. Sdjunf.

- coerulea. ভđjrb.

- Monelli. $\Re(\jmath\}$ b.

- tenella

- arvensis. $\mathfrak{N}$. $\mathfrak{B}$.

169. 372

91

371

171

171

171

303. 398

63. 389

77

77

77

77

77

- officinalis

Andromeda

- polifolia

- Hepatica

- nemorosa

- pratensis

- Pulsatilla

- ranunculoides

- sylvestris

- Foeniculum

75

75

- graveolens

- Archangelica

149. 390

153

192. 364

199

199

199

199

200

199

68. 378

106

105

69. 377

- sylvestris

107

- arvensis

276. 383

300

300

- Cotula

300

Anthericum

119. 399

- Liliago

125

125 
Anthoranthum

4. 402

- odoratum

Anthriscus. Şffim.

- Cerefolium. SElim.

- sylvestris. நூரि.

Anthyllis vulgaris. \$ॄ⿰ץ.

- Vulneraria

- - ochroleuca

Antirrhineae

Antirrhinum

- arvense

- Cymbalaria

- Elatine

- Linaria

- majus

- minus

Apera spica venti. Beauv.

Aphanes arrensis

Apium

- graveolens

- Petroselinum

Apocyneae

Aquifoliaceae

Aquilegia

- vulgaris

Arabis

68. 376

105

114

392

391

191. 364

197

233. 378

240

- brassicaeformis. $9 \mathfrak{3}$ rr. 239

- Halleri

- hirsuta. $\sigma_{c}$.

- sagittata. Dec.

- Thaliana

Araliaceae

Arbutus Uva ursi

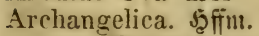

Arctium

officinalis

- Bardana. 20Iீ.

- Lappa

- majus. Sđjf.

- minus. $\left.\sigma^{\prime}\right)_{\text {t. }}$

Arctostaphylos. शిonż. 149. 390 Arenaria officinalis. $\mathfrak{3}$. Br.

240

240

239

244

379

153

64. 377

107

274. 383

286

286

286

286

153

150. 373

- rubra
- Orontium

- spurium

- arenosa. Ec.

Arenaria tenuifolia

$15 S$

- trinervia

159

- verna

Aristolochieae

159

Aristolochia

393

305. 393

- Clematitis 315

Armoracia. Fl. $\mathfrak{W}$. 232. 369

- rusticana. Fr. গুB. 237

Arnica

276. 383

- montana

298

Aroideae

400

Arnoseris. Srrtn.

- pusilla. Bistn.

285

Arrhenatherum. Bn. 14. 403

- elatius. IR. $\Re$.

- - bulbosum

Artemisia

- Abrotanum

- Absinthium

- campestris

- Dracunculus

- pontica

- vulgaris

Arum

274. 484

285

32

32

275. 382

290

290

290

291

290

291

315. 490

- maculatum

319

Arundo

14. 402

- arenaria

29

- Calamagrostis

- Epigeios

28

- - glauea

28

- Halleriana. Dec.

28

- Phragmites

29

- sylvatica. Sdjr.

Asarum

166. 393

- europaeum

Asclepiadeae

167

Asclepias Vincetoricum 397

Asparageae 400

Asparagus $\quad 118.400$

- officinalis 122

Asperula

48. 385

- cynanchica 52

- galioides. $\mathfrak{R}$. $\mathfrak{B} . \quad 53$

- odorata

52

Asphodeleae

Aspidium. $\Re$. $\mathfrak{B r}$.

399

406

- aculeatum. Sw. 354

- - Swartzianum 355

355

- serpyllifolia

159 
Aspidium Oreopteris. Siv. 355

- spinulosum. ऽiv.

Asplenium

- Adiantum nigrum

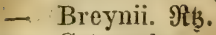

- Ceterach

- Filix femina. BBrnf.

- germanicum. 쮸.

- Ruta muraria

- Scolopendrium

- septentrionale. Sw.

- Trichomanes

Aster

- Amellus

- Novae Belgiae

- salignus

- Tripolium

Astragalus

- glycyphyllus

Athamanta Libanotis

276. 391

297

297

297

297

254. 367

265

112

Atriplex

67. 395

- angustifolium. Sm.

- hortense

101

- hastifolium. Sarre.

- - microcarpum

- - salinum

101

102

102

- oppositifolium. Dec.

- patulum

- - angustissimum

- patulum. Sin.

- roseum

- ruderale. $\mathfrak{B r}$ r.

Atropa

65. 392

- Belladonna

Avena

15. 403

- caryophyllea. $2 \mathfrak{3 g g}$.

- elatior

- fatua

- flavescens

- flexuosa. Bhfr.

- orientalis. 巨djeb.

- praecox. 28 .

- pratensis

- pubescens

- sativa

- strigosa. $3 \mathfrak{y}$.

- tenuis. Minds.

102

102

101

102

102

102

102

32

34

34

33

\section{B.}

Ballota

- alba.

207. 388

- borealis. Sdfum.

218

- foetida. Eam.

218

- - marrubioides. $\mathfrak{R} 6.218$

- hirta. H. b.

218

- nigra

218

Balsamineae

371

Barbarea. $\Re$. $\mathfrak{B r}$. 223. 378

- arcuata. $\Re d b$.

240

- hirsuta. Mghe.

2 '10

- praecox. R. $\mathfrak{B r}$.

- stricta. 2 tnbr.

241

- vulgaris. $\mathfrak{A}$. $\mathfrak{B}$ r. $\quad 250$

Barkhausia foetida. Dec, 280

Bellis

- perennis

276. 381

Berberideae

293

Berberis

118. 364

364

- vulgaris

120

Berula. Rłk.

71. 377

Beta

- vulgaris

- - Cicla

111

- - rapacea

Betonica

- hirta. $\varepsilon \pi$.

- officinalis

67. 395

102

102

102

207. 388

220

220

- officinalis. Sur.

220

220

Betula

318. 396

- alba

339

85

- carpati

ca. MIIto.

339

- davurica. \$all.

339

- odorata. $B$ diff.

339

- pubescens. (S6rf). 339

Betulineae

396

Bidens

275. 382

- cernua

290

- - eradiata

290

- - minima

290

- - radiata

290

- tripartita

Biscutella

290

231. 370

234

Blechnum

406

358 
Blechnum Spicant. $\Re(i f)$.

Blitum

1. 395

- Bonus Henricus. Mew. 99

- capitatum

- virgatum

Boragineae

Borago

- officinalis

Botrychium. Siv.

386

63. 396

74

405

359

- matricariaefolium. Sm.359

- rutaceum. Siv.

359

Brachypodium. $\mathfrak{B v}$.

- caespitosun. 5 fit.

- pinnatum. $\mathfrak{B} v$.

16. 403

45

45

Brassica

- alpina

- - esculenta

- - oleifera

- nigra. Riff.

- oleracea

- acephala

- - botrytis

- - capitata

- - gemmifera

- - gongyloides

- _ sabauda

- orientalis

- Rapa

- - campestris

- _ esculenta

_ _ oleifera

Briza

- media

15. 403

233. 369

239

242

243

243

243

242

242

242

242

242

242

242

242

242

242

2,4

242

- _ flavo-virens

Bromus

- arvensis

- asper

- commutatus. Sđjro.

- grossus. (S).

- grossus. $\mathfrak{B G}$ ?

- inermis

- mollis

- pinnatus

- racemosus

- secalinus

- - grossus

- _ velutinus

42

43

43

45

43

42

42

42
Bromus sterilis

44

— tectorum ... 44

- velutinus. Sifrs.

Bryonia

318. 380

- alba

340

340

Bulliarda. Dec. 50. 365

- aquatica. Dec. 62

Bunium Bulbocastanum 105

Bupleurum $\quad 68.376$

$\begin{array}{ll}\text { - falcatum } & 104 \\ \text { - longifolium } & 104\end{array}$

- longifolium 104

Butomus 148. 379

- umbellatus 148

Buxus 317. 393

- sempervirens $\quad 335$

\section{C.}

Calamagrostis Epigeios. アRth. 28

- glauca. $\Re\left(\xi \mathbb{G}_{\text {. }}\right.$

- lanceolata. $\Re$ th.

- sylvatica. Dec. 29

Calamintha. Mind). 207. 387

- Acinos. (51. 222

- officinalis. IInd). 222

Calendula officinalis. $\quad 303$

Calla

315. 400

- palustris

318

Callitriche

1. 393

- angustifolia. jovve. 2

- autumnalis 3

- hamulata. Rib.

- intermedia. நvve. 2

- minima. Sappe. 2

- platycarpa. R̄t. 2

- stagnalis. ఠcop. 2

- stellata. Fुppe. 2

- vernalis. $\mathfrak{\text { Ib. … }} 2$

Callitrichineae 293

Calluna vulgaris. $ธ$ เซื 143

Caltha

192. 364
- palustris

Camelina. Crng̨.

- dentata. \$eri.

- sativa. Cornt.

Campanula
- sylvestris. J̃r.
195

232. 369

238

237

237

65. 381 
Campanula Cervicaria

- elliptica. Rit.

- farinosa. Atnor.

- glomerata

- - aggregata

- - elliptica

- - farinosa

- hispida. \&ej.

- latifolia

- Medium

$\therefore$ patula

- persicifolia

- - canescens

- - scabriuscula

- rapunculoides

- - racemosa

- Rapunculus

- glabrata

- rotundifolia

- - velutina

- Speculum

- Trachelium

- - dasycarpa

- urticifolia. Sd

Campanulaceae

Cannabis

- sativa

Caprifoliaceae

Capsella. Bnt.

Bursa pastoris. Iit). 237

Cardamine

$$
\begin{aligned}
& \text { - amara } \\
& \text { - - glaberrima } \\
& \text { - dentata. Sfilte. } \\
& \text { - hirsuta } \\
& \text { - } \text { - multicaulis } \\
& \text { - impatiens } \\
& \text { - pratensis } \\
& \text { - sylvatica. } \mathfrak{i n f} .
\end{aligned}
$$

Carduus

- acanthoides

- acaulis

- crispus

- lanceolatus

- Marianus

- nutans

- - integrifolius

- palustris
89

89

89

89

89

89

89

88

88

89

87

88

88

88

88

89

88

88

87

87

89

88

88

88

380

341. 394

347

232. 370

234. 378

246

246

246

246

245

245

245

245

246

245

274. 383

287

288

287

287

287

286

287

288
385
Carduus tenuiflorus. (8)t. $28 \%$

Carex

316. 401

- acuta

327

- agastachys. (Eீ)ry. 330

- ampullacea. \$5ood. 333

- arenaria

- argyroglochin. S5rm. 325

- axillaris. Bood.

- binervis. ভm.

327

- Boenninghaus. $\mathfrak{B h e . ~} 326$

- brizoides

325

- Buxbaumii. 236 (6. 328

- caespitosa

327

- canescens

326

- clandestina. Bood. 329

- curta. \$000.

- Davalliana

- digitata

326

- - argyroglochin 330

- dioica

- distans

- disticha. 5968.

- divulsa. Bovo.

- - gracilis

- Drymeja. Eryry.

- elongata

- ericetorum. ßoff.

- filiformis

- flava

- - angustifolia

- fulva. Brocb.

- - glaúca

- glauca. હrp.

- guestphalica. Bnngh. 324

- heleonastes. 86rh. 326

- hirta 334

- - glabrata 334

- hirtaeformis. \$err. 334

- Hornschuchiana. 5ૃ๋e. 332

- humilis. \&ff. $\quad 329$

- intermedia. (3000.. 323

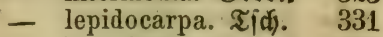

- leporina 325

- leptostachys. EGrh. 330

- limosa 326

- loliacea $\quad 326$

- maxima. ธ๙р. 330

- montana 328

- muricata 323

- nemorosa. Iam. 


\section{Re if iter.}

Carex neinorosa. গึrı.

- Oederi. (Ehrh.

- pallescens

- paludosa. Sordo.

- panicea

- paniculata

_ pendula. (5seró.

- pilulifera

- praecox. Ira.

- Pseudo-Cyperus

- pulicaris

- recurva.

- remota

- riparia. (5ntr.

- Schreberi. Eifft.

- stellulata. SJood.

- stricta. (5000b.

- strigosa. Şסв.

- sylvatica. \$203.

- teretiuscula. Bono.

- umbrosa. 5 fif.

- vesicaria

- virens. \&am.

- virens. J̦ppe.

- vulgaris. Fr..

- vulpina

- nemorosa

Carlina

- acaulis

- vulgaris

Carpinus

- Betulus

Carum

- Bulbocastanum. Riti. 105

- Carvi

Castanea

- rulgaris. $\Omega_{m}$.

Caucalis

\section{- daucoides}

- grandiflora

- latifolia

- leptophylla

Celastrineae

Centaurea

\section{- benedicta}

- Calcitrapa

- Cyanus

- decipiens. $\mathfrak{2}$.

- Jacea

- montana

317. 396
323 | Centaurea nigra

331

331

333

330

324

330

328

3:9

332

322

330

325

333

325

325

327

330

332

32 't

329

333

324

324

327

323

323

274. 383

289

289

318. 396

338

68. 376

105

338

69. 379

106

107

107

107

374

277. 383

302

302

302

301

301

302

- plirygia

- Scabiosa

- solstitialis

Centunculus

- minimus

Cerastium

- arvense

Ceratophylleae

Ceratophyllum

Chaerophyllum

- bulbosum

- hirsutum

- sylvestre

- temulum

Chaiturus. Şf̂.

Cheiranthus

- Cheiri

Chelidonium

- majus

Chenopodeae

Chenopodium
- nigrescens. Dec.

- pratensis. Th.

- - spinulosa

Cephalanthera Rids.

302

301

301

301

302

302

302

49. 389

55

ensifolia.

- ensifolia. Ri(t).

- pallens. Ridj.

- rubra. Ridr.

311

- aquaticum

- brachypetalum. Dix. 164

- - eglandulosum

- glomeratum. Thfl.

- - apetalum

- glutinosum. Tr.

- pumilum. Flutt.

- semidecandrum

- triviale. \&nt.

150.

311
373

164

165

— - subglabrum

- demersum 336

165

164

$16 \pm$

165

165

167

165

165

394

- platyacanthum. (8fm. 336

- submersum

336

70. 379

110

110

111

110

207. 389

- Marrubiastrum. 9idjb. 221

233. 278

239

- _ fruticulosus

239

- laciniatum. शnill 193

193

395

6\%. 395

- acutifolium. Rit.

101

100

- - albo-viride $\quad 100$

- - cymigerum

100

100 
Chenopod. album spicatum 100

- - viridi-album 100

- Bonus Henricus

- ficifolium. Sm.

- glaucum

99

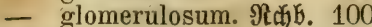

- hybridum

- murale

- olidum. Curt.

- opulifolium. Sffrb.

- paganum. $\Re$ đb.

- polyspermum

- - cymoso-racemos.101

- - spicato-racemos.101

- rubrum

- urbicum

- viride

- Vulvaria

Chrysanthemum

- corymbosum

- inodorum

- leucanthemum

- - hirsutum

- segetum

Chrysocoma

- Linosyris

Chrysosplenium

- alternifolium

- oppositifolium

Cichorium

- Endivia

- Intybus

Cicuta

- virosa

Cineraria

- palustris

101

99

99

100

101

100

100

101

01

100

101

276. 382

299

299

299

299

298

275. 381

289

149. 380

153

153

274. 384

286

286

72. 377

114

276. 383

296

- spathulaefolia. $\mathbf{G m}$.

Circaea

- alpina

- intermedia. (Eghrf.

- lutetiana

Cirsium. Trnf.

- acaule. Arrt.

- - caulescens

- arvense. Sc.

- - mite

- - vestitum

- decoloratum. Rifi.

- hybridum. Reff.

- lanceolatum. Sc.
4. 380

11

11

11

274. 383

288

288

288

288

288

289

288

287
Cirsium oleraceum. Sc.

288

- palustre. Sc.

288

- rigens. Wlltr.

289

Cistineae

370

Cistus Helianthemum

195

Cladium. $\mathfrak{3}$. $\mathfrak{B r}$.

4. 401

- germanicum. ๔djrab. 12

- Mariscus. $\mathfrak{A}$. $\mathfrak{B r} . \quad 12$

Claytonia perfoliata

Clematis

- Vitalba

Clinopodium

192. 364

200

- vulgare

207. 387

Cnicus acauli-oleraceus 222

289

- palustri-olerac. Effo. 288

Cochlearia

232. 369

- Armoracia

237

- Coronopus

235

- officinalis

237

Colchicacear

397

Colchicum

119. 397

- autumnale

133

Collomia grandiflora

Comarum

80

- palustre

Compositae

Coniferae

Conium

- maculatum

Convallaria

- bifolia

- majalis

- multiflora

- Polygonatum

- verticillata

Convolvulaceae

Convolvulus

- arvensis

64. 39

80

80

Conyza

275

- squarrosa

293

Corneae

Cornus

- mascula

- sanguinea

Coronilla

379

49. 379

56

56

255. 367

270

270

Corrigiola

72. 273

116 
Corydalis. $\mathfrak{3}$ ent.

- bulbosa. \$erí.

- cava. Erfiv.

- claviculata. Der.

- digitata. \$erí.

- fabacea. \$erí.

- lutea. Dec.

- solida. ভin.

Corylus

- Avellana

- tubulosa. Mntro.

Cotoneaster. Yito.

Cotula

- coronopifolia

Crassulaceae

Crataegus

- Aria

- monogyna. Jarq.

- Oxyacantha

- - digyna

- - intermedia

- - monogyna

_ - villosiuscula

- torminalis

Crepis

- agrestis. $\mathfrak{R}$. .

- biennis

- foetida

- paludosa

- pinnatifida. Minfr.

- praenorsa. Tij.

- tectorum

- virens

- - agrestis

Critamus. $\mathfrak{B} 11$.

Cruciferae

Cucubalus

- bacciferus

- Behen

Cucumis Melo

- sativus

Cucurbita Pepo

Cucurbitaceae

Cupuliferae

Cuscuta

- Epithymum

- Epilinum. \$rge.
253. 371

255

255

256

256

256

256

256

318. 396

338

338

169. 375

174

275. 382

293

365

169. 375

175

173

173

173

173

173

173

175

273. 385

281

280

280

281

$2 \mathrm{S1}$

280

281

281

281

71. $37 \pi$

113

278

150. 372

157

157

340

340

340

380

395

67. 391

99

99
Cuscuta europaea

Cydonia. Эッाা.

99

170. 375

- maliformis. MR氏. 175

- pyriformis. Ilill. 175

- vulgaris. ßer. 175

Cynanchum. $\mathfrak{R}$. $\mathfrak{B r}$.

67. 392

- Vincetoxicum. $\Re$. $\mathfrak{B r} .97$

Cynodon. Ridy.

13. 402

Cynoglossum

- montanum. Ram.

- officinale

Cynosurus

- coeruleus

16. 404

63. 386

73

74

- cristatus

Cyperaceae

Cyperus

- flav̀escens

- fuscus

Cypripedium

- Calceolus

Cystopteris. Bernh.

- fragilis. Bernh.

Cytisus

- Laburnum

- - quercifolia

- sagittalis

45

45

401

13. 401

20

20

304. 399

314

406

256

253. 366

260

260

250

\section{D.}

Dactylis

15. 404

- glomerata 44

Daphne

138. 395

144

Datura

64. 392

- Stramonium 81

Daucus

69. 378

106

106

Delphinium 191. 365

196

- Ajacis

196

Dentaria

233. 378

243

149

Dianthus

155

155

156

156

155 
Dianthus deltoides

- prolifer

- superbus

Digitalis

- fulva. Rinol.

- grandiflora. \&am.

- lutea

- purpurea

Digitaria

Diplotaxis. Dec.

- tenuifolia. Dec.

Dipsaceae

Dip'sacus

- fullonum

Draba

pilosus

-- verna

Drosera

- anglica. J20

- intermedia. 5 กู.

- longifolia

- rotundifolia

Droseraceae

154

156

156

209. 391

230

231

230

230

230

234. 369

246

385

48. 385

50

51

232. 369

238

72. 370

117

117

117

117

370
- virgineus

- ambigua. Murt.

155

\section{E.}

Echinochloa Crus galli. Beaut 31 Echium

63. 386

- vulgare

73

- Wierzbickii. \$2а5.

Elatine

73

139. 374

- Hydropiper

Elatineae

147

374

Elsholtia. sistlo.

- cristata. Nillo.

Elymus

- caninus

- europaeus

Empetreae

Empetium

- nigrum

Endymion nutans. Dum.

Epilobium

- angustifolium

- collinum. Bs!

- hirsutum

- - glabriusculum

- latifolium. $\Re$ tf.
206. 387

213

16. 404

46

47

341

346

125

138. 379

140

141

140

140

140
Epilobium lanceolatum. S. $\$ 2.141$

- montanum

- lanceolatum

- - ovato-lanceolat. 141

- - ramosissimum

- - verticillatum

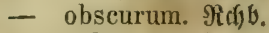

- palustre

- - dentatum

- parviflorum. Sd)rb.

- - subglabrum

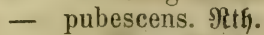

- rivulare. Bgftb.

- roseum

$1+1$

$1+1$

141

141

142

142

142

140

141

140

141

- Schmidtianum. Rfft. 142

- tetragonum

- virgatum. テัr.

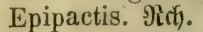

142

- atrorubens. $\Re$ d b b. $\quad 312$

- ensifolia. Siv. . 311

- latifolia. 2tIf.

311

- _ rubiginosa.(5) 312

- microphylla. Effr. 312

- pallens. $\Re$ is.

- palustris. Ex.

- rubra. Roth.

Epipogium. (Sm.

- aphyllum. (S) $\quad 314$

Equisetaceae

Equisetum

312

312

- arvense $\quad \mathbf{3 5 0}$

- - decumbens : 350

- nemorosum 350

- campestre. S(f) 350

- hyemale 351

- limosum ... 351

- nemorosum. Brm. $\quad 350$

- palustre 351

- - polystachium 351

- pratense. $\Re$ th. $\quad 350$

- sylvaticum $\quad 350$

- Telmateja. Sfrrf. 350

- umbrosum. Net). 351

Eragrostis poaeoides. Benuv. 27

Eranthis. S186. - hyemalis. ๔โริ6. 197

Erica

- Tetralix

- vulgaris

138. 390

144

143

Ericineae 
Erigeron

$$
\begin{aligned}
& \text { - acris } \\
& \text { - } \\
& \text { - } \text { - rumilis } \\
& \text { - canadensis }
\end{aligned}
$$$$
\text { - serotinus. } \mathfrak{W} \text { Łe. }
$$

Eriophorum

- angustifolium. $\Re(f y$.

- - elatius. Rat).

- - minus. R̂(f)

- gracile. $5 \mathrm{~m}$.

- gracile. Riff.

- latifolium. Spppe.

- polystachium

- triquetrum. Senpe.

- vaginatum

Erodium. ' 2 'S.

247. 373

- chaerophyllum. 巨as. 243

- cicutarium. $2 \mathfrak{x}$.

- moschatum. Ilit.

- pimpinellifolium. ๔m. 248

Erucastrum. ßrริ!.

233. 369

- inodorum. $\Re(b$.

- Pollichii. Sdfmit.

Ervum

- gracile. Dec.

- hirsutum.

- Lens

- monanthos

- tetraspermum

Eryngium

- campestre

Erysimum

\section{- Alliaria}

- Barbarea

- cheiranthoides

- hieracifolium. İ

- odoratum. (ङ̧rr).

- officinale

243

255. 367

269

269

269

270

269

67. 376

103

233. 369

244

240

211

211

241

244

- orientale. $\mathfrak{A}$. $\mathfrak{B}$ r.

Erythraea: $\Re$ (f).

- capitata. भ. (5)

- Centaurium. \$eri.

- pulchella. Fr.

- ramosissima. \$crí.

Eupatorium

- cannabinum

Euphorbia

275. 381

289

315. 393

320
Euphorbia dulcis

319

- Esula

- exigua

320

- Gerardiana. ฐ̃๕q.

319

- helioscopia

320

- Lathyris

319

- palustris

319

- Peplus

320

- platyphyllos

Euphorbiaceae

Euphrasia

319

319

393

- coerulea. Tfक.

208. 390

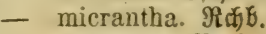

226

- nemorosa. \$erf.

- Odontites

- officinalis

- pratensis. $\Re$ f 5 .

226

- Rostloviana. 5ुne.

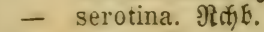

Evonymus

226

226

225

226

226

226

-- europaeus

Exacum

66. 374

91

49. 392

-_ filiforme. MIIÍ.

\section{F.}

Fagopyrum esculentum. Mid 147

Fagus

-- Castanea

317. 395

-- sylvatica 338

337

Farsetia. $\mathfrak{A}$. $\mathfrak{B}$ r.

232. 369

238

18

Fedia Auricula. $\mathfrak{B h f .}$

18

-- carinata. $\mathfrak{B} 6 !$.

-- dasycarpa. Stv.

18

-- dentata. 刃刃gr.

18

-- olitoria. Srtnr.

18

-- tridentata. Sicrib.

Festuca

18

-- arunainacea. Ecfrb. 41

-- aspera. Mi. R.

-- bromoides

43

-- capillata. $\mathfrak{I m}_{\mathrm{m}}$

39

-- decumbens

40

-- duriuscula

-- elatior. Sm.

-- elongata. (5i)ri.

-- gigantea. Biff.

-- glauca. Sतfró. 
Festuca guestphalica. $\$ 3$ mugh. 40

-- heterophyl'a $\mathrm{in}$.

-- loliacea. 508.

-- Myurus

-- ovina

_- _- duriuscula

_- _- glauca

_- .- valesiaca

-- paludosa. (5)D.

-- pratensis. \$ூరత.

-- Pseudo-Myurus. ๔oł. 39

-- rubra

-- sylvatica. Bill.

-- tenuifolia. Sbty.

-- valesiaca. Erffl.

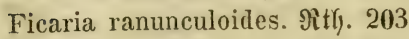
Filago arvensis

-- gallica

-_ germanica

-- pyramidata. (5)oud. 291

Filices

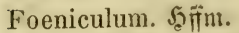

-- officinale. 2 rff.

Fragaria

-- chiloensis

-- collina. Effrf.

-- elatior. (Efrif).

-- grandiflora. (ङ

-- semperflorens

-- sterilis

-- vesca

-- -- pratensis

-- $\quad$ - semperflorens

-- virginiana. Ehth.

Fraxinus

-- americana

-- excelsior

-- pendula

Fritillaria

-- Meleagris

Fumaria

-- bulbosa

-- lutea

-- officinalis

-_ _- media

-- parvifiora. Eam.

-- Vaillantii. \&oiß.

Fumariaceae

\section{6.}

Gagea v. Ornithogalum. 119 Galanthus

118. 399

-- nivalis

120

Galeobdolon. ફூธรి.

207. 388

218

Galeopsis

207. 385

-- acuminata. $\Re$ dry.

217

-n angustifolia. Effrff.

-- bifida. Bimgli.

-- canescens. Ers.

216

-- cannabina. $\mathfrak{R}$ tfj.

217

-- Galeobdolon

216

218

-- grandiflora. Effrif. 217

-- Ladanum 216

-- latifolia. 5 ffin. $\quad 216$

-- ochroleuca. \&m. 217

- Tetrahit 217

-- versicolor. Crt. 217 Galium 48. 385

-- agreste. $\mathfrak{N}$ Ir.

-- Aparine

53

-- boreale

53.

-- Cruciata. ธ๕p.

54

-- hercinicum. IIggl.

52

-- Mollugo

-- palustre

-- saxatile

-- scabrum. §rf.

-- spurium

-- sylvaticum

-_ -- pubescens

-- sylvestre. $\Re$ off.

-- -- glabrum

-_ - hirtum

-- tricorne. $\mathfrak{B t}$ t).

-- uliginosum

-- Vaillantii. Dec.

-_ verum

54

54

53

54

54

53

53

54

54

54

54

52

53

53

53

-- _- ochroleucum 53

-- -- verosimile 53

Genista

-- anglica

253. 366

-- arcuata. $\mathfrak{A r}$.

259

-- germanica

259

-- pilosa

259

-- sagittalis

259

-- tinctoria 
Gentiana Amarella

$$
\begin{aligned}
& \text {-- -- uliginosa. } \\
& \text {-- campestris } \\
& \text {-. Centaurium } \\
& \text {-- ciliata } \\
& \text {-- cruciata } \\
& \text {-- filiformis } \\
& \text {-- germanica } \\
& \text {-- Pneumonanthe } \\
& \text {-- uliginosa. SMgirto. } \\
& \text {-- verna }
\end{aligned}
$$

Gentianeae

Geraniaceae

Geranium

-_ cicutarium

-- columbinum

-- dissectum

-- lucidum

-- macrorrhizon

-- molle

-- moschatum

-- palustre

-- phaeum

-- pratense

-- pusillum

- pyrenaicum

-- Robertianum

-- rotundifolium

-- sanguincum

-- sylvaticum

Geum

-- intermedium. Cinify.

-- rivale

-- urbanum

(iladiolus imbricatus

Glaux

-- maritima

Glechoma

-- hederacea

-- -- major

-_ _- villosa

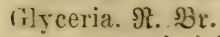

-- aquatica. Эะ\{1.

-- distans. Mmদrlb.

- fluitans. $\Re$. RBr.

-- spectabilis. 2)t. Gnaphalium

-- arenarium

-- arrense. פisílo.

-- dioicum
95

98

98

79

98

97

55

98

97

98

98

391

373

248. 373

248

251

251

250

249

251

248

250

249

249

251

250

250

251

249

249

150. 365

190

190

190

19

66. 389

96

206. 388

214

214

214

15. 404

37

36

36

36

275. 382

293

291

292
Gnaphalium gallicum Sm. 292

-- germanicum. গ3గto. 291

-- -- pyramidatum 291

-- luteo-album

292

-- margaritaceum

292

-- minimum. $5 \mathrm{~m}$.

-- montanum. 2⿰氵冗帀.

291

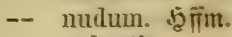

-- sylvaticum

-- uliginosum

291

292

292

-- -- glabrum

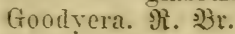

292

292

-- repens. গR. $\mathfrak{B}$ :

Gramineae

Grammitis. Sir.

-- Ceterach. Siv.

Gratiola

-- officinalis

Grossularieae

304. 398

313

401

405

353

3. 391

9

375

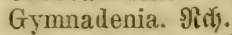

303. 398

-- conopsea. গ̊. S3r. 308

-- odoratissima. Ad 309

Gypsophila

-- muralis

149. 372

156

\section{II.}

Habenaria albida. $\mathfrak{A}$. 3 r. $\quad 309$ -- riridis. $\Re .3 \mathrm{r}$. $\quad 309$

Halorageae

330

Hedera

66. 379

96

Heleocharis acicularis. $\Re$. $\mathfrak{B}$ เ 20 -- multicaulis. Rínol. 21

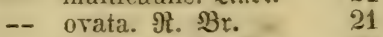

-- palustris. $\Re$. 3 r. 20

-- uniglumis. Inf.

Helianthemum

191. 370

-- rulgare. Bitn.

Helianthus

-- annuus

-- tuberosus

Helleborus

-- hyemalis

-- niger

-- viridis

277. 382

301

301

192. 364

197

195

198

Helminthia. эuा.

273. 384

281 
Helosciadium. $\mathfrak{R}$ ity.

71. 376

Hippurideae

393

-- inundaturn. $\mathfrak{N}(\mathfrak{f})$.

-- nodiflorum. Rirj.

-- repens. Iits.

Hemerocallis fulva

114

113

113

123

Hepatica triloba. Def.

Heracleum

199

-- elegans. İr.

-- Sphondylium

69. 378

108

103

-- _- angustifolium

108

Herminium. $\mathfrak{R}$. $\mathfrak{B r}$.

30\%. 398

-- Monorchis. $\mathfrak{R}$. $\mathfrak{B}$ r. 310

Herniaria

-- glabra

67. 373

-- hirsuta

102

Hesperis

102

\section{-- inodora \\ -- matronalis \\ -- tristis}

378

239

239

Hieracium

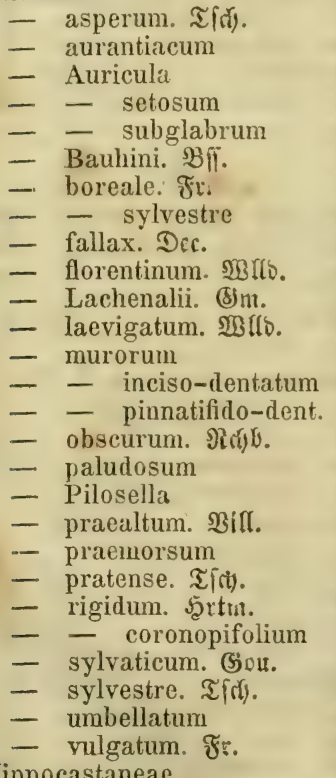

239

273. 385

283

28.

281

281

281

282

283

283

282

282

283

283

282

283

283

282

281

231

282

280

282

283

283

283

283

25't

283

Hippocastaneae

Hippocrepis

255. 367

Hippuris

1. 393

Holcus vulgaris

14. 403

- bulbosus. હifito.

- lanatus

32

- mollis

Holosteum

- umbellatum

32

Hordeum

16. 372

- bulbosum. Pּutt.

14. 404

- distichum

30

- hexastichon

30

- murinum

30

- pratense. 52br.

30

- secalinum. Săkb.

30

- strictum. DeEf.

30

- vulgare

30

- coeleste

29

- Zeocriton

30

Hottonia

30

- palus

64. 389

79

Humulus

341. 394.

- Lupulus

347

Hutchinsia. $\Re$. Br. $\quad$ 232. 370

- petraea. $\mathfrak{R}$. $\mathfrak{B r}$.

Hyacinthus botryoides

237

Hyacinthis botryoides

122

Hydrocharideae

Hydrocharis

125

- Morsus ranae

Hydrocotyle

- vulgaris

Hyoscyamus

399

- agrestis. Ifft.

- niger

342. 399

348

67. 376

103

64. 392

81

- - agrestis 81

Hyoseris pusilla . 285

Hypericineae

Hypericum

271.373

- commutatum. RIte.

- dubium. Ers.

- elodes

- hirsutum

- humifusum

- montanum

27.

- comosa

371

- perforatum

- - latifolium

272

271

272

271

- pulchrum

271

270

quadrangulum

271 
Hỵpericum quadrangulare.

$$
\text { Sill. }
$$

- tetrapterum. $\widetilde{.}$

Hypochoeris

$$
\begin{aligned}
& \text { - glabra } \\
& \text { - maculata } \\
& \text { - radicata } \\
& \text { Hyssopus } \\
& \text { - officinalis } \\
&
\end{aligned}
$$

\section{I.}

Jasione

65. 381

\section{- montana}

86

- - littoralis. Fr. Iberis nudicaulis

Ilex

86

50. 391

Illecebrum

\section{- verticillatum}

- pallidum

Impatiens

$$
\text { rubens }
$$

- Noli tangere

Imperatoria

274.

271

206. 387

211

66. 373

96

96

96

66. 371

91

70. 378 109

- Ostruthium

Inula

pimpinelloides. Bngh. 108

- britannica

- dysenterica

- Helenium

- Pulicaria

- salicina

Irideae

Iris

- germanica

- Pseudacorus

Isatis sibirica

- tinctoria

Isnardia

276. 382

297

298

297

298

297

399

12. 399

19

19

19

231. 370

234

49. 379

57

palustris

Juglandeae

Juglans

396

318. 396

338

400

Juncaceae

Juncagineae

Juncus

119. 400

- acutiflorus. E5fr\%.

- albidus
Juncus alpinus. Biłl.

- articulatus

129

- bottnicus. 9i3flb. 131

- bufonius

131

- - hybridus

131

- bulbosus

130

- campestris

- capitatus. Mgrr.

131

- compressus. J̊sq. 130

- conglomeratus 127

- - subefiusus 128

- diffusus. SEpwe. $\quad 128$

- effusus 128

- - compactus. Jywe. 128

-- filiformis

- fluitans. $\mathbb{I m}$. 128

.

-- fusco-ater. Sdjub. 129

-- Gerardi. Lolf. 131

-- glaucus. (E) rf. 128

-- lamprocarpus. Eேrri). 129

-- _- fluitans 129

-- $\quad$ - multiflorus 129

-- maximus. (5frf. 132

-- obtusiflorus. Efyrh. 129

-- pilosus 131

-- squarrosus 130

-- subverticillatus. গูกโf. 130

-- supinus. IIndy. $\quad 130$

-- -- fluitans 130

-- -- nigritellus 130

-- -- repens 130

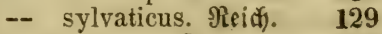

-- _- multiflorus 129

-- -- pallescens $\quad \mathbf{1 2 9}$

-- Tenageia 131

-- uliginosus. $\Re$ th. 130

-- ustulatus. 5ॄwpe. 129

Juniperus

-- communis

342. 396

349

349

\section{h.}

Knautia arvensis. (6ft.

51

-- sylvatica. Duh.

51

Koeleria. Beri.

16. 403

-- cristata. ßetî.

-- -- gracilis

-- glauca. Drf. 


\section{L.}

Tabiatae

387

Lactuca

-- muralis. Frf.

-- sativa

- Scariola

273. 385

280

280

280

-_ _- integrifolia

tamium

-n album

-- amplexicaule

-- incisum. $\mathfrak{B}$ frø.

-- maculatum

-- purpureum

-_ - decipiens

-- westphalicum. SRge.

Lappa minor. Dec.

- tomentosa. \&m.

Lapsana

-- communis

Laserpitium aquilegifol. J゙ฯq. 106

Lathraea

208. 390

-- Squamaria

Lathyrus

-- heterophyllus

-- latifolius

255. 367

267

267

- palustris

267

-- platyphyllus. $\Re$ k.

-- pratensis

-- sylvestris

-- tuberosus

Lavandula Spica

Lavatera thuringiaca

Ledum

-- palustre

Leersia. Sw.

Lemna

-- gibba

-- minor

-- polyrrhiza

-- trisulca

- Lemnaceae

Lentibularieae

Leontodon

-- autumnalis

-- hastilis

-_ _- glabratus

-- -- hyoseroides

-- hispidus

216

215

215

215

215

215

215

286

286

274. 384

285

266

266

266

266

214

253

149

151

14: 402

29

3. 401
Leontodon Taraxacum

Leonurus

207. 284

-- Cardiaca

221

-- Marrubiastrum

221

Lepidium

232. 370

-- campestre. $\Re$. $\mathfrak{Z}$ i.

-- Draba

-- graminifolium

235

-- latifolium

235

-- petraeum

236

-_ ruderale

236

-- sativum

237

235

Lepigonum v. Alsine

235

Leucorchis. Itey.

159

-- albida. Metr.

303. 398

309

Leucojum

-- aestivum

118. 399

-- vernum

121

Levisticum. Sitl.

120

69. 378

-- officinale. Sidy.

108

Libanotis montana. str. 112

Ligusticum Levisticum 108

Ligustrum

5

Liliaceae

399

Lilium

118. 399

-- bulbiferum

123

-- Martagon

122

Limnanthemum nymph. Inf. 80 Limosella

209. 391

-- aquatica

231

Linaria

209. 391

-- arvensis. D8ร. 230

-- Cymbalaria. NRff. 229

-- Elatine. গ)Rill.

229

-- minor. Dิß龴⿵.

-- simplex

229

230
-- spuria. MRifl.

Lineae.

229

Linosyris vulgaris. (Efi. $\quad 289$

Linum

-- catharticum

-- Radiola

72. 373

-- usitatissimum

116

-- -- crepitans

Listera. $\mathfrak{R}$. $\mathfrak{B} \mathrm{r}$,

-- ovata. $\Re$. $\mathfrak{B}$.

Lithospermum

-- arvense
62

116

116

304,398

313

63. 386

73
-- vulgaris. פRiti. 
Lithospermum officinale -- purpureo-coeruleun Littorella 316. 38 -- lacustris

Lobelia -- Dortmanna

Lobeliaceae

Lolium

-- arvense. İth.

-- italicum. গิ. 23 .

-- perenne

-- -- ramosum

-- -- tenue

-- speciosum. $\Omega$ iff.

-- temulentum

-- -- speciosum

-- -- submuticum

Lonicera

-- Caprifolium

-- Diervilla

-- nigra

-- pallida. Şfí.

-- Periclymenum

-- Xylosteum

Lorantheae

Lotus

-- corniculatus

-- -- ciliatus

-. - - hirsutus

-- uliginosus. Sdjt.

Lunaria

-- annua

-- biennis. IInd).

-- rediviva

Luzula

-- albida. Dec.

-- _- rubella. Şџpe.

-- campestris. Dec.

-- congesta. \&ej.

-- maxima. Dec.

-- multiflora. \&ej.

-- pallescens. Şppe.

-- pilosa. शुiflo.

-- vernalis. Dec.

Lychnis

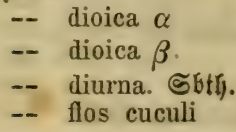

150. 372

164

163

164

163

380

16. 40 '

47

47

47

65. 386

90

91

90

90

90

90

380

264

26 't

264

265

233. 369

238

238

238

119. 400

132

132

131

132

132

132

132

131

131
73

73

331

65. 380

86

47

47

46

47

47

47

254. 367

Lycopsis

-- arvensis

Lycopus

-- europaeus

Lysimachia

-- ciliata

-- nemorum

-- Nummularia

-- punctata

-- thyrsiflora

-- vulgaris

-- -- guestphal. 2ære.

Lythrarieae

Lythrum

-- Salicaria

\section{II.}

Majanthemum. $\mathfrak{B}_{\mathrm{g} g .} \quad$ 49. 400 -- bifolium. Dec. 56

Malachium aquaticum. ₹r. 164

Malaxis. Siv.

-- Loeselii. Sw.

-- paludosa. ธ1v.

Malva

- alcea

-- borealis. $\mathfrak{I}$ IIm.

-- crispa

-- mauritiana

-- moschata.

-_ neglecta. 23 Itr.

-- pusilla. $\mathfrak{X}$ t5.

-- rotundifolia

-- sylvestris

-- vulgaris. $\Im$.

Malvaceae

Marrubium

- vulgare
304. 399

163

405

405

352

352

353

353

353

352

352

63. 396

75

4. 387

10

53. 389

78

78

78

78

71

78

371

166. 271

167

314

314

248. 371

252

252

253

253

252

252

252

252

252

252

371

207. 388 
Marsileaceae

Matricaria

-- Chamomilla

-- Parthenium

Medicago

-- falcata

-- -- major

-_ -. minor

-_ -n versicolor

-- lupulina

-- -- glandulosa

_- .- vulgaris

-- media. \$rв.

-- minima

-- procumbens. $\mathfrak{B}$ ரा.

-- sativa

-- Willdenowii. Dec.

Melampyrum

-- arvense

-- cristatum

-- nemorosum

-- pratense

- sylvaticum

Melica

-- ciliata

-- nutans

-- uniflora

Melilotus

-- alba. Deorr.

-- macrorrhiza. Herí.

-- officinalis. Defr.

-_ - alba

-- officinalis. Millo.

-- Petitpierreana. $23 i l f s$.

-- vulgaris. $\mathfrak{B} i f r o$.

Molissa Calamintha

Mentha

-- aquatica

-- arvensis

-- austriaca. Icq.

-- candicans. Erntg.

-- citrata. Effrif.

-- crispa

-- crispata. Srfirb.

-- dentata. Mincs.

-- gentilis

-- -_ crispa

-- hirsuta

-- hirta. MBtllo.

-- mollissima. Biff
276. 382

299

299

254. 367

264

264

264

264

264

264

264

264

264

264

26

264

208. 390

227

227

227

227

228

15. 403

35

35

36

254. 367

261

261

261

261

261

261

261

222

206. 387

212

213

213

211

212

212

212

213

213

213

212

212

211
Mentha nemorosa. Willo. 211

-_ nepetoides. Rej. 212

-_ - angustifolia 212

-_ _- latifolia 212

-. niliaca. 23illo. 211

-- parviflora. Sdyls. 213

-- piperita 212

-- pratensis crispa. 23 ॥t. 213

-- pubescens. গXiflo. 212

-- Pulegium

213

-- rotundifolia

211

-- sativa

212

-- sylvestris

211

-- sylvestris. 2ூี

-- viridis

Menyanthes

-- nymphoides 80

-- trifoliata

Mercurialis

-- annua

-- perennis

Mespilus

-- Cotoneaster

169. 375

-- germanica

Milium

342. 393

345

348

174

174

-- effusum

$14 \quad 402$

Moehringia

27

$150 \quad 373$

159

Moenchia. (5)ry.

- erecta. F็. 23. 62

Molinia. Erturf.

15. 404

- coerulea. Indij. 36

Monotropa

149. 374

- Hypopitys

151

- - glabra

151

- Hypophegea. 22rrr. $15 \mathrm{~L}$

Monotropeae

Montia

374

- fontana

13. 372

- - major. $\mathfrak{R}(\mathfrak{l})$.

- - minor. Ritj.

- minor. Sint.

- rivularis. (3)

Morus

- alba

316. 394

19

- nigra

335

335

alpinum. Dec. 279 Muscari

118. 400

- botryoides

122

Myagrum dentatum. Millo. 238 
Mragrum paniculatum Myosotis

- arvensis. Effrit.

- _ multicaulis

- caespitosa. ๔u্tb.

- collina. Efrth.

- hispida. Edflor.

- intermedia. \&nf.

- - elatior. Bnngr.

- laxiflora. গđéb.

- palustris. 20tץ.

- - laxiflora

- - repens

- - strigulosa

- repens. Rib́b.

- scorpioides

- strigulosa. 9ajb.

- stricta. \&nf.

- sylvatica. 5 हाँ

- - lactea

- versicolor. \$erí.

Myosurus

- minimus

Myrica

- Gale

Myriceae

Myriophyllum

- alterniflorum

- spicatum

- verticillatum

Myrrhis. Sc.

- odorata. Ec.

\section{N.}

Najadeae

Najas

Narcissus

major. গtต.

- pocticus

- Pseudo-Narcissus

Nardus

13. 404

- stricta

Narthecium. Mafr.

119. 400

- ossifragum. 5208.

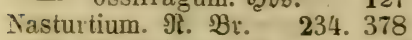

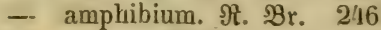

- anceps. গidjb.

315. 401

320

121. 399

121

121

75

75

76

76

77

117

347

396

337

$33 \pi$

336

107

100

Ononis

- mitis. (8)u.

\section{0.}

Ocymum Basilicum

Oenanthe

- fistulosa

71. 377

112

- peucedanifolia. ßorl. 113

- Phellandrium. Ram. 113

Oenothera

- biennis

138. 379

- muricata

Onagrarieae

Onobrychis

140

140

379

255. 367

270

254. 366

260

- procurrens. 刃ื่tr. 260

- repens

- spinosa

Onopordon

- Acanthium

Ophioglossum

- vulgatum

Ophrys

— aranifera. 505.

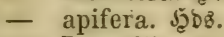

- Loeselii

- Monorchis

- muscifera. 5ூธิ์.

- myodes. Siv.
260

260

274. 383

287

405

359

303. 395

310

310

314

310

310

310 
Ophrys ovata

- paludosa

- spiralis

Orchideae

Orchis

- angustifolia. 20. (5). 308

- bifolia

- conopsea

- coriophora

- fusca. Эॄ⿰.

- haematodes. Ridjo.

- incarnata

- latifolia

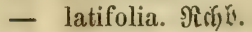

- laxiflora. \&m.

- maculata.

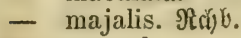

- mascula

- militaris

- Morio

- odoratissima

- palustris. İq.

- pyramidalis

- sambucina

- ustulata

- variegata. Afrf.

Origanum

- Majorana

- vulgare

Orlaya grandiflora. Sffm. 107

Ornithogalum

- arvense. Berf.

- luteum

- nutans

- spathaceum. 5 In.

- stenopetalum. Frt.

- - Schreberi. 9idjo.

- umbellatum

Ornithopus

- perpusillus

Orobanche

119.

306

313

314

313

397

309

308

306

305

308

308

308

308

307

307

308

307

305

306

309

307

308

307

306

306

206. 387

214

214

126

127

127

126

126

- coerulea

- caryophyllacea. ธm.

- Epithymum. Dec.

- Galii. Dub.

- major

- minor. Sttr.

- ramosa

- rapum. Tf.

- rubens. $\mathfrak{B} \mathfrak{m}$.

126

127

255. 367

270

208. 390

225

224

224

224

224

225

225

224
Orobancheae

390

Orobus

- niger

- tenuifolius. Mith.

- tuberosus

- vernus

Osmunda

- Lunaria

- regalis

- Spicant

- Struthiopteris

Oxalideae

Oxalis

- Acetosella

- corniculata

- stricta

254. 367

265

266

266

265

405

359

359

358

358

373

150. 373

163

163

16.3

\section{P.}

Panicun

14. 401

- Crus galli

31

- Dactylon

27

- germanicum. $\Re$ th.

- glabrum. (8)

- glaucúm

- italicum

- _ germanicum

- miliaceum

- sanguinale

- verticillatum

- virile

- - gracile

32

31

31

31

32

31

30

31

31

31

- Weinmanni. 92. (5d). 31

Papaver

191. 368

- Argemone

- - glabrum

- dubium

193

224
- Rhoeas

- - strigosum

- somniferum

Papaveraceae

Papilionaceae

Parietaria

- diffusa. IR. $\Re$.

- erecta. II. $\Omega$.

- judaica

- officinalis. $\mathfrak{W}$.

Paris

- quadrifolia

Parnassia
193

193

193

193

193

368

366

49. 394

57

57

57

57

138. 400

147

72. 370 
Parnassia palustris

Paronichieae

Pastinaca

- sativa

Pedicularis

- palustris

- sylvatica

Peplis

- Portula

Persica

- vulgaris

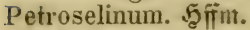

- sativum. गुरीजr.

Peucedanum

- Carvifolia. Bill.

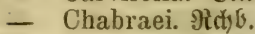

- palustre. Nindf.

- Silaus

Phalaris

\section{- arundinacea \\ - - picta \\ - canariensis \\ - oryzoides}

Phaseolus

- multiflorus. গTEltro.

- vulgaris

- _ nanus

Phellandrium aquaticum

Philadelpheae

Philadelphus

- coronarius

Phleum

\section{- Boehmeri. Sib.}

- nodosum

- pratense

- - bracteatum. B̉ng. 26

- - viviparum. $\Re$ tris.

Phragmites. Trin.

- communis. Trin.

- - pallescens

- _ uniflora

Physalis

Phyteuma

14. 403

65. 392

- orbiculare

- spicatum

- _ album

- _ coeruleum

- _ nigrum
85

116

373

106

106

228

228

120

171

114

108

108

109

111

26

26

26

29

268

267

267

113

375

170

13. 402

27

26

26

3

381

86

87

87

87

87
Phyteuma spicatum vchro-

. leucum si

Picris

273. 354

279

405

Pilularia

351

68. 376

Pimpinella

104

10\%

- magna

104

- nigra. Willo.

104

Pinguicula

4. 359

- vulgaris

Pinus

9

- Abies

- Cembra

- Larix

318. 396

- Picea

340

340

340

340

- Strobus

- sylvestris

340

Pisum

340

- arvense

255. $36 \tau$

- ramulare. NRor.

267

- sativum

Plantagineae

Plantago

267

267

- Coronopus

- lanceolata

- - lanuginosa

- - pumila

- major

- media

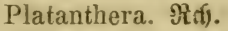

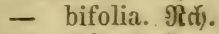

- chlorantha. Eit.

- viridis. $\mathfrak{B}$.

Poa

- annua

389

49. 389

55

55

55

55

55

55

- aquatica

- bulbosa

- - vivipara

- compressa

- distans

- Eragrostis

- fertilis. ఏீt.

- humilis. Efrrf.

- nemoralis

303. 398

309

309

309

15. $40 \frac{1}{x}$

37

36

37

37

39

36

37

38

39

35

- - coarctata. (56). 38

- - firmula. (3). 
Poa nemoralis montana

- _ rigidula

- palustris. 刃iff.

- pratensis

- - anceps

- - angustifolia

- - latifolia

- serotina. Srfre.

- sudetica. Rif.

- trivialis

Podospermum laciniat. Dec. 277 Polemoniaceae

Polemonium

- coeruleum

Polygala

- amara

- - genuina

- - uliginosa

- amarella. Ernk.

- austriaca. $\Re(x) b$.

- comosa. Erft.

- depressa. গ̇indr.

- oxyptera. ภํㅏ․

- _ collina

- pratensis

- serpyllacea. $2 \mathfrak{B h c}$

- vulgaris

Polygaleae

Polygoneae

Polygonum

- amphibium

- - coenosum

- natans

- - terrestre

- aviculare

- - erectum

- Bistorta

- Convolvulus

- dumetorum

- Fagopyrum

- Hydropiper

- - Persicario-Hydropiper

- incanum. Sfym.

- lapathifolium.

- laxiflorum. Whe.

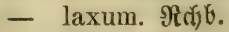

- Minori-Persicaria $\mathfrak{B r} 146$

- minus. 5505.

- mite. S๘ruf.
38

38

38

38

39

39

39

38

38

38

391

64. 391

80

253. 390

258

258

258

258

258

257

258

257

257

257

258

257

390

393

138. 393

144

144

144

145

146

146

144

146

147

147

146

146

145

145

146

145

146

146
Polygonum nodosum. \$3ชช. 145

- Persicaria

145

- - Lapathifolio-Persicaria

145

- - minus 145

- tataricum 147

Polypodium

405

- aculeatum

35.1

- calcareum. Siv.

354

- cristatum

356

- dilatatum. Sூரfnt.

356

- Dryopteris

- Filix femina

354

- Filix mas.

357

- fragile

355

- Phegopteris

356

- Robertianum. $\mathfrak{H} f \mathfrak{m}$. 354

- Thelypteris

- vulgare

355

353

- _ auriculatum 354

- - serratum

Polystichum. $\Re$ th $\bar{\zeta}$.

354

- cristatum 9 th

-

- Filix mas. Rth.

- Oreopteris. Dec.

- spinulosum. Dec.

- - dilatatum

355

355

356

- Thelypteris. $\Re t$ r. 355

Pomaceae

375

Populus

- alba

342. 396

- balsamifera

347

- canescens. SIII.

- dilatata IItt.

348

- monilifera. গ̂lit.

348

- nigra

348

- pyramidalis

348

347

348

Portulaceae 372

Potameae

397

Potamogeton

50. 397

- compressus

60

- crispus

60

- densus

61

- - angustifolius

61

- - lancifolius

61

- - latifolius

- fluitans. $\Re$ th́.

59 
APotamogeton gramineus graminifolius

- - heterophyllus

59

- heterophyllus. Sतfirb. 59

- Hornemanni. SAles.

- lucens

59

59

- natans

58

- _- angustatus. SIutt. 55

- -- oblongus

- -- prolixus

- oblongus. Biv.

- obtusifolius. MR. $\Omega$.

- pectinatus

- perfoliatus

- _- lanceolatus

- -- oblongifolius

- -- rotundifolius

-- plantagineus Ducr.

-- pusillus

-_ _- major

- $\quad$ tenuissimus

- - vulgaris

- rufescens. Sifro.

- serratus

- zosteraefolius. ธđim. 60

Potentilla

- anserina

- - sericea

150. 366

187

187

- - viridis

- argentea

- collina. Wib́.

187

188

- Fragariastrum. G5rr. 189

- Guentheri. ßurij.

- inclinata. Bifl.

- opaca

- palustris. Sc. $^{-}$

- procumbens. Sitf.

- pusilla. $\mathfrak{S}_{\mathfrak{j} f \text {. }}$

- recta

- reptans

- rupestris

- supina

- Tormentilla. Sutf. - verna

Poterium

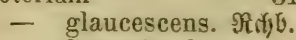

- Sanguisorba

Prenanthes muralis

Primula

- acaulis. Ј๕q.

5s

os

61

60)

60

60

60

59

60

60

60

60

59

61

185

188

189

$15 \tau$

189

189

185

188

188

157

189

188

317. 394

337

337

280

64. 389
Primula elatior. ฐ๙a.

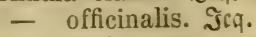

78

- veris

78

Primulaceae

389

Prismatocarpus. ๕`गูer. 65. 381

- hybridum. \&'Ser. 90

- Speculum. ¿'ફer. 89

Prunella

208. 358

- grandiflora
- laciniata
- varviflora. \$oir.

Prunus

223

- acida. E5fry.

- Armeniaca

- austera. Ẽfrf.

- avium

- cerasifera. Efyrf.

223

- Cerasus

223

223

169. 372

172

171

172

172

- Chamaecerasus. Jir. 172

- domestica

- duracina. Dec.

- fruticans. $2 \mathfrak{f}$ e.

172

- hispanica. Dec.

- insiticia

- italica. Brffr.

- Juliana. Dec.

- nigricans. Effrh.

172

- Padus

171

- semperflorens. Eேfurj.

- spinosa

- - coetanea

- syriaca. Brtfy.

- varia. E5frfy.

172

171

172

172

172

173

Pteris

172

171

171

172

172

406

- aquilina

358

Pulegium vulgare. গ্গుilf. 213

Pulicaria. Sirtu. 276. 382

- dysenterica. Bsitn. 298

- vulgaris. Sitn.

Pulmonaria

298

- angustifolia 74

- azurea 74

- mollis 74

- officinalis 73

- stricta. Bungh. 74

Pulsatilla vulgaris. Ditf. 199

Pyrethrum. Sill. 276. 382

- corymbosum. গুแા 299

- inodorum. Sm. 
Pyrethrum Parthenium Pyrola

- media. Sm.

- minor

- rotundifolia

- secunda

- umbellata

- uniflora

Pyrolaceae

Pyrus

- acerba. Mer.

- communis

- Achras

- Pyraster

- - sativa

- Cydonia

- Malus

- - glabra

- - tomentosa

29
149.37
15
15
15
15
15
15
37
170.375
17
17
17
17
17
17
17
17
17

318. 395

Quercus

- intermedia. S2unghy.

- pedunculata. EIrry.

- Robur

- sessiliflora. Sm.

\section{R.}

Radiola

- linoides. (85m.

- millegrana. Em.

Panunculaceae

Ranunculus

- aconitifolius

- acris

- aquatilis

- arvensis

- auricomus

- _ major

- bulbosus

- divaricatus. Edjrf.

- Flammula

- - reptans

- Ficaria

- fluitans. Ram.

- hederacens

- hirsutus. Eutet.

- lanuginosus
50. 373

62

62

364

192. 364

202

203

202

204

203

20:3

205

202

203

203

203

202

201

205

203
Ranunculus Lingua 203

- nemorosus. Dec. 204

- paucistamineus. T\{氏 202

- Petiveri. Лif. 202

- peucedanifolius. அ2rf. 202

- Philonotis. Efrre 205

- platanifolius 202

- polyanthemus 202

- repens 204

- sceleratus 205

Raphanistrum arvense. গ⿰冫广\}. 2/13 - segetum. $\Re$ d b. 243

Raphanus 233. 370

- niger. Dec. 343

- Radiola. Dec. 243

- Raphanistrum 243

- sativus 243

- - major 243

- - minor 243

- - sylvestris 243

Resela 167. 366

- alba 168

- lutea 168

- luteola 168

- odorata 168

Resedaceae 366

Rhamneae 371

Rhamnus 66. 371

- cathartica 91

- Frangula 91

Rhinantaceae 390

Rhinanthus 208. 390

- Alectorolophus. \$olf. 227

- angustifolius. (35. 226

- Crista galli 226. 227

- major. Efrri. 226

- $\quad$ angustifolius 227

- minor. EFirfy. 226

- - fallax 226

Ribes 66. 375

- alpinum 95

- Grossularia 95

- nigrum 95

- reclinatum 95

- rubrum 95

- $\quad$ sylvestre 95

- Uva crispa 95

Robinia

251. 367

265

Rosa

170. 366 
Rosa Acharii. Bittr.

- aciphylla. Rau.

- agrestis. હy.

- andegavensis. $\mathfrak{B f f}$.

- arvensis. אูปซ.

- caesia. \&not.

- canina

- - micrantha

- caryophyllacea. $\mathfrak{B}$ గi.

- centifolia

- cinnamomea

- corymbifera. Buffy.

- damascena. Mifil.

- dumalis. Bidjit.

- dumetorun. ז̇gr.

- gallica

- lutea. Mill.

- micrantha. Em.

- mollissima. গistr.

- muscosa. Mill.

- nitens. 刃er.

- pimpinellifolia

- pomifera. ๖ู้m.

- rubiginosa

- sepium. জm. Thfr.

- Swartzii. Fr.

- tomentosa. ธ่m.

- turbinata. 2it.

- umbellata. \&r3.

- villosa. $\mathfrak{2} 1 \mathfrak{f}$.

Rosaceae

Rubia

Rubiaceae

- tinetorum

Rubus

- affinis. $\mathfrak{B G}$.

- apiculatus. $\mathfrak{B g}$ ge.

- argenteus. Nake.

- caesius

- candicans. $\mathfrak{3}$ be.

- carpinifolius. গ⿰氵3冖

- cordifolius. $23 \mathfrak{e}$.

- corylifolius. Siv.

- discolor. MBke.

- fastigiatus. særje.

- foliosus. 935e.

- fruticosus

- fruticosus. NBלe.

- fusco-ater. WBge.

- fuscus. IJKe.
178

177

178

178

179

177

177

177

178

179

177

178

179

177

178

179

176

178

179

179

177

176

179

178

178

177

178

177

178

179

365

49. 385

54

385

170. 365

180

183

182

186

180

181

180

185

182

180

183

179

179

183

183
Rubus glandulosus. Bifl.

185

- hirtus. $\mathfrak{X}$. $\mathbb{R}$.

185

- humifusus. NBrje.

- Hystrix. NBe.

184

- Idacus

185

- infestus. 92re. $\quad 184$

- Lingua. 2036. 184

- macroacanthus. Niffe. 182

- macrophyllus. গ3Łe. 181

- Menkei. 23he. 183

- nemorosus. Syyme. 183

- nitidus. 236e. 180

- pallidus. MBGe. 183

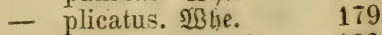

- pubescens. 23ije 182

- Radula. W3ije. 181

- phamnifolius. myre. 180

- rosaceus. 23je. 181

- rudis. $13 g$ e. 185

- saxatilis 186

- scaber. İae. 184

- Schlechtendalii. $\mathfrak{2}$ 〔je. 181

- Schleicheri. \$3Ge. 183

- silvaticus. פकshe. 182

- Sprengelii. 2369. 181

- suberectus. P̂thor. 180

- thyrsflorus. $\mathfrak{3 G e . ~} 184$

- tomentosus. Brth. 180

- vestitus. 2̧3দ⿹. 182

- vulgaris. WJge. 181

Rudbeckia laciniata 301

Rumex 119. 393

- Acetosa 135

- - auriculatus $\quad \mathbf{1 3 6}$

- - multifidus 136

- Acetosella 136

- aquaticus 135

- conglomeratus. \$urr. 134

- crispus 134

- cristatus. $\mathfrak{3}$ Ir. $\quad 135$

- Hydrolapathum. 5ூb8. 134

- maritimus 133

- maximus. Sdyrb. 134

- Nemolapathum. (Eீrb. 134

- nemorosus. Sdirb. 135

- obtusifolius 13/4

- palustris. Em. 133

- Patientia 135

- pratensis. शR. $\Re . \quad 135$

- sanguineus 
Rumex sanguineus viridis

- seutatus

Ruta

Rutaceae

ylvestris. $\mathfrak{B} \mathbb{l t}$.

148. 374

151

374

\section{S.}

Sagina

- apetala

- ciliata

- depressa. Sijlz.

- erecta

- procumbens

Sagittaria

- sagittaefolia

Salicineae

Salix

- alba

- ambigua. Estf.

- amygdalina

- aquatica. Sm.

- arenaria

- argentea. Sil.

- aurita

- - humilis

- babylonica

- caprea

- cinerea

- - obovata

- Doniana. Sm.

- fragilis

- - sericea

- fusca. ธm.

- Helix

- hippophaefolia. $\mathfrak{2}$.

- Lambertiana. ๔u.

- mollissima. Effrh.

- pentandra

- purpurea

- purpurea. Sm.

- repens

- rosmarinifolia

- rubra. $\$ 208$.

- Russeliana. Snt.

- triandra

- undulata. Érb.

- viminalis

- vitellina
50. 372

61

61

61

62

61

317. 397

337

396

341. 396

343

345

343

345

346

3!6

345

345

343

$3 ! 5$

345

345

346

343

343

346

344

344

344

345

343

344

344

346

$3 \frac{1}{4} 6$

344

343

343

344

344

343
Salvia

- officinalis

- pratensis sclarea

Sambucus

- Ebulus

- laciniata. Mifr.

- nigra

- - laciniata

- variegata

- racemosa

Samolus

- Valerandi

Sanguisorba

- officinalis

Sanguisorbeae

Sanicula

- europaea

Santalaceae

Saponaria

- officinalis

- Vaccaria

10

72. 385

114

115

115

115

115

115

65. 389

86

49. 39 '

57

394

67. 376

103

393

149. $3 \pi 2$

156

156

Sarothamnus scoparius $\mathfrak{2}$ m. 258

Satureja

206. 337

- hortensis

Satyrium albidum

214

- Epipogium

309

- repens

- viride

314

313

Saxifraga

309

- caespitosa

149. 380

- decipiens. Efrrf.

154

- granulata

154

- tridactylites

154

Saxifrageae

Scabiosa

154

380

- arvensis

- columbaria

51

- longifolia

- succisa

51

51

51

- sylvatica

51

Scandix

70. 379

- Cerefolium

111

- infesta

109

- odorata

107

- Pecten

Schoenus

110

- albus

13. 401

23

- compressus

23

- ferruginens 
Schoenus fuscus

\section{- Mariscus}

- nigricans

Schollera Oxicoccos $\Re$ tr 143

Scilla

- amoena

119. 400

- nutans

Scirpus

\section{- acicularis}

- Baeothryon. Efrrr.

- caespitosus

- - nemorosus. $\Re$ th.

- campestris. গtth.

- compressus. \$erf.

- Duvalii. SEppe.

- fluitans

- lacustris

- maritimus

- - compactus. Rrorf.

- multicaulis. Sm.

- ovatus. 9itf.

- palustris

- pauciflorus. \&ightf.

- radicans. Srijt.

- setaceus

- sylvaticus

- Tabernaemontani. Gm. 22

- triqueter

- tuberosus. De8ీf.

- uniglumis. \$3飞โ.

Sclerantheae

Scleranthus

- annuus

- perennis

Scolopendrium. Sm.

Scorzonera

- hispanica

- laciniata

- _ integrifolia

Scrophularia

- aquatica

- Balbisii. 5yrmm.

- Ehrharti. Stv.

- Neesii. IBrtg.

- nodosa

- vernalis

Scutellaria

- galericulata

- hastifolia
13. 401

$24 \mid$ Scutellaria minor

12 Secale

24

126

125

20

21

21

21

21

23

22

21

22

23

23

21

21

20

21

23

22

23

22

23

20

395

149. 395

153

153

406

358

273. 384

277

277

277

208. 391

228

228

228

228

228

228

208. 389

222

222

- cereale

- acre

- reflexum

- - viride

- rupestre

- Telephium

- villosum

Selinum

- Carvifolia

- palustre

Sempervivum

- tectorum

Senebiera. ßerí.

Senecio

- erucifolius

- Jacobaea

- paludosus

- sylvaticus

- viscosus

- vulgaris

- longifolia

Serratula
16. 404

46

- - densum

150. 365

162

162

- laxum

- boloniense. Rotz.

162

- latifolium. $\mathfrak{B r t}$.

162

- maximum. Eut.

161

- purpurascens. Iffy.

161

161

162

- - glaucum

- - glomeratum

- sexangulare

- sexangulare. Itutt.

162

- - ochroleucum

- - purpureum

162

162

162

162

162

161

161

161

162

69. 378

108

109

167. 365

169

231. 370

Coronopus. ßofr.

235

- aquaticus. 5ூరణ.

276. 383

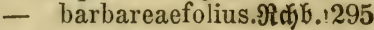

- erraticus. Brt.

295

- Fuchsii. (5im.

294

- nemorensis

- ovatus. 2Bitlo.

296

295

295

- Sadleri. \&ng.

296

- salicifolius. $\mathfrak{X} \mathfrak{H}$ r. 296

- sarracenicus

- tenuifolius. Э๕q.

Serapias atrorubens. SEfm. 312

312

274. 383 
Serratula arvensis

- tinctoria

Seseli

\section{- annuum}

- Libanotis. Rif.

Sesleria. 2 rro.

- coerulea. $\mathfrak{A}$ tro

Setaria glauca. Beauv.

- italica. $\mathfrak{B y}$.

- verticillata. 20 .

- viridis. $\mathfrak{B}$ v.

Sherardia

- arvensis

Silaus. $\mathfrak{B}$.

Silene

$$
\begin{aligned}
& \text { - anglica } \\
& \text { - Armeria } \\
& \text { - conica } \\
& \text { - gallica } \\
& \text { - inflata } \\
& \text { - noctiflora } \\
& \text { - nutans }
\end{aligned}
$$

Sileneae

Siler. (j)rtn.

- aquilegifolium. G5rtr. 106

- trilobum. ๔r.

Silybum. Bailf.

\section{Sinapis}

$$
\begin{aligned}
& \text { - alba } \\
& \text { - arvensis } \\
& \text { - nigra }
\end{aligned}
$$

Sison inundatum

Sisymbrium

- Alliaria. Sr.

- amphibium

- anceps

- austriacum. İ๘.

- Nasturtium

- officinale. Sc.

- palustre. \&if.

- Sophia

- strictissimum

- sylvestre

- tenuifolium

Sium

Thalianum

_ angustifolium
288 | Sium Falcaria

286

71. 377

112

112

16. 403

45

31

31

31

31

48. 385

52

71. 377

111

150. 372

157

158

158

157

157

158

158

157

372

69. 378

106
106

274. 383

287

234. 369

245

245

243

114

234. 369

244

246

247

244

246

244

247

244

244

247

246

244

70. 377

111

- repens

Solaneae

Solanum

- nigrum

Solidago

Sonchus

- alpinus

- asper

Sorbus

Sparganium

- erectum

- natans

Spartium

Spinacia

Spiraea

- Ulmaria

$$
\text { - latifolium }
$$

- nodiflorum

111

113

- Sisarum

113

111

392

- Dulcamara

- humile. $B$ rnff.

65. 392

85

- miniatum. $\mathfrak{B}$ rnh్

84

84

- pterocaulon. $\Re$ b 65

- tuberosum

275. 381

- Virga-aurea

- arvensis

273. 385

279

279

279

- fallax. M̉lfr.

279

- oleraceus

279

- palustris

279

- Aria. Erig.

170. 375

175

- aucuparia

175

- torminalis. Crib.

175

316.400

321

- ramosum. 5ூסช.

322

- simplex. 5208.

321

321

- scoparium 258

- - lacteum 258

Spergula 150. 372

- arvensis 166

- maxima. SצJgr. $\quad 166$

- Morisonii 166

- nodosa 166

- pentandra 165

- sativa. $\mathfrak{B n n g h . ~} \quad 166$

- vulgaris. 23 mgh. $\quad 166$

341. 395

- inermis. Mndy. $\quad 347$

- oleracea

347

- spinosa. Mnch. $\quad 347$

170. 365

- Filipendula $\quad 176$

- salicifolia 
Spiranthes. $\Re i d$. Stachys

- alpina
- ambigua. am.
- annua
- arvensis
- palustris
- - ambigua
- - segetum
- sylvestris

- palustri-sylvat.

- recta

- sylvatica

Staphylea

Stellaria

- crassifolia. Egrff.

- glauca. Sithx.

- graminea

$-\quad \beta \mathrm{L}$.

$-\gamma \mathrm{L}$.

- Holostea

- media

- - major

- - minor

- nemorum

- neglecta. $\mathfrak{W h E}$.

Stellatae

Stratiotes

- aloides

Struthiopteris. SBIllb.

304. 398

313

207. 388

219

219

220

219

218

219

219

219

219

(d). 219

220

219

72. 374

115

150. 373

161

160

160

160

161

160

160

160

160

160

160

161

385

342. 399

349

406

358

Succisa pratensis. Mndi.

Symphytum

- officinale

- - patens. S6th.

Syringa

- persica

- vulgaris

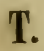

Tanacetum

- vulgare

Taraxacum
Taraxacum laevigatum. Dec. 284

- palustre. Dீc. 28't

- officinale. $\mathfrak{B g}$. 284

- salinum. Şppe. 294

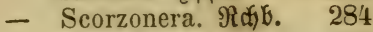

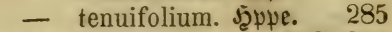

Taxus 3 396

- baccata 349

Teesdalia. $\Re$. $\mathfrak{B r}$. 232. 370

- nudicaulis. $\Re$. 3 r. 236

Teucrium

210. 389

- Botrys

- Chamaedrys

210

- Chamaepitys

210

- montanum

210

210

210

$\begin{array}{lr}\text { Thalictrum } & 210 \\ \text { Therodonia } & \text { 192. } 364\end{array}$

- flavum

200

- minus

200

Walrothii. 3 mngh. 200

Thesium 66. 393

- alpinum

- montanum

96

- pratense

Thlaspi

- alpestre

- arvense

- Bursa pastoris

- campestre

- montanum

- perfoliatum

Thrincia. $\Re$ th).

- hirta. $\Re$ th.

Thymeleae

Thymus

96

96

232. 370

236

236

237

235

236

236

273. 384

278

395

207. 387

222

- angustifolius. Sdjrb. 222

- Chamaedrys. Fr. 221

- citriodorus. \&nf. 222

- lanuginosus. Sஞjf. 222

- Serpyllum 221

- subcitratus. Sdirb. 222

- sylvestris. ๔ffrr. 222

- vulgaris

222

Thysselinum palustre. $\mathscr{S}$ fim. 109

Tilia 191. 371

- aurea. Jgft. 194

- europaea 194

- grandifolia. Efr.h. 194 
Tilia parvifolia. (8)

Tiliaceae

Tillaea

- aquatica

- muscosa

Tordylium Anthriscus

Torilis. 2108.

- Anthriscus. (5iml.

- helvetica. "\$m.

- infesta. Jปfïm.

- nodosa. (Sitn.

Tormentilla erecta

- reptans

Tragopogon

- minor. Fr.

- porrifolius

- pratensis

- - tortilis

Trapa

- natans

Trientalis

Trifolium

europaea

- agrarium

- alpestre

- arvense

- campestre. Sarrb.

- elegans. Śv.

- filiforme

- fragiferum

- hybridum

- incarnatum

- medium

- montanum

- pratense

- procumbens

- - majus

- - minus

- repens

- sativum. Mill.

- striatum

Trichlochin

- maritimum

- palustre

Triodia. $\Re$. 33 r.

- decumbens. $\mathfrak{B y}$.

Triticum

- caninum. Sdurb.

- repens
$194 \mid$ Triticum vulgare

194 - - aestivum

46

371

17. 365

62

48

109

70. 379

109

109

109

109

189

189

273. 384

277

277

277

277

49. 380

56

137. 389

137

254. 367

263

262

262

263

263

263

262

263

262

262

263

261

263

263

263

263

261

262

119. 397

133

133

15. 403

47

16. 404

46

46

- - hybernum

Trollius

- europaeus

Tulipa

- sylvestris

Turritis

- glabra

- hirsuta

Tussilago

- Farfara

- hybrida

- Petasites

- - femina

46

46

192. 364

198

119. 399

123

233. 379

241

240

275. 381 .

294

294

294

- - hybrida

29 !

- - officinalis. Mndor. 294

Typha 316. 400

- augustifolia

321

- latifolia

Typhaceae

321

400

\section{U.}

Ulex

254. 366

- europaeus

260

Ulmus

67. 394

- campestris

- ciliata. E5rrf.

103

- effusa. 9Billo.

103

- suberosa. (Efrrf.

103

Umbelliferae

103

Urtica

- dioica

375

- urens

Urticeae

316. 394

335

335

394

Utricularia

4. 389

- intermedia. Јูลษณ.

9

- minor

- vulgaris

10

9

Vaccinieae

380

Vaccinium

138. 380

- Myrtillus

- Oxycoccos

143

143

143

- uliginosum

143

- Vitis Idaea

52 
Valeriana

- angustifolia. T的.

- dioica

- exaltata. Nif.

- Locusta olitoria

- officinalis

- - major. Rifi.

- - minor. $\Omega(t)$.

- Phu

- sambucifolia. IRtif.

Valerianeae

Valerianella. ßoff.

- Auricula. Dec.

- carinata. \&uib.

- dentata. \$oll.

- Morisonii. Der.

- olitoria. 92nd.

Verbasceae

Verbascum

— adulterinum. $\Omega$ กิ千.

- Blattaria

- collinum. Sifro.

- - stellato-pubescens

- cuspidatum. Sdjro.

- Lychnitis

- Nigro-Lychnitis.Sdyrt. 83

- - brevipedicellatum 83

- nigrum

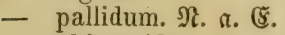

- phlomoides

- Schiedeanum. R̂.

- Schraderi. 9)(ey.

- thapsiforme. Sifro.

- thapsiformi-nigrum. (c) 10.

- Thapso-nigrum. Sdyb. 82

- Thapsus

Verbena

- officinalis

Veronica

- agrestis

- Anagallis

- arvensis

- Beccabunga

- Buxbaumii. Ten.

- Chamaedrys

- hederaefolia

- latifolia

- longifolia

- montana
12. 385

17

17

18

17

17

17

17

17

385

12. 385

18

18

18

18

18

391

64. 391

82

84

82

82

82

83

83

81

82

83

81

82

82
82

81

209. 391

231

3. 391

\section{8}

6

7

6

8

6

9

6

7

6

Veronica officinalis

- opaca. Fr.

- polita. Fr.

- pulchella. Dec.

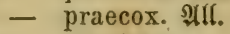

- prostrata

- scutellata

- serpyllifolia

- spicata

- triphyllos

- verna

Viburnum

- Lantana

- Opulus

- - sterile

Vicia

- angustifolia. $\Re$ th.

- - angustissima

- Bobartii. Frft.

- Cracca

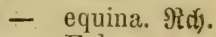

- Faba

- - minor

- lathyroides

- montana. Fri.

- sativa

- segetalis. $\mathfrak{T} \mathfrak{h}$.

- sepium

72. 386

- - angustifolia

- - intermedia

- - ochroleuca

- sylvatica

- tenuifolia

Vignea v. Carex

Villarsia. Bent.

269

268

269

269

269

268

268

268

269

268

268

268

268

268

268

- 64.392

nymphoides. Bent.

Vinca

- minor

Viola

- arenaria. Dec.

- arvensis

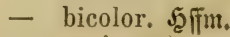

- canina

322

64. 392

- _ albida

65. 392

66. 371

- - ericetorum

93

- - lucorum

94

- degener. Sdiwgg.

- elatior. Fr.

- ericetorum. Sdirb.

94

93

- hirta 


\begin{tabular}{|c|c|c|c|c|c|}
\hline iola & hirta brev & 92 & Vitis & 66. & 374 \\
\hline - & mirabilis & 94 & vinifera & & 91 \\
\hline - & odorata & 92 & & 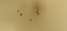 & \\
\hline - & - alba & 92 & & & \\
\hline - & - albido-coerulea & 92 & & & \\
\hline - & - eflagellis & 92 & Woodsia hyperborea. & R(t). & \\
\hline - & - major & 92 & $\beta$ ilvense & & 354 \\
\hline - & palustris & & & & \\
\hline - & $\overline{\text { persicifolia. }} \mathfrak{\text { major }} \Omega$ & & X. & & \\
\hline- & Riviniana. $\Re$ d) b. & 93 & & & \\
\hline - & saxatilis ভffm. & 9 & Xanthiu & 317 & \\
\hline 一 & stagnina. Rit. & 9 & & 1 & \\
\hline - & sylvestris. $\mathfrak{R}$ am. & 93 & strumarium & & 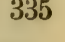 \\
\hline 一 & - Riviniana & 9 & & & \\
\hline - & tricolor & 94 & 7 & & \\
\hline - & - arvensis & 9 & & & \\
\hline - & bicolor & 9 & Zannichellia . & 316. & 397 \\
\hline - & saxatilis & 94 & - palustris & & \\
\hline & & & repens. $\mathfrak{B}^{\text {Bnngh. }}$ & & \\
\hline & $m$ & & & 316. & \\
\hline & & & & & \\
\hline
\end{tabular}

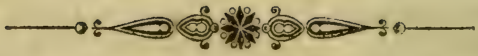

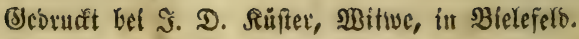






\section{New York Botanical Garden Library}

QK314.J85 1852

Jungst, Ludwig Volrad/Flora Westfalens

|| ||

|| || ||||||||||||||||||||||||||||||||||||||||||||||||||||||||||||

35185001214152 


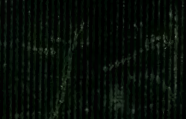

